22021

University of California.

GIFT OF

Bumths mian Anstelution

func 1883 






\section{SMITHSONIAN}

\section{MISCELLANEOLS COLLECTIONS.}

\section{VOL. XXIII.}

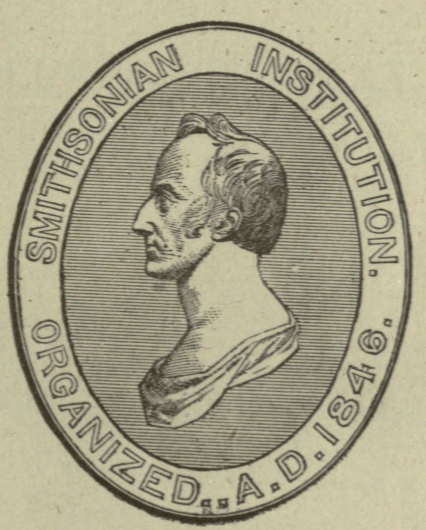

“EVERY MAN IS A VALUABLE MIEMBER OF SOCIETy WHO BY HIS OBSERVATIONS, RESEABChes, AND EXPERTMENTS PROCURES KNOWLEDGE FOR MEN."-SMITHSON.

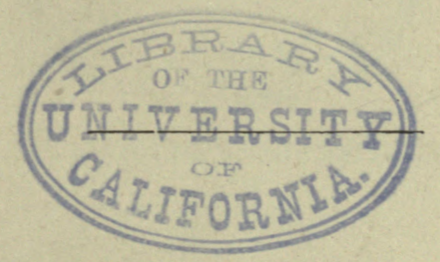

W A SHIN G T ON :

PUBLISHED BY THE SMITHSONIAN INSTITUTION. 1882. 
Q 
Department of the Trnterior:

U. S. NATIONAL MUSEUM.

\section{BULLETINS}

OF THE

\section{UNITED STATES NATIONAL MUSEUM.}

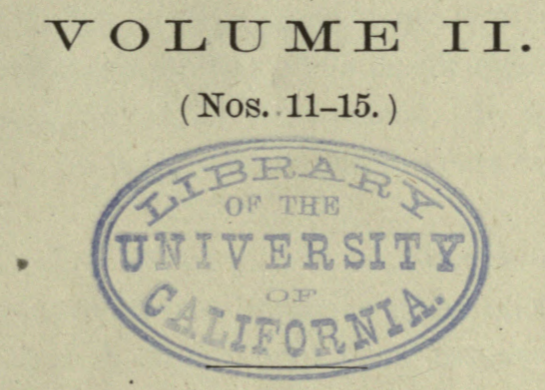

PUBLISHED UNDER THE DIRECTION OF THE SMITHSONIAN INSTITUTION.

WASHINGTON:

GOVERNMENT PRINTING' OFFICE.

1882. 



\section{A D V E R T ISE M E N T.}

The present series, entitled "Smithsonian Miscellaneous Collections," is intended to embrace all the publications issued directly by the Smithsonian Institution in octavo form; those in quarto constituting the "Smithsonian Cantributions to Knowledge." The quarto series includes memoirs, embracing the records of extended original investigations and researches, resulting in what are believed to be new truths, and constituting positive additions to the sum of human knowledge. The octavo series is designed to contain reports on the present state of our knowledge of particular branches of science; instructions for collecting and digesting facts and materials for research; lists and synopses of species of the organic and inorganic world ; museum catalognes; reports of explorations; aids to bibliographical investigations, etc., generally prepared at the express request of the Institution, and at its expense. The assigument of a work to one or the other of the two series will sometimes depend upon whether the required illustrations can be presented more conveniently in the quarto or the octavo form.

In the Smithsonian Contributions to Knowledge, as well as in the present series, each article is separately paged and indexed, and the actual date of its publication is that given on its special title page, and not that of the volume in which it is placed. In many cases works have been published, and largely distributed, years before their combination into volumes.

While due care is taken on the part of the Smithsonian Institution to insure a proper standard of excellence in its publications, it will be readily understood that it eannot hold itself responsible for the facts and conclusions of the authors, as it is impossible in most cases to verify their statements.

S. F. BAIRD,

Secretary S. I. 



\section{TABLE OF CONTENTS.}

Article I.-Bibliography of the Fishes of the Pacific Coast of the United States to the end of 1879. By Theodore Gill. 1882. 8vo., pp. 78. Bulletin of the National Museum, No. 11.

Article II.-Contributions to North American Ichthyology, based primarily on the collections of the United States National Museum. (Part III.) A.-On the Distribution of the Fishes of the Alleghany Region of South Carolina, Georgia, and Tennessee, with descriptions of new or little known species. By DAvid S. Jordan and Alembert W. Brayton. B.-A Synopsis of the Family Catostomidæ. By David S. Jordan. 1878. 8vo., pp. 237. Bulletin of the National Museum, No. 12.

Article III.-The Flora of St. Croix and the Virgin Islands. By Baron H. F. A. EgGers. 1879. 8vo., pp. 136. Bulletin of the National Museum, No. 13.

Article IV.-Catalogue of the Collection to Illustrate the Animal Resources and the Fisheries of the United States, exhibited at Philadelphia in 1876 by the Smithsonian Institution and the United States Fish Commission, and forming a part of the United States National Museum. Prepared under the direction of $\mathrm{G}$. Brown Goode. 1879. 8vo., pp. 367. Bulletin of the National Museum, No. 14. Article V.-Contributions to the Natural History of Aretic America, made in connection with the Howgate Polar Expedition, 1877-78. By Ludwig Kumlien. 1879. 8vo., pp. 179. Bulletin of the National Museum, No. 15.

\section{CONTENTS.}

Kumures, L. Ethnology, mammals, and birds.

BeAN, T. H. Fishes.

Verrill, A. E. Annelides, molluscoids, and radiates.

DALL, W. H. Mollusks.

INSECTS :

Edwards, W. H. Diurnal lepidoptera.

Scudder, S. H., and others. Hymenoptera, nocturnal lepidoptera, diptera, coleoptera, neuroptera, and arachnida.

Gray, A. Plants.

Tuckerman, E. Lichens.

Farlow, W. G. Algæ. 

Department of the Interior:

U. S. NATIONAL MUSEUM.

\author{
$-11$ \\ BULLETIN
}

OF THE

\title{
UNITED STATES NATIONAL MUSEUM.
}

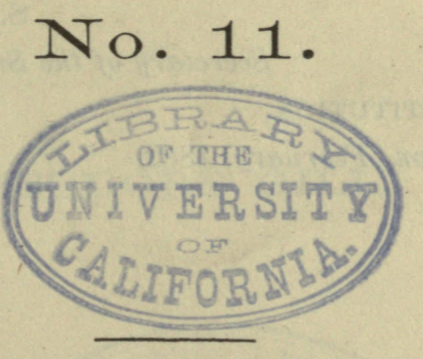

PUBLISHED UNDER THE DIRECTION OF THE SMITHSONIAN INSTITUTION.

WA SHINGTON:

GOVERNMENT PRINTING OFFICE.

1882. 
A D VERTISEMENT.

This work is the eleventh of a series of papers intended to illustrate the collections of natural history and ethnology belonging to the United States, and constituting the National Museum, of which the Smithsonian Institution was placed in charge by the act of Congress of August 10, 1846.

It has been prepared at the request of the Institution, and printed by authority of the honorable Secretary of the Interior.

\section{S. F. BAIRD,}

Secretary of the Smithsonian Institution.

Smithsonian Institution,

Washington, February, 1882. 


\section{BIBLIOGRAPHY}

OF THE

\section{FISHES OF THE PACIFIC COAST}

OF THE

\section{UNITED STATES}

\section{THEODORE GILL.}

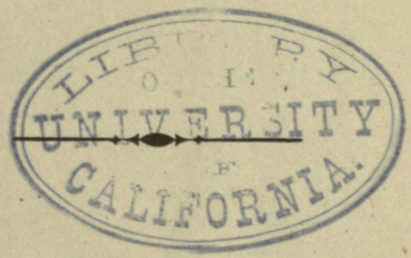

WASHINGTON:

GOVERNMENT PRINTING OFFICE.

1882 . 



\section{BIBLIOGRAPHY \\ OF}

THE FISHES OF THE PACIFIC UNITED STATES.

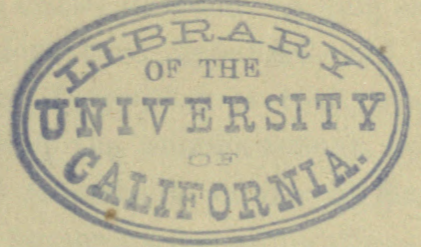

Bull. N. M. No, 11-1 



\section{PREF A TOR Y.}

The scientific literature relative to the fishes of the western coast of North America is of unusually recent, as well as rapid, growth. Nothing exact was kuown till the present century had far advanced, for the accounts of the earlier writers, such as Venegas, intead of enlightening the reader, convey absolutely false ideas respecting the character of the ichthyic fauna. Exclusive of incidental notices, the beginnings of an ichthyography of the northwest coast were first published in 1831 (but printed in 1811) in the "Zoographia Rosso-Asiatica" of Pallas; a few species from British Columbia were described by Richardson in 1836, while the fishes of California remained absolntely unknown till 1839, when a glimpse, but an entirely inadequate one, was furnished by Lay and Bennett in their notes and account of species collected during the voyage of the English vessel Blossom. A long silence then supervened, and, with the exceptions thus signalized, and the addition by Storer of a single species of Syngnathus in 1846, west-coast ichthyography commenced in 1854 with the announcement, by Professor Agassiz, of the discovery of the remarkable family of Embiotocoids. This was speedily followed by numerous communications, by Dr. Gibbons, Dr. Girard, and Dr. Ayres, on new species of fishes, mostly from the Californian waters, but partly from the Oregonian ones. As early as 1858, nearly 200 species had been made known, and the descriptions of most were collected in a general report by Dr. Girard. The main features of the ichthyology of the Pacitic slope were then already known; but more recent laborers have not only extended largely our knowledge of species, but added a number of entirely new forms, and thrown much light on the relations of the fish-fauna of that region to others.

The following bibliography is a nearly complete enumeration, in chronological order, of the memoirs and articles of all kinds that have been published on the fishes of the region in question. The chronological order has been determined by the date of reading of the articles 
communicated to learned societies. In cases of question of prioits, the right depends, of course, on the period of publication; but this is sometimes with great difficulty ascertainable, and motives of convenience have dictated the sequence adopted.

Perhaps some will be disposed to believe that the compiler has sinned in redundancy rather than deficiency in this bibliography. The evils of the former are, however, easily remedied, while those of the latter must leave the consulter in more or less doubt. Many popular works have been catalogued where original information of even slight value was contained, and when such works were among the earliest published on the regions in question. Besides those enumerated, works on California, too numerous to mention, contain incidental information (very rarely of any original value, however) respecting the fishes and fisheries of that State; and a number on the British possessions belong to the same category. Among those relative to British Columbia and Vancouver's Island worthy to be mentioned, but not to be particularized, are the volumes of $\mathrm{Wm}$. Carew Hazlitt (1558), J. Desford Pemberton (1560), Duncan George Forbes Macdonald (1862), Capt. C. E. Barrett Lennard (1862), Alexander Rattray (1862), Com. R. O. Mayne (1862), G. M. Sproat (1868), Francis Poole (1872), and Capt. W. F. Butler (1873).

The titles of the Government publications are taken from a manuscript compilation embracing notices of all the reports published by the General and State governments on scientific explorations, and intended to be more particular than the present work. They are retained with the bars ( $\mid$ ), indicating the distribution, on the title. pages of the lines, etc.

Several societies have, or have had, the custom of publishing communications, sometimes of an elaborate and extended nature, withont any titles. This strange and senseless mode of procedure seems to have originated in some freak or affectation of modesty on the part of authors, perhaps, rather than a deliberate intention to shirk labor or confuse matters. Confusion and trouble to others are nerertheless the result of this vicious negligence, and a consequence is an ignoring of the papers thus unentitled or an irreconcilable variation of titles in different bibliographies. Whether the custom originates with authors or not, the assumption of it is discreditable to the editor or editors of the publications adopting it. A number of the papers here recorded belong to this category of the unentitled or disentitled: the titles fol. 
lowing preceded by an asterisk $\left(^{*}\right)$ are selected from the remarks prefatory to the paper in the proceedings, and those preceded by a dagger $(t)$ have been composed by the present writer, since nothing intelligible precedes the papers themselves. It is to be hoped that the senseless and causeless $\sin$ in question may speedily be discontinued. There is no reason why any one should be compelled to read the whole of an article (as is sometimes necessary) to obtain an idea of what the paper relates to; and the "Catalogue of Scientific Papers (1800-1863) compiled and published by the Royal Society of London" shows how a bibliography edited under the best auspices may be involved in grave errors by the negligence adverted to. 



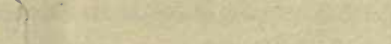

\section{TITLES OF WORKS.}

1757-Noticia de la California, y de su conquista temporal y espiritual hasta el tiempo presente. Sacada de la historia manuscripta, formada en Mexico año de 1739. por el Padre Miguel Venegas, de la Compañia de Jesus; $y$ de otras Noticias, $\boldsymbol{J}$ Relaciones antiguas, $\boldsymbol{y}$ modernas. Añadida de algunos mapas particulares, $\boldsymbol{J}$ uno general de la America Septentrional, Asia Oriental, y Mar del Sùr intermedio, formados sobre las M morias mas recientes, y exactas, que se publìcan juntamente. Dedicada al Rey N.too Señor por la Provincia de Nueva-España, de la Compañia de Jesus. Tomo primero [-Tomo tercern].-Con licencia. En Madrid: En la Imprenta de la Viuda de Manuel Fernandez, y del Supremo Consejo de la Inquisicion. Año de M.D.CCLVII. [80, 3 vols. $]$

[Translated as follows:-]

I Natural and Civil History of California : containing an accurate descrip. tion of that country, its soil, mountains, harbonrs, lakes, rivers, and seas ; its animals, vegetables, minerals, and famous fishery for pearls. The customs of the inlabitants, their religion, government, and manner of living, before their couversion to the Christian religion by the missionary Jesuits. Together with accounts of the several voyages and attempts made for settling California, and taking actual surveys of that country, its gulf, and coast of the Soutb-Sea. Illustrated with copperplates, and an accurate map of the country and adjacent seas. Translated from the original Spanish of Miguel Venegas, a Mexican Jesuit, published at Madrid 1758.-In two volumes.-Vol. I [-II]. = London : printed for James Rivington and James Fleteber, at the Oxford Theatre, in Pater-Noster-Row. 1759. [8०, vol. i, 10 k, 455 pp., 1 pl.; vol. ii.]

[The onily references to fishes are as fullows (v. i, pp. 47-48):- "But if the soil of California be in general barren, the scarcity of prorisions is supplied by the adjacent sea; for both in the Pacifick ocean and the Gulf of California, the multitude and rariety of fishes are incredible. Father Antonio de la Ascencion, speaking of the hay of San Lucas [Lower California], says, ' With the nets which every ship carried, they caught a great quantity of fish of different kinds, and all wholesome and palatable: particalarly holybuss, salmon, turbots, skates, pilchards, large oysters, thornbacks, mackerel, barbels, bonetos, soals, lobsters, and pearl oysters.' And, speaking of tho bay of San Francisco, on the western coast, he adds: 'Here are such multitndes of fish, that with a net, which the commodore had on board, more was canght every day than the ship's company conld make use of: and of these a great variety, as crabs, oysters, breams, mackerel, cod, barbels, thornbacks, \&c.' And in other parts he makes mention of the infinite number of sardines, which are left on the sand at the ebb, and so exquisite that those of Laredo in Spain, then famous for this fish, do not exceed them. Nor are fish less plentiful along the gulf [of California], where to the above mentioned species Father Picolo adis, tunnies, anchories, and others. Even in the rivulets of this peninsula are found barbels and erayfish : but the most distinguished fish of both seas are the whales; which induced the ancient cosmographers to call California, Punta de Balenas, or Cape Whalo: and these fish being found in multitudes along both coasts, give name to a channel in the gudf, and a bay in the South sea" ( 
1772 -Voyage en Califorvie pour l'observation du passage de Vénus sur le disque dn soleil, le 3 juin 1769 ; contenant les observations de ce phénomène et la discription historique de la route de l'auteur à travers le Mexique. Par feu M. Chappe d'Auteroche, ... Rédigé et publié par M. de Cassini fils . . . À Paris: chez Charles-Antoine Jombert. MDCCLXXII. [4, half-title, title, 170 [2] pp., plan, and 2 pl.-Sabiv.]

[Translated as follows:-]

A Voyage to California, to observe the Transit of Venus. By Mons. Chappe d'Auteroche. With an bistorical description of the author's route through Mexico, and the natural history of that province. Also, a voyage to Newfoundland and Sallee, to make experiments on Mr. Le Roy's time keepers. By Monsieur dө Cassini. London: printed for Edward and Charles Dilly, In The Poultry. MDCCLXXVIII. [ $\left[8^{c}, 4\right.$ p. 1., 315 pp., with "plan of City of Mexico".]

Extract of a letter from Mexico addressed to the Royal Acadewy of Sciences at Paris, by Don Joseph Anthony de Alzate y Ramyrez, now a correspondent of the said academy, containing some curious particulars relative to the uatural bistory of the country adjacent to the City of Mexico. pp. 77-105.

[It is undoubtedly this work that is meant in the statement that has so largely gone the rounds of the periodical press, to the effect that the Californian viviparous fishes were ob. served dnring the voyage for the observation of the transit of Venus to Lower California, 1769. A perusal of the accounts given, however, renders it evident that the fishes in question were not Enabiotocids but rather Cyprinodontids, probably of the genus Mollienesia. The account by Don Alzate (pp. 89-91) is as follows:-

"I send you some viviparous scaly fishes, of which I had formerly given you an accouut. What $I$ have observed in them this year is-'If you press the belly with your fingers, you force ont the fry before their time, and upon inspecting them through the microscope yon may discern the circulation of the blood, such as it is to be when the fish is grown up.' If you throw these little fishes into water, they will swim as well as if they had been long accustomed to live in that element. The fins and tail of the males are larger and blacker than those of the females, so that the sux is easily distinguished at first sight. These fish have a singular manner of swimming; the male and the female swim together on two par. allel lines, the female always uppermost and the male undermost; they thus always keep at a constant uniform distance from each other, and preserve a perfect parallelisu. The feruale never makes the least motion, either sideways or towards the bottom, but directly the male does the same."

To this account is added a foot-note (p. 90) containing the following additional informa. tion :-

"Don Alzate has sent those fishes preserved in spirits; their skin is covered with very small scales; they vary in length from an inch to eighteen lines, and they are seldom abovo five, six, or seveu lines in the broadest part. They have a fin on each side near the gills, two small ones under the belly, a single one behind the auus, which lies between the fin and the single one; the tail is not forked; lastly, this fish has a long fin on the back, a little above the fin, which is under the belly.

"We know of some viviparous fishes in our seas, such as loach, \&c. most of these have a smooth skin without any scales. The needle of Aristotle is viviparous, and yet covered with broad and hard scales, I have caught some that had young ones still in their womb. As to these viviparous fishes, it is a particular and new sort, and we are obliged to Don Alzate for making us acquainted with it. It breeds in a lake of fresh water near the City of Mexico."

This is, so far as known, the earliest notice of the viriparity of Cynrinodontids. The mode of consorting together (exaggerated in the account) is common to a number of representatives of the family, and is alluded to by Prof. Agassiz in a name (Zygonectes, i.e. swimming in pairs) conferred on one of the genera of the family.]

1808-Piscium Camtschaticorum [Tcrpuk] et [Wachnja]. Descriptiones et iconos auctore [W. G.] Tilesio. D. 26 Octobri 1808. Conventui exhib. die 2 Nov. 1808. <Mém. Acad. Sci. Pétersb., v.2, pp. 335-375, 1810, viz:-

I. Hexagrammos Stelleri, Rossis Terpuc dictus novum genus piscium Carntschaticorum. pp. 335-340, tab. 15. 
II. Dimensiones piscis, beato Stellero Hexagrammos asper dicti, Rossis Teerpuk [ Terpuk] i. e. lima (captus d. $20 \mathrm{Maij} 1741$ in portu Divi Petri et Panli pondebat pondere medicinali duas nsque ad sex uncias). pp. $340-341$.

III. Hexagrammos Stelleri, quænam genera sit interponendus cuinam classi ordinique systematico sit inserendus. Labrax Pallassii (vid. ej. Monograph.). pp. $34: 2-343$.

IV. Descriptio Stelleri anno 1741 concepta. pp. 343-34\%

V. Observationes anatomicæ. pp. 347-349.

VI. Wachnja Camtschatica est Gadús dorso tripterygio, Callariis speciatin Lusco affinis. pp. 350-353, tab. 16, 17.

VII. Wachniæ Camtschaticæ altera species, (Gadus gracilis mihi,) quæ ab indigenis Camtscbaticis aeque Üachal, Rossis Wachnja [ Wachnja] dicitur, dimensionibus illustrata. pp. 354-356, tab. 18.

VIII. Stelleri Descriptio piscis ovos sire asini antiquorum. Turneri ad Gesnerum aselli 3 sivi Egglefini Rondelet et Gesneri. Aglefini Bellonii, Anglorum Hadok, Russis Wachnja [ Wachnja] dicti corrupta roce Itaelmannica, in qua Ưakal audit. pp. :356-359.

IX. Observationes anatomicæ. pp. 360-363.

X. Observationes ex aliorum individuorum ejusdem speciei dissectionibus, pp. 363-364.

XI. Ad historiam Gadi dorso tripterygio ore cirrato caudo æquali fere cam radio primo spinoso (Kabeljau vel Cabiljau Belgarum) (Gadus morrhua L. Bloch. tab. 64), adhuc annotata sequentia. pp. 364-370.

XII. Annotationes anatomica. pp. 370-371.

XIII. Tabularun explicatio. pp. 372-375.

1809-Labraces, novum genus piscium, oceani orientalis, auctore P. S. Pallas. Conventui exhib. die 5 Julii $1809 .<$ Mém. Acad. Sci. St. Pétersb., r. 2, pp. 382-398, 1810.

[2.. sp. L. decagrammus, L. superciliosus, L. monopterygius.]

Description de quelques poissons observés pendant son voyage antour du monde. Par W. G. Tilesius. <Mém. Soc. Imp. des Naturalistes de Moscon. t. 2, pp. 212-249, with 5 pl., 1809.

1811 -Icônum et Descriptionum piscinm Camtschaticornm continuatio tertia tentamen monographiæ generis Agoni Blochiani sistens. Anctore [W. G.] Tilesio. Cum tabulis vi æeneis.-Conventni exhibita die 11 Decembris 1811 . <Mém. Acad. Sci. Pétersb., r. 4, pp. 406-478, 1812, viz:-

De novis piscium generibus, Agouo Blochii et Phalangiste cel. Pallasii, propter synonymiam conjugendis. pp. 406-454.

Appendix de Cyprino rostrato et cultrato, Trachino trichodonto et Epenephelo ciliato. pp. 454-457.

Descriptio Cyprini rostrati Tnngusis ad Covymam fluv. Tschukutscham et Jucagiris Onatscha dicti. pp. 457-474, tab. xv, fig. 1-5.

Epinephelưs ciliatus Cantschaticus et Americanus. pp. 474-478, tab. xvi, fig. 1-6.

Zoographia Rosso-Asiatica, sistens Omnium Animalium in extenso imperio Rossico et adjacentibus maribus observatorum Recensionem, Domicilia, Mores et Descriptiones, anatomen atque Icones plurimorum. Auctore 
Petro Pallas, Eq.Aur. Academico-Petropolitano.-Volumen tertium.-Petropoli in Officina Caes. Academiæ Scientiarum Impress. M.DCC.CXI. Edit. MDCCCXXXI. [4\%, vii, 428 , exxv pp., 6 pl. $]$

[As indicater on the title-page, the "Zoographia Rosso-Asiatica" was not regularly published till 1831, but was printed in 1811 , and was only detained by the loss of the copper-plates. The letter-press was, however, to a slight extent, distributed before the regular publication of the edition, and a copy was possessed by Cuvier, who bas given a summary of the third volume in the Histoire Naturelle des Poissons (t. 1, pp. 200-201).

Describes species of which specimen had been obtained from the Russian possessions in Northwestern America. The following are published as if new, although several had previously been described :-

Phalangistes acipenserinus (p. 110, pl. 17).

Cottus polyacanthocephalus (p. 133, pl. 23).

Cottus platycephalus (p. 135, p!. 24).

Cottus trachurus (p. 138, pl. 25).

Cottus pistilliger (p. 143, pl. 20, f. 3, 4).

Blennius dolichogaster (p. 175, pl. 42, f. 2).

Blennius anguillaris (p. 176, pl. 42, f. 3).

Gadus wachna (p. 182, pl. 44).

Gadus pygmaeus (p. 199).

Gadus fimbria (p. 200).

Ammodytes hexapterus (p. 226).

A mmodytes septipinnis (p. 227, pl, 48, f. 3 ).

Trachinus trichodon (p. 235, pl. 50, f. 1).

Trachinus cirrhosus (p. 237, pl. 50, f. 2).

Perca variabilis (p. 241).

Labrax decagrammus (n. 278, pl. 62, f. 2).

Labrax superciliosus (p. 279, pl. 63, f. 1).

Labrax monopterygius (p. 281, pl. 63, f. 4).

Labrax octogrammus (p. 283, pl. 64, f. 1).

Salmo lagocephalus (p. 372, pl. 77, f. 2).

Salmo proteus (p. 376, pl. 78, f. 2, p!. 79 ).

Pleuronectes quadritubercu?atus ( 2.422$)$.

Pleuronectes cicatricosus (p. 424).

The plates reforred to were never published.

The only other species signalized as inhabitants of the A merican waters are the fol. lowing:-

Raja batis (, .57$)$.

Salmo socialis (p. 389, pl. 81, f. 2).

Pleuronectes stellatus (p. 416).

Pleuronectes hippoglossus (p. 421).]

1814 -History | of | the expedition | under the command of | Captains Lewis and Clark, | to | the sources of the Missouri, | thence | across the Rocky Mountains $\mid$ and down the | River Columbia to the Pacific Ocean. | Performed during the Jears 1804-5-6. | By order of the / Government of the United States. | Prepared for the press | by Paul Allen, Esquire. I In two volimes. | Vol. I [-II]. | Philadelphia: | Published by Bradford and Inkskeep; and | Abm. H. Inskeep, Newyork. | J. Maxwell, Printer. | 1814. [80, vol. i, lxxviii; 470 pp., maps ; vol. ii, ix, 522 pp., maps.]

[Vol. ii, chap. vii, contains "A general description of the beasts, birds, and plants, \&c., found by the party in this expedition" (pp. 148-201). Incidental allusions and quasidescriptions of a popular kind are given of come fishes, but nothing of an ex ct naturo is made known.

"An account of the various publications re!ating to the travels of Lewis and Clarke, with a commentary on the zoological, results of their expedition", has been published by Dr. Elliott Cones, U. S. A. (Bull. U.! S. Geol. and Geog. Surv. Terr., v. 1, pp. 417-444, Fob. $8,1876)$.]

1820-Relation d'un voyage à la côte du nord-ouest de l'Amérique septentrionale dans les années 1810-1814. Par Gabriel Franchère. [Réligé par Michel Bibaud.] Montréal, 1820. [8॰,284 pp.-Sabin.] 
[Translated as follows:-]

Narrative of a vorage to the northwest coast of America in the jears 1811, 1812, 1813, and 1814, / or the first American settlement on the Pacific / By Gabriel Franchere | Translated and edited by J. V. Huntington | - | Redfield | 110 and 112 Nassau street, New York | 1854. [12॰,376 pp., 3 p].]

[The salmon is noticed in chapter 18.$]$

1822 - Vorage pittoresque autour du monde, avec des portraits de sauvages d'Amérique, d'Asie, d'Afrique, et des lles du grand océan; des pajsages, des vues maritimes, et plusieurs objets d'histoire naturelle; accompagné de deseriptions par M. le Baron Cavier, et M. A. de Chamisso, et d'observations sur les crânes humains par M. le Docteur Gall. Par M. Lcuis Choris, Peintre.Paris, de l'imprimerie de Firmin Didot, ... 1822. [Fol., 2 p. l., vi pp.+[i], 12 pl., 17 pp.+[ii], 10 pl., 20 pp.+[iii], 14 pl., 10,3 pp. $+[$ iv $], 18$ pl., 24 pp. + [v], 19 pl., 22 pp. + [vi ], 23 pl., 28 pp. + [vii], 7 pl., 19 pl.]

[Partie vi.] Chapeau de bois, sur lequel sont peintes divers animaux ma-

rins. Planche v. Par G. Cuvier. pp. 21-2:.

[Cnvier considers that one of the figures $(h)$ represents a Diodon, and such seems to be the case; but no species of that t5pe has been fonnd so far northward as Cnalashka, where the hat was obtained. ("Eu $h$, est un Diodon ou orbe épincux, qui est pris à la ligne tandis que les grands cétacés du reste de ce tableau sout poursuivis arec des lances" (p. 22).1

1823 -Account | of | an expedition | from | Pittsburgh to the Rocky Mountains, | performed in the years 1819 and '20, | by order of $j$ the Hon. J. C. Calboun, Sec'y of War: | under the command of | Major Steplien H. Long. | From the notes of Major Long, Mr. T. Say, and other gen- | tlenen of the exploring party. | - | Compiled | by Eawin Jazmes, | botanist and geolugist for the expedition. | - | In two vols. - With an atlas. | Vol. II. | - | Philadelphia: | H. C. Carey and J. Lea, Chesnut st. | 1823. [2 v.,80. Vol.i,2 p. 1., 503 pp.; vol. ii, 3 p. I., 442 pl.]

1828-Histoire Naturelle des Poissons, par M. le Bon Cuvier, . . . ; et par M. Valenciennes,.... Tome premier. À Paris, chez F. G. Levrault,...., 1823. [8० ed. xvi, 574 pp., 1 1.; $4^{\circ}$ ed. xiv, 422 pp., 1 1.-pl. 1-8 (double).]

Livre premièr.-Tableau historique des progrès de l'ichthjologie, depuis sou origine jusqu’à nos jours.

Livre deuxième.-I Iée générale de la nature et de l'organisation des poissons.

[Pallas" "Zoographia Rosso-Asiatica" noticed at pp. 200-201.]

Histoire Natnrelle des Poissons, par M. le Bon Cuvier, . . . ; et par M. Valenciennes, .... Tome deuxième. A Paris, chez F. G. Levrault,... 1323. [30 el. xxi, (1 1.), 490 pp.; 40 ed. xvii, (1 1.), : : 1 pp.-pl. 9-40.]

Livro troisième.-Des poissons de la famille des Perches, ou des Percoides. [Par Cuvier.]

[No west-coast species specified.]

1829-Histoire Naturelle des Poissons, par M. lo Bon Cuvier, . . . ; et par M. Valen. ciennes, .... Tome troisième. À Paris, chez F. G. Levrault, . . . , 1829. [ $8^{\circ}$ ed. $x x$ viii, 500 pp., 1 l.; $4^{\circ}$ ed. xxii, (1 1.), 368 pp.-pl. 41-71.]

Livre troisième.-Des poissons de la famille des Perches, ou des Percoïdes. [Par Cuvier.]

[N. sp. name, Trichodon Stelleri, based on Trachinus trichodon Pallas.] 
1829 -Histoire Naturelle des Poissons, par M. le Bon Cuvier, . . . ; et par M. Valenciennes, ..... Tome quatrième. À Paris, chez F. G. Levrault, . . . , 1829. [ $8 \circ$ ed xxvi, (1 l.), 518 pp. ; $4^{\circ}$ ed. $x x$, (1 1.), $3 \% 9$ pp.-pl. $72-99,97$ bis.] Livre quatrième.-Des Acanthoptérygiens à joue cuirassée. [Par Cnvier.]

[N. sp. Cottus ventralis, Hemilepidotus Tilesii.]

Zoologischer Atles, enthaltend Abbildungen und Beschreibungen nener Thierarten, wäbrend des Flottcapitains von Kotzebue zweiter Reise um die Welt, auf der Russisch-Kaiserlichen Kriegsschlupp Predpriatië in den Jahreu 1823-1826 beobachtet von Dr. Friedr. Eschscholtz, Professor und Director des zoologischen Museums an der Universität zu Dorpat, Mitglied mebrerer gelehrten Gesellschaften, Russ. Kais. Hofrathe und Ritter des Ordens des heil. Wladimir. Drittes Heft.-Berlin, 1829. Gedruckt und verlegt bei G. Reimer. [Fol., title, 18 pp., pl. 11-15.]

[N. sp. Blepsias vintricosus (p. 4, pl. 13), on which was subsequently based the genus Temnistia of Richardson.]

1830-Histoire Naturelle đés Poiseons, par M. le Bon Cuvier, . . . ; et par M. Valenciennes, .... Tome cinquième. Ȧ Paris, chez F. G. Levrault, . . . , 1830. [ $8^{\circ}$ ed. xxviii, 499 pp., 2 l.; 40 ed. xx, 374 pp., 2 l.-pl. 100-140.]

Livre cinquième.-Des Sciénoïdes. [Par Cuvier.]

[No west-coast species noticed.]

Histoire Naturelle des Poissons, par M. le Bon Cuvier, ... . ; et par M. Valenciennes, .... Tome sixième. À Paris, chez F. G. Levrault. . . . , 1830. [ $8^{\circ}$ ed. xxiv, 559 pp., 3 l.; $4^{\circ}$ ed. xviii, (3 l.), 470 pp. - pl. 141-169. 162 bis, 162 ter, 162 quarer, 167 bis, 168 bis.]

Livre sixième.-(Partie. I.-Des Sparoïdes. Partie II.-Des Ménides.)

[Par Cuvier et Valencieunes.]

[No west-coast species noticed.]

1831 -Histoire Naturelle des Poissons, par M. le Bon Cuvier, . . . ; et par M. Valenciennes, .... Tome septième. À Paris, chez F. G. Levrault, . . . , 1831. [ $8 \circ$ ed. xxix, 531 pp., 3 l.; $4^{\circ}$ ed. xxii, (3 1.), 399 pp.-pl. 170-208.]

Livro septième.-Des Squamipennes. [Par Cuvier?]

Livre buitième.-Des poissons à pharyngiens labyrinthiformes. 「Par Cuvier ?]

[No west-coast species noticed.]

Histoire Naturelle des Poissons, par M. le Bon Cuvier, . . . ; et par M. Valenciennes, ..... Tome huitième. À Paris, chez F. G. Levrault, . . . . 1831. [ 80 ed. xix, (2 l.), 509 pp. ; 4 od. xv, (2 1.), 375 pp.-pl. 209-245.]

Livre neuvième.-Des Scombéroïdes. [Par Cuvier et Valenciennes.]

[No west-coast species noticed.]

Zoographia Rosso-Asiatica. See 1811.

1833 - Kiistoire Naturelle des Poissous, par M. le Bon Cuvier, . . . ; tt par M. Valen. ciennes, .... Tome neuvième. À Paris, chez F. G. Levrault, ...., 1833. [ $8 \circ$ ed. xxix, 512 pp., 1 l.; $4^{\circ}$ ed. xxiv, (1 1.), 379 pp. -pl. 246-279.]

Livre neuvième.-Des Scombéroïdes. [Par Cuvier et Valenciennes.]

[No west-coast species noticed.] 
1835 - Histoire Naturelle des Poissons, par M. le Bon Cuvier, . . . ; et par M. Valenciennes, .... Tome dixième. ¿ Paris, cbez F. G. Levrault, . . . , 1835. [8० ed. xxiv, 482 pp., 1 l.; $4^{\circ}$ ed. xix, (1 1.), 358 pp.-pl. 280-306.]

Suite du livre neuvième-Des Scombéroïdes. [Par Cuvier et Valenciennes?]

Livre dixiè $x$ e.-De la famille des Teuthies. [Par Cuvier et Valencieunes?] Livre onzième.-De la famille des Tænioïdes. [Par Cuvier et Valeneiennes?]

Livre douzième.-Des At herines. [Par Cuvier et Valenciennes ? ]

[No west-coast species noticed.]

1836-Fauna Boreali-Americana; or the Zoology of the Northern Parts of British America : containing descriptions of the objects of Natural History collected - on the late northern land expeditions under command of Captain Sir John Franklin, R. N. Part third. The Fish. By John Richardson, M. D., F. R. S., F. L. S., Member of the Geographical Society of London, and Wernerian Natural History Society of Edinburgh; Honorary Member of the Natural History Society of Montreal, and Literary and Philosophical Society of Quebec; Foreign Member of the Geographical Society of Paris; aud Corresponding member of the Academy of Nataral Sciences of Pbiladelpbia; Surgeon and Naturalist to the Expeditions.-Illustrated by numerous plates.-Pnblished under the authority of the Right Hononrable the Secretary of State for Colonis, Affairs.-London: Richard Bentley, New Burlington street,

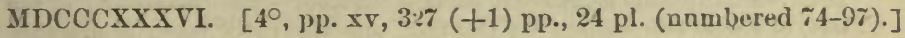

[N. g. and n. sp. Temniztia (n. g., 59), Cyprinus (Leuciscus) gracilis (120), Salmo Scoule, i (152, 223), Salmo quinnat (219), Salmo Gairdneri (221), Salmo paucidens (222), Salmo tsuppitch (2:24), Salmo Clarkii $(225,307)$, Salmo (Mallotus?) pacificus (226), Acipenser transmontamus (273), Petromyzon tridentatus (:93); (ADDENDA:) Cottus asper (295,313), Cyprinus (Abramis) balteatus (301), Cyprinus (Leuciscus) caurirus (304), Cyprinus (Leuciseus) cregonensis (305).]

Report on North American Znology. By John Richardson, M. D., F. R. S. <Rep. 6th meeting Brit. Assoc. Adv. Sci., Ang. 1836, =v. 5, pp. 121-224, 1837 .

Pisces, pp. 202-223.

Astoria, or anecdotes of an enterprise beyond the Rocky Mountains. By Washington Irving. [1st ed.] In two volumes. Vol. I [-II]. Philadelphia : Carey, Lea \& Blanchard. 1836. [2 vols., $8^{\circ}$. Vol. i, 225 pp.; vol. ii, 279 pp., 1 map folled.]

[The fishes and fisheries, especially salnuon, are noticed in roi. 2, chapters 9 and 14.]

Histoire Naturelle des Poissons, par M. le Bon Cuvier, . . . . ; et par M. Valenciennes, .... Tome onzième. À Paris, chez F. G. Levrault, ....

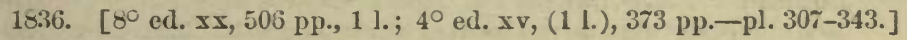

Livre troisième.-Des Mngiloĩles.

Livre quatorzième.-De la famille des Gobioĩdes.

[No west-coast species noticed.]

1837 - Histoire Naturelle des Poissons, par M. le Bon Cuvier, . . . ; et par M. Valenciennes, . . . Tome duzième. À Paris, chez F. G. Levrault, . . . , 1837. [8. ed. $x x i v, 507+1$ pp.; $4^{\circ}$ el. xx, 377 pp., 1 l.-pl. 344-368.]

Suite du livre quatorzième.-Gobioĩdes.

Livre quinzièıns.-Des Acauthoptérygiens à pectorales pédiculées:

1839 -Histuire Naturelle des Poissons, par M. le Bon Cuvier, . . .; et par M. Valenciennes, ... Tome troisième. Á Paris, chez Pitois-Levranlt et $\mathrm{C}^{\bullet}, \ldots$, 1839. [80 ed. xix, 505 pp., 1 1.: $4^{\circ}$ ed. xvii, 370 pp.-pl. 369-383.]

Livre seizième-Labroïdes.

[No west-coast species noticed.] 
1839-Histoire Naturelle des Poissons, par M. le Bon Cuvier, . . . ; et par M. Valenciennes, ... Tome quatorzième. İ Paris, ehez Pitois-Levrault et Ce, . . . , 1839. [ $8^{\circ}$ ed. $x x i i, 464$ pp., 3 1.; $4^{\circ}$ ed. $x x, 344$ pp., 3 1.-pl. 389-420.]

Suite du livro seizième.-Labroïdes.

Livre dix-septième.-Des Malacoptórygiens. Des Siluroïdes.

[No west-coast species noticed.]

The Zoology of Captain Beechey's Voyage; compiled from the collections and notes made by Captain Beechey, the officers and naturalist of the Expedition, during a Voyage to the Pacifie and Behring's straits performed in his Majesty's Ship Blossom, under the command of Captain F. W. Beechey, R. N., F. R. S., \&c., \&e. in the years 1825, 26, 27, and 28. By J. Richardson, M. D., F. R. S., \&c. ; N. A. Vigors, Esq., A. M., F. R. S., \&c. ; G. T. Lay, Esq. ; E. T. Bennett, Esq., F. L. S., \&c.; tho Rev. W. Bucklind, D. D., F. R. S., F. L. S., F. G. S., \&c. and G. B. Sowerby, Esq.-Illustrated with upwards of fifty finely coloured plates, by Sowerby.-Published under the authority of the Lords Commissioners of the Admiralty:=London: Henry G. Bohn, 4, York Street, Covent Garden.-MDCCCXXXIX.

Fishes; by G. T. Lay, Esq.. and E. T. Bennett, Esq., F. L. S., \&c. pp. 41-75, pl. 15-23.

[N. sp. Chimara colliei (p. 71, pl. 23).

This volume is interesting as being the first publication in which any attempt has been made to scientifically indicate the fishes of the coast. The "naturalist" of the expedition was, however, incompetent for the task, and the notes taken evince that he was not sufficiently rersed in the rudiments of ichthyology to know what to observe. Nevertheless, the notes have an interest, if not of importance, enojgh to transcribe what relates to the regions in question :-

"Off Saint Lawrence Island was caught, in the dredge a fish apparently allied to the genus Liparis, Art. It had the 'ventral fins placed before the pectorals, but united and continuous with them; a flat, raised, and rough tubercle, of nearly the diameter of an English sixpence, was seated forward between the pectorals, its anterior part reaching as far as the ventrals; this may be of use iu copulation : its caeca were pretty numerous.'-C. The roughness of this tubercle renders it difficult to refer the fish to any known species; but it is probably nearly related to the Cyclopterus gelatinosus, Pall., a Lipuris which is known to inhabit the seas in which this was obtained. The existence of caec $a$ removes it from Lepadogaster, Gouan.

"Kotzebue Sound afforded a specimen of a new species of Ophidium, L., the Oph. stigma.

"On the coast of California, a little to the northwards of the harbour of San Francisco, an Orthagoriscus was met with, apparently the Orth. mola., Bl. They swam about the ship with the dorsul fiu frequently elevated abore the surface." (p. 50.)

"On the coast of California, at Monterey, Mr. Collie's notes mention the occurrence of [1] a species of Sparus, of two Scombri, and of a Clupea. [2] The first of the Scombridae is apparently a Scomber, Cuv.; it was 'smaller than the mackerel; it was marked on the back with cross waved narrow bands of black and greenish blue; its first dorsal fin had nine spines, and there were four small pinnules behind the second dorsal and the anal : it had a simple air-bladder of moderate size, and an immense number of coec $\alpha$, with a stomach extending the whole length of the abdomen, narrow, tapering to the posterior part, and covered throughout nearly its whole length with the milt.? Its internal membrane forns longitudinal folds; the intestines have three convolutions.'-C. This fisl occurred in shoals. [3] The second species was met with but once. It is a Caranx, Cur., of which 'the teeth in the upper maxillary are scarcely to be felt: the pectorals reach neariy to opposite the anus: a double narrow stripe of deeper blue than the general surface runs backwards on each side of the first dorsal fin to opposite its termination, the two parts being separated by a broad line of dirty white, which has a narrow, dark-colunred line along its middle: there are no distinct divisions in the anal and second dorsal fins: the air-bladeler is simple, and small, and extends from the faucer to the anus; the stomach is much shorter than in the preceding species; the coeca, although numerous, are less so than in it, and the tutestine is folded in the same manner.'-C. From the nature of the colouring of this fish, as described by Mr. Collie, there can be little doubt of its constituting a clistinct species. 
[4] Aloug with the first species of Scomber, there occurred in shoals a small species of Clapea, L., 'without teeth; with the dorsal fin a little before the ventral; and with the back dark greenish blue, and having one line and part of another of rounded black spots on each side nearly on a level with the eye: the gill membranes contain six rays, and orerlap each other at their lower part; the stomach resembles that of the first Scomber; it has also nnmerous caeca; the air-bladler is small and tapering.' - C. The other fishes observed at Monterey were [5] a new species of Ohimara, Cur., differing essontially from the Chimcera of the Atlantic, and approaching somewhat in the position of its second dorsal fin to the Callorhynchus, Cuv.; [6] a species of Torpedo, Dum.; and [7] a Raia" (pp. 54-55).]

1839-Narrative of a Journey across the Rocky Mountains, to the Columbia River, and a Visit to the Sandwich Islands, Chili, \&c. With a Scientific Appendix. By John K. Townsend, Member of the Academy of Natural Sciences of Philatelphia. Philadelphia : Henry Perkins, 134 Chestnut street. Boston: Perkins \& Marvin.-1839. [8०, 352 pp. ]

[A few incidental popular notices of salmon and trout are giren.]

[Reprinted in England under the following title:-]

Sporting Excrirsions in the Rocky Monntains, including a Journey to the Columbia River, and a Visit to the Sandwich Islands, Chili, \&c. By J. K. Towshend [sic!], Esq. In two volumes. Vol. I [-II]. Londoi: Heury Colburn, Publisber, Great Marlborough Street. 1840. [8०. Vol. i, xii [+i], 312 pp., 1 pl.; vol. ii, xii, 310 pp., 1 pl.]

[In vol. i, chap. 7, are given details respecting salmon and the mode of catching them, and the froutispiece illustrates a native woman "spearing the salmon".]

1840 - Histoire Naturelle des Poissons, par M. lo Bon Cuvier, . . . et par M. Valenciennes, ... To Tome quinzième. đ Paris, chez Ch. Pitois, éditeur, ...., 1840. [ $8^{\circ}$ ed. $x x x i, 540$ pp., 1 l.; $4^{\circ}$ ed. xxiv, 397 pp.-pl. 421-455.]

Suite du livre dix-septième.-Siluroïdes.

[No west-coast species noticed.]"

Narrative of a whaling voyage round the globe, from the year 1833 to $18: 36$, comprising sketches of Polynesia, California, the Indian Archipelago, etc. with an aecount of Southern Whales, the Sperm Whale Fishery, and the Natural History of the climates visited. By Frederick Debell Bennett, Esq., F. R. G. S., Fellow of the Royal College of Surgeous, London. In two volumes. Vol. I [-II]. London: Richard Bentley, New Burlington street, publisher in orlinary to her Majesty. $-1840 . \quad\left[8^{\circ}\right.$, vol. i, xv, 402 pp., 1 pl., 1 map; vol. ii, vii, 396 pp., 1 pl.]

1842-Histoire Naturelle des Poissons, par M. le Bon Cuvier, . . . , et par M. Valenciennes, . . . . Tome seizième. À Paris, chez P. Bertrand, . . . , 184?. [ $3^{\circ}$ ed. $x x, 472$ pp., 1 l.; $4^{\circ}$ ed. $x$ viii, 363 pp., 1 1.-pl. 456-487.]

Livre dix-huitième.-Cyprinoîdes.

Zoology of New-York, or the New-York Fauna; comprising detailed descriptions of all the animals hitherto observed within the State of New-York, with brief notices of those occasionally found near its borders, vand accompanied by appropriate illustrations.-By James E. DeKay.-Part IV.Fishes. Albany: Printed by W. \& A. White and I. Visscher. 1842. [4ํ, xiv [1, errata ], 415 pp.; atlas, 1 p. $1 ., 79$ pl. ]

[The letterpress of the Peptiles and Fishes, each separately paged, forms one rolume, and the plates, each separately numbered, another. Eight of the northwest-coast Malacopterygian species (Abramis balteatus, Leuciscus caurinus, Leuciscus oregonensis, Salmo quinnat, Salmo Gairdnerii, Salmo Scouleri, Salmo tsuppitch, aud Salmo nitidus) and the Sturgeon (Acipenser transmontanus) enumerated by Richardson (1836) are briefly indicated as "extra-limital".] 
1844-Histoire Naturelle des Poissons, par M. le Bon Cuvier, . . . ; et par M. Valenciennes, . . . . Tome dix-septième. À Paris, chez P. Bertrand, . . . , 1844. [8० ed. xxiii, 497 pp., 1 l.; $4^{\circ}$ ed. xx, 370 pp. 1 l.-pl. 487 (bis)-519.]

Suite du livre dix-huitième.-Cyprinoïdes.

1845-Description of a new species of Syngnathus, brought from the western coast of California by Capt. Phelps. By Dr. D. H. Storer. < Proc. Boston Soc. Nat. Hist., v. 2, p. 73, December, 1845.

[N. sp. Syngnathus californiensis.]

1846-A Synopsis of the Fishes of North America. By David Humphreys Storer, M. D., A. A. S., . . . < Mem. Am. Acad. Arts and Sci., new series, vol. ii, pp. 253-550, Cambridge, 1846.

[739 nominal species from all North America, including the West Indies, are described. The descriptions, however, are most inaptly compiled and entirely insufficient.]

A Synopsis of the Fishes of Nurth America. By David Humphreys Storer, M. D., A.A.S., . . . Cambridge: Metcalf and Company, Printers to the University. 1846. [4, 1 p. l. (=title), 298 pp. $]$.

[A rep int, with separate pagination, title-page, and index, of the preceding.

- According to Dr. Storer (Mem. Acad., p. 260; Syn. p. 8), "the following species inhabit the northwestern coast of America :-

Trichodon stelleri.

Cottus pistilliger.

Cottus polyacanthocephalus.

Cottus asper.

Aspidophorus acipenserinus.

Hemilepidotus Tilesii.

Blepsias trilobus.

Sebaster variabilis.

Cyprinus balteatus.

Leuciscus caurinus.

Isuciscus oregonensis.

\author{
Salmo salar. \\ Salmo quinnat. \\ Salmo Gairdnerii. \\ Salmo pauiidens. \\ Salmo Scouleri. \\ Salmo tsuppitch. \\ Salmo nitidus. \\ Mallotus pacificus. \\ Cyclopterus ventricosus. \\ Acipenser transmontanus."]
}

Histoire Naturelle des Poissons, par M. le Bon Cuvier, . . . ; et par M. Valenciennes, .... Tome dix-huitième. A Paris, chez P. Bertrand,...., 1846. [ $8^{\circ} \mathrm{ed}$. xix, 505 pp., 2 l.; $4^{\circ}$ ed. xviii, 375 pp., 2 l.-pl. 520-5.53.]

Snite du livre dix-huitième:-Cyprinoīles.

Livre dix-neuvième.-Des Esoces on Lucioïdes.

Histoire Naturelle des Poissons, par M. le Bon Cuvier, . . . ; et par M. Valenciennes, . . . Tome dix-neuvième. Ã Paris, chez P. Bertraud, . . . , 1846. [8० el. xix, 544 pp., 3 1.; $4^{\circ}$ ed. xv, 391 pp., 2 l.-pl. 554-590.]

Suite du livre dix-neuvième.-Brochets ou Lucioîldes.

Livre vingtième.-De qnelques familles" de Malıcoptérygiens, intermédiaires entre les Brochets et les Clapes.

[No west-coast species described.]

Histoire Naturelle des Poissons, par M. Le Bon Cuvier, . . . ; et par M. Valenciennes, . . . . Tome vingtième. Ā Paris, chez P. Bertrand, . . . ; 1846. [8० ed. xviii, 472 pp., 1 l.; $4^{\circ}$ ed. xiv, 346 pp. 1 1.-pl. 591-505.]

Livre vingt et unième.-De la famille des Clupéoïdes.

1848-Historia Fisica y Politica de Chile seguu documentos adquiriclos en esta república durante doce años de residencia en ella $\mathbf{y}$ publicada bajo los auspicios del Supremo Gobierno. Por Claudio Gay, cindadano Chileno, indi-

* The families referred to are:-Chirocentres (with the genus Chirocentrus); Alepocéphales (with Ale. pocephalus); Lutodeires (with Ohanos and Gonorhynchus); Mormyres (with Mormyrus); Hyodontes (with Osteoglo: sum, Iochnosoma, and Hyodon); Batirins (with Albula = Butirinus); Elopiens (with Elops and Megalops); Amies (with Amia); Vastres ou Amies? (Vastres); famille particulière, ou Amies? (Heterotis); Erythrö̈des (with Erythrinus, Macrodon, Lebiasina, and Pyrrhulina); and Ombres (with Umbra). 
viluo de varias sociedades eientificas nacionales $\mathbf{y}$ etrangeras. Zoologia. Tomo segundo. Paris, en casa del antor. Chile, en el Museo de Historia Natural de Santiago. MDCCCXLVIII. [Text, $8^{\circ}$; atlas, fol.]

[Peces, pp. 137-370 and index.-In this work are described screral species afterward discorered along the coast of Cali.ornia.]

1848-Thirtieth Congress-first session. $|=|$ Ex. Doc. No. 41. $|-|$ Notes of a military reconnoissance, | from | Fort Leavenworth, in Missouri, | to | San 1)iego, in Califoruia, | including part of the / Arkansas, Del Norte, and Gila Rivers. 1.- | By Lieut. Col. W. F. Emory. | Made in 1846-7, with the advanced gnard of the "Army of the West." | - | February 9, 1848.-Ordered to be printed. | February 17, 1848.-Ordered, That 10,000 extra copies of each of the Reports of Lien- I tenant Emory, Captain Cuoke, and Lieutenant Abert, be printed for the use of the House; | and that of said num:ber, 250 copies be furnished for the use of Lientenant Emory, Captain |

- Cooke, and Lieutenant Abert, respectively. | Washington: / Wendell and Van Beuthuysen, printers. | : : : : | 1843. [ [ ${ }^{\circ}, 614$ pp., 50 lith. pl. not numbered, 14 numbered, 2 sketch-maps, and 3 maps folded.]

[This work has been so badly edited that the following analysis may prove useful, and will facilitate the understandiug of the work:-1

\section{CONTENTS.}

Notes | of | a military reconnoissance, | from | Fort Leavenworth, in Missouri, to San Diego, | in California, | including | part of the Arkansas, Del Norte, and Gila Rivers. | pp. 5-126, 26 lith. pl., 2 sketch-maps.

Appendix No. 1. [Letter on Indians by Albert Gallatio, and reply by W. H. Emory.] pp. 12i-134., 1 pl.

Appendix No. 2. [Report on botany.]

[1. Phanerogams and ferns. By John Torrey. pp. 135-155, pl. 1-12.]

[2. Cactacea. By G. Engelmann. pp. 155-159, 14 litb. pl., 2 not numbered.]

Appendix No. 3. Table of neteorological observations. pp. 160-174. Appendix No. 4. Table of geographical positions. pp. 175-178.

Appendix No. 5. Table of astronomical observations. pp. 179-35.;.*

Appendix No. 6. [Report on natural history. By J. W. Abert.] pp. $3^{2} 6-414$.

Appendix No.7. [Itinerary of Sonora, Mexico. Bs P. St. Geo. Cooke.] pp. $415-416$.

Report of Lieut. J. W. Abert, | of his / examination of New Mexico, | i: the years 1846-47. pp. 41\%-546, 22 litb. pl., 1 map folded.

Notes concerning the minerals and fossils, collected by Lieutenant $J$. W. Abert, while engaged in the geographical examination of New Mexico, by J. W. Bailey, professor of chemistry, mineralogy, and geology, at the United States Military Academy. pp. 547-548, 2 lith. pls.

Report of Lieut. Col. P. St. George Cooke | of | his march from | Santa Fé, New Mexico, | to | San Diego, Upper California. pp. 549-563, 2 maps folded.

Journal | of | Captain A. R. Johnston, | First Dragoons. pp. 565-614.

[A species of Gila is noticed at p. 62, and illnstrated by a poor plate opposite the tert. It is said:- "We heard the fish playing in the water, and soon those who were disengaged were after them. At first it was snpposed they were the monntain trout, but, being comparatirely fresh from the hills of Maine, I soon saw the difference."']

Histoire Naturelle des Pois ons, par M. le Bon Cuvier, . . . ; et par M. Valenciennes, . . . Tome vingt et unième. À Paris, chez P. Bertrund, . . ., 1848. [ $8^{\circ}$ ed. xiv, 536 pp.; $4^{\circ}$ ell. xiii (+ iii), 391 pp.-pl. 607-633.]

Bull. N. M. No. 11-2 
Suite du livre vingt et unième et des Clupéoïdes.*

Livre vingt-deuxième.-De la famille des Salmonoïdes.

[No west-coast species deseribed.]

1849 -Frank Forrester's Fish and. Fishing of the United States and British Provinces of North America. Illustrated from uature by the author. By Henry William Herbert, author of "Field Sports," "Warwick Woodlands," etc. New York, Striuger \& Townsend, 222 Broadway, 1849. 80.

Histoire Naturelle des Poissons, par M. le Bon Cuvier, . . . ; et par M. Valenciennes, . . . Tome vingt-deuxièıne. Ȧ Paris, chez P. Bertrand, . . . , 1849. [ $8^{\circ}$ ed. xx, 532, (index) $91(+1)$ pp.; $4^{\circ}$ ed. xvi, 395, (index) $81(+1)$ pp. - pl. 634-650.]

Suite du livre vingt-deuxième. - Suite de la famille des Salmonoïdes.

[No west-coast species described.]

A Monograph of the Fresh water Cottus of North Ainerica. By Charles Girard. Aug. 1849. < Proc. Am. Assoc. Adv. Sci., v. 2, pp. 409-411, 1850.

On the genus Cottus Auct. By Charles Girard. Oct. 17, 1849. < Proc. Bost. Soc. Nat. Hist., v. 3, pp. 183-190, 1849.

1850-Some additional observations on the nomenclature and classification of the geuus Cottus. By Charles Girard. June 19, 1350. < Proe. Bost. Soc. Nat. Hist., v. 3, pp. 302-305, 1850.

1851-On a new genus of American Cottoids. By Charles Girard. Feb. 5, 1851. < Proc. Bost. Soc. Nat. Hist., v. 4, pp. 18-19, 1851.

Révision du genre Cottus des auteurs. Par Charles Girard, de l'Association américaine pour l'avancement des sciences, membre de la Société d'histoire naturelle de Buston. [1851. $\left.4^{\circ}, 28 \mu p\right]<N$. Denkschr. allg. Schweizer. Gesell. gesammt. Naturw., B. 12, 1852.

Snithsonian Contributions to Kuowledge. = Contributions to the Natural History of the Fresh Water Fisbes of North America. By Charles Girard. I. A Mosograph of the Cottoids. Accepted for publication by the Smithsonian Iustitution, December, 1850. [Smithsoniau Contributions to Knowledge,] vol. iii, art. 3. $\left[4^{\circ}, 80\right.$ [p., 3 pl. $]$

Description of a new form of Lamprey from Australia, with a Synopsis of the Family. By J. E. Gray, Esq., F. R. S., V. P. Z. S., etc. < Proc. Zool. Soc. London, part xix, pp. ₹35-241, plates, Pisces, iv, v, 1851.

List of the specimens of Fish iu the collection of the British Muneum.-Part I.-Chondropterygii.-Printed by order of the trustees. London, 1851. [120, $\mathrm{x}$, [1], 160 pp., 2 pl.]

[The name of the compiler is not publisbed on the title-page. In the usual introduetion, Mr. Gray states:- "The characters of the genera of Sharks and Rays, with their synonyms, have principally been derived from the work of Professory Müller and Henle. 'The specimens which were not named by those authors wheu eugaged in their work, or by Dr. Andrew Smith, have been determined by Mr. Edward Gerrurd." The responsibility of the compilation, however, apparently levolves on JOIIN EDWARD GRAY. The diagnoses of the groups, and, for 'the most part, the synonymy of the species, are, in faet, translated or transer bed from Müller and Henle's great work on the Plagiostomes. entitled is follows:-Syrtematische Beschreibung der Plagiostomen von Dr. J. MUULLER, o. ö. Professor der Auatomie und Phys.ologie, und Director des auatomischen Theaters and Museums in Berlin, und Dr. J. JENLE, o. ö. Professor der Anatomie and Director des anatomischen Theaters nud $\boldsymbol{Y}^{\prime}$ useums in Zürich. Mit sectzig Steindrucktafeln. Berlin, Verlag von Veit und Comp -1841. [Folio, xxii, 200 pp., $21 ., 60$ pl., mostly colored, unnumbered.] Au epoch-markins, work, but with no notices of W estern A nier ican species.]

- The Notoptères are differentiated from the Clupecïlos as a very uistince family (une famillo trèsdistincte). 
1851 -Supplement to Frank Forrester's Fish and Fishiug of the United States and British Provinces of North America. By William Henry Herbert, anthor of the "Field Sports of North America," "Frank Forrester and his Friends," etc. New York, Stringer \& Townsend, 222 Broadway, 1851. pp. 1-86.

1853-Descriptions of some new Eishes from the River Zuñi. By S. F. Baird and Charles Girard. June 28, 1853. ～Ｐroc. Acad. Nat. Sci., vol. 6, pp. 368-369, June, 1853.

[N. g. and sp. Gila (n. g. 363), Gila robusta (369), Gila elegans (369), Gila gracilis (369).]

Descriptions of New Species of Fishes collected by Mr. John H. Clark, on the U. S. and Mexican Boundary Survey, under Lt. Col. Jas. D. Graham. By Spencer F. Baird and Charles Girard. Angust 30, 1853. < Proc. Acad. Nat. Sci. Phila., v. 6, pp. 387-390, August, 1853.

(N. sp. Catostomus latipinnis (388), Gila Emoryi (388), Gila Grahami (389), Cyprinodon macularius (389), Heterondria offinis (390), Heterondria occidentalis (390). 1

32d Congress, | 2 d session. \}Senate. \{ Executive | No.59. | - | Report of an Expedition | down the | Zuñi and Colorado Rivers, | by | Captain I. Sitgreaves, | Corps Topographical Engineers. | - Accompanied by maps, sketches, views, and illustrations. | - | Washiugton: | Robert Armstrong, public printer. | 1853. [ $\left[8^{\circ}, 190\right.$ pp., $11 ., 24 \mathrm{pl}$. of scenery (pl. 1 folded), $6 \mathrm{pl}$. of mammals, $6 \mathrm{pl}$. of birds, $2 \mathrm{pl}$. of reptiles, $3 \mathrm{pl}$. of fishes, $21 \mathrm{pl}$. of botany, 1 folded map, all at end.]

Title. p. 1.

Report of the Secretary of War, communicating, [etc.] p. 3 .

[Sitgreaves's report.] pp. 4-29.

Report / on / the natural history / of the / country passed over by the exploring expedition | ander the command of Brevet Captain L. Sitgreaves, | U. S. Topographical Engineers, during the Jear 1851. | By S. W. Woodhouse, M. D., I surgeon and naturalist to the expedition. | pp. $31-40$.

Zoology. | - | Mammals and Birds, by S. W. Woodhouse, M. D. I Reptiles, by Edward Hallowell, M. D. | Fishes, by Prof. S. F. Baird and Charles Girard. | pp. 41-152.

Mammals. By S. W. Woodhouse, M. D. pp. 43-57, 6 pl. (1-6).

Birds. By S. W. Woodhouse, M. D. pp. 58-105, 6 pl. (1-6).

Reptiles. By Edward Hallowell, M. D. pp. 106-147, 21 pl. $(1-20+$ 10 a).

Fishes. By Spencer F. Baird and Charles Girard. pp. 148-152, 3 pl. (1-3).

Botany. | - | By Professor John Torrey. pp. 153-178, 21 pls. (1-21).

Medical Report. | - | By S. W. Woodhonse, M. D. pp. 179-185.

List of illustrations. pp. 187-190.

Table of contents. [ [ 11 l.]

Extraordinary Fishes from California, constituting a new family, described by I. Agassiz. <Am. Journ. Sci. and Arts, (:), v. 16, pp. 380-390, Nov. 1853; also reprinted in Edinbnrgh New Phil. Jonrn., v. 57, pp. 214-227; translated in Archiv fiir Naturgeschichte (Berlin), Jah:g. 20, B. 1, pp. 149-162, 1853.

[Family named "Family Holconoti or Embiotocoidæ" (p. 383). N. g. and n. sp. Embiotoca (n. g., 3ะ6) :-1. Embiotoca Jacksoni (387); 2. Embiotoca Caryi (389).]

[This article was translated into German as follows:-]

Ueber eine neue Familie von Fischen aus Californien. Von I. Agassiz. Ans Silliman's Amer. Journ. vol. xvi. p. 380 übersetzt. Vom Herausgeber [F. H. Troschel]. <Archiv für Naturgeschichte, 20. Jahrg., B. 1, pp. 14!) $162,1854$. 
[This translation was followed by the following original comnunication, in which ihe systematic relations of the family were definitely determined:-]

Ueber die systematische Stellung der Gattung Embiotoca. Bemerkung zur vorigen Abhandlung. Vom Helausgeber [Dr. F. H. Troschel]. < Archiv fïr Naturgeschichte, 20. Jahrg., B. 1, pp. 163-168, 1854.

$1854-T h e$ Zoology of the Voyage of H. M. S. Herald, uuder the command of Captain Henry Kellett, R. N., C. B., durng the jears 1845-51.-Published under the Authority of the Lorus Commissioners of the Admiralty.-Edited by Professor Edward Forbes, F. R. S. Vertebrals, inclucing Fussil Manmale. By Sir John Richardson, Knt., C. B., M. D., F. R. S.-London: Lovell Reeve, 5, Henrietta streer, Covent Garden.--1854. [4, xi, vi, [1],171 [+1] pp., $3:$ pl.]

Fish. pp. 156-171, and pl. xxviii, pl. xxxii.

[Describes Platessa stellata, mouth of Coppermine River (164, p!. 32, f. 1-3); Platessa glacialis, Bathurst's Iulet (166, pl. 32); Sxlmo consuetus, Yuknu River (167, pl. 32); Salmo dermatinus, Yukon River (169, pl. 33, f. 3-5).]

Notice of a collection of Fishes from the sonthern bend of the Tennessee River, in the State of Alabama. By L. Agassiz. < Am. Journ. Sci. and Arts, (2), v. 17, pp. 297-303, Mar. 1854 ; v. 17, pp. 353-369, May, 1854.

Appendix.-Additional voles on the Holconoti. pp. 365-369, May, 1854.

[N. g. and n. Ap. Embiotoca lateralis (366), Rhacochilus (n. g.) toxotes (367), Amphistichrı (n. g.) argenteus (367), Hoiconotus (a. g., 367) rhodoterus (368).]

[Translated as follows:-]

Nachträgliche Bemerkungen über die Holconcti. Von Prof. I. Agassiz. Aus Silliman Amer. Jourb. xvii. p. 365. Uebersetzt vom Heransgeber [J. II. Troschel]. < Archiv für Naturgeschichte, 21. Jahrg., B. 1, pp. 30-34, 1855.

Description of four new species of Viviparous Fishes from Sacramento River and the Bay of San Franciseo. Read before the California Academy of $\mathrm{Na}^{4}$. ural Sciences, May 15, 18.4. By W. P. Gibbons, M. D. June 27, 1854. <Proc. Acad. Nat. Sci. Phila., v. 7, pp. 105-106, 1854.

[N. s]. Hysterocarpus Traskii (105), Hyperprosopon aryenteum (105) and var. a. punctatum (106), Cymatogaster aygregatus (106), Cymatogaster minimus (206) ]

Description of new Species of Viviparous Marine an: Fresh-water Fishes, from the Bay of San Francisco, and frons the River and Lagoons of the Sacramento. By W. P. Gibbons, M. D. [Read before the Califoruia Academy of Natural Scienees, Jan. 9th and May 15th, 22l, and 29th, 1854.] July 25, 1854. < Proc. Acad. Nat. Sei. Phila., v. 7, pp. 122-126, July, 1854.

[N. g. and n. sp. Holconotus (122), H. Agassizii (122), H. Gibbonsii, "Cal. Acad. of N. S." (122), H. fuliginosus (123), Cymatogaster (घ. g), O. Larkinsii (123), C. pulchellus (123), C. ellipticus (124), Hysterocarpus (n. g.), H. Traskii (124), Hyperprosopon (n. g), H. argenteus (125), H. arcuatus (125), Micrometrus (n. g.), M. aggregatus (125), MI. minimus (125), Mytilophagus (n g.), M. faciatus (125), Pachylabrus (n. g.), P. variegatus (126).]

[Translated as follows:-]

Beschreibung neuer Fische aus der Familie Holconoti aus dem Busen von San Francisco, ans dem Sacramento-Flues und dessen Lagunen. Von W. P. Gibbons. Aus den Proceedings of the Acad. of nat. sc. of Philadelphia vol. vii. 1854. p. 122. übersetzt vom Herausgeber [F. H. Troschel]. <Archiv für Naturgeschichte, 21. Jahrg., B. 1, pp. 331-341, 1855.

Descriptions of new Fishes, collected by Dr. A. L. Heermann, Naturalist attached to the survey of the Pacific Railroad Route, under Lieut. R. S. Williamson, U.S. A. By Charles Girard. Aug. 29, 1854. <Proc. Acad. Nat. Sci. Phila., r. 7, pp. 129-140, 1854.

[N. g. and n. sp.:-1. Centrarchus interruptus (129), 2. Cottcpsis gulosus (129), 3. Aspicottus (n. g.) bison (130), 4. Leptocottus (n. g., 130) armatus (131), 5. Scorpanichthys (n. g.) marmoratus (131), 6. Sebastes auriculatus (131), 7. Chirus pictus (132), 8. Chirus guttatus (132), 9. 
Opliocion (n g.) elongatus (133), 10. Gasterosteus Williamsoni (133), 11. Gasterosteus micro. cephahus (133), 12. Atherinopsis (n. g.) californiensis (134), 13. Gobius gracitis (134), 14. Embiotoca lineata (134), 15. A mphistichus similis(135), 16. Amphistichus Heermanni (135), 1i. Gila conocephala (135), 18. Poyonichthys incequilobus (136), 19. Pogonichthys symmetricus (136), 20. Lavinia (n. g.) exilicauda (137), 21. Lavinia crassicauda (137), 22. Lavinia conformis (137), 23. Leucosomus occilentalis (137), 24. Ulupea mirabilis (138), 25. Meletía carrulea (138), 26. Engraulis mordax (133), 27. Platichthys (u, g.) rugosus (139), 2子. Pleuronichthys (n. g.) conosus (139), 29. Parophrys (n. g. 139) vetulus (140), 30. Psettichthys (n. g.) melanostictus (140).]

1854 -Enumeration of the species of marine Fishes, collected at Sau Francisco, California, by Dr. C. B. R. Kennerly, naturalist attached to the survey of the Pacifie R. R. Route, uniler Lient. A. W. Whipple. By Charles Girard. Ang. 29, 1854. < Proc. Acad. Nit. Sei. Puila., v. T, pp. 141-142, Ang. 1854.

[N. g. and n. sp.:-1. Chirus constellatus (141), 3. Porichthys (n. g.) notatus (141), 8. Gadus proximus (141), 10. Prettichthys sordiaus (142).1

Observations upos a collection of Fisbes made on the Pacilic coast of the U. States, by Lieut. W. P. Trowbridge, U. S. A., for the Museum of the Smithsouian Institution. By Charles Girard. Aug. 29, 1854. <Proc. Acall. Nat. Sci. Philia., v. 7, pp. 142-156, $1 \times 54$.

[N. g. and n. sp.:-1. Labrax nebulifer (142), 2 Labrax clathratus (143), 3. Heterostichus (n. g ) rostratus (143), 4. Sphyrana argentea (144), 5. Cottopsis parous (144), 8. Scorpaenichth's lateralis (145), 9. Scorpcena guttata (145), 11. Sebastes rosaceus (146), 12 Sebastes fasciatus (146), 15. Gasterosteus plebeius (147), 16. Gasterosteus inopinatus (147), 17. Cr.brina undulata (14:), 18. Glyplisadon rubicundus (145). 19. Belone exilis (14), 20. Ble:inius gentilis (149), 21. Gunnellus ornatxs (149). 22. A podichthys (n. g.) flavidus (150), 23. A podichthys viclaceus (150), 24. Ararrhichas felis (150), :6. Julis modestus (151), 29. Embiotoca lineata (151), 30. Embiotoca Cassidyi (151), 32. Holconotus Trosobridyii (152), 33. Holcono'us megalops (15:2), 31. Phanerodon (n. g.) furcatus (153), 36. Pogon chthys argyiciosus (153), 37. Fundulus parvipinnis (154), 42. Engraulis delicatissimus (154), 43. Argentina pretiosa (150), 44. Pleuronectes maculosus (155), 48. Lepadogaster reticulatus (155), 49. Syngnathus brevirostris (156), 50. Syngnathus leptorhynchus (156).]

t Descriptions of two species of fish, believed to be new. Sept. 4, 1854. By Wm. O. Ayres. < Proc. Cal. Acad. Sci., v. 1, pp. 3-4,1854; 2d ed., pp. 3-4, 1873.

[N. sp. Labrus pulcher, Hemitripterus marmoratus.]

$\uparrow$ Descriptions of two new species of Sebastes. Sept. 11, 1854. By Wm. O. Ayres. < Proc. Cal. Acad. Sci., v. 1, pp. 5-6, 1854; 2d ed., pp. 5-6, 187.3.

[N. sp. S. nebulosus, S. parcispinis.]

t Descriptions of new species of fish. Sept. 18, 1854. By Wm. O. Ayres, M. D. < Proc. Cal. Acad. Sci., v. 1, pp. 7-8, 1854; 2 d ed., pp. 7-8, 1 ๙ 3.

[N. sp. Sebastes ruber, Sebastes ruber rar. parvus, Sebastes variabilis, Centrarchus maculosus.]

t Observations on the development of Anableps Gronovii, a viviparous fish from Surinam. By Prof. Jeffies Wyman. Sept. 20,1854. < Proc. Bosto:1 Soc. Nat. Hist., v. 5, pp. 80-81, Dec. $1254 .{ }^{*}$

- Remarks in relation to the Mode of Development of Embiotocoidx. B5 Charles Girard. Sept. 20,1 1854. <Proc. Boston Soc. Nat. Hist., v. 5, pp. 81- $\times 2$, Dec. 1854 .

* Two new fishes, Morrbua califoruica and Grystes lineatus. By Wm. $\mathbf{~}$. Ayres. Oct. 2, 1854. < Proc. Cal. Acad. Sci., v. 1, pp. 9-10, 18.4; 2d cd., pp. 8-10, 1873.

[N. sp. Morrhua californica, Grystes lineatus.]

*Sec, also, Olservations cn the devtlopment of Anable ps Groncrii (Cuv. and Val.). By JeffriesWyman. M. D. Read Srpt. 20, 1<54. < Boston Jonrn. Nat. Hist., r. 6, rp. 43\$-443, pl. 17, Nov. $18 j 4$. 
1854- Descriptions of a new species of cottoid fish, and remarks on the American Acanthocotti. By Wm. O. Ayres, M. D. Oct.9, 1854. <Proc. Cal. Acad. Sci., v. 1, p. 11, 1854; 2 d ed., p. 11, 1873.

[N. sp. Clypeocottus robustus (=Aspicottus bison.Grd.).]

+Deseriptions of two new species of fish. By Wm. O. Ayres, M. D. Oct. 23, 1854. < Proc. Cal. Acad. Sci., v. 1, pp. 13-14, 18.54; 2d. ed., pp. 12-13, 1873.

[N. sp. Brasmius marginatus, Symgnathus griseolineatus.]

New species of Californian Fisbes, by William O. Ayres, M. D. Nov. 1, 1854. < Proc. Boston Ssc. Nat. Hist., v. 5, pp. 94-103, Dec. 1854, aid Feb. 1855.

[N. sp. Sebastes paucispinis (94), Sebastes nebulosus (96), Sebastes ruber (97), Sebastes ruber var. parvus (98), Centrarchus maculosus (99), MForrhwa cadifornica (100), Labrus pulcher (101).]

* Descriptions of the Sturgeons [Acipenser] found in our [Californian] waters. By Wm. O. Ayres, M. D. Nov. 27, 1854. < Proc. Cai. Acad. Sci., v. 1, p. 15, Dec. 1s54; 2d ed., pp. 14-15. 1873.

[N. sp. A. acutirostris, A. medirostris, A. brachyrhynchus.]

Characteristics of some Cartilaginous Fishes of the Pacific coast of North America. By Charles Girard. Nov. 28, 1854. < Proc. Acad. Nat. Sci. Phila., v. 7, pp. 196-197, $18 j 4$.

[N. sp.:-1. Cestracion francisci (196), 2. Triakis semifasciatum (196), 3. Spinax (Acanthias) Suckleyi (196), 5. Raja binoculata (196).]

Abstract of a Report to Lieut. Jas. M. Gilliss, U. S. N., upon the Fishes collected during the U. S. N. Astrouomical Expedition to Chili. By Charles Girard. Nov.28, 1854. < Proc. Acad. Nas. Sci. Phila., v. 7, pp. 197-199, 1854.

[Genus Atherinopsis noticed, and the Mlelttta coerulea of Ang. 29, 1844, v. 7, p. 138, rede scribed as a new species, under the nams $A$ losa musicx.]

†Descriptions of two new spectes of fish. By Wm. O. Ayres, M. D. Dec. 4, 1854. <Proc. Cal. Acad. Sci., v. 1, pp. 17-18, 18j4; 2d өd.,pp. 16-17, 1873.

[N. sp. Osmerus elongatus, Mustelus felis.]

†Deseriptions of two new soecies of Cyprinoid - By Wm. O. Ayres, M. D. Dec. 11, 1854. < Proc. Cal. Acad. Sci., v. 1, pp. 18-19, 1854; 2d ed., pp. 17-18, 1873.

[N. sp. Catostomus occi.entalis, Gila grandis.]

* Descriptions of two new Cyprinoid fish. By Wm. O. Ayres, M. D. Dec. 18, 1854. < Proc. Cal. Acad. Sci., v. 1, pp. 20-21, 1854; 2d ed., pp. 19-20, 1873.

[N. sp. Lavinia gibbosa, L. compressa. ]

-Description of a new. Cyprino fish. Br Wm. O. Ayres, M. D. Dec. 25, 1854. < Proc. Cal. Acad. Sci., v. 1, pp. 21-22, 1854; 2d ed., pp. 20-21, 1823.

[N. sp. Gila microlepidota.]

A list of the Fishes collected in California, by Mr. E. Samnels, with descriptions of the new species. By Charles Girard, M. D. [1854.] < Boston Journ. Nat. Hist., v. 6, pp. 533-544, pl. 24-26, 1857.

1855-Synopsis of the Ichthyological Fanna of the Pacific Slope of North Ameriea, chiefly from the collections made by the U. S. Exp. Exped. under the command of Capt. C. Wilkes, with recent addit:ons and comparisuns with eastern types. By Louis Agassiz. <Am. Journ. Sci. and Arts, v. 19, pp. 71-99, Jan., 1855; v. 19, pp. 215-231, March, 1855.

[N. g. and n. sp. Catostomus occidentalis (94), Acrocheilus (n. g., 96) alutaceus (99), Ptychocheilus (n. g., 227), Ptychocheilus gracilis (229), Ptychocheilus major (229), Mylocheilus (n. g. 229) lateralis 291).] 
$1855-{ }^{*}$ On two species of Liparis. By Wm. O. Ayres, M. D. Jan. 8, 1855. < Pros Cal. Acad. Sci., v. 1, pp. 23-24, Feb. 1, 1855; 2 d ed., pp. 21-23, 1873.

[N. sp. L. pulchellus, L. mucosus.]

t Description of a new genus (Leptoguncllus) and two new species of fishes.

By Wm. O. Ayres, M. D. Jan. 22, 1855. < Proc. Cal. Acad. Sci., v. 1, pu. 25-27, 1555; $2 d$ ed., pp. 24-25, 1873.

[N. sp. Leiostomus lineatus, Leptogunellus gracilis.]

† Description of a Lampres, from the vicinity of San Francisco. By Wm. O. Ayres, M. D. Feb. 5, 1855. <Proc. Cal. Acad. Sci., v. 1, p. 28, Feb. 19, 1855 ; 21 ed., p. 27, 1873.

[N. sp. Petromyzon plumbeus.]

"Remarks on the fostal Zygæna (Hammer-headed Shark). By Jeffries Wyman. Feb. 21, 1855. <Proc. Boston Soc. Nat. Hist., v. 5, p. 157, Márch, 1855 .

f Description of a new generic typo among fishes. Ry Wm. O. Ayres, M. D. Feb. 26, 1855. < Proc. Cal. Acad. Sci., v. 1, pp. 31-32, 1855; 2 d ed., pp. $30-31,1873$.

[N. sp. Anarrhichthys ocellatus.]

Description of a new species of Catastomus. By Wm. O. Ayres, M. D. March 5, 1855. < Proc. Cal. Acad. Sci., v. 1, pp. 32-33, 1855; 2d ed., pp. 31$32,1873$.

[N. ep. Catostonrus labiatus.]

"Description of a new ichthyic type. Bs Wm. O. Ayres, M. D. March 12, 185.5. < Pruc. Cal. Acad. Sci., v. 1, pp. 33-35, 1855; 2 d ed., pp. 32-34, 1873.

[N. g. and n. sp. Mybopharodon (n. g) robustus.]

"Description of a new Trout. By W. P. Gibbons. Murch 19, 1855. <Proc. Cal. Acad. Sci., v. 1, pp. 36-37, 1855; 2d ed., pp. 35-36, 1873.

[N. op. Salmo iridea.]

- On specimens of Gasterosteus plebeins, Gir., brought from San José by the Rev. Mr. Douglas. By Wm. O. Ayres, M. D. April 2, 1855. <Proc. Cal. Acad. Sci., v. 1, p. 40, 1855; 2d ed., p. 39, 1873.

t Deseription of a new Platessa, and remarks on the Flatfish of the San Francisco markets. By Wm. O. Ayres, M. D. April 2, 1855. < Proc. Cal. Acad. Sci., v. 1, pp. 39-40, 1855 ; 2 d ed., pp. 39-40, 1873.

[N. sp. Platessa bilineata.]

+Description of a new Salmo and a new Petromyzon. By Wm. O. Ayres. April 16, 18.55. < Proc. Cal. Acad. Sci., v. 1, pp. 43-45, 1855; $2 d$ ed., pp. 42-44, 1873.

[N. sp. Salmo rioularis, Petromyzon ciliatus.]

Notice upon the Viviparous Fishes inhabiting the Pacific coast of North America, with an euumeration of the species observed. By Charles Girard. April 24, 1855. < Proc. Acad. Nat. Sci. Phila., v. 7, pp. 318-323, 1-55.

[N. g. and n. вp. :-3. Embiotoca Webbi (320), 5 Embiotoca orvata (32i), 6. Embiotoca perspicabilis (3.21), 7. Damalichthys (u. g.) vacca (321), 9. Abeona (n. g.) Trowbridgii (3:22), 11. Enrichthys (n. g., 322), Ennichthys megalops (323), 12. Ennichthys Hcermansti (323).]

[Translated into German by Dr. Troschel as follows:-]

Ueber die lebendig gebärenden Fische an der Westküste von Nordamerika. Von Charles Girard. (Proceedings of the Acarlemy of nat. sc. of Philadelphia April 1855.) Uebersetzt vom Herausgeber [Prof. Dr. Troschel]. <Archiv für Naturgeschichte, 21. Jahrg., B. 1, pp. 342-354 [numb. 344], 1855. 
1855-tDescription of a Gasterosteus believed to be new, and on the American species of the genus. By Wm. O. Ayres. April 30, 1855. < Proc. Cal. Acid. Sci., v. 1, pp. 47-4ฬ, 1855; 2 d ed., pp. 46-47, 1873.

[N. sp. Gasterosteus serratus; name Gasterosteus dekayi proposed for Gasterosteus biaculeatus DeKay.]

$\dagger$ Description of a new species of Apodichthys. By William O. Ayres, M. D. May 21, 1855. < Proc. Cal. Acad. Sci., v. 1, pl. 55-56, 1855; 2d ed., pp. 545.), 1873.

[N. sp. Apodichthys virescens.]

†Description of a new generic type of Blennoids. By William O. Ayres, M. D June 4, 1855. < Proc. Cal. Acad. Sci., v. 1, pp. 58-59, 185̈; ; 2d cd., pp. 58-59, 1873.

[N. sp. Cebedichthys cristagalli.]

†Description of a new Carangoid fish. By William O. Ayres, M. D. July 2, 1855. < Proc. Cal. Acad. Sci., v. 1, pp. 6:2-63, 1865 ; 2d ed., p. 64, 1873.

[N. sp. Caranx symmetricus.]

tDescription of a new species of Whiting. By William O. Ayres, M. D. July 16, 1855. < Proc. Cal. Acad. Sci., v. 1, p. 64, 1855; 2d ed., pp. 65-66, 187:3.

[N. sp. Meriangus productus.]

* Description of a fish, representing a type entirely new to our waters. By Wm. O. Ayres, M. D. Ang. 6, 1855. <Proc. Cal. Acad. Sci., v:1, pp. 66-6r, $1855 ; 2 d$ ed., p. 69, 1873.

[N. sp. Saurus lucioceps.]

* Deseription of a new species of Cramp fish. By William O. Ayres, M. D. Sept. 10, 1855. < Proc. Cal. Acad. Sci., v. 1, pp. 70-71, 1855; 2d ed., pp. 74-75, 1873.

[N. sp. Torpedo californica.]

t On a viviparous fish from Japan. By Louis Agassiz. Sept. 11, 1855. < Proc. Am. Acad. Arts and Sci., v. 3, p. 204, 1855.

"A Flying Fish, Exocotus fasciatus Le Sneur, from the Pacific Ocean, lat. 30" $06^{\prime}$ N., long. $113^{\circ} 02^{\prime} \mathrm{W}$. [Gulf of California], presented by Dr. Lanszweert." Sept. 24, 1855. < Proc. Cal. Acad. Sci., v. 1, pp. 71-73, 1855.

†Description of a Shark of new generic type. By Wm. O. Ayres, M. D. Oct. $8,1855 . \quad<$ Proc. Cal. Acad. Sci., v. 1, pp. 72-73, 1855; 2d ed., pp. ; $6-i 7,1873$.

[N. sp. Notorhynchus maculatus.]

* Remarks concerning a colleetion of fishes made by Lieut. W. P. Trowbridge at or near Cape Flattery, W. T. By Wm. O. Ayres, M. D. Oct. 22, 1855. <Proc. Cal. Acad. Sci., v. 1, p. 74, 1855; '2d ed., p. 79, 1873.

[10 species enumerated.]

† On a supposed new genus of Cottoids. By Wm. O. Ayres, M. D. Dec. 24, 1855. < Proc. Cal. Acad. Sci., v. 1, pp. 75-77, 1855; 2l ed., pp. 81-82, 1873.

IN. sp. Calycilepidotus spinosus, Scorpcenichthys lateralis Grd.=Calycilepidotus lateralis. 
1856-Contributions to the Ichthyology of the Western Coast of the United States, from specimens in the Museum of Swithsonian Institution. By Charles Girard, M. D. June 24, 1856. < Proc. Acad. Nat. Sci. Phila., v. 8, pp. 131-137, 1855.

[N. g. and n. 8j. Paralabrax (n. g., 131), Homa'opomus (n. g.) Trowbridgii (132), Oligocottus (n. g., 13:) maculosus (133), Leiocottus (n. g.) hirundo (133), A rtedius ( $\because$ g., 134). A rtcdius notospilotus (134), Sebastes melanops (135), Oplopoma (1. E.) paniherina (135), Gaste. rosteus intermedius (135), Gasterosteus pugetti (135), Gobius Newberryi (136), Limbiotıca a:gyrosoma (136), Coregonus Williamsoni (136), Platichthys umbrosus (136), Pleurcnichthys guttulatus (137), Ammodytes personatus (137), Rhinoptera vespertil o (13i).]

Researches upon the Cyprinoids inbabiting the fresh water Fishes of the United States of America, west of the Mississippi Valler, from specimens in the Museum of the Smithsonian Institution. By Charles Gira:d, M. D. Sept. 30, 1856. < Proc. Acad. Nat. Sci. Phila., v. 8, pp. 165-i13, 1856.

[N. g. and n. 8p. Mylocheilus fraterculus (169), Catostomus (Acomus, n. \&. g.) gencro॰r: (174), Catostomus.macrocheilus (175), Cxtostomus bernardivi (175), Alganscc (a. E), Algxnsea bicolor (183), Algansea obesa (183), Algansea formosa (183), Lavinia hurengus (ir 4), Argyrenes nubilus (186), Argyreus osculus (186), Argyreus notabilis (186), A gasia (1. g.), A geria

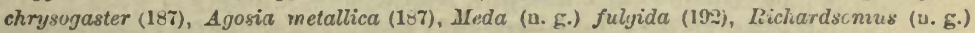
lateralis (202), Tiaroga (n. g.) cobitis (204), Tigona (3. g.). Tigoma bicolor (:06), Tigonna purpurea (206), Tigoma intermedia (206), Tigoma obesa (206), Tigoma Humboldti (206), Tigoma lineata (206), Tigoma gracilis (206), Tigoma niyresccns (207), Tigoma crassa (207), Chionda (n. ..), Cheonda Cooperi (207), Cheonda coerilea (207), Siboma (n. g.) atraria (2(8), P'iychochcilus rapax (209), Ptychocheilus lucins (209), Plychocheilus vorax (20\%).]

Notic: upon the Species of the Genus Salmo of autbors, observed cbiefly in Oregron and California. By Charles Girard, M. D. Oct. 28, 1856. <Proc. Acad. Nat. Sci. Phila., v. 8 , pp. 217-220, $1<56$.

[N. sp. Salmo spectabilis $\left(21^{\circ}\right)$, Fario aurora (218), Fario argyreus (21*), Fario stellatus (219), Salar Levoisi (219), Salar vi gina is (220).]

33d Congress, | 2d Session. $\}$ House of Representatives. $\{$ Ex. Doc. | No. 9\%. $\mid=1$ Narrative / of | the Ex edition of an American Squadron | to | the Chiụa Seas aud Japan, I performed in the years 1852, 1853 and 1854, | under the command of | Commodore M. C. Perry, United States Navy, | by | erder of the Government of the United States. | - | Volume II. With illustrutions. | | Washiugton: | A. O. P. Nicholson, printer. | 1856. [4ㅇ, 4 p. 1., 414 pp.; [Treaty,] 2 p. l., 14 pp.; [Ivdex,] iii-xi pp., 1 l.]

Notes on some fircures of Japanese Fish, taken from recent specimens by the artists of tho U. S. Japau Expedition. By James Carson Brevoort. (pp. 253-256, pl. iii-xii.)

[Contains notice of Ditrema and first notice of the recognition of the afinity between the Embiotocoids of Califorsia and the Japaneso geu us.]

33d Congress, 2d Session. $\}$ Seuate. $\{$ Ex. Doc. No. 78. $|=|$ Reports $\mid$ of $\mid$ Explorations and Surveys, | to | ascertain tbe most practicable aud economical ronto for a railroad | from the | Mississippi River to the Pacilic Occan | made under the direction of the Secretary of War, | in 185:3-4, | according to acts of Congress of March 3, 1853, May 31, 1854, and Angust .5, 1954. | - | Volume V. | - | Washington: | Beverley Tucker, Priuter. | 1856.

Explorations and Surveys for a railroad route from the Mississippi River to the Pacific Ocean. | War Department. $|=|$ Routes iu Califor nia,toconnect with the routes near the thirty-fith and thirty-second | parallels, explored by Lieut. R. S. Williamson, Corps Topographical Engineers, in 1853. | - | Geological report, | by | William P. Blake, | Geologist and Mineralogist of the Expedition. [ [With appendix.] | - | Wasbington, D. C. | 185\%. $=$

Appendix.-Article I. Notice of the fossil fishes.-By Professor Louis Agassiz.-(pp. 313-316, and 1 plate ("Fossils plate 1")) 
1856-33d Congress, | 2d Session. $\}$ Senate. $\{$ Ex. Doc. | No. $78 .=$ Reports $\mid$ of $\mid$ Explorationsand Surveys, | to | ascertain the most practicable and econonical ronte for a railroad | from the | Mississippi River to the Pacific Ocean | made under the direction of the Secretary of War, in | 1853-4, | according to acts of Congress of March 3, 1853, May 31, 1854, and August 5, 1854. |-- Volume IV. | - | Washington: | Beverley Tucker, Priuter. | 1856.

Explorations and surveys for a railroad route from the Mississippi River to the Pacific Ocean. | War Department. $|=|$ Route near the thirty-fifth parallel, explored by Lieut. A. W. Whipple, Torographical | Engineers, in 1853 and 1854. | - | Report on the zoology of the expedition. | - | Washington, D. C. $\mid 1856 .=[17$ pp., 1 l. $]$

No. 1.-Field notes and explanations.-By C. B. R. Kennerly, M. D., Physician and Naturalist to the Expedition.-pp. 5-17.

1857--The Northwest Coast; or, Three Years' Residence in Washington Territory. By James G. Swan. [Figure of terr. seal.] With numerous illustrations. New York: Harper \& Brothers, Publishers, Frankliu Square. 1857. [12॰, 435 pp. (incl. 26 tigs. and pl.), frontispiece, 1 map.]

[Popular notices of fishes-especially salmon and fishing for salmon-are given in chap. ters $3,7,9$, and 14.$]$

* Account of some observations on the development of Anableps Gronovii, as compared with that of the Embiotocas of California. By Jeffries $W_{y}$ man. Nov. 18, 1857. < Proc. Boston S. c. Nat. Hist., v. 6, p. 294, Jan. 1858.

Notice upon new Genera and new Species of Marine and Fresh-water Fishes from Western North America. By Charles Girard, M. D. Nov. 24, $185 \%$. <Proc. Acad. Nat. Sei. Phila., v. 9, pp. 200-202, Nov. 1857.

[N. g. axd n. 8p. Chiropsis (n. g., 201), Oligocottus analis (201), Oligocottus globiceps (201), Zaniolepis (n. g.) latipinnis (202), Blepsias oculofascialus (20:2).]

33d Congress, | 2d Session. $\}$ Senate. $\{$ Ex. Doc. $\mid$ No. 78. $|=|$ Reports $\mid$ of $\mid$ Explorations and Surveys, | to | ascertain the most practicable and economical route fur a railroad | from the | Mississippi River to the Pacific Ocean. | Made under the direction of the Secretary of War, in | 1854-5, | according to Acts of Congress of March 3, 1853, May 31, 1854, and August 5, 1854. I- I Volume VI. | - | Washiugton: | Beverley Tucker, Printer. | 1857.

Explorations and Surveys for a Railroad Route from the Mississippi River to the Pacific Ocean. | War Department. $|=|$ Routes in California and Oregon explored by Lieut. R. S. Williamson, Corps of Topographical | Eogineers, and Lient. Henry L. Abbo:, Corps of Topographical Engineere, in 1855. | - | Zoulogical Report.- | Washington, D. C. | 1857. | =

No. 1. Report upon Fishes collected on the Survey.-By Charles

Girard, M. D.-pp. 9-34, with plates xxii $a$, xxii $b, \mathrm{xxv} a, \mathrm{xxv} b, \mathrm{xl}$ a, xlvi, lxii, lxvi, lxviıi, lxx, lxxiv.

Report on the fauna and medical topography of Washington Territory. By Geo. Suckley, M. D. May, 1857. < Trans. Am. Med. Assoc., v. 10, pp. 181$217,1857$.

[Fishes noticed at pp. 202-203.]

1858-Description of several new species of Salmonidæ from the north-west coast of America. By George Suckley, M. D. Real December 6, 1858. <Ann. Lyc. Nat. Hist. New York, v. 7, pp. 1-10, 1862.

[N. sp. Salmo Gibbsii (1), Salmo truncatus (3), Salmo gibber (6), Salmo conjluentus (8), Salmo canis (9).]

Ichthyological Notices, by Chas. Girard, M. D. Dec. 28, 1858. < Proc. Acad. Nat. Sci. Phila., vol. 10, pp. 223-225, Dec. 1858.

[\$ 1-4, n. sp. "Fario Newberrii, or else Salmo Newberrii" (225).] 
1858-Denkwürdigkeiten einer Reise nach dem russiseben Amerika, nach Mikronesien and durch Kamtschatka. Von F. H. v. Kittlitz.-Erster Band [-Zweiter Band].-Gotha. Verlag von Justus Perthes. 1858. [ [ ${ }^{\circ}$, vol. i, xvi, 383 pp., 2 pl.; vol. ii, 2 p. l., 463 pp., 2 pl.]

1859-33ג Congress, | 2d Session. $\}$ Senate. $\{$ Ex. Doc. $\mid$ No. 78. $|=|$ Reports $\mid$ of $\mid$ Explorations and Surveys, | to | ascertain the most practicable and economical route for a railroad | from the | Mississippi River to the Pacific Ocens. | Marke under the direction of the Secretary of War, in | 1853-6, | according to Acts of Congress of March 3, 1853, May 31, 1854, and August 5, 1854. | - 1 Volume X. | - | Washington: ! Beverley Tucker, Printer. | 1859.

Explorations and Surveys for a railroad route from the Mississippi Rirer to the Pacific Ocean. | War Department. | = | Fishes: by Charles Girard, M. D. | - | Washington, D. C. | $1858 .{ }^{*}=[x i v, 400$ pp., with plates vii-viii, xiii-xiv, xvii, xviii, xxii $c$, xxvi, xxix, xxx, xxxiv, sxxvii,

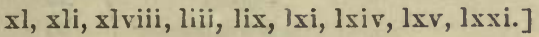

[N. g. and n. sp. Oligocottus globiceps (58), Nautichthys (n. g., 74), Amblodon saturnus (9ษ), Pelamys lineolata (106), Trachurus boops (108), Ephippus zonatus (110), Ncoclinus (1. 1., 114), Neoclinus Blanchardi (114), Xiphidion (n. g., 119), Xiphidion mucosum (119), Ophidion Taylori (138), Paralichthys (n. g., 146), Tigoma egrejia (:91), Thalcichthys (n. g., 325), Thalsichthys Stevensii (325), E graulis narus (335), Engraulis corr.pressus (336), Tetraodon politus (340), Hippocampus ingens (342), Syngnathus Abboti (346), Syngnathus arundinaceus (346), Raja Cooperi (372), Petrunyzon lividus (379), Petromyzon astori (3£0), Ammocœetes cibarius (383). $\dagger$

As this report brings up our kuowledge of the fish fauna of the Pacific coast slope of the United States to the time of its publication, and ma ks as epoch in the ichthyography of the region in question, the species described are hereiubelow enumerated. Of the several columns, (1) the first contains tho family name, (2) the sc cond the generic, (3) the third the specific, and (4) the right hand one, the page where the species are described :-

\section{Order I.-ACANTHOPTERI.}

$\begin{array}{llll}\text { Percidæ } & \text { Ambloplites } & \text { interruptus } & 10 \\ & \text { Paralabrax } & \begin{array}{l}\text { pebulifer } \\ \text { clathratus }\end{array} & 33 \\ \text { Trachinidæ } & \text { Heterostichus } & \text { rostratus } & 34 \\ \text { Sphyrænidæ } & \text { Sphyræna } & \text { argentea } & 39 \\ \text { Heterolepididæ } & \text { Chiropsis } & \text { constellatus } & 42 \\ & & \text { pictus } & 43 \\ & & \text { guttatus } & 44 \\ & & \text { nelulosus } & 45 \\ & \text { Oplopoma } & \text { pantherins } & 46 \\ & \text { Ophiodon } & \text { elongatus } & 48 \\ & \text { Cottopsis } & \text { asper } & 51 \\ & & \text { gulosus } & 53 \\ & & \text { parvus } & 54 \\ & \text { Oligocottus } & \text { maculosus } & 56 \\ & & \text { avalis } & 57 \\ & & \text { globiceps } & 58 \\ & & \text { armatus } & 60 \\ & \text { Leptocottus } & \text { hirundo } & 62 \\ & \text { Leiocottus } & \text { marmoratus } & 64 \\ & \text { Scorpænichtbys } & \text { bison } & 66 \\ & \text { Aspicottus } & \text { spinosus } & 68 \\ & \text { Hemilepidotus } & \text { laterals } & 70\end{array}$

* General Report upon the Zoology of the sereral Pacific Railroad Routes. Part IV.

† Dionda grisea (2:30), "from twenty miles west of Chcetaw agency", is the only other new species lescribed. 
Order I.-ACANTHOPTERI-Continued.

\begin{tabular}{|c|c|c|c|}
\hline \multirow[t]{3}{*}{ Cottidæ } & Artedius & notospilotus & 71 \\
\hline & Zaniolepis & latipinnis & 73 \\
\hline & Nautichthys & oculo-fasciatus & 75 \\
\hline \multirow[t]{6}{*}{ Scorpænidæ } & Scorpæua & guttata & $\pi$ \\
\hline & Sebastes & rosaceus & \\
\hline & & fasciatus & 79 \\
\hline & & auriculatus & 80 \\
\hline & & melanops & 81 \\
\hline & & paucispinis & 83 \\
\hline \multirow[t]{7}{*}{ Gasterosteidæ } & Gasterosteus & plebeius & 86 \\
\hline & & scrratus & $\varepsilon 8$ \\
\hline & & intermedius & 89 \\
\hline & & inopinatus & 90 \\
\hline & & microcephalus & 91 \\
\hline & & pugetti & 92 \\
\hline & & Williamsonii & 93 \\
\hline \multirow{3}{*}{ Sciænidæ } & Amblodion & saturuus & 98 \\
\hline & Leiostomus & lineatus & 99 \\
\hline & Umbrina & undulata & 101 \\
\hline Atherinidro & Atherinopsis & californiensis & 103 \\
\hline \multirow[t]{4}{*}{ Seombridæ } & Scomber & diego & 105 \\
\hline & Polamys & lineolata & 106 \\
\hline & Trachuras & symmetricus & 107 \\
\hline & & boops & 108 \\
\hline Squamipennes & Ephippus & zonatus & 110 \\
\hline \multirow[t]{9}{*}{ Blennidœ } & Blennius & gentilis & 113 \\
\hline & Neoclinus & Blanchardi & 114 \\
\hline & Guunellus & oruatus & $116^{\circ}$ \\
\hline & Apodichtbys & flavidus & 117 \\
\hline & & virescens & 118 \\
\hline & Xiphidion & mucosus & 119 \\
\hline & Cebidichthys & violaceus & $1: 1$ \\
\hline & Lnmpenus & anguillaris & 123 \\
\hline & Anarrbichthys & felis & 125 \\
\hline \multirow[t]{2}{*}{ Gobidæ } & Gobius & lepidus & 127 \\
\hline & & Newberri & 128 \\
\hline \multirow[t]{2}{*}{ Cyclopteridæ } & Lepadogaster & neandricus & 130 \\
\hline & Cyclogaster & pulcbellus & 132 \\
\hline \multirow[t]{3}{*}{ Batrachidæ } & Pcrichtliys & notatus & 134 \\
\hline & der II-ANACAD & THINI. & \\
\hline & Subolder I.-APC & ES. & \\
\hline \multirow[t]{3}{*}{ Ophididæ } & Ophidion & Taylori & 138 \\
\hline & Aminodytes & personatus & 139 \\
\hline & bonder II.-THor & & \\
\hline \multirow[t]{4}{*}{ Gadidæ } & Brosmius & marginatus & 141 \\
\hline & Merlangus & productus & 141 \\
\hline & Morrhua & proxima & 142 \\
\hline & Homalopomus & Trowbridgii & 144 \\
\hline \multirow[t]{9}{*}{ Pleuronectidæ } & Platessa & bilineata & 146 \\
\hline & Paralichthys & maculosus & 147 \\
\hline & Platichthys & rugosus & 148 \\
\hline & & umbrosus & 149 \\
\hline & Pleuronichtbys & cœnosus & 151 \\
\hline & & guttulatus & 152 \\
\hline & Pacophrys & vetulus & 153 \\
\hline & Psettichthys & melanostictus & 154 \\
\hline & & sordidus & 155 \\
\hline
\end{tabular}


Order III.-PHARYNGOGNATHI.

Suborder I.-MALACOPTERYGI.

Scomberesocidæ Belone exilis

Suborder II.-ACANTHOPTERYGII.

$\begin{array}{llll}\text { Pomacentridæ} & \text { Glyphisodon } & \text { rubicundus } & 161 \\ \text { Lab: idæ } & \text { Labrus } & \text { pulcher } & 162 \\ \text { Embiotocoidæ } & \text { Julis } & \text { modestus } & 163 \\ & \text { Embiotoca } & \text { Jacksoni } & 169 \\ & & \text { Cassidii } & 171 \\ & & \text { Webbi } & 173 \\ & & \text { lineata } & 174 \\ & & \text { ornata } & 176 \\ & & \text { perspicabilis } & 178 \\ & \text { Damalichthys } & \text { argyrosoma } & 180 \\ & \text { Phanerodon } & \text { vacea } & 182 \\ & \text { Abeona } & \text { Trowbridgii } & 184 \\ & \text { Rhacochilus } & \text { toxotes } & 186 \\ & \text { Hysterocarpus } & \text { Traskii } & 190 \\ & \text { Holconotus } & \text { rhodoterus } & 193 \\ & \text { Ennicthys } & \text { megalops } & 197 \\ & & \text { Heermanni } & 199 \\ & \text { Amphistichus } & \text { argenteus } & 201 \\ & & \text { similis } & 203\end{array}$

Order IV.-PHYSOSTOMI or MALACOPTERi.

Suborder II.-ABDOMINALES.

نxprinidæ Tribe of Cyprini.

Mylocheilus
Mylopharodon

caurinus

Tribe of Catostomi.

$\begin{array}{lll}\text { Acomus } & \text { generosus } & 221 \\ \text { Catostomus } & \text { occidentalis } & 224 \\ & \text { labiatus } & 224 \\ & \text { macrocheilus } & 2: 5\end{array}$

Tribe of Chondrostomi.

$\begin{array}{lll}\text { Orthodon } & \text { microlepidotus } & 237 \\ \text { Algansea } & \text { bicolor } & 238 \\ & \text { obesa } & 239 \\ & \text { formosa } & 239 \\ \text { Lavinia } & \text { exilicauda } & 241 \\ & \text { harengus } & 242\end{array}$

Tribe of Pogonichthi.

$\begin{array}{lll}\text { Argyreus } & \text { dulcis } & 243 \\ \text { Pubilus } & 244 \\ & \text { inæquilobus } & 245 \\ & \text { symmetricus } & 246 \\ & \text { argyreiosus } & 246 \\ & \text { communis } & 247\end{array}$


Order IV.-PHYSOSTOMI or MALACOPTERI-Continued.

Cyprinidæ

Tribe of Alburni.

Cyprinella

Gunnisoni $\quad 267$

lugubris $\quad 271$

ludibunda $\quad 271$

Richardsonins balteatus 278

lateralis 279

occidentalis

robusta 285

elegans $\quad 286$

gracilis 287

Tigoma conformis 289

bicolor $\quad 289$

obesa. $\quad 290$

humboldti 291

egregia 291

lineata 292

gracilis 293

crassa 293

Chionda Cooperi 294

cœrulea 295

Siboma crassicauda 296

atraria 297

Ptychocheilus oregonensis 298

grandis 299

rapax $\quad 300$

vorax 301

Cyprinodontidø Fundulus parvipinnis 303

$\begin{array}{llll}\text { Salmonidø Salmo } & \text { Scouleri } & 305\end{array}$

quinnat $\quad 306$

spectabilis $\quad 30^{7}$

Fario aurora 308

tsuppitch $\quad 310$

argyreus $\quad 312$

Gairdneri $\quad 313$

Clarkii $\quad 314$

stellatus $\quad 316$

virginalis $\quad 320$

iridea 321

Osmerus pretiosus 324

Thaleichthys Stevensi 325

Coregonus Williamsoni 326

Scopelidø Laurus (Laurida) lucioceps 328

Clupeid» Clupea mirabilis 329

Meletta cœrulea 330

Engraulis mordax 334

nanus 335

delicatissimus $\quad 335$

compressus $\quad 335$

Order V.-PLECTOGNATHI.

$\begin{array}{lll}\text { Balistidæ } & \text { Balistes } & \\ \text { Gymnodontidæ } & \text { Tetraodon } & \text { politus }\end{array}$

Order VI.-LOPHOBRANCHII.

Hippocampidæ Hippocampus ingens 342

$\begin{array}{lll}\text { Syngnathidø } & \text { Syngnathus } & \text { californionsis } 344\end{array}$

brevirostris $\quad 345$

leptorhynchus $\quad 345$

Abboti $\quad 346$

arundinacens $\quad 346$ 
Order VII.-GANOIDEI.

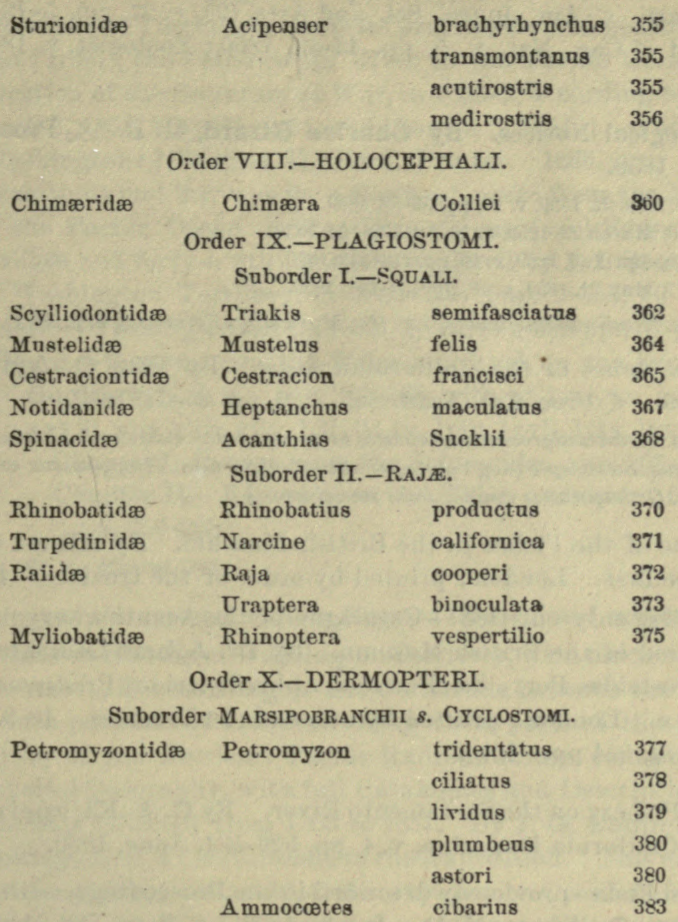

Explorations and Surveys for a Railroad route from the Mississippi River to the Pacific Ocean. | War Department. $|=|$ Route near the 3\$:h and 39 th parallels, explored by Captain J. W. Gunnison, and near the 41 st I parallel, explored by Lieutenant E. G. B ckwith. $|-|$ Zoological Report. ${ }^{1}|-|$ Washington, D. C. $|1857|=.\mid{ }^{1}$ The report to which the present article belongs will be fuund in Vol. II of 1 he series.

No. 4. Report on Fishes collected on the Survey.-By Charles

Girard, M. D.-(pp. 21-27, with pl. xxiii, xlix, liv, lvi, lxxiii, lxxv.)

Explorations and surveys for a railroad route from the Mississippi River to the Pacific Ocean. | War Department. $\mathrm{i}=\mid$ Route near the thirtyfifth parallel, explored by Lieutenant A. W. Whipple, Topographical | Engineers, in 1853 and 1854. | - | Zoological Report. | - | Washington, D. C. $|1859|=$.

No. 5. Report upon Fishes collected on the Survey.-By C. Girard, M. D.-pp. (47-59, with pl. iii-vi, ix, x, xxi, xxiv, $x \times v, x \times x v$, $\mathrm{xl} b$, lii, lvii, 1viii.)

Explorations and Surveys for a Railroad Route from the Mississippi River to the Pacific Ocean. | War Department. $|=|$ Routes in California, to connect with the routes near the thirty-fifth and thirty-second I parallels, explored by Lient. R. S. Williamson, Corps of Top. Eng., in 1853. | - I Zoological Report. | - | Washington, D. C. | 1859. =

No. 4. Report on Fishes collected on the Survey.-By Charles Girard, M. D. -(pp. 83-91, with pl. ii, xii, xxii, xxvii, xxviii, xxxi, xxxvi, xxxviii, xxxix, xlvii.) 
1859 -On some unusual modes of gestation in Batrachians and Fishes. By Jefries Wyman. <Am. Journ. Sei. aud Arts, (2), v. 27, pp. 5-13, Jan., 1859; repriuted < Can. Nat., v. 5, pp. 42-49, 1860; Zoologist, v. 18, pp. 7173-7179, 1860.

Ichthyological Notices. By Charles Girard, M. D. < Proc. Acad. Nat. Sci. Phila., 1859.

§ 5-27, Feb. 22, 1859, v. 10, pp. 56-58, 185 .

$\S 28-40$, March 29, 1859, г. 10, pp. 100-104, 1859.

$\S 41-59$, A pril $26,1 \leq 59$, v. 10, pp. 113-122, 1859 .

$\S 60-7 \tau$, May 31, 1859, v. 10, pp. 157-161, 1859.

[N. sp. Neoclinus satiricus $(\S 5$, p. 56), Mfyrichthys tigrinus $(\$ 6$, p. 58$)$.]

† On new fishes of the Californian coast. By Wm O. Ayres, M. D. Oct. 17, 1859. < Proc. Cal. Acad. Sei., r. 2, pp. 25-3:, 18.59.

[N. sp. Sebastes nigrocinctus, Sebastes helvomaculatus, Sebastes elongatus, A nopl poma (n. g.) merlangus, Stereolepis (n. g ) gigas, Squatına californica, Hippoglossus cnlifornicus, Ifuronx mordax, Orthagoriscus analis, Julis semicinctus.]

Catalogue of the Fishes in the British Museum. By Albert Günther, . . . . Volume first. London: printed by order of the trustees. 1859. [Augnst.]

At first only entitled:-Catalogue of the Acanthoptersuian Fishes in the collection of $\mathrm{the}$ British Museum. By Dr. Albert Günther. Volume first. Gasterosteidæ, Beryeidæ, Percidæ, Aphredoderidæ, Pristipomatida, Mullidæ, Sparidie. London: printed by order of the Trustees. 1859. [Geueral title $+\mathrm{xxxix}, 5: 24$ pp. -108.$]$

1860-Salmon Fishery on the Saramento River. By C. A. Kirkpatrick. < Hutchings's California Magazine, v. 4, pp. 529-534, June, 1860.

† Notes on Fishes previously described in the Proceedings, with figures of seven. By Wm. O. Ayres, M. D. July 2, 1860. < Proc. Cal. Aead. Sei., v. 2, pp. $5 *-59,1860$.

[N. g. Halins for Brosmius marginatus.]

Beiträge zur Kenntniss der Gobioiden. Von Franz Steindachner. (Mit 1 Tafel.) < Sitzungsb. mathem.-naturw. Classe [K. Akad. Wissenseh.] rom 12. Juli 1860 , xlii. Band, No. 23 , Sitzung vom 18 . October 1860 , pp. $2 \triangleleft 3-293$.

*Deseription of new fishes. By Wm. O. Ayres, M. D. Aug. 6, 1860. <Proe. Cal. Acad. S.i., v. 2, pp. 60-61, 1860.

[N. sp. Trichodon lineatus, Osmerus thaleichthys, with fignres.]

Catalogue of the Fishes in the British Museum. By Albert Günther, . . . . Volume second. London: printed by order of the trustees. 1860. [Sept.]

At first only entitled :-Catalogue of the Acanthopterygian Fishes in the collection of the British Musenm. By Dr. Albert Günther, . . . . Volnme second. Squamipinnes, Cirrbitidæ, Triglidæ, Trachinidæ, Sciænidæ, Polynemidæ, Sphyrænidæ, Trichiuridæ, Scombridæ, Carangidæ, Xiphiidæ. London : printed by order of the Trustees. 1860. [General title $+x x i, 54 \mathrm{~s} p \mathrm{p}$. -8 . $6 d$.]

[Nov. loc. Naucrates ductor (374), Echeneis remosa (378), Echeneis naucrates (384). N. sp. Cottus criniger (522), Aspidophoroides inermis (524).]

Reports of Explorations and Surveys to ascertain the most practicable and economical ronte for a Railıoad from the Mississippi River to the Pacitic Ocean, made under the direction of the Secretary of War, in 1853-6, \&c. Vol. X. Washington, 1859. Fishes; by Chaıles Girard, M. D. Washington, D. C., 1858. [Review, by Theodore Gill.] < Am. Journ. Sci. and Arts, 2 d series, vcl. 30, pp. 277-281, Sept. 1860. 
1860-36th Congress, 1s' Session. $\}$ Senate. $\{$ Ex. Doc. $|=|$ Reports $\mid$ of $\mid$ Explorations and Surveys | to | ascertain the most practicable and economical ronte for a railroad | from | the | Mississippi River to the Pacific Ocean. Made under the direcrion of tho Secretary of War, in 1853-5, according to act of Congress of Disrch 3, 1853, May 31, 1854, and Angust 5, 1854. | -Volume XII. | Book II. | Washington: | Thomas H. Ford, Printer. 1860.

Explorations an 1 Surreys for a R vilroad route from the Mississippi River to the Pacific Ocean. | War Department. $|=|$ Route near the fortyseventh and forty-n ntl parallels, explored by I. I. Stevens, / Governor of Washington Territory, in 1853-55. [pp. 9-353, 70 pl.] Zoological roport.-Washington, D. C., 1860. [viii, (1), 399 pp., 47 pl.]

No. 5.-Report upon the fishes colleeted on the survey.-B5 Dr. G. Suckley, U. S. A. (pp. 30 -369 , with pl. i, xi, xv, xvi, xix, xx, xxxii, xxxiii, slii, xliii, xliv, l, li, lv, lx, lxiii, lxvii, lxix, lxxii, lxxv, viz:

Chapter I. Report "pon the Salmonidæ. pp. 307-349.)

Chapter II. Report npon the Fishes exclusive of the Salmonidze. pp. :350-368.

[N. sp. Salmo Mrasoni (345).]

[This volume also appeared wi h the following title-page and modifications:-]

The Natural History of Washington Territory, with much relating to Minnesota, Nebraska, Kansas, Oregon and California, between the thirty-sixth and fort $y$-ninth parallels of Latitude, being those parts of the final Reports on the Survey of the Northern Pacific Railroad Route, containing the Climate and Physical Geography, with full Catalogues and Descriptions of the Plants and Animals collected from 1853 to 1857 . By J. G. Cooper, M. D., and Dr. G. Suckley, U. S. A., Naturalists to the Expedition. This edition contains a new preface, giving a sketch of the explorations, a classified table of contents, and the latest additions by tho anthors. With fifty-five new plates of scenery, botany, and zoology, and an isothermal chart of the route.-New York: Baillière Brothers, 440 Broad way. [otc.] 1859. [4. xvii, $26+72+$ viii, 399 pp. ( +1-4 pp. betw. 368 and 369$), 61$ pl., 1 map.]

tDescriptions of the Californian Atherinidro, with figures of the species. By Wm. O. Ayres, M. D. Oct. 1, 1860. <Proc. Cal. Acad. Sci., v. 2, pp. 73$77,1860$.

[N. sp. Atherinopsis afinis, Atherinopsis tenuis, with figures.]

† Descriptions of two new Sciænoids, with figures. By Wm. O. Ayres, M. B. Nov. 5, 1860. <Proc. Cal. Acad. Sci., v. 2, pp. 77-81, 1860.

[N. g. and sp. Johnius nobilis, Scriphus (n. g.) politus.]

tDescription of new Californian fishes, with figures. By $\mathbf{W m}$. O. Ayres, $\mathbf{M}$.

D. Dec. 3, 1860. < Proc. Cal. Acarl. Sci., v.2, pp. 82-86, April, 1362.

[N. g. and sp. Camarina (n.g.) nigricans, Poronotus simillimus.]

1861-Observations on the genus Cottus, and description of two new species (abridged from the forthcoming report of Capt. J. H. Simpson), by Theodore Gill. March 20, 1861. < Proc. Boston Soc. Nat. Hist., v. 8, pp.40-42. April, 1861.

[N. g. asd v. sp. Potamocottus (n. g. 40), Potamocettus punctulatus.]

Description of a new species of the genus Tigoma of Girard (abridged from tho forthcoming report of Capt. J. H. Simpson), by Theodore Gill. March 20, 1851. < Proc. Boston Soc. Nat. Hist., r. 8, p. 42, April, 1861.

IN. sp. Tigoma squamuta.

Bull. N. M. No. $11 \longrightarrow-3$ P. A 
1861 -Notes on the described species of Holconoti, found on the western coast of North' America. By Alezander Agassiz. March 20,1861. < Proc. Boston Soc. Nat. His t., v. 8, pp. 122-134, 1861.

[The number of species is reduced to 15 , which are grouped under 9 genera. N. g. Toeniotoca > Embiotoca lateralis; n. sp. Hyperprosopon analis, - neither described.]

† Communication on several new generic types of fishes, $i$. e., Podothecus, Hoplopagrus, and Stephanolepis. By Theodore Gill. April 16, 1861. <Proc. Acad. Nat. Sci. Phila., [v. 13], pp. 77-78, 1861.

[N. g. and sp. Podothecus (n. g.).]

Revision of the geuera of North American Sciæninæ. Bj Theodore Gill. April 30, 1861. < Proc. Acad. Nat. Sci. Phila., [v. 13], pp. 79-89, 1861.

[N. g. Rhinoscion (85) for Amblodon saturnus Grd., Genyonemus (87) for Leiostomus line. atus Ayres.]

On the Liostominæ. By Theodore Gill. April 30,1861. < Proc. Acad. Nat. Sci. Phila., [v. 13], pp. 89-93, 1861.

[Remarks on Leiostomus lineatus (92).]

Salmonidæ of Frazer River, British Columbia. By C. Brew. < Edinburgh New Philos. Journ., v. 13, p. 164, 1861.

On the Haploidonotinæ. By Theodore Gill. May 28,1861. < Proc. Acad. Nat. Sci. Phila., [r. 13], pp. 100-105, 1861.

[Remarks on Amblodon saturnus (105).]

Notices of Certain New Species of North American Salmonidæ, chiefly in tho Collection of the N. W. Boundary Commission, in charge of Archibald Campbell, Esq., Commissioner of the United States, by Dr. C. B. R. Kennerly, Naturalist to the Commission. By George Suckley, M. D., late Assistant Surgeon, U. S. Army. Read before the New York Lyceu of Natural History, June, 1861. < Ann. Ljc. Nat. Hist. New York, v. 7, pp. 306-313, 1862.

[N. g. and sp. Salmo Kennerlyi (307), Salmo brevicauda (308), Salmo Warreni (308), Salmo Bairdii (309), Salmo Parkei (309), Oncorhynchus (n. g., 312), Salmo Campbelli (313).]

Notes on some genera of fishes of the western coast of North America. By Theodore Gill. Jnly 30,1861. <Proc. Acad. Nat. Sci. Phila., [v. 13], pp. 164-168, 1861.

[N. g. Atractoperca (164), Archoplites (165), Parephippus (165), Hypsypops (165), Sebastodes (165), Acantholebius (166), Pleurogrammus (166), Grammatopleurus (166), Megalocottus (166). Olinocottus (166), Blennicottus (166), Anoplagonus (167), Brosmophycis (168), Hypsagonus. (167), * Paragonus (167).]

On new types of Aulostomatoids, found in Washington Territory. By Theodore Gill. July 30, 1861. < Proc Acad. Nat. Sci. Phila., [v. 13], pp. 168-170, 1861.

[N.g. and sp. Aulorhynchus (n. g., 169) favidus (169).]

On the genus Podnthecus. By Theodore Gill. Sept. 24, 1861. < Proc. Acad. Nat. Sci. Phila., [v. 13], pp. 258-261, Sept. 1861.

Description of a new generic type of Blennoids. By Theodore Gill. Sept. 24, 1861. < Proc. Acad. Nat. Sci. Phila., [v. 13], pp. 261-263, Sept. 1861.

[N.g. and sp. Anoplarchus (n. g., 261) purpurescens (262).] 
1861-Catalogue of the Fishes in the British Musenm. By Albert Guintlee Volume third. Loudon: printed by order of the trustees. 1861. [Oct.]

At first only entitled:-Catalogue of the Acanthopterygian Fishes in the Collection of the British Museum. By Dr. Albert Guinther. Volumio third. Gobiidæ, Discoboli, Oxndercidæ, Batrachidæ, Pediculati, Blennida, Acanthoclinidæ, Comephoridæ, Trachypteridæ, Lophotidæ, Tenthididæ, Acronuridæ, Hoplognathidæ, Malacanthidie, Nandidæ, Polycentridæ, Labyrinthici, Luciocephalidæ, Atherinidæ, Mugilidæ, Ophiocephalidæ, Trichonotidæx, Cepolidæ, Gobiesocidæ, Psychrolutidæ, Centriscidie, Fistulariidæ, Mastacembelidæ, Notacanthi. London: printed by order of the Trustees. 1861. [Published in Oct. $8^{\circ}$. General title $+\mathrm{xxv}, 586+\mathrm{x}^{*}$ pp. $\left.-108.6 d.\right]$

[N. g. and n. sp. Cyclopterus orbis (158), Liparis cyclopus (163), Centronotus crista-galli (289) = inoplarchus crista-galli (564), Psychrolutes (n. g.) paradoxus (516).]

* Description of a new ichtlyyic form from the coast of Lower California. By Wm. O. Ayres, M. D. Dec. 1, 1861 . < Proc. Cal. Acad. Sci., vol. 2, pl. 156-158, 1862.

[N. sp. Cynoscion parvipinnis.]

Analytical synopsis of the order Squali and revision of the nomenclature of the genera. By Theodore Gill. Dec. 16, 1861. < Ann. Lyc. Nat. Hist., N. Y., r. 7, pp. $363^{*}-370^{*}+371-408,1862$.

Squalorum generum novorum descriptiones diagnosticæ. Theodore Gill, auctore. Dec. 16, 1861. < Ann. Lyc. Nat. Hist. N. Y., v. 8, pp. 409-413, 1862.

1862-Description of a new species of Hemilepidotns, and remarks on the gronp (Tewnistiæ) of which it is a member. By Theodore Gill. Jan. 28, 1862. < Proc. Acad. Nat. Sci. Phila., [ซ. 14], pp. 13-14, 1862.

[N. sp. Hemilepidotus Gibbsii (13).]

On the subfamily of Argentininæ. By Theodore Gill. Jan. 28, 1862. < Proc. Acad. Nat. Sci. Phila., [v. 14], pp. 14-15, 1862.

[N. g. Mesopus (14) or Hypomesus (15).]

Note on the Sciænoids of California. By Theodore Gill. Jan. 28, 1862. < Proc. Acad. Nat. Sci. Phila., [v. 14], pp. 16-18, 1862.

[5 species enumerated.]

$\ddagger$ Notice of fresh water Fishes taken in the Bay of San Francisco. By Wm. O. Ayres, M. D. Feb. 3, 1862 . <Proc. Cal. Acad. Sci., vol. 2, p. 16:3, Sept. 1862.

[8 sp. specified.]

On the limits and arrangement of the family of Scombroids. By Theodore Gill. March 25, 1862. <Proc. Acad. Nat. Sci. Phila., [v. 14], pp. 124-127, 1862.

Description of new species of Alepidosauroilæ. By Theodore Gill. March 25, 1862. < Proc. Acad. Nat. Sci. Phila., [v. 14], pp. 127-132, 1862.

[N. sp. Alepidosaurus (Caulopus) borealis (128), Alepidosaurus (Caulopus) serra (129).]

Catalogne of the fishes of Lower California in the Smithsonian Institution, collected by Mr. J. Xantus. By Theodore Gill. Part I. March 25, 1862. < Proc. Acad. Nat. Sci. Phila., [r. 14], pp. 140-151, 1862.

On a new genus of fishes allied to Aulorhynchus, and on the affinities of the family Aulorhynchoidæ to which it belongs. By Theodore Gill. April 29, 1862. < Proc. Acad. Nat. Sci. Phila., [マ. 14], pp. 233-261, 1862. 
1862-Catalogue of the Fishes of Lower California, in the Smithsonian Institution, collected by Mr. J. Xantus. By Theodore Gill. Part II. April 29, 1862. <Proc. Acad. Nat. Sci. Phila., [v. 14], pp. 242-246, 1862.

Catalogue of the Fishes of Lower California, in the Smithsonian Institution, collected by Mr. J. Xantas. By Theodore Gill. Part III. May 27, 1862. <Proc. Acad. Nat. Sci. Phila., [v. 14], pp. 249-262, 1862.

Notice of a collection of the Fishes of California presented to the Smithsonian Institution by Mr. Samuel Hubbard. By Theodore Gill. June 24, 1862.

- CProc. Acad. Nat. Sci. Phila., [v. 14], pp. 274-282, 186?.

[N. g. and sp. Hypocritichthys (n. g., 275) analis (275), ${ }^{*}$ Brachyistius (n. g., 275) frenatus (275), Hyperprosopon Agassizii (276), Oxylebius (n. g., 277) pictus (278), Apodichthys sanguineus (279), *Apodichthys inornatus (279), Parophrys Hubbardii (231), Alausa californica (281), Isoplagiodon sp. (282).]

Synopsis of the species of Lophobranchiate Fishes of Western North America. By Theodore Gill. June 24, 1862. < Proc. Acad. Nat. Sci. Phila., [v. 14], pp. 282-284, 1862.

[N. g. and sp. Dermatostethus (n. g., 283) punctipinnis (283), Syngnathus dimidiatus (283 284).]

Catalogue of the Fishes in the British Museum. By Albert Günther, . . . Volume fourth. London: printed by order of the trustees. 1862.

Also entitled:-Catalogue of the Acanthopterygii pharyngognathi and Anacanthini in the collection of the British Museum. . . L London : printed by order of the Trustees. 1862. [ $8^{\circ}$. General title $\left.+\mathrm{xxi}, 534 \mathrm{pp} .-88.6 d.\right]$

[N. sp. Ditrema brevipinne (248), Pleuronectes Franklinii (442), Pleuronectes digrammus (445), Parophrys Ayresii (456).]

Notes on the family of Scombroils. By Theodore Gill. July 29, 1862. < Proc. Acad. Nat. Sci. Phila.; [v. 14], pp. 328-329, 1862.

Note on some genera of Fishes of Western North America. By Theodore Gill. July 29, 1862. < Proc. Acad. Nat. Sci. Phila., [v. 14], pp. 329-332, 1862.

[N. g. and sp. Eucyclogobius (n. g., 330), Caularchus (n. g., 330), Eumicrotremus (n. g, 330) Hypsifario (n. g., 330), Lepidopsetta (n. g., 330), Hypsopsetta (n. g., 330), Orthopsetta (n. g., 330), Uropsetta (n. g., 330), Hydrolagus (n.g., 331), Gyropleurodus (n. g., 331), Holorhinus (n. g., 331), Entosphenus (u. g., 331). 42 genera are stated to have been added to the Californian fauna, either as entirely new or in substitution for others erroneously identifled, since the publication of Girard's work.]

On the classification of the families and genera of the Squali of California. By Theodore Gill. Oct. 28, 1862 . < Proc. Acad. Nat. Sci. Phila., [v. 14], pp. 48:3-501, 1862.

[N. g. and sp. Rhinotriacis (n. g., 486) Henlei (486).]

+ Statement in regard to Sebastes rosacens and S. ruber. By Wm. O. Ayres, M. D. Nov. 3, 1862. < Proc. Cal. Acad. Sci., v. 2, p. 207, January, 1863.

* Description of Fishes believed to be new. By Wm. O. Ayres. M. D. Nov. 3, 1862. < Proc. Cal. Acad. Sci., v. 2, pp. 209-211, January, 1863.

[N. sp. Sebastodes favidus, Sebastodes ovalis.]

* Remarks in relation to the fishes of California which are included in Cuvier's genus Sebastes. By Wm. O. Ayres, M. D. Nov. 3, 1862. <Prnc. Cal. Acad. Sci., v. 2, pp. 211-218, Jauuary, 1863. 
1862 -Notices of certain new species of North American Salmonidæ, chiefly in the collection of the N. W. Boundary Commission. By George Suckley, M. D. See 1861, June.

1863-The Resources of California, comprising Agriculture, Mining, Geography, Climate, Commerce, etc., etc. and the past and futare development of the State. By John S. Hittel.-San Fraucisco: A. Roman \& Company. New York: W. J. Middleton. $1863 . \quad\left[12^{\circ}, \mathrm{xvi}, 464 \mathrm{pp}\right.$. $]$

[Zoology, chap. vi (pp. 140-146); fishing (pp. 313-317).]

List of the Fishes sent by tho Museum [of Comparative Zoology] ta different Institutions, in exchange for other specimens, with Annotations. By $\mathbf{F}$. W. Putnam. < Bull. Mus. Comp. Zool., No. 1, = v. 1, pp. 2-16, March 1, 1863.

* Remarks in relation to the genus Notorhynchus. By Wm. O. Ayres, M. D. March 2, 1863. < Proc. Cal. Acad. Sci., v. 3, p. 15, April, 1863.

Catalogne of the Fishes of Lower California, in the Smithsonian Institution, collected by Mr. J. Xantus. By Theodore Gill. Part IV. March 31, 1863. < Proc. Acad. Nat. Sci. Phila., [v. 15], pp. ' \&0-88, 1863.

Descriptions of some now spocies of Pediculati, and on the classification of the group. By Theodore Gill. March 31, 1863. <Proc. Acad. Nat. Sci. Phila., [v. 15], pp. 88-92, 1863.

On an unuamed generic type allied to Sebastes [Sebastoplns, Gill]. By Theodore Gill. August 25, 1863. < Proc. Acad. Nat. Sci. Phila., [v. 15], pp. 207-209, 1863.

[Contains reference to A yres's views on the Californian Sebastoids.]

* Remarks on ichthyic types new to the California Coast. By Wm. O. Ayres, M. D. Sept. 7, 186:3. < Proc. Cal. Acad. Sci., v. 3, p. 66, Nov. 1863.

[N. sp. (undescribed) Scomberesox n. sp., Alopias n. sp.]

Synopsis of the Pomacentroids of the Western Coast of North and Central America. By Theodore Gill. Sept. 29, 1863. <Proc. Acad. Nat. Sci. Phila., [v. 15], pp. 213-221, 1863.

Notes on the Labroids of the Western Coast of North America. By Theodore Gill. Sept. 29, 1863. < Proc. Acad. Nat. Sci. Phila., [₹. 15], pp. 221-224. 1863.

Synopsis of the North American Gadoid Fishes. By Theodore Gill. Sept. 29, 1863. < Proc. Acad. Nat. Sci. Phila., [v. 15], pp. 229-242, 1863.

Descriptious of the genera of Gadoid and Brotuloid Fishes of Western North America. By Theodore Gill. Sept. 29, 1863. < Proc. Acad. Nat. Sci. Phila. [v. 15], pp. 242-254, 1863.

Synopsis of the family of the Lycodoidæ. By Theodore Gill. Sept. 29, 1863. < Proc. Acad. Nat. Sci. Phila., [ r. 15], pp. 254-262, 1863.

Descriptions of the Gobioid genera of the Western Coast of Temperate North America. By Theodore Gill. Sept. 29, 1863. < Proc. Acad. Nat. Sci. Phila., [v. 15], pp. 262-267, 1863.

[N. g. and sp. Coryphopterus (n. g., 262) glaucofraenum (263).]

On New Genera and Species of California Fishes.-No. I. By J. G. Cooper, M. D. Nov. 3, 1863. < Proc. Cal. Acad. Nat. Sci., v. 3, pp. 70-77, Nov. 1863.

[N. g. and n. sp. Dekaya (n.g.) anomala, A yresia (n. g.) punctipinnis, Orcymus pacificus.] 
1863 -Notes on the Sebastoid Fishes occurring in the Coast of California. By Wm.

O. Ayres, M. D., C. M. D.S. Nov. 10, 1863. < Proc. Zool. Soc. London pp. $390-402,1863$.

On New Genera and Species of California Fishes.-No. II. By J. G. Cooper, M.

D. Nov. 16, 1863. < Proc. Cal. Acad. Nat. Sci., v. 3, pp. 93-97, Dec. 1863.

[N. sp. Exocoetus californicus, Urolophus Halleri.]

Description of the genus Stereolepis Ayres. By Theodore Gill. Nor. 24, 1863. < Proc. Acad. Nat. Sci. Phila., [v. 15], pp. 329-330, 1863.

Description of the genus Oxyjulis Gill. By Theodore Gill. Nov. 24, 1863. < Proc. Acad. Nat. Sei. Phila., [r. 15], pp. 330-331, 1863.

1864 - Catalogne of the Fishes in the British Museum. By Albert Günther, . . Volume fifth. London : printed by order of the trustees. 1864.

Also entitled:-Catalogne of the Physostomi, containing the families Siluridæ, Characinidæ, Haplochitonidæ, Sternoptychidæ, Scopelidæ, Stomiatidx, in the collection of the British Museum. . . L London : published by order of the Trustees. 1864. [ $8^{\circ}$. (Including general title) xxii, $455 \mathrm{pp}$.]

Beschreibung des Heterodontus Phillipii Bl. (Cestracion Phillipii Cuv.) mit Rücksicht auf seine fossilen Verwandten. Von Johannes Strüver (Göttingen). Dresden, 1864. [4 $\left.4^{\circ} 32 \mathrm{pp}, 2 \mathrm{pl}.\right]<$ Verbandl. K. Leopold-Carol. Akad. der Naturf., v. 31.

On new Genera and Species of Californian Fishes.-No. III. By J. G. Cooper, M. D. Jan. 4, 1864. <Proc. Cal. Acad. Nat. Sci., v. 3, pp. 108-114, 1864.

[N. g. and sp. Myxodes (or Gibbonsia, n. g.) elegans, Gillichthys (n.g.) mirabilis, Pteroplatea marmorata.]

Description of a new Labroid genus allied to Trochocopus, Gthr. By Theodore Gill. Mar. 29, 1864. < Proc. Acad. Nat. Sci. Phila., [v. 16], pp. 57-59, 1864.

[N. g. Pimelometopon (58), Sebastomus (59), Sebastosomus (59).]

Note on the nomenclature of Genera and Species of the family Echeneidoidw. By Theodore Gill. Mar. 29, 1864. < Proc. Acad. Nat. Sci. Phila., [v. 16], pp. 59-61, 1864.

Critical remarks on the genera Sebastes and Sebastodes of Ayres. By Theodore Gill. May 31, 1864. < Proc. Acad. Nat. Sci. Phila., [v. 16], pp. 145-147 1864.

[N. sp. Sebastosomus pinniger (147), Sebastosamus simulans (147).]

Second contribution to the Selachology of California. By Theodore Gill. May 31, 1864. < Proc. Acad. Nat. Sci. Phila., [v. 16], pp. 147-151, 1864.

[N. sp. Mustelus californicus (148), Notorhynchus borealis (150).]

tSeveral points in Ichthyology and Conchology, viz: Percopsis Hammondii, n. sp., Paralepidoids and Alepidosauroids, Gymnotoids, and Campeloma vico Melantho. By Theodore Gill. June 7, 1864. < Proc. Acad. Nat. Sci. - Phila., [v.16], pp. 151-15\%, 1864.

†Ayresia punctipinnis named Chromis punctipinnis fide Gill. By J. G. Cooper, M. D. July 18, 1864. <Proc. Cal. Acad. Sci., v. 3, p. 160, 1864. 
1864-Note on the Paralepidoids and Microstomatoirs, and on some peculiaritisz of Arctic Ichthyology. By Theodore Gill. Sept. 27, 1864. < Proc. Acad. Nat. Sci. Phila., [v. 16], pp. 187-189, 1864.

Synopsis of the Cyclopteroids of Eastern North America. By Theodore Gill. Sept. 27, 1864. < Proc. Acad. Nat. Sci. Phila., [v. 16], pp. 189-194, 1864.

Synopsis of the Pleuronectoids of Californian and North-western America. By Theodore Gill. Sept. 27, 1864. < Proc. Acad. Nat. Sci. Phila., [v. 16], pp. 194-198, 1864.

Description of a new generic type of Plenronectoids in the Collection of tho Geological Survey of California. By Theodore Gill. Sept. 6,1864. < Proc. Acad. Nat. Sci. Phila., [v. 16], pp. 198-199, 1864.

[N. g. and sp. Metoponops (n. g., 198) Cooperi (199).]

Note on the family of Stichæoids. By Theodore Gill. Sept. 7, $18 C 4$. <Proc. Acad. Nat. Sci. Phila., [v. 16], pp. 208-211, 1 ¿64.

1865-Note on the family of Myliobatoids, and on a New species of Ætobatis. By Theodore Gill. April 3, 1865. < Ann. Lyc. Nat. Hist. New York, v. 8, pp. 135-138, May, 1865.

[N. sp. Myliobatis californicus (137), Etobatis laticeps (137).]

On the Genus Caulolatilus. By Theodore Gill. April 25, 1865. < Proc. Acad. Nat. Sci. Phila., [v. 17], pp. 6j-6'^, 1865.

On the Cranial Characteristics of Gadus [Microgadus] proximus, Grd. By Theodore Gill. April 25, 1865. < Proc. Acad. Nat. Sci. Philan, [v. 17], p. $69,1865$.

[N. g. Microgadus.]

Note on several Genera of Cyprinoids. By Theodore Gill. April 25, 1865. < Proc. Acad. Nat. Sci. Phila., [v. 17], pp.69-70, 1865.

Some remarks on Labrus pulcher (Ayres). By Albert Günther, M.A., M. D., . Ph. D. May 30, 1865. < Proc. Acad. Nat. Sci. Phila., [v. 17], 1. 77, 1865.

On a new Generic type of Sharks. By Theodore Gill. Sept.26, 1865. <Proc. Acad. Nat. Sci. Phila., [v. 17], p. 177, 1865.

[N. g. and sp. Micristodus (n. g., 177) punctatus (177).]

Histoire naturelle des Poissons ou Ichthyologie générale par Aug. Duméril Professeur-administrateur au Muséum d'Histoire Naturelle de Paris.-Ouvragus accompagné de planches.-Tome premier [.] Elasmobranches [i.e.] Plagiostomes et Holocéphales ou Chimères.-Première partie [-Seconde partie]. . . Paris. Librairie Encyclopédique de Roret, . . . 1865, [Text, 2 p. 1., pp. 1-352; seconde partie, 2 p. l., pp. 353-720.] [8०; atlas larger $\left.8^{\circ}, \mathrm{pl} .1-14, \mathrm{pp} .1-8.\right]$

Vancouver Island and British Columbia. Their History, Resources, and Prospects. H5 Matthew Macfie, F. R. G. S., five years resident in Victoria, V. I. London: Longman, Green, Longman, Roberts, \& Green, 1865. . [8०, xx pp. (inclnding blank leaf and frontispiece), 1 1., 574 pp., 2 maps.]

Chapter V. General Resources of Vancouver's Island. pp. 131-171.

Fisheries. pp. 163-171. 
1866-Catalogue of the Fishes in the British Museum. By Albert Günther, . . . Volume sixtl. Loudou: printed by order of the trustees. 1866.

Also entitled:-Catalogue of the Physostomi, containing the families Salmonidæ, Percopsidæ, Galaxidæ, Mormyridæ, Gymuarchidæ, Esocidæ, Umbridæ, Scombresocidæ, Cyprinodontidæ, in the collection of the British Museum. . . . London: printed by order of the Trnstees. 1866. [ $8^{\circ} \mathrm{xv}$, 368 pp.]

[N. sp. Salmo lordii (148).]

The Naturalist in Vancouver Island and British Columbia. By John Keast Iord, F. Z. S., Naturalist to the British North American Boundary Commission. [Vignettes.] In two volumes. Vol. I [-II]. London: Richard Bentley, New Burlington Street, publisher in ordinary to Her Majesty. 1866. [2 vols., 120. Vol. i, xiv (incl. frontisp.), 2, 353 pp., 8 pl.; vol. ii, vii (incl. frontisp.), $2,375 \mathrm{pp} ., 5 \mathrm{pl}$.

Volume i.

Chapter II.-Victoria-The Salmon: its haunts and habits. pp. 36-61.

Chapter III.-Fish Harvesting. pp. 62-96.

Chapter IV.-The Round-fish, Herrings, and Viviparous Fish. pp. 97-120

Chapter V.-Sticklebacks and their Nests-The Bullbead-The Rockcod-The Chirus-Flatfish. pp. 121-141.

Chapter VI.-Halibut Fishing-Dogfish-A trip to Fort Rupert-Ransoming a Slave-A promenade with a Red skin-Bagging a Chief's headQueen Charlotte's Islanders at Naniamo. pp. 142-174.

Chapter VII.-Sturgeon-spearing-Man-sucker-Clams. pp. 175-198.

Appendix.

Volume ii.

List of Fishes collected in the Salt and Fresh Waters of Vancouver Island and British Columbia. pp. 351-356.

[In the list are ennmorated species which almost certainly were not "collected" in the waters in question.]

- Hr. W. Peters machte eine Mittheilung über Fische (Protopterus, Auliscops, Labrax, Labracoglossa, Nemotocentris, Serranus, Scorpis, Opisthognathus, Scombresox, Acharnes, Anguilla, Gymnnmurcena, Chilorhinus, Ophichthys, Helmichthys). <Mouatsberichte der Königl. Akadenie der Wissenschaften zu Berlin, 1866, pp. 509-526, 1 pl.

[N. g. and sp. Auliscops (n. g., 510) spinescens (510), Scom.bresox brevirostris (521).]

$1867-O n$ the identity of the genus Alepisaurus Lowe with Plagyodus Steller. By Dr. Albert Gïnther. <Ann. and Mag. Nat. Hist., (4), v. 19, pp. 185-18\%.

On the nourishment of the fotus in the Embiotocoid Fishes. By James Blake, M. D., F. R. C. S. Jan. 21, 1867. < Proc. Cal. Acad. Nat. Sci., v. 3, pp. $314-317$, Sept. $186 \%$.

On the organs of Copulation in the Male of the Embiotocoid Fishes. By James Blake, M. D., F.R. C.S. Nov. 4, 1867. < Proc. Cal. Acad. Nat. Sci., v. 3, pp. 371-372, May, 1868.

1868-Some Recent Additions to the Fauna of California. By J. G. Cooper, M. D. Jan. 13, 1868. < Proc. Cal. Acad. Sci., v. 4, pp. 3-13, Nov. 1863.

[The number of fishes is stated (p.3) to be 196 in 1868, against 133 known in 1862.]

Nourishment of the Fœtus in Embiotocoid Fishes. By James Blake, M. D., Lond., F. R. C. S. < Journ. Anat. and Physiol., v. 2, pp. 280-282. 
1868-On the aulal fin appendage of Embiotocoid Fishes. By James Blake, M. D., F. R. C. S., Professor of Obstetrics in Tolard Medical College, St. Franciseo, California. < Journ. Anat. and Physiol., v. 3, pp. 30-32, pl. 2, figs. 1 and 2, Nov. 1868.

The Natural Wealth of California. Comprising early history; geography, topography, and cenery; climate; agriculture and commercial products; geology, zoology, and botany ; mineralogy, mines, and mining processes; manufactures; steamship lines, railroads, and commerce; immigration, population and society ; educational institutious and literature; together with a detailed description of each county; its topography, scencry, cities and towns, agricultural advantiges, nineral resources, and varied productions. By Titus Fey Cronise. San Francisco: H. H. Buncroft \& Company. 1868. [8०, xri, $696 \mathrm{pp}$.

Chapter VII. Zoology. pp. 434-501.

Fishes. [By J. G. Cooper, M. D.] pp. 487-498.

Chapter XIII. Miscellaneous Subjects. pp. 668-684.

Fisheries. p. 680.

[Tho list of fishes was eridently prepared by Dr. J. G. Cooper, although ouly genaral acknowledgment for assistance was rendered in the preface. It was acknowledged by Dr. Cooper, as author, in the communication to the California Academy of Sciences, indicated above. Inasmuch as this was intended to be a complete env veration of the fishes of California, the names are reproduced here.]

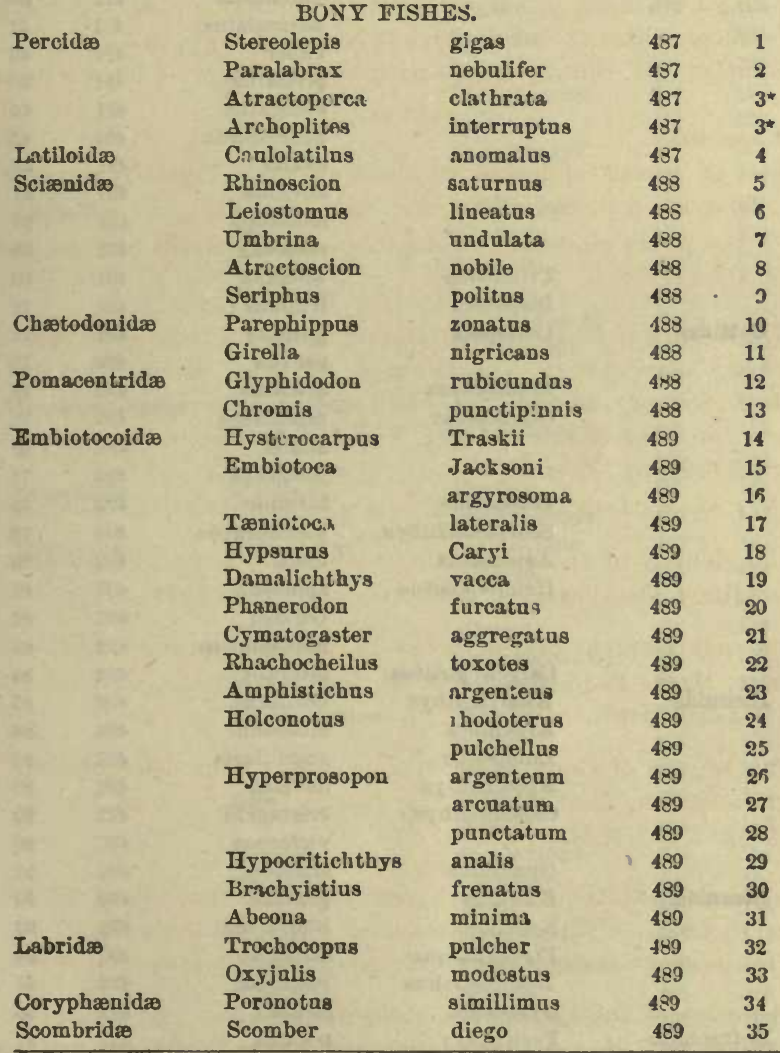

- Repeated. 
BONY FISHES-Continued.

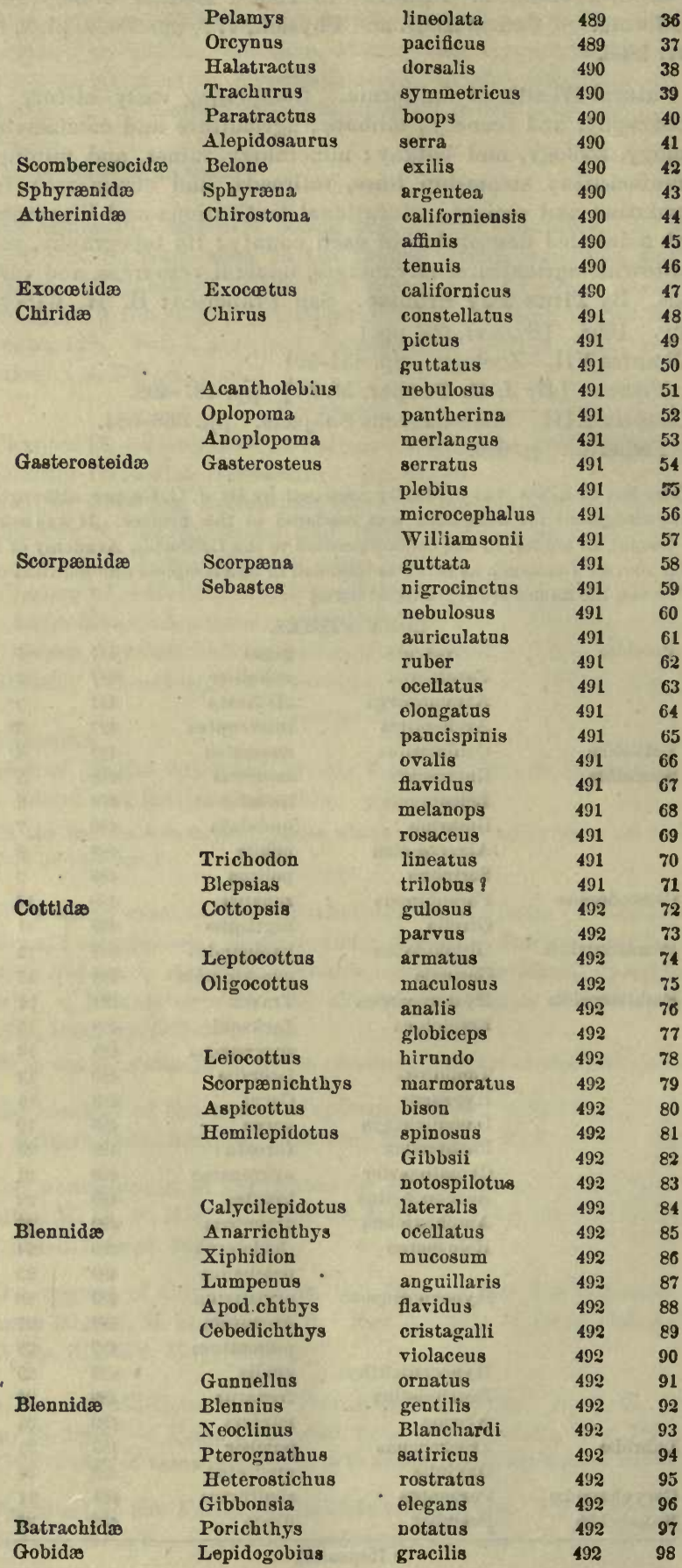


BONY FISHES-Continued.

\begin{tabular}{|c|c|c|c|c|}
\hline & Eucyclogobius & newberrii & 492 & 90 \\
\hline & Gillichthys & mirabilis & 492 & 100 \\
\hline \multirow[t]{3}{*}{ Cyclopteridæ } & Caularchus & reticulatus & 493 & 101 \\
\hline & Liparis & pulchellus & 493 & 102 \\
\hline & & mucosus & 493 & 103 \\
\hline \multirow[t]{13}{*}{ Pleuronectidæ } & Hippoglossus & californicus & 493 & 104 \\
\hline & & vulgaris & 493 & 105 \\
\hline & Platichthys & stellatus & 493 & 106 \\
\hline & Parophys & vetulus & 493 & 107 \\
\hline & Parophrys? & Ayresii & 493 & 108 \\
\hline & Platessa? & bilineata & 493 & 109 \\
\hline & Paralichthys & maculosus & 493 & 110 \\
\hline & Pleuronichthys & cœnosus & 493 & 111 \\
\hline & + & Hubbardii & 493 & 112 \\
\hline & Hypsopsetta & guttulata & 493 & 113 \\
\hline & Psettichthys & melanostictus & 493 & 114 \\
\hline & & sordidus & 493 & 115 \\
\hline & Metoponops & cooperi & 493 & 116 \\
\hline \multirow[t]{4}{*}{ Gadidæ } & Merlucius & produetus & 493 & 117 \\
\hline & Brosmophyeis & marginatus & 493 & 118 \\
\hline & Gadus & proximus & 493 & 119 \\
\hline & Ammodytes & personatus & 493 & 120 \\
\hline Ophidiidæ & Ophidion & Taylori & 493 & 121 \\
\hline \multirow[t]{8}{*}{ Salmonidæ } & Salmo & quinnat & 494 & 122 \\
\hline & & Scouleri & 494 & 123 \\
\hline & & Masoni & 494 & 124 \\
\hline & & stellatus & 494 & 125 \\
\hline & & iridea & 494 & 126 \\
\hline & Coregonus & Williamsonii & 494 & 127 \\
\hline & Hypomesus & pretiosus & 494 & 128 \\
\hline & Osmerus & thaleichthys & 494 & 129 \\
\hline Scopelidæ & Synodus & lucioceps & 495 & 130 \\
\hline \multirow[t]{7}{*}{ Clupeidæ } & Alausa & californica & 495 & 131 \\
\hline & Clupea & mirabilis & 495 & 132 \\
\hline & Meletta & cærulea & 495 & 133 \\
\hline & Engraulis & mordax & 495 & 134 \\
\hline & & delicatissimus & 495 & 135 \\
\hline & & compressus & 495 & 136 \\
\hline & & nanus & 495 & 137 \\
\hline \multirow[t]{3}{*}{ Cyprinodontidæ } & Cyprinodon & californiensis & 495 & 138 \\
\hline & Fundulus & parvipinnis & 495 & 139 \\
\hline & & ? & 495 & 140 \\
\hline \multirow[t]{2}{*}{ Murænidæ } & Muræna & mordax & 495 & 141 \\
\hline & Ophidiurus & californiensis & 495 & 142 \\
\hline \multirow[t]{19}{*}{ Cyprinidæ } & Catostomus & occidentalis & 495 & 143 \\
\hline & & labiatus & 495 & 144 \\
\hline & Acomus & generosus? & 495 & 145 \\
\hline & Mylopharodon & robustus & 496 & 146 \\
\hline & & conocephalus & 496 & 147 \\
\hline & Mylocheilus & fratereulus & 496 & 148 \\
\hline & Ptychocheilus & grandis & 496 & 149 \\
\hline & & lucius & 496 & 150 \\
\hline & & rapax & 496 & 151 \\
\hline & Gila & robusta & 496 & 152 \\
\hline & & elegans & 496 & 153 \\
\hline & Luxilus & occidentalis & 496 & 154 \\
\hline & Tigoma & conformis & 496 & 155 \\
\hline & & crassa & 496 & 156 \\
\hline & Siboma & erassicauda & 496 & 157 \\
\hline & Orthodon & microlepidotus & 496 & 158 \\
\hline & Algansea . & formosa & 496 & 159 \\
\hline & Lavinia & exilicauda & 496 & 160 \\
\hline & & harengus & 496 & 161 \\
\hline
\end{tabular}


BONY FISHES-Continued.

$\begin{array}{llll}\text { Pogonichthys } & \text { inæquilobus } & 496 & 162 \\ & \text { symmetricus } & 496 & 163 \\ & \text { argyreiosus } & 496 & 164\end{array}$

CARTILAGINOUS FISHES.*

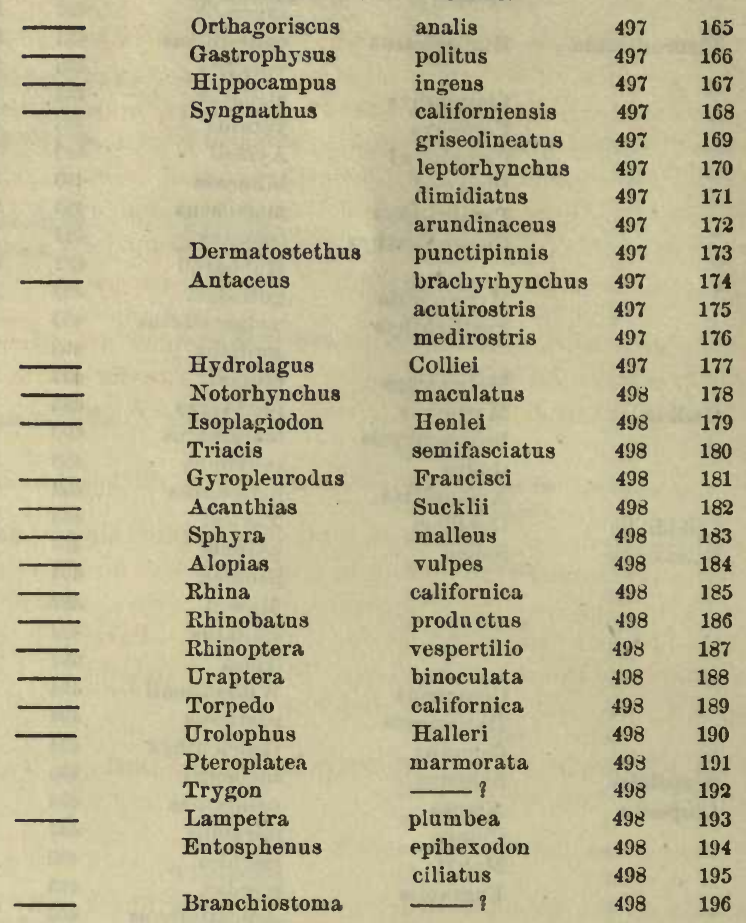

1868-Catalogue of the Fishes in the British Museum. By Albert Günther, . . Volume seventh.-Londun: printed by order of the trustees. 1868.

Also entitled :-Catalogue of the Physostomi, containing the families Heteropygii, Cyprinidæ, Gonorhynchidæ, Hyodontidæ, Osteoglossidæ, Clupeidæ, Chirocentridæ, Alepocephalidæ, Notopteridæ, Halosauridæ, in the collection of the British Museum. . . L London: printed by order of the Trustees. 1868. $\left[8^{\circ}, \mathrm{xx}, 512 \mathrm{pp}.\right]$

1870-Alaska and Its Resources. By William H. Dall, Director of the Scientific Corps of the late Western Union Telegraph Expedition. Boston: Lee and Shepard. 1870. [8०, xii, $628 \mathrm{pp}, 15 \mathrm{pl} ., 1$ map. $]$

Part II.

Chapter VI. Fisheries, Fur Trade, and other resources not previously mentioned. pp. 481-505.

Appendix.

-Appendix G. Natural History. pp. 5z6-594.

List of the fishes of Alaska. p. 579.

Marine Fishes. p. 579.

Fresh-water fishes of the Yukon. p. 579.

[The list is very imperfect.]

\footnotetext{
* No families are recognized among the so-called cartilaginous fishes. These are indicated by the present writer by the lines in the family column.
} 
1870-Mackerel-catching. [By John C. Cremony.] < Overland Monthly, v. 4, pp. 161-168, Feb. 1870.

The Pacific Coast Cod-fishery. [By Capt. C. M. Scammon.] < Orerland Monthly, v. 4, pp. 436-440, May, 1870.

Catalogue of Fishes in the British Musenm. By Albert Günther, .. Volume eighth. London: printed by order of the trustees. 1870.

Also entitled:-Catalogue of the Physostomi, containing the families Gymnotidæ, Symbranchidæ, Murænidæ, Pegasidæ, and of the [orders] Lophobranchii, Plectognathi, [aud subclasses] Dipnoi, Ganoidei, Chondropterygii, Cyclostomata, Leptocardii, in the British Musenm. . . . London: printed by order of the Trustees. 1870 . [ $\left.8{ }^{\circ}, \mathrm{xxv}, 549 \mathrm{pp}.\right]$

[Sp. new to coast:-Galeus canis (379). N. g. Ichthyomyzon (506).]

Uber einige Pleuronectiden, Salmoniden, Gadoiden und Blenniiden aus der Decastris-Bay und vou Viti-Levn. Von Franz Steindachner and weil. Prof. Dr. Rudolph Kner. < Sitzb. K. Akad. Wissensch., B. 61, Abth. i, pp. 421-447, pl. 1, 1870.

[7 species identified as common to Decastris Bay and the American coast.]

Histoire naturelle des Poissons ou Ichthyologie générale par Aug. Duméril [,] Membre de l'Iustitnt [,] professenr-administrateur an Muś́nm d'Histoire Naturelle de Paris.-Onvrage accompagné de planches.-Tome secoud [.] Ganoīdes, Dipnés, Lophobranches. . . . 1870.-Paris [,] Librairie Encyclopédique de Roret, ... . 1870. [4 juin.-Text, 80,2 p. 1., 624 pp. ; Atlas, larger $\gamma^{\circ}$, pl. 15-26, pp. 9-12, with balf titlo.]

1871-The Food Fishes of Alaska. By William Healy Dall. < Rep. Comm. Agric., 1870, pp. 375-392, 1871.

[14 species specifled: no new species deścribed.]

† Remarks on the mode of attack of the Thrasher Shark. By George Davidson. July 11, 1870. < Proc. Cal. Acad. Sci., v. 4, p. 127, April, 1871

1872 -Notice of an apparently new marine animal from the Northern Pacific. By P. I. Sclater, M. A., Ph. D., F. R. S., Secretary of the Zoological Society of London. < Rep. 42 d meeting Brit. Assoc. Adr. Sc., Ang. 1872, Tr. Sec., pp. 140-141.

Notice of a supposed new marine animal from Washington Territory, northwest America. [By P. L. Sclater.] < Nature, v. i, p. 436, Sept. 26, 1872.

[The supposed new animal was represented by "sereral specimens which at first sight appeared to resemble long thin peeled white willow-wand more than anything else." Mr. Sclater, in the first instance, "was inclined to regard them as possibly bones of one of the gigantic rays," and afterwards (when he had been told what they were !) "as the hardened notochord of a low organized fish." They were, in truth, the axial skeletons of Pennatulid zoophytes!!!

Utber eine neus Gattung von Fischen ans der Familie der Cataphracti Cnr., Scombrocottus salmoneus, von der Vancouvers-Insel. Von W. C. H. Peters. <Monatsb. K. Prenss. Akad. Wissensch. Berlin, pp. 568-570, 1872.

[N. g. and sp. Scombrocottus (v. g., 568) salmoneus (569).]

Report of the Commissioners of Fisheries of the State of California for the years 1570 and 1871. Sacramento: T. A. Springer, State printer. 1872. $\left[8^{\circ}\right.$, col. title, 24 pp. $]$ 
187 2-Arrangement of the families of Fishes, or classes Pisces, Marsipobranchii, and Leptocardii. Prepared for the Smithsonian Institution. By Theodore Gill, M. D., Ph. D. Washington: published by the Smithsonian Institution. November, 1872. (Smithsonian Miscellaneous Collections. 247.) " $\left[8^{\mathrm{C}}\right.$, xlvi, 49 pp.]

12d Congress, $2 d$ session. | Senate. | Ex. Doc. No. 34. | Message | from the | President of the United States, | communicating, | in complianee with a resolution of the 19th of January, 1869, information | in relation to the resources and extent of the fishing-grounds of the North / Pacific Ocean, opendd to the United States by the treaty of Alaska. [Washington: Government Printing Office. $\left.1872 .-8^{\circ}, 85 \mathrm{pp}.\right]$

On p. 2 entitled "The Fisheries and Fishermen of the North Pacific." By Richard D. Cutts.

Preliminary Report of the United States Geological Survey of Wyoming, and portions of contiguous Territories, (being a second [really fourth] annual report of progress,) conducted under authority of the Secretary of the Interior, by F. V. Hayden, United States Geologist.-Washington : Government Printiug Office. 1872. [ $8^{\circ}, 511$ pp.]

Part IV. Special Reports.

VII. On the Fishes of the Tertiary Shales of Green River, Wyoming Territory. By Prof. E. D. Cope. pp. 425-431.

VIII. Recent Reptiles and Fishes. Report on the Reptiles and Fishes, obtained by the Naturalists of the Expedition. By E. D. Côpe, A. M. pp. 432-442.

Preliminary Report of the United States Geological Survey of Montana, and portions of adjacent Territories; being \& fifth annual report of progress. By F. V. Hayden, United States Geologist.-Conducted under authority of the Secretary of the Interior.-Washington: Government.Printing Office. 1872. [8०, i-vi, 3-538 pp. (with 64 fig.), 2 pl., 5 maps folded.]

Part IV. Zoology and Botąny.

VI. Report on the Recent Reptiles and Fishes of the Survey, collected by Campbell Carrington and C. M. Dawes. By E. D. Cope, A. M. pp. $46 \tau-476$.

1873-A contribution to the Ichthyology of Alaska. By E. D. Cope. Jan. 17, 1873. < Proc. Am. Phil. Soc. Phila., v. 13, pp. 24-32, 1873. [Extras, March 11, 1873.]

[17 species enumerated : n. sp. Salmo tudes, Spratelloides bryoporus, Xiphidium cruoreum, Centronotus laetus, Chirus balias, Chirus ordinatus, Ohirus trigrammus, Ammodytesalascanus, Gadus periscopus, Gadus auratus, Bathymaster signatus, Pleuronectes arcuatus.]

Note on the Scombrocottus salmoneus of Peters, and its identity with Anoplopoma fimbria. By Theodore Gill, M. D. March 17, 1873. < Proc. Cal. Acad. Sci., v. 5. pp. 56-57, 1873 (April); reprinted. <Ann, and Mag. Nat. Hist., (4), v. 12, pp. 74-75, Sept. 1873.

* The first shad (Alausa præstabilis DeKay) canght in the waters of California. By S. R. Throckmorton. May 5, 1873. < Proc. Cal. Acad. Sci., v. 5, p. 85, May, 1873.

* On the introduction of exotic Food Fishes into the waters of California. By S. R. Throckmorton. May 5, 1873. < Proc. Cal. Acad. Sci., v. 5, pp. 8688, May, 1873.

United States Commission of Fish and Fisheries.-Part I.-Report on the condition of the sea-fisheries of the sonth coast of New England in 1871 and 1872. By Spencer F. Baird, Commissioner.-With supplementary papers.Washington: Government Printing Office. 1873. [8c, xlvii, 852 pp., 40 pl., with 38 l. explanatory (to pl.1-38), 1 folded map.] 


\section{$1873-$}

Notes on Liparis and Cyclopterus. B5 F. W. Putnam. August, 1873. < Proceedings of the American Association for the Advancement of Science, vol. 22, B, pp. 335-340, June, $18 \% 4$.

1873-Annual Record of Science and Industry for 18\%2. Edited by Spencer F. Baird, with the assistance of eminent men of science.-New York: Harper \& Brothers, Publishers, Franklin Square. 1873. [120.]

I. Pisciculture and the Fisheries.

Fish Culture in California, pp. 407, 408.

Report of California Fish Commissioners, p. 408, 409.

Stocking California waters with Trout, p. 409.

Transporting Black Bass to California, p. 409.

Transferring Shad to the Sizcramento River, p. 430.

Stocking California with Shad, p. 430.

Oil-works on Unalaschka, p. 436.

Spawning of Cod-fish in Alaska, p, 436 .

Cod-fishing in the Shumagin Islands, p. 436.

Salmon Fisheries in the Columbia River, p. 440.

Capture of Sacramento Salmon with the Hook, p. 441.

Fisheries of the Shumagin Islands, p. 444.

Peculiarities of Reproduction of California Salmon, pp. 445, 446.

Alleged Discovery of Young Shad in the Sacramento River, p. 44i.

Report on the Prybilov Group or Seal Islands of Alaska. By Henry W. Elliott, Assistant Agent Treasury Department. Washington: Government Printing Office. 1873. [4to, $16 \frac{1}{2}$ folios, not paged, with text parallel with back, and extending from bottom to top, 50 phot. pl.]

Chapter VIII. Fish and Fisheries.

See. also. 1875 .

87 - - Note on Subteri anean Fishes in California. By A. W. Chase. <Am., Journ. Sc. and Arts (3), v. 7, p.74, Jan., 1874; Forest and Stream, v.2, p. 70, March 12, 1874.

+ On the edible qualities of the Sacramento Salmon. By Livingston Stone. $<$ Forest and Stream, v. 1, p. 331, Jan.1,1874.

Preparing Salmon on the Columbia River. By Charles Nordhoff. <Forest and Stream, v. 1, p. 397, Jan.29, 1874. (From Harper's New Monthly Magazinc.)

Salmon-fishing on the Novarro. [By Thomas Bennett.] < Overland Monthly, v. 12, pp.119-124, Feb., 1874 ; Forest and Stream, v.2, p. 29, Feb. 19, 1874.

Is the Yellow Perch (Perca flavescens) a good fish to introduce into California? [By Livingston Stone] < Forest and Stream, r.2, p. 84, March 19,1874.

On the Plagopterinæ and the Ichthyology of Utah. By Edward D. Cope, A. M. Read before the American Philosophical Society, March 20,18.4. <Proc. Am. Phil. Soc. Phila., v. 14, pp. 129-139, 1874.

[N.g. and n. sp. Plagopterus (n. g., 130), argentissimus (130), Lepidomeda (n. g., 131), Lepidomeda vittata (131), Lepidomeda jarrovii (132), Clinostomus tonia (133), Rhinichthys henshavii (133), Hybopsis timpanogensis (134), Minomus platyrhynchus (134), Minomus jarrovii (135), Ceratichthys ventricosus (136), MYyloleucus parovanus (136), Clinostomus phlegethontis (137), Uranidea vheeleri (138).]

Geographical and Geological Explorations and surveys west of the 100th Meridian. First Lieutenant G. M. Wheeler, Corps of Engineers, U. S. A., in charge.

On the Plagopterinze and the Ichth yology of Utah. By Edward D. Cope, A. M. - Reprinted from the Proceedings of American Philosophical Society of Phila. Philadelphia: McCalla \& Stavely, Prs., 237-9 Dock street. 1874. $\left[8^{\circ}, 14 \mathrm{pp}\right.$. $]$ 
187 -The Introduction of Eastern Fish into the waters of the Pacific Slope, together with an account of operations at the United States Salncon breeding Establishment on the Mccloud River, California. [By Livingston Stone.]

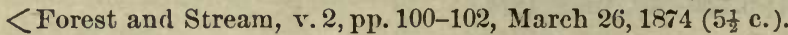

On the Speckled Trout of Utah Lake.-Salmo virginalis, Girard. By Dr. H. C. Yarrow, U. S. A. < Am. Sportsman, v. 4, pp. 68, 69, May 2, 1874.

Shad in California. [By S. R. Throckmorton.] < Forest and Stream, v.3, p. 229, May 21, $18 i 4$.

California Salmon [: its rapidity of growtl. By Livingston Stone.] $<$ Forest and Stream, v.2, p.260, June 4, 1874.

Sports in California.-No. II.-Trout fishing at Humboldt Bay. [By Monmouth.] < Forest and Stream, v. 2, pp. 273, 274 (5 c.), June 11, 1874.

Will the Columbia Salmon take the fly? [Anon.] <Am. Sportsman, v. 4, p. 166 , June $13,18 \% 4$.

The Salmon Fisheries of Oregon. [By A.] < Forest and Stream, v.2, p. 290, June 18, 1874.

Sacramento Salmon vs. Eastern Salmon. [By Livingston Stone.] <Am. Sportsman, v. 14, p. 198, June 27, $18 \% 4$.

On the use of Giant Powder (Dynamite) for obtaining Specimens of Fish at Sea. By A. W. Chase, U. S. Coast Survey. July 6, 1874. < Proc. Cal. Acad. Sci., v. 5, pp. 334-337, Dec., 1874.

Ichthyic Fauna of Northwestern America. [By Mortimer Kerry, pseudon.

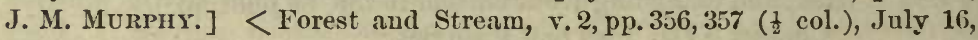
1874.

The Salmonidæ of the Pacific. [By Mortimer Kerry, pseudon. J. M. MURPHY.] < Forest and Stream, v. 2, pp. 369, 370 (6 c.), July 23, 1874.

Salmo Quinnat and Salmo Salar. [By Charles G. Atkins.] < Forest and Stream, v. 2, pp. 388, 339 (2 c.), July 30, 1874.

Eastern Fish in California. What they are and what was done with them. [From "Sacramento Record."] < Am. Sportsman, v.4, p. 358, Sept.5, 1874.

Oregon Salmon Fisheries. [From "Portland Oregonian."] <Am. Sportsman, v. 4. p. 378 , Sept. 12, 1874 .

United States Fish Hatching in California. [Editorial.] < Forest and Stream, v. 3, p. 84 (3 col.), Sept. 1\%, $18 \% 4$.

Salmon Fisheries on the Columbia. <Am. Sportsman, v. 4, p. 412, Sept. 26, 1874.

The Salmon Fisheries of Oregon. <Forest and Stream, v. 3, pp. 155, 172, Oct. $15,22,18 \pi 4$.

Annual Record of Science and Industry for 1873. Edited by Spencer F.

- Baird, with the assistance of eminent men of science.-New York: Harper \& Brothers, Publishers, Franklin Square. 1874. [12०.]

Shipments eastward of California Salmon, p. 433.

Shad in the Sacramento River, p. 449.

Shad in California waters, p. 449.

Pacific Cod-fisheries of 1873, p. 458.

Taking California Salmon with the Hook, p. 464.

Révision des espèces du groupo des Epinoches. Par M. H. E. Sauvage. <Nouv. Arch. Mus. d'Hist. Nat., t. 10, pp. 5-32, pl. 1, 1874. 
1874-Report of the Commissioners of Fisheries of the State of California for the jears $1872^{\circ}$ and 1873.-San Francisco: Francis \&. Valentine, printers aud engravers, 517 Clay street; 1874 . [ $\left[8^{\circ}, 28 \mathrm{pp}.\right]$

United States Commission of Fish and Fisheries. Part II.-Report of the Commissioner for 1872 and 1873. A-Inquiry into the decrease of the FoodFishes. B-The propagation of Food-Fishes in the waters of the United States. With supplementary papers. Washington: Government Printing Office. 18\%4. [80,5 p.l., cii, (1), 808 pp., 38 pl., 3 maps folded.]

Report of the Commissioner. pp. i-xeii.

Appendix B.-The Salmon and the Trout, (species of Salmo). pp. 89-384.

III.* - On the North American species of Salmon and Trout. By George Suckley, Surgeon, United States Army. (Written in 1861.) pp. 91-160.

VI.-Report of operations during 1872 at the United States SalmonHatching Establishment on the M'Cloud River, and on the California Salmonidæ generally; with a list of specimens collected. By Livingston Stone. pp. 168-215.

XII.-On the Speckled Trout of Utah Lake, Salmo virginalis, Girard. By Dr. H. C. Yarrow, U.S. A. [ete.]. pp. 363-368.

XIII.-Miscellaneous notes and correspondence relative to Salmon and Trout. (pp. 369-379), viz:-

D-On the edible qualities of the Sacramento Salmon. [By S. R. Throckmorton.] pp.373-374.

E-On the Salmon-Fisheries of the Sacramento River. By Livingston Stone.] pp. 374-379.

1875-Salmon-hatchin. on MeCloud River. [By Wm. M. Turner.] <Overland Month/y, v. 14, pp. 79-85, Jan. 1875.

Korte Bidrag til nordisk Ichthyographie.-I. Forelobige Meddelelser om nordiske Ulkefske. Af Dr. Chr. Lütken. (Meddelt den 31te Marts og 19de Maj 1875.) < Videnskabelige fra den Naturhistoriske Forening Kjobenhavn, 1876, pp. 355-388; Fr. traus., pp. 72-98, 1876.

Ichthyologische Beiträge (II). Von Franz Steindachner. 29. April 1875. <Sitzl. K. Akad. Wissensch., B. 71, Abth. i, pp. 443-480, 1875.

[4 Californian species mentioned.]

Ichthyologische Beitrüge (III). Von Franz Steindachner. 17. Juni 1875. <Sitzb. K. Akad. Wissensch., B. 72, Abth. i, pp. 29-96, 1875.

[12 Califurnian species particularized: n. sp. Xenichthys californiensis, Scorpis califor. niensis, Corvina stearnsii, Otolithus californiensis, Atherinops n. g. or n. s. g. >Atherinopsis affinis Ayres.]

Description of a New Species of Trout from Mendocino County. [Typical specimen in the collection of California Academy of Natural Sciences.] By W. R. Gibbons, Alameda. June 22, 18\%5. <Proc. Cal. Acad. Sci., v. 6, pp. 14\%-144.

[n. sp. Salmo mendocinensis.]

California Fishplanting. [Signed E. J. Hooper.] <Forest and Stream, v. 5, pp. 19,20, Aug. 19, 1875.

Trouting in Colorado. [Signed "Warren."] < Forest and Stream, v. 5, p. 35, Aug. 26, $18 \pi 5$.

Edible Fish of the Pacific. [Signed E. J. Hooper.] < Forest and Stream, v. 5, p. 36, Ang. 26, 1875.

Salmon Fishing east and west-How they take them in California. [Signed Horace D. Dunn.] <Forest and Stream, v. 5, p. 38, Aug. 26, $18 \% 5$.

* These numbers are continuous through the volume and not subordinated to the parts.

Bull. Nat. Mus. No. $11-4$ 
1875-California Salmon. When to take them with a fly. [Signed "Podgers."] < Forest and Stream, v. 5, pp. 53, 54, Sept. 2, 1875.

Salmon Scores from the McCloud River. [By Sir Rose Price.] < Forest and Stream, v. 5, p. 54, Sept. 2, 1875.

Fishing in Montana. [Signed A. B. Keeler.] < Forest and Stream, v.5, p. 54, Sept. 2, $1>75$.

The Speskled Beauties [Salmo fontinalis] in Colorado. [From "Denver News." $]<$ Rod and Gun, v. 6, p. 348, Sept. 4, 1875.

Fishing in the McCloud River. [By Sir Rose Price.] < Rod and Gun, v. 6, p. 362, Sept. 11, $1 \times 75$.

Carp in California. [By E. J. Hooper.] < Forest and Stream, v. 5, p. 115, Sept. 30, 1875.

California Angling. [By E. J. Hooper.] < Forest and Stream, v.5, p. 133, Oct. 7, 1875.

Flora and Fauna of California. [By W. M. Hinckley.] < Forest and Stream, v. 5, p. 146 , Oct. $14,1875$.

Lake Tahoe, Cal. Its Scenery and Trout Fishing. [By E. J. Hooper.] < Forest and Stream, v. 5, p. 151, Oct. 14, 1875.

Shipments of California Salmon eggs. [By Livingston Stone.] < Forest and Stream, v. 5, p. 179, Oct. 28, 1875.

Sea and Bay Fishing in California.-Wonders of the deep. [By E. J. Hcoper.] < Forest and Stream, v. 5, pp. 197, 198, Nov. 4, 1875.

Illegal traffic in Salmon. <Forest and Stream, v. 5, p. 217, Nov. 11, $18 \% 5$. [From San Francisco Daily Evening Post.]

Progress of Fish-culture in California. [BJ E. J. Hooper.] < Forest and Stream, v. 5, pp. 19. -227 , Nov. 18,1875 .

The Oregon Salıon Fisheries. [Anon.] < Forest and Stream, v.5, p. 230, Nov. 18, 1875.

Comparative size of Tront in Europe and America. [By S. C. C. i. e. Clarke.] <Forest and Stream, v.5, p.230, Nov. 18, 1875.

On what do Salmon Feed? [Editorial from E. J. Hooper's observations.] $<$ Forest and Stream, v. 5, p.280, Dec. 9, 1875.

Distribution of California Ova. < Forest and Stream, v. 5, p. 291, Dec. 16, 1875.

Ichthyologische Beitrïge (IV). Von Franz Steindachner. 16. December, 1875. < Sitbz. K. Akad. Wissensch., B 72, Abth. i, pp. 551-616, 1875. :

[2 west-coast species described.]

Truckee River Trout. [Anon.] < Forest and Stream, v. 5, p. 308, Dec. 23, 1875.

What do Salmon eat? [By R. Tallant.] < Forest and Stream, v. 5, p.308, Dec. 23, 1875.

Annual Record of Science and Industry for 1874. Edited by Spencer F. Baird, with the assistance of eminent men of science.-New York: Harper \& Brothers, Publishers, Franklin Square. 1875. [12०.]

J. Pisciculture and the Fisheries, pp. 419-428.

Alaska Cod-fisheries in 1873. p. 424.

Stocking a pond in Utah with Eels. p. 428.

Destruction of Fish on the Oregon coast, with nitro-glycerine, p. 428. 
1875-A report on the condition of affairs in the Territory of Alaska. By Henry W. Elliott, special agent of the Treasury Department.-Washington : Government Printing Office. 1875. [8०, $277 \mathrm{pp}$.

Chapter VIII.-Fish and Fisheries. The Fisheries of Alaska. pp. 165-167.

[This is essentially a second edition of the report of Mr. Elliott, published in 1873.]

Department of the Interior.-Bulletin of the United States Geological and Geographical Survey of the Territories. F. V. Hayden, United States Geologist-in-Charge. 1874 and 1875. Vol 1.-Washington: Government Printing Office. 1875. [ $\left[8^{\circ}\right.$, xiii pp. +28 pl. +77 pp. +499 pp. +19 1l. unpaged, 26 pl., 3 maps, 1 woodent.]

[Consisting of the separately paged Bulletins Nos. 1, 2, "First Series," and of the continuously pagel Bulletins Nos. 1 to 6 inclusive, "Second Series," furnished with xiii pp. extra (title, table of contents, etc.). The distinct.on "Series" is not maintained after No. 6, which completes vol. 1.]

\section{First Series, 1874.}

No. 2. $\left[8^{\circ}, 77\right.$ pp., 1.]

Review of the Vertebrata of the Cretaceons Period, found west of the Mississippi River. By Edward D. Cope, A. M. pp. 5-48.

Supplementary Notices of Fishes from the Fresh water Tertiaries of the Rocky Mountains. [By Edward D. Cope, A. M.] pp. 49-51.

No. 1. $\left[8^{\circ}, 47\right.$ pp. $]$

Second Series, 1875-1876.

On the Fishes of the Tertiary Shales of the Sonth Park [Colorado]. By E. D. Cope, A. M. pp. 3-5.

La Chasse aux animaux marins et les pêcheries chez les Indigènes de la côte nord-ouest d'Amérique, par m. Alph. Pinart.-Bonlogne-sur-mer, Imp. de Charles Aigre, 4, Rue des Vieillards. 1875. [80,15 pp.]

Engineer Department, United States Arıny.-Report upon Geographical and Geological Explorations and Surveys west of the One Hundredth Meridian, in charge of First Lieut. G. M. Wheeler, Corps of Engineers, U. S. Army, under the direction of Brig. Gen. A. A. Humphreys, Chief of Engineers, U. S. Army. Published by authority of Hon. Wm. W. Belknap, Secretary of War, in accordance with aets of Congress of June 23, 1874, and February 15, 1875. In six volumes, accompanied by one topographical and one geological atlas.-Vol. V.-Zoology.-Washington: Government Printing Office. 1875. [4 $\left.{ }^{\circ} \cdot\right]$

Chapter VI.-Report | upon | the collections of Fishes | made in portions of | Nevada, Utah, California, Colorado, New Mexico, and Arizona, | during | the years 1871, 1872, 1873, and 1874. | By | Prof. E. D. Cope and Dr. H. C. Yarrow.=pp. 635-703, pl. 26-32.

Appendix.-Description of a Mugiloid Fish from the Mesozoic Strata of Colorado [Syllæmus latifrons, Cope], pp. 701-703.

[N. sp. Apocope concesii, Yarrow (p. 648, pl. 27, f. 2), Gila nigra, Cope (p. 663, pl. 30,f. 3), Gila scminuda, Cope and Yarrow (p. 666, pI. 31, f. 1), Hyborlynchus siderius, Cope (p. 670, pl. 31, f. 6,) Gila ardesiaca (p. 660, pl. 30, f. 1), Gila seminuda (p. 666, pl. 31, f. 1), Pantosteus, Cope (n. g., p. 673), Catostomus fecundus (p. 678, pl. 32, f. 1).

"The most extended list is that of the Colorado basin" (p. 699) :-

$\begin{array}{llll}\text { Cyprinidæ } & \text { Plagopterus } & \text { argentissimns } & 640 \\ \text { Meda } & \text { fulgida } & 642 \\ \text { Lepirlomeda } & \text { vittata } & 642 \\ & \text { jarrorii } & 643 \\ & \text { Ceratichthys } & \text { squamilentus } & 000 \\ & & \text { oscula } & 647 \\ & \text { Apocope } & \text { couesii } & 648 \\ & & \text { ventricosa } & 648\end{array}$




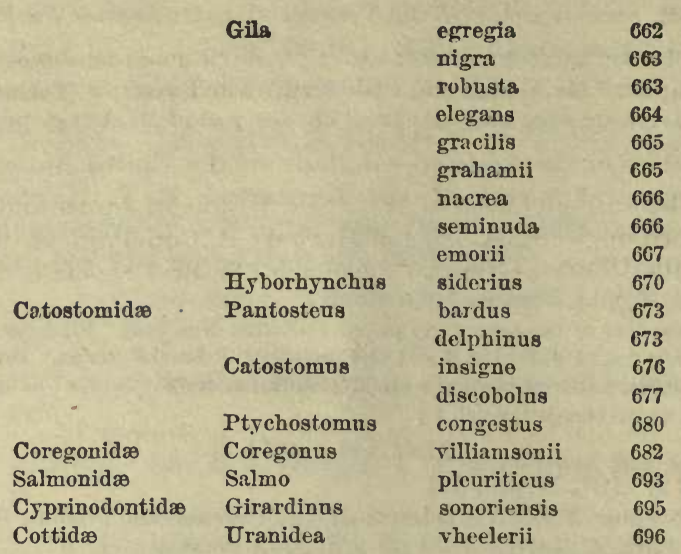

"The following species are those of the basin of Utah, whether from tributaries of the Great Salt Lake or not" (p. 700):-

\begin{tabular}{|c|c|c|c|}
\hline Cyprinidæ & Apocope & carringtonii & 645 \\
\hline & & henshavii & 645 \\
\hline & & vulnerata & 646 \\
\hline & Ceratichthys & bignttatus & 651 \\
\hline • & Hybopsis & timpanogensis & 654 \\
\hline & & bivittatus & 000 \\
\hline & Gila & phlegethontis & 657 \\
\hline & & montana & 657 \\
\hline & & hydrophlox & 658 \\
\hline & & tænia & 658 \\
\hline & & egregia & 662 \\
\hline & Siboma & atraria & 667 \\
\hline & Myloleucus & pulverulentus & 669 \\
\hline & & parovanus & 669 \\
\hline Catostomidæ & Pantosteus & platyrhynchus & 673 \\
\hline & & jarrovii & 674 \\
\hline & Catostomus & fecundus & 678 \\
\hline Coregonidæ & Coregonus & villiamsonii & 682 \\
\hline Salmonidæ & Salmo & virginalis & 685 \\
\hline & & pleuriticus & 693 \\
\hline Cottidæ & Uranidea & rheelerii & 696 \\
\hline & & punctulata & 697 \\
\hline
\end{tabular}

[In both of the preceding lists the enumeration is in the order of the descriptions, and not of the lists, which deriate considerably from the former.]

1876.-Salmon Fishing on the Mayo River, California. [Anon.] < Forest and Stream, v. 5, p. 267, 1876.

California Salmon for New Hampshire. < Forest and Strean, v. 5, p. 339, Jan. 6, 1876.

The McCloud River Reservation. [Editorial.] < Forest and Stream, r. 5, p. 355 , Jan. 13, 1876.

Habits of Pacific Salmon. [By Livingston Stone.] < Forest and Stream, จ. 5, p. 372, Jan. 20, 1876.

California Shad. [Anon.] < Forest and Stream, v. 5, p. 372, Jan. 20, 1876. (6 lines.)

Angling for Eastern Salmon (Salmo salar) in California waters. [Anon.] $<$ Forest and Stream, v. 5, p. 390, Jan. 27, 1876. 
1886-The Fisheries and Sea Lions of California. [Anon.] < Forest ond Stream, v. 6, p. 387, Feb. 24, 1876.

The Natural and Economic History of the Salmonidæ-geographical distribntion and artificial culture. By Philo-Ichthyos. < Forest and Stream, pp. 68-69 (No. 3), 106 (No. 4), 116 (No. 5), 131 (No. 6), 147 (No. 7), 164 (No. 8), 179 (No. 9).

Check List of the Fishes of the Fresh Waters of North America. By David S. Jordan, M. S., M. D., and Herbert E. Copeland, M. S. March 3, 1876. $<$ Bulletin of the Buffalo Society of Natural Sciences, v. 2, pp. 133-164, 1876.

Viviparous Perch: [their abundance at Santa Barbara. By H. C. Yarrow.] $<$ Forest and Stream, v. 6,p. 132, April 6,1876.

Angling for Smelts in California. [By E. J. Hooper.] < Forest and Stream, v. 6, p. 166, April 20, 1876.

A Viviparous Perch. [Editorial.] <Forest and Stream, v. 6, p. 180, with fig., April 27, 1876.

Noget om Slægten Soulv (Anarrhichas) og dens nordiske Arter. Af Proffessor Japetus Steenstrup. Med en Tavle. < Videnskabelige Meddelelser fra den Naturhistorisk Forening i Kjobenhavn, 1876, pp. 159-202, tav. 3.

Salmon Fisheries on the Columbia River. [Anon. By Barnet Phillips.From Appleton's Journal.] < Rod and Gun, v. 8, pp. 131-132 (5 col.), May 27, 1876, with 2 figs.

Remarks on the Various Fishes [of the family of Scorpænidæ] known as Rock Cod. By W. N. Lockington. July 17, 1876. < Proc.Cal.Acad.Sci., v.7, pp. 79-82.

[N. sp. Sebastes Ayresii proposed as a substitute for S. rosaceus of AJres, but not of Girard.

Notes on Some California Marine Fishes, with description of a new species. By W. N. Lockington. July 17, 1876. < Proc. Cal. Acad. Sci., v. 7, pp. 83-88.

[N. sp. Argyreiosus Pacificus, Magdalena Bay.]

Ichthyologische Beitrüge (V.) Von Franz Steindachner. 20. Juli 1876. < Sitzb. K. Akad. Wisseusch., B. 74, Alth. i, pp. -, 1876.

[13 west-coast species elucidated: n. sp. Artedius pugetensis, Siphagonus barbatus, Hypsagonus Swanii, Blakea n. g. <Myxodes elegans Cooper.]

Lake Fishing in California. [BУ E. J. Hooper.] < Forest and Stream, v. 7, p. 5, Aug. 10, 1876.

Fishing this Season [summer of 18\%6] in California. [By E. J. Hooper.] $<$ Forest aud Stream, v. 7, p. 21, Aug. 17, 1876.

Notes on Californian Fishes. By W. N. Lockington. September 4, 1876. < Proc. Cal. Acad. Sci., v. 7, pp. 108-110.

[N. sp. Centropomus viridis (provisionally named on p. 100) from Asuncion Island, Lower California.]

Connecticut River Shad for California. [By S. F. Baird.] < Forest and Stream, v. 7, pp. 66-67, Sept. 7, 1876.

California Slıad. [Anon.] < Forest and Stream, v. 7, p. 83, Sept. 14, 1876.

The Big Fish [Salmon weighing 100 pounds] of Alaska. [Anon.] < Forest and Stream, v.7, pp. 213-214, Nov. 9, 1876. 
1876-Annual Record of Science and Industry for 1875. Edited by Spencer F. Baird, with the assistance of eminent men of science. New York: Harper \& Brothers, Publishers, Franklin Square. 1876. [120.]

J. Piseiculture and the Fisheries. pp. 405-440.

Salmon in the San Joaquin. pp. 430-431.

Salmon Trade of the Columbia River. pp. 431-432.

Salmon in the Sacramento River. p. 432.

United States Salmon-hatehing Establishment, pp. 434-435.

Engineer Department, U. S. Army.= Report of explorations across the Great Basin of the Territory of Utah for a direct wagon-route from Camp Floyd to Genoa, in Carson Valley, in 1859. By Captain J. H. Simpson, Corps of Topographical Engineers, U. S. Army [now colonei of engineers, bvt. brig. gen., U.S.A.]. Made by authority of the Seeretary of War, and under instructions from Bvt. Brig. Gen. A. S. Johnston, U. S. Army, commanding the Department of Utah. Washington: Government Printing Office. 1876.

Explorations across the Great Basin of Utah.=Appendix I.-Report on ichthyology. By Prof. Theo. Gill. pp. 383-431, 8 pl., with 8 1. explanatory.

[This chapter was written in 1861, and not subsequently revised.]

United States Commission of Fish and Fisheries. Part III.-Report of the Commissioner for 1873-4 and 1874-5. A-Inquiry into the decrease of the Food-Fishes. B-The propagation of Food-Fishes in the waters of the United States. Washington: Government Printing Office. 1876. [8०, li, $777 \mathrm{pp}$.$] .$

Report of the Commissioner. pp. vii-xlvi.

Appendix A.-Sea fisheries and the fishes and invertebrates used as food. pp. 1-319.

V.-Account of the fisheries and seal-hunting in the White Sea, the Aretic Ocean, and the Caspian Sea. By Alexander Schultz. 1p. 35-96.

Appendix B.-The river fisheries. pp. 321-540.

XX.-Report of operations in California in 1873. By Livingston Stone. pp. $377-429$.

A-Clear Lake. pp. 377-381.

B-Sacramento River. pp. 382-385.

C-California aquarium-car. pp. 385-390.

D-Overland journey with live shad. pp. 390-402.

E-The MeCloud River station. pp. 402-423.

F-Catalogne of collections sent to the Smithsonian Institution in 1873. pp. 424-427.

G-A list of MeCloud Indian words supplementary to a list contained in the report of 1872 . pp. 428-429.

XXI.-Hatehing and distribution of California salmon.

A-Report on California salmon-spawn hatched and distributed. By J. H. Slack, M. D. pp. 431-434.

B-Hatehing and distribution of California salmon in tributaries of Great Salt Lake. By A. P. Rockwood, Superintendent of Fisheries in Utah Territory. pp. 434-435.

XXII.-Report of operations during 1874 at the United States salmonhatching establishment on the MeCloud River, California. B5 Livingston Stone. pp. 437-478.

XXIII.-Correspondence relating to the San Joaquin River and its fishes. pp. 479-483. 
1877-The Trout of Washington Territory. <Forest and Stream, v.7, p.413, Feb. 1,1877 .

Canned Salmon. [Anon.] < Forest and Stream, v. 8, p.32, Feb. 22, 1877.

On the Genera of North American Fresh-wafer Fishes. [By David S. Jordan and Charles H. Gilbert. Feb. 27, 1877. <Proc. Acad. Nat. Sc. Phila., v. -, pp. 83-104, April 17, 1877.

The Oregon Fisheries. [Anon. From "Pacific Life."] < Forest and Stream, จ. 8, p. 49, March 1, 1877 .

Fish Culture in California. < Forest and Stream, v. 8, pp. 16, 81, 207, 224. 1877.

Annual Record of Science and Industry for 1876. Edited by Spencer $F$. Baird, with the assistance of eminent men of science.-New York: Harper \& Brothers, Publishers, Franklin Square. 1877. [12०.]

I. Pisciculture and the Fisheries, pp. 385-410.

Biennial Report of the California Fish Commission [abstract]. pp. 401-403.

Cultivation of Carp in California. p. 403.

Department of the Interior: U. S. National Museum.-Bulletin of the United States National Museum.-No. 7.-Published nnder the direction of the Smithsonian Institution. Washington: Government Printing Office. 1877. [80.]

No. 7.-Contributions to the Natural History of the Hawaiian and Fanning Islands and Lower California. By Thos. H. Streets, M. D.

Trout Fishing in Southwestern Colorado. < Forest and Stream, v. 8, pp. 189, 190, May 3, 18\%\%.

California Salmon Spawn for Shipment. < Forest and Stream, v.8, p. 191, May 3, $187 \%$.

Fishing in Lakes San Andreas and Pilercitas, California. [By E. J. Hooper.] $<$ Forest and Stream, v. 8, p. 270, May 31, $18 \%$.

Contributions to North American Ichthyology. Based Primarily on the Collections of the United States National Museum.

A. Notes on the Cottidx, Etheostomatidx, Percidæ, Centrarchidx, Aphododeridæ, Dorysomatidæ, and Cyprinidæ. With Revisions of the Genera and Descriptions of New or Little-known Species.-B. Synopsis of the Siluridxe of the Fresh Waters of North America. By David S. Jordan. Washington: Government Printing Office. 187\%. [ $8 \mathrm{C}$, 2 title-pages, $120 \mathrm{pp} ., 45$ plates.]

(Bulletin of the U.S. National Mnsenm, No. 10.)

M'Cloud and Sacramento River Trout. [From "San Francisco Pacific Life."] < Folest and Stream, v. 8, p. 299, June 14, $18 \% 7$.

Stocking the Barren Waters of the Great Divide. [By J.W.B.] < Forest and Stream, v. 8, p. 400, July 19, 187\%.

California Salmon in Lake Ontario. [By Sam. Wilmot.] < Forest and Stream, v. 8, p. 419, July 26, 187 .

tCalifornia Salmon in the James River, Va. <Forest and Stream, v. 8, p. 400 , July 19, 1877.

Hatching on the Columbia. <Forest and Stream, v. 8, p.420, July 26, 1877. 
1897 -The Long-Jawed Goby. By W. N. Lockington. < The American Natur alist, v. 11, pp. 474-478, Aug., 1877.

[An interesting account of some peculiarities in the habits of Gillichthys mirabilis.]

The Coregoni-Their natural history, native waters, economic value, and implements connected with their production. [Anon.] < Forest and Stream, v. 8 , pp. $439,440.1877$.

The Coregoni. No. Part 2. < Forest and Stream, r. 9, pp. 3, 4, Aug. 3, 1877.

A Contribution to the knowledge of Ichthyological Fauna of the Green River Shales. By E. D. Cope. <Bull. U. S. Geol. and Geog. Surv. Terrs., v. 3, pp. 807-819, Aug. 15, 1х77.

California Salmon. [By Emery D. Potter.] < Forest and Stream, v.9, p. 63, Aug. 30, 1879.

Notice of the Utah Trout in Provo rising to the fly. By W.V.S. <Forest and Stream, v.9, p. 88, Sept. 6,187\%.

Canning Salmon. <Forest and Stream, v.9, p. 88, Sept.6,187\%.

Operations of the McClond River (Cal.) Fish Hatching Establishment. $<$ Forest and Stream, v.9,p. 206, Oct. 13,187\%.

The Salmon Fisheries of California. < Forest and Stream, v.9, p. 233, Oct. $25,1877$.

Salmon Trout on the Pacific Coast. <Forest and Stream, v.9, p. 247, Nov. $1,1877$.

More about McLeod River Trout. < Forest and Stream, v. 9, p. 247, Nov. 1,1877.

The Sportsman's Gazetteer and General Guide. The Game Animals, Birds and Fishes of North America: their habits and various methods of capture. Copious Instructions in Shooting, Fishing, Taxidermy, Wooderaft, etc. Together with A Directory to the Principal Game Resorts of the Country; illustrated with maps. By Charles Hallock, Editor of "Forest and Stream"; Author of the "Fishing Tourist"; "Camp Life in Florida," etc. New York: "Forest and Stream" Publishing Company, American News Company, agents. 1877. $\left[12^{\circ}, 668\right.$ pp., +208 pp., 3 maps, 1 portrait.

Part I.-Game Animals of North America. Fishes of the Northwest, pp. 339-353. Pacific Coast Fishes, pp. 354-369.

1878-Beneficial Results of Salmon Hatching on the Sacramento River. [Editorial.] $<$ Forest and Stream, v. 10, p. 18, Feb. 14, 1878.

Trout Fishing at Lake Bigler, California. [Anon.] < Forest and Stream, v. 10, p. 28, Feb. 14, 1878.

California Salmon Fishing and the Game Laws. [Sıgned E. J. Hooper.] < Forust and Stream, v. 10, p. 47, Fel. 21, 1878.

[Price of first four Shad of the season in San Francisco $=\$ 10$ each.] <Forest and Stream, v. 10, p. 67, Feb. 28, 1878.

Birds and Salmon in California. [Anon.] <Forest and Stream, v. 10, 1. 95, March 14, 1078.

Spawning of California Salmon. [Signed B. B. Redding.] < Forest and Stream, v. 10, p. 155, April 4, 1878.

Red Trout, or Redfish of Oregon and Idaho. [By Charles Bendire, U. S. A.] $<$ Forest and Stream, v. 10, p. 156, April 4, $18 \% \dot{8}$.

Carp in San Francisco. [From "Pacific Life."] < Forest and Stream, v. 10, p. 174, April 11, 1878. 
1878-The Norway Tront of the Yellowstone. [Anon.] < Forest and Stream, $\nabla$. 10, p. 175 [195], April 11, 1878.

Prof. Jordan on Characteristics of Trout. [Signed D.S. Jordan.] < Forest, and Stream, v. 10, p. 196, April 11, 1878.

[Contains suggestion that the original Redfish is Hypsifario lennerlyi.]

Manual of the Vertebrates of the Northern United States, including the District east of the Mississippi River and north of North Carolina and Tennessee, exclusive of marine species. By David Starr Jordan, Ph. D., M. D., Professor of Natural History in Butler University. Sesond Edition, revised and enlarged.-Chicago: Jansen, McClurg \& Company, 1878. [12c. 407 pp., pub. May I6.]

[Contains synopsis of the American Salmoninoe and Coregonina.]

California Fishing Prospects. [Signed I. J. Hooper.] < Forest and Stream, v. 10, p. 239, May 2, 1878.

Notes on a Collection of Fishes from the Rio Grande, at Brownsville, Texas. By David S. Jordan, M. D. <Bull. U. S. Geol. and Geog. Surv. Terr. v. 4, [pp. 397-406, May 3 ;] v. 4, pp. 663--667, July 29, 1879.

[Specimens of Hysterocarpus Traskii indicated as an unknown Labroid form at p. 399, and described as the type of a new genus and sp. at p. 667. The specimens had been probably misplaced.]

A Catalogue of the Fishes of the Fresh Waters of North America. By David S. Jordan, M. D. <Bull. U. S. Geol. and Geog. Surv. Terr., v. 4, pp. 407-442, May 3, 1878.

[A simple nominal list of the fresh-water specics north of the Mexican region.]

Spawning of California Brook Trout in New York. [By James Annin, jr., Caledonia, N. Y.]. <Chicago Field, v. 9, p. 18:, May 4, 18i8. [F. M.]

California Salmon on Long Island, success of. By a member of the South Side Club. <Chicago Field, v. 9, p. 182, May 4, 1878. [F. M.]

Trout Hybrids. [Possibjlity of intercrossing Eastern and Californian Trouts. Editorial.] <Forest and Stream, v. 10, p. 255, May 9, 1878.

Colifornia. [Notice of distribution of land-locked Solmon and Eastern Trout by Fish Commissioners.] <Forest and Stream, v. 10, p. 255, May 9, 1878.

The heaviest American Salmon. [Notice of one weighing 82 pounds canght at the mouth of the Columbia River. By John Goudy.] <Forest and Stream, v. 10, p. 265, May $9,1878$.

Salmon canning on Frazer River. [By Fred. Mather.] <Chicago Field, v. 9, p. 196, May 15, 1878. [F. M.]

-.-A. On the Distribution of the Fishes of the Allegheny Region of Sonth Carolina, Georgia, and Tennessee. With Descriptions of New or Littleknown Species. By David S. Jordan and Alembert W. Brayton.-B. Synopsis of the Family Catostomidæ. By David S. Jordan. Washington : Government Printing Office. 1878. (8vo, 237.)

Run of Salmon in California. Note by A. R. <Chicago Field, v. 9, p. 229, May 25, 1878. [F.M.]

Shad in California. Announcement of two taken in San Francisco Bay May 1. Note by B. B. Porter. <Chicago Field, v. 6, p. 229, May 25, 1873. [F. M.]

California Salmon. [Notice of their ascent up the McCloud and Sacran ento rivers in May.] < Forest and Stream, v. 10, p. 350, June 6, 1878.

Salmon canning in Oregon and California. [Editorial. With three woodcuts.] <Forest and Stream, v. 10, p. 393, June 27, 1878. 
1878-Another shipment of Shad to California. Notice by Fred. Mather. <Chicago Field, v. 9, p. 308, July 6, 1878. [F. M.]

California Salmon in Lake Ontario. [By John J. Robson.] < Forest and Stream, v. 10, p. 48:2, July 25, 1878.

Salmon canning in Alaska. An account of the objections of the Indians to the landing of a lot of Chinese fish canners. From Alaska Cor. "N. Y. Sun." <Chicago Field, v. 9, p. 371, July 27, 1878. [F.M.]

Notes on a Collection of Fishes from Clackamas River, Oregon. By David S. Jordan, M. D. <Proc. U. S. Nat. Museum, v. 1, pp. 69-85, Aug., 1878.

The Labrador and Columbia River Fisheries. [From the "New York Sun."] $<$ Forest and Stream, v. 10, p. 507, Aug. 1, 1878.

The Mysterious Salmon. A quotation from the "Astorian" on the subject of the salmon taking the artificial fly, with editorial comment by Fred.Mather. < Chicago Field, v.9, p. 387, Ang. 3, 1878. [F. M.]

The McCloud River Hatchery. [By K. B. Pratt.] < Forest and Stream, v. 11, p. 2, Aug. 8, 1878.

Fish Gossip: Abundance of Salmon in the McCloud River, and their annoyance to anglers when fishing for Trout. [Item from "San Francisco Chronicle," with editorial comment by Fred. Mather. < Chicago Field, v. 9, p. 403, Aug. 10, 1878. [F.M.]

Gameness of the Quinnat Salmon. [By Tarleton H. Bean.] < Chicago Field, v. 10,p. 4, Aug. 17, 1878. [F. M.]

The Fraser River Salmon Season. [From the "New York World."] <Forest and Stream, v. 11, p. 50, Ang. 22, 1878.

Fishing in Northeru California. [By Е. J. Hooker.] < Forest and Stream, v. 11, p. 51, April 22, 1878.

Trout Fishing in Truckee River. Correspondent of the "Sacramento Union." <Chicago Field, v. 10, p. 20, Aug. 24, 1878. [F. M.]

- Trouting in Nevada. Catching them in the water-works at Gold Hill and Virginia City. [From "Virginia City Chronicle."] <Chicago Field, v. 10, p. - Sept. 14, 1878. [F.M.]

Good News from California. [An account of fish-ladders in the Truckee River, from the "Truckee Republican."] <Clicago Field, v. 10, p. ४4, Sept.21, 1878.

Salmon One Cent Each. [Item from Frazer River, from California paper, with editorial comment by F. Mather.] <Chicago Field, v. 10, p. 101, Sept. 28, 1878. [F.M.]

Salmon Canning on Columbia River. An account of the process, with statistics. By Fred. Mather. <Chicago Field,v.10,p. 101,Sept. 28,1878. . [F. M.]

Note on the Saurus lucioceps of Ayres. [By W. N. Lockington.] < Aun. \& Mag. Nat. Hist. (5), v. 2, pp. 348, 349, Oct., 1878.

McCloud River Hatching Station. Daily Record of Salmon taken. [Signed Livingston Stone.] < Forest and Stream, v. 11, p. 203, Oct.10, 1878.

California Trout in New York. [By Seth Green.] < Forest and Stream, v. 11, p. 203, Oct. 10, 1878.

MeCloud River Hatchery. [Table of Distribution of Salmon Eggs during 1878.] < Forest and Streain, v. 11, p. 222, Oct. 17, 1878. 
1878-Land-locking the Quinnat Salmon. Experiment of H. G. Parker, Commissioner on Fisheries for Nevada, in Pyramid and Walker Lakes. < Chicago Field, v. 10, p. 165, Oct. 26, 1878. [F.M.]

The Yellowstone as a Trout stream. [Anon.] < Forest and Stream, v.11, p. 263 , Oct. $31,1878$.

Another Devil Fish Story. Account of devil-fish (Ceratoptera) interfering with a submarine diver, from California paper. < Chicago Field, v. 10, p. 181, Nov. $2,1878 . \quad$ [F.M.]
[

Walks around San Francisco. By W. N. Lockington. No- III.-Lake Honda and Seal Rock. <Am. Nat., v. 12, pp. 786- r93, Dec., 1878.

[N. Sp. Bdellostoma Stoutii, p. 793.]

Note.-"No. I.-The Ocean Beach" (v. 12, pp. 347-354) and [No. II.-]

"The Bay Shore" (

Salmo quinnat in France. [By Fred. Mather.] < Forest and Stream, v.11, p. 360 , Dec. 5,1878 . [See, also, pp. 339,340 , Nov. $28,1878$.

On the occurrence of Stichæus punctatus, (Fabr.) Kröyer, at St. Michæi's, Alaska. By Tarleton H. Bean. <Proc. U. S. Nat. Museum, v. 1, pp. 2:9281, Dec. 17,1878 .

Report on the collection of Fishes made by Dr. Elliott Cones, U. S. A., in Dakota and Montana during the seasons of 1873 and 1874. By David S. Jordan, M. D. < Bull. U. S. Geol. and Geog. Surr. Terr., v. 4. pp. 777-799, Dec. $11,1878$.

Note.-[Contains an "analysis of the genera of American Cyprinidæ, and reference of Pacific slope genera to European types, at pp. 785-790.]

California Salmon in Holland. [Editorial.] < Forest and Stream, v. 11, p. 420 , Dec. $2 \% .18 \% 8$.

45th Congress, 3d session. $\}$ Honse of Representatives. \{ Ex. Doc. 1, pt. 2. Vol. II. $|=|$ Annual Report $\mid$ of the $\mid$ Chief of Engineers $\mid$ to the $\mid$ Secretary of War | for the | year 1878. | - | In three parts. | - | Part III. | - | Washington: | Government Printing Oftice. | 1878. |

Appendix NN. | - | Annual Report of Lieutenant George M. Wheeler, | Corps of Engineers, for the fiscal year ending | June 30, 1878. [p1). $1421-$

Appendix K. | Report upon the Fishes collected during the years 1875, 1876, and $18 \% 7$, in / California and Nevada, by Prof. David S. Jordan and $\mathbf{H}$. W. Henshaw. [pp. 1609-1622, pll. 1-4.]

Appendix K 1. | List of Marine Fishes collected on the coast of California near Santa | Barbara in 18\%5, with notes by Dr. H. C. Yarrow, Acting Assistant Surgeon | U. S. A., and H. W. Henshaw. [Ip. 1623-1627.]

P. 1610, pl. 1,2, Catastomus tahoensis Gill and Jordan.

P. 1610, pl. 3, Catastomus arceopus Jordan.

P. 1619, pl. 4, Salmo Henshavi Gill and Jordan.

The Sportsman's Gazetteer and General Guide. The Game Animals, Birds, and Fishes of North America: Their Habits and Various Methods of Capture. Copious Instructions in Shooting, Fishing, Taxidermy, Woodcraft, etc. Together with maps. By Charles Hallock, Editor of "Forest and Stream"; Author of the "Fishing Tourist," "Camp Life in Florida," etc. Fourth Edition. New York: Forest and Stream Publishing Co. 18iz. (12mo.) 
1878-Manual of the Vertebrates of the Northern United States, Including the District East of the Mississippi River, and North of North Carolina and Tennessee, exclusive of Marine Species. By David Starr Jordan, Ph. D., M. D., Professor of Natural History in Butler University. Second Edition, Revised and Enlarged. Chicago: Jansen, McClurg \& Co. 1878. (12mo, 407 pp.)

The Californian Salmon. With an Acconnt of its Introduction into Victoria. By Sir Samuel Wilson, Member of the Legislative Council of Victoria. Melbourne: Sands \& MeDongall, Printers, Collins street West. 1878.

1879. - The Nevada Fish-hatchery. [From Carson City "Appeal."] <Chicago Field, v. 10, p. 332, Jan. 4, 18r9. [F. M.]

Capture of a Devil-fish [Ceratoptera]. From California paper. <Chicago Field, v. 10, p. 395, Feb. 1, 1879. [F. M.]

The Fisheries and Other Resources of Alaska. Br H.A.R. <Chicago Field, v. 10, p. 395, Feb. 1, 1879 . [F. M.]

Viviparous Perch [Embiotocidæ. By Charles Hallock. From "Sportsman's Gazetteer."] < Forest and Stream, v. 11, p. 512, Jan. 23, 1879.

Fish and Fishing of Oregon. [By Wm. Lang.] < Forest and Stream, v. 12, p. 35, Feb. 13, 1879.

Report of the Nevada Fish Commission. [Notice by Fred. Mather.] <Chicago Field, v. 11, p. 3, Feb. 15, 1879.

Rapid growth of the Calif ornian Salmon. [Anon.] <Forest and Stream, v. 12, p. 55, Feb. 20, 1879.

[An abstract from the "German Fishing Gazette."]

Eastern Trout on the Pacific Slope. [By H. H. Holt, Kaloma, W. T. <Forest and Stream, v. 12, p. 105, March 13, 1879.

Rearing Whitefish in confinement. [Ву B. B. Redding.] <Chicago Field, v. $11, \mathrm{pp} .67,68$, March $15,1879$.

Interesting Facts from Washington Territory. [By Chs. Bendire.] < Forest and Stream, v. 12, p. 154, March 27, 1879.

|Refers to "Salmo Kennerlyi", \&c.]

The Flounders of our Markets. Rearl by W. M. Lockington before the Sam Francisco Acad. of Sciences, March 17, 1879. <Scientific Press Supplement, April, 1879; Mining and Scientific Press, April 12 and 19, 1879.

Salmon Fishing in Oregon. [By H. B.] < Forest and Stream, v. 12, p. 174, April 3, 1879.

Traits of Rocky Mountain Trout. [By W.N. Byers.] < Forest aud Stream, v. 12, p. 174, April 3, 1879.

[Notice of a "Devil Fish' recently taken on the Pacific coast whose body was four feet long, with a spear-shaped tail and tentacles seven feet long," i. e., a species of Ceratoptera. From the "Santa Barbara Press."] <Chicago Field, v. 11, p. 148, April 19, 1879.

Description of a species of Lycodes ( $\bar{L}$. Turneri), from Alaska, believed to be undescribed. By Tarleton H. Bean. <Proc. U. S. Nat. Museum, v. 1, pp. 463-466, April 25, 1879.

The Fishes and Birds of the Pacific Coast. [By Calamink, preudon of John L. Wilson. <Chicago Field, v. 11, p. 163, April 26, 1879.

[Note relative to the Fisheries of British Columbia. Notice of Report to House of Commons.] <Chicago Field, v. 11, p. 165, April 26, 1979. 
1879-Notes on some Fishes of the Coast of California. No. I. By W. N. Lockington. < Am. Nat., v. 13, pp. 299-308, May, 1879.

California Mountain Trout in Eastern Waters. [By Seth Green.] <Forest and Stream, v. 12, p. 264, May 8, 1879.

[See, also, v. 12, p. 288.]

Trout and Salmon Season in California. [Anon.] < Forest and Stream, v. 12, p. 277, May 8, 1579.

Angling in California. [Abstract from "Pacific Life."] < Chicago Field, v. 11, pp. 195, 196, May 10, 1879.

[Catfish in California.] < Chicago Field, v. 11, p. 196, May 10, 1879.

Pacific Trout [Salmo iridea] in Eastern Waters. [Note signed H. W. De Long, with description appended from Hallock's Sportsman's Gazetteer.] < Forest and Stream, v. 12, p. 288, May 15, 1879.

Does the Western Salmon die after spawning? [By MAJor, pseudon.] < Chicago Field, v. 11, p. 221, May 17, 1879.

California Salmon do not all die after spawning. [By B. B. Redding.] < Chicago Field, v. 11, p. 236, May 24, 1879.

The Roe of the Salmon the Indian's Bait. [By Jonas C., Portland, Oregon.] $<$ Chicago Field, v. 11, p. 237, May 24, 1879.

California News. [Notice of expected consignment of eggs from U. S. Commission Fish and Fisheries. Anon. From Sacramento "Record-Union."] $<$ Chicago Field, v. 11, p. 244, May 31, 1879.

On a new Genus of Scombridæ. By W. N. Lockington. <Proc. Acad. Nat. Sci. Phila. [v. - ], pp. 133-135.

[N. g. and sp. Chriomitra (p. 1s3) concolor, p. 134.]

Who branded the Salmon? [Notice of capture of four salmon branded with W. at Westport, Oregon. By Geo. H. Heather.] < Chicago Field, v. 11, p. 260, June 7, 1879.

Lake Tahoe. [Anon. From "Philadelphia Press."] < Chicago Field, v. 11, p. 260, June 7, 1879.

Grand Success of Shad and Salmon Culture. [By B. B. Redding.] < Chicago Field, v. 11, p. 277, Jnne 14, 1879.

Salmon at the Antipodes, being an account of the successful introduction of Salmon and Trout into Anstralian waters. By Sir Samuel Wilson, Member of the Legislative Council of Victoria, [etc.]; author of a work on the Angora Goat, and papers on the Ostrich, the Chinese Yam, etc. London: Edward Stanford, 55, Charing Cross, S. W., 1879. [3d ed., 12०, viii, $25 \%$ pp., 1 phot. pl., 1 map folded.]

\section{Partial Contents.}

Chap. V. The tirst introduction of Californian Salmon Ova. pp. 24-25.

Chap. VII. The second importation of Californian Salmon Ova. pp. 29-38.

Chap. VIII. The Californian Salmon. pp. 39-58.

Chap. IX. Is the Californian Salmon suitable to the Marray River? pp. 59-66.

Chap. XIX. The Growth and Development of the Salmonidæ. pp. 160-172.

Chap. XXII. The Distribution and Liberation of the Californian Salmon Fry. pp. 193-244.

[Introduction dated June 16, 1879.

"The substance of this work, in a slightly different form, under the title of "Tho Californian Salmon,' was originally published in the Transactions of the Zoological and Acclimatization Society of Melbourne for the year 1878, and a second small edition was reprinted in Victoria."-From "Preface to the third edition." - See 1878] 
1879-The Chinese and other Fishermen of California. [Condensed froin San Francisco "Chronicle" by Fred. Mather.] <Chicago Field, v. 11, p. 291, June 21,1879 .

On the Occurrence of Hippoglossus vulgaris, Flem., at Unalashka and St. Michael's, Alaska. By Tarleton H. Bean. <Proc. U.S. Nat. Museum, v. 2, pp. 63-66, July 1, 1879 .

Pacific Coast Shad. [By William Lang.] < Forest and Stream, v. 12, p. 487, July 24, 1879.

Notes on New and Rare Fishes. Rend before the California Acad. Science by W.IJ. Lockington.] < Scientific Press Supplement, July, 18r9; Mining and Scientitic Press, Aug. 2 and 16, 1879.

Fish Notes from the Pacific Coast. [By Robt. E. C. Stearns.] < Chicago Field, v. 11, p. 389, Aug. 2, 1879.

[Extract from "American Naturalist."]

Curious Facts about Trout [i.e., jumping from flume into water below. By B. B. R., i.e. B. B. Redding. ] < Chicago Field, v. 11, p. 404, Aug. 9, 1879.

Alaska in Summer.-Second Paper. [By "Prseco," i. e. Lester Beardslee.] $<$ Forest and Stream, v. 13, 1. 553, A.ug. 14, $1 \times 79$.

[Refers, inter alias, to capture and curin ; of salmon at Port Hunter.]

Largest Salmon on Recorl. [Anon.] < Forest and Stream, v. 13, p. 557, Aug. 14.1879 .

["VICTORIA, June 26.-A salmon that weighed 98 pounds when eaught has been received here from the Skeena Rirer Fishery by Mr. Turner, Mayor of Victoria. Its length is 5 feet 11 inehes from nose to tail."]

Shad in the Columbia. [By "S."] < Forest and Stream, v. 13, p. 585, Aug. 28, 1879.

[Refers probably to Pornolobus.]

Trolling for Salmon. [Anon.] < Forest and Stream, v. 13, p. 588, Aug. 28, 1879. [Relates to Columbia River.]

Oregon. [Record of a trout-fishing expedition. By William Lang.] $<$ Forest and Stream, v.13, p. 589, Aug. 28, 1879.

The McCloud River Fishery. [Anon.] < Forest and Stream, v. 13, p. 604, Sipt. 4, 1879.

Salmon a Nuisance to Tront Fishers. [Anon. By Fred. Mather.] < Chicago Field, v. 12, p. 52, Sept. $6,18 i 9$.

The North Pacific Ccdfishery. [By W. N. Lockington. Reprinted from "Pacific Life."] < Chicago Field, v. 12, p. 53, Sept. 6, 1879.

[Notice of Trout passing throngh flume uniler pressure of 376 pounds to the square inch. Anon.] <Chicago Field, v. 12, p. 53, Sept. 6, 1879.

[Notice of Catfish-Amiurns albidus? -5 to 15 inches long, taken in Sausal Lagoon, where planted three years before. Anon.] < Chicago Field, v. 12 , p. 53, Sept. $6,1879$.

The Pacific Salmon Fisheries. [Anon.] <Chicago Field, v. 12, p. 69, Sept. 13, $18 \% 9$.

[Notice of Catfish-Amiurus albidus?-taken in McCloud's Lake, Stockton. Anon.] < Chicago Field, v. 12, p. 69, Sept. 13, 1879.

The Trans-Continental Expedition of the California Fish Commissioners. [By H. A. L.] < Forest and Stream, v. 13, p. 645 (3 col.), Sept. 18, 1879. 
1879-Review of the Pleuronectidx of San Froncisco. By W. N. Lockington. <Proc. U. S. Nat. Museum, v. 2, pp. 69-96, July 2-Sept. 19, 1879.

[N. sp. HippoglossoidesJordani, p. 73; Glyptocephalus Pacificus, p. 86; Glyptocephalus zachi. rus, p. 88.

[Notice of Catfish for Susan River and Eel Lake. Anon.] < Chicago Field, v. 12, p. 85 , Sept. $20,1879$.

The first biennial report of the Nevada Commission. [Notice by Fred. Mather.] < Chicago Field, v. 12, p. 85, Sept. 20, 1879.

Habits of California River Salmon. [Anon. Extract from "Sacramento Bee."] <Chicago Field, v. 12, p. 100, Sept. 27, 1879.

Fish Culture Operations in California. [By Livingston Stone. $]<$ Forest and Stream, v. 13, p. 685, Oct. 2, 1879.

[Refers to Salmon.]

Why Salmo Quinnat does not take the Fly. [Anon. by Charles Hallock. <Forest and Stream, v. 13, p. 685, Oct. 2, 1879.

Washington Territory. [By "Multwomah," pseudon.] <Forest and Stream, v. 13, p. 687 , Oct. 2,1879 .

[Relates to fishing in "the great Spokane country."]

Salmon Fishing on the Pacific. [Incomplete. By C. R.] <Forest and Stream, v. 13, p. 689, Oct. 2, 1879.

The Fishery of Mr. A. P. Rockwood [near Salt Lake City. Anon. From "The Jnvenile Instructor."] <Chicago Field, v. 12, p. 115, Oct. 4, 1879.

Do Fish hear? [By W. N. Lcckington. From "Pacific Life."] <Chicago Field, v. 12, p. 116, Oct. 4, 1879.

Trout in the Truckee. [Anon. From "Sacramento Bee."] <Chicago Field, v. 12, p. 117 , Oct. $4,1879$.

California. [Record of good Grilse-fisling in September.] Bу B. B. Redding < Forest and Stream, v.u13, p. 715, Oct. 9, 1878.

The Game and Fish of Alaska. [By "PIsEco," $i$. e. Lester Beardslee, U. S. N.] <Forest and Stream, v. 13, pp. 723-724, Oct. 16, 1879.

Salmon Eggs from the Pacific. [By Livingston Stone.] <Forest ard Stream, v. 13, p. 725, Oct. 16, 1879.

California Fishing. [Bу Е. J. Hooper.] <Forest and Stream, v. 13, p. 7 $\$ 8$ Oct. 16, 1879.

Wyoming Territory. [Note on Trout-fishing. By "Multwomall," preudon.] <Forest and Stream, v. 1:3, p. 728, Oct. 16, 1879.

Spawn in off season [of Californian Trout. By E. C. Tallant. With editorial note.] < Forest and Stream, v. 13, p. 744, Oct. '23, 1879.

The Redfish of the Northwest. [By Ch. Bendire. With editorial note.] <Forest and Stream, v. 13, p. 745, Oct. 23, 1879.

Rocky Mountain Trout. [By Flyfisher, pseudon., J. J. Stranahan, Chagrin Falls, 0.] <Chicago Field, v. 12, p. 164, Oct. 25, 1879.

"Mountain Trout".-(Salmo virginalis). [By Gordon Lamb.] <Chicago Field, v. 12, p. 164, Oct. 25, 1879.

Fishing in Gray's Harbor [i. e. Solmon-fishery. Anon. From "Olympia (Washington 'Terr.) Transcript." <Chicago Field, v. 12, pp. 164, 165, Oct. $25,1879$. 
1879-Codfishing in the Pacific. [Anon.] From "San Francisco Alta.") <Chicago Field, v. 12, p. 165, Oct. 25, 1879.

California Trout in New York State. [By Clarence A. Farnum.] < Forest and Stream, v. 13, p. 765, Oct. 30, 1879.

Salmon Fishing on the Pacific. [By C. R.] < Forest and Stream, v. 13, p. 767, Oct. 30, 1879 .

Why Salmo Quinnat does not take the Fly. [Editorial.] < Forest and Stream, v. 13, p. 7\%0, Oct. 30, $18 \% 9$.

Notes on Pacific Coast Fishes and Fisheries. By W. N. Lockington. < Am. Nat., v. 13, pp. 684-687, Nov., $18: 9$.

Notes on some undescribed Fishes of the Pacific Coast. By W. N. Lockington. < Scientific Press Supplement, v. -, p. 76, Nov., 1879.

Carp Breeding in California. [Anon. From "Sonoma Index."] < Chicago Field, v. 12, p. 180, Nov. 1, 1879.

Trout Culture in Nevada. [Anon. From "Virginia City Enterprise."] < Chicago Field, v. 12, p. 180, Nov. 1, 1879.

Fish in Washington Territory. [Anon. From the "Experiment."] $<$ Chicago Field, v. 12, p. 180, Nov. 1, 1879.

Washington Territory. [Abundance of Trout. By Multwomah, pseudon.] < Forest and Stream, v. 13, 1p. 795-796, Nov. 6, 1879.

The Redfish of Idaho. By Charles Bendire. < Forest and Stream, v. 13, p. 806, with fig., Nov. 13, 1879.

[The figure appears to represent Hysifario kenuerlyi.]

California Notes. (From the "San Francisco Bce.") < Chicago Field, v. 12, p. 213, Nor. 15, 1879.

Some Fishes of Oregon. By C. J. Smith. < Forest and Stream, v. 13, p. 826 , Nov. 20, 1879.

The Trout of Utah. [Notice of its rising to a fly.] Fy C. B. Western $<$ Forest and Stream, v. 13, p. 8:26, Nov. 20, 1879.

California Fishing Notes. [From "Sacramento Bce."] < Chicago Field, v. 12, p. 229, Nov. 22, 1879.

California Fishes. By B. B. Recäing. ～Forest and Stream, v. 13, p. 847 Nov. 27, 1879.

Mountain Tront.-Salmo virginalis. By Gordon Land. < Chicago Field, v. 12, p. 245, Nov. 29, $18 \% 9$.

The Fishes of Klamath Lake, Oregon. By E. D. Cope. < Am. Nat., v. 13, pp. 784-785, Dec., 1879.

[N. sp. Chasmistes luxatus (p. 784); Chasmistes brcvirostris (p. 785); ? Mylopharodon sp. (785).]

Annual Record of Science and Industry for 18\%8. I Edited by Spencer F. Baird with the assistance of eminent men of science. I New York: | Harper \& Brothers, Publishers, Franklin Square. 1879. [12०.]

The North American 'Trout and Salmon. pp. 467-470.

Ichthyologische Beitrïge (VIII). Von Dr. Franz Steindachner. < Sitzb. K. Alkad. Wissensch., B. 80, Abth. i, pp. . ("Juli-heft.") [Author'sextra, received by mail Oct. $22,1879$.

[N. sp. Corvina (Johniux) Jacobi, San Diego, p. 3 ; n. g. and sp. Typhlngobius californiensis, San Diego, p. 24; and Gobius Newberrii, p. 17, Engraulis ringens, p. 62, also commented upon.] 


\section{N D E X.}

Page.

Amia................................ 16

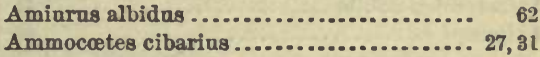

Ammodytes alascanus................... $\quad 46$.

hexapterus ................. 10

personatus ................25, 28, 43

septipinnis .................. 10

Amphistichns argenteus .................20,29,41

Heermanni............... 21

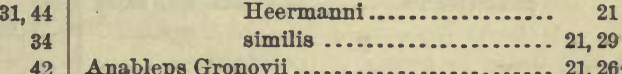

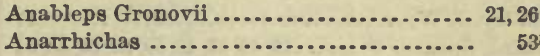

felis ..................... 21, 28

Anarrhichthys ......................... 23

felis.................... 28

ocellatus.................. 23,42

Anguilla ............................ 40

Annin, James, jr................... 57

Anon ............................. 48, 50

Anoplagonus.......................... 34

Anoplarchns .......................... 34

crista-galli................ 35

purpurescens ............... 34

Anoplopoma ........................ 32 fimbria .................. 46

merlangus .................. 32,42

Antacens acutirostris .................. 44

brachyrhynchus ............... 44

medirostris ................... 44

Apocope carringtonii................... 52 conesii....................... 51

henshavii ..................... 52

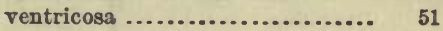

vulnerata ...................... 52

Apodichthys............................ 21

flavidns ................21, 28, 42

inornatus.................. 36

sanguinens ................. 36

violaceus................... 21

virescens................. 24, 28

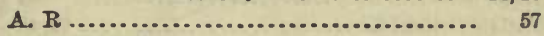

Archoplites ............................. 34

interruptus................. 41

Argentina pretiosa ...................... 21

Argyreiosus pacificus .................... 53

Argyreus dulcis....................... $\quad 29$

notabilis...................... 25

nubilus ................... 25, 28

osculus ..................... 25

Artedins .............................. 25

Jateralis ...................... 27

notospilotus ................... 25, 28

pugetensis..................... 53

Amblodon saturnus .....................27, 28, 34

Ambloplites interruptus

5 
Page.

Aspicottus............................ 20 bison ...................20, 22, 27, 42 Aspidophoroides inermis................. 32

Aspidophorus acipenserinus ............. 16

Atherinopsis .........................21, 22, 49 affinis ..................... 33,49

californiensis............. 21, 28 tenuis ...................... 33

Atkins, Charles G..................... 48

Atractoperca ......................... 34 clathrata...................

Atractoscion nobile.....................

Auliscops spinescens.

Aulorhynchus. flavidus ...................... A res, Dr. TWm. $0,3,21,22,23,24,32,33,35,36,37,38$ Ayresia............................. 37 punctipinnis.................. 37,38

B.

Bailes, J. W.

Baird Spencer

Balistes

Bathymaster signatns .................. 46

Bdellostoma Stontii ..................... 59

Bean, Tarleton H ..................58, 59, 60, 62

Beardslee, Lester......................62, 63

Beckwith, Lieut. E. G ................... 31

Beechey, Capt. F. W ..................... 14

Belone exilis ..........................21, 29, 42

Bendire, Charles ....................56, 60, 63, 64

Bennett, E. T ........................... 14

Bennett, Frederick Debell ............... 15

Bennett, Thomas...................... 47

Blakea ............................... 53

Blake, James ........................ 40,41

Blake, William P ......................

Blennicottus ..............................

Blennius anguillaris.................... dolichogaster .................... gentilis .....................21, 28, 42

Blepsias oculofasciatus. trilobus ....................... 16,42 ventricosus .........................

Brachyistius .

Brachyistius frenatus.

Branchiostoma - 1 ...................

Brayton, Alembert W.

Brevoort, James Carson...................

Brew, C .

British Columbia..

Brosmius marginatus.

Brosmophycis marginatus.

Brotaloid fishes .

Backland, Rev. W

Bull head

Butirinus .

Butler, Capt. W. F

Bjers, W. N .

\section{C.}

Calamink
California, natural wealth of ............. sea lions -2.0.

Californian fish culture ................ 47

salmon ..................... 60

Callorhynehus .......................... 15

Calycilepidotus ......................... 24

lateralis................. 24, 42

spinosus ................. 24

Camarina ............................ 33

nigricans .................. 33

Campbell, Archibald .................... 34

Caranx............................. 14

symmetricus .................... 24

Carrington Campbell .................... 46

Catostomidæ.......................... 57

Catostomus aræopus ................... 59

bernardini ................... 25

discobulus .................. 52

fecundus.................. 51, 52

(Acomus) generosus .......... 25

insigne ..................... 52

labiatus ..................23, 29, 43

latipinnis .................. 19

macrocheilus ................ 25, 29

occidentalis................22, 29,43

tahoensis................... $\quad 59$

Caularchus ........................... $\quad 36$

reticulatus .................. 43

Canlolatilus ........................... 39

anomalus................... 41

Cebedichthys crista-galli............... 24,42 violaceus ................ 28, 42

Centrarchus interraptus ................ 20

maculosus.................. 21, 22

Centronotus crista-galli .................. 35

lætus ....................... 46

Centropomus viridis...................... 53

Ceratichthys biguttatus................. 52

oscula ..................... 51

squamilentus............... 51

rentricosus................. 47

Ceratoptera .......................... 59, 63

Cestracion francisci .................... 22, 31

Philipii .................... 38

Chanos............................. 16

Chappe d'Auteroche, M................. 8

Chase, A. W ......................... 47, 48

Chasmistes brevirostris ................. 64

luxatus ...................... 64

Cheonda ............................ 25

cœrulea......................... 25

Cooperi....................... 25

Chilorhinus ......................... 40

Chimæra ............................... 15

colliei ......................... 14, 31

Chionda cœrulea ...................... 30 cooperi ......................... 30

Chirocentrus .......................... 16

Chiropsis............................ 26

constellatus................... 27

guttatus...................... 27

nebulosus ...................... 27

pictus......................... 27

Chirostoma affinis ...................... 42

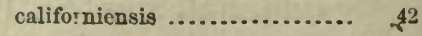


Page.

Chirostoma tenuis

Chirus

$$
\text { balias }
$$

constellatus

guttatus

ordinatus

pictas

trigrammus

Choris, Louis

Chriomitra

$$
\text { concolor }
$$

Chromis punctipinnis

Clams .

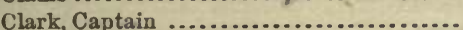

Clark, S. C

Clinocottus.

Clinostomus phlegethontis tænia.

Clupea

$$
\text { mirabilis. }
$$

Clypeocottus rubustus

Codfishery, Pacific

Cooke, P. St. Geo

Cooper, J.G

Cope, E. D

Copeland, Herbert $\mathbf{E}$

Coregoni...

Coregoninæo

Coregonus IVilliamsoni.............. 25, 30,43,52

Corvina (Johnius) Jacoh.

$$
\text { stearnsii }
$$

Coryphopterus

Coryphopterus glaucofrænum .............

Cottoids.

Cottopsis asper. gulosus ....................20, 27,42 parvus.....................21, 27, 42

Cottus

Cottus asper

13,16

criniger.

pistilliger.

platycephalus ......................

polyacanthocephalus

0,16

trachurus. 10

ventralis......................... 12

Coues, Dr. Elliot........................ 10

C. R................................ 63, 64

Cremony, John C........................ 45

Cronise, Titus Fey .................... 41

Cutts, Richard D....................... 46

Cuvier \& Valenciennes.....11, 12, 13, 14, 15, 16, 17, 18

Cyclogaster pulchellus ................... 28

Cyclopteroids, synopsis of............... 39

Crclopterus........................... 47

gelatinosus .................. 14

orbis ....................... $\quad 35$

ventricosus .................. 16

Cymatogaster .......................... 20

aggregatus ................ 20,41

ellipticus .................. 20

Larkinsii .................. 20

minimus.................. 20

pulchellus ................. 20

parvipinnis................ 35

Cyprinella grunisoni.

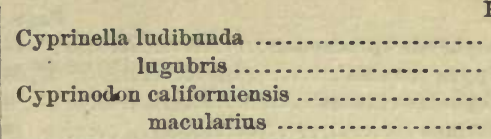

Cyprinus (A bramis) balteatus............ balteatus......................

(Leuciscus) caurinus ............ cultratus ......................

(Leaciscus) gracilis .............. (Leuciscus) oregonensis .......... rostratus .......................

\section{D.}

Dall, William $\mathbf{H}$

Damalichthys......................... 23

vacca.................. 23, 29, 41

Davidson, George...................... 45

Dawes, C. M......................... 46

De Kay, James E....................... 15

Dekaya ............................. 37

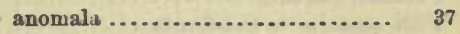

De Long, H. W. ....................... 61

"Denver News" ......................... $\quad 50$

Dermatostethus ........................ 36

punctipinnis ............. 36, 44

Devil fish .............................. 60

Diodon ................................ 11

Dionda grisea .......................... 27

Ditrema ............................. 25

brevipinne.................... 36

Dogfish ............................ 40

Duméril, Ang .......................... 39, 45

Dunn, Horace D........................ 49

Dynamite, for fishing.................. 48

E.

Echeneidoidæ......................... 38

Echeneis naucrates...................... 32

remora ..................... 32

Elliott, Henry W..................... 47,51

Elops ............................... 16

Embiotoca ......................... 19, 20

argyrosoma .................25, 29, 41

Caryi....................... 19

Cassidii ..................... 21, 29

Jacksoni ...................19, 29,41

lateralis ...................... 20,34

lineata ...................... 21, 29

ornata....................... 23, 29

perspicabilis ................. 23, 29

Webbi ..................... 23, 29

Embiotocoidæ.......................... 21

Embiotocoids.......................... 3

Emory, Lieut. Col. W. H ................. 17

Engelmann, G ........................ 17

Engraulis compressus ................27, 30,43

delicatissimus ...............21, 31,43

mordax ................... 21, 30,43

מanus................... 27, $3^{\circ}, 43$

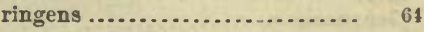

Ennichthys .......................... 23

Heermanni ................. 23, 29

megalops ................... 23,29

Entosphenus .......................... 36 ciliatus $\ldots \ldots \ldots \ldots \ldots \ldots \ldots \ldots$ 44 


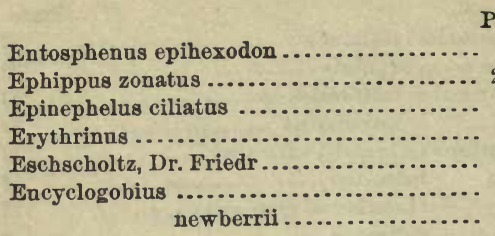

Eumicrotremus.........................

Exocotus californicus................... 38, 42

fasciatns

F.

Fario argyruus

25,30

aurora.

25,30

Clarkii

Gairdneri.

Newberrii

stellatus.

tsuppitch

Farnum, Clarence A.

Fish, eastern, in California

Fisheries of North Pacific

Fisheries, Oregon

Fishes of Wyoming

subterranean, in California.........

Tertiary

Flat-fish

of San Francisco.

Flounders of San Francisco

Forbes, Edward

Fraqchère, Gabriel

Fundulus

parvipinnis $.21,30,43$

G.

Gadoid fishes, synopsis of

$$
\text { genera }
$$

Gadus auratus

\section{dorsotripterygia}

fimbria

gracilis...........................

morrhua

periscopus

proximus.

pygmæus

wachna

Galens eanis

Gallatin, Albert.

Gasterosteus biaculeatus .................

$$
\text { dekayi .................... }
$$

inopinatu

intermedius ................ 25,28

microcephalus..............21, 28,42

plebeius..............21, 23, 28, 42

pugetti................... 25, 28

serratus...............24, 28, 42

Williamsoni .............21, 28, 42

Gastrophysus politus ................... 44

Gay, Claudins......................... 16

Genyonemus ......................... 34

Gibbons, Dr............................ 3

Gibbons, W.P ........................ 20,23

Gibbons, W. R....................... 49

Gibbonsia............................ 38

clegans.................... 38,42

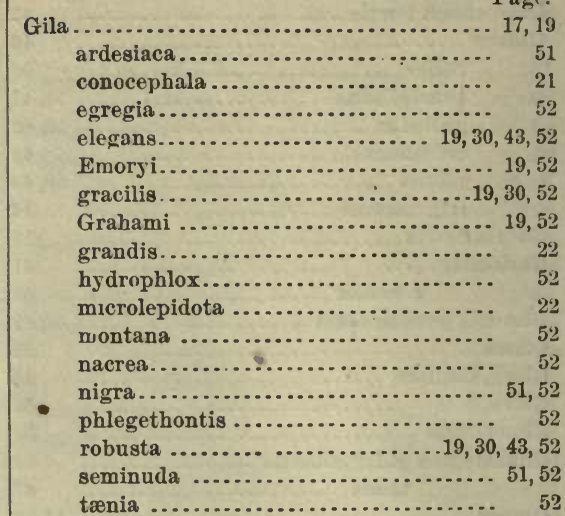

Gilbert, Charles $H$..................... 55

Gill, Theodore .................... 32, 39, 46, 54

Gillichthys .......................... 38 mirabilis .................. $38,43,56$

Gilliss, Lieut. Jas. M ................. 22

Girard, Dr. Charles ...3, 18, 19, 20, 21, 22, 23, 25, 26, 27,

31,32

Girard, Edward ..................... 18

Girardinns sonoriensis ................. 52

Girella nigricans ...................... 41

Glyphisodon rubicundu ..............21, 29, 41

Glyphtocephalus pacificus .............. 63

zachirus............... 63

Gobioid genera..................... 37

Grobius gracilis...................... 21

lepidus ........................ 28

Newberryi ....................25, 28, 64

Gonorhynchus ...................... 16

Goudy, John ........................ 57

Grammatopleurus....................... 34

Gray, J. E......................... 18

Green, Seth ......................... 58, 61

Grystes lineatus....................... 21

Gunnellus ornatus ..................21, 28, 42

Gunnison, Capt. J. W................. 31

Günther, Albert.......... 32, 35, 36, 38, 39, 40, 44, 45

Gymnomuræna....................... 40

Gymnotoids........................... 38

Gyropleurodus ...................... $\quad 36$

francisci................ 44

H.

Halatractus dorsalis................... 42

Halias.............................. 32

Halibut fishing ......................... 40

Hallock, Charles ..................56, 59, 60, 63

Hallowell, Edward ...................... 19

H. A. L . . . . . . . . . . . . . . . . . .

H. A. R........................... 60

Hayden, F. V ....................... 46, 51

Hazlitt, William Carey .................. 4

H.B............................... 60

Heather, George H.................... 61

Heermann, A. L...................... 20

Helmichthys ....................... 40

Hemilepidotus Gibrsii .................. 35, 42

notospilotus ............. 42 


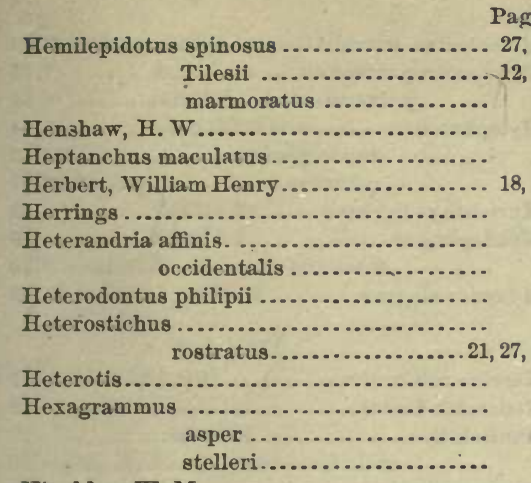

Hinckley, W. M

$$
\text { stelleri }
$$

Hippocampus ingens . ... 50

Hippoglossoides Jordani

Hippoglossus californicus. vulgaris .

$.27,30,44$

................. 32,43

Hittel, John S 43,62

Holconoti.

Holconotus Agassizii

fuliginosus....................

Gibbonsii....................

megalops ....................

pulchellus ...................

rhodoterus...

$.20,29,41$

Trowbridgii .

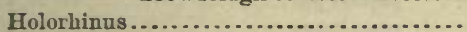

Holt, H. H.

Homalopomus...

Trowbridgii............... 25, 28

Hooper, E.J ........... 49, 50, 53, 55, 56, 57, 58, 63

Hoplopagrus ...........................

Hubbard, Samuel .......................

Humphreys, A. A ......................

Huntington, J. $\nabla$.

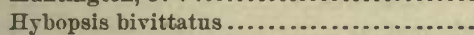
timpanogensis

Hyborhyuchus siderius

Hydrolagus

Colliei......................

Hyodon

Hyperprosopon

Agassizii..................

analis....................

arcuatum ................

arcuatus ................

argenteum ................

argenteum var. $a$ punctatum
argenteus.................

punctatum...............

Hypocritichthys .........................

$$
\text { analis. }
$$
31,41

Hypomesus ........................... pretiosus.

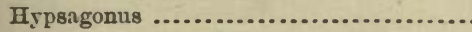

Swanii.....................

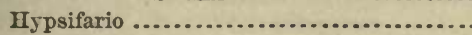

Kennerlyi $\ldots \ldots \ldots \ldots \ldots \ldots \ldots \ldots \ldots$
Hrpsopsetta $\ldots \ldots \ldots \ldots \ldots \ldots \ldots \ldots \ldots \ldots \ldots$

Hypsurus Caryi

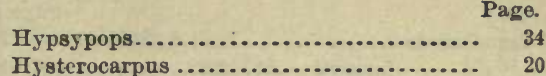

Traskii.............20, 29, 41, 57

I.

Ichthyomyzon $\ldots \ldots \ldots \ldots \ldots \ldots \ldots \ldots \ldots \ldots . \quad 45$

Irving. Washington $. . \ldots \ldots \ldots \ldots \ldots \ldots \ldots . .13$

Ischnosoma ............................ 16

Isoplagiodon ......................... $\quad 36$

Henlei................... 44

J.

James, Edwin......................... 11

Johnius nobilis.......................... 33

Johnston, Capt. A. R ................... 17

Jonas, C.............................. 61

Jordan, D. S.................53, 55, 57, 58, 59, 60

Julis modestus ...................... 21, 29 semicinctus....................... 32

J. W. B ............................ 55

$\mathbf{K}$.

Keeler, A. B....................... 50

Kennerly, Dr. C. B. R............... 21, 26, 34

Kerry, Mortimer ...................... 48

Kirkpatrick, C. A ..................... 32

Kittlitz, F. H. $\nabla$..................... 27

Kner, Dr. Radolph ..................... 45

L.

Labraces ............................. 9

Labracoglossa......................... 40

Labrax........................... 9,40

clathratus....................... 21

decagrammus .................... 9,10

monopterygius.................. 9,10

nebulifer....................... 21

octogrammus.................... 10

superciliosus .................... 9, 10

Labroids ............................... 37

Labrus pulcher ................. 21, 22, 29, 39

Lamb, Gordon ....................... 63, 64

Lampetra plumbea................... 44

Lang, William ..................... 60, 62

Lanszweert, Dr ........................ 24

Lavinia ............................. 21

compressa .................... 22

conformis..................... 21

crassicauda.................... 21

exilicauda $\ldots \ldots \ldots \ldots \ldots \ldots \ldots \ldots . \ldots \ldots 21,29,43$

harengus ..................... 25, 29, 43

gibbosa....................... 22

Las, G. T ........................... 14

Lebiasina ........................... 16

Leiocottus ............................ 25

hirundo..................25, 27, 42

lineatus.................23, $28,34,41$

Leuciscus caurinus .................... 15, 16

oregonensis................. 15, 16

Leucosomus occidentalis ............... 21

Lennard, Capt. C. E. Barratt............. 4

Lepadogaster ......................... 14

meandricus ................ 28

reticulatus................ 21

Lepidogobius gracilis ................. 42 
Lepidomeda .................... Page. jarrovii .................. 47,51 vittata................... 47,51

Lepidopsetta

Leptocottus

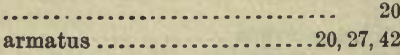

Leptogunnellus gracilis ................. 23

Lewis, Captain........................ 10

Liparis ........................... 14, 47

Liparis cyclopus ...................... $\quad 35$ mucosus ..................... 23, 43 pulchellus .................... 23, 43

Lockington, W. N..... 53, 56, 58, 59, 60, 61, 62, 63, 64 Long, Maj. Stephen H ................. , 11

Lord, John Keast .................... 40

Lumpenus auguillaris.................. 28,42

Lütken, Dr. Chr ...................... 49

Luxilus occidentalis.................... 30,43

Lycodes Turnerii ..................... $\quad 60$

Lycodoidæ.......................... 37

\section{M.}

McDonald, Duncan George Forbes .......... Macfie, Matthew

Mackerel catching

Macrodon

Major

Mallotus pacificus.

Man-sucker .

Mather, Fred .................57, 58, 59, 60, 62, 63

Mayne, Com. R. C

Meda...

$$
\text { fulgida }
$$

Megalocottus 25,51

Megalops

Meletta cœrulea.................... $21,22,30,43$

Merlangus productus .................24, 28, 43

Mesopus.

Metoponops

Micristodus punctatns ................... 39

Microgadus .......................... 39 proximus

Micrometrus aggregatus minimus...

Microstomatoids, note on

Minomus jarrovii

Mollienesia

$$
\text { platyrhynchus }
$$

Monmouth

Mormyrus

$$
\text { proxima }
$$

Müller \& Henle

Multnomah :...

Muræna mordax

Murphy,J. M

Mustelus californicus ....................

$$
\text { felis. }
$$

Myliobatis californicus

Mylocheilus

caurinus

fraterculus

\section{M}

Mylocheilus lateralis................... 22, 29

Mylolencus parovanus ................. 4i, 52

pulrerulentus................. 52

Mylopharodon ....................... 23, 64

conocephalus .............. 29,43

robnstus ................23, 29,43 .

Myrichthys tigrinus ................... 32

Mytilophagus ........................ 20 fasciatus ............... 20

Mysodes elegans...................... 38, 53

N.

Narcine californica..................... 31

Naucrates ductor....................... 32

Wautichthys ......................... 27

oculo-fasciatus............. 28

Nematoceutris ........................ 40

Neoclinus .......................... 27

Blanchardi................27, 28, 42

satiricus .................... 32

Nerada fish hatchery .................. 60

Nordhoff, Charles ..................... 47

Notorhynchus........................ 37

borealis................. 38

maculatus .............. 24, 44

O.

Oligocottus........................... 25

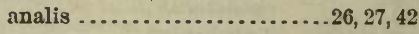

globiceps.................. 26, 27, 42

maculosus................ 25, 27, 42

Oncorhynchus....................... 34

Ophichthys............................ 40

Ophidion Taylori .....................27, 28, 43

Ophidium ......................... 14

stigma....................... 14

Ophidiurus californiensis ................ 43

Ophiodon............................. 21

elongatus ................... 21, 27

Ophisthognathus ...................... 40

Oplopoma ............................ 25

pantherina $. . . \ldots \ldots \ldots \ldots \ldots \ldots . .25,27,42$

Orcynus pacificus .................... 37,42

Orthagoriscus ........................ 14

analis.................... 32,44

mola.................... 14

Orthodon microlepidotus ............... 29,43

Orthopsetta .......................... 36

Osmerus elongatus ...................... 22

pretiosus....................... 30

thaleichthys ................... 32,43

Osteoglossum ....................... 16

Otolithus californiensis................. 49

Oxylebius .............................. 36

pictus......................... 36

Oxyjulis ............................ 38 modestus..................... $\quad 41$

$\mathbf{P}$.

Pachylabrus .......................... 20

variegatus.................. 20

Pallas ............................... $\quad 3$

Pallas, Petro......................... 10

Pallas, P.S.......................... 9

Pantosteus.......................... 51 


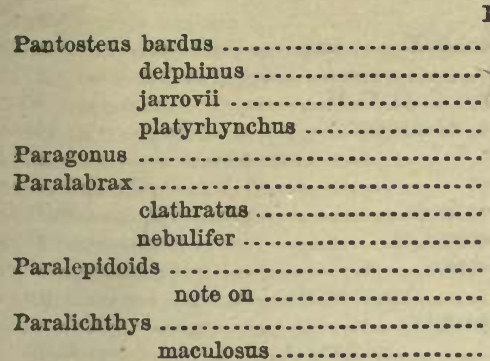

Paratractrs boops........................

Parephippus ........................... zonatus....................

Parker, H. G ...........................

Parophrys ...............................

Parophrys Ayresii ...................... 36, 43

Hubbardii .................... 36

vetulus ....................21, 28,43

Pediculati........................... 37

Pelamys lineolata ................... 27, 28, 42

Pemberton, J. Desford .................... 4

Perca flavescens ........................ variabilis

Perch, viviparous

Percopsis Hammondii ......................

Perry, Com. M. C ..........................

Peters, W

Peters, W. C. H

Petromyzon astori.

lividus .................... 27, 31

plumbetus .................. 23, 31

tridentatus ................... 13, 31

Phalangistes ............................ acipenserinus .............. 10

Phanerodon ............................. 21 furcatus ..................21, 29,41

Phillips, Barnet

Philo-Ichthyos

Pimelometopon ...........................

Pinart, Alph.

Piseco.

47

53

Pt

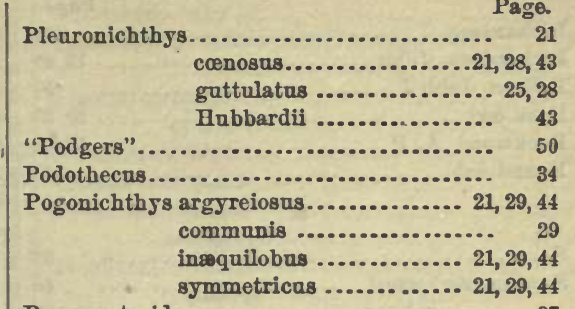

Pomacentroids ......................... 37

Pomolobus ............................. 62

Poole, Francis .......................... 4

Porichthys ........................... 21

notatus ...................21, 28,43

Poronotus simillimus. ................... 33, 41

Porter, B. B ........................ 5

Portland Oregonian ..................... 48

Potamocottus .......................... 33

Potter, Emery punctulatus..................

Pratt, K. B .......................... 58

Price, Sir Rose........................... 50

Protopterus .......................... 40

Psettichthys ........................... 21

Psettichthys melanostictus .............21, 28, 43 sordidus.................21, 28,43

Psychrolutes ............................. 35 paradoxus .................. 35

Pterognathus satiricus ................. $\quad 42$

Pteroplatea marmorata................... 38, 44

Ptychocheilus .......................... 22

gracilis.................. 22

grandis.................... 30,43

lucius $\ldots \ldots \ldots \ldots \ldots \ldots \ldots . . \ldots 25,43$

major .................... 22

oregonensis ................. 30

$\operatorname{rapax} \ldots \ldots \ldots \ldots \ldots \ldots \ldots \ldots \ldots, 30,43$

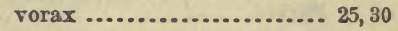

Ptychostomus congestus ................. $\quad 52$

Putnam, F. W ....................... 37, 47

Pyrrhalina........................... 16

\section{R.}

Raia................................ 15

Raja batis ............................ 10

binoculata ....................... 22

Cooperi .......................... 27, 31

Rattray, Alexander.................... 4

Redding, B. B ................56, 60, 61, 62, 63, 64

Reptiles of Wyoming ................... 46

Rhachocheilus toxotes ................. 41

Rhacochilus toxotes................... 20,29

Rhinichthys henshavii.................. 47

Rhina californica...................... 44

Rhinobatus productus.................. 31,44

Rhinoptera vespertilio .................25, 31, 44

Rhinoscion .......................... 34

Rhinotriacis...........................

Henlei ..................... 36

Richardson ........................... 3

Richardsonius........................... 25

balteatus................. 30

lateralis.................. 25, 30

Pleuronectidæ of San Francisco ..............

Pleuronectoids, sjnopsis of................ 
Richardson, J ....................... Page.

Richardson, John ..................... 13, 20

Robson, John J ........................ 58

Rock cod .......................... 40,53

Rockwood, A. P .................... 54, 63

Round-fish ............................ 40

S.

$\mathrm{S}$

Sacramento record ........................

$$
\text { salmon. }
$$

Salar iridea

Salmo

virginalis....................... 25, 30

brevicanda

campbelli........................ 34

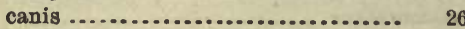

Clarkii .......................... 13

confluentus......................... 26

consuetus ......................... 20

dermatinus ........................ 20

fontinalis ........................ 50

Gairdneri ......................13, 15, 16

gibber......................... 26

Gibbsii.......................... 26

Henshawi ...................... 59

iridea..........................23, 43,61

Kennerlyi ..................... 34, 60

lagocephalus .................... 10

lordii .......................... 40

Masoni ............................ 33, 43

mendocinensis.................. 49

Newberrii ....................... $\quad 26$

nitidus ......................... 15, 16

(Mallotus?) pacificus ................ 13

paucidens ........................ 13, 16

Parkei .......................... 34

pleuriticus ..................... $\quad 52$

proteus........................ 10

quinuat $\ldots \ldots \ldots \ldots \ldots .13,15,16,30,43,48,63,64$

rivularis...................... 23

salar...........................16, 48, 52

Scouleri .................13, 15, 16, 30, 43

socialis ........................ 10

spectabilis....................... 25, 30

stellatus ....................... 43

truncatus ....................... 26

tsuppitch......................13, 15, 16

tades.......................... 46

virginalis.................48,49,52,63, 64

Warreni ........................ 34

Salmon............................. 40

California .................... 50,57

canned ........................ 55

Salmon fisheries, Oregon ................... 48

Salmon-fishing $. . . \ldots \ldots \ldots \ldots \ldots \ldots \ldots \ldots \ldots . .26$

Salmon, heaviest American ............... 57

Salmonidø .........................33, 49, 57

history, \&c., of ................ 53

North American ............... 37

of Pacific .................... 48

Saurus lucioceps ...................... 24, 58

(Saurida) lucioceps ............... 30
Sanvage, H. E Page.

Say, T . . . . . . . . . .

Scammon, Capt. C. M ................... 45

Schaltz, Alexandor .................... 54

Sclater, P. L......................... 45

Scomber ........................... 14, 15

Scomber diego....................... 28,41

Scomberesox ......................... $\quad 37$

Scombresox ........................ 40

brevirostris................ 40

Scombrocottus ........................ 45

salmoneus ............. 45, 46

Scorpæna guttata ...................21, 28, 42

Scorpænichthys...................... 20

lateralis ............. 21, 24

marmoratus ...........20, 27, 42

Scorpænidæ....................... 53

Scorpis............................ 40

californiensis................... 49

Seal Islands of Alaska, report on ........ 47

Sebastes .......................... $36,37,38$

auriculatus ..................20, 28, 42

Ayresii ...................... 53

elongatus ................... 32,42

fasciatus...................... 21, 28

flavidus..................... 42

helvomaculatus................ 32

melanops ....................25, 28, 42

nebulosus.................21, 22, 42

nigrocinctus .................. 32,42

ocellatus..................... 42

oralis......................... 42

paucispinis .................21, 22, 28,42

rosaceus...............21, $28,36,42,53$

ruber...................21, 22, 36,42

ruber var. parvus ............... 21, 22

variabilis ..................... 16, 21

Sebastodes ......................... 34, 38

flavidus.................... 36 .

ovalis ...................... 36 .

Sebastoid fishes ...................... $\quad 38$

Sebastoids............................. 37

Sebastomus .......................... 38

Sebastoplus ......................... 37

Sebastosomus....................... 38

pinniger................. 38 .

simulans................ 38

Seriphus ............................ 33 politus......................... 33,41

Serranus ............................ 40.

Shad, California................. $46,48,52,53,57$

first California .................... 46 .

Siboma............................ 25

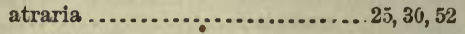
crassicauda.................... 30,43

Simpson, Capt. J. H ................. 33, 54

Siphagonus barbatus.................. 53

Sitgreaves, Capt. L..................... 10

Slack, J. H......................... 54

Smelts, California..................... 53

Smith, C. J......................... 64

Dr. Andrew ..................... 18

Sowerby, G.B ....................... 14

Sparus ............................. 14

Sphyræna argentea.................21, 27, 42 
Page.

Sphyræna malleus

Spinax (Acanthias) suckleyi..............

Spratelloides bryoporus

sproat, G. M

Squali, synopsis of .

Squatina californica

Stearns, Robert E. C

Steenstrup, Japetus

Steindachner, Franz.

Stephanolepis

Stereolepis.

$$
\text { gigas }
$$

Stevens; I. I...

Stichæoids, note on

Stichæus punctatus

Sticklebacks

Stone, Livingston

Storer

Storer, David Humphreys.

Stranahan, J. J

Streets, Thos. H

Strüver, Johannes

Sturgeon spearing.

Suckley, Geo., M. D.

Swan, James G

Syllæmus latifrons

Syngnathus

Abboti

arundinaceus

$32,45,49,50,53,64$

(6)

(On

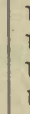

Page.

.

Trachinus cirrhosus...................... 10

Trachurus boops ....................... 27, 28

symmetricus............... 28, 42

Triacis semifasciatns.................... 44

Triakis semifasciatum ................. 22,31

Trichodon lineatns ..................... 32, 42

stelleri ...................... 11, 16

Trocbocopas ......................... 38

Troschel, D pulcher .......................

Troschel, F. H ....................... 20

Trowbridge, Lient. W. P ............... 21, 24

Trygon $-1 . . . \ldots \ldots \ldots \ldots \ldots \ldots \ldots . . .64$

Turner, William N ................... 49

Typhlogobius californiensis ............. 64

Umbra ............................. 16

Embrina undulata ....................21, 28,41

United States Fish Commissioner's report.. 49, 54

Uranidea punctulata .................... 52 vheeleri .................... 47,52

Uraptera binoculata...................... 31, 44

Urolophus Halleri..................... 38, 44

Uropsetta ............................ 36

Vanconver Island ....................... 39,40

Vastres ............................... 10

Venegas.................................. 3

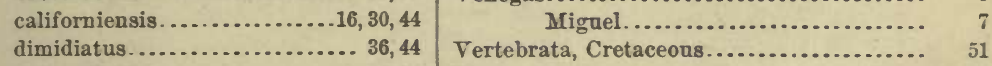

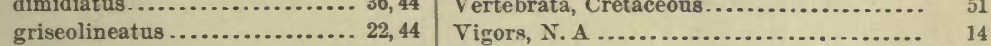

leptorhynchus..............21, 30,44 Viviparous fish $\ldots \ldots \ldots \ldots \ldots \ldots \ldots \ldots . .23,24,40$

Synodus lucioceps..................... 43

Viviparous fish ..........................23, 24,40

fishes, notice upon ............. 23

perch........................ 60

\section{W.}

Wachnija Camtschatica .................. 9

"Warren" ............................... 49

Western, C. B ........................... 64

Wheeler, Lieut. G. M .................47, 51, 59

Whipple, Lieut. A. W ................. 26, 31

Williamson, Lieut. R. S..............20, 25, 26, 3 k

Wilmot, Sam ........................ 55

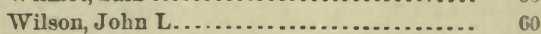

Sir Samuel ....................60, 61

Woodhouse, S. W ...................... 19

W. V.S................................... 56

Wyman, Jeffries ................. 21, 23, 26, 32

Xantus, $J$......................... 36,37

Xenichthys californiensis ................ 49

Xiphidion ........................... 27

mucosum ..................... 27, 42

mucosus .................... 28

Xiphidinm cruoreum................... 46

Yarrow, H. C $\ldots \ldots \ldots \ldots \ldots \ldots \ldots \ldots 48,49,51,53,59$

Yukon River fishes..................... 44

Zaniolepis ........................... 26 latipinnis ...................... 26, 28

Tilesius, W. G....................... 8,9

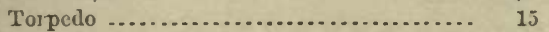

californica .................... 24, 44

Torrey, John.

17,19

Z sgæna, remarks on the foetal ............. 23

Zygonectes........................... 8 



\section{Department of the Interior:}

U. S. NATIONÁL MUSEUM.

\section{$-12-$}

\section{BULLETIN}

OF THE

\section{UNI'TED STATES NATIONAL MUSEUM.}

\section{No. 12 .}

PUBLISHLD UNDER THE DIRECTION OF THE SMITHSONIAN INSTITUTION.

\section{WASHINGTON :}

GOVERNMENT PRINTING OFFICE. 1878. 


\section{A D VERTISEMENT.}

This work is the twelfth of a series of papers intended to illustrate the collections of Natural History and Ethuology belonging to the United States and constituting the National Museum, of which the Smithsonian Institution was placed in charge by the act of Congress of Augast 16, 1846.

It has been prepared at the request of the Institution, and printed by authority of the honorable Secretary of the Interior.

\section{JOSEPH HENRY,}

Sucretury of the Smithsonian Institution.

SMithsonian Institution,

Washington, May, 1878.

2 


\section{CONTRIBUTIONS}

ro

\section{NORTH AMERICAN ICHTHYOLOGY.}

BASED PRIMARHY ON THE

COLLECTIONS OF THE UNITED STATES NATIONAL MUSEUM.

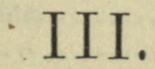

A.-On the Distribution of the Fishes of the Alleghany Region of South Carolina,

Georgia, and Tennessee, with Descriptions of New or Little Known Species.

BY.

\section{DAVID S. JORDAN}

AND

\section{ALEMBERT W. BRAYTON.}

B.-A Synopsis of the Family Catostomidæ.

BY

DAVID S. JORDAN.

WASHINGTON :

GOVER MENT PRINTING OFFICE. 


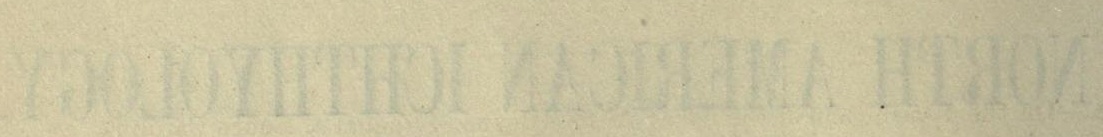




\section{TABLE OF CONTENTS.}

A.-On the distribution of the fishes of the Alleghany Region of South Caroina, Georgia, and Tennessee, with descriptions of new or little known species.

List of stream

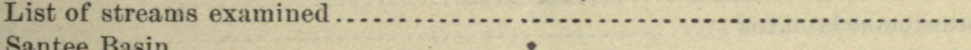

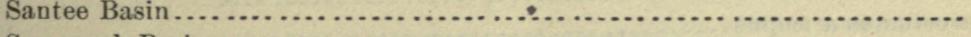

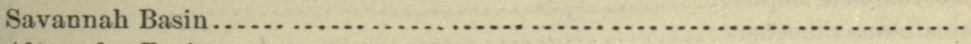

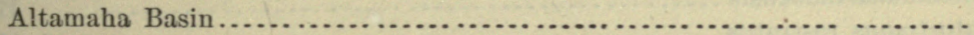

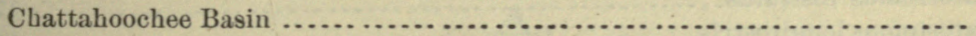

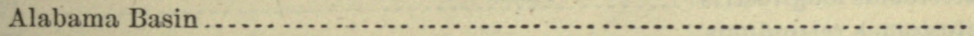

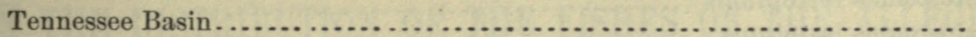

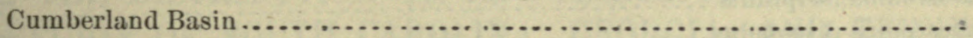

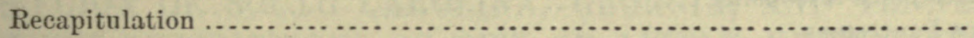

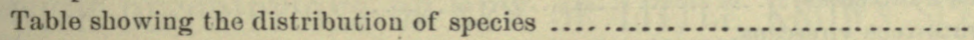

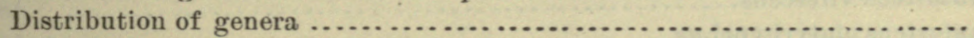

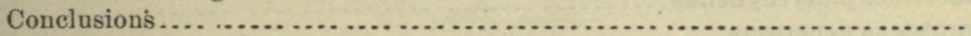

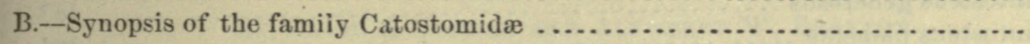

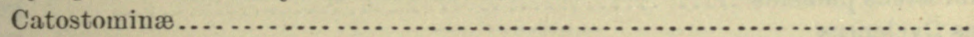

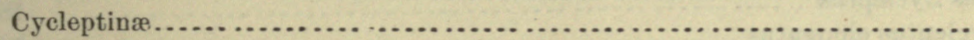

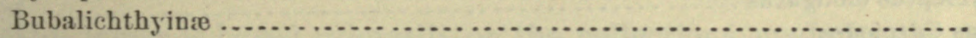

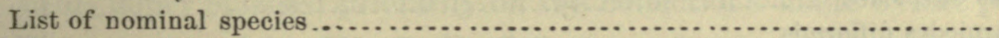

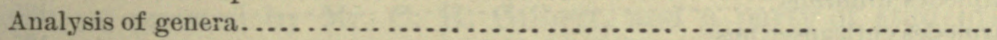

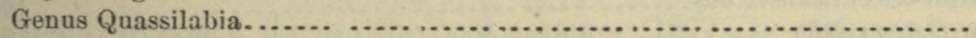

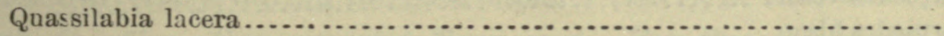

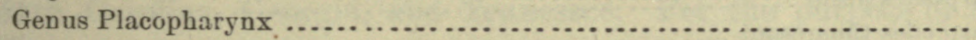

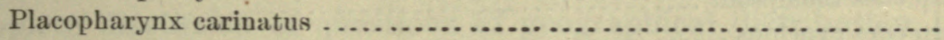

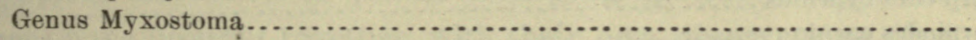

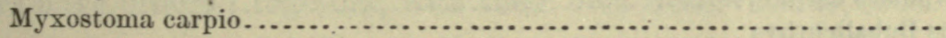

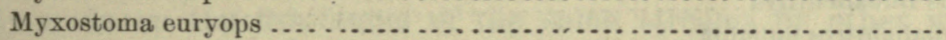

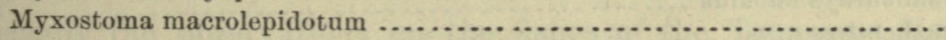

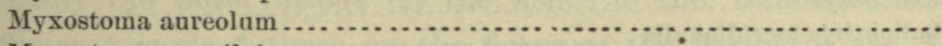

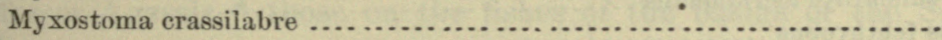

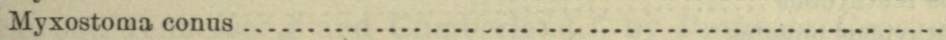

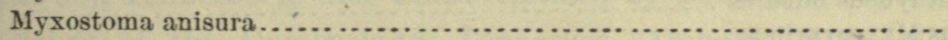

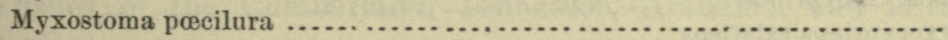

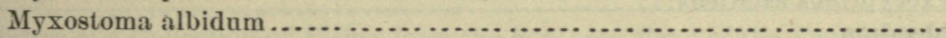

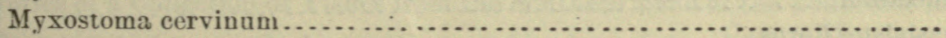

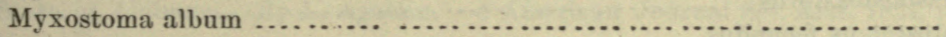

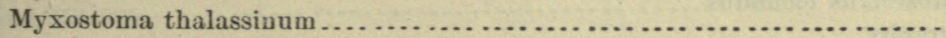

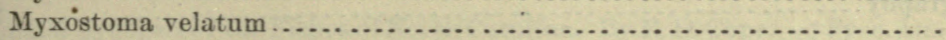

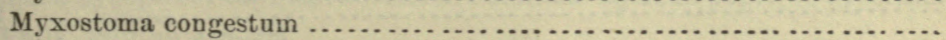

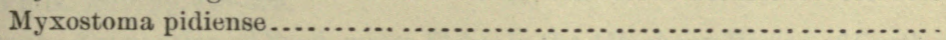

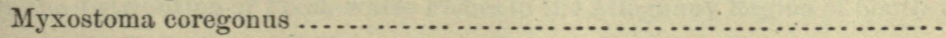

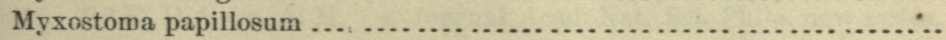

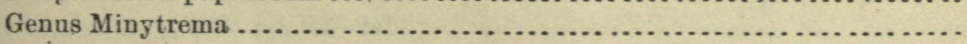

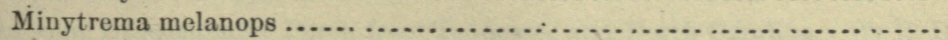




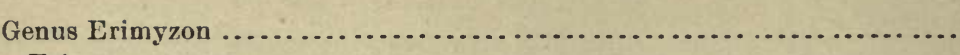

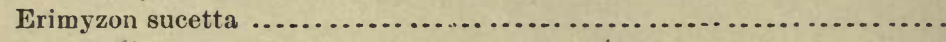

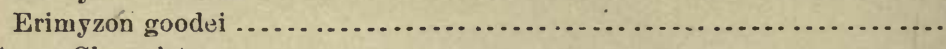

Genus Chasmistes ........................................

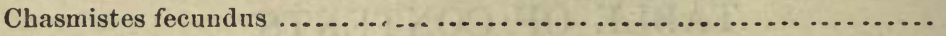

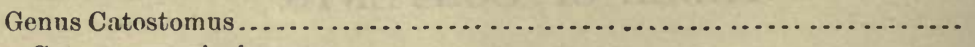

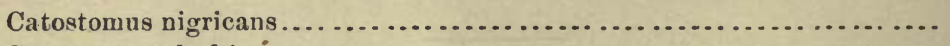

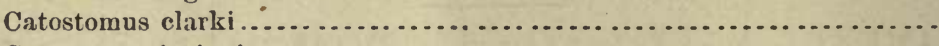

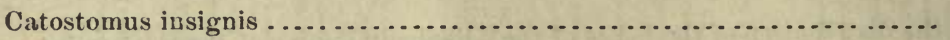

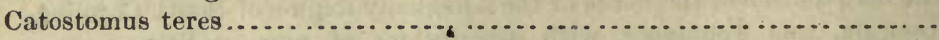

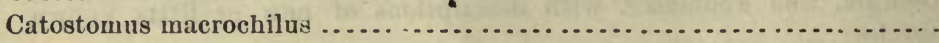

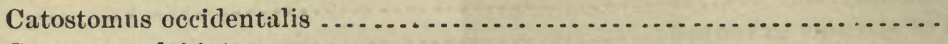

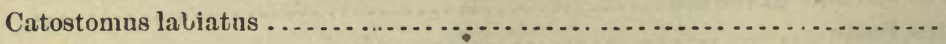

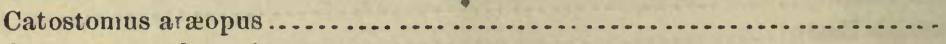

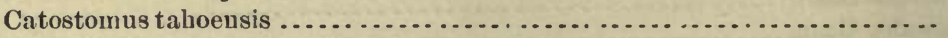

Catostomus rostiatus...................................

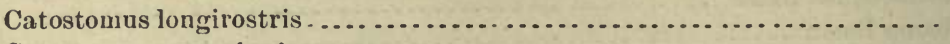

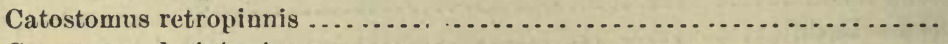

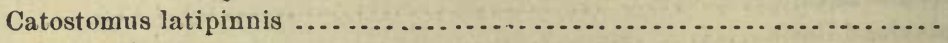

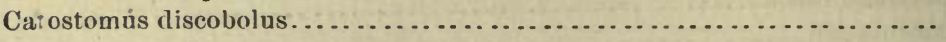

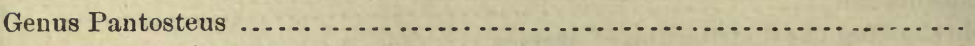

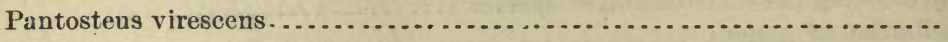

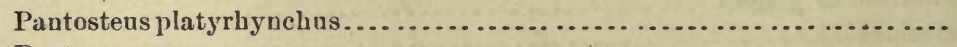

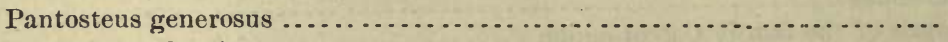

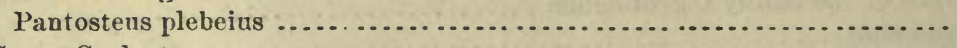

Genus Cycleptus ........................................

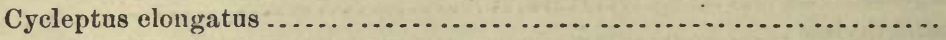

Genus Carpiodes ........................................

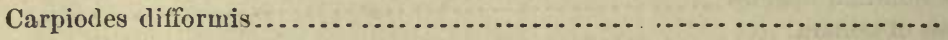

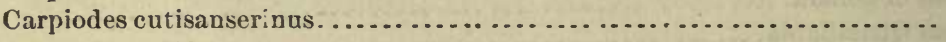

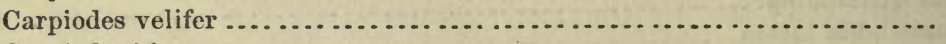

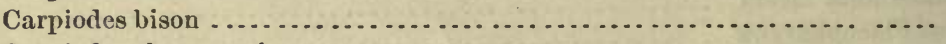

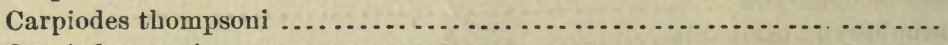

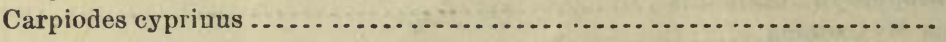

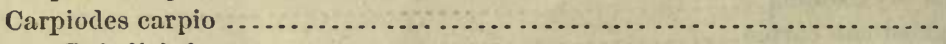

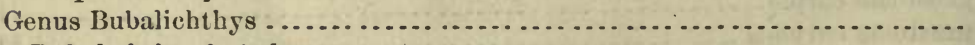

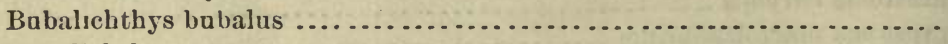

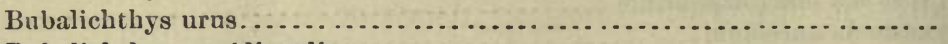

Bubalichthys meridionalis ................................... 210

Genus Ichthyobus ........................................... 211

Ichthyobus bubalus . ....................................... 214

Genus Myхөсyprinus ..................................... 217

Myxocyprinus asiaticus................................. 217

Addendum ............................................. 219

Chasmistes liorus........................................... 219

Catostomus fecundus ....................................... 219

Bibliography .............................................. 221

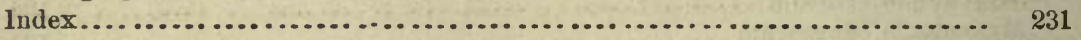




\title{
CONTRIBUTIONS
}

TO

\section{NORTH AMERICAN ICHTHYOLOGY.}

No. 3.

\begin{abstract}
A.
ON THE DISTRIBUTION OF THE FISHES OF THE ALLEGHANY REGION OF SOUTH CAROIINA, GEORGIA, AND TENNESSEE, WITH DESCRIPTIONS OF NEW OR LITTLE KNOWN SPECIES.
\end{abstract}

By David S. Jordan and Alembert W. Brayton.

This paper is based primarily on the collections made by the present writers, assisted by Mr. C. H. Gilbert, and a party of students from Butler University, during the past summer (1877), in various streams of South Carolina, Georgia, and Tennessee. For the purpose of a more complete discussion of questions of geographical distribution, the authors have brought together, with their own observations, those previously made on the fish-faunæ of the same streams by other writers, especially the observations on the fishes of the Tennessee Basin by Professor Agassiz;* those on the fishes of the basins of the Santee $f$ (Catawba), Tennessee, $\ddagger$ and Cumberland, $\|$ by Professor Cope, and on the fishes of the Cumberland, Tennessee, Alabama, and Altamaha

* Notice of a Collection of Fishes from the Southern Bend of the Tennessee River, in the State of Alabama. By L. Agassiz. < American Journal Sci. Arts, 1854, pp. 297308 and $353-365$.

†Partial Synopsis of the Fishes of North Carolina. By E.D. Cope. < Proc. Am. Philos. Soc. Phila. 1870, pp. 448-495.

$\ddagger$ On the distribution of Fresh-water Fishes in the Alleghany Region of South-western Virginia. By E. D. Cope, A. M. < Journal Acad. Nat. Sci. Phila. new series, vol. vi, part iii, January, 1869, pp. 207-247.

II On some Etheostomine Perch from Tennessee and North Carolina. By E. D. Cope. < Pric. Am. Philos. Soc. 1870, pp. 261-270. 
basins by Professor Jordan.* The purpose of this paper is to gire a résumé of all that is certainly known in regard to the ichthyologs of the seven hydrographic basins embraced in its scope, riz, the Santee, Sarannah, Altamaha, Chattahoochee, Alabama, Tennessee, and Cumberland. For purposes of comparison, a table of distribution of species is added, which includes, in addition, what is known of the fish-faunæ of the James, Roanoke, Neuse, Great Pedee, and Ohio.

The following is a classified list of the streams which have been examined in each water-basin included in this paper, with a word or two suggestive of the character of each stream. The collections in every case were made by one or both of the present writers, unless otherwise stated.

\section{LIST OF STREAMS EXAMINED.}

I.-SANTEE BASIN.

1. Catawba Rirer aud tributaries in North Carolina. (Cope, 1S69.)

2. Ennoree River, near (hick Springs, S. C. (Deep, muddy, and rapid.)

3. Reedy River, at Greenville Court-House, S. C. (Muddy.)

4. Saluda River, at Farr's Mills, west of Greenville. (Clear and rapid; a fine seining-ground.)

\section{II.-SAVANNAH BASIN.}

1. Tugaloo River, Habersham County, Ga., just below mouth of Panther. (Clear, broad rapids.)

2. Panther Creek, north of 'Toccoa City, Ga. (Clear mountain-stream.)

3. Toccoa Creek, below Toccoa Falls, Ga. (Clear, cold mountainstream ; contains little besides Hydrophlox rubricroceus.)

4. Toxaway and Chatuga Rivers and tributaries about the foot of Whiteside Mountain. (Clear mountain-streams, abounding in Trout.)

III.-ALTAMAHA BASIN.

1. Oconee River, at Sulphur Springs and Fuller's Mills, Hall County, Georgia. (Clear.)

2. Ocmulgee River, Reed's Fish-pond, south of $\Lambda$ tlanta, Ga. (Headwaters; clear.)

3. Ocmulgee River, South Fork, Flat Rock, De Kalb County, Georgia. (Partly clear; a small falls, and a deep basin worn in granite rock; a fine stream for seining.)

* A Partial Synopsis of the Fishes of Upper Georgia ; with Supplementary Papers on Fishes of Tennessee, Kentucky and Indiana. By David Starr Jordan, M. D., Ph. D $<$ Aunals N. Y. Lyceum Nat. Hist. vol. xi, 18\%7, pp. 307-37\%. 
4. Ocmulgee River, Macon, Ga. (Collection of Dr. T. H. Bean and other members of the United States Fish Commission.)

\section{IV.-CHATTAHOOCHEE BASIN.}

1. Chattahoochee River at Shallow Ford, northwest of Gainesville, Ga. (Broad, shallow, rapid; water moderately clear.)

2. Suwannee Creek, near Suwannee, Gwinnett County, Ga. (Deep, muddy, and very cold. Contains chiefly Codoma eurystoma.)

3. Peach Tree Creek, just north of Atlanta. (Deep and muddy.)

4. Nancy's Creek, northwest of Atlanta. (Clear aud rapid.)

5. Flint River, in Taylor County. (Collection of Dr. Hugh M. Neisler in United States National Museum.)

\section{V. - ALABAMA BASIN.}

A.-Etorcah River.

1. Pettis Creek, near Cartersville, Ga. (Clear, rock5.)

2. Silver Creek, near Rome, Ga. (Clear, rapid; a fine stream for collecting.)

3. Dyke's Creek and Pond, near Rome, Ga. (Clear and cold.)

\section{B.-Oostanaula River.}

4. Rocky Creek, near Floyd Springs, Ga. (A fine, clear stream.)

כ. John's Creek, near Floyd Springs. (Clear.)

6. Lorejoy's Creek, near Floyd Springs. (A small sandy stream, full of fishes.)

7. Big Armuchee Creek, above Rome. (Clear.)

8. Big Dry Creek, near Rome. (A succession of weedy rock-pools.)

9. Little Dry Creek, near Rome. (Like the preceding.)

10. Waters's Creek, abore Rome. (Mudds and rocky.)

11. Lavender Creek, in Texas Valles, Ga. (A small clear stream.)

\section{C._Coosa River.}

12. Beecl Creek, near Rome. (Muddy.)

13. Horse-leg Creek, near Rome. (Rocky, clear.)

14. Little Cedar Creek, at Cave Spring, Ga. (A fine, clear, cold stream. One of the best for the collection of fishes. Abounds in Xenisma stelliferum, Hydrophlox chrosomus, Codoma callistia, and other beautiful species.)

D.-Alabama River, near Montgomery, Ala. (Collection of Dr. Bean and others, 1876.) 
VI.-TENNESSEE BASIN.

A.- Upper Course.

1. Clinch River, tributaries in Southwestern Virginia. (Cope, 1868.)

2. Powell's River, near Cumberland Gap. (Clear.)

3. Indian Creek, near Cumberland Gap. (Clear.)

4. Station Creek, near Cumberland Gap. (Clear.)

5. Holston Rirer, various tributaries in Southwestern Virginia. (Cope, 1868.)

6. French Broad River, at Newport, Tenn. (Rather deép and muddy.)

7. French Broad River, about Warm Springs, N. C., Asheville, N. C., and elsewhere.) (Cope, 1869.) (Rapid, rocky, and generally clear.)

8. Big Pigeon River, at Cliffton, Tenn. (Rather clear.)

9. Swannanoa Rirer, at foot of Black Mountain. (Clear, cold mount. ain stream, with trout.)

\section{B.-Lower Course.}

10. Chickamauga River, at Ringgold, Ga. (Rather clear and very rocky.)

11. Tributaries of Tennessee River, about Huntsville, Ala. (Agassiz; Newman's collection, 1853.)

12. Tributaries of Tennessee River, about Florence, Ala. (Storer, 1845.)

13. Elk River and tributaries, at Estill Springs, Teun. (Clear, rock5, and cold.)

$$
\text { VII.-CUMIBERLAND BASIN. }
$$

1. Round-Stone River, Rock Castle County, Kentucky. (Clear.)

2. Rock Castle River, Livingston, K.y. (Clear and rocky.)

3. Big Laurel River, Laurel County, Kentucky. (Clear.)

4. Cumberland River, abont Pineville, Ky. (Clear, rocky.)

5. Yellow Creek, near Cumberland Gap. (Rather muddy.)

6. South Fork of Cumberland Rirer, in Tennessee. (Cope, 1869.)

7. Cumberland Rizer and tributaries, near Nashrille. (IVinchell, 18i6.)

8. Stone River, Murfreesboro', Tenn. (Clear and rocky.)

It will be noticed that almost without exception the abore mentioned localities are in the mountainons or upland parts of the different waterbasins. Of the fishes inbabiting distinctively the lowland courses of most of the streams, little is yet definitely known. 
The Santee, Savannah, Altamaha, and Chattahoochee bave been examined only in that part of their course which flows orer metamorphic rocks. The three western streams have been studied chiefly in the limestone regions. The lithological character of the bed of a stream has a certain influence on its fish-fauna, as will be seen hereafter. Generally limestone streams are richer in species than those with granitic bottoms.

The types of the new species described below are deposited in the Uniter States National Museum at Washington, and in the Museum of Butler University, Indianapolis, Indiana.

\section{I.-SANTEE BASIN.}

Thirty-nine species are ascertained to occur in the headiwaters of the Santee Rirer, thirty-three haring been obtained by Professor Cope in the Catawba River in North Carolina, and thirty by the present writers in the Saluda and Ennoree in South Carolina. Of these thirty nine species, ten are not as yet known from any other hydrographic basin. These are: Alvordius crassus, Nothonotus thalassinus, Ceratichthys labrosus, Ceratichthys zanemus, Codoma pyrrhomelas, Codoma chloristia, Photogenis niveus, Alburnops chlorocephalus, Alburnops saludanus, and Myxostoma album. The apparent absence of Luxilus cornutus in the Great Pedee, Santee, Savannah, Altamaha, and Chattahoochee Basiụs is remarkable, as that species is abundant in the tributaries of the Neuse on the east and the Alabama on the west, as in all streams northward to Minnesota and New Euglaud.

The species most abuudant as to individuals, in the Saluda at least, is probably Notropis photogenis. Next to this come Codoma pyrrhomelas and Ceratichthys biguttatus. Of the Catostomida, Myxostoma cervinum seems to be the predominant species; of the Silurida, Amiurus brunneus, and of the Centrarchidce, Lepiopomus auritus. The chief foodfishes at Greenville, S. C., are the "Mud Cats" (Amiurus brunneus and platycephatus), the "Fine-scaled Sucker" (Catostomus commersoni), the Eel (Anguilla vulgaris), the "Spotted Sucker" (Minytrema melanops), the "Perch" (Lepiopomus auritus), the "War-mouth Perch" (Chanobryttus viridis), the "Jack" (Esox reticulatus), and the "Jump Rocks" (Myxostoma cervinum). 


\section{ETHEOSTOMATID A.}

\section{Genus ALVORDIUS Girard.}

\section{AlVORDIUS CRASSUS, $s p$. nov.}

Etheostoma maculatum var. Cope, Proc. Am. Philos. Soc. 1870, 261, 262, and 449. (Not Hadropterus maculatus Girard.)

A species bearing considerable resemblance to $A$. aspro, but less distinctly marked and more heavily built, the form being less graceful than that of the other mémbers of the genus. Body consiclerably compressed, the depth $4 \frac{1}{2}$ times in length to origin of caudal (as in all cases in this paper). Head comparatively short, $3 \frac{4}{5}$ in length; the snout medium, not acuminate as in $A$. phoxccephalus, nor especially obtuse. Eje moderate, as long as snout, 4 in head. Mouth rather small for the genus, nearly horizontal, the upper jaw but little the longer: upper jaw not projectile: maxillary reaching anterior margin of eye.

Cheeks naked: opercles with a few scales above: back and breast naked : middle line of belly in some specimens naked: in others with enlarged plates. Scales on the body rather larger than usual, about 7-55-7.

Fins moderately developed: dorsal XII-I, 10, rarying to XI-I, 11; an increase in the number of the spines, as usual, accompanying a decrease in the number of soft rays, a rule apparently not hitherto noticed, and perhaps not of general application. The two dorsal fins are well separated, the first being longer than the second, but considerably lower.

Anal fin shorter, but higher than second.dorsal, II, 9; the tro spines well developed. Caudal fin deeply lunate, almost furcate. Pectorals and ventrals large, their tips about equal.

Coloration rather plain. General hue olivaceous; the back marked with darker, as in the other species of the genus. Sides with a series of lark olive, rounded blotehes, connected along the lateral line by a narrow, dark band; a dark streak forward, and one downward from the eye. First dorsal with a dark spot in front, and another on its last rajs. Second dorsal, caudal, and pectorals barred with dark spots. Anal and rentrals uncolored.

Length of longest specimens observed, 3 inches.

Habitat.-Saluda, Ennoree, and Reedy Rivers, in rapid water, espe. cially abundant in the Saluda at Farr's Mills. Also recorded by Cope from the Catawba. 


\section{Genus BOLEOSOMA DeKay.}

\section{Boleosona maculaticeps Cope.}

Boleosoma maculaticeps Cope (1870), Proc. Am. Philos. Soc. 269 and 450. (Catawba R.)-Jordan \& Copeland (1z76), Check List (Bull. Buffalo Soc. Nat. Hist.), 163. (Name only.)

Arlina maculaticep8 Jordax (1877), Bull. U. S. Nat. Mus. $\leq$, 15. (Name only.)

Boleosoma olmstedi Jordax (1877), Ann. N. Y. Lyc. Nat. Hist. 368. (Ocmulgee River.)

A single specimen taken in the Saluda River at Farr's Mills answers closely to Professor Cope's description. The upper part of the cheeks have, however, a few scattering scales. This species is a true Bolcosoma. Althougl the type of Bolcosoma has but a single anal spine and $B$. effulgens and $B$. maculaticeps hare two anal spines, the essential character of those spines is the same in both cases, and the genus Arlina, based on B. effulgens, is a synonym of Boleosoma. In Boleosoma, the spines are all weak and flexible, and those of the anal especially so. In most or all of the other genera of Etheostomatida, the anal spines are stiff and loug, and, with scarcely an exception, the first spine is the longer of the two. In the species of Boleosoina, with trco anal spines, the two spines are unequal, the second the longer, both extremely slender and flexible; not at all "spine"-like, except that they are not inarticulate. This feeble condition of the spines seems to constitute the chief generic character of Boleosoma.

Two of the species provisionally referred by Professor Jordan (Bull. U. S. Nat. Mus. x) to "Arlina", riz, Arlina stigmoea Jor. and A. atripinnis Jor., have the anal spines well developed, as usual in Etheostomatida. These two species and their congeners apparently constitute a distinct genus, differing from Diplesium in the toothed romer and from Nothonotus in the protractile upper jaw. For this genus, the name of Ulocentra (Jordan) has been suggested (Man. Vert. ed. 2d, p. 223), in allusion to the derelopment of the spives.

\section{Genus NOTHONOTUS Agassiz.}

\section{Nothoyotus thalassinus, $s p$. nov.}

A handsome species, differing from the others now referred to this genus in tine entire nakedness of the head.

Bolly rather stout, the depth about 5 times in the length, com. pressed behind, the back somewhat arched. Head large, 4 in length, the snout rather blunt and convex in profile; a pretty decided augle 
opposite the eye. Eyes large, ligh up, longer than the muzzle, $3 \frac{1}{2}$ in head: interorbital space ratber narrow, the eye having some npward range. Mouth moderate, slightly oblique, the maxillary reaching to orbit. Upper jaw slightly longer than the lower, not protractile. Head entirely naked, both cheeks and opercles being destitute of scales.

Scales large, 5-43-5. Belly scaled: throat naked: neck anteriorly naked, but scaly in front of the dorsal : lateral line complete.

Fins all large: D, X-I, 10, or IX-I, 11, the membrane of the first dorsal continued to the base of the second: longest dorsal spine a little over half the length of the head, scarcely shorter than the soft rays; the base of the spinous dorsal a little longer than that of the soft dorsal. Anal II, 8, rather smaller than second dorsal, the first spine longer and larger than the second. Caudal tin deeply lunate, almost forked. Pectoral and rentral fins large; the former reaching nearly to the vent, the latter somewhat shorter.

Color, in spirits: Olive, closely mottled and tessellated abore with dark green; this color extending down the sides, forming six or eight irregular dark green bars. Head dark green; a dark green line downward from eye and another forward. Fins in males nearly plain, the spinous dorsal with a black edge; females with all the tins except the ventrals closely barred or speckled with dark green. Two pale orange spots at the base of the caudal.

Life-colors: The colors of a male specimen in life are as follows: Body dark olive and blotehed above: sides with nine dark blue-green vertical bars, the five next the last most distinct, and reaching down wearly to the anal. Spinous dorsal reddish at base, then with a broad black band, the uppermost third being of a bright ferruginous orange-red : second dorsal blackish at base, reddish above: caudal with two orange blotches at base, black mesially, pale orange externally. Anal fiu of a brilliant blue.green color at base, pale at tip. Pectorals barred, the middle of the fin grass green. Ventrals dusky mesially, with a green shade. Opercular region more or less grass-green : streaks about eye blackish-green.

Length of largest specimens taken, $2 \frac{1}{2}$ inches.

Habitat.-Very abundant in all the streams seined, especially so in the rocky shoals of Reedy River in the city of Greenville.

This handsome little fish may be easily known from its congeners by the smooth head, and by the general greenness of its coloration, which resembles somewhat that of the species of Diplesium. 


\section{Genus ETHEOSTOMA Rafinesque.}

4. Etheostoma flabellare Raf.

(Catonotus flabellatus Auct.)

Three specimens doubtfully referred to this species were obtained by Professer Cope in the Catawba River.

\section{CENTRARCHIDE.}

\section{Genus MICROPTERUS Lacépède.}

\section{Micropterus pallidus (Rafinesque) Gill \& Jordan.}

Professor Cope obtained this species in the Catawba. We collected none in the Saluda or Ennoree, but we were told that "Tront", as the species of Micropterus are universally called in the South, are frequently taken there.

\section{Genus CHANOBRYTTUS Gill.}

\section{Uhanobryttus viridis (Cuv. \& Val.) Jordan.}

The War-mouth Perch oceurs in abundance in the Saluda, and apparently in all the South Atlantic streams. Cope says that it is exceedingly common in all the streams of Eastern North Carolina, and that it is known as the Red-eyed Bream on the Catawba. This species is very closely related to $C$. gulosus, differing chiefly in the color and in the somewhat less robust form. It may be only a variety.

\section{Genus LEPIOPOMUS Rafinesque.}

\section{Lepinpomus aURITUS (Linnaus) Raf.}

All my specimens of this species from the Saluda have a dusky blotch or bar at the base of the soft dorsal, a feature of coloration not shown by my Northern specimens. This is a widely diffused species, and, like most such, is quite variable.

\section{Genus EUPOMOTIS Gill $\mathfrak{e}^{\bullet}$ Jordan.}

8. Eupomotis aureus (Walbaum) Gill \& Jordan.

Professor Cope obtained this species in Catarba River. We have never collected it in the Southern States. It is probably chiefly confined to the lowland regions. 


\section{ESOCIDA.}

\section{Genus ESOX Linnaus.}

9. Esox Reticulatidus Le Sueur.

Very common. We are unable to distinguish the. Southern form (phaleratus Say, affinis Holbrook) as eren varietally distinct from the Northern réticulatus.

10. Esox RAVEneli Holbrook.

Obtained by Professor Cope in the Catawba. Its specific distinction from $E$. americanus Gmelin appears questionable.

\section{SALMONID A. \\ Genus SALVELINUS Richardson.}

11. Salvelinus fontinalis (Mitchill) Gill d Jordan.

This species was found by Professor Cope in the headwaters of the Catawba River.

\section{CYPRINID E.}

Genus CAMPOSTOMA Agassiz.

12. Campostoma anomalum (Raf.) Ag. Subspecies prolixum (Storer) Jor.

A few specimens from Saluda River. Also in the Catawba (Cope).

\section{Genus HYBOGNATHUS Agassiz.}

13. Нybognathus argyritis Girard.

A few specimens were obtained in Saluda River, not distinguishable from others from Ohio River and others (types of $H$. osmerinus Cope) from New Jersey. Professor Cope found it abundant in Catawba River.

\section{Genus ALBURNOPS Girard.}

\section{Alburnots saludanus, sp. nov.}

Hybopsis amarus, "variety from the Catawba," Copre (1870), Proc. Am. Philos. Soc. 460.

A species belonging to "Hybopsis, Group A", of Cope, which is equi- 
valent to the subgeneric section of Alburnops or "Hybopsis", called Hudsonius by Girard.

Body elongate, but compared with its immediate relatives, hudsonius, amarus, and storerianus, short and thick; moderately compressed, the depth $4 \frac{2}{5}$ in length : caudal peduncle shortened, $4 \frac{3}{5}$ in length : head large, 4 times in length, relatively heavy and gibbous forward, the snont rounded in profile, as in A. hudsonius. Eye large, rather wider than interorbital space, about equal to snout, $3 \frac{1}{4}$ in head.

Mouth moderate, subinferior, the maxillary not reaching to eye.

Scales large, thin, and loose, $5-39-3$, about twelve in front of the dorsal fin. Lateral line somewhat decurved in front.

Fins moderately developed. Dorsal beginuing in advance of rentrals, I, 8; its first ray nearer snout than caudal. Anal I, 8, rather small. Pectorals not reaching to ventrals, the latter not to vent.

Color clear olivaceous, nearly white, like the rest of the group, some specimens showing a faint plumbeous lateral line.

Teeth 1,4-4, 1, two or three of the principal row obtuse, not hooked; only one or two of the teeth usually showing a masticatory face.

Habitat.-Abundant in Saluda River, where it reaches a length of about four inches. Also obtained by Professor Cope from the Catawba.

The peculiar characters of this species have been noticed by Professor Cope, who, however, was disposed to consider it a variety of H. amarus. It differs from our specimens of what we consider to be the latter species (from Ocmulgee Rirer) in the smaller eye, the thicker head, shorter, deeper body, more decurved front, and shorter caudal peduncle. In amarus, the eye is 3 in head, the head $4 \frac{3}{4}$ in length, and the caudal peduncle $3 \frac{4}{5}$.

We have been disposed to unite, under the generic name Luxilus, a large number of species forming a series the extremes of which bear little resemblance to each other or to the means, but which form a chain so unbroken that it is difficult to draw any generic lines among them. That this group may ultimately be broken up into natural genera is very probable, but the groups thus far proposed have not received very satisfactory definition.

These species agree $(a)$ in the absence of any special modification, either of mouth, fins, or alimentary canal; $(b)$ in the dentition, the teeth being in one or two rows, always four in the principal row of the raptorial type, and some or all of them provided with a grinding surface; often, and in some species always, one edge of the masticatory

Bull. N. M. No. 12-2 
surface is more or less crenate, especially in joung individuals; (c) the anal fin is always short, containing from seven to nine rays; $(d)$ the dorsal fin is never inserted very far behind the ventrals; $(e)$ the lateral line is developed and continuous.

The species differ much among themselves in size, uuptial dress, and general appearance, nutably in the squamation, the scales of the typical species of Luxilus bein g closely imbricated and much higher than long, while in the group called Hudscnius the two dimensions of the scales are nearly eqnal. The scales themselres, in Hudsonius, are thin and loosely imbricated. Within certain limits, the position of the dorsal varies also. In Hudsonius, its first ray is in advance of the insertion of the ventrals; in Luxilus and Allurnops, usually directly opposite; in Photogenis and Hydrophlox, distinctly posterior. The form of the mouth varies largely: in L.coccogenis, it is wide and oblique, the lower jaw projecting. In the typical species of Alburnops and Hudsonius, the mouth is small and more or less inferior.

The species may be provisionally grouped as follows, under five groups, four of which may be considered as distinct genera. Those species whose position is doubtful are indicated by a mark of interrogation :A.-Luxilus Rafinesque. (Scales very closely imbricated, much deeper than long: teeth $2,4-4,2$, entire: dorsal fin inserted directly opposite ventrals: mouth terminal: size large: nuptial dress peculiar; type Cyprinus cornutus Mit.)

cornutus Mit.

coccogenis Cope.

selene Jor.

B.-Photogenis Cope. (Scales pretty closely imbricated, deeper than long: teeth $1,4-4,1$, more or less crenate (rarely one-rowed ?): dorsal fin behind ventrals, always with a black spot on the last rays behind: males in spring tuberculate, the lower fins and the tips of the vertical fins filled with satin-white pigment in spring: mouth terminal, the upper jaw longest: size medium; type $P$. spilopterus Cope $=$ Cyprinella analostana).

analostanus Girard.

niveus Cope.

galacturus Cope.

leucopus J. \& B.

iris Cope (?).

C.-Hydrophlox Jordan. (Scales less closely imbricated, somewhat deeper than long; teeth usually $2,4-4,2$, often more or less crenate : dorsal fin distinctly behind rentrals, unspotted : breeding dress peculiar, the ma es almost always red : mouth terminal, 
oblique, the upper jaw usually sligbtly the longer: size very small ; type Hybopsis rubricroceus Cope.) rosenss Jordan.
chrosomus Jor.
rubricroceus Cope.
xcnocephalus Jor.
lutipinuis J. \& B. plumbeolus Cope.
chiliticus Cope. birittatus Cope.
chalybaus Cope. lacertosus Cope.

D.-Alburnops Girard. (Scales rather loosely imbricated: teeth $4-4$, or $1,4-4,1$ : dorsal fin inserted over ventrals, unspotted : sexes alike: mouth more or less inferior, horizontal or oblique: size small; type Alburnops blennius Grd.)
microstomus Raf.
timpanogensis Cope.
volucellus Cope. chlorocephalus Cope.
spectrunculus Cope. fretensis Cope.
procne Cope. mubilus Forbes.
stramineus Cope. blennius Grd.
tuditanus Cope (?). shumardi Grd. missuriensis Cope. illecebrosus Grd.

scylla Cope.

E.-Hudsonius Girard. (Scales thin and loosely imbricated : teeth 1, 4-4, 1 or 2, the grinding surface often distorted: dorsal inserted in adrance of rentrals: colors silvery: sexes alike: mouth inferior: body elongate, the head comparatively short: size medium; type Clupea hudsonia Clinton.)
saludanus J. \& B.
amarus Girard.
hudsonius Clinton. storerianus Kirtland.

We hare substituted the name Alburnops Grd. for the earlier name Hybopsis, as we think that the latter genus was founded on a species of Ceratichthys.

\section{5. alburnops chlorocephalus (Cope) J. \& B.}

Hybopsis chlorocephalus Cope (1870), Proc. Am. Philos. Soc. 461.

This beautiful little fish is abundant in the clear rapid waters of the Saluda. It resembles $H$. rubricroccus, but is smaller and stonter-bodied, with sma!ler mouth. The scales in front of the dorsal are fewer (about 16) in number. The teeth are $1,4-4,1(2,4-4,2$, in rubricroceus). The male specimens are profusely tuberculate on the snout and ante-dorsal region. Professor Cope found this spccies abundant in the clear waters of the tributaries of the Catamba. 


\section{Genus PHOTOGENIS Cope.}

\section{Photogenis niveus (Cope) J. \& B.}

Hybopsis niveus Cope (1870), Proc. Am. Philos. Soc. 461.

A very pale species, related to Photogenis analostanus and $P$.galacturus, rather than to the species of "Hybopsis", to which genus Professor Cope referred it. My specimens are all very white, with a narrow biuish stripe along the caudal peduncle, which sometimes forms a faint spot at base of caudal. In male specimens, the snout and ante-dorsal region are covered with small tubercles. In males, the dorsal fin is considerably elevated. In color, the dorsal fin is largely dusky on the last rays, the most of the fin somewhat creamy-tinted. The tip of the dorsal fin and the tips of the caudal are filled with milk-white pigment, as in the related species. The anal fiu is entirely milky. The teeth are $1,4-4,1$, provided with a narrow masticatory surface.

Photogenis niveus is abundant in the Saluda River. It was first discovered by Professor Cope in the Catawba River.

17. Photogenis analostanus (Girard) Jordan.

We did not find this species in the Saluda, although Professor Cope states that it is abundant in the Catawba. It is perhaps possible that Professor Cope mistook our Codoma chloristia, a species which resembles it very much, except in dentition, for the true analostanus. The "Cyprinella analostana" has been a stumbling-block in the classification of these fishes, as to the masticatory surface of Luxilus it adds the crenations of Cyprinella. We are inclined to think that Cyprinella should be restricted to those species whose teeth are without grinding surfaces and are permanently crenate. The relations of Luxilus analostanus, spilopterus, galacturus, leucopus, and niveus are much more intimately with the species of Codoma than with Luxilus, but the development of grinding surfaces on the teeth renders it necessary to refer them to the latter genus, unless Photogenis be admitted as a distiuct genus.

\section{Genus CODOMA Girard.}

(Subgenus EROGALA Jordan.)

Photogenis Jordan (1877), Ann. Lyc. Nat. Hist. N. Y. 335. (Not of Cope, whose type, $P$. spilopterus, proves to be a species closely related to $L$. analostanus, if not identical with it.)

Examination of a large number of specimens supposed to be Plotogenis spilopterus, from Saint Joseph's River, in Northern Indiana, Professor 
Cope's original locality, has convinced u's that the spilopterus, the type of the genus Photogenis, loes not belong to the group of colored species for which Professor Jordan lately adopted the latter name. The genus Photogenis (Jordan) being thus left without a name, that of Erogala has been suggested $(\tilde{\gamma} \rho$, spring-time; $r a \dot{\lambda} \alpha$, milk, in allusion to the milk-white pigment with which the male fishes are ornamented in the nuptial season).

Codoma Grd. differs from Erogala in the form of the head, which is short, blunt, and rounded, as in Pimephales. We do not now think that the two are distinct as genera, and prefer to consider Erogala as a subgenus of Codoma.

The type of Erogala is Photogenis stigmaturus Joruan. This subgenus is remarkable for its geographical distribution. All of the species thus far known belong to the Southern States, and each of the Southeru river-basins probably has from two to four species of the genus; not a single species, so far as known, being common to two different riverbasins.

The distribution of the species of Erogala is as follows:-

Santee Basin : pyrrhomelas Cope.

$$
\text { chloristia J. \& B. }
$$

Savannah Basin : none known.

Altamaha Basin : xcenura Jor. callisema Jor.

Chattahoochee Basin: eurystoma Jor.

Flint River: formosa Putn.

Alabama Basin: callistia Jor.

trichroistia J. \& G.

coerulea Jor.

stigmatura Jor.

Farther west their place is taken by the species of Cyprinella having serrated teeth, and farther north by the species of Luxilus, section Photogenis, having teeth with dereloped grinding surfaces.

The species of Codoma are remarkable for their exquisite coloration, most of them being adorned with bright red in addition to the milky pigment. The black dorsal spot is present iu all the species.

\section{Codoma CHLORISTIA, sp. nov.}

Body short and deep, strongly compressed, the form elliptical, resembling that of $\boldsymbol{C}$.pyrrhomelas, but rather deeper, the depth of adults being, $3 \frac{3}{4}$ to 4 in length. Head rather small and pointed, $4 \frac{1}{4}$ in length. 
Eje moderate, less than snout, 4 in head. Mouth rather small, quite oblique, the maxillary not attaining the line of the orbit, the upper jaw projecting beyond the lower, especially in spring males. The head and mouth considerably resemble those parts in $P$. analostanus.

Scales much deeper than long, very closely and smoothly imbricated, more or less dark-edged above. 5-37-3. Lateral line decurved.

Fins moderately developed : dorsal distinctly behind ventrals, its first ray about midway between uostrils and the base of the caudal. Dorsal 1, 8. Anal 1, 8.

Nuptial tubercles in the male greatly developed, covering rather sparsely the top of the head and the region anterior to the dorsal. In addition, similar tubercles cover the caudal peduncle and the whole sides of the body, except the space below the lateral line and in front of the ventrals. The tubercles on the body are cousiderably smaller than those on the head, and smaller than in xcenura or pyrrhomelas, but they cover a much larger area than in any of the latter species of the genus. Chin tuberculate.

Teeth 1, 4-4, 1, entire, without masticatory surface.

Coloration, in life: General color a dark steel-blue, a very distinct blue stripe along each side of the caudal peduncle, as in $C$. cœrulea, but fainter: sides of body with fine steely-purple lustre: back clear green : head clear brownish : iris white : cheeks of a pale violet color: lower part of sides becoming rather abruptly milky-white: dorsal fin with the usual large black spot on the last rays well developed, and the usual milk-white pigment in the tips: lower part of the dorsal fin with pigment of a tine clear green color, somewhat as in analostanus, but unusually bright: caudal fin chiefly dusks, its tips milky and the base somewhat so; the middle of the fin has a slight reddish tinge: anal fin entirely milky, a faint dusky spot on its last rays, resembling that on the dorsal : ventral fins milky.

Female and young specimens are more slender, and the bright colors are usually wanting or obscured.

Size small ; length of largest specimens less than three inches.

In form, this species resembles $C$. pyrrhomelas, but the short anal (eight rays instead of ten) will always distinguish the species. The coloration of the male is different, being much less brilliant, although perhaps more delicate. C. chloristia resembles in color $C$. corulea most, but the latter species has a much more slender form.

Habitut.-Abundant in the clear waters of Saluda River, with $C$. 
pyrrhomelas, Photogenis niveus, Alburnops chlorocephalus, and other handsome species.

19. Codoma PYRRHOMElas (Cope) Jor.

Photogenis pyrrhomelas CuPE (1870), Proc. Am. Philos. Soc. Phila. 463.

This species, the most ornate of the genus, and one of the most brilliant of Cyprinida, is extremely abundant in the clear rapid waters of the Saluda and its tributaries. The general color of the males is dark steel-blue above, with the scales darker-edged, the bclly abruptly milkywhite. The head is pale reddish; the snout, the tip of lower jaw, and the iris above and below are scarlet; the dorsal fin is dusky at base, has a large black spot on the last rays, is red in front, and broadly milkwhite at tip. The tips of the caudal fin are milk-white; next to this coines a dusky crescent; a wide bright scarlet crescent lies inside of the black and extends into the two lobes of the tin. The base of the fin is pale.

The top of the head and the region in front of the dorsal are covered with small pale tubercles. The sides of the caudal peduncle are prorided with rather larger tubercles, arranged in rows along the series of scales.

This is the most abundant fish in the waters of Catawba River, according to Professor Cope.

\section{Genus NOTROPIS Rafinesque.}

(Minnilus Rafinesque; Alburnellus Girard.)

20. Notropis Photogexis (Cope) Jordan.

Squalius photogenis Cope (1864) Proc. Ac. Nat. Sc. 280.

Photogenis leucops Cope (1866), Trans. Am. Phil. Suc. 379, and elsewhere.

My specimens differ considerably from the typical forms of this species, but correspond to Professor Cope's "var. a a a a $a$ " from the Ca. tawba. It is the most abundant species in the Saluda waters, especially in more sluggish tributaries. Two forms, perhaps rarieties, perhaps different sexes, occur, the one pale, with deep, compressed body; the other darker, with the scales dark-edged and the body much more elongate. It is difficult to distinguish the latter form from $N$. telescopus (Cope). The pale form has the head above and uncier jaw covered with small pointed tubercles. 


\section{Genus GILA Baird \& Girard.}

\section{(Subgenus CLINOSTOMUS Girard.)}

21. Grla vandoisula (Cuv. \& Val.) Jor.

Lenciscus vandoisulus C. \& V. (1844), Hist. Nat. Poiss. xvii, 317.

Clinostomus affinis GIRaRd (1856), Proc. Ac. Nat. Sc. 212.

This species is common in the Saluda waters, as in the Catawba, Yadkin, and other Southern streams. It seems to prefer still, or even muddy waters, as we found it more abundant in the Reedy River than in either Saluda or Enuoree. Our specimens were greenish or bluish in color, the back mottled with scales of a different hue, as usual in this genus. In the males, the region behind the head and above the pectorals and extending backward to the anal are of a bright rosy-red, brightest just behind the head. There is no distinct dark lateral band. None of our specimens were noticed to be tuberculate. The characters rlistinguishing this species from the more northerly Gila (Clinostomus) funduloides have been well given by Professor Cope (Journ. Ac. Nat. Sci. 'Phila. 1868, 228).

\section{Genus NOTEMIGONUS Rafinesque.}

\section{Notemigonus AMERICANUS (Linn.) Jordan.}

Notemigonus ischanus JoRdAN (1877), Ann. Lyc. Nat. Hist. p. 364.

This is the true Cyprinus americanus of Linnæus, as has been elsewhere shown. We obtained but a single specimen in the Reedy River. Professor Cope found it abundant in the sluggish waters of the Cata wba. The long anal, more compressed body, larger eye, and peculiar breeding colors distinguish this species from the Northern and Western $N$. chrysoleucus.

\section{Genus CERATICHTHYS Baird.}

23. Ceratichthys zanemis, sp. nov.

A small, peculiar species, allied to $C$. labrosus (Cope), but apparently differing in the longer barbel, smaller scales, and in the coloration.

Body long and siender, not much compressed, the depth about $4 \frac{1}{4}\left(5 \frac{1}{2}\right.$ in young) in length. Head rather long, narrow, and pointed, $4 \frac{1}{4}$ in length, very slender in young specimens, stouter in adults : snout decurved in profile, with an angle in front of the nostrils. Eye moderate, 
rather shorter than the long muzzle, placed nearly midway in head, about $3 \frac{1}{3}$ in head.

Mouth rather large, inferior, the lips much thickened, Sucker-like; upper jaw extremely protractile; the lower with a conspicuous interuai fringe of papillæ.

Barbels extremely long, probably longer than in any other of our Cyprinoids; their length $\frac{2}{3}$ to $\frac{3}{4}$ the diameter of the eye.

Scales moderate, pretty closely imbricated, $5-40-3 ; 15$ or 16 in frout of dorsal. Lateral line continuous, slightly deflected forward.

Fins rather small, high, and short. Dorsal 1, 8, originating slightly behiud the base of the ventrals, as in C.labrosus and C.monachus. Anal 1, 7. Caudal deeply forked, its pednncle long and slender.

Coloration, in spirits, quite pale; a small, round, black spot at base of caudal : dorsal scales dark-edged : some dark points along caudal peduncle, forming a dark stieak : muzzle punctate. Large specimens with a large dark patch on the last rays of dorsal, as in C. monachus and the species of Codoma : base of dorsal fin with dark points. Cheeks and opercles silvery.

In the spring, the male fishes are profusely tuberculate on the head and neck, and the fins are flushed with crimson. Teeth 1, 4-4, 1, hooked, without masticatory surface.

The largest specimens taken were nearly three inches long, but most were less than two.

This species is abundant in Saluda River. It appears to be distinet from $C$. labrosus, that species having larger scales and some other points of difference. C. lubrosus, monachus, and zanemus differ from their congeners in the backward position of the dorsal and in the greater development of the lips.

\section{Ceratichthis labrosus Cope.}

Ceratichthys labrosus CoPE (1870), Proc. Am. Philos. Soc. 458.

Professor Cope found this species not uncommon in the upper waters of the Catawba. We did not find it in the Saluda or the Ennoree.

\section{Cenatichthys hypsinotos Cope.}

Ceratichthys hypsinotus Cope (1870), Proc. Am. Philos. Soc. 458.

This species is not uncommon in the Saluda. Breeding males are violet-tinted, and the fins are quite red. The head is more or less rosy and tuberculate ahove. This species has a very small barbel, and might easily be taken for a Hydrophlox of the rubricroceus type. 
26. Ceratichthys biguttatus (Kirt.) Baird.

- The common Horned Chub is very abundant in all the tributaries of the Saludid.

\section{Genus SEMOTILUS Rafinesque.}

27. Semotilus Corporalis (Mit.) Putn.

This common species occurs in the tributaries of the Saluda.

\section{CATOSTOMIDA.}

\section{Genus MYXOSTOMA Rafinesque.}

(Moxostoma and Teretulus Raf.; Ptychostomus Ag.)

\section{Myxostoma cervinum Cope.}

Teretulus cervinus COPE (1868), Journ. Ac. Nat. Sc. Phila. 235.

Ptycliostomus cervinus Cope (1870), Proc. Am. Philos. Soc. 478.

This little Sucker is exceedingly abundant in the Saluda, Reedy, and Eunoree. It abounds in rapids and rocky shoals, and is popularly known as "Jump-rocks", from its habit of leaping from the water. It is not much valued, except by negroes, small boys, and naturalists. The black outer margin of the dorsal is a characteristic color-mark.

29. Myxostoja papillosum (Cope) Jor.

Ptychostomus papillosus Cope (1870), Proc. Am. Philos. Soc. 4i0.

A ferr specimens of this peculiar species were taken in Saluda Rirer. Professor Cope found it abundant in the Catawba and Yadkin Rivers.

30. Myxostoma velatum (Cope) Jordan.

Pt $t_{j}$ chostomus collapsius Cope (18:0), Proc. Am. Philos. Soc. 471.

Wo obtained no specimens of this widely diffused species in any of the Southern rivers. Professor Cope found it in the Neuse, Yadkin, and Catawba.

31. Mrxostuma coregonus (Cope) J. \& B.

Ptychostomus coregonus Cope (18j0), Proc. Am. Phil. Soc. 472.

The "Blue Mullet" was found very abundant in the Catarba and Yadkiu Rivers. We did not take it in the Saluda. 
32. Myxostoma album (Cope) J. \& B.

Ptychostomus albus Cope (1870), Proc. Am. Phil. Soc. 472.

The species-the "White Mullet"-was found by Professor Cope in the Catawba River only. We obtained no specimens from the Saluda, which is perhaps due to the fact that our collections were not made during the season of the migrations.

\section{Genus ERIMYZON Jordan.}

(Moxostoma Agassiz, but not of Raf.)

33. Ermyzon sucetta (Lac.) Jordan.

Cyprinus sucetta LACÉPÈDE.

C'yprinus oblongus MitchiLL.

This species is moderately abundant in the Saluda River. Professor Cope found neither this species, nor the next, in the Catawba.

\section{Genus MINYTREMA Jordan.}

34. Minytrema Melanops (Raf.) Jor.

Catostomus melanops RAFINesque, KirTland, etc.

Moxostoma victorice GIRARD.

Erimyzon melanops JoRDAN.

This widely diffused species is abundant in the mill-ponds, etc., of the Saluda River, and is known as the Striped Sucker. It is considerably ralued as a food-fish. Many specimens were taken at Bannister's Mills, on the Ennoree, the proprietor of the mill, Mr. Bannister, having kindly drawn off the water from his pond, in order to enable us better to examine its fishes. Our specimens seem to be precisely like the ordinary melanops from the Ohio River and the Great Lakes.

\section{Genus CATOSTOMUS Le Sueur.}

35. Catostomus commersoni (Lac.) Jor.

The Fine-scaled Sucker is common in the Saluda, as in nearly erery stream east of the Rocky Mountains. It is especially abundant in millpouds. 


\section{SILURIDA.}

\section{Genus AMIURUS Rafinesque.}

\section{AMIURUS BRUNNEUS Jordan.}

Amiurus platycephalus Cope (1670), Proc. Am. Philos. Soc. 485. (Not Pimelodus platy. cephalus Grd.)

Amiurus brunneus JoRdan (1870), Ann. Lyc. Nat. Hist. 366.

This is the common cat-fish of the Saluda, and is known as the Mud Cat. Adult specimens reach a length of abont 18 inches, and bear little resemblance to the young, from which the species was first described. The adults are extremely elongate, nearly terete behind, , with flat, thin, broad heads. In color, they are of a more or less clear jellowish.green, more distinctly green than is auy other species. The name "brunneus" only applies well to the young. The species may be kuown from the related $A$. platycephalus by the more elongate form, the shorter anal fin (16 to 18 rays instead of 20 ), and by the mouth, which is somerbat inferior, the lower jaw being much the shorter, while in A. platycephalus the jaws are equal. The color is also different in the two species. $A$. platycephalus is yellowish, dark above, and more or less marbled on the sides with darker, resembling, in that respect, $A$. marmoratus. In $A$. brunneus, the caudal fin is usually unequal, the upper lobe being the longer, and the rudimentary caudal rays are unusually numerous. A specimen nearly a foot long had the alimentary canal four times the length of the body, and filled with Podostemon ceraiophyllum. The stomach contained eight adult males of Codoma pyrrhomelas.

As Professor Cope counted 17 anal rays in his "platycephalus", it is likely that he had this species instead of Girard's, which bas pretty uniformly 20 or 21 rays. Both Amiurus brunneus and platycephalus are valued as food.

\section{Amivrus platycephalus (Girard) Gill.}

Pimelodus platycephalus Grrard (1859), Proc. Ac. Nat. Sci. Phila. 160.

Many specimeus of this species were taken in Bannister's mill-pond, on the Ennoree. The fishermen confound it with the preceding under the name of Mud Cat, but the species may be readily distinguished by the characters given above.

A "Blue Cat" is said to occur in the Saluda, but we obtained no specimens. 


\section{Genus NOTURUS Rafinesque.}

38. Noturus insignis (Richardson) Gill \& Jor.

Noturus marginatus BAIRD.

This species is abundant in the rock-pools of Reedy River. It probably occurs in all the Atlantic streams as far north as Pennsylvania.

\section{ANGUILLID A.}

\section{Genus ANGUILLA Thunberg.}

39. ANguilla vulgaris Fleming.

The common Eel is abuudant in all the streams of the Southern States thus far explored.

\section{LEPIDOSTEIDAE.}

\section{Genus LEPIDOSTEUS Lacépède.}

40. Lepidosteus osseus (L.) Ag.

This fish is said to occur in the Saluda, but we obtained no specimens.

\section{II.-WATER-BASIN OF TIE SAVANNAH RIVER.}

Fifteen species are ascertained to occur in the water-basin of the Savannah. Of these, two species are recorded from specimens in the United States National Museum; one on the authority of Professor Agassiz, the others from our collections in the Tugaloo River and in Toccoa Creek. None of these species are peculiar to the Savannah Basin. The common Cyprinidce are all of Tennessee Rirer types; the others are either species of general distribution, or else are shared with other Southern streams.

In seining the Tugaloo River, two rather unexpected features were made manifest : first, the rery smail number of small fishes, both Cyprinidce and Etheostomatida inlabiting the river. There seem to be very fer species present, and these few are represented by rery few individuals. Although the islands below the mouth of Panther Creek firnish a most excellent seining-ground, yet our fishing was a series of "waterbauls". A single draw of the seine in the Saluda or the Etowah would often yield more species and more individuals than were secured in the Tugaloo in a whole day. 
The second peculiarity of the Tugaloo fauna is that its characteristic fishes are all of types abundant in the Tennessee River, but not known from any other of the Atlantic streams. Of these may be mentioned Photogenis galacturus, Luxilus coccogenis, Hydrophlox rubricroceus, and Catostomus nigricans. The close proximity of the sources of the Tugaloo and the Little Tennessee, War Woman Creek and Little Tennessee River rising on opposite sides of Rabun Gap, and of the Tallulah and the Hiawassee, may perhaps belp to explain this anomaly of distribution.

\title{
ETHEOSTOMATIDAE.
}

\section{Genus HADROPTERUS Agassiz.}

1. Hadropterus Nigrofasciatus $A g$.

A single large specimen was taken in Toccoa Creek, near Toccoa Falls.

\section{OENTRARCHIDA.}

\section{Genus MICROPTERUS Lacépède.}

\section{Micropterus salmoides (Lac.) Gill.}

\author{
(Var. salmoides.)
}

The small-mouthed Black Bass or "Trout" of the Southern streams (i. e., Savannah, Altamaha, Chattahoochee, Alabama) differs so constantly from Northern representatives of the same species that the tro forms may be taken as geographical varieties of one species, and it is probably worth while to distinguish each by name. The Labrus salmoi. des of Lacépède was collected by Bose near Charleston, S. C. It was therefore presumably the Southern variety, which should be designated as var. salmoides. The oldest name known to apply to the Northern form is that of Bodianus achigan Raf. The Northern form may therefore be designated as Micropterus salmoides var. achigan, whenever it is deemed desirable to call attention to these rariations.

The body is appreciably longer and slenderer in var. salmoides than in var. achigan, the head being about $3 \frac{1}{4}$ in length instead of about $2 \frac{3}{4}$. The anal rays in salmoides are usually 10 instead of 11 ; the dorsal formula $\mathrm{X}, \mathrm{I}, 12$, insteal of $\mathrm{X}, \mathrm{I}, 13$. The scales are larger in salmoides, there being about 70 in the lateral line instead of 77 . The coloration of salmoides is uniformly unlike that of achigan. The lower part of the sides 
is marked by pretty regular lines of dark olive-green spots along the series of scales. The lower fins are usually more or less red, and the black, sellow, and white coloration of the caudal fin, so conspicuous in young specimens of the Northern form-in the Western States, at leastis not noticeable in the Southern variety.

This species is abundant in the tributaries of the Sarannah, where it is known as the "Trout".

\section{Genus XENOTIS Jordan.}

\section{Xenotis SANGUINolentes (Agassiz) Jordan.}

Jordax (1877), Aun. Ljc. Nat. Hist. 318.

A single specimen of this beautiful fish is in the National Museum from Augusta, Ga. It is identical with my specimens from the Etowah, mentioned in the paper above cited, but it is possibly not the species to which Agassiz gare the name of sanguinolentus. The species of the genus Xenotis are extremely difficult either to define or to recognize.

\section{CYPRINODONTID AE. \\ Genus ZYGONECTES Agassiz.}

4. ZYGONECTES NOTTII Agassiz.

A "Zygonectes guttatus" is recorded by Professor Agassiz from the Saranuah near Augusta, Professor Putnam informs me, from the examination of the type-specimens, that the species is identical with $Z$. nottii Ag.

\section{SALMONID 瓜.}

\section{Genus SALVELINUS Richardson.}

5. Salvelinus fontinalis (Mitch.) Gill \& Jor.

The common Brook Trout is very abundant in the clear tributaries of the Chatuga and Toxaway Rivers, at the foot of the Blue Ridge. This is very near the soutbern limit of the species, although it is said to occur in certain tributaries of the Upper Cbattahoochee, farther west.

\section{CYPRINIDEE.}

\section{Genus LUXILUS Rafinesque.}

6. Luxilun Coccogenis (Cope) Jordan.

This beantiful species is common in the Tugaloo. The numerous specimens were all pale, and showed ouly traces of the distiuctive red markings. 


\section{Genus PHOTOGENIS Cope.}

7. Photogenis galacturus (Cope) J. \& B.

Hypsilepis galacturus Cope (1870), Proc. Ac. Nat. Sc. 160

The most abundant fish in the Tugaloo. Our specimens were very pale and dull colored, but they are not otherwise different from specimens of P. galacturus from the Tennessee and Cumberland Rivers.

\section{Genus HYDROPHLOX Jordan.}

\section{Hydrophlox rubricroceus (Cope) J. \& B.}

Hybopsis rubricroceus CoPe (1863), Journ. Ac. Nat. Sc. 231.

This surpassingly beautiful little fish abounds in the rock-pools of the smaller tributaries of the Tugaloo. In Tocena Creek, it is very abundant, far outnumbering all other species. We obtained many specimens from the pool at the foot of Toccoa Falls.

The life-colors are as follows: Dark steel-blue; a dark lateral band of coaly punctulations, which is usually distinct on the anterior half of body, and passes through the eye around the snont. All the fins of a rich clear red; the dorsal rather crimson, the caudal pink, the lower fins full bright scarlet. Head all pale scarlet-red, the lower jaw flushed, as if bloody, a lustrous streak along the sides, below which is a distinct silvery lustre. Eyes silvery, somewhat flushed with red. In high coloration, the entire body becomes more or less red. This red pigment becomes more evident when a fish is first placed in alcohol. First ray of dorsal dusky on anterior edge.

Top of head and whole ante-dorsal region in males dusted with tine white tubercles.

Female specimens are pale olivaceous or silvery.

Testh 2, 4-4, 2, with masticatory surface, the edge of which is usually crenate.

This species and the preceding were hitherto known only from the headiraters of the Tennessee River.

\section{Genus CERATICHTHYS Baird.}

\section{Ceratichthys rubrifrons Jordan.}

Nocomis rubrifrons Jordai (18\%7), Ann. N. Y. Lyceum Nat. Hist. 330.

A few specimens of this species were taken. They were brighter in color than the original types from the Ocmulgee. The muzzle was in the wales br:ght red, aud the fins somewhat rosy. 
This species is related to C. hypsinotus (Cope), but has a less elevated dorsal region and longer barbels.

10. Ceratichthys biguttatus (Kirtland) Girard.

The "Horny Head" is abundant in all the small streams falling into the Tugaloo. It furnishes much harmless sport for the amateur angleri who yearly visit the beautiful Tallulah region.

\section{CATOSTOMIDE.}

Genus MYXOSTOMA Rafinesque.

11. Myxostoma Cervindu (Cope) Jor.

The little "Jump Rocks" occurs in some abundance in the Tugaloo and its tributaries.

\section{Genus CATOSTOMUS Le Sueur.}

$$
\text { (Hylomyzon Agassiz.) }
$$

12. Catostomus nigricans Le S.

The Hog-sucker occurs in rapid waters of the Tugaloo and Toccoa. It is not known to occur in any other of the Atlantic streams south of the Potomac.

\section{SILURIDA.}

\section{Genus AMIURUS Rafinesque.}

13. Amiurus platycephalus (Girard) Gill.

The original types of this species in the Smithsonian Institution were from a tributary of the Sarannah at Auderson, S. C.

\section{Genus ICHTH ÆLURUS Rafinesque.}

14. ICHTHALURUS PUNCTATUS (Raf.) Jor.

The common "Channel Cat" is found in some abundance in the Trgaloo River.

\section{ANGUILLIDAE.}

\section{Genus ANGUILLA Thunberg.}

\section{Anguilla vulgaris Fleming.}

The common Eel is an inhabitant of the waters of the Tugaloo:

Bull. N. M. No. $12-3$ 
III.-WATER-BASIN OF THE ALTAMAHA RIVER.

Twenty-three species are known to occur in the water-basin of the Altamaha, exclusive of the Shad (Alvsa sapidissima), which ascends all the Southern rivers until prevented by the dams Of these twenty-three, four are known only from the Oconee and Ocmulgee, viz, Nothonotus inscriptus, Hydrophlox lutipinnis, Codoma callisema, and Codoma xcenura. The others are chiefly species of general distribution. Five species were obtained by the writers in the headwaters of the Oconee River, viz, Nothonotus inscriptus, Micropterus salmoides, Hydrophlox lutipinnis, Ceratichthys rubrifrons, and Ceratichthys biguttatus. The other species mentioned below are from the Ocmulgee.

\section{ETHEOSTOMATID広.}

Genus HADROPTERUS Agassiz.

1. Hadroptereus Nigrofasciatus Agassiz.

Taken at the Flat Shoals in the South Fork of the Ocmulgee.

\section{Genus BOLEOSOMA DeKay.}

\section{Boleosoma maculaticeps Cope.}

A specimen, apparently of this species, from the Ocmulgee River at Macon, Ga.

\section{Genus NOTHONOTUS Agassiz.}

3. NothHONOTUS INSCRIPTUS, $s p$. nov.

Body rather stout and deep, pretty strongly compressed behind, less so anteriorly : depth $4 \frac{3}{4}$ in length : caudal peduncle rather deep.

Head large, $4 \frac{3}{4}$ in length, rather obtuse, the profile quite gibbous: a consirlerable angle formed opposite the eyes, which are high up and rather close together.

Eye about equal to snout, $3 \frac{1}{2}$ in head. Mouth moderate, slightly oblique, the maxillary reaching eye, the upper jaw the longer. Uheeks and opercles entirely scaleless, as in $N$. thalassinus. Region in front of dorsal scaly: breast naked. Belly covered with ordinary scales. Scales rather large, closely imbricated, the lateral line continuous and nearly straight. Scales 5-46-5.

Fins well developed. The spinous dorsal larger than the soft dorsal, 
which is somewhat larger than the anal; the two dorsal fins connected by membrane. Dorsal XI-I, 11. Anal II, 8.

Dorsal spines a little more than half the length of head. Pectorals and ventrals well developed.

Color, in spirits : Olire, with an orange spot on on each scale, these forming continuous lines along the rows of scales. These lines are quite conspicuous, as in Xenisma catenatum. Three dark blotches across the back : one in front of dorsal, forming a black spot on the anterior dorsal spines; one between the two dorsal fins, forming a similar black spot on the last part of the spinous dorsal; and one on the caudal peduncle, behind the second dorsal.

Sides with about six irregular dark olive blotches just below the lateral line. Second dorsal, caudal, and pectoral extensively duskyshaded. Anal unicolor. Head dusky above, a dark line downward, and one forward from eye.

A female specimen taken lacked the lines of orange spots, and it was more distinctly blotched on the sides. In life, the male specimen had the entire anal fin, the cbeeks, opercles, and a bar below the eye bright blue. The extreme edge of the spinous dorsal was blackish; below this bright orange red, and a dusky bar at the base. The colored lines of spots were ferruginous, or scarlet-red, rather than orange.

Length $2 \frac{1}{2}$ inches.

Two specimens only were taken, in the upper waters of the Oconee River, at Sulphur Springs, in Hail County, Georgia.

This is one of the most beautiful of this interesting genus. In the smooth head, it resembles $N$. thalassinus, and differs from the others known. The entirely dissimilar coloration separates it at once from $N$. thalassinus.

\section{CENTRARCHIDAE.}

\section{Genus MICROPTERUS Lacépède.}

\section{Mrcropterus salmoides (Lac.) Gill.}

Var. salmoides.

Abundant in the Oconee and Ocmulgee.

\section{Genus CHANOBRYTTUS Gill.}

5. Chanobryttus viridis $(C . \& V$.) Jordan.

The "War-mouth Perch" is abundant in the Ocmulgee. 


\section{Genus LEPIOPOMUS Rafinesque.}

6. Lepiopomus $\Lambda$ URitus (L.) Raf.

Common in the Ocmulgee Rirer.

\section{Genus CENTRARCHUS Cuvier \& Valenciennes.}

7. Centrarchus macropterus (Lacépède) Jordan.

Several specimens of the large-finned Centrarchus are in the United States National Museum, from the Ocmulgee River, near Macon, Ga. The characters distinguishing this species from $C$. irideus are given in Bulletin No. 10 of the National Museum, p. 31.

\section{ESOCIDA.}

\section{Genus ESOX Linnaus.}

8. Esox reticulatus Le Sueur.

Found in the Ocmulgee River.

\section{CYPRINIDAE.}

\section{Genus ALBURNOPS Girard.}

(Subgenus HUDSONIUS Grd.)

9. Alburnops amarus (Grd.) Jordan.

Fybopsis hudsonius var. amarus Jordax (1877), Ann. Lyc. Nat. Hist. N. Y. 362.

Very abundant in the South Fork of the Ocmulgee. This is possibly not Girard's amarus, but at present I think that it is. Leuciscus spirlingulus $\mathrm{C}$. \& V. seems to be $A$. hudsonius.

\section{Genus HYDROPHLOX Jordan.}

10. HYDROPHLOX LUTIPINNIS, sp. nov.

A brilliantly colored little fish allied to $H$. rubricroceus.

Body stout and rather strongly compressed, the depth $4 \frac{1}{4}$ in length, the dorsal region somewhat elevated, the outline of the back sloping each way from the base of the dorsal fin.

Head short and rather deep, 4 to $4 \frac{1}{4}$ in length, broad and flattish 
above, the muzzle moderately rounded. Eye rather large, nearly as long as the muzzle, $3 \frac{1}{2}$ to $3 \frac{3}{4}$ in head.

Mouth large, quite oblique, the maxillary reaching to orbit, the mandible included.

Scales medium, 6-40-3, rather closely imbricated, about 21 in front of the dorsal. Dorsal nearer caudal than muzzle, distinctly behind the ventrals. Dorsal $\mathrm{k}$ 8. Anal I, 8. Pectorals not reaching nearly to rentrals, the latier not to vent.

Color, in spirits: Clear olire; a dark, burnished, plumbeous lateral band, which extends through the eye aud up the caudal fin: whole borly bright crimson : fins yellow.

Colors, in life: Clear olive above, with very intense green dorsal and vertebral lines; an intense metallic blackish band along sides; below this the sides bright silvery, in the males bright, clear red, the color of red berries; the whole body more or less flushed with red, the belly especially bright : iris crimson.

Fins all bright gollen-yellow: silvery space below eye strongly marked : tip of lower jaw black.

Teeth $2,4-4,2$, with masticatory surface developed.

Length $2 \frac{1}{2}$ to 3 iuches.

This species is extremely abundant in the headwaters of the Oconee, in clear rapid streams. It is one of the most brilliant of the genus.

Hydrophlox lutipinnis is deeper-bodied than $H$. rubricroceus. It has also a smaller mouth and different coloration, especially of the fins. From A. chlorocephalus, it differs in the larger mouth, larger size, and smaller seales: the pectoral and rentral fins are also usually shorter. The teeth, also, are 2,4 , insteal of 1,4 .

\section{- Genus CODOMA Girard.}

\section{CODOMA XENURA Jordan.}

Minnilus (Photogenis) xanurus Jordan (1877), Proc. Ac. Nat. Sc. Phila. 79.

This beautiful fish is the inost abundant species in the rapids of the Ocmulgee at Flat Shoals.

\section{CODOMA CALLISEMI Jordan.}

Episema callisema JuRdan (1877), Ann. Ljc. Nat. Hist. 363.

This species, one of the most elegant of the genus, is very abundant in the Sonth Fork of the Ocmulgee. It differs from the other species of 
the genus in the presence of a single row of teeth and in the more anterior position of the dorsal, which is scarcely at all posterior to the rentrals. It is, however, rather a Codoma than an Episema.

\section{Genus NOTEMIGONUS Rafinesque.}

13. NotemigonUs AMERICANUS (L.) Jor. Notemigonus ischanus JoRDAN (1877), Ann. Lyc. Nat. Hist. 364.

Very abundant everywhere in the Ocmulgee in still or deep waters. Adult specimens have the lower fins yellow, tipped with scarlet.

\section{Genus CERATICHTHYS Baird.}

\section{Ceratichthys rubrifrons Jordan.}

Nocomis rubrifrons Jordan (1877), Ann. Lyc. Nat. Hist. N. Y. 330.

This handsome little fish was first described from the Ocmulgee River, where it is abundant. It is also common in the Oconee.

15. Ceratichthys biguttatus (Kirt.) Girard.

Abundant in the Oconee; not noticed in the Ocmulgee.

\section{Genus SEMOTILUS Rafinesque.}

16. Senotilus corporalis (Mit.) Puinam.

From a small brook, tributary to the Ocmulgee. In the South, this species is almost confined to the smaller creeks and spring runs.

\section{CATOSTOMIDA.}

\section{Genus MYXOSTOMA Rafinesque.}

17. Myxostoma Cervinum (Cope) Jordan.

The little "Jump Rocks" is very abundant at the Flat Shoals of the Ocmulgee.

18. Myxostoma papillosum (Cope) Jordan.

Common in the Ocmulgee.

Genus ERIMYZON Jordan.

19. ERIMYZon SUCETTA (Lac.) Jordan.

From the Ocmulgee. 


\section{SHLURIDAE.}

\section{Genus ICHTH ELURUS Rafinesque.}

20. Ichti alunus punctatus (Rafinesque) Jordan.

Very common in the Ocmulgee.

\section{Genus AMIURUS Rafinesque.}

21. Amiorus marmoratus (Holbrook) Jordan.

A single specimen is in the National Museum, collected by Dr. Holbrook in the Altamaha River. The species oceurs in abundance in the streams and sloughs of Sonthern Iliinois.

\section{AMIURUS BRUNNEUS Jordan.}

Very abundant in the Ocnulgee, from which river it was first described.

\section{ANGUILLIDA.}

\section{Genus ANGUILLA Thunberg.}

23. ANGuilla vulgaris F'leming.

Eels occur in all the larger tributaries of the Oconee and Ocmulgee.

IV. - WATER-BASIN OF THE CHAT'TAHOOCHEE RIVER.

Our collections in the Chattahoochee Basin have been rather unsatisfactory, as only twenty-one species bare been obtained. Of these, three seen to be characteristic of the river, and have not set been obtained elsewhere: Semotilus thoreauianus, Photogenis leucopus, and Codoma eury. stoma. The other species taken are found also either,in the Altamaha or Alabama, or both.

The Chattaboochee is noteworthy as being, so far as is at present known, the easternmost limit in the Southern States of the Rock Bass (Ambloplites rupestris) and the Red Horse (Myxostoma duquesnii), as the westernmost limit of the range of the "Green Cat" (Amiurus brunneus), the War-mouth Perch (Chonobryttus viridis), and the "Jump Rocks" (Myxostoma cervinum). It is also the westerumost of the series of rivers-Great Pedee, Santee, Savannah, Altamaha, and Chattahoocheein which Lnxilus cornutus does not occur. 
Four of the species here mentioned were collected several years ago by Dr. Hugh M. Neisler at some point in Georgia, the record of the locality not eertainly preserved, but supposed to be Flint River, and are now in the Musenm of the Smithsonian Institution. These are Campostoma anomalum, Semotiius thoreauianus, Codoma formosa ("grandipinnis"), and Aphododerus sayanus ("Asternotremia mésotrema").

\section{ETHEOSTOMATIDA.}

Genus HADROPTERUS Agassiz.

1. HADROPTERUS NIGROFASCTATUS Agassiz.

Abundant at the Shallow Ford of the Chattahoochee near Gainesville, Ga.

\section{CENTRARCHIDAE. .}

Genus MICROPTERUS Lacépède.

2. Micropterus pallidus (Raf.) G. \& J.

Not very abundant.

3. Mrcropterus salmomes (Lac.) Gill.

Very common.

Genus AMBLOPLITES Rafinesque.

4. Ambloplites rupestris (Raf.) Gill.

Abundant.

Genus LEPIOPOMUS Rafinesque.

5. Lepiopomus pallidus (Mit.) G. \& J.

(Ichthelis incisor Holbrook.)

A few specimens taken in Peach Tree Creek near Atlanta.

6. Lepiopomus auritus (L.) Raf.

Abundant at the Shallow Ford of the Chattahoochee. My specimens are more elongate than those from the Saluda, and they differ somewhat in coloration and squamation. The dark blotches at the base of the dorsal are wanting. I am not, however, disposed to consider them as specifically distinct. 


\section{APHODODERIDA.}

\section{Genus APHODODERUS Le Sueur.}

\section{7. aphododerus sayants' (Gill) DeK.}

The specimen described in Bulletin No. 10, U. S. Nat. Mus., as Asternotremia mesotrema Jor., doubtless belongs to this species. The "genus" Asternotremia is probably an immature stage of Aphododerus.

\section{CYPRINIDE.}

\section{Genus PHOTOGENIS Cope.}

\section{S. Photogenis leucupus, sp. nov.}

A slender, rather plain species, closely resembling Photogenis niveus from the Saluda.

Body elongate, compressed, tapering toward the snont and the long caudal peduucle. Depth $4 \frac{1}{3}$ in length. Head moderate, $4 \frac{1}{2}$ in length, larger than in $P$. niveus, rather pointed, wide on top. Snout rather long and somewhat pointed. Mouth large, quite oblique, the intermaxillaries on the level of the pupil: upper jaw slightly longest. Eye moderate, ratber less than snout, $3 \frac{1}{2}$ in head. Scales moderate, rather closely imbricated, but less so than in P. analostanus, 6-39-3.

Fins moderate, D. I, 8, A. I, 8, the dorsal evidently behind the rentrals. Pectorals not reaching nearly to ventrals, the latter not quite to vent. Neither dorsal nor anal specially elevated.

Teeth 1, 4-4, 1, hooked, with narrow griuding surfaces and nsually somewhat crenate.

Color olivaceous, the sides bright silvery: a rather inconspicnous dark blotch on last rays of dorsal, as in related species. A round black - spot, nearly as large as eye, at base of caudal, precisely as in Corloma eurystoma. In life, the coloration is pale; the dorsal fin is chiefly of a clear jellowish-green color, as thongh yellowish pigment were mixed with white; the upper part is of a pale ferrugineous-red and the extreme tip milky-white. The caudal fin is ferrugiveous, with milk-white tips. The lower fins, especially the rentrals, are milk-white. The suont in males is tuberculate, and very minute prickles occur on the sides of the candal peduncle. Length $3 \frac{1}{2}$ to 4 inches.

Very abundant in the Chattahoochee River at the Shallow Ford; not noticed elsewhere. 
Compared with $P$. niveus, $P$. leucopus has a different form, the dorsal region is less elevated, and the nuchal region less depressed. The mouth is larger, the maxillary extending to nearly opposite the eye, instead of falling short. The eye is larger and the wouth is less inferior in P. leucopus. The coloration is somewhat different.

Photogenis leucops also resembles Codoma eurystoma, but that species has a heavier head, larger eye, stouter body, and different dentition and coloration.

\section{Genus CODOMA Girard.}

\section{Codoma EURystoma Jordan.}

Photogenis eurystomus Jordan (1877), Ann. Lyc. Nat. Hist. 356.

This is the most abundant Cyprinoid in the tributaries of the Chattahoochee River. It frequents especially the cold streams, but does not seem to be adverse to mud. In Suwannee Creek, a deep, cold, muddy stream flowing through the woods, this was almost the only species obtained.

Its life-colors are as follows: General color of Luxilus cornutus on body, but the sides with considerable coppery lustre. Dorsal fin with a sharp, black, horizontal bar about half-way up. In young fishes, this bar is red. The fin above is somewhat milky; below, it is pale. There is a small, but distinet, round, black, caudal spot. The caudal fin is chiefly of a rather dull ferruginous red. The base of the fin is pale, the tips rather milky. The anal fin is unmarked. 'There are gilt liues along the back and sides. A dark humeral bar is usually present, and the upper edge of the pectoral tin is largely black.

The teeth of this species are usually $1,4-4,1$, as at first described, but we have found sereral individuals $1,4-4,2$. This species resembles somewhat Phologenis leucopus, but it is stouter every way, with deeper body, larger head, and much larger eye.

\section{Codoma Formosa (Putnam) Jordan.}

(Alburnus formosus Putnam, Leuciscus hypselopterus Günther, Photogenis grandipinnis Jordan.)

The typical specimens of $P$. grandipinnis are supposer to have beer. collected in Flint River. Leuciscus hypselopterus of Günther is doubtless the same species. We follow Giinther in identifying Alburnus formosus Putuam as the same, aithough there is little in the vers imperfect original description to warrant it. 


\section{Genus CAMPOSTOMA Agassiz.}

11. Campostoma anomalum (Raf.) Ag.

Specimens in Dr. Neisler's collection, supposed to have been taken in the Flint River, in Taylor County, Georgia.

\section{Genus SEMOTILUS Rafinesque.}

12. Semotilus thoreauianus Jordan.

The types are in Dr. Neisler's collection, probably from Flint River.

\section{Genus CERATICHTHYS Baird.}

13. Ceratichthys biguttatus (Kirtland) Girard.

Very abundant in the Chattahoochee.

\section{UATOSTOMIDEE.}

Genus MYXOSTOMA Rafinesque.

14. Myxostoma duquesnil (Le Sueur) Jordan.

A species which we are unable to distinguish from the common "Red Horse" of the Ohio is abundant in the Chattahoochee.

15. Myxostoma cervinum Cope.

A few specimens taken in the Shallow Ford.

\section{Genus ERIMYZON Jordan.}

16. ERIMyzon sucetTa (Lac.) Jor.

From Peach Tree Creek near Atlanta.

\section{SILURID AE.}

Genus ICHTH ÆLURUS Rafinesque.

17. IсhтH жlurus punctatus (Raf.) Jor.

The Channel Cat is exceedingly abundant in the Chattahoochee. 


\section{Genus AMIURUS Rafinesque.}

18. Amiurus brunneus Jordan.

This is the most abundant edible fish in the Chattahoochee. We secured upwards of forty large specimens in two hours' seining at the Shallow Forl. It grows to the length of about 18 inches, aud is much valued as food. It is usually known as the Mud Cat.

\section{Genus NOTURUS Rafinesque.}

19. Noturus LePtacantuls Jordan.

Noturus leptacanthus Jordax (1877), Ann. Lyc. Nat. Hist. N. Y. 352.

This species was originally described from a single specimen takt:ll iu Silver Creek, a tributary of the Etowah. A second specimen. similar to the first, was taken by us at the Shallow Ford during the past sum. mer, and since then a third, at the same locality as the first. In color, this species is of a rich pale transparent brown, very slightly mottleil with darker.

\section{LEPIDOSTEIDE.}

Genus LEPIDOSTEUS Lacépède.

20. Lepidosteus osseus (L.) Ag.

Taken at the Shallow Ford.

\section{ANGUILLIDAE.}

\section{Genus ANGUILLA Thunberg.}

21. ANguilla vulgaris Fleming.

Eels, of course, abound in the Chattahoochee.

\section{V.-WATER.BASIN OF THE ALABAMA RIVER.}

The fish-fauna of the Alabama River is now better known than that of any other of the Southern streams. Fifty-five species are now known as inhabitants of that river and of its great tributaries, the Etowah, Oostanaula, and Coosa. A slight examination of any suitable tributary of the Alabama is sufficient to show that it is much richer in species than are any of the rivers lying to the eastriard of it.

Of these fifty-six species, thirteen are as yet only known from the 
Alabama Basin. These are: Xenisma stelliferum, Zygonectes guttatus, Zygonectes hieroglyphicus, Hydrophlox xcnocephalus, Hydrophlox chrosomus, Codoma callistia, Codoma trichroistia, Codoma corulea, Codoma stigmatura, Notropis stilbius, Phenacobius catostomus, Catostomus nigricans etovanus, and Myxostoma euryops. I exelude from this enumeration one or two species recorded from the Black Warrior River, as it is likely that the fauna of that stream will prove, in part at least, different.

Certain common Northern or Western types, apparently absent in the streams hitherto noticed, make their appearance in the waters of the Alabama. Among these are Luxilus cornutus, Notemigonus chrysoleucus, Chanobryttus gulosus, Hyodon, Phenacobius, etc.

\section{ETHEOSTOMATIDA.}

\section{Genus PERCINA Haldeman.}

1. Percina caprodes (Raf.) Grd.

Abundant: precisely like Northern specimens.

Genus HADROPTERUS Agassiz.

2. Hadropterus nigrofasciatus Agassiz.

Abundant: first described from near Mobile.

\section{Genus ULOCENTRA Jordan.}

3. UlOCENTRA STIGMAEA Jordan.

Boleosoma stigmaa JoRdan (1877), Ann. Lye. Nat. Hist. N. Y. 311.

Common in clear water. This species also occurs in the streams of Louisiana.

\section{Genus BOLEICHTHYS Girard.}

4. Boleichthys elegans Girard.

Abundant in clear, weedy ponds. This may not be identical with Girard's species, which was originally described from Texas.

\section{PERCIDAE.}

\section{Genus STIZOSTETHIUM Rafinesque.}

\section{Stizostethium salmoneum Rafinesque.}

In the river-ehannels of the Oostanaula. We have had no opportunity to examine specimens, and we are not sure that the Alabama fish is the original salmoneum. 


\section{CENTRARCHIDAE.}

Genus MICROPTERUS Lacépède.

6. Micropterus palitidus (Raf.) G. $\& J$.

Abundant.

7. Micropterus salmoides (Lac.) Gill.

(Var. salmoides.)

Abundant, but less so than the preceding. The two species are known indiscriminately as "Trout".

Genus CHÆNOBRYTTUS Gill.

8. Chenobrytuus gulosus $(C . \&$ V.) Gill.

From the Alabama River at Montgomery.

Genus AMBLOPLITES Rafinesque.

9. Ambloplites rupestris (Raf.) Gill.

From the Etowah and Oostanaula; rather common.

Genus LEPIOPOMUS Rafinesque.

10. Lepioponus pallidus (Mit.) G. $d$ J $J$.

Abundant in the Etowah and Oostanaula.

11. Lepioponus obscurus (Agassiz) Jor.

Not rare in the Etowah and Oostanaula.

\section{Genus XENOTIS Jordan.}

12. XeNotis INscriptus (Agassiz) Jor.

From the Oostanaula.

13. Xenotis sanguinolentus (Agassiz) Jor.

Very abundant in the Etowah and Oostanaula.

\section{Genus EUPOMOTIS Gill \& Jordan.}

14. Eupomotis PALLIDUs (Agassiz) G. \& J .

Specimens from the Alabama River near Montgomery. This species and the three preceding were first described from the Tennessee River in Alabama. 


\section{Genus CENTRARCHUS Cuvier \& Valenciennes.}

15. Centrarchus irideus (Lac.) $C . \& \nabla$.

Specimens from Alabama River, at Montgomery, similar to others from the Neuse and from about Charleston. This species has been found by Prof. S. A. Forbes in Southern Illinois.

\section{Genus POMOXYS Rafinesque.}

16. Pomoxys nigromaculatus (Le S.) Girard.

Specimens from the Alabama Rirer at Montgomery.

17. Pomoxys anNularis Raf.

From Round Lake near Montgomery.

\section{SCIANID E.}

Genus HAPLOIDONOTUS Rafinesque.

18. Haploidonotus grunniens Rafinesque.

Abundant in the Oostanaula.

\section{COTTIDE.}

\section{Genus POTAMOCOTTUS Gill.}

19. Potamocottus meridionalis (Girard) Gill.

Potamocottus carolince GrLL (1861), Proc. Bost. Soc. Nat. Hist.

Potamocottus zopherus Jordan (18z7), Ann. Ljc. Nat. Hist. N. Y. 320.

Exceedingly abundant in all the clear and cold tributaries of the Etowah, Oostanaula, and Coosa. Mans specimens from the cold waters of the Cave Spring Creek. We are unable to satisfactorily distinguish the forms called zopherus, carolina, and meridionalis, and, believing them specifically identical, we unite them under the oldest name.

\section{APHODODERIDE.}

\section{Genus APHODODERUS Le Sueur.}

(Aphredoderus Le S.; Sternotremia Nelson.)

20. Aphododerus sayanus (Gilliams) DeKay.

Specimens from Alabama River near Montgomery. The fish described by Professor Jordan from Fliut River, under the name of Asternotremia mesotrema, is undoubtedly a variation of this species. 


\section{CYPRINODONTIDAE.}

\section{Genus XENISMA Jordan.}

21. Xenisma stelliferum Jordan.

Xenisma stellifera Jordan (1877), Aun. Lyc. Nat. Hist. N. Y. 322.

This most exquisitely colored fish is very abundant in all the clear tributaries of the Etowah, Oostanaula, and Coosa. It prefers cold waters, and ascends the "spring.runs" to their fountain-heads.

\section{Genus ZYGONECTES Agassiz.}

22. Zygonectes NotTII Agassiz.

Many specimens in the Museum of the Academy of Natural Sciences of Philadelphia, from near Mobile. This and the next belong to the group of short-bodied species called Micristius by Professor Gill.

23. Zygonectes guttatus Agassiz.

Recorded by Professor Agassiz from near Mobile.

24. ZyGoneCtes HIEROGLYPHICUS Agassiz.

Recorded by Professor Agassiz from near Mobile. We have never seen either this or the preceding, and doubt if any one will ever recog. nize them from the pulblished descriptions.

\section{ESOCID AE.}

Genus ESOX Linnaus.

25. Esox Reticulatus Le Sueur.

Abundant in tributaries of the Etowab.

26. Esox raveneli Holbrook.

A few specimens in the United States National Museum from the Alabama River.

\section{HYODONTID AE.}

Genus HYODON Le Sueur.

27. Hyodon SELenops Jordan \& Bean.

Hyodon selenops Jordan \& BEaN (1877), Bulletin U. S. Nat. Mus. x. 65.

A single specimen in the National Museum from the Alabama River at Montgomery. 


\section{DOROSOMATIDEE.}

Genus DOROSOMA Rafinesque.

28. Dorosoma cepedianum (Lac.) Gill.

(Var. heterurum Raf.)

Specimens in the United States National Museum from Round Lake at Montgomery, Ala.

\section{CYPRINIDAE.}

\section{Genus CAMPOSTOMA Agassiz.}

29. Саmpostoma anomalum (Raf.) Ag.

Var. prolixum (Storer).

Abundant in the Etowah and Oostanaula.

\section{Genus LUXILUS Rafinesque.}

30. Luxilus CoRnutus (Mit.) Jor.

Very abundant in all the tributaries of the Etowah, Oostanaula, and Coosa Rivers.

My specimens do not obviously differ from those from New. York and the Northwest.

\section{Genus HYDROPHLOX Jordan}

31. HydRophlox CHRosomus Jordan.

Hybopsis chrosomus JoRdAN (1877), Ann. Lye. Nat. Hist. N. Y. 333.

Very abundant in the clear tributaries of the Oostanaula, Coosa, and Etowah. In Cedar Creek, at Cave Spring, it is the commonest species occurring in the clear, cold waters, with Codoma callistia and Xenisma stelliferum. None of our Cyprinida excel Hydrophlox chrosomus in delicacy of coloration. It is of a clear hyaline-green above; clear silvery below : a scarlet band straight from upper edge of opercle to caudal: dorsal, anal, and caudal each with a scarlet bar. In this species, the mouth is rather less terminal than is usual in the group called Hydrophlox.

\section{HydRophlox x mNOCEPHALUS Jordan.}

Hybopsis xanocephalus JoRDAN (1877), Ann. Lje. Nat. Hist. 334.

With the preceding, but rather less common. This species bears some resemblance to the young of Codoma callistia.

Bull. N. M. No. $12-4$ 


\section{Genus CODOMA Girard.}

\section{Codoma stigmatura Jordan.}

Photogenis stigmaturus Jordan (1877), Ann. Lyc. Nat. Hist. N. Y.337.

This elegant species is very abundant in the tributaries of the Etowah, Oostanaula, and Coosa. In those streams which are neither rery clear and cold nor very muddy, it is usually the most abundant species.

\section{Codoma callistia Jordan.}

Photogenis callistius JoRdan (1877), Ann. Lyc. Nat. Hist. N. Y. 337.

A large, ornate species, more brilliantly colored than the preceding, but less graceful in form. Female specimens are dull dark olive, with the dorsal fin brick-red. 'This species occurs with the preceding, but is rather less abundant.

35. Codoma trichroistia Jordan \& Gilbert, sp. nov.

A small, slender species, graceful in form and elegant in coloration. It is most nearly related to $C$. callistia, but may be readily distinguished.

Body rather slender, considerably compressed, the depth $4 \frac{1}{4}$ in length. Head rather slender and pointed, $4 \frac{1}{8}$ in length. Eye of moderate size, $3 \frac{1}{3}$ in head. Mouth quite large, very oblique, the maxillary extending' to opposite the anterior margin of the eye, and the premaxillaries being on a level with the middle of the pupil, the mouth thus being similar to that of the species of Notropis. In $C$. callistia, the mouth is much more interior, nearly horizontal; the maxillaries do not extend to the eye, and the premaxillaries are entirely below the level of the orbit.

Scales rather closely imbricaterl, 6-42-3; lateral line considerably decurved, usually with an abrupt angulation between pectorals and ven. trals; 18 or 19 scales before dorsal fin (15 or 16 in $C$. callistia).

Fins moderately developed: clorsal well behind ventrals, rather nearer caudal than muzzle. Dorsal I, 7. Anal I, 9. Pectorals falling somewhat short of ventrals; the latter reaching beyond vent nearly to base of aual.

Color: Bright steel-blue above : siles bright silvery; in males, more or less milky. A large black spot at base of caudal, precisely as in $C$. callistia, not nearly so distinct as in C.stigmatura. Head silvery; above bluish. Dorsal fin with a broad, dusky, horizontal band at base; the membrane of the last rays abore jet.black, blacker than in the other species; the tip of the fin milk-white. The rest of the dorsal fin, espe- 
cially the anterior part, is of a bright pale vermillion-red. The caudal fin is chiefly rosy, the tips milk-white. The anal is milky, with a decided flush of rose-color. The ventrals are milky.

Female specimens are duller, but the black fin-markings and the candal spot are similar in all. In the female of $\boldsymbol{C}$. callistia, the dorsal markings are obliterated.

In the males, in spring, the head and anterior dorsal region are rather sparsely tuberculate. The caudal peduncle and the space below the lateral line as far forward as the ventrals are covered with similar tubercles.

Teeth 1, 4-4, 1, of the usual type, hooked and sharp-edged. Maximum length $2 \frac{3}{4}$ inches. C. callistia reaches a length of 4 inches.

Codoma trichroistia is veri abundant in the clear tributaries of the Etowah and Oostanaula. Specimens were taken by Messrs. Jordan and Gilbert in 1876, but the species was at first confonnded by us with $C$. callistia, which it much resembles in coloration. The entirely different mouth will distinguish the two species at once.

\section{Erogala carelea Jordan.}

Photogenis caruleus Jordax (1877), Ann. Lyc. Nat. Hist. N. Y. 338.

This most delicate and graceful fish has thus far been only found in the Oostanaula River and its tributary, Rocky Creek. It prefers clear waters.

\section{Codoma Formosa (Putnam) Jordan.}

The typical specimens of Alburnus formosus Putnam and of Leuciscus hypselopterus Günther were obtained from near Mobile. The species therefore belongs to the fauna of the Alabama Basin. Guinther's description applies well to "Photogenis grandipinnis Jor.", and Alburnus formosus is probably the same.

The following is an analysis of the characters of the species of the subgenus Erogala at present known:-

Section I. Anal fin elongate, its rays I, 10, or I, 11: teeth 1, 4-4,1.

a. Dorsal fin entirely posterior to ventrals, its rays, in males, longer than head, reaching nearly to the base of the candal : body sbort, much compressed: back elevated; depth 4 in length: head $4 \frac{1}{4}$ : mouth large, very oblique, the jaws equal : black dorsal blotch very distinct: a distinct black candal spot: coloration and tubercles unknown: size small; length $2 \frac{1}{2}$ inches........................................................

aa. Dorsal fin slightly posterior to ventrals, its longest rays, in males, shorter than the head, and not reaching nearly to base of candal: candal pedunclo tuberculate: fins with much red: size medium; length $3 \frac{1}{6}$ inches. 
b. Body deep, compressed; depth $3 \frac{1}{2}$ to $3 \frac{8}{4}$ in length : fins all greatly elevated; the height of the dorsal five-sixths the length of the head: muzzle, anterior part of dorsal fin, and a broad crescent in the middle of the caudal fin bright scarlet: posterior margin of caudal ilackish; no black spot at base of caudal.............................. PYRRHOMELAS, 2 .

bb. Body more elongate, less compressed, its depth 4 to $4 \frac{1}{6}$ in length : fins all rather low, the longest dorsal ray scarcely $\frac{2}{8}$ length of head: dorsal, anal, and caudal fius chiefly bright crimsou: no defiuite dark margin to caudal: a faint black candal spot ........................ X đNURA, 3 .

Section II. Anal fin short, its rays I, 8, or I, 9.

* Teeth one-rowed, 4-4. Dorsal fin scarcely at all posterior to ventrals, its first ray nearer snout than base of caudal: body elongate, compressed : month smallish, oblique, rather inferior : dorsal fin greatly elevated, the longest ray, in males, longer than the head: black dorsal blotch well marked: dorsal, anal, and caudal fins chiefly of a bright ferruginous-orange; a blue streak along sides: size small; length 28 inches... .CALLiSLMA, 4.

** Teeth two-rowed, 1, 4-4, 1 (often 1, 4-4, 2, in C. eurystoma).

c. Black markings of the dorsal fin not in the form of a borizontal bar across the fin.

d. Adult males without red markings on the fins.

e. No distinct black or dark blue spot at base of caudal: body short and deep, strongly compressed: fins not greatly elevated, the dorsal largely of a bright lustrous palo green : black dorsal markings distinct : a bluish streak along sides: males with the whole body tuberculate, except the space anterior to the ventrals and below the lateral line: head pointed: month oblique, the upper jaw projecting: size snall; length 3 in-

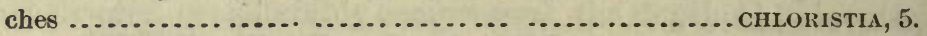

ee. A rather faint dark blue caudal spot, preceded by a very distinct lateral band of clear blue : sides chiefly blue and silvery: fins clear yellow, the black markings obscure: body slender : mouth small : fins not greatly elevated : size small; length $2 \frac{8}{4}$ inches ............... CдRULEA, 6 .

eee. A large, very conspicuous jet-black spot at base of caudal : body elongate, moderately compressed : color pale olivaceous or bluish: sides silvery : fin-markings rather obscure : fins rather low : mouth oblique, the lower jaw the shorter : scales large; size large: levgth 4 inches.. STIGaratura, 7.

$d d$. Adult males with the vertical fins chiefly red : a well-marked black caudal spot, less Gistinct than in C. stignatura.

f. Mouth large, quite oblique, the jaws about equal, the maxillary reaching to opposite the eye and the premaxillaries anturiorily on the level of the pupil : body slender, compressed : dorsal fin dusky at base, jet-black on last rays, the fin otherwise, as well as the anal and caudal pale vermillion : caudal peduncle tuberculate: dorsal markings usually distinct in both sexes : size small; length $2 \frac{8}{4}$ inches .......... Tricmroistia, 8.

$f f$. Mouth nearly horizontal, overlapped by the heary suout, the maxillary not reaching to the eye, and the puemaxillaries anteriorly below the level of the orbit: dorsal fin dusky at the base and on the last rays, the greater part of the fin, as well as of the caudal, bright carmine : coloration of body quite dark, blue in males, olive in females : dorsal markings obscure in the latter: body stout, not greatly compressed, the back somewhat elevated : size large; length 4 inches ................ callistia, 9. cc. Black markings of the dorsal fin in the form of a horizontal bar across the fin midway: body stout and deep, not greatly compressed: head heavy : mouth large, oblique, with equal jaws : eye very large; a small but distinct black caudal spot: fins with pa'e red : teeth sometimes 1, 4-4, 2 : size large; length 4 inches: appearauce of Luxilus...... EURYSTOMA, 10. 


\section{Genus NOTROPIS Rafinesque.}

\section{NOTROPIS LIRUS Jordan.}

Nototropis lirus JoRdan (1877), Ann. Lyc. Nat. Hist. N. Y. 342.

Common in tributaries of the Etowah, Oostanaula, and Coosa in still, deep waters. This species is not, by any means, a typical member of the genus. In form, coloration, squamation, and nuptial tubercles, it resembles the species of Lythrurus, from which it is technically separated by the want of masticatory surface on the teeth. Notropis matutinus approaches it in the small size of its scales.

39. Notropis stilbius Jordan.

Nototropis stilbius JoRDAN (1877), Ann. Lyc. Nat. Hist. N. Y. 343.

Abundant in the water-basin of the Alabama. The species of this genus greatly need revisiou.

\section{Genus NOTEMIGONUS Rafinesque.}

40. Notemgonus CHRYSOLEUCUs (Mit.) Jor.

(Stilbe americana of most writers; not Cyprinus americanus Linnæus, which is a Southeastern species-Notemigonus ischanus Jor.)

This familiar species is very abundant in bayous and weedy streams in the basin of the Alabama.

\section{Genus PHENACOBIUS Cope.}

\section{Phenacobius catostomus Jordan.}

Phenacobius catostomus Jordan (1877), Ann. Lyc. Nat. Hist. N. Y. 332.

This strongly marked species was found in abundance in two clear streams, Silver Creek and Cedar Creek, tributaries respectively to the Etowah and the Coosa. This is a much stouter species than $P$. uranops Cope; it has less developed lips and is in various other ways dissimilar.

\section{Genus CERATICHTHYS Baird.}

\section{Ceratiohthys winchelli (Girard) Jordan.}

Hybopsis winchelli GrRard (1856), Proc. Ac. Nat. Sc. Phila. 1856, 211.

Ceratichthys hyalinus Cope (1868), Journ. Ac. Nat. Sc. Phila. 1868, 236.

Very common in the Alabama Basin. C.biguttatus was not obtained by us in any of the tributaries of the Alabama. It seems, however, to have been described by Girard, from the Black Warrior, under the name of Nocomis bellicus. 


\section{Genus SEMOTILUS Rafinesque.}

43. Semotilus corporalis (Mit.) Putnam.

Commou in the smaller streams.

\section{Genus RHINICHTHYS Agassiz.}

44. Rhinichthrs obtusus Agassiz.

Very common in the spring.runs tributary to the Etowah and Oosta. naula.

\section{CATOSTOMIDAE. \\ Genus MYXOSTOMA Rafinesque.}

45. MYXostoma MacRolepidotum DUQUESNII (Le S.) Jordan.

The "Red Horse" is common in the Etowah and Oostanaula. Var. lachrymale (Cope) also occur;s.

46. Mrxostoma Euryops Jordan. Myxostoma euryops JoRdaN (18i7), Ann. Lyc. Nat. Hist. N. Y. 348.

From Lovejoy's Creek, a tributary of the Oostanaula. The type-specimen of this singular species still remains unique.

\section{Genus CATOSTOMUS Le Sueur.}

47. Catostomus nigricans etowanus Jordan. Catostomus nigricans var. etowanus Jordan (1877), Ann. Lyc. Nat. Hist. N. Y.

The Hog Mullet,-or Crawl-a-bottom, is very abundant in all rapid streams in the Alabama Basin. The characters separating var. etowanus from nigricans seem to be pretty constant. I do not, however, think them distinct species.

\section{Genus ERIMYZON Jordan.}

48. Erimyzon sucetta (Lac.) Jordan.

This species, known locally as the May Sucker, is abundant in the water-basin of the Alabama.

\section{Genus MINYTREMA Jordan.}

49. Minytrema Melanops Jordan.

The "Sand Sucker" is abuudant in the waters of the Alabama. 


\section{Genus CARPIODES Rafinesque.}

50. Carpiodes cyprinus (Le S.) Ag.

A single specimen from Round Lake near Montgomery, Ala., apparently identical with Pennsylvania examples.

Genus BUBALICHTHYS Agassiz.

51. Bubalichthys (taurus) Agassiz.

Recorded by Professor Agassiz from the Alabama. Other species of "Buffalo Fish" doubtless occur in the Alabama, but the species have never been studied.

\section{SILURIDA.}

Genus ICHTH ÆLURUS Rafinesque.

52. IсHтHALURUS PUNCTATUS (Raf.) Jor.

Abundant in the basin of the Alabama.

Genus AMIURUS Rafinesque.

53. Amiurus natalis antoniensis (Grd.) Jor.

Abuudant in muddy tributaries of the Etowah and Coosa.

\section{Genus NOTURUS Rafinesque.}

54. Noturus Leptadanthus Jordan.

Two specimens, taken in Silver Creek, and a third specimen, from the Chattahoocinee, are all that are at present known of this curious little species.

\section{ANGUILLID E.}

Genus ANGUILLA Thunberg.

55. ANGUILla vUlgaris Fleming.

Abundant.

\section{LEPIDOSTEIDAE.}

Genus LEPIDOSTEUS Lacépède.

56. Lepidosteus osseus (L.) Ag.

From the Oostanaula; probably common. 


\section{VI.-WATER-BASIN OF THE TENNESSEE RIVER.}

The fish-fauna of the Tennessee River has been pretty fully studied, especially as to its Cyprinida. Thirty-seven species were obtained by Professor Cope in the French Broad, thirty-four in the Holston, and twenty-five by Professor Jordan in tributaries of the Clinch and French Broad, making in all some sixty different species known to inbabit the upper waters of the Tennessee. In the lower course of the river, thirtyfour species are recorded by Professor Agassiz from the Tennessee River at Huntsville, Ala.; twenty species were obtained by the writers from the Chickamauga River at Ringgold, Ga., and seventeen species from Elk River at Estill Springs in Tennessee. About sixty-eight species are therefore known to occur in the lower course of the river. In all, eighty-two different species are known to inhabit the waters of the Tennessee. To this number many species of large fishes in babiting the Obio at the mouth of the Tennessee might, with certainty, be added; but it is not the province of this paper to record guesses. Forty-six species are therefore certainly common to the upper and lower courses of the Tenuessee River.

The species at present known in the Tennessee Basin, only from the upper course,--the Clinch, Holston, and French Broad Rivers,-are the following :-

Hadropterus aurantiacus.

Diplesium simoterum.

Nothonotus zoualis.

Nothonotus vulneratus.

Nothonotus rufilineatus.

Etheostoma flabellare.

Salvelinus fontinalis.

Alburnops spectrunculus.

Hydrophlox rubricroceus.
Hydrophlox lacertosus.
Episema leucioda.
Notropis micropteryx.
Notropis atherinoides.
Hemitremia vittata.
Placopharynx carinatus.
Noturus eleutherus.

In all, sixteen species.

From the lower course of the river only, the following are known :-

("Etheostoma") cinerea.

("Etheostoma") tessellata.

Pœcilichthys jessiæ.

Chænobryttus gulosús.

Lepiopomus obscurus.

(Lepiopomus) bombifrons.

Eupomotis pallidus.
Xenotis inscriptus.

Esox (crassus).

Hyodon selenops.

Pomolobus chrysochloris.

Dorosoma cepedianum heterurum.

Notropis lirus.

Phoxinus flammeus. 
Gila estor.

Quassilabia lacera.

Carpiodes bison.
Bubalichthys urus.

Amia calva.

Acipenser maculosus.

In all, twenty species.

Increased knowledge will considerably modify these lists. It is probable that the sixteen species in the first list, with the probable exceptions of Noturus eleutherus and Salvelinus fontinalis, will be found to inhabit the lower part of the river-basin, if sought for in suitable localities. It is likely that the tributaries of the Tennessee having their source in the Cumberland Mountains in Alabama have the same fishfauna as similar streams rising in the Cumberland Mountains in Virginia.

About twelve species are at present known only from the Tennessee River and its tributaries. These are :-

Hadropterus aurantiacus.

(Etheostoma) cinerea.

(Etheostoma) tessellata.

Nothonotus vulneratus.

Nothonotus rufilineatus.

Pœeilichthys jessiæ.

\begin{abstract}
(Lepiopomus) bombifrons. Alburnops spectrunculus. Hydrophlox lacertosus. Phoxinus flammeus. Episema lencioda. Ceratichthys monachus.
\end{abstract}

As we go from the Alabama to the Tennessee, we note an increased resemblance in the fish-fauna to that of the Ohio and Upper Mississippi region. The following are some of the Northern or Western types added :-

Diplesium, Etheostoma, Poeilichthys, Labidesthes, Zygonectes (proper), Episema, Hemitremia, Chrosomus, Phoxinus, Placopharynx, Quassilabia.

\section{COTTIDA.}

\section{Genus POTAMOCOTTUs Gill.}

1. Ротамосотtus meridionalis (Girard) Gill.

From Chickamauga River. Also a single specimen from the Cave Spring at Cumberland Gap. Abundant in the French Broad River (Cope) and in the Holston.

\section{ETHEOSTOMATIDA.}

\section{Genus PERCINA Haldeman.}

2. Percina caprodes (Raf.) Grd.

Generally abundant in clear streams. 


\section{Genus ALVORDIUS Girard.}

3. Alvordius maculatus Girard.

(? Alvordius maculatus Grd.; Hadropterus maculatus Grd.; Etheostoma blennioides Agassiz, etc.; Alvordius aspro Cope \& Jor.)

From the Clinch and French Broad Rivers. Also abundant in the Chickamauga at Ringgold.

Genus HADROPTERUS Agassiz.

4. Hadropterus aurantiacus (Cope) Jordan.

French Broad River (Cope).

Genus DIPLESIUM Rafinesque.

5. Diplesium blenjioides (Raf.) Jor.

Holston and French Broad Rivers. Also from Chickamauga River. Described by Professor Agassiz from Huntsville, Alabama, under the name of Hyostoma newmani.

\section{Diplesium simoterum (Cope) Copeland.}

From the Clinch and Holston Rivers.

\section{Genus BOLEOSOMA DeKay.}

7. Boleosoma maculatum Agassiz.

$$
\text { (B. brevipinne Cope.) }
$$

Abundant in the Holston River.

\section{Genus NOTHONOTUS Agassiz.}

8. Nothonotus zonalis (Cope) Jordañ.

Holston and French Broad Rirers (Cope).

9. Nothonotus vulneratus (Cope) Jor.

French Broad River at Warm Springs.

10. Nothonotus RUfilineatus (Cope) Jor.

French Broad River. We have not examined this species and the preceding. One or both of them may perhaps belong to Pocilichthys. 


\section{Genus PECILICHTHYS Agassiz.}

11. Pecilichthys Jessia Jor. \& Brayt.

Jordan, Man. Vert. E. U. S. ed. 2d, 1878, 22\%.

Bodly fusiform, rather deep and compressed, the depth 5 to $5 \frac{1}{2}$ in length, the form of the body similar to that of $P$. spectabilis.

Head rather large, moderately pointed, 4 in length. Mouth rather large, terminal, the upper jaw slightly longest, not protractile. Eye pretty large, high up, $3 \frac{1}{2}$ in head, about equal to snout.

Cheeks naked, scaly above: opercles scaly: throat naked: neck abore scaly : scates medium, 6-45 to 50-7. Lateral line incomplete, but extending farther than in $P$. variatus and $P$. spectabilis, on about 35 scales, or nearly to the end of the second dorsal.

Fins moderate. Dorsal, XII-about 12. Anal II, 9.

Color, iu spirits, olivaceous, with about nine squarish, bar-like blotches along the sides, and about fire dark cross-blotches on the back. Dorsal and caudal fins faintly barred.

In life. the fish is chestuut-colored above, and the squares on the sides are bright dark blue : the fins are mottled with chestnut. A dark yellow or orange band across the dorsal. Second dorsal and anal with dark and golden specklings.

Several specimens, each about two inches long, taken in Chickamauga River at Ringgold. The specimens are certainly not fully grown, and the coloration of the adult male is doubtless much more brilliant. It will be at once distinguished from $P$. variatus and $P$. spectabilis by the scaliness of the upper part of the cheeks, by the greater development of the lateral line, the more numerous dorsal spines, and the coloration. This species is named for Mrs. Jessie D. Brayton.

\section{Genus ETHEOSTOMA Rafinesque.}

\section{Etheostoma FLABELLARE Rafinesque.}

Abundant in the upper waters of the Tennessee in clear rapid streams.

\section{Genus ? -}

13. (ETHEOSTOMA) CINEREA Storer.

Described from Florence, Ala. The description has reference chiefly to the coloration. Neither this species nor the next hare been recognized by any author subsequent to their description.

14. (Etheostoma) tessellata storer.

From the Tennessee River at Florence, Ala. 


\section{PERCID AE.}

\section{Genus STIZOSTETHIUM Rafinesque.}

15. Stizosteturum vitreum (Cuv. \& Val.) Jor. \& Copel.

Found by Professor Cope in the French Broad.

16. Stizostethium SALMoneum Raf.

Species of this genus occur throughout the Tennessee Basin. Professor Cope ascribes this species and the preceding to the French Broad. As we have seen no specimen, we follow his identifications.

\section{CENTRARCHIDAE.}

Genus MICROPTERUS Lacépède.

17. Mrcropterus pallidus (Raf.) Gill \& Jordan.

Not uncommon in the Tennessee Basin.

18. Micropteres salmoides (Lac.) Gill.

Very common in the Tennessee River.

Genus AMBLOPLITES Rafinesque.

19. Ambloplites rupestiris (Raf.) Gill.

Common in the Tennessee Basin.

\section{Genus CHANOBRYTTUS Gill.}

20. Chanobrytús gulosus (C.\& V.) Gill.

Lower Tennessee River; probably common.

Genus LEPIOPOMUS Rafinesque.

21. LePiopomus PALLIDUs (Mitch.) Gill $\&$ Jor.

Very common in the Teunessee Basin.

22. LePiopomus obsCURUS (Agassiz) Jordan.

Described by Professor Agassiz from Huntsville, Ala.

23. (LEPIOPOMUS) BOMBIFRONS (Agassiz).

Only the type-specimens of this species are yet known. They were 
from Huntsville, Ala. We are unable to decide, from the description and a MS. drawing kindly forwarded by Professor Bliss, whether this species is a Lepiopomus or a Xenotis.

\section{Genus XENOTIS Jordan.}

\section{Xenotis SANGUinolentus (Agassiz) Jordan.}

Originally deseribed from the Tennessee River at Huntsville. We bave seen no specimens from that locality, and are unable to decide whether Agassiz's species is the one to which we have applied the name sanguinolentus, or whether it be one of the forms of the Northern $X$. megalotis.

25. Xenotis INSCRIPTUS (Agassiz) Jor.

Originally described from the Tennessee River at Huntsville. Also found by Professor Oope in the upper waters of the same river.

\section{Genus EUPOMOTIS Gill \& Jordan.}

26. Еupomotis Pallidus (Agassiz) G. $\& J$.

Originally described from Huntsville, Ala.

\section{Genus XYSTROPLITES Jordan.}

27. XYstroplites NOTATUS (Agassiz).

Originally described from Huntsville, and later found by Professor Cope in the upper waters of the Tennessee. This species may be a Eupomotis instead of a Xystroplites. It much resembles the Texan Xystroplites heros B. \& C.

\section{SCI ANID A.}

\section{Genus HAPLOIDONOTUS Rafinesque.}

28. HAPLOIDONOTUS GRUNNIENS Raf.

Abundant in the Tennessee Basin. The form called by Professor A gassiz Amblodon concinnus needs re-examination before it can be admitted as a species.

\section{ATHERINID AE.}

Genus LABIDESTHES Cope.

29. Labidesthes sicculus Cope.

Found by Professor Cope in Coal Creek, a tributary of the Clinch River. 


\section{CYPRINODONTIDAE.}

Genus XENISMA Jordan.

30. Xenisma catenatum (Storer) Jordan.

Originally described from Florence, Ala. It is abundant in the Elk, Clinch, and Holston in clear waters.

\section{Genus ZYGONECTES Agassiz.}

31. ZYGONECTES NOTATUS (Raf.) Jor.

Described by Dr. Storer from Florence, Ala., under the name of Poecilia olivacea. This species prefers still, deep waters.

\section{ESOCID AE.}

Genus ESOX Linnaus.

32. Esox (CRAssus Agassiz).

A species is recorded by Professor Agassiz under the name of Esox crassus. The description is insufficient and the species is at present unrecognized.

\section{HYODONTID A.}

\section{Genus HYODON Le Sueur.}

33. Hyodon selenops Jordan \& Bean.

The original type of this species came from the Tennessee River at Chattanooga. Hyodon tergisus doubtless also occurs in the lower course of the river.

\section{CLUPEIDAE.}

Genus POMOLOBUS Rafinesque.

34. Pomolobus chrysochloris Raf. Abundant in the channel of the Lower Tennessee. 


\section{DOROSOMATIDAE.}

\section{Genus DOROSOMA Rafinesque.}

35. Dorosoma Cepedianum heterurum (Raf.) Jor.

The "Gizzard Shad" is abundant in the Lower Tenuessee.

\section{SALMONIDAE.}

\section{Genus SALVELINUS Richardson.}

36. Saldelinus fontinalis (Mitchill) Gill \& Jor.

This species occurs in abundance in Swannanoa River, at the foot of Black Mountain, and in all clear tributaries of the French Broad in Western North Carolina. In Southwestern Virginia, it occurs in certain tributaries of the Holston. In Rabun County, in Northeastern Georgia, it abounds in the headwaters of the Little Tennessee. Professor Cope states, on the authority of Dr. Hardy, of Asheville, that it "occurs in the headwaters of the Chattahoochee, on the south slope of the Alleghanies, in Georgia".

\section{CYPRINID胥.}

Genus CAMPOSTOMA Agassiz.

37. Campostoma anomalum (Raf.) Ag.

Var. prolixum Storer.

Everywhere abundant. In the clear pools of the Swannanoa River, at the foot of Black Mountain, this fish is extremely abundant, and the large specimens are brilliantly colored, so that they appear to be luminous or phosphorescent as one looks down on them throngh the crystal water.

\section{Genus HYBORHYNCHUS Agassiz.}

38. Нувовнуnchus notatus (Raf.) Agassiz.

Numerous specimens from the Chickamauga River. These are narrower-beaded than the common Western form (H. superciliosus Cope) and want the barbel, which is usually distinct on the latter. It is not improbable that we have two distinct species. 


\section{Genus LUXILUS Rafinesque.}

39. Luxilus CoRnutus (Mitch.) Jor.

Abundant in every stream examined.

40. LuXiLus COCCOGENIS (Cope) Jor.

Abundant in every stream examined.

\section{Genus PHOTOGENIS Cope.}

41. Photogenis galacturus (Cope) Jor.

Abundant in every stream examined.

Genus HiYDROPHLOX Jordan.

42. HXdrophlox RUBRICROCEUS (Cope) Jor.

Described by Professor Cope from tributaries of the Holston. It prefers boisterous mountain-streams.

43. HydRophlox LACERTosus (Cope) Jor.

Described from the Holston.

\section{Genus ALBURNOPS Girard.}

44. ALBURnops microstomus (Raf.) Jor.

Minnilus microstomus RAF.

Hybopsis longiceps COPE.

Obtained by Professor Cope in tributaries of Clinch River.

45. Alburnops spectrunculus (Cope) Jor.

Obtained by Professor Cope in the Holston and French Broad.

Genus Episema Cope \& Jordan.

46. Iipisema leucioda Cope.

Found by Professor Cope in the Holston and French Broad.

Genus NOTROPIS Rafinesque.

(Notropis et Minnilus Raf.; Alburnellus Girard.)

47. Notropis ATHERINOIDES Raf.

From tributaries of Clinch River. 
FISHES OF THE TENNESSEE BASIN.

48. NotRopis MICROPTERYX (Cope) Jor.

From tributaries of the Holston and Clinch.

49. Notropis PHOTOGENIS (Cope) Jor.

(Squalius photogenis Cope; Photogenis leucops Cope.)

Abundant in the French Broad River.

50. Notropis telescopus (Cope) Jor.

Holston and French Broad Rivers (Cope). Also abundant in Elk River. If our specimens are correctly identified, this is a true Notropis. We find it not easily distinguishable from $N$. photogenis.

\section{NOTROPIS LIRUS Jordan.}

This little species abounds in both the Elk and the Chickamanga.

\section{Genus HEMITREMIA Cope.}

52. Hemitremia vittata Cope.

Described from the Holston River near Knoxville.

\section{Genus CHROSOMUS Rafinesque.}

53. Chrosomus erythrogaster Raf.

Recorded by Professor Agassiz from Huntsville, Ala. We have seen no specimens from the Tennessee River.

\section{Genus PHOXINUS Rafinesque.}

54. Phoxinus flammeus Jordan \& Gilbert.

Jordan, Man. Vert. E. U. S. ed. 2d, p. 303.

A very distinct species, resembling " Gila" margarita (Cope), but with the short lateral line of $P$. neogoeus Cope.

Body stout, rather more slender and more compressed than in $P$. neogaus, the form being. nearly that of G. margarita. Depth 4 in length, about equal to the length of the head.

Head short and deep, smaller than in neogoeus, the upper outline rounded, the muzzle quite blunt and rather short. Eye rather large, $3 \frac{1}{3}$ in head, longer than snout. Mouth small, oblique, the lower jaw projecting, the intermaxillary in front on the level of the pupil, and the maxillary extending to opposite the front of the orbit.

Scales much larger than in $P$. neogaeus, but still quite small, in appearBull. .N. M. No. $12-5$ 
ance similar to those of the species of Gila; dorsal and rentral regions scaled ; 7-43-5. Lateral line short, decurved, not reaching to base of ventrals, on only 14 scales.

Teeth 2, 4-5, 2, as in $P$. neogoeus, without masticatory surface.

Fins small : dorsal well behind ventrals : pectorals reaching nearly to ventrals, the latter to vent. D. I, 8, A. I, 8; the latter fin rather high.

Coloration that of the species of Clinostomus, especially C. margarita (which species, having the lateral line wanting on the last three to eight scales, might perhaps with propriety be referred to Phoxinus).

Back dark, the scales profusely punctate: a dusky band formed of dark specks along the sirles: cheels pearly: space below lateral line silvers; in the type-specimen flushed with rich scarlet-red.

Length of type $2 \frac{1}{2}$ inches.

A single specimen taken in Elk Rirer, at Estill Springs, in company with Gila estor, which species it much resembles in color. Phoxinus flammeus bears the same relation to $P$. ncogaus that Gila estor does to the small-scaled Gila elongata.

\section{Genus GILA Baird \& Girard.}

\section{(Subgenus CLINOSTOMUS Girard.)}

55. GILA ESTOR Jordan \& Brayton.

Jordan, Man. Vẹrt. ed. 2d, p. 300.

A large and handsome species, related to $G$. elongata and $G$. proriger, but well distinguished from both.

Body elliptical-elongate, rather deep and compressed; the caudal peduncle lung. Greatest depth $4 \frac{1}{4}$ in length. Head very long and large, 32 in length ; flattish abore, but not wide. Mouth exceedingly large, very oblique, the premaxillaries anteriorly on the level of the pupil, the maxillary extending to opposite the middle of the orbit, and the length of the gape of the mouth a little more than half the length of the head. Lower jaw decidedly the longer.

Eye quite large, less than snout, 4 in head.

Scales small, but large for the genus, their outlines well defined, especially above, 8-50-5. Lateral line strongly decurred; about 23 scales on the back anterior to the dorsal fin.

Fins high. Dorsal I, 8, well behind ventrals, its first ray nearer the caudal than the snout. Anal I, 8 , short and high. Pectorals falling just short of ventrals, the latter just short of vent.

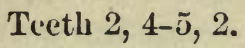


Color dark olive above, with a bluish lustre, many scales larker, as is usual-in this genus. Sides somewhat silvery. No dark lateral band. A broad shade of deep rose color along the sides, below which most of the belly is bright crimson, the red colors brightest anteriorly.

Length of largest specimens about 4 inches. Numerous specimens from the Elk River at Estill Springs, and from Stone River at Murfreesboro'. This striking species resembles most G. elongata and G.proriger. Both those species have much smaller scales (70 to 75 in the lateral line in elongata, 60 to 65 in proriger). The coloration is likewise different, the two latter species haring a dusky band along the sides, the anterior half of which in elongata is red in spring. G. clongata is much more elongate, as is also $G$. proriger. The month appears largest in $G$. estor. The distinction between $G$. proriger and G. elongata' is perhaps questionable.

\section{Genus NO'TEMIGONUS Rafinesque.}

56. Notemigonus chrysloleudus (Mit.) Jur.

Common in still waters in the Tennessee Basin.

\section{Genus PHENACOBIUS Cope.}

\section{Phenacobius uranops Cope.}

Kather common in the Elk and Chickamauga Rirers. A few specimens from the French Broad. Originally described from the Holston iu Virginia.

\section{Genus RIIINICHTHYS Agassiz.}

5s. Rhinichthys ob'tusus Agassiz.

(Rhinichthys lunatus Cope.)

This species is abundant in all clear rocky brooks and in outlets of springs.

\section{Genus CERATICHTHYS Baird.}

\section{Ceratichthys monachus Cope.}

Abundant in Cbickamauga River. Originally described from the Holston.

60. Ceraticnthis dissinilis (Kirt.) Cope.

Obtained in Elk River. 
61. Ceratichtirys winchelli (Girard) Jordan.

$$
\text { (Ceratichthys hyalinus Cope.) }
$$

Every where abundant in Tennessee River. This is probably Hybopsis gracilis Ag., the original type of the genus Hybopsis. In that ease; it will be necessary to substitute the specific name gracilis for vinchelli.

62. Ceratichthys biguttatus (Kirtland) Girard.

Everywhere very abundant.

\section{Genus SEMOTILUS Rafinesque.}

63. Semotilus corporalis (Mit.) Putn.

Tributaries of the Clinch and French Broad; chiefly in small mount. ain-streams.

\section{CATOSTOMIDAE.}

\section{Genus QUASSILABIA Jordan \& Brayton.}

64. Quassilabia lacera Jordan \& Brayton.

Lagochila laccra Jordan \& Brayton (1877), Proc. Ac. Nat. Sc. Phila.

Two specimens of this singular fish were taken in the Chickamauga River at Ringgold and one specimen in Elk River at Estill Springs. In the Chickamauga, we were told that it is quite common, and that it is much valued for food. It is usually known as the "Hare-lip" or "Splitmouth Sucker". We have lately received a fine specimen taken in the Scioto River, Ohio, by Mr. J. H. Klippart, where it is well known to the fishermen under the name of "May Sucker".

\section{Genus MYXOSTOMA Rafinesque. \\ 65. Myxostoma velatum (Cope) Jor. (Ptychostomus collapsus Cope.)}

Obtained by Professor Cope in Clinch River, and by us in the Chickamauga.

66. MYXostoma MACROLEPIDOTUM DUQUESNII (Le S.) Jor.

From the Holston, Ginch, French Broad, and Chickamauga. Proba. bly generally abundant. 


\section{Genus PLACOPHARYNX Cope.}

67. Placopharynx carinatus Cope.

This large species is the common "Red Horse" of the French Broad. It much resembles the preceding, but has a much larger month and lips, besides the different dentition.

\section{Genus ERIMYZON Jordan.}

68. Erimyzon sucetta (Lac.) Jor.

Obtained in Clinch River.

Genus MINYTREMA Jordan.

69. Minytrema melanops (Raf.) Jor.

Obtained by Professor Agassiz at Huntsville, Ala.

Genus CATOSTOMUS Le Sueur.

70. Catostomus nigricans Le S.

Very abundant throughout the Tennessee Basin.

71. Catostomus commersoni (Lac.) Jor.

- Generally abundant.

\section{Genus CARPIODES Rafinesque.}

72. CARPIODES BISON Agassiz.

Lower Tennessee River (Cope.) The Bubalichthyina of the Tennessee River are as yet unstudied.

\section{Genus BUBALICHTHYS Agassiz.}

73. Bubalichthys urus Agassiz.

Recorded by Professor Agassiz from the Tennessee River.

\section{SILURID E.}

Genus ICHTH ELURUS Rafinesque.

74. IchthaluRus punctatus (Raf.) Jor.

Very abundant in the Tennessee River. 
CONTRIBUTIONS TO NORTH AMERICAN ICHTHYOLOGY-III.

\section{Genus AMIURUS Rafinesque. \\ 75. AMIURUS natalis (Le S.) Gill. \\ Var. cupreus (Raf.).}

Rather abundant in Tenuessee Rirer. Other species of this genus are doubtless common; but they have not been distiuguished.

\section{Genus PELODICHTHYS Rafinesque.}

76. Pelodichthys olivaris (Raf.) Gill \& Jor.

Abundant in the channels of the larger streams. Several specimens from the French Broad.

This species probably occurs in the channels of all the streams mentioned in this paper; but, from its babits, it is not easily taken with a small net.

\section{Genus NOTURUS Rafinesque.}

77. Noturus eleutherus Jordan.

Noturus cleutherus JoRdan (1877), Ann. Lyc. Nat. Hist. N. Y. 372.

The type-specimen of this species was from Big Pigeon River, in Cocke Counts, Tennessee, near its junction with the French Broad. Many other specimens have siuce been obtained in Tar River, Nortl Carolina.

\section{ANGUILLID A.}

Genus ANGUILLA Thunberg.

78. ANGuill $\Lambda$ vulgaris Fleming.

Eels occur in Tennessee River, though rather less abundantly than in the streams farther south.

\section{AMIID AE.}

Genus AMIA Linnæus.

79. AMIA CALVA $L$.

Recorded by Professor Agassiz from Huntsrille, Ala. 


\section{LEPIDOSTEIDAE.}

\section{Genus LEPIDOSTEUs Lacépède.}

80. Lepidosteus osseus ( $L$. . $A g$.

Generally abundant.

81. Lepidosteus platystomus Raf.

From Huntsville, Ala. (Agassiz).

\section{ACIPENSERID死.}

Genus ACIPENSER Agassiz.

82. Acipenser maculosus Le Sueur.

Huntsville, Ala. (Agassiz).

83. Acipenser rubicundus Le Sueur.

From Huntsville, Ala. (Agussiz).

\section{POLYODONTIDA.}

\section{Genus POLYODON Lacépède.}

84. Polyodon Folium "Lac."

Abundant in the river-channels.

VII.-WATER-BASIN OF CUMBERLAND RIVER.

Sixty-fire species are known to occur in the waters of the Cumberland River. Of these, forty-seren have been obtained in the lower course of the river, i. e., in the vicinity of Nashville, by Professor Winchell, and in Stone River, at Murfreesboro', by the present writers. In the upper course of the stream, thirty-three species have been obtained by Professor Cope in the South Fork of the Cumberland in Tennessee and by Professor Jurdan at the Falls and in the Rock Castle, Round Stone, Big Laurel, and other tributaries in Kentucky. Only fifteen species are, therefore, known to be common to both the upper and lower courses of the stream. The actual differences between the upper and lower faunæ are, howerer, probably very small, if similar streams are compared. The differences really existing are probably chiefly due to the fact that the large fishes inhabiting the lower part of the river are unable to ascend above the falls of the Cumberland.

Cowparing the Cumberland River with the Tennessee, the disappear- 
ance of one or two Southern types will be noticed, as will be the appearance of certain forms abundant in the basin of the Ohio. Of these latter may be noticed Pocilichthys variatus, Apomotis, Iythrurus, and Pimephales. But two species, both Darters, are at jresent known only from the Cumberland River. These are Ulocentra atripinnis and Nothonotus sanguifuus.

The National Museum is indebted to the kindness of Professor Winchell for the following interesting -

List of Fishes of Nashville, as given by a Fisherman, Daniel A. Birchett, to A. Winchell.

"PERCI TRIBE."

Sun Perch.

Coon Perch.

White Perch.

Black Perch.

Red Perch.

Speckled Perch.

Brama Perch.

Bass or Rock Bass.

\section{"TROUT TRIBE."}

White Trout.

Black Trout.

"SUCKER TRIBE."

White Sucker.

Spotted Sucker.

Hog Sucker.

Red Horse, creeks and river.

Black Horse.

Carp, creeks and river.

Mullet.

$$
\text { "BUFFALO TRIBE." }
$$

White Buffalo.

Blue Buffalo.

$$
\text { "CAT TRIBE." }
$$

Yellow Cat.

Blue Cat.
Nigger-lip Cat.

Chisel-head Cat.

Kerkin Cat.

Shorel-bill Cat.

"MINNOW TRIBE."

Silver Side.

Stone Toter.

Horny Head.

White Roach.

Creek Mullet.

Steel Back. MISCELLANEOUS.

Thunder Head.

Drum.

Jack.

Chover.

White Chorer.

Gizzard Shad.

Skip Jack.

Tooth Herring.

Sand Pike.

Pike.

Top Water (several species).

Gar.

Sturgeon.

Eel.

Lamprey Eel. 


\section{COTTIDE.}

Genus POTAMOCOTTUS Gill.

1. Potamocottus meridionalis (Grd.) Gill.

From Cumberland Rirer at Nashville.

\section{ETHEOSTOMATIDA. \\ Genus PERCINA Haldeman. \\ 2. Percina caprodes (Raf.) Grd.}

Abuudant.

\section{Genus ALVORDIUS Girard.}

3. Alvordius maculatus (Girard) Cope \& Jordan.

From the Rock Castle and Cumberland at various points.

4. Altordius phoxocephalus (Nelson) Cope \& Jordan.

From the Cumberland River at Nashville. Specimens of this interesting species are in the National Museum from Marais du Cygne, Kansas. I have others from the Wabash River. Nelson's types were from Illinois River.

\section{Genus DIPLESIUM Rafinesque.}

5. Diplesium blennioides (Raf.) Jor.

South Fork of the Cumberland River (Cope). Also from Cumberland and Stone Rivers.

6. Diplesium simoterum (Cope) Copeland.

From the Rock Castle River at Livingston, Ky.

\section{Genus ULOCENTRA Jordan.}

7. ULOCENTRA ATRIPINNIS Jordan.

Arlina atripinnis Jordan (1877), Bulletin X, U. S. Nat. Museum, 10.

The type of this species was collected in the Cumberland River at Nashville by Professor Winchell. 


\section{Genus NOTHONOTUS Agassiz.}

\section{Nothonotus camurus (Cope) Jor.}

Professor Cope's types were from the South Fork of the Cumberland. We have seen others from White River in Indiana, and from Mahoning River and other streams in Ohio. This species is not identical with Nothonotus maculatus Ag. (Etheostoma maculata Kirt.), as has been supposed.

Nothonotus maculatus has a pointed instead of rounded snout; its jairs are equal ; its mouth is larger, the body is more compressed, and its dorsal fin more elevated, the soft rays when depressed reaching to the candal.

Specimens in the National Museum, collected in Mahoning River by Professors Baird and Kirtland, show the following characters :-

Body moderately elongated, rery deep, strougly compressed, the depth $4 \frac{2}{3}$ in length. Head 4 in length, the jaws equal, the mouth large. Eye $4 \frac{1}{3}$ in head. Spinous dorsal with a long base, larger than soft dorsal, the spines high, the two fins slightly connected. Soft dorsal elevated, the longest rays when depressed reaching base of caudal, the ciudal peduncle very short and deep. Caudal fin short and rounded. Anal somewhat smaller than second dorsal. Pectorals and ventrals moderate.

Scales not large, 58 to 60 in the lateral line, which is continuous: cheeks naked : opercles scaly.

Fin-rays : Dorsal XII-13; A. II, 8.

An elaborate colored drawing of a male fish in life colors, in the Smithsonian Institution, shows the following features of coloration. As we have never seen this species in life, we cannot vouch for their accuracy :-

Back olive; belly becoming yellowish. Sides and back profusely speckled with carmine-red, the blotches rather less than the size of the eye, not round, nor arranged in rows.

Dorsal fiu with a dull red stripo at base, a brown interval, then a bright red stripe, finally margined with white. Second dorsal dull brown at base, then a broad red stripe; a broad marginal band of white. Caudal similarly tricolor, chicfly crimson, with' a broad dusky band at base and a wide white band at the tip. Anal chiefly crimson, with a terminal band of white. Pectorals and rentrals nearly plain. Head olivaceons. 
FISHES OF THE CUMBERLAND BASIN.

9. Notionotus SANGuifluds (Cope) Jor.

From the South Fork of the Cumberland in Tennessee (Copc).

\section{Genus BOLEOSOMA DeKay.}

10. Boleosoma maculatum $A g$.

From the Rock Castle River.

\section{Genus PECILICHTHYS Agassiz.}

11. Peeilichthys variatús (Kirt.) Ag.

From the South Fork of the Cumberland River (Cape).

Genus ETHEOSTOMA Rafinesque.

12. Etheostoma flabellare Raf.

Abundant in the mountain tributaries of the Cumberland.

\section{PERCIDA.}

\section{Genus STIZOSTETHIUM Rafinesque.}

13. Stizostethium salmoneum Raf.

One or two small specimens from the Rock Castle Rirer.

\section{CENTRARCHIDA. .}

\section{Genus MICROPTERUS Lacépède.}

14. Micropterus pallidus (Raf.) $G . \& J$.

The "White Trout", as this species is often called, is common in the Cumberland. It is said that this species and the next were not fouud above the falls until introduced.

15. Micropterus salmoides (Lac.) Gill.

The "Black Trout" occurs with the preceding, and is still more abundaut.

\section{Genus AMBLOPLITES Rafinesque.}

16. Ambloplites rupeistris (Raf.) Gill.

Everywhere abundant. 
Genus APOMOTIS Rafinesque.

17. A POMUTIS CYANELLUS (Raf.) Jor.

Abundant in the Cumberland River at Nashville.

Genus LEPIOPOMUS Rafinesque.

18. Lepiopomus pallidus (Mit.) Gill \& Jordan.

Very abundant in the Cumberland.

19. Lepiopoyus obscurus (Agassiz) Jor.

Collected by Professor Winchell in the Cumberland River at Nashville.

\section{Genus XENOTIS Jordan.}

20. Xenotis Megalotis (Raf.) Jor.

Aunndant in the Cumberland River.

Genus POMOXYS Rafinesque.

21. Pomoxys nigromaculatus (Le S.) Grd.

Collected by Professor Winchell at Nashville.

22. Pomoxys annularis Raf.

From the Cumberland at Nashville.

\section{SCIAENID AE. \\ Genus HAPLOIDONOTUS Rafinesque.}

23. HAPLOIDONOTUS GRUNNIENS Raf.

Abundant in the river-channel.

\section{ATHERINID AE.}

\section{Genus LABIDESTHES Cope.}

\section{Labidesthes sicculus Cope.}

Abundant in Stone River at Murfreesboro'. This interesting species was named by Rafinesque in 1832 Zonargyra virescens. This latter name was, however, not accompanied by a description, and therefore canuot be employed. 


\section{CYPRINODONTIDEE.}

Genus XENISMA Jordan.

25. Xenisma cátenatom (Storer) Jordan.

Collected by Professor Winchell in streams about Nashrille

Genus ZYGONECTES Agassiz.

26. ZYGONECTES NOTATUS (Raf.) Jor.

From Cumberland and Stone Rivers. Rafinesque's original specimens were from the Cumberland at Williamsburg.

\section{HYODONTID A.}

Genus HYODON Le Sueur.

27. Hyodon TERGISUs Le Sueur.

Abundant in the Cumberland.

28. HYodon sELenops Jordan \& Bean.

Two or three specimens in the National Museum from Cumberland River.

\section{CLUPEID AE.}

Genus POMOLOBUS Rafinesque.

29. Pomolobus cHrysochloris Rafinesque.

Abundant in the Lower Cumberland.

\section{DOROSOMATIDE.}

Genus DOROSOMA Rafinesque.

30. Dorosoma cepedianum heteruruir (Raf.) Jor.

Abundant in the Lower Cumberland.

\section{CYPRINID AE.}

Genus CAMPOSTOMA Agassiz.

31. Campostoma anomalum (Raf.) Ag.

Abundaut. 


\section{Genus PIMEPHALES Rafinesque.}

32. Pimepinales promelas Rafinesque.

Collected by Professor Winchell in tributaries of the Cumberland.

\section{Genus HYBORHYNCHUS Ágassiz.}

33. HхвоRHYNCHUS Notatus (Raf.) Ag.

Abundant every where in the Cumberland.

Genus LUXILUS Rafinesque.

34. Luxilus CoRnutus (Mit.) Jordan.

Exceedingly abundant ererywhere.

\section{Genus PHOTOGENIS Cope.}

35. Photogenis galacturus (Cope) Jor.

$V$ ery abundant everywhere in the Cumberland. Some specimens from Nashville have the caudal fin pale red. This species does not seem to occur in the Ohio. The quotations from that river were founded ou erroneous identifications.

36. Photoghis analostanus (Grd.) Jor.

From the Cumberland at Nashville.

Genus ALBURNOPS Girard.

37. Alburnops merostomus (Raf.) Jor.

From the South Fork of the Cumberland (Cope).

Genus LYTHRURUS Jordan.

38. LythruRus ARDENs (Cope) Jor.

Very abundant ererywhere in Cumberland River. One of the most charcteristic species, as it apparently does not occur either in the Kentucky or the Tennessee.

Genus NOTROPIS Rafinesque.

39. Notropis $A$ THERINOIDES $(R a f$. $)$ Jor.

Very abundaut in the Rock Castle and other upper tributaries of the Cumberlaud. 
JISHES OF THE CUMBERLAND BASIN.

40. Notropis MiCROPTERTX (Cope) Jor.

Abuntant in the Rock Castle.

41. Notropis telescopus (Cope) Jor.

Stone River at Murfreesboro'.

Genus HEMITREMIA Cope.

42. Hemitremia vittata Cope.

Abundant in Big Laurel River in Laurel County, Kentucky.

Genus GILA Baird \& Girard.

43. Gila Estor Jordan \& Brayton.

Several specimens from Stone River at Murfreesboro'.

Genus CHROSOMUS Agassiz.

44. Cinrosomus erythrogaster $A g$.

From the tributaries of the Rock Castle.

Genus NOTEMIGONUS Rafinesque

45. Notemigonus Chrysoleucus (Mit.) Jor.

Common in sluggish waters.

\section{Genus PHENACOBIUS Cope.}

46. Phenacobius uranops Cope.

Taken in Rock Castle Rirer.

\section{Genus CERATICHTHYS Baird.}

47. Ceratichthys dissimilis (Kirtland) Cope.

From Cumberland River at Nashrille.

48. Cenatichthys amblops (Raf.) Grd.

From Cumberland River at Nashrille.

49. Ceratichthys miguttatus (Kirt.) Grd.

Every where abundant. 


\section{Genus SEMOTILUS Rafinesque.}

50. Semotilus corporalis (Mit.) Put.

From Rock Castle Rirer.

\section{CATOSTOMIDE.}

Genus MYXOSTOMA Rafinesque.

51. MyXostoma MACROLEPIDOTUM DUQUEsir (Le S.) Jor. Common in the Cumberland.

Genus ERIMYZON Jordan.

52. ERIMYzon sucetta (Lac.) Jor.

From the Cumberland at Nashville and from the Rock Castle.

Genus MINYTREMA Jordan.

53. Minytrema melanops (Raf.) Jor.

From the Cumberland at Nashville.

Genus CATOSTOMUS Le Sueur.

54. Catostomus nigricans Le $S$.

Common in the Cumberland.

55. Catostomus commersoni (Lac.) Jor.

Very common in the Cumberland.

Genus CYCLEPTUS Rafinesque.

56. Cyclepitus elongatus (Le S.) Ag.

From the Cumberland at Nashrille. This species is known as "Black Horse", "Gourd-seed Sucker", and "Missouri Sucker".

Genus CARPIODES Rafinesque.

57. Carpiodes cutisanserinus Cope.

From the Cumberland River at Nashville. 
FISHES OF THE CUMBERLAND BASIN.

\section{SILURIDA.}

Genus ICHTH ELURUS Rafinesque.

58. ICHTH жLURUS PUNCTATUS (Raf.) Jor.

Very abundant.

Genus AMIURUS Rafinesque.

59. Amiruds natalis (Le S.) Gill.

Collected at Nashville by Professor Winchell.

60. Amiurus nigricans (Le S.) Gill

From the Falls of the Cumberland.

Genus PELODICHTHYS Rafinesque.

61. Pelodichthys olivaris (Raf.) Gill \& Jor.

From the Rock Castle at Livingston, and from the Cumberland below the Falls.

\section{ANGUILLIDAE.}

Genus ANGUILLA Thunberg.

62. ANguilla vUlgaris Fleming.

Common in the Cumberland. A very large specimen taken in the Rock Castle at the mouth of Round Stone River.

\section{LEPIDOSTEIDA.}

Genus LEPIDOSTEUS Lacépède.

63. Lepidosteus osseus ( $L$. $) A g$.

From the Cumberland at Nashville.

\section{POLYODONTIDAE.}

Genus POLYODON Lacépède.

64. Polyodon Folium "Lac."

From the Cumberland River.

Bull. N. M. No. 12-6 


\section{RECAPITULATION.}

The following table shows the distribution of the species in the seven river-basins especially treated in this paper. For purposes of comparison, I have introduced the results of Professor Cope's explorations in the Roanoke, James, Neuse, and Great Pedee, of Prof. Forbes and Mr. Nelson in the Illinois, and of myself and others in the Oh.o. A few unverified species hare been introduced, but all doubtful quotations and, in general, all "guesswork" have been excluded.

Toble shouting the Distribution of the Species in the Different River-Basins.

Lota lacustris, (Walb.) Gill

Potamncottus meridionalis, (Grd.) Fill.

Potamocottus bairdii, (Grd.) Gill.

Pleurolepis asprellu's, Jur.*

"'enrolepis / ellucidus, (Baird) Ag.

Ina vitrea, (Cope) Jor

Percina caprosea, (Iaf.) Grd

Percina manitou, Jor

Alvordius maculatus, Grd

Alvordins macrocepbalus, Cope.

Alvordius phoxocephalus, (Nels.) C. \& J

Alvordius crassus, J. \& B

Alvordius nevisensis, Cope

Ericosma evides, J. \& C . .

Rheocrypta copclandi, Jor

JaCiropterus aurantiacns, (Cope) Jor

Hadropterus nigrof.ısciatus, $\mathbf{A g}$

Hadropterus tessellatus, Jor .

Imostoma shumardii, (Grd.) Jor

Ulocentra atripinnis, Jor

Ulocentra stigmæa, Jor.

Diple:ium blennioides, (Raf.) Jor

Diplesium simoterum, (Cope) Copel

Boleosoma maculaticeps, Cope.

Boleosoma olmstedi, (Stor.) $\mathbf{\Lambda} \mathrm{g}$

Boleosuma maculatum, $\mathrm{Ag}$.

Boleosoma asopus, Cope .

Nothonotus z nillis, (Copu) Jor.

Nothonotus maculatus, (Kirt.) $\mathrm{Ag}$

Noth:notus camurus, (Cope) Jor.

Notbonotus sanguifluus, (Cope) Jor...........

Nothonotus vulneratus, (Cone) Jor

Nothonotus thalassinus, $\mathbb{3}$. \& $\mathrm{IB}$

Nothonotus inscriptus, J. \& B

Nothonotus rufilineatus, (Cufer) $]$ or

'œcilichthys variatus, (Kirt.) $\mathbf{A g}$

Pocilichthys spectabilis, Ag.

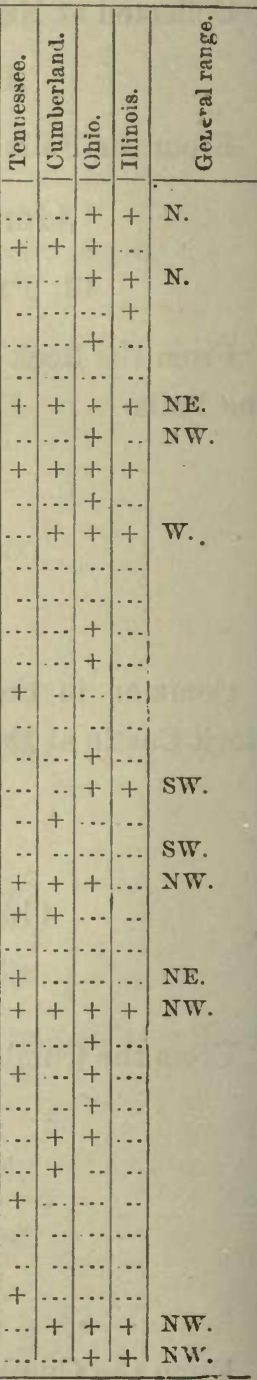


Table showing the Distribution of the Specics in the Different River-Basins-Continued.

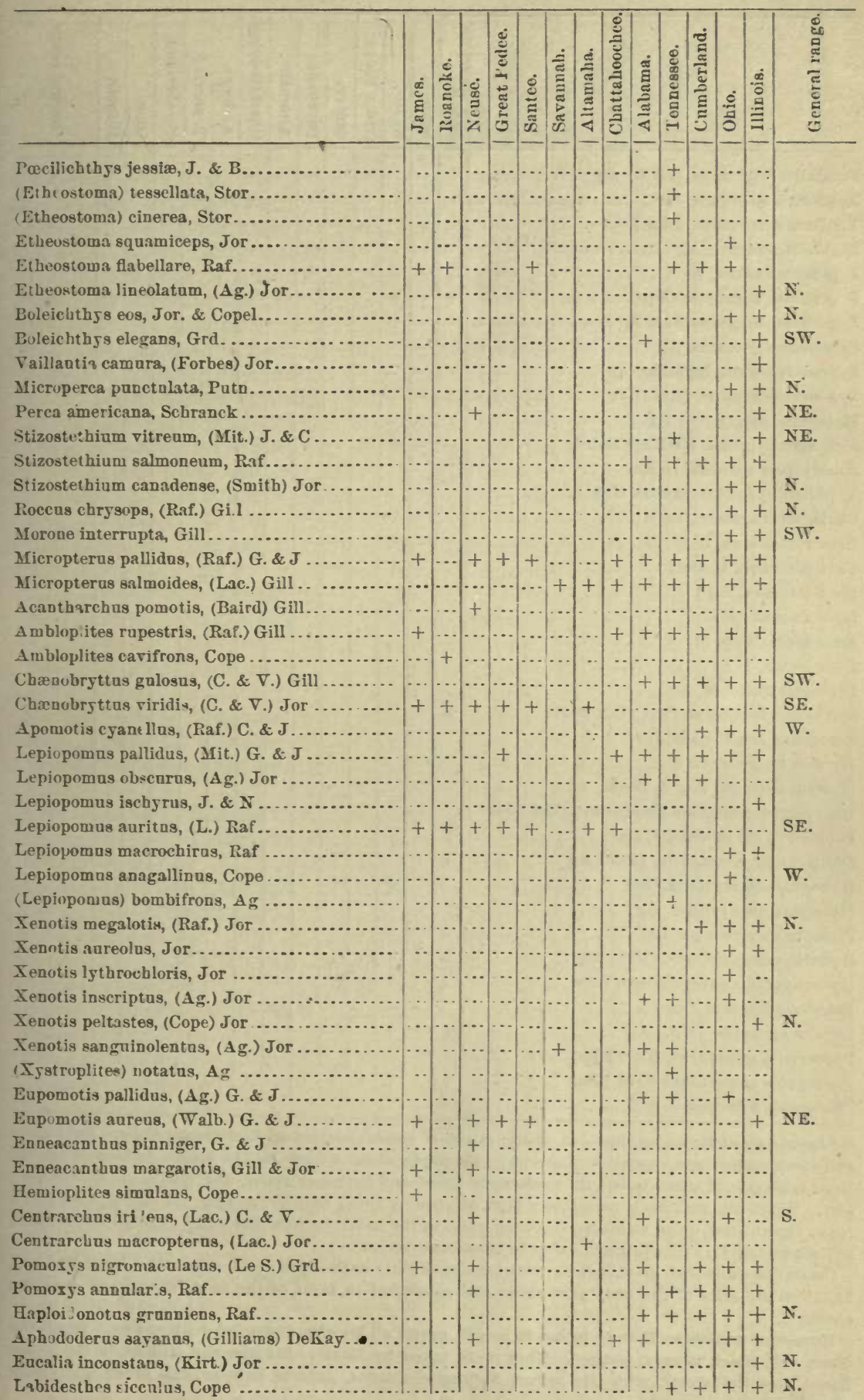


Table showing the Distribution of the Specics in the Different Rirer-Basins-Continned.

Fundnins diaplianns, (Le S.) Ag

Xenisma s: elliferum, Jor

Xenisma catenatum, (Stor.) Jor.

Zygonectes dispar, Ag

Zygonectes nottii, Ag

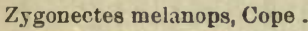

Zygonectes atrilatus, J. \& B.*

$Z_{5}$ ronectes guttatus, Ag

Zygonectes hieroglyphicus, Ag.

Zygonectes notatus, (Raf.) Jor

Melanura limi, (Kirt.) $\mathbf{\Delta g}$.

Melanura pygmæa, (DeKay) Baird.

Amblyopsis spelæus, DeKay.

'Tsphlichthys subterraneus, Grd

Chologaster agessizi, Putn

Esox reticulatus, Lo $S$

Esox (rareneli, Holbr.)

Isox (crassus, Ag.)

Esox salmoneus, Raf .

Esox cypho, Cope.

Lsox lucius, L

Percopsis guttatus, $\mathbf{A g}$

Sulvelinus fontinalis, (Mit.) Gill \& Jor ........

Coregonus artedi sisco, Jor..................

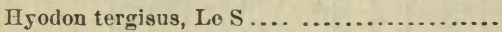

Hyodon selenops, Jor. \& Bean

Dorosnma cepediannm heterurum, (Rat.) Jor

Pomolobus chrysochloris, Raf.

Campostoma, anomalum, (Raf.) $\mathrm{Ag}$..........

Hybngnathus argyritis, Grd

Hybognathus nuchalis, Ag.

Pimephales promelas, Raf .

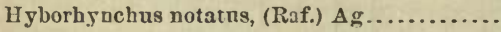

Hybnrhynchus superciliosus, Cope.

Ericymba buccata, Cope

Luxilus cornutus, (Mit.) Jor .

Photogenis galacturus, (Cope) Jor

Photogenis analostanus (Grd.) Jor.

Photogenis lencopus. J. \& B

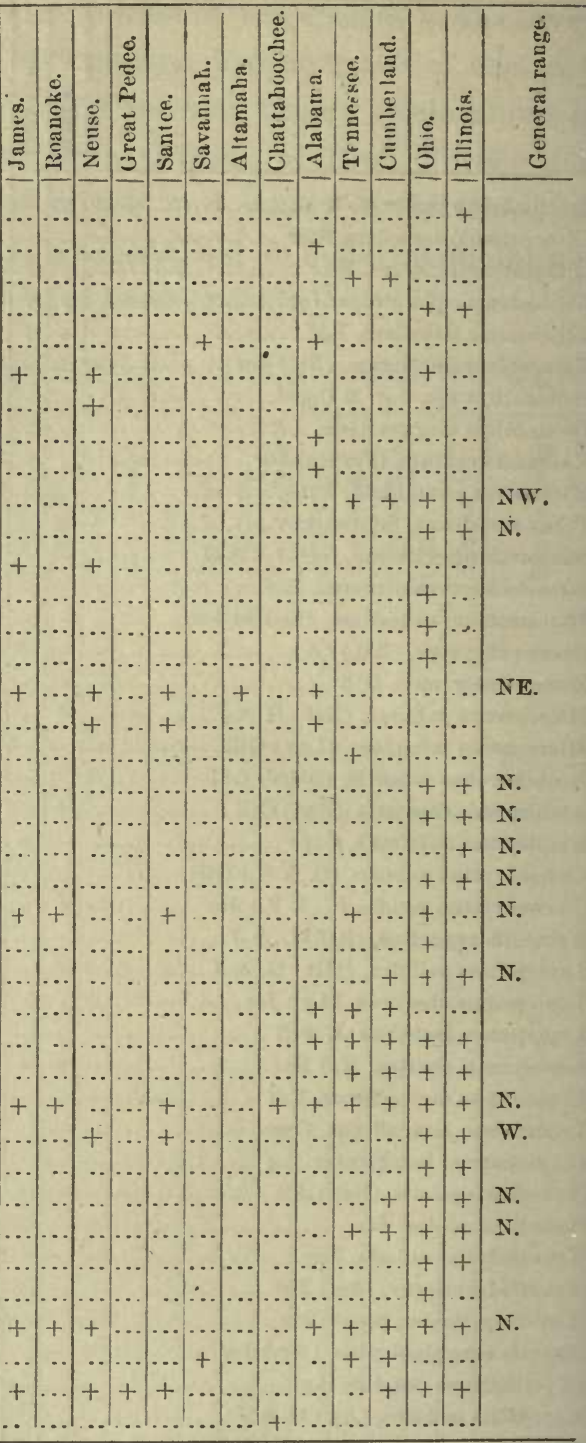

-Zygonetes atrilatus, sp. nor.-A short, thick-set species, related 10 Z. melanops Copo. Body short nud stont, compressed, especially posteriorly, the depth about 4 times in the length to base of candal. Head moderate, $3 \frac{3}{4}$ times in length, moderately broarl and flattened abore, the month of the ordinary sort. Dorsal fin well back, moderately high, of about 8 rays; anal larger than the dorsal, with seven rafs: rentral fins quite small, not reaching quite to the anal: pectoral fins small : caudal fin rounded, of the usual form: scales large, in about 30 transverse series.

Coloration dull ulive; no stripes nor bars: scales slightly dark-edged : each side with a large jet-black blotch on the sides of the body just above and somewhat in front of the vent: dorsal and anal fins speckled.

Namerons specimens, $1 \frac{1}{2}$ to $1 \frac{3}{4}$ inches in length, nearly all females, distended with spawn. In all, the black side-blotch is very distinct. They were taken by Messrs. Brayton and Gilbert, in the Neuse River, near Goldsboro', with Ioa vitrea, Notumus eleutherus, Achirus lineatus, and otber intere3ting species. 
Table showing the Distribution of the Specics in the Different River-Basins-Continued.

$\longrightarrow$

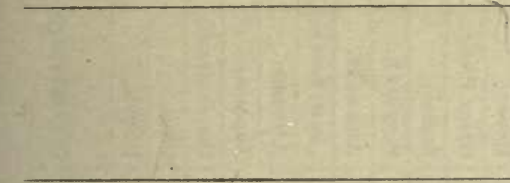

Photogenis nireus, (Cope) Jor

1.uxilus coccogenis, (Cope) Jor

II ydrophlox rubricroceus, (Cope) Jor

Alburnops chlorocephalus, (Cope) $\mathrm{Jcr}$

Ilydrophlox latipinnis, J. \& B .

II ydrophlox chiliticus (Cope) Jor

Ji.ulyulox chrusumps, Jur....

Hydrophlox xænocephalus, Jor

IIydrophlox lacertosns, (C: pe) Jor

Alburnops spectrucculus, (Cope) Jer

Alburnops stramineus, (Cop?) Jor

Alburnops fretensis, (Ccpe) Jor.

Allurnops microstomus, (Raf.) Jo:

Alburnops saludanus, J. \& B

A!burnops amarus. (Gril) Jor

Notropis divemus, (Raf.) Jor.

Notropis i ubellus, (Ag.) Jor

Notropis rubrifrons, (Cope) Jor.

Notrcpis micropteryx, (Cope) Jor.

Notropis dilectus, (Grd) Jor.

Notropis altip.nnis, (Cope) Jor.

Notropis stilbius, Jor.

Notropis telesco ous, (U(up

Notropis photogenis. (Cope) Jor

Notropis matutinus, (Cope) Jor.

Notropis lirus, Jor

Lythrurus ardeus, (Cope) Jor.

Lythrarus diplæmius, (Raf.) Jor

Codoma xænura. Jor

Colloma pyrrhomelas (Cope) Jor

Codoma formosa, (Putn.) Jor

Codoma callisema, Jor

Codoma chloristia, J. \& B

Codoma cærulea, Jor.

Codoma trichroistia, Jer. \& Gilbert

Codoma callistia, Jor.

Codoma stigmatura, Jor

Codoma eurystoma, Jor

Episeraa leuciorla, Cope.

Episema scabriceps, Cope

Episena ariomma, Cope.

Hemitremia vitta: $a$, Copo

IIenitremia heterodon, Copo

Chrosomus erythrogaster, Ruf

Phoxinas nucgæus, Copo

Phoxinus flammeus, Jor. \& Gillbert

('ila elongata, (Kirt.) Jur

Gila proriger, Copo.

Gila estor, J. \& B

Gila vandoisula, (C. \& V.) Jor

Notemigon -s chrysoleucus, (Mit.) Jor.
N.

NE.

$\mathrm{N}$.

W. 
Table showing the Distribution of the Species in the Different River-Basins-Continued.

Notemigonus americanus, (L.) Jor.

Pheuacobius teretulus, Cope

Phenacobins uranops, Cope

Phenacobius scopiferus, (Cope) Jor

Phenacobius catostomus, Jor

Rhinichthys atronasus, (Mit.) $\mathbf{A g}$............

Thinichthys obtusus, $\mathbf{A g}$.

Iihinichthys moleagris, $\mathbf{A g}$

Rhinichthys nasutus, (Ayres) Ag

Ceratichthys zanemus, J. \& B

Ceratichthys labrosus, Copo

Ceratichthys monaclius, Copo

Ceratichthys dissimilis, (Kirt.) Gri.

Ceratichthys amblops, (Raf.) Grd .

Ceratichthys winchelli, (Grd.) Jor

Ceratichthys rubrifrons, Jor

Ceratichthys bypsinotus, Core

Ceratichthys biguttatus, (Kirt.) Baird .

Semotilus bullaris, (Raf.) Jor .

Semotilus corporalis, (Mit.) Put

Semoti us thoreauianus, Jor.

Exoglossam maxillilingua, (Lө S.) Mald........

Quassilabia lacera, J. \& B

Placopharynx carinatus, Cono.

Myxostoma velatum, (Raf.) Jor.

Myxos:oma album, (Cope) Jor

My rostoma coregnnn., (Cope) Jor

Myxostoma couus, (Cope) Jor

Myxostoma thalassinum, (Cope) Jor

My xostoma pidiense, (Cope) Jor

Myxostom? crassilabre, (Copo) Jor

Myxost. macrolepidotum, (Le S.) Jor. et rars .

Myxostoma aureolum, (LeS ) Jor

Myxostoma anisurum, (Raf.) Jor

Myxostoma euryops, Jor

Myxostoma cervinum, (Cope) Jor

Mrxostoma papillosum, (Cope) Jor

Minytrema melanops, (Raf.) Jor

Erimjzon sucetta, (Lac.) Jor.

Hypentelium nigricans, (Le S ) Jor.

Hypentelium etowanum, Jor.

Catostomns commersoni, (Lac.) Jor.

Catostomus longirostris, LeS

Cycleptus elongatus, (Le S.) Raf.

Carpiodes difformis, Copo

Carpiodes cutisanserinus, Cope

Carpiodes velifer, (Raf.) $\mathbf{A g}$.

Carpiodes cyprinus, (Le S.) $\Delta \mathrm{g}$

Carpiodea bison, $\Delta \mathrm{g}$

Carpiodes carpio, (Raf.) Jor

Iclithyobus bubalus, (Raf.) $\mathbf{\Delta} \mathbf{g}$

Bubalichthys cyanellus, (Nels.) Jor

$+$

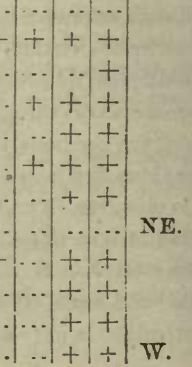


Table showing the Distribution of the Species in tive Different River-Basins-Continued.

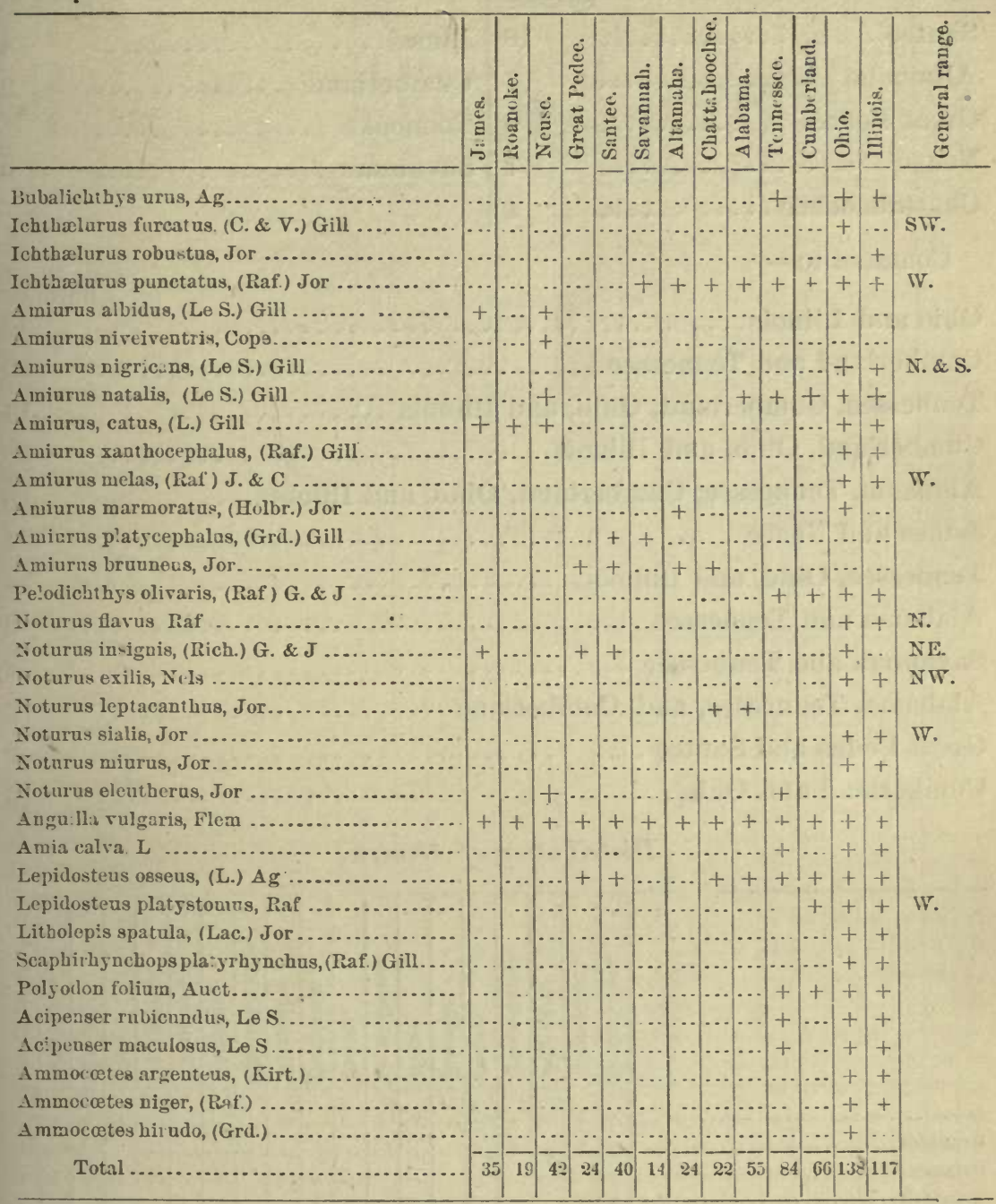

From the above table, it will be seen that the number of species inhabiting any one river-basin rapidly increases as we leave the Atlantic streams for those of the Gulf. The following table shows the arrangement of the species from another point of view-omitting reference to the range of the species outside of the thirteen rirers includerl in this table:

Kuown ouly from the-

Ohin

Alabama
Species.
Knowu only from theSpecies. Tennessee $. . . \ldots \ldots \ldots \ldots . \quad 16$ 
Known only from the-

Santeo

Altamaha

Great Pedee

Neuse

Chattahoochee

\section{Species.}

10

7

6

7

4
Known only from the-

James

Cumberland ............. 2

Roanoake ............. 1

Savannah .............. 0

\section{Common to-}

Ohio and Illinois.............................. 39

Cumberland and Tennessee $\ldots . . . \ldots \ldots \ldots \ldots \ldots \ldots \ldots \ldots . .10$

Tennessee, Cumberland, Ohio, and Illinois .............. 10

Cumberland, Obio, and Illinois..................... 10

Alabama, Tenuessee, Cumberland, Ohio, and Illinois......... 6

James and Neuse ............................... 4

Tennessee, Ohio, and Illinois......................... 4

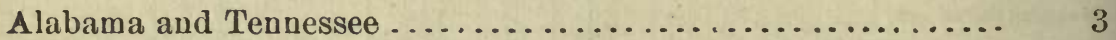

Savannah and Tenuessee ........................... 2

Alabama, Tennessee, and Cumberland ................. 2

Great Pedee and Santee.......................... 2

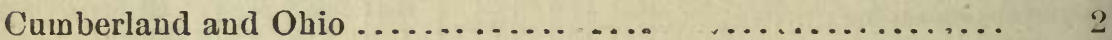

\section{Distribution of Genera.}

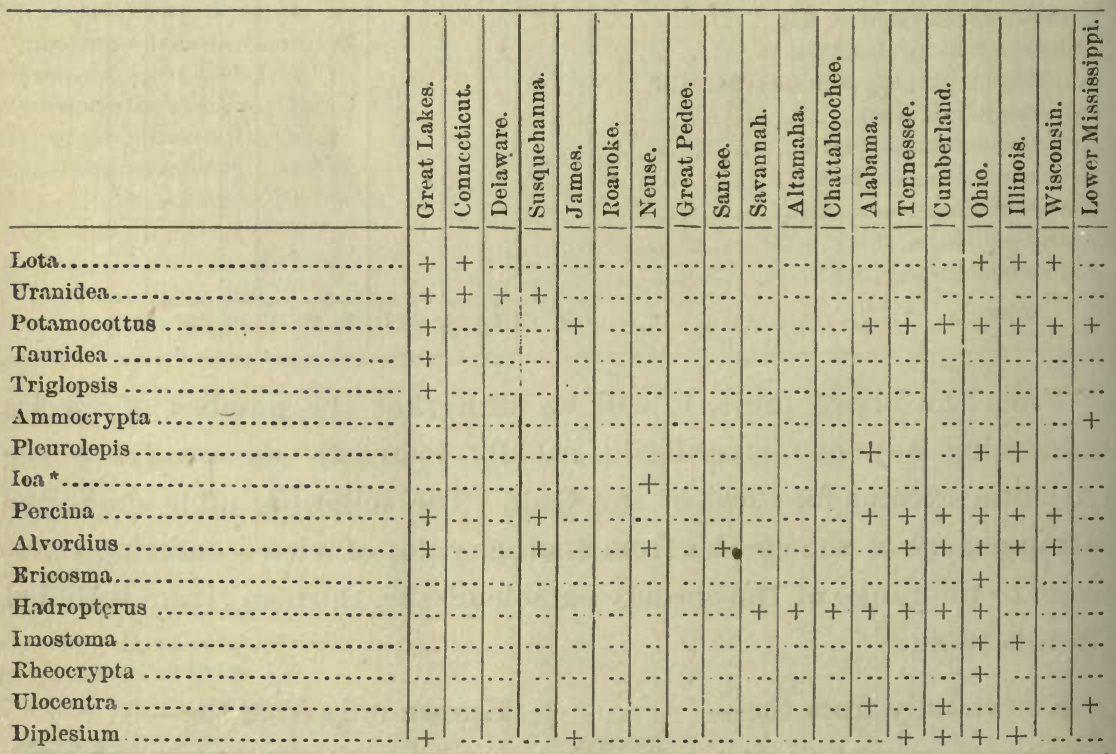

*IOA (J. \& B.), gen. nov.: type Pacilichthys vitreus Cope. This genus is distinguished from Peurolepis by the presence of two anal spines instead of one, and by the greater scaliness of the rentral region. The name is from tos, an arrow or dart. 
Distribution of Genera-Contiuued.

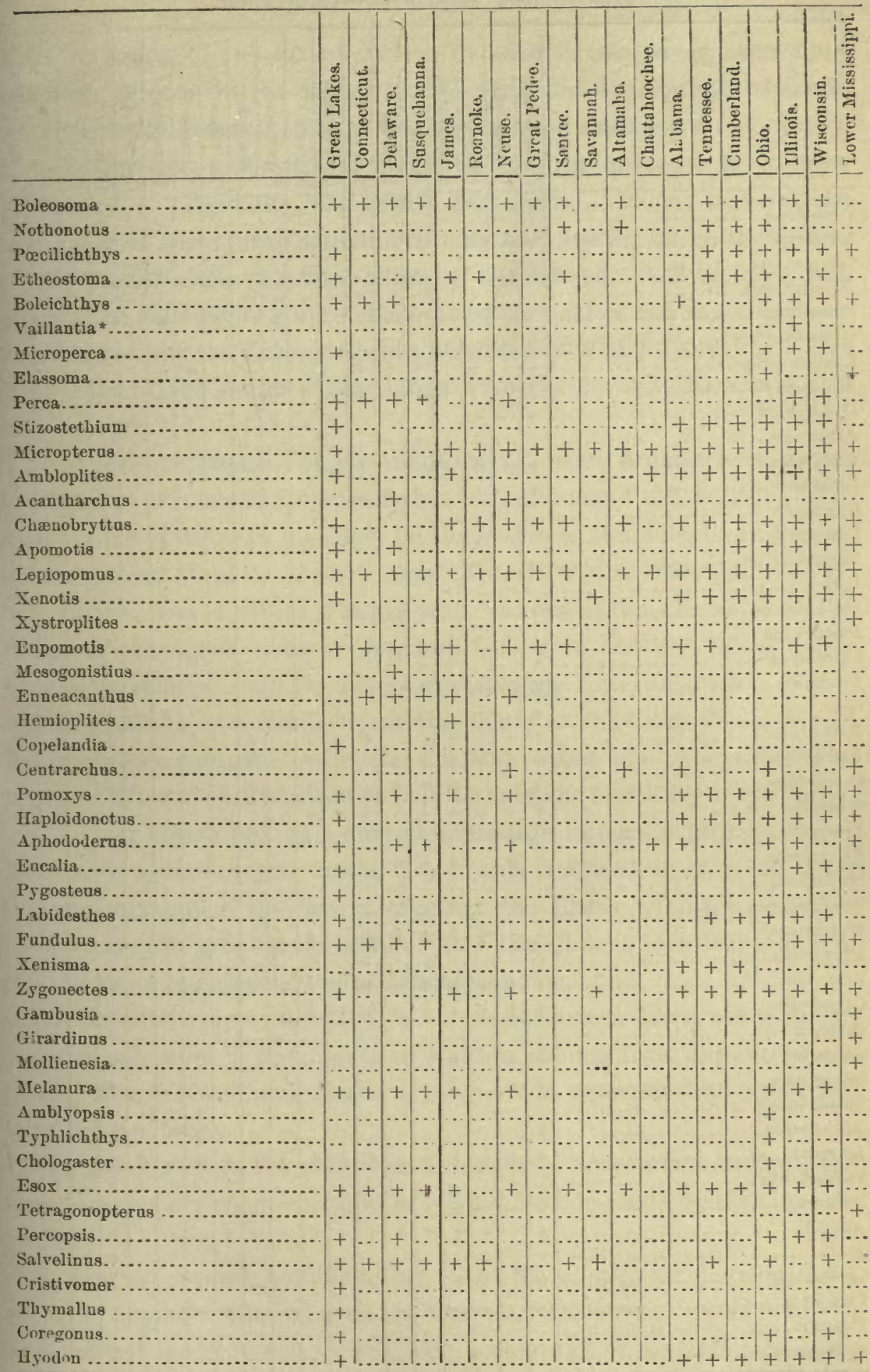

* Valllaxtla (jordan), gen. nov.: type Buleosoma Camurum Forbes. This genus differs from BBo $_{0}$ leichthys if having tho upper jaw protractile, and the anal spines very feeble. From Boleosoma, with which it agroes in thess respects, it is distinguished by the incomplete lateral line. It is named for Prof. Léon Vull unt, of Paris, whose thoroughly excellent monograph of the Etheostomatidoe is still the starting-point for all work ou that difficult but most interesting group. 
Distribution of Gencra-Continued.

\begin{tabular}{|c|c|c|c|c|c|c|c|c|c|c|c|c|c|c|c|c|c|c|c|}
\hline & 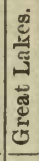 & 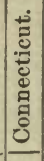 & 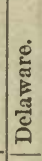 & 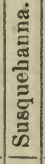 & 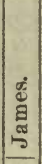 & 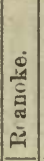 & & 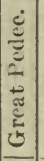 & & 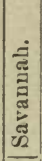 & 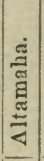 & 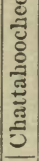 & 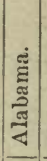 & 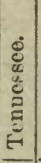 & 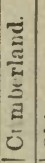 & 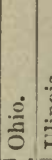 & 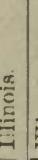 & & \\
\hline omolobus & t & & & & & & & & & & & & & t & +1 & t & + & & \\
\hline Dorosoma . & + & & & & & . & & & & & & .. & + & + & + & + & + & & \\
\hline Lampostoma & + & & & & + & + &.. & & + & & .. & + & + & + & + & + & + & & \\
\hline Aybognathu & ... & & t & & & ... & + & & + & & & $\cdots$ & ... & .. & $\cdots$ & t & + & & \\
\hline Pimephales & + & & & & & & & & & & & .. & & + & + & + & + & + & \\
\hline Hyborhyneh & + & & & & & $\cdots$ & & & & & & . & ... & .. & + & + & + & + & \\
\hline Luxilus (proper) & + & + & + & + & + & + & + & $\cdots$ & $\cdots$ & & & $\cdots$ & + & + & + & + & + & + & \\
\hline Photogenis. & t & $\cdots$ & + & + & + & $\cdots$ & + & t & + & + & $\cdots$ & + & ... & + & + & + & + & + & \\
\hline 1yaropl & + & .. & + & $\cdots$ & $\cdots$ & $\ldots$ & $\ldots$ & + & + & + & + & $\cdots$ & + & + & + & $\cdots$ & & & \\
\hline Idourno & + & .. & + & + & + & + & $\cdots$ & $\cdots$ & ... & & $\cdots$ & $\cdots$ & + & + & + & + & + & + & \\
\hline uasom & + & $\cdots$ & + & + & & $\cdots$ & + & $\cdots$ & + & & + & & & & $\cdots$ & ... & & & \\
\hline & + & & & & & t & & & & & & & & & + & t & + & + & \\
\hline & & & & & & & & & & & & & & & & t & & & \\
\hline & & & & & & & & ... & + & & + & + & + & + & & $\ldots$ & & & \\
\hline otI & + & .. & t & ... & .. & $\ldots$ & + & + & + & & ... & $\cdots$ & + & + & + & + & + & & \\
\hline 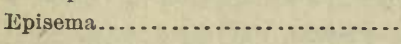 & & & & & & & & & & & & & & + & & + & & & \\
\hline bius . & $\cdots$ & $\cdot \cdot$ & -. & $\cdots$ & .. & $\cdots$ & . & & .. & & .. & .. & + & + & + & + & + & & + \\
\hline Hem & ... & + & + & + & $\cdots$ & . & . & .. & . & & .. & .. & $\ldots$ & + & + & $\ldots$ & + & + & \\
\hline $\mathrm{Cbrc}$ & + & $\ldots$ & $\ldots$ & + & + & + & & ... & . & & .. & .. & ... & + & + & + & + & + & \\
\hline Pho & + & $\ldots$ & $\ldots$ & + & $\ldots$ & $\ldots$ & .. & & .. & & .. & $\ldots$ & .. & + & & $\cdots$ & + & + & \\
\hline iila & + & $\cdots$ & + & $\ldots$ & + & + &.. & + & + & $x+2+3$ & $\cdots$ &.. & $\ldots$ & + & + & + & + & + & \\
\hline Notemigonv & t & + & + & + & $\therefore$ & $\ldots$ & + & + & + & .. & + & $\cdots$ & + & + & + & + & + & + & \\
\hline Rhin & + & + & + & + & + & + & $\cdots$ & $\ldots$ & ... & $\cdots$ & $\ldots$ & ... & + & + & + & + & + & + & \\
\hline erat & + & $\ldots$ & $\ldots$ & + & + & + & + & + & + & + & + & + & + & + & + & + & + & + & \\
\hline emo & + & + & + & + & + & $\ldots$ & + & + & + & $\ldots$ & + & $\cdots$ & + & + & + & + & + & + & \\
\hline rieym t & .. & & & & $\cdots$ & .. & & & & & $\cdots$ & & & & &.+ & & & \\
\hline rosto-8um & ... & .. & .. & + & + & + & .. & & .. & & . & .. & $\cdots$ & & . & + & & & \\
\hline > & ... & .. & &.. & & & .. & & .. & & .. & .. & .. & + & & + & & & \\
\hline $\mathrm{nx}$. &. & .. & & $\cdots$ & & & & & & & 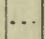 & .. & $\ldots$ & + & & + & + & & \\
\hline 1 a.... & + & $\cdots$ & + & + & + & + & + & + & + & + & + & + & + & + & + & + & + & + & \\
\hline ...... & + & ... & $\ldots$ & $\cdots$ & $\cdots$ & $\cdots$ & $\cdots$ & & + & $\cdots$ & $\cdots$ & $\cdots$ & + & + & + & $\begin{array}{llll}+ & & l & \end{array}$ & + & + & \\
\hline ........ & + & + & + & + & + & + & + & + & + & + & + & + & + & + & + & + & + & + & \\
\hline Catostomus .... & + & + & + & + & + & + & + & + & + & $\ldots$ & $\ldots$ & $\ldots$ & ... & + & + & + & + & + & \\
\hline $5 \mathrm{cl}$ & $\cdots$ & .. & & $\ldots$ & $\ldots$ & $\ldots$ & $\ldots$ & & & .. & .. & . & $\ldots$ & $\ldots$ & + & + & + & + & $f$ \\
\hline les..... & + & .. & $\ldots$ & + & . & $\ldots$ & .. & & & . & .. & . & + & + & + & + & + & & \\
\hline 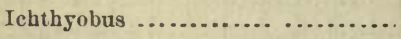 & I. & . & & ... & .. & . & .. & & & . & & . & .. & $\ldots$ & .. & + & + & + & \\
\hline ys... & $\cdots$ & ... & & $\cdots$ & $\therefore$ & .. & ... & . & & $\cdots$ & ... &.. & + & + & + & + & + & + & \\
\hline .... & + & ... & & $\cdots$ & $\cdots$ & ... & ... & $\cdots$ & $\cdots$ & + & + & + & + & + & + & + & + & + & \\
\hline & + & + & + & + & + & + & + & + & + & + & + & + & + & + & + & + & + & + & \\
\hline & & & & $\cdots$ & & $\ldots$ & & $\ldots$ & & & & & ... & + & + & + & + & + & \\
\hline & + & ... & + & + & + & ... & + & + & + & & ... & + & + & + & + & + & 4 & + & \\
\hline & + & + & + & + & + & + & + & + & + & + & + & + & + & + & + & + & + & + & \\
\hline & + & & & $\ldots$ & & ... & & .. & & & ... & & ... & + & ... & + & + & + & \\
\hline Ler & + & . & + & + & & ... & & + & + & & $\cdots$ & + & + & + & + & + & + & + & \\
\hline & $T^{2}+2+3$ & & & & & & & & & & & & & & & + & + & & \\
\hline Poly & & & & & & & & & & & 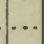 & & .. & t & t & + & + & & \\
\hline Acinenser & + & & & & & .. & & . & 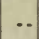 & & .. & & .. & + & ... & + & + & + & \\
\hline achops. & & & &.. & & . & & 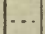 & & & 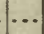 & & & & . & + & + & & \\
\hline 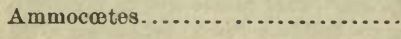 & + & & & $\cdots$ & & & & & & & ... & $\cdots$ & .. & ... & & + & + & + & \\
\hline Total...... & 69 & 21 & 35 & 32 & 32 & 19 & 29 & 19 & 28 & 1.2 & 19 & 15 & 40 & 59 & 56 & 83 & $\overline{63}$ & 65 & \\
\hline
\end{tabular}




\section{conCLUSIONS.*}

In the course of the investigations detailed in this paper, some light has been thrown on the laws which govern the distribution of freshwater fishes in general. The writer has collated the known facts into a series of general propositions, which, without any pretense to exhaustiveness or to originality, are here briefly stated. It may be premised that some of these propositions are ouly half truths, to be more completely stated when our knowledge of the sulject shall be increased. Most of the statements also refer chiefly to the smaller and non-migratory fishes, especially the Etheostomatidae, Centrarchida, and Cyprinida. Our knowledge of the range of the larger Catostomidee and Siluridce is still very meagre.

For the first statement of several of the following propositions, we are indebted to Professor Cope, who has ably discussed the sulject of the distribution of tishes in his paper on the Fishes of the Alleghang Region of Southwest Virginia, Journ. Acarl. Nat. Sc. Pbila. 1868, pp. 239-247.

I. In the case of rivers flowing into the ocean, the character of the funa of the upper waters, compared one with another, bears no, or very little, relation with the places of discharge. In illustration of this we may note $(a)$ the similarity of the faunæ of the Chattahoochee and Altamahi, as compared with the Chattahoochee and Alabama. The faunæ of Wisconsin River and of Red River of the North are very similar.

II. River-basins having a similar discharge into some larger river or lake bave a similarity of fauua, due to this fact, and, in general, other things being equal, the nearer together the places of discharge, if in fresh weter, the greater the similarity. The almost identical faunæ of the Catawha and the Saluda will illustrate this.

III. Parallel rivers tributiary to the same stream have, other things being equal, more in common than streams coming from opposite directions. The Wabash and Miami have more in common than either has with the Kentucky.

IV. The higher or the older the water-shed between two streams, the ferrer species are common to both. (This matter needs further in restigation.)

V. Certain species, not inclucling "species of general distribution", occur on opposite sides of even the highest watersheds. This fact was first noticed by Professor Cope. The occurrence of Luxilus coccogenis,

* An abstract of the remaining part of this paper appeared in the American Naturaiist for October, 1877 (pp. 607-613). For this part, Professor Jordan is alone responsible. 
Hydrophlox rubricroceus, Photogenis galacturus, and Catostomus nigricans, both in the Tennessee and Savannah, will illustrate this. Neither of the two first-named species are as yet known from any other river-basins.

VI. When the watershed between two streams is a swampy upland instead of a mountain.range, the same species may be found in the headwaters of both, although the species inhabiting the lower courses may be different. In case the ove stream flows northward and the other south. ward, the common fauna will be nearest like that of the northern stream.

In Northern Indiana, the same species are found in the waters of Saint Joseph's, Manmee, Wabash, and Illinois Rivers, although these streams discharge their waters in widely different directions. The swampy watershed between them is often overflowed in the spring, aftording to the smaller fishes an easy means of migration.

VII. In any river-basin, many of the species iubabiting small streams are different from those occurring in the river-channels. Among the brook species may be mentioned Eucalia inconstans, Precilichthys spectabilis, Xenotis lythrochloris, Xenisma stelliferum, Salvelinus fontinalis, Ericymba buccata, Semotilus corporalis, Chrosomus orythrogaster, the species of Rhinichthys, etc. Of chaunel species, Haploidonotus, Hyod,n, Dorosoma, Pomolobus, Roccus chrysops, all the "Buftalo fishes", and the larger Silurida, Ichthalurus punctatus, Pelodichthys olivaris, Amiurus nigricans, aud the like, will serve as examples.

VIII. Many species inhabiting the upper course of a stream are different from those of the lower. This sulject has been ably discussed by Professer Cope, but further investigations, especially of the rivers of the Southeru States, are very desirable.

IX. This difference between the upper famna and the lower is due to differences in the character of the rirer itself, such as climate, condition of water, character of river-bed, supply of food, etc.

$\mathrm{X}$. Hence, if in the same river basin there are two streams flowing into a larger stream, the one near its source, the other near its month, if the two streams are similar in all known physical respects, their faunæ will be similar, and if dissimilar, they will have different faunæ. The general identity of the faunæ of Elk River and Powell's Rirer may be noticed in this comnection.

XI. Some species of fishes are confined strictly to a single river-basin, while other species, with apparently no better means of diffusion or of defense, are widely distributed, inbabiting many rivers. In illustrition of this, the limited range of each of the species of Codoma may be com- 
pared with the range of Luxilus cornutus. In the genus Ceratichthys, C. biguttatus probably occurs in every stream from the Susquehanva to the Great Salt Lake, while four other species of the same genns, C. micro. pogon, C. monachus, C. zanemus, and $C$. labrosus, are each, so far as is known, contined to a single rirer-basin.

XII. In any river-basin, the most abundant species (of small fishes) are usually $(a)$ those peculiar to it, or $(b)$ those of the widest distribution. In illustration of this, we may notice the abundance of Codoma pyrrhomelas and Notropis photogenis in the Santee; of Codoma stigmatura and Luxilus cornutus in the Alabama; of Codoma eurystoma and Ceratichthys biguttatus in the Chattahoochee; of Codoma xcenura and Notemigonus americanus in the Ocmulgee. To this rule, however, there are many exceptious and modifications.

XIII. In general, the further sonth any rirer-basin lies, the more species are peculiar to it, and the greater the differences between its fauna and that of the neighboring streams. In illustration of this, tho differences existing between the faunæ of the Alabama aud Chatta. hoochee may be compared with those between the faunæ of the Susquehisnna and Delaware. Twelve genera are known to be common to the Clattahoochee and Alabama, and twenty-three to the Susquehanna and Delaware. In the Southern streams, the process of evolution of specific forms seems to have gone on more rapidls. This matter, bowever, requires further investigation.

$\mathrm{XIV}$. Species of the widest distribution often have breaks in their range which cannot be accounted for by any facts now in our possession. Luxilus cornutus, so abundant in all the waters of the North and West, does not occur, so far as is known, in any of the rives between the Neuse and the Alabama, in both of which streams it is abundant. Virious species range over sereral rirer-basins and then cease abruptly. Amiurus brunneus is abundant from the Santee to the Chattahoochee, in the latter river the most abundant food-fish, while in the very next riverbasin, the Alabama, it is unknown.

$\mathrm{XV}$. Many species of wide distribution which are absent in certain streams are there represented by certain other related species, which may be regarded as modified descendants. Thus, in the South Atlantic streams, Chanobryttus gulosus is represented by Chconobryttus viridis, Notemigonus chrysoleucus by Notemigonus americanus. In the Southwest, Eupomotis aureus is represented by Eupomotis pallidus; in the West, Noturus gyrinus by Noturus sialis, Noturus insignis by Noturus 
exilis, Noturus eleutherus by Noturus miurus, Melanura pygmaca by Me. lanura limi.

XVI. Other species under similar circumstances have no such representatives. The case of Luxilus cornutus will again illustrate.

XVII. Certain species have been known to extend their geographical range since the opening of the cinals. Such are more especially the migratory species of probably marine origin, as Dorosoma heterura, Pomolobus chrysochloris, and Anguilla vulgaris. These species are now abundant in Lake Michigan and Lake Erie, although formerly unknown there. The range of certain Percidae aud Centrarchidce has undoubtedly been extended by the same means.

XVIII. The characteristically American forms of fisbes are, generally speaking, rare or absent in the waters of New England and of the Pacific slope. This fact has been well stated by Professor Agassiz, who called New England "a zoological island".

About 105 genera of fresh-water fishes occur in the waters of the United States east of the Mississippi River. Of these, about 76 llo not occur in New England (exclusive of Lake Champlain, the fauna of which is nearly identical with that of Lake Ontario.) Of these 30 or fewer-genera occurring in New England, all but Salvelinus, Curegonus, Esox, Semotilus, Rhinichthys, and possibly Amiurus, are representerl by a single species each. From 30 to 35 genera occur in the waters of the Pacific slope.

XIX. The larger the river-basin, the greater its variety of forms, both genera and species. In the little Wbite River at Indianapolis, belonging to the Mississippi basin, 70 species, representing 48 genera, are known to oceur-bwice as many as inhabit all the rivers of New England.

$\mathrm{XX}$. Other things being equal, a river whose course lies in a region of undisturbed stratified rocks or of glacial drift contains most genera and species.

XXI. Conversely, rivers in regions of igneous or metamorphic rock contain fewest species.

XXII. Sources of streams on opposite sides of a high watershed often hare species in common which do not occur in the lower courses of the same rivers. The distribution of several mountain species, as Saivelinus fontinalis and Hydrophlox rubricroceus, will exemplify this.

XX!II. Certain species have a compact geographical range, occurring in all the rivers within this range, without apparent regard to the direction of their flow. Such are Lepiopomus obscurus in the Alabama, Ten- 
nessee, and Cumberland, and Alburnops microstomus in the James, Roanoke, Kentucky, Cumberland, and Clinch.

XXIV. Certain species have a wide east and west range, without apparent regard to the courses of the rivers, but are bounded on either the north or the south by parallels of latitude.

Eucalia inconstans occurs from Western New York to Kansas and northward, but it is nerer found sonthward of a line passing abont fifty miles south of Lake Erie. Percopsis guttatus has a like range, but its southeru boundary is in the Potomac and Ohio. Lota lacustris is similarly circunnscribed, but ranges farther to the east. The three species of Lythrurus have each a belt of latitude: L. cyanocephalus belonging to the Great Lakes and Upper Mississippi; L. diplamius to the Ohio and the Potomac; L. ardens to the Roanoke, James, and Cumberland. The three species of Hyodon are similarly arranged.

XXV. Certain species have a peculiar northern and eastern range, occursing in the waters of the Upper Mississippi, in the headwaters of the Illuols, Wabash, and Scioto, thence through the Great Lakes to New Englaud, thence to South Carolina on the eastern slope of the Alleghanies. Such species are Eupomotis aureus, Perca americana, and Amiurus catus.

XXVI. Certain species bave a peculiar northern and western range, oceuring in the Middle States and in the Great Lakes, and usually southward in the east to some point in Virginia or North Carolina, ceasily in the same latitude on both sides of the Alleghanies, but extending southwestward through the Mississippi Valley to the Gulf of Mexi o. Among these may be mentioned Luxilus cornutus, Notemigonus chrysoleucus, Ambloplites rupestris, Apomotis cyanellus. The dast-named species. however, scarcely ranges east of the Alleghanies.

XXVII. Certain species have a wide range north and south, either east or west of the Alleghanies, but do not cross that cbain. Of these may be wentioned Lepiopomus auritus, Enneacanthus olesus, Esox reticulatus, e., on the east, and Haploilionotus grunniens, Hyodon tergisus, Noture iniurus, Noturus sialis, etc., on the west.

$\mathrm{XXVII}$. The distribution of fresh-water fishes is dependent $(a)$ on fresh-wat er communication; $(b)$ on character of stream, $i$. e., of water-as to pur is, depth, rapidity, regatable growth, etc.; $(c)$ on the character of the river bed; $(d)$ on climate, as determined by latitude aud by eleration abore the seal ; and $(e)$ finally on various unkncrn factors arising from the nuture or past history of the species in question, and from the geo$\operatorname{logical}$ history of the rivers. 



\section{Ḅ.}

\section{A SYNOPSIS OF THE FAMILY CATOSTOMIDE.}

BY Davil, S. Jordan.

\section{Class PISCES.}

\section{SubCLASS TELEOSTEI.}

\section{Order TELEOCEPHALI.}

\section{SUBORDER EVENTOGNATHI.}

\section{Family CATOSTOMIDA.}

Catostomoida GrLt, Proc. Acad. Nat. Sc. Phila. v. 13, p. 8, 1861.

Catostomida Cope, Prce. Am. Assoc. Adv. Sci. v. 20, p. 332; 1872.

Catostomida Jordan, Man. Vert. E. U. S. p. 292, 1876.

Cyprinido gen. Rafinesque, Risso, Cuvier, Bonaparte, Girard, Blekker.

Cyprinidae subfam. Heckel, Agassiz, Bleeker, GÜNther.

The family of Catostomida, or the "Suckers", may be briefly defiued as follows:-Eventognathous fishes, having the pharyngeal teeth peetiniform, in a single row, closely approximated, very numerous, and compressed at right angles to the direction of the bone, and the intermaxillaries forming but a small part of the upper arch of the mouth, the maxillaries entering into it largely on each side.*

* The following more elaborate diagnosis is given by Professor Gill (Johnson's Universal Cyclopædia, vol.iv, p. 15:4) :- "The body varies between an elongated subcylin- drical and an oblong more or less compressed contour; the scales are of medium or rather large size, cycloid ; the lateral line is generally present and decurved, but some-

Bull. N. M. No. $12-7$ 
Larly writers on fishes, as well as most foreign ichthyologists, hare considered the Suckers as forming a mere tribe or subfamily of the Cyprinida, which group has been variously denominated Catostomi, Catostomina, and Catostomina, but the characters above noted, of teeth and mouth, seem to the writer to fully justify their separation as a distinct family: Tle dorsal fin in Catostomido is more developed than is

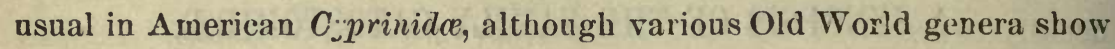
similar characters. The development of the lips and the great protrac. tility of the mouth are features ustally diagnostic, but in the genus Quassi'abia the mouth is scarcely protractile, and among our Cyprinidoe certain species of Phenacobius and Ceratichthys have thicker lips than have some of the Catostomidoe.

The Catostomido fall at once into three well-marked subfamilies, first indicated by Professor Gill, and termed by him Catostomina, Cycleptina, and Bubalichthyino. These may be charactericed as follows:-

Catostomince.-Body oblong or elongate, subterete or more or less compressed: dorsal fin nearly median, short and subquadrate, with from nine to eighteen developed rays : rentral fins under the dorsal, of nine or ten rass : anal fin high and short, normally of seven rays, nearer the base of the caudal th:ı that of the ventral fins: lips well developed, usually papillose or plicate: gill-rakers little developed. Genera Quassilabia. Placopharynx, Myxostoma, Erimyzon, Minytrema, Chasmistes, Catostomus, Pantosteus.

Cycleptina.-Body elongate, siender : dorsal fin falciform, of about 30 rays, beginning over the interval between the pectoral and ventral fins, and extending as far back as the beginning of the anal fin: ventral fins 10 rayed; anal fin small, of about 7 rays: bead extromely small: scales moderate, with the exposed surfaces broad : fontanelle entirely obliter-

tımes absent; the head is diversiform; the opercular bones normally developed; the nostrils double; the mouth more or less inferior, and provided with fleshy and generally papillose or crenated lips; the upper jaw is formed on the middle by the small and lamelliform intermaxillaries, and on the sides by the supramaxillaries; teeth are wanting in the jaw 3 ; the pharyngeal bones are developed in a falciform manner, and provided with a row of numerous comb-like teeth; the branchial apertures are restricted to the sides; brauchiostegal rays three on each side ; dorsal variable in development; anal posterior, and generally short and high; caudal large, and mure or less emarginated; pectoral fins low down, but lateral and with their rays branched; ventral fins abdominal ; the intestinal canal is very long; the stomach simple and destitute of pyloric cæca; the air-bladder is large, unprotected by an osseous capsule, and divided by transverse coustrictions into two or three regions." 
ated by the union of the parietal bones: mouth inferior, with thick papillose lips : gill-rakers moderate, soft. 'Genus Cycleptus.

Bubalichthyince.-Body stout, oblong-oval, and compressed. Dorsal fin elongate, beginning more or less in front of the ventral fins, and extending at least as far as the commencement of the anal, its rays 20 to 50 in number, the anterior ones more or less elongate: ventral rays usually 10: anal rays 8 to 12 : head stout and heary: mouth moderate or small, with thin lips: fontanelle open: gill-rakers of anterior arch long, slender, and stiff above, growing smaller downwards. Genera Carpiodes, Bubalichthys, Ichthyobus, Myxocyprinus.

As the chief purpose of this paper is to ascertain and make known the proper nomenclature of the ralid genera and species of Catostomidae, I shall omit further discussion of family and subfamily characters, and proceed at once to a catalogue of described species, arranged in chronological order, with the date and my identification of each species opposite its name. As is the case in nearly every group of American fishes, the number of nominal species is about three times the number really existing. It will be noticed that the number of species which I have admitted is in most of the Catostomoid genera fewer than has been recognized by previous writers. This seems to me to result not from any peculiar theories as to what constitutes a species, but from the fact that I have had a greater range of specimens of most forms than any previous writer has had. I am confident that in the presence of a still greater amount of material, the characters of several other species will be found to melt away. To indicate which these species are, in default of such material, would, howerer, be an unprofitable task. In this group, as in so many others, the truth well stated by Dr. Coues* becomes apparent:"We can only predicate and define species at all from the mere circumstance of missing links. 'Species' are the twigs of a tree separated from the parent stems. We name and arrange them arbitrarily, in default of a meais of reconstructing the whole tree according to Nature's ramitications."

- Birds of the Northwest, p. 227. 


\section{List of Nominal Species of Catostomida, with Identifications.}

\begin{tabular}{|c|c|c|}
\hline I.ominal species. & Date. & Identification. \\
\hline Cyprinus catostomus Forster.......... & 1773 & Catostomus longirostris. \\
\hline "Le cyprin commersonien" " Lacépède.... & $180: 3$ & Catostomus teres. \\
\hline Crprinus sucetta Lacépètle............. & 1803 & Erimyzon sucetta. \\
\hline Crprinus rostratus Tilesius........... & 1813 & (Catostomus) rostratus. \\
\hline Cృprınus teres Mitchill.............. & 1814 & C'atostomus teres. \\
\hline Cур: inus oblongus Mitchill....... & $1^{R 14}$ & Erimyzon sucetta. \\
\hline Catostomus cyprinus Le Sueur........ & 1817 & Carpiodes cyprinus. \\
\hline Catostomus gibbosus Le Sueur......... & 1817 & Erinyzon sucetta. \\
\hline Catostomus iuberculatus Le Sueur.... & 1817 & Erimyzon sucetta. \\
\hline Catostomus macrolepidotus Le Sueur.. & 1817 & Myxostoma macrolepidotum. \\
\hline Catostomus aureolus Le Sneur......... & 1817 & Myxostoma aureolum. \\
\hline Catostomus communis Le Sueur ...... & 1817 & Catostomus teres. \\
\hline Catostomus longirostrum Le Sucur.. & 1817 & Catostomus longirostris. \\
\hline Catostomus nigricans Le Sueur..... & 1817 & Catostomus nigricans. \\
\hline Catostomus maculosus Le Sueur.... & 1817 & Catostomus nigricans. \\
\hline Catostomus elongatus Le Sueur.... & 1817 & Cycleptus elongatus. \\
\hline Catostomus vittatus Le Sueur.......... & 1817 & Erimyzon sucetta. \\
\hline Catostomus duquesnii Le Sueur........ & 1817 & Myxostoma macrolepidotum duquesni. \\
\hline Catostomus bostoniensis Le Suenr... & 1817 & Catostomus teres. \\
\hline Catostomus hudsonius Le Suenr.... & 1817 & Catostomus longirostris. \\
\hline Catostomus bubalus Rafinesque ....... & 1818 & Ichthyobus bubalus. \\
\hline Catostomus erythrurus Rafinesque.... & 1818 & Myxostoma macrolepidotum duquesni. \\
\hline Exoglossum macropterum Rafivesque.. & 1818 & Catostomns nigricans. \\
\hline Amblodon niger Rafinesque ........ & 1819 & Bubalichthys sp. ? \\
\hline Crcleptus nigrescens Rafinesquo... & 1819 & Cycleptus elongatus. \\
\hline Rutilus melanurus Rafinesque..... & 1820 & Myxostoma macrolepidotum duquesni. \\
\hline Catostomus anisurus Rafinesque..... & 1820 & Myxostoma anisura. \\
\hline Catostomus anisopterus Rafinesque.... & 1820 & Carpiodes sp. \\
\hline Catostomus carpio Rafinesque........ & 1820 & Carpiodes carpio. \\
\hline Catostomus velifer Rafinesque...... & 1820 & Carpiodes velifer. \\
\hline Catostomus xanthopus Rafinesque... & 1820 & Catostomus nigricans. \\
\hline Catostomus melanops Raficesque...... & 1820 & Minytrema melanops. \\
\hline Catostomus fasciolaris Rafinesque .. & 1820 & Erimyzon sucetta. \\
\hline Catostomus flexuosus Rafinesque...... & 1820 & Catostomus teres. \\
\hline Catostomus megastomus Rafinesque... & $18: 20$ & A myth. \\
\hline Catostomus forsterianus Richarilson.... & 1823 & Catostomus longirostris. \\
\hline Catostomus lesueurii Richardson..... & $|1923|$ & Msyostoma anreolum. \\
\hline
\end{tabular}

*'This species is quoted by Dr. Günther as "Cyprinus commersonnii Lacépède". I have been unable to examine Lacépède's original work, but in the reprints of it, sup. posed to be literal, I find only the French form, "Le Cyprin Commersonien". Unless Lacépèdo really bestowed a Latinized specific name on the species, "commer soni" or "commersonianus" should not claim priority over teres of Mitchill. 
List of Nominal Species of Catostonida, with Identifications-Continued.

\begin{tabular}{|c|c|c|}
\hline Nominal species. & Date. & Identification. \\
\hline Cyprinus (Catostomus) sueurii Rich.... & $1 \times 36$ & Myxostoma aureolum? \\
\hline Csprinus(Catostomus) reticulatus Rich. & 1836 & Catostomus teres. \\
\hline Catostomus gracilis Kirtland.......... & 1833 & Catostomus teres. \\
\hline Labeo elegans DeKay ............ & 184: & Erimyzon sucetta. \\
\hline Labeo esopus DeKay................ & 1842 & Erimyzon sucetta. \\
\hline Catostomus oneida DeKay ........ & 1842 & My xostoma macrolepidotum. \\
\hline Catostomus pallidus DeKay.......... & 1842 & Catostomus teres. \\
\hline Labeo elongatus DeKay.............. & 1842 & Erimyzon sucetta. \\
\hline Catostomus fasciatus Le Sueur, MsS.... & 1844 & Minytrema melanops. \\
\hline Catostomus planiceps Valenciennes... & 1844 & Catostomus nigricans. \\
\hline Catostomus carpio Valenciennes ... & 1844 & Myxostoma carpio. \\
\hline Catostomus tilesii Valenciennes ... & 1844 & (Catostomus) rostratus. \\
\hline Sclerognathus cyprinella Valenciennes. & 1844 & Ichtbyobus bubalus. \\
\hline Catostomus forsterianus Agassiz....... & 1850 & Catostomus teres. \\
\hline Catostomus aurora Agassiz............ & 1850 & Catostomus longirostris. \\
\hline Catostomus latipinnis Baird \& Girard.. & 1853 & Catostomus latıpinnis. \\
\hline Carpiodes urus Agassiz ............... & 1854 & Bubalichthys urus. \\
\hline Carpiodes taurus Agassiz ............. & 1854 & Bubalichthys sp. \\
\hline Carpiodes bison Agassiz......... & 1854 & Carpiodes bison. \\
\hline Carpiodes vitulus Agassiz ......... & 1854 & Bubalichtbys sp. \\
\hline Carpiodes vacca Agassiz............... & 1854 & Carpiodes cyprinus. \\
\hline Castotomus congestus Baird \& Girard.. & 1854 & Myxostoma congestum. \\
\hline Catostomus clarki Baird \& Girard .... & 1854 & Catostomus clarki. \\
\hline Catostomus insignis Baird \& Girard... & 1854 & Catostomus insignis \\
\hline Catostomus plebeius Baird \& Girard... & 1854 & Pantostens plebeius. \\
\hline Carpiodes tumidus Baird \& Girard..... & $18: 4$ & Carpiodes cyprinus. \\
\hline Catostomus occidentalis Ayres.......... & 1854 & Catostomus occidentalis. \\
\hline Ichthyobus rauchii Agassiz...... & 1855 & Ichthyobus bubaius. \\
\hline Ichthyobus stolleyi Agassiz.... & 1855 & Ichthyobus bubalus. \\
\hline Moxostoma tenue Agassiz............. & 1855 & Erimyzon oblongus. \\
\hline Carpiodes thompsoni Agassiz ........... & 1855 & Carpiodes thompsoni. \\
\hline Bubalichthys niger Agassiz...... & 1855 & Bubalichthys urus. \\
\hline Bubalichthys bubalus Agassiz ..... & 1855 & Bubalichthys bubalus. \\
\hline Bubalichthys bonasus Agassiz......... & 1855 & Babalichthys urus. \\
\hline Catostomns occidentalis Agassiz....... & 1855 & Catostomus occidentalis. \\
\hline Catostomus labiatus Ayres ....... & 1855 & Catostomus labiatns. \\
\hline Carpiodes damalis Girard.......... & 1856 & Carpiodes cyprinus. \\
\hline Moxostoma claviformis Girard..... & 1856 & Erimyzon sucetta. \\
\hline Mnxostoma kennerlyi Girard ........... & 1856 & Erimjzon sucetta. \\
\hline Moxostoma victoriæ Girard ............ & 1856 & Mingtrema melanops. \\
\hline Moxostoma campbelli Girard.......... & 1856 & Erimyzon sucetta. \\
\hline Ptychostomus albilus Girard ...... .... & $1 \times 56$ & M5xostoma albidum. . \\
\hline Ptyehostomus haydeni Girard .......... & 1856 & Minytrema melanops. \\
\hline
\end{tabular}




\section{List of Nominal Species of Calostomida, with Identifications-Continued.}

\begin{tabular}{|c|c|c|}
\hline Nominal species. & Date. & Identification. \\
\hline Catostomus (Acomus) guzmanensis Gir. & 1856 & Catostomus latipinnis. \\
\hline Catostornus (Acomus) generosus Girard. & 1856 & Pantosteus generosns. \\
\hline Catostomus (Acomus) griseus Girard... & 1856 & Catostomus longirostris. \\
\hline Catostomus (Acomus) lactarius Girard. & 1856 & Catostomus longirostris. \\
\hline Catostomus macrocheilus Girard....... & 1856 & Catostomus macrochilus. \\
\hline Catostomus sucklii Girard............. & 1856 & Catostomus teres. \\
\hline Catostomus bernardini Girard.......... & 1856 & Catostomus occidentalis. \\
\hline Catostomus texanus Abbott ........... & 1860 & Catostomus teres. \\
\hline Catostomus chloropteron Abbott... & 1860 & Catostomus teres. \\
\hline Carpiodes asiaticus Bleeker........... & 1864 & Myxocyprinus asiaticus. \\
\hline Teretulus cervinus Cope............... & 1868 & Myxostoma cervinum. \\
\hline Sclerognathus meridionalis Günther .. & 1868 & Bubalichthys meridionalis. \\
\hline Placopharynx carinatus Cope.......... & 1870 & Placopharynx carinatus. \\
\hline Ptychostomus pappillosus Cope........ & 1870 & Myxostoma papillosum. \\
\hline Ptychostomus velatus Cope............ & 1870 & Myxostoma ve'atum. \\
\hline Ptychostomus collapsus Cope........... & $18 \% 0$ & Myxostoma velatum. \\
\hline Ptychostomus pidiensis Cope....... & $18: 0$ & Myxostoma pidiense. \\
\hline Ptychostomus coregonus Cope..... & $18 \% 0$ & Myxostoma coregouus. \\
\hline Ptychostomus albus Cope........... & 1870 & Myxostoma album. \\
\hline Ptjchostomus thalassinus Cope......... & $18 \% 0$ & Myxostoma thalassinum. \\
\hline Ptychostomus robustus Cope.......... & 1870 & Myxostoma macrolepidotur. \\
\hline Ptychostomus lachrymalis Cope... & 1870 & Myx. macrolepidotum lachrymase. \\
\hline Ptychostomus crassilabris Cope......... & 1870 & Myxostoma crassilabre. \\
\hline Ptychostomus breviceps Cope ...... & 1870 & Myxostoma anisura. \\
\hline Ptychostomus conus Cope.......... & 1870 & Myxostoma conus. \\
\hline Carpiodes difformis Cope........... & 1870 & Carpiodes difformis. \\
\hline Carpiodes cutisanserinus Cope.......... & $1<70$ & Carpiodes cutisanserinus. \\
\hline Carpiodes selene Cope............... & $1 \times 70$ & Carpiodes cutisanserinus. \\
\hline Carp:odes grayi Cope ............. & $18 \% 0$ & Carpiodes cyprinus. \\
\hline Carpiodes nummifer Cope .............. & 1870 & Carpiodes carpio. \\
\hline Catostomus discobolus Cope........... & $18 \% 2$ & Catostomus discobolus. \\
\hline Minomus delphinus Cope.......... & 1872 & Pantosteus (plebeius ?). \\
\hline Minomus bardus Cope $\ldots . . . \ldots \ldots \ldots . . . .$. & 1872 & Pantosteus (plebeius ?). \\
\hline Ptychostomus bucco Cope............. & 1872 & Myxostoma congestum. \\
\hline Minomus platyrhynchus Cope .......... & 1874 & Pantosteus platyrhynchus. \\
\hline Minomus jarrovii Cope................ & 1874 & Pantosteus generosus. \\
\hline Catostomus alticolus Copo............. & 1874 & Catostomus teres. \\
\hline Icbthyobus cyanellus Nelson.......... & 1876 & Bubalichtbjs bubalus. \\
\hline Pantosteus virescens Cop $\theta . . . \ldots \ldots \ldots . .$. & $18 \pi 6$ & Pantosteus virescens. \\
\hline Catostomus fecundum Cope \& Yarrow. & 1876 & $\begin{array}{l}\text { Chasmistes fecundus. } \\
\text { Catostomus teres. }\end{array}$ \\
\hline $\begin{array}{l}\text { Moxostoma trisignatum Cope......... } \\
\text { Ichthyobus ischyrus Nelson .......... }\end{array}$ & $\begin{array}{l}1876 \\
1877\end{array}$ & $\begin{array}{l}\text { Catostomus teres. } \\
\text { Ichthyobus bubalus. }\end{array}$ \\
\hline Bubalichthys altus Nelson............ & 1877 & Bubalichthys bubalus. \\
\hline
\end{tabular}


List of Nominal Species of Catostomida, with Identifications-Continued.

\begin{tabular}{|c|c|c|}
\hline Nouninal species: & Date. & Identification \\
\hline Myxostoma euryops Jordan ......... & $18 \pi 7$ & My xostoma euryops. \\
\hline Bubalichthys bubalinus Jordan........ & 1877 & Bubaliçthys bubalns. \\
\hline Myxostoma pœeilura Jordan....... & $1877^{\circ}$ & Myxostonia pœcilura. \\
\hline Lagochila lacera Jordan \& Brayton.... & 1877 & Quassilabia lacera. \\
\hline Erimyzon goodei Jordan ............. & 1878 & Ėrimyzon goodei. \\
\hline Catostomus aræopus Jordan........... & 1878 & Catostomus aræopus. \\
\hline Catostomus retropinnis Jordau ,....... & 1878 & Catostomns retropinnis. \\
\hline
\end{tabular}

ANALYSIS OF GENERA OF CATOSTOMIDE.

" Dorsal fin short, sabquadrate, with ten to eighteen developed rays: body oblong or elongate: gill-rakers feeble. (Catostomince.)

a. Mouth siugular, the upper lip not protractile, greatly eularged, the lower lip developed as two separate lobes : operculum very short: air-bladder in three parts: scales large : fontanelle well developed: lateral line present: pharyngeal bones and teeth ordinary...... QUASSILABIA, 1.

aa. Mouth normal, the lower lip entire or merely lobed, either tubercular or plicate.

b. Air-bladder in three parts: lateral line continuons: fontanelle present: scales large, subequal.

c. Pharyngeal bones very strong, with the lower teeth much enlarged, subcylindrical and truncate, the teeth of the upper part of the bcne small and compressed: mouth large, soméwhat oblique, with very thick

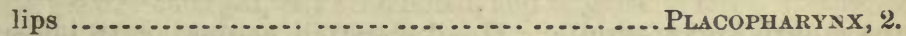

cc. Pharyngeal bones moderate, the teetb compressed, gradually larger downwards: mouth moderate or small, the lips usually plicate.

bb. Air-bladder in two parts.

Myхот́ота, 3.

d. Lateral liue interrupted or wanting : scales large (40 to 50 in the course of the lateral lice): lips plicate.

e. Lateral line incomplete, obsolete in the young, becoming developed in the adult, but always müre or less interrupted: mouth small, inferior.

Minytrema, 4.

ee. Lateral line entirely wanting: mouth somewhat oblique.. Erimyzon, 5. $d d$. Lateral line complete and continuous : scales small, 55 to 115 in the conrse of the lateral line.

$f$. Fontanelle present.

g. Mouth very large, terminal, oblique : lips thin, nearly smooth.

Chasmistes, 6.

gg. Mouth inferior, moderate or smail, with thick, papiilose lips.

Catostomus, 7.

$f f$. Fontanelle obliterated by the union of the parietal bones: mouth small, inferior, with thick, papillose lips, the lower jaw provided with a cartilaginous sheath........................ PANTosteus, 8. 


\section{4}

* Dorsal fin elongate, more or less elevated in front, of about 25 or more doveloped rays : air bladder in two parts.

tFontanelle obliterated by the union of the parietal bones: head short and small: body elongate. (Cycleptina.)

h. Mouth small, inferior, with very thick, papillose lips : scales small, 55 to 60 in the course of the lateral line .................... Cycleptus, 9. †t Fontanelle well developed : head large: body oblong or ovate: scales large, 35 to 45 in the course of the lateral line. (Bubalichthyinc.)

$i$. Dorsal rays in moderate number (24 to 33 ).

$j$. Mouth comparatively small, inferior, protractile downwards.

k. Pharyngeal bones narrow, with the teeth comparatively thin and weak.

Carpiodes, 10.

$k k$. Pharyngeal bones strong, the teeth comparatively coarse and large, increasing in size downwards...................... Bubalichtнys, 11 .

jj. Mouth quite large, terminal, protractile forwards: pharyngeal bones and teeth moderate: lips thin, nearly smooth .......... ICHTH yoBUs, 12.

ii. Dorsal fin very long, of about 50 developed rays .......... Mrxocyprinus, 13

\section{Genus QUASSILABIA Jordan \& Brayton.}

Lagochila Jordan \& Brayton, Proc. Ac. Nat. Sc. Phila. 280. 1877. (Preoccupied in conchology as Lagochilus.)

Quassilabia (JoRdan \& BraYton) Jordan, Man. Vert. E. U. S. ed. 2d, 401, 1878.

Type, Lagochila lacera Jordan \& Brayton.

Etymology, quassus, broken or torn; labia, lip.

Suckers like Myxostoma in every respect excepting the structure of the mouth and opercula. Head shortish, conical, with lengthened snout; its length $4 \frac{1}{2}$ to 5 times in that of the body, the opercular region being reduced, so that the eye is well backwards: suborbital bones narrow : fontanelle large, widely open. Mouth large, singular in structure, inferior, the upper lip not protractile, greatly prolonged, closely plicate. Lower lip much reduced, divided into two distinct elongate lobes, which are weakly papillose. The split between these lobes extends backwards to the edge of the dentary bones, which are provided with a rather hard, horny plate, as in Pantosteus. The lower lip is entirely separated from the upper at the angles by a deep fissure. The skin of the cheeks forms a sort of cloak over this fissure, the crease separating this skin from the mouth extending up on the sides of the muzzle. The crease between the lips extends down on the under side of the head. System of muciferous tubes well developed.

Pharyngeal bones not dissimilar from the usual type in Myxostoma, rather weak, with numerous small teeth.

Body elongate, not much compressed, not elevated. Fins moderate, of precisely the type usual in Myxostoma. 
Scales large, precisel. $y$ as in Myxostoma, the lateral line well dereloped and nearly straight, with about 45 scales in its course.

Air-bladder in three parts.

- Sexual peculiarities unknown; probably little marked.

But a single species of this genus is known. It is a sort of offshoot from the genus Myxostoma, but its uon-protractile mouth and singular lower lip wonld seem to indicate some real affinity with the genus Exoglossum.

The name Lagochilus had been previously applied to a genus of Gasteropods by Blanford, and to agenus of Insects by Loew. As Lagochila is substantially the same word, with the same etymology, and as, if written in strict correctness, it would be Lagochilus also, its authors have seen fit to substitute the name Quassilabia, and thus to forestall all discussion as to whether the name Lagochila should be retained. As this substitution was made soon after the origiual description of the genus, aud before the name Lagochila bad come into any general use, it is to be hoped that it will be accepted by succeeding ichthyologists.

\section{Generic Characterizations.}

LAGochila Jordan \& Brayton, 1877.- "Similar to Myxostoma (Ptychostomus Agassiz) except in the structare of the mouth parts. Dorsal fin short; lateral line well developed; scales large, subequal ; air-bladder in three parts; fontanelle between parietal bones well developed; pharyngeal bones weak, with numerous small teeth; upper lip not all protractile, greatly enlarged, but attennated, and siogular in form. It consists of two elongated and narrow lobes, separated by a narrow, deep fissure, which extends in ward to the edge of the mandible proper, which seems to be armed with a rather hard or almost horny plate, about as in the genus Pantostens. The two lobes of the lip are weakly papillose. The lower lip is entirely separated from the upper at the angles by a deep fissure. Over this fissure the skin of the chee's lies as a sort of cloak; the crease separating this skin from the mouth, exteuding np on the sides of the muzzle. The fissure between the lips extends down on the skin of the under side of the head. The opercle is extremely short and the eye is entirely $ı$ the posterior part of the head."(Jordan \& Braytox, Proc. Ac. Nat. Sc. Phila. p. 280, 1877.)

QUassilabia Jordan \& Brayton, 1878. - "When the name Lagochila was first proposed for this genus, its anthore were not aware that the masculine form, Lagochilus, had been already given to two different genera, to one of Gasteropods by Blanford, asd to one of Insects by Loew. The words Lagochila and Lagochilus are identical in etymology and in all except terminations, and many writers would consider them insufficiently distinct, and would hold that the name Lagochila should be changed. At present, I am inclined to the contrary opinion; nevertheless, as the matter stands, and as the name Lagochila bas not jet come into general use, less confusion perhaps will result from renaming the genus, than from any otber course. The name Quassilabin (Jordan \& Brayton) is accordingly suggesterl as a substitute for Lagochila, cousidered to be preoccupied in concbology. The etymology is quassus, broken or torn; labia, lip. 
- The case is precisely like that of the genus of Doves, Leptoptila Swainson, lately named EEchmoptila by Dr. Coues, on account of the previous Leptoptilus of Lesson."-(JORDAN, Bull. C. S. Geol. Surv. Terr. vol iv, No. 2, p. 418, 1878.)

\title{
ANALYSIS OF SPECIES OF QUASSILABIA.
}

"Head short, conical, with lengthened snout, the region between the eyes flattened 'and with prominent mucous ridges : cheeks and lower part of head rather swollen: opercle much reduced, its greatest length scarcely greater than the diameter of the eye : head abont $4 \frac{2}{8}$ in length : eye $4 \frac{1}{8}$ in length of head, about 2 in length of the snout, its situation thus quite posterior; length of the top of the head $1 \frac{2}{8}$ in the distance from the snout to the base of the dorsal. Body rather slender, the form being between that of Myxostoma cervinum and $M$. macrolepidotum, the depth $4 \frac{2}{8}$ in the length. Dorsal fin rather low; its rays I, $12 ;$ A. I, 7; V.9. Scales 5-45-5. Color olive or bluish-brown above; sides and belly silvery; lower fins faintly orange...LACERA, 1.

\section{QUASSILABIA LACERA Jordan \& Brayton.}

\author{
Hare-lip Sucker. Split-mouth Sucker. May Sucker of the Scioto. Cut-lips.
}

1877-Lagochila lacera Jokdan \& Brayton, Proc. Ac. Nat. Sc. Phila. 280, 1877.

Lagochila lacera JorDAs, Man. Vert. ed.2d, 311, 1878.

Quassilabia lacera JuRdaN, Man. Vert. ed. 2d, 406, 1878.

Quassilabia lacera Jordan, Bull. U. S. Geol. Surv. Terr. 418, 1878.

Habitat.-Tennessee River. Scioto River.

Only three specimens of this singular Sucker are yet known. Two of these were taken by Professor Brayton and myself in the Chickamauga River at Ringgold, Catoosa County, Georgia, and the other in Elk River near Estill Springs, Tennessee. In both these streams, the species was well known to the fishermen, who said that it is one of the most abundant species in those waters, and one of the most highly valued for food. In the Chickamauga, it is known as the Hare-lip or Split-mouth Sucker None of the specimens tak'n were mature, the largest being but ten inches long, so that its maximum size cannot be giren.

Since the above was written, a fine large specimen has been sent to me by J. H. Klippart, Esq., of the Ohio Fish Commission. It was taken in Scioto River near Columbus, in April, 1878. Mr. Klippart informs me that the species is well known to the Scioto fishermen, who call it May Sucker, as it runs up the river in May. That so strongly marked a spe. cies has so long estaped the attention of ichthyologists in the State of Ohio is singular.

Specimens in United States National Museum.

\begin{tabular}{c|c|c}
\hline Number. & Locality. & Collector. \\
\hline- & Chickannanga River .................................. Sordan. & D. S. \\
\hline
\end{tabular}




\section{Genus PLACOPHARYNX Cope.}

Placopharynx Cope, Proc. Am. Philos. Soc. Phila. 467, 1870.

Type, Placopharynx carinatus Cope.

Etymology, $\pi \lambda \grave{u} \xi$, a broad surface ; $\phi u ̈ \rho v \gamma \xi$, pharynx.

Suckers like Myxostoma in all respects, except that the pharyngeal bones are much more developed, and the teeth reduced in number, those on the lower half of the bone very large, 6 to 10 in number, nearly cylindric in form, being but little compressed, and with a broad, rounded or flattened grinding surface. The forms and positions of these enlarged teeth vary greatly. In a specimen before me, the first tooth is the highest and most compressed, its summit being rounded and then abruptly truncate. The second tooth is notably shorter and thicker, much larger, and rounded on top, the body of the tooth serving as a peduncle for the swollen grinding surface. The third tooth is still shorter and similar in form. The fourth tooth is similar to the first, being much higher than the second and third, and flat ou top. The others seem to be irregularly alternated or arranged in pairs, a long one and a short one, the long teeth in all cases being the most truncated, as if their surfaces had been most worn off.

As I hare at present no perfect specimens of this genus, nothing but very young specimens, and pharyngeal jaws of adults, I cannot do better than to copy Professor Cope's original description, which seems to be an accurate one. I substitute the generic names used in this paper (Myxostoma, etc.) for those used by Professor Cope (Ptychostomus, etc.), whenever a difference occurs :-

"Allied to Myxostoma. The pharyngeal teeth much reduced in number, only seren on the proximal half of the bone, cylindric in form, with a broad, truncate triturating surface. These play agaiust a broad, crescentic, chitin-like shield on the posterior roo $i$ of the pharyngeal carity. Three divisions of the vesica ratatoria.

"With a great superficial resemblance to Myxostoma, the masticatory apparatus is different from that of any Catostomoid form known to me, and combines peculiarities observed in some forms of true Cyprinidac. The chitin-like shield is found in some of the latter; it is represented in Catostomus, Myxostoma, and Carpiodes by a narrow and very thin pellicle of the same material, frequently interrupted in the middle line."

But one species of the genus is known. It is apparently widely distributed through the Mississippi Valley and the Great Lakes, but its 
peculiarities are rarely noticed unless the pharyngeal teeth are exposed. The writer has obtained four sets of the pharyngeal jaws and one entire skeleton, but has seen only two small specimens, collected by Professor Brayton in the Illinois River, and has obtained none in life.

Since the foregoing was written, I have collected numerous large specimens in the French Broad River, North Carolina, where it is the most abundant member of the family, known to all fisbermen as the "Red Horse". With a great superficial resemblance to the Northern Red Horse (Myxostoma macrolepidotum), Placopharynx carinatus differs from all the species of Myxostoma in its larger and more oblique mouth and extremely thick lips.

\section{PLACOPHARYNX CARINATUS Cope.}

\section{Big-jawed Sucker.}

1870-Placopharynx carinatus Cope, Proc. Am. Philos. Soc. Phila. 467, 1870.

Placopharynx carinatus Jornas, Fishes of Ind. 221, 1875. (Name only.)

Placopharynx carinatus Jordax, Man. Vert. 296, 1876.

Placopharynx carinatus Nelson, Bull. No. 1, Ills. Mus. Nat. Hist. 49, 1876.

Placopharynx carinatus Jordan \& Copeland, Check List, 158, 1876. (Name only.).

Placopharynx carinatus Jordan, Proc. Ac. Nat. Sc. Phila. 72, 1877.

Placopharynx carinatus Jordan \& Grubert, in Klippart's Rept. 53, 1877. (Name unly.)

Placopharynx carinatus Klippart, First Report Ohio Fish Commission, 86, 187\%.

Placopharynx carinatus Jondan, Bull. U. S. Nat. Mus. ix, 50, 187\%. (Name only.)

Placopharynx carinatus JoRdan, Man. Vert. ed. 2d,311, 1878.

Placopharynx carinatus Jokdan, Bull. U. S. Geol. Surv. vol. iv, No. 2, p. 417, 1878.

Habitat.-Mississippi Valley and Upper Great Lakes. Wabash River (Cope, Jordan). Scioto River. Ohio River. Detroit River. Illinois River. French Broad River.

The following is Professor Cope's description of this species:-

"The physioguomy and proportions of this sucker are those of the Pt. erythrurus or the 'red horse' of the Western Rivers.

"The lips are large and plicate, the anterior pendent like that of the $P$. collapsus, the posterior full like that of Pt. cervinus. Muzzle vertically truncate. Length of head in that of body four times; depth of body in same 3.66 times; scales $6-41-5$. Radii D. XIV, V.9, A. 7. Free margin of dorsal straight, not elevated anteriorly. Occipital region more elevated medially than in Pt. erythrurus, superior ridges well marked, with a special addition characteristic of this species, and of none other with which I am acquainted. This is a median longitudinal frontal ridge, extending from the fontanelle to between the nasal ridges. Only 
the posterior extremity of this ridge appears in some Ptychostomi. Orbit longitudinally oval, 4.5 times in length of head, twice in interorbital width. Type, fourteen inches in length.

"Color in alcohol like that of other species, uniform straw or whitish silvery.

"The pharsngeal bones of this species are much stonter than those of other species of its own and greater size, e. g., Pt. aureolus of eighteen inches, where they are comparatively slight. The exteroposterior ala is twice as wide as the body inside the teeth is deep, and but for its short base and narrowed tip would do for that of a Semotilus. But while there are seven broad teeth without heel or cusp on the basal half, there are at least forty on the distal half, they becoming more compressed and finally like those of other allied genera. There are fourteen with truncate extremities. The pharyngeal plate has narrow horns directed upwards and forwards, and is thickened medially. It is placed immediately in alvance of the opening of the cesophagus. I hare but one specimen of this curious species, which I obtained at Lafayette, on the Wabash River, in Indiana."

The writer has in his collection two young specimens obtained in Illinois River by Prof. Braston, a skeleton of a very large individual found in Scioto River by Dr. J. W. Wheaton, and a pair of pharyngeal bones taken by Dr. G. M. Levette from a fish taken in the Wabash at Terre Hante. I hare also seen a pair of pharyngeals and an air-bladder of one taken in Detroit River by Professor Baird, and now in the United States National Museum, and a jaw from "Post-pliocene" deposits near the Falls of the Ohio, found by Dr. John Sloan. The jars and airbladder above noticed are the only specimens of this species preserved in the National Museum.

Since the foregoing was written, the writer has obtained numerous living specimens of Placopharynx carinatus from the French Broad at Wolf Creek and other localities in North Carolina. From one of these, the following description was taken :-

Body oblong, moderately compressed, heavy at the shoulders: head very large, $3 \frac{2}{3}$ in length of the body : eye small, behind the middle of the head: mouth extremely large, the lower jaw oblique when the mouth is closed, the month, therefore, protractile forwards as well as downwards : lips rery thick, coarsely plicate, the lower lip full and heary, truncate behind: head above evenly rounded, in my specimens not showing the carination described by Professor Cope : scales 6-45-6 : dorsal rays 13 ; ventral 9: color brassy-green abore; lower fins red. 


\section{Genus MYXOSTOMA (Rafinesque) Jordan.}

Catostomus sp. LE SUEUR, and of all writers till 1855.

Moxostoma RAFrnesque, Ichthyologia Obiensis, 1820, 54. (Proposed as a subgenus for those species of Catostomus with eight ventral rays and the caudal lobes unequal: type $C$. anisurus Raf.)

Teretulus RAFINEsQUe, Ichthyologia Ohiensis, 1820, 57. (As a subgenns, to include those species of Catostomus with nine ventral rays: no type designated-most of the species recorded belong to the present genus. C. aureolus Le Sueur is the species first mentioned, and to this species and its relatives the name Teretulus was afterwards restricted by Professor (lope.)

Ptychostomus Agassiz, American Journal of Science and Arts, 1855, p. 203. (No type designated : the species mentioned are $P$. aureslus, $P$. mincrolepidotus, $P$. duquesnii, and $P$. melanops. $\quad P$. aureolus has been considered the type of the genus.)

Teretulus Cope, Journ. Ac. Nat. Sc. Phila. 1868, 236.

Moxostoma Jordan, Manual of Vertebrates, 1876, 295.

Myxostoma Jordan, Ann. Lyc. Nat. Hist. 1877, 348. (Corrected orthography.)

Etymology, $\mu \hat{\varepsilon} \xi \omega$, to suck ; $\sigma \tau^{\prime} \mu \alpha$, mouth.

Type, Catostomus пnisurus Rafinesque.

Borly more or less elongate, sometimes nearly terete, usually more or less compressed.

Head variously long or short, its length ranging from $3 \frac{1}{2}$ to $5 \frac{1}{2}$ in that of the body : eye usually rather large, varying from 3 to 6 times in the length of the side of the head, its position high up and median or rather posterior: suborbital bones very narrow, always much longer than broad, their width less than one-fourth that of the fleshy part of the cheel: fontanelle on top of head always well open, the parietal bones not coalescing.

Mouth varying much in size, always inferior in position, the mandible being horizontal or nearly so: lips usually well developed, the form of the lower varying in different sections of the genus, usually with a slight median fissure, but never deeply incised; the lips with transverse plicæ-the folds rarely so broken up as to form papillæ: jaws without conspicuous cartilaginous sheath : muciferous system considerably developed, a chain of tubes along the supraorbital region, a branch of which extends around behiud the eye and forwards along the suborbital bones and the lower edge of the preorbital : opercular bones moderately developed, nearly smooth : isthmus broad: gill-rakers weak, moderately long, in length about half the diameter of the eye.

Pharyngeal bones rather weak, much as in Erimyzon and Catostomus, 
the teeth rather coarser, strongiy compressed, the lower five or six much stronger than the others, wlich are rapidly diminished in size upwards, each with a prominent internal cusp.

Seales large, more or less quadrate in form, nearly equal in size over the body, and not specially crowded anywhere, nsually abont 44 in the lateral line ( 41 to 56), and about twelve series between dorsal and rentrals. Lateral line well developed, straight or anteriorly decurred.

Fins well dereloped, the dorsal inserted about midway of the body, its first rays usually rather nearer snout than the caudal, the number of dereloped rays usually about 13 , but rarying in different species from 11 to 17 : anal fin short and high, usually emarginate in the male fish, probably always with seven dereloped rays : ventrals inserted nearly under the middle of the dorsal; their number of rays normally 9 , occasionally varying to 10 ; the occurrence of ten ventral rass is probably an accidental individual character, and not a permanent specific one : caudal fin deeply forked, the lobes about equal, except in two species.

Air.bladder with three chambers: skeleton essentially as in Catostomus, the vertebræ in $\mathbf{M}$. carpio 27-14 (Günther).

Sexual peculiarities little marked, the males in the spawning season with the lower fins reddened, and the anal rays swollen and somewhat tuberculate.

This genus is widely diffused, some of its species occurring in all the waters of the United States east of the Rocky Mountains, excepting those of the New England States. Some of the more aberrant species seem to be quite local; other species are of the widest distribution. The principal species in the genus, although not the technical trpe, $M$. $m a$ crolepidotum, is very widely diffused, and is subject to much variation.

This genus is one readily recoguizable by external appearance, its species being known to the fisbermen as "Red Horse" and "Mullet"; those of other genera being called rather "Suckers". Its proper nomeuclature has, howerer, been a subject of considerable uncertainty.

The subgenus Moxostoma was originally proposed by Rafinesque to include $\boldsymbol{C}$. anisurus Raf., with the following diagnosis :- "Body oblong, compressed; head compressed, eight abdominal rays; dorsal fin commonly longitudinal; tail commonly unequally forked."

The characters here noticed are either common to several genera, or else merely specific, and the use of the generic name must depend on our identification of the original typical species. By some 


\section{2}

process of reasoning not now explainable, Professor Agassiz identified this with the common Chub Sucker of the West, a species which I con. sider 1dentical with Cyprinus oblongus Mitchill. He thus transferred the name Moxostoma from the "Red Horse" to the "Chub Sucker" group.. Rafinesque's description, howerer, renders it evident that his fish was one of the Red Horse kind; and as Moxostoma is the first generic name applied to species of that group, it must be retained in spite of the incompleteness of the original diagnosis.

Teretulus Rafinesque was proposed three pages later for "an extensive subgenus, to which belong all the following species of Le Sueur: C.au. reolus, C. macrolepidotus, C. longirostrum, C. nigricans, C. vittatus, C. maculosus, C. sucetta, besides the C. teres and C. oblongus of Mitchill." To these he adds his own species, C. melanops, C. melanotus (= Campo. stoma), C. fasciolaris, C. erithrurus, and C. flexuosus. This "omnium ga. therum" receives the following diagnosis:- "Body elongate cylindrical or somewhat quadrangular, 9 abdominal rays, dorsal fin coumonly small, tail equally forked."

A name proposed for a group of this kind, in the opinion of the pres. ent writer, should not be set aside, but should be retained for some one o: more of the species originally referred to it, and when any writer adopts such a geuus, he shall have the right to select any of the species as its type, and the name should be considered thereafter as applying to such typical species only, not to be revired in case such typical species be afterwards found to have bad a prior generic nanie. In case no such type has been selected by any author, then the "principle of exclusion" should be applied, and the name be retained for such species as may be left to the last, on subtracting from the mongrel group the different component genera in chronological order.

In this view, Teretulus, baving been by Professor Cope, in 1S68, restricted to $C$. aureolus Le S. and its affines, these being congeneric with species previously called Moxostoma, becomes a synonyu of Moxostoma, and cannot be used for a distinct genus. The principle of exclusiou, if unmodified, would require us to use the name Teretulus for those species left on subtracting Catostomus proper, Moxostoma, Campostoma, Erimyzon, and Hypentelium, i. e., in place of Minytrema.

Ptychostomus Agassiz was proposed for this same group, without reference to the two names conferred by Rafinesque. This genus was well cliaracterized by Professor Agassiz on the peculiarities of the scales 
and lips, although the species of Minytrema was inadrertentiy included in it. The most important generic feature, the tricellular air.bladder, was first noticed by Professor Cope.

- I have seen fit to change the orthography of the name from Moxostoma to Myxostoma, in accordance with its apparent etymology. This change is rather desirable from the fact that it tends to aroid confusion, the name Moxostoma having been commonly used in connection with a different genus.

The genus Myxostoma contains two well marked sections, typified respectively by $\boldsymbol{M}$. velatum and $\boldsymbol{M}$. macrolepidotum, and characterized by the form of the mouth and lower lip : that of M. velata being as in the genus Erimyzon; that of $\boldsymbol{M}$. macrolepidotum being of the character most common in this genus.

\section{Generic Characterizations.}

Moxostoma Rafinesque, 1820.-_"Body oblong, compressed; bead compressed, eight abdominal rays, dorsal fin commo 3 ly longitudinal ; tail commonly unequally forked."(Ichthyologia Ohiensis, p. 54.)

Teretulus Rafinesque, 1820.- " Body elongate cylindrical or somewhat quadrangular, 9 abdo.ninal rays, dorsal fics commonly small; tail equally forked. An extensive subgenus, to which belong all the following species of Le Sueur: C. aureolus, C. macrolepidotus, C. longirostrum, C.nigricans, C. vittatus, C. maculssus, C. sucetta, besides the C. teres and C. oblongus of Dr. Mitchill."-(Ich. Oh. p. 57.)

Prychostomus Agassiz, 1855.- "In respet to form of body and the structure and position of the fins, this genus dees not differ from Catostomus proper, but may be distinguished by the following structural peculiarities. The lips are marked by transverse ridges or folds, and hardly bilobed below; they are not papillated as in Catostomus proper. The generic name of this type is derived from this character of the lips The head is shorter and stouter. The dorsal is longer than it is high, but in the males, it is longer in proportion than in the females. The anal of the male is also broader than that of the female, and its lower margin lobed, while in the female it is trapezoidal and narrow.

"The ecales are as large on the anterior as on the posterior region of the body; their" verical diameter about as great as the longitudinal, so that the scales are nearly quadrangular, with rounded edges; the ornamental concentric ridges not longer nor broader upon the posterior than upon the lateral and auterior fields; the radiating furrows few, only one or two in the posterior field and one on each side limiting that field from the lateral fields; those of the anterior field are more numerous, and jet not crowded: Tube of the lateral line arising in the centre of radiation or farther back upon the posterior field.

"The pharyngeals are strong, their entire edge spreading like a wing, and that spreading margin is separated from the symphysis by a deep emargination. The teeth increasing rather rapidly in size from above downwards, are more apart from one

Bull. N. M. No. $12-8$ 


\section{- 114 CONTRIBUTIONS TO NORTH AMERICAN ICHTHYOLOGY-III.}

another than in the preceding genera, and arched inward as in Moxostoma, the inuer edge of the lower ones square, its inner margin rising into a broad cusp in the mirldle and upper teeth." -(American Journ. Sci. Arts, xix, p. 203.)

Teretulus Cope, 1868.- "The essential character of this genus is the division of the natatory bladder into three chambers, while Catostomus and all Cyprinidæ, exhibit but two. This feature is accompanied by plicate lips, as Agassiz has indicated, and nine rays to the ventral fin, already pointed ont by Rafinesque. The species are the largest scaled of the typical suckers. Le Sueur and Valenciennes have pointed out the generic features in the $P$. macrolepidotus; Prof. Baird informs me that it occurs in Pt. florealis Bd., and I find it in Pt. cervinus and Pt. duquesnii. It no doubt exists also in the Pt. aureolus. Other species described by Baird and Girard from the Sonthwest probably possess it.

"It is difficult to assign a name to this genus. Rafinesque proposes it upon untenable characters, and includes with it species of Moxostoma and Catostomus. Agassiz purged it of these elements, but did not express its essential character, apparently relying on the plicate lips. I have taken the older name, leaving for others the final decision."-(Journal Acad. Nat. Sci. Phila. 1868, p. 236.)

Pтrсhоsтomus Cope, 1870.- "The development of the lips furnish important diagnostic indications in this genus. In those most nearly allied to Moxostoma, the inferior lip resembles that of that genus in being varrower and deeply incised, emarginate posteriorly forming a figure $\mathbf{V}$ with the apex forwards, at the same time the superior lip is very thin and often narrow. Such species are shorter, and tend to a great development of dorsal fin. Others of this type are more elongate. Some species of both are distinguished by their very prominent conic muzzle and minute, inferior mouth, reminding one of the Carpiodes. In one species the lips are papillose instead of plicate. In some species, the mouth is very projectile, in others scarcely so at all.

"Rafinesque proposed a genus Teretulus on the characteristic peculiarity of nine ventral radii, belonging to most species of this genus. He however included species of two other genera. On this account, Agassiz, in rearranging the suckers, imposed on it the name standing at the head of this article, regarding the plicate lips as a primary character. I think Rafinesque's name is to be rejected, owing to its ill application; the more as $I$ find two species in which there are ten ventral radii. I adopt that of Agassiz, though I showed, when describing the Pt. cervinus, that the tricellular natatory bladder was a more distinctive feat ure. This becomes the more obvious now that I have found a species where the lips are tubercular instead of plicate."-(Proc. $\mathrm{dm}$. .Philos. Soc. Phila. p. 460.)

Moxostoma Jordan, 18\%6.- "Dorsal moderate, of 11 to 20 rays: air bladder in three parts: lips usually plicate: lateral line very distinct : pharyngeal teeth numerous and all small, of the usual type, the bones slender" (in comparison with those of Placopharynx).-(Man. Vert. E. U. S. p. 292.)

Moxоsтомa Cope \& Jordan, 1877.- "Body oblong or elongate, with a short subquadrate dorsal fin of 10 to 17 developed rays : air bladder in three parts : lateral line present: fontanelle present: scales large, subequal : pharyngeal bones not especially enlarged, the teeth of the usual type."-(Jordan, Proc. Acad. Nat. Sci. Phila. 1877, p. 81.) 
ANALYSIS OF SPECIES OF MYXOSTOMA.

- Lips distinctly plicate.

† Lower lip full, its posterior edge truncate, not infolded and " $\mathbf{\Lambda}$-shaped".

a. Species with the body distinctly compressed, the depth $3 \frac{1}{8}$ to nearly 5 in length.

b. Dorsal fin largely developed, its rays 15 to 18 in number : head rather large, $3 \frac{2}{8}$ to $4 \frac{1}{4}$ in length, broad above : mouth large, with full lips: eye rather large: body deep, strongly compressed, the back somewhat elevated, the depth about $3 \frac{1}{4}$ in length: dorsal fin high and large, larger than in any other species of the genus, the first ray about as long as the base of the fin: scales 5-43-4, quite large: coloration very pale and silvery, the lower fins white ............................................ 3.

$b b$. Dorsal fin moderate, its rayo 12 to 14 in number.

c. Scales large; 41 to 50 in the course of the lateral line.

d. Candal fin normal, the two lobes about equal and similarly colored.

e. Head singular in form, much shortened, the muzzle very abruptly decurved, descending almost perpendicularly in front of the eye: the head wedge-shaped from behind forwards, and less so from below npwards, its sides subvertical and the lower cross-diameter of the head greater than the upper.

$f$. Eye very large, more than one-third the length of the side of the head (in an individual of six inches in length): lips thin, very faintly plicate: width of head through the opercles greater than the thickness of the bedy: head $4 \frac{1}{8}$ in length; depth about the same: dorsal rajs 13 : scales 6-43-5: body shortish, closely compressed, the back somewhat elevated, and the candal peduncle unusually long in proportion : color smoky-blue; lower fins white: size probably small............................ EURYoPs, 4 .

c. Head normal in form, not as above.

g. Mouth moderate or large, not very small, nor very much overpassed by tho muzzle: lips thick, strongly plicate: body stoutish, rarying to moderately elongate: dorsal fin medium, its developed rays 12 to 14 , usually 13 in number: scales large, about 6-45-5: lower fins in the adult red or orange.

h. Head comparatively elongate, 4 to 5 in length: mouth large: size very large, reaching a length of two feet

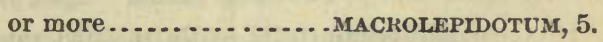

$x$. Head quite elongate, 4 to $4 \frac{3}{5}$ in length : back little elevated: body rather elongate, not greatly compressed : scales pretty large, 6-42 to 49-5: back bluish or olive; sides brilliantly silvery, with bright reflections; dorsal fin dusky above; lower fins bright red ...............duquesnii.

$x x$. Head a little shorter, $4 \frac{1}{8}$ to $4 \frac{3}{5}$ in length: form of the preceding: scales distinctly smaller, 7 or $8-48$ to $50-6$ : back with much smoky shading lachrymale. 
- Lips distinctly plicate-Continued.

$x x x$. Head still shorter and deeper, $4 \frac{1}{2}$ to 5 in length, its upper profile concurrent with the curve of the back, which is considerably elevated, the form being thus somewhat elliptical : sides compressed : dorsal rays usually 13 : coloration little silvery, the sides reflecting brownish and golden; back smoky, some of the scales dusky at base : scales $6-42$ to $50-5$.... macrolepidotum.

hh. Head comparatively short, low and small, 5 to $5 \frac{1}{2}$ in length; back elevated and compressed; depth $8 \frac{1}{8}$ in length : mouth rather small, more or less overpassed by the snout: coloration bright yellowish-brown, etc., not silvery; lower fins bright red : dorsal rays 13 : scales $6-4 \dot{2}$ to $48-5$ : size large.

AUREOLUM, 6.

gg. Mouth very small, much overpassed by the conic muzzle : head small, about 5 in length.

i. Body flattish, the back elevated and compressed; depth $3 \frac{8}{4}$ : muzzle contracted : scales large, 5-44-5: dorsal rays usually 12: dorsal fin elevated in front, its first soft ray longer than the base of the fin: color silvery, with smoky shading abore, some of the scales blackish at their bases; lower fins white; top of head, humeral bar, and dorsal fin dusky.

CRASSILABRE, 7.

ii. Body flattish, the dorsal outline elevated, the form being like that of $M$. coregonus: head small and conic: mouth exceedingly small, the snout far overpassing it, the muzzle being much longer than in $M$. crassilabre: dorsal rays 14 : eye large: coloration smoky above, some scales dusky at their bases ; sides pale; lower fins white...............coxus, 8 .

$d d$. Candal fin with the upper lobe falcate, much longer than the lower, at least in the adult, the lobes similarly colored: dorsal fin short and high, falcate: body compressed; back somewhat elevated; deptb $3 \frac{1}{2}$ in length: head conic, flattish, $5 \frac{1}{4}$ in leugth : mouth very small, much as in aureolum. D. 12-13, balf higher than long: scales 6-46-5.

ANISURA, 9.

ddd. Caudal fin with the lower lobe much longer than the upper and differently colored, the upper lobe in the adult being red, the inferior jet-black, its two lowermost developed rajs and their membranes abruptly white ( in both sexes). Body elongate, moderately compressed, somewhat elevated forwards; depth $4 \frac{1}{8}$ in length: head about the same: mouth medium, the lips full : dorsal rays 13 : scales large, 5-44-4: coloration usual, except of the caudal fin; other fius all red, with blackish shadings : size small......... PøecrLura, 10. 
"Lips distinctly plicate-Continued.

cc. Scales very small for the genus, about 9-56-8 in number : body moderately elongate, the depth about 4 in the length.

ee. Head shortish, conic, the snont not unuch projecting, about 4 in length : eye large: dorsal fin small, with about eleven rass, the last rapidly shortened (characters of mouth unknown, but probably similar to macrolepidotum and pecilura; it is said to be "much larger than in $P$. congestus") ............................. ALBIDUM, 11.

aa. Species with the body elongate, little compressed, broad, the depth about 5 in length, not very much greater than the thickness.

j. Head very short, roundish above, rather pointed forwards, about 5 in length : cheeks subvertical : mouth rather large, with thick lips, which are strongly plicate, the folds somewhat broken up: eje small: fins very small, the dorsal rajs 10 to 12 : scales rather large, 6-44 to $49-5$ : color greenish-brown, a pale blotch on each scale, these forming continuous streaks along the rows of scales: back with more or less distinct brownish cross-blotches; fins brownish, not much red; the dorsal blackish at tip : size smallest : length less than a foot . CERvintu, 12.

t+ Lower lip thin, not infolded and " $\Lambda$-shaped", forming a narrow, crescent-shaped border around the mandible.

$k$. Head small, 5 times in length: muzzle prominent, but less so than in $\boldsymbol{M}$. coregonus : mouth moderate: back a little elevated: depth about $3 \frac{1}{6}$ in length : dorsal rays 12 to 14 , its free border of incised : scales $6-45-5$ : coloration very pale; lower fins white: size large; reaches a weight of four pounds or more.............. ALBUM, 13.

$k i k$. Head stont, as in $M$. velatum, rather long, 4 in length, flattish above, muzzle truncate, not very prominent: mouth moderate: back elevated: dorsal fin long, of 14 or 15 rays: sea-green above; white below; lower fins white .......................... THALASSLNUM, 14 .

ttt Lower lip infolded, $\boldsymbol{\Lambda}$-shaped when viewed from below, with a distinct median crease, in which the two halves of the lip meet, forming an acute angle: mouth small.

l. Dorsal large, with 16 (15 to 17 ) developed rays.

$m$. Body stout, deep, compressed, the back elevated, the depth 3 to 4 in length : head short, heavy, flattish and broad sove, thick through the cheeks, $3 \frac{8}{4}$ to $4 \frac{1}{4}$ in length: eye rather large, midway in head, 4 to 5 in its length: muzzle rather prominent, bluntish, overhanging the very small mouth : fins very large: dorsal long and high, its height five-six ths the length of the head: pectorals nearly reaching ventrals . color silvery, smoky above; lower fins red : size large ......................... velatum, 15 . 
"Lips distinctly plicate-Continued.

ll. Dorsal moderate, with 12 to 14 ileveloped rays.

$n$. Head comparatively large, about 4 in length: dorsal rays usually 12.

o. Head short and very wide through the opereles, flat above: body stout, the back somewhat elevated, depth 4 in length: muzzle subtruncate, slightly projecting : scales 6-40-5 : olivaceous, silvery below; dorsal fin dusky.

CONGESTUM, 16.

oo. Head rather long, $4 \frac{1}{2}$ in length, flattish above: body elongate, more nearly cylindrical, little compressed: muzzle truncate: olivaceous, sometimes with rows of faint spots along the series of scales; dorsal and caudal fins black-edged: size quite small: resembles $M$. cervinum, but the mouth entirely different ......... PIDIENse, 17.

$n n$. Head very small, about 5 in length: muzzle conic, much projecting beyond the very small mouth; body broadly fusiform, much compressen, the back elevated and arched : dorsal rays 14 : color silvery, with plumbeous shades above; lower fins white: size small ......... COREgones, 18.

** Lips full, strongly papillose, much as in the subgenus Hypentelium.

p. Body comparatively stout, the dorsal region somewhat elevated and rounded, the depth being about 4 in length, the head about the same : eje rather large, high up and well back, the preorbital space being longer than in the other species : top of head flat: dorsal rays 12 to 14 : scales rather large, 6-42-5: lips well developed, deeply incised : color silvery; back with smoky shadiug; lower fins white: size large, reaches a length of about two feet

PAPILLOSUM, 19.

\section{MYXOSTOMA CARPIO (Valenciennes) Jordan.}

\section{Carp Mullet. White Lake Mullet.}

1844-Catostomus carpio Valenciennes, Cuv. et Val. Hist. Nat. des Poiss. xvii, 457, pl. 517.

Catostomus carpio Storer, Synopsis, 426, 1846.

Catostomıs carpio GÜNTHer, Cat. Fishes Brit. Mus. vii, 20, 1868.

Ptychostomus carpio Cope, Proc. Am. Philos. Soc. Phila. 476, 1870.

Ptychostomus carpio Jordan, Fishes of Ind. 221, 1875. (Name only.) 
Moxostoma carpio JordaN, Man. Vert. 296, 1876.

Teretulus carpio Nelson, Bull. No. 1, Ills. Mus. Nat. Hist. 49, 1876.

Teretulus carpio JondaN \& COPELAND, Check List, 157, 1876. (Name only.)

Moxostoma carpio Jordan \& GILBERT, in Klippart's Rept. Fish Comm. Ohio, 53, 1877. (Name only.)

Myxostoma carpio Jordax, Man. Vert. E. U. S. ed. 2d, 312, $18 \pi 8$.

Habitat.-Great Lake Region and northward. Also in the Ohio River.

This species is apparently not very common, and its distribution is probably chiefly northward. I bave obtained but one living specimen, a fine large one, from Lac des Buttes des Morts, in Northeastern Wisconsin. This specimen in life was extremely pale and silvery, its fins having none of the orange coloration common to most of the species. $M$. carpio is related to $M$. macrolepidotum, but the much greater derelopment of the dorsal will always distinguish it.

Specimens in United States National Museum.

\begin{tabular}{|c|c|c|}
\hline Number. & Locality. & Collector. \\
\hline 10793 & 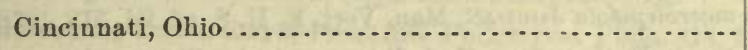 & J. W. Milner. \\
\hline 11214 & Alpena, Mich. (Lake Huron) ....................... & J. W. Milner. \\
\hline $122 \div 0$ & Cincinnati, Ohio.............. & J. W. Milner. \\
\hline 12271 & 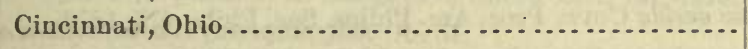 & J. W. Milner. \\
\hline 12293 & 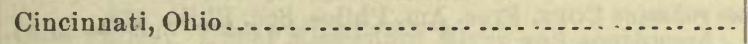 & J. W. Milner. \\
\hline- & Marietta, Ohio............. & Prof. Andrews. \\
\hline
\end{tabular}

\section{MYXOSTOMA EURYOPS Jordan.}

Snub-nosed Sucker.

1876-Teretulus euryops Jondan \& Copelaxd, Check List, 157. (Name only.) Myxostoma euryops Jond.ıN, Ann. Lyc. Nat. Hist. N. Y. xi. 348, $18 \pi 7$. Myxostoma euryops Jordas, Man. Vert. ed. 2d, 312, 1678.

Habitat.-Alabama River.

This species is still known only from the type-specimen obtained in Lovejoy's Creek, a small tributary of Oostanaula River, a few miles north of Rome, Ga. The species is most nearly related to $M$. macrolepidotum, and it is barely possible that the type-specimen is a monstrosity of that species. The peculiarities of the mouth, and the fact that the bones of the head seem to be normally developed, lead me to consider it a distinct species. 


\title{
5. MYXOSTOMA MAOROLEPIDOTUM (Le Sueur) Jordan.
}

\author{
Common Red Horse. Mullet. White Sucker. Large-scaled Sucker.
}

a. Subspecies macrolepidotum.

1817-Catostomus macrolepidotus Le Sueur, Journ. Ac. Nat. Sc. Phila. i, 94.

Catostomus macrolepidotus DeKAY, New York Fauna, part iv, Fishes, 202, 1842.

Catostomus macrolepidotus Cuvier \& Valenciennes, Hist. Nat. des Poissons, xvii, 447, 1844.

Catostomus macrolepidotus Stoler, Synopsis, 420, 1846.

Ptychostomus macrolepidotus AGassiz, Am. Journ. Sci. Arts, $2 d$ series, xix, 204, 1855.

Ptychostomus macrolepidotus Cope, Proc. Am. Philos. Soc. Phila. 475, 1870.

Ptychostomus macrolepidotus Jondan, Fishes of Ind. 221, 1875. (Name only.)

Moxostoma macrolepidotum Jordan, Man. Vert. 296, 1876.

Teretulus macrolepidotum Necsox, Bull. No. 1, Ills. Mns. Nat. Hist. 49, 1876.

Catostomus macrolepidotus Uhler \& LUGGer, Fishes of Maryland, 140, 1876.

Teretulus macrolepidotus Jordan \& Copeland, Check List; $\mathrm{x}, 157,1876$. (Name only.)

Moxostoma macrolepidota Jordan \& Gmbert, in Klippart's Rept. 53, 1876. (Name only.)

Myxostoma macrolepidota Jolnan, Man. Vert. E. U. S. ed. 2d, 313, 1878.

1842-Catostomus oneida DeKAY, New York Fauna, part iv, Fishes, 198.

Catostomus oneida STorer, Synopsis, 425, 1846.

Ptychostomus oneida Cope, Proc. Am. Philos. Soc. Phila. 4r6, 1870.

1870-Ptychostomus robustus Cope, Proc. Am. Philos. Soc. Phila. 473.

Teretulus robustus JoRdan \& Copeland, Check List, 157, 1876. (Name only.)

1876-Ptychostomus congestus Cope \& Yarrow, Lieutenant Wheeler's Expl. W. 100th Mer. v, 680, 1876. (Not of Girard.)

Habitat. - North Carolina to Vermont, and northwestward through the Great Lake Region and the Upper Mississippi-the only form of the species occurring east of the Alleghany Mountains. (Also in Arizona?)

b. Subspecies lachrymale (Cope) Jordan.

1870 - Ptychostomus lachrymalis Cope, Proc. Am. Philos. Soc. Phila. 474.

Teretulus lachrymalis Jordan \& Copeland, Check List, 157, 1876. (Name only.)

Myxostoma duquesnii var. lachrymalis Jondan, Ann. Lyc. Nat. Hist. N. Y. xi, 349, 1877.

Myxostoma macrolepidota var. Tachrymalis Jondax, Man. Vert. ed. 2d, 313, 1878.

Habitat.-North Carolina to Alabama.

c. Subspecies duquєsnei (Lo Sueur) Jordan.

1817-Catostonus duquesnii Le Sueur, Journ. Ac. Nat. Sc. Phila. 105.

Catostomus duquesnii Rafinesque, Ich. Ob. 60, 1820.

Catostomus duquesnii Knimtand, Rept. Zool. Ohio, 16 $\{$, 1838.

Catostomus duquesnii DeKay, New York Fauna, part iv, Fishes, 203, 1842. 
Catostomu duquesnii Cuvier \& Valencienses, Hist. Nat. des Poissons, xvii, $458,1844$.

Catostomus duquesnii Kirthand, Boston Jonrn. Nat. Hist. v, 268, 1845.

Catostomus duquesnii Storer, Synopsis, 42:3, 1846.

Ptychostomus duquesnii Agassiz, Am. Journ. Sc. Arts, 2d series, xix, 204, 1855.

Catostomus duquesnii Günther, Cat. Fishes Brit. Mus. vii, 18, 1868.

Teretulus duquesnei Copr, Journ. Ac. Nat. Sc. Phila. 236, 1868.

Ptychostomus duquesni Cope, Proc. Am. Philos. Soc. Phila. 476, 1870.

Ptychostomus duquesnei Jondax, Bull. Buffalo Soc. Nat. Hist. 95, 1876.

Moxostoma duquesnii Jondax, Man. Vert. 295, 1876.

Catostomus duquesnii UhLer \& LUGGer, Fishes of Maryland, 139, 1876.

Teretulus duquesnii Nelson, Bull. No. 1, Ills. Mus. Nat. Hist. 49, 1876.

Teretulus duquesnii Jondan \& Copelaxd, Check List, 157, 1876. (Name only.)

Moxostoma duquesnei Jordan \& GILBErT, in Klippart's Rept. 53, 1876. (Name only.)

Myxostoma duquesnii Jordan, Ann. Lyc. Nat. Hist. N. Y. xi, 349, 1877.

Myxostoma duquesnii Jordax, Bull. U. S. Nat. Mus. ix, 37, 187\%.

Myxostoma miacrolepidota var. duquesni Jordan, Man. Vert. ed. 2d, p. 313, 1878. 1818-Catostomus erythrurus, Rafixesque, Am. Montb. Mag. and Crit. Rev. 354.

Catostomus crythrurus RAFINESQUE, Ich. Oh. 59, 1820.

Catostomus erythrurus KIRTLAND, Rept. Zool. Ohio, 168, 1838.

Ptychostomus erythrurus Cope, Proc. Am. Philos. Soc. Phila. 474, 1870.

Ptychostomus erythrurus JoRdan, Fishes of Ind. 221, 1875. (Name only.)

Teretulus erythrurus JoRdan \& COPELAND, Check List, 157, 1876. (Name only.) 1820-Rutilus melanurus RAFINESQUE, Ich. Oh. 51.

Habiтat.-Ohio Valley. Upper Mississippi River and southward; most abundant from Wiscousin to Georgia.

Examination of a rery large series of "Mullet" and "Red Horse" from various parts of the country has led me to the conclusion, at first rather unexpected, that all the various forms included in the above synonymy belong to one widely diffused and somewhat variable species.

The "Mullet" of the lakes and of Eastern Pennsylvania appears generally to differ in the more elevated and compressed body, shorter, deeper head, and brownish or brassy rather than silvery coloration. This represents the general tendency of "var. macrolepidotum"; but specimens of "duquesnei" can be found which will match the average macrolepidotum in each of these respects. The form which $\mathrm{I}$ have identified with Professor Cope's lachrymale is to some extent intermediate, but has the additional peculiarity of smaller scales. In this respect, however, occasional individuals, both of duquesnei and of macrolepidotum, can be found which approach it.

The form inhabiting the waters of the eastern and northern parts of the United States is the variety macrolepidotum. It is sold commonly as a food- 
fish in the winter and spring in the markets of Washington and Philadelphia, as well as in the markets of those eities in the West which are supplied by the fisheries of the Great Lakes. It is probably much more abundant in Lake Erie than $M$. aureolum is, and it has been frequently coufounded with the latter species. I once obtained two specimeus, each of nearly twelve pounds weight, in the Fox River in IVisconsin.

In the Ohio River and its tributaries, and in the rivers of the Southwest generally, the var. duquesnii is the prevailing form. This variety is more delicately colored than the other, the silvery lustre of the stales is more strongly marked, and the red of the fins is rather more vivid. This form, too, is valued somewhat as a food-fish, although the flesh, like that of all the Suckers, is comparatively coarse, tasteless, and full of bones. The variety duquesnei is every where known by the curious vernacular name of "Red Horse", a name possibly to be accounted for by the color of the fins and the form of the head. This variety also grows to a large size.

The variety lachrymale I only know from specimens obtained in Etowah River, Georgia, in company with the variety duquesnei. Nothing distinctive was noticed in regard to its habits.

The Red Horse prefer rather deep, clear. water, seldom ascending very small streams, and then chiefly in the spawning season-in May-at which time they may be found in great abundance in any rapid of a river or a creek, or below a mill.pond. They are generally caught by nets, traps, or snares, but will frequently bite at a hook baited with a worm.

In the confinement of an aquarium, the Red Horse are not very hards. Foul water kills them at once.

Synonyms. - The earliest name given to a Red Horse is that of Catostomus macrolepidotus Le Sueur. The specific name macrolepidotus must therefore be retained for this species. The specific name oneida, given by DeKay to an individual from Oneida Lake, New York, doubtless belongs here, as the var. macrolepidotum is the only nember of this genus known to inhabit that part of New York, and there are no serious discrepancies in the rather poor description.

Ptychostomus robustus Cope may possibly be different; but as its describer has failed to note any distinctive characters which I consider likely to be permanent, I am compelled to refer it here. It is from Yad. kin River in North Carolina. A Ptychostomus congestus is described by Cope and Yarrow from Arizona. It is probably not Girard's species of 
that name, and I am unable to distinguish it from typical macrolepidotum, although the mouth is rather small, more like that of aureolum.

I have identified certain specimens with Professor Cope's $P$. lachrymale with a little doubt, as the points of differentiation which I notice are not those emphasized by Professor Cope. The original types, which I believe are now lost, were from the Neuse River in North Carolina. In describing this species, Professor Cope remarks, "This species is quite near the last ( $P$. erythrurus) aud may at some future time be shown to be a local variety of it, but in this case $P$. macrolepidotus must follow also."

The synouyins of var. Auquesnei may now be noticed. Of these, the only one of importance is that of Catostomus erythrurus Rafinesque, recently recognized by Professor Cope as a species distinct from $P$. duquesnii.

The presence of ten ventral rays in duquesnii, as contrasted with nine ventral rays in erytirurus, is the chief point on which Professor Cope relies to distinguish the two species. He also finds the mouth rather more inferior in duquesnii, and the scales rather smaller, 7-48-7, instead of $5-42-4$.

In regard to the number of ventral rays, my experience is that in erery species of the genus the normal number is nine, but that ten-rayed individuals oceur in the proportion of about one in twenty in any of the species. I have seen specimens of duquesnii with nine rays on one side and ten on the other. I have therefore discarded all consideration of the number of ventral rays as a specific character. In regard to the number of scales in the lateral line, the usual number in most of the species is 43 to 44 ; but of every species in which I have been enabled to examine a large series of indiriduals, I have found a range extending from 42 to 49 . I have seen ten-rayed specimens of duquesnei with large scales, and nine-rased erythruri with small ones. Within the limit of 42 to 50 I therefore do not consider the number of scales as a permanent specific character. The greater prominence of the muzzle in duques. $n e i$, as observed by Professor Cope, is perhaps accidental or individual. At all events, it is too uncertain a feature to base a species on.

The Rutilus melanurus of Rafinesque is, as I have elsewhere shown, probably a young Red Horse, with a disky-shaded dorsal and caudal, which that acute, but superficial, observer mistook for a species of Dace. 
Spccimens in United States National Museum.

\begin{tabular}{|c|c|c|}
\hline Number. & Locality. & Collector. \\
\hline & Var. macrolepidotum. & \\
\hline 7995 & & \\
\hline 8754 & "Probably North Carolina"......... & \\
\hline 9056 & …........................... & \\
\hline 10631 & Potomac River ....................... & J.W. Milner. \\
\hline 10682 & 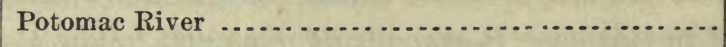 & J. W. Milner. \\
\hline 10689 & Potomac River .............. & J. W. Milner. \\
\hline 11106 & Potomac River ....... & J. W. Milner. \\
\hline 12316 & Potomac River ....................... & J. W. Milner. \\
\hline 12317 & Potomac River ...................... & J. W. Milner. \\
\hline 12318 & Potomac River ................ & J. W. Milner. \\
\hline 12319 & Potomac River .................. & J. W. Milner. \\
\hline 16755 & Ash Creek, Arizona ("congestus") ..... & Dr.J.T.Rockrock. \\
\hline 18251 & Potornac River ......................... & G. B. Goode. \\
\hline 18253 & Potomac River ................. & G. B. Goode. \\
\hline 18254 & Potomac River ........................ & G. B. Goode. \\
\hline 18255 & Potomac River .......................... & G. B. Goode. \\
\hline 18256 & Potomac River .................. & G. B. Goode. \\
\hline 18257 & Potomac River ........................ & G. B. Goode. \\
\hline 19451 & Potomac River .......................... & J.W. Milner. \\
\hline 20230 & Black River, New York. ..................... & S. F. Baird. \\
\hline 20263 & Nebraska, Pacific Railroad Survey ................. & Governor Stevens \\
\hline 20278 & 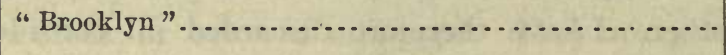 & J. C. Brevoort. \\
\hline & Var. duquesnii. & \\
\hline 8025 & Yellow Creek, Ohio ................ & S. F. Baird. \\
\hline 8526 & 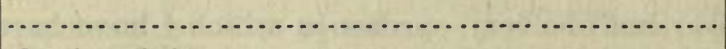 & \\
\hline 10794 & Cincinnati, Ohio ............................ & J.W. Milner \\
\hline 12268 & Cincinnati, Obio...$\ldots \ldots \ldots \ldots \ldots \ldots \ldots \ldots$ & J. W. Milner. \\
\hline 12269 & 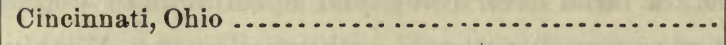 & J. W. Milner. \\
\hline $1227 \cdot 2$ & 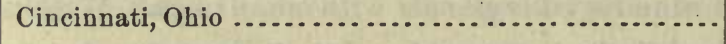 & J. W. Milner. \\
\hline 20040 & Cumberland River, Tennessee $\ldots . . . . . . . . . . . . .$. & A. Winchell. \\
\hline 20075 & 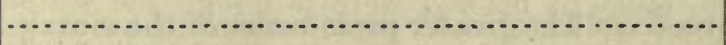 & \\
\hline 20773 & 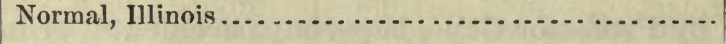 & S. A. Forbes. \\
\hline
\end{tabular}

\section{MYXOSTOMA AUREOLUM (Le Sueur) Jordan.}

\section{Golden Red Horse. Lake Mullet.}

1817-Catostomus aureolus LE SUeur, Journ. Ac. Nat. Sci. Phila. i, 95.

Catostomus aureolus KIRTI,AND, Rept. Zool. Ohio, 168, 1838.

Catostomus aureolus Kirtland, Boston Journ. Nat. Hist. iii, 349, 1840.

Catostomus aureolus DeKaY, New York Fauna, part iv, Fishes, 201, 1842. 
Catostomus aureolus STORER, Synopsis, 420, 1846.

Catostomus aureolus AGASsIz, Lake Superior, 357, 1850.

Ptychostomus aureolus Agassiz, Am. Journ. Sc. Aris, 2d series, xix, 204, 1855.

Ptychostomus aureolus Potram, Bull. Mns. Comp. Zool. 10, 1863.

Ptychostomus aureolus Cope, Proc. Ac. Nat. Sc. Phila. 28j, 1864.

Catostomus aureolus Gǘther, Cat. Fishes Brit. Mns. vii, 16, 1568. (In part; description apparently copied and confused.)

Ptychostomus aureolus Cope, Proc. Am. Philos. Soc. Phila. 476, 1870

Moxostoma aureolum JoRdAx, Man. Vert. 295, 1876.

Teretulus aureolum Nerson, Bull. No. 1, Ills. Mus. Nat. Hist. 49, $18 \% 6$.

Teretulus aureolus Jordan \& Copeland, Check List, 15\%, 1876. (Name only.)

Moxostoma aureola Jordax \& GiLbert, in Klippart's Rept. 53, 1876. (Name only.)

Myxostoma aureola Jordan, Man. Vert. E. U. S. ed. 2d, 314, 1878.

1823 -Catos omus lesueurii RichaRdson, Franklin's Journal, 772, 1823.

1336-Cyprinus (Catostomus) sueurii Richardson, Faun. Bor.-Am. Fishes, pp. 118, 303, 1836.

Catostomus sueurii CUv. \& VAL, Hist. Nat. des Poissons, Xvii, 465, 1844.

Catostomus sueuri DEKAY, New York Fanna, part iv, Fishes, 203, 1842.

Catostomus 8ueurii STORER, Synopsis, 425, 1846.

Ptychostomus sueurii Cope, Proc. Am. Philos. Soc. Phila. 477, 1870.

Teretulus sueurii Jordan \& Coreland, Check List, 157, 1876. (Name only.)

1868-Catostomus macrolepidotus Güxther, Cat. Fisbes Brit. Mus. vii, 18, 1868. (Excl. syn. part. Not of Le Sueur.)

Habitat.-Great Lake Region, Upper Missouri and Ohio Valleys, and northward.

This species is rery closely related to the last, and may possibly be a variety of it, as specimens of var. macrolepidotum often occur which are with difficulty distinguished from it. In general, howerer, the smaller head, smaller mouth, and deeper body of aureolum sufficiently distinguish them. This species is less abundant than macrolepidotum, and is apparently more northerly in its distribution. It has been well figured by DeKay.

The synonymy of this species needs no special remark. It seems probable that $C$. lesueuriu belongs here, although the statement that "the muzzle projects an inch beyond the mouth" in a specimen 19 inches long, if correct, would indicate difference. The name "le sueurii" was first given, and afterwards changed to "sueurii" on the ground that the article "le" is not an integral part of Le Sueur's name. 
Specimens in United States National Museum.

\begin{tabular}{|c|c|c|}
\hline Number. & Locality. & Collector. \\
\hline 7756 & & \\
\hline 8252 & 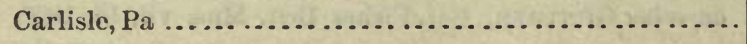 & S. F. Baird. \\
\hline 11074 & 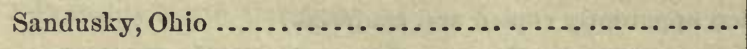 & J. W. Milner. \\
\hline 11151 & 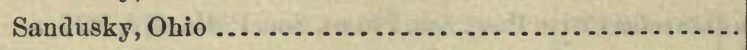 & J. W. Milner. \\
\hline 12267 & Cincinnati, Ohio...$\ldots \ldots \ldots \ldots \ldots \ldots \ldots \ldots \ldots \ldots \ldots \ldots \ldots$ & J. W. Milner. \\
\hline 12294 & 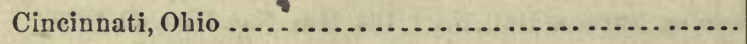 & J. W. Milner. \\
\hline 12446 & 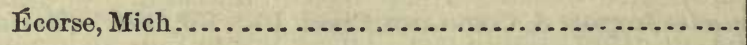 & J. W. Milner. \\
\hline $202 \% 2$ & 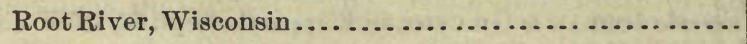 & S. F. Baird. \\
\hline
\end{tabular}

7. MYXOSTOMA CRASSILABRE (Cope) Jordan.

Thick-lipped Mullet.

1870-Ptychostomus crassilabris Cope, Proc. Am. Philos. Soc. Phila. 477, 1870.

Teretulus crassilabris JoRdaN \& CoPELAND, Check List, 157, 1876. (Name onl 5.)

Myxostoma crassilabris Jordan, Man. Vert. ed. 2d, 314, 1878.

Habitat.-Neuse River, North Carolina.

This species is known only from Professor Cope's description. It appe:irs to be distinct from $M$. aureolum, which is probably its nearest relative. Nothing has been noted in regard to its habits.

\section{MYXOSTOMA CONUS (Cope) Jordan.}

\section{Long-nosed Mullet.}

1870-Ptychostomus conus, Cope, Proc. Am. Philos. Soc. Phila. 478.

Teretulus conus, JoRdan \& Copeland, Check List, 157, 1876. (Name only.)

Myxostoma conus, JoRdax, Man. Vert. ed. 2d, 314, 1878.

Habitat.-Yadkin River, North Carolina.

This species is also known only from Professor Cope's account. There appears, however, to be no room for doubt as to its specific distinction. As stated by Professor Cope, "this fish represents the $P$. coregonus in the section with fully-developed lips."

It is taken in large numbers in the Yadkin River, "with Pt. collapsus, Pt. robustus, etc., but is of less value than they."

\section{MYXOSTOMA ANISURA (Rafinesque) Jordan.}

\section{Long-tailed Red Horse.}

1820-Catostomus anisurus RAFINESQue, Ichthyologia Ohiensis, 54.

Myxostoma anisura JoRdan, Man. Vert. ed. 2d, 315, 1878. 
1870-Ptychostomus breviceps Cope, Proc. Am. Philos. Soc. Phila. 478.

Teretulus breviceps JoRdan \& Copeland, Check List, 157, 1876. (Name only.)

Moxostoma breviceps JoRDAN \& GILBERT, in Klippart's Rept. 53, 1876. (Name only.)

Myxosioma breviceps JoRdan, Bull. U. S. Nat. Mus. 9, 50, 1877. (Name only.)

Habitat.-Ohio Valley and Great Lakes.

This species, first described by Rafinesque in 1820, has been entirely lost sight of by succeeding writers, and I, doubting the existence in the Ohio River of a species characterized by the marked inequality of the caudal lobes, bave hitherto followed Dr. Kirtland in using the name anisura for the fish recently named collapsus by Professor Cope. Some specimens lately examined by me from the Ohio River have shown the existence of a fish corresponding very closely to Rafinesque's account, and which really has the inequality of the caudal fin, on which he lays such emphasis, and which suggested the name anisurus (unequal-tail). This fish appears to be the same as that to which Professor Cope has given the name of breviceps. Professor Cope had, however, but a single specimen, in poor condition, and did not notice the falcation of the caudal, or, more likely, that fin was not preserved intact. I have, some time since, examined Professor Cope's type, preserverl in the Museum of the Academy of Natural Sciences, at Philadelphia, and beliere it to be identical with $M$. anisura Raf. The form of the head and borly and of the mouth are similar in the two, and the dorsal in both is similarly falcate.

This species resembles aureolum in every respect, except that the dorsal fin is shorter, and elevated or falcate in front, the free border being deeply incised, and that the caudal fin is similarly elongated, the upper lobe being much the longer and greatly attenuated.

The following are the measurements of three specimens: 10,788 , from Sandusky, and 12,267 and 12,294 from Cincinnati. The fractions indicate percentage of the length to the base of the caudal :- 
Measurements of three specimens of Myxostoma anisura.

\begin{tabular}{|c|c|c|c|}
\hline 34 & 10788. & $1226 \%$. & 12394. \\
\hline Length, inches................ & $2 \frac{1}{4}$ & $8 \frac{8}{4}$ & $10 \frac{1}{4}$ \\
\hline Depth ....................... & .28 & .27 & .26 \\
\hline 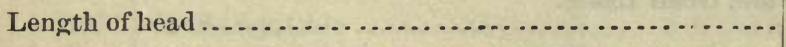 & .18 & .17 & .18 \\
\hline Width of interorbital area ................... & .08 & ........ & -....... \\
\hline Length of snout.................. & $.07 \frac{1}{2}$ & & \\
\hline Eve ............................... & .05 & ....... & ....... \\
\hline Length of luase of dorsal....................... & $.15 \frac{1}{2}$ & $.14 \frac{1}{2}$ & .16 \\
\hline Height of longest ray of dorsal............... & .22 & .22 & $.23 \frac{1}{8}$ \\
\hline Height of last ray of dorsal ................. & .10 & ....... & ….... \\
\hline Length of upper caudal lobo................... & .31 & .29 & .31 \\
\hline Length of lower caudai lobe................ & .26 & .25 & .25 \\
\hline Length of middle caudal rays............. & .13 & (.......... & ...... \\
\hline 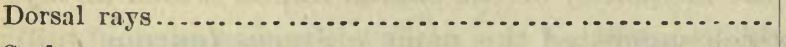 & 2,13 & 2,12 & 2,13 \\
\hline 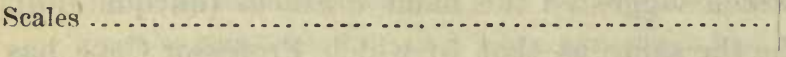 & $6-46-5$ & $6-45-5$ & \\
\hline
\end{tabular}

It is perhaps barely possible that this fish is the male of aureolum at a certain age, but it seems to me decidedly improbable. The resemblance between the two is, however, very strong, and, except for the fins, they conld hardly be distinguished.

Specimens in United States National Museum.

\begin{tabular}{|c|c|c|}
\hline Namber. & Locality. & Collector. \\
\hline 8505 & $\ldots . .$. & \\
\hline $10 \pi 88$ & Sandusky, Ohio........... & J. W. Milner. \\
\hline 11105 & Cincinnati, Ohio.. & J. W. Milner. \\
\hline 11107 & Cincinnati, Ohio ................ & J. W. Milner. \\
\hline 11108 & Cincinnati, Ohio ............ & J. W. Milner. \\
\hline
\end{tabular}

10. MYXOSTOMA PQECILURA Jordan.

Variegated-tailed Red Horse.

1877-Myxostoma pocilura Jonds, Bull. U. S. Nat. Mus. x, 66, 1877.

Myxostoma pocilura Jordax, Man. Vert. ed.2d, 315, 1878.

Habitat.-Tangipahoa River, Southeastern Louisiana.

This singular species is known only from two specimens in the United States National Museum, recently collected by Mr. Fred. Mathcr, of the United States Fish Commission. Whether the peculiar form and coloration of the caudal is general or is confined to the male sex is not certain. In any event, it will serve to sharply distinguish this species from all the others now known. In other respects, it most approaches M. macrolepidotum lachrymale. 
Specimens in United States National Museum.

\begin{tabular}{c|c|c}
\hline Number. & Locality. & Collector. \\
\cline { 2 - 2 }${ }^{*} 16928$ & Tangipahoa River, Louisiana....................... Fred. Mather. \\
\hline
\end{tabular}

11. MYXOSTOMA ALBIDUM (Girard) Jordan.

Small-scaled Red Horse.

185̌6-Ptychostomus albidus Grrard, Proc. Ac. Nat. Sci. Phila. 172.

Ptychostomus albidus Girard, U. S. Mex. Bound. Surv. Ichth. 36, pl. xix, f. 5-8, 1859.

Teretulus albidus Jordan \& Copeland, Check List, 157, 1876. (Name only.) Myxostoma albidum Jordan, Man. Vert. E. U.S. 315, 1878.

Habrtat.-Rio San Juan, near Monterey, New Leon, in Mexico.

This species is known ouly from Girard's figure and description. No account of the lips is given, but the mouth is said to be a "great deal larger" than in $M$. congestum. The description is trivial, but the figure, if at all correct, represents a species quite unlike our other members of the genus; the chief character being the much smaller size of the scales, which in the description are merely stated to be "smaller than in congestus". The species may possibly belong to some section of the genus other than the one in which it is here placed. The original types, No. 170, U. S. Nat. Museum, from Rio San Juan, near Monterey, New Leon, are no longer to be found.

\section{MYXOSTOMA CERVINUM (Cope) Jordan.}

Jump-rocks. Jumping Mullet.

1868-Teretulus cervinus Cope, Journ. Ac. Nat. Sci. Phila. 236.

Ptychostomus cervinus Cope, Proc. Am. Philos. Soc. Phila. 478, $18 \% 0$.

Moxostoma cervinum Jordan, Man. Vert. 296, 1876.

Teretulus cervinus JoRdan \& Copeland, Check List, 157, 1876. (Name only.)

Myxostoma cervinum JordAN, Ann. Lyc. Nat. Hist. N. Y. xi, 365, 1877.

Myxostoma cervinum Jordan, Man. Vert. E. U. S. ed. 2d, 315, 1878.

1868-Catostomus duquesnii Günther, Cat. Fishes Brit. Mus. vii, 483. (Not of Le

Sueur, nor of p. 18.)

Habitat.-Rivers of the South Atlantic States, from the James to the Chattahoochee.

This is a strongly marked and very abundant species, the smallest of its genus, and one of the smallest of the Catostomida. It occurs in the

*Two specimens, types of the species.

Bull. N. M. No. $12-9$ 
greatest abundance in the swift streams of the Soutb, frequenting especially the rapids or "shoals", and often throwing itself from the water in its endeavors to reach some higher rock-pool. It is too small and the flesh spoils too quickly to be much valued for food, but great numbers are caught for "fun" by negroes and boys. The largest specimens which $I$ have seen were taken in the CLattahoochee, and are about ten incles in length; ordinary individuals are four to six inches long.

Specimens in United States National Museum.

\begin{tabular}{|c|c|c|}
\hline Number. & Locality. & Collector. \\
\hline 7633 & .................... & \\
\hline 8835 & 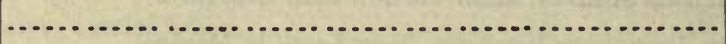 & \\
\hline *14994 & 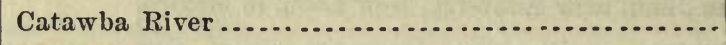 & E. D. Cope. \\
\hline- & Ocmulgee River $\ldots . \ldots \ldots \ldots \ldots \ldots \ldots \ldots \ldots \ldots \ldots \ldots$ & D. S..Jordan. \\
\hline - & Saluda River $\ldots \ldots \ldots \ldots \ldots \ldots \ldots \ldots \ldots \ldots \ldots \ldots \ldots$ & D. S. Jordan. \\
\hline - & 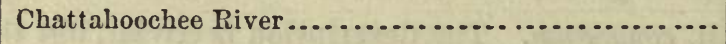 & D. S. Jordan. \\
\hline
\end{tabular}

13. MYXostoma ALBUM (Cope) Jordan.

White Mullet.

1870-Plychostomus albus Cope, Proe. Am. Philos. Soc. Phila. 472.

Teretulus albus Jondax \& Copeland, Check List, 158, 1876. (Name only.)

Myxostoma alba Jordan, Man. Vert. edl. 2d, 316, 1878.

Habitat.-Catawba and other rivers of Eastern Nurth Carolina.

This species is well marked by the peculiar form of the uuder lip, which is quite small-a narrow, regular crescent following the boundary of the mandible, not full, as in the species previously noted, nor with the sides folding so as to meet on the middle line, as in the remaining species (excepting thalassinum). Specimens from North Carolina in the National Museum correspond well to P'rofessor Cope's description, except that the back is rather more elevated than one would infer from Professor Cope's remarks. The dorsal rays are 12 and 13 instead of 14 . The following are the measurements of two of them, 18,535 and 14,943, both from Kinston, N. C.:- 
Measurements of two specimens of Myxostoma album.

\begin{tabular}{|c|c|c|}
\hline & 18535. & 14943. \\
\hline Length, inches.......................... & 13 & $11 \frac{1}{2}$ \\
\hline Depth (percentage of length to base of caudal). & .32 & .30 \\
\hline 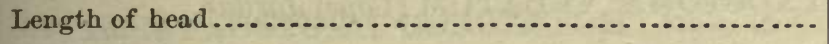 & .20 & .20 \\
\hline Width of interorbital area ............................. & .10 & .10 \\
\hline Length of snout $. . . \ldots \ldots \ldots \ldots \ldots \ldots . . . . . .$. & $.08 \frac{1}{2}$ & -.... \\
\hline Diameter of orbit............................ & .04 & ........... \\
\hline Length of base of dorsal............................. & .19 & .17 \\
\hline Height of dorsal....................................... & .22 & $.18 \frac{1}{2}$ \\
\hline Height of last ray of dorsal................... & .09 & ..... \\
\hline Length of outer caudal rays.............................. & .24 & \\
\hline Length of middle caudal rays .............................. & .24 & $\cdots$ \\
\hline Length of pectorals........................ & .21 & (............ \\
\hline 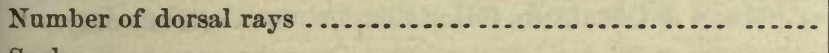 & 2,13 & 2,12 \\
\hline 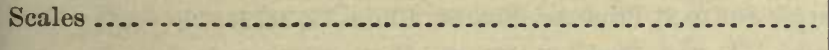 & $6-45-5$ & \\
\hline
\end{tabular}

The form is elliptical, not much compressed, but rather elerated, somewhat as in Erimyzon sucetta. Head short and stout, bluntish, broad, and rounded above; mouth somewhat inferior; the plicæ of the lips few and rather broken; dorsal fin high, its free border somewhat concave; caudal strongly forked; color lustrous white, with greenish reflections.

This is one of the largest species, reaching the weight of four pounds or more. Professor Cope states that it is much valued as a food-fish by pecple living in the neighborhood of Catawba River, where it is known as the White Mullet.

Specimens in United States National Museum.

\begin{tabular}{|c|c|c|}
\hline Namber. & Locality. & Collector. \\
\hline 10632 & North Carolina .............. & G. B. Goode. \\
\hline 14943 & 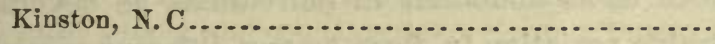 & G. B. Goode. \\
\hline 14990 & North Carolina ........ & G. B. Goode. \\
\hline 18535 & 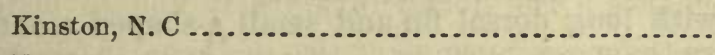 & J. W. Milner. \\
\hline 19450 & 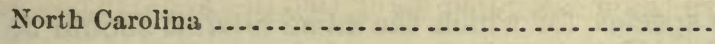 & G. B. Goode. \\
\hline
\end{tabular}

\section{MYXOSTOMA THALASSINUM (Cope) Jordan.}

Green Mullet.

1870-Ptychostomus thalassinus Cope, Proc. Am. Philos. Soc. Phila. 472, 1870.

Teretulus thalassinus Jordan \& Copelaxd, Check List, 158, 1876. (Name only.)

Myxostoma thalassina Jordan, Man. Vert. ed. 2d, 316, 1878.

HaBITAT. - Yadkin River. 
I have not seen this species. From Professor Cope's description, it would appear to be allied to $M$. album, but distinguishable by the longer head. It is a large species, abundant in the Yadkin River, where it is used for food.

\section{MYXOSTOMA VELATUM (Cope) Jordan.}

\section{Small-mouthed Red Horse.}

1815-Catostomus anisurus Krrtland, Boston Journ. Nat. Hist. v, 269 (with plate). (Not of Rafinesque.)

- Catostomus anisurus Storer, Sjnopsis, 424, 1846.

Ptychostomus anisurus Jordan, Bull. Buffalo Soc. Nat. Hist. 94, 1876. (Name only.)

Moxostoma anisurus JordaN, Man. Vert. 295, 1876.

Teretulus anisurus Nelson, Bull. No. 1, Ills. Mus. Nat. Hist. 49, 1876.

Teretulus anisurus Jordan \& Copeland, Check List, 158, 1876. (Name only.)

Moxostoma anisurum Jordan, Proc. Ac. Nat. Sc. Phila. 72, $187 \%$.

Moxostoma anisurum Jondan, Proc. Ac. Nat. Sc. Phila. 80, 1877.

Moxostoma anisura JORDAN \& GILBERT, in Klippart's Rept.53, 1877. (Name only.)

Myxostoma anisura Jordan, Bull. U. S. Nat. Mus. ix, 33, 1877.

1870-Plychostomus velatus Cope, Proc. Am. Philos. Soc. Phila. 471.

Moxostoma velatum Jordan, Man. Vert. 296, 1876.

Teretulus velatum Nelsos, Bull. No. 1, Ills. Mus. Nat. Hist. 49, 1876.

Teretulus velatus Jordan \& Copwland, Check List, 158, 1876. (Name only.)

Moxostoma velata JordaN \& GILBERT, in Klippart's Rept.53, 1576. (Name only.) Myxostoma velata JoRdAN, Man. Vert. ed. 2d, 317, 1878.

1870 - Ptychostomus collapsus Cope, Proc. Am. Philos. Soc. Phila. 471.

Habitat.-Upper Mississippi Valley to Georgia and South Carolina. Neuse, Yadkin, Catawba, Clinch, Youghiogheny and Wabash Rivers (Cope). Chickamauga, Ohio Wabash, Illinois, Rock, and Wisconsin Rivers (Jordan). Lake Erie (Jordan).

This species is one of the most widely distributed species, although it does not secm to be as abundant in individuals as several others. There is considerable variation in form among different specimens, but all the species with long dorsal fin and small $\Lambda$-shaped mouth appear to belong to one species, for which the name velatum should be retained.

The finding of a species with unequal caudal lobes renders it evident that the identification of Rafinesque's anisurus with this species is incorrect. The name next in order is velatus Cope. The difference in the size of the eye between collapsus Cope and velatus Cope appears to be due to difference in age merely. Younger specimens have the eye proportionally larger. 
I did not find any specimens of this species in the United States National Museum. The types of velatus and collapsus, preserved in the Museum of the Academy of Natural Sciences, at Philadelphia, I have examined.

\section{MYXOSTOMA CONGESTUM (Baird \& Girard) Jordan.}

\section{Gibbous Sucker.}

1854-Catostomus congestus BaIrd \& Girard, Proc. Ac. Nat. Sc. Phila. 27.

Ptychostomus congestus GIRARD, Proc. Ac. Nat. Sc. Phila. 172, 1856.

Ptychostomus congestus Girard, U. S. Mex. Bound. Surv. Ichth. 36, pl. xxi, f. 5-8, 1859.

Catostomus congestus Güntmer, Cat. Fishes Brit. Mus. vii, 19, 1868.

Teretulus congestus JoRdaN \& Copeland, Check List, 157, 1876. (Name only.)

Myxostoma congesta Jondax, Man. Vert. ed. 2d, 317, 1878.

1872-Ptychostomus bucco Cope, Hayden's Geol. Surr. Wyoming, 1870, 437.

Teretulus bucco JoRdan \& Copelaxd, Check List, 157, 1876. (Name only.)

Haвiтат.-Kansas to Texas.

The original type of congestus, No. 171, from Rio Salado, Texas, collected in 1851 by Johu H. Clark, seems to hare disappeared from the Museum. No description of the mouth has been given, except that it is "very small". The species, therefore, probably has a mouth similar to that of velatum, and, if so, is probatily identical with the species since described as $P$. bucco by Professor Cope. I have not seen the type of $P$. bucco, and, therefore, can only suggest the probable identity of the two; but, as the matter is likely to remain long unsettled, it seems best provisionally to unite them. "P. congestus" Cope \& Yarrow is certainly not this species; more likely a form of $\boldsymbol{H}$. macrolepidotum.

\section{MYXOSTOMA PIDIENSE (Cope) Jordan.}

Mullet of the Great Pedee.

18r0-Ptychostomus pidiensis Cope, Proc. Am. Philos. Soc. Phila. 471.

Teretulus pidiensis JoRDAx \& Copeland, Check List, 158, 1876. (Name only.) Myxostoma pidiensis Jordan, Man. Vert. ed. 2d, 317, 1878.

Habrtat.-Great Pedeo River, North Carolina.

This appears to be a slender species, resembling "P. cervinus in color, form, and size". Professor Cope obtained it in the Yaụkin Rirer. I have not seen it. No specimens are in the National Museum. 


\section{MYXOSTOMA COREGONUS (Cope) Jordan.}

\section{Blue Mullet.}

1870-Ptychostomus coregonus Cope, Proc. Am. Philos. Soc. Phila. 472.

Teretulus coregonus Jordan \& CoPELAND, Check List, 158, 1876. (Name only.)

Myxostoma coregonus Jokdan, Man. Vert. ed. 2d, 317, 1878.

Habitat.-Catawba and Yadkin Rivers, North Carolina.

I have not seen this species. Professor Cope states that "it nerer exceeds a foot in length, and is very abundant in the Catawba and Yadkin Rivers. It is caught with the preceding two species and is used for food, but is the least valued of all the species. It is called at Morganton, Blue Mullet." There are no specimens in the National Museum.

\section{MYXOSTOMA PAPILLOSUM (Cope) Jordan.}

\section{Papillose Mullet.}

1870-Ptychostomus pappillosus Cope, Proc. Am. Philos. Soc. Phila. 470.

Teretulus pappillosus Jordan \& CoPELAND, Check List, 158, 1876. (Name only.) Myxostoma papillosum Jordan, Ann. Lyc. Nat. Hist. N. Y. xi, 366, 1877. (Ocmulgee River.)

Myxostoma papillosa Jordan, Man. Vert. ed. 2d, 318, 1878.

Habitat.-North Carolina to Georgia.

This species appears to be very abundant in all the streams from the Great Pedee to the Altamaha. In its general character and appearance, it is very similar to the rest of the genus; but the mouth is remarkably different, the lower lip being full, thick, decidedly papillose, strongly incised behind, being very much as in Catostomus nigricans.

My specimens do not agree rery well with Professor Cope's description; but this is probably due to their greater size. Still, a posssibility exists that two species of this type inhabit our South Atlantic States.

The head in my specimens is vers large, flattish above, narrowed forwards, and more than one fourth of the length, without candal. The mouth is very large and inferior. The body is oblong, compressed, heavy forwards; the back moderately elevated. The eye is quite large, high up, and well back. The free border of the dorsal fin is sometimes 
conrex, sometimes concare. The following are the measurements of two specimens:-

\begin{tabular}{|c|c|c|}
\hline & 14989. & 18536. \\
\hline 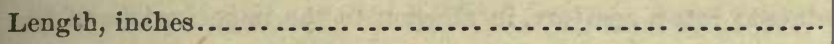 & $16 \frac{1}{2}$ & - in \\
\hline 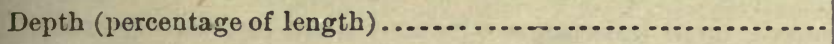 & .29 & $\cdot .2 \pi$ \\
\hline 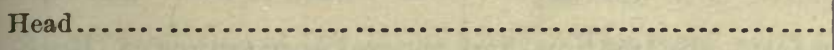 & .26 & .24 \\
\hline Width of interorbital area $\ldots . . . \ldots \ldots \ldots \ldots \ldots . . . . . . .$. & .10 & ......... \\
\hline Length of snout ..................... & .12 & ......... \\
\hline Diameter of orbit................. & .05 & ........ \\
\hline 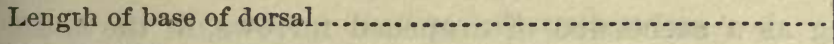 & .19 & .......... \\
\hline Height of longest ray $\ldots . . . . . . . . . . . . . . . . . . .$. & .16 & .19 \\
\hline Height of last ray ................... & .10 & .......... \\
\hline Dorsal rays........................................... & 2,14 & 2,10 \\
\hline 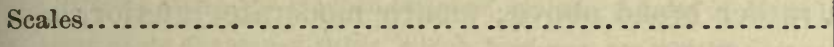 & $6-46-5$ & (.......... \\
\hline
\end{tabular}

In color, this species is smoky abore, the sides silvery, the lower fins white.

Professor Cope says that "they attain one foot in length, and do not exceed one pound in weight". I have specimens a foot and a half long and of three pounds or more weight.

In the Ocmulgee, the species is next to M. cervinum the most abundant, and is called the White Mullet, or Sucker. Professor Cope found it quite abundant in the Catawba and the Yadkin Rivers, where it "is highly valued by the inhabitants as an article of food. It is regarded as the best of the Catostomi for that purpose. It is less frequentry caught on the hook than some other species, but in the autumn, they come upon the weirs in considerable numbers. The fishermen call it the 'Shiner'."

Specimens in the United States National Museum.

\begin{tabular}{|c|c|c|}
\hline Number. & Locality. & Collector. \\
\hline 14939 & Kinston, N. C .......... & J. W. Milner. \\
\hline 18536 & 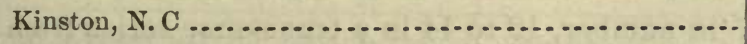 & J. W. Milner. \\
\hline $1 \times 5: 37$ & Kinston, N. C .......... & J. W. Milner. \\
\hline 18538 & Kinston, N. C ......... & J. W. Milner. \\
\hline 18970 & 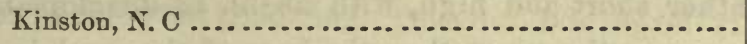 & J. W. Milner. \\
\hline 20906 & 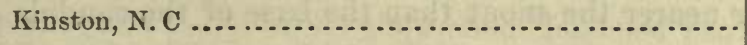 & J. W. Milner. \\
\hline- & Ocmulgee River, Ga............................ & D. S. Jordan. \\
\hline
\end{tabular}




\section{Genus MINYTREMA Jordan.}

Minytrema JoRdaN, Man. Vert. ed. 2d, 313, 1878.

Catostomus, Ptychostomus, Moxostoma, and Erimyzon sp.: Authors.

Type, Catostomus melanops Rafinesque.

Etymology, $\mu \iota v v \varsigma$, reduced; $\tau \tilde{\eta} \mu a$, aperture, in allusion to the imperfections of the lateral line.

Species with the form, squamation, and general appearance of Myxostoma, but with the air-bladder in two parts, as in Erimyzon, and the lateral line imperfect-in the very young entirely obsolete, in half-grown specimens showing as a succession of deepened furrows, in the adult with perfect tubes, but interrupted, these tubes being wanting on some of the scales, especially posteriorly.

Head moderate, rather broad above; mouth moderate, inferior, horizontal, the upper lip well developed, freely protractile, the lower rather 'small, infolded, $\Lambda$-shaped in outline, plicate, with 12 to 20 plicæ on each side; lower jaw without cartilaginous sheath; ese moderate, rather high up, placed about midway of the head. Suborbital bones consid. erably developed, not very much narrower than the fleshy portion of the cheek below them, the posterior suborbital concavo-conrex, about twice as long as deep, sometimes divided, the anterior somewhat deeper than long, often divided into two, sometimes united with the preorbital, which is well developed and much longer thau broad. The number and form of these bones, except as to their depth, are not constant in the same species, and do not afford specific characters. Opercular bones well developed, not much rugose. Fontanelle evident, rather large. Gillrakers rather long, in length about half the diameter of the eye. Isthmus moderate. Pharyngeal bones essentially as in Myxostoma.

Body rather elongate, subterete, becoming deep and rather compressed with age. Scales rather large, nearly equal over the body, the radiating furrows not specially marked. Lateral line as above described, interrupted in the adult, but with perfect tubes, imperfect in partly grown specimens, entirely obsolete in the joung. Scales in a longitudinal series 44 to 47 in number, 12 to 14 in a transverse series from dorsal to ventrals.

Dorsal fin rather short and high, with about 12 dereloped rays, beginning rather nearer the snout than the base of the caudal. Pectoral fins moderate, not reaching ventrals, the latter not to rent. Ventrals rather in advance of the middle of the dorsal, their rays normally 9 , 
rarely 8 or 10. Anal fin high and short, often more or less emarginate in males. Caudal fin moderately forked, the lobes about equal.

Air-bladder with two chambers.

Males in spring with the head covered with mans small tubercles.

But on $\Theta$ species of this genus seems to be kuown. It is widely distributed in the raters of the Western and Southern States.

This genus has been recently separated from Erimyzon, on account of the peculiarities of the lateral line. The form of the bod 5 , the form of the mouth, and the character of the squamation differ considerably in the two genera.

\section{Generic Characterizations.}

Minytrema Jordan, 1878.-- "Yonng specimens of this epecies (melanops) have no trace of a lateral line, as in Erimyzow. Older ones (6 to 8 inches) show a deepening of the furrows along the median series of scales. Adults of 12 to 18 inches show a series of completely developed tabes, which, hotrever, are wanting on some of the scales, especially behind. As Erimyzon never shows any traces of the tubes of the lateral line, these peculiarities may be held to indicate generic distinction, and the name Minytrema is here proposed for E. melanops."-(JoRDan, Man. Vert. ed.2d, 318, 1878.)

\section{ANALYSIS OF SPECIES OF MINYTREMA.}

* Body oblong, little compressed; the young nearly terete; the adnlts deeper-bodied; the dorsal region not elerated : depth about 4 in length, varying from about 3 in adults to $4 \frac{1}{2}$ in the soung: head not very large, $4 \frac{1}{8}$ in length of body ( $4 \frac{1}{4}$ to $4 \frac{1}{2}$ ), not specially depressed : mucous pores ratber strong: eye small, 5 to 6 in head: mouth quite inferior, horizontal, rather small: scales large, firm, regularly and smoothly imbricated, in 46 (44-4i) longitudinal series and 13 (12 to 14) transverse series, the scales not crowded forwards : fin-rays usually, dorsal $12,{ }^{*}$ anal 7 , ventrals 9.

Coloration dusky abore, with usually a black blotch behind the dorsal fin : each scale along the sides with a small, more or less distinct blackish spot at is base, these spots forming interrupted longitudinal lines along the rows of scales. These lines are usually very distinct, 1 specially in the adult, but young specimens often show them faintly: sides and belly silvery, with a coppery lustre: sexual peculiarities moderately marked; very old males with the head covered with small tubercles in spring : no great changes with age, either in form or coloration: size large; maximum length about 18 inches ..................... velanops, $z 0$.

* As in all cases in the present paper, the number of deceloped rays is here understood, the one, two, or three rudimentary rays not being counted, and the last or double ray of the dorsal and anal being connted as one. 


\title{
20. MINYTREMA MELANOPS (Rafinesque) Jordan.
}

\author{
Striped Sucker. Sand Sucker.
}

1820-Catostomus melanops RAFINESQUE, Ich. Oh. 57.

Catostomus melanopsis Kirtlasd, Zool. Ohio, 168, $183 \overline{\text { s. }}$

Catostomus melanops Kirtuand, Boston Journ. Nat. Hist. v, 271, 1845.

Catostomus melanops STorer, Synopsis, 424, 1846.

Ptychostomus melanops AGASsiz, Am. Journ. Sc. Arts, 2d series, xix, 204, $18: 5$.

Ptychostomus melanops Cope, Proc. Am. Philos. Soc. Phila. 478, 1870.

Erimyzon melanops Jordan, Bull. Buffalo Soc. Nat. Hist. 95, 1876.

Erimyzon melanops JoRDax, Man. Vert. 294, 1876.

Erimyzon melanops NeLson, Bull. No. 1, Ills. Mus. Nat. Hist. 48, 1876.

Erimyzon melanops JoRdan \& Copeland, Check List, 157, 1876.

Erimyzon melanops Jondan, Ann. Ljc. Nat. Hist. N. Y. xi, 347, 1877.

Minytrema melanops Jordax, Man. Vert. ed. 2d, 318, 1878.

1844-Catostomus fasciatus (Le SUlur MSS.) Cuvier \& Valenciennes, Hist. Nat. des

Poissons, xvii, 449.

Catostomus fasciatus STORER, Synopsis, 426, 1846.

Catostomus fasciatus Günther, Cat. Fishes Brit. Mus. vii, 19, 1868.

1856-Moxostoma victorice Girand, Proc. Ac. Nat. Sc. Phila. 171.

Moxostoma victoric Girard, U. S. Mex. Bound. Surv. Ichth. 35, pl. xx, f. 1-3, 1859.

1856-Ptychostomus haydeni Girard, Proc. Ac. Nat. Sc. Phila. 172.

Ptychostomus haydeni Girard, U. S. Pac. R. R. Expl. x, 220, pl. xlix, f. 1-4, 1858.

Teretulus haydeni JoRdan \& Copeland, Check List, 157, 1876.

1877-Teretulus succtta Jordan \& GILBERT, in Klippart's Rept. Fish Commr. Obio, 53.

(Supposed to be $C$. sucetla Lacépède, as it was perhaps in part the C. suceti of Cuv. \& Val. and of Bosc.)

Erimyzon sucetta Jordax, Bull. U. S. Nat. Mus. x, 35, 1877.

Habitat.-Great Lake Region to South Carolina and Texas.

This fish, altbough a very abundant one in the Mississippi Basin, seems to have been overlooked by most recent writers. Rafinesque described it rather poorly. Dr. Kirtland was able to recognize the fish from Rafinesque's account, and has given a very good description and an indifferent figure. Valenciennes described it fairly, and Agassiz seems to have been acquainted with it, although, deceived by its external appearance, he took it for a Myxostoma (Ptychostomus). Girard next described and figured it as two species, belonging to two different genera. Professor Cope, for some reason, did not obtain it in any of his collections, and seems to bave had much difficulty in identifying Kirtland's account. In 1875, the writer, noticing certain resemblances to Erimyzon oblongus, was led to dissect a number of indiriduals, and found that the 
air-bladder in all cases was bicellular, as in the genus Erimyzon. At that time he had never seen any specimens with a developed lateral line and then unquestioningly referred the species to Erimyzon. Later, Mr. Nelson noticed the occasional partial development of the lateral line, and recently, by the examination of a full series of specimens, the writer has been enabled to trace the stages in its growth.

This fish inhabits all the Western streams and lakes, usually in company with Erimyzon sucetta. It is fond of clear sluggish waters, and abounds in ponds and bayous. It is used for food, and is pretty good for a "Sucker", which is not saying much. This species is more than usually tenacious of life, and young specimens are rather interesting as aquarium fishes.

The synonymy of this species needs a few words. It was originally described by Rafinesque as a species with a lateral live. This first description is quite indifferent, but the account of the coloration, and the name, Striped Sucker, enabled Dr. Kirtland readily to identify it, but the latter writer found the "lateral line obsolete". Later, Valenciennes described it under Le Sueur's MSS. name of fasciatus, and found a lateral line. As Le Sueur's specimens were from the Wabash, there can be no doubt of their identity with mclanops. Later, Dr. Girard described and figured Texan specimens without the lateral line under the name of Moxostoma victorice, and specimens with the lateral line from the Upper Missouri Region as Ptychostomus haydeni. The types of neither of these species are preserved, but no distinctions from melanops are noticed in either case by the describer, and the range of melanops certainly includes the Missouri river and the waters of Texas.

The name sucetta has been once or twice employed by me for this species, erroneously, as I am now convinced. I found this species in abundance in South Carolina; and Le Sueur, apparently quoting from Lacépède, says :- "Silles silvery, with brown spots at the base of the scales." Nevertheless, on inspection of Lacépède's description, and especially of the colored figure which he gives from a drawing by Bosc, it becomes evident that the Cyprinus sucetta Lacépède is the same as Cyprinus oblongus of Mitchill, a species equally abundaut in the same waters. Bosc's drawing, although not giving the details of structure minutely, represents the general form and coloration of the body and fins, and this figure can only represent the Cyprinus oblongus. As the Cyprinus sucetta Lacépède is based entirely on information derired from Bosc, the name must be retained for the species which Bose had fig. 
ured: As for the expression, "brown spots at the base of the scales," if really originating with Bosc, as appears to be the case, it may have arisen from the confusion of sucetta with melanops, which species inhabits the same waters, or it may simply refer to the obscure duskiness of the bases of the scales, common to both species.

I have examined many specimens of Minytrema melanops from the Great Lakes, from various places in the Mississippi Valley, and from the Tennessee, Alabama, Santee, and other Southern rivers, and can find no differences of any importance. Indeed, the species seems to be very little variable for one so widely distributed.

Specimens in the United States National Museum.

\begin{tabular}{|c|c|c|}
\hline Number. & Locality. & Collector. \\
\hline 7694 & $\ldots \ldots$ & \\
\hline 7768 & ........... & \\
\hline 8434 & 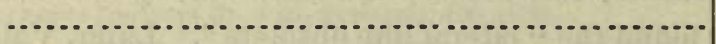 & \\
\hline 11050 & Sandusky, Obio.......................... & J. W. Milner. \\
\hline 11144 & Sandusky, Ohio........................... & J. W. Milner. \\
\hline 11145 & Sandusky, Ohio................................ & J. W. Milner. \\
\hline 12449 & 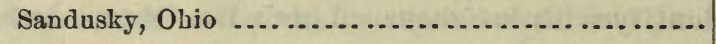 & J. W. Milner. \\
\hline 17800 & Round Lake, Montgomery, Ala.................... & Kumlien \& Bean. \\
\hline 17808 & 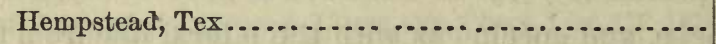 & Kumlien \& Earil. \\
\hline 20275 & $\ldots \ldots \ldots \ldots \ldots \ldots \ldots \ldots \ldots \ldots \ldots \ldots \ldots \ldots \ldots \ldots$ & Dr. Kenners. \\
\hline - & 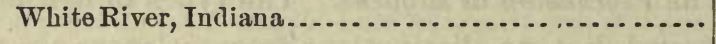 & D. S. Jordan. \\
\hline - & Etowah River, Georgia......................... & D. S. Jordan. \\
\hline - & Saluda River, South Carolina...................... & D. S. Jordan. \\
\hline
\end{tabular}

\section{Genus ERIMYZON Jordan.}

Mroxostoma AGASsiz, Am. Journ. Sc. Arts, 1854, 200. (Not of Rafinesque.)

Erimyzon Jordan, Bull. Buff. Soc. Nat. Hist. 1876, 95.

Teretulus Cope, Synopsis of Fishes of N. C. $2 d$ ed. Addenda, 187\%. (Not of Rafinesque.)

Cyprinus, Catostomus, and Labeo sp., Early Autrors.

Type, Cyprinus oblongus Mitchill = Cyprinus sucetta Lac.

Etymology, $\varepsilon \rho$, an intensive particle; $\mu \hat{v} \zeta \omega$, to snck.

Head moderate, rather broad above : mouth moderate, somewhat inferior, the upper lip well developed, freely protractile, the lower moderate, infolded, $\Lambda$-shaped in outline, plicate, with $12-20$ plicæ on cach side: lower jaw without cartilaginous sheath, rather stronger than usual, 
and oblique in position when the mouth is closed, the mouth thus similar to that of Ichthyobus. Eye moderate, rather high up, placed about midway of the head: suborbital bones considerabls developed, not very much narrower than the fleshy portion of the cheek below them, the posterior suborbital concaro-convex, about twice as long as deep, sometimes divided, the anterior somewhat deeper than long, sometimes divided into two, sometimes united with the preorbital bone, which is well dereloped and much longer than broad. Opercular bones moderately developed, scarcely or not rugose. Fontanelle evident, rather large. Gill-rakers rather long, about half the diameter of the eje in length. Isthmus moderately developed, abont the width of the eye.

Pharyngeal bones weak, the teeth quite small, slender, and weak, rapidly diminishing in length upwards, each tooth narrowly compressed, with a cusp on the inver margin of the cutting surface, and some inequalities besides.

Body oblong, rather shortened, heary forwards and considerably compressed.

Scales rather large, more or less crowded forwards, sometimes showing irregularities of arrangement, the longitudinal radiating furrows much stronger than usual, the scales rather longer than deep, but so imbricated in the adult that the exposed surfaces appear deeper than long.

Lateral line entirely wanting. Scales in the longitudinal series from head to base of caudal 35 to 45 in number; scales in transverse row from base of ventral to dorsal 12 to 18 .

Dorsal fin rather short and high, with from 10 to 14 developed rays, the number usually 11 or 12 .

Beginning of dorsal fin rather nearer snout than base of caudal. Pectoral fins moderate, not reaching ventrals; the latter not to vent.

Ventrals under a point rather in advance of the middle of dorsal; their rays normally 9 , but occasionally 8 or 10 .

Anal fin high and short, more or less emarginate or bilobed in adult males; candal fin moderately forked or merely lunate, its two lobes about equal.

Air-bladder with two chambers.

This genus has a very wide range, one of its two known species probably occurring in all the streams of the United States east of the Rocky Mountains.

The existence of this genus seems to have been first noticed by DeKay, who, however, erroneously supposed it to be identical with the Afri- 
can genus Labeo of Cuvier and Valenciennes. Its essential characterthe absence of the lateral line-was first noticed by Professor Agassiz, who identified its typical species with Catostomus (Moxostoma) anisurus Kafinesque, and therefore erroneously called the genus Moxostoma. The application of the name Moxostoma to the Red Horse group was pointed out by the present writer in 1876 ; the name Erimyzon being then suggested for the group now under consideration.

The use of the name Teretulus for this genus has been lately suggested by Professor Cope, its species being among those enumerated by Rafinesque as composing his "omnium gatherum" to which the name Teretulus was applied. If we subtract from the original group Teretulus, the different component genera in order of time of proposal, the last one left would be Erimyzon, or rather Minytrema. But the name Teretulus has already been restricted by Professor Cope to the Red Horse group, the principal component of Rafinesque's Teretulus. In my opinion, it should remain there, although the earlier name Myxostoma renders it but a synonym. We cannot afford to reconsider our use of these old collective generic names whenever a new genus is proposed. The "rule of exclusion", if stiffly adhered to, would require the substitution of Acomus for Pantosteus, inasmuch as a species of the latter genus was referred by Girard to the former. This question is further discussed under Myxostoma.

\section{Generic Characterizations.}

Labeo DeKay, 1842.- "Dorsal long. No spines nor barbels. Lips fleshy, and frequently crenated."-(DEKAY, New York Fauna, Fishes, 192.)

Moxostoma Agassiz, 1855.- "The species of this genus contrast greatly with those of all other genera of the family of Cyprinoids, by the total absence of external openings in the lateral line, visible upon the scales. There is indeed no row of perforated scales upon the sides of the body, to mark the main course of the system of tubes pervading the skin in most fishes, aud the pores traversing the skin which covers the skull and cheeks, as well as the lower jaw, are so minute as to escape the unarmed eye. In this respect the genus Moxostoma differs greatly from all other abdominal fishes in which the lateral line is distinctly marked by a series of tubes traversing a prominent row of scales along the sides, and extending through the mastoids to the forehead, and along the preopercle to the symphysis of the lower jaw. This total absence of a lateral line is compensated by the presence of a few deeper radiating furrows in the posterior field of all the scales.

"The longitudinal diameter of the scales exceeds greatly the transverse, but the scales are imbricated in such a manner that the portion visible externally appears higher than long. The centre of radiation is placed in the middle of the scales; there are no radiating furrows upon the lateral fields, those of the posterior field are ferwer and deeper than those of the anterior field; the concentric ornamental ridges of the 
posterior field are also much broader and farther apart than those of the lateral and anterior fields. The scales are smaller upon the anterior portion of the body than upon the sides. Another remarkable peculiarity of this genus consists in the great difference there is among the adults in the form of their fins in the several sexes. The young also differ strikingly from the adults both in form and coloration. . . . The body of Moxostoma is elongated and somewhat compressed, thongh stonter than that of Ptychostomus and Catostomus proper. The greatest depth is over the ventrals.

"The head is small; the small mouth opens obliquely forwards and downwards; when open the lower jaw is quite prominent. The lips are small and transversely ridged; the lower one is slightly bilobed. The dorsal is over the ventrals; its length considerably exceeds its height in the males; in the females its dimensions are more nearly equal. The pectorals and ventrals are more pointed and longer in the males than in the females. The lower margin of the anal fin is bilobed in the males, while in the females it is simply emarginated ; in both sexes, the anal when bent backwards reaches the candal.

"The pharyngeal bones have a greater resemblance to those of the genus Ichthyobus than to any other of the tribe of Catostomi; the symphysis however is shorter, and the teeth are neither so minute nor so numerous; they increase also more rapidly in size from above downwards, and are more strongly curved inwards, the innermost edge rising into an acnte point, which is more prominent in the middle and upper teeth, than in the lower ones."-(AGsssiz, Am. Journ. Sci. Arts, 1855, p. 200.)

Moxostoma Girard, 1856. - "May be circumscribed by characters more natural than the preceding ones. And the most striking of these, it must be conceded, is the absence of that lateral line possessed by almost all fishes. The body is elongated and compressed; the head small; the mouth small also, opening obliquely forwards and downwards. The lips being small and transversally ridged; the inferior one being slightly bilobed. The anterior margin of the dorsal is situated in advance of the insertion of the ventrals. The dorsal fin is either higher than long or else its length is equal to its height, varying somewhat according to the sexes, as well as the anal, which is, however, always deeper than long. The shaft of the pharyngeal bones constitutes a very open curve, the convex margin of which is regular and entire. The teeth themselves are very much compressed, strongly curved inwardly, and mach larger inferiorly than superiorly."-(Grand, Proc. Ac. Nat. Sc. Phila. 1856, p. 171.)

Moхоsтома Günther, 1868.- "Scales of moderate size; lateral line none; fins, mouth, gills and pharyngeal teeth, identical with those of Catostomus in all essential points."-GüNTHer, Cat. Fishes Brit. Mus. vii, p. 20.)

Erimyzon Jordan, 1876.-[Name suggested as a substitute for Moxostoma Ag., the type of Moxostoma Raf. (Catostomus anisurus Raf.) not being a member of this genus.](Jorddar, Bull. Buff. Soc. Nat. Hist. p. 95.)

Ermyzon Jordan, 1876.- "Dorsal moderate; air-bladder in two parts; no lateral line; lips usually plicate."-(Jordas, Man. Vert. ed. 1st, p. 292.)

\section{ANALYSIS OF SPECIES OF ERIMYZON.}

"Body oblong, compressed, becoming gibbous with age, the ante-dorsal region more or less elevated in the adults; the depth $3 \frac{1}{2}$ in length, ranging from $2 \frac{3}{4}$ in adults 
to 4 in young : head stout, short, about $4 \frac{1}{4}$ in length ( 4 to $4 \frac{1}{2}$ ), the interorbital space wide and depressed, the lower parts narrower, so that it is somewhat wedgeshaped downwards : eye not large, $4 \frac{8}{4}$ in head ( $4 \frac{1}{2}$ to $\left.5 \frac{1}{2}\right)$ : month protractile downwards and forwards, the mandible oblique: scales usually closely imbricated and zore or less crowded for wards, but often showing various irregularities in arrangement, about $43(39-45)$ in a longitudinal series and 15 (14 to 16) in a transverse series between the ventrals and the dorsal. Fin-rays somewhat variable, the doreal with 11 (10 to 13) developed rays, the anal with 7 , and the ventrals with 9 (rarely 8).

Coloration varying with age; never distinct series of black spots along the rows of scales; young with a broad black lateral band bordered above by paler; in some specineus from clear water, this band is of a jet-black color and very distinct; in others, it is duller; later this band becomes broken into a series of blotches, which often assume the form of broad transverse bars; in adult specimens, these bars disappear, and the color is nearly uniform brown, dusky above, paler below, everywhere with a coppery or brassy, never silvery, lustre; the fins are dusky or smoky brown, rarely reddish-tinged: sexual differences strong; the znales in spring with usually three large tubercles on each side of the snout, and with the anal fin more or less swollen and emarginate: adult specimens with the back gibbous and the body strongly compressed, in appearance quite unlike the young. Maximum length about 10 inches..................... sticetTa, 21 .

** Body oblong, the back more elevated, the body deeper and more compressed than in the preceding, the greatest depth in advance of the dorsal fin being contained about $2 \frac{8}{4}$ times in the length; nape less gibbous than in 8ucetta; head quite small and short, the large eyo being almost exactly midway in its length, its length $4 \frac{1}{8}$ in that of the body; eye $4 \frac{1}{4}$ in head ; interorbital spaco rather narrow, strongly transversely convex, less than half the length of the head : mouth small, protractile forwards, the lower jaw oblique; lips as in the preceding.

Scales large, much larger and much more uniform in their imbrication than in $E$. sucetta; 36 in a longitudinal series, and about 13 in a transverse series from the ventrals to the dorsal. Dorsal fin high, of 12 developed rays; anal moderate, with 7 ; ventrals large, with 10. Color dark olivaceous above, each scale along the sides reflecting pale from the strongly ridged middle part; these giving in certain lights the appearance of pale stripes along the rows of scales: fins dusky, especially at their tips...............................................

\section{ERIMYZON SUCETTA (Lacépède) Jordan.}

\section{Chub Sucker. Creek Fish. Mullet.}

1803-Cyprinus sucetta LACÉPìde, Hist. Nat. des Poissons, v, 606, 610.

Catostomus sucetta Le Sueur, Journ. Ac. Nat. Sc. Phila. 109, 1817.

Catostomus sucetta DEKAY, New York Fauna, part iv, Fishes, 203, 1842.

Catostomus suceti Cuvier \& Valenciennes, Hist. Nat. des Poissons, xvii, 466, 1844.

Catostomus suceti STorer, Synopsis, 419, 1846.

Moxostoma sucetta $\Lambda$ GASSIZ, Am. Journ. Sc. Arts, 2d series, xix, 202, 1855.

Moxostoma sucetta PutNam, Bull. Mus. Comp. Zool. 10, 1863. 
Erimyzon sucetta JondaN, Mạn. Vert. 295, 1876.

Erimiyzon sucetta JoRDAN \& CoprLAND, Check List, 157, 1876.

Erimyzon sucetta, Jordax, Man. Vert. ed. 2d, 319, 1878.

1814-Cyprinus oblongus Mitchill, Lit. \& Phil. Trans. New York, 1, 459.

Catostomus oblongus Le Sueur, Journ. Ac. Nat. Sc. 108, 1817.

Catostomus cblongus Trompsox, Hist. Vt. 134, 1842. (Synonymy, bat not description, which applies to $\mathbf{M}$. macrolepidotum.)

Labeo oblongus DEKaY, New York Fauna, part iv, Fishes, 193, 1842.

Catostomus oblongus Cuvien \& Valexcienves, Hist. Nat. des Poissons, xvii, 441, 1844.

Catostomus oblongus Storer, Synopsis, 423, 1846.

Moxostoma oblongum AGassiz, Am. Journ. Sc. Arts, 2d series, xix, 203, 1855.

Moxostoma oblongum PutNaM, Bull. Mus. Comp. Zool. 10, 1863.

Moxostoma oblongum Gis., Canadian Nat. p. 19, Ang. 1865.

Moxostoma oblongum Güstrier, Cat. Fishes Brit. Mus. vii, 21, 1868.

Moxostoma oblongum Cope, Proc. Am. Philus. Soc. Phila. 468, 1870.

Moxostoma oblongum Jondan, Fishes of Ind. 221, 1875. (Name only.)

Erimizon oblongus Jordan, Bull. Buffalo Soc. Nat. Hist. 95, 18r6. (Name only; generic diagnosis of Erimyzon.)

Erimyzon oblongus Jordax, Man. Vert. 294, 1876.

Moxostoma oblongum Uhler \& LUGGer, Fishes of Maryland, 140, 1876.

Erinyzon oblongus Nelsox, Ball. No. 1, Ills. Mus. Nat. Hist. 48, 1876.

Erimyzon oblongus JordaN \& COPELAND, Check List, 157, 1876. (Name only.)

Teretulus oblongus Jordax \& Gindert, in Klippart's Rept. 53, 1876. (Name only.)

Teretulus oblongus JoRdax \& GLbErt, in Klippart's First Report, Ohio Fish Commission, 85, pl. xii, f. 20, 1877.

Erimyzon oblongus Jordan, Ann. Lyc. Nat. Hist. N. Y. xi, 346, 1877.

Erimyzon oblongus JoRdAx, Ann. Lyc. Nat. Hist. N. Y. xi, 365, 1877.

Erimyzon oblongus JoRdax, Bull. U. S. Nat. Mus. ix, 36, 18 i7.

1817-Catostomus gibbosus Le Sueur, Jourc. Ac. Nat. Sc. Phila. i, 92.

Catostomus gibbosus STorer, Rept. Ichthy. Mass. 183, 1838.

Labeo gibbosus DeKaY, New York Fauna, part iv, Fishes, 194, 1842.

Catostomus gibbosus STorer, Synopsis, 420, 1846.

Catostomus gibbosus KintuAnd, Hamilton Smith's Annals of Science.

Catostomus gibbosus Storkr, Hist. Fishes Mass. 291, pl. xxii, f. 4, $186 \%$.

1817-Catostomus tuberculatus Le Sueur, Journ. Ac. Nat. Sc. Phila. i, 93.

Catostomus tuberculatus DeKA X, New York Fanna, part iv, Fishes, 193, 1842.

Calostomus tuberculatus Cuvier \& Valexcienses, Hist. Nat. des Poissons, xvii, $444,1844$.

Catostomus tuberculatus Tho?EAU, Week on Concord and Merrimack, 38, 1868.

1817-Catostomus vittatus Le Suecr, Journ. Ac. Nat. Sc. Phila. 104.

Catostonıus vittatus DeKaY, New York Fauna, part iv, Fishes, 203, 1842.

Catostomus vittatus Cuvier \& Valexciexnes, Hist. Nat. des Poissons, xvii, 459, 1844.

Catostomus vittatus Storer, Synopsis, 422, 1846.

1820-Catostomů fasciolaris RAFLYESQUE, Ich. Oh. 58.

Bull. N. M. No. 12-10 
1842-Labeo elegans DeKaY, New York Fauna, part iv, Fishes, 192.

Catostomus elegans Storer, Synopsis, 425, 1846.

1842-Labeo esopus DEKaY, New York Fauna, part iv, Fishes, 195.

Catostomus esopus Storer, Synopsis, 425, 1846.

1842-Labeo elongatus DeKAY, New York Fauna, part iv, Fishes, 394.

1855-Moxostoma anisurus AGassiz, Am. Journ. Sc. Arts, 2d series, xix, 202. (Nut of Rafinesque.)

1855-Moxostoma tenue Agassiz, Am. Journ. Sc. Arts, 2d series, xix, 203.

Moxostoma tenue PUTnay, Bull. Mas. Comp. Zool. 10, 1863.

Moxostoma tenue GÜNTHER, Cat. Fishes Brit. Mus. vii, 21, 1868.

Erimyzon tenuis JoRdan \& Copeland, Check List, 157, 1876.

1856-Moxostoma claviformis Girard, Proc. Ac. Nat. Sc. Phila. 171.

Moxostoma claviformis GiRakD, U. S. Pac. R. R. Expl. ×, 219, pl. xlviii, f. 5-9, 1858.

Erimyzon claviformis JoRdan \& COPELAND, Check List, 157, 1876.

1856-Moxostoma kennerlyi Grrard, Proc. Ac. Nat. Sc. Phila. 171.

Moxostoma kennerlyi Grrard, U. S. Mex. Bound. Surv. Ichth. 34, pl. xx, f. 7-9, 1859.

1855-Moxostoma campbelli Grrard, Proc. Ac. Nat. Sc. Phila. 172.

Moxostoma campbelli GIRARD, U. S. Mex. Bound. Surv. Ichth. 35, pl. xx, f. 4-6, 1859.

Erimyzon campbelli JoRdaN \& CuPELAND, Cbeck List, 15\%, 1876.

Habitat.-All waters of the United States east of the Rocky Mountains.

This protean species is, next to Catostomus teres, the most abundant and the most widely diffused of our species of Suckers. It occurs in every stream from Maine to Texas, and thrives in all sorts of waters, from the Great Lakes to the smallest ponds and brooks. Its rariations in color and form are remarkable; but after the elimination of those which are known to be due to differences of sex, age, and surroundings, I find nothing left on which a difference of species or even a varietal difference may be based. I therefore unite all the nominal species of this genus, with a single exception, under the oldest specific name applied to any of them, sucetta of Lacépède.

The name sucetta has been passed from author to author for a loug time, all the descriptions being based on the notes of Bosc and the account given by Lacépède, no one seeming to have any clear idea of what the original species was. The reasous for identifying sucetta with oblongus bave been already given.

The name sucetta was spelled suceti by Valenciennes. I see no reason for this change. The derivation of the word is from the French sucet, a sucker; and sucetta is an agreeable latinization of the barbarous word. The identity of the nominal species oblongus, giblosus, tuberculatus, rittatus, esopus, elongatus, and elegans was conclusively shown by Professor $\Delta$ gassiz. The fasciolaris of Rafinesque, as I bave shown, is probably this species, which Rafinesque could hardly have orerlooked. 
Professor Agassiz's anisurus, considered by him as the Western representative of oblongus, must belong here. Professor Agassiz's tenuis from Mobile is not described; but as sucetta occurs abundantly in Alabama, it is safe to presume their identity. The type of Moxostoma claviformis Girard is now lost. Both figure and description point to the joung of sucetta. The figure represents the scales rather smaller than usual, but it mar not be correct. The types of Moxostoma kennerlyi Girard and of Moxostoma campbelli Girard, from Texas, have also disappeared; but they too seem to have been based on the joung of the present species, and as sucetta certainly occurs in Texas, these nominal species must fall into the synouymy.

The Chub Sucker is one of the smallest species, rarely reaching a length of more than a foot. It is tenacious of life, and bites readily at a small hook, but is not much ralued for food. The soung are rather handsome, the black lateral band being sometimes very distinct. In the aquarium, they act as scarengers. The adult fishes, especially the males, are very dusky in color, and the males in spring are provided with three large tubercles arranged in a triangle on each side of the head. The fins of the adults are usually black, sometimes tinged with red.

Specimens in United States National Museum.

\begin{tabular}{|c|c|c|}
\hline Number. & Locality. & Collector. \\
\hline 144 & Sugar Loaf Creek, Arkansas.................... & H. B. Möllhausen. \\
\hline 6860 & 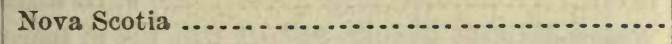 & \\
\hline 7638 & & \\
\hline 7646 & 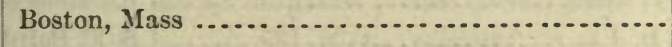 & \\
\hline $7 / 71$ & 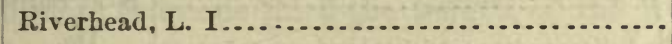 & S. F. Baird. \\
\hline $77 \% 6$ & 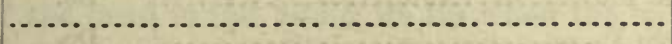 & \\
\hline 8280 & 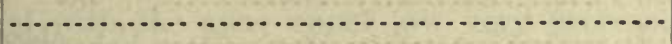 & S. F. Baird. \\
\hline $83 \pi 6$ & North Carolina ............................... & MeNair. \\
\hline 8459 & 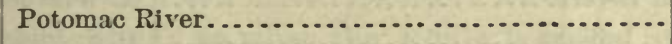 & - \\
\hline 8497 & 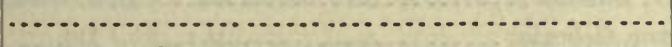 & \\
\hline 8700 & Holliston, Mass.................................. & \\
\hline 8742 & 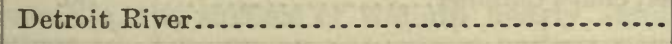 & S. F. Baird. \\
\hline 8933 & Brimfield...$\ldots \ldots \ldots \ldots \ldots \ldots \ldots \ldots$ & \\
\hline$\$ 975$ & 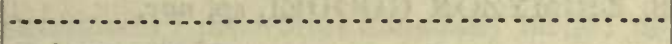 & \\
\hline 9007 & 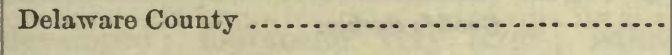 & \\
\hline 9042 & 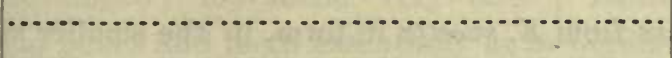 & \\
\hline $\begin{array}{l}91182 \\
9160\end{array}$ & $\begin{array}{l}\cdots \\
\cdots \ldots\end{array}$ & \\
\hline 9162 & Jackson, Ill............................ & R. Kenvicott. \\
\hline
\end{tabular}


Specimens in United States National Museum-Continued.

\begin{tabular}{|c|c|c|}
\hline Number. & Localits. & Collector. \\
\hline 9166 & Abbeville, S. C............ & \\
\hline 9275 & ........................ & \\
\hline 9446 & Aux Plaines River, Illinois...... & R. Kennicott. \\
\hline 9551 & Lake Oconomowoc, Wisconsin............... & S. F. Baird: \\
\hline 9660 & 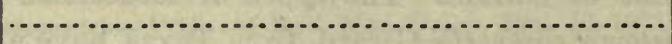 & \\
\hline 10631 & Potomac River.............. & J. W. Milner. \\
\hline 10814 & Sandusky, Ohio.............. . & Do. \\
\hline 11033 & ...... do ................... & Do. \\
\hline 11034 & ...... do $\ldots . . . . . . . . .$. & Do. \\
\hline 11035 & 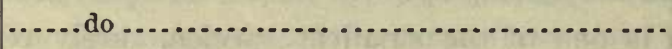 & Do. \\
\hline 11199 & ...... do .................... & Do. \\
\hline 11200 & ...... do $\ldots . . . . . . . . . . . .$. & Do. \\
\hline 12441 & Halifux, Nova Scotia........... & Do. \\
\hline $1497 \pi$ & Potomac River ................ & G. B. Goode. \\
\hline 16990 & ...... do ...................... & J. W. Milner. \\
\hline 16991 & ...... do $\ldots . . . . . . . . . . . . .$. & Do. \\
\hline 16992 & ...... do $\ldots . . . . . . . . . . . .$. & Do. \\
\hline 16993 & ...... do ........................ & Do. \\
\hline 16994 & ...... do ..................... & Do. \\
\hline 17816 & Clear Creek, Texas............. & Kumlicn \& Earll. \\
\hline 17821 & ......do ..................... & Do. \\
\hline 17838 & New Bedford, Mass.............. & Thomas. \\
\hline 19158 & Aux Plaines River, Illinois ................. & R. Kennicott. \\
\hline 20061 & Cedar Swamp, New Jersey.............. & S. F. Baird. \\
\hline 20064 & Schuylkill, Rirer ................ & J. H. Richard. \\
\hline 20105 & Fox River, Wisconsin....................... & S. F. Baird. \\
\hline 20157 & Montgomery, Ala ........................... & Kumlien \& Maxson. \\
\hline 20231 & 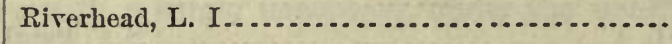 & S. F. Baird. \\
\hline 20254 & 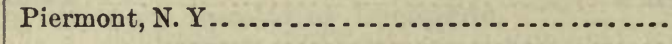 & Do. \\
\hline 20269 & Sing Sing, N. Y........................ & Do. \\
\hline 20360 & 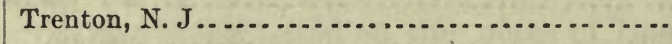 & C. C. Abbott. \\
\hline- & Cumberland River......................... & A. Wincluell: \\
\hline - & White River, Indiana .......................... & D. S. Jordan. \\
\hline - & 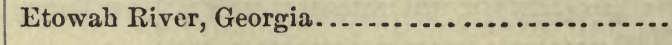 & Do. \\
\hline - & Saluda River, South Carolina.................... & Do. \\
\hline
\end{tabular}

\section{ERIMYZON GOODEI, sp. nov.}

Goode's Sucker.

This species differs from $E$. sucetta in form, in the smaller size of the head, in its greater convexity above, and in the larger size and greater nniformity of the scales, which are not at all crowded or reduced forwards. 
The type is a fine specimen, $10 \frac{1}{4}$ inches long, collected by Professor G. Brown Goode in the Saint Johu's River, Florida. It is numbered 19071 on the Museum Register. I hare named the species for my friend, Professor Goode, one of the best of American ichthyologists, to whom we are indebted for the discovery of the species.

Specimens in Cnited States National Museum.

\begin{tabular}{r|c|c}
\hline Number. & Locality. & Collector. \\
\cline { 2 - 2 } 19071 & Saint John's River, Fla ................................ Brown Goode. & G. \\
\hline
\end{tabular}

\section{Genus CHASMISTES Jordan.}

Chasmistes Jordix, Bull. Hayden Geol. Surv. Terr. 417, 1878.

Type, Ca:ostomus fecundus Cope \& Yarrow.

Etymology, $\chi a \sigma \mu u ́ \omega$, to jawn or gape.

Fishes related to Catostomus, having the teeth, scales, and airbladder as in that genus, but distinguished by the size and position of the mouth, the great development of the mandible, and by the small, smooth lips.

Head disproportionally large, forming more than one-fourth of the length, broad and flattish above; sides of head vertical, slightly directed inwards, the breadth through the cheeks less than the breadth above the eyes; eyes small, high up, rather posterior: mouth exceedingly large, terminal, the lower jaw in the closed mouth being very oblique, placed at an angle of about 45 degrees; the lower jaw very long and strong, its length more than one-third the length of the head, nearly half the length of the head in the adult, its tip when the mouth is closed about on a lerel with the eye; upper jaw very protractile; upper lip very thin (for a Sucker), and nearly smooth; snout elerated abore the rest of the head, notably so when the mouth is closed; lower lip moderate, consisting of a broad flap on each side of the mandible, in front reduced to a narrow rim, the surface of the lip nearly smooth, without evident papillæ: nostrils large; suborbital bones narrow, but rather broader than in Catostomus ; preorbital unusually large: mucous channels moderately dereloped; fontanelle very large; isthmus rather narrow: pharyngeal bones and teeth essentially as in Catostomus.

Body rather slender, tapering pretty regularly from the shoulders to the tail, but little compressed : caudal peduncle rather stout. 
Fins moderate, the dorsal rass about 12 , the anal 7 : pectorals rather long, not quite reaching rentrals : rentrals reaching vent: anal tin high, reaching caudal : caudal fin rather long, its lobes equal.

Scales moderate, large on the caudal peduncle, much smaller and crowded anteriorly, 60 to 65 in the lateral line, about 18 in a transverse series from dorsal to ventrals.

Sexual peculiarities unknown.

Coloration usual.

Air-bladder in two parts.

Size moderate or rather large.

The single species now included in this genus is known only from Utah Lake. Its describers referred it to the genus Catostomus, but made no mention of its singular mouth and lips. The original type of the species is in very bad condition, the mouth being shrunken and dis. torted, and the bones of the head protruding through the skin, so that the peculiarities of the species are hardly recognizable.*

\section{Generic Characterizations.}

Chasmistes Jordan, 1878. - "This genus is distinguished from Catostomus by the very large, terminal mouth, the lower jaw being very strong, oblique, its length about one-third that of the head. The lips are little dereloped, and are very nearly smooth. The type of the genus is C. fecundus Cope \& Yarrow."-(Jordan, Bull. U. S. Geol. Surr. Terr. vol. iv, No. 2, p. 417, 1878.)

ANALYSIS OF SPECIES OF CHASMISTES.

* Depth about 5 in length; head $3 \frac{2}{3}$; interorbital space broad, $2 \frac{1}{4}$ in head; eye 6 to 7 in head; width of the open mouth $3 \frac{1}{2}$ in head. Dorsal 12. Anal 7. Scales 9-63-8. Color dusky above, pale below ; the scales of the back and sides profusely covered with dark punctulations...............................

23. CḦASMISTES FECUNDUS (Cope \& Yarrov) Jordan.

Sucker of Utah Lake.

1876-Catostomus fecundus COPE \& YarRow, Wheeler's Expl. W. 1noth Mer. v, Zool. 678, pl. xxxii, f. 1, 1 a.

Catostomus fecundus Jordan \& Copeland, Check List, 156, 1876.

Chasmistes fecundus Jol:Das, Bull. Hayden's Gcol. Sarv. Terr. vol. iv, No. 2, 41\%, 1878.

Habitat.-Utah Lake, Utah, where it is excessively alunndant. Not jet noticed elsewhere.

This singular species has been overlooked until quite lately. Dr. Yarrow states that it " is abundant in Utah Lake, and is called Sucker

* In fact, this specimen in its present condition looks to me more like Calostomus occidentalis, but the figure published by Cope \& Yarrow represents $C$. fecundus. Both species occur in Utah Lake. 
by the inhabitants. They run up the rivers to spawn in June; feed on the bottom and eat the spawn of better fish ; spawning beds on gravel; bite at hook sometimes; are extremely numerous, and are considered a nuisance by the fishermen, but they meet with a ready sale in winter at an average price of $2 \frac{1}{2}$ cents per pound."

Specimens in United States National Museum.

\begin{tabular}{|c|c|c|}
\hline Number. & Locality. & Collector. \\
\hline 12894 & Utah Lake, Utah ... & Yarrow \& Henshaw. \\
\hline 20337 & Utah Lake, Utah ..... & Dr. H. C. Yarrow. (Many specimens) \\
\hline 20932 & Utah Lake, Utah .............. & Dr. H. C. Yarrow. (Тype Chasmistes.) \\
\hline- & Utah Lake, Utah ............... & Dr. H. C.Yarrow. (Types of thespecies.) \\
\hline
\end{tabular}

\section{Genus CATOSTOMUS Le Sueur.}

Catostomus Le Sunur, Journ. Ac. Nat. Sc. Phila. i, 1r17, ع9. (Equivalent to family Catostomidar.)

Hypentelium RAFINESQUe, Journ. Ac. Nat. Sc. Phila.i, 1818, 421. (As subgenus of Eroglossum.)

Decactylus RAF IXEsQUe, Ichthyologia Ohiensis, 1820,60. (As subgenus of Catostomus, including the 10-rayed species.)

Bylomyzon AGassiz, Am. Journ. Sc. Arts, 1855, 205.

Minomus Grrard, Proc. Ac. Nat. Sc. Pbila. 1856, 173.

Acomus Girard, Proc. Ac. Nat. Sc. Phila. 18j6, 173.

Catastomus GrLL, Canadian Naturalist, 1865, August.

Decadactylus Jordax, Man. Vert. 2d ed.1878, 319. (As subgenus.)

Type, Cyprinus catostomus Forster, = Catostomus hudsonius Le Sueur, = Catostomus longirostrum Le Sueur.

Etymology, като, low ; бт́́ $\mu \alpha$, mouth.

\section{Etymology of Synonyms.}

Hypentelium : probably $\dot{v} \pi \partial$, below ; $\pi_{\varepsilon}^{\prime} \nu \tau \varepsilon$, five; $\lambda_{0,30}$, lobe, as the name is said to refer to the 5-lobed lower lip, supposed to distinguish it from the 3-lobed subgenus

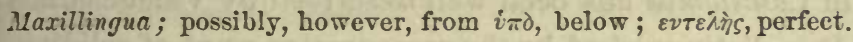

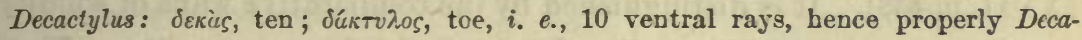
dactylus.

Hylomyzon : $i \lambda_{\varepsilon}$, mud ; $\mu v \zeta u \omega \omega$, to suck.

Acomus ajd Minomus are probably meaningless words, without etymology.

Head more or less elongate, its length ranging from $3 \frac{1}{2}$ to 5 times in that of the body, its form varying considerably in the different subgenera. Eje usually rather small, high up and median or more or less pos- 
terior in position : suborbital bones narrow, longer than broad, much as in Myxostoma: fontanelle always present, usually widely open, in two species reduced to a narrow slit, but never wholly obliterated.

Mouth rather large, always inferior, and sometimes notably so; the upper lip thick, protractile, papillose ; the lower lip greatly developed, with a broad free margin, deeply incised behind, so that it forms two lobes, which are often more or less separated: mandible horizontal, short, not one-third the length of the head and not reaching to opposite the eye: lower jaw usually without distinct cartilaginous sheath : oper. cular apparatus moderately developed, not rugose : pharyngeal bones moderately strong, the teeth shortish, vertically compressed, rapidly diminishing in size npwards, the upper surface of the teeth nearly eren, or somewhat cuspidate.

Body oblong or elongate, more or less fusiform, subterete, more or less compressed.

Scales comparatively small, typically much smaller and crowded anteriorly, the number in the lateral line ranging from about 50 to 115 , the number in a transverse series between dorsal and ventrals from 15 to 40 : lateral line well developed, straightish, somewhat decurved anteriorly.

Fins variously developed : dorsal with its first ray nearly midway of the body, with from 9 to 14 dereloped rays; anal fin short and high, with probably always 7 developed rays; ventrals inserted under the middle or posterior part of the dorsal, typically with $10 \mathrm{rays}$, in one subgenus usually 9 , the number often subject to rariation of one ; caudal fin usually deeply forked, the lobes nearly equal.

Sexual peculiarities not much marked, the fins higher in the male and the anal somewhat swollen and tuberculate in the spring: breeding males in some species with a rosy or orange lateral band.

Air-bladder with two chambers. Vertebræ in $C$. teres and $C$. nigri. cans 45 to 47 .

"The skeleton in Catostomus has been well described by Valenciennes (XVII. p. 433). It is distinguished by the comparative want of solidity, certain bones consisting merely of a network of osseous matter. There is a large and broad fontanelle on the upper surface of the head, separating the parietal bones, and leading directly into the cerebral cavity. The occipital process is, below the anterior vertebræ, enlarged into a bladder-like swelling, which is not solid, but consists of a delicate network only. The prefrontal is advanced to the anterior part of the orbit. 
The jaw-bones are very feeble, the intermaxillary being reduced to a thin lamella, which does not descend to the middle of the maxillary. The anterior part of the mandible is horizontal, thin and slightly dilated. The apophyses of the four anterior vertebræ are very strong and long."(GüNTHER, Cat. Fishes Brit. Mus. vii, 13.)

This genus as at present restricted comprises three well-marked groups, which may be accepted as subgenera, under the names Catostomus, Dccudactylus, and Hypentelium. One of these groups, Hypentelium, has been asually considered as a distinct genus, on account of the differences in the form of the head and in the squamation. These differences are, however, indiridually of subordinate value, and should probably be held to designate a subgeneric section, rather than a distinet genus.

The group Decadactylus as here giren is nearly equivalent to Minomus and Catostomus of Girard, while our Catostomus is Girard's Acomus. The type of Catostomus, as restricted by $\mathbf{A}$ gassiz, prior to Girard being Cyprinus catostomus Forster, oi:e of the small-scaled group, the name belongs properly to that group, and Acomus is a simple synonym. Decactylus Rafinesque was not originally defined in any very tangible way, inasmuch as its author included in it species of Iyxostoma and Cycleptus. As, howerer, it was intended for 10-rayed species, and as one among those originally placed in it was $C$. teres (as $C$. bostoniensis), the the name Decactylus (Decadactylus) mas be used instead of Minomus as a designation for the subgenus to which $C$. teres belongs.

The genus Catostomus is, next to Myxostuma, the most rich in species. It is much the most widely distributed of the genera of Suckers, some of its members abounding in every river of North $A$ merica, and one of them being found in Asia.

\section{Generic Characterizations.}

"Catostonus Le Sueur, 1817.

"Back with a single fin.

"Gill-membrane three-rajed.

"Mead and opercula smooth.

"Jaws toothless and retractile.

"Mouth beneath the snout; lips plaited, lobed, or carunculated, suitable for sucking.

" Throat with pectinated teeth.

"The species which are here described are all possessed of the following general characters :-

"Body.-The body in general is elongated and varied in its form.

"Scales.-The scales in almost all the species are marked with radiated lines, and fimbriated on their edges; their form more or less rhomboidal or roundish. 


\section{CONTRIBUTIONS TO NORTH AMERICAN ICHTHYOLOGY-III.}

"Gill-covers.-The gill-covers are large, and composed of three pieces; the anterior piece small in some, as is exemplified in the C.macrolepidotus, and in others large, as in the $C$. communis; opening or expansion wide.

"Nostrils.-The nostrils are double on each side, and separated by a membrane; tle largest aperture near the eyes.

"Eyes.-The eyes in general are pretty large, a little oblong, without nictituting membrane : pupil black and roundish : irides yellowish, sometimes brown, as in the C. gibhosus.

"Teeth.-No teeth in the jaws, but those of the throat, on each side, are composel of a range of bones, generally blunt and thick at their summits, placed in a pectinated form, on an osseous, arcuated base, of which they are a component part, and sonetimes terminate in a hooked point, as in the C. maculosus; these teeth are enveloped in a thick mass of whitish substauce, which covers the throat, and supplies the place of a tongue.

"Mouth.-The mouth is generally lunated; to the palate is attached a membrane.

"Viscera.-The intestinal canal is very much developed, and it has its origin near the throat ; the stomach, which is simple, and without plaits and curvatures, being a continuation of this canal, and appears to be confounded with it. The intestines make a number of circumvolutions; in a speci-men of the C. macrolepidotus of 16 inches in length, they were 3 feet 5 inches in length. The liver is deliquescent, and soon passes into oil after exposure to the atmosphere. The air-bladder is subcylindrical, aud divided, in most species, into two parts; in the C. macrolepidotus, it is separated into four parts. I have remarked in the intestines of these fisbes river-shells of the geuera Lymnasa, Bulimus, etc., which dwell on aquatic plants and on the rock at the bottom of the rivers; these shells the Catostomi are enabled to take with their lips, which are protruded forwards by means of their jaws.

"It is necessary to remark that in all the species which I have examined there is a line which runs from the nape, beneath the eyes, and another along the head, above the eyes, of small orifices, for the passage of mucus, which lines are well defined after the fish is dead and desiccated, but not so conspicuous when recent; these lines Forster improperly terms sutures. I will add that some species, in a dried state, have also a tuberculated appearauce on the head, which tubercles are not discernible when the animals are living."-(Le Sueur, Journ. Ac. Nat. Sc. i, p. 8').)

Hypentelium Rafinesque, 1818. - "This species [Exoglossum macropterum] distinguished by so many secondary characters may be the type of a sulgenus, which may be called Hypentelium, in reference to the five lobes of the lower jaw. The species with a three-lobed jaw may form then another section under the former name of Maxillingua."-(RAFINESQUe, Journ. Acad. Nat. Sc. p. 420, 1818.)

Catostomus Rafinesque, 1820.- "Body oblong cylindrical, scaly. Vent posterior or nearer to the tail. Head and opercules scaleless and smooth. Mouth beneath the snout, with fleshy, thick or lobed sucking lips. Jaws toothless and retractible. Throat with pectinated teeth. Nostrils double. Gill-cover double or triple. Three branchial rays to the gill membrane. A single dorsal fin commouly opposite to the abdominal fins, which have from eight to ten rajs."-(Rarinesque, Ich. Oh. p. 53.)

Decactylus Ratinesque, 1820._- Body nearly cylindrical, abdominal fins with ten 
rays; tail equally forked. Besides the two following species (C. duquesnii; C. elongatus) the C.bostoniensis and C.hudsonius must be enumerated here."-(RAFINEsQCe, Ich.Ol. p. 60.)

Hypentelicm Rafinesque, 1820.- "Body pyramidal slightly compressed, with very minute scales. Vent posterior. Head scaleless, nearly square, mouth terminal protruded beneath toothless, jaw shorter with five lobes, the middle one larger, lips very small. Abdominal fins anterior removed from the vent, dorsal fin anterior, opposed to them.

"This genus belongs to the family of the Csprinidia, and is next to my genus Exoglos8um, with which I had united it; but this last differs from it by an oblong body, flat head, lower lip trilobe not protruded, abdominal fins and dorsal fin medial, \&c. The name expresses the character of the lower lip."-(Rafinesque, Ich. Oh. p. 68.)

Catostomus DeKay, 1842._- "Both lips thick, fleshy; and crenated or plaited; the lower lip pendant. Doreal placed above the ventrals and usually short."-(DEKAY, New. York Fauna, Fishes, p. 196.)

Catostomus Heckel, 1843.- “Os infernnı; labia carnea, lata, rugosa, suctni apta; cirrhi nulli; præoperculum ante occiput. Pinna dorsalis brevis, rarius elongata ; analis brevior, utraque radio osseo nullo. Dentes pharyngei pectiniformes.

$$
\mathrm{D}: 3 \mid \frac{8-13-29}{\mathrm{~A}: 2}
$$

(Characters of Tribus IV, including Catostomus, Rhytidostomus, and @ Exoglossum.)

"Dentes pectiniformes $40-40$. Os inferum; labia carnea; lata, rugosa ad suctum apta; cirrbi nulli. Pinna dorsalis et analis brevis, illa ante pinnas ventrales incipiens;

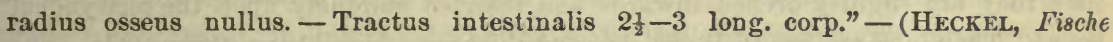
Syriens, p. 33.)

Catostomus Valencienues, 1844.- "Ils different des ables [Leuciscus], avec lesquels ils ne sont pas sans affinité, par la position de leur boucbe et par la forme des lèvres qui la bordent. Ces organes sont assez distincts do ceux des Chondrostomes.

"L'absence des barbillons les éloigne aussi des Labéons [ Labeo], avec lesquels ils ont d'ailleurs moins de rapports que M. Cuvier ne le supposait quand il a rédigé le Règne Animal. Enfin ils different de tous ces genres par leurs dents pharyngiennes.

"Par la forme générale de leur corps, ils ressemblent à nos barbeaux [Barbus], dont ils ont presque tous la tête alongée, lisse et nue, et le musean un peu proéminent, mais ils n'ont pas leurs barbillons, et la dorsale manque de rayons épineux et dentelés. La bouche est située sous le musean; elle est sans dents, et les lèvres, élargies, lobées, caronculées, mais sans prolonguements filiformes, servent à constituer une sorte de ventouse au moyen de laquelle ces poissons peuvent adherer ou sucer. Les pharyngiens sont grands et arqués, presque en demi-cercle; tout le bord interne est garni de dents comprimées, à conronne striée, un pen plus large que la base; toutes ces dents décroissent regulièrement depuis les inferiéures jusqu'aux suçérieures, le nombre en varie selon les espèces; elles forment nn.peigne sur le corps l'os. Les opercules sont grands; les narines ont chacune, comme à l'ordinaire, deux ouvertures rapprochées; les jeux assez larges, sont elliptiques, et ont l'iris ordinairement jaune; les écailles sont en général petites sur la nuque et près de la tête, et elles vont ensuite en augmentant à mésure qu'on s'en approche de la queue; elles sont plus on moins rhomboïdales et striées ou frangces. 


\section{CONTRIBUTIONS TO NÓRTH AMERICAN ICHTHYOLOGY-III.}

"Les viscères rappellent ceux des cyprinoïdes en général, mais l'intestin, à cause de ses nombreux replis, a ezcore plus d'étendue. ... Le foie se résout bientôt en huile; la ressie aérienne est communément divisé en deux et communique avec le haut de l'œsophage comme dans nos cyprins."-(Valexciennes, Hist. Nat. des Poissons, xvii, pp. 423-424.)

Hylomyzon Agassiz, 1855.- "The name of this genus is a mere translation of the vernacular name of its type, the Mnd-Sucker of the West, framed in imitation of Petromyzon, but expressing its habits of living in the mud. The body is stout and heavy in front, and tapers off rapidly from the shoulders towards the tail; behind the dorsal it is nearly cylindrical in form.

"The short quadrangular head is broad and flat above, its sides are vertical. The eyes are of moderate size and elliptical in form; the superorbital ridges are elevated above the general level of the head. The mouth is inferior, and encircled by broad fleshy lips which are covered with sıall grains or papillæ. The lower lip is bilobed. The dorsal is over the ventrals, and nearer the head than the tail; its height and length are nearly equal. The pectorals and ventrals are broad and rounded, the anal fin is slender and reaches the caudal. The scales are largest on the anterior portion of the body. They are slightly longer than high, the ornamental concentric ridges of the posterior field are broader and fartber apart than those of the lateral and anterior fields; those of the anterior and posterior fields rather remote, abont equal in numiber. Tubes of the lateral line arising from the centre of radiation.

"The teeth are compressed, so that their sharp edge projects inwards; at the same time they are slightly arched inwards and inserted obliquely upon the pharyngeal bones. They increase gradually in size and thickness from above downwards. The masticating ridge of the teeth is transverse, compressed in the middle and sharp; its upper and lower edges are rounded and more projecting, the inuer point, however, more projecting than the outer one."-(AGassiz, Am. Journ. Sci. Arts, 1855, p. 205.)

Catostomus Agassiz, 1855.- "I have retained the name of Catostomus for the type to which it was origiually applied by Forster. The body is elongated, fusiform and slightly compressed. The snout is short and blunt, and projects but little beyond the mouth, which is inferior. The lower jaw is short and broad. The lips are fleshy and strongly bilobed below; their surface is conspicuously granulated or papillated. The head is considerably longer than high. The dorsal is large and mostly in advance of the ventrals; its length is greater than its height. The anal fin is long and slender, and reaches the caudal. The sexual differences, so conspicuous in the genus Moxostoma and Ptychostomus, are hardly to be noticed in this genus. The other fins are of moderate size, and more or less pointed.

"The scales are much smaller on the anterior than on the posterior portion of the body; nearly quadrangular, with rounded angles, but somewhat longer than high; the ornamental concentric ridges of the posterior field broader than those of the lateral and anterior fields; the radiating furrows more numerous than in Hylomyzon and Ptychostomus, and encroaches upon the lateral fields, where, in some species, they are nearly as numerous as upon the anterior and posterior fields. Tubes of the lateral line wider thau in Hylomyzon and Ptychostomus, extending from the centre of radiation to the posterior margin.

"The pharyngeals are stout and compact, the outer margin not so spreading as 
in Ptychostomus; the teeth are blunter and larger comparatively than iu any other genus of the tribe, increasing more rapidly in size from above downwards, so that those of the middle of the arch are already of the same cast as those of the lower part of the comb ; their crown is blunt and the inner edge rises into a blunt cusp."(Agassiz, Am. Journ. Sc. Arts, 1855, p. 207.)

Mrnowus Girard, 1856. - "We propose to include under the head of Minomu8, such species as are characterized by an elongated and fusiform body, a head longer than deep; a dorsal fin either higher than long, or with both dimensions equal. The l.ps being tuberculated, moderately bilobed. The pharyngeals not expanded laterally, but considerably bent inwardly. The teeth compressed, decidedly bicuspid, but the inner projection more developed than the outer. The scales being nearly of the same size, but slightly smaller auteriorly than posteriorly." (Includes C. insignis, C. plebeius, aud C. clarkii.)-(Grrard, Proc. Ac. Nat. Sc. Phila. 1856, p. 173.)

Acomus Girard, 1856.- "And then giving the name of Acomus to those species in which the head is very elongated, the dorsal higher than long, and the scales much smaller upon the anterior region of the body than upon the posterior. The lips being papillated and very deeply cleft. The pharyngeals are gently arched and not expanded; the teeth compressed and bituberculated, the inner projection conspicuous; the outer one obsolete, though existing." (Includes C.forsterianus, C. aurora, C. latipinnis, C. guzmaniensis, C. generosus, C. greseus, and C. lactarius.)-(Girard, Proc. Ac. Nat. Sc. Phila. 1856, p. 174.)

Catostomus Girard, 1856.- "The genus Catostomus, Le Sueur, would then be restricted to such species in which the head is moderately elongated, the dorsal fin generally longer than high, and the size of the scales less disproportionate anteriorly and posteriorly than in Acomus. The lips are papillated and deeply cleft. The pharyngeals provided with a little expansion inferiorly. The teeth are compressed, with the inner projection of the crown alone developed." (Includes $C$. hudsonius, C. communis, C. occidentalis, C.labiatus, C. macrocheilus, C. sucklii, and C. bernardini.)-(GIRaRd, Proc. Ac. Nat. Sc. Phila. 1856, p. 174.)

Catastonos Gill, 1865.- "Snont long. Lateral line present, nearly straight. Lips papillated."-(GrLL, Canadian Naturalist, Aug. 1865, p. 19, reprint.)

Catóstonos Giinther, 1863.-- "Scales of small, moderate or large size. Lateral liue present, running along the middle of the tail. Dorsal fin of moderate extent, with not more than about seventeen rays, opposite to the ventrals, without spine. Anal fin very short, but deep. Fins of the males generally more produced than those of the females, and frequently with horny tubercles. Mouth inferior, with the lips more or less thickened and papillose, the lower frequently bilobed. Barbels none. Gill-rakers well developed, soft, the upper lanceolate, the lower quite nembranaceous, low folds crossing the bone. Pseudobranchiæ. Pharyngeal bones sickle-shaped, armed with a comlslike series of numerous compressed teeth, the teeth becoming larger and broader towards the luwer end of the series."-(Güsther, Cat. Fishes Brit. Mus. vii, p. 12.)

Catostomus Jordan, 1876. - "Air bladder in two parts ; lateral line well developed; lips papillose; scales much smaller anteriorly than posteriorly; interorbital spaco convex ; body sub-terete."-(Jordav, Man. Vert. 1876, p. 292.)

Hypentelicm Jordan, 1876. - "Air bladder in two parts; lateral line well developed; lips papillose; scales about as large on front part of body as on tail; body 
tapering rapidly from shoulders to tail ; interorbital space concave; length of head greater than depth of bodf."-(Jondax, Man. Vert. 1876, p. 292.)

Catostomus Cope \& Jordan, 1877.- "Body oblong or elongate, with a short, subquadrate dorsal fin ; air bladder in two parts ; lateral line well developed ; fontanelle distinct."-(Jordan, Proc. Ac. Nat. Sc. Phila. 1877, p. 81.)

Hypentelium Jordan, 1878. - "Body oblong or elongate, with a short subquadrate dorsal; anal rays uniformly 7 ; mouth normal, the lower lip undivided or deeply lobed ; lips tuberculate; lateral line well developed; fontanelle distinct; no mandibulary sheath; scales moderate, not crowded forwards, about equal over the body ; body long, and little compressed; head transversely concave between orbits, long and flattened, the physiognomy being therefore peculiar; ventral rays 9."-(Jordan, Man. Vert. ed. 2d, 1878, pp. 309-310.)

Catostomus Jordan, 1878.-[As in the preceding except] "Scales small, smaller anteriorly and much crowded; head transversely convex between orbits; ventral rays normally 10."-(JoRDAN, Man. Vert. ed. 2d, 1878, pp. 309-310.)

Decadactylus Jordan, 1878 (as subgenus).- "Lateral line with 60 to 65 scales; snout comparatively short."-(JoRDaN, Man. Vert. ed. 2d, p. 319.)

Catostomus Jordan, 1878 (as subgenus).- "Lateral line with about 100 scales; snout much produced."-(Jordan, Man. Fert. ed. 2d, p. 320.)

The three subgenera here recognized are characterized below. The single species of Hypentelium is found only eastward of the Rocky Mountains. C'atostomus and Decadactylus each have representatires on both sides of the mountains. It is a curious fact that the Southwestern representatives of each, as a rule, have the upper lip more developed, and with more numerous series of papillæ, than the Eastern ones. In this respect as in others, these Western species approach the genus Pan. tosteus, a group exclusively Western in its distribution.

ANALYSIS OF SPECIES OF CATOSTOMUS.

" Scales moderate; not crowded anteriorly, nearly equal over the body; 48 to 55 in the lateral line; 12 to 15 in a transverse series from dorsal to ventrals : head flattened above, transversely concave between the orbits, the froutal bone thick, broad, and short, the physiognomy being therefore peculiar: ventral rays normally 9: upper lip very thick, strongly papillose, with a broad, free margin, which has upwards of 8 to 10 series of papillæ upon it. Lower lip greatly developed, strongly papillose, considerally incised behind, but less so than in Catostomus proper : fontanelle shorter and smaller than in Decadactylus : pectoral fins unusually large. (Hypentelium.)

$x$. Depth $4 \frac{1}{3}$ to 5 in length; head 4 to $4 \frac{1}{2}$; eyo rather small, $4 \frac{1}{2}$ to 5 in head: color olivaceous; sides with brassy lustre; belly white; back brown. with several dark cross-blotches, irregularly arranged, these becoming obsolete in old individuals; lower fins dull red, with some dusky shading : size large; maxinum length

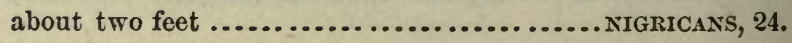


$y$. Dorsal with 11 developed rays: scales $7-50-5$ : head rather longer, 4 to $4 \frac{1}{2}$ in length : pectoral fins rather longer: colors relatively dull; no distinct whitish stripes along the rows of scales.

nigricans.

yy. Dorsal with 10 developed rays: scales 6-48-5: head rather shorter, $4 \frac{1}{8}$ in length : pectoral fins rather shorter : colors brighter ; blackish above; belly abruptly white; a pale spot at the base of each scale, these forming conspicuous whitish streaks along the rows of scales...........................etoncanus.

** Scales small, reduced, and crowded anteriorly more or less; 58 to 72 in the lateral line and about 20 to 25 in a transverse series from the ventrals to the dorsal : snout moderate or rather short. (Decadactylus.)

† Upper lip comparatively thin, with but few ( 2 or 3 ) rows of papillæ.

a. Dorsal fin with but 10 or 11 developed rays; scales but little reduced in size forwards.

b. Body moderately stout; depth $4 \frac{2}{8}$ in length ; head very small and short, about 5 in length; eje moderate; fins all notably small: scales small, subequal, 9-70-9, larger on the middle of the body than on the caudal peduncle: body with scattered, dusky, nebulous spots . CLARKI, 25.

$b b$. Body rather elongate, subterete, heary at the shoulders and tapering backwards, the depth about 5 in length; head moderate, about $4 \frac{1}{4}$ in length; mouth comparatively small; lips moderate, the upper narrow, with about two rows of large tubercles: scales little crowded forwards, 58 to 63 in the lateral line, 19 in a cross-series : a series of dusky spots along each row of seales, as in Minytrema melanops; the spots sometimes obscure.

INSIGNIS, 26.

aa. Dorsal with 11 to 13 developed rays : scales much reduced and crowded anteriorly.

c. Body moderately stout, varying with age, subterete, heavy at the shoulders, the depth 4 to $4 \frac{2}{8}$ in length: head rather large and stont, conical, flattish above, its length 4 to $4 \frac{1}{2}$ in body ( $3 \frac{1}{2}$ to $4 \frac{1}{4}$ in soung); suout moderately prominent, scarcely orerpassing the mouth; mouth rather large, the lips strongly papillose, the upper moderate, with two or three rows of papillæ: scales crowded anteriorly, much larger on the sides than below ; scales $10-64$ to $70-9$ : coloration olivaceous; males in spring with a faint rosy lateral band; young brownish, more or less mottled, often with about three large confluent lateral blotches, which sometimes form an obscure lateral band.

TERES, 27.

tt Upper lip thick and full, with several (5 to 8) rows of papillæ: scales crowded forwards. 
fFnntanelle well dereloped : lips without evident cartilaginous sheath.

d. Dorsal fin comparatively long, of 12 to 14 rays.

e. Mouth quite large, with very large lips, the upper fall and pendent, with 6 to 8 rows of strong papillæ: head large, $4 \frac{1}{4}$ in length, rather narrow, quadrangular, the snout projecting: eje large: dorsal fin much longer than high, its rays abont 14 : scales 12-72-10: coloration rather dark; a dusky lateral

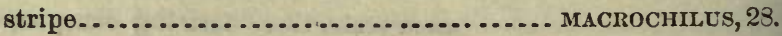

ee. Mouth comparatively small, smaller than in C. teres; the upper lip thick, with 5 or 6 rows of papillæ, which are moderately large: head rounded above, $4 \frac{1}{2}$ in length, the profile steeper than in $C$. teres, the snout more pointed, the two sides of the head more convergent forwards: eje small : dorsal fin longer than high, its rays 12 to 14 : scales $13-72-10$.

occidentalis, 29.

$d d$. Dorsal fin short, higher than long, of about 11 developed rays: head $4 \frac{1}{8}$ in length, rather bluntish : mouth moderate, the labial papillæ largely developed, the upper lip full, with about 5 rows of large but rather sparse papillæ: scales 12-74-10: color dark above; sides clonded with black and jellow... LABIATus, 30.

\$Fontanelle very small and narrow : bcth jaws with a weak cartilaginous sheath: body elongate, fusiform, subterete, the greatest depth $4 \frac{1}{4}$ to $4 \frac{1}{2}$ in length: head small, conical, $4 \frac{2}{8}$ in length: mouth quite large, with full, thick lips, the upper very wide and pendent, with about 6 rows of very strong papillæ: lower lip twolobed, similarly papillose : interorbital space wide, convex: eye elevated, posterior, quite small: fins moderate; dorsal higher than long, with 10 , rarely 11 , rays: ventral rays 10 : scales small, crowded forwards, 10 or 9-70-8: color dark; scales with dark punctulations................ 1 \&OPUs, 31 .

*** Scales very small, much reduced and crowded anteriorly; 83 to 115 in the lateral line, and 25 to 40 in a transverse series from the ventrals to the dorsal : body and head more or less elongate : sides with a broad rosy or orange lateral band in spring males. (Catostomus.)

$\$$ Fontanelle well developed: jaws without evident cartilaginous sheath.

f. Upper lip comparatively thin and narrow, with but few $(3$ or 4$)$ rows of papillæ.

g. Bodly shorter than in the next, but still elongated, its greatest depth $4 \frac{1}{2}$ to 5 in length : head very large and long-acuminate, the muzzle nearly one-half its length, overhanging the rather large mouth: lips moderate; the npper pendent, with about 3 rows of small papillæ; the lower rather full, similarly papillose: eye nearly median, rather small, $8_{\frac{1}{2}}^{\frac{1}{2}}$ in head: scales small and crowded forwards, closely imbricated, 53 to 87 in 
the course of the lateral line and about 28 in a cross-series from dorsal to ventrals : coloration very dark; fins dusky; scales every where finely punctate. Size large.. TAноExsis, 32.

99. Body elongate, subterete, the depth $4 \frac{1}{4}$ to $4 \frac{8}{4}$ in length : head quite long and slender, $4 \frac{1}{4}$ to 4 年 in length, depressed and flattened above, broad at base, but tapering into a long snout, which considerably overhangs the large month: lips thick, coarsely tuberculate, the npper lip narrow, with 2 or 3 rows of tubercles: eye rather small, behind the middle of the head: scales very small, much crowded forwards, 95 to 114 in the course of the lateral line, and abont 29 (26 to 31 ) in a cross row from dorsal to ventrals: dorsal rays 10 or 11 : males in spring with the head and anal fin profusely taberculate, the tubercles on the head small; the sides at that season with a broad rosy band: size large; the largest species in the gerus.............................. LovgIrostris, 34 .

ff. Upper lip very broad, with several (5 or 6 ) rows of large papillæ.

$i$. Body long and slender, subterete, compressed behind, the form essentially that of $C$. longirostris, the depth contained $5 \frac{1}{3}$ times in the length: head large, 4 in length of bod $y$, the interorbital space broad and flat, $2 \frac{1}{2}$ in length of head: eye small, high up and rather posterior: preorbital bone very long and slender, its length about three times its depth: mouth large, precisely as in $C$. Tatipinnis, the upper lip pendent, very large, with 5 to 8 eries of tubercles: dorsal lin not elongated or especially elevated, its rays 11, the beginning of the dorsal much nearer base of caudal than snont: caudal fin long and strongly forked : anal fin long and high, reaching base of candal : ventrals not reaching vent: candal peduncle stout and deep, its least depth more than one-third length of head, its length about two-thirds that of head: scales quite small, abont as in longirostris, the exposed portion not notably lengthened: chest with well-developed scales; scales 16-100-14 : coloration dusky brown, a dusky lateral band, pale below, the dark colors extending low; snout quite dark : size large... KETROPLNNIS, 35.

ii. Body slender and elongate, the caudal peduncle especially long and very slender, the depth 51 in the length: head moderate, 48 in length, rather slender, with prominent snout and ratber contracted, inferior mouth; outline of the mouth triangular, the apex forwards; the lips very thick, greatly developed, lower lip incised to the base, its posterior margin extending backwards to opposite the eje: jaws with a slight cartilaginous pellicle: eye small, high up: preorbital boue broad, scarcely twice as long as deep: scales long and low, posteri- orly rounded, their horizontal diameter greater than the ver-

Bu!!. N. M. No. $12-11$ 
tical, $17-98$ to $105-17$ : fins excessively developed, much more elevated in the males than in the females, the free border of the dorsal, in the males at least, deeply incised: in the males, the height of each of the three vertical fins is greater than the length of the head: dorsal rays 13 , its beginning rather nearer snout than base of dorsal: candul fin especially strong, the rudimentary rays at its base unusually developed : least depth of caudal peduncle less than one-third length of head: coloration rather silvery, the males probably rosy and tuberculate in spring............... LATIPINNIS, 36 .

$\oint \oint$ Fontanelle almost obliterated, reduced to a narrow slit : each jaw with a welldeveloped cartilaginons sheath (as in Pantosteus).

$j$. Body subterete, compressed behind, the depth 5 in length: interorbital space 2 in head: head quite short, broad and rounded above, $4 \frac{8}{4}$ in length : eye small, far back and high up, 6 in head: mouth very large, inferior, beneath the projecting snout : upper lip very full, pendent, with about 5 rows of tubercles $u_{2}$ on it: lower lip very full, moderately incised, with about 10 rows, a notch separating the upper lip from the lower, each jaw with a slightly curved cartilaginous sheath ou its edge, the two parallel with each other and fitting closely together: fins small: dorsal rays 11 ; caudal little forked: scales 15-90-11, very much reduced forwards and subject to many irregularities : colors dusky : size small .. DISCOBOLCs, 36 .

\section{UATOSTOMUS NIGRICANS Le Sueur.}

Log Sucker. Hog Mullet. Hog Molly. Crawl-a-bottom. Stone Roller. Stone Toter. Stone Lugger. Hammer-head. Mud Sucker.

a. Sulspecies nigricans.

1817-Catostomus nigricans Le Sceur, Jouru. Ac. Nat. Sc. Phila. 102.

Catostomus nigrans (sic) KinTLAND, Rept. Zool. Ohio, 168, 1838.

Catostomus nigricans DEKAY, New York Fauna, part iv, Fishes, 202, 1842.

Catostomus nigricans Cuvier \& Valenciennes, Hist. Nat. des Poiss. xvii, 453, 1844.

Catostomus nigricans Storer, Synopsis, 421, 1846.

Hylomyzon nigricans AGassiz, Am. Jouru. Sci. Arts, 2d series, xix, 205, 1855.

Hylomyzon nigricans Putxam, Bull. Mus. Comp. Zool. 10, 1863.

Hylomyzon nigricans Cope, Proc. Ac. Nat. Sc. Phila. 285, $1 \times 64$.

Catostomus nigricans Cope, Journ. Ac. Nat. Se. Pbila. 236, 1868.

Catostomus nigricans Günther, Cat. Fishes Brit. Mus. vii, 17, 1868.

Catostomus nigricans Cope, Proc. Am. Philos. Soc. Phila. 468, 1870.

Hylomyzon nigricans JORDAN, Fishes of Ind. 221, 1875.

Hypenłelium nigricans JORDAx, Bull. Buffalo Soc. Nat. Hist. 95, 1876.

Hypentelium nigricans Jordax, Man. Vert. 294, 1876.

Catostomus nigricans UHLer \& LUGGer, Fishes of Maryland, 128, 1276

Hypentelium nigricans NeLson, Bull. No. 1, Ills. Mus. Nat. Hist. 48, 1876 $\mathrm{f}_{\mathrm{i}}$ 
Hypentelium nigricans JoRdAN \& CoPELAND, Check List, 156, 1876.

Catostomus nigricans Jordax, Ann. LJc. Nat. Hist. N. Y. xi, 345, 1877.

Hypentelium nigricans JORDAN \& GILBERT, in Klippart's Rept. 53, 1876.

Hypentelium nigricans Jordax, Bull. U. S. Nat. Mus. ix, 34, 18 i7.

Hypentelium nigricans JoRDax, Man. Vert. ed. 2d, 319, 1878.

1817-Catostomus maculosus Le Sueur, Journ. Ac. Nat. Sc. Phila. 103.

Catostomus naculosus DEKAY, New York Fanna, part iv, Fishes, 203, 1842.

Catostomus maculosus Cuvier \& Valexciennes, Hist. Nat. des Poiss. xvii, 454, 1844.

Catostomus maculosus Storer, Srinopsis, 422, 1846.

Catostomus maculosus UnLer \& LUGGer, Fishes of Maryland, 139, 1876.

1817-Exoglossum macropterum RAFinesQue, Jonrn. Ac. Nat. Sc. Phila. 420.

Hypentelium macropterum RAFINESQUE, Ich. Oh. 68, 1820.

Hypentelium macropterum Krrtuaxd, Rept. Zool. Ohio, 168, 1838.

Exoglossum macropterum Cuvier \& VALENCIENies, xvii, 486, 1844.

Exoglossum macropterum STORER, Synopsis, 428, 1846.

1820-Catostomus xanthopus RAFINESQUE, Ich. Ob. 57.

1820-? Catostomus ? megastomus RartNesque, Ich. Ob.59. (Most likely mythical.)

1844-C'atostomus planiceps Cuvier \& Valexciennes, Hist. Nat. des Poissons, xvii, 450, pl. 516.

Catostomus planiceps Storer, Synopsis, 426, 1846.

an. Subspecies etorvanus.

1877-Catostomus nigricans var. etowanus Jordax, Ann. Lyc. Nat. Hist. N. Y. xi, 345.

Habrtat.-New York and Maryland to North Carolina; west to the Great Plains. Var. etonoanus in the Alabama River. Most common in the Central Mississinpi Basin; not known from the streams of the South Atlantic States, excepting the Savannah River.

This species is one of the most abundant and widely distributed of our Suckers. It abounds in rapicls and shoals, especially in the larger streams, and its singular, almost comical form is familiar to every school-boy in the West. Its powerful pectoral fins render it a swifter fish in the water than any others of its family. Its habit is to rest motionless on the bottom, where its mottled colors render it difficult to distinguish from the stones amoug which it lies. When disturbed, it darts away very quickly, after the manner of the Etheostomoids. They often go in flocks of eight to ten. I have never yet found this species in really muddy water, and when placed in the aquarium it is one of the rery first fishes to feel the influence of impure water. In my experience, it is a fish as peculiar to the clear streams as the species of Etheostoma or Uranidea are. Professor Agassiz speaks of it as the Mud Sucker, and has named it Hylomyzon, in allusion to its mud-loving habits. It is fortunate that that name has become a synonym, for it is certainly a inisnomer.

This Sucker reaches a length of about 18 inches. It is not much valued 
as food, but is often caught by boys with a spear or snare. In company with other species of Catostomus and .Myxostoma, it ascends all our Western streams in April for the purpose of depositing its spawn.

The Southern form, which I have designated as var. etowanus, is more intensely colored and differs in some minor respects. It frequents, in great abundance, the clear tributaries of the Etewah, Oostanaula, and Coosa Rivers, in company with Potamocottus meridionalis (zopherus), a species to which the joung of the Catostomus bears much resemblance as seen in the water.

The synonymy of this species has been well worked out by Professor Agassiz. The variations in age and appearance have given rise to a number of nominal species, most of which have, however, already been disposed of. The oldest specific name, nigricans, has been the one most generaily employed. The generic name used depends on whether we consider this species generically distinct from the type of Catostomus or not. It would seem-if we may so speak-as if Nature had intended Hypentelium for a distinet genus, but not being an expert in generic characters, had failed to provide it with any which can stand our tests. The name Hylomyzon, being a simple synonym of Hypentelium, of course cannot be used. Rafinesque's account is much inferior to that of Professor Agassiz, and the figure given by him is one of the worst ever published, still his typical species is readily identifiable, and his name for it cannot be set aside.

Specimens in United States National Museum.

\begin{tabular}{|c|c|c|}
\hline Number. & Locality. & Collector. \\
\hline 7644 & & \\
\hline 8446 & Cayuga Lake, New York ........................... & \\
\hline 8762 & .......................... & \\
\hline 9061 & (................ & \\
\hline 9069 & $\ldots \ldots \ldots \ldots \ldots \ldots \ldots \ldots \ldots \ldots \ldots \ldots \ldots \ldots \ldots$ & \\
\hline 12295 & Cincinnati, Ohio............. & J. W. Milner. \\
\hline-- & Ecorse, Mich.......................... & J. W. Milner. \\
\hline 15246 & Bainbridge, Pa....................... & T. H. Bean. \\
\hline 20066 & Black River, Ohio ................. & S. F. Baird. \\
\hline 20106 & Tennessee ............................ & Beckwith. \\
\hline 20260 & 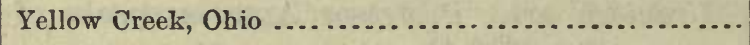 & S. F. Baird. \\
\hline 20270 & Root River, Wisconsin ..................... & \\
\hline- & Etowah River, Georgia (types of var. etowanus) ..... & D.S.Jordan. \\
\hline- & White River, Indiana .......................... & D.S. Jordan. \\
\hline- & Savannah River ................................. & D. S. Jordan. \\
\hline
\end{tabular}




\section{CATOSTOMÙS CLARKI Baird \& Girard.}

Clark's Sucker.

1854-Catostomus clarkii BaInd \& Girard, Proc. Phila. Ac. Nat. Sc. 27.

Catostomus clarkii AGassiz, Am. Journ. Sc. Arts, 2d keries, xix, 208, 1855.

Minomus clarkii GIRaRd, Proc. Ac. Nat. Sc. Phila. 173, 1856.

Minomus clarkii GiraRd, U. S. Méx. Bound. Surv. Ichth. 38, pl. xxii, f. 5-8, 1859.

Catostomus clarkii JoRdan \& COPELAND, Check List, 156, 1876.

Habitat.-Rio Santa Craz in Arizona.

Nothing is known of this species except from the figure given by Girard and the descriptions published by Baird and Girard. The original types of the species are not to be found in the Museum, and there are no specimens of recent collection which appear to belong to it. It seems, however, to be a valid species, related to $C$. insignis. Its lips have not been figured, hence I can only infer that it belongs to the group with a narrow upper lip.

\section{CATOSTOMUS INSIGNIS Baird \& Girard.}

\section{Spotted Sucker.}

1854-Catostomus insignis BaIrd \& Girard, Proc. Phila. Ac. Nat. Sc. 28, 1854.

Minomus insignis GrRakd, Proc. Ac. Nat. Sc. Phila. 173, 1856.

Minomus insignis GrRard, U. S. Mex. Bound. Surv. Ichth. 37, pl. xxi, f. 1-4, 1859.

Catostomus insigne CoPE \& YARRow, Wheeler's Expl. W. 100th Mer. v, Zool. $676,1876$.

Catostomus insignis JoRdaN \& Copeland, Check List, 156, 1876.

Habitat.-Tributaries of the Rio Gila.

The original types of this species, from the Rio San Pedro, are now lost. The specimens collected by Dr. Rothrock in Ash Creek, Arizona, and referred to this species by Professor Cope, undoubtedly belong here. The species is a well-marked one, both as to form and coloration. The genus Minomus, of which it was made the type, appears, however, to have no tangible existence.

Specimens in United States National Museum.

\begin{tabular}{|c|c|c|}
\hline Number. & Locality. & Collector. \\
\hline 16756 & Ash Creek, Arizona .................. & Dr. J.T. Rothrock. \\
\hline
\end{tabular}




\section{CATOSTOMUS TERES (Mitchill) Le Sueur.}

Common Sucker. White Sucker. Brook Sucker. Fine-scaled Sucker.

1803-Le Cyprin commersonien LAC飞é̀̀̀, Hist. Nat. des Poiss. v, 502, 508.

Catostomus commersonii Jordan, Man. Vert. ed. 2d, 320, 1878.

18_-Cyprinus catostomus PeCK, Mem. Am. Acad. ii, pt. 2, p. 55, pl. 2, f.4. (Not of Forster.)

1814-Cyprinus teres Mrtchil,, Lit. and Phil. Trans. New York, i, 458.

Catostomus teres Le Sueur, Journ. Ac. Nat. Sc. Phila. 108, 1817.

Catostomus teres Thompson, Hist. Vt. 134, 1842.

Catostomus teres Cuvier \& Valenciennes, xii, 468, 1844.

Catostomus teres STORER, Synopsis, 423, 1816.

Catostomus teres Agassiz, Am. Journ. Sc. Arts, 2 d series, xix, 208, 1855.

Catostomus teres Gunther, Cat. Fishes Brit. Mus. vii, 15, 1868.

Catostomus teres Cope, Proc. Am. Philos. Soc. Phila. 463, 1870.

Catostomus teres JoRdan, Fishes of Ind.221, 1875.

Catostomus teres Jordan, Man. Vert. 293, 1876.

Catostomus teres Nelson, Bull. No. 1, Ills. Mus. Nat. Hist. 48, 1876.

Catostomus teres Joḱdan \& Cophland, Check List, 156, 1876.

Catostomus teres JoRDAN \& GILIERT, in Klippart's Rept. 53, 1876.

Catostomus teres Jordan \& GrLbert, in Klippart's First Report Ohio Fish Commission, 84, pl. xii, f. 18-19, 1877.

Catostomus teres Jordan, Bull. U. S. Nat. Mus. ix, 37, 1877.

1817-Catostomus communis Le Sueur, Journ. Ac. Nat. Sc. Phila. i, 95.

Catostomus communis DeKAY, New York Fauna, part iv, Fishes, 196, 1842.

Catostomus communis Cuvier \& Valenciennes, Hist. Nat. des Poissons, xvii, $426,1844$.

Catostomus communis Kirtland, Boston Journ. Nat. Hist. v, 265, 1845.

Catostomus communis STOKER, Synopsis, 421, 1846.

Catostomus communis Cope, Journ. Ac. Nat. Sc. Phila. 236. 1868.

Catostomus communis UhLer \& LUGGer, Fishes of Maryland, 138, 1876.

1817-Catostomus bostoniensis Le Sueur, Journ. Ac. Nat. Sc. Phila. 105.

Catostonus bostoniensis Storer, Repł. Ich. Mass. 84, 1838.

Catostomus bostoniensis Cuvier \& Valenciennes, Hist. Nat. des Poissons, xvii, $432,1844$.

Catostomus bostoniensis STORER, Synopsis, 423, 1846.

Catostomus bostoniensis Putnam, Bull. Mus. Comp. Zool. 10, 1863.

Catostomus bostoniensis GrLL, Canadian Nat. p. 19, Aag. 1865.

Catostonus bostoniensis Storer, Hist. Fishes Mass. 290, pl. xxii, f. 3, 1867.

Catostomus bostoniensis Thorenu, Week on Cencord and Merrimack, 38, 1868.

1820-Catostomns flexuosus RAFINEsque, Ich. Oh. 59.

1823-Catostomus hudsonius Richardsox, Franklin's Journal, 717, 1823. (Not of Le Sueur.)

Cyprinus (Catostomus) hudsonius Richardsox, Fauna Bor.-Am. Fishes, 112, 1836.

(Excl.syn.)

1836-Cyprinus (Catostomus) reticulatus Richardson, Fauna Bor.-Am. Fishes, 303. 
1838-Catostomus gracilis Kirtu.AND, Rept. Zool. Ohio, 168.

183ళ-Catostomus nigricans STORER, Rept. Ich. Mass. 86 . (Not of Le Sueur.)

Calostomus nigricans Thompsox, Hist. Vermont, 135, 1842.

1842-Catostomus pallidus DeKay, New York Fanna, part iv, Fishe ',200.

Catostomus pallidus STORER, Synopsis, 426, 1846.

1844-Catostomus aureolus Cuvier \& Valenciennes, Hist. Nat. des Poiss. xvii, 439.

(Not of Le Sueur.)

Catostonus aureolus GÜNTHER, Cat. Fishes Brit. Mus. vii, 16, 1868.

1550-Catostomus forsterianus AGASsiz, Lake Superior, 358.

1855-Catostomus forsterianus AG.sssiz, Am. Journ. Sc. Arts, 2d series, xix, 208.

Acomus forsterianus Grsard, Proc. Ac. Nat. Sc. Phila. 173, 1856.

1856-Catostomus sucklii Girard, Proc. Ac. Nat: Sc. Pbila. 175.

Catostomus sucklii GrRard, U. S. Pac. R. R. Expl.x, pl. li, 226, 1858.

Catostomus sucklii Cope, Hayden's Geol. Surv. Wyoming, 1870, 434, 1872.

Catostomus suckleyi Jordan \& Copeland, Check List, 156, 1876.

1860-i Catostomus texanus Аввотт, Proc. Ac. Nat. Sc. Phila. 473.

? Catostomus texanus Jordan \& Copeland, Check List, 156, 1876.

1860-Catostomus chloropteron Аввотт, Proc. Ac. Nat. Sc. Phila. 473.

Catostomus chloropterum Cope, Proc. Ac. Nat. Sc. Phila. 85, 1865.

Catostomus chloropterus Jordax \& CopkLANd, Check List, 156, $18 \pi 6$.

1876-Catostomus alticolus CoPE \& YARRow, Wheeler's Expl. W. 100th Mer. v, Zool. 677.

Catostomus alticolus Jordan \& Copelaxd, Check List, 156, 1576.

1876-Moxostoma trisignatum (COPE) COPE \& YARROW, Wheeler's Expl. W. 100th Mer. v, Zool. $6 \pi 9$.

Erimyzon trisignatus JoRdaN \& Copeland, Check List, 157, 1876.

HABITAT. - All streams from Labrador to Florida and westward to the Rocky Mountians. Every where abundant. The most widely distributed of the Catostomida.

This species is the commonest of all the Sucker's in nearly every stream east of the Rocky Mountains. In Canada, in New England, in the Great Lakes, in the Mississippi Valley, in South Carolina, in Georgia, in Alabama, it is everywhere the commonest Sucker, aud it certainly occurs in Dakota, Nebraska, Kansas, Colorado, and Texas, though how abundantly I am unable to say.

This species is everywhere the one to which the name of "Sucker" primarily belongs, the other species, though often called "Sucker", as a sort of general term, receiving the special names of Red Horse, Buffilo, Mullet, Chub Sucker, etc.

This species is subject to considerable variations in different waters. In shaded brooks, it is dark-colored and rather slender. In open or nunddy waters, it becomes pale. In the Great Lakes, it often reaches a considerable size and a proportional stoutness of body. The adult is usually uniformly colored above. Young fishes $1 \frac{1}{2}$ to 3 inches in lergth are often rariegated, and sometimes show three or four lateral dark

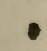


blotches, which are sometimes confluent into an irregular dusky band. Such little fishes usually have the lateral line imperfect. On such, the nominal species Moxostoma trisignatum was based.

The male fishes in the spring show a more or less distiuct pinkish or rosy lateral band. The males and females ascend the small streams in the spring for the purpose of depositing their spawn. The coincidence of their times of migration with that of sone of the early settlers of Illinois, who used to come up from New Orleans in the spring, returning in the fall, has given to the natives of that State the slang name of "Suckers", as natives of Michigan were called "Wolverenes"; of Minne. sota, "Gophers"; of Wisconsin, "Badgers"; of Indiana, "Hoosiers"; of Ohio, "Buckeyes"; and of Missouri, "Pukes".

I have elsewhere adopted the name "commersoni" for this species, inasmuch as there is little doubt that it is the "Cyprin commersonien" * of Lacépède, as has long since been noticed by Valenciennes.

Dr. Günther quotes, in the synonymy of Catostomus teres, "Cyprinus commersonnii Lacépède"; but, on examination of Lacépède's work, I am unable to find that he uses the name commersoni, or in fact any classical name whatever for the species, and as priority of date can hardly be claimed for a French name like "Cyprin commersonien", I am compelled to fall back on Mitchill's very appropriate name teres for the species. The identity of $C$. teres of Mitchill, C. communis and $C$. bostoniensis of Le Sueur, C. reticulatus of Richardson, C. gracilis of Kirtland, and C.pallidus of DeKay has been long since shown, and has been generally admitted by late writers. C. nigricans of Storer and Thompson, from the Connecticut, is evidently the dusky brook form of this species, and not the true nigricans of Le Sueur. It is equally evident that the species ealled $C$. aureolus by Valenciennes and Gïnther is the present one and not Myxostoma aureolum. Agassiz's Catostomus forsterianus is doubtless the common lake form of $\boldsymbol{C}$. teres, as indicated by Dr. Günther. The

\footnotetext{
* The following is Lacépède's description of his "Le Cyprin Commersonien" :-
}

"Onze rayons à la dorsale; huit à la nageoire de l'anus; dix à ehaque ventrale; huit ou neuf à chaque pectorule; la nageoire du dos et celle de l'anus quadrilatères; l'anal étroite; l'angle de l'extrénité de cette derniòre nageoire très aigu; la caudale en eroissant; la ligne latérale droite; la machoire supérieure plus avancée que celle d'en bas; les écailles arrondies et très petites.

"Le commersonien, dont nous publions les premiers la description, et que le savant Commerson a observé, présente un double orifice pour chaque narine; sa tête est dénuée de petites écailles; ses ventrales et ses pectorales sont arrondies à leur extrémité; la dorsale s'élève vers le milieu de la longueur totale de la poisson." 
types of $C$. sucklii are lost, but $C$.teres occurs in the Upper Missouri region, and Girard's description hints at no specific difference. Catosto. mus chloropteron Abbott is evidently the same. Catostomus texanus Abbott, described from a dried specimen, is less clear, but what there is of specific characterization in the description points to $C$.teres. The dorsal carination is frequently obserred in stuffed fishes in which some flesh is left in the back to shrink in drying, leaving the back "carinated".

I have examined sereral of the types of Catostomus alticolus Cope. They are all small fishes, not one-fourth grown, and, as usual in young fishes, the head appears proportionally large. I see, however, no reason for considering them different from Catostomus teres. Moxostoma trisignatum I have already referred to. The absence of the lateral line is due to their youth, not to their belonging to a different genus. The three large lateral spots, "not seen in any other of the order," are found on young specimens of Catostomus generally. I have examined the types of "Moxostoma trisignatum", and have found specimens of similar size, similarly colored and without lateral line, from Michigan and from other Western States. I would undertake to match them from any stream in the West. The reference of these specimens to Moxostoma (Erimyzon) was probably the result of a very hasty examination.

Specimens in United States National Museum.

\begin{tabular}{|c|c|c|}
\hline Number. & Locality. & Collectcr. \\
\hline 1592 & Carlisle, Pa............. & S. F. Baird. \\
\hline 6239 & Maryland.$\ldots \ldots \ldots \ldots \ldots \ldots \ldots \ldots \ldots \ldots \ldots \ldots \ldots \ldots \ldots \ldots$ & Dr. Kennerls. \\
\hline 6853 & Summerville, S. C............................. & \\
\hline 7067 & 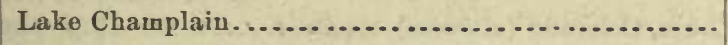 & S. F. Baird. \\
\hline 7607 & 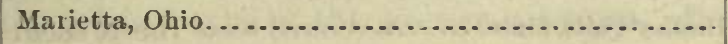 & Prof. Andrews \\
\hline$\pi 6 \pi$ & 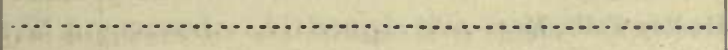 & 10 \\
\hline 7678 & (.................... & \\
\hline 7706 & ................. & \\
\hline 7707 & 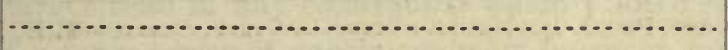 & \\
\hline 7717 & n....................... & \\
\hline 5797 & 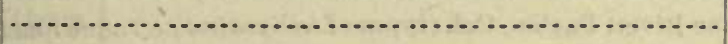 & \\
\hline 7781 & 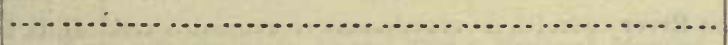 & (3) \\
\hline 8329 & Port Huron, Mich.............................. & \\
\hline 8409 & 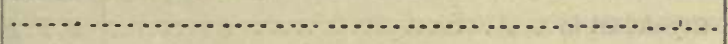 & \\
\hline 8440 & $\ldots \ldots \ldots \ldots, \ldots$ & 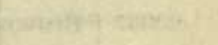 \\
\hline 8451 & 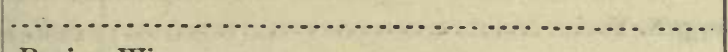 & \\
\hline 8489 & 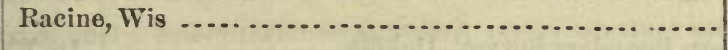 & \\
\hline 2501 & 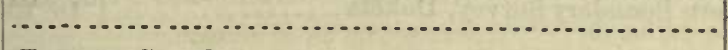 & \\
\hline 8573 & Toronto, Canada.......................... & \\
\hline
\end{tabular}


CONTRIBUTIONS TO NORTH AMERICAN ICHTHYOLOGY-III.

Specimens in United Slates National Museum-Continued.

\begin{tabular}{|c|c|}
\hline Number. & Locality. \\
\hline 8664 & \\
\hline 8671 & …......... \\
\hline 8689 & \\
\hline 8728 & Huron River, Michigan........... \\
\hline 8759 & 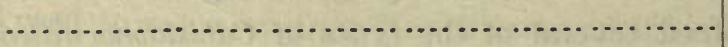 \\
\hline 8834 & 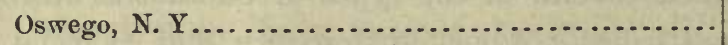 \\
\hline 8870 & Alabama ........................ \\
\hline 8927 & 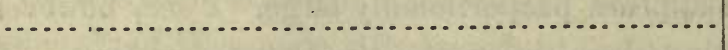 \\
\hline 8984 & $\ldots \ldots \ldots \ldots \ldots \ldots \ldots \ldots \ldots \ldots \ldots \ldots \ldots \ldots$ \\
\hline 9041 & Missouri (q) $\ldots \ldots \ldots \ldots \ldots \ldots \ldots \ldots$ \\
\hline 9054 & (.................. \\
\hline 9059 & $\ldots \ldots \ldots \ldots \ldots$ \\
\hline 9157 & ....... \\
\hline 9170 & 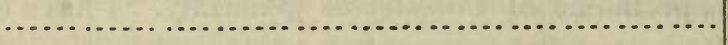 \\
\hline 9182 & Pembina, Red River of the North............. \\
\hline 9195 & Aux Plaines River, Inlinois.............. \\
\hline 9207 & Lake Champlain ..................... \\
\hline 9393 & Ecorse, Mich............................. \\
\hline 9404 & 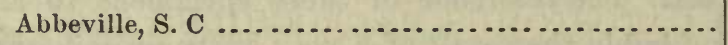 \\
\hline 9503 & Mississippi Valley...................... \\
\hline 9646 & \\
\hline 9875 & Black River . ............................. \\
\hline 10540 & Lake Superior...................... \\
\hline 11146 & 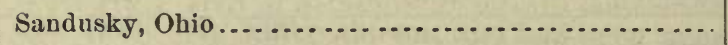 \\
\hline 11147 & 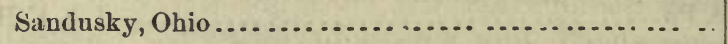 \\
\hline 11148 & 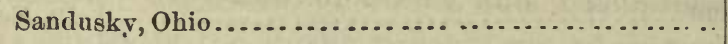 \\
\hline 12320 & 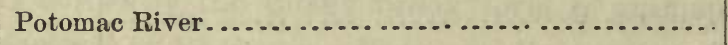 \\
\hline 12915 & Twin Lakes, Colorado (alticolus) .................. \\
\hline 12936 & South Hadley Falls, Mass.................... . \\
\hline 12937 & South Hadley Falls, Mass ..................... \\
\hline 12939 & South Hadley Falls, Mass........................ \\
\hline 12940 & South Hadley Falls, Mass....................... \\
\hline 15356 & 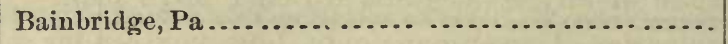 \\
\hline 15777 & Twin Lakes, Colorado (types of alticolus)............. \\
\hline 17099 & Arkansas River, Pueblo, Col. (types of trisignatum)..... \\
\hline 18258 & 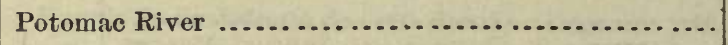 \\
\hline 18259 & Potomac River .......................... \\
\hline 20010 & 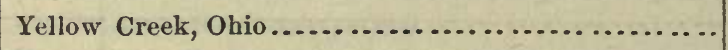 \\
\hline 20057 & 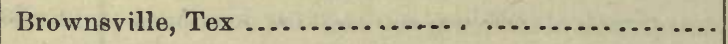 \\
\hline 20097 & 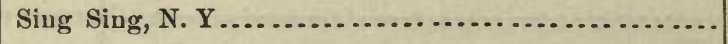 \\
\hline $\begin{array}{l}20194 \\
20195\end{array}$ & \}orthern Boundary Survey, Dakota.................. \\
\hline
\end{tabular}

Collector.

Barry.

S. F. Barrd.

R. Kennicott.

R. Kennicott.

G. Clark.

S. F. Baird.

J. W.M lcer.

J.W. Milner.

J. W. Milner.

J.W. Milner.

J. W. Milner.

J. T. Rothrock.

J. W. Milner.

J. W. Milner.

J. W. Milner.

J. W. Miluser.

T. H. Bean.

J. T. $\mathrm{R}$ throck.

C. E. Aiken.

G. B. Goode.

G. B. Goode.

S. F. Baird.

S. F. Baird.

Dr. Elliott Coues. 
Specimens in United'States National Museum-Continued.

\begin{tabular}{|c|c|c|}
\hline Namber. & Locality. & Collector. \\
\hline 20241 & 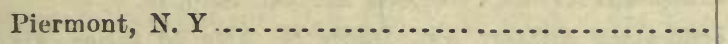 & S. F. Baird. \\
\hline 20238 & 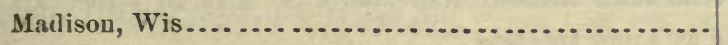 & S. F. Baird. \\
\hline 20256 & ${ }^{\prime}$ & \\
\hline 20262 & Quebec, Canada................................ & S. F. Baird. \\
\hline 20266 & Fox River, Wisconsin $\ldots \ldots \ldots \ldots \ldots \ldots \ldots \ldots \ldots \ldots$ & S. F. Baird. \\
\hline 20267 & Sing Sing $\ldots \ldots \ldots \ldots \ldots \ldots \ldots \ldots \ldots \ldots \ldots \ldots \ldots \ldots \ldots \ldots \ldots$ & S. F. Baird. \\
\hline 20268 & Root River, Wisconsin ....................... & S. F. Baird. \\
\hline 20316 & 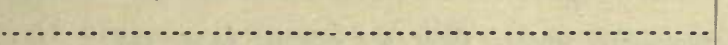 & \\
\hline 20344 & 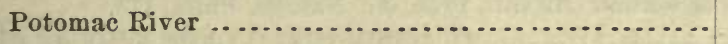 & Goode \& Bean. \\
\hline 20377 & Potomac River..$\ldots \ldots \ldots \ldots \ldots \ldots \ldots \ldots \ldots \ldots$ & House. \\
\hline 20382 & Platte Valley, Nebraska............................ & \\
\hline 20454 & 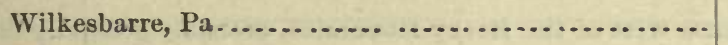 & L. H. Taylor. \\
\hline- & 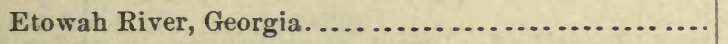 & D. S. Jordan. \\
\hline- & Salnda River, Sonth Carolina....................... & D. S. Jordan. \\
\hline 20918 & Fort Bridger, Wyoming . ......................... & \\
\hline
\end{tabular}

\section{8.* CATOSTOMUS MACROCHILUS Girard.}

Large-lipped Suc er.

1856-Catostomus macrocheilus Girand, Proc. Ac. Nat. Sc. Phila. 175.

Catostomus macrocheilus GIRARD, U. S. Pac. R. R. Expl. x, 225, 1858.

Catostomus macrochilus GÜxther, Cat. Fishes Brit. Mus. vii, 20, 1868.

Catostomus macrochilus Jordax \& Copeland, Check List, 156, 1876.

Habitat,-Columbia River.

Only the original type of this species is known. It is an adult specimen, well preserved. Although this species seems closely related to C. occidentalis, I am disposed to consider it distinct, as the mouth is notably larger than in any occidentalis which I bave seen. The examination of a large series of specimens may, however, render it necessary to unite them.

Specimens in Cnited States National Museum.

\begin{tabular}{r|c|c}
\hline Number. & Locality. & Collector. \\
\hline 240 & Astoria, Oregon (type macrochilus) ............... & Lieut. Trowbridge. \\
\hline
\end{tabular}

${ }^{*}$ For 28 (b). Catostomus jecundus Cope \& Yarrow, see Addenda, p. 219. 


\section{CATOSTOMOS OCCIDENTALIS Ayres.}

Western Sucker.

1854-Catostomus occidentalis AYres, Proc. Cal. Ac. Nat. Sc. i, 18.

Catostomus occidentalis Agassiz, Am. Journ. Sc. Arts, 2d series, xix, 209, 1855.

(Described as a new species.)

Catostomus occidentalis Grrard, Proc. Ac. Nat. Sc. Phila. 174, 1856.

Catostomus occidentalis Girard, U. S. Pac. R. R. Expl. x, 224, 1858.

Catostomus occidentalis GÜNther, Cat Fishes Brit. Mus. vii, 17, 1868.

Catostomus occidentalis Jordan \& Copeland, Check List, 156, 1876. (Name only.)

1856- Catostomus bernardini Grrard, Proc. Ac. Nat. Sc. Phila. 175.

? Catostomus bernardini Girard, U. S. Mex. Bound. Ichth. 40, pl. 23, f. 1-5, 1859.

I Catostomus bernardini GÜNTHER, Cat. Fishes Brit. Mus. v. 7, 17, 1863.

HaBitat,-Streams west of the Rocky Mountains, probably generally distribuied.

This species was described almost simultaneously under the same name by Dr. Ayres and Professor Agassiz. Since then it has been little noticed by ichthyologists, and its distribution has remained uucertain. The few specimens in the National Museum indicate, however, a wide distribution. I have here united Catostomus bernardini Girard to $C$. occidentalis. The single specimen made the type of $C$. bernardini is lost, so that we can probably never know exactly for what the author in. tended the name. The size of the dorsal and the form of the mouth its given in Girard's figure indicate a species of Catostomus rather than Pantosteus, and as I am unable to distinguish it from $U$. occidentalis, I let it fall into the synonymy. The scales of $O$. bernardini as figured seem, however, smaller than usual in $C$. occidentalis.

$C$. occidentalis is apparently related to $C$. teres, but is distinguished by the form of mouth and by the somewhat smaller scales. The species is "brought to the market in San Francisco, and is said to be quite common in the Sacramento and San Joaquin Rivers."-(GIRARD.)

Specimens in United States National Museum.

\begin{tabular}{|c|c|c|}
\hline Number. & Locality. & Collector. \\
\hline 15527 & Green River, Wyoming ............ & Livingston Stone. \\
\hline 20814 & McLend River, California .................... & Livingston Stone. \\
\hline
\end{tabular}


30. UATOSTOMUS LABIATUS Ayres.

Thick-lipped Sucker.

1855-Catostomus labialus AYres, Proc. Cal. Ac. Nat. Sc. i, 32.

Catostomus labiatus Girand, Proc. Ac. Nat. Sc. Phila. 175, 1856.

Catostomus labiatus GiraRd, U. S. Pac. R. R. Expl. x, 224, 1858.

Catostomus labiatus JoRdaN \& Copeland, Check List, 156, 1876.

HaBitat.-Streams of Oregon (Klamath Lake).

I have seen only the specimen from which Girard's description was taken. Like macrochilus, this species appears distinct from occidentalis, but the examination of a larger series of specimens is necessary to prore it. At present, it appears to differ from macrochilus and occidentalis in the smaller size of the dorsal fin.

Specimens in United States National Museum.

\begin{tabular}{r|c|c}
\hline Number. & Locality. & Collector. \\
\hline 239 & Klamath Lake, Oregon......................... & Dr. John S. Newberrs. \\
\hline
\end{tabular}

31. CATOSTOMUS ARAEOPUS Jordan, sp. nov.

Hard-headed Sucker.

1878-Catostomus arcoopus JoRDAN, MSS., Wheeler's Refort Surv. W. 100th Mer. (ined.).

This species represents $C$. discobolus in the section Decadactylus. Its very narrow fontanelle and sheathed lips indicate its close relation to

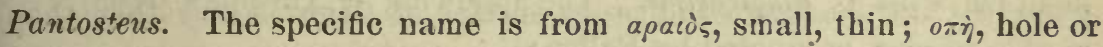
aperture. The typical specimens were from Kern River, California.

Specimens in United States National Museum.

\begin{tabular}{|c|c|c|}
\hline Number. & Locality. & Collector. \\
\hline 17107 & Kern River, Cal. (type) ...................... & H. W. Henshaw. \\
\hline 17103 & Carson River, Nevada ..................... & H. W. Henshaw. . \\
\hline
\end{tabular}

32. CATOSTOMUS TAHOENSIS Gill \& Jordan.

Sucker of Lake Tahoe.

1863-Acomus generosus Cooper, Cronise's Nat. Wealth Cal. 495. (Not of Girard.) 1878 - Catostomus tahoensis Gill \& JordaN, Bull. U. S. Nat. Mus. xi, p. -

Habitat.-Lake Tahoe, Nevada.

The Sucker of Lake Tahoe is closely related to Catostomus longirostris, but seems to differ constantly in the shorter head and mors contracted 


\section{CONTRIBUTIONS TO NORTH AMERICAN ICHTHYOLOGY-III.}

body. It is said to be very abundant in Lake Tahoe. "They are eaught in nets and sometimes with the hook, but like all this family are rather poor as fool" (Cooper). Acomus generosus of Girard, with which this species has been identified, is a rery different species, belonging to a different genus.

Specimens in United States Natioival Museum.

\begin{tabular}{|c|c|c|}
\hline Number. & Locality. & Collector. \\
\hline 5240 & Lake Tahoe (types $C$. tahoensis) ................... & J. G. Cooper. \\
\hline 17109 & 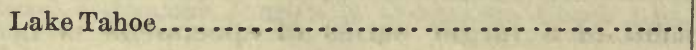 & H. W. Heusbaw. \\
\hline
\end{tabular}

\section{CATOSTOMUS ROSTRATUS (Tilesius) Jordan.}

Siberian Sucker.

1813-“ Cyprinus rostratus Tilesıus, Mém. Ac. Sc. St. Pétersbourg, iv, p. 454, tab. 15, figs. 1-2, 1813."

Cyprinus rostratus PALLAS, Zoogr. Rosso-Asiat. iii, 308.

Cyprius rostratus GỮsther, Cat. Fishes Brit. Mus. xii, 12, 1868. (As doubtful species of Catostomus.)

1844-Catostomus tilesii Cuvikr \& Valenciennes, Hist. Nat. des Poissons, xvii, 469, 1844.

Habitat.-Eastern Siberia.

No writer since Tilesius seems to have observed this fish. It is, how. ever, unquestionably a species of Catostomus, allied to and perhaps even identical with $C$. longirostris. The following is Tilesius's description of this species, as quoted by Pallas :-

"Descriptio Cyprini rostrati Tungusis ad Covymam fluv., Tschuknlschan et Jucagins Onatscha dicti. Tab. XV, Fig. 1-5. (Der Rüffelkarpfen, Rampkopf.)

"Magnitudo in adultis pedem superat, sed trium spithamarum longitudinem vix attingit. Caput osseum longum antico rostro descendente truncatum e quino simile quam ob rem Ruthenis.

"Koub dicitur aliis Produst, quoniam os subtus, ut In (sic) Cotto cataphracto vel Agono accipenserino, sed rictus oris vel orificium lunatum non amplum sed augustum labiis crassis pinguibus marginatum, labium anterius fornicatum, ambitu semicirculare ossibus labialibus vel mystaceis ad frenum oris descendentibus arcuatis lateraliter lectum, labium posterius minus, rectum, ab anteriori inclusum amplexum papillis numerosissimis granulatum.

"Oculi lateralis a rostro remoti operculo posteriori branchiali approximati ovales, iridibus aureis superne angnstioribus, pupilla supra centrum posita. Nares ad marginem orbitæ anteriorem duplices in sulco profundo osseo. Operculo branchialia trilamellata, lamella anterior cum ossibus maxillæ superioris conjuncta ellyptica angusta ad orbitæ marginem anteriorem ascendens inferius lamellø sccundo tenerrimæ angustiori orbitam inferiorem formanti imposita, lamina ossea suljacens, operculum 
medium formans, subtus plica itshmo juguli adnata, carne tegitur suborbitali. Lamina posterior maxima latissima ossea conchæ adinstar fornicata, anterius cum obitæ margine posteriori juncta. Membrana branchiostega triradiata inter operculi laminam anteriorem subtus utrinque approximatam coarcta et in isthmo gulø conjuncta. Corpus oblongum erectum microlepidotum, squamis lævibus subtilissime radiatostriatis oblungis, ad caput minoribus versus anum et caudam majoribus imbricatum crassiusculum leviter compressum, ventre-dorsusque convexum. Linea lateralis recta versus medium corporis paululum descendens per seriem squamarum postice incisarum expressa versus caudam magis conspicna. Color in dorso atro cœruleus nitidus, versus latera subargenteus, subtus albeus. Pinnce pectorales quatnordecim radiatæ, radii medii longissimi, ventrales decemradiatæ, radia primo osseo acuminato, dorsalis decemradiata et duodecimradiata, radio primo cum adminiculo radicali, nltimo brevissimo ad basin usque fisso, omnibus ad apices quadrifidis, dorsalis pinna ventralibus opposita, analis p. septemradiata, radio primo simplici cum adminiculo radicali, reliquis quadrifidis, tertio longissimo eeptimo brevissimo. Caudalis pinna bifurca lacinia inferior paulo major nndecimradiata, superior novemradiata tota pinna viginti radiis suffulta extremis lateralibus cum adminiculo radicali connatis. Radii pennarum ad extremitatis quadrifidi et extremi ad radices duplicati vel ex binis truncis connati, quam ab rem primus dorsalis longitudinaliter ad basin sulcatus est, quod etiam in primo analis et caudalibus extremis fere ex tribus compositis cernitur. In dorsali et anali pinna ralii valde distant, pectorales ventrales et analis pinnæ aureo-rubescentes et ad basin prominentes, pectorales adeo tuberosæ, ventralinm radices per membranosam laminam triangnlarem squamatam obteguntur. Anus caudæ propior. Iuterna non exploravi. Characteribus cæterum generis cyprinacei ore nimirum edentulo, dentibus post branchialibus, membraua branchiostega triradiata utrinque instructus est. A celeberrimo Merck plura specima ex siccata ex Covymæ fluvio allata sunt, quæ nominæ Tschukutschan designata sunt. Annotavit simul idem, 'piscem in Lena et Indigirca ejusque collaterali lapidoso Dogdo fluviis copiosum esse sed propter nationis velocitatem captn difficilem esse et non nisi in cœeis fluminum ramis hamo capi, gregatim et velocissime natare, sapidissimum cæterum, excepto vere, cum, ova spargunt nec aristis impeditum piscem esse, attamen ab accolis Covynæ et Indigircæ (qui caput tantem in deliciis habet, reliqua canibus cedunt) non multum æstimari." "(PALLAs, Zoographia Rosro-Asiatica, pp. 308-310.)

\section{CATOSTOMUS LONGIROSTRIS Le Sueur.}

Long-nosed Sucker. Northern Sucker. Red-sided Sucker.

1773- "Cyprinus catostomus Forster, Philos. Trans. lxiii, 155, tab. 6, 1773."

Cyprinus catastomus SchNeIDER, ed. Bloch, 444, 1802.

1817-Całostomus longirostrum Le Sukur, Jouru. Ac. Nat. Sc. Phila. 102.

Catostomus longirostrum Trомpson, Hist. Vt. 135, 1842.

Catostomus longirostris DeKaY, New York Fanna, part iv, Fishes, 203, 1842.

Catostomus longirostrum CUVIER \& VAlenCienves, xvii, 453, 1844.

Catostomus longirostrum STORER, Synopsis, 421, 1846.

Catostomus longirostrum JoRdax \& Copeland, Check List, 156, 1876.

Catostomus longirostris JoRDAN \& Gilbert, in Klippart's Rept. 53, 1877.

1817 - Catostomus hudsonius Le Sueur, Journ. Ac. Nat. Sc. Phila. 107. 
Catostomus hudsonius Cuvier \& Valenciennes, Hist. Nat. des Poissons, xvii, 459, 1844.

Catostomus hudsonius Storer, Synopsis, 419, 1846.

Catostomus hudsonius AGAssiz, Am. Journ. Sc. Arts, $2 d$ series, xix, 208, 1855.

Catostomus hudsonius GÜNTher, Cat. Fishes Brit. Mus. vii, 13, 1868.

Catostomus hudsonius Jokdan, Man. Vert. 293, 1876.

Catostomus hudsonius Nelson, Bull. No. 1, Ills. Mus. Nat. Hist, 48, 1876.

1823-Catostomus forsterianus RICHAndson, Franklic's Journal, 720.

Catostomus forsterianus Richandson, Fauna Bor.-Amer. iii, Fishes, 116, 1836.

Catostomus forsterianus DeKa , New York Fauna, part iv, Fishes, 203, 1842.

Catostomus forsterianus Cuvrer \& Valencienses, Hist. Nat. des Poissons, xvii, $463,1844$.

Catostomus forsterianus Storer, Synopsis, 419, 1846.

Acomus forsterianus Girard, Proc. Ac. Nat. Sc. Phila. 172, 1856.

Catostomus forsterianus PUTvis, Bull. Mus. Comp. Zool. 10, 1863.

Catostomus forsterianus Jordan \& Coperand, Check List, 156, 1876.

1850-Catostomus aurora AGAssiz, Lake Superior, 360, pl. 2, f. 3-4.

Acomus aurora Grrard, Proc. Ac. Nat. Sc. Phila. 173, 1856.

Catostomus aurora Putxam, Bull. Mus. Comp. Zool. 10, 1863.

1856-Acomus griseus Girard, Proc. Ac. Nat. Sc. Phila. 174.

Acomus griseus Grrard, U. S. Pac. R. R. Expl. x, 222, pl. xlix, 1858.

Catostomus griseus Gưnther, Cat. Fishes Brit. Mus. vii, 14, 1868.

Catostomus griseum Cope, Hayden's Geol. Surv. Wyoming, 1870, 434, 1 s72.

Catostomus griseus Jordan \& Copeland, Check List, 156, 1876.

1856-Catostomus lactarius Girard, Proc. Ac. Nat. Sc. Phila. 174.

Acomus lactarius Girard, U. S. Pac. R. R. Expl. x, 223, 1858.

Catostomus lactarius Jordan \& Copeland, Cheek List, 156, 1876.

Habrtat.-New England to Nebraska and north to Alaska and the Arctic Sea. Extremely abundant in British America and along the northern boundaries of the United States, but not found sonth of $40^{\circ}$ north latitude.

This is another of our numerous species which have an extremely wide range of distribution and a considerable range of variation. It has been longer known than any other of the Suckers. The oldest specific name giren was that of catostomus, which, however, had to be set aside when the generic name Catostomus was proposed for it. The next name in order of time is the very appropriate one of longirostrum Le Sueur (more properly spelled longirostris), given to some specimens from Vermont. Five pages later, the name hudsonius was giren as a substitute for $c a$ tostomus of Forster. The slight priority of longirostrum over hudsonius, howerer, seems to entitle it to preference, although the latter name has been most frequently used. Later, specimens considered by Dr. Günther to be identical with ludsonius received from Richardson the name "forsterianus", aud, still later, the name forsterianus was, without evident reason, transferred from this species to teres by Professor Agassiz, who 
gare to this species the name of aurora, in allusion to the red breeding colors of the male. Western specimens were still later described by Girard as two distinct species, griseus and lactarius, apparently without comparison with the Eastern forms.

The examination of the large series of specimens noticed belor, together with others from the Great Lakes and Upper Mississipli, has convinced me that all belong to one species, rariable to some degree, but not more so than is Catostomus teres and less so than Erimyzon sucetta. Some of the Upper Missouri specimens referable to C. griseus Grd. have on an average rather smaller scales $(95$ in the lateral line instead of 100 to 110); but I am uvable to distinguish a tangible variery. The original trpes of $C$. lactarius Girard are not now to be found, but the description indicates no difference from $C$. longirostris.

Specimens in Cnited States National Muscum.

\begin{tabular}{|c|c|c|}
\hline Number. & Locality. & Collector. \\
\hline 1054 & Lake Superior ........................ & J. W. Milner. \\
\hline $20-7$ & 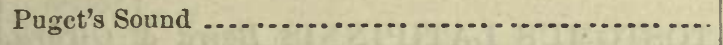 & R. Kennicott. \\
\hline 2563 & 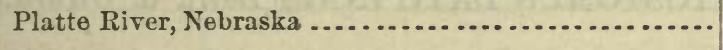 & Capt. Simpson. \\
\hline $6 \% 09$ & Youghiogheny River $\ldots \ldots \ldots \ldots \ldots \ldots \ldots \ldots \ldots \ldots \ldots$ & Prof. Andrews. \\
\hline 7047 & Lake Winnipeg ...................... & R. Kennicott. \\
\hline 7610 & 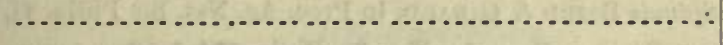 & \\
\hline ร993 & Nulato, Youcon River, Alaska...................... & W. H. Dall. \\
\hline 8136 & & 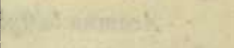 \\
\hline 8435 & & 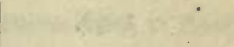 \\
\hline $84: 37$ & 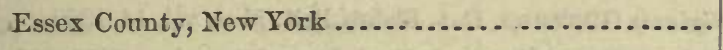 & dunstatas \\
\hline 8802 & 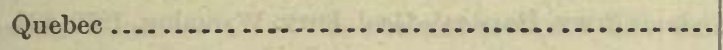 & S. F. Baird. \\
\hline 8905 & Great Slave Lake ..................................... & R. Kennicott. \\
\hline 9010 & Pole Creek, Nebraska ............................... & Lient. Wood. \\
\hline 9116 & (n. & \\
\hline $91 \% 5$ & & \\
\hline 9522 & Saint Michael's, Alaska ............................. & Dr. Bannister. \\
\hline 11212 & Au Sable River, Michigan ........................ & J. W. Milner. \\
\hline 11213 & Au Sable River, Michigan ........................... & J. W. Milner. \\
\hline 12210 & Au Sable River, Michigan ......................... & J. IV. Milner. \\
\hline 20075 & 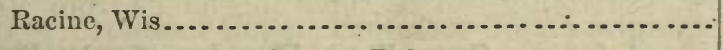 & \\
\hline 20191 & Northern Boundary Survey, Dakota................. & Dr. Elliott Cones. \\
\hline 20223 & 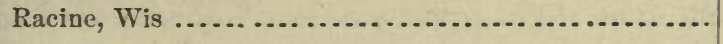 & S. F. Baird. \\
\hline 20235 & Lake Superior $\ldots \ldots \ldots \ldots \ldots \ldots \ldots \ldots \ldots$ & J. W. Milner. \\
\hline $20: 5 \%$ & $\begin{array}{l}\text { (Probably original types of griseus; the old number } \\
\text { and locality obliterated.) }\end{array}$ & Bowman. \\
\hline 20282 & Platte River, Nebraska........................ & \\
\hline 20689 & 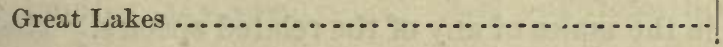 & \\
\hline
\end{tabular}

Bull. N. M. No. 12-12 
35. CATOSTOMUS RETROPINNIS Jordan, sp. nov.

1878-Catostomus retropinnis JoRdan, Bull. Haydden's Geol. Surv. Terr. (ined.).

This fine species combines the mouth of $C$. latipinnis with the form and general characters of $C$. longirostris. The type is No. 21,197, collected by Dr. Elliott Coues in Milk River, Montana. It is a mäle specimen $16 \frac{3}{4}$ inches in length. A specimen previously examined from Platte Valley was identified as probably the female of $C$. latipinnis, but the discovery of this large male specimen forbids such a supposition.

Specimens in the United States National Museum.

\begin{tabular}{|c|c|c|}
\hline Number. & Locality. & Collector. \\
\hline 20933 & Platte Valley ....... & \\
\hline 21197 & Milk River, Montana (type) $\ldots \ldots \ldots \ldots \ldots \ldots \ldots$ & Dr. Elliott Coues. \\
\hline
\end{tabular}

\section{CATOSTOMUS LATIPINNIS Baird \& Girard.}

\section{Great-finned Sucker.}

1853-Catostomus latipinnis Barled \& Girand, in Proc. Ac. Nat. Sc. Phila. vi, 388. Acomus latipinnis GIRakd, Proc. Ac. Nat. Sc. Phila. 173, 1856.

Acomus latipinnis Girard, U. S. Mex. Bound. Surv. Ichth. 39, pl. xxiv, f. 1-6, 1859.

Catostomus latipinnis Günther, Cat. Fishes Brit. Mus. vii, 14, 1868.

Catostomus latipinnis Cope, Hasden's Geol. Surv. Wyoming, 1870, 434, 1872.

Catostomus latipinnis JoRdan \& Copeland, Check List, 156, 1876.

1856-Catostomus guzmaniensis Girard, Proc. Ac. Nat. Sc. Phila. 173.

Acomus guzmaniensis Grara, U. S. Mex. Bound. Surv. Ichth. 39, pl. xxiii, f. 6-10, 1859.

Catostomus guzmaniensis GƯnther, Cat. Fishes Brit. Mus. vii, 15, 1868.

Catostomus guzmaniense CoPE \& Yarrow, Wheeler's Expl. W. 100th Mer. ₹, Zool. $679,1876$.

Catostomus guzmaniensis JoRdan \& Copeland, Check List, 156, 1876.

Habrtat.-Arizona and Sonora. Green River, Wyoming (Cope). Probably not abundant.

This species is one of the most strongly marked of our Suckers. The male fish may be known at once by the slender form and excessire development of the fins, and probably in the females the fins are more dereloped than in the males of any of the related species. The squama. 
tion also is peculiar, and the form of the mouth is unlike that of any other species. These features are all well shown in Girard's figure of the species in the Ichthyology of the Mexican Bonndary.

The distribution of the species has not been well made out. I hare seen but one specimen, an adult male from the Gila region, apparently the one from which Girard's figure was made.

The type of Catostomus guzmaniensis cannot be found. The figure was made from a young fish, and the distinctions between it and latipinnis are such as often distinguish a young fish from an old one. It is better, therefore, to unite the two than to admit an insufficiently characterized nominal species.

Specimens in Cnited States National Mruseum.

\begin{tabular}{c|c|c}
\hline Number. & Locality. & Collector. \\
\hline 20078 & $\begin{array}{c}\text { (Type of latipinnis undoubtedly, but the locality, Rio San } \\
\text { Pedro, tributary of Rio Gila, and old number, 254 ?, oblit- } \\
\text { erated.) }\end{array}$ & J. H. Clark. \\
\hline
\end{tabular}

\section{CATOSTOMUS DISCOBOLUS Cope.}

Large-lipped Sucker.

1872-Catostomus discobolus Cope, Hayden's Geol. Surv. Wyo. 1870, 435.

Catostomus discobolus Cope \& YarRow, Wheeler's Expl. W. 100th Mer. v, Zool. $677,1876$.

Catostomus discobolus Jordan \& Copeland, Check List, 156, 1876.

Habitat.-Idaho to Arizona.

This interesting species is a Pantosteus in all but the technical character of the open fontanelle, and in this respect it is really intermediate, as the fontanelle, in the adult at least, is reduced to a narrow slit. The characters given in the analysis were taken from the Snake Rirer specimen, 20,475, larger and in better condition than most or all of those examined by Professor Cope. Professor Cope's original types came from Green River in Wyoming. 
Specimens in Cnited States National Museum.

\begin{tabular}{|c|c|c|}
\hline Namber. & Locality. & Collector. \\
\hline 12914 & 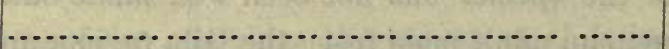 & Newberry. \\
\hline 15783 & Zuñi, N. Mex................................. & Yarrow \& Henshaw. \\
\hline 15791 & Arizona...$\ldots \ldots \ldots \ldots \ldots \ldots \ldots \ldots \ldots \ldots \ldots \ldots$ & C. G. Newberry. \\
\hline 20475 & Snake River, Idaho $\ldots . . . \ldots \ldots \ldots \ldots \ldots \ldots$ & F. V. Hayden. \\
\hline
\end{tabular}

\section{Genus PANTOSTEUS Cope.}

Minomus Cope, U. S. Geol. Surv. Wyoming, 1870, 434 (1872). (Not of Girard.)

Pantosteus Cope, Lieut. Wheeler's Expl. W. 100th Mer. v, 673, 1876.

Catostomus, Acomus et Minomus sp. Grrard.

Type, Minomus platyrhynchus Cope.

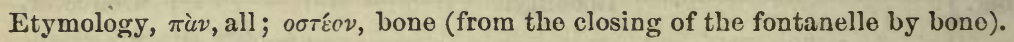

Head moderate or rather small, 4 to 5 times in length of body, flattish and rather broad abore, anteriorly somewhat pointed; eye rather small, usually behind the middle of the head : suborbital bones narrow, as in Catostomus; bones of head rather thick, the two parietal bones firmly united, entirely obliterating the fontanelle.

Mouth rather large, entirely inferior; each jaw with a more or less, developed cartilaginous sheath, separable in alcohol, essentially as in Chondrostoma, Acrochilus, and related genera; upper lip broad, papillose, with a rather broad, free margin, and several series of tubercles; lower lip largely developed, with an extensire free margin deeply incised behind, but less so than in Catostomus. Pharyngeal bones and teeth essentially as in Catostomus. Isthmus quite broad.

Body generally elongate, subterete, and little compressed.

Scales quite small, from 80 to 105 in the course of the lateral line, and 30 to 35 in a cross-series between dorsal and ventrals, usually more or less reduced in size and crowded forward, as in Catostomus; lateral line well dereloped, straightish.

Fins generally rather small ; first ray of dorsal usually about midway of body, its rays few, 9 to 12 in number; rentrals inserted rather under pasterior part of dorsal, their rays 10 or $\mathbf{9}$; anal short and high, with 7 dereloped rass; caudal rather shallow, emarginate; pectorals well dereloped : air-bladder with two chambers.

The characters of Pantosteus are essentially those of Catostomus, except that the fontanelle is obliterated. The usual scale-formula is interme. 
diate betreen that of Catostomus proper and that of the subgenus Decadactylus.

The genus was first indicated by Professor Cope in 1874, under the name of Minomus, he supposing at the time that Catostomus insignis, the type of Girard's Minomus, was a species with closed fontanelle. On obtaining specimens of $C$. insignis, it became evident that such was not the case, and the new name Pantosteus was proposed for the genus. Pantostcus runs very close to Catostomus, two species referred to the latter genus (C. discobolus and $C$. arcoopus) being almost intermediate.

\section{Generic Characterizations.}

Mrvomus Cope, 1872.- "I have proposed to adopt as valid (Proc. Amer. Philos. Soc. $1870,430)$ seven genera of this family. I will now add an eighth, which embraces species which combine with the characters of Catostomus proper, a complete union of the parietal bones, which obliterates the fontanelle so universal among the suckers. The only other exception is seen in, Cycleptus, Raf., as I have already mentioned. In all the members of the family where I bave examined it, this fontauelle is quite open and of no doubtful proportions, and nowhere reduced to the slit so often seen in Silurida. In searching for the characters of Girard's so-called genera Minomus and Acomus, I find that the type of the former, M.insignis, B. G., presents the character above mentioned. I therefore adopt his nawe for the new genus, and add two new species, $M$. delphinus and $M$. bardus. Whether his two other species, M. plebeius and $M$. clarkii, belong to it is uncertain as jet, but they have the same physiognomy."-(Cope, Hayden's Geol. Surv. Wyoming for 1870, p. 434, 1872.)

Pantosteus (Cope) Yarrow, 1876.- "Professor Cope, in 1870, purposed to adopt as valid seven genera of this family; but in $18 \% 2$, he stated bis belief that an eighth s hould be added, which should embrace species combining the characters of Catostomus proper, a complete uniou of the parietal bones, which obliterates the fontanelle, so universal anong the suckers; the only other exception being seen in Cycleptus, Raf., as he has already observed. In all the members of the family that he has examined in this regard the fontanelle has been found quite open and of no doubtful proportions, and is wowhere reduced to the slit often seen in the Siluridx, unless it be in the Catostomus discobolus. In searching for the characters of Girard's so-called genera Minomus and Acomus, he expressed the view that the type of the former, M. insignis, Baird \& Girard, presents the character in question. This conclusion was based on a specimen sent to the Academy of Natural Sciences from Washington, bearing that name. Having since examined five specimens of the $M$. insignis, obtained by the geologists of this sulvey, he finds them to be true Catostomi as determined by the presence of the fontanelle. It therefore requires a name, and he proposes for it that of Pantosteus. It embraces $P$. platyrhynchus, $P$.jarrovii and $P$. virescens Cope of the present essay and $\boldsymbol{P}$. delphinus and P. bardus, Cope, Hayden's Report, I.c."-(Yarrow, Lieut. Wheeler's Expl. W. 100ti Mer. vol. 5, p. 673, 1876.)

Paxtosteus Cope \& Jordan, 1877. - "Body oblong or elongate, with a short, subquadrate dorsal fin; air bladder in two parts; lateral line well developed; fontanelle obliterated by the union of the parietal bones."-(Jondax, Proc. Ac. Nat. Sc. Plita. 18i7, p. 81.) 


\section{ANALYSIS OF SPECIES OF PANTOSTEUS.}

* Scales very small, 100 to 105 in the lateral line; 18 above and 16 below, in a crossseries : body elongate, compressed, the caudal peduncle contracted : head short, wide, 5 in length : muzzle obtuse, little projecting ; upper lip wide; lower lip full, emarginate; jaws with well doveloped cartilaginous sheaths : scales much reduced in size forwards: dorsal rays 10; ventral 9: color clive; lower surface jellow.

VIRESCENS, 33.

** Scales small, 80 to 85 in the course of the lateral line.

† Scales very much reduced and crowded anteriorly : npper lip full, pendent; cartilaginous sheaths on jaws well developed, the commissure transverse and abruptly angulate at the corners of the mouth.

a. Body extremely elongate, the depth $5 \frac{1}{2}$ to 7 in length : head $4 \frac{8}{4}$ in length, short and wide, with depressed and expanded muzzle, which considerably overhangs the mouth : isthmus very wide : dorsal rays 11 ; ventral rays 9 : scales $15-86-12$ : belly and lower fins yellowish, probably red in life ....... PLATYRHYNCHUS, 39 .

aa. Body moderately elongate, the depth $4 \frac{1}{2}$ to 5 in the length : head rather short, $4 \frac{2}{8}$ in length, not specially broadened; muzzle not greatly overhanging the mouth : dorsal rays 9 (rarely 10 ); ventral rays 10 (rarely 9 ): scales 11 to $14-83$ to $87-13$ to 15 : light brown above, with dusky spots and clouds; males with the chin and fins red, and a crimson lateral band............ GENERosus, 40.

It Scales subequal over the body, not much reduced forwards: upper lip rather narrow, not pendent; cartilaginous sheath on jaws obsolete (?).

$b$. Body comparatively stout, the caudal peduncle short aud thick, the back somewhat arched, the depth $4 \frac{1}{2}$ to 5 in length : head short and wide, flattish above, $4 \frac{2}{8}$ to 5 in length : scales $14-84-15$ : dorsal rays 9 to 11 ; ventral rays 10 : blackish above, with one or two dark lateral shades ............... PLEBEIUs, 41.

\section{PANTOSTEUS VIRESUENS Cope.}

\section{Grcen Sucker.}

1876-Pantosteus virescens (COPE) CoPe \& Yarrow, Wheeler's Expl.W. 100th Mer. $\nabla$, Zool. 675.

Pantosteus virescens Jordan \& Copeland, Check List, 156, 1876.

Habitat.-Arkansas River in Colorado.

Only a single specimen of this species is known, collected by Mr. C. E. Aiken at Pueblo, Colo. The small size of its scales indicates its distinctness from the other species of Pantosteus. The greenness of coloration of the typical specimen is probably due to its having been kept in a copper tauk.

Specimens in United States National Museum.

\begin{tabular}{c|c|c}
\hline Number. & Locality. & \multicolumn{1}{c}{ Collector. } \\
\cline { 2 - 3 }- & Arkansas River, Pueblo, Colo. (type)........... & C. E. Aiken. \\
\hline
\end{tabular}




\section{PANTOSTEUS PLATYRHYNCHUS Cope.}

Flat-headcd Sucker.

1874-Minomus platyrhynchus Cope, Proc. Am. Philos Soc. Phila. 134.

Pantosteus platyrhynchus Cope \& Yarrow, Wheeler's Expl. W. 100th Mer. v, Zool. 673, pl. xxix, f. 3, $3 a, 1876$.

Pantostcus platyrhynchus Jordan \& Copeland, Check List, 156, 1876.

Pantosteus platyrhynchus Jordax, Bull. U. S. Nat. Mus. xi, p. -, $187 \varepsilon$.

Habitat.-Utah Lake and tributaries.

The specimens which I have seen of this species are all small aud in poor condition. Their remarkable slenderness is doubtless in part due to their flabbiness. The species as noted by Professor Cope much resembles Catostomus discobolus. It is also very similar to Pantosteus generosus, but at present I consider it distinct.

Specimens in Uuiled States National Mureum.

\begin{tabular}{|c|c|c|}
\hline Number. & Locality. & Collector. \\
\hline 12906 & Utah Lake ....................... & Yarrow \& Henshaw. \\
\hline 15163 & 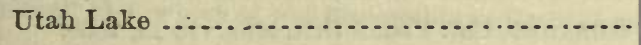 & Yarrow \& Henshaw. \\
\hline
\end{tabular}

40. PANTOSTEUS GENEROSUs (Girarā) Jordan.

Farrou's Sucker.

1856-Catostomus (Acomus) generosus Girakd, Proc. Ac. Nat. Sc. Phila. 174.

Acomus generosus GiraRD, U. S. Pac. R. R. Expl. x, 221, 1858.

Catostomus generosus Jordax \& Corkland, Check List, 156, 1876.

1874-Minomus jarrovii Cope, Proc. Am. Philos. Soc. Phila. 35.

Pantosteus jarrovii CoPe \& YArrow, Wheeler's Expl. W. 100th Mer. v, Zool. 674, pl. xxix, 2, 2 a $18 \% 6$.

Pantosteus yarrouti Jordan \& Copelaxd, Check List, 156, 1876.

Habitat.-Rio Grande, Colorado Basin, and Great Basin of Utah; very abundant.

This species is the most characteristic and most widely diffused of the Suckers of the Great Basin. It was first described by Girard in 1556, under the name of Catostomus gencrosus. Girard's description, unaccompanied by a figure, was so very loose and irrelevant that it has hitherto remained unidentified. I have, however, had the opportunity of examining Girard's original types, and of comparing them with the types of Pantosteus jarrovii. They seem to me to belong to the same species, and I am therefore compelled to substitute the name generosus 
for that of jarrovii. If I had not been able to compare generosus with jarrovii, I should never have suspected their identity.

Specimens in United States National Museum.

\begin{tabular}{|c|c|c|}
\hline Nuruber. & Locality. & Collector. \\
\hline 256 & Cottonwood Creek (types of generosus) ........... & Lient. Beckwith. \\
\hline 5910 & Ojo de Gallo, N. Mex ......................... & Lieut. Beale. \\
\hline 15802 & Zuñi River, New Mexico (types of jarrovii) ...... & H. W. Henshaw. \\
\hline 17080 & 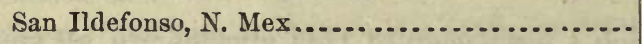 & Yarrow \& Cope. \\
\hline 17095 & Mohave Desert, California............ & Dr. O. Loew. \\
\hline 18009 & New Mexico ................................. & H. C. Yarrow. \\
\hline 20102 & Pacific Railroad Survey, $38^{\circ}$................. & Lieut. Beck with. \\
\hline
\end{tabular}

\section{PANTOSTEUS PLEBEIUS (Baird \& Girard) Jordan.}

\section{Plain Sucker.}

1854-Catostomus plebeius Baird \& Girard, Proc. Ac. Nat. Sc. Phila. 28.

Catostomus plebius Agassiz, Am. Journ. Sc. Arts, 2d series, xix, 208, 1855.

Minomus pleveius Grrard, Proc. Ac. Nat. Sc. Phila. 173, 1856.

Minomus plebeius Girand, U. S. Mex. Bound. Surv. Ichth. 38, pl. xxii, f. 1-4, 1859.

Catostomus plebejus Günther, Cat. Fishes Brit. Mus. vii, 15, 1868.

Catostomus plebejus Jordan \& Coperand, Check List, 156, 1876.

Pantosteus plebeius Jordan, Bull. U. S. Nat. Mus. xi, p.-, 1878.

1872-Minomus delphinus Cope, Hayden's Geol. Surv. Wyoming, 1870, 435, 1872.

Pantostens delphinus CoPE \& YARrow, Lieut. Wheeler's Rept. Expl. W. 100th Mer. vol. 5, 673, 1876.

Pantosteus dolphinus JoRdan \& Copeland, Check List, 156, 1876. (Misprint for delphinus.)

1872-Minomus bardus CoPe, Hayden's Geol. Snrv. Wyoming, 1870, 436.'

Pantosteus bardus Cope, Lieut. Wheeler's Expl. W. 100th Mer. vol. 5, p. 673, 1876.

Pantosteus bardus Jordan \& Copeland, Check List, 156, $18 \% 6$.

Habitar.-Basin of the Colorado. Lake Guzman.

The types of Catostomus plebeius are not to be found, and no specimens referable to the species are in the National Museum. The types of Pantosteus delphinus and $P$. bardus I have been unable to examine. The scale-formula and small dorsal fin of $C$. plebeius indicate that it is a species of Pantosteus. Assuming that it is so, I find myself unable to draw from the printed descriptions of plebeius, delphinus, and bardus any sort of specific characters. Until such characters are shown, the burden of proof lies with the proposer of those species, and I shall consider them as identical until they are proved to be distinct. In characters of mouth, 
scales, and form of body, Pantosteus plebeius seems to resemble Catostomus insignis and $C$. clarkii, and to direrge from the type of discobolus, generosus, and platyrlynchus.*

* Professor Cope (in lit.) dissents from the identification above made, maintaining that $P$. delphinus and $P$. bardus are at least specifically distinct from each other, whatever may be the relation of either to P.plebeius. As I have seen none of the three forms in question, I let the above stand as I had written it, and quote the original descriptions of the three nominal species:-

MiNomus Pleberus Grd.- "Body sub-fusiform, compressed. Head elongate, subconical, forming the fifth of the entire length. Mouth of medium size. Eyes large, subelliptical, their longitudinal diameter being contained about five times in the length of side of head. Dorsal fin subquadrangular, its anterior margiu being equidistant between the tip of the snout and the first Indimentary rays of the upper lobe of the caudal. The latter is slightly concave posteriorly, and the lobes rounded off. The base of the anal is contained nearly three times in its height, and when bronght backwards its tip extends to the rudimentary rays at the inferior lobe of the caudal fin. The ventrals are inserted under the posterior third of 1 be dorsal ; bent backwards, their tip does not reach as far as the anus. The pectorals are of medium development, subovate, posteriorly acute.

"The scales are of medium size, considerably largest on the peduncle of the tail. Twenty-eight to thirty rows from the base of the ventrals to the dorsal fin. About eighty in the lateral line, which is not discernible as far back as the base of the caudal fin.

"The color as preserved in alcohol, is dark brown on the upper regions, faintly mottled with blackish patches. The sides and belly $\epsilon$ xhibit traces of orange in some of the specimens, in others it is pale rellowish. The fins are unicolor; the dorsal, caudal, and pectorals, blackish brown; the anals and ventrals yellowish."-(GrranD, Ich. U. S. and Mex. Boundary Surv. - p. 38, figs. 1-4, plate xxii.)

MrNomus DeLPHives Cope.-"The subequal size of the scales of this species would refer it indifferently to the true group Catostomus of Girard, or his group Minomus, which he did not distinguish clearly. The preceding species would enter his Acomus, which is, however, only an undefined group of species, to which, by the way, the type of Catostomus, C. teres, be'ongs. This species is especially distinguished from those heretofore described by the shortening of the caudal part of the vertebral colnmn, and the consequent posterior position of the dorsal fin. Add to this a short, wide head, and thick body, and its physiugnomy is expressed.

"The dorsal outline is arched, the head flat abore, but elerated behind, and much depressed on the muzzle. The muzzle is wide and does not project beyond the upper lip, which is appressed to its lower face and bears four rows of warts; its smooth commissural part is narrow. On the lower lip the tubercles advance nearly to the comwissure ; this lip is deeply emarginate posteriorly; the eye enters the length of the head five times, $t$ wo and one-half times measuring tho muzzle, and twice the interorbital region. Head four and two-thirds times in length to end of caudal basal scales. Scales in thirty longitudinal series, between dorsal and ventral fins; ventrals remark- 


\section{Genus CYCLEPTUS Rafinesque.}

Cycleptus Rafinesque, Journal de Physique, de Chimie et d'Histoire Naturelle, Paris, 1819, p. 421.

Rhytidostomus HeckeL, Fische Syriens, Russegger's Reisen, 1842, p. 1023.

Catostomus et Sclerognathus sp. AUCr.

Type, Cycleptus nigrescens Rafinesque, = Catostomus elongatus Le Sueur.

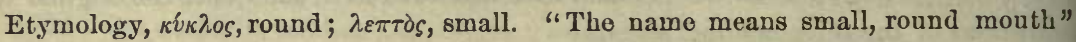
(Rafinesque).

Head very small, short and slender, its length contained 6 to 7 times in that of the body, its upper surface rounded; eje quite small, nearly median, not very high up, its length 6 to 8 in that of the side of the head; suborbital bones rather small and quite narrow; fontanelle entirely obliterated by the union of the parietal bones.

Mouth small, entirely inferior, overlapped by the projecting snout, the upper lip thick, pendent, covered with 3 to 5 rows of tubereles, the outer quite large, the inner small; lower lip moderate, formed some-

ably short, extending little more than half way to vent, originating under posterior third of dorsal. Pectorals well separated. Isthmus wide.

"Color above blackish, with a strong inferior marginal shade on the lower part of the sides, and the lighter tint above; a brown spot just above axilla, is cut off from it by a band of the jellow color which covers the belly and head below.

"The only species concerning which any doubt can arise in the nomenclature of this one is $C$. bernardini of Girard. That writer states that the latter possesses 15 D. radii ; this, with the ascription of a slender form and other peculiarities, will always separate them. Three species in Professor Hayden's collection without locality. This should be probably a tributary of Green River."-(Cope, Hayden's Geol. Surv. Terr. 18\%2, p. 436.)

Mrnomus Bardes Cope.- "This species is distinguished by its rery short head, and marked coloration, resembling in that respect the C. guzmaniensis of Girard; with this species, it has, however, nothing else in common.

"Head wide, muzzle not rrojecting bejond upper lip; latter not pendent, with narrow, smooth commissure and three or four rows of tubercles. Lower lip deepl5 incised, tubercular to near inner edge. Eye 5.25 times in length of head, twice in interorbital width. Head five times to end of basal caudal scales. Form stout : body cylindric anteriorly. Dorsal fin nearer end of muzzle than end of caudal scales. Scales of body subequal, in thirty longitudinal rows between dorsal and ventral fins, latter originating beneath hinder border of dorsal, not quite reaching veut. Pectorals well separate; istbmus wide, narrower than in $M$. delphinus. Color blackish above, a broad olive baud from upper part of opercular border along upper half of caudal peduncle, and a brcad black band below, narruwing to a line along the niddle of the peduncle: below, yellowish, a band of the same cutting off a blackish area above the axilla, as in the last species."-(Cope, Hayden's Geol. Surv. Terr. 1872, p. 436.) 
what as in Catostomus, but less full, incised behind; jaws without cartilaginous sheath; muciferous system not greatly dereloped; opercular apparatus not greatly dereloped, the operculum smooth and narrow. Isthmus moderate; gill-rakers moderatel 5 long, soft; pharyngeal bones strong, the teeth stout, increasing in size down wards, rather wide apart.

Body elongate, moderately compressed, not much elevated, the caudal peduncle long, the greatest depth contained 4 to 6 times in length.

Scales moderate, about equal over the bods, not closely imbricated, with wide exposed surfaces, the number in the lateral line from 55 to 60 , and about 17 in a transverse series from dorsal to rentrals; edges of scales serrate; lateral line well dereloped, nearly straight.

Fins rather large; dorsal fin beginning in front of rentrals and ending just before anal, of about 30 rays, strongly falcate in front, the first and second dereloped rass in length more than half the length of the base of the fin, the rays rapidly shortened to about the eighth, the length of the remaining rass being nearly uniform and all short; caudal fin large, widely forked, the lobes about equal; aual fin quite small, low, of 7 or 8 developed rass, scaly at base ; rentrals moderate, with 10 rays; pectorals elongate, somewhat falcate.

Sexual peculiarities somewhat marked; the males in spring with black pigment; the head then covered with small tubercles.

Air-bladder with two chambers, the anterior short, the posterior elougate.

But a single species of this singular genus is as yet known. It is found in the waters of the Mississippi Valley, and, although not a rare fish, it is by no means as generally abundant as are many others of its family.

\section{Generis Characterizations.}

Cycleptus Rafinesque, 1819. - "Cycleptus, (abdominal). Différent du genre Catostomus. Denx nageoires dorsales, bouche petite, ronde, au bout du museau; lèvres circulaires. Famille Cyprinidia! C. nigrescens, noirâtre; ventre blanchâtre, bouche retroussée ; queue fourchée. Parvient à deux pieds de long; très bon à manger, rare dans l'Ohio et le Missouri."-(Rafivesque, Journ. de Phys. etc. 1819, p. 421.)

CrCleptus Rafinesque, 1820._"Difference from the foregoing genus [Catostomus]two dorsal fins, mouth round and terminal."-(RAFinesqee, Ich. Oh. p.6.)

Riftidostonus Heckel, 1842. - "Dentes pectiniformes C0-60. Pinna dorsalis basi elongata; radio tertio vel quarto longissimo. In reliquis cum genere Catostomo congruit."-(HגскеL, Fische Syriens, p. 33, or Russeger's Reisen, p. 1023.-Species referred to the genus, Cyprinus catostomus Forster and Catostomus elongatus Le Sueur.)

Cyclertus Agassiz, 1855.- "As in many other instances, Rafinesque has named, but neither defined nor characterised the genus to which I now call attention. He has not 
himself even seen the fish upon which the genus is founded, and refers to another genus a species which cannot be separated from this. Moreover, the characteristics of the genus, as given by Rafinesque, are not true to nature. Yet, notwithstanding these oljections, I do not feel at liberty to reject his generic name, since it is possible to identify the fish he meant by the vernacular name under which it is known in the West. There is anotber reason why Rafinesque's description of our western fishes ought to be carefully considered and every possible effort made to identify his genera and species, the fact that he was the first to investigate the fishes of the Ohio and its tributaries upon a large scale, and that notwithstanding the looseness with which he performed the task and the lamentable inaccuracies of his too short descriptions, his works bear almost upon every page the imprint of his keen perception of the natural affinities of species, and their intimate relations to one another; so much so, that even where he has failed to assign his genera any characters by which they may be recognized, yet, when the species upon which they were founded can be identified, we usually find that there are good reasons for considering them as forming distinct genera.

"The trouble with Rafinesqne is, that he too often introduced in his works species which he had not always seen himself, and which he referred almost at random among his genera, thus defacing his well characterised groups, or that he went so far as to found genera upon species which he had never seen, overlooking perhaps that he had already described such types under other names.

"The genus Cycleptus affords a striking example of all these mistakes combined together. In his remarkable paper upon the genus Catostomus, Lesueur describes and figures one species from the Ohio River, ander the name of C. elongatus, peculiar for its elongated cylindrical body, and for its long dorsal fin beginning half way between the pectorals and ventrals, and extending as far back as the insertion of the anal. The epecies Rafinesque introduces in his subgenus Decactylus among the genuine $C a$ tostomi, without perceiving that it belongs to his own genus Cyclptus. This mistake arises undoubtedly from his belief that in Cycleptus there are two dorsals, which indeed he mentions as characteristics of this genus; but this statement is erroneous: the rays of the dorsal are, in fact, enclosed in a continuous meminrane, the anterior rays only being much longer than those of the middle and posterior portion of the fin; occasionally these long rays split, and accidentalls separate from the following ones, when they seem to form two dorsals.

"The character of this genus, so far as the dorsal is concerned, consists in reality not in its division, but in its great extension along the back, and the elongation of its anterior rays. The anal is very long in proportion to the size of the fish, and inserted far back, so that the length of the abdominal cavity is greater than in the genera Carpiodes, Ichthyobus, and Bubalichthys, with which Cycleptus is closely allied by the peculiar form of its dorsal. Again, Rafinesque remarks that the mouth is terminal, round and small. This requires also to be qualified. The mouth appears terminal and round only when the jaws are protruded to their utmost extent; when closed, it is rather crescent-shaped and entirely retracted under the projecting, pointed snout; the lips are covered with numerous projecting papillæ and spread horizontally,-these are moreover, continuous around the angles of the mouth, so that the upper and lower 1 ps are hardly separated by a small fold, and the lower lip is slightly cmarginate in the middle, while in other genera of this tribe it is actually bilobed. 
"The pharyngeal bones are strong, their anterior surface being flattened and the greatest diameter being the transverse one, as in Bubalichthys, and not laterally. compressed and thin as in Carpiodes and Ichthyobus.

"The symphysis is short and its peduncle flat and square, separated from the curved arch by a deep semicircular emargination. The teeth are also stronger and stouter than in Carpiodes and Ichthyobus, as is also the case in Bubalichthys, and they are gradually increasing in size, and relative thickness from the upper part of the arch to the symphysis, but they are much fewer and farther apart than in the latter genus. Their inner edge is transverse, rather blunt, though the middle ridgo is somewhat projecting; the lower teeth are so shaped that their inner angle is hardly higher than tho outer, while in the middle aud apper teeth it is gradually more projecting, and from the middle of the arch upwards forms a prominent point al ched outwards.

"The scales are considerably longer than high, with a rather prominent posterior margin; numerons radiating furrows upon the anterior and posterior fields, some across the lateral fields; the concentric ridges of the posterior field are not only broader than those of the other fields, but instead of running parallel to the margin of the sciles they are curved in concentric gothic arches between each two radiating furrows. Heckel mentions this genus nnder the name of Rhytidostomus, but Rafinesque's name Cycleptus has the priority. Properly it ought to be called Leptocyclus, according to its etymology, (see my Nomenclator Zoolugicus; Index Universalis, p. 109,) but under thi * form nobody would recognise it as Rafinesque's name. I shall therefore not urge the change."-(AGassiz, Am. Journ. Sci. Arts, 1855, p. 197.)

Cycleptus Copo \& Jordan, 1877. - "Body much elongated, subcylindrical forwards : dorsal elongate, falciform, of 30 or more rays ; fontanelle obliterated by the union of the parietal bones; mouth small, inferior, with papillose lips."-(JonDas, Proc. Ac. Nat. Sc. Phila. 1877, p. 81.)

\section{ANALYSIS OP SPECIES OF CYCLEPTUS.}

* Depth 4 to 5 in length : head 6 to $6 \frac{1}{2}$ : eje small, 6 to 7 in length of head: longest dorsal rays a little longer than head : pectorals rather longer than head : dorsal rays 30 ; anal 7 or 8 : scales $9-56-7$ : coloration very dark, the males almost black ; size large; length of adult $1 \frac{1}{2}$ to $2 \frac{1}{2}$ feet ..................... ELONGatus, 42.

\section{CYCLEPTUS ELONGATUS (Le Sueur) Agassiz.}

\section{Black Horse. Gourd-seed Sucker. Missouri Sucker. Suckerel.}

1817-Catostomus elongatus Le Suevr, Journ. Ac. Nat. Śc. Phila. 103.

Catostomus elongatus RAFINESQUE, Ich. Oh. 60, 1820.

Catostomus elongatus Knrtuand, Rept. Zool. Ohio, 168, 1839.

Catostomus elonyatus DeKay, New York Fauna, part iv, Fishes, 203, 1842.

Catostomus elongatus Cuvier \& Valexciennes, Hist. Nat. des Poiss. xvii, 455, 1844.

Catostomus elangatus KirtLaxd, Boston Journ. Nat. Hist. v, 267, 1845.

Catostomus elongatus Storer, Synspsis, 422, 1846.

Cycleptus elongatus AGASsiz, Am. Journ. Sc. Arts, 2d series, xix, 197, 1855.

Sclerognalhus elongatus Güvther, Cat. Fishes Brit. Mus. vii, 23, 18 C8. 
Cycleptus elongatus Jondan, Fishes of Ind. 222, 1875.

Cycleptus elongatus Jordas, Bull. Buffalo Soc. Nat. Hist.95, 1876. (Name only.)

Cycleptus elongatus Jords, Man. Vert. 298, 1876.

Cycleptus elongatus Nelson, Bull. No. 1, Ills. Mus. Nat. Hist. 50, 1876.

Cycleptus clongatus JoRdan \& Copeland, Check List, 158, 1876. (Name only.)

Cycleptus elongatus JoRdAN \& GiLBert, in Klippart's Rept. 53, 1876. (Name only.)

Cycleptus elongatus Jordax, Bull. U. S. Nat. Mus. ix, 38, 1877.

Cycleptus elongatus Jordan, Man. Vert. ed. 2d, 1878.

1818-Cycleptus nigrescens Rafinesque, Journal de Physique, 421.

Cycleptus nigrescens RAFINesQUE, Ich. Oh. 61, 1820.

Habitat.-Mississippi Valley, in all the larger streams.

This species is found in some abundance in the larger streams. At the Falls of the Ohio, it is taken in nets, and meets a ready sale. It is, howerer, much less abundant than the Buffalo fishes are. From the general use of the name "Missouri Sucker", its abundance in the State of Missonri may be inferred; but, as to the facts in the case, I am not informed. This fish is as sharply distinguished from the other Suckers in its appearance as in its anatomy. The dusky colors and the small size of the head attract attention at once.

But one species is yet known. That being the case, the synonymy of the species needs no discussion, its oldest name being the one in common use.

Specimens in United States National Museum.

\begin{tabular}{|c|c|c|}
\hline Number. & Locality. & Collector. \\
\hline 107 & $\ldots \ldots \ldots . . .$. & \\
\hline 8673 & 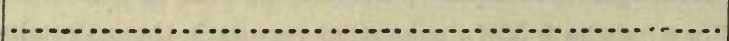 & \\
\hline 10790 & Cincinnati, Ohio $\ldots \ldots \ldots$ & J. W. Milner. \\
\hline 12278 & 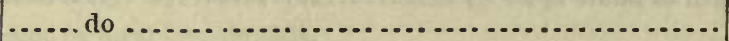 & Do. \\
\hline
\end{tabular}

\section{Genus CARPIODES. Rafinesque.}

Carpiodes RAFINESQUe, Ich. Oh. 56, 1820. (As subgenus of Gatostomus.)

Sclerognathus Valenciennes, Hist. Nat. des Poissons, xvii, 472, 1844.

Trpe, Catostomus cyprinus Le Sueur.

Etymology, Latin carpio, a carp ; i. c., carp-like.

Head comparatively short and deep, sometimes conic, sometimes blunt, its length ranging from $3 \frac{1}{2}$ to 5 in that of the body, its upper surface always rounded; eje moderate, median or anterior in position; suborbital bones well dereloped, their depth more than half that of 
the fleshy portion of the cheek below; fontanelle always present, well dereloped.

Month always small, horizontal and inferior, the mandible less than one-third the length of the head, the lips thin, the upper protractile, narrow, the lower quite narrow, $\Lambda$-shaped, or rather $n$-shaped, behind; both lips feebly plicate or nearly smooth, the plicæ often more or less broken up; jaws without cartilaginous sheath; muciferous system moderately dereloped; opercular apparatus well developed, the sub. operele broad, the operculum in the adult more or less rugose; isthmus moderate; pharyngeal bones remarkably thin and laterally compresser, with a shallow furrow along the anterior margin on the inside, and another more central one on the outline of the enlarged surfaces; teeth very small, compressed, nearly equally thin along the whole inner edge of the bone, forming a fine comb-like crest of minute serratures; their cutting edge rises above the inner margin into a prominent point. Gillrakers of anterior arch slender and stiff above, becoming reduced clownwards.

Body ovate or oblong, the dorsal outline more or less arched, the rentral outline more nearly straight, the depth from half to one-third the length, the sides compressed; the back notably so, forming a sort of carina ; caudal peduncle short and deep; scales large, about equal over the body, their posterior margins slightly serrate; lateral line well developed, nearly straight, with 34 to 41 scales, 12 to 15 scales in a cross-row from dorsal to rentrals; dorsal fin beginning near the middlo of the body, somewhat in advance of rentrals, falcate, its anterior rays rery much elevated and usually filamentous, their height ranging from $\frac{1}{2}$ to $1 \frac{1}{8}$ the length of the base of the fin, the number of dereloped rays ranging from 23 to 30 ; caudal fin well forked, the lobes equal; anal fin comparatively long and low, emarginate (in males?), its number of developed rays usually 8 ; ventrals shortish, with usually 10 rays; pectorals short.

Sexual peculiarities little marked; in some species, at least, the males in spring have the snout minutely tuberculate.

Coloration alwass plain; pale olivaceous above, white below, but bardly silvery, the fins all partaking of the color of the region to which they belong.

Air-bladder with two chambers.

Size medium or rather large.

This genus was first recognized and defined by Professor Agassiz in 
1855. Since then it has been generally received by authors under tho same name and with the same limits. It was first briefly outlined by Rainnesque in 1820 under the name of Carpiodes, then afterwards by Valenciennes defined more fully under the name of Sclerognathus. Both Carpiodes and Selerognathus having the same typical species (Catostomus cyprinus Le Sucur), the older and preferable name, Carpiodes, is the one to be adopted.

The recognition of species in this genus is a matter of extreme diff. culty, from their great resemblance to each other in color, size, form, and general appearance. Uur knowledge of the species thus far has been almost entirely due to the labors of Professor Cope (A Partial Synopsis of the Fishes of North Carolina", Proc. Am. Philos. Soc. Phila. 1870). I have myself examined specimens agreeing with each of Professor Cope's descriptions, and, with two exception (Carpiodes selene and Carpiodes grayi), I am disposed to admit all his species. It is true, howerer, that in every large collection of Carpiodes there are specimens disagreeing more or less from the typical forms of each species, and which should, in consistency, be described as distinct species, or else the species which they appear to connect should be united. I have not, however, examined a sufficiently full series of Carpiodes to be prepared to accept either of these alternatives. I have, therefore, taken Professor Cope's analysis of the species, and added to it such additional features as I bave been able to observe, and I give the whole as our best knowledge at present on the subject, leaving for future study the consideration of the degree of relationship existing between cyprinus, velifer, and thompsoni. The other four species, carpio, bison, cutisanserinus, and difformis, seem to be manifestly distinct, unless difformis be a monstrous form of cutisanserinus.

Species of this genus are found in all the fresh waters of the United States east of the Rocky Mountains. They seldom ascend the small streams, and aro taken by means of nets from the larger rivers and lakes. From their resemblance in form to the European Carp (Cyprinus carpio), they are popularly known as "Carp". This resemblance has suggested the name of the genus and of two of its species. As foodfishes they are rather indifferent, the flesh being rather coarse and flavorless and full of small bones. The geographical distribution of the species has been little studied. C. cyprinus is the common species east of the Alleghanies, and, if " $C$. damalis" and " $C$. tumidus" be the same, in the Upper Missouri region and the Rio Grande also. C. thompsoni is the 
common Carp of the Great Lakes. C. carpio is the most abundant species in the Ohio River, where $C$. velifer and $C$. cutisanserinus also occur in immense numbers.

I am convinced that neither the number of scales nor the number of fin-rays can be relied on to distinguish species in this genus, the entire range of variation being probably found in every species. The height of the anterior rays of the dorsal, although subject to considerable variation with age and wear, seems to be suffieiently constant to divide the species into two groups.

\section{Generic Characterizations.}

Carpiodfs Rafinesque, 1820.- "Body oblong, somewbat compressed; head compressed, nine abdominul rays, dorsal fin commonly elongate, tail equally forked." (RAFINESQUE, Ich. Oh. p. 56.)

SCLEROGNATHUS Storer, 1846.- " Snout slightly advanced bejound the mouth; the extremity of the mouth is supported, as in the Catostomi, by the intermaxillary, which is furnished in front with a well developed, projecting, cartilaginons ethmoid. The upright branch is long, and of a styloid forw, while the horizontal is shortened, and is a mere keel, the inferior edge of which serves merely to support the superior angle cf the moutb. The remainder of the maxillary arch is formed by a fibrous ligament covered by a thin, undilated lip, reduced to a thin and fleshy protuberance. The npper $\mathrm{jaw}$ is a wide, very solid bouy piece, under which the upper lip is partly drawn; this bone is concealed by the first two suborbitals, being wider and no less advanced than those of the Catostomi. As to its lips, it is a Lenciscus; but the osteology of its mouth resembles that of the Catostomi. The dorsal is long, like that of the Carps. The head is naked, marked by lines of mucous pores. Pharyngeal teeth comb-like, finer and more equal than those of the Catostomi. The air-bladder is divided into two large lowes; the anterior is large and rounded, with a slight depression at its superior face: the second conical, twice as long as the first and followed by two small lobes; the second communicates with the esophagus by an air-pipe."-(STorer, Mcm. Am. Ac. Arts and Sc. 1846, p. 427 ; essentially a translation from Valenciennes's aceount.)

CARPIOdes Agassiz, 1855. - "The body is very high and strongly compressed, the narrow ridge on the back forming the outline in front of the dorsal is very much arched, and regularly continuous downwards with the rather steep picile of 1 lic head.

"The head is short, its height and length differ but little. The snout is short and blunt. The small mouth is entirely inferior, and surrounded by narrow thin lips, which are more or less transversely folded. The lower jaw is short and broad. The pharyngeal bones of Carpiodes are remarkably thin, compressed laterally, with a shallow furrow along the anterior margin on the side, and another more central one on tho ontline of the arched surfaces; the teeth are very small, compressed, equally thin along the whole inner edge of the bone, forming a fine comb-like crest of minute serratnres; their cutting edge rises above the inner margin into a proninent point.

"The anterior lobe of the long dorsal is slender, its third and fourth rays being prolonged beyond the following ones into long filaments. The lower fins are all pointed, Bull. N. M. No. 12-13 


\section{CONTRIBUTIONS TO NORTH AMERICAN ICHTHYOLOGY-III.}

rather small, and hence different from one another. The ventral ridge of the body is flat. The scales have many narrow, radiating furrows upon the anterior field, and aro more deeply marked, in a straight line, across tlıe lateral fields, or limiting the lateral and posterior fields, hardly any upon the anterior field, the waving of the broader concentric ridges producing only a radiated appearance upon that field. Tube of the lateral line straight and simple, arising in advance of the centre of radiation, which is seated in the centre of form of the scales."-(AGASsiz, Am. Journ. Sc. Arts, 1855, p. 189.)

Carpiodes Günther, 1868._- "Distinguished from Sclerognathus (i.e. Bubulichthys and Ichthyobus) by its very thin, compressed pharyngeal bones, which are armed with a comb-like series of nearly equally minute compressed teeth."-(Günther, Cat. Fishes Bit. Mus. vii, p. 24.)

Carpiodes Cope.\& Jordan, 1877.- " Body oblong oval, compressed; dorsal elongate, elevated in front, of 20 or more rays; fontanelle present; pharyngeal bones narrow, with the teeth relatively thin and weak; mouth small, inferior, protractile downwards."-(Jordan, Proc. Ac. Nat. Sc. Phila. 1877, p. 82.)

\section{ANALYSIS OF SPECIES OF CARPIODES.}

*Dorsal fin with the anterior rays very much elevated and attenuated, equalling or more usually exceeding the length of the base of the fin.

† Muzzle very abruptly obtuse, almost vertically truncate in front.

a. Muzzle exceedingly blunt, so that the anterior edge of the mandible is in line with the anterior rim of the orbit, and the maxillary reaches to the anterior edge of the pupil: anterior suborbital deeper than long: head $4 \frac{1}{4}$ in length: eye quite large, $3 \frac{1}{2}$ to 4 in head : body arched, the depth somewhat less than half the length: first ray of dorsal nearer muzzle than base of caudal:

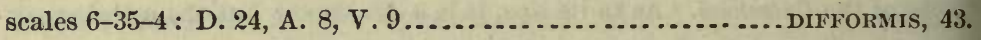

aa. Muzzle notably blunt, but less so than in the preceding : anterior edge of the mandible in advance of the orbit, and the maxillary just reaching the lire of the lower rim of the orbit: anterior suborbital bone deeper than long (longer than deep, "selene"): head 4 times in length: eye smallish, $4 \frac{1}{2}$ in head: body arched, the depth about $2 \frac{1}{2}$ in length : anterior rays of dorsal about midway between snout and base of caudal: scales 7-37-5: D. 26, A.

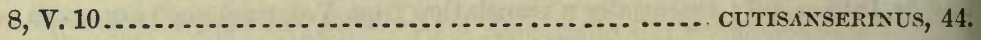

H Meuzzle conic, projecting, obtusely pointed: end of the mandible reaching to opposite nostrils : anterior suborbital as deep as long: head 38 in length: eye moderate, 4 to $4 \frac{1}{2}$ in length of head: body arched above, the depth $2 \frac{1}{4}$ to $2 \frac{1}{2}$ in length : first ray of dorsal nearer muzzle than base of caudal: scales 7-

- $\quad 37-5$ : D. 26 or 27 (" 22 ", Cope) ........................ velHFER, 45.

** Dorsal fin with the anterior rays more or less shortened, their length one-half to two-thirds that of the base of the fin : muzzle more or less conic and projecting.

b. Head long, contained about $3 \frac{1}{2}$ times in length to base of candal : muzzle elongate-conic, so that the eye is nearly median, the middle of the length of the head falling in front of its posterior margin: body not much arched; depth 3 in length: anterior rays of dorsal pretiy high, not much shorter than the base of the fin, not thickened at base: lips well developed : eje large, $4 \frac{1}{2}$ in head: scales $7-40-5$ : D. 27, A. 7, V. $10 \ldots \ldots \ldots \ldots \ldots \ldots \ldots \ldots$ Bison, 46. 
bb. Head intermediate, its length contained about 4 times ( $3 \frac{8}{4}$ to $4 \frac{1}{8}$ ) in that of bods: anterior rays of dorsal not thickened at base.

c. Body stout, short, the back much arched, the depth $2 \frac{1}{2}$ in length: head 4 to $4 \frac{1}{4}$ in length, the muzzle moderately pointed: dorsal rays considerably elevated, two-thirds as long as base of fin : eye small, $5 \frac{1}{4}$ in head: tip of lower jaw much in advance of nostrils; maxillary reaching line of orbit: anterior suborbital large, deep, roundish: origin of dorsal abont midway of body: scales rather closely imbricated, 8-39 to 41-6: D. 27, A. 7, V. 10.

THOMPSONI, 47.

cc. Body elongate, not much elevated, the depth 28 in length: head $3 \frac{8}{4}$ to 4 , the muzzle prominent but rather bluntish: front scarcely concave above eyes, the profile forming a somewhat nniform curve: eye small, nearly 6 in head : anterior rays of dorsal moderately elevated, nearly three-fourths tho length of the fin, the first ray nearly midway between snout and base of caudal : scales $6-37-5:$ D. 24 to $27, A .8, V_{1} 10 \ldots \ldots . . . . .$. cyprives, 48.

$\checkmark b b$. Head comparatively short, its length contained $4 \frac{1}{2}$ to 5 times in the length of the body: body more fusiform than in the others, compressed, but not much arched, the depth $2 \frac{\circ}{3}$ to 3 times in the length: anterior rays of dorsal short, notably thickened and osseous at base, the first ray nearer the end of the muzzle than the base of the caudal fin : eye small, anterior, $4 \frac{1}{2}$ in head: muzzle short, but projecting much beyond month : size largest of the genus.

CARPIO, 49.

\section{CARPIODES DIFFORMIS Cope.}

\section{Deformed Carp Sucker.}

1870-Carpiodes difformis Cope, Proc. Am. Philos. Soc. Phila. 480.

Carpiodes difformis Jondan, Man. Vert. 297, 1876.

Carpioües difformis Jondax \& Copeland, Check List, 158, 1876.

Carpiodes difformis Jondax, Proc. Ac. Nat. Sc. Phila. 72, 1877.

Carpiodes difformis Jordan \& GILBERT, in Klippart's First Report Ohio Fish Commission, 86, pl. xiii, f. 21, $18 i 7$.

Carpiodes difformis Jordax, Bull. U. S. Nat. Mus. 9, 50, 1877.

Carpiodes difformis Jordax, Man. Vert. ed. 2d, 321, 157..

Habitat.-Ohio Valley; less common than the other species.

The only specimen which $I$ have seen of this species was from the Wabash River, in which stream Professor Cope's original types were collected. No specimens are in the United States National Museum, which, indeed, at present contains very few of the Carp Suckers or Buffalo-fish.

\section{CARPIODES CUTISANSERINUS Cope:}

Long-finned Carp Sucker. Quillback.

1570-Carpiodes cutisanserinus Cope, Proc. Am. Philos. Soc. Phila. 481.

Carpiodes cutisanserinus Jordax \& Copelaxd, Check List, 158, 1876. 
Carpioctes cutisanserinus Jondsx, Bull. U. S. Nat. Mus. 9, 50, 1877.

Carpiodes cutisanserinus Jordañ \& GILbert, in Klippart's Rept. 53, 1876.

Carpiodes cutisanserimus Jondan, Man. Vert. ed. 2d, 321, 1878.

1870-Carpiodes selene Cope, Proc. Am. Philos. Soc. Phila. 481.

Carpiodes selene Jondan \& Copeland, Check List, 158, 1876.

Carpiodes selene JondaN \& Gilbert, in Klippart's Rept. 53, 1876.

Carpiodes selene Jondan, Man. Vert. ed. 2d, 321, 1878.

1876-Ichthyobus difformis Nelson, Bull. No. 1, U. S. Nat. Mus. 49.

HaBitat.-Mississippi Valley; generally abundant.

This species is closely related to $C$. velifer, but differs in the abruptly truncate snout, that of velifer being conic. I am unable to recognize C. selene as a distinct species at present, the form of the anterior sulorbital being the only distinguishing feature of much importance, and that probably not a constant one. C. cutisanserinus is as abuuclant in the Ohio as $C$. velifer, and I have seen many specimens from the Illinois River.

Specimens ia United States National Museum.

\begin{tabular}{|c|c|c|}
\hline Number. & Locality. & Collector. \\
\hline 20032 & Cumberland River....... & A. Winchell. \\
\hline 20033 & & Do. \\
\hline
\end{tabular}

45. CARPIODES VELIFER (Rafinesque) Agassiz.

Carp Sucker. Skimback. Quillback. Sailor. Sailing Sucker. Spear-fish.

1820-?? Catostomus anisopterus RAFINESQUe, Ich. Oh. 45. (Description at second hand and unrecognizable.)

1820-Catostomus velifer RAFintesque, Ich. Ob. 56.

Catostomus velifer Kirtland, Rep. Zool. Ohio, 168, 1838.

Carpiodes velifer Agassiz, Am. Journ. Sc. Arts, 2d series, xix, 191, 1855.

Carpiodes velifer Cope, Proc. Am. Philos. Soc. Phila. 482, 1870.

Carpiodes velifer Jomdan, Fishes of Ind. 22:, 1875.

'Carpiodes velifer Jondan, Bull. Buffalo Soc. Nat. Hist. 95, 1876.

Carpiodes velifer Jondax, Man. Vert. :997, 1876.

Carpiodes velifer JoRda \& Copeland, Check List, 158, 1876.

Ichthyobus velifer NeLson, Bull. No. 1, Ills. Mus. Nat. Hist. 49, 1876.

Carpiodes velifer JoRDAN \& GILBERT, in Klippart's First Report Ohio Fish Commission, 87, 187\%.

Carpiodes velifer Jordan, Bull. U. S. Nat. Mus. ix, 34, 1877.

Carpiodes velifer JoRdan, Man. Vert. ed. 2d, 321, 1878. 
1846-Sclerognathus cyprinus KIRTLAND, Bost. Journ. Nat. Hist. vol. v, 275. (In part; not of C. \& V.)

Habitat.-Western streams and lakes (Cayuga Lake, New York, to Mississippi River).

This species is quite abundant in the Ohio River, and I hare seen specimens not evidently distinguishable, from Lake Erie and from other waters tributary to the Great Lakes. Indiscriminately with $C$. cutis. anserinus, it is known to the fishermen as Quillback, Skimback, etc., the lower-finned species being called rather "Carp". Most of the synonymy above quoted includes sereral species, the true velifer being first distinguished by Professor Cope. Rafinesque's anisopterus I bring in to the synonymy of this species, simply to refer to it somewhere. It is really unidentifiable. Kirtland's Sclerognathus cyprinus refers most to this species, but his tignre represents no known fish. The head is too small, and the form, etc., incorrect.

Specimens in Cnited States National Museum.

\begin{tabular}{|c|c|c|}
\hline Number. & Locality. & Collector. \\
\hline $2027 \tau$ & Cayuga Lake, New York....... & $\alpha=$ \\
\hline
\end{tabular}

There are also several other specimens in the collection, bnt without locality.

\section{CARPIODES BISON Agassiz.}

Long-headed Carp Sucker.

1854-Carpiodes bison AGassiz, Am. Journ. Sci. Arts, 356.

Carpiodes bison AgAssiz, Am. Journ. Sci. Arts, 190, 1855.

Carpiodes bison Cope, Proc. Am. Philos Soc. Phila. 483, 1870.

Carpiodes bison Jordax, Man. Vert. 297, $18 \% 6$.

Carpiodes bison Jor:daN \& Copeland, Check List, 158, $18 \% 6$.

Ichthyobus bison Nelson, Ball. No. 1, Ills. Mus. Nat. Hist. 49, 1876.

Carpiodes bison Jordax \& Gilbert, in Klippart's Rept. 53, 1876.

Carpiodes bison Jordan, Bull. U. S. Nat. Mns. ix, 50, 1877.

Carpiodes bison Jord.s, Man. Vert. ed. 2d, 322, 1878.

Habrtat.-Mississippi Valley (Osage River, Agassiz; Mississippi River, Wabash River, Teunessee River, Cope).

What the fish is to which Professor Agassiz gare the name "bison" caunot be ascertained from the published descriptions. Professor Cope has described the present species under that name, and we accept the 
name bison on his authority. This species is not generally common in so far as my experience goes. I have, however, seen one or two from the Ohio River. I found no specimens in the National Museum.

\section{CARPIODES THOMPSONI Agassiz.}

\section{Loke Carp.}

184:-Catostomus cyprinus Thompson, Hist. Vt. 133.

1855-Carpiodes thompsoni AGassiz, Am. Journ. Sc. Arts, 2d series, xix, 191.

Carpiodes thompsoni Cope, Proc. Ac. Nat. Sc. Phila. 285, 1864.

Carpiodes thompsonii Cope, Proc. Am. Phiios. Soc. Phila. 483, 1870.

Carpiodes thompsoni Jordan, Man. Vert. 297, 1876.

Ichthyobus thompsoni Niuson, Bull. No. 1, Mls. Mus. Nat. Hist. 49, 1876.

Carpiodes thompsoni Jordan \& Copeland, Check List, 158, 1876.

Carpiodes thompsonii Jordan \& GILBERT, in Klippart's Rept. 53, 1876.

Carpiodes thompsoni Jordan, Man. Vert. ed. 2d, 322, 1878.

Habrtat.-Great Lake region; abundant.

This species occurs in more or less abundance throughout the Great Lake region. It is the shortest and most arched of all the species. Its dorsal fin is about intermediate between that of velifer and that of carpio. I have examined rery many specimeus of this species, and I find little variation among them. This fish reaches a length of something over a foot, and is sold by the Lake fishermen as "Carp".

\section{Specimens in United States National Museum.}

\begin{tabular}{|c|c|c|}
\hline Number. & Locality. & Collector. \\
\hline 11040 & 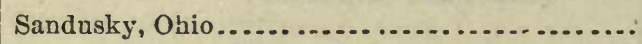 & J. W. Milner. \\
\hline 11127 & ...... do ............. & Do. \\
\hline 11128 & ...... do .................. & Do. \\
\hline 11130 & ...... do $\ldots . . . . . . . .$. & Do. \\
\hline 11131 & ......do ............. & Do. \\
\hline 11132 & ...... do ............ & Do. \\
\hline
\end{tabular}

\section{CARPIODES CYPRINUS (Le Sueur) Agassiz.}

Eastern Carp Sucker. Nebraska Carp Suclier. Rio Grande Carp.

1817-Catostomus cyprinus Le Surur, Journ. Ac. Nat. Sc. Phila. i, 91.

Labeo cyprinus DeKAY, New York Fauna, part iv, Fishes, 194, 1842.

Sclerognathus cyprinus Cuvier \& Valenciennes, Hist. Nat. des Poissons, xvii,

$4 \pi 4,1844$.

Sclerognathus cyprinus Storer, Synopsis, 427, 1846.

Carpiodes cyprinus AGassiz, Am. Journ. Sc. Arts, 2d series, xix, 191, 1855. 
Carpiodes cyprinus Gevxrmer, Cat. Fishes Brit. Mus. vii, 24, 1868.

Carpiodes cyprinus Cope, Proc. Am. Philos. Soc. Phila. 484, 1870.

Carpiodes cyprinus Jondan, Fishes of Ind. 202, 1875.

Carpiodes cyprinus Jordan, Man. Vert. :97, 1876.

Carpiodes cyprinus Unler \& LugGer, Fishes of Maryland, 140, 1876.

Carpiodes cyprinus Jordan \& Copranan, Check List, 158, 1876.

Carpiodes cyprinus Jol:Das, Man. Vert. ed. 2d, 323, 1878.

1854-Carpiodes vacca AGıssiz, Am. Journ. Sci. Arts, 356.

1854-Carpiodes tumidus Bannd \& Grrard, Proc. Phila. Ac. Nat. Sc. 28.

Ictiobus tumidus Ginand, U. S. Mex. Bonnd. Surv. Ich. 34, pl. xxx, f. 1-4, 1859.

Ichthyobus tumidus Jomdan \& Copeland, Check List, 158, 1876.

1856-Carpiodes damalis Girand, Pruc. Ac. Nat. Sc. Phila. 170.

Carpiodes damalis Grnal:D, U. S. Pac. R. R. Expl. x, 218, pl. xlviii, f. 1-4, 1858.

Carpiodes damalis Core, Proc. Ac. Nat. Sc. Phila. 85, 18005.

Carpiodes damalis Jondax \& Copeland, Check List, 155, 1876.

1870-Carpiodes grayi Copk, Proc. Am. Philos. Soc. PLila. 482, 1870.

Carpiodes grayi Jolidax \& Copelaxd, Check List, 158, 1 \% 6.

Carpiodes grayi Cope \& Yannow, Wheeler's Expl. W. 100th Mer. v, Zool. 681, $18 ; 6$.

Habitat.-New Englard to Alabama; thence to Mexico and north to the Upper Missouri.

I hare elsewhere alread $y$ united the nominal species grayi and tumidus, for the following reasons:-Girari's "Ictiobus tumidus" is certainly a Carpiodes, as is plainly shown by the published figure, the mouth be ing represented as small and inferior, beneath the projecting siout. I have numerous young specimens of a Carpiodes from the livo Grande, at Brownsville, Texas, the original locality of Icticbus tumidus. But wy specimens do not disagree in any important respect from Carpiodes grayi, frot the same river, nor am I able, on examination of atuthentic specimens of the latter species, to point out any differences between them aurl my Brownsville specimens. Therefore, if tumidus and grayi are really different, the differences have escaped my notice. It is of course possible that iny Brownswille specimens, although from the original locality of tumidus, may not be that species; but, as the types of tumidus have leen lost, I do not see how the question can erer be settled.

I am furthermore unable to separate tumidus as thus characterized from damalis Grd., and the close relationship existing between damalis and cyprinus has already been noticed by Professor Cope. As I now believe that cyprinus, tumidus, damalis, and grayi were all based on members of a single widely diffused species, I unite them in the abovo synonymy.

This species is the common Carp Sucker of Pennsylrania and the 
Middle States. I have no specimens referable to this species from the Great Lakes, nor from the Mississippi or the Ohio. If cyprinus, tumi. dus, and damalis are identical, howerer, one of two things must be true. Either $C$. cyprinus really inhabits the whole Mississippi Valley, but has been overlooked or confounded with others, or else we have a very curi. ous anomaly in the distribution of the species, it being an inhabitant of waters of two widely separated areas, having little in common. The former supposition seems the most probable, and I accordingly look for specimens of $C$. cyprinus in the Mississippi Valley.

Speciniens in United States National Museum.

\begin{tabular}{|c|c|c|}
\hline Number. & Locality. & Collector. \\
\hline - & Round Lake, Montgomery, Alabama ............ & Kumlien \& Bean. \\
\hline 179 & Fort Pierre, Nebr. (types of $C$. damalis)........... & Dr. Evans. \\
\hline$: 550$ & 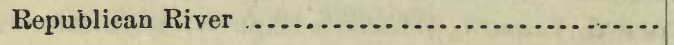 & Wood \& Hammond. \\
\hline 13012 & Rio Grande, New Mexico (grayi) ................. & Dr. O. Loew. \\
\hline 15891 & Nebraska ................................. & \\
\hline 20109 & "U.S. Mex. Boundary Survey" (types of tumidus?). & \\
\hline- & 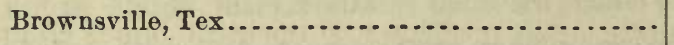 & \\
\hline
\end{tabular}

\section{CARPIODES CARPIO (Rafinesque) Jordan.}

Big Carp Sucker. Olive Carp Sucker.

1820-Catostomus carpio RAFinesQue, Ich. Oh. 56.

Carpiodes carpio Jordan, Bull. Buffalo Soe. Nat. Hist. 95, 1876.

Carpiodes carpio Jordan, Man. Vert. 297, 1876.

Ichthyobus carpio Nelson, Bull. No. 1, Ills. Mus. Nat. Hist. 49, 1876.

Carpiodes carpio JoRdaN \& Copeland, Check List, 158, 1876.

Carpiodes carpio JoRdan \& GILBERT, in Klippart's Rept. 53, 1876.

Carpiodes carpio Jondan, Proc. Ac. Nat. Sc. Phila. $72,1877$.

Carpiodes carpio Jordax, Bull, U. S. Nat. Mus. ix, 34, 1877.

Carpiodes carpio Jordan, Man. Vert. ed. 2d, 322, 1878.

1870-Carpiodes nummifer Cope, Proc. Am. Philos. Soc. Phila. 484.

Habitat.-Mississippi Valley. Abundant in the Obio River.

This is the most abundant species of its genus in the Ohio River and its tributaries. It is the largest species, the most elongate, and has the lowest fin-rays and the smallest head. The peculiar enlargement of the anterior rays of the dorsal I have found to be an excellent diagnostic character. This species has been well described by Professor Cope under the name of $C$. nummifer. There can, however, be but littlo 
doubt that Rafinesque had the same fish in mind as his C. carpio, and I. have accordingly adopted the latter name.

Specimens in United States National Museum.

\begin{tabular}{|c|c|c|}
\hline Number. & Locality. & Collector. \\
\hline 12291 & Ohio River, Cincinnati ........ & J. W. Milner. \\
\hline 12292 & 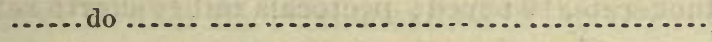 & Do. \\
\hline
\end{tabular}

\section{Genus BUBALICHTHYS Agassiz.}

Bubalichthys AGassiz, Am. Journ. Sci. Arts, 1855, 192.

Sclerognathus GÜNTHER, Cat. Fishes Brit. Mus. vii, p. 22, 1868.

Catostomus et Carpiodes sp. of authors.

Type, Carpiodes urus Agassiz.

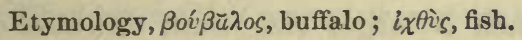

Head moderate or rather large, deep and thick, its superior ontline rapidly rising, its leugth about 4 in that of the body: eye moderate, median or rather anterior in position; suborbital boues comparatively narrow; fontanelle always present and widely open.

Mouth moderate or small, more or less inferior, the mandible short, little oblique, or typically quite horizontal, the mandible less than one-third the length of the head, the premaxillaries in the closed mouth below the level of the lower part of the orbit; lips rather thin, thicker than in Ichthyobus, the upper protractile, narrow, plicate, the plicæ sometimes broken up into granules; lower lip comparatively full (for a Buffalo. fish), faintls plicate, the plica b: oken up into granules, the lower lip) having the general $n$-shaped form seen in Carpiodes; jaws without cartilaginous sheath; muciferous system well developed; opercular apparatus well developed, but less so than in Ichthyobus, the operculum strongly rugose; isthmus moderate; pharyngeal bones triangular, with large teeth, which increase in size from above downwards; teeth compressed, their grinding edge blunt, slightly arched in the middle, and provided with a little cusp along the inner margin, which is bardly detached from the crown, and does not rise abore the surface: gill-rakers of anterior arch slender and stiff above, growing shorter downwards.

Body ovate or oblong, the dorsal outline more or less arched, the sides of the body compressed, the rentral outline curved also, but to a less degree: scales very large, about equal over the body, their posterior 
- outlines somewhat serrate; lateral line well developed, nearly straight, with 35 to 42 scales, 12 to 14 in a cross-series from ventrals to clorsal; dorsal fin beginning near the middle of the body, somewhat in advance of the veutrals, its anterior rays elevated, their height about equal to half the base of the fin, the number of rays in the dorsal fiu ranging from 25 to 32 ; caudal fin well forked, the lobes about equal, not falcate; anal fin comparaticely long and rather low, of 8 or 9 developed rass; rentrals moderate, 10-rayed; pectorals rather short: sexual peculiarities, if any, unknown : coloration dull dark brown, nearly plain, not silvery ; fins olivaceous or more or less dusky.

Air-bladder with two chambers.

Size quite large.

In general appearance, the species of Bubalichthys bear a considerable resemblance to those of Carpiodes. The form is, however, coarser than that of any Carpiodes, the dorsal fin is lower, and the coloration is darker and duller. The species reach a larger size than do those of Carpiodes, but whether larger or not than the species of Ichthyobus I am unable to say. In external appearance, Bubalichthys is intermediate between Carpiodes and Ichthyobus, the one species, bubalus, resembling Carpiodes most, the other, urus, being most like Ichthyobus.

Our knowledge of the species of this genus is very incomplete. Many species were named and indicated by Professor Agassiz, but with such fragmentary descriptions that not a single one of them is certainly known by any one. I have, however, been able to identify in specimens from Quincy, Ill., the fishes termed by him B. bubalus and B. niger, the small-mouthed and the large-mouthed Buffalo. Assuming these two well-separated species as a basis, I have compared with them numerous Buffalo-fishes from various localities, and in all cases I have found them identical with either the one or the other. I have therefore adopted the hypothesis, possible, and perhaps probable, that all of the nominal species of Professor $A$ gassiz were based on the one or the other of these two forms. As to this, I may say that the sole basis of some of these nominal species was the difference in locality. From what we know of the range of other species of Catostomida, there is nothing antecedently improbable in the same fish being found in the Wabash and Mobilo Rivers, or in the Tennessee and Osage. Myxostoma macrolepidotum, Erimyzon oblongus, Minytrema melanops, Catostomus teres, and others are known to occur in all four of those streams. The questions of locality may, I think, be safely elimiuated from the discussion. The 
descriptions published by Professor Agassiz are almost worthless for the distinction of species. It has accordingly seemed best to me, as a temporary arrangement, at least until more than two species are shown to occur in our waters, or until some one is able to show from examination of Professor Agassiz's types what he really had in mind, to distribute his nominal species in the synonymy of the two which we know. I have accordingly considered each of Agassiz's species and made it identical with either the small-mouthed or the large-wouthed species, as the description seemed to indicate. A third species, from Central America, which I suppose belongs to this genus, is added from Dr. Günther's description.

\section{Generic Characterizations.}

Bebalichtmys Agassiz, 1855.- "At the time I vindicated the propriety of restoring some of the genera established by Rafinesque among Cyprinoids, I did not suspect that the genus Carpiodes, as I then represented it, still contained two distinct tspes, thongh I had noticed that some of the species had the anterior margin of their dorsal greatly prolonged, whilst in others it hardly rises above the middle and posterior of that fin. Having since examined the pharyngeals of all the species of this tribe which $I$ havo been able to secure from different parts of the country, I find that those with a high dorsal which constitute the genus Carpiodes, have, in addition, very thin flat pharyngeals with extremely minute teeth, wh.lst those with a low dorsal have triangular pharyugeals with larger teeth, increasing gradually in size and thickness, from the upper margin of the bones towards the symphysis. The difference in form of these bones arises from the circumstance that the slight ridge upon the outer surface of the arch in Carpiodes is transformed in this second type into a prominent edge, dividing the outer surface of the arch into a posterior and anterior plane, meeting under an acute angle. This structural homology is satisfactorily traced by the difference of the external appearance of these two planes, the posterior one being full as the posterior half of the flat outer surface of the arch in Carpiodes, whilst the anterior plane is coarsely porous, indeed studded with deep pits analogous to the porons character of the anterior half of the outer surface of that bone in Carpiodes. The teeth themselves are compressed ; their grinding edge is rather blunt, slightly raised in the middle; and provided with a little cusp along the inner margin, which is hardly detached fron: the crown, and does not rise above its surface, as in Carpiodes, Ichthyobus and Cycleptus.

"In this genus the bulk of the body is not placed so far forwards as in Carpiodes, the greatest height being between head and tail. The npper ontline of the body is less strongly arched in advance of the dorsal; the head is longer than high, and the snout not more prominent than the moutb. The mouth opens obliquely downwards and forwards, the lower jaw being nearly as long as the upper. The lips are suall and granulated. The anterior rays of the dorsal are not separately prolonged beyond the rest of the fin, though its anterior margin is higher than its middle and posterior portion. The lower fins are as in Carpiodes.

"The scales have many narrow radiating furrows upon the anterior field, none across the lateral fitdd, and few upon the posterior fields, converging to the centre of radia- 
tion, to which the tubes of the lateral line extend also. For this new genus I propose the name of Bubalichthys, intending to recall the name of Buffalo fish, commonly applied to this species. To this genus belong the species $I$ have described as Carpiodes urus from the Tennessea River, C.taurus from Mob.le River, and C. vitulus from the Wabash, and also the Catostomus niger of Rafinesque and Catostomus bubalus of Dr. Kirtland from the Ohio, but not C. bubalus Rafinesque, which is the type of the genus Ichthyobus described in the following paragraph. I have another new species from the Osage River, sent me by Mr. George Stolley. This shows this type to be widely distributed in our western waters, but thus far it has not been found in the Atlantic states. I have some doubts respecting the nomenclature of these species which are rather difficult to solve. It will be seen upon reference to Rafinesque's Ichthyologia Ohiensis, p. 55 and 56, that he mentions two species of his subgenus Ichthyobus, one of which he calls $C$. bubalus, and the other $C$. niger ; the second he has not seen himself, but describes it on the authority of Mr. Audubon as 'entirely similar to the common Buffalo fish,' his C. bubalus, but ' larger, weighing upwards of fifty pounds.' Dr. Kirtland, on the other hand, describes the C. bubalus as the largest species found in the western waters, and adds that the young is nearly elliptical in its outline and is often sold in the market as a distinct species under the name of Buffalo Perch. If the $\theta$ was only one species of Buffalo in those waters the case would be very simple, and the $\mathrm{Ca}$ tostomus bubalus and niger of Rafinesque, and C. bubalus of Dr. Kirtland, should simply be considered as synonymous, but Dr. Rauch of Burlington bas sent me fine specimens of this Buffalo Pereh, to which the remark of Dr. Kirtland, 'elliptical in its outline,' perfectly applies, and I find that it not only differs specifically but even geuerically from the broader, high backed, common Buffalo, and being the smaller species, I take it to be Rafinesque's C. bubalus, the type of his genus Ichthyobus, which is more fully characterised below, whilst the larger species, Rafinesque's $C$. niger, can be no other than Dr. Kirtland's C. bubalus, 'the largest species of the western waters.' It seems therefore hardly avoidable to retain the name of $C$. niger or rather Bubalichthys niger for the common Buffalo, though Rafinesque, who first named the fish, never saw it, or if he saw it mistook it for his own bubalus, and though Dr. Kirtland, who correcrly describes and figures it, names it C. bubalus, for such is the natural result to which the history of the successive steps in our investigation of these fishes lead. But our difficulties here are not yet at an end. Among the splendid collections I received from Dr. Rauch, I found two perfectly distiuct species of Bubalichthys, one with a large mouth, and the other with a small mouth, and one of Ichthyobus, living together in the Mississippi River, in the neighborlood of Burlington, Iowa ; and the next question, probably never to be solved, will be, if they all three occur also in the Ohio, whether Rafinesque's C. niger was the big mouthed or the small mouthed Bubalichthys. Judging from the figure given by Dr. Kirtland in the Boston Journal of Natural History, vol. v, pl. fig. 2, I believe his C. bubalus to be the small mouthed species. I myself have, however, seen only one specimen of the big mouthed species from the Ohio, and that in rather an indifferent state of preservation; for which I am indebt ed to Prof. Baird, and Lone of the small mouthed species. Shonld, however, all three, as is possible, occur in the Ohio as well as the Mississippi, to avoid introducing new names, I will call the big mouthed species B. niger, preserving for it Rafinesque's specific name,--the small 
montbed, B. bubalus, retaining for it the vame which Dr. Kirtland has giren it, even though the species of Ichthyobus must bear the same specific name, being that originally applied by Rafinesqne. It may be that either my $B$. vitulus or my $B$. urus is identical with Dr. Kirtland's C. bubalus, bat until I can obtain original specimens of this species, this point must remain undecided, as it is impossible for mere descriptious to institute a suficiently minute comparison. The specimens from Osage River I shall call $B$. bonasus.

"Compared with one another, these species differ as follows: $B$. niger, (the bigmonthed Buffalo) differs from B. bubalus (the small-monthed Buffalu) by its larger month, opening more forwards; its more elongated body, the first rays of the dorsal rising immediately above the base of the ventrals, and its anterior lobe being broade:, and the anal fin not emarginated; B. bonasus differs froin $B$. bubalus and from $B$. niger in having the mouth larger than the first and smaller than the second, and from $B$. bubalus by its less emarginated dorsal, which renders its larger lobe broaler, anal fin not emarginated, opercle larger. A farther comparison with the Southern species conid only be satisfactory, if accompanied by accurate figures."-(AGAssiz, Am. Journ.Sc. Arts, 1855, p. 192.)

SCLEROGNATHUS Günther, 1863._ "Scales of moderate or rather large size. Lateral line running along the midale of the tail. Dorsal fin much elongate, with about 30 or more rays, none of which are spinous. Anal fin short. Mouth small, inferior (Baba. 7ichthys) or subterminal (Sclerognathus), with the lips more or less thickened. Barbc's none. Gill-rakers long, stiff in the npper two-thirds of the first branchial arch, modified into low membranaceous transverse folds in the lower third. Pseudobranchio. Pharyngeal bones sickle-shaped, armed with a comb-like series of numerous, compressed teeth, increasing in size downwards."-(Güxtmer, Cat. Fishes Brit. Mus. vii, 22, 1868.)

Bubalichthrs Cope \& Jordan, 187\%. - "Body oblong oval, compressed ; dorsal elongate, elevated in front, of 20 or more rays; fontanelle preseut; pharyngeal bones strong, the teeth comparatively coarse and large, increasing in size downwards; mouth inferior."-(Jordan, Proc. Ac. Nat. Sc. Phila. 1877, p. 82.)

\section{ANALYSIS OF SPECIES OF BUBALICHTHYS.}

* Body considerably elevated and compressed above; the dorsal region subcarinate; belly thicker; depth $2 \frac{1}{2}$ to $2 \frac{8}{4}$ in length; axis of body abore the ventrals below the lateral line and nearly twice as fir from the back as from the belly: head moderate, triangular in outline when viewed from the side, 4 in length: eye equal to snoat, + to 5 in length of head, much larger than in $B$. urus : month quite small, notably smaller and more inferior than in $B$. urus : mandible about equal to eye: forsal fin elevated in front and rapidly declined, the bighest ray reaching much beyond the middle of the fir, the seventh ray about half the length of the third or longest; anal rays rapidly shortened behind, the micidle rays much shorter than the first long ones: scales 8-39-6; dorsal, 29; anal, 10; ventrals, 10: coloration paler, the lower fins slightly dusky .............. BCBALCs, 50 .

** Bods much less elevated and less compressed than in the preceding, the back not at a!l carinated ; axis of body above ventrals about at the lateral line, and but very little farther from the dorsal outline than from the ventral; depth 3 to $3 \frac{1}{4}$ in length: head very etout, strongly transversely conrex, thicker, larger, and less pointed 
than in the next, about 4 in length: eyo about equal to snout, $5 \frac{1}{2}$ in head, much smaller than in B. bubalus : mouth large, considerably oblique, opening well forwards : mandible longer than eye : dorsal fin lower and less rapidly depressed than in the next, the longest ray scarcely half the length of the base of the fin; anal fin rounded, its rays not rapidly shortened, the middle ones not much shorter than the longest: colors very dark; fins all black : scales 8-41-7; dorsal, 30;

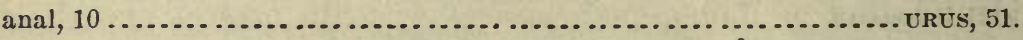

*** Mouth small, inferior, slightly corrugated: depth $3 \frac{1}{8}$ to $3 \frac{1}{4}$ in length head 4 to $4 \frac{1}{2}$, not much longer than high : eye rather small, one-lifth of the length of the head and $\frac{2}{5}$ that of the snout: suborbitals narrow. Anterior rays not much prodnced, shorter than the head; caudal forked. Origin of ventral vertically below the fourth dorsal ray. Pectoral fin not extending to ventrals. There are five longitudinal series of scales between the lateral line and the root of the ventral. Coloration uniform. Scales 7-38-7; dorsal 29 ; anal 10..... MERIdoNaLIS, 52.

\section{.50. BUBALICHTHYS BUBALUS Agassiz.}

\section{Buffalo-fish. Small-mouthed Buffalo. High-backed Buffalo.}

1838-Catostomus bubalus Kirtland, Rept. Zool. Ohio, 168. (Not of Rafinesq'10.)

Catostomus bubalus Kirtland, Boston Journ. Nat. Hist. v, 266, 1845.

Catostomus bubalus Storer, Synopsis, 424, 1846.

Bubalichthys bubalus Agassiz, Am. Journ. Sc. Arts, 2d series, xix, 195, 1855.

Bubalichthys bubalus Jondan, Fishes of Ind., 222, 1875.

Bubalichthys bubalus JondaN \& Copeland, Check List, 158, 1876.

Bubalichthys bubalus Jordan, Proc. Ac. Nat. Sc. Phila. 74, 1877.

Bubalichthys bubalus JorddN \& GiLbert, in Klippart's Rept. 53, 1877.

1854-? ? Carpicdes taurus AGassiz, Am. Journ. Sci. Arts, 355. (Not identifiable.)

9? Bubalichthys laurus AGsssiz, Am. Journ. Sc. Arts, 2d series, xix, 193, 1855.

I Bubalichthys taxus Jordan \& Copeland, Check List, 15׳, 1876.

18.j4-? ? Carpiodes vitulus Afassiz, Am. Jonrn. Sci. Arts, 356. (Not identifiıble.)

?? Bubalichthys vitulus Agassiz, Aın. Journ. Sc. Arts, 2d series, xix, 193, $185 \bar{a}$

9? Iiubalieluthys vitulus Jondan \& Copkland, Check List, 158, 1876.

9? Bubalichthys vitulus Jondan \& Gilbert, in Klippart's Rept. 53, $18 \% 6$.

1863-Sclerognalhus urus GÜNtner, Cat. Fishes Brit. Mus. vii, 22.

1876-Icthyobus cyancllus NeLson, Bull. No. 1, Ills. Mus. Nat. Hist. 49.

Ictkyobus cyancllus Jondan \& Copeland, Check List, 158, 1876.

Ithyobus cyanellus Jol:Dan, Proc. Ac. Nat. Sc. Phila. 73, 1877.

Icthyobus cyanellus Jordan \& GrLBLRT, in Klippart's Rept. 53, 1876.

Ichthyobus cyanellus Jordan, Man. Vert. ed. 2d, 323, 1878.

18:- - Bubalichthys altus Netson, MSS.

Bubalichthys altus Jondan, Proc. Ac. Nat. Sc. Phila. 73, 1877.

Bubalichthys altus Jordan, Man. Vert. ed.2d, 324, 1878.

1877-Bubalichihys bubalinus Jordds, Bull. U. S. Nat. Mus. ix, 50.

Butalichthys bubalinus Jordan, Man. Vert. ed.2d, 325, 1878.

Habitat.-Mississippi Valley; abundant in all the larger streams. 
This is probably the most generally distributed of the rarions species known popularly as Buffalo-fish. The question as to its proper nomenclature is eren more complicuted than that of the next species. It may be that this is the true bubalus of Rafinesque, as supposed by Dr. Kirtland. But as that species was the type of the genus Ictiobus, the ilentification of Rafinesque's species with the present one would lead to changes in nomenclature far from desirable. The name Ichtingobus would then belong to Bubalichthys and the genus Ichthyobus would receive a new name. As this can never be proven, it is best to cousider Agassiz's identification as correct and that of Dr. Kirtland wrong. The first mention of this species was that of Dr. Kirtland as Catostomus bubalus. The name bubalus, however, was giren through an erroneous identification, and must be passed over. Next come Agassiz's names taurus and vitulus, both possibly belonging here, but just as likely belonging to urus. Both of them, from the exasperating insufficiency and irrelevance of the descriptions, are practically unidentifiable. Next is $\Lambda$ gassiz's bubalus, noticed below. The next name in order is that of Ichthyobus cyanellus Nelson, which was based on this species, as I have ascertained by examination of his type. This is the first tenable name certainly belonging to this species, unless we adopt the name bubalus. Next comes Nelson's altus. A specimen answering Nelson's description in all respects, and as evidently belonging to the species now under consideration, is at present before me. It is a fine adult example. Lastly comes my own bubalinus, intended merely as a substitute for the name "bubalics", not then considered tenable as the specific name of this species, haring been giren to it originally by an error in identification. The adoption of the name bubalus by $\mathbf{A}$ gassiz after the knowledge of this error may, howerer, be considered as a proposal of a new name. The original descriptions of taurus, vitulus, cyane!lus, and altus are here suljoined.

Carpiodes taurus Agassiz, Am. Journ. Sci. Arts, 1855, p. 355.-—" From Mobile Rirer, Alabama. The form of the body is intermediate between that of C. Cyprinus and C. Urus. The gill-cover has the same form as in $C$. Urus, but it is larger and more strongly arched behind. The hind margin of the scales is waving, owing to a somewhat prominent mid. dle angle. The anterior rays of the dorsal equal in length two-thirds of that of the base of the fin. Anal not lunate behind. The ventrals do not reach to the anal opening. Candal not so deeply furcate as in C. Cyprinus." 
Carpiodes vitulus Agassiz, Am. Journ. Sc. Arts, 185̃, p. 356.-_ "From the Wabash River, Indiana. This seems to be a smaller species than the preceding ones. The form of the body resembles that of $C$. Taurus, but the eyes are smaller; the opercle is more broadly rounded behind; the subopercle has its posterior and free border regularly arched above and below, and not emarginate as in C. Taurus. The direction of the numerous water-tubes on the head and cheeks also differ. The upper and lower border of the scales are nearly straight. The dorsal does not extencl quite so far forward. I am indebted to Col. Richard Owen of New Harmony for this species."

Ichthyobus cyanellus Nelson, Bull. Ills. Mus. Nat. Hist. i, 1877, p. 49."Blue Buffalo. A number of specimens of this species are in the state collection, from the Illinois river, and in Prof. Jordan's collection, from the Mississippi at St. Louis. The following is the description, taken from several specimens, measuring from 8 to $9 \frac{1}{4}$ inches in length :-

"Head about $3 \frac{1}{3}$ in length. Depth $2 \frac{1}{3}$ to $5-6$. Eye $4 \frac{1}{3}$ to $5 \frac{1}{2}$ in head. Dorsal I, 30. Anal I, 8. Ventrals 10. Lat. 1. 33. Longitudinal rows $7-5$ to $7-6$. Body compressed, high. Anteriorly broad, compressed behind. Longest ray reaching 18th ray. Pectorals shorter than reutrals, both shorter than head. Anal scarcely reaching caudal; head very short, high and thick; its thickness $\frac{3}{4}$ length, depth $1 \frac{1}{5}$ in leugth. Mouth quite small, oblique, and overlapped by a slightly projecting snont. Mandible short, 4 in head. Opercle becoming wrinkled with age. Head small, short and thick; muzzle obtuse, conic, not twice the length of eye. Anterior ray of dorsal, in type from Illinois river. slightly nearer snout than base of caudal. In specimens from St, Louis the dorsal is about equidistant. Color above, light steel blue in adults, becoming lighter below. Young lighter with distinct stripes along the rows of scales. Although the species is described from specimens but nine inches long, when full grown it undoubtedly reaches similar dimensions to its congeners."

Bubalichthys altus Nelson, MSS.; Proc. Acad. Nat. Sc. Phila. 1877, 74.- "This specimen is very deep and much compressed. The back is much arehed and the profile descenc's steeply in front to end of snout, not forming an angle with it as in many species of Ichthyobus.

" Depth of bod5, $2 \frac{1}{2}$ iu length; head, 4 in length; greatest thickness of body, $1 \frac{2}{5}$ in length of head; depth of head, $1 \frac{1}{5}$ in its length; width, $1 \frac{1}{2}$ in lengtb. Eye, $5 \frac{1}{2}$ in head, $2 \frac{1}{2}$ in interorbital space, which is but little rounded. 
"Lateral line perfectly straight from upper edge of opercle to caudal.

"Scales, 8-35-5. Dorsal I. 25 ; A. I. 9.

"Color in spirits, dull yellowish olive; fins dusky.

"Type specimen 12 inches long, in Ills. State Museum, from Cairo, Illinois."

\section{BUBALICHTHYS URUS Agassiz.}

Big-mouthed Buffalo. Black Buffalo. Mongrel Buffalo.

1818- ? Amblodon niger Rafinesque, Jonrnal de Physique Phila. 421. (Entirely un. recognizable.)

? Catostomus niger RAFinesque, Ichth. Oh. 56, 1820. (Unrecognizable; more likely Cycleptus elongatus.)

Bubalichthys niger Agassiz, Am. Jonrn. Sc. Arts, 2d series, xix, 195, 1855.

Bubalichthys niger Jordan, Fishes of Iud. 222, 1875.

Bubalichthys niger Jordan, Bnll. Buffalo Soc. Nat. Hist. 95, 1876.

Bubalichthys niger Jordan, Man. Vert. 298, 1876.

Bubalichthys niger Nelsox, Bull. No. 1, Ills. Mns. Nat. Hist. 50, 1876.

Bubalichthys niger JoRdaN \& CoPELAND, Check List, 158, 1876.

Bubalichthys niger Jordan, Proc. Ac. Nat. Sc. Phila. 75, 1877.

Bubalichthys niger JondAN \& GILBERT, in Klippart's Rept. 53, 1876.

Bubalichthys niger JoRdan, Bull. U. S. Nat. Mus. ix, 34, 1877.

Bubalichthys niger Jopdax, Man. Vert. ed. 2d, 323.

1854-Carpiodes urus AGassiz, Am. Journ. Ss. Arts, 355.

Bubalichthys urus AGAssiz, Am. Journ. Sc. Arts, 2d ser:es, xix, 193, 1855.

Bubalichthys urus Petnam, Bull. Mus. Comp. Zool. 10, 1863.

Bubalichthys urus Jordax, Fishes of Ind. 222, $18 \%$ \%.

Bubalichthys urus JoRdax \& COPELANd, Check List, 158, 1876.

1855-Bubalichthys bonasus A Gassiz, Am. Journ. Sc. Arts, $2 d$ series, xix, 195.

Bubalichthys bonasus Jordar \& COPELAND, Check List, 158, 1876.

Habitat.-Mississippi Valley, in the larger streams.

This is an abandant species in the Mississippi and its larger tributaries. It is very distinct from the preceding, almost intermediate between Bubalichthys bubalus and Ichthyobus bubalus. It may indeed be nccessary to unite these two genera on account of this species.

The question of the name which should be borne by this species is a very difficult one. Inasmuch as Rafiuesque's $C$. niger was known to him only through the accounts of Mr. Audubon, a gentleman known to have played sereral practical jokes ou the too credulous naturalist, and to have led him thereby to describe and name sereral impossible animals, and inasmuch as no real description whaterer is given by Rafinesque, it seems to me that the name niger can be used only on the authority of Agassiz, and not on that of Rafinesque. That being the case, the name

Bull. N. M. No. $12-14$ 
urus of Agassiz, which unquestionably belongs to this species, has a year's priority orer niger, and is really the first tenable name applied to any species of Bubalichthys. The original account giren by Rafinesque of his Catostomus niger and that by Professor Agassiz of his Bubalichthys urus I here append. Agassiz's descriptions of $B$. niger and B. bonasus have been previously given under the head of the genus.

Catostomus (Ictiobus) niger Raf. Ich. Oh. 1). 56.-" Entirely black; lat. eral line straight; I have not seen this fish. Mr. Audubon describes it as a peculiar species found in the Mississippi and the lower part of the Ohio, being entirely similar to the common Buffalo.fish, but larger, weighing npwards of fifty pounds, and living in separate schools."

Carpiodes urus Agassiz, Am. Journ. Sci. Arts, 1854, p. 355.- " From the Tennessee River. It grows very large, weighing occasionally from 30 to 40 pounds. The body in this species is not so high as in $C$. cyprinus, nor is it so compressed above; the scales are also not so high, but more angular behind, and the anterior portion of the dorsal is not so elongated. The gill-cover is larger, and the distance from the hind border of the eye to the inferior angle of the subopercle near the base of the pectorals and the distance from the same point to the superior and posterior angle of the opercle, are nearly equal. In C. cyprinus the distances differ by nearly one third. The subopercle is not triangular, but its hind border is nearly regularly arched from the upper angle to the posterior angle of the interopercle. The anal has its posterior margin full and not lunate; the caudal is not so deeply furcate as in C. cyprinus. The ventrals do not reach the anal. All fins are of a dark color. I am indebted to Dr. Newman for this species."

I found no specimens of Bubalichthys urus in the collections of the United States National Museum.

\section{BUBALICHTHYS MERIDIONALIS (Günther) Jordan.}

\section{Central American Buffalo.}

1868-Sclerognathus meridionalis GÜNTHER, Trans. Zool. Soc. p. Sclerognathus meridionalis GÜNTHER, Cat. Fishes Brit. Mus. vii, 23, 1868.

Habitat.-Rio Usumacinta, Guatemala.

I know nothing of this species except from Günther's description. From its remote locality, it is probably distinct, but the description shows no especial difference from $B$. bubalus, unless it be that the body is slenderer. The following is Dr. Günther's account:-

"D. 29-30. A. 10; lat. 1. 38, l. transv. $7 \frac{1}{2}-7 \frac{1}{2}$. Mouth small, inferior, 
slightly corrugated. The height of the body is contained thrice and one third or thrice and one fourth in the total length (withont caudal), the length of the head four times or four times and a half; head not much longer than high. Eye rather small, one fifth of the length of the head and two thirds of that of the snout; suborbitals narrow. The anterior dorsal rays are not much produced, being shorter than the head. Caudal fin forked. The origin of the rentral fin is vertically below the fourth dorsal ray. Pectoral fin not extending to the ventral. Tbere are five longitudinal series of scales between the lateral line and the root of the rentral. Coloration uniform. Pharyngeal teeth very numerous and small, increasing somewhat in size downwards.

"Rio Usumacinta (Guatemala)."

\section{Genus ICHTHYOBUS Rafinesque.}

Amblodon Rafinesque, Journal de Physique, de Chymie et d'Histoire Naturelle, Paris, 421, 1819. (Part.)

Ictiobus RAFINESQUE, Ich. Ob. 1820, p. 55. (As subgenus of Catostomu8.)

Ichthyobus AGassiz, Am. Journ. Sci. Arts, 1855, p. 195.

Tspe, Amblodon bubalus Rafinesque.

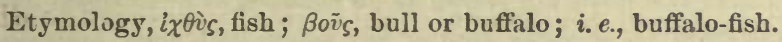

Head rery large and strong, wide and deep, its length $3 \frac{1}{2}$ to $3 \frac{3}{4}$ in that of the body, its upper surface broad and depressed; eye moderate, wholly anterior in position, the middle of the head being entirely behind it ; suborbital bones proportionately narrow; fontanelle large, well open; opercular apparatus largely developed, the subopercuium broad, the operculum broad, strongly furrowed.

Mouth very large for a Sucker, terminal, protractile forwards, the middle of the premaxillaries rather above the line of the middle of the eye, the posterior edge of the maxillary extending about to the line of the nostrils; mandible rery strong, oblique, placed at an angle of 45 degrees or more when the month is closed, its posterior end extending to beyond opposite the front of the eye, its length a little less than onethird that of the head. Lips very little developed, the upper narrow and smooth, scarcely appreciable, the lower narrow, rather full on the sides, but reduced to a narrow rim in front, entirely destitute both of papillæ and plicæ; jaws without cartilaginous sheath; muciferous system of head well dereloped; isthmus narrow; pharyngeal bones in form intermediate between those of Curpiodes and those of Bubalichthys, the outer surface of the arch standing outwards, and presenting a porous 
outer margin. The peduncle of the symphysis is much longer proportionally, and more pointed than in Carpiodes and Bubalichthys. The teeth are very numerous, small, thin and compressed in Carpiodes, but the lower ones are gradually larger than the upper ones. Their inner edge is slanting outwards, and not uniformly arched as in Bubalichthys, or truncate as in Cycleptus, the innermost margin rising somewhat in the shape of a projecting cusp. Gill-rakers of anterior arch long and slender above, becoming shorter downwards.

Body heary, robust, not especially arched above nor greatly compressed, the form somewhat elliptical, the depth $2 \frac{1}{2}$ to $3 \frac{1}{2}$ in the length of the body.

Scales large, thick, nearly equal over the body, their posterior edges somewhat serrate, the lateral line well developed, but not as distinct as in Carpiodes, slightly decurved anteriorly, the number of scales in its course 36 to $42 ; 13$ to 15 in a transverse series from dorsal to ventrals.

Dorsal fin with an elongate basis, its number of rays 25 to 30 , the anterior rass somewhat elevated, their length about half that of the base of the fin; caudal not much forked; anal fin not much elevated, its rays about 9 in number; pectorals and ventrals moderate, the latter with about 10 rays.

Sexual peculiarities, if any, unknown. Coloration dark, not silvery, above dusky olive; lower fins more or less black.

Air-bladder with two chambers.

Size very large.

The claim of this group to generic rank has been questioned by Professor Cope and others. The differences in the pharyngeal teeth are perhaps bardly sufficient to distinguish it from Carpiodes, but at present I am inclined to think that the great development of the mandible, which forms a large and terminal mouth, amply sufficient for generic distiuction. The relations of the group to Bubalichthys are doubtless, in reality, closer. Ichthyobus bears much the same relation to Buba. lichthys that Chasmistes does to Catostomus, and, so far as the mouth is concerned, but in a greater degree, that Erimyzon bears to Minytrema and Placopharynx to Myxostoma. The head of Ichthyobus is much larger and stouter, and the whole body more robust and less compressed than in Carpiodes. I know from autopsy but a single species of Ichthyobus. It has, however, been described under several different names. So far as is known, the genus is confined to the ralley of the Mississippi, no species having been recorded from the Great Lakes, or from any streams 
east of the Alleghanies. No members of the suborders Cycleptince and Bubalichthyince are known from the United States west of the basin of the Rio Grande.

The typical species was first described under the name of Amblodon. The genus Amblodon of Rafinesque, 1819, is based on the same species as his Ictiobus of 1820 . The name Amblodon, however, was given in allusion to the pharyngeal teeth of Huploidonotus grunniens, popularly supposed to be the teeth of the Buffalo-fish, the presence of which teeth was supposed to distinguish Amblodon from Catostomus. This error was afterwards discorered by Rafinesque, and the name Amblodon transferred to the Sciænoid fisb. As Amblodon of Rafinesque included the present genera Haploidonotus and Ichthyobus, erroneously confounded, and as on the discovery of this error its author restricted the name to Haploidonotus, I tbink that we are justified in retaining Ichthyobus instead of Amblodon for the genus of Catostomoids.

\section{Generic Characterizations.}

Amblodon Rafinesque, 181\%.-_"16. Amblodon. (Abdominal.) Différent du genre Catostomus. Machoire inférieure pavée de dents osseuses serrées arrondies, à couronne plate, inégales.-Les poissons de ce genre, qui abondent dans l'Ohio, le Missouri et le Mississippi, sont distinguées par le nom vulgaire de Buffaloe-Fish (Poisson bouffle) et les François de la Lonisiane les nomment Piconeau. Il ẏ en a plusieurs espèces qui parviennent souvent à nne très grosse taille. Les deux suivants habitent dans l'Ohio. 1. A. bubalus. Brun olivâtre pâle dessous, jones blanchâtres. D. 28, A. 12, P. 16, A. 9, C. 24. L'A. niger est entièrement noir; tous deux ont la ligne latérale droite, queue bilobée, tête tronquée, etc. Ils sont très-bons à manger."-(RAFinesque, Journal de Physique, etc. p. 421.)

ICтіовus Rafinesque, 1820._- "Body nearly cylindrical. Dorsal fin elongated, abdominal fins with nine rays, tail bilobed, commonly equal."-(RAFINesque, Ichthyologia Ohiensis, p. 55.)

Iснтн YoBus Agassiz, 1855. - "In the form and position of the fins, as well as in the general outline of the body, this genus is very nearly related to Bubalichthys, but in the structure of the parts of the head, it is quite dissimilar. The month opens directly forwards, and is large and round. The lips are small, smooth and thin; the upper one is not thicker than the intermaxillary itself, and tapers to a narrow edge. At the symphysis of the lower jaw, which is larger than in any other genus of this group, the lower lip is hardly more than a thin membrane connecting its small lateral lobes.

"The ejo is small, and the opercul ir pieces very large.

"The scales have many narrow radiating furrows upon the anterior field; none across the lateral fields, few upon the margin of the posterior field and these not extending to the centre of radiation. Tubes of the lateral line straight and simple, arising nearly in the middle of the posterior field.

"Pharyngeal bones are neither flat as in Carpiodes nor triangular as in Bubalichthys, 
but present an intermediate form; the outer surface of the arch standing outwards and presenting a porous outer margin. The peduncle of the symphysis is much longer proportionally and more pointed than in Carpiodes and Bubalichthys. The teeth are very numerous, small, thin and compressed as in Carpiodes, but the lower ones are gradnally larger than the upper ones. Their inner edge is slauting outwards, and not uniformly arched as in Bubalichthys or truncate as in Cycleptus, the innerncst margin rising somewhat in the shape of a projecting cusp."-(AGAssiz, Anı.Journ. Sc. Arts, 1855, p. 196.)

Iснтнуовиs Cope \& Jordan, 1877. - "Body oblong oval, compressed ; dorsal elevated in front, of 20 or more rays ; fontanelle present; pharyngeal bones narrow, with the teeth relatively thin and weak; mouth large, subterminal, protractile forwards." (Jordan, Proc. Ac. Nat. Sc. Phila. 1877, p.82.)

\section{ANALYSIS OF SPECIES OF ICHTHYOBUS.}

* Body robust, moderately compressed, the outline somewhat elliptical, but the back rather more curved than the belly; depth $2 \frac{1}{2}$ to $3 \frac{1}{2}$ in length : head very large and thick, $3 \frac{1}{2}$ in length of body : opercular apparatus very strong, the operculum itself forming nearly half the length of the head : scales very large: developed rays of the dorsal 27 to 29 ; anal rays 9 ; ventrals 10 : scales 7-37 to 41-6: coloration dull brownish-olive, not silvery ; fins dusky : size very large, reaches a length of nearly three feet and a weight of 20 to 30 pounds..................... BuBALUs, 53 .

\section{ICHTHYOBUS BUBALUS (Rafinesque) Agassiz.}

\section{Red-mouth Buffalo Fish. Large-mouthed Buffalo.}

1818-Amblodon bubalus Rafinesque, Journal de Physique, 421.

Catos:omus bubalus RAFinesque, Am. Month. Mag. and Crit. Rev. 354, 1818.

Catostomus bubalus RaFinesque, Ich. OL. 55, 1820.

Icthyobus bubalus AGassiz, Am. Journ. Sc. Arts, 2d series, xix, 196, 1855.

Icthyobus bubalus JorDAN, Fishes of Iud. 222, 1875.

Ichthyobus bubalus Jordan, Bull. Buffalo Soc. Nat. Hist. 95, 1876.

Icthyobus bubalus Jordax, Man. Vert. 298, 1876.

Icthyobus bubalus Necsov, Bull. No. 1, Ills. Mus. Nat. Hist. 49, 1876.

Icthyobus bubalus JordAN \& Copeland, Check List, 158, 1876.

Icthyobus bubalus JORDAN \& GiLBERT, iu Klippart's Rept. 53, 18 if.

Icthy:bus bubalus Jondan, Proc. Ac. Nat. Sc. Phila. $72,1877$.

Icthyobus bubalus JORDAN, Bull. U. S. Nat. Mus. ix, 34, 1877.

Ichthyobus bubalus Jordan, Man. Vert. ed. 2d, 322.

1844-Sclerognathus cyprinella Cuvier \& Valenciennes, Hist. Nat. des Poissons, xvii, $4 i 7, \mathrm{pl} .518$.

Sclerognathus cyprinella STORER, Synopsis, 428, 1846.

Ichthyobus cyprinella AGAssiz, Am. Journ. Sci. Arts, 196, 1855.

Sclerognathus cyprinella Güntukr, Cat. Fishes, Brit. Mus. vii, 24, 1868.

Ichthyobus cyprinella Jordan, Man. Vert.298, 1876.

Ichthyobus cyprinella JoRDan \& Copeland, Check List, 158, 1876.

1855-Icthyobus rauchii AGAssiz, Am. Journ. Sc. Arts, 2 d sories, xix, 196. 
Icthyobus rauchii PutnaM, Bull. Mus. Comp. Zool. 10, 1863.

Icthyobus rauchii JurdaN \& Copelaxd, Check List, 158, 1876.

Icthyobus rauchii JoRDAN \& GilberT, in Klippart's Rept. 53, 1876.

Ichthyobus rauchii JoRdan, Man. Vert. ed. 2d, 323, 187 .

1855-Icthyobus stolleyi AGAssiz, Am. Journ. Sc. Arts, $2 d$ series, xix, 196.

Icthyobus stolleyi Jordax \& Copeland, Check List, 158, 1876.

1877-Icthyobue ischyrus Nelson, MSS.-Jordan, Proc. Ac. Nat. Sc. Phila. 72.

Icthyobus ischyrus JoRDAN \& Copeland, Check List, 158, 1876.

Icthyobus ischyrus JORDAN \& GILBERT, in Klippart's Rept. 53, 18 ;6.

Ichthyobus ischyrus Jordd, Man. Vert. ed. 2d, 323, $18 \pi 8$.

Habitat.-Mississippi Valley; generally abandant in the larger streams.

An examination of a large series of wide-moutbed Buffalo-fishes from the Ohio, Wabash, Illinois, and Mississippi Rivers has convinced me, contrary to my previous impressions, that all belong to a single species. It is not absolutely certain what Rafinesque's Catostomus bubalus was. It is perhaps as likely to have been a species of Buba. lichthys, as supposed by Dr. Kirtland, as an Ichthyobus. I howeve: follow Professor Agassiz in identifying it with the present species, which is, at the Falls of the Ohio, where Rafinesque's collections were made, probably the most abundant of the Buffalo-fishes. Neither Rafinesque nor Professor Agassiz has, however, recognizably described the species. In my Manual of Vertebrates, in 1876, I gave a short account of Ichthyobus bubalus, drawn from two large specimeus taken in Wabash River at Lafayette. Besides these, I have numerous smaller specimens, obtained in the Mississippi at Saint Louis. As these differed in the greater compression of the body and higher fius, I have identifiel them as belonging to Ichthyobus rauchii Agassiz, an identification which I still think correct. In 1877, Mr. Nelson described an Ichthyobus ischyrus, from Mackinaw Creek, a tributary of the Illinois River, near Peoria. His typical specimen was very stout and deep, and at the time I thought with him that it was probably distinct from I. bubalus. Lately I have been enabled to re-examine the type of $I$. ischyrus in the State Museum of Illinois, and to compare it with a numerous series from the same locality. I found it possible to establish an unbroken series among them, connecting the nominal species which 1 had termed bubalus, rauchi, and ischyrus, the differences separating them being, in my opiuion, due either to differences of age or to individual peculiarities. As no description of any importance has been published of $I$. stolleyi, I include it as a synonym of $\boldsymbol{i}$. bubalus. I know nothing whatever concerning it. Ichthyobus cyanellus Nelson, as below stated, is a species of 
Bubalichthys. The description of Selerognathus cyprinella Valenciennes refers principally to the generic features of these fishes. It agrees fully with $I$. bubalus, except in the number of scales above the lateral line, a difference doubtless due to a difference in the place or the manner of making the count. As no specific characters are known, and as the Ich. thyobis bubalus doubtless abounds in the Lower as in the Upper Missis. sippi, I refer I. cyprinella to the synonymy of $I$. bubalus, the original type having probably been a young specimen of that species. This species is perhaps the largest of the Catostomidce, reaching a weight of 20 to 30 pounds and a length of more than two feet. The young (" ischyrus") are sold in the Illinois markets under the name of Red-mouth Buffialo, the adult being called simply Buffalo. A species which I suppose to be the present one I have seen taken in immense numbers, by means of seines, in the Mississippi River at Burlington, Iowa. The flesh is good, although not first-rate. It is rather coarse, and is full of small bones.

For purposes of comparison I here add the original descriptions of $S$. cyprinella, I. rauchii, I. stolleyi, and $I$. ischyrus :-

Sclerognathus cy prisella Valenciennes.-" Rien ce me semble, ne justifio micux la séparation des se lérognat hes du genre des Catostomes que l'espèce dont je vais ilouner ici la description. Avec ure bouche, formée comme celle du Sclerognathus cyprinus, nous voyons l'ouverture portée au bout du museau, la lèvre inférieure plus longue que la supérieure, et par consequent il n's a plus de possibilité d'employer la bouche pour sucer.

"Ce poisson a le corps assez semblable au précédent [Sclerognathus cyprinus]; si hauteur est trois fois et un tieıs daus sa longueur totale; la longueur do la tête y est comprise quatre fois et demie; l'œil est petit, ot sur le haut de la joue, le diamètre est contenn cinq fois et un tiers dans la tête, et deux dianetres et demi, donuant la mesure de l'iutervalle entre les deux yeux; le dessus du crâne, couvert comme à l'ordinaite, d'une peau une est moins convexe ; les deux lignes de pores sont tracées à leur place ordinaire, et sont sinueuses, cornme celles de l'espèce précédente ; l'opercule est strié et bombé et est plus grand, ce qui rend le sous-opercule plus petit que dans l'autre sclérognathe. L'on sent les intermaxillaires à l'extrémité supérieure du museau, soutenant an lèvre très mince. L'inférieure est woins épaisse, et le nombre des papilles est unoins faible. La dorsale a la même forme que celle de l'autre espèce; mais l'anale est plus pointue; la caudale est échancrée et large.

"D. 33. $\Lambda .12$, etc.

"Les écailles sont beaucoup plus petites; j'en compte quarante et une le long des eótés; dix uu dessus, et sept au dessous de la ligne latérale, qui est étroite et mince.

"La couleur est un doré verdâtre, avec les nageoires plus foncées.

"Notro individu est long de sept pouces; il vient du Lac Pontchartrain."-(VALENCiennes, Hist. Nat. des Poiss. xvii, pp. 4i7-479.)

IChthyobus raUChil Agassiz.- "Doreal much higher than in L. bubalus, all other fins much larger, and the scales much higher than long ; from Burliugton, Iowa." 
ICHTHYOBUS stolleyr Agassiz.- "Body higher than in Ichthyobus rauchii, profile steeper, and hence snout blunter, opercular bones larger; fins proportionally of the same size. From Osage River, Missouri."

ICHTHYOBUs IschYRUs Nelson.- "This is a very stout and heavily built species: depth $2 \frac{1}{2}$ in length; head extremely broad between the eyes and but slightly convex; its length $3 \frac{1}{2}$ times in length of body; snout short and rounded, opercular apparatus large; depth of head $1 \frac{1}{5}$ in its length; width of head $1 \frac{1}{2}$; eye $6 \frac{2}{8}$ in head, $1 \frac{2}{8}$ in snout, 4 in interorbital space ; caudal pednncle a little deeper than long; scales 7-37-7, nearly uniform, a littlo crowded anteriorly, finely punctate ; fins all small; dorsal I, 27 ; anal I, 8, bluish olive above; yellowish below ; fins blackish."

Specimens in United States National Museum.

\begin{tabular}{c|c|c}
\hline Number. & Locality. & Collector. \\
\cline { 1 - 3 } 20774 & Illinois River at Peoria (very large; ty pical of bubalus) ..... & S. A. Forbes. \\
\hline
\end{tabular}

\section{Genus MYXOCYPRINUS Gill.}

Myxocyprinus GiLl, Johnson's Cyclopædia, p. 1574, 1878.

Carpiodes et Sclerognathus sp. BLEekER, GÜNTHER.

Type, Carpiodes asiaticus Bleeker.

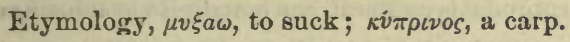

This genus is known to me only from Dr. Bleeker's description of its typical species. Whether it differs from its relatives, Ichthyobus, Bubalichthys, etc., in any other character than the obrious one of the great increase in the number of its dorsal rays and the smaller scales, I do not know. In any eveut, however. its right to independent generic rank is unquestionable.

\section{Generio Characterizations.}

MYXOCYPRINUs Gill, 1878.- "Myxocyprinus is a name proposed for the Carpiodes asiaticus of Bleeker, which is distinguished by the multiradiate dorsal and anal fins (e.g. D. 52 ; A. 13)."-(GiLL, Johnson's Cyclopadia, Appendix, p. 1574.)

\section{MYXOCYPRINUS ASIATICUS (Bleeker) Jordan.}

1864-Carpiodes asiaticus Blekker, Nederl. Tydschr. Dierk. ii, 19.

Sclerognathus asiaticus GǗNTHkR, Cat. Fishes Brit. Mus. vii, 23, 1868.

HaвrTaT.-China.

My only knowledge of this species is from Dr. Bleeker's original description, which I here subjoin :-

"Carpiodes asiaticus Blkr.-Carpiod. corpore oblongo compresso, altitudine 21 fere in ejus longitudine absque, $3 \frac{1}{b}$ circiter in longitudine corporis cum pinna caudali, 


\section{CONTRIBUTIONS TO NORTH AMERICAN ICHTHYOLOGY-III.}

dorse valde elevato maxime compresso ; latitudine corporis $2 \frac{1}{2}$ circiter in ejus altitudine ; capite obtuso 5 fere in longitudine corporis absque 6 circiter in longitudine corporis cum pinna cauduli; oculis in media capitis longitudiue sitis, diametro 5 circiter in longi udine capitis, diametris $2 \frac{2}{8}$ circiter distantibus ; linea rostro-dorsali vertice et fronte declivi rectiuscula, rostro valde convexa; naribus orbitæ approximatis, posterioribus valvula claudendis; rostro obtuso truncatiusculo valde carnoso aute rictum prominente ; labiis valde carnosis papillatis, inferiore lobis parum product is ; osse suborbitali anteriore sat longe ante orbitam sito, scaphæformi, duplo circiter longiore quam alto apice acuto antrorsum spectante; osse suborbitali $\%$ oblique tetragono æque alto circiter ac longo; ossibus suborbitalibus ceteris gracilibus oculi diametro quadruplo circiter humilioribus; operculo duplo circiter altiore quam lato marginibus posteriore et inferiore convexo ; osse scapulari valde brevi et obtuso; ossibus pharyngealibus compressis sat validis altioribus quam latis, dentibus 30 ad 50 compressis corona vulgo unituberculatis; squamis dimidio libero et dimidio basali subradiatim striatis, 50 in liuea laterali, 24 in serie transversali absque ventralibus iufimis quarum 12 lineam lateralum inter et initium pinnæ dorsalis; sqnamæ linea laterali postice medio enarginatis; linea lateralis singulis squamis tubulo simplice marginem squamarum liberum attingente notata ; pinnis dorsali et anali basis vagina squamosa inclusa, dersali basi non multo plus que 2 in longitudine totius corporis, longe ante pinnas ventrales incipiente, antico valdo elevata corpore vix bumiliore, acuta, valde emargınata, medio et postice co: pore quadruplo circiter humiliore radio postico radio anali postico subopposito; pinnis pectoralibus rotundales capite longioribus, ventrales non attingentibns; ventralibus acute rotundatis pectoralibus non multo brevioribus, analem non attingeutibus; anali corpore minus duplo humiliore, duplo altiore quam basi longa, acntiuscule rotundata nou emarginata ; caudali profunde emarginata lobis acutis $4 \frac{2}{8}$ cerciter in longitudiné corporis; colore corpore fuscescente-olivaceo, pinnis fusco vel fusco-violaceo.

"B. 3. D. 4-49. P. 1-17. V. 2-11. A. 3-11 vel 4-10. C. 1-16-1 et lat. brev.

"Hab. China.

"Longitudo speciminis descripti $508^{\prime \prime}$.

"Rem. La présence de Catostomini dans les eaux de l'Asie orientale est un fait assez cürieux. Tilesius déjà en avait fait connaitre un représentant, vivant dans le CQvyma, dans le Léna, l'Indigirca et le Dogdo, espèce qu'il nomma Cyprinus rostratus, que M. Valenciennes rebaptisa Catostomus Tilesii et qui parait êtro un Acomus. Mais cette espèce était jusqu'ici la seule du groupe qu'on savait habiter l'Asie. L'espèce actuelle prouve l'existence dans les fleuves de l'Asie orientale d'une seconde espèce du groupe et elle appartient manifestement au genre dont la Carpiodes cyprinus est le type. Mais elle est remarquable parmi tous les poissons de la division des Ichthyobi (Carpiodes Raf., Cjcleptus Raf., Ichthyobus Raf., et Bubalichthys $\Lambda$ g.) par son dos très6́levé et anguleux et par sa très-longue dorsale à plus de 5 n rayons. C'est un espèce éninemment distiucte qu'on ne pourrait confondre avec aucune des espèces américaiues."-(BLekKer, Notices sur Quelques Genres et Espèces des Cyprinoïdes de Chine, $<$ Nederlandisch Tijdschrift voor de Dierkunde, 1864, ii, pp. 19-21.) 


\section{A D D E N D A.}

\section{CHASMISTES LIORUS Jordan, sp. nov.}

Big-mouthed Sucker of Utah Lake.

1878-Chasmistes fecundus Jundax, Bull. Hayden's Geol. Surv. Terr. iv, No. 2, 417. (Not Catostomus fecundus Cope \& Yarrow.)

Chasmistes fecundus Jondax, p. 150 of the present work.

Since pages $149-151$ of the present work were in press, I have carefully recompared Cope and Yarrow's description and figure of their Cato. stomus fecundus, and my notes on their typical specimens, with the specimens on which the genus Chasmistes was based, and I have come to the conclusion, hinted at in the text, that the Chasmistes is a species distinct from $C$. fecundus, and thus far undescribed. The specific name liorus

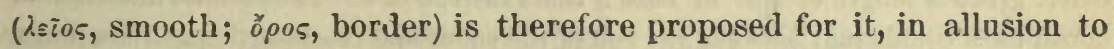
the smooth lips.

\section{8 (b). CATOSTOMUS FECUNDUS Cope \& Yarrow.}

\section{Sucker of Ctah Lake.}

1876-Catostomus fecundus Cope \& YARkow, Zool. Lieut. Wheeler's Exp'. W. 100th Mer. 678 , plate xxxii, figs. $1,1 \mathrm{a}$.

Catostomus fecundus Joridan \& Copeland, Check List, 156, 1-76. (Name only. Not Calostomus fecundus Jordan, Bull. U. S. Nat. Mus. xi; nor Chasmistes fecundus Jordan, Bull. Hayden's Geol. Surv. Terr. iv, No. 2,417.)

HaBitat.-Utab Lake.

As stated above, I at first identified Chasmistes liorus from Utah Lake with this species from the same waters, the two being very similar as to scales and fins, and the form of the month and snout in the figure of $C$. fecundus suggesting, though not resembling, the form of those parts in Chasmistes. The finding of one of the typical specimens of Catostomus fecundus in the National Museum has shown me that it is a true Catostomus, and not a Chasmistes. I did not ascertain the lip characters of the species while at the Museum, the mouth-parts being in poor condition, and I therefore am not now able to place it in the ana- 
lytical key to the species of the genus. If the upper lip is narrow, with few rows of tubercles, it will not be easy to separate fecundus from teres. If the lip is broad, with many series of tubercles, it will be approximated to $C$. occidentalis, differing, however, in the larger scales (about 60 in the literal line, instead of 72). I therefore quote the original descrip. tion, and leave the relations of the species to be finally settled at some future time:-

"It is a true Catostomus having the parietal fontanelle well marked and widely open. The head enters in entire length 5 times, the diameter of the orbit 6 times in greatest length of side of head. The insertion of the dorsal fin anteriorly is nearer to the end of the muzzle than insertion of caudal ; the ventrals originating below middle of dorsal. The width of the dorsal to ventral enters the $\mathrm{entire}$ length to insertion of caudal 6 times.

"Radii : D. 12-13. A. 1-8. P. 7. V.11. Scales are in 20 longitudinal rows from the insertion of the first dorsal to pectoral, and in 60 transverse rows from branchiæ to insertion of caudal : they are elongate and octagonal, smaller on dorsal region, and larger on ventral. Body elongated, subfusiform. It differs from C. (Acomus) generosus, Gir., in many particulars, as may be seen from the following comparisons.

"Girard's species has no fontanelle; is shorter and narrower; the diameter of orbit enters greatest length of side of head 5 timcs instead of 6 . The anterior insertion of dorsal fin is equidistant between the end of the snout and the insertion of the caucual, while in C. fecundus, it is nearer the end of the snout than insertion of caudal. The ventrals in C.generosus originate under the posteitor third of the dorsal; in C.fecundus under the niddle third of the dorsal. The radii in C. generosus are: D. 10, A 2, 7, P. 16, V.10, C. 27 ; in C.fecundus: D. 12-13, A. 1, 8, P. 17, V. 11.

"This species is abundant in Utah Lake, and is called 'Sucker' by the settlers. They run well up the rivers to spawn in June; feed on the bottom and eat spawn of better fish ; spawning beds on gravel ; bite at hook sometimes; are extremely numerons, and are considered a nuisance by the fishermen, but they meet with a ready sale in winter, at an average price of $2 \frac{1}{2}$ cents a pound."-(COPE \& YARRow, l. c.)

Specimens in United States National Museum.

\begin{tabular}{|c|c|c|}
\hline Number. & Localits. & Collector. \\
\hline $\begin{array}{c}12894 \\
-\end{array}$ & $\begin{array}{l}\text { Urah Lake. ............. } \\
\text {.... . do .................. }\end{array}$ & $\begin{array}{c}\text { Yarrow \& Henshaw. } \\
\text { Do. }\end{array}$ \\
\hline
\end{tabular}




\section{BIBLIOGRA PHY.}

The following list comprises all the works known to the writer in which new species or genera of Catostomido are indicated, or in which original descriptions are given of genera or species previously known. In general, I hare endeavored to inciude all papers in which anything of importance was added to or subtracted from the sum of our knowledge of these fishes :-

FORSTER (John Reinhold). [Description of Cyprinus catostomus Forster.] <Philosophical Transactions, vol. 63, London, 1773.

LACÉPÈDE (Bernard Germain Étienne de la Ville-sur-Illon, Comtede). Histoire Naturelle des Poissons par le Citoyen La Cépède, membre de l'Institnt national, et Professeur du Muséum de histoire naturelle. Tome premier à cinquième. À Paris, cbez Plassan, imprimeur libraire, Rue du Cimetière André-des-Arcs, No. 10. L'an VI de la République, - 1798 [-L'an XI de la République, i. e. 1飞03].

[Descriptions of Le Cyprin catostome, Cyprinus catostomus Forster, Le Cyprin commersonien, and Le Cyprin sncet, Oyprinus sucetta Lacépède.]

BLOCH (Mark Elieser) and SCHNEIDER (Johann Gottlob). M. E. Blochii Doctoris Medicinæ Berolinensis, et societatibus literariis multis adscripti, Systema Ichthyolngiæ iconibus CX illustratum.-Post obitum auctoris opue inchoatum absolvit, correxit, interpolavit Jo. Gottlob Schneider, Saxo.-Berolini, sumtibus Auctoris impressum et bibliopolio Sanderiano commissum, 1801.

[Description of Cyprinus catostomus Forster.]

TILESIUS (-). "Piscium Camtschatcicorum descriptiones et icones. <Mem. Ac. Sc. St. Pétersb. I and III, 1810-1811."

[Description and figure of Cyprinus rostratus, ep. nov., from Eastern Siberia.]

PALLAS (Petro). Zoographia Rosso Asiatica sistens Omnium Animalium in exterso Imperio Rossico et adjacentibus maribus observatorum, recensionem, domicilia, mores et descriptiones, anatomen atque icones plnrimorem auctore Petro Pallas, Eq. Aur. Academico Petropolitano. Volnmen tertium. Petropoli, in officina Caes. Academiae Scientiarum Impress. MDCCCXI. Edit. MDCCCXXXI.

[Description of Cyprinus rostratus quoted from Tilesins.]

MITCHILI (Samuel Latham). The Fishes of New York Described and Arranged. $<$ Transactions of the Literary and Philosophical Society, New York, 1814.

[Cyprinus teres and Cyprinus oblongus, sp. nov.]

LE SUEUR (Charles A.) A new genus of Fishes, of the Order Abdominales, proposed, utder the name of Catostomus; and the characters of this genus, with those of its species, indicated. By C. A. Le Sueur. Read September 16,1817. < Journal of the Acsdemy of Natnral Sciences of Philadelphia, vol. i, 1817, pp. $88-96$ and 102-111.

[Describes Catostomus, gen. nor., and the following new species, most of which are figured:-C. cyprinus, C. gibbosus, C. tuberculatus, C. macrolepidotus, C. aurcolus, C. communis, C. longirostrum, C. nigricans, C. maculosus, C. elongatus, C. vittatus, C. duquesnii, C. bostoniensis, and C. hudsonius. C. teres (Mitch.), C. oblongus (Mitch.), and C. sucetta (Lac.) are also described. This paper is an excellent one, and compares favorably with most that bas zinco been written on this group.] 
RAFINESQUE (Constantine Samuel). Discoveries in Natural History made during a Journey through the Western Region of the United States by Constantine Samuel Ratinesque Esq. Addressed to Samuel L. Mitchill, President, and other members of 1 he Lyceum of Natural History in a letter dated at, Louisville, Falls of the Ohio, 20th July 1818. < American Monthly Magazine and Critical Reviow, Now York, September, 1818.

[Dëscription of Catostomus bubalus and Catostomus erythrurus, sp. nov., and notice of the discovery of tho "Carp" "Catostomus macropterus" and the "Sucker" Catostomus duquesnei.]

Description of three new genera of fluviatile Fish, Pomoxis, Sarchirus and Exoglossum. By.C. S. Rafinesque. Read December 1st \& 8th. < Journal of the Academy of Natural Sciences of Philadelphia, i, 1818, pp. 417-422.

[Description of Exoglossum (Hypentelium) macropterum; subgenus and species new.]

Prodrome de 70 nouveanx Genres d'Animaux découverts daus l'intérieur des États-Unis d'Amérique durant l'année 1818. < Journal de Chymie, de Physique et d'Histoire Naturelle, Paris, June, 1819.

[Description of Amblodon, gen. nov., based on the pharyngeals of Haploidonotus grunniens, erroneously ascribed to a Buffalo-fish, with the species $A$. bubalus and $A$. niger, sp. nov., and of Cycleptus nigrescens, gen. et sp. nov.]

LACÉPÈdE (Bernard Germain Étienne). Histoire Naturelle des Poissons, par M. le Comte Lacépède, snite et complément des EEuvres de Buffon. Tome cinquième, avec vingt-trois nouvelles planches en taille-douce. Paris, Rapet, Rue SaintAndré-des-Ares, No. 10, Editeur du Temple de la Gloire on les Fastes Militaires de la France, ouvrage in-folio, avec figures, 1819.

[A reprint of Lacépède's work.]

RAFINESQUE (Constantine Samuel). Ichthyologia Ohiensis or Natural History of the Fishes Inhabiting the River Ohio and its tributary streams. Preceded by a physical deseription of the Ohio and its branches by C. S. Rafinesque, Professor of Botany and Natural History in Transylvania University, Autbor of the Analysis of Nature \&c. \&c., member of the Literary and Philosophical Society of New York, the Historical Society of New York, the Lyceum of Natural History of New York, the Academy of Sciences of Philadelphia, the American Antiquarian Society, the Roval Institute of Natural Sciences of Naples, the Italian Society of Arts \& Sciences, the Medical Societies of Lexington and Cincinnati \&c., \&c. The art of seeing well, or of distinguishing with accuracy the objects which we perceive is a bigh faculty of the mind, nufolded in few individuals, and despised by those who ean neither acquire it, nor appreciate its results. Lexington, Kentucky, printed for the Autbor by W. G. Hunt, (price one dollar),-1820. (1 vol. 8 vo. 90 pp.)

[Originally printed in the Western Review and Miscellaneons Magazine, Lexington, Kentucky, 1819-20. It contains descriptions of the genera and species of Catostomi found in the Ohio River, they being referred to three geners, Catostomus, Cycleptus, and Hypentelium, the genus Catostomus being divided into five new subgenera, Moxostoma, Ictiobus, Carpiodes, Teretulus, Eurystomus, avd Decactylus.

The following is the arrangenent of the species described :Genus Catostomus.

Subgenus Moxostoma. anisurus, sp. nov. anisopterus, sp. nov.

Sabgenus Ictiobus. bubalus. ciger.

Subgenus Carpiodes. carpio, sp. nov. velifer, op. nov. xanthopus, sp. nov.

Subgenus Teretulus. melanops, sp. nov. melanotus, sp. nov. fasciolaris, sp. nov. erythrurus. flexuosus, sp. nov.

Subgenus Eurystomus. megastomus, 8p. nov.

Subgenus Decactylus.

Genus Cycleptus. duquesni.

Genus Hypentrlium nigrescens. macropterum.] 
RICHARDSON (John). [Franklin's Journal.] 1823.

[Descriptions of Catostomvs forsterianus, sp. nor., and Catostomus le sueurii, sp. nov., and notes on some other species.]

Fauna-Boreali-Americana; or the Zoollogy of the Northern Parts of British America, containing descriptions of the objects of Natural History collected on the late Northern Land Expeditions ander command of Captain John Franklin, R. N. Part thirl. The Fish. By John Richardson M. D. F. R. S. F. L. S. member of the Geographical Society of London, and the Wernerian Natural Histury Society of Ediuburgh ; Honorary Menber of the Natural History Society of Mcntreal, and Literary and Philosophical Society of Quebec, Foreign Member of the Geographical Society of Paris; and Corresponding Member of the Academy of Natural Sciences of Philadelphia ; Surgeon and Naturalist to the Expeditions.Illnstrated by numerous plates.-Published under the authority of the Right Honorable the Secretary of State for Colonial Affairs. London: Richard Bentley, New Burlington St. MDCCCXXXVI.

[Contains notices or descriptions of Catostomus hudsonius, C.forsterianus, C. aureolus, C. nigricans, and C. sueuri.]

KIRTLAND (Jared Potter). Report on the Zoology of Ohio, by Prof. J. P. Kirtland, M. D. < Second Annual Report ou the Geological Survey of the State of Ohio, by W. W. Mather, Principal Geologist, and the several assistants. Columbus: Samuel Merlary, Printer to the State. 1838.

[Catalogue of Fishes, pp. 168-1i0. Notes ou species mentioned, pp.190-197. Nino species referrel to Catostomus are inclnded, as follows:-velifer Raf., aurcolus Le S., elongatus Le S., Duquesnii Le S., erythrurus Raf., bubalus Raf, gracilis Kirt., melanopsis Raf., nigrans Le S., and Hypsntelium nacropterum Raf. ' $C$. gracilis Kirt. [sp. nov.] is briefly characterized as distingnished by the minuteness of the scales on the anterior part of the body, and as the ecales approach the cantal fin they increase to a medium cize" (l. c. p. 193).]

STORER (David Humphreys). A Report on the Fishes of Massachusetts. By D. Humphress Storer, M. D. < Bcston Journal of Natural Histors, vol. ii, 1839, pp. $289-558$.

[Descriptions of Catostomus gibbosus, C.tuberculatus, C. nigricans, and C. bostoniensis.]

KIRTLAND (Jared Potter). Description of the Fishes of the Obio Rirer and its Tributaries. By Jarerl P. Kintland, Professor of the Theory and Practice of Medicine in the Medical College of Ohio, at Cincinnati. < Bosion Journal of Natural History, vols. iii-v, 1e40-1844.

- [Describes and figures Catostomus aureolus, C. communis, C.bubalus, C. elongatus, C. duquesni, C. anisurus, C. melanops, C. nigricans, and Sclerognathus cyprinus.]

[Papers on the Fishes of Ohio-in Family Visitor and in Annals of Science. Cleveland, 1840-1846.]

[Descriptions of the species found in the vicinity of Cleveland, with figures, most of them from the same plates as in his "Fishes of the Ohio". Catostomus gracilis, sp. nov., also Catostomus gibbosus, not desc:ibed in the previous paper, here described and fignred.]

THOMPSON(Zadcck). Fishes of Vermont. = Chapter V, (pp. 12\%-151). <Natural History of Vermont, in History of Vermont, Natural, Civil, \& Statistical, by Rer. Zadock Thompson, Burlington, Vermont, 1842.

[Descriptions of Catostomus cyprinus, C. oblongus (=M. macrolepidotum), C. teres, C. nigricans (=C. terer), and $\boldsymbol{C}$. longirostrum.]

CUVIER (Georges Chrétien Léopold Dagobert) and VALENCIENNES (Achille). Histoire Naturelle des Poissons par M. le B. on Cavier, Pair de France, Grand Officier de la Légion d'houneur, Conseilleur de l'État et au Conseil royal 


\section{CUVIER (G. C. I. D.) and VALENCIENNES (A.)-Continued.}

de l'instruction publique, l'un des quarante de l'Académie française, Associé libre do l'Acarléuie des Belles-Lettres, Secrétaire perpetuelle de celle des Sciences, Membre des Sociétés et Académies royales de Londres, de Berlin, de Pétersbourg, de Stockholm, de Turin, de Gættinguo, des Pays-Bas, de Munich, de Modène, etc.; et par M. A. Valenciennes, Professeur de Zoologie an Muséum d'Histoire naturelle, Membre de l'Académie royale des Sciences de Berlin, de la Société Zoologique de Londres, etc. Tome dix-septième. 1842. (Cyprinoïdes.)

[Descriptions of Catostomus hudsonius, O. forsterianus, C. suceti, C. gibbosus, O. tuberculatus, C. macrolepidotus, C. aureolus, O. communis, C. longirostrum, O.nigricans, C. maculosus, C.elongatus, C. vittatus, O. duquesnii, O. bostoniensis, C. teres, C. oblon: us, C. fasciatus (sp. nov.), C. planiceps (sp. nov.), O. carpio (sp. nov.), O. tilesii (sp. nov.), Sclerognathus (gen. nov.) cyprinus, Sclerognathus eyprinelia (sp.nov.), and Exoglossum macropterum. This volume was written after the death of Cuvier by Valenciennes.]

DEKAY (James E.) Zoologg of New York, or the New York Fauna; comprising detailed descriptions of all the animals hitherto observed within the State of New York, with notices of those occasionally found near its borders, and accompanied by appropriate illustrations. By James E. Dekay. Part IV. Fishes. Albany : printed by W. \& A. White \& J. Visscher. 1842.

[Descriptions of Labeo elegans (sp.nov.), Labeo oblongus, Labeo cyyrinus, Labeo gỉbosus, Labeo esopus (sp. nov), Catostomus communis, Catostomus oneida (sp. nor.), Catostomus tuberculatus, Catostomus pallidus (sp. nov.), Catostomus aureolus, Catostomus niyricans. Catostomus macrolepidotus, with notices of other species. In the Appendix, the name Labco elongatus is su gested as a substitute for Labeo oblongus, to prevent confusion with Labeo oblongus C. \& V.]

FECKEL (Johann Jakob). Abbildungen und Beschreibungen der Fische Syriens nebst eicer neuen Classification and Characteristil sämmtlicher Gattungen der Cypricen von Johann Jakob Heckel, Inspector am K. K. Hof-Nat uralienkabinet in Wien, mehr. gelehrt. Gesellsch. Mitglied. Stuttgart, E. Schweizerbart'sche Verlagshandlung. 1843. pp. 109. (=pp. 991-1099, Russegger's Reisen.)

[Contains a classification of the Oyprinida according to their teets; our species cf Catostoridae being divided between Catostomus and Rhytidostom.us, gen. nov., corresponding to Catostomina and Cycleptince. No allusion is mado to the Bubalichthyinoe.]

STORER (David IIumphreys). A Synopsis of the Fishes of North America, by David Humpreys Storer, M. D., A. A. S., Vice president of the Boston Society of Natural History; Member of the American Philosopbical Society, Corresponding Member of the Academy of Natural Sciences of Philadelphia, etc. Cambridge: Metcalf \& Compans, Printers to the University. 1846. (Repriuted from Memoirs of the American Academy, ii, 1846.)

[Brief descriptions of 27 nominal species of Catostomus, two if Sc e-ogna hus, and ono referred erroneously to Exoglossum.]

AGASSIZ (Louis). Lake Superior: its Physical Character, Vegetation and Animas compared with those of other and similar regions, by Louis Agassiz, with a narrative of the tour by J. Elliott Cabot, and contributions by other scientifie gentlemen. Elegantly illustrated. Boston: Gould, Kendall and Lincoln, 59 Washington Street. 1850.

[Descriptions of several species, with notes and remarks; Catostomus aurora described as a new species, and the name 0 . forsterianus used in a now sense.]

BAIRD (Spencer Fullerton) and GIRARD (Charles). Description of new specits of Fishes collected by John H. Clark on the U. S. and Mexican Boundary Survey under Lt. Col. Jas. D. Graham. By Spencer F. Baird and Charles Girard. August :30, 1853. < Proceedings of the Academy of Natural Scieuces of Philadelphia, vol. 6, pp. 387-390. August, 1853.

[Oatostomus latipinnis, sp. nov.] 
STORER (David Humphreys). A History of the Fishes of Massachusetts. By David Humphreys Storer. - Memoirs of the American Academy of Arts and Seiences (Boston), new series, (1853 to $1 \div 6 \overline{\text { ) }}$.

[Descriptions and excellent figures of Catostoms bostoniensis and C. gibbosus.]

AGASSIZ (Louis). Notice of a collection of Fishes from the sonthern bend of the Tennessee River, in the State of Alabama; by L. Agassiz. <Americun Journal of Science and Arts, second series, xviii, 1854, pp. 297-308, 353-365.

[Rerives the Rafincsquian genera Carpiodes, Ictiobus, Cycleptus, and Moxostoma; describes 8p. nov. Carpiodes urus, Carpioles taurus, Carpiodes bison, Carpiodes vitulus, and Carpiodes vacca, and records Catostomus communis, C.nigricans, C.duquesnii, and O. melanops from Huntsville, Ala. The specific descriptions are comparative only, and are not readily identifiable.]

BAIRD (Spencer Fullerton) and GIRARD (Charles). Description of New Species of Fishes collected in Texas, New Mexico aud Sonora by Mr. John H. Clark on the United States and Mexican Boundary Survey asd in Texas by Capt. Stewart Van Vliet, U. S. A., by S. F. Baird and Charles Girard. <Proceedings of the Academy of Natural Sciences of Philadelphia, vol. vii, 1854, pp. 24-29.

[Descriptions of Catostomus congestus, C. clarki, O. insignis, and C. tumidus, sp. nov.]

AYRES (William O.) Descriptions of two new species of Cyprinoids. By Wm. O. Ayres, M. D. Dec. 11, 1854. < Proceedings of the California Academy of Sciences, vol. i, pp. 18-19, 1854; 2 d ed., pp. 17-18, 1873.

[Catostomus occidentalis, sp. nor.]

Description of a new species of Catostomns. By Wm. O. Ayres, M. D. Feb. 26, 1855. < Proceedings of thc California Academy of Sciences, vol. i, pp. 31-32, 1855; $2 d$ ed., pp. 30-32, 1873.

[Catostomus labiatus, sp. nov.]

AGASSIZ (Louis). Synopsis of the Ichthyological Fauna of the Pacific Slope of North America, chiefly from the collections made by the U. S. Expl. Exped., under the command of Capt. C. Wilkes, with recent Additions and Comparisons with Eastern types ; by L. Agassiz. < American Jourual of Science and Arts, $2 d$ series, vol. xix, 1855, pp. 186-231.

[Characterizes rery fully the genera, viz:-Carpiodes Raf.; Bubalichthys Ag., gen. nov.; Ichthyobus Raf.; Cycleptus Raf.; Moxostoma Raf.; Ptychostomus Ag., gen. nov.; Hylomyzon Ag., gen. nov.; and Catostomus Le Sueur. The species of each genus are noticed, and the fullowing new species are very briefly and in most cases unsatisfactorily described:-Carpiodes thompsoni, Bubalichthys bonasus, Ichthyobus rauchii, Ichthyobus stolleyi, Moxostoma tenue, and Catostomus occidentalis.]

GIRARD (Charles). Researches npon the Cyprinoid Fishes inhabiting the fresh waters of the United States of America, west of the Mississippi Valley, from specimens in the Museum of the Smithsonian Institution. By Charles Girard, M. D. $<$ Proceedings of the Academy of Natural Sciences of Philadelphia, 1856, pp. 165213.

[Twenty-8ix species enumerated-most of them briefly described. Two new genera are proposed, Minomus and Acomus, and the following new species are characterized:-Carpiodes damalis. Moxostoma claviformis, Moxostoma kennerlii, Moxostoma victoria, Moxostoma campbelli, Ptychastomus albidus, Ptychostomus haydeni, Acomus guzmaniensis, Acomus generosus, Acomus griseus, Acomus lactarius, Catostomus macrochilus, Catostomus sucklii, and Catostomus bernardini. These descriptions are mostly short and insuficient.]

Geueral Report upon the Zoology of the Several Pacific Railroad Routes. $=$ Reports of Explorations and Surveys to Ascertain the most practicable and Economical Route for a Railroad from the Mississippi River to the Pacific Ocean, made under the direction of the Secretary of War, in 1853-6, according to Acts of

Bull. ‥ M. No. 12-15 


\section{GIRARD (Charles)-Continued.}

Congress of March 3, 1853, May 31, 1854, and August 5, 1854. Volume X. Washington, A. O. P. Nicholson, Printer, 1859. (Part 4, Fishes, by Dr. Charles Girard.)

[Descriptions of Carpiodes damalis, Moxostoma claviformis, Ptychostomus haydeni, Acomus generosus, Acomus griseus, Acomus lactarius, Catostomus occidentalis, Catostomus labiatus, Catostomus macrocheilus, and Catostomus sucklii; all of the species except Acomus generosus, $O$. cccidentalis, C. labiatus, and $C$ macrocheilus being accompanied by figures.]

United States and Mexican Boundary Survey, under the order of Lieut. Col. W. H. Emory, Major First Cavalry and United States Commissioner.-Ichtbyology of the Boundary, by Charles Girard, M. D. < United States and Mexican Boundary Survey, vol. ii, part i, 1859.

[Descriptions and figures of Ictiobus tumidus, Moxostoma kennerlii, Moxostoma victorice, Moxostoma campbelli, Ptychostomus congestus, Ptychostomus albidus, Minomus insignis, Minomus plebeius, Minomus clarki, Acomus latipinnis, Acomus guzmaniensis, and Catostomus bernardini.]

BLEEKER (Pieter van). "Conspectus systematis Cyprinorum. < Naturl. Tijdschr. Nederl. Ind. XXI, 1860."

[Systematic arrangement of the genera.]

ABBOTT (Charles Conrad). Descriptions of Four New Species of North American Cyprinidæ, by Charles C. Abbott. < Proceedings of the Academy of Natural Sciences of Philadelphia, 1860, pp. 473-474.

[Describes Catostomus texanus and Catostomus chloropteron.]

GILI (Theodore Nicholas). On the classification of the EventograthI or CyPRINI, a suborder of Thleocepinal, by Theodore Gill. <Proceedings of the Acaderny of Natural Sciences of Philadelphia, 1861, pp. 6-9.

[Characterizes the suborder Eventognathi, equivalent to "the true Cyprinoids of Agassiz, without teeth in the jaws, and with large falciform lower pharyngeal bones". This suborder is dirided into four families,-Homalopteroidoe. Cobitoida, Cyprinoidoe, and Caiastomoidoe; the latter family being in turn divided into three subfamilies,_Catastomina, Cycleptince, and Bubalichthyince.]

PUTNAM (Frederick Ward). List of the Fishes sent by the Museum to different Institutions, in exchange for other Specimens, with Annotations. By F. W. Putvam. = Bulletin of the Museum of Comparative Zoology, Cambridge, Massachusetts, U. S. A., 1863, (No. 1).

[Contains names of 10 species, with references to descriptions by Professor Agassiz.]

COPE (Edward Drinker). Partial Catalogue of the Cold-blooded Vertebrata of Michigan. Part 1. By Prof. E. D. Cope.

[Notes on several species.]

GILI (Theodore Nicholas). Synopsis of the Fishes of the Gulf of St. Lawrence and the Bay of Fundy. By Prof. Theodore Gill, M. A. < Canadian Naturalist, August, 1865, (pp. 1-24 in reprint).

[Records Catastomus bostoniensis and Moxostoma oblongum.]

BLEEKER (Pieter van). Notices sur Quelques Genres et Espèces des Cyprinoïdes de Chine par P. Bleeker. < Nederlandsch Tijdschrift voor de Dierkunde, uitge. geven door het Koninklijk Zoologisc's Genootschap, Natura Artis Magistra, te Amsterdam, ouder Redaktio van P. Bleeker, H. Schlegel en G. F. Westerman, tweede jaargang, $1 \varsigma 65$.

[Description of Carpiodes asiaticus, sp.nov.]

THOREAU (Henry David). A Week on the Concord and Merrinack Rivers, by Henry D. Thoreau, author of "Walden," etc. Now and revised edition. Boston : Ticknor and Fields. 1868.

[Contains an account of tho habits of Catostomus bostoniensis and 0 . tuborculatus.] 
GÜNTEER (Albert). Catalogue of the Physostomi, containing the families Heteropygii, Cyprinidæ, Gonorbynchidæ, Hyodontidæ, Osteoglossidæ, Clupeidæ, Chirocentridæ, Alepocephalidæ, Notopteridæ, Halosauridæ, in the collection of the British Museum, by Dr. Albert Güntber. London: Printed by order of the trustees. 1868. = Catalogue of the Fishes of the British Musem by Albert Günther, M. A., M. D., Ph. D., F. R. S., F. Z. S., etc., etc. Volume seventl.

[Contains descriptions of twenty-four species, besides twenty-one donbtfal species mercly enuruerated, arranged in four genera, Catostomus, Moxostoma, Sclerognathus, and Carpiodes.]

COPE (Edward Drinker). On the Distribution of Fresh Water Fishes in the Alleghany Region of South-Western Virginia. By E. D. Cope, A. M. < Journal of the Academy of Natural Sciences of Philadelphia, new series, vol. vi, part iii, January, 1869, pp. 20خ-247.

[Description and figure of Teretulus cervinus, sp. nov., with notes on T. duquesnei, Catostomus nigricans, and $C$. communis.

GÜNTHER (Albert). An Accont of the Fishes of the States of Central America based on Collections made by Capt. J. M. Dow, F. Godman, Esq., and O. Salvin, Esq. 13y Albert Günther, M. A., M. D., Ph. D., F. R. S., F. Z. S. < Transactions - of the Zoological Society of London, vol. vi, 1869, pp. 377-494.

[Description of Bubalichthys meridionalis, sp. nov.]

COPE (Edward Drinker). Partial Synopsis of the Fishes of the Fresh Waters of North Carolina, by Edw. D. Cope, A. M. < Proceedings of the American Philosophical Society of Philadelphia, 1870, pp. 448-495.

[Descriptions of Placopharynx carinatus (gen. et sp. nov.), Ptychostomus papillosus (sp. nov.), $P$. velatus (sp. nov.), P. collapsus (sp. nov.), P. pidiensis (sp. nov.), P. coregonus (sp. nov.), P. albus (ep. nov.), $P$. thalassinus (sp. nov.), $P$. robustus (sp. nov.), $P$. erythrurus, $P$. lachrymalis (sp. nor.), $P$. macrolepidotus, $\boldsymbol{P}$.duquesnei, $\boldsymbol{P}$. carpio, $\boldsymbol{P}$. oneida, $\boldsymbol{P}$. aureolus, $\boldsymbol{P}$. sueurii, $\boldsymbol{P}$. crassilabris (sp. nov.), $P$. breciceps (sp. nov.), P. conus (sp. nov.), P.cervinus, Carpiodes difformis (sp. nov.), C. cutisanserinus (sp. nov.). C. selene (sp. nov.), C. velifer, C.grayi (sp. nov.), C. thompsoni, C. bison, C. cyprinus, and D. nummifer (sp. nov.), with notes on other species, and a very useful analysis of the sfecies of Ptychostomus and Carpiodes.]

Report on the Reptiles and Fishes obtained by the Natnralists of the Expedition, by E. D. Cope, A. M. < Prelimiuary Report of the United States Geological Snrvey of Wyoming, and contiguons territories, (being a second annual report of progress,) conducted under the authority of the Secretary of the Interior by F. V. Hayden, United States Geologist. Washington: Government Printing Office. 18 i2.

[Catostomus discobolus, Minomus delphinus, Minomus bardus, and Ptychostomus bucco, sp. nov.]

- On the Plagopterina and the Ichthyology of Utah. By Edward D. Cope, A. M. Read before the American Philosophical Society, March 20th, 1874. < Proceedings of the American Philosophical Society of Philadelphia, vol. 14, pp. 129-139, 1874.

[Minomus platyrhynchus and Minomus jarrovii described as new species.]

JORDAN (David Starr). Synopsis of the Genera of Fishes to be looked for in Indiana, by Prof. David S. Jordan, M. D. < Sixth Annual Report of the Geological Survey of Indiana, made during the jear 1874, by E. T. Cox, State Geologist: assisted by Prof. John Collett, Prof. W. W. Borden, and Dr. G. M. Levette. Indianapolis. Sentinel Company, Printers. 1875. pp. 197-228.

[Nine genera characterized and one or two species mentioned under each.]

Concerning the Fishes of the Ichthyologia Ohiensis, by David S. Jordan, M. S., M. D. < Proceedings of the Buffalo Society of Natural History, 1E76, pp. 91-9\%.

[Contains identifications of the species described by Rafinesque; a new genus, Erimyzon, bcing proposed for Cyprinus oblongus Mitchill.] 
JORDAN (David Starr). Manual of the Vertebrates of the Northern United States, including the district east of the Mississippi River, and north of North Carolina and Tennessee, exclusive of marive species. By David Starr Jordan, M. S., M. D., Professor of Natural History in N. W. C. University and in Indiana State Medical College. Chicago: Jansen, McClurg \& Company. 1876.

[Twenty-three species briefly described, and referred to nine genera.]

NELSOIN (Edward W.) A Partial Catalogue of the Fisbes of Illinois, by E. W. Nelson. < Builetin of the Illinois Museum of Natural History, i, 1876.

[Notes on 21 species; Ichthyobus cyanellus described as a new species, and the genns Carpiodes united to Ichthyobus.]

UHLER (P. R.) and LUGGER (Otto). List of Fishes of Maryland, by P. R. Ubler and Otto Lugger. <Report of the Commissioners of Fisheries of Marylaud, pp. $67-176,(187 \mathrm{C})$.

[Seven species described.]

COPE (Edward Drinker) and YARROW (Henry C.) Report upon the collections of Fishes made in portions of Nevada, Utah, California, Colorado, New Mexico and Arizona during the years 1871, 1872, 1873 and 1874, by Prof. E. D. Cope and Dr. H. C. Yarrow. = Chapter VI. < Report upon Geographical and Geological Explorations and Surveys West of the Ooe Hundredth Meridian, in charge of First Lieut. Geo. M. Wheeler, Corps of Engineers, U. S. Army, under the direction of Brig. Gen. A. A. Humphreys, Chief of Engineers, U. S. Arms, published by authority of Hon. Wm. W. Belknap, Secretary of War, in accordance with acts of Congress of June 23, 1874, and February 15, 1875. In six volumes. Accompanied by one topographical and one geological atlas. Vol. V.-Zoology. Washiugton: Government Printing Office. 1875. (Issued in 1876.)

[Contains descriptions of Pantosteus (gen. nov.), Pantosteus platyrhynchus, Pantosteus jarrovii, Pantosteus virescens (ap. nov.), Catostomus insigne, Catostomus alticolum, Catostomus discobolum, Catostomus fecundum (sp. nor.), Catostomus guzmaniense, Moxostoma trisignatum (sp. nov.), Ptychostomus congestus, aud Carpiodes grayi, with figares of most of the species.]

JORDAN (David Starr) and COPELAND (Herbert Edson). Check List of the Fishes of the Fresh Waters of North America, by David S. Jordan, M. S., M. D., and Herbert E. Copeland, M. S. < Bulletin of the Buffalo Society of Natural History, ii, 1876, pp. 133-164.

[Eighty-three nominal species enumerated, referred to ten genera, viz:-Catostomus, Pantostcus, Hypentelium, Erimyzon, Teretulus, Placopharynx, Carpiodes, Ichthyobus, Bubalichthys, and Cyclep. tus.]

JORDAN (David Starr). On the Fishes of Northern Indiana. < Proceedings of the Academy of Natural Sciences of Philadelphia, 1877.

[Notes on several species; Ichthyobus ischyrus and Bubalichthys altus described as new species, from MSS. left with the anthor by Mr. Nelson; an analysis of the genera of Catostomidoe is given, nine of them being "accepted by Prof. Cope and the writer".]

A Partial Synopsis of the Fishes of Upper Georgia, by David S. Jordan, M. D. $<$ Annals of the New York Lyceum of Natural History, 18\%6. (Published in 187\%.)

[Notes on numerous species, Myxostoma euryops being described as new.]

IZIPPART (John H.) First Annual Report of the Ohio State Fish Commission to the Goveruor of the State of Ohio, for the jears 1875 and 1876. Columbus: Nevins \& Myers, State Printers. $18 \%$.

[Descriptions of Catostomus tercs, Teretulus oblongus, Placopharynx ca-inatus, Carpiodes difformis, and Carpiodes velifer, with woodcuts of all but $P$. carinatus and $O$. vclifer. The desciptions are by Charles H. Gilbert, mostly arranged from MSS. notes of D. S. Jordan; the notes on habits, etc., by Mr. J. H. IKlippart.] 
JORDAN (David Starr) and BRAYTON (Alembert Winthrop). On Lagochila, a new genus of Catostomoid fishes. < Proceedings of the Academy of Natural Sciences of Philadelphia, 187\%, pp. 280-2\&3.

[Description and figure of Lagochila lacera (gen.et sp. nor.), with an analysis of the genera of Catostomida admitted, viz:-Lagochila, Pheopharynx, Iryxos:oma. Erinyzon, Hypente'ium, Cato. stom.us, Pantosteus, Cycleptus, Carpiodes, Ichthyobus, Bubulichthys, ad Myxocyprinus.]

HALLOCK (Charles). The Sportsman's Gazetteer and General Gnifle. The Game Animals, Birds and Fishes of North America : their Habits and Various Methorls of Capture. Copions Instructions in Shooting, Fishing, Taxidermy, Wooderaft, etc. Together with a Directory to the Principal Game Resorts of the Conntry: illustrated with maps. By Chasles Hallock, Editor of "Forest and Stream", Author of the "Fishing Tonrist", "Camp Life in Florida", etc. New York: Forest and Stream Publishing Company. 1877.

[Contains descriptions and notices of numerons specics; the Red Horse, M. macrolepidotum, being on p. 338 inadvertently called " Catostomus cepedianum".]

JORDAN (David Starr). Contributions to North American Ichthyology, based primarily on the Collections of the United States National Musenm. I. Review of Rafinesque's Memoirs on North American Fishes, by David S. Jordan. Washington: Government Printing Office. 18\%7. = Bulletin of the United States National Museum, No. 9. pp. 53.

[Contains identifications of the various nominal species described by Rafinesque.]

Contributions to North American Ichthyology, based primarily on the Collectious of the United States National Mnsenm. II. A.-Notes on Cotiddx, Etheostomatida, Percida, Centrarchide, Aphododerida, Dorysomatida, and Cyprinida, with revisions of the genera and descriptions of new or little known species. B.-Synopsis of the Silurida of the fresh waters of North America. By David S. Jordan. Washington: Government Printing Office. 1877. = Bulletin of the United States National Museum, No. 10. pp. 116.

[Description of Myxostoma poerilura, sp. nov.]

GILL (Theodore Nicholas). Johnson's New Universal Cjclopæủia; a scientific and popular treasury of nseful knowledge. Illustrated with maps, plans and engrarings. Editors in chief, Frederick A. P. Barnard, S. T. D., LL. D., L. H. D., M. N. A. S., President of Columbia College, New York; Arnold Gryot, Pb. D., LL. D., M. N. A. S., Professor of Geology and Physical Geography, College of New Jersey. Associate Editors-[29 persons, among them Theodore Gill, A. M., M. D., Ph. D., M. N. A. S., Late Senior Assistant Librarian of the Library of Congress]. With numerous contributions from writers of distinguished eminence in every department of letters and science in the United States and in Europe. Complete in four volumes, including appendix. Volume IV, S-Appendix. (Testimonials at the end of the volume.) Alvin J. Johnson \& Son, 11 Great Jones Street, New York. MDCCCLXXVIII.

[Contains a description of the family Catastomida, a list of the genera, and a diagnosis of Myxaeyprinus, gen. nov.]

JORDAN (David Starr). Manual of the Vertebrates of the Northern United States, inciuding the district East of the Mississippi River, and North of North Carolina and Tennessee, exclusive of Marine Species, by Darid Starr Jordan, Ph. D., M. D., Professor of Natural History in Butler University. Second Edition Revised and Eularged. Chicago: Jansen, McClurg \& Company. 1878.

[Descriptions of forty species, referred to eleven genera :-Lagochila, Placopharynx, Mysastoma, Minytrema (gen.nov.), Erimyzon, Hypentelium, Catostomus, Cycleptus, Carpiodes, Ichthyobus, and Bubalichthys. In the Addenda, the vame Quassilabia is suggested as a substitnte for Lagochila.] 
JORDAN (David Starr). A Catalogue of the Fishes of the Fresh Waters of North A merica. By David S. Jordan, M. D. < Bulletin IV, Hayden's Geological Survey of the Territories, No. 2, pp. 407-442. Washington, May 3, 1878.

[Fifty-one species enumerated; arranged in thirteen genera, viz:-Bubalichthys, Ichthyobus, Carpiodes, Cycleptus, Pantosteus, Catostomus, Chasmistes (gen. nov.), Erimyzon, Minytrema, Myxo. stoma, Placopharynx, and Quassilabia.]

Notes on a Collection of Fishes from the Rio Grande, at Brownsville, Texas. By David S. Jordan, M. D. < Bulletin Hajden's United States Geological and Geographical Survey, vol. iv, No. 2. Washington, May 3, 1878.

[Synonymy and note on Carpiodes tumidus.]

A Catalogue of the Fishes of Illinois, by Prof. David S. Jordan. < Illinois State Laboratory of Natural History. The Natural History of Illinois. Bulletin No. 2. Bloomington, Ill., June, 1878.

[Twenty-three species enumerated, with notes; these are arranged in nine genera.]

FORBES (S. A.) The Food of Illinois Fishes by S. A. Forbes. < Bulletin of the Illinois State Laboratory of Natural History, No. 2, 1878.

[Valuable notes on the food of Catostomidoe.]

JORDAN (David Starr). Notes on a Collection of Fishes from the Rio Grande, at Brownsville, Texas, continued. By D. S. Jordan M. D. < Hayden's Bnlletin of the Geological and Geographical Survey of the Territories, vol. iv, No. 3. Washington, July 23, 1878.

[Remarks on the probable identity of Carpiodes grayi and Ictisbus tumidus with Carpiodes cyprinus.]

Catalogue of the Fishes of Indiana, in Article Pisciculture (by Alexander Heron). < Trenty-seventh Annual Report of the Indiana State Board of Agriculture, 1877. Volume XIX. Indianapolis. 1878.

[Twenty-two species enumerated, referred to ten genera.]

JORDAN (David Starr) and BRAYTON (Alembert Winthrop). On the Distribution of the Fishes in the Alleghany Region of South Carolina, Georgia and Tennessee, with Descriptions of New or Little Known Spccies. By David S. Jordan and Alembert W. Brayton. < Bulletin of the United States National Museum, No. 12. Washington, Government Printing Office, 1878.

[Notes on numerous species.] 


\section{INDEX.}

\begin{tabular}{|c|c|}
\hline Acantharchus ................. 89 & annularis (Pomoxys) ..........47, 76, 83 \\
\hline cipenser ................... 71,90 & anomalum (Campostoma)...16, 43, 49, 63, \\
\hline cipenseridø.................. $\$ 1$ & $\pi 7,84$ \\
\hline Acomus ........................151, 157 & antoniensis (Amiurus natalis) ..... 55 \\
\hline esopus (Boleosoma)............. 82 & Aphododeridæ .................41, 47 \\
\hline finis (Clinostomus)............. & Aphododerus ................41, 47,89 \\
\hline rassizi (Chologaster)............ & Apomotis .............. \\
\hline ba (Myxostoma) .................. & aræopus (Catostomus) ...........160, 173 \\
\hline is (Amiurus) .................. & ardeus (Lythrurus) ..............78,85) \\
\hline is (Ptychostomus) ........... & argenteus (Ammocotes)......... \\
\hline lus) $\ldots \ldots \ldots \ldots \ldots \ldots . . . .129$ & athas) $\ldots . \ldots \ldots \ldots 16,84$ \\
\hline oma) .......101, 117, 129 & 3) $\ldots \ldots \ldots \ldots 102,217$ \\
\hline (yxustoma) $\ldots .27,86,102,11 \%, 130$ & (Myхocyprinus)...... 10\%,217 \\
\hline .......... & vordius) $\ldots \ldots \ldots \ldots \ldots \ldots$ \\
\hline ychostomus)............ 130 & idø $\ldots \ldots \ldots \ldots \ldots \ldots \ldots \ldots 6,76$ \\
\hline s) $\ldots \ldots \ldots \ldots \ldots \ldots$. 206 & es (Notropis)..........64,78 \\
\hline tomus) $\ldots \ldots \ldots \ldots 102,167$ & (Zygonectes)........... 84 \\
\hline opis) $\ldots . . . . . . . .8$ & atripinnis (Arlina) .............. \\
\hline 8)...........102, 206 & atripinnis (Ulocentra)........... 73,8 \\
\hline$\ldots \ldots \ldots \ldots \ldots 12,58,73,88$ & bys)......... $8 \delta$ \\
\hline & pterus)........ 58, 82 \\
\hline & a) $\ldots \ldots \ldots \ldots \ldots \quad 125$ \\
\hline (bopsis hudsonius)...... 36 & ma)......... 125 \\
\hline$\ldots \ldots \ldots \ldots \ldots \ldots \ldots \ldots \ldots \ldots \ldots \ldots$ & ma)...100, 101, 116, 124 \\
\hline ............40,46, $60,75,89$ & s) $\ldots .100,124,125,167$ \\
\hline eratichthys) .......... 79 & omus).......... 125 \\
\hline 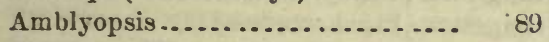 & s) $\ldots \ldots \ldots \ldots$ \\
\hline (Perca) ................ & us)....... $15,36,40,83$ \\
\hline 53 & $\ldots \ldots \ldots \ldots \ldots$ \\
\hline nigunus) $\ldots \ldots \ldots 24,38$ & ...........101, 17t \\
\hline .............. 70,90 & ottus) $\ldots \ldots \ldots \ldots . \quad 82$ \\
\hline ro & $\ldots \ldots \ldots \ldots \ldots 184,180^{\circ}$ \\
\hline$\ldots \ldots .28,33,39,44,55,70,81,90$ & s) $\ldots \ldots \ldots \ldots \ldots \quad 184$ \\
\hline etes ..................... 80 & ostomus) $\ldots \ldots \ldots 102,172$ \\
\hline $\begin{array}{l}\text { ta } \\
\text { s (Photogenis) } \ldots . . . . .20,78,84\end{array}$ & $\begin{array}{r}\text { biguttatus (Ceratichthjs).. } 26,3: 3,38,43,86 \\
68,79,86\end{array}$ \\
\hline $44,55,70,81,90$ & bison (Carpiodes) ......69, 86, 101, 194, 197 \\
\hline $39,44,55,70,81$ & lesium) ........ \\
\hline$\ldots \ldots \ldots 100,196$ & s (Etheostoma) ......... \\
\hline isura (Myxostoma).....86, 100, 102, 116, & Boltichthys .................. 45,89 \\
\hline $126,128,132$ & $\ldots \ldots \ldots \ldots \ldots 13,34,58,75,89$ \\
\hline nus) $. . .100,110,126,132$ & ons (Lepiopomas) ........ 60, 83 \\
\hline s.(Moxostoma) .......... 132, 146 & bonasus (Bubalichthys)......101, 249, 214 \\
\hline s (Ptychostomus)........... & bostoniensis (Catostomus) ........100, 166 \\
\hline 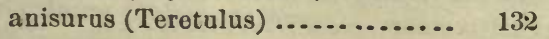 & breviceps (Moxostoma)............ \\
\hline 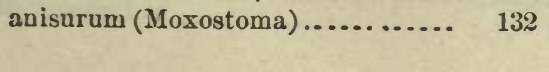 & breviceps (Myxostoma)............ \\
\hline
\end{tabular}


breviceps (Ptychostomus) ........102, 127

breviceps (Teretulus) ............. 127

brevipinne (Boleosoma)........... 58

brunneus (Amiurus).........28, 39, 44, 87

Bubalichthyinæ............... 99

Bubalichthys...55, 69, 90, 104, 201, 203, 205 bubalinus (Bubalichthys)........103, 206 bubalus (Amblodon) ............211, 214 bubalus (Bubalichthys)..101, 102, 205, 206 bubalus (Catostomus) ........100, 206, 214 bubalus (Ichthyobus) . 86, 100, 101, 102, 214 buccala (Ericymba)............ 84 bucco (Ptychostomus) ............ 102, 133 bucco (Teretulus).............. 133 bullaris (Semotilus)............. 86 callisema (Codoma) ................37, 85 callisema (Episema) ............. 37 callistia (Codoma) ................ 50,85 callistius (Photogenis) .......... $\quad 50$ calva (Amia) .................. 70,87 campluelli (Erimyzon)........... 146 camplelli (Moxostoma) .......... 101, 146 Campostoma ..........16, 43, 49, 63, 77, 90 camura (Vaillantia)............. 89 camurus (Nothonotus) .......... 74,82 canadense (Stizostethum) ....... 83 caprodes (Percina)..........45, 57, 73, 82 carinatus (Placopharynx)...69, 86, 102, 107, 108,109 carpio (Carpiodes) .....86, 100, 102, 195, 200 carpio (Catostomus) ...... 100,101, 118,200 carpio (Ichthyobus).............. 200 carpio (Moxustoma)............. 119 carpio (Myxostoma).......101, 11.5, 118, 119 carpio (Ptychostomus) .............. 118 carpio (Teretulus) ............... 119 Carpiodes....55, 69, 80, 90, 190, 193, 201, 217 catenatum (Xenisma) ..........62, 77, 84 Catostomidæ ...26, 33, 38, 43, 54, 68, 80, 97, 9 s, 103 Catostominæ .................... 98 Catostomus.... .27, 33, 54, 69, $20,103,110$, $136,140,151,153,154,155,158,1<0$, 201,219 catostomus (Cyprinus) .........166, 175, 193 catostomus (Phenacobius) ............53 cavifrons (Ambloplites)........... 83 Ceutrarchidæ.......15, 30, 35, 40, 46, 60, 75 Centrarchus..................36, 47, 89 cepedianum (Dorosoma) ...........49,63 Ceratichthys...24, 32, 38, 43, 53, 67, 79, 90 cervinum (Moxostoma) ...............129 cervinum (Myxostoma).. 26, 33, 38, 43, 86, 102,11 \%, 129 cervinus (Ptychostomus) .......... 129 cervinus (Teretulus) ............ 102, 129 Chænobryttus ........... $15,35,46,60,89$ Chasmistes ..............103, 149, 150, 219 chiliticus (Hydrophlox) ........... 85 chlor istia (Codoma)............. 21, 85 chlorocephalus (Alburnops) ........ 19, 8 . chlorocephalus (Hybopsis) ......... 19 chloropteron (Catostomus) ........102, 167 Chologaster .................... 89 Chrosonus ..................65, 79, 90 chrosomus (Hybopsis) ............ 49 chrosomus (Hydrophlox) ......... 49, 85 chrysochloris (Pomolobus) ......62, 77,84 chrysoleucus (Notemigonus)......53, 67, 79 chrysops (Roccus) .............. 83 cinerea (Etheostoma) ........... 59, 83 clarki (Catostomus) .............159, 165 clarki (Minomus) .............. 165 claviformis (Erimyzon)........... 146 claviformis (Moxostoma).........101, 146 Clinostomus ...................24, 66 Clupeidæ................... 62, 7 7 coccogenis (Luxilus) ...........31, 64, 85 Codoma .............. 20, 37, 42, 50, 90 cærulea (Codoma) ............. 85 coerulea (Erogala) .............. 51 collapsus (Ptychostomus) ........ 102, 13:2 commersoni (Catostomus)...27, 69, 80, 86, 100,166 commersonien (Le Cyprin).......100, 166 communis (Catostomus) ......80, 100, 166 congesta (Myxostoma) ........... 133 congestum (Myxostoma)......101, 118, 133 congestus (Catostomus) .......... 133 congestus (Ptychostomus) ........ 120, 133 congestus (Teretulus)........... 133 copelandi (Rheocrypta) .......... 82 Copelandia ................... 89

Coregonus................... 89 coregonus (Myxostoma), 26, 86, 102, 118, 134 coregonus (Ptychostomus) ........102, 134 cornutus (Luxilus) ............49, 64, 78 corporalis (Semotilus), 26, 38, 54, 68, 80,86 conus (Myxostoma) ......86, 1112, 116, 126 conus (Ptychostomus) ..........102, 126 conus (Teretulus)............. 126 Cottidæ................ 47, 57, 73 crassilabre (Myxostoma).. 86, 102, 116, 126 crassilabris (Ptychostomus)...... 102, 126 crassilabris (Teretulus) ......... 126 crassus (Alvordius) ............ 12, 82 crassus (Esox)................ 62, 84 Cristivomer .................. 89 
cupreus (Amiurus nataì:s)........ 70 cutisanserinus (Carpiodes) ....89, 86, 102, $194,195,196$

evanellus (Apomotis) ........... 76, 83 cyanellus (Bubalichthys)........ 86 cyanellas (Ichthyobus) .........102, 206 Cycleptins .................... 98 Cycleptus ........80, 20, 10-1, 186, 187, 189 cypho (Esox)

Csprinella.

cyprinellu (Iclithyobus) ......... 214 csprinella (Sclerognathus) .......214, 215 Csprinidæ ........16, 31, 36, $41,49,63, \pi 7$ Cyprinodontidæ............31, 48, 63, 77 Cyprinus ....................... 140 cyprinas (Carpiodes) ......55, 86, 101, 102, 195,198 cyprinus (Catostomus) ............ 100 cyprinus (Labeo) ................ 193 cyprinus (Sclerognatbus) ........197, 198 damalis (Carpiodes).............. 199 Decactylus ....................151, 154 Decadactylus...............151, 155, 159 delphinas (Minomns)............102, 184 delphinus (Pantosteus) ........... 184 diaphanus (Furdulas) ........... 84 difformis (Carpiodes)......86, 102, 194, 195 difformis (Ichthyobus) ........... 196 dilectus (Notropis) .............. 85 dinemus (Notropis) ............. 85 Diplesinm ..................58, 73, 88 discobolus (Catostomus) .... 102, 162, 179 Dorosoma ................49, G3, 77, 90 Dorosomatidx ..............49, 63, 77 dispar (Zygonectes)............. 84 dissimilis (Ceratichtbys) ......67, 79, 86 duquesnii (Catostomus), 100, 1\%0, 121, 129 duquesnii (Moxostoma) ........... 121 duquesnii (Myxostoma macrolepido-

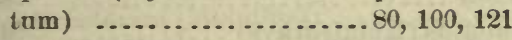
duquesuii (Myxostoma), 43, 54, 68, 80, 115, 120,124

Inquesnii (Ptychostomas)......... 121 duquesnii (Teretulus) ........... 121

Elassoma........................ 89 olegans (Boleichthys)......... . 45, 83 elegans (Catostomus)............. 146 elegans (Labeo)................101, 145 elentherus (Noturus) ............ 70,87 elongata (Gila) .................. 85 elongatus (Catostomus)..........100, 189 elongatus (Cycleptus), 80, 86, 100, 189, 190 elougatus (Labeo) ..............101, 146 elongatus (Sclerognathus)........ 189 Eaneacanthus eos (Boleichthys) ............. 83

Episema..................... 64; 90

Ericosma ...................... 88

Ericymba...................... 90

Erimyzon, 27, 38, 43, 54, 69, 80, 90, 103, 136, 140,143

Erogala ...................... 20 erytbrogaster (Cb:osomus) . .....65, 79, 85 erythruras (Catostomus) .........100, 121 erythrarns (Ptychostomns)....... 121 erjthruras (Teretulus).......... 121 Esocidr ..................16, 36, 48, 62 esopus (Catostomns) ............. 146 esopus (Labeo) .................101, 146 estor (Gila) .................. 66, 79 Esox..................16, 35, 48, 62,89 Etheostoma............15, 40, 59, 75, 89 Etheostomatidæ.... 12, 30, 34, 40, 45, 57, 73 etowanum (Hypentelinm)........ 86 etowanas (Catostomns nigricaus), 54, 159, 163

Encalia ...................... 89

Eupomotis................15, 46, 61, 89 euryops (Myxostoma), 54, 86, 103, 115, 119 euryops (Teretalus).............. 119 eurystoma (Codoma)............ 42, 85 eurystomus (Photogenis) ......... 42 evides (Ericosma)............... 82 exilis (No:urus) ................ 87

Exoglossum ................... 90 fasciatus (Catostomns) ..........101, 138 fasciolaris (Catostomus) ..........100, 145 fecundus (Catostouıs) ...... 10: 150, 219 fecundus (Chasmistes) .......... 102, 150 flabellare (Etheostoma) ...... 15, 59, 75, 83 flabellatus (Catonotus).......... 15 flammeus (Phoxinus) ............ 65, 85 flexnosus (Catostomus) .........100, 166 folium (Polyodon)............71, 81, 8 7 fontinalis (Salveliuus) ......16, 31, 63, 84 formosa (Codoma) .............. 42, 51 formosus (Alburnus)............ 42 forsterianus (Acomus) ........... 167, 176 forsterianus (Catostomus)... 100, 101, 16\%, fretensis (Alburnops)............ 8.5 Fundulus...................... 89 furcatus (Ichthælurus) .......... 87 galacturus (Hypsilepis) .......... 32 galacturus (Photogenis) .......32, 64, 78 Gambusia ..................... 89 generosus (Acomus).............. 183 generosus (Catostomus) ......102, 173, 183 generosus (Pantostens) ......102, 182, 183 gibbosus (Catostomus) ..........100, 145 
gibbosus (Labeo) ............... 145

Gila ..................24, 66, 79,90

Girardinus................... 89

goodei (Erimyzon)..........103, 144, 148 gracilis (Catostomus) ............101, 167 grandipinnis (Photogenis) ........ 42 grayi (Carpiodes)................102, 199 griseus (Acomus) .............. 176 grunniens (Haploidonotus)......47, 61, 76 galosus (Chsenobryttus)........46, 60, 83 guttatus (Percopsis) ............. 84 guttatus (Zygonectes)........... 48, 84 guzmaniensis (Acomus) .......... 178 guzmaniensis (Catostomus) ...... 102, 178 Hadropterus..........30, 34, 40, 45, 58, 88 Haploidonotus.............47, 61, 76, 89 haydeni (Ptychostomus).........101, 138 baydeni (Teretulus) ............. 138 Flemioplites .................. 89 Hemitremia $\ldots . . . \ldots \ldots \ldots \ldots 65,79,90$ heterodon (Hemitremia).......... 8.5 heterurum (Dorosoma cepedianım). 49, 77 hieroglyphicus (Zygonectes) ...... 48, 81 hirudo (Ammocœtes)............ 87 Hudsonius...................19, 36, 90 hudsonius (Catostomus).160, 166, 175, 176 hyalinus (Ceratichthys)......... 53, 63. Hsbognathus................. 16, 90 Hyborhynchus ...............63, 78, 90 Hydrophlox .........18, 32, 36, 49, 64, 90 Hylomyzon .................. 151, 156 Hyodon.............. 48, 62, 77, 89 Hyodontidæ................ 48, 62, 77 Hypentelium .......151, 154, 15j, 15\%, 158 hypselopterus (Leuciscus)........ $\quad 42$ hypsinotus (Ceratichthys) . ...........25 Ichtbælurus........33, $39,43,55,69,81,90$ Ichthyobus .........90, 104, 211, 213, 214 Ictiobus ......................211, 213 Imostoma ................... 88 inconstans (Eucalia) ............ 83 inscriptus (Nothonotus) .......... 34, 82 inscriptus (Xenotis) ...........46, 61, 83 insigne (Catostomus) ............ 165 insiguis (Catostomus)........101, 159, 165 insignis (Minomus) .............. 165 insignis (Noturus) .............. 29, 87 interrupta (Morone).............. 83 Ioa....................... 88 irideus (Centrarchus) .......... 47, 83 ischanus (Notemigonu ) .......... 24, 38 ischyrus (Ichthyobus) .......102, 215, 217 ischyrus (Lepiopomus) ........... 83 jarrovii (Minomus) ........... 102, 183 jarrovii (Pantosteus)............ 183 jessiæ (Pœcilichthys) .............59, 102 kennezlyi (Moxostoma) ......... 101, 146 Labeo ....................... 140, 142 labiatus (Catostomus) ..........160, 173 Labidesthes ...............61, 76, 89 labrosus (Ceratich thys) ......... 25,86 lacera (Lagochila)........68, 103, 104, 106 lacera (Quassilabia)...........68,86, 106 lacertosus (Hydrophlox).......... 64 lachrymals (Myxostoma)..... 102, 115, 120 lachrymalis(Myxostoma duquesnii). 120 lachrymalis (Myxostoma macrolepidota) $\ldots \ldots \ldots \ldots \ldots \ldots \ldots \ldots . \quad 120$ lachrymalis (Ptychosto mus)......102, 120 lachrymalis (Teretulus) .......... 120 lactarius (Acomus)............ 176 lactarius (Catostomus).........102, 176 lacustris (Lota) ................ 82 Lagochila ....................104, 105 latipinnis (Acomus)........... 178 latipinuis (Catosto mus) .. 101, 102, 162, 178 Lepidosteid $\circledast$...........29, 44, 55, 71, 81 Lepidosteus ..........29, 44, 55, 71, 81, 90 Lepiopomus.......15, 36, 40, 46, 60, 76,89 leptacantbus (Noturus) .......44, 55, 87 lesueurii (Catostomus) ..........100, 125 leucioda (Episema) ............ 64, 85 leucops (Photogenis)............ 2:3 leucopus (Photogenis)........... 41, 84 limi (Melanura)............... 84 lineolatum (Etheostoma)......... 83 liorus (Chasmistes) ............ 219 lirus (Notropis) ..............53, 65, 85 Litholepis .................. 90 longiceps (Hybopsis)............ 64 longirostris (Catostonuus), 86, 100, 102, 161,

longirostrum (Catostomus) .......100, 175

Lota ....................... 88

lunatus (Rhinichthys) ........... 67

lutipinnis (Hydrophlox) . ....... $\quad . \quad 36,85$ Luxilus .............18, 31, 49, 64, 78,90 lythrochloris (Xenotis).......... $8: 3$ Lythrurus ................... 78,90 macrocephalus (Alvordius) ....... 82 macrochilus (Catostomus)....102, 160, 171 macrochirus (Lepiopomus) ....... 83 macrolepidota (Myxostoma)....... 120 macrol epidotum (Moxostoma) ..... 120 macrolepidotum (Myxostoma), 54, 68, 80. $86,101,102,115,116,120,124$ macrolepidotum (Teretulus)....... 120 macrolepidotus (Catostomus), 100, 120, 125 macrolepidotus (Ptychostomus).... 120 macropterum (Exoglossum) ...... 100, 163 
macnopterum (Hypentelium) ...... 163 macropterus (Centrarchus) ........36, 83 maculaticeps (Arlina) ............ 13 macnlaticeps (Boleosoma)....... 13, 34 maculatum (Boleosoma).......... 58, 82 maculatum (Etheostoma) ........ 12 inaculatus (Alvordius) .........58, 73, 82 maculatus (Hadropterus) ......... 58 maculatus (Nothonotus)......... $8: 2$ maculosus (Acipenser) .......... 71, 87 maculosus (Catostomus) ........100, 163 manitou (Percina) ............... 82 margarotis (Enneacanthus) ........ 83 marginatus (Noturus)............ 29 marmoratus (Amiurus) .......... 39, 87 matutinus (Notropis)............ 85 maxillingua (Exoglossum) ....... 86 megalotis (Xenotis) .............76, 83 megastomus (Catostowus) .......100, 16:3 melanops (Catostomus) .. .27, 100, 1:36, 138 melanops (Erimyzon) ............27, 133 melanops (Minytretna), 2శ, 54, 69, 80, 86, $100,101,137,138$

melanops (Ptychostomus) ........ $13 \triangleleft$ mulanops (Zygonectes) ........... 84 melanopsis (Catostomus) ......... 138 Melanura....................... 89 melanurus (Rutilus) ............ 100, 121 melas (Amiurus) ................ 87 meleagris (Rhinichthys) .......... 86 meridionalis (Bubalichthys) .. 102, 206, 210 meridionalis (Potamocottus) . .47, 57, 73, 82 meridionalis (Sclerognathus) ...... 210 Mesogonistius ................. 89 Microperea .................... 89 Micropterus....15, 30, 35, 40, 46, 60, 75, 89 micropteryx (Notropis) ........65, 79, 85 microstomus (Alburnops)...... 04, 78, 85 microstomus (Minnilus) .......... 64 Miuomus .............1\%1, 15\%, 180, 181 Minytrema..27. 54, 69, г0, 90, 103, 136, 137 miurus (Noturus) ................

Mollienesia ......................

monachus (Ceratichthys)......... 67, 86 Moxostowa, 110, 113, 114, 136, 140, 14i2, 143 Mухосурriuus .................. 104, 217 Mrxostoma, 26, 33, 38, 43, 54, 68, <0, 90, 103,

110,113

nasutus (Rhinichthys) ........... 86 natalis ( $\Lambda$ miurus) ..........55, $r 0,81,87$ neogras (Phoxinus) ............. nuvisensis (Alvordins) . ............ niger (Amblodou). niger (Ammocotes) niger (Bubalichthys)

\section{niger (Catostomus)}

Page. nigrescens (Cscleptus).......100, 186, 190 nigricans (Amiurus) ............ 81, 87 nigricans (Catostomus), 33, 54, 69, 80, 100, $101,158,159,162,163,167$ nigricans (Hylomyzon)........... 162 nigricans (Hypentelium) .......96, 162, 163 nigrofasciatus (Hadropterus) ...30, 34, 40, 45,82 nigromaculatus (Pomoxys) ...... 47, 76 niveiventris (Amiurus) ........... 87 niveus (Photogenis)............. 20, 85 notatus (Hyborhynchus) .......63, 78, 84 notatus (Xystroplites)...........61, 83 notatus (Zygonectes)..........62, 77, 84 Notemigonus ........24, 38, 53, 67, 79, 90 Nothonotus.............13, :34, 58, 74, 89 Notropis..............23, 53, 64, 7 8,90 nottii (Zygonectes) ............31, 4 $\varangle, 84$ Noturus .................29, 44, 55, 70,90 nuchalis (Hybognathus) .......... 84 nummifer (Carpiodes) ........... 102, 200 occidentalis (Catostomus) ...101, 160, 172 oblongus (Cyprinus) .....27, 100, 140, 145 oblongus (Erimyzon) ........... 100, 145 oblongus (Labeo) ................ 145 oblongus (Moxostoma) ............ 145 oblongus (Teretulas) ............ 145 obscuras (Lepiopomus) ......46, 60, 76,83 obtusus (Rhinichth5s)........54, 67,86 oblongus (Catostomus) ............ 145 olivaris (Pelodichthys) ........ . $0,81,87$ olmstedi (Boleoeoma)............ 13, 82 oneida (Ca tostomus) .............101, 1:0 oneida (Ptychostomus)........... 120 osseus (Lepidosteus) .. 29, 44, 55, 71, 81, 87 pallidus (Catostomus) ..........101, 167 pallidus (Eupomotis) .........46, 61, 83 pallidus (Lepiopomus) ...40, 46, 60, 76, 83 pallidus (Micropterus), 15, 40, 46, 60, 75, 83 Pantos:eus..................103, 1飞0, 181 papillosa (Myxostoma)............ 134 papillosum (Myxostowa)...26, 38, 86, 102, 118,134 papillosum (Ptychostomus) .......102, 134 papillosum (Teretulus) ......... 134 pellucidus (Pleurolepis) .......... 82 Pelodichthys...............70, 81, 90 peltastes (Xerotis) .............. 83

Perca ........................ 89

Percidæ .................45, 60, 75 Percina..................45, 57, 73,88

Percopsis..................... 89

Phenacobius..............53,67,79,90 Photogenis........18, 20, 32, 41, 64, 78, 90 
photogenis (Notropis) .........23, 65, 85 photogenis (Squalius)........... 23 Phoxinus..................... 65,90 phoxocephalus (Alvordius)....... 73, 82 pidiensis (Myxostoma).......86, 118, 133 pidieusis (Ptychostomus) . ........ 133 pidiensis ('Teretulus) ............. 133 Pimephales .................. 78,90 pinniger (Euneacanthus)......... 83 Placopharynx..........69, 90, 103, 107 plariceps (Catostomus) .......... 163 platycephalus (Amiurus) ......28, 33, 87 platycephalus (Pimelodus) ........ 28 platyrbynchus (Minomus)........ 102, 183 platyrhynchus (Pantostens) .. 180, 182, 183 platyrhynchus (Scaphirhynchops).. 87 platystomus (Lepidosteus) ....... 71, 87 plebeius (Catostomus) ....... 101, 184 plebeius (Minomus) ............. 184 plebeius (Pantosteus) ....... 102, 182, 184 plebejus (Catostomus) ............ 184 Poeilichthys................59, 75, 89 pœcilura (Myxostoma) ...... 103, 116, 128 Polyodon ....................71, 81, 90 Polyodontidso ..................71, 81 Pomolobus.................6\%, 77,90 pomotis (Acantharchus) .......... 83 Pomoxys ...................47, 76,89 Potamocottus ............4 7 , 57, 73, 88 prolixum (Campostoma anonalum) 16 , 49,63 promelas (Pimephales) ........... 78, 84 proriger (Gila) ................. 85 Ptychostomus ...........110, 11:3, 114, 136 punctatus (Ichthælurus)...33, 39, 43, 55, 69,

punctulata (Microperca) .......... 81,87 pygmæa (Melauura) .............. Pygosteus ....................... pyrrhomelas (Codoma).......... 23, 85 pyrrhomelas (Photogenis)......... 23 Quassilabia ......68, 90, 103, 104, 10־, 106 rauchii (Iehthyobus)............214, 215 raveneli (Esox)................16, 48, 84 reticulatus(Cypriuus (Catostomus)) 166 reticulatus (Esox)..........16, 36, 48, 84 retropinnis (Catostomus) ........161, 178 Rheocrypta.................... 88 Rhinichtbys............... 54,67, 90 Rbytidostomus ................186, 187 robustus (Ichthyobus)............ 87 robustus (Ptychostomus)......... 120 robustus (Tcretulus) ............. 120 rostratus (Catostomus;........... 174 rostratus (Cyprinus).

174,218
Page.

rubellus (Notropis)............. 85 rubicundus (Acipenser) .......... 71, 87

rubricroceus (Hybopsis)......... $\quad 32$ rubricroceus (Hydrophlox)......32, 64, 85 rubrifrons (Ceratichthss) .......3:2, 38, 86 rubrifrons (Nocomis) ............. 32, 38 rubrifrons (Notropis) ............ 85 rufilineatus (Nothonotus) ......... 58, 82 rupestris (Ambloplites)...40, 46, 60, 75, 83 salmoides (Micropterus) ... 30, 35, 40, 46, 60, 75,83 salmonoum (Stizostethium)...45, 60, 75, 83 salmoneus (Esox) .............. 84 Salmonidx................... 16, 31, 63 saludanus (Alburnops) ........... 16, 85 Salvelinus ................. 16, 31, 63, 89 sanguifluus (Nothonotus)........ 75, 8 . sanguinolentus (Xenotis)....31, 46, 61, 83 sayauus (Aphododerus)........41, 47, 83 scabriceps (Episema)........... 85 Scaphirhynchops ............... 90 Sciænidæ ...................47, 61, 76 Scleroguathus .......190, 193, 201, 205, 217 scopiferus (Phenacobius) ......... $86^{\circ}$ selene (Carpiodes)..............102, 196 selenops (Hsodou) ........48, 62, 77, 84 Semotilns ........26, $38,43,54,68,80,90$ shumardii (Imostoma) ........... 8.2 sicculus (Labidesthes) . ...........61, 76 Siluridæ .........28, 33, 39, 43, 55, 69, 81 simoterum (Diplesinm) ........58, 73, 82 siuulans (Hemioplites) .......... 83 spatula (Litholepis) .............. 87 spectabilis (Pœeilichthss)....... 83 spectruuculus (Alburnops) ....... 64, 85 spelæus (Amblyopsis) ............ 84 subterraneus (Typhlichthys) ...... 84 sucetta (Catostomus) ............ 144 sucetta (Cyprinus).......27, 100, 140, 144 sucetta (Erimyzon), 27, 38, 43, 54, 69, 8n, 86, $100,101,138,144,145$

sucetta (Moxostoma)............. 144 sucetta (Teretulus) .............. 138 suckleyi (Catostomus) ........... 167 sucklii (Catostomus)......... 102, 167 superciliosus (Hyborhynchus) ..... 84 squamiceps (Etheostoma) ........ 83 stelliferum (Xenisma)........... 48, 84 stigmaa (Boleosoma) .......... 45 stigmæa (Ulocentra) ............ 45, 8 i2 stigmatura (Codoma) ............ 50 stigmaturus (Photogenis) ........ 50 stilbius (Notropis) .............. 53 Stizostethium.............45, 60, 75,89 stolleyi (Ichthyobus) ........ 101, 215, 217 


\begin{tabular}{|c|c|}
\hline stramineus (Alburnops) .... & vacca (Carpiodes) ... \\
\hline sueurii (Catostomus).... & Vaillantia .............. \\
\hline eurii (Cyprinus).................... & vandoisula (Gila).............. 24,85 \\
\hline urii (Cyprinus (Catostomus))... & vandoisulus (Leueiscus) ........... $\quad 24$ \\
\hline eurii (Ptychostomus) ........... & variatus (Pœeilichthys) .......... 75,82 \\
\hline neurii (Teretulus)................ & velata (Moxostoma) .............. 132 \\
\hline tahoensis (Catostomus) ...........161, 173 & velata (Myxostoma) ............. \\
\hline auridea $\ldots . . . \ldots \ldots \ldots \ldots \ldots \ldots . . .68$ & velatum (Moxostoma).......... -132 \\
\hline urus (Bubalichthys) ............55, 206 & velatum (Myxostoma) .......26, 68, 86, 102, \\
\hline arus (Carpiodes) .............101, 206 & 117,132 \\
\hline lescopns (Notropis).........65, 79, 85 & velatum (Teretulus) ............ 132 \\
\hline nue (Moxostoma) ..............101, 146 & velatus (Ptychostomns) ........ 102, 132 \\
\hline unis (Erimyzon) .............. 146 & velatus (Teretulns) ............ $1: 32$ \\
\hline teres (Catostomus)...100, 101, 102, 159, 166 & velifer (Carpiodes)............86, 194, 196 \\
\hline Teretulus.............110, 113, 114, 140 & velifer (Catostomus) ............100,196 \\
\hline us (Phenacobius) .......... $\quad 86$ & velifer (Icthyobus)............. 196 \\
\hline risus (Hyodon) $\ldots \ldots \ldots \ldots \ldots \ldots 77,84$ & victoriæ (Moxostoma) ...........27, 138 \\
\hline ssellata (Etheostoma) .......... 59, 83 & virescens (Pantosteus) ........... 102, 182 \\
\hline etragonopterus................ 89 & viridis (Chænobryttus) $\ldots \ldots \ldots \ldots 15,35,83$ \\
\hline xanus (Catostomus) $. . . \ldots \ldots \ldots . . .102,167$ & vitrea (Ioa) .................. 82 \\
\hline$($ Myxostoma $) \ldots \ldots \ldots \ldots \quad 131$ & vitreum (Stizostetbium) $\ldots \ldots \ldots \ldots 60,83$ \\
\hline ( Myxostoma) $\ldots .86,117,131$ & vittata (Hemitremia).........65, 79, 85 \\
\hline lassinus (Nothonotus) $\ldots \ldots \ldots \ldots$.... 13, 82 & vittatus (Catostomus) ...........100, 145 \\
\hline lalassiuus (Ptychostomus)....... 102, 131 & vitulus (Bubalichtbys)........... 206 \\
\hline nus (Teretulus) .......... 131 & vitulus (Carpiodes) ............. 101 \\
\hline thompsoni (Carpiodes) ...... 101, 195, 198 & vulgaris (Anguilla), 29, 33, 39, 44, 55, 70, \\
\hline nipsoni (Ichthyobus) ......... 198 & 81,87 \\
\hline eauianus (Semotilus) .......... & vulneratus (Nothonotus) ......... 58, 82 \\
\hline Thymallus ...................... & winchelli (Centrarchus) ........53, 68, 86 \\
\hline tilesii (Catostomus) .........101, 174, 218 & winchelli (Hybopsis)............ 53 \\
\hline stia (Codoma) ........... 50, 85 & xænocephalus (Hydrophlox)....... \\
\hline iglopsis ................... 88 & זænоcephalus (Hybopsis)........ 49 \\
\hline isignatum (Erimyzon) .........160, 167 & xæuura (Codoma) ................3ז, 85 \\
\hline gignatum (Moxostoma)........ 102, 167 & xænurus (Minnilus)............ \\
\hline ereula tus (Catostomus) ........10n, 145 & xanthocephalus (Amiurus) ......... \\
\hline amidus (Carpiodes) ....... ...... 101, 199 & xanthopus (Catostomus) ......... 163 \\
\hline tumidus (Ichthyobus)... & Xenisma................ $48,62,77,89$ \\
\hline Typhlichthys........... & $\ldots \ldots . .31,46,61,76,89$ \\
\hline Ulocentra...... & Xystroplites..................... 61,89 \\
\hline Urauidea $\ldots . . \ldots \ldots \ldots . . . . . . . .68$ & yarrowi (Pantosteus)............. 183 \\
\hline ranops (Phenacobius) ........67, 79, 86 & zanemus (Ceratichthys) ......... 24,86 \\
\hline rus (Bubalichthys) ..69, 87, 101, 206, 209 & zonalis (Nothonotns) ........... 58,82 \\
\hline urus (Carpiodes) ......... & Zygonectes .............31, 48, 62, 77,89 \\
\hline
\end{tabular}



Department of the Inferior:

t. S. NATIONAL MUSEUM.

\author{
$-13-$ \\ BULLETIN
}

OP THE

\title{
UNITED STATES NATIONAL MUSEUM.
}

No. 13.

PUBLISHED UNDER THE DIRECTION OF THE SMITHSONIAN INSTITUTION.

WASHINGTON:

GOVERNMENT PRINTING OFFICE. 1879. 


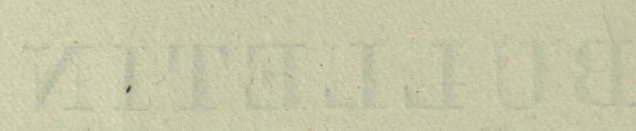




\section{THE FLORA}

OF

\section{ST. CROIX AND THE VIRGIN ISLANDS,}

BY

BARON H. F. A. EGGERS.

WASHINGTON :

GOVERNMENT PRINTING OFFICE.

1879. 


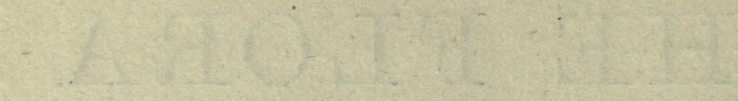

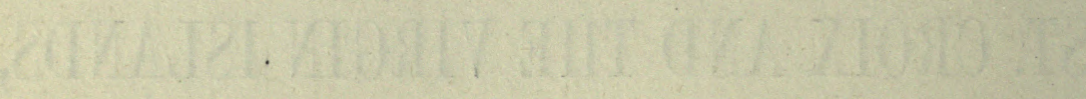

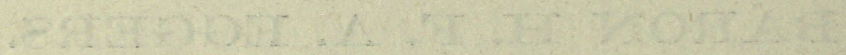


A D VERTISEMENT.

This work is the thirteenth of a series of papers intended to illustrate the collections of natural history and ethnology belonging to the United States, and constituting the National Museum, of which the Smithsonian Institution was placed in charge by the act of Congress of August 10, 1846.

It has been prepared at the request of the Institution, and printed by authority of the honorable Secretary of the Interior.

SPENCER F. BAIRD, Servetary of the Smithsonian Institution.

Smithsonian Institution, Washington, May, 1879. 



\section{FLORA OF ST. CROIX AND THE VIRGIN ISLANDS, WEST INDIES.}

By Baron H. F. A. EgGers.

To the east of the island of Porto Rico, between $18^{\circ} 5^{\prime}$ and $18^{\circ} 45^{\prime} \mathrm{N}$. lat. and $64^{\circ} 5^{\prime}$ and $65^{\circ} 35^{\prime} \mathrm{W}$. long., stretches a dense cluster of some larger and numerous smaller islands for a distance of about 85 miles, which are known by the name of the Virgin Islands. The principal islands are Vieques and Culebra, belonging to Spain, St. Thomas and St. Jan, belonging to Denmark, and Tortola, Virgin Gorda, and Anegada, belonging to England. The superficial area of the larger islands is only from 16 to 40 square miles, whilst the smaller ones are mostly uninhabited islets, or even rocks, some of which are nearly devoid of vegetation, the coast-line of them all being sinuous, and forming numerous small bays and ereeks. The whole group is evidently a submarine prolongation of the mountains of Porto Rico, showing its tops and higher ridges above the level of the sea, the depth of which between the various islands and Porto Rico is only from 6 to 20 fathoms. The declivities to the north and the south of the ridge on the reverse are rery steep, no bottom having been found 25 miles to the south in 2000 fathoms, and 80 miles to the north the Challenger Expedition found a depth of about 3850 fathoms, the greatest ever measured in the northern Atlantic Ocean.

The greatest height in the Archipelago is attained in its central part, St. Thomas reaching up to $1550^{\prime}$, Tortola even to $1780^{\prime}$, St. Jan and Virgin Gorda being a little lower, whilst the hills in Vieques and Culebra, to the west, are only $500^{\prime}-600^{\prime}$ high, and Anegada, the northeasternmost, is, as its Spanish name, the inundated, implies, merely a low or halfsubmerged island, elevated but a few feet over the level of the sea. The central islands, therefore, present the appearance of a steep ridge, precipitously sloping to the north and the south, and eut up by numerous ravines, which during heary rains are the beds of small torrents, but which generally are without running water, and which at their lower end widen into small level tracts on the sea-coast, often forming a lagoon on the sandy shore. Between these level tracts the coast is usually very

Bull. Nat. Mus. No. $13-1$ 
bold and rocky, forming abrupt promontories of eonsiderable height and picturesque appearance, the hills and ridges on the other hand being more rounded and of a softer outline.

The whole group of islands, with the exception of Anegada, which is built up of a tertiary limestone of very recent and probably pliocene date, belongs to the cretaceous period, ${ }^{*}$ showing as the principal rock a breccia of felsite and scoriaceous stones, the cementing part of which probably consists of decomposed hornblende, and having its cavities commonly filled with quartz or ealcareous spar. Besides this principal rock, which is often found distinctly stratified, and which is called Bluebit by the inhabitants, who generally employ the stone for building materials, limestone, diorite, clay-slate, and other less frequent minerals also occur in the islands, forming, however, only a poor substratum for vegetation everywhere. For the product of the decomposed rock is generally a red heavy clay. Only Vieques shows a more fertile soil, produced by the alteration of a syenite-like diorite, its more level surface at the same time allowing the fertile strata to remain on the surface; whilst in the other islands the heavy rains as a rule will wash the loose covering of the ground down to the sea.

From various facts observed in Anegada and Virgin Gorda by Sir R. Schomburgk, $t$ as well as by Mr. Scott, in Vieques, at Porto Ferro Bay, it appears that at the present period the whole chain of islands is slowly rising, so that perhaps in a geologically speaking not very distant time most of the islands may become connected reciprocally and with Porto Rico.

To the south of the Virgin Islands, at a distance of about 32 miles, and between $17^{\circ} 40^{\prime}$ and $17^{\circ} 47^{\prime} \mathrm{N}$. lat., $64^{\circ} 35^{\prime}$ and $64^{\circ} 54^{\prime} \mathrm{W}$. long., lies the island of St. Croix, geographically considered an outlying part of the former group, but separated from it by an immense chasm of more than 2000 fathoms, as stater above. This extraordinary crevice has no doubt been formed at an early period, and has in various respects contributed materially to isolating the island from its neighbours.

St. Croix is of about 57 square miles, and has a triangular form, with the greatest length, some 20 miles, from east to west, the greatest breadth being about 5 miles, in the western part of the island, which becomes gradually narrower towards the east. The coast-line is more connected and the surface more level than in most of the Virgin Islands, the hills stretching only along the northern coast and through the eastern part of

*Cleve: On the Geology of the North-eastern West India Islands. Stockholm, 1871.

+Berghaus: Almanach für das Jahr 1837, pp. 405 and 408. 
the island, reaching in some places as high as $1150^{\prime}$ (Mount Eagle), but averaging $600^{\prime}-800^{\prime}$ only.

The rock of these hills is nearly the same as in the above-named group, although the Bluebit of this latter occurs more rarely, and is substituted by a fine, greyish, stratified clay-slate, without vestiges of any organic remains. The strata of this slate are often very much disturbed, so as to present an exceedingly broken and overturned appearance. The greater, western part of the island forms a large, slightly inclined plain, sloping towards the south, and interrupted in a few places by low, short, isolated ridges only $200^{\prime}-300^{\prime}$ high, and formed of a tertiary limestone of the miocene period. This limestone is covered by a layer of detritus and marls some feet thick, but shows itself at the surface in various places, and contains several fossils, partly of still existing species of mollusca.

Along the coasts are found some new alluvial formations, often enclosing lagoons, some of which are of considerable size. These lagoons are being gradually filled up by regetable matter, as well as by sand and stones washed down by the rains from the hills; but whilst in the Virgin Islands many similar lagoons have been raised already sereral feet above the level of the sea, and laid completely dry, no such thing has been observed in St. Croix. This seems to indicate that no rising of the ground is taking place in the latter, as is the case in the former, as mentioned above. From its whole structure and formation it may be inferred that the soil is more fertile in St. Croix than in most of the Virgin Islands, Vieques excepted, the sugar-cane being cultirated to a considerable extent on the island.

Whilst thus the geology of St. Croix and the Virgin Islands presents some not unimportant differences, the climate may, on account of their similar geographical position, as well as elevation above the sea-lerel, be said to be materially the same in both.

In accordance with the geographical position of the islands, the temperature is very constant and high, the jearly mean average being $27.2^{\circ} \mathrm{C}$, divided nearly equally over all the months, the coldest, February, showing $25.6^{\circ}$, the warmest, September, $28.9^{\circ}$, a difference of $3.3^{\circ}$ only. The same uniformity is observul in the daily variation, which scarcely ever surpasses $5^{\circ}$, the thermometer rising gradually from 6 a. m. till 2 p. m., and falling just as gradually during the rest of the 24 hours.

Thus the difference of temperature at the various seasons of the year is too small to affect the life of regetation to any very perceptible ex 
tent, and it is therefore the variable degree of moisture at different times which chiefly produces any variation in the development of regetable life at the different seasons.

The lowest temperature observed at the sea-level, in the shade, is $18.1^{\circ}$; the highest, $35.5^{\circ}$. In the sun, the mercury will sometimes rise as high as $51^{\circ}$, but as a rule does not surpass $40^{\circ}$. Observations made in St. Thomas by Knox* and myself show a decrease of about $2 \circ$ for an elevation of every $800^{\prime}$, which gives to the highest ridges in St. Thomas and Tortola an annual mean temperature $32_{2}^{\circ}-4^{\circ}$ lower than that of the coast, a difference sufficient to produce some variation in the flora of these parts. The northern slope of the hills, from being the greater part of the year, viz, from August to May, less exposed to the rays of the sun, are generally also somewhat cooler and more moist than the southern ones, the consequences whereof are also felt in the life of plants to a considerable extent.

An equal regularity, as observed in the temperature, manifests itself with regard to the pressure of the atmosphere, the daily variations of the barometer being only about $0.05^{\prime \prime}$, and the maximum yearly difference only $0.2^{\prime \prime}$. It is only during strong gales and hurricanes that the barometer is more seriously affected, it then falling sometimes as much as $2^{\prime \prime}$. These hurricanes, as a rule, occur only during the months from August to October, at which period the trade-winds from the northeast, which otherwise blow most part of the year, generally become unsteady and uncertain. These constant winds, combined with the high temperature, no doubt are the reason why the moisture of the air is comparatively small, being on an arerage only 73 per cent. of the possible maximum, thus exciting a constant evaporation in plants, and rendering it necessary for them to obtain a greater supply of water through the soil than in more moist climates. For this reason a considerable quantity of rain becomes of the lighest importance to the vegetable life, as being the only form in which plants can obtain a sufficient amount of water necessary to their existence, even dew being very rare on account of the tradewinds blowing also during the night the greater part of the year.

Neither of the islands in question is of sufficient elevation above the sea to cool and condense the atmospheric moisture brought on by the trade-wind, nor is their configuration farourable for detaining the clouds, their greatest extent being parallel to the direction of the wind. Thus, for the greater part of the year they receive only a small quantity of

* Knox : An Historical Account of St. Thomas, W. I. (New York, 1852.) 
rain, falling chietly in the form of short, rapid showers of only a few minutes' duration, and it is not till the 'warmer part of the year that heavy and general rains become possible in these regions. During this latter time, the trade-winds become irregular and slight, or are even entirely suspended, as stated before; hence the moisture generated by the daily evaporation from the ocean is not carried off as soon as formed, but is allowed to gather into rain-clouds, and finally to precipitate itself again as rain nearly on the same spot where it was formed.

From observations made in various islands for a period of more than twenty-five years, the annual mean quantity of rain seems to be about the same in all the islands, averaging $42^{\prime \prime}-44^{\prime \prime}$; the eastern parts of all, as being more exposed to the direct action of the winds, always showing a considerably smaller quantity than the central and western ones. Although no month of the year is without rain, yet from the above it will be easily concluded that there is a remarkable difference between the rarious months in this respect: the driest, February, having only an arerage of $1.5^{\prime \prime}$; the wettest, October, of $7.0^{\prime \prime}$; and to this difference, at the various periods of the year, it is chiefly due, that notwithstanding the uniform temperature all the year round, yet some variations in the aspect and intensity of vegetable life are observed in the various seasons.

Both the annual and the monthly quantity of rain are subject to vary considerably, one year showing $23^{\prime \prime}$, or in some places $18^{\prime \prime}$ only, auother again $70^{\prime \prime}$ or $78^{\prime \prime}$. A still greater difference may be observed between the same months of different years: thus, February having had one year $0.19^{\prime \prime}$ only, another, on the contrary, $3.75^{\prime \prime}$; May 0.47" the one year and 16. $84^{\prime \prime}$ the other. These excessire rariations must, no doubt, materially affect vegetable life, indicating at the same time a considerable degree of hardiness in respect to drought in the perennial plants indigenous to the islands, and as alluded to above, acting upon them in a similar way as the variations in temperature in colder climates.

The number of days on which rain falls averages for the period from 1852-73, 161 a year, giving a mean fall of rain of $0.27^{\prime \prime}$ per diem: April showing the lowest nunber, 9; October the highest, 16. From what has been said before, it is evident, however, that the small monthly quantity of rain during the dry part of the year, viz, January to April, divided even over a great number of days (so as to amount to $0.14^{\prime \prime}$ or $0.18^{\prime \prime}$ only a day), can be of no great importance, as it is precipitated in a short shower, is insufficient for penetrating into the soil, and so is very soon 
eraporated again by the action of the sun and the trade-wind combined. It is not till May, when the increased quantity of rain is sufficient to penetrate the parched soil, that its influence and effect upon vegetation makes itself felt by renewed life and activity in all the various branches of the vegetable kingdom in general.

Looking at the regetation of St. Croix and the Virgin Islands in its generality, and without entering into details, we may consider it to be identical, as a whole, showing the same main features, and naturally divided into four distinct formations, as in most other West India Islands, viz. the littoral, the shrubby, the sylvan, and the region of cultivation, counected, of course, here and there by intermediate formations, but on the whole virtually distinct from different biological conditions.

Beginning with the littoral flora, we find along the coast in shallow water a multitude of Algæ, among which are found some marine Phanerogamæ, especially the common Thalassia testudinum and Cymodocea manatorum, and in less quantity the beautiful little Halophila Baillonii, a recently discovered Potamea, with oval delicate leaves, and growing gregariously on the bottom of the sea in coarse gravel. The regetation of tropical seashores is of a very uniform character all over the world, the physical conditions being similar on them all, and the migration from one shore to another being exceedingly facilitated by the sea as well as by birds, storms, and the action and intereourse of the inhabitants. Thus, the same species of littoral plants are found on nearly all the West India islands, many of them also inhabitants of far distant shores on the African and Asiatic continents,-belonging to the cosmopolitan and transoceanic species, a list of which was first prepared by Robert Brown, and afterwards augmented by A. DeCandolle, and which seem to possess an extraordinary faculty for migration. According to the different character of the coast, as sandy, rocky, or swampy, the vegetation on it also assumes a different aspect.

On the sandy shore, which is composed of a fine white gravel, consisting principally of innumerable pieces of broken shells and corals, and thus forming a thick layer of carbonate of lime, we see a luxurious flora of trees, shrubs, and minor plants, which all, on account of the underground water collecting from the hills above, generally have a green appearance all the year round, even when the hills of the interior present a withered aspect from want of rain. Among the trees growing here the most prominent are the Hippomane Mancinella, the Cocco- 
loba urifera, Chrysobalanus Icaco, and Canella alba, besides the Cocos mucifera, which is planted and naturalized, especially on the low sandy seashore. Under these taller forms appear many kinds of shrubs, such as Ecastophyllum Brownei, Tournefortia gnaphalodes, Borrichia arborescens, Ernodea litoralis, Suriana maritima, Erithalis fruticosa, Colubrina ferruginosa, Guilandina Bonduc and Bonducella, and several others. Still lower shrubs and suffrutescent herbs are Sccevola Plumieri, Tournefortia gnaphalodes, Sesuvium portulacastrum, Heliotropium curassavicum, Philoxcrus vermiculatus, Cakile aqualis, as well as several grasses and sedges, as Sporobulus litoralis, Stenotaphrum americanum, and Cyperus brunneus, as also some remarkable creepers or climbers, such as Ipomaca pes-caprce and Lablab vulgaris.

Most of these species disappear on the rocky cliffs, where they give room for others, mostly shrubs of a low growth, and with thicker or more coriaceous leaves, that are able to resist the force of the wind, which often bends the whole plant into a dwarfish individual, the branches of which are cut off at the top in a western direction. The most common of these shrubs are Jacquinia armillaris, Elacodendron xylocarpum, Plumieria alba, and Coccoloba punctata, as well as some. monocotyledonous plants, such as Pitcairnia angustifolia, Agave americana, and a few Cacti, principally the stout Melocactus communis.

Still more different forms appear where the coast becomes swampy from the presence of lagoons. Here predominates the Mangrove formation, composed chiefly of Laguncularia racemosa, Conocarpus erectus, Avicennia nitida, and Rhizophora Mangle, which all grow more or less in the water itself. In less moist places we find some others, such as Bucida Buceras, Anona palustris, Antherylium Rohrii, and the curious Batis maritima, which recalls to the mind the halophytes of the steppes.

However different these various forms of littoral plants may appear, compared to each other, yet they all have in common the predilection for the sea, the saline exhalation of which seems indispensable to their growth. Some have even, like Avicennia, their leaves always covered with small salt crystals; others, like Batis maritima, are true halophytes, and only very few of the plants of the coast in generality are found in the interior even of these small islands. An exception is made by the cocoanut palm, which is found growing all about on the islands, even on the top of the highest hills, as also by Coccoloba uvifera, found in similar localities.

In passing from the coast into the interior we find on the eastern, and 
partly also on the southern part of all the islands, a dry shrubby vegetation of a greyish or yellowish aspect, which, from the predominating genus composing its elements, I have called the Croton vegetation. This peculiar kind of dry shrub also occurs here and there in other parts of the islands, where the soil, through reckless cultivation, has become too exhausted to produce a growth of taller trees, and it cannot be estimated to cover less than one third part of the whole surface of the islands, predominating in some, as Tortola, St. Thomas, and Culebra, less conspicuous in others, as St. Jan, Vieques, and St. Croix.

The ravines as well as the northern and western parts of the islands are often covered with a growth of taller trees, forming a kind of forest, composed of species partly evergreen and partly with deciduous foliage, and which, from one of the most prominent forms, I have called the Eriodendron vegetation. The area covered by this formation may be taken to be about one fifth of the whole surface, the best wooded islands being St. Jan and Vieques, the least wooded ones St. Thomas and Virgin Gorda.

The remainder of the surface is either used for pasture or cultivated with sugar-cane or provisious, the former on a large scale in St. Croix and Vieques only, the latter everywhere on the islands where the soil seems proper for the purpose. This last section I term the cultivated region.

Considering first the Croton vegetation, we find here a number of plants which in rarious ways have become enabled to resist the deteriorating effects of the dry climate, and to exist on the barren rocky soil always found where the moisture is not sufficient for decomposing the natural rock of the surface. Thus, some of these plants, as the whole of the genus Croton, already mentioned above, have small leaves, which, like the stem, are covered with scales and tomentose hair, containing besides aromatic oil, all which contrivances tend to diminish evaporation as much as possible. The most common species of this remarkable genus are $C$. flavus, astroites, bicolor, and betulinus. Other forms obtain the same object by having very small, partly deciduous leaves and their stipules transformed into prickles, especially the Acaciæ, such as A. Farnesiana, maeracantha, tortuosa, and sarmentosa. Others, again, are rich in milky juice, as Euphorbia petiolaris, Rauwolfia Lamarckii, and the naturalized Calotropis procera, or merely in aqueous sap, as the Cactex, the commonest forms of which are Melocactus communis, Cereus floccosus, and several species of Opuntia. Others, such as Bromeliaceæ, on the contrary, have 
a very dry structure, and a dense cover of scales for protection, whilst others again, such as Anona squamosa, which are apparently without any means to resist the effects of dry weather, have no other remedy left than to shed their leaves during a part of the year, and thus preserve their existence at the temporary sacrifice of their vegetative organs.

All the forms mentioned above are of very slow growth, and, with the exception of a few that are used for burning charcoal, of scarcely any importance either to man or animals, for which reason the districts occupied by them as a rule present a very desolate and uninviting appearance.

Where the climate becomes sufficiently moist, and the soil in consequence thereof more decomposed and fertile, the forest appears in place of the Croton vegetation, on the uncultivated lands, especially in ravines and on steep declivities, which do not allow of cultivation or grassfarming. As nearly everywhere in the tropics, the forest here is com- posed of many different species of trees mixed together, a gregarious growth being very rare. From the forests of moister tropical countries, however, the woods in these islands are distinguished by possessing a quantity of forms with thin, herbaceous leaves, which for this reason shed their foliage during a part of the year, thus combining the appearance of the woods of colder climates with the dark evergreen forms of the intertropical countries. Some of these species with deciduous foliage have two periods for flowering: one precocious in the first months of the year, when the small quantity of rain seems insufficient to produce both leaves and flowers at a time, and another later in the year, when both foliage and blossoms are vigorously developed by the increased moisture of the summer. The evergreens for the same reason have a less fixed and more unlimited time for flowering, and seem to show their reproductive organs whenever the quantity of rain becomes sufficient for producing them besides maintaining the already existing foliage. Among the great variety of evergreen forms of trees and shrubs, I shall here only mention as the most common several species of Anona; of Guttiferæ, such as Calophyllum Calaba and Clusia rosea; of Sapotacex, such as Sideroxylon, Chrysophyllum, Lucuma, and Dipholis; of Rutaceæ, as Zanthoxylum and Tobinia ; of Lauraceæ, as Nectandra and Oreodoxylon, as well as many others, for the details of which I beg to refer to the systematical part of my treatise. Others are possessed of aërial roots by which to affix themselves to the stems of trees and rocks, as several species of Ficus; others again are vines, such as Bignonia, Serjania, Grouania, and Cissus. 
Interspersed between these evergreens are seen various species of arboreous plants with deciduous leaves, the number of which, however, seldom is large enough to seriously change the general aspect of the forest as being uniformly green all the year round. The time for shedding their foliage in these forms is generally from January to April, most of them, as stated before, flowering precociously at this time, as the moisture in the ground is not sufficient to allow them to retain their foliage together with the producing of the flowers. It appears evident that this is the reason for the shedding of the leaves, from the fact observed by me in several species (such as Piscidia Erythrina and others), that individuals which, from being too young or for some other reason, do not flower, do not shed their foliage, but evidently find moisture enough in the soil to resist the drought, not having to spend their resources on the production of flowers and fruits, as others of their kind.

The most prominent among the trees and shrubs with a deciduous foliage are Spondias lutea, Schmidelia occidentalis, the enormous Eriodendron anfractuosum, Hura crepitans, Casearia ramiflora, Sabinea florida, ' and several others, which all more than the evergreens contribute their share to the forming of a layer of leaf-mould under the taller forms. Yet this layer is but scanty in most places, and from the want of it, as well as from the dense shade produced by the evergreen trees and shrubs, the minor forms covering the ground are comparatively scarce, and chiefly confined to some Piperaceæ, Acanthaceæ, and Gramineæ, as well as a few ferns and mosses, among which Hemionitis palmata, Pteris pedata, and Asplenium pusillum are the most common.

A somewhat richer variety is presented by the numerous epiphytes that cover the branches and stems of trees and shrubs, notwithstanding that the bark of the latter, from the uniform temperature, is, as a rule, exceedingly smooth, and but rarely covered with lichens or mosses. Of real parasites only a few are met with, especially Loranthus emarginatus, whilst the non parasitical epiphytes are numerously represented by Bromeliacer (principally the genus Tillandsia), Aroideæ (among them the large-leaved Philodendron giganteum), and Orchidaceæ (chiefly Epidendrums and Oncidiums), as well as some ferns. Of these latter families, several species are found only on the highest ridges of the islands, at an elevation of over $1300^{\prime}$, there forming a formation peculiar to these regions, comprising, among others, some terrestrial Orchids, such as Habenaria maculosa and alata, as well as some Aroideæ, Bromeliaceæ, and ferns, among which the beautiful Cyathea arborea deserves special mention. 
The part of the island inhabited and cultivated by man of course rep. resents the least of interest in a phyto-geographical sense, as nature here has been modified and modelled according to the wishes and necessity of society to such an extent as to almost entirely obliterate its original character. As stated already, the principal object of cultivation is the sugar-cane, which, however, is cultivated on a large scale only in the two largest and most level of the islands, Vieques and St. Croix, the others, viz. St. Thomas, St. Jan, Tortola, and Virgin Gorda, having, with a few exceptions, long ago abandoned the cultivation of the cane as unremunerative, the two remaining of the larger islands, Culebra and Anegada, never having been appropriated to that purpose.

Besides the cane, some Sorghum vulgare is also cultivated in fields for herbage, the rest of the tilled soil being used for the planting of the common tropical regetables, generally in small quantities, on patches of soil selected here and there. The commonest of these plants are Yam (Dioscorea alata and altissima), Sweet Potato (Ipomca Batatas), Okro (Abelmoschus esculentus), Tanier (Xanthosoma sagittafolium), Pigeon-pea (Cytisus Cajan), Tomato, and Pepper (Capsicum), as well as some Cucurbitacex, as Pumpkin, Melon, and others.

Along with these useful plants follow a great number of herbaceous annuals, mostly cosmopolitan weeds, introduced after the settlement of the islands, and dependent on the continuous cultivation of the land, as without the clearing of the soil from shrubs and trees their existence would soon be terminated by the stronger arboreous species, which would deprive them of the necessary light and air.

Thus, much against his wish, man favours the propagation of innumerable weeds, which in their short period of regetation produce seeds enough to secure their continuance on the land notwithstanding the efforts to exterminate them by frequent weeding. Among the commonest of these forms are some Labiatæ (Leonurus sibiricus, Leonotis nepetafolia, and Leucas martinicensis), Argemone mexicana, Tribulus maximus, Boerhaavia erecta and paniculata, and especially many grasses and sedges, such as Panicum, Paspalum, Chloris, Digitaria, Cyperus, and others. The most troublesome of these, from an agricultural point of view, is the Bay-grass (Cynodon Dactylon), said to be introduced, but now found everywhere, and, on account of its long creeping rhizoma, inexterminable.

Similar forms to these are seen growing along roads and ditches, especially some Leguminosæ, as Crotalaria, Desmodium, Phaseolus, Clitoria, 
Centrosema, Teramnus, Vigna, Rhynchosia, and others; grasses, as Lappago, Aristida, Sporobolus, Eleusine, Dactyloctenium, and Eragrostis; or Synanthereæ, as Elephantopus, Distreptus, Bidens, and Pectis. Whilst all these latter forms flower during the greater part of the year, the beantiful Convolvulaceæ, such as Ipomoea fastigiata, Nil, umbellata, dissecta, violacea, and others, are in blossom only during the winter months, from December to February.

In some places that are moist enough, sedges and semi-aquatic plants will be seen growing; in a few rivulets which contain water all the year round, and which are limited to Vieques and St. Croix, a few aquatic forms occur, such as Echinodorus cordifolius, Lemna minor, Typha angustifolia, and Nymphaca ampla.

The pastures, which occupy a considerable extent of the land, are either artificial,-planted with Guinea-grass (Panicum maximum), a perennial plant, and, like most of the cultivated West India plants, introduced from the Old World,-or natural, covered with various forms of indigenous Gramineæ as well as low shrubs and trees, that have continually to be cleared away to prevent the land becoming overrun by them. The artificial pastures as a rule are fenced in, and often protected against the dry season by the planting of Thibet-trees (Acacia Lebbek), now commonly naturalized everywhere; the natural ones, on the contrary, are generally open and abandoned to the cattle, whilst the artificial oues are cut regularly, and the stock is not allowed to enter them.

The grasses composing the natural pastures are several species of Panicum, Paspalum, Dactyloctenium, and Sporobolus; some, as Tricholckna insularis, being very bitter and unfit for herbage. The roaming about of the cattle everywhere effectually prevents the re-establishment of trees or woods, which, for climatic reasons, would be desirable in many places; for the young buds are destroyed by sheep and goats, which no doubt have contributed largely to deteriorating even the still existing woods.

Around dwellings are found planted and naturalized most of the plants now common to nearly all tropical countries,-some fruit-bearing, as Tamarindus indica, Mangifera indica, Carica Papaga, Persea gratissima, Crescentia Cujete, Melicocca bijuga; others ornamental, as Poinciana regia, Calliandra saman, Casalpinia pulcherrima, and others Actual gardens are now very rare, flowers being mostly cultivated in pots or boxes. Some few vegetables of colder climates are cultivated in shady places where water is abundant, such as salad, radishes, cabbage, and others. In waste places are found most of the tropical weeds, as Ricinus com- 
munis, Datura Metel and Stramonium, Euphorbia pilulifera, heterophylla, and hypericifolia, Mirabilis jalapa, Jatropha curcns, Cassia occidentalis, and especially several kinds of Sida and Abutilon as well as some other Malvaceæ.

The four formations mentioned above are usually found only on the larger islands, the smaller ones, from their limited size, generally possessing chiefly the littoral and shrubby only. The island of Anegada, although being one of the larger ones, yet from its structure and the nature of its soil, seems to be chiefly covered by a vegetation composed of the plants of the sandy shore, besides some of the trees and shrubs following the settlement of man in these regions. Sir R. Schomburgk, who has given a description of the island in the Journal of the Royal Geographical Society, 1832, asserts that the island possesses several interesting species of plants, among others a peculiar kind of Croton. As, however, I have not been able to procure the work referred to above, I am not prepared to say which those species are, and they are not mentioned by Prof. Grisebach in his Flora of the British West India Islands.

Although, as stated abore, the general character of the flora both in St. Croix and the Virgin Islands, considered as a whole, is essentially the same and distinctly West Indian, yet, in looking more closely into detrils, we are soon struck by finding a great many species in the one which are not found in the other. This is the more remarkable, as from a geographical and climatical point of view the physical conditions must be said to be materially identical.

In referring to the list of plants giren at the end of my treatise it will be seen that out of a number of $\$ 81$ indigenous phanerogamous species no less than 215 , or c. $\frac{1}{4}$, are found in the Virgin Islands only, whilst 98 , or about $\frac{1}{y}$, occur only in St. Croix, thus leaving only 568 , or less than $\frac{2}{3}$, in common to both.

As may be expected from the general character of littoral vegetation, there are very fer species which are not found on both sides of the deen channel separating St. Croix from its northern neighbours, the principal exception being Baccharis dioica, which only occurs in St. Croix, aud Egletes Domingensis, found by me only in the Virgin Islands.

Some greater difference is found in the dry shrubby formation, where several very common plants, such as Euphorbia petiolaris, Acacia sar. mentosa, Mamillaria nirosa, and others, are to be seen in the Virgiu Islands only, St. Croix having to itself a few less common species, such as Sccurinega acidothamnus and Castela crecta. 
It is, however, in the forest regetation, which best represents the original flora of the islands, that the greatest and most varied differences are observed, showing especially the great variety of species in the Virgin Islands which are not all found in St. Croix, and among which are many of the commonest and most generally distributed forms. Belonging to St. Croix alone are comparatively few and rare species, chiefly some Rhamnacex; viz, Maytenus elcodendroides and Zisyphus reticulatus, Catesbaca parviflora, Beloperone nemorosa, Petitia Domingeisis, Buxus Vahlii, and Urera elata. All these forms occur only in a few localities, and are of no impertance to the general character of vegetation, as is the case on the Virgin Islands with many of the following species that are found on them, but not in St. Croix. It would be too much to mention all the different species here, for which I beg to refer to the appended list and tabular statement. I shall only enumerate a few of the most interesting, especially Malpighiacex (as Byrsonima lucida, Malpighia Cnida and angustifolia), Rutaces (Pilocarpus racemosus, Tobinia spinosa, Xanthoxylum ochroxylitm), Leguminosæ (Sabinea florida, Pictetia aristata, Sesbania sericea, and Acacia nudiflora), and Sapotacer (Sapota Sideroxylon). Among Monocotyledones are to be mentioned Arthrostylidium capillifolium, Rhynchospora pusilla, Dioscorea pilosiuscula, Catopsis nutans, and sereral Orchids. Several of these plants grow more or less gregariously, thus becoming characteristical to the formation. Among these are Malpighia Cnida, Reynosia latifolia, Acacia nudiflora, Sabinea florida, and sereral species of Pilea, most of them being very common, and even generally used for domestic pur poses.

Besides these species, entirely wanting in St. Croix, the Virgin Islands possess sevcral that are very common, or at least not uncommon on them, but which occur but very rarely in St. Croix, such as Thrinax argentea, Rondeletia pilosa, Faramea odoratissima, Miconia angustifolia, Mimosa Ceratonia, and others, and most of which I have not found myself in the latter island, but only found labelled with St. Croix as habitat in the Copenhagen herbarium, so that an error in some cases at least may be not at all impossible.

However great are the differences in the flora on the two groups of islands, yet this interesting fact is not due to their possessing endemic species, as all the plants known as growing on them are also found in other West India islands, especially Porto Rico, whence the regetation of both the Virgin Islands and St. Croix seems to be derived. Thus it 
is mainly to different periods of immigration under varied physical conditions that we must ascribe the remarkable discrepancies in the flora of those apparently homogeneous islands. Some few species, it is true, are indeed given in my list as having been found only in the Virgin Islands, such as a few Cacter, Vernonia Thoma, and the new species described by me on the present occasion. But as long as Porto Rico, Hayti, and eren Cuba, are still insufficiently explored, it may very well remain doubtful whether those species do not also occur in one or several of them, just as several Cuban plants, described as endemical in that island by Prof. Grisebach, have been found by me to occur not at all unfrequently in the Virgin Islands and St. Croix, such as Arthrostylidium capillifolium, Reynosia latifolia, and R. mucronata.

It may thus be confidently asserted that both the groups in question have derived their stock of plants from the neighbouring larger island of Porto Rico. The question that remains to be solved is merely why have they not all received the same species, and particularly why is it that St. Croix, although the largest of all, has received a comparatively and absolutely much less number of species than for instance the far smaller St. Thomas?

For the explanation of these interesting facts we have no doubt to look to the geological history of the islands, as the conditions for immigration over sea, even if possible to all the species, are essentially the same in both groups, and therefore give no solution of the problem in question.

I am thus led to think that at a former period all the West India islands have been connected mutually, and perhaps with a part of the American continent also, during which time the plants in common to all the islands, as well as to the West Indies and the continent, have expanded themselves over their present geographical areas, at least as far as they are not possessed of particular faculties for emigration orer the sea. By a subsequent voleanic revolution, St. Croix, as well as many of the other islands, has thereafter been separated from Porto Rico and the Virgin Islands, and put into its present isolated position, which it seems to have retained ever since, whilst the latter group of islands has either still for a long period remained in connection with Porto Rico, or, if separated at the same time from it as St. Croix, has, by another revolution, been again connected with the former.

The plants now found in the Virgin Group, but not occurring in St. Croix, would thus have immigrated into the former from Porto Rico 
after the separation of St. Croix from the latter, and immigration would finally have ceased by the separation between them, as it exists at the present period. Thus, the plants found in the Virgin Islands, but not in St. Croix, would seem to have been more recently created in the probable centre of vegetătion, Porto Rico, or some other of the larger Antilles; the endemic ones, as in the other islands also, being the youngest of all, not having been formed till after the complete separation between the islands had been effected. This latter suggestion, which perhaps seems contradictory to the general accepted theory of considering the endemic forms on oceanic isles as the remnants of the oldest original vegetation,* appears to be confirmed by the fact that even on such recent formations as the Bahamas, which have as yet been but imperfectly explored, already no less than eighteen endemic species have been discovered. $\dagger$

The supposition that the islands may have been separated from the beginning, and hare received their floras through immigration over the sea, is sufficiently confuted, partly by the great number of species common to them all, which clearly indicates the connection in former times with a larger country, partly by the circumstance that most of the species common to the islands are in no way better adapted for migration over the water than those peculiar to the Virgin Islands only; in fact, but few of them apparently possess the faculty of crossing salt-water even for a limited distance.

Supposing the theory of a prolonged or oftener repeated connection between Porto Rico and the Virgin Islands to be correct, it remains still to explain how St. Croix can have obtained a number of species which do not occur in the latter group. A few of these species, viz, Castela erecta, Maytenus elaodendroides, Zizyphus reticulatus, Anthacanthus jamaicensis, and Buxus Vahlii, occur in St. Croix on the tertiary limestone only, and seem thus to have avoided the Virgin Islands as not finding there the substratum suited to their organisation. The greater part, however, might, for all apparent reasons, as well occur in the Virgin group as in St. Croix, and their absence in the former cannot be explained in this way. It must, however, be understood that whilst my investigation of St. Croix has been thorough, and carried on for several years, my exploration of the Virgin Islands has been so for only a part of them, especially the Danish ones, my collections from the

* Hooker: On Insular Floras.

† Griseb.: Geogr. Verbr. der Pfl. Westindiens, p. 55. 
others being only imperfect. Without expecting too much from this cireumstance, jet I feel confident that not few of the St. Croix plants, apparently wanting in the Virgin group, may, by closer research, still be discovered growing there on some of them, whilst, on the other hand, I am equally confident that none, or scarcely any, of the Virgin Islands' species wanting in St. Croix will be found in the latter island.

It may furthermore be obserred that scarcely any of the St. Croix species which $I$ have given as being absent from the Virgin group are common or widely distributed over the island, and so are not possessed of any great faculty for conquering ground in the struggle for existence, for which reason some of them may not have been able to gain admission on the much smaller surface of the Virgin Islands, or, having obtained a footing, they may have lost it again by the later immigration of other species, now peculiar to the group compared with St. Croix, many of which, as will be remembered, are gregarious, and gifted with great facility for expanding themselves.

A very fer species form an exception as to the limited distribution in St. Croix, Bacharis Vahlii, Cordia alba, and AEgiphila martinicensis, occurring rather frequently in the island, but having as yet not been found at all in the Virgin group, although they occur in several others of the West India islands. I am not prepared to give a satisfactory explanation of this fact at the present moment; but such isolated exceptions will no doubt always be met with in the explanation of general phenomena, and most probably a more thorough investigation of vegetable biolog.y will at a future day afford a satisfactory explanation of such apparently inconsistent facts.

In drawing the necessary consequences of the above stated theory for explaining the geographical distribution of vegetable species in St. Croix and the Virgin Islands, it would thus appear necessary to conclude, for instance, from the occurrence of Sabinea florida both in Porto Rico, the Virgin Islands, and Dominica, but not in St. Croix, that the first-named islands were still all connected, when the latter had already been separated from them and put into its present isolated position. A similar inference might be drawn from the distribution of Malpighia Cnida, whilst the occurrence of Acacia nudiflora would seem to prove a similar thing for Hayti, Porto Rico, and Antigua.

It can, therefore, scarcely be presumed, as done by Prof. Grisebach in his Geogr. Verbreitung der Pfl. Westindiens, that the distribution of species is regulated chiefly by geographical distances. A closer investigation of the flora of the various islands no doubt will confirm the

Bull. Nat. Mus. No. $13-2$ 
theory drawn from the facts observed in regard to the mutual relation between St. Croix and the Virgin Islands, that geological revolutions have been equally or perhaps even more powerfully influential in arranging the distribution of species than the greater or smaller distance, and the similarity of physical conditions.

A full linowledge of these interesting facts can, howerer, not be expected till a more thorough exploration of all the West India islands has taken place. Few of them are as yet tolerably well known, and it is therefore earnestly to be hoped that such an exploration of all the West Indies may soon be effected, the result of which will no doubt be of the highest importance both to botany and to all other branches of natural science.

It generally requires the accumulated study and knowledge of generations before the less palpable and more delicate, but often most important, facts in natural history can be explained: the West Indies have been comparatively well studied since the middle of the last century; and it would seem well now to follow up the work in order to complete a thorongh investigation, which might be used as a basis for the explanation of similar facts observed in other and less well known parts of the world.

The flora of the Virgin Islands and St. Croix has been studied by sereral botanists, some of whom have published the results of their research, which has, however, among the former group, been chietly confined to the Danish islands, the English and particularly the Spanish ones having as yet been only imperfectly explored.

Publications on the flora of these islands are given by West in his Description of St. Croix (Copenhagen, 1793); Schlechtendal, Florula Ins. St. Thomæ, in Linnæa, 1828-31 and 1834; and Eggers, Flora of St. Croix, in the Vidensk. Medd. fra Naturhist. Forening (Copenhagen, 1876) besides minor contributions in Vahl's Eclogæ Anericanæ, Symbolæ Botanicæ, and Enumeratio Plantarum, Krebs in Naturl. Tidsskrift, 1847, on the flora of St. Thomas, De Candolle's Prodromus, and Grisebach's Flora of the British West India Islands. This latter work, no doubt from want of material, scarcely ever mentions the British Virgin Islands.

Collections of plants from the islands in question are found chiefly in the Museum of the Botanical Garden in Copenhagen, as well as scattered in other European herbaria, collected principally by v. Rohr, West, Dr. Ryan, Ledru, Riedlé, L'Herminier in the past century, by Benzon, Wahlmann, Ehrenberg, Dr. Ravn, Dr. Hornbeck, Duchassaing, Schomburgk, Plée, Wydler, Örsted, Krebs, and Eggers in the present. 
The following list of plants from St. Croix and the Virgin Islands formed on my own collections and the publications or collections of other botanists, comprises 1013* species of phanerogawous and vascular cryptogamous plants, of which $\$ 81$ are indigenous and 132 naturalized, those merely cultirated being added in brackets after each family.

In determining the species I have, besides consulting the more important general systematical works on botany, as much as possible followed Prof. Grisebach's standard work on the Flora of the British West India Islands, to which I therefore beg to refer when no other authority is given. Synonymes and references to other authors are given only where it was thought desirable to supplement the Flora of Grisebach in this respect.

To the specific names of plants $I$ have added only such statements as are not given in Grisebach's work, - as local name, time for flowering, technical use, as well as descriptive remarks, where my own observation shows a difference from the description given in the flora mentioned above.

In referring to Schlechtendal, or the herbarium of the Copenhagen Museum, I have used the abbreviations Schl. and Hb. Harn.; in quoting West or Schlechtendal, their respective works on St. Croix and St. Thomas, mentioned above, are understood to be referred to.

Special localities for habitats are given only where a plant is rare, or at all erents uncommon; otherwise the island alone is mentioned.

The expression, "All islands," is meant to imply that the species is found both in St. Croix and the Virgin group, without necessarily meaning to say that it occurs in erery island of the latter.

In summing up the statistical results from my list of species, nearly the same conclusions with regard to the most numerous families are arrived at as those given in Prof. Grisebach's Geogr. Verbr. der Pflanzen Westindiens, p. 73, for the Caribbean Islands.

The proportion between Mono- and Dicotyledonous plants indigenous and naturalized is $1: 5.8$, in the indigenous ones alone $1: 4.9$, thus showing the plurality of the recently introduced plants to have been Dicotyledonous. The proportion mentioned in the plants indigenous to the islands is somewhat lower than stated by Grisebach, as cited abore, to be the rule in the West Indies, where it is given as 1:4, indicating, no doubt, that the climate of St. Croix and the Virgin Islands is less moist than that of the West Indies in general.

\footnotetext{
* De Candolle (Geogr. Bot. p. 1274) gives to St. Thomas as the probable number of Phanerogama only 450; but my list shows about 900.
} 
Table showing the distribution of the Indigenous Species of Phanerogamoe and Cryptogomce Vasculares in St. Croix and the Virgin Islands.

\begin{tabular}{|c|c|c|c|c|}
\hline 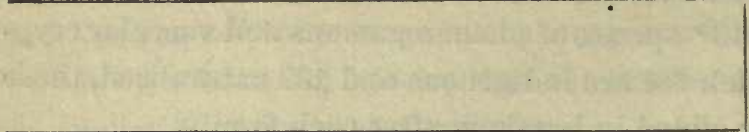 & 离 & 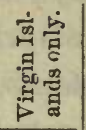 & 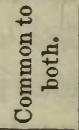 & 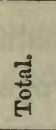 \\
\hline Dilleniacem & & & & \\
\hline 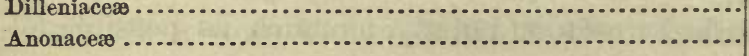 & 1 & 1 & 5 & $\begin{array}{l}1 \\
7\end{array}$ \\
\hline Menispermaceæ............... & & 1 & 1 & 2 \\
\hline 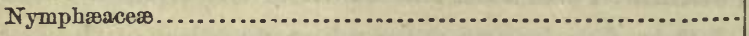 & & .... & 1 & 1 \\
\hline Papaveraceø .......... & & $\cdots$ & 1 & 1 \\
\hline Cruciferæ.............. & & $\cdots$ & 3 & 3 \\
\hline Capparidaceæ....... & & 1 & 7 & 8 \\
\hline Bixaceæ ............... & & 1 & 5 & 6 \\
\hline Violace ............... & & $\cdots$ & 1. & 1 \\
\hline Polygalacess ........... & & 3 & $\cdots$ & 3 \\
\hline Caryophyllace»........... & 1 & 2 & 9 & 12 \\
\hline Malvace»................. & 4 & 6 & 21 & 31 \\
\hline Bombaceæ ............ & 1 & $\cdots$ & 2 & 3 \\
\hline Büttneriaceø ........... & 1 & .... & 5 & 6 \\
\hline Tiliacer ................ & 1 & $\cdots$ & 7 & 8 \\
\hline Ternströmiaceæ ........ & & .... & 1 & 1 \\
\hline Guttiferæ.............. & & & 3 & 3 \\
\hline Canellaceæ............... & & .... & 1 & 1 \\
\hline Erythroxylaceæ ............... & & & 1 & 1 \\
\hline Malpighiaceæ................. & & 3 & 7 & 10 \\
\hline Sapindaceæ............. & 2 & 1 & 4 & 7 \\
\hline Meliaceæ .......................... & & $\cdots \cdot$ & 3 & 3 \\
\hline 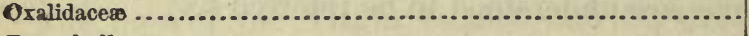 & & $\cdots$ & 1 & 1 \\
\hline Zygophyllaceæ ......... & 1 & $\cdots$ & 2 & 3 \\
\hline Rutacer......................... & 3 & 3 & 3 & 9 \\
\hline 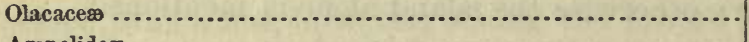 & & $\cdots$ & 1 & 1 \\
\hline Ampelideæ ........... & & .... & 4 & 4 \\
\hline Celastraceø............. & 1 & ......... & 5 & 6 \\
\hline Rhamnacer............ & 2 & - 1 & 4 & 7 \\
\hline Terebinthacer $\ldots . . . \ldots \ldots \ldots \ldots \ldots \ldots \ldots \ldots \ldots$ & 1 & 1 & 5 & 7 \\
\hline Leguminosø .............................. & 7 & 18 & 50 & 75 \\
\hline Chrysobalanaceæ ...... & & .... & 1 & 1 \\
\hline Myrtaceø ............... & 4 & 4 & 18 & 26 \\
\hline Melastomaces ............ & .... & 4 & 6 & 10 \\
\hline 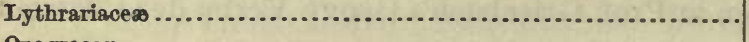 & & & 2 & 2 \\
\hline Onagracer................ & & $\cdots$ & 1 & 1 \\
\hline Rhizophoracer ......... & & & 1 & 1 \\
\hline Combretaces ............................ & & $\cdots$ & 3 & 3 \\
\hline Cucurbitaceø ....................... & 1 & 1 & 7 & 9 \\
\hline Papayacero.............. & & & 1 & 1 \\
\hline Passifloracer ............ & 2 & 1 & 5 & 8 \\
\hline Turneracem........................... & & 1 & 1 & 2 \\
\hline Cactaceæ $\ldots \ldots \ldots \ldots \ldots \ldots \ldots$ & & 4 & 8 & 12 \\
\hline Araliacer........................... & & 1 & & 1 \\
\hline Umbelliferæ ................... & & 1 & $\cdots$ & 1 \\
\hline Loranthacem............. & 1 & $\cdots$ & 1 & 2 \\
\hline 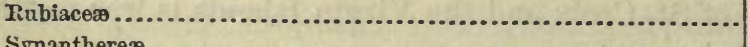 & 4 & 8 & 22 & 34 \\
\hline 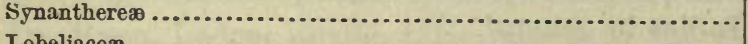 & 4 & 13 & 32 & 49 \\
\hline Lobeliacezo ............................. & & & 1 & 1 \\
\hline Goodenoviacer $\ldots . . . \ldots \ldots . . . . . . . .$. & & & 1 & 1 \\
\hline Myrsinaceæ......................... & & $\cdots$. & 2 & 2 \\
\hline Sapotaceæ ........................ & & 2 & 9 & 11 \\
\hline
\end{tabular}


Table showing the distribution of the Indigenous Species of Phanerogamas and Cryptogamos Vasculares in St. Croix and the Virgin Islands-Contiuued.

\begin{tabular}{|c|c|c|c|c|}
\hline 3 & 范 & 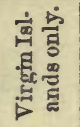 & 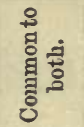 & हैं \\
\hline 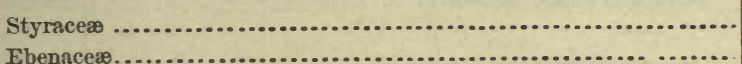 & & $\begin{array}{l}1 \\
1\end{array}$ & (........ & $\frac{1}{1}$ \\
\hline 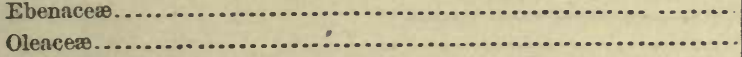 & & & 2 & 2 \\
\hline 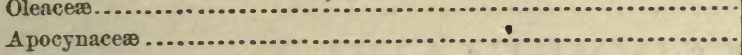 & & 2 & 9 & 11 \\
\hline Asclepiadaceæ............ & 1 & 3 & 3 & 7 \\
\hline Convolvulaceæ.................. & 3 & 7 & 24 & 34 \\
\hline Hydroleaceæ........... & ......... & ......... & 1 & 1 \\
\hline 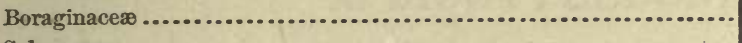 & 3 & 4 & 17 & 24 \\
\hline Solanaceæ $\ldots \ldots \ldots \ldots \ldots \ldots \ldots \ldots \ldots \ldots \ldots \ldots \ldots \ldots$ & 1 & 8 & 12 & 21 \\
\hline 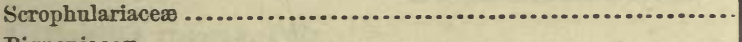 & 2 & 1 & 3 & 6 \\
\hline Bignoniaceæ..................... & 1 & 2 & 6 & 9 \\
\hline Acanthaceæ ....................... & 3 & 2 & 10 & 15 \\
\hline Gesneriaceæ......... & & $\ldots$ & 1 & 1 \\
\hline Labiatæ.............................. & 1 & 2 & 9 & 12 \\
\hline Verbenaceø ...................... & 5 & 2 & 13 & 20 \\
\hline Myoporaceæ.............. & & & 1 & 1 \\
\hline Plumiaginaceæ.............. & & $\cdots$ & 1 & 1 \\
\hline Phytolaccaceæ............. & 1 & ..... & 4 & 5 \\
\hline Chenopodiaceæ ................. & & … & 3 & 3 \\
\hline 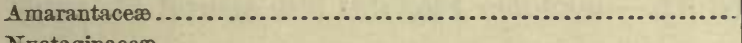 & -....... & 2 & 13 & 15 \\
\hline Nyctaginaceæ...$\ldots \ldots \ldots \ldots$ & 1 & $\cdots$ & 5 & 6 \\
\hline Polygonaceæ......................... & 4 & 1 & 3 & 8 \\
\hline Lauraceæ ............... & 2 & 3 & 4 & 9 \\
\hline Thymelæaceæ .................... & & 1 & …. & 1 \\
\hline Euphorbiace & 3 & 5 & $\mathbf{3 0}$ & 38 \\
\hline Urticacero................................ & 4 & 7 & 10 & 21 \\
\hline Aristolochiaceæ ...................... & 1 & $\cdots \cdots$ & 1 & 2 \\
\hline Begoniaceæ........................ & & 1 & & 1 \\
\hline 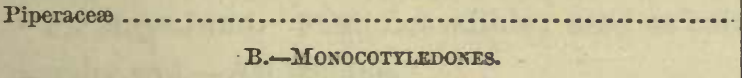 & 2 & 3 & 7 & 12 \\
\hline Alismaceæ........................... & 1 & & & 1 \\
\hline Hydrocharidaceæ.................. & & & 1 & 1 \\
\hline Potamero............................ & $\cdots$ & 3 & 2 & 5 \\
\hline A roideæ........$\ldots \ldots \ldots \ldots$ & 1 & 5 & 3 & 9 \\
\hline Турhaceæ ............... & & $\cdots$ & 1 & 1 \\
\hline Palmæ.......................... & & ...... & 2 & 2 \\
\hline Commelynaceæ......... & $\cdots$ & 2 & 3 & 5 \\
\hline 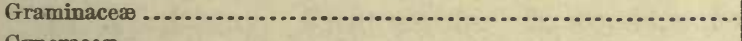 & 4 & 14 & 35 & 53 \\
\hline Cурстасеæ................... & 5 & 15 & 13 & 33 \\
\hline Liliaceæ $\ldots . . . \ldots \ldots \ldots \ldots \ldots \ldots \ldots$ & 1 & .......... & 7 & 8 \\
\hline Smilaceæ $\ldots \ldots \ldots \ldots \ldots \ldots \ldots \ldots$ & 1 & 1 & ;........ & 2 \\
\hline Dioscoreacers ......................... & & 3 & & 3 \\
\hline Bromeliacen ........................ & & 3 & 5 & 8 \\
\hline 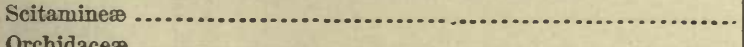 & & $\cdots$ & 1 & 1 \\
\hline C. -CRYPTOGAYX VASCULARES. & 1 & 12 & 2 & 15 \\
\hline Lycopodiaceæ .................................... & & 1 & .1 & 2 \\
\hline 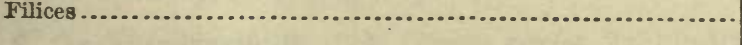 & 4 & 15 & 15 & 34 \\
\hline & 98 & 215 & 568 & 881 \\
\hline 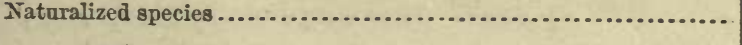 & 17 & 6 & 109 & 132 \\
\hline (2) & 115 & 221 & 677 & 1013 \\
\hline
\end{tabular}





\section{FLORA OF ST. CROIX AND THE VIRGIN ISLANDS. WEST INDIES.}

\section{PHANEROGAM AE.}

\section{A. DICOTYLEDONES.}

\section{DHLEENHACER.}

1. Davilla rugosa, Poir.

St. Thomas (Griseb. Fl. p. 3).

\section{ANONACER.}

2. Anona muricata, L. (v. Soursop, Susakka).

Fl. Feb.-May. Leaves with a peculiar strong scent, used against fever and vermin. Fruit edible; pulp resembling curdled milk, acidulous. In forests and thickets, common.-All islands.

3. A. laurifolia, Dun. (v. Wild Soursop).

Fl. Feb.-May. Resembling the former species in the foliage, but leaves of a quite different smell. Not uncommon in forests.-St. Croix; St. Thomas.

4. A. palustris, L. (v. Monkey-apple, Bunya).

Fl. May-June. Fruit not edible; used as bait for fishes. Common in marshy soil.-All islands.

5. A. squamosa, L. (v. Sugar-apple).

Fl. April-June. Foliage partly deciduous in March and April. Fruit edible, sweet, soft. Common in thickets.-All islands.

6. A. reticulata, L. (v. Custard-apple).

Fl. April-May. Fruit edible. In woods, not uncommon; also planted near dwellings.-All islands.-The enlarged top of the connective in all species of Anona is siliceous. None of the species enumerated above contains narcotic principles, as is the case with A. Cherimolia, Mill., and others.

7. Guatteria Ouregou, Dun.

St. Thomas (Griseb. Fl. p. 7).

8. Oxandra laurifolia, Rich. (Uvaria excelsa, Vahl in $\mathrm{Hb}$. Juss.).

St. Croix (Caledonia Gut, West, p. 292). 


\section{MIENISPERMACEAE.}

9. Cccculus domingensis, DC.

Fl. June-Aug. Stem woody, as much as two inches in diameter. Inflorescences often 3 or 4 uniserial in the same axil. (See Delessert, Icones, t. 96.) In forests, not common.-St. Thomas (near St. Peter, $\left.1000^{\prime}\right)$.

10. Cissampelos Pareira, L. (v. Velvet-leaf). a) Pareira and $\beta$ ) microcarpa, DC. Fl. Nov.-March. In forests and thickets, common.-All islands.

NYMPHEACAEA.

11. Nymphæa ampla, DC. (v. Water-lily). $\beta$ ) parviflora.

Fl. April-July. In rivulets._St. Croix (Kingshill Gut); Vieques (Port Royal).

\section{PATA VERACEAE.}

12. Argemone mexicana, L. (v. Thistle).

Fl. the whole year. A very common weed in dry places.-All islands.

\section{CRUCIFERAE.}

13. Nasturtium officinale, R. Br. (v. Wüter-cress).

Never seen flowering. Naturalized along rivulets.-St Croix; St. Thomas.

14. Sinapis brassicata, L. (

Fl. Jan.-June. Around dwellings and in waste places, not uncommon.-All islands.

15. Sinapis arvensis, $\mathrm{L}$.

Fl. cleistogamous in February. Regular flowers later in the year. Naturalized; rare.-St. Croix (near Anguilla).

16. Lepidium virginicum, $\mathrm{L}$.

Fl. the whole year. A common weed along roadsides and near dwellings.-All islands.

17. Cakile æqualis, L'Her.

Fl. Feb.-July. Rather common on sandy shores.-All islands.

[Cultivated species: Brassica oleracea, L. (v. Cabbage); Lepidium sativum, L. (v. Cress); and Raphanus sativus, L. (v. Radish).]

\section{CAPPAIRIDACEA.}

18. Cleome pentaphylla, L. (v. Massámbee).

Fl. the whole year. Flowers often polygamous. Leaves used as spinach. A common weed near dwellings aud in waste places.-All islands. 
19. C. pungens, W. (v. Wild Massímbee). c) and $\beta$ ) Swartziana.

Fl. the whole year. Common along roads and ditches.-All islands. .20. C. viscosa, L.

Fl. May-Dec. Naturalized here and there.-St. Croix; St. Thomas.

21. Moringa pterygosperma, G. (v. Horse-radish-tree).

Fl. the whole year. Root with a flavour of horse-radish. Naturalized and common near dwellings.-All islands.

22. Capparis amygdalina, Lam.

Fl. March-June. Leares on young radical shoots linear in this and the two following species. Not uncommon in thickets.-All islands.

23. C. jamaicensis, Jacq. (v. Black Willie). $a$ ) marginata and $\beta$ ) siliquosa.

Fl. April-Aug. a) not uncommon; $\beta$ ) less common along the shore and in thickets.-All islands.

24. C. cynophallophora, L. ( $\nabla$. Linguan-tree). $\quad \alpha$ ) and $\beta$ ) saligna.

FI. Feb.-Aug.-Glands 2-4, uniserial in the axils, exuding nectar when young before the time of flowering, and are to be considered as reduced branches or inflorescences.

25. C. verrucosa, Jacq.

Fl. April-May. A middle-sized tree. Not uncommon in forests on the Virgin Islands.

26. C. frondcsa, Jacq. (v. Rat-bean).

Fl. Feb.-May. Seeds very poisonous. Common in forests.-All islands.

27. Morisonia americana, L. a) and $\beta$ ) subpeltata, Gris. in litt.

Fl. May-Oct. A considerable-sized tree. $\alpha$ ) all islands; $\beta$ ) leares subpeltate.-St. Croix (Spring Gut).

\section{BIXACERE.}

28. Bixa Orellana, L. (iv. Roucon).

Fl. June-July. The red pigment of the fruit was generally used by the Caribs for anointing the whole body (Du Tertre). Naturalized in forests.-St. Croix (Crequis, Wills Bay); St. Thomas (Crown).

29. Trilix crucis, Griseb.

Fl. April-June. Stipules very rariable. Petals always abortive in my specimens. A low tree or shrub. Uncommon in forests.-St. Croix (Wills Bay, Mt. Eagle); St. Thomas (Flag Hill); St. Jan (Cinnamon Bay). 
30. Casearia sylvestris, Sw.

11. Jan.-Feb. and May-July. Seed corered by a red arillus. Common in forests and thickets.-All islands.

31. C. parvifolia, W. a) and $\beta$ ) microcarpa, Egg.

Fl. March-July. Flowers odorous. Stamens alternately of equal length. Not uncommon in forests. A low tree.-u) Virgin Islands; Æ) fruit small, $2^{\prime \prime \prime}$ diam., St. Croix.

32. C. ramiflora, Vahl. c).

Fl. Jan.-Feb. and July-Aug. Pedicel articulate below the middle. Arillus fibrous. Common in forests.-All islands.

33. Samyda glabrata, Sw.

Fl. Jume. Rare, in thickets on highest hill-tops.-St. Thomas (Crown, $\left.1400^{\prime}\right)$.

34. S. serrulata, L.

Fl. Feb.-May. Flowers odorous, precocious. Pedicels articulated at the middle. Leaves of young radical shoots linear. Common in thickets.-All islands.

VIOLACERE.

35. Ionidium strictum, Vent.

Fl. all the year round. Flower matutine. Rather uncommon in fissures of rocks in thickets.-St. Croix; Water Island.

TAMARICACER.

36. Tamarix indica, Willd. (v. Cypress).

Fl. Sept.-Oct. Naturalized in gardens._-St. Croix; St. Thomas.

POLYGALACER.

37. Polygala angustifolia, HB. Kth.

Fl. Dec.-Feb. In the shade of dense thickets. Rare.-St. Thomas (Comell's Hill).

38. Securidaca Brownei, Gr. (S. 8candens of West).

Fl. Feb.-April. Naturalized around Christiansted, r. Rohr.-St. Croix.

39. S. erecta, L.

St. Thomas (DC. Prodr. i, 341; Gris. Fl. 1. 30).

40. Krameria Ixina, $I$.

Fl. July. The three narrow petals, resembling abortive stamens, are bent forward and cover the anthers. The two lateral or.es are fleshy, 
and covered on the outer side with fleshy papillæ. Fruit 1 -seeded by abortion. Gregarious along roadsides in dry localities, but uncommon.-St. Thomas (Boroni).

\section{CARYOPIIYLLACER.}

\section{Paroxychiaces.}

41. Drymaria cordata, W. $\beta$ ) diandra.

Fl. May-June. In moist localities in the shade. Rare.-St. Croix (Spring Garden).

42. Cypselea humifusa, Turp.

Fl. July. Gṛegarious around a small fresh-water lagoon. Rare.Water Island.

\section{Molluglvee.}

43. Mollugo verticillata, L.

Fl. Aug. Leares often fleshy. On rocky shores. Rare--Buck Isl. and, near St. Thomas.

44. M. nudicaulis, Lam.

Fl. Sept.-Dec. Not uncommon in moist localities.-St. Croix; Buck Island near St. Croix; St. Thomas.

III. Portulacex.

45. Talinum triangulare, $W$.

Fl. all the year rouud. Flower open till 11 A. M. Sepals of nnequal size. The large one 1-ribbed, the smaller one 3-ribbed. Petals often yellow (as represented in Jacq. Stirp. Americ. t. 135). Rather uncommon. On rocks near the seashore.-St. Croix; St. Thomas.

46. T. patens, W.

F1. all the year round. Flower open from 3 P. M. till sunset. Petals palé red or yellow (Bot. Mag. t. 1543). Root tuberous. Here and there in rocky situations.-St. Croix; St. Thomas.

47. Portulaca oleracea, L. (v. Purslane). «) macrantha, $\beta$ ) micrantha, Egg.

Fl. the whole year. Flower open till $10 \mathrm{~A}$. M. a) brownish, 5 petals, as many as 25 stamens, corolla $6^{\prime \prime \prime}$ diam. $\beta$ ) green, 4 petals, 10-12 stamens, corolla $3^{\prime \prime \prime}$ diam. Both varieties common along roadsides and in open spots. $-A l l$ islands.

48. P. quadrifida, L. (Mant. 78).

Fl. all the year round. Petals 4 , yellow, $2^{\prime \prime \prime}$ long. Flower open from 11 A. M. till 3 P. M. Leares opposite, clasping together towards evening. A common weed in gardens and along roads.-All islands. 
49. P. pilosa, $\mathrm{L}$.

Fl. all the year round. Often nearly glabrous. Roots tuberous. Petals red or yellow, large. Corolla up to $16^{\prime \prime \prime}$ diam., open only till 9 a. m. Seeds dark brown. Leaves adpressing themselves downward to the stem towards evening. Not uncommon. Along ditches and in grass-fields.-St. Croix; St. Thomas.

50. P. halimoides, $\mathrm{L}$.

Fl. June-Dec. Common along roadsides and among rocks.-St. Croix; St. Thomas.

51. Sesuvium portulacastrum, L. (v. Bay-flower).

Fl. all the year round. Sepals rosy inside. Common on sandy shores.-All islands.

\section{Trianthema monogynum, L.}

Fl. all the year round. Branches always originating in the axil of the smaller leaf. Stamens 7-17. Sepals and stamens rosy or white. Common on rocky shores.-St. Croix; St. Thomas.

\section{MALVACEAS.}

53. Malvastrum spicatum, Gris. (v. Hollow-stock).

Fl. all the year round. Flower expanding in the aftermoon. Very variable. A common weed along roads and in fields.-All islands.

.54. M. tricuspidatum, Asa Gray.

F1. all the year round. Common along roads and ditches.-All islands.

55. Sida carpinifolia, L. a) and $\beta$ ) brevicuspidata.

Fl. Sept.-March. Pedicel geniculate at the base, or as often not so. Petals imbricate dextrorsely or sinistrorsely. Both forms very common weeds everywhere in dry localities.-All islands.

56. S. glomerata, Cav.

Fl. Aug.-Oct.-Buck Island near St. Thomas; Vieques.

57. 5. ciliaris, $\mathrm{L}$.

Fl. Sept.-March. Flower expanded till 10 A. M. Stipules always longer than the petioles. Leaves closely clasping the stem in the evening. Gregarious on roads and near ditches. Common.-All islands. 
58. Sida jamaicensis, $\mathrm{L}$.

Fl. Dec.-March. Flower expanded till 9 A. M. Calyx shorter than the corolla. In grass-fields and thickets. Often suffrutescent, $6^{\prime}$ high. Common.-All islands.

59. S. spinosa, L. $a$ ), $\beta$ ) angustifolia, Lam., and $\gamma$ ) polycarpa, Egg.

Fl. Sept.-March. $\gamma$ ) suffrutescent, $4^{\prime}$ high. Pedicel as long as the whole leaf. Pistils, ovaries, and carpids always $12 . \alpha$ ) and $\beta$ ) common in grass-fields and pastures. $\gamma$ ) near rivulets.-All islands.

60. S. rhombifolia, L. (v. Swart Marán). $\gamma$ ) retusa.

Fl. Dec.-March. Petals showing a purple blot at the base. Common in waste places.-All islands.

61. S. tristis, Schlecht. (Linnæa, iii, 271).

St. Thomas (Schl.).

62. S. supina, L'Her. a) glabra and $\beta$ ) pilosa, Egg.

Fl. Nov.-March. Two very distinct forms : $\alpha$ ) in shady, moist places ; $\beta)$ in dry localities. Not uncommon in thickets and forests.-All islands.

63. S. arguta, Cav. (not S. arguta, Sw., as stated in Griseb. Syst. Unters. p. 31)

St. Croix (West, 297); St. Thomas (Schl.).

64. S. nervosa, DC. a) and $\beta$ ) viscosa, Egg.

Fl. Dec.-April. $\beta$ ) viscous and glandular pilose. Petals reddish; pistils red. Not uncommon along roads and ditches.-All islands.

65. S. acuminata, DC. a) macrophylla and $\beta$ ) microphylla.

St. Thomas (Schl.). "In locis siccis."

66. S. cordifolia, L. B) althæfolia, Sw.

Fl. March. Here and there along roads.-St. Croix (West, 297); St. Jan (Bethania).

67. S. humilis, W. (?) Car.

St. Thomas (Schl.). "In locis umbrosis."

68. Abutilon periplccifolium, G. Don. a) and $\beta$ ) albicans, carpids 3-ovulate.

Fl. all the year round. Seeds dimorphous. The two seeds in the superior cell glabrous, the one in the inferior silky. $\alpha$ ) not uncommon along roads. $\beta$ ) uncommon.-St. Croix $(\alpha$ and $\beta)$; St. Jan $(\beta)$.

69. A. umbellatum, Sw.

Fl. Dec.-March. Seeds cordate, brown. Not very common in open, dry localities._All islands. 
70. A. indicum, G. Don (v. Mahoe). a) and $\beta$ ) asiaticum.

Fl. all the year round. Flower expanded after 3 P. M. only. Both forms common along roads and on waste places.-St. Croix ; St. Thomas.

71. A. lignosum, Rich. (v. Marsh-mallow).

F1. Nov.-May. Flower expanded during the afternoon only. Seeds irregularly triangular, verrucose, grey._-St. Croix.

72. Bastardia viscosa, Kth. a).

Fl. all the year round. Flower expanded during the afternoon only. Common along roads and in dry。 localities.-All islands.

73. Malachra capitata, L. a) and $\beta$ ) alceifolia, Jacq.

Fl. Dec.-March. Flower expanded only till 2 P. M. Along ditches and in moist places. $\alpha$ ) rather common; $\beta$ ) less common.-All islands.

74. M. urens, Poit.

Fl. April. Petals yellow, puberulous externally. Seeds smooth, glabrous. Uncommon on waste places.-St. Thomas (western shore of the harbour):

75. Urena lobata, L. a) americana.

F1. Hov.-June. Flower expanded till 10 A. M. In forests.-St. Croix (rare; Prosperity on the north coast); St. Thomas; St. Jan (not uncommon).

76. Pavonia spinifex, Cav.

FI. Oct.-Dèc. Rather common in thickets and forests.-All islands.

77. P. racemosa, Sw.

Fl. Oct. In marshy soil among Laguncularia and Conocarpus.-St. Croix (uncommon; Salt River).

78. Kosteletzkya pentasperma, Gr.

Fl. Aug. Flower expanded till 10 A. M. In marshy soil. Rare.-St. Thomas (Krumbay).

79. Abelmoschus esculentus. W. A. (

Fl. all the year round. Fruit used immature as a vegetable. Cultivated and naturalized near dwellings.-All islands.

80. Hibiscus clỳpeatus, $L$.

St. Croix (West, p. 29S).

81. H. vitifolius, $L$.

Fl. Dec.-March. Along roads and in thickets.-St. Croix (naturalized in the eastern part of the island). 
82. H. Sabdariffa, L. (v. Red Sorrel).

Fl. Oct.-Nor. Leares used as a regetable. Calyx at length fleshy, used for lemonade. Cultivated and naturalized here and there.-St. Croix; St. Thomas.

83. H. phœniceus, Jacq.

Fl. Sept.-March. Rather common in thickets, especially near dwellings.-St. Croix; St. Thomas.

84. H. brasiliensis, L.

St. Croix (West, p. 298)

85. Gossypium barbadense, L. (v. Cotton-tree), $a$ ) and $\beta$ ).

Fl. all the year round. Down stellate. Common in dry localities. Formerly cultivated.-All islands.

86. G. vitifolium, Lam.

Naturalized in St. Thomas (Schl.), perhaps from having been cultivated in former times.

87. Paritium tiliaceum, A. Juss. (v. Mahoe).

Fl. Oct.-March. Bark employed as rope. Along coasts, but rare.St. Croix (West, p. 297); St. Thomas (Schl.); St. Jan (Fish Bay).

88. Thespesia populnea, Corr. (v. Otaheite Tree).

Fl. all the year round. Very easily propagated by cuttings. A shady tree with very hard wood. Naturalized and cultivated everywhere, especially in moist localities. All islands.

All Malvaceæ are protandrous.

[Cultivated species: Althe rosea, L. (v. Hollyhock); Hibiscus rosasinensis, L. (v. Chinese rose); aud H. mutabilis, L. (v. Changeable Hibiscus).]

\section{BOMIBACER.}

89. Adansonia digitata, L. (v. Guinea Tamarind).

Fl. June-July. Leaves deciduous in March-A pril. The acid pulp of the fruit used for lemonade. Naturalized in wooded valleys.-St. Croix (Prosperity; Crequis); St. Thomas.

90. Eriodendron anfractuosum, DC. (v. Silk-cotton-tree).

Fl. Feb.-April. Leaves deciduous March-April. Stem growing to immense size. Common in forests. All islands.

91. Myrodia turbinata, Sw.

St. Croix (Spring Garden, West, p. 298). 
92. Helicteres jamaicensis, Jacq.

Fl. March-Aug. Spiral of carpids $2 \frac{1}{2}$. Common in thickets. -All islands.

\section{HÜTTNERIACEAE.}

93. Guazuma ulmifolia, Lam. (v. Jackass Calalu).

Fl. April-June. Woor used for oars. Not uncommon in pastures.St. Croix; St. Thomas.

94. Theobroma Cacao, L. (v. Cocoa-tree).

F]. June. Naturalized in shady valleys.-St. Croix (Prosperity; Mount Stewart).

95. Ayenia pusilla, L.

Fl. all the year round. Flowers often transformed into a hollow monstrosity by the larva of a wasp. Fruit muricate. In thickets, common.-All islands.

96. Melochria pyramidata, L.

Fl. all the year round. Common in pastures.-St. Croix.

97. M. tomentosa, L. (v. Broom-wood).

F1. All the year round. Calyx tomentose, greyish white. Tomentum interspersed with glandulous hairs. Used for brooms. Common in dry thickets.-All islands.

98. M. nodiflora, Sw.

Fl. Nov.-July. Common in pastures and along roads.-All islands. 99. Waltheria americana, L. (v. Marsh-mallow).

Fl. Oct.-May. Common in pastures.-All islands.

\section{TILIACEAE.}

100. Triumfetta Lappula, L. (v. Bur-bush).

Fl. Nov.-April. Common in thickets.-All islands.

101. T. althæoides, Lam. (v. Mahoe).

Fl. Dec.-March. In forests, uncommon.-St. Croix; St. Thomas. 102. T. semitriloba, L. (v. Bur-bush).

Fl. Oct.-March. In thickets and along roads, common.-All islands. 103. T. rhomboidea, Jacq.

Fl. Dec.-April. Uncommon in thickets.-St. Croix (Spring-gut). 104. Corchorus acutangulus, Lam.

Fl. June-Nor. The lowest serratures of the leaves in my syecimens often show one or two long setacenus bristles, as stated in DC. Prodr. 
i, 505. Griseb. Fl. p. 97, does not mention them, as he does in C. olitorius, neither does the figure in Wight's Icones, iii, t. 739, show them in this species. From observations made by me on $C$. acutangulus, as well as on $C$. hirtus, such bristles on the lower serratures of the leaves are of no specific value in this genus, being a variable feature. In gardens and near dwellings, not uncommon.-St. Croix; St. Thomas.

105. C. siliquosus, L. (v. Papa-lolo).

Fl. Nor.-July. Leaves used as a vegetable (Calalu). Along roads and in pastures, common.-All islands.

106. C. hirtus, L.

Fl. June-Sept. Two lowest serratures of the leaves sometimes showing one or two setaceous bristles. In gardens and along roads, not uneommon.-St. Croix; St. Thomas.

107. C. hirsutus, L.

Fl. all the year round. Hairs of the stem scabrous. On sandy shores, common. $-A l l$ islands.

\section{TERNSTRÖMIACEA.}

108. Ternströmia elliptica, Sw.

Fl. Feb.-April. The two bracts at the base of the persistent calyx are to be considered as such (Swartz, Flora Ind. Occ. p. 961; DC. Prodr. i, p. 523; and Hook. \& Benth. Genera Plant. i, p. 182), and not as sepåls (Griseb. Fl. p. 103) on account of their being deciduous, but the sepals not. The number of ovules in my specimens are about twenty in each cell. (Hook.and Benth. l. c. ascribe to the genus only two, rarely three to six, in each cell; Grisebach l. c. only two to four. In the Catal. Plant. Cub. p. 36, Griseb. mentions, however, a variety of $T$. obovalis, Rich., with ten to thirteen ovules in each cell.) Sepals rosy, flowers fragrant In forests on high hills, rare.-St. Croix (Maroon Hill, 900'); St. Jan (Bordeaux Hill, 1200').

\section{GUTTIFERE.}

109. Clusia rosea, L. (v. Chigger-apple).

Fl. May-Sept. Aërial roots as much as $20^{\prime}$ long, supporting the young trees on rocks or other trees. In forests._St. Croix (rare, Wills Bay); Virgin Islands (not uncommon).

110. C. alba, L. (r. Wild Mamey).

St. Croix (West, p. 312). Probably a mistake for the first named species.

Bull. Nat. Mus. No. $13 \longrightarrow 3$ 
111. Mammea americana, L. (v. Marney).

Fl. Feb. and later in Aug. Fruit generally one-seeded, eatable. Common in forests and planted along roads.-All islands.

112. Calophyllum Calaba, Jacq. (v. Santa Maria).

Fl. May-July. In forests along rivulets.-St. Croix (common in the northern part of the island); St. Thomas (rare).

\section{CANELLACERE.}

113. Canella alba, Murr. (v. White-bark).

Fl. Jan.-April. Berry dark crimson. Leaves used in warm baths for rheumatism. On sandy shores and in forests.-All islands.

\section{ERYTIROXYLACERE.}

114. Erythroxylum ovatum, Cav. (v. Wild Cherry, Brisselet).

Fl. April-Sept. Precocious. Branches, as a rule, transformed into brachyblasts. Common in thickets.-All islands.

(E. areolatum, West, p. 286, and E. brevipes, Bertero in Schlecht. Florula, are, no doubt, mistakes for the species mentioned above.)

\section{IIALPIGHIACE RE.}

115. Byrsonima spicata, Rich.

Fl. July-Aug. In forests, rare.-St. Croix (Parasol Hill); St. Thomas 'Signal Hill); St. Jan (Bordeaux).

116. B. Iucida, Rich.

Fl. Oct.-St. Thomas (DC. Prodr. i, 5\$0); Vieques (Campo Asilo).

117. Bunchosia Swartziana, Gris.

Fl. July. Pedicel uniglandular and bibracteolate at the joint. Very much attacked by insects. In thickets.-St. Croix (rare, Kingshill); St. Thomas (not uncommon); St. Jan.

118. Galphimia glauca, Cav. (Icon. v, p. 61) (G. gracilis, Bartl.).

Fl. all the year round. Naturalized in gardens.-All islands.

119. Malpighia glabra, L. (v. Cherry).

Fl. May-June. Fruit edible. Common in thickets.-St. Croix; St. Thomas.

120. M. urens, L. $a$ ) and $\beta$ ) lanceolata.

Fl. June-Oct. a) common in thickets.-All islands; $\beta$ ) rare, St. Croix (Spring-gut). 
121. M. Cnida, Spreng. (Neue Entdeck. iii, 51).

Fl. June-Sept. Along roads and in thickets, not uncommon.-St. Jan; Water Island; Vieques.

122. M. angustifolia, $L$.

Fl. June-Uct. In thickets, not uncommon.-Water Island; Vieques. 123. Stigmaphyllon periplocifolium, Juss.

Fl. all the year round. Samaræ red. In thickets, common.-All islands.

124. Heteropteris purpurea, Kth.

Fl. all the year round. Common in hedges and thickets.-All islands. 125. H. parvifolia, DC. (

Fl. all the year round. As common as the preceding species.-All islands.

\section{SAPINDACER.}

126. Cardiospermum Elalicacabum, L. (v. Balloon-vine).

Fl. Sept.-March. Rather common in thickets and near dwellings.St. Croix; St. Thomas.

127. C. micrccarpum, Kth.

Fl. Jan.-March. In thickets, rare.-St. Croix (Spring-gut); St. Jan (Enigheit).

123. Serjania lucida, Schnm. (v. White Vis, Cabrite rotting).

Fl. Dec.-June. Stem used as rope. Common in thickets.-All islands.-(Paullinia curassavica, West, p. 281, is no doubt a mistake for this species.)

129. Cupania fulva, Mart.

Fl. January. In forests, not uncommon.-Virgin Islands. 130. Sapirdus inæqualis, DC. (v. Soap-seed).

Fl. Dec.-Jan. Seeds used for ornaments. In forests along rivulets. Not uncommon.-St. Croix.

131. Schmidelia occidentaliz, Sw.

Fl. May-Sept. Not uncommon in forests, especially in St. Croix.All islands.

132. Melicocca bijuga, L. (v. Keneppy tree).

Fl. April-May. Leafless during flowering. Flowers fragrant. Fruit astringent, edible. Naturalized and now very common everywhere, 
often forming a secondary growth in cleared woodland. Introduced from the Spanish main.-All islands.

133. Dodonæa viscosa, $\mathrm{L}$.

Fl. April. On sandy seashores, rare.-St. Croix (Sandy Point).

\section{MELIACER.}

134. Melia sempervirens, Sw. (v. Lilac, Hagbush).

Fl. all the year round. Common in forests and near dwellings.-All islands.

\section{Trichilia hirta, L.}

Fl. June-July. Common in thickets.-All islands.

(Guarea trichilioides, Jacq., said to occur in St. Croix (West, p. 281), seems to me rather doubtful.)

136. Swietenia Mahagoni, L. (v. Mahogany).

Fl. April-June. In wooded valleys and along roads and dwellings. Not uncommon.-St. Croix; St. Thomas.

\section{GERANHACA.}

[Cultivated occur several species of Geranium, L'Her., and Pelargonium, L'Her.]

\section{BALSAMINACEAE.}

137. Balsamina hortensis, Desp. ( $v$. Lady-slippers).

Fl. all the year round. Naturalized everywhere in garlens. Seeds often germinating in the capsule.-All islands.

\section{AURA NTIACEAE.}

138. Citrus medica, L. a) (v. Citron). $\beta$ ) Limonum, Risso (v. Lime).

Fl. April-May. a) naturalized, but rare, in gardens. $\beta$ ) naturalized, common in gardens and near dwellings, also in forests.-All islands.

139. C. Aurantium, L. $\quad \alpha$ ) (v. Orange). $\quad \beta$ ) Bigaradia, Duh. (v. Seville Orange).

Fl. May-July. Both forms naturalized in gardens, especially $\alpha$ ). Common in St. Croix; rare in St. Thomas and St. Jan, where the species is said to have died out nearly, from disease.-(Mentioned also by Breutel, London Journal of Botany, ii.)

140. C. buxifolia, Padr. (v. Forbidden Fruit).

Fl. July. Naturalized in a few places._St. Croix; St. Thomas.

141. C. decumana, L. (v. Shaddock).

Fl. July-Aug. Fruit used for preserves. Naturalized in gardens.St. Croix; St. Thomas. 
142. Triphasia trifoliata, DC. (v. Sweet Lime).

Fl. April-June. Naturalized in thickets and near drellings. Common in all the islands.

[Cultivated species: Murraya exotica, L. (v. Cyprian), and Cookia punctata, Retz.]

\section{OXALIDACER.}

143. Oxalis Martiana, Zuce.

F1. May-Aug. Naturalized in gardens on all the islands.

144. O. corniculata, L. $\beta$ ) microphylla, Poir.

Fl. all the year round. Gregarious in fields.-St. Croix (Annally); St. Thomas.

\section{ZYGOPHYLLACEAE.}

145. Tribulus cistoides, $\mathrm{L}$.

Fl. all the year round. Along roads and in open spots, gregarious.St. Croix (in the eastermmost part of the island only).

146. T. maximus, L. (v. Centipee-root, Longlo).

Fl. all the year round. Stamens alternately of equal length. The whole plant is used in baths against boils. A very common weed along roads and in waste places.-All islands.

147. Guajacum officinale, L. (v. Lignum vitæ, Pockenholt).

Fl. March-April. Common in former times, but now nearly exterminated. On the seashore and in forests, rare.-All islands.

\section{RUTACE.}

148. Pilocarpus racemosus, Vahl.

Fl. Feb.-March. Leaves undivided, 3-foliate or impari-pinnate in the same specimen (as stated in Hook. \& Benth. Genera, i, 299, and Fl. Brasil. fasc. 65). Inflorescence terminal and axillary. A low tree. In forests, rare.-St. Jan (Kingslill, 1000'); Vieques (Ram in Hb. Havn.). (Specimen from Montserrat in Hb. Havn. also named P. laurifolius, Vahl.)

149. Tobinia punctata, Gr.

Fl. Sept. Leaves often pinnate. Dots on the leaves pellucid. In thickets, not uncommon.-St. Croix.

150. T. spinosa, Desv.

Fl. May-June. Leaflets prickly on the principal nerres on both sides, bearing 2 stipular prickles at the base. Carpids $3(2-1)$ globose, with a short beak, black, rerrucose, $3^{\prime \prime \prime}$ long. Seeds black, shining. Rare in forests.-St. Thomas (Flag Hill, 600'). 
151. Fagara microphylla, Desf. (v. Ramgoat-bush) ( $F$. tragodes, Jacq. in West).

Fl. June-Dec. Dots of the leares pellucid. The whole plant has a strong smell. Not uncommon in thickets.-St. Croix; Buck Island, near St. Croix.

152. Zanthoxylum Clava-Herculis, L. (

Fl. April-June. Aculei corky, $6^{\prime \prime \prime}$ long, greyish, with a narrow brown point. In forests, not uncommon.-All islands.

153. Z. flavum, Vahl (Naturh. Selsk. Skrift. vi, 132, 1810) (v. Yellow Sander).

Not seen flowering. A fine timber-tree, used for furniture. Not uncommon in forests in former times, but now nearly extinct.-St. Jan (Bordeaux Hills) (St. Croix? St. Thomas?) (Montserrat, Ryan in Hb. Havn.); Martinique (West in Hb. Havn.).

154. Z. Ochroxylum, DC. (v. Yellow Prickle) (Z. simplicifolium, Vahl in Hb. Havn.).

Fl. June-Nor. \& Panicle $1^{\prime \prime}$ long; pedicels $\frac{1}{2}^{\prime \prime \prime}$ long, bracteole at the base deciduous. Calyx 5-partite, $\frac{1}{2}^{\prime \prime \prime}$ diam. Petals 5, imbricate, white, $\frac{3}{4}$ '" long, pellucid-dotted. Style thick, $\frac{1}{4}{ }^{\prime \prime \prime}$ high; stigmas triangular. Ovaries 3 on a short gynophore. Carpids 3 (1-2) globose, verrucose, partly dehiscent, $1 \frac{1}{2}{ }^{\prime \prime \prime}$ diam. Seed shining-black. Stem armed with large corky aculei, often connected and forming long ridges down the stem. Wood yellow. The whole plant is possessed of the same strong smell as Fagara. Not uncommon in forests.-St. Thomas (Flag Hill 600'); St. Jan (Rogiers) (Montserrat, Ryan in Hb. Havn.; Martinique, South America, Hb. Havn.). (A branch without flowers, marked Z. macrophyllum, St. Croix, Ryan in Hb. Havn., seems to belong to this species.)

155. Quassia amara, L. fil. (v. Quassia).

Fl. Nov.-Feb. Naturalized in gardens.-All islands.

156. Castela erecta, Turp.

Fl. Feb.-June. Petals purple. $q$ with 8 rudimentary stamens, alternately of equal size. Carpids 2-3-4. In dry thickets along the south coast, not uncommon.-St. Croix.

157. Picræna excelsa, Lindl. (v. Bitter-ash).

Not seen flowering. Wood very bitter, used for stomachic properties in drinks. In forests, rare.-St. Croix; St. Jan.

\section{OLACA CEAE.}

158. Schœpfia arborescens, R. S.

F1. Feb.-March. Fruit nearly always 1-seeded by abortion: Here and there in forests.-St. Croix (Saltriver, Wills Bay); St. Thomas (Crown, 1400'). 


\section{AMPELIDEAE.}

159. Cissus sicyoides, L. (v. Lambrali, Pinna koop).

Fl. all the year round. Flowers purple or yellow. Aërial roots long, filiform. Common in forests.-All islands.

160. C. trifoliata, L.

Fl. all the year round. On rocks and trees, not common.-St. Croix; St. Thomas.

161. C. acida, L.

Fl. June-Aug. In thickets near the coast, common.-All islands.

162. Vitis caribæa, DC.

F1. June. In dense forests, rare.-St. Croix (Caledonia Gut); St. Thomas (Crown).

\section{CELASTRACETE.}

163. Maytenus elæodendroides, Gris. (Cat. Plant. Cub. p. 54). (Rhamnus polygamus, Vahl in Hb. Havn., and in West, p. 276.)

Fl. Dec. Flower brownish, small. Calyx 5-partite, $\frac{3 \prime \prime \prime}{4}$ diam. Petals 5 , oval, $1^{\prime \prime \prime}$ long. Stamens 5, often all or part of them transformed into petals and more or less sterile. Stigma subsessile, 2-lobed. Ovary 2 locular, 2-ovulate. Disc brown, undulate, $\frac{1}{2}^{\prime \prime \prime}$ high. Seed black with a red arillus. Rare in dry thickets.-St. Croix (Fair Plain).

164. M. lævigatus, Gris. in litt. (Rhamnus lavigatus, Vahl in Symb. Bot. iii, 41; Ceanothus, DC.).

Fl. May-Oct. Capsule tardily dehiscent, 1-3-seeded, $6^{\prime \prime \prime}$ long. Seeds brown, reticulate with red reins, $2^{\prime \prime \prime}$ diam. Arillus tough, white. A shrub or middle-sized tree. Not uncommon in forests.-All islands.

165. Elæodendron xylocarpum, DC. (v. Spoon-tree, Nut Museat).

Fl. Sept.-Dec. Stamens often transformed, as in Maytenus elocodendroides. Drupe orange-coloured, $S^{\prime \prime \prime}$ long. Common on rocky shores; more uncommon in St. Croix.-All islands.

166. Myginda pallens, Sw.

Fl. Oct.-May. Common in thickets, principally in marshy soil.-All islands.

167. M. latifolia, Sw.

St. Croix (Pflug, sec. Vahl Symb. Bot. ii, 32); St. Thomas (Schl.).

168. Schæfferia frutescens, Jacq.

Fl. Sept.-Dec. Common in thickets.-All islands. 


\section{RHAMNACER.}

169. Reynosia latifolia, Gris. (Cat. Pl. Cub. 34) (v. Guama). Emend. in Eggers, Videnskab. Medd. fra Naturhist. Forening, Copenhagen, 1878, cum icone,p. 173. Fl. June-July. Common in dry thickets.-Virgin Islands.

170. R. mucronata, Gris. (1. c.) (Eggers, 1. c).

Not seen flowering. Rare in dry thickets near the coast.-St. Croix (easternmost part of the island, near Tague Bay).

171. Condalia ferrea; Gris. (v. Edden-wood).

Fl. Sept.-Jan. Keel of the calyx-lobes foliaceous. Drupe oval, 2:2"' long. Not uncommon in thickets and forests.-All islands.

172. Colubrima ferruginosa, Brongn.

F1. Jan. and May-July. A low shrub. Common on sandy shores.All islands.

173. C. reclinata, Brongn. (v. Snake-root, Mabee-bark).

F1. Nor.-March. Style 2-3-partite. Leares used for the preparation of stomachic drinks. Not uncommon in thickets.-All islands.

174. Zizyphus reticulata, DC. (Prodr. ii,20) (Paliurus, Vahl, Ecl. Am. iii, 6).

Fl. July. Disc brownish. Capsule 3-locular, one seed in each cell, $5^{\prime \prime \prime}$ long, glabrous. Seeds purple; pulp reddish brown. In dry thickets, rare.-St. Croix (Fair Plain).

175. Gouania domingensis, L. (v. Soap-stick, Silvi).

Fl. Oct.-Jan. Stem used as rope. Commou in thickets.-All islands.

\section{TEREBHNTIICE $A$.}

176. Bursera gummifera, L. (v. Turpentine-tree).

Fl. April-Sept. Protandrous. Easily propagated by large cuttings, and generally used for forming fences. Common in forests and aloug roads.-All islands.

177. Hedwigia balsamifera, $\mathrm{Sw}$.

St. Croix (West in Hb. Havn. and p. 281 as Icica altissima).

178. Amyris sylvatica, Jacq. (v. Flamboyant).

Fl. Feb.-April and July-Sept. Inflorescence trichotomous. Wood resinous and used for torches, especially in catching lobsters at night. Not uncommon in forests.-All islands.

179. Spondias lutea, L. (v. Hog-plum).

Fl. March, coëtanous, and later July. Leaves deciduous in Feb. Fruit oval, edible. Common in forests.-All islands. 
180. S. purpurea, L. (v. Jamaica Plum).

Fl. Feb.-March, precocious. Naturalized in gardens and wooded valleys.-All islands.

131. Rhus antillana, Egg. (n. sp.).

Sect. Sumach. Leaves impari-pinnate; leaflets $4-5$-jugal, petiolulate, lanceolate, acuminate, obtuse at the base, entire, glabrous, chartaceous; veins prominulous beneath. Cyme ramose; branchlets bracteolate, equalling the leaves. Flower pedicellate, small, green, 5-merous, mostly $\delta$, the rest hermaphrodite. Calyx and petals persistent in the fertile flower. Stamens erect, a little longer than the petals, inserted into a fleshy central disc; filaments villous at the base. Ovary inserted upon a short fleshy gynophore. Drupe globose, glabrous, 1-seeded by abortion. A low tree. Approaching R. metopium, L. Fl. Jan. In forests, rare.-St. Thomas (Signal Hill, 1400'); St. Jan (Hb. Harn. as Xanthoxylum). (St. Croix, Stonj-ground?)

182. Comocladia ilicifolia, Sw. (v. Prapra).

Fl. March-May. Root containing a lasting red dye. Common on limestone.-All islands.

183. Mangifera indica, L. ( $v$. Mango-tree).

Fl. Feb.-April. Fruit edible. Introduced towards the close of last century, and now cultivated and naturalized everywhere.-All islands.

184. Anacardium cccidentale, L. (v. Cashew, Cherry).

Fl. Dec.-April. Pedicel becoming fleshy, and containing in abundance a slightly astringent juice. Seeds used as almonds. Common in forests and along roads.-All islands.

\section{LEGUMINOSAE.}

135. Crotalaria verrucosa, $\mathrm{L}$.

Fl. all the year round. Naturalized along roads. Very common.-All islands.

186. C. retusa, $\mathrm{L}$.

Fl. all the year round. Common along roads and in waste places. Naturalized.-All islands.

187. C. latifolia, L.

F1. Nov. Leaves golden sericeous beneath. Corolla greenish. Not uncommon in thickets.-All islands.

188. C.incana, L. (v. Rattle-bush).

Fl. all the year round. Stipules deciduous, the scar exuding nectar afterwards, as well as the base of the bracteoles. Common along roads and near dwellings._-St. Croix; St. Thomas. 
189. Indigofera tinctoria, $\mathrm{L}$.

Fl. April-Aug. Cultivated in former times, but now only found wild or naturalized. Common in dry localities.-All islands.

190. I. Anil, L.

Fl. all the year round. The whole plant is much attacked by insects. Very common in dry thickets.-All islands.

191. Tephrosia cinerea, Pers. $\alpha$ ) and $\beta$ ) litoralis, Pers.

Fl. Feb.-June. Both forms here and there in thickets.-All islands.

192. Cracca caribæa, Benth.

St. Croix (Schl.); St. Thomas (Gris. Fl. p. 183).

193. Coursetia arborea, Gris.

St. Jan (Gris. Fl. p. 183).

194. Sabinea florida, DC. (v. Waterpanna).

Fl. March-July. Precocious. Wood used for fishpots. Gregarious. Common in thickets and forests.-Virgin Islands. (Cultivated in St. Croix.)

195. Pictetia squamata, DC. (Prodr. ii, 314) (v. Fustic).

Fl. June. Flowering period ouly 5 or 6 days. Branches in this and the following species commonly transformed into brachyblasts. Common in forests and thickets.-Virgin Islands.

196. P. aristata, DC. (1. c.) (v. Fustic).

Fl. Feb., March, and June-Aug. Rather common in thickets.-Virgin Islands; St. Croix (Jacq. Hort. Schœenbr. ii, 60).?

(Both species are perhaps to be united, as proposed by Jacquin.)

197. Agati grandiflora, Desv.

Fl. all the year round. Naturalized in gardens, common.-All islands.

198. Sesbania sericea, DC.

Fl. Nov. In thickets near the coast, uncommon.-St. Thomas (Flag Hill).

199. Aschynomene americana, L.

Fl. Nov.-Jan. In pastures and along roads, not uncommon.-St. Croix.

200. Zornia diphylla, Pers.

Fl. July-Aug. In pastures on high hills, rare.-St. Thomas (Signal Hill, Crown).

201. Lourea vespertilionis, Desv.

Fl. Feb.-April. Naturalized in gardens.-St. Crnix; St. Thomas. 
FLORA OF ST. CROIX AND THE VIRGIN ISLANDS.

202. Alysicarpus vaginalis, DC.

Fl. Nov.-Dec. Leaves very variable. Along roads, common.-All islands.

203. Desmodium triflorum, DC.

Fl. Dec.-Feb. Common near ditches and in moist localities.-All islands.

204. D. incanum, DC.

Fl. Oct.-Jan. Common in pastures.-All islands.

205. D. scorpiurus, Desv.

Fl. Dec.-Jan. In pastures, not very common.-St. Croix; St. Thomas (Duchass).

206. Desmodium tortuosum, DC.

Fl. Oct.-Jan. Common in pastures.-St. Croix; St. Thomas.

207. D. spirale, DC.

Fl. Nor.-Jan. Not uncommon in pastures and along roads.-All islands.

208. D. molle, DC.

Fl. Dec.-Jan. Lomentum often 3-4-jointed. Rather common in pastures._St. Croix; St. Thomas.

209. Stylcsanthes procumbens, Sw.

Fl. Oct.-Dec. Lomentum in my specimens always 2-jointed. Common along roads.-All islands.

210. S. viscosa, Sw.

St. Croix (West, p. 301). (Perhaps a mistake for the former species.)

211. Arachis hypogæa, L. (v. Pindars, Ground-nuts).

Fl. May-Aug. Seeds used for making cakes or eaten roasted. Cultivated and naturalized.-All islands.

212. Abrus præcatorius, L. (v. Jumbee-bead, Scrubber, Wild Liquorice).

Fl. Oct.-Feb. Leaves used for washing clothes. Common in thickets and on hedges. - All islands.

213. Rhynchosia minima, DC. $u$ ) and $\beta$ ) lutea, Egg.

Fl. all the year round. Seeds black, with small grey spots. a) Standard reined with purple; a low climber. B) Standard uniformly yellow; climbing up to $6^{\prime}$. Both forms common in pastures and thickets.-All islands. 
214. R. phaseoloides, DC.

Fl. March. Stem laterally compressed. Rare in forests.-St. Thom us (Signal Hill, 1200').

215. $R$. reticulata, DC.

Fl. all the year round. Leaflets as long as $1 \frac{1}{2} "$. Common on fences and along roads.-All islands.

216. Cajanus indicus, Spreng. (v. Pigeon-pea, Vendu bountje).

Fl. all the year round. Seeds used as a common vegetable for soup. Cultivated and naturalized.-All islands.

217. Clitoria Ternatea, L. (v. Blue Vine).

Fl. all the year round. Common in thickets.-All islands.

218. Centrosema virginianum, Benth. $\omega)$ and $\beta$ ) angustifolium.

Fl. all the year round. Very common in ditehes and on fences.-All islands.

219. Teramnus uncinatus, Siv., var. albiflorus, Eggr.

Fl. Sept.-March. Corolla $1 \frac{1}{2}^{\prime \prime \prime}$ long, constantly white. Legume $1^{\prime \prime}$ long, black, pilose. Common in pastures and along roads.-St. Croix; St. Thomas.

220. Galactia filiformis, Benth.

Fl. Oct.-Jan. Roots often bearing small tubers. Common in thickets.-All islands.

221. G. tenuiflora, W. \& A.

Fl. Feb.-June. In forests, rare. There seems not to be sufficient reason for uniting this species to the preceding, as done by Griseb. Fl. p. 194.-St. Thomas (Flag Hill); St. Jan (Rogiers).

222. Vigna luteola, Benth. (v. Wild Pea).

Fl. all the rear round. Common in moist localities.-All islands.

223. Dolichos lablab, L. (D. benghalensis, Jacq.).

Fl. all the year round. Seeds brown. Very common along the seashores.-All islands.

224. Phaseclus lunatus, L. (v. Bonny Vis).

Fl. Dec.-Feb. Corolla white or rosy. Naturalized in thickets and near dwellings.-All islands.

225. $\mathrm{Ph}$. vulgaris, L. (v. White Bean).

Fl. Feb.-July. Cultivated and naturalized near dwellings.-All islands. 
226. Ph. alatus, $\mathrm{L}$.

St. Croix (West, p. 299).

227. $\mathbf{P h}$. semierectus, $\mathrm{L}$.

Fl. all the year round. Flower expanded only in the sun. Common along roads and in pastures.-All islands.

228. Canavalia parviflora, Benth. (Flor. Bras. xv, i, 177).

Fl. Feb. Inflorescence extra-axillary (as in C. bonariensis, Lindl. Bot. Reg. 1199). Legume broad on the back, without prominent ridges, $3^{\prime \prime}$ long, $1_{4}^{1 \prime \prime}$ broad. Seeds crimson, shining, $\frac{3}{4}$ l' long. In forests, rare.-St. Thomas (Signal Hill, $1300^{\prime}$ ).

229. C. gladiata, DC. $\beta$ ) ensiformis, DC. (v. Sour-eyes, Orerlook) (Dolichos acinaciformis, Jacq. Icon. Rar. t. 559). Bot. Mag. 4027.

Fl. Aug.-Dec. Naturalized in provision grounds.-St. Thomas (Signal Hill, $\left.1200^{\prime}\right)$.

230. C. obtusifolia, DC. (Dolichos rotundifolius, Vahl).

Fl. all the year round. Common along the seashore.-All islands.

231. Mucuna pruriens, DC. ( $\nabla$. Cow-itch).

Fl. Oct.-Nov. In shady valleys. Rare.-All islands.

232. Erythrina Corallodendron, L. (v. Flamboyant).

Fl. Feb.-April. Precocious. Stamens all of unequal length. Rather common, especially along roads and near dwellings._-All islands.

233. E. horrida, Egg. (n. sp.).

Fl. Feb.-March. Very prickly. Approaching to the preceding, but stem, branches, petiole, and leaf-ribs on both sides armed with stout and straight prickles; legume terete, long-beaked. A low tree, branches procumbent. In forests, not uncommon.-All islands.

234. Piscidia Erythrina, L. (v. Dog-wood, Stink-tree).

Fl. March-A pril. Precocious. Only those individuals that flower drop the leaves. Common in thickets.-All islands

235. Drepanocarpus lunatus, Mey.

St. Croix (Isert, 1787, in Hb. Harn; West, p. 298).

236. Hecastophyllum Brownei, Pers.

Fl. June-Dec. Not uncommon on sandy shores.-All islands. 237. Andira inermis, Sw. (

Fl. May-Aug. and Dec. Not uncommon in forests and along rirulets.-All islands. 
233. Sophora tomentosa, $\mathrm{L}$.

Fl. July-Jan. Along sandy shores, rare.-St. Croix (White's Bay, Turner's IIole).

239. Myrospermum frutescens, Jacq.

Fl. May-June. Legume resinous. Naturalized near dwellings.-St. Croix.

240. Hæmatoxylon campechianum, L. (v. Logwood).

Fl. Feb.-May. The young plants prickly on the stem. Here and there on sandy shores. More common in former times.-All islands.

241. Parkinsonia aculeata, L. (v. Horse-bean).

Fl. all the year round. Common in dry localities.-All islands.

242. Guilandira Bonduc, L. (v. Yellow Nickars).

Fl. May-Oet. Common along sandy shores.-All islands.

243. G. melanosperma, Egg. (n. sp.) (v. Black Nickars).

Fl. June-Oct. Resembling the preceding, but leaflets smaller, glabrous, shining, prickles red and seeds shining-black. Seeds used for ornaments. In dry thickets near the shore, rare.-St. Croix (Sandy Point, Grape-tree Bay).

244. G. Bonducella, L. (v. Grey Nickars).

Fl. all the year round. Anthers successively dehiscent. Flowers polvgamous. Very common along sandy shores.-All islands.

245. Cæsalpinia pulcherrima, Sw. (v. Dudeldu).

Fl. June-Dec. Bracteoles large, subulate, but deciduous before the expansion of the flower. Commonly naturalized along roads and near dwellings._-St. Croix; St. Thomas.

246. Poinciana regia, Boj. (Bot. Mag. 2884) (v. Flamboyant).

Fl. May-July. Bracteoles as in the preceding. Leaves deciduous Dec-April. A handsome tree of very quick growth. Naturalized in gardens and near dwellings.-St. Croix; St. Thomas.

247. Lebidibia coriaria, Schl. (v. Dividivi).

Fl. April-May. Legume used for tanning purposes. Rather common on dry hills.-Virgin Islands (St. Croix, cultivated).

248. Cassia Fistula, L.

Fl. Sept. Naturalized here and there in shady valleys.-St. Croix (The William).

2^9. C. grandis, L. (v. Liquorice-tree).

Fl. A pril-July. The pulp containing rhaphides in abundance. Naturalized and cultivated near dwellings._St. Croix; St. Thomas. 
250. C. bacillaris, $\mathrm{L}$.

Fl. Nov.-May. Common in thickets and woods on high hills.-St. Thomas.

251. C. bicapsularis, L. (v. Stiverbush, Styver bla).

Fl. all the year round. Very common in waste places.-All islands.

252. C. florida, Vahl.

Fl. Dec. Naturalized near towns.-St. Thomas.

253. C. biflcra, L. $\beta$ ) angustisiliqua, Lam.

Fl. Nov.-May. In thickets, rare.-St. Croix (Longford).

254. C. alata, L. (v. Golden Candlestick, Fleïti).

Fl. May-Nov. Along rivulets, not uncommon.-Virgin Islands (naturalized in St. Croix).

255. C. cccidentalis, L. (v. Stinking-weed).

Fl. all the year round. Root used against fever. A very common weed near dwellings and in waste places.-All islands.

256. C. obtusifolia, L.

Fl. June-Nov. Common in dry localities.-St. Croix; St. Thomas.

(C. triflora, Vahl (Eclog. Am. iii, p. 11) (West, St. Croix), is a doubtful species. I have not been able to find the original specimen of Vahl in Hb. Havn.)

257. C. glandulosa, L. $\alpha$ ) stricta, Schl, and $\beta$ ) ramosa.

Fl. all the year round. Both forms common in pastures and along roads.-All islands.

258. C. nicticans, $L$.

Fl. all the year round. In the same localities as the preceding.-St. Croix; St. Thomas.

259. Tamarindus indica, L. (v. Tamarind-tree).

Fl. March-June. Naturalized everywhere, especially near dwellings.-All islands.

260. Hymenæa Courbaril, L. (v. Locust-tree).

Fl. Jan. and July-Aug. Bracts large, early deciduous. The wood is an excellent timber on account of its being very hard and close-grained. In forests, here and there.-All islands.

261. Bauhinia tomentosa, L.

Fl. May-June. Leaves partly deciduous in March. Naturalized in gardens and near dwellings.-St. Croix; St. Thomas. 
262. B. ungula, Jacq

St. Thomas (Gris. Fl. 214).

263. Adenantbera pavonina, L. (v. Coquelicot).

Fl. July-Oct. Naturalized near dwellings and in shady valleys.All islands.

264. Neptunia pubescens, Benth.

Fl. Aug. Legume containing as many as $\mathbf{9}$ seeds. Rare.-Buck Island, near St. Thomas.

265. Desmanthus virgatus, W. $\quad$ ) and $\beta$ ) strictus, Bert.

Fl. all the year round. Both forms common in pastures and along roads.-All islands.

266. D. depressus, Kth.

St. Thomas (Schl.).

267. Mimosa pudica, L. a) ( . Gritchee).

Fl. all the year round. In pastures and along roads.-St. Croix (very rare, Mt. Stewart); Virgin Islands (common).

268. M. asperata, $\mathrm{L}$.

St. Thomas (Gris. Fl. 219).

269. M. Ceratonia, L. ( . Black Amaret, Amaretsteckel).

Fl. June-Dec. On high hills.-St. Croix (West, p. 312 ; his specimens are found in Hb. Havn.); Virgin Islands (common).

270. Leucæna glauca, Benth. (v. Wild Tamarind).

Fl. all the year round. Leaflets closing together in strong sunlight. Seeds used for fancy work, such as collars, baskets, etc. Very common everywhere, also as secondary growth on cleared woodlands.-All islands.

271. Acacia Catechu, W.

Fl. May-July. Stem furnished with strong black aculei. Naturalized in shady valleys.-St. Croix (Crequis).

272. A. nudiflora, W. (v. Amaret).

Fl. May and Nov.-Dec. Protandrous. Young foliage reddish. Wood used for fencing. A low tree. Common in thickets and woods.-Virgin Islands.

273. A. sarmentosa, Desv. (v. Catch-and-keep, White Police).

Fl. July-Sept. Stem generally angular or even winged. A very spiny climbing shrub, the recurved spines of which often make thickets impenetrable. Common on dry hills.-Virgin Islands. 
274. A. macracantha, HB. $\beta$ ) glabrens (v. Stink Cashá).

Fl. Dec.-April. A shrub or low tree. Wood exhaling a very disagreeable odour. "Common in thickets on dry hills.-All islands.

275. A. tortuosa, W. (v. Cashá).

Fl. all the year round. Flowers fragrant. Bracteoles rhomboid, ciliate. Often gregarious. Common on dry hills.-All islands.

276. A. Farnesiana, W. (v. Casha).

Fl. all the year round. Flowers fragrant; bracteoles spathulate, ciliate. Foliage of this and the two former pecies eaten by goats, and their wood generally used for making charcoal. Common in dry localities.-All islands.

277. A. arabica, W.

Fl. Nov.-Jan. Naturalized near dwellings.-St. Croix; St. Thomas. 278. A. Lebbek, IV. (v. Thibet-tree).

Fl. April-Sept. Leaves deciduous Nov.-March. Flowers fragrant. Foliage eaten by cattle. The tree is often overgrown by Loranthus emarginatus. Naturalized in pastures and elsewhere.-St. Croix (very common); Virgin Islands (common, except St. Jan, where the tree seems not to thrive).

(A. frondosa, W., var. eglandulosa, St. Thomas, is mentioned by Schlechtendal as spontaneous, but, being an East Indian species, is most probably only cultivated or at most naturalized. I have not seen the species in the island.)

279. Calliandra portoricensis, Benth.

Fl. Feb. Climbing by the aid of young branches that twine themselves around the hranches of other trees. In forests, rare.-St. Jan (King's Hill); Vieques.

280. C. purpurea, Benth. (v. Soldier-wood, West).

St. Croix (Gris. Fl. p. 224, probably on the authority of West. This author, however, says, p. 312, that the tree is only cultivated in the island. His specimens are in existence in Hb. Havn. I have not seen the tree on the island).

281. C. Saman, Gris. (v. Giant Thibet-tree).

Fl. May-Aug. A very large tree of quick growth. Naturalized pear dwellings and planted along roads.-St. Croix; St. Thomas.

282. Pithecolobium unguis-cati, Benth. $a$ ) and $\beta$ ) forfex, Kth. (v. Crab-prickle).

Fl. Sept.-Jan. 'Gynophore 1"' long. Seeds black, shining; arillus rosy. Wood used for fishpots. Both forms common on limestone and in marshy soil.-All islands.

Bull. Nat. Mus. No. $13-4$ 
283. Ingar laurina, W. ( $v$. Lady-finger-tree).

Fl. July-Sept. and Jan.-March. Petiole bearing a narrow wing on each side. Corolla greenish. (Jacquin's drawing does not show any wing on the petiole. In the letterpress, liowever, of his Stirp. Am., he expresses a doubt whether the petiole is winged or not.) Wood used for fences, etc. Common in forests.-All islands.

[Cultivated species: Pisum sativum, L. (v. Green Pea); Dolichos spharospermus, DC. (v. Black-eye Pea); D. sesquipedalis, L.; Poinciana Gilliesii, Hook.; and a Casparea.]

\section{CHRYSOBALANACEAE.}

284. Chrysobalanus Icacs, L. (v. Cocoa-plum, Cacos).

Fl. Dec.-Feb. and July-Aug. Fruit black or white; used for preserves. On sandy shores or in forests on high hills. Common.-All islands.

ROSA CEAE.

[Many varieties of Rosa gallica, L., and $R$. centifolia, L., are cultivated in gardens on all the islands, and are flowering abundantly all the year round. In the time of West (c. 1790), roses were rare, and flowered but seldom, so that we here seem to have an instance of gradual acclimatisation.]

\section{MYRTACERE.}

285. Calyptranthes Thomasiana, Berg (Linnæa, xxvii, 26).

St. Thomas (Ventenat and Ravn in Hb. Havn.).

286. C. Chytraculia, Sw. $\beta$ ) ovalis, Berg, and t) Zyzygium, Berg (1. c.p. 28).

In forests, rare.-St. Thomas; St. Croix.

287. C. pallens, Gris.

Fl. July-Aug. Branchlets quadrangular. In forests, rare.-St. Croix (Kingshill Gut); St. Thomas (Crown).

288. Myrcia coriacea, DC. $\gamma$ ) Imrayana, Gris.

Fl. June-July. In forests on high hills, uncommon.-A!l islands. 289. Jambosa malaccensis, DC.

Fl. April-May. Naturalized in shady valleys; rare.-St. Croix (Crequis).

290. J. vulgaris, DC. (v. Pomerose-tree).

Fl. March-June. Fruit used for preserves. Naturalized along rivulets and in forests, common.-All islands.

291. Eugenia buxifolia, W.

Fl. June-Sept. Petioles reddish. Gregarious, especially along the seashore.-St. Croix; St. Thomas. 
292. E. Poiretii, DC.

St. Thomas (Gris. Fl. 236).

293. E. monticola, DC.

Fl. July-Sept. Leaves variable, distichous. Flowers strongly fragrant. When not flowering, the shrub emits a fotid smell. Rather common in forests. $-\mathrm{All}$ islands.

294. E. axillaris, Poir.

Fl. Aug.-Oct. Leaves variable. Petiole reddish. In thickets; rare.-St. Croix (Lebanon Hill, Fair Plain).

295. E. lateriflora, W. (E. cordata, DC. Prodr. iii, 272, and probably E. 8cssiliflora, ib. 273).

Fl. Sept.-Nov. Leaves very variable, ovate, cuneate, or oblong. Flowers sessile or subsessile, crowded in the axils. Berry globose, purple, $2^{\prime \prime \prime}$ diam. Common in thickets and forests.-All islands.

296. E. sessiliflora, Vahl (Symb. Bot. iii, 64).

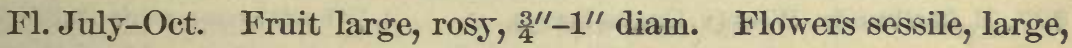
white, $5^{\prime \prime \prime}$ diam. In thickets, not uncommon.-St. Croix; St. Thomas (Cowell's Hill).

(Both DC. and Gris. seem to confound these two rery distinct species, the flowers and fruits of which are highly different in most respects. DC. Prodr. iii, 273, says of his E. sessiliflora: Fructus dimidio minor quam $E$. lateriflorce, yet immediately above he says of this latter species: Fructus et sem. ignoti. Vahl's description is very correct, also, of the fruit, of which he says: Pruni magnitudine, globosns.)

297. E. flavevirens, Berg (1.c.).

St. Jan (Ravn in $\mathrm{Hb}$. Havn.).

298. E. glabrata, DC. (Prodr. iii, 274).

St. Croix (Berg).

299. ․ pallens, DC. (E. nitida, Vahl in Hb. Havn.) (v. Cromberry).

Fl. Sept.-Nov. Leares shining. In forests, uncommon.-All islands. 300. E. acetosans, Poir. (DC. Prodr. 1. c. 283).

St. Jan (in forests, Berg in Linnæa, xxx, 662); St. Croix (Mount Eagle, Richard).

301. E. virgultosa, DC.

Fl. April-July. Leaves variable. Common along the seashore and in forests.-All islands. 
302. E. procera, Poir. (v. Black Cherry, Rock-myrtle) (Myrtus cerasina, Vahl in West, p. 290).

Fl. Feb. and Aug.-Nov. Flowers fragrant; fruit edible; a favourite food for wild pigeons. In torests, common.-All islands.

303. E. pseudopsidium, Jacq. (E. Thomasiana, Berg) (v. Bastard Guava, Christmas Cherry).

Fl. April-Dec. Flowers fragrant; fruit oval. A shrub or low tree. In forests, not uncommon.-All islands.

304. E. ligustrina, W.

Fl. April and Sept. In thickets and woods, common.-All islands.

305. E. portoricensis, DC. (Prod.iii, 266) (Stenocalyx, Berg).

St. Croix (ex Hb. Vahlii in Hb. Berol.).

306. E. uniflora, L. (v. Surinam Cherry).

Fl. March-Aug. Fruit edible, acidulous. A middle-sized tree. Naturalized and planted in gardens.-St. Croix; St. Thomas.

307. E. floribunda, West (v. Guava-berry).

Fl. June-Aug. Berry black, globose, shining, $4^{\prime \prime \prime}$ diam., aromatic ; used for preserves or put in rum. In forests, not uncommon.-All islands.

(E. marginata and E. micrantha, West, p. 290, are not mentioned in Vahl's Symb. Bot. pars iii, as stated, and are probably included in some of the species enumerated above.)

308. Anamomis punctata, Gris.

Fl. June. In forests, rare.-St. Croix (Maroon Hill, Wills Bay); St. Jan (Cinnamon Bay).

309. Pimenta vulgaris, W. \& A. (v. Cinnamon-bush).

Fl. June-July. In forests, rare. An excellent timber tree.-St. Croix (Maroon Hill); Virgin Islands.

310. P. acris, W. \& A. (v. Bay-leaf). $a$ ).

Fl. July-Aug. From the leaves the well-known bay-rum is distilled. In forests near the coast, not common.-St. Croix; Vieques.

311. Psidium Guava, Radd. (v. Guava). a).

Fl. all the year round. Fruit edible; also used for preserves. Very common, overrunning pastures and becoming troublesome in many places. - All islands.

312. P. cordatum, Sims. (v. Sperry Guava).

Fl. May-July. Fruit fragrant. In thickets on hills, not uncommon.Virgin Islands. 
313. Punica granatum, L. (v. Pomegranate).

Fl. April-Oct. Flowers crimson or yellow Fruit the same. Naturalized in valleys and near dwellings.-All islands.

314. Mouriria domingensis, Walp. (Petaloma Mouriri, Sw.).

St. Croix (Baudonius Gut, West, p. 285, and specimens in Hb. Havn.).

[Cultivated species: Myrtus communis, L. (v. Myrtle), and Couroupita guianensis, Aubl. (v. Nutmeg).]

\section{MELASTOMACEAE.}

315. Clidemia hirta, Don.

St. Thomas (Riedlé sec. Naudin, Ann. des sc. nat. 1853, xviii, p. 532). 316. C. spicata, DC.

Fl. June-July. In forests, not uncommon.-All islands. .

317. C. rubra, Mart.

St. Thomas (Gris. Fl. p. 248; Finlay sec. Naudin, 1. c.).

318. Diplochita serrulata, DC.

Fl. Feb.-May. Not uncommon in wooded valleys.-St. Croix; St. Thomas.

319. Tetrazygia elæagnoides, DC.

Fl. April-Aug. Common in forests and on high hills.-All islands. 320. Miconia argyrophylla, DC.

St. Thomas (Finlay sec. Naudin, Gris. Fl.p. 256).

321. M. impetiolaris, Don.

Leaves as long as $\mathbf{1}_{2}{ }^{\prime}$. - St. Croix (West in Hb. Havn.); St. Thomas (Gris. Fl. p. 256; Bonpland sec. Naudin. Montserrat (Ryan in $\mathbf{H b}$. Havn.).

322. M. prasina, DC.

St. Thomas (Riedlé sec. Naudin).

323. M. lævigata, bc.

Fl. March-July. In forests, not uncommon.-All islands.

324. M. angustifolia, Gris.

Fl. March. A good-sized shrub, often gregarious on limestone.-St. Croix (Benzon in Hb. Havn.); Virgin Islands (not uncommon. Montserrat (Ryan in Hb. Havn.).

[Several of the species mentioned by Naudin as having been collected in St. Thomas I omit as being a rather doubtful habitat. These are: Tshudya berbiceana, Gris. (Miconia, Naud.); Cremanium amygdalinum, Gris. (Osscea, DC.), and Nepsera aquatica, Naud.] 
325. Ammania latifolia, $\mathrm{L}$.

\section{LYTHIRA RIEAE.}

Fl. Dec.-June. Here and there in moist localities.-St. Croix (Lower Cove, Anna's Hope); St. Thomas (Flag Hill).

326. Antherylium Rohrii, Vahl (Symb. Bot. iii, 66) (v. Prickle-wood).

Fl. Oct.-March. Precocious. Petiole bibracteate above the middle. In marshy soil near the coast.-St. Croix (rare; Fair Plain, Stony Ground); Virgin Islands (common).

[Cultivated species: Lawsonia inermis, L. (v. Mignonette), and Lagerströmia indica, L. (v. Queen of Flowers).]

\section{ONAGRACEA.}

327. Jussieua suffruticosa, L. a) ligustrifolia, Kth.

Fl. all the year round. Here and there in moist places.-St. Croix (Crequis, Golden Rock); St. Thomas (Caret Bay).

\section{RHIZOPHORACEAE.}

328. Rhizophora Mangle, L. (v. Mangrove, Mangelboom).

Fl. all the year round. Gregarious along the shore of lagoons.-All islands. (See Botaniska Notiser, 1877, Lund, and Vidensk. Medd. fra Naturhist. Forening in Copenhagen, 1877-78.)

\section{Combreticese.}

329. Terminalia Catappa, L. (v. Almond-tree).

Fl. Jan.-April and Sept. Naturalized in valleys and near dwellings.St. Croix (common); Virgin Islands (rare).

330. Laguncularia racemosa, G. (v. White Mangrove).

Fl. all the year round. Wood used for fishpots. Common in saltwater lagoons.-All islands.

331. Bucida Buceras, L. (v. Gregery).

Fl. May-Aug. A splendid timber tree. Leaves often attacked by a fungus (Erineum, vide Kunze mycol. Hefte, ii, 148). Flowers often transformed into long monstrosities (figured already in P. Browne's Jamaica, tab. 23). Common in valleys and especially along the coast.-All islands.

332. Conocarpus erecta, L. (v. Button-wood). $\quad a$ ) and $\beta$ ) procumbens, Jacq.

Fl. all the year round. Common along the coast and in lagoons.All islands.

[Cultivated species: Quisqualis indica, L.] 
FLORA OF ST. CROIX AND THE VIRGIN ISLANDS.

\section{CUCURBHTACEA.}

(Griseb. Flora, and Naudin : Annales des sc. nat. 1859, '62, '63, and '66.)

333. Momordica Charantia, L. a) and $\beta$ ) pseudobalsamina (v. Maid-apple).

Fl. Dec. and April-Aug. Common on fences and near ditches.-All islands.

334. Luffa cylindrica, Roem. (Syn. Mon. ii, 63) (L. Petola, Ser. Wight Icon. ii, t. 499j) (v. Strainer-vine).

Fl. Oct.-Dec. Tendril 5-fid. Fruit brown, $4^{\prime \prime}$ long. Naturalized on fences.-St. Croix; St. Thomas.

335. Cucurbita Pepo, L. $\alpha$ ) (v. Pumpkin) and $\beta$ ) Melopepo (v. Squash).

Fl. May.-Nov. and Feb. Fruit used extensively as a vegetable. Naturalized and cultivated.-All islands.

336. Lagenaria vulgaris, Ser. $a$ ) (v. Gobie) and $\beta$ ) viscosa, Egg. (v. Bitter Gobie).

F1. Sept.-Jan. The whole plant has a strong smell. Tendril 2-fid. f) leaves viscous, petiole biglandular near the top. Used as a blister. Not uncommon in waste places. a) on fences. Fruit used for goblets.St. Croix; St. Thomas.

337. Melothria pervaga, Gris.

Fl. Dec.-April. Iu thickets, not uncommon.-All islands.

338. Cucumis Anguria, L. (v. Cucumber).

Fl. Jan.-March. Anthers glabrous in the bud, pilose after dehiscence, collecting the pollen. Berry used for soup and pickles. Common in pastures and on fences.-All islands.

339. Cephalandra indica, Naud. (1. c. 1866, p. 14) (Coccinia, W. \& A.).

Fl. Dec.-June. Naturalized near dwellings and in shady valleys.St. Croix.

340. Trianosperma graciliflorum, Gris. (T. Belangerii, Naud.).

F1. Nov.-Jan. Leaf 3-5-lobed. Tendril often bifid. In forests, not uncommon.-All islands.

341. T. ficifolium, Mart. (Syst. nat. med. veg. Bras. 79) (Bryonia, Lam.).

Fl. March. In forests, not uncommon.-St. Thomas (Soldier Bay); St. Jan (West, p. 301).

342. Anguria trilobata, L.

'St. Croix (Ham's Bluff, West, p. 305).

343. A. glomerata, Egg. (n. sp.).

Fl. Feb.-March and May-Aug. Root tuberous. Stem suffruticose, bark greyish. Leaves alternate, ovate-triangulate or 3-lobed, some- 
times 3-partite, narrowly cordate at the base, denticulate, acuminate, scabrous above, whitish pubescent beneath. Tondril simple. $\&$ flowers glomerate, sessile or subsessile, 8-20 in the glomerule. Calyx urceolatecylindrical, small. Petals 5, orange-coloured or red, lanceolate, erect, $5^{\prime \prime \prime}$ long. Style bifid; stigmas thick, globose, obsoletely 2-lobed. Ovary 2locular; ovules 3-8 in each cell. Berries densely glomerate, sessile or subsessile, oval, glabrous, striate, red, $8^{\prime \prime \prime}$ long. Seeds $3-8$, urceolateglobose, verrucose, brownish, $2^{\prime \prime \prime}$ long. ô unknown. A high climber. Stem often $\frac{1}{2}$ " diam. at the base, succulent. In forests, not uncommon.-St. Croix (Jacob's Peak, Claremont,); St. Thomas (Picaru Peninsula).

All Cucurbitaceæ are protogynous.

[Cultivated species: Sechium edule, Sw. (v. Choco); Cucumis sativus, L. (v. Mutton-cucumber); C. Melo, L. (v. Muskmelon), and Citrullus vulgaris, Schrader (v. Watermelon).]

\section{PAPAYACER.}

344. Carica Papaya, L. (v. Papaw).

Fl. March-Aug. Stem often branched. Fruit used as a vegetable. Common near dwellings and in waste places. All islands.

\section{PASSIFLORA CEAE.}

345. Passiflora suberosa, L. (v. Pop, Indigo-berry).

Fl. Sept.-Dec. Common on rocks and fences.-All isląnds.

346. P. pallida, $L$.

Fl. Oct.-Dec. In forests, rare.-St. Croix (Wills Bay); St. Jan.

347. P. hirsuta, L. (P. parvifora, Sw.)

St. Croix (West, p. 30.

348. P. peltata, Cav.

St. Thomas (Schl.).

349. P. rubra, L.

Fl. Sept.-Feb. In forests and on rocks.-St. Croix (rare); Virgin Islands (common).

350. P. laurifolia, L. (v. Bell-apple).

Fl. all the year round. Leaf-margin glanduliferous. Berry fragrant, containing an edible pulp. In thickets on high hills (perhaps only nàturalized) and cultivated.-All islands.

351. P. incarnata, $\mathrm{L}$.

St. Croix (West, p. 304). 
352. P. fotida, L. ( . Love in the mist).

Fl. Sept.-Jan. Protandrous. On fences and near ditches, common.St. Croix ; St. Thomas.

[Cultivated species : P. quadrangularis, L. (v. Grenadilla), the berry of which is edible.]

\section{TURNERACEAE.}

353. Turnera ulmifolia, L.

Fl. March-Oct. In waste places, common.-All islands.

354. T. parviflora, Benth.

Fl. Sept.-Dec. and Jan.-May. Leaves always eglandular; calyx not tomentose. Gregarious on rocky seashores, rare.-St. Thomas (Cowell's Hill); Buck Island, near St. Thomas.

\section{CACTACEB.}

355. Mamillaria nivosa, Link (Pfeiffer Enum. Cact. 1837, p. 11) (M. tortolensis, Hort. Berol.).

Fl. all the year round. Flower pale yellow; berry clavate, purple. Seeds brownish. On rocks near the seashore.-Buck Island and Flat Cays, near St. Thomas ; Tortola (Pf.).

356. Melocactus communis, DC. (v. Pope's Head).

Fl. all the year round. Berry clavate, purple, $\frac{3 \prime 4}{4}$ long. Seeds black, verrucose. Up to four feet high. On dry hills and rocks, especially near the shore.-All islands.

357. M. atrosanguineus, Hort. Berol.

St. Thomas (Pf. 1. c. p. 44).

358. Cereus floccosus, Hort. Berol. (v. Dildo).

Fl. Oct.-July. Berry depressed globose, dark crimson, $\mathbf{1}_{2}^{\frac{1}{2}}{ }^{\prime \prime}$ diam. Pulp red; seeds small, black. On dry hills in thickets, common.-All islands.

359. C. armatus, Otto.

St. Thomas (Pf. 1. c. p. 81).

360. C. triangularis, Haw. (v. Chigger-apple).

Fl. July. Berry large, crimson, edible, $5^{\prime \prime} \mathrm{long}$, oval. On trees and rocks in forests, not uncommon.-All islands.

361. C. grandiflorus, Haw. (v. Nightblooming Cereus).

Fl. May-July. Naturalized in gardens and near dwcllings._-St. Croix; St. Thomas. 
362. Opuntia curassavica, Mill. (v. Suckers).

Fl. all the year round. Berry purple, $\frac{3 \prime 4}{4}$ long, clavate. Gregarious in dry localities, which are often rendered impenetrable by its presence. Very common.-All islands.

363. O. Tuna, Mill. (v. Prickly Pear).

Fl. all the year round. Berry ovate, crimson, edible. Seeds small, black. Used for fencing purposes. In dry localities, very common.All islands.

364. O. horrida, Salm. (v. Bull-suckers).

Fl. all the year round. Flower reddish-yellow. In dry localities, common.-St. Croix; St. Thomas.

365. O. spinosissima, Mill.

Fl. all the year round. Spines white, 5-8 in each cluster, deciduous on the stem. Flower $\frac{3 \prime \prime}{4}$ diameter. Plant reaching $20^{\prime}-25^{\prime}$ high. In dry thickets, common.-All islands.

366. O. tuberculata, Haw. (v. French Prickly Pear).

Fl. the whole year. Flower small, yellow. Branches used for poultices. Plant $10^{\prime}-15^{\prime}$ high. Naturalized and planted near dwellings._ St. Croix; St. Thomas.

367. O. ccccinellifera, Mill.

Fl. all the year round. Plant $15^{\prime}-20^{\prime}$ high. On limestone, uncom. mon.-St. Croix; St. Thomas.

368. O. catocantha, Hort. Berol.

St. Thomas (Pf. 1. c. p. 166).

369. Peireskia aculeata, Mill. (v. Surinam Gooseberry).

Fl. July. Fruit acidulous, edible. Naturalized and cultivated.-St. Croix; St. Thomas.

370. P. Bleo, HB. K.

Fl. all the year round. Sepals accrescent on the fruit. Naturalized and cultivated in gardens.-St. Croix; St. Thomas.

[Cultivated species: Cereus peruvianus, Tabem.; C. monoclonos, DC.; C. repandus, Haw., and C. Phyllanthus, DC.]

\section{CRASGULACEAE.}

371. Bryophyllum calycinum, Salisb. (v. Wonderful Leaf).

Fl. Jan.-March.-Naturalized in dry localities, common, gregarious.All islands. 


\section{ARALIACEAE.}

372. Panax speciosum, Willd. (Spec. Plant.iv, p. 1126).

Not seen flowering. Leaflets 8 , of unequal size, the central ones largest. Margin slightly undulate and denticulate. Upper surface covered with distant and deciduous muricate hairs; tomentum on the lower surface deciduous. A low tree. In forests, very rare. St. Jan (King's Hill, $1000^{\prime}$, on the northern slope of the hills). (Cuba, Porto Rico, Caracas.)

\section{UMB ELLIFERE.}

373. Eryngium fotidum, $L$.

Fl. Sept.-May. Biennial. Along rivulets and in moist places, rare. -St. Thomas (Caret Bay).

374. Anethum graveolens, L. (v. Dill).

Fl. March-Oct. Naturalized along roads and near dwellings.-All islands.

[Cultivated species: Petroselinum sativum, Hoffin. (v. Parsley); Daucus Carota, L. (v. Carrot); Pimpinella Anisum, L. (v. Anise); Foniculum vulgare, Grertn. (v. Fennel); Anthriscus ccrefolium, L. (v. Chervil), and Apium graveolens, L. (v. Celery).]

\section{LORA N'THACEAE}

375. Loranthus emarginatue, Sw. (v. Baas-fram-boom).

Fl. all the year round. Inflorescences uniserial. On trees, especially Acacia Lebbek and Pisonia subcordata. Common.-All islands.

376. Phoradendron flavens, Gris.

Fl. April-June. Seed compressed, green, with white bands. On Pisonia subcordata, rare.-St. Croix (Stony Ground).

\section{CAPIRIFOLIACE AE.}

[Cultivated occur: Sambucus nigra, L. (Fl. April-July), and Lonicera Caprifolium, L. (v. Honey-suckle).]

\section{RUBIACEAE.}

377. Genipa americana, $L$.

Fl. July. In forests on high hills, rare.-St. Thomas (Crown); St. Jan (Rogiers).

378. Catesbæa parviflora, Sw.

Fl. Sept.-Dec. Fruit black, shining. In dry thickets, uncommon.St. Croix (Fair Plain). 


\section{Randia aculeata, L. $a$ ) and $\beta$ ) mitis.}

Fl. April-July. $\alpha$ ) in dry thickets, $\beta$ ) in shady valleys. Common.All islands.

380. Hamelia patens, Jacq.

Fl. all the year round. $6^{\prime}-15^{\prime}$ high. In shady valleys, not uncommon.-All islands.

381. H. lutea, Rohr.

Fl. all the year ronnd. In forests, uncommon.-St. Croix; St. Thomas. 382. Gonzalea spicata, DC.

Fl. May-Oct. In pastures on high hills, above $1000^{\prime}$, not uncommon.Virgin Islands.

383. Exostemma caribæum, R. S. (v. Black Torch).

Fl. June-Dec. Common in thickets.-All islands.

384. Portlandia grandiflora, $\mathrm{L}$.

Fl. June-Dec.-St. Thomas (DC. Prodr. iv, p. 405 ; Gris. Fl. p. 324); St. Croix (cultivated).

385. Rondeletia pilosa, Sw.

Fl. all the year round. In thickets.-St. Croix (rare, near Cane Bay); Virgin Islands (common).

3ọ6. Oldenlandia corymbosa, $\mathrm{L}$.

Fl. Feb.-March. Seeds brown, minutely verrucose. In waste places, rare.-St. Croix (Government House yard).

387. O. callitrichioides, Gris. (P1. Wright. p. 503).

Fl. Dec. Flower expanded early in the morning and late in the afternoon. Gregarious among stones.-St. Croix (Government House).

388. Spigelia anthelmia, L. (v. Worm-weed).

Fl. all the year round. In open, moist localities, uncommon.-St. Croix; St. Thomas.

389. Guettarda scabra, Lam.

Fl. June-Dec. Flower expanded towards evening. Drupe dark crimson, often 1-seeded by abortion. In woods, common.-All islands.

390. G. parvifolia, Sw.

Fl. July-Oct. In woods, not uncommon.-All islands.

391. Stenostomum lucidum, G.

Fl. Dec.-April. In forests, rare._St. Croix; St. Thomas (Signal Hill). 
392. Chione glabra, DC.

Not seen flowering. In forests, rare--St. Croix (Fair Plain); St. Thomas (Soldier Bay).

393. Scolosanthus versicolor, Vahl.

Fl. Oct.-Dec. Pedicels often transformed into spines, as mentioned by DC. (Prodr.iv, 484), Leares $2^{\prime \prime \prime}-3^{\prime \prime \prime}$ long.-St. Croix (West and Ryan in Hb. Havn.); St. Thomas (rather common in thickets); Water Island.

394. Erithalis fruticosa, L. $a$ ) and $\beta$ ) odorifera, Jacq.

Fl. Oct.-March. Along the coast, not uncommon.-All islands.

395. Chiococca racemosa, Jacq.

Fl. March-Dec. In forests, common.-All islands.

396. Ixora ferrea, Benth.

Fl. Feb.-May and Nov.-Dec. Among rocks on high hills over 1200', not uncommon.-St. Thomas (Crown).

397. Coffea arabica, L. (v. Coffee-tree).

Fl. May-July. Berry ripe Nov.-Dec. Naturalized in shady localities. Formerly cultivated on most estates on a small scale, principally in St. Jan.-All islands.

398. Faramea odoratissima, DC. (v. Wild Coffee).

Fl. June. In thickets on high hills.-St. Croix (West and Benzon in Hb. Havn.); Virgin Islands (not uncommon).

399. Psychotria glabrata, Sw.

Fl. June-Sept. Here and there in shady valleys.-All islands.

400. P. tenuifolia, $\mathrm{Sw}$.

Fl. May. In thickets on high hills, rare.-St. Thomas (Crown, 1500'). 401. P. Brownei, Sprg.

Fl. June-Sept. In woods, common.-All islands.

402. P. horizontalis, Sw.

Fl. May-Dec. Along roads and in thickets, common.-All islands.

403. Palicourea Pavetta, DC. $a$ ) and $\beta$ ) var. rosea, Egg.

Fl. Feb. and Aug. $\beta$ ) corolla-lobes rosy, anthers bluish, and stem brownish. In forests, not uncommon.- $\beta$ ) all islands. $\alpha$ ) St. Thomas (Signal Hill).

404. Morinda citrifolia, L. (v. Pain-killer).

Fl. June-Aug. Leaves used against headache. Naturalized in gardens.-St. Croix; St. Thomas. 
405. Geophila reniformis, Cham. \& Schl.

Fl. Dec.--Jan. and Aug. On the ground in dense woods, rare.-St. Thomas (Signal Hill, St. Peter); Vieques (Hb. Havn.).

406. Ernodea litoralis, Sw.

Fl. Dec.-May. Along sandy coasts, not uncommon.-All islands.

407. Diodia rigida,Cham. \& Schl. (Linnæa, iii, 341).

St. Thomas (Schl.).

408. D. sarmentosa, Sw.

St. Thomas (Schl.).

409. Spermacoce tenuior, Lam. (v. Iron-grass). a) and $\beta$ ) angustifolia, Egg.

Fl. all the year round. $\beta$ ) leaves linear-lanceolate. In pastures and along roads. Both forms common.-All islands.

410. Borreria verticillata, Mey.

Fl. May-Oct. Suffruticose. In pastures on hills.-St. Croix (Hb. Havn.); St. Thomas (not uncommon on Crown).

411. B. stricta, Mey. (Primit. Fl. Essequib. p. 83).

Fl. Dec.-March. In pastures, here and there.-St. Croix (Parade Ground).

(B. vaginata, Ch. \& Schl. (St. Thomas, Schl.), is a doubtful species (DC. Prod. iv, 551).)

412. B. parviflora, Mey.

Fl. March-June. Along roads and in forests.-St. Croix (Benzon in Hb. Havn.); St. Jan (Rustenberg, not uncommon).

[Cultivated species: Ixora Bandhuca, Roxb. (v. Burning Love), and I. stricta, Roxb.]

\section{SYNANTHERE $A$ E.}

413. Sparganophorus Vaillantii, G.

Fl. March-Sept. In moist localities, not uncommon.-St. Croix; St. Thomas (DC. Prod. v, 12).

414. Vernonia arborescens, Sw. $\alpha$ ) Swartziana, $\beta$ ) Lessingiana, $\gamma$ ) divaricata, Sw. Fl. May-Dec. In thickets, all three forms not uncommon.-All islands.

415. V. punctata, Sw.

Fl. all the year round. In thickets, common.-All islands.

416. V. Thomæ, Benth. (Vid. Medd. fra Nat. For. 1852, p. 66).

Fl. all the year round. In thickets, not uncommon.-St. Thomas. 
417. Elephantopus mollis, Kth.

Fl. March-May. Head 4-flowered. In pastures, here and there. All islands.

418. Distreptus spicatus, Cass.

Fl. Jan.-March. In pastures and along roads, common.-All islands. 419. Ageratum conyzoides, L.

Fl. Dec.-June. Achenium usually 4-gonous. Along roads and ditches, common.-All islands.

420. Hebeclinium macrophyllum, DC.

F1. June-Sept. Achenium black, 3-gonous. In forests.-St. Croix (rare; Caledonia, Wills Bay); St. Thomas (not uncommon).

421. Eupatorium odoratum, L. (v. Christmas-bush).

Fl. Nov.-March. Along roads and in thickets, common.-All islands. 422. $\Xi$. repandum, W.

Fl. Dec.-July. On hills, not common.-All islands.

423. E. atriplicifolium, Vahl (Symb. Bot. iii, 96).

Fl. Dec.-May. Leaves coriaceous, glabrous; glandular impressions numerous on the upper surface. Flower odorous. On sandy shores, common.-All islands.

424. E. canescens, Vahl.

Fl. Oct.-Nov. In thickets, uncommon. St. Croix (Spring-gut); St. Thomas (DC. Prod. , 155).

425. .. Ayapana, Vent.

St. Croix (naturalized sec. Vahl, who received it from Pflug; probably only cultivated).

426. E. cuneifolium, Willd.

St. Thomas (DC. Prod. $\nabla, 177$ ).

427. Mikania gonoclada, DC.

F1. Dec.-March. In forests.-St. Croix (rare; Caledonia); Virgin Islands (not uncommon).

428. Erigeron cuneifolius, DC. (Prod. $\nabla, 288$ ).

Fl. Dec.-July.-Rhizome perennial, for which reason this species must be considered sufficiently distinct from the annual $E$. Jamaicensis, Sw. The two species are united into one by Prof. Grisebach in his Fl. p. 365. In pastures on high hills, not uncommon above $1200^{\prime}$ - Virgin Islands. 429. E. spathulatus, Vahl.

Fl. April-July. Along roads and ditches, rather common.-All islands. 
430. $\mathrm{E}$. canadensis, $\mathrm{L}$.

'Fl. June-Nov. Ray-flowers often ligulate. Along roads, common.All islands.

431. Baccharis Vahlii, DC. (Prod. $v$, 411) (B. dioica, Vahl).

Fl. all the year round. As much as $30^{\prime}$ high. On rocky seashores, gregarious, not uncommon. (The specific name of DC. is to be preferred to that of Vahl, notwithstanding the priority of the latter, for the reasons stated in the Prodromus.)-St. Croix (northwestern coast).

432. Pluchea odorata, Cass. (v. Sweet Scent, Ovra bla).

Fl. Feb-April. Leaves used as tea against colds and as diuretic medicine. In moist localities, not uncommon.-All islands.

433. P. purpurascens, DC.

Fl. all the year round. Along rivulets, not uncommon.-St. Croix (Gallows Bay, Kingshill Gut).

434. Pterocaulon virgatum, DC.

Fl. all the year round. On dry hills, common.-All islauds.

435. Melampodium divaricatum, DC. (Prod. v, 520) (M. paludosum, Kth.).

Fl. Oct.-Feb. Along ditches, gregarious, rare-_St. Croix (Jolly Hill).

436. Ogiera ruderalis, Gris.

Virgin Islands (Gris. Fl. p. 369).

437. Acanthospermum humile, DC.

F1. all the year round. Leaves not glandular beneath. A common weed along roads.-St. Thomas.

438. Xanthium macrocarpum, DC. (Prodr. $\mathrm{r}, 523)$ ( $X$. orientale, L.).

Fl. Oct.-Feb. A common weed, naturalized around dwellings.-All islands.

439. Parthenium Hysterophorus, L. (v. Mule-weed, White-head-broom).

Fl. all the year round. A very common weed everywhere.-All islands.

440. Ambrosia artemisiæfolia, L. $\beta$ ) trinitensis.

Fl. Sept.-Oct. Naturalized in waste places.-St. Croix (Fredrikssted).

441. Zinnia multiflora, L. (v. Snake-flower).

Fl. Feb.-Aug. Along roads, not uncommon.-Virgin Islands.

442. Z. elegans, Jacq.

Fl. May-Oct. Naturalized in gardens.-All islands.

443. Eclipta alba, Hassk.

Fl. June-Feb. In moist localities, not uneommon.-All islands. 
444. Borrichia arborescens, DC.

Fl. all the year round. On sandy shores, gregarious.-St.Croix (common); St. Thomas (Smith's Bay).

445. Wedelia carnosa, Rich.

Fl. June-Jan. Along ditehes, gregarious.-St. Croix (western part of the island, not uncommon).

446. W. buphthalmoides, Gris. (v. Wild Tobaceo). a), $\beta$ ) antiguensis, Nichols, and $\gamma$ ) dominicensis.

Fl. all the year round. Leaves delicately fragrant. a) rare; $\beta$ ) and $\gamma$ ) commion along roads and in thickets.-All islands.

447. W. affinis, DC. (Prod. v, 541) (W. calycina, Rich.).

St. Thomas (Wydler).

448. W. acapulensis, HB. K.

St. Thomas (Schl. in Linnæa, 1831, 727).

(Grisebach, Fl. 372, thinks these two species to be included probably in W. frutescens, Jacq.)

449. W. cruciana, Rich.

St. Croix (DC. Prodr. v, 542).

450. W. discoidea, Less. (Linnæa, 1831, 728).

St. Thomas (Less. 1. c.).

451. Melanthera deltoidea, Rich.

St. Thomas (Less.).

452. Sclerocarpus africanus, Jacq. (Icon. Rar. i, t. 176).

Fl. Nov.-Dec. Along roads and in thickets, rare. (Naturalized?)St. Thomas (Parade ground).

453. Bidens leucanthus, $w$.

Fl. Sept.-Dec. Under trees, on high hills.-St. Croix (West, p. 303); Virgin Islands (common).

454. B. bipinnatus, $\mathrm{L}$.

Fl. Sept.-March. Achenium often 5-aristate. In pastures and along ditches, common.-All islands.

455. Cosmos caudatus, Kth.

Fl. Dec.-March. Along roads and in fields, not uncommon.-All islands.

456. Verbesina alata, $\mathrm{L}$.

Fl. Feb.-Ang. Naturalized in gardens.-St. Croix; St. Thomas. Bull. Nat. Mus. No. $13-5$ 
457. Synedrella nodiflora, G. (v. Fatten barrow).

Fl. all the year round. A common weed everywhere-All islands.

458. Pectis punctata, Jacq.

Fl. Oct.-March. In pastures and along ditches, common.-All islands.

459. P. linifolia, Less.

St. Thomaś (Less. Gris. Fl. p. 378).

460. P. humifusa, Sw.

Fl. all the year round. Gregarious on rocks and between stones, not uncommon.-All islands.

461. Egletes domingensis, Cass. a) glabrata, DC.; $\beta$ ) carduifolia, DC.; $\gamma$ ) genuina.

Fl. all the year round. On the sandy seashore, $\alpha$ ) and $\gamma$ ) rather common. $\beta$ ) found by Oersted (Vid. Medd. 1852, p. 106).-St. Thomas.

462. Erechthites hieracifolia, Raf. a) and $\gamma$ ) cacaloides, Less.

Fl. all the year round. In moist localities, not uncommon.-St. Croix $(\gamma)$; St. Thomas $(\alpha)$.

463. Emilia sonchifolia, DC.

Fl. Jan.-Oct. In shady localities. Naturalized, common.-All islands.

464. E. sagittata, DC. (Prodr. vi, 302) (Cacalia coccinea, Sims.).

Fl. all the year round. Naturalized in gardens.-St. Croix; St. Thomas.

(Cacalia coccinea, Sims., is, according to DC. Prodr. vi, 332, a synonym for Emilia coccinea. This latter species does, however, not occur in the Prodromus at all, and on a former page, 302, the Cacalia of Sims.is given as synonymous with $E$. sagittata.)

465. Leria nutans, DC.

F1. June-March. In shady localities on hills, not uncommon.-All islands.

466. Brachyrhamphus intybaceus, DC. (Jacq. Icon. Rar. i, t. 162).

Fl. all the year round. Near dwellings and in waste places, a common weed.-All islands.

467. Sonchus oleraceus, L. (v. Wild Salad).

Fl. all the year round. Achenium mostly 4-furrowed. Along roads and near dwellings, common.-All islands.

(Chrysogonum dichotomum, sp. nov., Vahl, mentioned in West, p. 303, as occurring in St. Croix, is not described in any of Vahl's publications; 
and as no specimens are to be found in Hb. Havn., I have not been able to identify the species.)

[Cultivated species: Helianthus annuиs, L. (v. Sunflower); Pyrethrum indicum, Cass.; Aster chinensis, L.; Tagetes patula, L.; Tithonia speciosa, Hook.; Georgina variabilis, Willd., and Lactuca sativa, L. (v. Salad).]

\section{LOBELIACER.}

468. Isotoma lougiflora, Prsl.

Fl. all the year round. The whole plant is poisonous. In shady localities and in pastures on high hills. St. Croix (rare, Mount Pleasant, Wills Bay); Virgin Islands (rather common on the hills).

\section{GOUDENOVIACER.}

469. Scævola Plumieri, $\mathrm{L}$.

Fl. Jan.-April. On sandy shores.-St. Croix (not uncommon); St. Thomas (Smith's Bay).

\section{MYRSINACE RE.}

470. Ardisia coriacea, Sw.

Fl. June-Aug. Leaves minutely spotted beneath. In forests and on high hills, not uncommon.-All islands.

471. Jacquinia armillaris, L. $\quad \omega$ ) and $\beta$ ) arborea, V. (v. Bay Sallio).

Fl. Sept.-Feb. On the rocky shore, not uncommon.-All islands.

\section{SAPOTACFE.}

472. Chrysophyllum Cainito, L. (v. Star-apple).

Fl. May-July. Fruit edible. In forests, rare.-St. Croix (Springfield); St. Thomas (Signal Hill).

473. C. pauciflorum, Lam.

Fl. June. In forests, uncommon.-St. Thomas (Flag Hill).

474. C. oliviforme, Sw. B) monopyrenum.

Fl. July. In forests, not very common.-St. Croix; St. Thomas.

475. C. microphyllum, Jacq. (v. Palmér).

Fl. Sept.-Jan. In wooded valleys, rare.-St Croix (Bugby Hole); St. Thomas (Santa Maria Gut).

476. C. glabrum, Jacq.

Fl. Sept.-Dec. and March-July. In woods and thickets, common.All islands.

477. Sapota Achras, Mill. (v. Mespel).

Fl. Sept.-Oct. and March. Fruit sweet, edible. In forests and culti. vated, common.-All islands. 
473. S. Siderozylcn, Gris. (v. Bully wood).

Not seen in flower. A tall tree, affording a splendid purple, very hard timber. In forests, rare.-St. Jan (Baas Gut).

479. Siderozylon Mastichcdendron, Jacq. (v. Mastic).

Fl. Aug.-Sept. An excellent timber tree. In forèsts, rare.-St. Croix (Lebanon Hill); St. Thomas (Northside Bay); St. Jan (Baas Gut) (Montserrat, Ryan in Hb. Havn.).

480. Dipholis salicifolia, DC.

Fl. Feb.-March. In thickets and forests.-St. Croix (not uncommon in the western part of the island); St. Jan (Klein Caneel Bay).

481. Bumelia cuneata, Sw. (v. Break-bill).

Fl. Feb.-April. Branches often transformed into long spines. Very good timber tree. Along the coast principally in marshy soil, not uncommon.-All islands.

482. Lucuma multiflora, DC. (Achras macrophylla, Vahl in Hb. Havn.).

Fl. June-July and Dec.-Jan. Leaves as much as $1_{2}^{1 \prime}$ long.-St. Croix (Hb. Havn. from Wills Bay); St. Thomas (here and there in forests; Signal Hill, 1500').

\section{STYRACER.}

483. Symplocos martinicensis, Jacq.

Fl. March- $\Lambda$ ug. In forests on high hills. Flowers fragrant.-St. Thomas (Signal Hill above $1200^{\prime}$, not uncommon).

\section{ERENACE AE.}

484. Maccreightia caribæa, A.DC.

Vieques (Duchassaing sec. Gris. System. Unters. p. 91).

\section{OLEACEAE.}

485. Linociera compacta, R. Br.

Fl. May-Oct. In forests, rather common.-St. Croix; St. Thomas.

486. Forestiera porulosa, Poir. $a$ ) and $\beta$ ) Jacquinii, Egg. (Jacq. Ic. Rar. t. 625).

Fl. Feb. and Sept.-Oct. In thickets near the coast, uncommon.- $\alpha$ ). St. Thomas (Cowell's Hill); $\beta$ ) St. Croix (northern shore near Claremont).

\section{JASMINACEAE.}

487. Jasminum pubescens, W. (v. Star Jessamine).

Fl. all the year round. Naturalized in gardens.-All islands.

[Cultivated species: J. officinale, L.; J. revolutum, L. (v. Nepaul Jessamine), and Nyctanthes Sambac, L. (v. Double Jessamine).] 


\section{APOCY NACE BE.}

483. Thevetia neriifolia, Juss. (v. Milk-bush).

Fl. all the year round. Wood employed for building boats. In thickets on dry hills, common.-All islands.

489. Rauwolfia nitida, L. (v. Milk-tree).

Fl. all the year round. In forests and thickets, common.-All islands. 490. R. Lamarckii, A. DC. (v. Bitter-bush).

Fl. all the year round. On dry hills, common.-All islands.

491. Nerium Oleander, L. ( $v$. Nerium).

Fl. all the year round. Naturalized in gardens and near dwellings. Common.-All islands.

492. Tabernæmontana (citrifolia, Jacq. ?).

Fl. June-Aug. In thickets, here and there.-St. Thomas (Frenchman's Bay).

493. Vinca rosea, L. (v. Church-flower).

Fl. all the year round. Near houses and on waste places, rery common.-All islands.

494. Plumieria rubra, L. (r. Red Franchipani).

Fl. all the year round. Naturalized near dwellings.-All islands.

495. P. obtusifolia, L. (v. White Franchipani).

Fl. all the year round. Naturalized in gardens.-All islands.

496. P. alba, L. (v. Snake-root, Klang hout).

Fl. all the year round. On rocks near the shore and in dry thickets, common.-All islands.

497. Echites agglutinata, Jacq.

Fl. July-Aug. In thickets, rare.-St. Croix (Cane Bay); St. Thomas (Flag Hili).

498. E. circinalis, Sw.

Fl. Dec. In forests, rare.-St.Thomas (Flag Hill).

499. E. neriandra, Gris.

F1. Oct.-Jan. Here and there in thickets, not uncommon.-All islands.

500. E. suberecta, Jacq.

Fl. May-Aug. In thickets, uncommon.-St. Thomas (Cowell's Hill); St. Croix (West, p. 277). 
501. E. barbata, Desv.

St. Croix; St. Thomas (DC. Prodr. viii, 453).

[Cultivated species: Allamanda cathartica, L., and Taberncemontana capensis, L. (v. Cape Jessamine).]

\section{ASCLEPIADACERE.}

502. Metastelma parviflorum, R. Br,

St. Thomas (Duchass).

503. M. Schlechtendalii, Decs. (M. albiflorum, Gris.).

Fl. all the year round. In dry thickets, very common.-All islands.

(The specific distinction of Grisebach's species does not seem to be sufficiently permanent to justify a separation into two.)

504. Asclepias curassavica, L. ( $v$. Wild Ipecacuana).

Fl. all the year round. Root used as an emetic. Along roads and ditches, common.-All islands.

505. A. nivea, L.

St. Thomas (Gris. Fl. 419).

506. Sarcostemma Brownei, Mey.

St. Thomas (West, p. 278, as Asclepias viminalis, Sw.).

507. Calotropis procera, R. Br. (v. Silk Cattún).

Fl. all the year round. Naturalized in dry localities, common.-All islands.

508. Ibatia muricata, Gris.

Fl. all the year round. In dry thickets, common.-All islands.

509. Fischeria scandens, DC.

Fl. Aug. In forests, rare.-St. Croix (Spring-gut).

[Cultivated species; Hoya carnosa, R. Br. (v. Wax-flower) and Stephanotis floribunda, A. Brongn.]

\section{CONVOLVULACE.S.}

510. Ipomæa bona-nox, L.

Fl. Oct.-May. Naturalized in gardens.-St. Croix; St. Thomas.

511. I. Tuba, Don.

Fl. all the year round. On shrubs near the coast, uncommon-All islands. 
512. I. tuberosa, L.

Fl. Feb.-March. In forests, rare-St. Croix (Bugby Hole); St. Thomas (Schl.).

513. I. dissecta, Pursh (v. Noyau Vine).

Fl. Nov.-May. Corolla-tube purple inside. The whole plant has a taste of prussic acid, and is used for the preparation of a liquor called Noyau. On fences and along roads, common.-All islands.

514. I. pentaphylla, Jacq.

Fl. Dec.-March. In thickets and along ditches.-St. Croix; St. Thomas.

515. I. quinquefolia, Gris.

Fl. Dec.-Jan. Corolla expanded from 8 A.M. to 3 P.M. In pastures and low thickets, common.--St. Thomas.

516. I. Batatas, Lam. (v. Sweet Potato). $\quad \omega$ ), $\beta$ ) leucorrhiza, and $\gamma$ ) porphyrorhiza.

Fl. all the year round. Propagated by cuttings. A common regetable. Cultivated and naturalized everywhere.-All islands.

517. I. fastigiata, Swt. a). ,

Fl. Oct.-Jan. In thickets, not uncommon.-St. Thomas.

518. I. violacea, L. (

Fl. Dec.-Feb. Coralla expanded towards evening. In forests and along rivulets, not uncommon.-All islands.

519. I. carnea, Jacq.

St. Croix (Wills Bay sec. West, p. 272).

520. I. Jeucantha, Jacq. (Icon. Rar. ii, t. 318).

F1. March-May. Capsule pilose; roots tuberous. On dry hills, not uncommon - St. Jan (near Klein Kanelbay).

521. I. triloba, L. $\alpha$ ) and $\beta$ ) Eustachiana, Jacq.

Fl. Sept.-March. Corolla expandled till 10 A. M. Both forms in moist localities, not uncommon.-St. Croix; St. Thomas.

522. I. umbellata, Mey.

Fl. Jan.-March. Along rivulets and ditches, common.-All islands. 523. I. pes-capræ, Sw. ( . Bay Vine).

Fl. all the year round. Corolla sometimes white. On sandy seashores, very common.-All islands. 
524. I. asarifolia, R. S.

Danish islands (Gris. Fl. p. 471).

(As this species is a native of Senegal, I doubt the correctness of the above habitat.)

525. I. quinquepartita, R. S. (Conv. ovalifolius, West (non Vahl) sec. DC. Prodr. ix, 367).

St. Croix (West, p. 271).

526. I. triquetra, R. S. (Conv. triqueter, Vahl, Symb. Bot. iii, 32).

St. Croix (West, p. 271); St. Thomas (Schl.).

527. I. repanda, Jacq.

Fl. Feb.-March. Leaves heteromorphous, often 2-4-lobed. Tubers large, a favourite food for wild hogs. In forests, uncommon.-St. Thomas (Flag Hill); St. Jan (Macumbi).

528. I. filiformis, Jacq.

Fl. Oct.-April. In thickets, often near the shore, not uncommon.-St. Croix; St. Thomas.

529. I. arenaria, Steud.

Fl. Dec.-April. Stem woody, as much as $\frac{3}{4}{ }^{\prime \prime}$ diam. Root large, tuberous. Flowering partly precocious. On dry hills, in thickets, not uncommon.-All islands.

530. I. Quamoclit, L. (v. Sweet William).

Fl. all the year round. Near dwellings and along roads, common.St. Croix; St. Thomas.

531. I. coccinea, L. (I. hederafolia, L.).

Fl. Dec.-March. In thickets, common.-All islands.

532. I. Nil, Rtll. (Bot. Mag. t. 188) (v. Morning-glnry).

Fl. Oct.-March. Corolla expanded till 9 A. M. Along ditches and near dwellings, common.-All islands.

533. I. purpurea, Lam.

Fl. Oct.-Feb. Naturalized in gardens.-St. Croix; St. Thomas.

534. I. acuminata, R. S.

Fl. Nov.-March. Corolla crimson, as stated in Symb. Bot. iii, 26. Near rirulets, on trees, rare.-St. Croix (Golden Rock).

535. I. tiliacea, Chois.

St. Thomas (Sehl.). 
536. Jacquemontia tamnifolia, Gris.

Fl. Dec.-Feb. Seeds glabrous, greyish. In thickets, common.-All islands.

537. Convolvulus pentanthus, Jacq. (Jacquemontia violacea, Chois.).

Fl. Aug.-Dec. In thickets, on hills, common.-All islands.

538. C. jamaicensis, Jacq.

Fl. Dec.-Feb. In thickets, on the sandy seashore, rare.-St. Croix (Sandy Point); St. Thomas (Cowell's); Water Island.

539. C. nodiflorus, Desr. (C albiflorus, West) (v. Clashi-mulat).

Fl. Oct.-March. Common in thickets.-All islands.

540. C. melanostictus, Schl. (Linnæa, vi, 737).

St. Thomas (Schl.).

541. C. sagittifer, HB. Kth.

St. Thomas (Schl.).

542. Evolvulus linifolius, $L$.

Fl. Dec.-April. In moist localities, here and there.-All islands.

543. E. mucronatus, $\mathrm{Sw}$.

Fl. Dec.-March. In marshy soil, not uncommon.-All islands.

544. E. nummularius, L.

Fl. Nov.-March. Among rocks in shady localities, not uncommon.All islands.

545. Cuscuta americana, L. (v. Love-weed).

Fl. all the year round. In dry thickets, covering shrubs and trees, often killing them. Very common.-All islands.

(West, p. 271, mentions two species, Convolvulus matutinus and C.venenatus, as occurring in St. Croix, and refers for their description to Vahl's Symb. Bot. pars 3, as spec. nov. As, however, they are not described in any of Vahl's publications, and no specimens are in existence in. $\mathrm{Hb}$. Havn., I am unable to say whether they are old species or new ones.)

[Cultivated species: Ipomaca Learii, Annal. Fl. et Pom. 1840, p. 381, and . Horsfallice, Hook.]

\section{IY DROLEACEAE.}

546. Nama jamaicensis, L.

Fl. March-Aug. Among stones and rocks, a common weed.-St. Croix; St. Thomas. 


\section{BORA GINACEAE.}

547. Cordia Gerascanthus, Jacq. $\beta$ ) subcanescens (v. Rosewood, Cuppar).

Fl. Oct. An excellent timber tree. In forests, not very common.Virgin Island.

548. C. alba, R. S. (v. White Manjack).

Fl. March-Sept. In thickets and along roads, not uncommon.-St. Croix (eastern part of the island).

549. C. Sebestena, Jacq. a) (Bot. Mag. t. 794). $\quad \beta$ ) rubra, Egg. (v. Searlet Cordia, Fluyte boom).

Fl. all the year round. $\beta$ ) leaf-ribs red; calyx scarlet as the corolla. Both forms common in forests and planted near dwellings. - All islands.

550. C. Collococca, L. (v. Manjack).

Fl. March-April. Precocious. In forests, common.-All islands.

551. C. nitida, Vahl.

Fl. Jan.-Feb. and Sept.-Oct. Flowers slightly odorous. In forests, not uncommon.-All islands.

552. C. lævigata, Lam.

St. Thomas (Schl.).

553. C. sulcata, DC.

Fl. June. Leaves up to $1 \frac{1}{2}$ long. In forests, not common.-Virgin Islands; St. Croix (West, p. 275).

554. C. ulmifolia, Juss. a) ovata, $\beta$ ) ovalis, and $\gamma$ ) lineata.

F1. May-Aug. In dry thickets, common.- $-\alpha$ all islands ; $\beta$ ) St. Thomas (Ledru); r) St. Croix (West).

555. C. cylindristachya, Sprengl. a) portoricensis, Sprgl. $\quad \beta$ ) floribunda, Sprgl. d) graveolens, Kth.

Fl. all the year round. On dry hills. All three forms common.-St. Croix; St. Thomas.

556. C. martinicensis, R. S.

St. Croix (Griseb. Fl. p. 481).

557. C. globosa, Kth.

Fl. July-Sept. In thickets, not uncommon.-St. Croix; St. Thomas.

558. Beurreria succulenta, Jacq. (v. Juniper).

Fl. June-Sept. In forests and thickets, common.-All islands.

559. Rochefortia acanthophora, Gris.

Fl. June-Sept. In thickets.-St. Croix (rare, Fair Plain, Jacob's Peak); Virgin Islands (not uncommon). 
560. Tournefortia gnaphalodes, R.Br. (v. Sea-lavender).

Fl. all the year round. On sandy shores, common.-All islands.

561. T. hirsutissima, L. (v. Chichery grape).

Fl. Sept.-April. Along roads and in thickets, especially on limestone, common.-All islands.

562. T. fœtidissima, $L$.

St. Croix (West, p. 270).

563. T. bicolor, Sw. $\beta$ ) lævigata, Lam.

Fl. May. Berry globose, white. Among rocks on high hills, rare.St. Thomas (Crown, 1500').

564. T. laurifolia, Vent.

St. Thomas (DC.).

565. T. volubilis, L.

Fl. May-Aug. Inflorescence extra-axillary, often transformed into a hollow, globose, muricate, green monstrosity, in which lives the larva of a dipterous insect. Common in thickets.-All islands.

566. T. microphylla, Desv.

Fl. May-Sept. In the same localities as the former, common.-All islands.

567. Heliotropium indicum, $\mathrm{L}$.

Fl. all the year round. Along roads and in waste places, common.All islands.

568. H. parviflorum, L. (v. Eye-bright).

Fl. all the year round. A common weed everywhere-All islands.

569. H. curassavicum, L.

Fl. the whole year. On the sandy seashore, common.-All islands.

570. H. fruticosum, L.

Fl. all the year round. Up to $6^{\prime}$ high. On dry lills.-St. Croix (common in the eastern part); Virgin Islands (not uncommon).

[Cultivated species: H. peruxianum, L. (v. Heliotrope.)]

\section{POLEMONIACEA.}

[Cultivated in gardens: Phlox Drummondii, Hook.]

SOLANACERE.

571. Brunfelsia americana, Sw. a) and $\beta$ ) pubescens (v. Rain-tree).

Fl. May-Dec. Flowers odorous before rain. In thickets and woods, common.-Virgin Islands (cultivated in gardens in St. Croix). 
572. Datura Metel, L. (v, Fire-weed).

Fl. all the year round. Flowers nocturnal. Along roads and in waste places, naturalized everywhere.-All islands.

573. D. fastuosa, L.

Fl. all the year round. Naturalized in gardens and near dwellings.All islands.

574. D. Tatula, L.

Fl. May-Dec. Along roads, naturalized, but rare--St. Croix (Hope).

575. D. Stramonium, L. (v. Fire-weed).

Fl. Sept.-Feb. Naturalized in waste places, common.-All islands.

576. Nicotiana Tabacum, $\mathrm{L}$.

Fl. May-Nov. Used as a medicine, but not for smoking. Naturalized near dwellings. - All islands.

577. Physalis peruviana, $\mathrm{L}$.

Fl. May-Nor. In fields, uncommon.-St. Thomas (Rapoon).

578. P. pubescens, L.

Fl. March-May. In shady valleys, uncommon.-St. Croix (Crequis); St. Thomas.

579. P. Linkiana, Ns.

Fl. Dec. In cultivated fields, not uncommon.-St. Thomas.

580. P. angulata, $\mathrm{L}$.

Fl. Sept.-Jan. Stamens of unequal length; anthers successively dehiscent. Along roads and ditches, common.-All islands.

581. Capsicum dulce, Hort. (DC. Prodr. xiii, i, 428) (v. Sweet Pepper).

Fl. March-July. Berry oblong. Naturalized in gardens.-St. Croix; St. Thomas.

582. C. frutescens, I. (v. Bird Pepper).

Fl. Aug.-Dec. Used as a condiment. Here and there in forests and cultivated.-St. Croix; St. Thomas.

583. C. baccatum, L. (v. Small Pepper).

Fl. Aug.-Jan. In forests and near dwellings, not uncommon.-All islands.

584. C. annuum, L. ( $v$. Pepper).

Fl. all the year round. Fruit universally used as a condiment. Cultivated and naturalized everywhere.-All islands. 
585. Lycopersicum cerasiforme, Dun. (Solan. p. 113) (v. Small Trovo).

Fl. May-Sept. Berry globose, small, yellow. Not uncommon near dwellings (perhaps only naturalized). Used as a regetable.-St. Croix; St. Thomas.

586. I. esculentum, Mill. ( $\nabla$. Tomato, Trovo).

Fl. all the year round. Berry used as a vegetable. Cultivated and naturalized everywhere.-All islands.

587. Solanum nodiflorum, Jacq. a) and $\beta$ ) olerace um, Dun. (v. Lumbush).

Fl. May-Dec. Stem often prickly. In fields and in waste places, common.-All islands.

588. S. verbascifolium, L. ( $\nabla$. Turkey-berry).

Fl. June-Oct. In waste places, not uncommon.-Virgin Islands; St. Croix (West, p. 274). .

589. S. racemosum, L. (v. Canker-berry).

Fl. all the year round. Proterandrous. In waste places, very common.-All islands.

590. S. igneum, L. ( . Canker-berry).

Fl. all the year round. Habitat of the preceding. Very common.All islands.

591. S. bahamense, L. (S. persicafolium, Dun.)

Fl. Jan.-Aug. Along coasts, not uncommon.-Virgin Islands.

592. S. lanceifolium, Jacq.

Not seen flowering. Leaves and stem very prickly. In forests, rare.St. Jan (King's Hill, 1000').

593. S. torvum, Sw. (v. Plate-bush).

Fl. all the year round. A shrub or sma!l tree. In forests and near dwellings, common.-All islands.

594. S. inclusum, Gris., var. albiflorum, Egg.

Fl. all the year round. Corolla white, $\frac{3 \prime \prime}{4}-1^{\prime \prime}$ diam. Stigma 3-5branched, stellate. Berry globose, somewhat depressed, hirsute, orange. coloured, $\mathbf{1}^{\prime \prime}$ diam. The excrescent calyx prickly. In dry thickets, not uncommon.-Virgin Islands.

595. S. aculeatissimum, Jacq.

Fl. April-May. Naturalized by mules from Montevideo.-St. Croix (Frederiksted).

596. S. mammosum, L.

St. Croix (West, p. 275). . 
597. S. polygamum, Vahl (v. Kakkerlakka-berry).

F1. all the year round. In dry thickets, common.-Virgin Islands.

(In DC. Prodr. xiii, i, 197, it is stated that this species has been found in St. Croix by Wydler, which, however, appears doubtful to me. West, 1. 275, only gives St. Jan as habitat, yet Vahl in his Symb. Bot. iii, 39, and after him probably Griseb. Fl. p. 443, refer to West as the authority for St. Croix as habitat.)

593. Cestrum laurifolium, L'Her.

F1. Jan.-April. Petiole black; berry dark purple. In forests, not uncommon.-All islands.

599. C. diurnum, L.

Fl. Feb.-June. In forests, uncommon.-Virgin Islands; St. Croix (West, p. 276).

600. C. nocturnum, L.

Fl. March. In forests, rare.-St. Jan (Rogiers, Joshee Gut).

|Cultivated species : Datura suaveolens, HBK.; Petunia nyctaginiflora, Juss., and P. violacea, Liudl.; Solanum Seaforthianum, And1., S. tuberosum, L. (v. Irish potato), and S. Melongena, L. (v. Egg-plant, Beranger).]

\section{SCROPHULARYACEA.}

601. Scoparia dulcis, $\mathrm{L}$.

Fl. all the year round. A common weed along roads and in moist localities. - All islands.

602. Capraria biflora, L. $a$ ) and $\beta$ ) pilosa (v. Goat-weerl).

Fl. all the year round. Leares used for tea. Both forms along roads, common. $\alpha$ ) in moist, $\beta$ ) in dry localities.-All islands.

603. Herpestis stricta, Schrad.

St. Thomas (Benth.).

604. H. chamædryoides, Kth.

Fl. Dec.-March. Pedicel bearing two bracteolæ at the base. The two innermost calyx-lobes setaceous. In, moist localities, rare.-St. Croix (Spring-gut).

605. H. Monniera, Kth.

Fl. all the year round. Along rivulets and on the margins of lagoons, common.-All islands.

606. Vandellia diffusa, $L$.

St. Croix (Ryan in Hb. Havn., Vahl's Eclogue, ii, 47) (Montserrat, Ryan in Hb. Havn., "vulgaris"). 
[Cultivated species: Maurandia Barclayana, Lindl. (v. Fairy Iry), and Russelia juncea, Zucc. (v. Madeira Plant).]

\section{BIGNONIACEE.}

607. Crescentia Cujete, L. (v. Calabash-tree).

Fl. all the year round. Leaves deciduous in Dec. The fruit is used for vessels. Near dwellings and in forests, common.-All islands.

608. C. cucurbitina, L. (v. Black Calabash).

Fl. March-Nov. Wood used for boat-building. In dense forests near rivulets, not uncommon.-All islands.

609. Catalpa longisiliqua, Cham.

St. Thomas (Gris. Fl. 446).

610. Tecoma Berterii, DC.

Fl. March-July. Leaves deciduous Feb.-April. In dry thickets, common.-Virgin Islands.

611. T. leucczylon, Mart. (v. White Cedar).

Fl. March-A pril, precocious, and later coëtanous in Sept.-Oct. Wood used for building boats. In forests and on dry hills, common.-All islands.

612. T. stans, Juss. (v. Yellow Cedar).

Fl. all the year round. Anthers pilose beneath. In thickets, common; often gregarious, especially in St. Croix.-All islands.

613. Blgnonia æquinoctialis, $\mathrm{L}$.

Fl. April-Sept. Anthers pilose or glabrous (hence Vahl's distinction on this account between his B. spectabilis (Symb. Bot. iii, p. 80) and this species not justified). Here and there in marshy forests.-St. Thomas (Northside Bay, Sta. Maria); St. Croix (Salomon's estate, West, p. 294).

614. B. unguis, L. (v. Cat-claw).

Fl. April-May, precocious, later again coëtanous in Nov. Stem 12" diam., showing the irregular structure peculiar to all climbing Bignoniacece. Fruit as much as $26^{\prime \prime}$ long. In forests, not uncommon.-All islands.

615. Distictis lactiflora, DC. (Prodr. ix, 191) (Eignomia, Vahl).

Fl. all the year round. On fences and in dry thickets, here and there.-St. Croix (Cotton Grove, Southgate Farm) (cultivated in St. Thomas).

[Cultivated species: Tecoma capensis, Lindl.] 


\section{ACANTHACEA.}

616. Ruellia tuberosa, L. (v. Christmas-pride).

Fl. all the year round; most abundantly towards Christmas. Along roads and ditches, common.-All islands.

617. R. strepens, L.

St. Croix (Isert sec. DC. Prodr. xi, 121).

618. Stemonacanthus coccineus, Gris.

Fl. Jan.-April. Cleistogamous flowers in July; also an intermediate form between cleistogamous and normal flowers. In shady forests, rare.-St. Croix (Caledonia, Wills Bay); St. Jan (Bordeaux Hills); St. Thomas (Wydl. sec. DC. Prodr. xi, 217).

619. Blechnum Brownei, Juss. (v. Penguin Balsam).

Fl. Dec.-April. Used against cough. In pastures and along ditches, common.-All islands.

620. Barleria lupulina, Lindl. (Bot. Reg. t. 1483).

Fl. Dec.-April. Naturalized near dwellings and in gardens.-St. Thomas; St. Jan.

621. Thyrsacanthus nitidus, Ns.

St. Croix (v. Rohr sec. Symb. Bot. ii, 5, and Isert sec. DC. Prodr. xi, $327)$; St. Thomas (Nees).

622. Dianthera pectoralis, Murr. (v. Garden Balsam).

Fl. Dec.-March. Used against coughs. Naturalized near dwellings and in gardens.-All islands.

623. D. sessilis, Gris. (Justicia pauciflora, Vahl in Eclog. Am. i, 2).

Fl. June-July. Flowers often cleistogamous. Rhizome perennial. In thickets, here and there.-St. Croix (Salt River); St. Thomas.

624. Justicia carthagenensis, Jacq.

Fl. Dec.-March. Along ditches and in forests.-All islands.

625. J. reflexiflora, Rich. (Vahl's Enum. Plant, i, 157), var. glandulosa, Egg.

Fl. all the year round. Bracts densely glanduliferous. Seeds globose, brown. Procumbent among bushes.-St. Croix (rare, Fair Plain); St. Thomas; Buck Island (not uncommon).

626. J. periplocæfolia, Jacq.

St. Thomas (Schl.).

627. Beloperone nemorosa, Nees.

Fl. Jan.-March. Calyx one-sixth of the length of the corolla. In forests, rare.-St. Croix (Caledonia, Ham's Bluff Valley). 
628. Crossandra infundibuliformis, Nees.

F.. March-June. Naturalized in gardens.-St. Croix.

629. Stenandrium rupestre, Ns. (DC. Prodr. xi, 283) (Ruellia?, Sw. Fl. Ind. Oec. p. 1071 ; Plum. Icon. ed. Burm. t. 75, as Gerardia). a) glabrous, $\beta$ ) pilose.

Fl. Dec.-May, cleistogamons. Normal flowers June-Aug. Corolla expanded till 9 A. M. Rhizome perennial; roots fusiform, tuberous. Gregarious on the ground in forests, rare.- $\alpha$ ) St. Thomas (Flag Hill, $\left.\left.700^{\prime}-900^{\prime}\right) ; \beta\right)$ St. Jan (Baas Gut).

630. Anthacanthus spinosus, Nees.

Fl. all the year round. Flowers heterostylous. On rocks and in forests, common, especially in St. Croix.-All islands.

631. A. jamaicensis, Gris.

Fl. June-July. Corolla-lobes glandular inside. On limestone, rare.St. Croix, in stony ground.

632. A. microphyllus, Ns.

Fl. May-Aug. In forests, here and there.-All islands.

633. Dicliptera adsurgens, Juss.

Fl. Jan.-Feb., eleistogamous; normal, March-April. In thickets and near ditches._St. Croix (common); St. Jan (less common).

634. Thunbergia volubilis, Pers.

Fl. all the year round. Naturalized along ditches and rivulets.-St. Croix (Caledonia, Mt. Stewart); St. Thomas (Tutu).

[Cultivated species: Graptophyllum hortense, Nees, Justicia bicolor, Andr., Thunbergia alata, Boj., Th. fragrans, Roxb., and Sesamum orientale, L. (v. Benyè).]

\section{GESTERIACE}

635. Martynia diandra, Glox. (v. Cocks).

Fl. Sept.-Dec. Three rudimentary filaments; $1^{\prime}-3^{\prime}$ high. Along roads and in waste places, not uncommon.-St. Croix; St. Thomas.

636. Ocimum Basilicum, L.

\section{LABIAT T.}

Fl. May-Aug. Naturalized in gardens.-All islands.

637. O. micranthum, W. (v. Passia Balsam).

Fl. Aug.-Nor. Corolla expanded during the morning. Used against coughs. Along ditches and in pastures, gregarious.-All islands.

638. Coleus amboinicus, L. ( $v$. East India Thyme).

Fl. April-May. Naturalized in dry localities, gregarious. - All islands.

Bull. Nat. Mus. No. $13-6$ 
639. Hyptis capitata, Jacq. (v. Wild Hops).

Fl. Nor.-March. Along rivulets, common.-St. Croix; St. Thomas.

640. F. suaveolens, Poit.

Fl. Oct.-Feb. $3^{\prime}-4^{\prime}$ high. In dry localities, common.-St. Croix; St. Thomas.

641. H. pectinata, Poit. (v. French Tea).

F1. Nov.-April. As much as $8^{\prime}$ high. In dry localities, not uncom. mon.-All islands.

642. H. verticillata, Jacq.

St. Thomas (Gris. Fl. p. 489).

643. Salvia occidentalis, $\mathrm{Sw}$.

Fl. Dec.-March. Rhizome thick. Along roads, common.-All islands.

644. S. tenella, Sw.

St. Thomas (Gris. Fl. p. 490 ; Schl.).

645. S. serotina, $L$.

Fl. Sept.-April. Leaves very bitter. Corolla white. In dry locaities, gregarious, common.-All islands.

646. S. coccinea, L. $a$ ) and $\beta$ ) ciliata, Benth.

Fl. all the year round. Along ditches and roads, common.-All islands.

647. Leonurus sibiricus, $L$.

Fl. all the year round. Corolla sometimes white. A common weed in fields and along roads.-All islands.

648. Leucas martinicensis, $\mathrm{R}$. Br.

Fl. March-Nov. A weed, common in gardens and along roads.-St. Croix.

649. Leonotis nepetæfolia, R. Br. ( . Hollow Stock).

Fl. all the year round. Corolla sometimes white. Gregarious, a very common weed everywhere.-All islands.

650. Mentha aquatica, L. (v. Mint).

Not seen flowering. Naturalized along rivulets, gregarious._St. Croix (Caledonia).

[Cultivated species: Rosmarinus officinalis, L. (v. Rosemary), Thymus vulgaris, L. (v. Thyme), and Origanum Majorana, L. (v. Sweet Marjorim Tea).] 


\section{VERB ENACEAE.}

651. Priva echinata, Juss.

Fl. all the year round. Corolla expanded till 10 A. M. A common weed along roads and in gardens.-All islands.

652. Bouchea Ehrenbergii, Cham.

FI. Dec.-May. Gregarious along roads and in dry localities, common.-St. Croix; St. Thomas.

653. Stachytarpha jamaicensis, V. (v. Vervain).

Fl. all the year round. Flower expanded till noon. Pollen 3-4branched, stellate. Leaves used against fever. Very common along roads and ditches.-All islands.

654. S. strigosa, Vahl.

St. Thomas (Ehrenb. sec. DC. Prodr. xi, 564; Gris. Fl. p. 494).

655. Lippia nodiflora, Rich:

Fl. all the year round. Gregarious in moist localities, not uncommon.-St. Croix (La Reine, Fair Plain).

656. Lantana Camara, L. (v. Sage).

Fl. all the year round. Berry considered to be poisonous. On dry hills, very common.-All islands.

657. L. polyacantha, Schaner (DC. Prodr. xi, 597) (L. scabrida, Ait.).

Fl. all the year round. In dry localities, here and there.-St. Croix (St. George); St. Thomas (Solberg).

658. I. involucrata, L.

Fl. all the year round. Corolla and berry violet. In thickets, commun, especially on limestone.-All islands.

659. I. reticulata, Pers.

Fl. all the year round. On limestone, rare.-St. Croix, in stony ground (King's Hill).

660. Citharexylum quadrangulare, Jacq. (v. Fiddlewood, Snsanna).

Fl. July-Sept. In forests, not uncommon.-St. Croix; St. Thomas.

661. C. cinereum, L. (v. Susanna).

Fl. July-Dec. Leaves of both these species becoming red in Feb., and dropping off at the same time that the new ones make their appearance. On young radical shoots the leaves are linear and deeply serrate. The wood is quite useless, even for firewcod. In dry thickets and forests, common, often gregarious.-All islands. 
662. C. villosum, Jacq. (Icon. Var. t. 118).

St. Thomas (Schlecht., Bertero, Duchass. sec. Gris. Syst. Unt.).

663. Duranta Plumieri, Jacq.

Fl. May-Dec. Along roads and in thickets, common.-All islands.

664. Callicarpa reticulata, Sw.

St. Croix (West, p. 269).

665. Ægiphila martinicensis, Jacq.

Fl. Aug.-Jan. Flowers often heterostylous. In forests, common.St. Croix.

666. Clerodendron aculeatum, L. (

Fl. all the year round. Common on dry hills and in marshy soil.All islands.

667. C. fragrans, $W$.

Fl. all the year round. Long creeping rhizome. Gregarious on high hills in shady places, naturalized. - St. Thomas (Dorothea, Liliendal).

668. Petitia domingensis, Jacq. a).

Fl. May-Sept. Leaves often ternate. Drupe commonly 4-loculate. A tree up to $50^{\prime}$ high. In forests, not uncommon.-St. Croix (Caledonia, Punch, Wills Bay).

669. Vitex divaricata, Sw.

Fl. May-July. Filaments glandular-pilose. A low tree, here and there in forests.-St. Croix (Caledonia, Wills Bay); St. Thomas (Crown); St. Jan (Cinnamon Bay).

670. Avicennia nitida, Jacq.

Fl. all the year round. Upper surface of leaves always covered with small salt crystals. Along the seashore and lagoons, common.-All islands.

671. A. tomentosa, Jacq.

St. Croix (West, p. 269); St. Thomas (Schl.).

[Cultivated species: Verbena chamcedrifolia, Juss., in several varieties, Petroea volubilis, Jacq. (v. Wreath-plant), Aloysia citriodora, Ortega (v. Lemon-scented Verbena), Vitex Agnus-castus, L. (v. Wild Black Pep. per), and Holmskjoldia sanguinea, Retz.]

\section{MYOPORACEAE.}

672. Bontia daphnoides, L. (v. White Alling).

Fl. all the year round. On sandy shores.-St. Croix (rare, Turner's Hole); Virgin Islands (not uncommon). 


\section{PLANTAGINACEBE.}

673. Plantago major, L. $\beta$ ) tropica (

Fl. Jan.-March. Proterogynous. Leaves used against inflammation of the eyes.

\section{PIUMBAGINACER:}

674. Plumbago scandens, Thunb. (v. Blister-leaf).

Fl. all the year round. Leaves used as blisters. In thickets and forests, common.-All islands.

[Cultivated species: $P$. capensis, Thunb.]

\section{PHYTOLACCACEAE.}

675. Suriana maritima, L.

- Fl. June-Dec. Stamens mostly 10. Filaments pilose. On sandy shores, not uncommon.-All islands.

676. Microtea debilis, Sw.

Fl. July-Sept. In shady places, rare-_St. Croix (Spring Garden, Wills Bay).

677. Rivina lævis, L. (v. Snake-bush, Stark mahart). $\quad \alpha$ ) and $\beta$ ) pubescens.

Fl. all the year round. A common weed everywhere, both forms.All islands.

678. R. octandra, L.

Fl. Feb.-Aug. Pedicel and calyx becoming reddish-brown as well as the fruit. Stamens in two whorls, mostly 12. In thickets and forests, common.-All islands.

679. Petiveria alliacea, L. (v. Gully-root).

Fl. all the jear round. A very common weed everywhere.-All islands.

\section{CHENOPODIACEAE.}

680. Chenopodium ambrosioides, $\mathrm{L}$.

Fl. March. In waste places and on walls, here and there.-St. Croix (Fredriksted); St. Jan (Cruz Bay).

681. Ch. murale, L.

Fl. Jan.-May. On walls, uncommon, naturalized.-St. Croix; St. Thomas.

682. Obione cristata, Moq. (DC. Prodr. xiii, ii, p. 110).

Fl. March-Aug. On sandy shores, uncommon.-St. Thomas (Water Bay); St. Jan; St. Croix (Schl.). 
683. Boussingaultia baselloides, Kth. (Bot. Mag. t. 3620).

Fl. all the year round. Naturalized in gardeus and cultivaterl.-St. Croix; St. Thomas.

684. Batis maritima, $\mathrm{L}$.

Fl. all the year round. Gregarious along the coast of lagoons, common.-St. Croix; St. Thomas.

[Cultivated species: Beta vulgaris, L. (v. Red Beet).]

\section{AMAFANTACE}

685. Celosia argentea, L. (C. margaritacea, L.).

Fl. all the year round. Naturalized around dwellings._-St. Thomas; St. Croix (West, 1. 277).

686. C. nitida, Vahl.

Fl. all the year round. In forests and thickets, not uncommon.-St. Croix; St. Thomas.

687. Chamissoa altissima, Kth.

Fl. Dec.-March. In forests, here and there--St. Croix (Lebanon Hill); St. Thomas (Signal Hill).

688. Achyranthes aspera, L. a) argentea, Lam. B) obtusifolia, Lam.

Fl. Dec.-March. In thickets and on waste places, common.-All islands.

689. Gomphrena globosa, L. (v. Bachelor's Button).

Fl. all the year round. Naturalized in gardens and near dwellings.All islands.

690. Iresine elatior, Rich.

Fl. Sept.-March. Uppermost leaves always alternate. In thickets, common.-All islands.

691. Philoxerus vermiculatus, R. Br. (v. Bay-flower).

Fl. all the year round. Along the coast, very common, gregarious.All islands.

692. Alternanthera polygonoides, R. Br. a).

Fl. all the year round. In sandy places, common.-All islands.

693. A. ficoidea, R. Br.

Fl. all the year round. In moist localities, uncommon.-St. Thomas (Haulover).

694. A. Achyrantha, R. Br.

Fl. March-Aug. Among rocks and stones, here and there.-St. Croix, St. Thomas (Schl.). 
695. Amblogyne polygonoides, Raf.

Fl. all the year round: $\delta$ flowers very few. In sandy places near the coast, common.-St. Croix; St. Thomas.

696. Scleropus amarantoides, Schrad.

Fl. all the year round. Leaves often discoloured with white crossstripes. In sandy localities, common.-All islands.

697. Euxolus caudatus, Moq.

Fl. all the year round. In waste places, common.-All islands.

698. E. oleraceus, Moq. (v. Lumbo).

Fl. all the year round. Near dwellings, common.-All islands.

699. Amarantus spinosus, L.

Fl. Jan.-April. Near rivulets and ditehes, uncommon.-St. Croix; St. Thomas.

700. A. tristis, L.

St. Thomas (Wydler sec. DC. Prodr. xiii, ii, 260).

701. A. paniculatus, L. (v. Bower).

Fl. all the year round. A troublesome weed on account of its long tap-root. Common everywhere.-All islands.

\section{NYCTAGINACEAE.}

702. Mirabilis Jalapa, L. (v. Four-o'clock).

Il: all the year round. Flower expanded from 4 P. M., purple, yellow, or pink. Around dwellings, common.-All islands.

703. Boerhaavia erecta, $\mathrm{L}$.

Fl. Dec.-Feb. Along ditches and in pastures, uncommon.-St. Croix (Mt. Stewart).

704. B. paniculata, Rich. (v. Batta-batta).

Fl. all the year round. Calyx often transformed into a hollow monstrosity by the larva of a wasp. A very common weed.-All islands.

705. Pisonia aculeata, L.

Fl. Feb.-April. In forests, common.-St. Croix; St. Thomas. 706. P. subcordata, Sw. (v. Mampoo, Loblolly).

Fl. April-June. Leaves partly deciduous. Wood useless for timber and fuel. Along coasts, common, growing to a large tree.-All islands. 707. P. inermis, Jacq.

Fl. April-May. Leaves on the young branches whorled. In forests, common.-All islands.

[Cultivated species: Bougainvillea spectabilis; Willd.] 


\section{POLYGONACEAE.}

708. Coccoloba uvifera, Jacq. (v. Sea-grape).

Fl. July-Dec. Wood hard, dark purple, used for ship-building. On the sandy seashore, common. Sometimes in the interior as high up as $1200^{\prime}$. All islands.

709. C. leoganensis, Jacq.

Fl. May-July. Flowers in fascicles of 3-4, of which, however, one only bears fruit. Drupe oval, violet, $4^{\prime \prime \prime}$ long. On sandy shores, rare.St. Croix (Sandy Point).

710. C. rugosa, Desf. (DC. Prodr. xiv, 152; Bot. Mag. t. 4536).

St. Thomas (DC. Prodr. 1. c.).

711. C. laurifolia, Jacq. (Hort. Schœnbr. iii, p. 9, t. 267).

Fl. March-July. Leaves deciduous April to May. Fruit purplish, pointed at both ends. In thickets, here and there.-St. Croix (Sandy Point, Hard Labour).

712. C. diversifolia, Jacq.

Fl. May-July. $6^{\prime}-\delta^{\prime}$ high. Along the coast, uncommon.-St. Croix (La Vallée, Claremont).

713. C. obtusifolia, Jacq.

St. Croix (West, p. 281).

714. C. punctata, Jacq. a) Jacquinii, $\beta$ ) barbadensis, Jacq., $\delta$ ) parvifolia ( $\nabla$. Red wood, Roehout), $\gamma$ ) microstachya, W.

Fl. Aug.-Dec. a) leaves as much as $1 \frac{3 \prime}{4}$ long. A shrub or low tree. o) and $\gamma$ ) common; $\alpha$ ) and $\beta$ ) uncommon.-All islands.

715. C. nivea, Jacq.

F1. June-Sept. Flowers delicately odorous. Fruit white when ripe. In forests, not uncommon.-All islands.

(C. Klotzschiana, Meissn., and C. Kunthiana, Meissn. (DC. Prodr. xiv, 155 and 166), are said to have been found in St. Thomas, but they are both very doubtful species, founded on single specimens, and have therefore been here omitted.)

[Cultivated species: Antigonon cordatum, Mart. \& Galeotti (v. Mexican Wreath-plant), and Rumex vesicarius, L.]

\section{LAURA CERE.}

716. Cinnamomum zeilanicum, Bl.

Fl. April-May. Naturalized in a few places in shady valleys.-St. Croix (Crequis). 
717. Phœbe antillana, Meissn. (DC. Prodr. $x v, i, p .31) . \quad \gamma$ ) cubensis.

St. Croix (West in Hb. Petrop. sec. DC. 1. c.).

(Ph. montana, Gris., said by Meissn. (DC. Prodr. 1. c. p. 236) to be synonymous with Laurus longifolia, Vahl, mentioned by West, p. $2: 2$, as a new species from St. Croix, ought perhaps to be added to this list; but as the specimens seen by me in Hb. Havn. as Laurus longifolia, Vahl, do not agree with Grisebach's, I prefer to omit the species here, as being doubtful.)

718. Persea gratissima, Gaertn. (v. Alligator Pear).

F1. March-May. Stamens, 9 perfect, 3 less perfect and sterile, 6 rudimentary. The fruit is a favourite vegetable. In gardens.-All islands.

719. Hufelandia pendula, Ns. (H. Thomca, Nees).

St. Thomas (sec. DC. Prodr. 1. c. p. 65, Hb. Kunth!).

720. Acrodiclidium salicifolium, Gris.

Fl. May-Aug. In forests, here and there.-St. Croix (Wills Bay, Spring-gut).

721. Nectandra coriacea, Gris.

Fl. May-Aug. In forests, rare.-St. Thomas (Soldier Bay); St. Jan (Hb. Havn.).

722. $\mathbf{N}$. membranacea, Gris.

Fl. June. In dense forests, uncommon.-St. Croix (Wills Bay); St. Thomas (Signal Hill).

723. N. antillana, Meissn. (DC. Prodr. 1. c. 153) (N. leucantha, Gris.).

- Fl. May-June. In forests, not uncommon. Fragrant.-All islands.

724. Oreodaphne leucozylon, Nees.

Fl. July. In dense forests on high hills, uncommon.-St. Thomas (Signal Hill) (Montserrat, Ryan in Hb. Havn.).

725. Cassyta americana, L.

Fl. March-April. Inflorescence often branched. On Manchineel and Acacia trees along the seashore, here and there.-St. Croix (Cotton Grove); St. Thomas (Water Bay); Vieques (Hb. Havn.).

\section{THYMELAEACEA.}

726. Daphnopsis caribæa, Gris.

Fl. July and Dec.-March. In forests, not uncommon.-St. Thomas (Flag Hill, Signal Hill). 


\section{EUPHORBIACERE.}

727. Buxus Vahlii, Baill. (DC. Prodr. xvi, i, p. 16) (Tricera lavigata, Sw., var. SanctieCrucis, Eggers in Fl. St. Crucis, p. 111).

Fl. June-Oct. On limestone, rare--St. Croix (Stony Ground).

728. Savia sessiliflora, W. (Spec. Plant. iv, p. 771).

Fl. June-Dec. In thickets on dry hills, not uncommon.-All islands. 729. Phyllanthus acuminatus, Vahl (Symb. Bot. ii, 95).

St. Thomas (Herb. DC. sec. DC. Prodr. xv, ii, 381). Vahl, howerer. gives only Cayenne (Rohr) as habitat.

730. Ph. Niruri, L. (v. Creole Chinine).

Fl. all the year round. Very common in gardens and along roads.All islands.

731. Ph. distichus, Müll. (DC. Prodr. 1. c. 413) (Cicca, L.) (v. Gooseberry).

Fl. June-Sept. Fruit used for preserves. Naturalized near dwellings.-All islands.

732. Ph. nobilis, Müll. (1. c. 415). $\eta$ ) Antillana (Cicca, Juss.) (v. Gongora-hout).

Fl. July, and afterwards precocious in Dec.-Jan. In forests, not uncommon.-All islands.

733. Ph. falcatus, Sw. (v. Boxwood).

Fl. all the year round. In marshy soil, not uncommon.-Vieques.

734. Securinega acidothamnus, Müll. (1. c. 451) (Flüggea, Gris.).

Fl. May-June. In thickets, not uncommon.-St. Croix (eastern part of the island).

(I have adopted Miiller's generie name, Flïggea being an older name for a genus of Ophiopogonece established by L. C. Richard.)

735. Drypetes lævigata, Gris. ined. (Excocaria polyandra, Gris. Cat. Pl. Cub. p. 20, \& Diagnos. neuer Euphorb. p. 180).

Fl. Sept. $\delta$. I have not found the female flower nor fruit, and am therefore not able to supply the deficiency in this respect in Grisebach's Diagnosis.-St. Croix (Fair Plain); St. Jan (Cinnamon Bay).

736. D. glauca, Vahl.

St. Croix (Hb. Havn. Ryan, Rohr; "Hollow berry of Bugby Hole") (Montserrat, Ryan in Hb. Havn.).

737. Croton astroites, Ait. (v. White Marán).

Fl. Dec.-July. Style 16-branched. In dry thickets, very common.All islands. 
738. C. betulinus, Vahl (Symb. Bot, ii, p. 98).

Fl. all the year round. A low shrub, brownish. Common in thickets.-All islands.

739. C. flavens, L. (v. Marán).

Fl. all the year round. Gregarious on dry hills, also as secondary growth; very common, and a troublesome shrubby weed.-All islands.

740. C. discolor, Willd. (Spec. Plant. iv, 352) (C. balsamifer, L.).

Fl. all the year round. Along roads in dry localities, common.-St. Croix (eastern part of the island); St. Thomas (Hb. Thunb. sec. DC. Prodr. 1.c. p. 615).

741. C. oval folius, West.

Fl. all the year round. Along roads and in waste places, very common.-All islands.

742. C. lobatus, L.

Fl. March-Dec. In the same places as the preceding, very common.All islands.

743. C. humilis, $L$.

St. Thomas (Bertero sec. DC. Prodr. 1. c. 670).

(An arboreous as yet undetermined Crotonea, not found in blossom, occurs in a few specimens on Flag Hill in St. Thomas.)

744. Aleurites Moluccana, Willd. (Spec. Plant. iv, 590) (A. triloba, Forst.) (v. Walnut).

Fl. all the year round. Naturalized near dwellings and in gardens.St. Croix; St. Thomas.

745. Ricinella pedunculosa, Müll. (Linnæa, xxxir, 153) (Adelia Ricinella, L.).

Fl. March-May, precocious. Always very spiny. In dry thickets, not uncommon.-All islands.

746. Argyrothamnia fasciculata, Müll. (Linnæa, 1. c. 146) (Ditaxis, Schl.).

Fl. Jan.-May and Sept. In thickets, not uncommon.-All islands.

747. A. candicans, Müll. (DC. Prodr. 1. c. 741) (Argythamnia, Sw.).

Fl. Sept.-April. Capsule dark blue; seeds verrucose. In thickets, common.-All islands.

748. Acalypha chamædrifolia, Müll. (1. c. 879). $\beta$ ) genuina (A. reptans, Sw.), $\gamma$ ) brevipes.

Fl. all the year round; female flowers developing gradually. Bracts persistent after dissemination. On rocks and in crevices, not uncommon.-St. Croix $(\beta)$; St. Thomas $(\gamma)$. 
749. Tragia volubilis, L. (v. Nettle, Bran-nettle).

Fl. Feb., Sept. Male flowers often transformed into a globose mon. strosity. The plant is believed by the negroes to give them luck in marketing. In thickets and along roads, common.-All islands.

750. Ricinus communis, L. a) (v. Castor-oil tree).

Fl. all the year round. Seeds used for pressing castor-oil. Naturalized on waste places, common.-All islands.

751. Manihot utilissima, Pohl (Plant. Bras. i, 32) (v. Cassava).

Fl. March-May. Root used for manufacturing starch and flour, which is made up into flat, thin cakes (bambam). Naturalized and cultivated.-All islands.

752. Jatropha Curcas, L. (v. French Physic-nut, Skitnetchi).

Fl. all the year round. Seeds very drastic. A low tree, often planted on graves. Naturalized near dwellings, common.-All islands.

753. J. gossypiifolia, L. (v. Physic-nut). a) staphysagriæfolia, $\beta$ ) elegans.

Fl. all the year round. The whole plant has a disagreeable smell. Suffrutescent, $1^{\prime}-4^{\prime}$ high. A troublesome weed near dwellings and in fields. Very common everywhere.-All islands.

754. J. multifida, L. (v. Coral-buish).

Fl. all the year round. Naturalized in gardens.-St. Croix; St. Thomas.

755. Sebastiania lucida, Müll. (DC. Prodr. 1. c. 1181) (Excoecaria, Sw.).

Fl. Feb.-June. A shrub or low tree, $5^{\prime}-20^{\prime}$ high. In thickets and forests, common.-All islands.

756. Hippomane Mancinella, L. (v. Manchineel-tree).

Fl. precocious, Feb.-April, coëtanous, May-June. Wood affording excellent timber, but very little used on account of the caustic milky juice. On sandy shores, often gregarious, sometimes in the interior of the islands on hills.-St. Croix (common); Virgin Islands (uncommon).

757. Excœcaria Laurocerasus, Muill. (1. c. 1202). $\gamma$ ) laurifolia.

Not seen flowering. A high tree; bark smooth, white. In dense forests, rare.-St. Jan (Cinnamon Bay).

758. Hura crepitans, L. (v. Sandbox-tree).

Fl. Sept. Leaves deciduous in Jan.-April. Seeds drastic. A high tree with horizontal branches and prickly stem. In forests and near dwellings, common.-All islands. 
759. Dalechampia scandens, $L$.

Fl. Feb.-June. Male inflorescence bearing at the base two resinous corpuscula, deciduous together with the male flowers. Baillon considers them to be sterile bracts; Müller takes them for monstrous anthers. Central female flower pedicellate. In thickets, common.-All islands. 760. Euphorbia buxifolia, Lam.

Fl. all the year round. On.the sandy shore, common.-All islands. 761. E. articulata, Burm.

Fl. all the year round. Along the seacoast, common.-All islands. 762. E. pilulifera, L.

Fl. all the year round. In waste places and along roads, very common.-All islands.

763. E. hypericifolia, L. a) and $\beta$ ) hyssopifolia, L.

Fl. all the year round. Leaves distichous. Used against dysentery. Same places as the preceding. A common weed.-All islands.

764. E. thymifolia, Burm.

FI. all the year round. The whole plant reddish. Leaves folding together during night and in rainy weather. Among stones and along roads, very common.-All islands.

765. E. prostrata, Ait.

Fl. the whole year. Together with the preceding, common.-All islands.

766. E. petiolaris, Sims (Bot. Mag. t. 883) (v. Manchineel).

Fl. the whole year. Partly precocious in the spring. On dry hills and in thickets.-Virgin Islands (common); St. Croix (West, p. 288?).

(West's $E$. cotinifolia, said to occur in St. Croix, is evidently meant for this species. I doubt, howerer, the correctness of the habitat, and an of opinion that it is a mistake for St. Thomas, where the species is exceedingly common.)

767. E. geniculata, Ortega (Decad. p. 16; DC. Prodr. xv, ii, 72). (E. prunifolia, Jacq. Hort. Schœnbr. iii, t. $27 \tau$, a form with larger, serrate leares.)

Fl. Dec.-March. In forests and near dwellings, not uncommon, often gregarious._St. Croix (Gorernment House); St. Thomas (Signal Hill). 768. E. heterophylla, L. $\beta$ ) cyathophora, Jacq.

Fl. all the year round. Gregarious in dry places, common.-All islands.

769. E. neriifolia, L. (DC. Plant. Grasses, i, t. 46).

Fl. March-June. A large tree, stem $2^{\prime}-3^{\prime}$ diam. Naturalized near dwellings, common.-All islands. 
770 Pedilanthus tithymaloides, Poit. $\alpha$ ), $\beta$ ) padifolius, Poit., and $\gamma$ ) angustifolius, Poit.

Fl. all the year round. In thickets and gardens, uncommon.-All islands.

All Euphorbiacece are proterogynous.

rCultivated species: Jatropha pandurcefolia, Andr., Codioum variegatum, Müll. a) pictum, Euphorbia pulcherrima, W., E. splendens, Boj., and E. antiquorum, L.]

\section{URTICACEAE.}

771. Celtis trinervia, Lam.

Fl. June-Dec. In forests and thickets, not uncommou.-All islands. 772. C. aculeata, Sw. $\alpha$ ) and $\beta$ ) serrata.

Fl. March-Sept. Proterogynous. Both forms not uncommon in thickets.-All islands.

773. Sponia micrantha, Decs.

Fl. April-Sept. In forests, here and there.-All islands.

774. Ficus crassinervia, Desf.

Fl. Jan. In forests, not uncommon.-St. Croix (Crequis, Wills Bay). 775. F. trigonata, $\mathrm{L}$.

F1. May-Aug. In forests.--St. Croix (rare, Crequis); Virgin Islands (not uncommon).

776. F. lævigata, Vahl.

Fl. Jan.-March. In forests and on rocks, not uncommon.-St. Croix (Crequis, Jacob's Peak).

777. F. lentiginosa, Vahl.

Fl. May. In forests on high hills, uncommon.-St. Thomas (Signal Hill).

778. F. populnea, W.

Fl. July-Aug. Figs geminate in the axils, red with dark spots. On rocks and epiphytic on trees, not uncommon. Long aërial roots.All islands.

779. F. pedunculata, Ait.

Fl. Jan.-May. Figs red, generally inhabited by a small hymenopterous insect. On rocks, walls, and trees, common. Iong aërial roots.All islands.

780. Artocarpus incisa, L. (v. Breadfruit-tree).

Fl. May-July. Fruit not edible. Naturalized in shady valleys.-All islands.

781. Cecropia peltata, L. (v. Trumpet-tree).

Fl. April-June. In shady forests, not uncommon.-All islands. 
782. Maclura tinctoria, Don (v. Fustic).

Fl. June-Oct. Young shoots with deeply serrate leaves. Wood affording an excellent timber, but now very scarce. In forests, here and there.-All islands.

783. Fleurya æstuans, Gaud.

Fl. June-Dec. On rocks in shady forests, here and there.-St. Croix (Spring Gardeu); St. Thomas (Crown).

784. Urera elata, Gris.

St. Croix (Spring Garden, West, p. 306 ; his specimen in Hb. Havn.).

785. U. baccifera, Gaud.

St. Thomas (Wedd. in DC. Prodr. xvi, i, 93).

(West's Urtica elongata, Vahl, said, p. 306, to occur in St. Croix, and probably intended for an Urera, I have not been able to identify, from want of description and specimens.)

785. Pilea microphylla, Liebm. $a$ ), $\beta$ ) trianthemoides, LindI., and $\gamma$ ) succulenta (v. Duck-weed).

Fl. all the year round. On rocks and stones in shady situations. $\alpha$ ) uncommon; $\beta$ ) and $\gamma$ ) common.-All islands.

787. P. semidentata, Wedd.

Fl. March-July. Gregarious among rocks on high hills, not uncommon.-St. Thomas (St. Peter).

788. P. grandis, Wedd.

Fl. June. In leaf-mould on high hills, gregarious, uncommon.-St. Thomas (Crown, 1500').

789. P. nummularifolia, Wedd.

St. Thomas (Hornbeck in Hb. Havn.); Vieques (near Campo Asilo). 790. P. inæqualis, Wedd.

Fl. July-Aug. Gregarious on rocks in forests, uncommon.-St. Thomas (Signal Hill, Crown).

791. P. Sanctæ-Crucis, Liebm. (Vid. Selsk. Skrift., v. Række, ii, 301).

St. Croix (Örsted, 1. c.).

792. Rousselia lappulacea, Gaud.

St. Thomas (DC. Prodr. xvi, i, 235; Gris. Fl. p. 160).

[Cultivated species: Ficus Carica, L. (v. Fig-tree), and F. elastica, L.]

\section{ARISTOLOCHIACER.}

793. Aristolochia trilobata, L. (v. Tobacco-pipe).

Fl. May-Aug. On fences and in forests on high hills.-St. Croix (West, p. 305); Virgin Islands (not uncommon). 
794. A. anguicida, L. (DC. Prodr. xv, i, 464; Bot. Mag. 4361; Descourtilz, Fl. Méd. des Antilles, iii, 202) (v. Crane's Neck).

Fl. Oct.-Dec. A number of dipterous insects are usually found imprisoned in the lower part of the perigonal tube, whence escape is impossible on account of the downward-bent hairs on the inner surface. The hairs dropping off after fertilization, the imprisoned insects are set at liberty again. In thickets, rare.-St. Croix (Recovery Hill).

\section{BEGONHA CER.}

795. Begonia humilis, Hort. Kew. (ed. i, vol. iii, 353).

St. Thomas (Finlay in Hb. Mus. Paris. sec. DC. Prodr. xv, i, 297). [Cultivated occur sereral species of Begonia.]

\section{AMENTACEAE.}

[Cultivated in gardens and near dwellings: Casuarina equisetifolia, Forst. (Fl. June-Aug.) Of very quick growth.]

\section{PIPERA CEAE.}

796. Piper Sieberi, Cas. DC. (Enckea, Miq.).

Fl. all the year round. In forests; often gregarious and forming a dense underwood, common. Used for walking-sticks.-All islands.

797. P. Bredemeyeri, Jacq. (Artanthe, Miq.).

Fl. Sept. In shady valieys, not uncommon.-St. Croix (Caledonia, Crequis).

798. P. auritum, Kth.

St. Thomas (DC. Prod. 1. c. 321).

799. P. Blattarum, Sprgl.

F1. Jan.-March. In forests, rare.-St. Thomas (Crown, Signal Hill). 800. P. peltatum, L. (v. Monkey's Hand) (Potomorphe, Miq.).

Fl. Feb.-Aug. In forests, along rivulets, and among rocks on high hills.-St. Croix (rare, Caledonia, Springfield); Virgin islands (not uncommon on high hills).

801. Peperomia pellucida, Kth.

Fl. May-Aug. In forests, rare.-St. Croix (Rohrs Minde); St. Thomas (DC. Prod. 1. c. 402).

802. P. acuminata, Miq. ( $P$. guadeloupensis, Cas. DC.) (v. Stone Ginger).

Fl. all the year round. On rocks in forests, common.-All islands. 803. P. glabella, Dietr.

Fl. May-Sept. In the same places as the preceding, common.All islands.

804. P. cubana, Cas. DC.

St. Croix (DC. Prod. 1. c. 413). 
805. P. obtusifolia, Cas. DC., Dietr., Miq. $\quad \omega$ ) and $\beta$ ) clusiæfolia.

Fl. April-July. On rocks and under shady trees in leaf-mould. Gregarious, not uncommon. a) all islands; $\beta$ ) St. Thomas (Crown).

806. P. scandens, Ruiz et Pav.

St. Thomas (DC. Prod. 1. c. 434).

807. P. polystachya, Miq.

Fl. Dec.-Jan. Stem and lower surface of the leaves reddish. Among rocks in forests, not uncommon, gregarious.-All islands.

\section{B. GYMNOSPERM E.}

\section{CYCADA CEAE.}

[Cultivated in gardens occurs Cycas revoluta, Thunb. (v. Sago Palm).]

\section{CONIFERE.}

[Cultivated in gardens occur several species of Thuja.]

\section{MONOCOTYLEDONES.}

\section{ALISMACERE.}

808. Echinodorus cordifolius, Gris.

Fl. April-Aug. Flower expanded only till 10 A. M. Leaves heteromorphous, the primordial ones submerged, linear-lanceolate, passing by degrees into the ordinary emersed ones. In rivulets, here and there.St. Croix (King's Hill Gut, Armas Hope Gut).

\section{HYDROCHARIDACEAE, L. C. Rich.}

809. Thalassia testudinum, Solander (Koenig).

Not seen flowering. Gregarious in shallow sea-water, very common.All islands.

\section{POTAME AE, Juss.}

810. Cymodocea manatorum, Ascherson (Naturf. Freunde in Berlin, Jun.-Oct., 1868).

Not seen flowering, gregarious on the bottom of the sea; mostly in shallow water.-All islands.

811. Halodule Wrightii, Aschers.(1. c., and Neumayers Anleit. zur wiss. Beob. auf Reisen).

St. Thomas (Krebs sec. Aschers.).

Bull. Nat. Mus. No. $13-7$ 
812. Halophila Baillonii, Aschers. (in Neumayer, 1. c. p. 367).

Rhizome creeping, thin. Leaves oval, denticulate, whorled or opposite, $3^{\prime \prime \prime}$ long, $1 \frac{1}{2}{ }^{\prime \prime \prime}$ broad. Monœcious.

Fl. $\sigma^{n}$ : 3 membranaceous white bracts; $1-3$ stamens; filament $\frac{2}{3}$ '” long; anther cylindrical, yellowish, glabrous, 1-celled. Pollengrains fusiform.

Fl. $q$ : 3 persistent bracts, as in $\delta$. Ovary sessile, ovate, $\frac{1}{3}$ "' long,

- loculate. Style bifid, 21:"' long; branches pointed, often of unequal length. Capsule oval, glabrous, $2^{\prime \prime \prime}$ long; seeds about 20; globose, hard, tessellate on the surface. Stareh-grains triangular.

Male flowers very rare compared to the number of female ones.

Fl. all the year round. Gregarious on the bottom of the seaon coarse coral sand in a depth of from two to four fathoms, here and there.-St. Thomas (harbour).

813. Ruppia rostellata, Koch.

Fl. all the year round. Gregarious in shallow rivulets, not uncommon.-St. Croix (King's Hill Gut, in company with a species of Chara); St. Thomas ('Tutu Gut, Krebs in Hb. Havn.).

[Another Potamea, possessing a creeping rhizome and delicate linear leaves, has been found by me in the harbour of St. Thomas at a depth of from 3 to 6 fathoms, but on account of only sterile specimens having been obtained it remains as yet undetermined.]

\section{AROIDERE.}

814. Anthurium Huegelii, Schott (r. Boyer) (A. acaule, Sch.).

Fl. July-March. Young radical leaves very different from the older ones, being lanceolate and long-petioled. I consider Schott's $A$. acaule not to be specifically distinct from this species. On rocks and trees, not uncommon, often gregarious.-All islands.

815. A. macrophyllum, Sch.

Fl. July-Dec. Among rocks in forests, uncommon. St. Jan (near Bethania).

816. A. cordifclium, Kth. (v. Wild Tanier, Maroon Jancole) (Bot. Mag. t. 2801, 5801 being a misprint in Gris. Fl. p. 508).

F1. July-Nov. Among rocks in forests, gregarious, here and there.St. Croix (Wills Bay, Blue Mountain); St. Jan (Macumbi, 1200').

817. Dieffenbachia Seguine, Sch. (v. Dumb Cane).

Fl. May-Dec. In moist places on himh hills, uncommon.-St. Thomas (Caret Bay, 1000'). 
818. Philodendron hederaceum, Sch.

Fl. Aug. On trees in dense forests, rare.-St. Thomas (Crown, 1400'). 819. Ph. giganteum, Sch. (Prod. Syst. Aroid. p. 261).

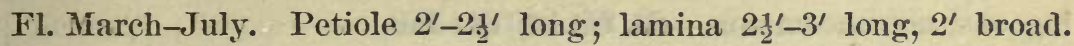
Peduncle $1 \frac{1}{2}{ }^{\prime \prime}-32^{\prime \prime}$ long; spathe $11^{\prime \prime}-12^{\prime \prime}$ long, opeuing itself only during two nights. Spadix white, giving out a strong odour and considerable high temperature during anthesis. 'Numerous aërial roots, stem $\mathbf{1}^{\prime}-2^{\prime}$ long. Among rocks in dense forests on high hills, gregarious on trees.St. Thomas (Signal Hill and Crown, 1500').

(The picture in Bot. Mag. t. 3314, of the much smaller Ph. fragrantissimum, Kth. (Caladium, Hook.), gives a good representation of the habit. of this species.)

820. Caladium smaragdinum, C. Koch (Schott, 1. c. 165) (v. Guinea Ginger).

F1. May-July. Rhizome tuberous, yellow. In pastures on high hills, not uncommon.-St. Thomas (Signal Hill, above St. Peter, 1400').

821. Xanthosoma atrovirens, C. Koch (v. Scratch-throat).

Not seen flowering. Rhizome large, tuberous, used as a regetable. Leaves pungent when eaten as spinach. Cultivated and naturalized on provision grounds.-St. Croix; St. Thomas.

822. $x$. sagit ææfol:um, Sch. (v. Tanier).

Fl. July. Lamina of the spathe white, with a delicate rosy tinge. Spathe disclosing itself during two nights from 7 to 10 o'clock; spadix meanwhile giving forth a strong fragrance and showing a temperature of $120 \mathrm{C}$. above that of the air. Leaves used as spinach and the tuberous rhizome as a common vegetable. Cultivated and naturalized on provision grounds.-All islands.

823. $\mathrm{x}$. ? hastatum, Egg. ( $\mathrm{rum}$, Vahl.) (v. Indian Kale).

Not seen flowering. Leaves hastate, with long pointed oblique basilar lobes; used for spinach. (Naturalized?) Cultivated and spontaneous in forests. - All islands.

824. Pistia cccidentalis, Bl.

Fl. all the year round. Cultivated and naturalized in gardens.-St. Thomas.

825. Lemna minor, $\mathrm{L}$.

Not seen flowering. In rivulets, not uncommon.-St. Croix (Jealousy Gut, Fair Plain Gut).

[Cultivated species: Caladium bicolor, Vent., ('. pictum, DC., and $C$. picturatum, Linden.] 
TYPLACEN.

826. Typha angustifolia, L., var. domingensis, Pers.

Fl. Sept.-March. Used for making mats. In rivulets and around lagoons, not uncommon.-St. Croix; St. Jan.

\section{PANDANACER.}

[Cultivated in gardens occurs Pandanus odoratissimus, L. fil. (v. Screw Pine).]

\section{PALIL AE.}

827. Thrinax argentea, Lodd. (v. Teyer-tree).

Fl. May-June. Stem $10^{\prime}-20^{\prime}$ high. Leaves used for making ropes, thatching roofs, and other domestic purposes. On the northern slope of the hills in forests and tickets.-St. Croix (very rare, only one specimen seen, near Bellevue Mill); Virgin Islands (common).

828. Oreodoxa regia, Kth. (v. Mountain Cabbage).

Fl. April-Aug. The young leaf-bud used as cabbage. Berries eaten by hogs. In forests and along roads, common.-All islands.

829. Cocos nucifera, L. (v. Cocoa-nut Tree).

Fl. Feb.-March. Leaves used for thatching roofs. The ripe fruit, -although occurring in abundance, is scarcely used, and of no economical importance. Naturalized along the seashore and along roads.-All islands.

\section{COMUELYNACEA.}

830. Tradescantia geniculata, Jacq. $\beta$ ) effusa, Mart.

Fl. March. Seeds bluish, verruculose.-Vieques (near Campo Asilo). 831. T. zebrina, Hortul. (v. Wandering Jew).

Fl. May. Naturalized in gardens.-St. Croix; St. Thomas. 832. T. discolor, $\mathrm{Sw}$.

Fl. April-Aug. Stamens often by retrograde metamorphosis transformed into petals. Naturalized in waste places and near dwellings.All islands.

833. Callisia repens, $L$.

Fl. Jan.-March. Gregarious in shady places, not uncommon.-All islands.

834. C. umbellulata, Lam.

Fl. Jan. Seeds white with a red spot. Flowers monandrous. Among rocks in shady places, rare.-St. Thomas (Signal Hill, 1200').

835. Commelyna cayennensis, Rich. (French Grass).

Fl. all the year round. Flower expanded till 9 A. M. One of the sterile stamens always abortive. In moist localities, common.-All islands. 
836. C. elegans, Kth. (v. French Grass).

Fl. all the year round. Flower ephemeral. In moist localities, very common.-All islands.

\section{GRAMINACEBE.}

837. Bambusa vulgaris, Schrad. (v. Bamboo Cane).

Not seen flowering. Naturalized along rivulets and in gardens.St. Croix; St. Thomas.

838. Arthrostylidium capillifolium, Gris. (Plant. Wright. in Mem. Amer. Acad. viii, $531,1862)$.

Not seen flowering. In forests, climbing among trees and shrubs to a considerable height, rare.-St. Thomas (Flag Hill, 700'); St. Jan (Hornbeck in Hb. Havn., from "a large cataract, called Battery"); Vieques (flowering specimens from Hornbeck in Hb. Havn.; others received from Campo Asilo by me).

839. Eragrostis poæoides, P. Br.

Fl. June-Dec. Stigmas white. Along roads and in dry localities, often gregarious, common.-St. Croix; St. Thomas.

840. ョ. ciliaris, Lk.

Fl. March-Dec. Anthers black. In dry localities, common.-All islands.

841. Sporobolus virginicus, Kth. (v. Shander).

Fl. May-Oct. Anthers and stigmas yellow. Used in baths for children. Along the coast and lagoons, common.-All islands.

842. S. litoralis, $K$ th. (v. Shander).

Fl. May-Dec. In the same places as the preceding, common.-All islands.

843. S. indicus, R. Br. (v. Hair-grass).

Fl. Maj-Oct. Anthers purple; stigmas jellow. Along roads and ditches.-All islands.

844. Aristida stricta, Mich.

Fl. March-Dec. Anthers yellow. Awns of unequal length, always longer than the glumes. Along ditches and in thickets, here and there.-St. Croix (Crequis, Fair Plain); St. Thomas (Schl.); St. Jan (Adrian Estate).

845. Olyra latifolia, L. $\beta$ ) arundinacea.

Fl. Dec.-Jan. In forests, rare--St. Jan (Cinnamon Bay); Vieques (Campo Asilo).

846. Pharus glaber, Kth.

Fl. June-Dec. Anthers Jellow; stigmas white. In forests, not uncommon.-All islands. 
847. Pappophorum alopccuro:des, Vahl.

Fl. Feb.-March. $1^{\prime}-3^{\prime}$ high. Among rocks near the coast, rare.Buck Island, near St. Thomas ; Virgin Gorda (Vall in Symb. Bot. iii, 10).

848. Bouteloua litigiosa, Lag.

Fl. Oct.-Jan. Anthers red; stigmas white. In thickets and waste places, not uncommon.-St. Thomas (Cowell's Hill-Town).

849. Leptochloa mucronata, Kth.

F1. May-Oct. Spikelets often 1-flowered. Along ditches, not uncommon.-St. Croix.

850. L. virgata, P. Br. a), $\beta$ ) gracilis, Ns., and $\gamma$ ) nıultiflora, Egg.

Fl. May-Dec. Anthers white; stigmas purple. $\gamma$ ) spikelets 9-flow. ered. Awns very short; fertile glumes not ciliate. Along roads, common. $-\alpha$ ) and $\beta$ ) all islands ; $\gamma$ ) St. Croix (Work and Rest).

851. Chloris eleusinoides, Gris.

Fl. May-Nov. Along ditches, here and there.-St. Croix (Beeston Hill, Mount Welcome).

852. Ch. radiata, $\mathrm{Sw}$.

Fl. May-Oct. Stigmas brown. Gregarious along roads, common.All islands.

853. Ch. ciliata, Sw.

Fl. Feb.-Sept. Anthers rosy. My specimens show only one sterile flower in each spikelet besides the fertile one (see Swartz's Flora Ind. Occ. p. 189). Along roads, not uncommon.-All islands.

854. Dactyloctenium ægyptiacum, W. (v. Ten-per-cent Grass).

Fl. March-Nov. Anthers straw-coloured; stigmas white. A good pasture-grass. Along roads and in fields, common.-All islands.

855. Eleusine indica, $\mathrm{L}$.

Fl. March-Dec. Anthers greyish; stigmas purple. Common everywhere.-All islands.

856. Cynodon Dactylon, Pers. (v. Bay Grass, Billy Grass).

Fl. May-Oct. Anthers straw-coloured, with purple spots; stigmas purple. A good pasturé-grass, and fit for making good hay, but at the same time a most troublesome weed in cane-fields on account of its long and creeping rhizome. Said to have been introduced. Along the coast and in fields, gregarious._-St. Croix and St. Thomas (very common); St. Jan (uncommon, Little Plantation). 
857. Paspalum compressum, Is. (v. Flat Grass).

Fl. June-Oct. Anthers light yellow; stigmas white. Near ditches and in shady localities, not uncommon.-All islands.

858. P. conjugratum, Berg.

Fl. June-Dec. Anthers yellow; stigmas white. In moist localities, common.-All islands.

859. P. pusillum, Vent.

St. Thomas (Flïgge sec. Gris. Syst. Unt., p. 114).

860. P. distichum, L. $a$ ) and $\beta$ ) vaginatum, Sw.

Fl. June-Aug. Proterandrous. Anthers light yellow; stigmas black. Along rivulets, not uncommon.-St. Croix; St. Thomas.

861. P. notatum, Flïgge.

St. Thomas (Flïgge sec. Gris. Syst. Unt., p. 114).

862. P. cæspitosum, Flïgge.

Fl. May-Sept. Anthers orange-coloured. In moist localities, not uncommon.-All islands.

863. P. glabrum, Poir.

Fl. May-July. Here and there along ditches.-St. Thomas (Schl.); St. Jan (Riff Bay).

864. P. plicatulum, Michx.

Fl. March-Sept. Along the seacoast, not uncommon.-All islands. 865. P. virgatum, L. $u$ ).

Fl. May-Oct. Anthers straw-coloured; stigmas white. In moist localities, not uncommon.-All islands.

866. P. paniculatum, L.

St. Thomas (Schlechtendal).

867. P. spathaceum, HB. K.

St. Thomas (Schlechtendal).

868. Digitaria filiformis, Mühl.

Fl. Dec. In dry thickets, here and there.-St.Thomas (Cowell's Hill).

869. D. marginata, Lk. (v. Running Grass).

Fl. March-Sept. Anthers purple with white stripes; stigmas purple. A good pasture-grass. Along ditches and roads, common.-All islands. 
870. D. setigera, Kunth.

Fl. June-Oct. Anthers and stigmas purple. Along roads, common.All islands.

871. Eriochloa punctata, Hamilt.

Fl. March-Sept. Anthers brownish; stigmas black. In moist localities, here and there.-St. Croix (Crequis, La Grange); St. Thomas (Schl.).

872. Stenotaphrum americanum, Schrank (v. Horse Grass).

Fl. May-Aug. Anthers orange-coloured; stigmas purple. Along the coast and in moist localities, gregarious, common.-All islands.

873. Orthopogon setarius, Spreng.

Fl. March-Dec. Anthers light purple; stigmas purple. In forests, common.-All islands.

874. Panicum paspaloides, Pers.

F1. March-Sept. Anthers reddish; stigmas straw-coloured. The hermaphrodite flower in this and all other species of Panicum is proterandrous, the stamens dropping off before the stigmas appear. These latter are then fertilized by the agency of the wind from other individuals before the stamens of the male flower make their appearance, selffertilization being thus evidently impossible. Along rivulets and in moist localities, not uncommon.-St. Croix; St. Thomas.

875. P. brizoides, L.

St. Thomas (Schlechtendal).

876. P. colonum, L.

Fl. March-Sept. Anthers purple; stigmas black. Along roads and ditches, common.-All islands.

877. P. prostratum, Lam. $a$ ) and $\beta$ ) pilosa, Egg.

Fl. June-July. Anthers orange-coloured; stigmas black. $\beta$ ) Rhachis of spikelets pilose.- $\alpha$ ) All islands (common); $\beta$ ) St. Croix (La Grange).

878. P. fuscum, Sw. (v. Sour Grass). $a$ ) and $\beta$ ) fasciculatum, Sw.

Fl. Feb.-Sept. Anthers orange-coloured; stigmas purple. Abhorred by the cattle.-a) All islands. $\quad$ ) St. Croix; St. Thomas (Schlechtendal). Not uncommon.

879. P. molle, Sw. (v. Yerba de Para, Spanish Grass).

Fl. May-Oct. Anthers yellow; stigmas purple. Naturalized here and there in pastures.-St. Croix (Cotton Grove). 
880. $P$. diffusum, Sw.

Fl. May-Oct. Anthers orange-coloured; stigmas dark purple. In moist localities, uncommon.-All islands.

881. P. maximum, Jacq. ( . Guinea Grass) (P. polygamum, Sw.).

Fl. June-Sept. Anthers brownish; stigmas light purple. A splendid pasture-grass, growing to the height of $12^{\prime}$, forming dense tufts and being propagated by the rhizome. Naturalized and cultivated everywhere.-All islands.

882. P. divaricatum, L. $\alpha$ ) and $\beta$ ) puberulum.

Fl. May-Dec. Anthers light yellow; stigmas white. Resembling a thin Bamboo Cane. $8^{\prime}-16^{\prime}$ high. Both forms not uncommon in forests, climbing over trees and shrubs.-All islands.

883. P. glutinosum, Sw.

St. Croix (West, p. 267).

884. P. brevifolium, L.

Fl. Aug.-Dec. Anthers and stigmas white. In gardens and along roads, here and there.-St. Thomas (Barracks).

885. P. cayennense, Lam.

St. Thomas (Schlechtendal).

886. Setaria glauca, P. Br. $a)$.

Fl. May-Uct. In forests, common.-All islands.

887. S. setosa, P. Br. $\quad \alpha$ ) and $\beta$ ) caudata, R. S. (v. Sour Grass).

Fl. April-Dec. Anthers orange-coloured; stigmas purple. $\alpha$ ) $3^{\prime}-7^{\prime}$ high; in forests and along ditches, common.-All islands. $\beta$ ) in dry thickets, uncommon.-St. Thomas (Cowell's Hill).

888. Cenchrus echinatus, L. $\beta$ ) viridis, Spreng. (

Fl. April-Dec. Anthers light yellow; stigmas white, with a purple spot in the middle. The ripe farinaceous seeds eaten by the cattle. Along the coast, very common.-All islands.

889. Anthephora elegans, Schreb.

Fl. Jan.-Oct. Anthers brownish. In thickets, here and there.-St. Croix; St. Thomas.

890. Tricholæna insularis, Gris. (v. Bitter Grass, Long Grass).

Fl. March-Dec. Anthers brownish; stigmas white. Never touched by cattle whilst green, on account of its bitter taste. Spikelets easily detached and carried far away by the wind. Very common along roads and in dry places.-All islands. 
891. Lappago aliena, Spreng.

Fl. May-Dec. Stigmas white. Generally both spikelets fertile. Near ditches and in thickets, common.-All islands.

892. Andropogon saccharoides, $\mathrm{L}$.

Fl. Aug.-Oct. Anthers light yellow; stigmas dark purple. Awn not twisted. Along roads, here and there.-St. Croix (Beeston Hill Grange). 893. Anatherum bicorne, P. Br. (v. Jolly Grass).

Fl. July-Oct. $2^{\prime}-4^{\prime}$ high. Used for thatching roofs. Not eaten by the cattle. Gregarious on high hills, where it is difficult to counteract its spreading, even by burning it now and then.-St. Thomas (northern slope of the highest ridge).

894. Sorghum vulgare, Pers. (v. Guinea Corn).

Fl. Dec. $8^{\prime}-16^{\prime}$ high. Naturalized and cultivated for herbage and for making flour of the grain.-All islands, principally St. Croix and Vieques.

895. Saccharum officinarum, L. (v. Sugar-cane).

Fl. Dec.-May. Naturalized and cultivated. Sugar-growing islands are now only two, viz., St. Croix and Vieques, whilst the other Virgin Islands have only a very few cane estates, principally for selling the raw cane in the markets. The average produce of sugar from both the above-mentioned islands is about 25 million pounds. The plant is propagated by cuttings that are laid entirely under ground.

(The genus Panicum excepted, all Graminacea are proterogynous.)

[Cultivated species: Andropogon Schonanthus, L. (v. Lemon-grass), Zea Mays, L. (v. Indian Corn), and Coix Lacryma, L. (v. Job's Tears).]

\section{CYPERACEA.}

896. Cyperus polystachyus, Rottb.

Fl. July. On high hills, rare.-St. Thomas (Crown, 1500').

897. C. lævigatus, L. (Cod. p. 61) (C. mucronatus, Rottb.). a) albidus.

Fl. March-Oct. Connective pointed. Along rivulets, not uncommon.-St. Croix; St. Thomas (Schl., Böckeler).

893. C. compressus, $L$.

Fl. Dec. Flowers 2-androus. Near the coast in moist places, uncommon.-St. Thomas (Haven Sight).

899. C. confertus, Sw.

Fl. Dec. In thickets, here and there.-St. Thomas (Cowell's Hill); St. Croix (Gris. Fl. 563). 
900. C. ochraceus, Vahl.

Fl. May-Oct. In moist localities, uncommon.-St. Croix (Crequis). 901. C. viscosus, Ait.

Fl. April-Nov. Stamens always 3 (see Swartz's Fl. Ind. Occ. p. 113). Seeds germinating in moist weather on the parent, and often growing out into joung plants an inch or two in length. Along rivulets and ditches, not uncommon.-St. Croix; St. Thomas.

902. C. surinamensis, Rottb.

St. Thomas (Schl.).

903. C. articulatus, L. (v. Sting Bisom).

Fl. March-Sept. In ditches, not uncommon.-St. Croix; St. Thomas. 904. C. rotundus, L. (v. Nut Grass).

F1. all the year round. Tubers sweet, eaten by hogs. A troublesome weed, very common in fields and along roads.-All islands.

905. C. brunneus, Sw. (C. planifolius, Rich.).

Fl. May. On the coast and near lagoons, not uncommon.-All islands. 906. C. sphacelatus, Rottb.

Fl. Feb. On high hills in pastures, uncommon.-St. Thomas (Signal Hill).

907. C. distans, L.

Fl. Aug. In pastures on high hills, common.-St. Thomas (Signal Hill).

908. C. unifolius, Bøckler (Linnæa, Neue Folge, ii, 374).

St. Croix (Ravn in Reliq. Lehm.).

909. C. filiformis, Sw.

Fl. all the year round. In moist localities, not uncommon.-St. Thomas.

910. C. odoratus, L.

Fl. April-Oct. Near rivulets and ditches, here and there.-St. Croix (Mount Pleasant, Annas Hope).

911. C. pennatus, Lam. (Burckler, 1. c. 404) (C. Ehrenbergii, Kth., C. flexuosus, Vahl).

Fl. all the year round. Along the coast, not uncommon.-St. Thomas. 912. C. ligularis, L.

Fl. March-Dec. Along rivulets, not uncommon.-All islands. 
913. C. flavomariscus, Gris. (C. flavus, Bœckler).

Fl. Ang. In pastures on hills, here and there-St. Thomas (Signal Hill); Buck Island (near St. Thomas).

914. Kyllinga filiformis, Sw. 4 ) and $\gamma$ ) capillaris, Gris.

Fl. June-Dec. Involucral leaves of various lengths. Both forms not uncommon in forests.-St. Croix (The William, Eliza's Retreat).

915. K. triceps, Rottb.

Fl. March. In shady moist localities._St. Jan (Baas Gut).

916. K. monocephala, Rottb.

Fl. all the year round. In moist places in forests, common.-All islands.

917. K. brevifolia, Rottb. (Emend. in Bœckler, Linnæa, 1867, 425). $\beta$ ) longifolia.

St. Thomas (Ehrenberg sec. Bœckler).

918. Scirpus capitatus, L.

Fl. all the year round. Achenium black. Along rivulets, common.All islands.

919. S. nodulosus, Kth.

Fl. March-Dec. Along rivulets and in ditches, uncommon.-St. Croix (Adventure).

920. S. subdistichus, Bœckler (Linnæa, 1869-70, 490).

St. Thomas (Bcklr.).

921. S. mutatus, Vahl.

Fl. March-Dec. Filaments flat; style often bifid. In moist places, not uncommon.-St. Croix; St. Jan.

922. S. ferrugineus, L.

Fl. all the year round. Filaments flat. Gregarious in tufts on the sandy seashore and near lagoons, uncommon.-St. Croix (Frederiksted); St. Jan (Reef Bay).

923. S. brizoides, Sw. (Fimbristylis polymorpha, Bœckler).

Fl. Aug.-Sept. In pastures on high hills, common.-Virgin Islands. 924. Rhynchospora pusilla, Gris.

Fl. Feb.-July. Anthers $\mathbf{1}_{4}^{\prime \prime \prime \prime}$ long. In pastures on hills, rare.-St. Thomas (Signal Mill, 1400').

925. R. pura, Gris.

Fl. Feb.-Aug. Seeds often germinating on the parent. In the same places as the preceding. St. Thomas (Signal Hill). 
926. Scleria pratensis, Lindl. (v. Cutting Grass).

Fl. April-Nov. In forests and pastures on high hills, uncommon.St. Croix (Springfield, Mount Eagle); St. Thomas (Signal Hill).

927. S. scindens, Ns. ( . Razor-grass).

Fl. Aug.-Sept. In forests, rare.-St. Thomas (Signal Hill, 1500').

928. S. filiformis, Sw. (S. lithosperma, W.).

Fl. May-Nov. In thickets, not uncommon.-St. Croix (King's Hill); St. Thomas (Cowell's Hill).

[All Cyperacece are proterogynous, with white stigmas and light yellow anthers.]

\section{LILIACER.}

929. Aloe vulgaris, L. (v. Sempervivie).

Fl. March-April. Gregarious on limestone (naturalized?), common.All islands.

930. Yucca gloriosa, $L$.

Fl. June-Aug. Naturalized in gardens and near dwellings.-St. Croix; St. Thomas.

931. Agave americana, L. (v. Karata).

Fl. Feb.-May. On dry hills, common.-All islands.

932. A. sobolifera, Salm-Dyck. (v. Karat爪).

Very seldom or never bearing flowers. Propagated by bulblets in June-July, growing out to a considerable size whilst still on the parent. On hills and in thickets, not uncommon.-All islands.

933. Fourcroya cubensis, Haw. (v. Female Karata).

Fl. March and July-Aug. In dry thickets, not uncommon.-St. Croix; St. Thomas.

934. Pancratium caribæum, L. (v. White Lily, Ladybus).

Fl. May-Nov. Flowers nocturnal; fragrant. On rocky coasts, not uncommon.-All islands.

935. Crinum erubescens, Ait.

Fl. all the year round. Flowers nocturnal; fragrant. Along rivulets, here and there.-St. Croix (Hógensborg).

936. Amaryllis equestris, Ait. (v. Red Lily).

Fl. March-Oct. On rocky shores, gregarious, not uncommon.-All islands. 
937. A. tubispatha, Ker. (v. Snow-drop).

Fl. April-Oct., especially after heavy rains. In fields and near dwellings, not uncommon.-All islands.

[Cultivated species: Allium fistulosum, L. (v. Ciboule), Polyanthes tuberosa, L. (v. Tuberose), and Crinum giganteum, Andr.]

\section{ASPARA GINACEAE.}

938. Sanseviera guineensis, W. (Spec. ii, 159) (Bot. Mag. t. 1179) (r. Guana-tail).

Fl. Nov.-Dec. Fibres of the leaves yield a good material for ropes. Naturalized here and there on dry hills, gregarious.-St. Croix (Frielensfeld); St. Thomas (around town).

\section{SMILACEAE.}

939. Smilax havanensis, Jacq.

Not seen flowering. In forests, here and there.-St. Croix (Caledonia, Wills Bay, Rohr's Minde).

940. S. populnea, Kth. (Enum. Plant. v, 192).

Fl. June-July ( $ð$ ). Unarmed. Leaves $4^{\prime \prime}-5^{\prime \prime}$ long, $3^{\prime \prime}-4^{\prime \prime}$ broad. In forests, a high climber, rare.—St. Thomas (Flag Hill, 9c0').

\section{DIOSCOREACEAE.}

941. Dioscorea pilosiuscula, Bert.

Fl. Dec., but rarely. Older leaves purple beneath, broad white stripes on the upper surface. Male inflorescence $3^{\prime \prime}$ long, pendulous. Axillar bulbs large, often bifid, greyish-brown, generally producing leaves whilst still in connection with the parent, dropping off later and forming new plants. In shady forests, uncommon.-St. Thomas (Signal Hill, northern slope above St. Peter, 1000').

942. D. alata, I. (v. Yam). a), $\beta$ ) vulgaris, Miq.

Not seen flowering. Propagated by the rhizome. Naturalized and cultivated in provision gromuls. Rhizome affording a nutritive vegetable.-All islands.

943. D. altissima, Lain. (v. Yam).

Not seen flowering. Stem cylindrical. Occurring in the same places and used in the same way as the preceding.-All islands.

944. Rajania pleioneura, Gris.

Fl. Dec. In forests, rare.-St. Thomas (Flag Hill, $\mathrm{S} 00^{\prime}$ ). 
945. R. hastata, L.

Fl. Sept.-Dec. In forests and on fences on high hills, not uncommon.-St. Thomas (Signal Hill, Northside) (St. Croix ?).

\section{IRIDACERE.}

946. Cipura plicata, Gris. (v. St. Jan Grass, Bloodroot).

Fl. all the year round. Bulbs crimson. Naturalized in gardens and valleys.-All islands.

\section{BROHELIACER.}

947. Bromelia Pinguin, L. (v. Pinguin).

Fl. Dec. and April-June. Pulp edible, acid. Used for fences. Gregarious in forests and thickets, common.-All islands.

948. Chevalliera lingulata, Gris.

Fl. March-July. Petals white, with a bluish point. Berry glabrous, pink or blue. On trees and rocks on high hills, not uncommon.-St. Thomas (Crown, Signal Hill, 1500'); St. Jan (Macumbi).

949. Pitcairnia engustifolia, Ait.

Fl. Aug.-Sept. Seeds red, pointed at the base; appendage white, truncate. On trees and rocks.-St. Croix (rare, King's Hill Gut); Virgin Islands (common, especially on the coast).

950. Tillandsia fasciculata, Sw.

F1. Jan.-Feb. Capsule a little shorter than the bract. On trees in forests and on high hills, uncommon.-St. Thomas (Crown); St. Jan (Baas Gut).

951. T. utriculata, L. (v. Wild Pine).

Fl. Feb.-Aug. Inflorescence over $S^{\prime}$ high. On trees and rocks, common.-All islands.

952. T. recurvata, L. (r. Old Man's Beard).

Fl. Jan.-Feb., but very rarely. Seeds often germinating in the capsule. Used for stuffing mattresses. On trees, gregarious, very common.-All islands.

953. T. usnecides, L. (v. Old Man's Beard).

Fl. March, rarely. Petals greenish. On shrubs, common, gregarious.-All islands.

954. Catopsis nutans, Gris.

Fl. June-Ang. Petals fleshy, white. Seeds brown; pappus $1 \frac{11}{4}$ 
long, white, silky. On trees and rocks on high hills, not uncommon.St. Thomas (Signal Hill, Crown, $\left.1400^{\prime}-1500^{\prime}\right)$.

[Cultivated species: Ananassa sativa, Lindl. (v. Pine-apple).

\section{IIUSACERE.}

955. Musa paradisiaca, L. (v. Plantain).

Fl. May-Aug. Fruit eaten only bolled or fried. Naturalized and cultivated, but rare.-All islands.

956. M. sapientium, L. (v. Banana).

Fl. May-Nov. Fruit eaten raw or fried. Naturalized and cultivated everywhere, occurring in several varieties (Bacuba, Fig, Lady-finger, St. Vincent Banana, etc.).-All islands.

\section{SCITAMINERE.}

957. Renealmia sylvestris, Gris.

Fl. Aug. In forests in shady and moist localities, rare.-St. Croix (Golden Rock); St. Thomas (Signal Hill, 1400').

958. Zingiber officinalis, Rosc. (v. Ginger).

Fl. Sept. Naturalized and cultivated in forest districts, here and there.-St. Croix; St. Thomas.

959. Canna indica, L. (v. Indian Shot).

Fl. all the year round. In moist places and near dwellings, not uncommon.-All islands.

960. C. Lamberti, Lindl. (v. Scarlet Indian Shot).

Fl. all the year round. Naturalized in gardens.-All islands.

961. C. edulis, Ker. (v. Tout-le-mois).

Fl. all the year round. Tubers used for producing salep. Naturalized and cultivated along rivulets.-All islands.

962. Maranta arundinacea, L. (v. Arrow-root).

Not seen flowering. Tubers yielding the best kind of salep. Naturalized and cultivated here and there.-All islands.

[Cultivated species: Alpinia nutans, Raf. (v. Shell-plant), and Curcuma longa, L. (v. Turmeric).

963. Liparls elata, Lindl.

ORCHIDACE RE.

FI. June-Dec. Bracts purple. My specimens on the whole somewhat smaller than the picture in Bot. Mag. t. 1175. On red clay among 
rocks on high hills, here and there.-St. Thomas (Liliendal, Bonne Resolution).

964. Epidendrum subæquale, Eggers, n. sp.

Fl. Feb.-March. Tubers cylindrical, small, several-leaved. Leaves 2-5, linear, channelled, pointed, much shorter than the scape; sterile bracts short, distant, pointed, floral ones smaller; flowers in a simple raceme, 3-4. Perigonial divisions lanceolate, pointed, nearly conform. Lip slightly adnate to the column, 3-lobed; lobes rounded, the two lateral ones a little shorter than the middle one. Column auricled below the anther; auricles small, purple. Ovary linear, striate, $\frac{1}{2}$ "long. Allied to $E$. aciculare, Batem., but leaves several, much shorter than the scape, and lip broadly 3 -lobed. Leaves $5^{\prime \prime}-6^{\prime \prime}$ long, $2^{\prime \prime \prime}$ broad; scape $20^{\prime \prime}-24^{\prime \prime}$ high, straight. Peduncles $\frac{1}{2}$ "long; perigonial divisions greenish, with brown spots, $\frac{1}{2}$ " long; lip purple, with darker stripes and a jellow crest in the middle, $\frac{1}{2}$ " long. The whole plant of a sometimes darker, sometimes lighter hue, flowers even sometimes quite white. On rocks and the roots of trees in dry thickets, here and there.-St. Thomas (Cowell's Hill, Solberg).

965. E. bifidum, Aubl.

Fl. May-Dec. On trees and rocks, not uncommon.-All islands. 966. E. ciliare, $\mathrm{L}$.

Fl. June-Feb. Flowers fragrant. Gregarious on rocks and old treetrunks, common.-All islands.

967. E. cochleatum, L. (Bot. Mag. t. 151, bad).

Fl. April-May. On trees in forests, rare.-St. Croix (Mount Eagle, 1150'; Jacob's Peak, 950').

968. E. patens, Sw.

Fl. July-Aug. Leaves distichous; scape compressed, $1^{\prime}-2^{\prime}$ high. On rocks in leaf-mould, rare, on high hills.-St. Thomas (Signal Hill, 1500').

969. Brassavola cucullata, R. Br.

Fl. June-Octb. Gregarious on rocks, rare.-St. Thomas (John Bruce Bay).

970. Polystachya lateola, Hook.

Fl. March-Nov. Flowers often cleistogamous and nórmal on the same branch and at the same time. Both forms yielding good seeds. On rocks and old tree-trunks, not uncommon on hills.-St. Thomas (Signal Hill, 1200'-1500').

Bull. Nat. Mus. No. $13-8$ 


\section{Oncidium Lemonianum, Liudl.}

Fl. May-July. Never giving fruit, but propagating itself by producing young plants from buds in the axils of the sterile bracts below the flowers, which remain in connection with the parent plant, and thus often forming long colonies of plants from one tree to another. In forests and thickets, gregarious, but rare.-St. Thomas (Picara Peninsula, Fortuna).

(The lateral sepals in my specimens being distinct, I am inclined to retain Lindley's specific name instead of uniting my plant with $O$. tetrapetalum, W., as done by Grisebach.)

972. 0 . variegatum, $\mathrm{Sw}$.

Fl. July-Octb. On rocks and trees in shady places, not uncommon.Virgin Islands.

973. Prescottia myosurus, G. Rehb.

Fl. March. In grass-fields on high hills, nncommon.-St. Thomas (Signal Hill, 1400').

974. Spiranthes elata, Rich.

Fl. March. Leaves deciduous during anthesis. In leaf-mould on high hills, not uncommon.-Virgin Islands.

975. Stenorrhynchus lanceolatus, Rich.

Fl. May. Leaves deciduous during anthesis. Only $\frac{1}{2}^{\prime}-1^{\prime}$ high. In clayey soil among rocks on high hills, rare.-St. Thomas (Signal Hill, Crown).

976. Habenaria maculosa, Lindl.

Fl. Feb. Spur $1^{\prime \prime}$ long, nectariferous. In pastures on high hills, rare.-St. Thomas (Signal Hill).

977. H. alata, Hook.

Fl. Feb. Spur $6^{\prime \prime \prime}$ long, nectariferous. In the same localities as the preceding, rare.-St. Thomas (Signal Hill, above St. Peter, $1400^{\prime}$ ).. 


\section{CRYPTOGAMA VASCULARES.}

\section{LYCOPODIACEAE.}

978. Lycopodium cernuum, L.

Gregarious among rocks on high hills, here and there.-St. Thomas (Crown, Signal Hill).

979. Psilotum triquetrum, Sw.

In shady places among rocks, not uncommon.-St. Croix (Crequis); St. Thomas (Signal Hill).

\section{FILICES.}

980. Ophioglossum reticulatum, L.

In pastures under rocks on high hills, not uncommon.-St. Thomas (Crown).

981. Davallia aculeata, Sw. (v. Prickly Fern).

In pastures on high hills, here and there.-St. Thomas (Signal Hill, above St. Petèr, $\left.1300^{\prime}\right)$.

982. Adiantum villosum, $\mathrm{L}$.

Among rocks in forests, uncommon.-St. Croix (Crequis, Vieques). 983. A. intermedium, Sw.

On high hills, not uncommon.-St. Thomas (Signal Hill).

984. A. microphyllum, Kaulf.

Fragrant in the morning. In dense forests, uncommon.-St. Thomas (Crown).

985. A. tenerum, Sw. (v. Maiden-hair).

In thickets, not uncommon.-All islands.

986. A. fragile, Sw.

In the same localities as the preceding, uncommon.-All islands.

987. Cheilanthes microphylla, Sw.

St. Croix (West, p. 313, Benzon in Hb. Havn.); St. Thomas (Ravn in Hb. Havn.).

988. Pteris longifolia, $\mathrm{L}$.

Along rivulets in forests, rare.-St. Croix (Crequis). 
989. P. pedata, L.

Gregarious in forests, here and there.-St. Thomas (Signal Hill, near St. Peter).

990. Tænitis lanceolata, R. Br.

In leaf-mould on rocks, not uncommon.-All islands.

991. Antrophyum lineatum, Kaulf.

In forests, rare.-St. Thomas (St. Peter).

992. Blechnum occidentale, $\mathrm{L}$.

Gregarious in pastures and forests, very common.-All islands.

993. Chrysodium vulgare, Fée.

In marshy soil, gregarious; up to $15^{\prime}$ high. Not uncommon.-All islands.

994. Hemionitis palmata, L. (v. Strawberry Fern).

Propagating itself by buds from the serratures of the frond. Gregarious in shady forests, here and there.-St. Croix (Eliza's Retreat); St. Jan (Rogiers, King's Hill).

995. Gymnogramme calomelanos, Kanlf. (v. Silvery Fern).

On hills and among stones, not uncommon.-All islands.

Var. pumila, Egg.

Dwarfy, cartilaginous. On old walls, here and there.-St. Croix (Bodkin); St. Thomas (Cowell's Battery).

996. Asplenium serratum, L.

Frond up to $4^{\prime}$ long. On rocks in forests, very rare.-St. Thomas (Signal Hill, 1400').

997. A. firmum, Kze.

St. Thomas (Griseb. Syst. Unters. p. 134) (A. abscissum, W.).

998. A. pumilum, $\mathrm{Sw}$.

On clayey soil in forests, gregarious, here and there.-St. Thomas (Matthis Gut); St. Jan (Rogiers).

999. Aspidium punctulatum, Sw.

In forests, not uncommon.-St. Thomas.

1000. A. semicordatum, Sw.

In shady localities, not uncommon.-Virgin Islands. 
1001. A. patens, Sw.

In forests, here and there.-St. Croix (Crequis); St. Thomas (Crown). 1002. A. molle, Sw.

In the same localities as the preceding, not uncommon.-St. Thomas (Signal Hill).

1003. A. invisum, Sw. a).

In shady localities, rare.-St. Croix (Crequis).

1004. Polypodium tetragonum, Sw.

In forests, not uncommon.-All islands

1005. P. crenatum, Sw.

St. Croix (West, p. 313, Benzon in Hb. Havn.); St. Thomas (Hb. Havn.).

1006. P. aureum, L.

On dead trees and rocks, not uncommon.-All islands.

1007. P. areolatum, Thunb.

In the same places as the preceding, but rare.-St. Thomas (Crown). 1008. P. incisum, $\mathrm{Sw}$.

St. Croix (West, p. 313).

1009. P. incanum, Sw.

Among roots of large trees, gregarious, not uncommon. All islands. 1010. P, piloselloides, L.

In forests and pastures among rocks on high hills, here and there.St. Thomas (Signal Hill, 1300').

1011. P. serpens, Sw.

On trees and rocks on high hills, rare.-St. Croix (top of Mount Eagle, $\left.1150^{\prime}\right)$.

1012. P. Phyllitidis, L. $a$ ) and $\beta$ ) repens.

In forests on rocks and trees, not uncommon.-All islands.

1013. Cyathea arborea, Sw.

Stem $12^{\prime}-15^{\prime}$ high, $3^{\prime \prime}$ diam. In forests on high hills, rare.-St. Thomas (Crown, western slope, 1400'; Caret Bay Gut). 


\section{CORRECTIONS AND ADDITIONS.}

Page 19. Fourteenth line from above, after "local name" read-which as a rule is derived either from the English or the Dutch language, except in Vieques and Culcbra.

Page 84. To Avicennia nitida.-The ground under the tree is sometimes covered with a peculiar kind of aerial roots, proceeding from the underground roots erect into the air to a height of four to six inches.

Page 99. To Aroidec. - A supposed Aroidea with an immense, nearly aphyllous, climbing, terete, green stem, about $100^{\prime}$ long, $1^{\prime \prime}$ diam., with scaly, early deciduous leaves and aerial roots resembling those of Vanilla, is met with in a fow places in St. Thomas (among rocks on Flaghill in the forest). As, however, neither fruit nor flower has as yet been found, it is still doubtful even to which family this interesting species may belong.

Page 100, No. 827. Cancel the lines, "Leaves used for making ropes, thatching roofs, and other domestic purposes."

Add before No. 828:

827. Th. parviflora, Sw. (v. Bull-Seger). Fl. May-July; stem $30^{\prime}-40^{\prime}$ high, up to $3^{\prime}$ in circumference. Berry in both species black, fleshy. Leaves of this species are used for making ropes, hats, roofs, and for other domestic purposes. On the northern slopes of the hills, common.-Virgin Islands.

Add before Commelynacex:

(Cultivated species : Phœnix spinosa, Thonning, and Latania borbonica, L.) 118 


\section{INDEX.}

The names in itakics are those of the cultivated plants of the islands.

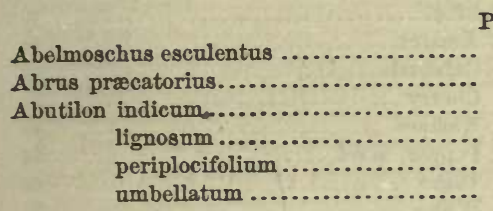

Acacia arabica

Catechu ...........................

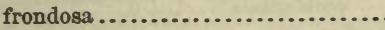

Lebbek..........................

macracantha.....................

nudiflora........................

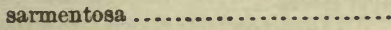
tortuosa

Acalypha chamædrifolia

ACANTHACEEE

A canthospermum hpmilo

Achyranthes aspera......................

Acrodiclidium salicifolium ................

Adansonia digitata ......................

Adenanthera pavonina ....................

Adiantum fragile......................... intermedium ................. microphyllum ................ tenerum $. . . \ldots \ldots \ldots \ldots \ldots \ldots . . . . .$. villosum

Ėgiphila martinicensis.

Eschynomene americana................. Agati grandiflora.

A gave americana........................ sobolifera.

Ageratum conyzoides .

Aleurites Moluccana .....................

ALISMACE $\nexists$..........................

Allamanda cathartica

Alligator Pear.

Alling, white....

Allium fistulosum

Almond, Dog.

Almond-tree............................

Aloe valgaris ...........................

Aloysia citriodora ........................ Alpinia nutans ............................

Alternanthera Achyrantha................. ficoidea ................... polygonoides.

Althoea rosea ............................

Alysicarpns vaginalis ................... AMARANTACEEE.

Amarantus paniculatus

spinosus.

tristis $\ldots . . . \ldots \ldots . . . . . . . .$.

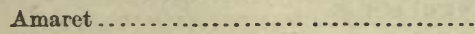

Page. Page.

Amaretsteckel ....................... 48

Amaryllis equestris ................... 109

tubispatha .................. 110

Amblogyne polygonoides................ 87

Ambrosia artemisiæfolia ............... 64

AMENTACEAE...................... 96

Ammannia latifolia.................... 54

AMPELIDE更..................... $\quad 39$

Amyris sylvatica..................... 40

Anacardium occidentale............... 41

Anamomis punctata.................... $\quad 52$

Ananassa sativa...................... 112

Anatherum bicorne .................... 106

Andira inermis...................... 45

Andropogon saccharoides ............... 106

Schoenanthus............... 106

Anethum graveolens ................... 59

Anguria glomerata................... 55

trilobata .................... 35

Anise ............................. 59

Anona laurifolia...................... 23

muricata...................... 23

palustris ....................... 23

reticulata ...................... 23

squamosa ...................... 23

ANONACEAE...................... 23

Anthacanthus jamaicensis................ 81

microphyllus............. 81

spinosus................. 81

Anthephora elegans................... 105

Antherylium Rohrii................... 54

Anthriscus Cerefolium................... $\quad 59$

Anthurium cordifolium ................. 98

Huegelii.................. 98

macrophyllum ............... 98

Antigonon cordatum.................... 88

Antrophyum lineatum................. 116

A pium graveolens ...................... 59

APOCYNACEA...................... 69

Apple, Bell......................... 56

Chigger ....................... 33, 57

Custard ....................... 23

Maid ........................ 55

Monkey ....................... 23

Pine........................... 111

Star ........................ 67

Sugar ......................... 23

A rachis hypogæa...................... 43

ARALIACE $\$$....................... 59

Ardisia coriacea ...................... 67

Argemone mexicana..................... 24

Argyrothamnia candicans............... 91

fasciculata.............. 91

Aristida stricta .................... 101 
trilobata .....................

96

A RISTOLOCHIACEX

$\triangle R O I D E A E$

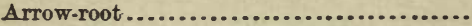

Arthrostylidium capillifolium

Artocarpus incisa

ASCLEPIADACE无.

Asclepias curassavica

$$
\text { nivea }
$$

Ash, Bitter.

ASPARAGINACEXE

Aspidium invisum

molle $\ldots . . . . . . . . . . . . . . . . .$.

patens.........................

punctulatum .................

semicordatum

Asplenium firmum

$$
\text { pumilum }
$$

serratum

Aster chinensis

\section{AURANTIACEE}

Avicennia nitida...

$$
\text { tomentosa }
$$

Ayenia pusilla.

Baas-fram boom

Baccharis Vahlii

Bachelor's Button

Balloon-vine..

Balsam, Garden ........................

Passia.......................

Penguin .

Balsamina hortensis.

BALSAMINACEZE.

Bamboo Cane.

Bambusa vulgaris.

Banana.

Barleria lupulina.

Barrow, Fallen

Bastard Guava

$$
\text { Mahogany }
$$

Bastardia viscosa.

Batta-batta

Banhinia tomentosa

$$
\text { ungula . }
$$

Bay-flower

$$
\text { Grass. }
$$

Leaf

Sallie

Vine

$$
\text { Rat. }
$$

White

Beet

Begonia humilis

BEGONIACEZE

Beloperone nemorosa

Benye.

Beta vulgaris.

Beurreria succulenta.

Bidens bipiunatus.

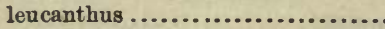

Bignonia æquinoctialis

$$
\text { unguis. }
$$

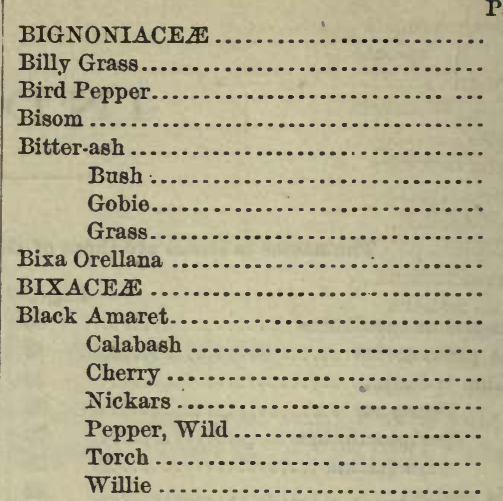

Page.

79

102

76

107

38

69

55

105

25

25

48

79

52

46

84

60

25

Black-eye Pea......................... 50

Blechnum Brownei..................... 80

occidentale................. 116

Blister-leaf ............................ 85

Blood-root......................... 111

Blue Vine ......................... 44

Boerhaavia erecta ....................... 87

paniculata.................. 87

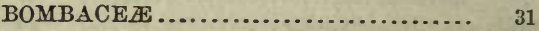

Bonny Vis........................... 44

Bontia daphnoides..................... 84

BORAGINACEAE.................. 74

Borreria parviflora ..................... 62

stricta ....................... 62

verticillata.................... 62

Borrichia arborescens ................. 65

Bouchea Ehrenbergii.................. 83

Bougainvillea spectabilis................. $\quad 87$

Boussingaultia baselloides............... 86

Bouteloua litigiosa ................... 102

Bower............................. 87

Boxwood ............................ 90

Brachyrhamphus intybaceus............ 66

Bran Nettle .........................

Brassavola cucullata .................... 113

Brassica oleracea...................... 24

Breadfruit-tree........................ 94

Break-bill ........................... 68

Brisselet .............................. 34

Bromelia Pinguin ................... 111

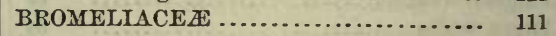

Broom, white-head........................ 64

Broom-wood........................... 32

Brunfelsia americana................... 75

Bryophyllum calycinum................ 58

Bucida Buceras ....................... 54

Bull-suckers......................... 58

$\nabla$ is................................ 35

Bully Wood ......................... 68

Bumelia cuneata ..................... 68

Bunchosia Swartziana.................. 34

Bunya............................. 23

Bur-bush.......................... 32

Burning Love........................ 62

Burr Grass......................... 105

Bursera gummifera ................... 40

BUTTNERIACEAL.................. 32

Button-woor ......................... 54

Buxus Vahlii...................... 90 
Byrsonima lucida. spicata.

Cabbage. Mountain

Cabrite.

Cacalia coccinea.

Cacos.

CACTACEE

Cæsalpinia pulcherrima

Cajanus indicus

Cakile æqualis

Calabash, Black

Calabash-tree.

Caladium bicolor

$$
\text { pictum. }
$$

picturatum

smaragdinum

Calalu, Jackass.

Calliandra portoricensis purpurea.

$$
\text { Saman... }
$$

Callicarpa reticulata.

Callisia repens

$$
\text { umbellulata }
$$

Calophyllum Calaba

Calotropis procera

Calyptranthes Chytraculia

$$
\text { pallens ..... }
$$

Thomasiana

Canavalia gladiata obtusifolia. parviflora

Candlestick, Golden.

Cane, Bamboo

$$
\text { Dumb }
$$$$
\text { Sugar }
$$

Canella alba.

\section{CANELlaCE}

Canker-berry

Canna edulis

$$
\text { indica... }
$$

Lamberti

Cape Jessamine.

CAPPARIDACE正.

Capparis amrgdalina. cyno allophora

frondosa.

jamaicensis...................... verrucosa

Capraria biflora .....

\section{CAPRIFOLIACEAE}

Capsicum annuum. baccatum .

dulce .....

frutescen

Cardiospermum Halicacabum

microcarpum ..............

Carica Papaya............................

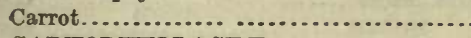

\section{CARYOPHYLLACEX}

Casearia parvifolia

$$
\text { ramiflora. }
$$

sylvestris

Cashá

Cashew

Casparea
Cassava Page.

Cassia alata ........................ 47

angustisiliqua.................... 47

bacillaris........................ 47

bicapsularis .................... 47

biflora

Fistula ...................... 46

florida......................... 47

glandulosa .................... 47

grandis........................ 46

nicticans ...................... 47

obtusifolia....................... 47

occidentalis ..................... 47

Cassyta americana....................... $\quad 89$

Castela erecta ........................... 38

Castor-oil tree.......................... 92

Casnarina equisetifolia................... 96

Cat-claw .............................. 79

Catalpa longisiliqua .................... $\quad 79$

Catch-and-keep....................... 48

Catesbæa parviflora ...................... $\quad 59$

Catopsis nutans ........................ 111

Cattún ............................. 70

Cecropia peltata.......................... 94

Cedar .............................. $\quad 79$

CELASTRACEA...................... 39

Celery................................ $\quad 59$

Celosia argentea........................ 86 nitida ......................... 86

Celtis aculeata ......................... 94 trinervia......................... 94

Cenchrus echinatus ..................... 105

Centipee-root.......................... 37

Centrosema virginianum ............... 44

Cephalandra indica..................... 55

Cerens, Night-blooming ................. $\quad 57$

Cereus armatus ...................... 57

floccosus....................... 57

grandiflorus ...................... 57

monoclonos ....................... 58

peruvianus ...................... 58

Phyllanthus :.................. 58

repandus ....................... 58

triangularis..................... 57

Cestrum diurnum ..................... $\quad 78$

laurifolium.................... 78

nocturnum................... 78

Chamissoa altissima................... 86

Changeable Hibiscus..................... 31

Cheilanthes microphylla.................. $\quad 115$

CHENUPODIACEA................. 85

Chenopodium ambrosioides............... 85

murale................... 85

Cherry .............................. 34, 41

Black......................... 52

Christmas ....................... 52

Surinam $\ldots \ldots \ldots \ldots \ldots \ldots \ldots \ldots \ldots . . . \ldots \ldots$

Wild............................ 34

Chervil............................... 59

Chevalliera lingulata................... 111

Chichery Grape........................ 75

Chigger-apple......................... 33, 57

Chinese Rose........................ 31

Chiococca racemosa ..................... 61

Chione glabra .......................... 61

Chloris ciliata........................ 102 
Page.

Chloris eleusinoides.................... 102 radiata........................ 102

Choco .................................

Christmas-bush

Cherry

Pride.........................

CHRYSOBALANACEES

Chrysobalanus Icaco

Chrysodium vulgare.....................

Chrysogonum dichotomnm...............

Chrysophyllum Cainito................... glabrum ................. microphyllum oliviforme................. panciflorum ................

Chuc-chuc.............................

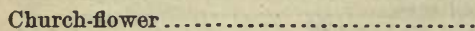

Ciboule ................................

Cinnamomum zeilanicum.................

Cinnamon-bush

Cipura plicata.

Cissampelos Pareira

Cissus acida

sicyoides

trifoliata.

Citharexylum cinereum quadrangulare villosum

Citron

Citrullus vulgaris.

Citrus Aurantium.

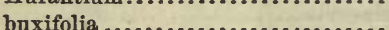

decumana ......................... medica ...

Clashi-mulat

Cleome pentaphylla pungens viscosa

Clerodendron aculeatum fragrans

Clidemia hirta.

rubra .......................... spicata.

Clitoria Ternatea

Clusia alba

rosea.

Coccoloba diversifolia

Klotzschiana

Kunthiana

laurifolia.

leoganensis

nivea

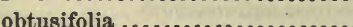

punctata

rugosa

nvifera

Cocculus domingensis

Cocks .

Cocoannut tree

Cocoa-plum

Tree

Cocos nncifera

Codiceum variegatum .....................

Coffea arabica

Coffee-tree.

Coix Lacryma.

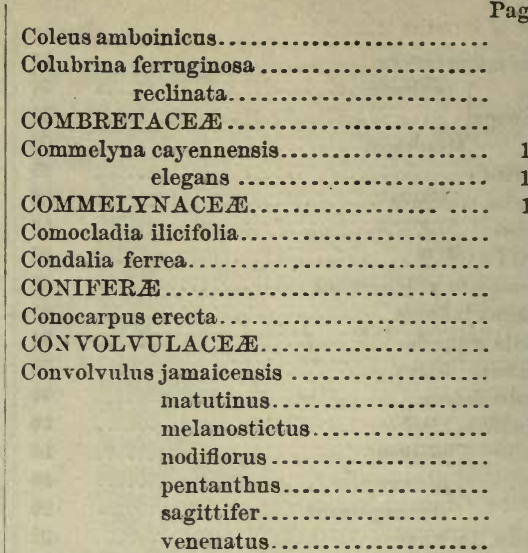

Page.

81

40

40

54

100

101

100

41

40

97

54

70

73

Cookia punctata......................... 37

Coquelicot............................ 48

Coral-bush ........................... 92

Corchorus acutangulus.................. 32

hirsutus.................. 33

hirtus..................... 33

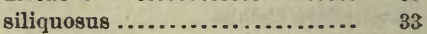

Cordia, Scarlet ...................... 74

Cordia alba .......................... 74

Collococca....................... 74

cylindristachya................. 74

Gerascanthus .................. 74

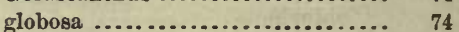

lævigata....................... 74

martinicensis................... 74

nitida ......................... 74

Sebestena ...................... 74

sulcata...................... 74

ulmifolia ....................... 74

Corn, Guinea....................... 106

Indian ......................... 106

Cosmos candatus........................ 65

Cotton-tree.......................... 31

Couroupita guianensis.................. 58

Coursetia arborea .................... 42

Cow-itch ............................ 45

Crab-prickle......................... 49

Cracca caribiea........................ 42

Crane's Neck............................ 96

CRASSULACEE..................... 58

Cremanium amygdalinum ................ 53

Creole Chinine........................ 90

Crescentia cucurbitina ................. 79

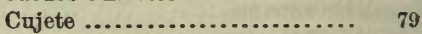

Cress ............................... 24

Crinum erubescens.................. 109

giganteum ...................... 110

Cromberry ......................... 51

Crossandra infundibuliformis............ 81

Crotalaria incana....................... 41

latifolia.................. 41

retusa..................... 41

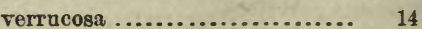

Croton astroites ...................... 90

betulinus ....................... 91

discolor......................... 91

flavens...................... 91 
Croton humilis .

Page.

lobatus

ovalifolius

Crotonea

CRUCIFER $\mathbb{E}$

Cucumber

\section{Mutton}

Cucumis Anguria selo...

Cucurbita Pepo .......................... CUCURBITACEZ

Cupania fulva..

Cuppar.

Curcuma longa

Cuscuta amerieana

Custard-apple.

Cntting Grass

Cyathea arborea.

CYCADACEA

Cycas revoluta.

Cymodocea manatorum...................

Cynodon Dactylon.

CYPERACE

Cyperus articulatus

$$
\text { brunneas ...................... }
$$$$
\text { compressus. }
$$

confertus........................

distans .........................

filiformis .

flavomariscus .....................

lævigatus .

ligularis.

ochracens .......................

odoratns.........................

pennatus........................

polystachyns..

rotundas ........................

sphacelatus ......................

surinamensis....................

unifolius .......................

viscosus........................

Cypress

Cyprian

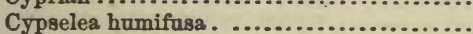

Dactyloctenium ægyptiacum ..............

Dalechampia scandens.

Daphnopsis caribæa .

Datura fastuosa

\section{Metel}

Stramonium

suaveolens

Tatula

Daucus Oarota...

Davallia aculeata.........................

Davilla rugosa ..

Desmanthus depressus..................... virgatus .

Desmodinm incanum. (n....................

Scorpiarus

spirale

triflorum .

Dianthera pectoralis.

sessilis.
Page.

Dieffenbachia Seguine.................. 98

Digitaria filiformis ...................... 103

marginata.................. 103

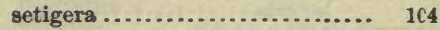

Dildo............................... $\quad 57$

Dill ................................. 59

DILLENIACE $\mathbb{E}$.................... 23

Diodia rigida......................... 62

sarmentosa..................... 62

Dioscorea alata ...................... 110

altissima..................... 110

pilosinscula................... 110

DIOSCOREACEZE.................... 110

Dipbolis salicifolia ..................... 68

Diplochita serrulata................... 53

Distictis lactiflora ....................... $\quad 79$

Distreptus spicatus..................... 63

Divi-divi ........................... 46

Dodonæa viscosa ..................... $\quad 36$

Dog Almond ......................... 45

Dogwood ............................ 45

Dolichos Lablab....................... 44 sesquipedalis ................... $\quad 50$

sphoerospermus................ 50

Drepanocarpas lunatus................. 45

Drymaria cordata..................... $\quad 27$

Drypetes glanca....................... 90

lævigata..................... 90

Duck-weed ............................. 95

Dudeldu................................ 46

Dumb Cane .......................... 98

Duranta Plumieri ..................... 84

East India Thyme.................... 81

EBENACE正 ......................... 68

Echinodorus cordifolius ................. 97

Echites agglatinata.................... 69 barbata....................... 70

circinalis ......................... 69

neriandra ..................... 69

suberecta $. . . \ldots \ldots \ldots \ldots \ldots \ldots \ldots . .6 \%$

Eclipta alba ........................... 64

Edden-wood........................... 40

Egg-plant .......................... $\quad 78$

Egletes domingensis................... 66

Elæodendron xylocarpum ............... $\quad 39$

Elephantopus mollis.................... 63

Eleusine indica....................... 102

Emilia sagittata....................... 66 sonchifolia $. . . \ldots \ldots \ldots \ldots \ldots \ldots \ldots . .66$

English Plantain ...................... 85

Epidendrum bifidum.................... 113

ciliare..................... 113

cochleatum.................. 113

patens.................... 113

subæquale................... 113

Eragrostis ciliaris ....................... 101

poæoides ..................... 101

Erechthites hieracifolia ................. 66

Erigeron canadensis..................... 64

cuneifolius................... 63

spathulatus.................... 63

Eriochloa punctata ...................... 104

Eriodendron anfractuosum .............. 31

Erithalis fruticosa...................... 61

odorifera...................... 61 
Ernodea litoralis

Page.

Eryngium fotidum .....................

Erythrina Corallodendron ................

horrida ......................

\section{ERYTHROXYLACEZE.}

Erythroxylum areolatum.

brevipes..................

ovatum .

Eugenia acetosans.

$$
\text { axillaris ........................ }
$$

buxifolia

flavovirens

floribunda.....................

glabrata.

lateriflora

ligustrina .....................

marginata

micrantha

monticola.

pallens

Poiretii.

portoricensis

procera.

pseudopsidium

sessiliflora.

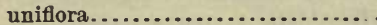

virgultosa .....................

Eupatorium atriplicifolium...............

Ayapana ...................

canescens .....................

cuneifolium .................

odoratum....................

repandum ...................

Euphorbia antiquorum ....................

articulata ......................

buxifolia ......................

cotinifolia .....................

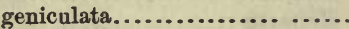

heterophylla ..................

hypericifolia .

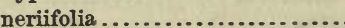

petiolaris......................

pilulifera......................

prostrata.....................

pulcherrima...................

splendens .

thymifolia.

EUPHORBIACE 2

Enxolus caudatus

oleraceus

Evolvalus linifolius .

$$
\text { mucronatus }
$$

nummularius.

Excœcaria Lanrocerasus...................

Exostemma caribaum.

Eye-bright

Fairy Ivy

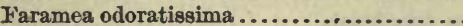

Fatten Barrow

Female Karatá ..........................

Fennel ................................

Fern, Prickly ........................

Silvery

Strawberry.

Ficus Carica.
Page.

Ficus crassinervia..................... 94

elastica.......................... 95

lævigata........................ 94

lentiginosa...................... 94

pednnculata.................... 94

populnea........................ 94

trigonata....................... 94

Fiddlewood........................... 83

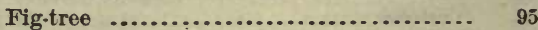

FILICES .......................... 115

Fire-weed ........................... $\quad 76$

Fischeria scandens .................... $\quad 70$

Flamboyant .......................40,45, 46

Flat Grass........................... 103

Fleïti............................. 47

Fleurya æstuans ..................... 95

Fluyte boom......................... 74

Foniculum vulgare..................... 59

Forbidden Fruit ..................... 36

Forestiera porulosa.................... 68

Fourcroya cubensis ................... 109

Four-o'clock....................... 87

Franchipani......................... 69

French Grass.........................100, 101

Physic-nut ................... 92

Prickly Pear..................... 58

Tea.......................... 81

Fustic............................ 42,95

Galactia fliformis .................... 44

tenuiflora ..................... 44

Galphimia glauca.................... 34

Garden Balsam....................... $\quad 80$

Genipa americana .................... $\quad 59$

Geophila reniformis ................... 62

Georgina variabilis ................... 67

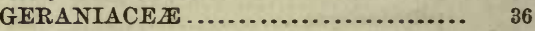

Geranium .......................... 36

GESNERIACE $\mathbb{E} \ldots \ldots \ldots \ldots \ldots \ldots \ldots \ldots . \ldots \ldots$

Giant Thibet-tree .................... $\quad 49$

Ginger .......................... 112

Gninea ...................... 99

Stone........................ 96

Groat-weed......................... 78

Gobie .............................. 55

Golden Candlestick.................... 47

Gomphrena globosa .................... 86

Gongora-hout ....................... 90

Gonzalea spicata ..................... 60

GOODENOVIACEAE ................. 67

Gooseberry............................ 90

Surinam .................. 58

Gossypium barbadense................. 31

vitifolium .................. 31

Gonania domingensis................. $\quad 40$

GRAMINACE $\ldots$.................... 101

Granni Vine......................... 71

Grape, Chichery..................... 75 Sea.......................... 88

Graptophyllum hortense................. 81

Grass, Bay ....................... 102 Billy ....................... 102

Bitter ......................... 105

Burr ......................... 105

Cutting ....................... 109

Flat.......................... 103

French.................... 100, 101 
Grass, Guinea....................... 105

Hair......................... 101

Horse ......................... 104

Jolly ......................... 106

Lemon ......................... 106

Long ........................... 105

Nut.......................... 107

Razor ......................... 109

Running ....................... 103

St. Jan ........................ 111

Sour ............................104, 105

Spanish ....................... 104

Ten-per-cent ................... 102

Green Pea.

Gregery

Grenadilla.

Grej Nickars

Gritchee

Ground-nuts

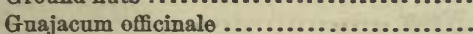

Guama

Grana-tail

Guarea trichilioides .......................

Guara.

Bastard

Sperry .

Guava-berry.

Guatteria Ouregou

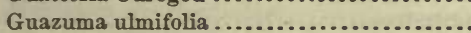

Guettarda parvifolia .................... scabra..

Guilandina Bonduc.

Bonducella .................... melanosperma

Guinea Corn. .

Ginger.

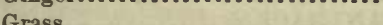
Tamarind.

Gully-root .

GUTTIFERE.

Gymnogramme calomelanos

Habenaria alata. maculosa.

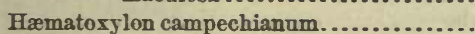

Hagbush ...............................

Hair-grass

Halodule Wrightii.......................

Halophila Baillonii ........................

Hamelia lutea.. patens ..........................

Hebeclinium macrophyllum................

Hecastophyllum Brownei..................

Hedwigia balsamifera ...................

Helianthus annuus........................

Helicteres jamaicensis.....................

Heliotrope..............................

Heliotropium curassavicum .............. fruticosum ................. indicum .................... parriflortum ................. peruvianum ..................

Hemionitis palmata.

Herpestis chamædryoides .................. Monniera . ...................... stricta .......................

Heteropteris parvifolia.
Heteropteris purpurea ...................

Page.

Hibiscus, Changeable ................... 31

Hibiscus brasiliensis.................... 31

clypeatus .................... 30

mutabilis....................... 31

phœniceus ..................... 31

Rosa-sinensis.................. 31

Sabdariffa..................... 31

vitifolius.................... 30

Hippomane Mancinella................ 9:

Hog.plum ............................ 40

Hollow-stock....................... 28, 82

Hollyhock........................... 31

Holmskjoldia sanguinea.................. 84

Hon Kloot............................ 45

Honey-suckle...................... 59

Hops, wild ......................... 82

Horse-bean.......................... 46

Grass.......................... 104

Horse-radish-tree..................... 25 .

Hoya carnosa ........................ 70

Hufelandia pendula ................... 89

Hura crepitans......................... 92

HYDROCHARUDACEEE .............. 97

HYDROLEACEEE.................... 73

Hymenæa Courbaril...................... 47

Hyptis capitata....................... 82 pectinata....................... 82

suaveolens ...................... 82

verticillata.................... 82

Ibatia muricata ......................... 70

Indian Corn............................ 106

Kalo.......................... 99

Shot.......................... 112

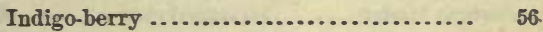

Indigofera Anil ...................... 42 tinctoria ..................... 42

Inga laurina.......................... 50

Ionidium strictum..................... 26

Ipecacuana........................... 70

Ipomcea acuminata...................... 72

arenaria...................... 72

asarifolia...................... 72

Batatas ......................... 71

Bona-nox..................... 70

carnea ......................... 71

coccinea...................... 72

dissecta..................... 71

fastigiata..................... 71

filiformis ..................... 72

Horsfalliø ................... 73

Learii......................... 73

leucantha ..................... 71

Nil........................ 72

pentaphylla ................... 71

pes-capræ..................... 71

purpurea...................... 72

Quamoclit ...................... $\tau_{2}$

quinquefolia................... 71

quinquepartita................. 72

repanda......................... $\quad \tau 2$

tiliacea ....................... 72

triloba ........................ 71

triquetra ..................... $\pi_{2}$

Tuba........................ 70

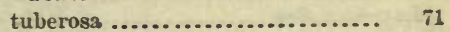




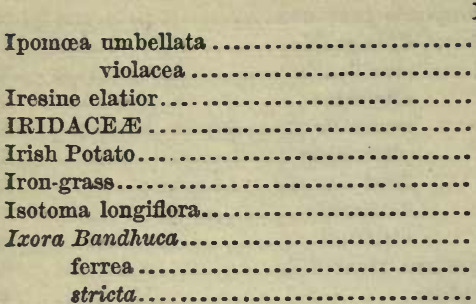

Jackass Calalu

Jacquemontia tamnifolia

Jacquinia armillaris

Jamaica Plum

Jambosa malaccensis. vulgaris

JASMINACE

Jasminum officinale pubescens revolutum

Jatropha Curcas ...... multifida. pandurafolia.

Jcssamine, Cape.

$$
\text { Double. }
$$

Nepaul

Star.

Job's Tears

Jolly Grass

Jumbee-bead.

Juniper

Jussiena suffruticosa.

Justicia bicolor

carthagenensis .................... periplocæfolia reflexiflora

Kakkerlakka-berry

Kale, Indian

Karatá.

Klang hout

Kosteletzkya pentasperma

Krameria Ixina. .........................

Kyllinga brevifolia filiformis monocephala triceps.

\section{LABLAT}

Lactuca sativa

Ladybus

Lady-finger-tree.

$$
\text { -slippers }
$$

Lagenaria vulgaris

Lagerströmia indica

Laguncularia racemosa....................

Lambrali

Lantana Camara.

involucrata.

polyacantha reticulata.

Lappago aliena.

Latania borbonica

IAURACEA

Lavender, Sea

Lawosonia inermis
Page.
Lebidibia coriaria ................... Page.

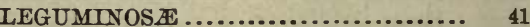

Lemna minor......................... $\quad 99$

Lemon Grass........................... 106

Lemon-scented Verbena............... 84

Leonotis nepetæfolia .................... $\quad 82$

Leonurus sibiricns ................... 82

Lepidium sativum ? ..................... 24 virginicum.................. 24

Leptochloa mucronata.................... 102 virgata................... 102

Leria nutans .......................... $\quad 66$

Leucæna glauca ........................ 48

Leucas martinicensis................... $\quad 82$

Lignum.vitæ ....................... 37

Lilac .................................. 36

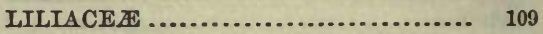

Lily, Red.......................... 109

Water............................ 24

White........................... 109

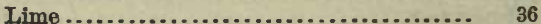

Sweet........................... 37

Linguan-tree........................ 25

Linociera compacta ................... 68

Liparis elata .......................... 112

Ilppia nodiflora ...................... 83

Liquorice, Wild ...................... 43

Liqnorice-tree......................... 46

LOBELIACE $A$........................ 67

Loblolly ........................... 87

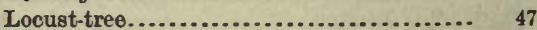

Logwood ........................... 46

Long Grass........................... 105

Longlo ............................ $\quad 37$

Lonicera Caprifolium .................. 59 LORANTHACE $\$$..................... 59

Loranthus emarginatus ................. 59

Lourea vespertilionis.................. 42

Love-in-the-mist...................... 57

Love-weed .......................... 73

Lucuma multiflora .................... 68

Luffa cylindrica..................... $\quad 55$

Lumbo .............................. 87

Lumbush........................... 7

Lycopersicum cerasiforme.............. 77

esculentum............... 77

LYCOPODIACE正 ................... 115

Lycopodium cernuum .................. 115

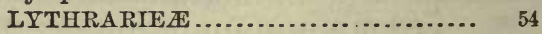

Mabec-bark ........................ 40

Maccreightia caribæa .................. 68

Maclura tinctoria........................ 95

Madeira Plant........................ 79

Mahoe..............................30, 31, 32

Mahogany........................... $\quad 36$

bastard.................... 45

Maid-apple.......................... 55

Maiden-hair.......................... 115

Malachra capitata.................... $\quad 30$ urens....................... 30

Malpighia angustifolia ................... 35 Cnida..................... 35 glabra...................... 34 urens....................... 34

MALPIGHIACE 2 ..................... 34

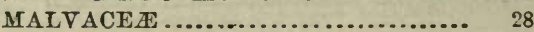


Malrastrum spicatum................... tricuspidatum............... 28

Mamey. Wild.

Manillaria nivosa

Mammea americana

Mampoo.

Manchineel

Manchineel-tree.

Mangelboom

Mangifera indica

Mango-tree.

Mangrore..

White........................

Manihot utilissima

Manjack

Marán.

Swart.

White ............................

Mararka arundinacea.....................

Maroon Jancole ...........................

Marsh-mallow.

Martynia diandra.

Mastúmbee.

$$
\text { Wild.. }
$$

Mastic ...............................

Maurandia Barclayana

Maytenns elæodendroides.

lævigatus

Melampodium divaricatum.

Melanthera deltoidea.

MELASTOMACEAE

Melia sempervirens.

MELIACEE.

Melicocca bijuga

Melocactus atrosanguineus.

communis

Melochria nodiflora.

$$
\text { pyramidata. }
$$

tomentosa

tomentosa .......................

(n) pervaga.......................

MENISPERMACEAE.

Mentha aquatica

Mespel

Metastelma parviflorum

Mexican Wreath-plant

Miconia angustifolia

argyrophylla.

impetiolaris.

lævigata .

prasina.

Microtea debilis

Mignonette.

Mikania gonoclada

Milk-bush.

Milk-tree.

Mimosa asperata

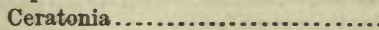

pudica.

Mint

Mirabilis Jalapa.

MOLLUGINE互.

Mollugo nudicaulis

verticillata.

Momordica Charantia
Monkey-apple.......................... ${ }_{23}$

Monkey's Hand ......................... 96

Morinda citrifolia ...................... 61

Moringa pterygosperma.................. 25

Morisonia americana................... 25

Morning-glory....................... 72

Mountain Cabbage...................... $\quad 100$

Mouriria domingensis.................... 53

Mucuna pruriens....................... 45

Mule-weed .............................. 64

Murraya exotica....................... 37

Musa paradisiaca........................ $\quad 112$

sapientium ........................ 112

MUSACEA.......................... 112

Muscat, nut .......................... 39

Muskmelon ........................... 56

Mustard, Wild ........................ 24

Mutton-cucumber...................... 56

Myginda latifolia...................... $\quad 39$ pallens ........................ 39

MYOPORACEA....................... 84

Myrcia coriacea ......................... $\quad 50$

Myrodia turbinata..................... $\quad 31$

Myrospermum frutescens ............... 46

MYRSLNACEA..................... 67

MYRTACEE ......................... 50

Myrtle.............................. 53

Rock......................... 52

Myrtus communis .................... 53

Nama jamaicensis..................... 73

Nasturtium officinale................... 24

Nectandra antillana................... $\quad 89$

coriacea.................... 89

membranacea ............... 89

Nepsera aquatica.................... 53

Neptunia pubescens..................... 48

Nerium Oleander ..................... 69

Nettle.............................. 92

Bran ............................ 92

Nickars, Black....................... 46

Grey ...................... 46

Yellow ........................ 46

Nicotiana Tabacum .................... $\quad 76$

Nightblooming Cereus .................... 57

Noyau Vine.......................... 71

Nut, Ground ......................... 43

Nut Grass.......................... 107

Mnscat.......................... 39

Nutmeg.......................... 53

NYCTAGINACEA ................... 87

Nyctanthes Sambac .................... 68

Nymphra ampla...................... 24

NYMPH正ACE正 ................... 24

Obione cristata....................... 85

Ocimum Basilicum ..................... 81

micranthum.................... 81

Ogiera ruderalis....................... 64

Okro ................................ 30

OLACACE $\mathbb{Z E}$............................ 38

Old Man's Beard......................... 111

Oldenlandia callitrichioides ............... 60

corymbosa ................ 60

OLEACE

Olyra latifolia....................... 101

ONAGRAACEE ...................... 54

Oncidium Lemonianum.................. 114 
Opuntia catocantha .....................

coccinellifera ....................

curassavica......................

horrida ........................

spinosissima.....................

tuberculata.....................

Tuna ..........................

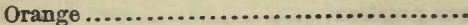

Seville.

\section{ORCHUDACEX}

Oreodaphne leucoxylon.

Oreodoxa regia

Origanum Majorana......................

Orthopogon setarius.......................

Otaheite-tree

Overlook

Orra bla.

OXALIDACEA

Oxalis corniculata.

Martiana.

Oxandra laurifolia.

Pain-killer

Palicourea Pavetta.

Palm, Sago

PALMAE

Palmér

Panax speciosum

Pancratium caribæum.....................

PANDANACEAE........................

Pandanus odoratissimus....................

Panicum brevifolium......................

brizoides .......................

cayennense.....................

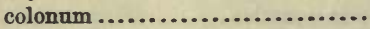

diffusum.......................

divaricatum $. . . . . . \ldots \ldots \ldots . . . . .$.

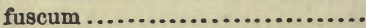

glutinosum ...................

maximum ......................

molle

paspaloides.....................

prostratum.....................

Papa-1olo ..............................

PAPAVERACEEA......................

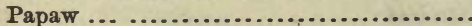

PAPAYACEAE ........................

Pappophorum alopecuroides...............

Paritium tiliacenm.......................

Parkinsonia aculeata......................

\section{PARONYCHLACEA}

Parsley

Parthenium Hysterophorus ...............

Paspalum cæspitosum

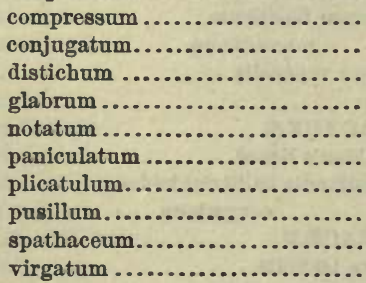

Passia Balsam.
Page.

115

58

58

58

58

58

58

36

36

112

89

100

82

104

31

45

64

37

37

37

23

61

61

97

100

67

59

109

100

100

105

104

105

104

105

105

104

105

105

104

104

104

33

24

56

56

102

31

46

27

59

64

103

103

103

103

103

103

103

103

103

103

103

81
I'acre.

Passiflora fœtida..................... 57

hirsuta..................... 56

incarnata................... 56

laurifolia.................... 50

pallida...................... 56

peltata....................... 56

quadrangularis ................ 56

rubra ....................... 56

suberosa..................... 56

PASSIFLORACE

Pavonia racemosa ....................... $\quad 30$ spinifex ...................... 30

Pea, Black-eye..................... 50

Green .......................... 50

Pigeon....................... 44

Wild ........................... 44

Pear, Alligator....................... 89

French Prickly .................. 58

Priekly ....................... $\quad 58$

Pectis humifusa....................... 66

linifolia ........................ 66

punctata....................... 66

Pedilanthus tithymaloides............... 94

Peireskia aculeata...................... $\quad 58$

Bleo ....................... 58

Pelargonium .......................... $\quad 36$

Penguin Balsain ..................... 80

Peperomia acuminata ................. 96

cubaua...................... 96

glabella.................... 96

obtusifolia .................. 97

pellucida..................... 96

polystachya................. 97

scandens................... 97

Pepper.............................. 76

Bird.......................... 76

Small........................ 76

Sweet ........................ $\quad 76$

Wild Black.................... 84

Persea gratissima .................... 89

Petitia domingensis .................... 84

Petiveria alliacea...................... 85

Petraea volubilis ........................ 84

Petroselinum sativum .................... 59

Petunia nyctaginiflora................... 78

violacea...................... 78

Pharus glaber.......................... 101

Phaseolus alatus ...................... 45

lunatus..................... 44

semierectus................... 45

rulgaris ..................... 44

Philodendron giganteum ................ 99

hederaceum ............... 99

Philoxerus vermiculatus................ $\quad 86$

Phlox Drummondii ..................... $\quad 75$

Phøbe antillana........................ $\quad 89$

montana...................... 89

Phœnix spinosa ....................... 118

Phoradendron flavens .................. 59

Phyllanthus acuminatus ................ 90

distichus.................. 90

falcatus ................... 90

Niruri .................... 90

nobilis .................... 90

Physalis angulata...................... 76

Linkiana ................. 76 
Physalis peruviana

Phrsic-nut

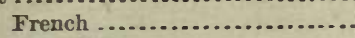

PHYTOLACCACEA:

Picræna excelsa

Pictetia aristata. squamata

Pigeon-pea

Pilea grandis

inæqualis..

(1).....................

nummularifolia.....................

Sanctæ-Crucis.

semidentata

Pilocarpus racemosus ....................

Pimenta acris. vulgaris.

Pimpinella Anisum......................

Pindars

Pine, Screw

Wild

Pine-apple

Pinguin

Pinna koop.

Piper auritum .

\section{Blattarum}

Bredemejeri.

peltatum

Sieberi

\section{PIPTRACE正}

Piscidia Erythrina

Pisonia aculeata. inermis .......................... subcordata .................... 59,87

Pistia occirlentalis....................... 99

Pisum sativum ......................... $\quad 50$

Pitcaimia angustifolia..................

Pithecolobium unguis-cati.................

PLANTAGINACEE.

Plantago major.

Plantain.

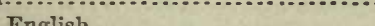

Plate-bush

Plucher odorat

purpurascens .......................

Plum, Cocoa.

$$
\text { Hog..... }
$$

PLUMBAGINACE玉.

Plumbago capensis. scandens

Plumieria alba obtusifolia..................... rubra ...........................

Pockenholt.

Poinciana Gilliesii.

POLEMONIACEE

Police

Polyanthes tuberosa.

Polycala angustifolia.

POLXGALACE王

POLYGONACEE .

Polspodium areolatum

Polspodinm crenatum ...... Page.

incannm ................... 117

incisum................... 117

Phyllitidis.................. 117

piloselloides ................. 117

serpens.................... 117

tetragonum................. 117

Polystachya luteola .................... 113

Pomegranate......................... 53

Pomerose-tree......................... 50

Pop . . ................................ 56

Pope's Head............................ 57

Portlandia grandiflora.................. 60

Portulaca halimoides..................... 28

oleracea ....................... 27

pilosa........................ 28

quadrifida ...................... 27

PORTULACE EE ....................... 27

POTAMEE.......................... 97

Potato, Irish.......................... 78

Sweet ........................ 71

Prapra................................ 41

Prescottia Myosurus.................... 114

Prickle, Crab ........................... 49

White......................... 38

Yellow .......................... 38

Prickle-wood .......................... 54

Prickly Fern .......................... 115

Pear ............................ 58

Priva echinata........................ 83

Psidinm cordatum..................... 52

Guara........................ 52

Psilotum triquetrum ................... 115

Psychotria Brownei ..................... 61

glabrata ..................... 61

horizontalis................. 61

tenuifolia .................... 61

Pteris longifolia......................... $\quad 115$

pedata ........................ 116

Pterocanlon virgatum..................... 64

Pumpkin............................. 50..

Punica granatum....................... 53

Purslane............................ 27

Pyrethrum indicum ...................... 67

Quassia .............................. $\quad 38$

Quassia amara.......................... 38

Queen of Flowers ...................... 54

Quisqualis indica....................... 54

Radish ................................ 24

Rain-tree............................ 75

Rajania hastata ...................... 111 pleioneura ..................... 110

Ramgoat-bush........................ 38

Randia aculeata....................... 60

Raphanus sativus...................... 24

Razor-grass .......................... 109

Rat-bean ............................ 25

Rattle-bush ........................... 41

Rauwolfia Lamarckii....................... 69

Red Beet................................

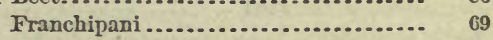

Lily .......................... 109

Sorrel .............................. 31

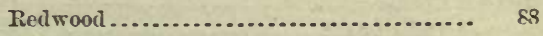

lienealmia sylvestris .................. 112 
Reynosia latifolia........................ mucronata .....................

RHAMNACEEE

Rhizophora Mangle .......................

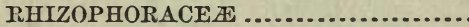

Rhus antillana .........................

Rhynchosia minima ....................... phaseoloides.................. reticulata.

Rhynchospora pura . pusilla

Ricinella pedunculosa

Ricinus communis..

Rivina lævis.

Rochefortia acanthophora

Rock-myrtlo

Roehout

Rondeletia pilosa.

Rosa centifolia gallica ................................

ROSACEAE

Rose, Chinese ..........................

Rosemary -............................

Rosewood

Rosmarinus officinalis ......................

Roucou..................................

Rousselia lappulacea .....................

RUBIACEE.

Ruellia strepens........................ tuberosa

Rumex vesicarius.

Running Grass...

Ruppia rostellata.

Russelia juncea.

RUTACEAE

Sabinea florida

Saccharum officinarum

Sage . .

Sago Palm

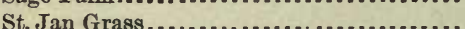

Salad. Wild.

Sallie, Bay. .

Salvia coccinea.......................... occidentalis serotina ............................... tenella .............................

Sambucus nigra.

Samyda glabrata.

Sandbox-tree.

Sander, Yellow.

Santa Maria.

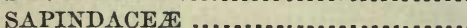

Sapindus inæqualis.......................

Sapota Achras Sideroxylon

SAPOTACE

Sarcostemma Brownei

Savia sessiliflora.

Scævola Plumieri

Scarlet Cordia Indian Shot

Schæffcria frutescens
Page.
Schmidelia occidentalis................... Schœpfia arborescens..................... Scirpus brizoides......................... capitatus ....................... ferrugineus...................... mutatus. subdistichus....

Scleria fliformis ........................ 109 pratensis ........................ 109 scindens....................... 109

Sclerocarpus africanus................... $\quad 65$

Scleropus amarantoides ................. 87

Scolosanthus versicolor................... $\quad 61$ Scoparia dulcis......................... $\quad 78$

Scratch-throat......................... 99

Screw Pine............................. 100 SCROPHULARIACEAE ................ 78

Scrubber .............................. 43

Sea-grape............................ 88

Sea-lavender.......................... $\quad 75$

Sebastiania lucida....................... $\quad 92$

Sechium edule.......................... 56

Secnridaca Brownei ..................... 26

erecta...................... 26

Securinega acidothamnus ............... 90

Sempervivio........................... 109

Serjania lucida ......................... $\quad 35$

Sesamum orientale....................... 81

Sesbania sericea........................ 42

Sesuvium portulacastrum ................. 28

Setaria glauca........................... 105 setosa........................... 105

Seville Orange........................... 36

Shaddock............................... $\quad 36$

Shander............................... 101

Shell-plant ............................ 112

Shot, Indian........................... 112

Scarlet Indian ................... 112

Sida acuminata......................... $\quad 29$

arguta........................... 29

carpinifolia......................... 28

ciliaris ............................. 28

cordifolia......................... 29

glomerata ......................... 28

humilis......................... 29

jamaicensis.......................... 29 nervosa .......................... 29 rhombifolia........................ 29 spinosa............................. 29 supina............................ 29

tristis ............................ 29

Sideroxylon Mastichodendron .............. 68 Silk Cattún.............................. $\quad 70$ Silk-cotton-tree.......................... 31

Silvery Fern ... ....................... 116 Silvi ................................ 40 Sinapis arvensis.......................... 24 brassicata...................... 24

Skitnetchi............................. 92

Small Pepper............................. $\quad 76$

Trovo.......................... 77

SMULACEAE........................... 110

Smilax havanensis......................... 110 populnea....................... 110 
Snake-bush.

Page.

Snake-flower

Snake-root

Snow-drop

Soap seed

Soap-stick.

SOLANACEE.

Solanum aculeatissimum

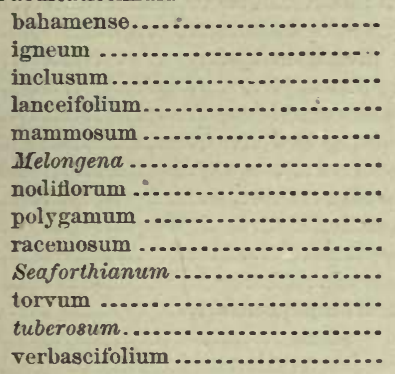

Soldier-wood verbascifolium

Souchus oleraceus.

\section{Sophora tomentosa}

Sorghum vulgare.

Sorrel, Red

Sour Grass

Sour-eyes.

Soursop

Spanish Grass............................

Sparganophorus Vaillantii.

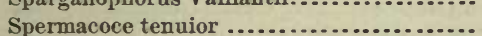

Sperry Guava ......

Spigelia anthelmia

Spiranthes elata. purpurea

Sponia micrantha.

Spoon-tree ............................

Sporobolus indicus litoralis .

virginicus ....................

Squash

Stachytarpha jamaicensis .................

$$
\text { strigosa } . . . . . . . . . . . . . . . . .
$$

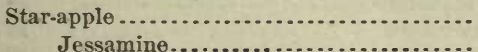

$$
\text { Jessamine }
$$

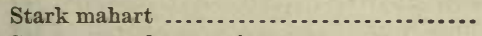

Stemonacanthus coccineus

Stenandrium rupestre ......................

Stenorrhynchus lanceolatus ...............

Stenostomum lucidnm....................

Stenotaphrum americanum..............

Stephanotis floribunda....................

Stigmaphyllon periplocifolium............

Sting Bisom

Stink Cashá ............................

Stink-tree ...............................

Stinking-weed..

Stiverbush .

Stone-ginger..........................

Strainer-vine .............................

Strawberry Fern ........................

Stylosanthes procumbens ................. viscosa

Styver bla........................ Page.

Suckers .............................. 58

Sugar-apple $\ldots . . \ldots \ldots \ldots \ldots \ldots \ldots \ldots \ldots \ldots \ldots . . \ldots 23$

Sugar-cane ........................... 106

Sunflower............................ 67

Suriana maritima...................... 85

Surinam Cherry...................... $\quad 52$

Susakka. Gooseberry $\ldots . . . \ldots \ldots \ldots \ldots \ldots \ldots . . .28$

Susanna.............................. 83

Swart Marán.......................... 29

Sweet Lime ............................ 37

Marjoram Tea.................. 82

Pepper.......................... 76

Potato........................... 71

Scent.......................... 64

William ........................ 72

Swietenia Mahogoni..................... $\quad 36$

Symplocos martinicensis ................ 68

SYNANTHERE $\$$..................... 62

Synedrella noditlora ..................... 66

Tabernoemontana capensis ................. $\quad 70$

Tænitis lanceolata...................... 116

Tagetes patula .......................... 67

Talinum patens ......................... 27

triangulare...................... 27

TAMARICACE E.................... $\quad 26$

Tamarind, Guinea ..................... $\quad 31$

Wild ........................ 48

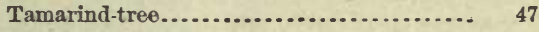

Tamarindus indica ..................... 47

Tamarix indica........................... 26

Tanier ............................. 98, 99

Tea, French ......................... 82

Sweet Marjoram.................. 82

Tecoma Berterii....................... $\quad 79$

capensis ........................ 79

leucoxylon...................... 79

stans .......................... 79

Ten-per-cent Grass....................... 102

Tephrosia cinerea ...................... 42

Teramnus uncinatus .................... 44

TEREBINTHACE $\ldots$................... 40

Terminalia Catappa ................... 54

Ternströmia elliptica................... $\quad 33$

TERNSTRÖMUACEAE................... 33

Tetrazygia elæagnoides ................. 53

Teyer-tree...........................100, 118

Thalassia testudinum .................. 97

Theobroma Cacao ..................... $\quad 32$

Thespesia populnea .................... $\quad 31$

Theretia neriifolia .................... 69

Thibet-tree.......................... 49

Thistle............................... 24

Thrinax argentea ..................... 100

parriflora .................... 118

Thuja ................................ $\quad 07$

Thunbergia alata ....................... 81

fragrans................... 81

volubilis...................... 81

Thyme ............................... 82

East India...................... 81

THYMEL $\mathbb{A E A C E}$...................... 89

Thymus vulgaris....................... 82

Thyrsacanthus nitidus................. 80 
TILIACEAE

Tillandsia fasciculata

recurvata.

usneoides

ntriculata

Tithonia speciosa.

Tobacco, Wild.

Tobacco-pipe ...........................

Tobinia punctata.

spinosa.

Tomato.......

Tournefortia bicolor

fœtidissima ..................

gnaphalodes ..................

hirsutissima.

laurifolia ...................

microphylla

volubilis .

Tout-le-mois...........................

Tradescantia discolor.....................

geniculata..................

zebrina.....................

Tragia volubilis

Trianosperma ficifolium.

graciliflorum...............

Trianthema monogynum..................

Tribulus eistoides...................... maximus ......................

Trichilia hirta.

Tricholæna insularis ...................

Trilix erucis. ...........................

Triphasia trifoliata......................

Triumfetta althæoicles................... Lappula.................... rhomboidea semitriloba

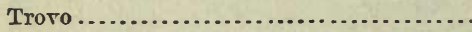
Small .............................

Trumpet-tree...........................

Tshudya berbiceana.....................

Tuberose.

Turkey-berry .........................

Turmeric..............................

Turnera parviflora ..................... ulmifolia ........................

TURNERACE E

Turpentine-tree .........................

Typha angustifolia.....................

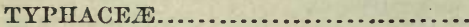

UMBELLIFER $A$......................

Urena lobata ..........................

Urera baccifera

elata.

Urtica elongata..........................

URTICACE互.

Vandellia diffusa

$\nabla$ elvet-leaf

Vendu bountje.

Verbena, Lemon-scented..................

Verbena chamoedrifolia .....................

VERBENACEZE.

Verbesina alata.

Vernonia arborescens ................... punctata

Thomse.
Page.

32
111

111

111

111

67

65

95
37

37

37

77

60

75

75

75

75

75

75

75

112

100

100

100

92

55

55

28

37

37

36

105

25

37

32

32

32

32

77

77

34

53

110

77

112

57

57

57

40

100

100

59

30

95

95

95

94

78

24

44

44
84

84

83

65

62

62

62
Vervain

Vigna luteola........................... 44

Vinca rosea ............................ 69

Vine, Blue............................. 44

VIOLACEAE........................ 26

Vis, Bonny ............................. 44

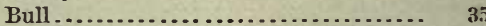

White ........................... 35

Vitcx Agnus-castus ..................... 84

divaricata....................... 84

Vitis caribæa........................ 39

Waltheria americana ................... $\quad 32$

Wandering Jew....................... 100

Water-eress ........................... 24

Water-lily ............................. 24

Watermelon........................... 56

Waterpanna.......................... 42

Wax-flower ........................... 70

Wedelia acapulcensis.................... 65 aftinis .......................... 65 buphthalmoides................. 65 carnosa....................... 65 cruciana........................ 65 discoidea...................... 65

White Alling ......................... 84 -bark............................ $\quad 34$

Bean ............................. 44

Cedar........................... 79

Franchipani..................... 69

Lily .......................... 109

Mangrove..................... 54

Manjack ....................... 74

Marán......................... 90

Police......................... 48

Prickle......................... $\quad 38$

Vis............................. 35

White-head-broom.................... 64

Wild Black Pepper .................... 84

Cherry ......................... 34

Coffee ............................ 61

Hops ......................... 82

Ipecacuana....................... 70

Liquorice......................... 43

Mamey....................... 33

Massámbee...................... 25

Mustard........................ 24

Pea........................... 44

Pine ............................ 111

Salad............................ 66

Tamarind ...................... 48

Tanier ......................... 98

Tobacco........................ 65

Wonderful Leaf ........................ 58

Worm-weed ............................ 60

Wreath-plant.......................... 84

Mexican .................. 88

Xanthium macrocarpum................. 64

Xanthosoma atrovirens.................. 99

hastatum................. 99

sagittæfolium ............... 99

Yam.................................. $\quad 110$

Yellow Cedar........................ $\quad 79$

Nickars ....................... 46

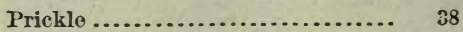

Sander......................... 38

Yerba de Pará.......................... 104 
Yucca gloriosa

Zanthoxylum Clava-Herenlis.

Zingiber officinalis

Zinnia elegans.

flavum....................

macrophyllum ...............

Zea Mays................................. 

Departient of the Dnferior:

U. S. NATIONAL MUSEUM.

$$
-14-
$$

\title{
BULLETIN
}

OF THE

\section{UNITED STATES NATIONAL MUSEUM.}

\author{
No. 14.
}

PUBLISHED UNDER THE DIRECTION OF THE SMITHSONIAN INSTITUTION.

WA SHINGTON: GOVERNMENT PRINTING OFFICE. 1879 . 


\section{ADVERTISEMENT.}

This work is the fourteenth of a series of papers intended to illustrate the collections of Natural History and Ethnology belonging to the United States and constituting the National Museum, of which the Smithsonian Institution was placed in charge by the act of Congress of August 10, 1846.

It has been prepared at the request of the Institution, and printed by authority of the honorable Secretary of the Interior.

SPENCER F. BAIRD, Secretary Smithsonian Institution.

SMITIISONIAN Instritution,

Washington, April 3, 1879.

ii 
INTERNATIONAL EXHIBITION, 1876.

\section{CAT A LOGUE}

OF THE

COLLECTION T0 ILLUSTRATE

THE

\section{Animal Resodrces and the Fisheries}

\section{OF THE \\ UNITED STATES,}

EXHIBITED AT PHWADELPHIA IN 1876 BY THE SMITHSONIAN INSTITUTION AND THE UNITED STATES FISH COMMISSION, AND FORMING A PART OF THE UNITED STATES NATIONAL MUSEUM.

PREPARED UNDER THE DIRECTION OF

G. BROWN GOODE.

WASHINGTON:

GOVERNMENT PRINTING OFFICE. 
- 


\title{
LIST OF PERSONS ENGAGED IN THE PREPARATION OF THE COLLECTION.
}

\author{
JOSEPH HENRY, \\ Secretary Smithsonian Institution. \\ SPENCER F. BAIRD, \\ Director of the Exhibition. \\ G. BROWN GOODE, \\ In charge of Collection.
}

\section{CHAIRMEN OF COMMITTEES.}

Committee on Economical Invertebrates.-William H. DaLL, Washington, D. C. Committee on Fresh and Preserved Fish.-Eugene G. BlackFord, New York. Committee on Fishing Boats and Fittings.-A. R. Crittenden, Middletown, Conn. Committee on Hunting Apparatus and Sportsman's Equipment.-Forest AND STREAM PUBLISHING COMPANY, New York.

Committee on Fishing Nets.-American Net and Twine Company, Boston and New York.

Committee on Anglers' Equipments and Apparatus.-BRADFORD \& ANTHONY, Boston. Committee on Alcoholic Collections, \& c.--Dr. T. H. BEAN, Washington, D. C.

Committee on Furs.-C. A. HerPICH \& Co., New York.

Committee on Fish Culture and its Apparatus.-J. W. Muner, Washington.

Committee on Whaling Apparatus.-E. B. \& F. MACY, New Bedford, Mass.

Committee on Whale and Fish Oils.-Capt. N. E. ATwOoD, Provincetown, Mass.

Committee on Chemical Products.-E. R. SQuiBB, M. D., Brooklyn, N. Y. Artists.-J. H. Richard and A. ZeNo SHINDLER.

Modeler.-Joseph PaLMer.

Taxidermist.-Julius STOERZER.

Photographer.-T. W. SMmLIIE. 



\section{TABLE OF CONTENTS.}

INTRODUCTORY NOTE.

SEction A.-LIST OF ANIMALS OF NORTH AMERICA BENEFICIAL OR INJURIOUS TO MAN.

I. Mammals ............................................ 1

1. Ferre (carnivores) ....................................... 1

Fissipedia (land carnivores) $\ldots \ldots \ldots \ldots \ldots \ldots \ldots \ldots \ldots \ldots \ldots \ldots \ldots \ldots \ldots . \ldots \ldots$

Piunipedia (seals, \&c.) ................................ 5

2. Ungulata (hoofed animals) ..................................

3. Sirenia (sea-cows, \&c.) ................................... 9

4. Cete (whales) ....................................... 10

Denticete (sperm whales and dolphins) ....................... 10

Mysticete (baleen whales) $\ldots . \ldots \ldots \ldots \ldots \ldots \ldots \ldots \ldots \ldots \ldots \ldots \ldots \ldots \ldots \ldots . \ldots \ldots$

5. Insectivora (moles, \&c.) ................................... 13

6. Glires (gnawers) ........................................ 14

7. Marsupialia (marsupiates) ................................ 20

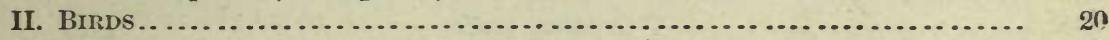

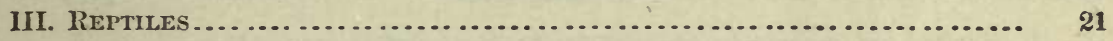

8. Crocodilia (crocodiles) $\ldots . \ldots \ldots \ldots \ldots \ldots \ldots \ldots \ldots \ldots \ldots \ldots \ldots \ldots \ldots \ldots \ldots \ldots . \ldots \ldots$

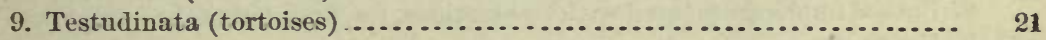

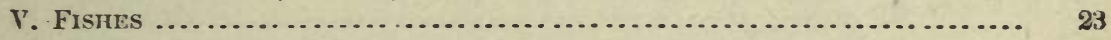

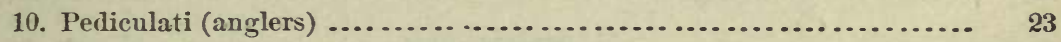

11. Plectognathi (globe, trunk, and file fishes) $\ldots \ldots \ldots \ldots \ldots \ldots \ldots \ldots \ldots \ldots \ldots . . \ldots$

12. Lophobranchii (pipe-fishes, \&c.) ............................ 25

13. Teleocephali........................................... 26

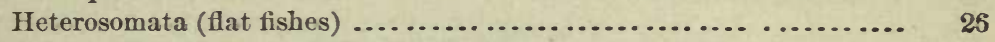

Anacanthini (cods, \&c.) .................................. 28

Acanthopteri (spiny-finned fishes) $\ldots \ldots \ldots \ldots \ldots \ldots \ldots \ldots \ldots \ldots \ldots \ldots \ldots . \ldots \ldots$

Percesoces (mullets, \&c.) ............................... 53

Synentognathi (gar-fishes and flying-fishes) $\ldots \ldots \ldots \ldots \ldots \ldots \ldots \ldots \ldots . \quad 54$

Haplomi (pikes, \&c.) .................................. 55

Isospondyli (salmon, herring, \&c.) ........................ $\quad 56$

Eventognathi (carps) ................................... 61

14. Nematognathi (cat-fishes) $\ldots \ldots \ldots \ldots \ldots \ldots \ldots \ldots \ldots \ldots \ldots \ldots \ldots \ldots \ldots \ldots \ldots . \ldots \ldots$

15. Apodes (eels) .......................................... 63

16. Cycloganoidei (amias) .................................... 63

17. Rhomboganoidei (gar-pikes) $\ldots . \ldots \ldots \ldots \ldots \ldots \ldots \ldots \ldots \ldots \ldots \ldots \ldots \ldots \ldots \ldots .64$

18. Selachostomi (paddle-fish) ................................ 64

19. Chondrostei (sturgeons) .................................... 64

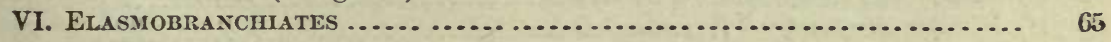

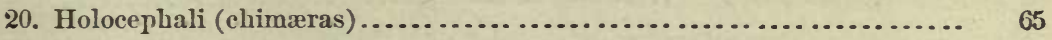

21. Raiz (skates and rays) ..................................... 66

22. Squali (sharks) ....................................... 67 
VII. Marsipobranchiates..................................... 70

23. Hyperoartia (lampreys) .................................. 70

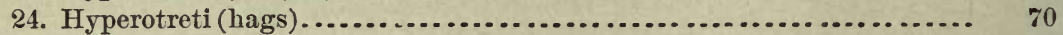

VIII. LEPTOCARDians ........................................... 70

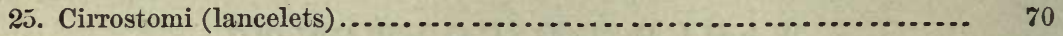

\section{SECTION B.-MEANS OF PURSUIT AND CAPTURE.}

†Apparatus of direct application.

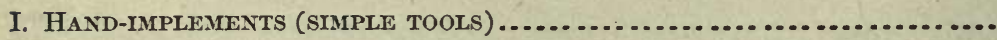

* For striking.

1. Clubs 71

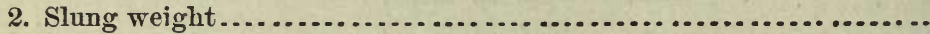

** For cutting.

3. Knives ................................................... 71

4. Axes ................................................. 76

*** For thrusting.

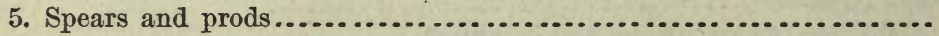

II. IMPLEMENTS FOR SEIZURE OF OBJECT

6. Scoops

* Scooping-instruments.

** Grasping-hooks.

7. Hooked implements (used with single motion, that of hooking)......

8. Barbed implements (used with two motions, the first that of thrusting).

9. Tongs, \&c

*** Grasping-lines.

10. Nooses (lariats and snares) $. . . \ldots \ldots \ldots \ldots \ldots \ldots \ldots \ldots \ldots \ldots . \ldots \ldots$

11. Loaded lines (bolas) $\ldots \ldots \ldots \ldots \ldots \ldots \ldots \ldots \ldots \ldots \ldots \ldots \ldots \ldots \ldots \ldots . \ldots \ldots \ldots$

**** Entangling-lines.

12. Tangles

†t Apparatus of indirect application.

III. Mrssmes

* Simple missiles (those propelled by the unaided arm).

13. Hurled weights..........................................

14. Hurled sticks............................................

15. Hurled spears, lances.

** Centrifugal missiles (propelling power augmented by artificial lengthening of the arm).

16. Slings, and spears thrown by straps .......................... 88

17. Missiles thrown by "throwing-sticks" ........................ 88

*** Missiles propelled by a spring.

† Spring consisting of bent rod.

18. Bows and arrows 
III. Missiles-Continued.

Page.

沛 Spring consisting of elastic cord.

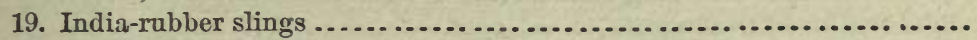

$\ddagger \ddagger$ Spring consisting of metallic helix.

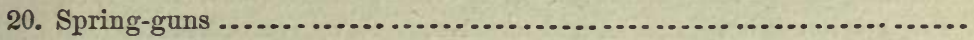

**** Missiles propelled by compressed air or water.

21. Air-guns

22. Water-guns

***** Missiles propelled by combustion of gunpowder.

23. Fire-arns

24. (Accessory.) Ammunition and its preparation......................

25. (Accessory.) Accessories of loading, repairing, and testing fire-arms ..

26. (Accessory.) Accessories for carrying tire-arms. (Accontrements) ....

IV. BaIted HOOKS-ANGLING-TACKLE ...............................

27. Hooks with movable lines. - Hand-tackle .........................

28. Hooks with stationary lines. - Set-tackle ..........................

29. (Accessory.) Parts and accessories to angling-apparatus .............

t+t Apparatus to a greater or less extent automatic.

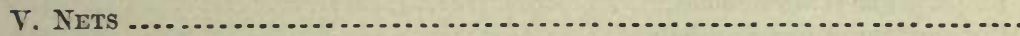

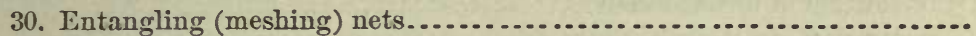

31. Encircling nets ..............................................

\section{$++t+$ Apparatus entirely automatic.}

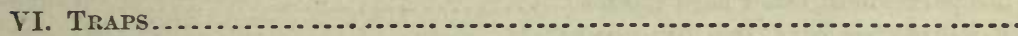

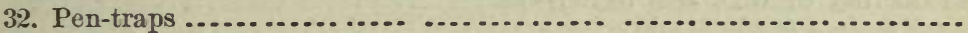

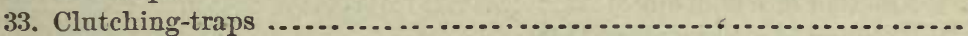

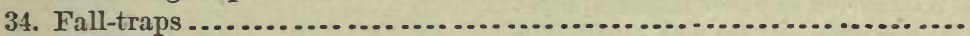

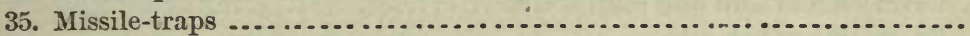

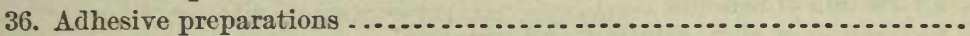

VII. ApPaRATUS FOR WHOLESALE DESTRUCTION.

37. Poisons

38. Asphyxiating apparatus ........................................

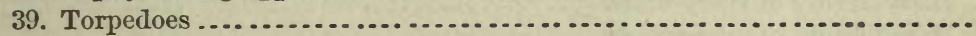

131

134

135

135

135

136

136

136

136

tttt+ Accessories to the chase and fishing.

VIII. HuNting-Avinats

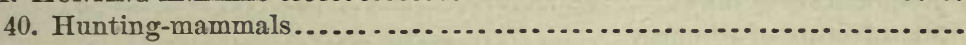

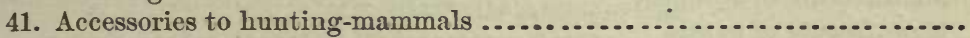

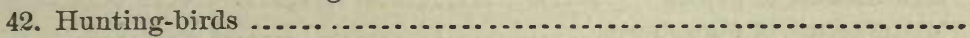

43. Accessories to hunting-birds...................................

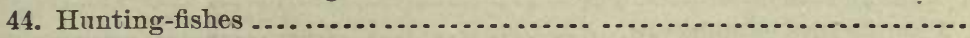

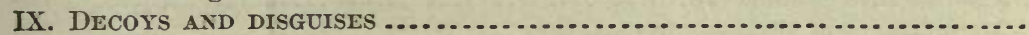

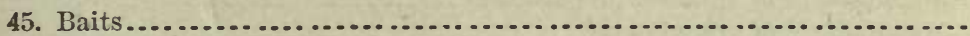

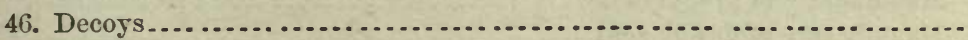

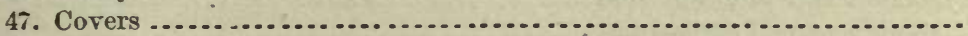

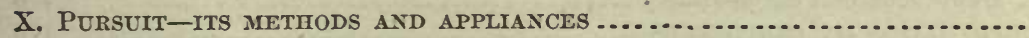

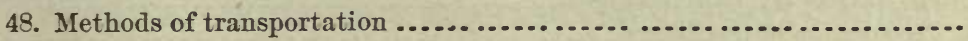

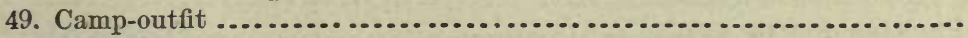

50. Personal equipments. 


\section{SECTION C.-METHODS OF PREPARATION.}

I. Preparation and preservation of foods $\ldots \ldots \ldots \ldots \ldots \ldots \ldots \ldots \ldots \ldots . . \ldots \ldots$

1. Preservation of the living animals (see E, 3) .................. 169

2. Preservation of fresh meats.................................. 169

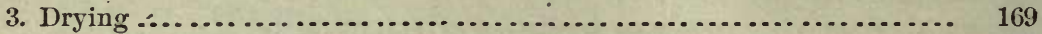

4. Canuing and pickling .................................... 169

5. Preparation of baits ................................... 170

II. Manufacture of textile fabrics, felts, and stuffings .......... 170

6. From hair of mammals ... .............................. 170

7. From whalebone ...................................... 170

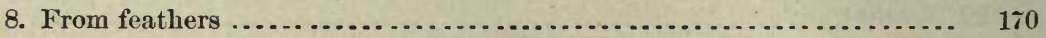

9. From silk of insects.................................... 171

10. From soft parts of other invertebrates ...................... 171

III. Prgparation of the skin and its applendages ................. 171

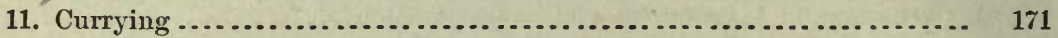

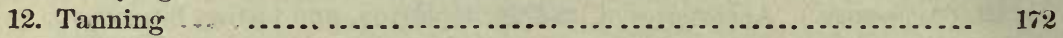

13. Fur-dressing ........................................... 172

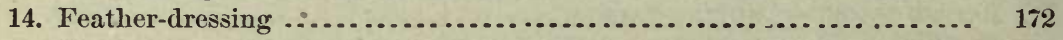

15. Manufacture of quill articles ........................... 172

16. Hair and wool work .................................... 172

IV. Preparation of the hard tissues .......................... 173

17. Ivory eutting and carving ............................. 173

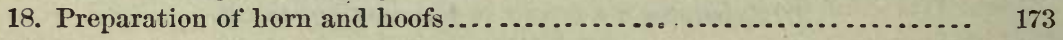

19. Preparation of whalebone................................ 173

20. Preparation of tortoise-shell ............................. 174

21. Preparation of fish-seale work, \&e ........................ 174

22. Preparation of nacre... .................................. 174

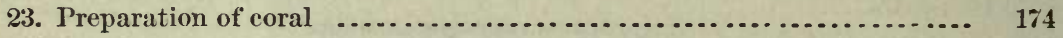

24. Preparation of other hard tissues.......................... 174

V. Preparation of olls and Gelatines ......................... 174

25. Extraction of whale-oils ................................ 174

26. Extraction of other mammal oils .......................... 175

27. Extraction of bird and reptile oils.......................... 175

28. Extraction of fish-oils .................................. 175

29. Extraction of glue, gelatine, and isinglass................... 175

VI. Preparation of drugs, perfumes, and chemical products ........ 175

30. Preparation of perfumes ............................... 175

21. Manufacture of ivory-black .............................. 175

32. Manufacture of prussiates............................... 175

33. Manufacture of murexides ................................ 175

34. Manufacture of cochineal colors ............................ 175

35. Manufacture of inks .................................... 175

36. Manufacture of albumen ............................... 175

37. Manufacture of pepsin ................................... 175

38. Manufacture of phosphorus ............................. 175

39. Manufacture of sal ammoniac ............................. 175

40. Maunfacture of ammonia.................................. 175

41. Manufacture of albumen preparations ........................ 175

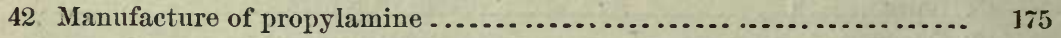

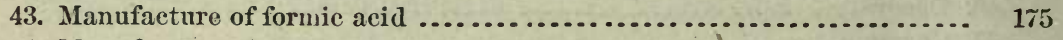

44. Manufacture of carbazotates .............................. 175

VII. Preparation of fertilizers................................ 176

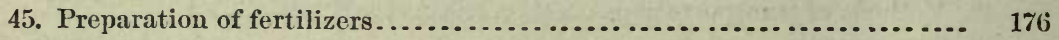

VIII. Preparation of lines.................................. 176

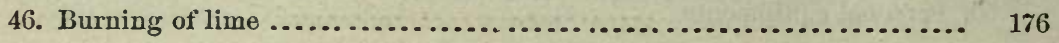


IX. Preservation of the animal for scientific uses.............. 176

47. Preservation of wet preparations ........................... 176

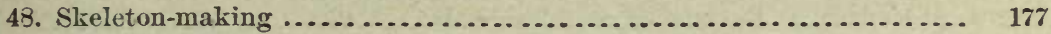

49. Modeling ........................................... 177

50. Taxidermy ......................................... 178

51. (Accessory.) Photographic and other delineating apparatus......... 178

SECTION D.-ANIMAL PRODUCTS AND THEIR APPLICATIONS.

I. Foods

1. Foods in a fresh condition .................................. 179

2. Foods dried and smoked .................................. 182

3. Foods salted, canned, and pickled ............................. 184

4. Gelatiues $($ see 24$) . \ldots \ldots \ldots \ldots \ldots \ldots \ldots \ldots \ldots \ldots \ldots \ldots \ldots \ldots \ldots \ldots \ldots \ldots$

5. Baits and foods for animals ................................ 187

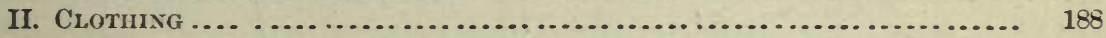

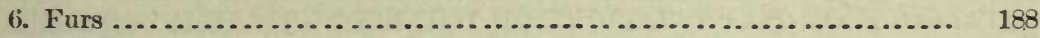

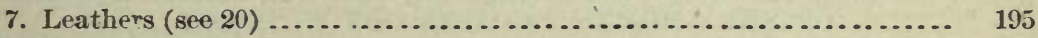

8. Textile fabries ............................................ 195

III. Materlals EMPloyed in THE ARTS AND MANUFaCtures.............. 197

\section{* Hard materials.}

9. Ivory and bone........................................ 197

10. Horn ................................................ 201

11. Hoofs and claws ........................................ 202

12. Baleen ................................................ 203

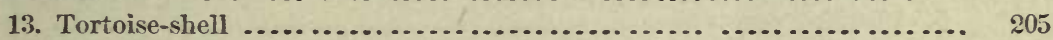

14. Seales.............................................. 205

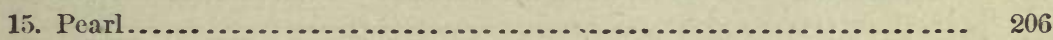

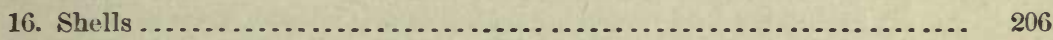

17. Coral ................................................ 207

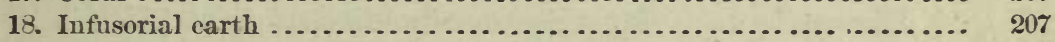

19. Other materials derived from invertebrates...................... 208

** Flexible materials.

20. Leather ................................................ 208

21. Hair and wool (see also 8$)$................................ 217

22. Quills .................................................. 219

23. Feathers ................................................. 219

24. Gelatine and isinglass...................................... 220

25. Flexible materials from insects and mollusks..................... 222

26. Sponges................................................ 223

\section{***Fuids and soft materials.}

27. Oils and fats .........................................

28. Perfumes.............................................

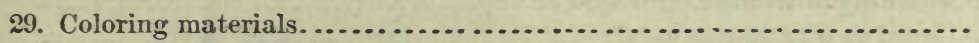

30. Chemical products and agents employed in the arts and medicine......

31. Fertilizers...............................................

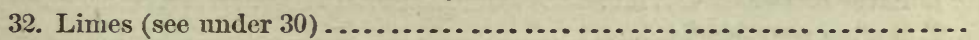

33. Other materials .........................................

SECTION E.-PROTECTION AND CULTURE OF USEFUL ANIMALS.

1. The methods of the United States Fish Commission. 


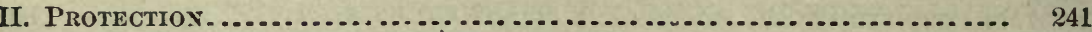

2. Preservation of game and fish ................................ $\quad 241$

4. (Accessory.) Enemies of useful animals.......................... 244

III. Propagation . . . . . . . . . . . . . . . . . . . . . . . . . . . . . . . . . . . . . . . . . . . 244

5. Propagation of mammals ..................................... 244

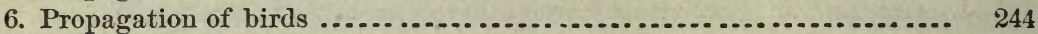

7. Propagation of reptiles ...................................... 245

8. Propagation of amphibians ................................. 245

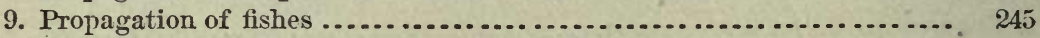

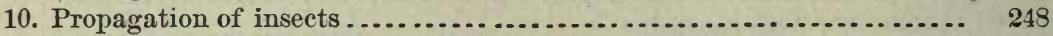

11. Propagation of leeches ........................................... 248

12. Propagation of mollusks.................................... 248

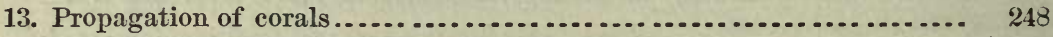

14. Propagation of sponges ....................................... 248

\section{CATALOGUE OF ILLUSTRATIONS OF THE ECONOMICAL INVERTEBRATES} OF THE AMERICAN COASTS. BY W. H. DALL.

Molrusca CEPHalopoda.-Squids and Cuttles........................ 251

Mollusca Gasteropoda.-Sea-Snails, \&c.......................... 251

A. Useful .................................................... 251

1. Used for food or bait..................................... 251

2. Useful by producing pearl-shell, \&c...................... 251

3. Affording eameo and porcelain stock ........................ 252

4. Used in Indian trade ...................................... 252

5. Affording dyestuffs ........................................ 252

6. Affording bird-lime ....................................... 252

B. Injurious .................................................. 253

1. By destroying food-producing mollusks or shell-fish, such as clams, mussels, oysters, and razor-fish ............................ 253

2. Injurious by destroying vegetable substances and garden plants.... 253

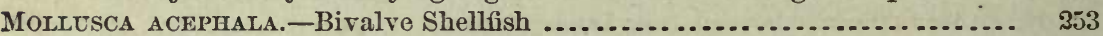

A. Producing food or used as bait.................................. 253

1. Series illustrating distribution and geographical varieties ........ 253

Ostrea virgixica, Gmelin.-East American Oysters . ...................... 253

Ostrea lurida, Cpr._-West Coast Ojsters.... . . . . . . . . . . . . . . . . . . . . . 253

1. Extra limital ............................................. 254

2. Series illustrating culture and individual variations.............. 255

Ostrea virgrica, Gmelin.-East American Oysters . . . . . . . . . . . . . . . . . . 255

a. Growth. 1-20 years old ........................................ 255

b. Peculiarities of form and growth............................... 255

c. Enemies and parasites . ......................................... 255

\section{*** Other bivalves.}

A. Affording or available for food or bait......................... 256

B. Useful or ornamental bivalves other than those affording food......... 256

a. Pearl-producing .......................................... 256

1. River mussels ........................................... 256

2. Marine pearl-shells....................................... 258

b. Otherwise useful........................................... 258

C. Injurious bivalves........................................ 258

a. Destroying submerged timber................................ 258

1. Specimens of wood showing ravages ....................... 258

D. Prepared foods........................................ 259 
Crustacea phyllopoda

A. Useful. Converted into fertilizers. Carapax used as a scoop or boatbailer

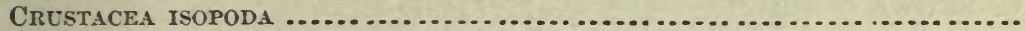

A. Useful; by removing wrecks or snags ............................. 260

B. Injurious; by destroying submerged timber ....................... 260

Crustacea stomatopoDA.......................................... 260

Crustacea decapoda.-Lobsters, Shrimp, Crawfish, Crabs................. 260

A. Useful; food-supplying ....................................... 260

B. Commensal with other food supplies ............................... 261

C. Injurious by burrowing into and weakening levees and dams ......... 261

D. Prepared foods .................................................. 261

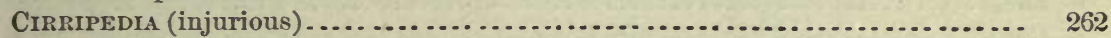

a. By dulling the edge of knires and spades employed in "cutting in" whale blubber............................................. 262

b. By obstructing the progression of vessels upon which they affix them-

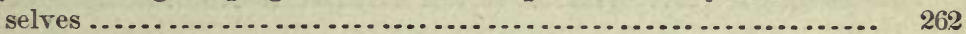

AvNELIDA. - Worms and Leeches.................................... 262

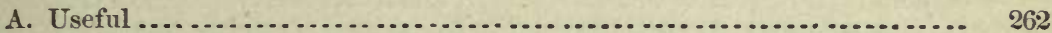

1. In surgery and medicine ................................. 262

2. For bait in fishing ......................................... 262

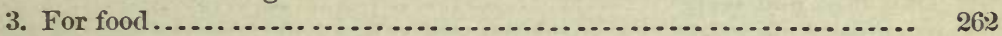

B. Injurious ................................................... 262

1. By boring into and destroying oyster-shells ................... 262

RaDrates.-Sea-Urchins, Starfish, Corals, Medusae, etc ................... 262

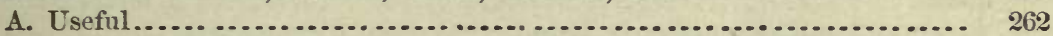

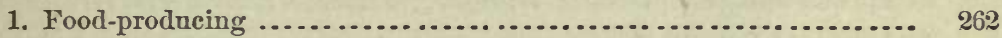

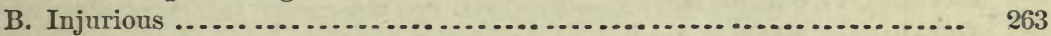

1. Destroying oysters, clams, \&c........................... 263

2. By their urticating powers annoying bathers and "fouling" nets and fishing lines with slime-rarious acalephs ................ 263

Protozixs.-Sponges, etc.......................................... 263

U'seful .......................................................... 263

1. For conveyance of fluids requiring an elastic and temporary menstruum, and as a detergent..............................

2. Useful as an elastic medium or absorbent ....................... 264

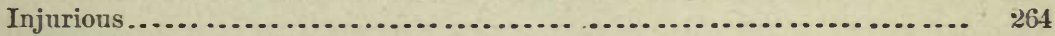

1. By destroying oysters.................................... 264

RuIzopods .................................................... 264

MISCELLANEOUS PRODUCTS OF SEA OR SHORE, NOT OF AN ANIMAL NATURE.

a. Lichens................................................ 264

b. Algæ .... ................................................. 265

1. Having economical applications........................... 265

2. Ornamental algæ .... .................................... 265

IroRGAIIC MATERIALS ............................................ 271 
COMMERCIAL STATISTICS OF ANIMAL PRODUCTS IN THE UNITED STATES. A REVIEW OF A PORTION OF THE REPORT OF THE CHIEF OF THE BUREAU OF STATISTICS FOR THE FISCAL YEAR ENDING JUNE 30, 1877. BY G. BROWN GOODE.

Living animals.

Page.

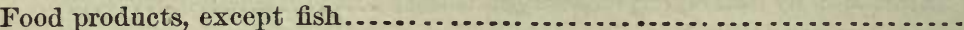
$2 \% 2$

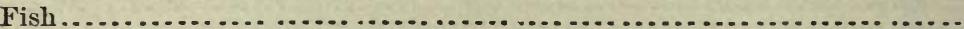
274

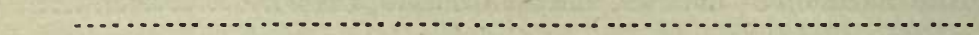
277

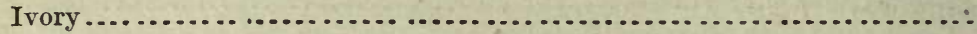
282

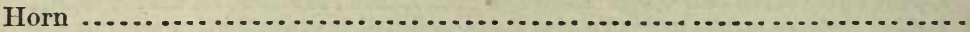
288

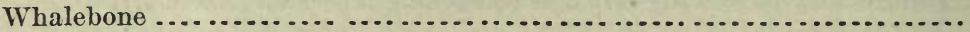
289

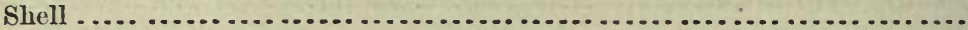
289

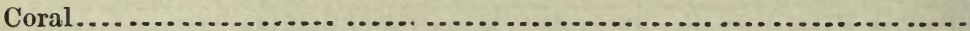
289

Leather 289

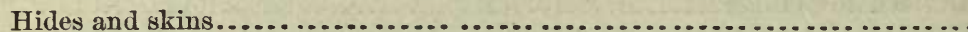
289

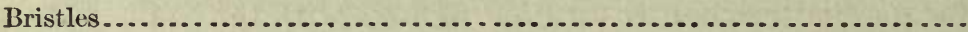
290

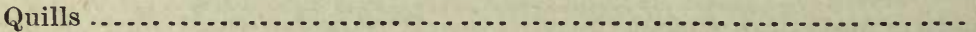

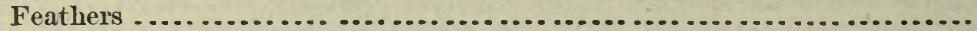
294 295

Glue and gelatine.........................................

Spouges .............................................

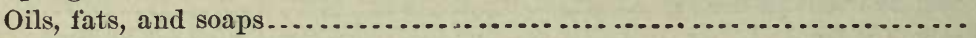

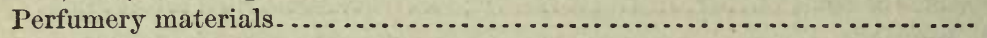

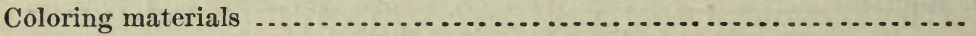

Chemical preparations, medicines, \&c.............................

Bones ............................................

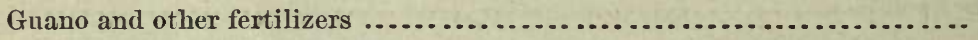

Specimens of natural history $\ldots \ldots \ldots \ldots \ldots \ldots \ldots \ldots \ldots \ldots \ldots \ldots \ldots \ldots \ldots \ldots$

Alphabetical index......................................... 


\section{INTRODUCTORY NOTE.}

On the occasion of the International Exhibition, in 1876, certain appra-

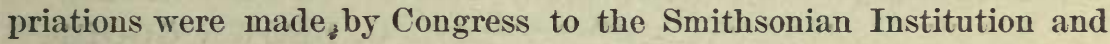
the United States Fish Commission. The former was called upon to prepare an exhibition to illustrate the economical value of the mineral and animal products of the country, while the latter was to perform a similar task for the national fisheries. It was subsequently found desirable for the Smithsonian Institution to unite with the Indian Bureau in displaying the condition of the aboriginal tribes of the United States in prehistoric and modern times. Four distinct departments of work were thus provided for, (1) an ethnological exhibition, (2) an exhibition $o_{2}^{\mathrm{e}}$ minerals, (3) an exhibition of animal resources, and (4) a fishery exhib:tion. The first and second were arranged on opposite sides of the nave in the Government building, at Philadelphia, and at its north end. The latter, it was found, could not be separated, since the character of the specimens and the methods of arrangement required were the same. They were arranged in one series on the north side of the east transept and to the east of the nave extending north to the beginning of the mineral series.

The following catalogue is a simple enumeration of the objects exhibited in this series, and illustrative of the animal resources and the fisheries of the United States. It is essentially a reproduction of the cardcatalogue prepared in $\mathbf{1 8 7 6}$ and still in use in the administration of the collection, which, having been greatly augmented by systematic efforts in the United States and by donations from foreign governments, now forms an important section of the United States National Museum. The eatalogue has been as far as practicable made complete up to the present time, in so far as it relates to North America. No effort has, however, been made to include the collateral series of specimens from foreigu countries.

The plan of arrangement is fully shown in the TABLE of Contents. Beginning with the Useful and Injurious Animals, it next takes up the Means of Pursuit and Capture, then, successively, the Methods of Preparing them for Use, The Useful Products, and, finally, 
the Means of Protection and Culture. The preliminary plan of classification is given in full, whether specimens were obtained to illustrate it or not, and indicates wherein the collection isstill imperfect.*

It seems appropriate to remark that a very large number of the specimens included in this catalogue and exhibited in Pliladelphia were borrowed from the permanent collections of the National Museum, and have for many years been on exhibition in the Smithsonian building.

G. BROWN GOODE.

Washington, April 11, 1879.

* For a fuller exposition of this plan see the following pamphlet:

International Exhibition 1876. | Board in Behalf of United States Executive Departments. $|=|$ Classification | of the | Collection to Illustrate | the Animal Resoures of the United States. | A List of Substances derived from the Animal Kingdom, with Synopsis of the Useful and Injurious Animals | and a Classification of the Methods | of Capture and Utilization. | — | By G. Brown Goode, M. A., | Assistant Curator | U. S. National Museum. | - | Washington: | Government Printing Office. | 1876. | 8vo. pp. xiii (1) 126. Also published as Bulletin No. 6, Department of the Interior, United States National Museum; and as Article VI in Vol. XII of the (Smithsonian Miscellaneous Collections, Washington, 1878. 


\section{SECTION A.}

\section{LIST OF ANIMALS OF NORTH AMERICA BENEFICIAL OR INJURIOUS TO MAN.}

\section{*I. MA MMALS. \\ Order FER $A$.}

SUBORDER FISSIPEDIA.

\section{FELID $A$.}

Lynx rufus, (Guldenstädt,) Raf.-BAY LYNX or WHD CAT.-North America.

12476. Mounted. Denver, Col. C. E. Aiken. Dec. 14, 1875.

12477. Mounted. (Young.) Denver, Col. C. E. Aiken.

Lynx canadensis, (Geoff. \& Desm.,) Raf.-CANADA LrnX.-Northern North America.

12475. Mounted. Houlton, Me. Rev. R. R. McLeod. Dec. 15, 1875.

Felis eyra, Desm.-ExRA CAT.-Southwestern. North America.

9532. Mounted. Tehuantepec, Mex. F. Sumichrast.

Felis yaguarundi, Desm.-YAGUARUNDI CAT.-Southwestern North America.

8480. Monnted. Tabasco, Mex. Col. Sarto.

Felis concolor, Linn.-Puma or Cougar.-America generally.

11813. Mounted. Central Colorado. James Stevenson. 1874.

Felis onca, Linn.-JAGUAR.-Southwestern States, Central and South America.

$10390 \div 12296$. Mounted. Died in captivity at Government Insane Asylum, Washington.*

* The nnmbers prefixed to the enumeration of specimens are Smithsonian catalogue numbers. When two numbers are given, separated by the mark of division $(\div)$, the first mentioned refers to the particular preparation of the animal in question; the second, to some other related part entered in a different series. For example, in $10390 \div 12296$, the first number belongs to the skin and the second to the skeleton of a specimen of Felis onca.

Bull. N. M. No. 14-1 
Felis pardalis, Linn.-OcELOT or TIGER CAT.-Southwestern North America.

$12179 \div 14179$. Mounted. Talamanca, Costa Rica. Talamanca expedition. Prof. W. M. Gabb.

12187. Mounted. Talamanca, Costa Rica. Talamanca expedition. Prof. W. M. Gabb.

\section{CANGESA.}

Canis Iupus, Linn., var. griseo-albus.-Grax WoLF.-North America generally.

$3573 \div 3520$. Mounted. (Winter pelage.) Platte River, Neb. C. Drexler.

Vulpes fulrus, (Desm.,) var. Culvas, (Desm.)-RED Fox.-Northern North America.

7124. Mounted. (Male.) La Pierre's House, Rocky Mts. R. Kennicott. Dec., 1861.

6403. Mounted. (Female.) Yukon River. R. Kennicott. Oct. 21, 1860.

Vulpes fulvus, (Desm.,) var. decussatus.-Cross Fox.

6407. Mounted. (Female). Ft. McPherson, Peels River, Hudson's Bay Territory. R. Kennicott. Nov. $28,1861$.

"A very fine cross fox, nearly silver, small and apparently young. The Indians told me she would be a silver fox next year."-Kennicott.

6408. Mounted. (Female.) Ft. McPherson, Pecls River, H. B. T. R. Kennicott. Nov. 30, 1861.

"A good typical cross fox; tail rather small."-Kennicott.

6404. Mounted. (Male.) Yukon River. R. Kennicott. Oct. 22, 1860.

"A rather fine cross fox, approaching more nearly the silver fox than the red."-Kennicott.

12466. Mounted. Houlton, Maine. Rev. R. R. McLeod. Dec. 31, 1875.

Vulpes fulvus, (Desm.,) var. argentatus.-Silver Fox: BlacK Fox.

6410. Mounted (Male.) Yukon River. R. Kennicott. Nov. 17, 1860.

"A fino silver fox."-Kenn.

6411. Mounted. (Female.) Ft. McPherson, Peels River, H. B. T. R. Kennicott. Oct. 17, 1861.

"Black fox; some had still less silver."-Kenn.

Vulpes macrurus, Baird.-PraIrIe Fox.-Western States.

- Mounted. Wyoming.

Vulpes velox, (Say,) Aud. \& Bach.-Krt Fox or SwIFT Fox.-Western States.

12470. Mounted. Colorado. Chas. E. Aiken. Jan. 15, 1876.

12469. Mounted. Colorado. Chas. E. Aiken. Jan. 15, 1876.

11085. Mounted. Rocky Mountains.

Vulpes lagopus, (Linn.,) Gray.-ARCtic Fox.-Alaska.

- Skin. St. Paul's Id., Alaska. G. R. Adams. 
ANIMAL RESOURCES AND FISHERIES OF UNITED STATES.

Urocyon virginiamus, (Schreber,) Gray.-Grat Fox.-United States generally.

-. Mounted. Virginia.

Urocyon vinginianus, (Schreber, ) var. littoralis.-COAST GraY Fox.-Islands of the California coast.

12440. Mounted. Santa Cruz, Cal. H. W. Henshaw. U. S. Survey W. of 100 M.

\section{VIUSTELIDA.}

Mustela Penmanti, Erxl.-Fisher.-Northern North America.

12472. Mounted. Houlton, Maine. Rev. R. R. MeLeod. Jan. 15, 1876.

32r9. Mounted. Olympia, W. T. Geo. Gibbes.

Mustela amenicana, Turton.-PIne Martin or American Sable. Northern United States.

12544. Mounted. Hndson's Bay Territory. R. Kennicott.

379. Mounted. Hudson's Bay Territory. R. Kennicott

- Mounted. Hudson's Bay Territory. R. Kennicott.

1015. Mounted. Hudson's Bay Territory. R. Kennicott.

6414. Mounted. Yukon River, mouth of Porcupine, Hudson's Bay Territory. R. Kennicott.

6429. Mounted. Yukon River, mouth of Porcupine, Hudson's Bay Territory. R. Kennicott.

Putorius erminea, (Linn.,) Cuvier.-White Weasel : Ermme.Northern United States.

9355. Monnted. Kodiak. F. Bischoff. 1868.

$6498 \div 1029$. Mounted. (Male.) Yukon River, month of Poreupine R. R. Kennicott.

1427. Mounted. (Male.) Middleboro, Mass. J. W. P. Jenks.

Putorius Iongicauda, Bonaparte-Long-TAmED WEASELWestern United States.

9350. Mounted. Wyoming Territory. Dr. F. V. Hayden.

Putorius vison, Rich.-Mnvk.-North America generally.

12432. Mounted. (Male.) Moore's Lake, Minn. J. H. Batty.

4396. Monnted. Liard River. R. Kennicott.

$1653 \div 12309$. Mounted. United States.

2392. Mounted. Cape Flattery, W. T. Dr. Suckley.

Putorius nigripes, Aud. \& Bach.-Black-Footed FerREt.Western States (in holes of Prairie dogs).

12409. Mounted. Spotted Tail Agency, Neb. Col. A. Chambers, U. S. A. Oct. $1,1875$.

12462. Mounted. Cheyenne, Wyoming. Capt. Jas. Gilliss, U. S. A. Dec. 27, 1875. 
Gulo Iuscus, Sabine.-Wolverene or Glutton.-Northern North America.

3747. Mounted. Great Salt Lake, Utah. Capt. Stansbury.

4361. Mounted. Ft. Simpson, H. B. T. B. R. Ross.

Taxidea americana, Waterh.-AVERICAN BADGER.-Western United States and Pacific Slope.

12471. Mounted. Colorado. Chas. E. Aiken. Jan. 15, 1876.

Mephitis mephitica, (Shaw) Baird.-Coyron SKunK.-Easteru United States.

4348. Mounted. Washington, D. C. C. Drexler.

12522. Mounted. Golden, Col. C. E. Aiken.

1071. Mounted. Middleboro, Mass. J. W. P. Jenks.

4127. Mounted. Lynn, Mass. George Welch.

1070. Mounted. (Male.) Middleboro, Mass. J. W. P. Jenks. Dec. 3, 1855.

Mephitis mexicana, Gray.-Mexican Skunk.-Mexico.

8566. Mounted. Orizaba, Mox. Mr. Botteni.

Spilogale zorilla, (Linn.) Coues.-Little StrIPed SkunK.Western United States and Pacific Slope.

1188. Mounted. Santa Clara, Cal. Dr. J. S. Newberry. Nov., 1855.

Conepatus mapurito, (Gmelin) Coues. - WHITE-BACKL; SkUNK.-Southwestern United States.

$790 \div 1886$. Skin. Western Texas. Capt. J. Pope, U. S. A.

\section{LUTRIN AE.}

Lutra canadensis, Sab.-AMERICAN OTTER.-North America generally.

3280. Mounted. Steilacoom, Wash. Ter. George Gibbs.

$5145 \div 4456$. Mounted. Washington, D. C. National Institution.

\section{ENHYDRINA.}

Enhydra marima, Fleming.-SeA OTTER.-Pacific Coast of the United States.

9457. Mounted. (Adult.) Alaska. Dr. T. T. Minor.

9458. Mounted. Alaska. Dr. T. T. Minor.

\section{URSID AE.}

Ursus horribilis; Ord.-GRIzzLr BEAR.-Western United States and Pacific Slope.

12308. Mounted. (16 years old.) Laramie, Wyoming. Major Twiss. (Confined in the Government Insane Hospital, Washington, from 1858 to 1874.) 
ANIMAL RESOURCES AND FISHERIES OF UNITED STATES.

Ursus americanus, Pallas.-BLACK BEAR.-United States generally.

12380. Mounted. Northern Michigan. John Wallace.

Thalarctos maritimus, (Linn.) Gray.-WHITE or Polar BEAR. -Northern America, Europe and Asia.

12379. Mounted. Greenland. John Wallace.

\section{PRDCYONIDAE.}

Procyon lotor, (Linn.) Storr.-RAccoon.-United States generally.

5148. Mounted. National Institution.

5147. Mounted. National Institution.

26789. Mounted. Wyoming, N. Y. H. A. Ward. Rochester, N. Y.

Nasua fusca, -CoAtrundi-Texas.

12757. Mounted. Brownsville, Texas. Dr. J. C. Merrill, U. S. A.

\section{PINNIPEDIA.}

\section{OTA TRIDIE.}

Callirhinus ursinus, (Schreber) Gray.-Fur SEAL.-North Pacific Ocean and Bering's Sea.

12918-34. Mounted. (Group of 17.) Prybilov Islands, Alaska. Alaska Commercial Company, Sän Francisco.

12935. Mounted. Alaska. H. W. Elliott.

Eumetopias Stelleri, (Fischer) Gray.-SeA Lion.-Pacific Coast.

12489. Mounted. (Female.) Prybilov Islands, Alaska. Alaska Commercial Company, San Francisco.

12488. Mounted. (Male.) Prybilov Islands, Alaska. Alaska Commercial Co., San Francisco.

12936. Mounted. (Young.) North Pacific.

Zalophus Gilliespii, (Macbain) Gill.-THE SEA DOG.-Pacific Coast.

12937. Mounted. Southern California. Capt. Baker.

\section{PHDCEDAE.}

\section{PHOCINAE.}

Phoca vitulima, Linn.-The Common Seal; Harbor Seal.North Atlantic.

12453. Cast. Provincetown, Mass. 1875.

623. Photograph. (Young.) U. S. Fish Commission.

624. Photograph. U. S. Fish Commission. 
Phoca Richardsii, (Gray) Gill.-Leopard Seat.-North Pacific.

3742. Mounted. California.

12494. Mounted. Adakh Id. Alaska. W. H. Dall.

Pagophilus grcenlandicas, (Müll.,) Gray.-HARP SEAL.-Aretic Seas.

5853. Mounted. Sable Island, N. S. P. W. Dodd.

8122. Mounted. Franklin Harbor, Arctic Seas. R. McFarlane.

5851. Mounted. Sable Island, N. S. P. W. Dodd.

12040. Mounted. St. John's, N. F. Rev. M. Harvey.

5852. Mounted. Sable Island, N. S. P. W. Dodd.

12039. Mounted. St. John's, N. F. Rev. M. Harvey.

12038. Mounted. St. John's, N. F. Rev. M. Harvey.

Erignathus barbatus, (O. Fabricius) Gill.-SQUARE-FLIPPER SeaL.-Arctic Seas.

12422. Skin. Newfoundland. Government of Newfoundland.

Histriophoca equestris, (Pallas) Gill.-BANDED SEAL.-Pacific Coast, Aretic Seas.

7580. Skin (in collectiou of Furs). Cape Romanzoff. W. H. Dall.

Pusa gryphus, (O. Fabricius) Gill.-Gray SEaL.-Atlantic Coast. 8694. Mounted. Seeland. Zoological Museum, Copenhagen.

\section{CTSTOPHORINAE.}

Cystophora cristata, (Erxl.) Nilsson.-HOODED SEAL.-Atlantic Coast.

12043. Mounted. St. John's, N. F. Rev. M. Harvey.

Macrorhinus angustinostris, Gill.-SEA ÉLEPHANT; ELEPIIANT SeaL.-Pacific Coast.

12441. Mounted. (Male.) California. Capt. C. M. Scammor.

\section{ROSILARIDAE.}

Rosmarus obesus; (Hlig.) Gill.-WaLrus.-North Atlantic.

11870. Mounted. Greenland. Dr. I. I. Hayes.

Rosmarus Cookii, (Fremery) Gill.-WaLrus.-Northern Pacific.

12493. Mounted. Prybilor Islands, Alaska. Alaska Commercial Co., San Francisco. 


\section{ORDER, UNGULATA. BOVHDA.}

\section{BOVINAE.}

Bison americanus, (Gmelin) Gray.-American BUFFaLo.Plains betreen Rocky Mountains and Missouri River.

12919. Mounted. Colorado. C. E. Aiken.

Dvibos moschatus, Blainville.

12298. Mounted. (Female.) Arctic Coast, H. B. T. W. L. Hardestie. Jan. 23,1875 . Also skeleton of same animal.

12297. Mounted. (Male.) Arctic Coast, H. B. T. W. L. Hardestie. Jan. 23, 1875. Also skeleton of same animal.

6255. Mounted. (Male.) Ft. Good Hope, H. B. T. J. S. Onion.

\section{ANTILOPIN BE.}

Mazama montama, (Ord) Gill.-Mountarn Gost.-Northern Rocky Mountains of the United States and British America.

11894. Mounted. (Male.) Montana. W. F. Wheeler and J. Armitage.

11893. Mounted. Washington Territory. U. S. Northern Boundary Survey.

\section{OVIN AE.}

Ovis montana, Cuvier.-BIGHorn; MountaIn SHeEP.-Rocky Mountain regions.

11891. Mounted. (Male.) Ft. Fetterman, Dakota. James Stevenson, U. S. Geol. Survey.

1608. Horns. H. B. Möllhausen.

\section{ANTILOCAPRIDAE.}

Antilocapra americama, Ord.-PRONGHORN ANTELOPE or CABREE.-Plains west of Missouri from Lower Rio Grande to Saskatchewan.

2034. Mounted. (Male.) Yellowstone River. Dr. F. V. Hayden.

2471. Horns. Ft. Chadbourne, Texas. Dr. Swift, U. S. A.

6914. Horns. Ft. Whipple, Arizona Ty. Dr. Elliott Coues, U. S. A.

5084. Horns. Upper Missouri. ?

\section{CER VTDAE.}

Alces machlis, (Limn.) Gray.-MoosE.-Northwestern United States.

11868. Mounted. (Adult male.) Nova Scotia. Geo. A. Boardman.

12542. Mounted. (Adult male.) Nova Scotia. Mr. Jack.

11861. Mounted. (Young calf.) Nova Scotia. Dr. Bernard Gilpin.

857. Antlers. Maine. General S. Churchill, U. S. A.

- Antlers. Adirondacks, N. Y. Henry J. Biddle. 
Tarandus rangifer, J. Brookes, subspecies caribou, Aud. \& Bach.-WOOdLAND CARIBOU.-Northeastern North America.

12473. Mounted. Houlton, Me. Rev. R. R. McLeod. 12407. Mounted. Houlton, Me. Rev. R. R. McLeod. 11865. Mounted. Lake Superior. J. Barnston. 3289. Antlers. (Female.) Nelson River. 3290. Antlers. (Female.) Nelson River.

Tarandus rangifer, (Br.) subsp. groenlandicus, Br.-BARREN Ground CaRIBOU.-Arctic America.

6255. Mounted. Arctic America.

905. Antlers. North Greenland. S. Sternberg.

903. Antlers. North Greenland. S. Sternberg.

6782. Antlers. Plover Bay. Capt. C. M. Scammon, U. S. R. M.

7539. Antlers. Yukon River. W. H. Dall.

4636. Antlers. Port Foulke, N. Greenland. Dr. I. I. Hayes.

Cervus canadensis, Erxl.-AMERICAN ELK.-Northern North America.

12474. Mounted. Ft. Sanders, Wyoming. Col. A. G. Brackett, U. S. A.

4457. Antlers. Elk Co., Penna. Prof. S. S. Haldeman.

2911. Antlers. Ft. Berthold, Missouri River. Lt. Warren, U. S. A., Dr. F. V. Haydon.

867. Antlers. Utah. Col. O. Cross, U. S. A.

2579. Antlers. Platte River. Lt. Bryan, U. S. A.

3552. Antlers. Ft. Tejon, Lower Cal. John Xantus.

3551. Antlers. Ft. Tejon, Cal. John Xantus.

840. Antlers. Ft. Union, Mo. A. Culbertson.

761. Antlers. Ft. Union, Mo. A. Culbertson.

760. Antlers. Ft. Union, Mo. A. Culbertson.

2916. Antlers. Ft. Berthold, Missouri River. Lt. Warren, U. S. A., Dr. F. V. Hayden.

2905. Antlers. Ft. Berthold. Dr. F. V. Hayden.

2903. Antlers. Ft. Berthold. Dr. F. V. Hayden.

2910. Antlers. (Male.) Ft. Berthold. Dr. F. V. Hayden.

3486. Antlers. Oregon. U. S. Expl. Exped. Capt. Wilkes, U. S. N.

3487. Antlers. Oregon. U. S. Expl. Exped. Capt. Wilkes, U. S. N.

\section{Cariacus virginianus, (Boddært) Gray.-Virania Drer.-} United States east of the Missouri.

12461. Mounted. Cumberland, Md. D. P. Welpley. Dec. 26, 1875.

$1889 \div 2587$. Mounted. (Young female.) Medicine Bow River, Ark. W. S. Wood. Sept. 6, 1856.

12349. Mounted. (Albino.) Peshtigo, Wis. J. H. Leavenworth.

2909. Antlers.

763. Antlers. (Male.) Lewisburg, Pa. J. C. Barber.

4174. Antlers.

668. Antlers. (Male.) Cumberland, Md.

3386. Antlers. (Male.) Ft. Mason, Tex. Maj. G. H. Thomas.

914. Antlers. (Male.) Washington, D. C.

961. Antlers. (Male.) Arkansas. J. M. Stanley. 
Cariacus virginianus, (Boddært) Gray-Continued.

3383. Antlers. (Male.) Ft. Mason, Tex. Maj. G. H. Thomas.

3387. Antlers. (Male.) Ft. Mason, Tex. Maj. G. H. Thomas.

896. Antlers. St. Louis, Mo. J. S. Bowman.

3388. Antlers. (Male.) Ft. Mason, Tex. Maj. G. H. Thomas.

667. Antlers. (Male.) Cumberland, Md.

3062. Antlers. (Male.) Essex Co., N. Y.

895. Antlers. (Male.) St. Louis, Mo. J. S. Bowman.

9843. Antlers. Near Denver, Colo. E. Palmer.

5077. Antlers. (Male.) Washington, D. C.

5083. Antlers. Upper Missouri ?

Cariacus virginianus, (Bodd.) Gray, var. mexicanus.-VIRGINIA DEER.

11859. Mounted. Talamanca, Costa Rica. Prof. W. M. Gabb.

Cariacus macrotis, (Say) Gray.-MULE DEER.-Central North America.

11864. Mounted.

12583. Mounted. Cheyenne, Wyo. Capt. J. M. Gilliss, U. S. A.

6615. Antlers. Prescott, Ariz. Dr. E. Coues.

831. Antlers. Big Sioux.? T. Culbertson.

4175. Antlers.

6918. Antlers. Ft. Laramie. Col. W. O. Collins.

3682. Antlers. Mountains of New Mexico. Dr. J. S. Newberry.

Cariacus columbiamus, (Rich.) Gray.-ColunBIA BLACK-TALLED DEER.-Pacific Slope.

8154. Antlers. Puget Sound. J. G. Swan.

3203. Antlers. Whidby's Island, Puget Sound, W. T. Dr. Geo. Suckley.

5080. Antlers. Puget Sound. Dr. C. B. Kennerly.

3204. Antlers. Whidby's Island, Puget Sound. Dr. Geo. Suckley.

Cervus dama, Linn.-Fallow DeER (introduced).

1200. Antlers. Park, Clarke Co., Va. Col. J. Fuley.

2257. Antlers. Clarke Co., Va. Col. J. Fuley.

\section{DICOTYLITIE.}

Dicotyles torquatus, Cur.-PECCARY.-Red River, Arkansas, and South.

12346. Mounted. Talamanca, Costa Rica. Talamanca Exped. Prof. W. M. Gabb.

\section{ORDER, SIRENIA.}

\section{TRICHECHIDE.}

Trichechus manatus, Linn.-MavateE.-Florida, West Indies, and N. E. South America.

12295. Mounted. Florida. P. T. Barnum.

16037. Skeleton. Florida. H. A. Ward. 


\section{ORder, CETE.}

\section{DELPHINIDAE.}

\section{DELPIINA PTERIN BE.}

Delphinapterus catodon; (Linn.) Gill.-White-FISH or White WHALE.-Arctic and Subarctic Seas (ascending large rivers).

12490. Cast. Gulf of St. Lawrence. G. R. Renfrew \& Co., Quebec. 16038. Skeleton. Gulf of St. Lawrence. G. R. Renfrew \& Co. 389. Photograph. U. S. Fish Commission.

Monodon monoceros, Linn.-NARWHAL.-Arctic Seas. 15304. Tusk. Greenland. Purchased from George Y. Nickerson.

\section{DELPHININ E.}

Leucorhamphus borealis, (Peale) Gill--RIGHT-WHaLe PoRPOISE.-Pacific Coast.

一. Skeleton.

Delphimus Baindii, Dall.-BAIRD's PorPorse.-California Coast.

16042. Skeleton. California. W. H. Dall.

15403. Skull. San Gabriel River, Cal. Lient. Bergland, U. S. A.

Delphinas bombifrons, Cope.-PorPorse.-Atlantic Coast.

12481. I Cast. New York Harbor. John Wallace.

Tursiops enebennus, (Cope) Gill.-Porporse.-Atlantic Coast. 15786. Skeleton. Rockaway, Long Id. Alfred Lawrence.

Tursiops Gillii, Dall.-Cow-FISH.-Pacific Coast.

16043. Skeleton. California. W. H. Dall.

Lagenorhynchus perspicillatus, Cope.-SkUnK Porpoise.Eastern Coast.

12305. Cast. Cape Cod. Vinal N. Edwards.

Lagenorhymehus obliquidens, Gill.-STRIPED or CoMnoN PoRPOISE.-Pacific Coast.

14329. Skeleton. California. C. M. Scammon.

Lagenorhynchus gubermator, Cope.-Eastern Coast.

- Cast. Casco Bay, Me. U. S. Fish Commission.

Lagenorhynchus levcopleurus, (Raasch) Gray.-Cow-FISH.Eastern Coast.

12939. Cast. Cape Cod, Mass. U. S. Fish Commission. 
ANIMAL RESOURCES AND FISHERIES OF UNITED STATES.

Lagenorhynchus thicolea, Gray.-PoRPoIsE.-West coast of North America.

Orea atra, Cope.-Krmler.-Pacific Coast.

13018. Jaw. California. Capt. C. M. Scammon.

Drea gladiator, (Bonnaterre) Gray.-KHLER.-Atlantic Coast.

11918. Skull. South Atlantic. S. F. Baird.

Phocana vomerima, Gill.-BAY PorPoIse.-Pacific Coast.

16044. Skeleton. California. W. H. Dall.

Phocana lineata, Cope.-STRIPED PORPOISE.-Atlantic Coast.

621. Photograph. U. S. F. C.

Phocaena brachycion, Cope.-The Snuffing Pig or Herring HoG.-Atlantic Coast.

12302. Cast. Cape Cod. Vinal N. Edwards.

\section{GLOBICEPHALINAE.}

Globicephalus Scammøni, Cope.-BLACK-FISH.-Pacific Coast. 9076. Skull. California. Capt. C. M. Scammon.

Globicephalus intermedius, (Harlan) Gray.-BLACK-FISH.Atlantic Coast.

12479. Cast. (Fœtus.) Cape Cod. U. S. Fish Commission.

12480. Plaster cast, (7 feet.) Cape Cod. Edwards. Nov. 14, 1874.

12480. Cast.

12840. Cast 351. Cast of head. South Dennis, Mass. U. S. Fish Commission. 1875.

12841. Cast 352. Cast of head. South Dennis, Mass. U. S. Fish Commission. 1875.

Grampus griseus, (Cuv.) Gray.-GraMPUs; Cow-FISH.-North Atlantic.

$15771 \div 12759$, 508. Cast. Dec. 2,1875 .

$15772 \div 12760$, 503. Skulls. Nov. $29,18 \% 5$.

$15773 \div 12761$, 506. Cast of head and cast of whole. Nov. 30,1875 .

506 A. Cast. (Over entrance.)

622. Photograph. U. S. Fish Commission.

12940. Cast of head. Cape Cod, Mass. V. N. Edwards.

12941. Cast of head. Cape Cod, Mass. V. N. Edwards.

12942. Cast of head. Cape Cod, Mass. V. N. Edwards.

Grampus Stean'asii, Dall.-White-heAded or Mottled Grampus.-Pacific Coast.

13021. Skeleton. California. W. H. Dall. 


\section{ZHPHIID $A$.}

ZIPHINAE.

Mesoplodon Sowerbiensis, (Blainv.,) Gervais.-SowERBY's WHALE.-Atlantic Coast.

\section{ANARNACINEE.}

Anarnacus semijunctus, (Cope) Gill.-BOTTLE-HEAD WHALE.Atlantic Coast.

\section{PHYSETERIDAE.}

\section{PHYSETERINAE.}

Physeter macrocephalus, Linn.-SPERM WhaLE.-Tropicopolitan Seas.

25052. Iron model. Made by captain of whaling ship. J. H. Thompson. New Bedford, Mass.

16046. Jaws. U. S. Fish Commission.

16047. Jaws. National Institute.

25004. Wooden model. Capt. Benj. Russell. New Bedford, Mass.

\section{KOGIINAE.}

Kogia Floweri, Gill.-Porpoise SPERM WhaLe.-Pacific Coast.

8016. Lower jaw. Lower California.

\section{BALANOPTERIDAE.}

\section{AGAPHELINAE.}

Agaphelus gibbosus, (Cope) Cope.-ScraGG Whate.-Atlantic Ocean.

Rhachianectes glaucus, Cope.-GRAY Whale.-Pacific Ocean. 13803. Skull. California. W. H. Dall.

\section{MEGAPTERINE.}

Megaptera versabilis, Cope.-HuMPBack WhaLE.-Pacific Coast. 13804. Vertebra. Aleutian Islands. W. H. Dall.

Megaptera osphyia, Cope--Huмpваск WHaLE.-Atlantic Coast.

Eschrichtius robustus, Lilljeborg.-GRäsö WHALE.-Atlantic Coast.

\section{BALENOPTERENAE.}

Sibbaldius tectirestrins, Cope.-FnnaCK WHALE.-Atlantic Ocean.

16045. Skeleton. Cape Cod. U. S. Fish Commission. 
Sibbaldius tuberosus, Cope.-FnBACK WhaLE.-Atdantic Ocean.

Sibbaldius borealis, (Fischer) Geoffroy.-SULPHUR-вотTом WHALE.-Atlantic Ocean.

16039. Skeleton. Cape Cod. U. S. Fish Commission.

Sibbaldius sulfureus, Cope.-SULPHUR-воттом WHALE. Pacific Ocean.

Balanoptera rostrata, (Müller) Gray.-Gravrus.-Atlantic Coast.

Balanoptera velifera, Cope--Fnnack WhaLe; Oregon FirNER.-Pacific Ocean.

Balanoptera Davidsonii, Scammon.-SharP-heAded FinNer W.HALE.-Pacific Coast.

16040. Skeleton. California. Capt. C. M. Scammon.

\section{BALAENID AE.}

Balaena mysticetus, Linn.-Bowhead WhaLE.-Arctic Seas.

12938. Model in plaster. From drawings and measurements of Capt. C. M. Scammon.

16041. Jaws. Arctic Ocean. U. S. Fish Commission.

Eubalana Cullamach, (Chamisso) Cope.-Pacific Right WHALE.- North Pacific.

12988. Model in plaster. From drawings and measurements of Capt. C. M. Scammon.

Eubalaena cisarctica, Cope.-RIGHT WhaLe.-Atlantic Coast.

\section{ORDER, INSECTIVORA.}

\section{TALPIDA.}

Scalops aquaticus, (Linn.) Cur.--Eastern United States.

3965. Mounted. (Male.) Washington, D. C. G. Exall.

5830. Mounted. (Fumale.) Washington, D. C. G. Exall.

3966. Mounted. District of Columbia, 1858. C. Drexler.

3964. Mounted. (Albino.) Virginia, October 30, 1846. D. F. Kent.

Scalops argentatus, And. \& Bach.-SILvery Mole.-Western

United States.

11351. Alcoholic. Mt. Carmel, IIl. R. Ridgway.

783. Mounted. Tremont, IIl. W. J. Shaw. 
Scapanus Townsendii, (Bachman) Pomel.-OREgon MOLE.Pacific Slope.

3963. Mounted. Oregon. T. R. Peale. U. S. Exploring Expedition.

1963. Mounted. Ft. Steilacoom, Wash. Ter. Dr. George Suckley, U. S. A.

Scapanus Breweri, (Bachman) Pomel.-HAIRY-TAILED MOLE.Eastern United States.

823. Mounted. Cleveland, Ohio. Dr. J. P. Kirtland.

Condylura cristata, (Linn.) Mliger.-STAR-NOSED MOLE.-Northern cismontane States.

3968. Mounted. Washington, D. C.

\section{ORDER, GLIRES.}

\section{SCIURIDA.}

Sciurus cinereus, Linn.-Fox SquIRREL.-Eastern United States.

4143. Mounted. District of Columbia. C. Drexler.

321 - 1240. Mounted. Western Missouri. Dr. P. R. Hoy. 1854.

4044. Mounted. (Male.) District of Columbia. A. R. Jenkins.

Sciurus carolinemsis, Gmelin.-GRAY SQUIRREL.-United States.

4042. Mounted. District of Columbia. S. F. Baird.

$334 \div 1252$. Mounted. Racine, Wis. Rev. A. C. Barry.

$332 \div 1250$. Mounted. Racine, Wis. Dr. P. R. Hoy.

11071. Mounted. New York. J. G. Bell.

5844. Mounted. Washington, D. C. J. K. Townsend.

Sciurus fossor, Peale.-CALIFORNIA GRAY SqUIRREL.-Pacific Slope.

4040. Mounted. (Male.) California. Dr. Heerman.

Sciurus Abertii, Woodhouse.-TUFT-EARED SQUIRREL.-Southern Colorado, New Mexico, \&c.

12576. Mounted. (Male.) Colorado Springs, Colo. C. E. Aiken.

12578. Mounted. (Male.) Colorado Springs, Colo. C. E. Aiken.

2430. Mounted. San Francisco Mts., N. M. Dr. Woodhouse.

Sciurus hudsomius, Pallas.-Red SQUIRrel; ChICKaree.Cismontane United States and Alaska.

12435. Mounted. (Male.) Hartford, Minn. J. H. Batty.

9241. Mounted. New Brunswick. G. A. Boardman.

3264. Mounted. Laramie Peak. J. Henman.

Tamias striatus, (Linn.) Cuv.-ChIPMunK.-Eastern United States.

4013. Mounted. Washington, D. C. A. J. Falls. 
ANIMAL RESOURCES AND FISHERIES OF UNITED S FATES.

\section{Tamias quadrivittatus, (Say) Rich.-MissourI STrIPed SquirReL.-Pacific Slope, in mountains.}

4661. Mounted. Yreka, Cal. W. Vielle.

4662. Mounted. Yreka, Cal. W. Vielle.

Tamias lateralis, (Say) Allen.-SAY's STRIPED SQUIRREL.Rocky Mountains, from Mexico northward.

9320. Mounted. Carson City, Nevada. U. S. Survey of Fortieth Parallel. Robert Ridgway. March, 1868.

Spermophilus grammurus, (Say) Bach.-CALIFornta Ground SqUIRREL.-Western Texas and New Mexico west to Sierra Nevada Mountains.

1046 $\div 2215$. Mounted. Los Nogales, Sonora. Maj. W. H. Emory, U. S. A.

Spermophilus grammurus, (Say) Bach., var. Beechyi.CALIFORNIA GRound SQUIRREL.-Cala. and Lower Cala., west of Sierra Nevadas.

469. Mounted. Tejon Valley, Cal. Dr. A. L. Heerman.

470. Mounted. Tejon Valley, Cal. Dr. A. L. Heerman.

Spermophilus Harrisi, Aud. \& Bach.-HARrIs' Ground SquIRREL.-The Great Interior Basin and Lower California.

471 $\div$ 1600. Mounted. Mohave Desert. Lient. R. S. Williamson.

Spermophilus Franklini, (Sabine) Rich.-Grax GoPHER.Northern Mllinois, northward to the Saskatchewan.

985. Skin. Racine, Wis. Dr. P. R. Hoy.

Spermophilus tereticaudis, Aud. \& Bach.-Round-TAILED GROUND SQUTRREL.-A Arizona.

1584. Skin. Fort Yuma, Cal. Maj. G. H. Thomas.

Spermophilus tridecem-lineatus, (Mitchell) Aud. \& Bach.StrIPEd GopHer; PratrIE SquIRREL.-The prairies of the United States.

437 $\div$ 1303. Mounted. Head of Arkansas River. Capt. E. G. Beckwith.

Spermophilus mexicamus, (Erxleben) Wagner--Mexicar Ground SQUIRREL.-Southwestern Texas and Southern New Mexico, southeastward into Mexico.

3662. Mounted. Eagle Pass, Texas. Dr. W. S. King, U. S. A.

Spermophilus rParryi, Rich.-PARRY's MARMot.-Northern parts of the Continent, from Hudson's Bay to Behring's Strait.

8736. Mounted. Pelly Lake. R. R. MacFarlane. June 21, 1864.

5789. Mounted. Lockhart River, H. B. T. B. R. Ross. July 4, 1860.

9366. Mounted. Kodiak. F. Bischoff. Sept. 13, 1868. 
Spermophilus spilosoma, Bennett.-Sorora Ground Squir. REL.- Eastern base of the Rocky Mountains north to Western Wyoming.

2620. Fort Thorn, N. Mex. Dr. T. C. Henry.

Spermophilus Richardsoni, (Sabine) Baird.-Yellow GOPHER.-Plains of the Saskatchewan southward to the Upper Missouri.

12360. Skin. Fort Saunders, Wyo. Col. A. G. Brackett.

Spermophilus Townsendi, Bach.-Townsend's Ground SQUIRREL.-Plains of Columbia.

3775. Camp Lloyd, Utah. Capt. J. H. Simpson, U. S. A.

Spermophilus anmulatus, Aud. \& Bach.-RInged Ground SquIRrEL.-Plains of Colima, Mexico.

—. Skins.

Cynomys Iudovicianus, (Ord) Baird.-PratrIE DoG.-Great plains east of the Rocky Mountains.

4057. Mounted. (Female.) Platte River, Ark. Dr. Woodhouse. $7770 \div 345$. Mounted. (Male.) Ft. Larned. Dr. E. Coues. May 31, 1864. 11458. Mounted. Colorado. J. H. Batty.

9559. Mounted. Soda Springs, Colo. Jas. Stevenson.

Cynomys columbianus, (Ord) Allen.-Short-tamled Pratrie DoG.-The parks and plains within and west of the Rocky Mountains to the plains of Columbia.

5849. Mounted. Fort Bridger, Utah. C. Drexler.

Aretomys monax, Linn.-WoopcHuck.-Eastern North America. 26788. Mounted. Wyoming, N. Y. H. A. Ward, Rochester, N. Y.

Arctomys caligatus, Eschscholtz.-NORTHWESTERN MARMOT.Puget's Sound northward, west of the Rocky Mountains. 9493. Mounted. Ft. Kenag, Alaska. F. Bischoff. May 16, 1869. 12485. Mounted.

Arctomys flaviventer, Aud. \& Bach.-YeLlow-Footed MARMOT.-Rocky Mountains west of the Pacific Coast.

8834. Mounted. Fort Anderson. R. McFarlane.

12753. Mounted. Near Fort Ellis, Montana. W. B. Platt.

\section{HAPLODONTIDAE.}

Haplodontia leporina, Rich.-SEWELLEL; SHOWT'L.-Pacific Slope (especially about Puget's Sound).

1966. Mounted. (Male.) Ft. Steilacoom, Wash. Ter. Dr. Geo. Suckley. 4046. Mounted. Puget's Sound. Ex. Ex. 
ANIMAL RESOURCES AND FISHERIES OF UNITED STATES.

\section{CASTORTID.}

Castor camadensis, Kuhl.-A A MERICAN BEAVER.-United States generally.

9724. Mounted. (Young.) Henry Fork, G. R. Dr. F. V. Hayden. Oet., 1870.

\section{GEOMYIDAE.}

Geomys bursarius, Rich.-Pouched or Pocket Gopher.-Missouri to Minnesota and Nebraska.

91. Mounted. Columbia River, Oregon. Acad. Nat. Sci. Phila.

Geomys tuza, (Ord,) Cones.-Florida SAlamander.-Southeastern States.

11905. Skins. Jacksonville, Fla. G. Brown Goode.

Geomys castanops, Baird.-Texas Pouched Gopher.-Texas and New Mexico.

4007. Mounted. Bent's Fork. Lt. Abert.

Thomomys talpoides, (Rich) Baird.-CALIFORNIA GOPHER.Northern and Western North America.

$366 \div 1280$. Mounted. Monterey, California. Lt. W. P. Trowbridge.

Thomomys clusius, Cones.-Syall-footed Pouched Gopher. -Rocky Mountains.

- Skins. Ft. Bridger, Utah.

\section{MURID}

Ius decumanus, Pallas.-Brown RAT.-United States generally. (Introduced.)

5847. Mounted. Washington, D. C.

His rattus, Linn.-BLACK RAT.-United States generally, but rare. (Introduced.)

$12 \div 921$. Skin. Foxburg, Pa. S. F. Baird.

Yus musculus.-Conron Mouse.-United States generally. (Introduced.)

4051. Mounted. (Albino.) District of Columbia.

Hesperomys leucopus, Wagner.-White-footed Mouse.Northern United States west of the Mississippi River.

13.5. Monnterl. Halifax, N. S. A. Downes.

Bull. N. M. No. 14 
ANIMAL RESOURCES AND FISHERIES OF UNITED STATES.

Neotoma foridana, Say \& Ord.-Flonida Rat; Woon RaT.Atlantic Slope northward to New York.

4334. Mounted. Hillsboro, Va. N. Janney.

Neotoma cinerea, (Ord) Baird.-Rocky Mountain Ra't.-Pacific Slope and Upper Missouri.

5665. Mounted. Fort Liard, Hudson's Bay Terr. Ross and Hardesty.

Fiber zibethicus, Cur.-Musk Rat.--United States generally.

4060. Mounted. (Female.) District of Columbia. R. O. Pollard.

\section{HYSTIRICIDAE.}

Erethizon dorsatus, (Linn.) Flem., var. dorsatus.-WhireIIAIRED PORCUPINE.-Northern United States.

11086. Mounted. Maine. John Wallace.

12402. Mounted. (Female.) Mt. Washington, N. H. C. J. King. July 3, 18 r5.

Erethizon dorsatus, (Linn.) F. Cuv., var. epixanthus.-YkLLOW-HAIREd PORCUPINE.-Pacific Slope and Upper Missouri region.

9745. Mounted. Fort Bridger, Wyoming. Dr. F. V. Hayden, U. S. Geologist. Sept. 29, 1870.

\section{SuBorder DUPLICIDENTATA.}

\section{LEPORID A.}

Lepus timidus, Fab., var. arcticus.-POLAR HARE.-Aretic and Subarctic America.

1356. Mounted. (Young.) Newfoundland. John Downes. Summer 1856.

5181. Mounted. Newfoundland. J. R. Willis.

353. Mounted. Newfoundland. J. G. Bell. Winter 1854.

Lepus americanus, Erxl, var. americanus, Allen.-NonthERN HARE; White HARE.-Northeastern North America.

124i8. Mounted. Cumberland, Md. D. P. Welpley.

Lepus americanus, Erxl.-Northern HARe; White Rabij'Alaska and British North Ameriea east of the Rociry Mountains.

4430. Mounted. (Male.) Ft. Liard, H. B. T. Robert Kennicott.

Lepus americanus, var.'virginianus.-VIRGINIA HARE.-

Eastern United States south of Nova Scotia.

11067. Mounted. J. G. Bell.

959. Mounted. Middleboro, Mass. J. W. P. Jenks. 
Lepus americanus, Erxl., var. Washingtonii.-RED HARE.West of Rocky Mountains from Columbia River into British Columbia.

381\%. Mounted. Chiloweyuck Depot, Oregon. Dr. C. B. Kennerly, U. S. A. June, 1859.

Lepus americanus, Erxl., var. Bairdii.-BATRD's HARE.Higher parts of Rocky Mountains.

4265. Mounted. (Female.) Wind River Mountains. Dr. F. V. Hayden.

5882. Mounted. Head of Flathead River, Washington Ty. Dr. C. B. Kennerly, N. W. Boundary Survey. Winter 1860.

3791. Mounted. Ft. Bridger, Utah. J. H. Simpson.

303. Mounted. Shoalwater Bay. Dr. J. G. Cooper, Pacific R. R. Survey. March 5, 1854.

Lepus campestris, Bach.-PraIrIE HARE.-Central plains of North America.

1552. Mounted. Upper Missouri. Dr. F. V. Hayden.

4240. Mounted. (Male.) Deer Creek. Dr. F. V. Hayden. Dec. 18, 1859.

$69 \div 972$. Mounted. Ft. Union, Neb. T. Culbertson.

12013. Mounted. (Male.) Frenchman's Creek, Montana. Dr. E. Coues, U.S.A., Northern Boundary Surrey. July 5, 1874.

Lepus callotis, Wagler.-JACKASS HARE; JACK RABBIT.-Southwestern United States.

11\%0. Mounted. Klamath Lake. Dr. J. S. Newberry.

8477. Mounted. (Female.) Ft. Whipple, Arizona. Dr. E. Coues, U. S. A. May 17, 1865.

450. Mounted. Red River, Ark. Capt. Marcy.

Lepus californicus, Gray.-CALIFORNIA HARE.-California.

11070. Mounted. California. J. G. Bell.

1980. Mounted. Petaluma, California. E. Samuels.

12586. Mounted. Cape St. Lneas. John Xantus.

Lepus sylvaticus, Bach.-Gray RABBiT.-Eastern United States.

12483. Mounted. Fairfax Co., Va. G. Brown Goode.

11069. Mounted. New York? J. G. Bell.

11068. Mounted. New York? J. G. Bell.

4017. Mounted. New York. J. G. Bell.

Lepus Bachmani, Waterhouse.-Bachrax's Hare.-Texas.

234 ; 243. Skins. Brownsville, Texas. Couch and Van Vliet.

Lepus sylvaticus, Bach., var. Audubonii.-AuduBon's HARE. - Southern Arizona and California.

1596. Mounted. San Diego, Cal. Dr. J. F. Hammond. Dec., $18 \pi 5$.

1594. Mounted. (Female.) San Diego, Cal. Dr. J. F. Hammond. Dec. 23, 1856. 
Lepus sylvaticus, Bach., var. Nuttalli._SAGE RABBIT._United States west of 97 th meridian.

8æ96. Mounted. (Female.) Camp Grant, Ariz. Edward Palmer. Feb. 20, 1867.

Lepus Trowbridgii, Baird.-TrowbrIDGE's HARE.-California.

1183. Mounted. Santa Clara, Cal. Dr. J. S. Newberry. Nov., 1855.

$2974 \div 351$. Mounted. Petaluma, Cal. E. Samuels.

Lepus aquaticus, Bach.-W -WTER RABBit.-Gulf States.

2306. Mounted. Prairie Mer Rouge, La. James Fairie.

2309. Mounted. Prairie Mer Rouge, La. James Fairie.

Lepus palusteris, Bach._MARsII RABBIT._-Southeastern United States, on lowlands.

4018. Mounted. St. Simon's Island, Ga. Dr. Wilson. 1860.

1256. I Mounted. Society Hill, S. C. M. A. Curtis. 1856.

1621. Mounted. St. Simon's Island, Ga. Dr. S. M. Wilson.

\section{Order, EDENTATA.}

\section{DASYPODID A.}

Tatusia septem-cinctus, (Linn.,) Gray.-ARMadILLo.-Southwestern United States and South.

10197. Mounted. Tobasco, Mexico. C. II. Laszlo.

\section{ORder, AMARSUPIALI.}

\section{DIDEIPIIDAE.}

Didelphys virginiana, Shaw.-Possur.-CUnited States generally.

12951. Stuffed skins. Family group of nine. Washington, D. C. G. Brown Goode.

\section{BIRDS.}

From want of space it has not been thought desirable to exhibit a collection of North American birds. 


\section{REPTILES. \\ Order, CROCODILIA.}

\section{CROCODHLID $\mathrm{AE}$.}

Crocodilus americanus, Seba.-FloridA Crocodile.-Southern Florida.

8384. Mounted. Biscayne Bay, Fla. Purchased from H. A. Ward.

Alligator mississippiensis, Daudin.-ALLIGATOR.-Southeastern North America.

9980. Cast. Jacksonville, Fla. F. C. Goode.

8543. Cast. Jacksonville, Fla. G. Brown Goode.

\section{ORDER, TESTUDINATA.}

\section{TESTUDINID $\boldsymbol{A}$.}

Testudo carolina, Linn.-FLORIDA GOPHER-TorTOISE.-Southeastern North America.

9627. Cast. Florida. G. Brown Goode.

Testudo Berlandieri, Agassiz.-Southwestern United States.

8926. Brownsville, Tex. Dr. J. C. Merrill, U. S. A.

\section{EMYDIDA.}

Malacoclemmys palustris, Gmelin.-DIAMOND-BACK TERRAPIN. - Coast from New York to Texas.

8709. Washington Market. J. W. Milner.

9028. Cast. Mandeville, La. G. Kohn.

Pseudemys rugosa, Shaw.-Red-Bellied Terrapin.-New Jersey to Virginia.

891i. Cast. Kinston, N. C. J. W. Milner.

Pseudemys concimna, Leconte.-Florida Terrapin.-Southeastern United States.

8907-8. Cast. Florida. Professor Baird.

\section{Pseudemys mobiliensis,}

9026. Cast. Mandeville, La. G. Kohn. 


\section{CHELYDRID A.}

Iacrochelys Iacertina, Schw.-Alligator TuRtLe.

9211. Cast. Greenville, Miss. S. W. Ferguson.

Chelydra serpentina, Linn.-SNAPPING TORTOISE.-Canada to Ecuador.

8916. Cast. Washington, D. C. Joseph Palmer.

\section{TRIONYCHIDAE.}

Aspidonectes ferox, Schw.-SoFT-SHELL TURTLE.-Georgia to Western Louisiana.

8708. Cast. Milledgeville, Ga. Tarleton H. Bean.

8899. Florida. Professor Baird.

Aspidonectes spinifer, Les.-SOFT-SIELL TURTLE.-Middle and northern tributaries of the Mississippi and the Saint Lawrence.

8309. Mounted. Rising Sun, Ind.

9614. Alcoholic. Mt. Carmel, Ill. R. Ridgway.

\section{CHELONIIDAE.}

Chelonia mydas, Schw.-Green TurTLE.-Atlantic Coast south of Long Island.

$8392 \div 15267$. Cast in papier-maché. Newr York market. E. G. Blackford.

Chelonia virgata, Schw.-PACIFIC GREen TURTLE.-Pacific Coast.

9639. Cast. San Diego, Cal. G. N. Hitchcock.

Thalassochelys caouana, Linn.-Loggerhead TuRtLe.

$8386 \div 15259$. Cast. New York market. E. G. Blackford.

Eretmochelys imbricata, Linn.-HAWr's BILL TURTLE.Southern Atlantic Coast.

-. Cast. New York market. E. G. Blackford.

Eretmochelys squamata, Linn.-PACIFIC HAWK's BILL TURTLE. -Pacific Coast.

12388. Shells. Fiji Island. U. S. Expl. Expedition.

\section{SPHA RGIDIDAE.}

Sphargis coriacea, Rondelet.-Leatherback TurtLE.-Atlantic Coast to Massachusetts.

8389-15265. Cast. New York market. E. G. Blackford. 


\section{FISHES. \\ Order, PEUICULATI.}

\section{MALTHEIDE.}

Malthe cubifrons, Rich.-SEA BAT.-West Indian Fauna.

16\%2\%. Cast. St. Angustine, Fla. Dr. J. M. Laing, U. S. A.

800. Photograph. U. S. Fish Commission.

Malthe vespertilio, (Linn.) Cuv._SEA BAT._-West Indian Fauna.

12575. Alcoholic specimen. Amazons. British Museum.

\section{LOPHIID AE.}

Iophius piscatorius, Linn.-GoosE FISH; ANGLER.-Nova Scotia to Cape Hatteras.

15086. Alcoholic specimen. Tompkinsville, N. Y. Copley.

14910. Cast. Wood's Holl, Mass. U. S. Fish Commission. June 22, 1873.

16657. Cast. Wood's Holl, Mass. U. S. Fish Commission.

12, 13, 14, 15. Photographs. U. S. Fish Commission.

\section{ANTENNARIIDE.}

Pterophryne histrio, (Linn.) Gill._Mouse-FISH.-Pelagic. 20683. Alcoholic specimens. Wood's Holl, Mass. V. N. Edwards.

\section{ORDER, PLECTOGNATHI.}

\section{MOLIDE.}

Mola rotunda, Cuv.-SuN-FISH.-Newfoundland to Cape Hatteras. 15832. Cast. Noank, Conn. U. S. Fish Commission. Sept. 16, 1874. 15833. Cast. Noank, Conn. U. S. Fish Commission. Sept. 16, 1874.

1. Photograph. U. S. Fish Commission. 784. Color sketch. (Richard.) U. S. Fish Commission.

\section{DIODONTID $A$.}

Chilomycterus geometricus, (Linn.) Kaup.-BUR-FISH.South of Cape Cod; West Indian Fauna, \&c.

15572. Cast. New York market. E. G. Blackford. Oct. 7, 1875.

15883. Cast. Wood's Holl, Mass. U. S. Fish Commission. Aug. 1, 1873.

523-4-5. Color sketch. (Richard.) U. S. Fish Commission. 
Chilomycterus fuliginosus, (De Kay,) Gill.

13938. Alcoholic specimen. Watch Hill, R. I. U. S. Fish Commission. Sept. $18,1874$.

Trichodiodon pilosus, (Mitch.) Bleeker.-HAIRY Box-FISH.Cape Cod to Cape Hatteras.

—. Alcoholic specimen. Beesly's Point, N. J. Prof. S. F. Baird. 1854.

\section{TETRODONTID $A$.}

Tetrodon lavigatus, (Linn.) Gill._RaBbit-FIsH.-Cape Cod to Florida.

14867. Cast. Vineyard Sound, Mass. U. S. Fish Commission. July 13, 1874. 2, 3. Photographs. U. S. Fish Commission.

Chilichthys turgidus, (Mitch.) Gill.-SwELL-FISH.-Cape Cod to Florida.

10740. Cast. Wood's Holl, Mass. U. S. Fish Commission.

499. Color sketch. (Richard.) U. S. Fish Commission.

615-16. Color sketch. Prof. Alex. Agassiz.

\section{OSTRA CIIDE.}

Ostracium quadricorne, Linn.-Cow-FISIr.-West Indian Fauna.

10008. Cast. Bermudas. G. Brown Goode. March, $187 \%$.

664. Color sketch. (Burkhardt.) Florida. Prof. Alex. Agassiz. Alive in Boston Aquarial Garden June, 1860.

Ostracium triquetrum, Linn.-CucKoLD.-West Indian Fauna.

579-80. Color sketch. (Burkhardt.) Santa Cruz. Prof. Alex. Agassiz; Dr. Jeffries.

Lactophrys trigonus, (Linn.) Poej.-Trunk-FISH.-West Indian Fauna; occasional in Massachusetts.

20610. Alcoholic specimens. Wood's Holl, Mass. V. N. Edwards.

\section{BALISTIDA.}

Balistes ringens, Linn.-SPOTTED FILE-FISH.-West Indian Fauna.

581. Color sketch. (Burkhardt.) Island of Sombrero, W. I. Prof. Alex. Agassiz. Sept., 1859.

Balistes vetula, Linn.-OLDWIFE; FILE-FISH.-West Indian Fauna; accidental on coast.

14909. Cast. Wood's Holl, Mass. U. S. Fish Commission. Oct. 8, 1873.

11380. Photograph. U. S. Fish Commission. 
ANIMAL RESOURCES AND FISHERIES OF UNITED STATES.

\section{Balistes capriscus,}

1.7233. Alcoholic specimen. East Coast. John Sutherland.

Stephanolepis setifer, (Bennet) Gill.-STORER's FILE-FISH.Nova Scotia to Florida.

16519. Alcoholic specimen. Wood's Holl, Mass. U. S. Fish Commission. Sept., 1875.

617. Color sketch. (Burkhardt.) Cape Cod. Prof. Alex. Agassiz. Aug., 1859.

498. Color sketch. (Richard.) Wood's Holl, Mass. U. S. Fish Commission. Aug., 1875.

Canthorhimus occidentalis.-Ẃ - West Indian Fauna, \&c.

16746. Alcoholic specimen. Chesapeake Bay. Capt. John Evans. Oct., 1875.

Alutera cuspicauda, De Kay.-Long-TAmED FLLE-FISH.-Cape Cod to Florida.

16341. Cast. Wood's Holl, Mass. U. S. Fish Commission. Sept. 13, 1875.

15569. Cast. New York. E. G. Blackford.

15827. Cast. New York market. E. G. Blackford.

15839. Cast. New York market. E. G. Blackford. Oct. 9, 1875.

412-13-14. Color sketches. U. S. Fish Commission.

Ceratacanthus aurantiacus, (Mitch.) Gill.-ORANGE FILEFISH.-Cape Cod to Florida.

14914. Cast. Wood's Holl, Mass. U. S. Fish Commission. Aug. 14, 1873.

15870. Cast. Wood's Holl, Mass. U. S. Fish Commission. Aug. 14, 1873.

14916. Cast. Wood's Holl, Mass. U. S. Fish Commission. Aug. 14, 1873.

5, 6, 7, 8, and 9. Photographs, U. S. Fish Commission.

500. Color sketch.

\section{ORDER, LOPHOBRANCHII.}

\section{HHPPQCAMPIDAE.}

Hippocampus antiquorum, Leach.-SEA-HORSE ; HORSE-FISH. - Cape Cod to Cape Hatteras.

21044. Alcoholie specimen. St. George's Banks. G. Brown Goode.

\section{SYNGNATHIDA.}

Syngnathus Peckianus, Storer.-PIPE-FISH.-Newfoundland to Cape Hatteras.

16492. Alcoholic specimen. Wood's Holl, Mass. U. S. Fish Commission. 


\section{ORDER, TELEOCEPHALI.}

\section{HETEROSOMATA.}

\section{SOLEIDAE.}

Achirus lineatus, (Linn.) Cuv.-American Sole; Hog ChoKer. - Cape Cod to Florida.

15743. Cast, (upper side.) Wood's Holl, Mass. U. S. Fish Commission. Feb. $21,1874$.

15743. Cast, (under side.) Wood's Holl, Mass. U. S. Fish Commission. Feb. 21, 1874.

380. Photograph. U. S. Fish Commission.

448. Photograph, (upper side.)

449. Photograph, (under side.)

561. Color sketch. Prof. Alex. Agassiz.

Solea vulgaris, Quensel.-SoLE.-Coast of Europe.

12513. Cast. England.

16. Photograph. U. S. Fish Commission.

\section{PLEURONECTIDE.}

Euchalarodus Putnami, Gill.-Putnam's Flat-Fish.-Found only in Salem Harbor.

5368. Alcoholic specimen. Salem, Mass. F. W. Putnam.

Pseudopleuronectes americanus, (Walb.) Gill.-Flat-Fish; WINTER Flounder.- Nova Scotia to Cape Hatteras.

14911. Cast. Wood's Holl, Mass. U. S. Fish Commission. July 22, 1873.

15692. Cast. Wood's Holl, Mass. U. S. Fish Commission. Dec., 1873.

15709. Cast. Wood's Holl, Mass. U. S. Fish Commission. Feb. 28, 1874.

14891. Cast. Wood's Holl, Mass. U. S. Fish Commission. Feb. 20, 1874.

14913. Cast. Wood's Holl, Mass. U. S. Fish Commission. Feb. 2, 1874.

15934. Cast. Wood's Holl, Mass. U. S. Fish Commission.

18, 19, 20, 21, 22, 380. Photographs. U. S. Fish Commission.

785. Color sketch. (Richard.) U. S. Fish Commission.

Myzopsetta ferruginea, (Storer) Gill.-Rusty Flounder.Nova Scotia to Cape Cod.

15068. Cast. New York market. E. G. Blackford.

15067. Cast. New York market. E. G. Blackford. March 22, 1875.

23. Photograph. U. S. Fish Commission.

786. Color sketch. (Richard.) U. S. Fish Commission.

Pleuronectes glaber, (Storer) Gill.-Syooth-BACK Flounder.Northern New England Coast.

20873. Cast. Portland, Me. Tarleton H. Bean. 
Glyptocephalus cynoglossus, (Linn.) Gill.-POLE Flounder. -Maine.

24. Photograph. U. S. Fish Commission.

12585. Alcoholic specimen. Treat's Island, Eastport, Me. U. S. Fish Commission. Aug., $18 \% 2$.

Lophopsetta maculata, (Mitch.) Gill.-WATERY Flounder; Spotted Turbot.-Cape Cod to Cape Hatteras.

15693. Cast. Wood's Holl, Mass. U. S. Fish Commission.

10652. Cast. Wood's Holl, Mass. U. S. Fish Commission.

25, 25. Photographs. U. S. Fish Commission.

780-1. Color sketch: (Richard.) U. S. Fish Commission.

Chanopsetta ocellaris, (De Kay) Gill.-Common Flounder.Cape Cod to Cape Hatteras.

15177. Cast. Norfolk, Va. U. S. Fish Commission.

10721. Cast. Wood's Holl, Mass. U. S. Fish Commission.

14899. Cast. Block Island, R. I. U. S. Fish Commission. Sept. 24, 1874.

10684. Cast. Wood's Holl, Mass. U. S. Fish Commission.

15176. Cast. Norfolk, Va. U: S. Fish Commission.

27, 28. Photographs. U. S. Fish Commission.

533-4. Color sketch. (Richard.) U. S. Fish Commission.

Chanopsetta oblonga, (Mitch.) Gill.-Four-SPOTTED FLounder. - Cape Cod to Cape Hatteras.

10716. Cast. Wood's Holl, Mass. U. S. Fish Commission. 10661. Cast. Wood's Holl, Mass. U. S. Fish Commission. 29, 30. Photographs. U. S. Fish Commission.

Chrenopsetta dentata, (Linn.) Gill.-SOUTHERn Flounder.Cape Hatteras to Florida.

18048. Alcholic specimen. St. John's River, Fla. Professor Baird.

Hippoglossus americanus, Gill.-HALIBUT.-Newfoundland to Cape Hatteras.

15698. Cast. Eastern Mass. U. S. Fish Commission. Feb. 28, 1874.

15\%05. Cast. Eastern Mass. U. S. Fish Commission. Feb. 28, 1874.

16587. Cast. Boston, Mass. F. H. Johnson. Sept. 24, 1875.

15732. Cast.

31, 32. Photographs. U. S. Fish Commission.

767. Color sketch. (Richard.) U. S. Fish Commission.

\section{Hippoglossoides limandoides, Günther.-SAND DAB.}

21037. Alcoholic specimen. Halifax, N. S. U. S. Fish Commission. Sept. 11, 1877.

21818. Alcoholic specimen. Gloucester, Mass. U. S. Fish Commission. July 29, 1878.

14913. Cast. Wood's Holl, Mass. V. N. Edwards. Feb. 2, 1874. 


\section{Reinhardtius hippoglossoides, (Walb.) Gill._GreenLand} Turвот.-Greenland.

14859. Cast, (upper side.) Newfoundland. E. G. Blackford. Feb., 1874.

14869. Cast. Newfoundland. E. G. Blackford. Feb., 1874.

33. Photograph. U. S. Fish Commission.

21564. Cast. Le Have Bank. U. S. Fish Commission.

Psettichthys melanostictus, Girard.-CaLIFornia "SPOTtED SoLE."-Coast of California.

16701. Cast. San Francisco, Cal. L. Stone. Jan. 27, 1876.

16699. Cast. San Francisco, Cal. L. Stone. Jan. 27, 1876.

16700. Cast. San Francisco, Cal. L. Stone. Jan. 27; 1876.

16699, 16700, 16701. Alcoholic specimens. San Francisco. U. S. Fish Commi 36, 39. Photographs. U. S. Fish Commission.

777. Color sketch. U. S. Fish Commission.

754. Color sketch. (Agassiz.) Prof. Alex. Agassiz.

Platichthys stellatus, (Pall.) Gill.-Rough FLOUNDER.-Coast of California.

16698. Cast. San Francisco, Cal. L. Stone,

38. Photograph. U. S. Fish Commission.

531-2. Color sketch. (Richard.) U. S. Fish Commission.

657. Color sketch. (Agassiz.) San Francisco. Prof. Alex. Agassiz. Nov., 1859.

\section{Parophrys vetulus. - "SOLE." - Coast of California.}

17064. Alcoholic specimen. San Francisco, Cal. U. S. Fish Commission.

776. Color sketch. (Richard.) U. S. Fish Commission.

\section{Ancylopsetta quadrocellata, Gill.}

17123-4. Alcoholic specimens. Charleston, S. C. Prof. S. F. Baird. March, 1877.

17123. Cast. Charleston, S. C. Prof. S. F. Baird. March, 1877.

Rhombus maximus, Will.-TURвот.-Coasts of Europe.

12511. Cast. England. Middleton, Carman \& Co.

35, 391. Photograph. U. S. Fish Commission.

Rhombus lavis, Rondel.-BrILL.-Coasts of Europe.

12512. Cast. England. Middleton, Carman \& Co.

34. Photograph. U. S. Fish Commission.

\section{ANACANTHINI.}

\section{MACRURIDA.}

Macrurus rupestris, Bl.-OnIoN-FisH.-North Atlantic.

15608. Cast. St. George's Banks. E. G. Blackford. Oct. 27, 1875.

786. Color sketch. (Richard.) U. S. Fish Commission. 
Macrurus Bairdii, Goode \& Bean.-_SpIKE-TaIL.

21014. Alcoholic specimen. (Type.) Gulf of Maine. U. S. Fish Commission. Ang. 19, $187 \%$.

\section{GADID A.}

Pollachius carbonarius, (Linn.) Bon.-PoLLACK.-Greenland to Cape Hatteras.

15971. Cast. Wood's Holl, Mass. U. S. Fish Commission.

16254. Cast. Martha's Vineyard. U. S. Fish Commission. July 30, 1875.

41, 42, 43. Photographs. U. S. Fish Commission.

78\%. Color sketch. (Richard.) U. S. Fish Commission.

Gadus morrhua, Linn.-CoD-FISH.-Polar Regions to Cape Hatteras.

167\%0. Cast. Irish Sea. Liverpool Free Public Museum.

14902. Cast. New York market. E. G. Blackford. April 3, 1874.

15923. Cast. Portland, Me. U. S. Fish Commission.

44, 45, 381, 392. Photographs. U. S. Fish Commission.

610. Color sketch. Prof. Alex. Agassiz.

Mićrogadus proximus, (Girard) Gill.-Tox CoD.-Coast of California.

16696. Cast. San Francisco, Cal. L. Stone. June 27, 1876.

47. Photograph. U. S. Fish Commission.

616. Color sketch. (Agassiz.) San Francisco. Prof. Alex. Agassiz. Nov., 1859.

Microgadus tomcodus, (Walb.) Gill.-Tom CoD ; FrosT-Fish.Newfoundland to Cape Hatteras.

14884. Cast. Wood's Holl, Mass. U. S. Fish Commission. June 11, 1873.

14885. Cast. Wood's Holl, Mass. U. S. Fish Commission. June 11, 1873.

16608. Cast. Wood's Holl, Mass. U. S. Fish Commission. Sept. 27, 1875.

46. Photograph. U. S. Fish Commission.

662. Color sketch. (Agassiz.) Prof. Alex. Agassiz.

Melanogrammus aglefinus, (Linn.) Gill.-HaDDock.-Newfoundland to Cape Hatteras.

14897. Cast. Wood's Holl, Mass. U. S. Fish Commission. June 18, 1873.

14896. Cast. Portland, Me. U. S. Fish Commission. Ang. 2, 1873.

48, 49, 50. Photograph. U. S. Fish Commission.

42\%. Color sketch. (Richard.) U. S. Fish Commission.

Phycis chuss, (Walb.) Gill.-HAKE.-Newfoundland to Cape Hatteras.

16598. Cast. Boston, Mass. F. H. Johnson.

Phycis tenuis, (Mitch.) De Kay.-Squirrel HaKe.-Newfoundland to Cape Hatteras.

15729. Cast. Wood's Holl, Mass. U. S. Fish Commission. June 18, 1873.

51. Photograph. U. S. Fish Commission. 
Phycis Chesteri, Goode \& Bean.-Long-finved Hake.

21840. Aleoholie specimen. (Type.) Gulf of Maine. U. S. Fish Commission. Ang. 27, 1878.

Urophycis regius, (Walb.) Gill._SPOTTED CodLing.-Cape Cod to Cape Hatteras.

788. Color sketch. (Emerton.) U. S. Fish Commission. 16845-6. Casts and alcoholie specimens. New York. Fred. Mather.

Molva vulgaris, Fleming.-LING.-Polar Seas.

16775. Cast. Coast of England. Liverpool Free Public Museum. 390. Photograph. U. S. Fish Commission.

Rhinonemus caudacuta, (Storer) Gill.-Four-BEARDED RockLING.-Nova Scotia to Cape Cod.

16656. Alcoholic specimen. Wood's Holl, Mass. V. N. Edwards.

Ciliata argentata, (Reinh.) Gill.-MACKEREL MIDGE.-Greenland to Cape Hatteras.

16179. Alcoholie specimen. Vineyard Sound, Mass. U. S. Fish Commission.

Hypsiptera argentea, Giinther.

21831. Aleoholic specimen. Off Cape May, N. J. Capt. R. H. Hurlbert.

Brosmius americanus, Gill.-Cusk.-Nova Scotia to Cape Cod.

16605. Cast. Boston, Mass. Wm. Prior, jr., \& Co. Sept. 25, 1875.

15886. Cast. Wood's Holl, Mass. U. S. Fish Commission. , Feb. 21, 1874.

52. Photograph. U. S. Fish Commission.

429. Color sketch. (Richard.) U. S. Fish Commission.

Haloporphyrus viola, Goode \& Bean.-BLuE HaKe.

2183\%. Alcoholic specimen. (Type.) Banquereau. Capt. Jos. W. Collins. Aug., 1878.

Lota maculosa, (Les.) Rich.-Bunвot.-Fresh waters of Northern North America.

16640. Cast. New York. E. G. Blackford.

16638. New York. E. G. Blackforrl.

53, 54, 55. Photograplis. U. S. Fish Commission.

428. Color sketch. (Richard.) U. S. Fish Commission.

491. Color sketcl. (Rötter.) Prof. Alex. Agassiz.

\section{MERHUCIIDAE.}

Merlucius bilimearis, (Mitch.) Gill.-Whiting; SILver HaKe.Nova Scotia to Cape Hatteras.

15747. Cast. U. S. Fish Commission.

15931. Cast. Wood's Holl, Mass. U. S. Fish Commission. Oct. 28, 1873.

56. Photograph. U. S. Fish Commission.

562. Color sketch. Prof. Alex. Agassiz. 


\section{OPHIDIIDE.}

Dphidium marginatum, Mitch.-Cape Cod to Cape Hatteras.

10762. Alcoholic specimen. Tompkinsville, N. Y. C. Copley.

\section{LYCODIDA.}

Zoarces anguillaris, (Peck) Storer.-EEL PouT.-Newfoundland to Cape Hatteras.

14888. Cast. New York market. E. G. Blackford. March, 1874.

15694. Cast. Nantucket Shoals. U. S. Fish Commission.

651. Color sketch. Prof. Alex. Agassiz.

\section{CRYPTACANTHIDA.}

Cryptacanthodes maculatus, Storer.-SPOTTED WRY-MOUTH. -Nova Scotia to Cape Cod.

16621. Provincetown, Mass. U. S. Fish Commission.

15889. Cast. Portland, Me. U. S. Fish Commission.

15890. Cast. Portland, Me. U. S. Fish Commission.

423. Coler sketch. (Richard.) U. S. Fish Commission.

613. Color sketch. (Burkhardt.) Boston. Prof. Alex. Agassiz. Dee., 1861.

Cryptacanthodes inornatus, Gill._GHosT-FISH. - Coast of Massachusetts.

1761. Alcoholic specimen. Maine. W. Stimpson.

\section{AVMODY'THDE.}

\section{Ammodytes americanus.-SAND EEL.}

382. Photograph. U. S. Fish Commission.

422. Color sketch. (Richard.) U. S. Fish Commission.

\section{STICHAIDA.}

Stichaeus punctatus, (Fabr.) Reinh.-North Atlantic Coast.

590. Color sketch. (Burkhardt.) Prof. Alex. Agassiz.

21068. Aleoholic specimen. Halifax, N. S. U. S. Fish Commission. Sept. 4, 1877.

Eumesogrammus subbifurcatus, (Storer) Gill. - Nova Scotia to Cape Cod.

21067. Alcoholic specimen. Halifax, N. S. U. S. Fish Commission. Aug. 25, 1877. 


\section{XIPHIDIONTIDA.}

Muraenoides mucronatus, (Mitch.,) Gill.-Rock EEL.-Nova Scotia to Cape Hatteras.

13847. Aicoholic specimen. Eastport, Me. U. S. Fish Commission.

488. Color sketch. Prof. Alex. Agassiz.

Muraenoides ornatus, (Girard) Gill.-PACIFIC Rock EEL.Pacific Coast.

639. Color sketch. (Agassiz.) Ft. Roberts, Gulf of Georgia, Wash. Terr. Prof. Alex. Agassiz. July, 1859.

\section{ANARRHICHADIDAE.}

Anarrhichas vomerimus, (Ag.) Storer.-WoLF-FISH.-Greenland to Cape Hatteras.

16439. Cast. Boston, Mass. F. H. Johuson. Sept. 8, 1875.

14900. Cast. Coxswain's Ledge, R. I. U. S. Fish Commission. July 25, 1875.

57. Photograph. U. S. Fish Commission.

7\%0. Color sketch. (Richard.) U. S. Fish Commission.

Amarrhichas Iupus, Linn.

21875. Specimen in brine. Gloucester. U. S. Fish Commission. 1878.

\section{BATRA CWIDAE.}

Batrachus tau, Linn.-Tond-FISH; OYsTER-FISH.-Nova Scotia to Gulf of Mexico.

10743. Cast. Wood's Holl, Mass. U. S. Fish Commission.

501-2. Color sketch. (Richard.) U. S. Fish Commission.

Porichthys notatus.-Pacific Coast.

640. Color sketch. (Agassiz.) Simiahmoo, Wash. Terr. Prof. Alex. Agassiz. June, 1859.

\section{URA NOSCOPIDAE.}

Astroscopus anoplus, (Cuv. \& Val.) Brevoort.-Naked STaRGAZER.-New York to Florida.

4622. Aleoholic specimen. Norfolk, Va. Prof. Theo. Gill.

571. Color sketch. (Burkhardt.) Pensacola, Fla. Prof. Alex. Agassiz; Dr. Jeffreys. April, 1854.

572. Color sketch. (Burkhardt.) Hampton Roads, Va. Prof. Alex. Agassiz; T. Leib. April, 1854.

584. Color sketch. (Burkhardt.) Jacksonville, Fla. Prof. Alex. Agassiz. 1853.

585. Color sketch. (Burkhardt.) Charleston, S. C. Prof. Alex. Agassiz. 1854.

586. Color sketch. (Burkhardt.) Coney Island, N. Y. Prof. Alex. Agassiz. Aluril, 1854. 


\section{CYCLOPTERIDA.}

Cyclopterus Iumpus, Linn.-LuMr-FISII.-North Atlantic.

15688. Cast. New York. E. G. Blackford. May 15, 1874.

15730. Cast. New York. E. G. Blackford. April 18, 1874.

16660. Cast. Wood's Holl, Mass. U. S. Fish Commission.

58. Photograph. U. S. Fish Commission.

788. Color sketch. (Emerton.) Young specimen. Fisher's Island Sound. U. S. Fish Commission. Aug., 1874.

\section{LIPARIDIDAE.}

Liparis lineata, (Lepechin) Kroyer.-STRIPED LIPARIS.-North Atlantic.

13960. Alcoholic. Watch Hill Reef, R. I. U. S. Fish Commission. Ang., 1874. 788. Color sketch. (Emerton.) U. S. Fish Commission.

Liparis Montagui, Don.-SEA SNAIL.-North Atlantic.

20432. Alcoholic. Wood's Holl, Mass. U. S. Fish Commission.

\section{TRIGLID $A$.}

Dactylopterus volitans, (Linn.) Lacep.-FlyngG GuRNard.Temperate and Tropical Atlantic and Mediterranean.

15873. Cast. Wood's Holl, Mass. U. S. Fish Commission. Ang. 8, 1873.

- Color sketch. (Richard.) U. S. Fish Commission.

Prionotus carolimus, (Linn.) Cuv. \& Val.-BroAd-FIngered SEa Robin.-Cape Cod to Florida.

59. Photograph. U. S. Fish Commission.

443. Color sketch. (Richard.) U. S. Fish Commission.

566. Color sketch. (Burkhardt.) Prof. Alex. Agassiz.

Prionotus evolans, (Linn.) Gill.-STRIPEd SEA RoBIN.-Cape Cod to Florida.

15735. Cast. Wood's Holl, Mass. U. S. Fish Commission.

15727. Cast. Wood's Holl, Mass. U. S. Fish Commission.

16411. Cast. Wood's Holl, Mass. U. S. Fish Commission. Sept. 25, 1575.

60, 61, 62. Photographs. U. S. Fish Commission.

401, 402. Color sketch. (Richard.) U. S. Fish Commission.

\section{AGONIDAE.}

Aspidophoroides monopterygius, (Bloch.) Storer.-Polar Seas and south to Connecticut.

21700. Alcoholic. Massachusetts Bay. U. S. Fish Commission.

Bull. N. M. No. 14-3 


\section{COTTIDA.}

Cottus octodecimspinosus, Mitch.-ScULPIN.-Nova Scotia to Cape Hatteras.

16437. Cast. Boston, Mass. F. H. Johnson. Sept. 8, 1875.

63. Photograph. U. S. Fish Commission.

537-8. Color sketch. Prof. Alex. Agassiz.

Cottus groenlandicus, Cuv. \& Val.-Greenland Sculpin.Polar Regions to Cape Cod.

16436. Cast. Boston, Mass. F. H. Johnson.

65. Photograph. U. S. Fish Commission.

545. Color sketch. Prof. Alex. Agassiz.

Cottus Mitchilli, Cuv. \& Val.-Pigmy Sculpin.-New England Coast.

14806. Alcoholic specimens. Wood's Holl, Mass. U. S. Fish Commission.

62. Photograph. U. S. Fish Commission.

546. Color sketch. Prof. Alex. Agassiz.

Uranidea viscosa, (Hald.) De Kay.-A merican Mrluer's Thunb.

609. Color sketch. (Roetter.) Plymouth, Mass. Prof. Alex. Agassiz. March, 1869.

\section{HEMITRIPTERIDAE.}

Hemitripterus americanus, (Gmel.) Cuvier.-SEA RAVEN.Newfoundland to New York; Seas of Japan.

15736. Cast. Wood's Holl, Mass. U. S. Fish Commission.

16414. Cast. Wood's Holl, Mass. U. S. Fish Commission. Sept. 2, 1875.

66, 67. Photographs. U. S. Fish Commission.

471-2. Photographs.

476. Photograph of young.

\section{SCORP AENID $A$.}

Sebastes marinus, (Linn.) Lütken.-NoRWAY.HADDOCK; HEMDURGaN ; RED PERCH.-Polar Seas and south to Cape Cod.

-. Alcoholic. Eastport, Me. U. S. Fish Commission.

Sebastes viviparus, Kroyer.-RoSE-FISH.-North Atlantic.

15879. Cast. Wood's Holl, Mass. U. S. Fish Commission.

397. Photograph. U. S. Fish Commission.

789. Color sketch. Prof. Alex Agassiz.

Sebastomus rosaceus, (Girard) Gill.-Rosy RocK-FISH.-Coast of California.

16688. Cast. San Francisco, Cal. L. Stone.

68. Photograph. U. S. Fish Comamission. 
ANIMAL RESOURCES AND FISHERIES OF UNITED STATES.

Sebastomus auriculatus, (Girard) Gill.-BLACK-EARED RockFISH.-Coast of California.

612. Color sketch. (Agassiz.) San Francisco, Cal. Prof. Alex. Agassiz. Nov., 1859.

Sebastomus fasciatus, (Girard) Gill.-BANDED Rock-FISH.Coast of California.

483. Color sketch. (Richard.) San Francisco. Livingston Stone. U. S. Fish Commission. March, 1876.

614. Color sketch. (Agassiz.) Deep Bay, Mayne Id., W. T. Prof. Alex. Agassiz. May 20, 1859.

Sebastomus elongatus, (Girard) Gill.-Pacific Coast.

643. Color sketch. (Agassiz.) San Francisco. Prof. Alex. Agassiz. Nov., 1859.

Sebastosomus melanops, (Girard) Gill.-BLACK-HEADED RocKFISH.-Coast of California.

653. Color sketch. (Agassiz.) San Francisco. Prof. Alex. Agassiz. Nov., 1859.

16689. Cast. San Franciseo, Cal. L. Stone.

482. Color sketch. (Richard.) U. S. Fish Commission.

Sebastodes paucispinis, (Ayres) Gill.-Coast of California.

637. Color sketch. (Agassiz.) San Francisco. Prof. Alex. Agassiz. Nov., 1859.

Chirus constellatus, (Girard) Gill._"Rock TrouT."-Coast of California.

16697. Cast. San Francisco, Cal. L. Stone.

69. Photograph. U. S. Fish Commission.

455. Photograph. U. S. Fish Commission.

Chipus pictus, Girard.-Pacific Coast.

642. Color sketch. (Agassiz.) San Francisco. Prof. Alex. Agassiz. Nov., 1859.

Chirus guttatus, Girard.-Coast of California.

638. Color sketch. (Agassiz.) San Francisco. Prof. Alex. Agassiz. Nov., 1859.

SCARIDAE.

Scarus squalidus, Poey.-TAWNY PARROT-FISH.-West.Indian Fauna.

973. Stuffed skin. Havana market. Prof. F. Poey.

Scarus Abildgaardii.-PARRot-FISH.-West Indian Fauna.

9738. Stuffed skin. Havana market. Prof. F. Poey. 
Scarus radians, Val._Spanish PorgY.- West Indian Fauna.

550. Color sketch. (Burkhardt.) New Providence. Prof. Alex. Agassiz; F. S. Shaw. April, 1861.

Pseudoscarus coeruleus.-Blue Parrot-fish; Kumagore.West Indian Fauna.

9733. Stuffed skin. Havana market. Prof. F. Poey.

\section{CABRIDA.}

Tautoga onitis, (Linn.) Günther.-TAUTOG; BLACK-FISH.-Bay of Fundy to South Carolina.

10598. Cast. Wood's Holl, Mass. U. S. Fish Commission. 15622, Cast. Wood's Holl, Mass. U. S. Fish Commission. 14893. Cast. Chesapeake Bay. U. S. Fish Commission. May 12. 10599. Cast. WVood's Holl, Mass. U. S. Fish Commission. May 12. 10643. Cast. Wood's Holl, Mass. U. S. Fish Commission. 15959. Cast. Wood's Holl, Mass. U. S. Fish Commission. 10599. Cast. Wood's Holl, Mass. U. S. Fish Commission. 70, 71. Photographs. U. S. Fish Commission.

450. Color sketch. (Adult.) (Richard.) U. S. Fish Commission.

451. Color sketch. (Young.) U. S. Fish Commission.

554. Color sketch. (Burkhardt.) Prof. Alex. Agassiz.

661. Color sketch. Prof. Alex. Agassiz.

\section{Tautogolabruis adspersus, (Walb.) Gill.-CUNNER; CHOGSET.-} Newfoundland to Cape Hatteras.

14894. Cast. Wood's Holl, Mass. Uv S. Fish Commission. 10746. Cast. Wood's Holl, Mass. U. S. Fish Commission.

381. Photograph. U. S. Fish Commission.

383. Photograph.

645. Color sketch. Prof. Alex. Agassiz.

431-433. Color sketch. U. S. Fish Commission.

Harpe rufus (Linn.) Gill._SPANISH LADY-FISH.-West Indian Fauna.

597. Color sketch. (Burkhardt.) Santa Cruz. Prof. Alex. Agassiz; Dr. Jeffries.

Chnerojulis radiatus, (Linn.) Goode.-BLUE-FISH.-West Indian Fauna.

596. Color sketch. (Burkhardt.) New Providence. Prof. Alex. Agassiz; F. S. Shaw. April, 1861.

\section{Lachnolamus falcatus, (Linn.) Val._West Indian Fauna.}

20780. Cast. Key West, Fla. E. G. Blackford.

598. Color sketch. Prof. Alex. Agassiz.

599. Color sketch. (Burkhardt.) Prof. Alex. Agassiz.

600. Color sketch. Prof. Alex. Agassiz.

601. Color sketch. Prof. Alex. Agassiz. 


\section{POVIACNTIRIDA.}

Glyphidodon saratilis, (Linn.) Cuv.-SERGEANT-MAJOR.-West Indian Fauna.

589. Color sketeh. (Burkhardt.) Prof. Alex. Agassiz.

591. Color sketch. (Dall.) Bermudas. Alive in Barnum's Aquarium. Prof. Alex. Agassiz. Dec., 1862.

Pomacentrus leucostictus, M. \& T.-West Indian Fauna. 21703. Alcoholic. Ft. Jefferson, Fla. Thos. Moore.

Heliastes insolatus, C. \& V.-West Indian Fauna.

21704. Alcoholic. Ft. Jefferson, Fla. Thos. Moore.

\section{EMIBIOTOCIDA.}

Embiotoca Webbi, Girard.-Coast of California.

626. Color sketch. (Agassiz.) San Francisco. Prof. Alex. Agassiz. Nov., 1859.

Embiotoca Jacksoni, Agassiz.-Coast of California.

625. Color sketch. (Agassiz.) San Franciseo. Prof. Alex. Agassiz. Nov., 1859.

Taeniotoca lateralis, (Ag.) A. Ag.-Striped Perch.-Coast of California.

16691. Cast. San Francisco, Cal. L. Stone.

72. Photograph. U. S. Fish Commission.

456. Photograph. U. S. Fish Commission.

658. Color sketch. (Agassiz.) Crescent City, Cal. Prof. Alex. Agassiz. May, 1859.

659. Color sketch. (Female.) (Agassiz.) San Francisco. Prof. Alex. Agassiz. Nov., 1859.

660. Color sketch. San Francisco. Prof. Alex. Agassiz. April, 1860.

Damalichthys vacca, Girard.-Coast of California.

62\%. Color sketch. (Agassiz.) San Francisco. Prof. Alex. Agatssiz. April, 1860.

Metrogaster aggregatus, Ag.-Pacific Coast.

641. Color sketch. (Female.) (Agassiz.) San Francisco, Cal. Prof. Alex. Agassiz. Dec., 1859.

Hypsurus Caryi, Agass.-Perch.-Pacific Coast.

606. Color sketch. San Francisco, Cal. Prof. Alex. Agassiz. April 1, 1860.

Phanerodon furcatus, Girard.-Coast of California.

636. Color sketch. (Female.) (Agassiz.) San Francisco. Prof. Alex. Agassiz. Nov., 1859. 
Amphistichus argenteus, Ag.-Coast of California.

635. Color sketch. (Agassiz.) (Male.) San Francisco. Prof. Alex. Agassiz. April, 1860.

Amphistichus similis, Girard.-Coast of California.

634. Color sketch. (Agassiz.) San Francisco. Prof. Alex. Agassiz. Nov., 1859.

Rhachochilus toxotes, Agassiz.-Coast of California.

633. Color sketch. (Agassiz.) San Francisco. Prof. Alex. Agassiz. March, 1860.

Holconotus pulchellus, A. Ag.-Coast of California.

632. Color sketch. (Male.) (Agassiz.) San Francisco. Prof. Alex. Agassiz. April, 1860.

Holconotus rhodoterus, Girard.-Coast of California.

641. Color sketch. (Female.) (Agassiz.) San Francisco. Prof. Alex. Agassiz. Dec., 1859.

Hyperprosopon argenteus, Gibbon.-Coast of California.

620. Color sketch. (Female.) (Agassiz.) San Francisco. Prof. Alex. Agassiz. March, 1860.

628. Color sketch. (Female.) (Agassiz.) San Francisco. Prof. Alex. Agassiz. April, 1860.

Abeona Trowbridgii, Girard.-Coast of California.

629. Color sketch. (Female.) (Agassiz.) California. Prof. Alex. Agassiz.

\section{TENTHIDIDAE.}

Acanthurus chirurgus,(Bl.) Schn.-Doctor-FIsH.-West Indian Fauna.

569. Color sketch. (Burkhardt.) Florida. Prof. Alex. Agassiz. Alive in Boston Aquarial Gardens. June, 1860.

570. Color sketch. (Burkhardt.) Florida. Prof. Alex. Agassiz. Alive in Boston Aquarial Gardens. June, 1860.

Acanthirus nigricans, (Linn.) Gill.-BLACK DocTor-FISH.West Indian Fauna and occasional north.

21367. Alcoholic. Bermudas. G. Brown Goode.

21698. Dried specimen. Key West, Fla. Thomas Moore. Nov., 1878.

\section{CHA E'TODON'TIDAE.}

Sarothrodus capistratus, (Linn.) Poey.-Coquetre.-West Indian Fauna.

588. Color sketch. (Burkhardt.) New Providence. Prof. Alex. Agassiz; F.

S. Shaw. April, 1861.

592. Color sketch. (Burkhardt.) Prof. Alex. Agassiz.

603. Color skotch. Prof. Alex. Agassiz. 


\section{Sarothrodus maculocinctus, Gill.}

16955. Alcoholic specimens. Wood's Holl, Mass. U. S. Fish Commission. 1876.

Holacanthus tricolor, (BI.) Lac.-BLACK ANGEL-FISH.-West Indian Fauna.

593. Color sketch. (Burkhardt.) Santa Cruz. Prof. Alex. Agassiz; Dr. Jeffries.

594. Color sketch. (Burkhardt.) Sombrero Id., W. I. Prof. Alex. Agassiz; S. R. Knox.

Holacanthus ciliaris, (Linn.) Lac.-ANGEL-FISH.-West Indian Fauna.

575. Color sketch. (Burkhardt.) Florida. Prof. Alex. Agassiz. Alive in Boston Aquarial Gardens. June, 1860.

576. Color sketch. (Burkhardt.) Florida. Prof. Alex. Agassiz. Alive in Boston Aquarial Gardens. June, 1860.

577. Color sketch. (Burkhardt.) Florida. Prof. Alex. Agassiz. Alive in Boston Aquarial Gardens. June, 1860.

21876. Alcoholic. Bermudas. G. Brown Goode.

583. Color sketch. (Burkhardt.) Bermudas. Prof. Alex. Agassiz. Alive in Baruum's Aquarium. 1862.

Pomacanthus arcuatus, (Linn.) Cuv.-Palometta.-West Indian Fauna.

602. Color sketch. (Burkhardt.) Florida. Prof. Alex. Agassiz. Alive in Boston Aquarial Garden. June, 1860.

\section{IIPHIIDAE.}

Xiphias gladius, Sword-FisH.-Atlantic and Mediterranean.

16126. Cast in papier-maché. Off Noman's Land, Mass. U. S. Fish Commission. Aug., 1875.

21699. Sword $1 \frac{5}{3}$ inches long. Taken from nostril of Lamna cornubica. Gloncester, Mass. U. S. Fish Commission. Sept. 26, 1878.

Tetrapturus albidus, Poey.-SPIKE-FISH.-Cape Cod to West Indies.

15834. Cast. Wood's Holl, Mass. U. S. Fish Commission. July 23, 1873.

73. Photograph. U. S. Fish Commission.

411. Water-color sketch. U. S. Fish Commission.

Histiophorus americanus, Cuv. \& Val.-SAIL-FISH.-Atlantic Coast of America.

16664. Cast. Wood's Holl, Mass. U. S. Fish Commission. Ang., 1872.

74. Photograph. U. S. Fish Commission.

\section{TRICHIURIDA.}

Trichiurus lepturus, Linn.-HAIR-TaIL; SCABBARD-FisH.Temperate and Tropical Atlantic.

14874. Cast. Wood's Holl, Mass. U. S. Fish Commission.

559. Color sketch. (Burkhardt.) Prof. Alex. Agassiz. 


\section{SCOMIRIDAE.}

Scomber scombrus, Linn.-MACKEREL.-Northern Atlantic.

16443. Cast. New York market. E. G. Blackford. Sept. 10, 1875.

10604. Cast. (Male.) Washington market. S. F. Baird.

10650. Cast. Wood's Holl, Mass. U. S. Fish Commission.

10650. Cast. Wood's Holl, Mass. U. S. Fish Commission.

76, 77, 78, 393, 395. Photographs. U. S. Fish Commission.

755-6-7. Color sketches. U. S. Fish Commission.

654. Color sketch. Prof. Alex. Agassiz.

Sarda pelamys, (Linn.) Cuv.-Bonito.-Atlantic and Mediterranean.

16325. Cast. Wood's Holl, Mass. U. S. Fish Commission.

15748. Cast. New York market. E. G. Blackford.

79, 80, 81. Photographs. U. S. Fish Commission.

467-8. Color sketches. (Richard.) Wood's Holl. U. S. Fish Commission. 1875.

558. Color sketch. New York. Prof. Alex. Agassiz. Oct. 20, 1847.

Orcynus secundi-dorsalis, (Storer) Gill.-TunNY; HORSEMACKEREL.-Newfoundland to Florida.

16509. Cast. New York market. E. G. Blackford.

82, 83, 84. Photographs. U. S. Fish Commission.

436, 37, 96, 513. Color sketches. (Richard.) U. S. Fish Commission.

Orcymus alliteratus, (Raf.) Gill._Little TunNY; Albicore.Pelagic.

15710. Cast. Noank, Conn. U. S. Fish Commission.

15683. Cast. Noank, Conn. U. S. Fish Commission.

85. Photograph. U. S. Fish Commission.

497. Color sketch. (Richard.) U. S. Fish Commission.

Drcynus pelamys, (Linn.) Poey.-Oceanic Bonito.-Temperate and Tropical Seas.

21852. Alcoholic. Chilmark, Mass. U. S. Fish Commission.

21562-3. Casts. Wood's Holl, Mass. U. S. Fish Commission.

21566. Alcoholic. New York market. E. G. Blackford.

Orcymus alalonga, (Gmelin) Risso.-Long-FINNED BONITO.Atlantic, Mediterranean.

21844. Alcoholic. Banquereau. Capt. Wm. Thompson.

Orcynus argenti-vittatus, (C. \& V.) Goode \& Bean?-Atlantic. 21702. Skins. Banquereau. Capt. Wm. Thompson. 
Cybium maculatum, (Mitch.) Cuv.-SPANISH MACKEREL.-Atlantic shores of Tropical and Temperate America.

15367. Cast. Norfolk, Va. U. S. Fish Commission.

16407. Cast. Wood's Holl, Mass. U. S. Fish Commission.

15750. Cast. New York. E. G. Blackford.

86. Photographs. U. S. Fish Commission.

514. Color sketch. (Richard.) U. S. Fish Commission.

663. Color sketeh. Prof. Alex. Agassiz.

Cybium regale, (Bl.) Cuv.-Spotted Cero.-West Indian Fauna and north to Cape Cod.

16622. Cast. Key West, Fla. E. G. Blackford.

87, 88, 89. Photographs. U. S. Fish Commission.

406-515. Color sketch. (Richard.) /U. S. Fish Commission.

21612. Stuffed. Cuba. Prof. Felipe Poey.

Cybium caballa, Cuv. \& Val.-Cero.-Atlantic Shores of Tropical and Temperate America.

16478. Cast. New York market. E. G. Blackford. Sept. 14, 1875.

90, 91, 92, 93, 94, and 95. Photographs. U. S. Fish Commission.

405-486-7. Color-sketch. (Richard.) U. S. Fish Commission.

21611. Stuffed. Cuba. Prof. Felipe Poey.

\section{CARAMGIDA.}

Vomer setipinnis, (Mitch.) Ayres.-SuvEr-FISH.-Maine to Florida. West Indian Fauna.

16915. Cast. Wood's Holl, Mass. V. N. Edwards. Sept. 7, 1873.

16615. Cast. New York. E. G. Blackford.

Argyreiosus vomer, Lac.-Silver-FisH.-Cape Cod to Florida, and West Indian Fauna.

16475. Cast. New York. E. G. Blackford.

15905. Cast. Wood's Holl, Mass. V. N. Edwards.

96. Photograph. U. S. Fish Commission.

440, 495. Color shetches. (Richard.) U. S. Fish Commission.

Paratractus pisquetus, (Cuv. \& Val.) Gill.-Yellow CreVALLÉ.-Cape Cod to Florida.

16471. Cast. Woơ's Holl, Mass. U. S. Fish Commission. Sept. 14, 1875.

15843. Cast. Wood's Holl, Mass. U. S. Fish Commission.

15888. Cast. Wood's Holl, Mass. U. S. Fish Commission.

15887. Cast. Wood's Holl, Mass. U. S. Fish Commission.

98, 99, 100. Photographs. U. S. Fish Commission.

778-9. Color sketches. (Richard.) U. S. Fish Commission.

Trachurops crumenophthalmus, (Bloch.) Gill.-BIG-EYED SCAD ; GOGGLE-EYE.-Pelagic.

16181. Aleoholic. New York market. E. G. Blackford.

97. Photograph. U. S. Fish Commission. 
Decapterus punctatus, (Mitch.) Gill.-Round Robin.-West Indian Fauna and north to Massachusetts.

18951. Alcoholic. Wood's Holl, Mass. U. S. Fish Commission.

21365. Alcoholic. Bermudas. G. Brown Goode.

Decapterus macarellus, (C. \& V.) Gill.-MACKEREL ScAD.West Indian Fauna and north to Massachusetts.

16239. Alcoholic specimen. 'Wood's Holl, Mass. U. S. Fish Commission. 21630. Alcoholic. Newport, R. I. Samuel Powel.

Carangus hippos, (Linn.) Gill.-Horse CrevaluÉ.-Atlantic Coasts of Temperate and Tropical America, East Indian and Australian Seas.

14859. Cast. Florida. E. G. Blackford.

101. Photograph. U. S. Fish Commission.

21654. Alcoholic. Newport, R. I. Samuel Powel.

Carangus chrysos, (Mitch.) Gill.-Yellow MACKerel.-West Indian Fauna and north to Cape Cod.

15708. Cast. Wood's Holl, Mass. U. S. Fish Commission. Sept. 15, 1373. 15746. Cast. Wood's Holl, Mass. U. S. Fish Commission. Oct. 8, 1873. 15696. Cast. Wood's Holl, Mass. U. S. Fish Commission. 102, 103. Photographs. U. S. Fish Commission.

Blepharichthys crimitus, (Akerly) Gill.-THrEAD-FISH.-West Indian Fauna and north to Cape Cod.

16520. Cast. Wood's Holl, Mass. U. S. Fish Commission. Sept. 18, $18 \% 5$. 105-105. Photographs. U. S. Fish Commission.

475. Color sketch. (Richard.) U. S. Fish Commission.

Zonichthys fasciatus, (Bloch.) Sw.-BErmudA Bonito; MEDREGLL.-Cuba, South Carolina, Bermuda.

15828. Cast. New York. E. G. Blackford.

404. Color sketch. U. S. Fish Commission.

Trachynotus carolinus, (Linn.) Gill. - PoMpavo. - Atlantic Coasts of America south of Cape Cod.

15904. Cast. Norfolk, Va. U. S. Fish Commission. June 20, 1873.

15809. Cast. New York market. E. G. Blackford. October 12, 1875.

106, 107. Photographs. U. S. Fish Commission.

473-4. Color sketches. (Richard.) U. S. Fish Commission.

Trachynotus ovatus, (Linn.) Gthr.-Short Ponrpano.-Pelagic.

16707. New York. E. G. Blackford.

400. Color sketch. (Young.) (Richard.) Vineyard Haven, Mass. U. S. Fish Commission.

547. Color sketch. (Richard.) U. S. Fish Commission. 
Halatractus zonatus, (Mitch.) Gill.-BANDED RUDDER-HISH.Cape Cod to Florida.

16472. Cast. Wood's Holl, Mass. U. S. Fish Commission. Sept. 14, 1875.

16532. Cast. Wood's Holl, Mass. U. S. Fish Commission.

108-9. Photographs. U. S. Fish Commission.

477. Color sketch. U. S. Fish Commission.

478. Color sketch. U. S. Fish Commission.

479. Color sketch. U. S. Fish Commission.

Seriola Lalamdii, C. \& V.?-Anner-FIsH.-Atlantic Ocean; Japan.

16r09. Cast. Florida. E. G. Blackford.

110. Photograph. U. S. Fish Commission.

Oligoplites occidentalis, (Linn.) Gill.-LeATHER JACKET.West Indies ; occasional on coast.

16354. Cast. New York market. E. G. Blackford. Ang. 13, 1875.

111. Photograph. U. S. Fish Commission.

429. Color sketch. (Richard.) U. S. Fish Commission.

\section{CORYPHANID A.}

Coryphana Sueuri, Cuv. \& Val.-DoLPHrN.-Pelagic; occasional on coast.

16441. Cast. New York market. E. G. Blackford.

- Color sketch. (Richard.) U. S. Fish Commission.

16420. Cast. New York. E. G. Blackford.

16482. Cast. New York. E. G. Blackford.

Coryphana punctulata, (Cuv. \& Val.) Gthr.-SMALL-SPOTTED DolPHIN.-Pelagic; occasional on coast.

16406. Cast. Noank, Conn. J. H. Latham. Ang. 25, 1875.

112, 113, and 114. Photographs. U. S. Fish Commission.

\section{STROMATEID E.}

Palinurichthys perciformis, (Mitch.) Gill.-BLACK RUDDERFISH.-Newfoundland to Cape Hatteras.

16616. Cast. Martha's Vineyard. U. S. Fish Commission. Sept. 25, $18 \% 5$.

15935. Cast. Wood's Holl, Mass. U. S. Fish Commission.

544. Color sketch. (Richard.) U. S. Fish Commission.

Poronotus triacanthus, (Peck.) Gill.-Harvest-Fish; ButterFISH.-Maine to Cape Hatteras.

16591. Cast. Wood's Holl, Mass. U. S. Fish Commission.

115. Photograph. U. S. Fish Commission.

359-60-61. Color sketches. (Richard.) U. S. Fish Commission.

516-17. Color sketches. 
Peprilus Gardenii, (Bl., Schn.) Gill.-Short Harvest-Fish.West Indian Fauna and north to New York.

16819. Cast. Chesapeake Bay. Sibley.

15234. New York market. John Sutherland.

\section{LATILID AE.}

Caulolatilus microps, Goode \& Bean.-Gulf of Mexico.

20971. Alcoholic. Pensacola, Fla. Silas Stearns.

\section{IBERYCID A.}

Holocentrum sogo, Bloch.-SQuirrel.-West Indian Fauna, accidental on coast; found at Newport, R. I.

578. Color sketch. (Burkhardt.) Bermudas. Prof. Alex. Agassiz. Alire in Barnum's Aquarium. Dec., 1862.

595. Color sketch. (Burkhardt.) New Providence. Prof. Alex. Agassiz; F S. Shaw. April, 1861.

21232. Alcoholic. Bermudas. J. M. Jones.

\section{SCIA ENIDA.}

Cynoscion regalis, (BI.) Gill.-Squeteague; Weak-Fish.-Cape Ann to Florida.

16216. Cast. Wood's Holl, Mass. U. S. Fish Commission. July 27, 1875.

12216. Cast. Wood's Holl, Mass. U. S. Fish Commission. Julr 27, 1875.

116, 117, 118, 119. Photographs. U. S. Fish Commission.

469-70. Color sketches. (Richard.) U. S. Fish Commission.

Cymoscion carolinensis, (Cuv. \& Val.) Gill.-SPotted SQUETEAGUE.-Gulf of Mexico and Southern Atlantic States.

15928. Cast.

15929. Cast.

120, 121, 122. Photographs. U. S. Fish Commission.

790. Color sketch. (Richard.) U. S. Fish Commission.

Cynoscion nothus, Holbrook.-SILver SqueTEAGUE.-Southern Coast.

21480. Alcoholic. Pensacola, Fla. Silas Stearns.

Pogonias chromis, Lacep.-Drux.-Cape Cod to Florida; Gulf of Mexico.

15699. Cast. Wood's Holl, Mass. U. S. Fish Commission.

15686. Cast. Fisher's Island Sound. Charles Potter. July 10, 1874.

123, 124, 125. Photographs. U. S. Fish Commission.

791. Color sketch. (Richard.) U. S. Fish Commission.

21282. Alcoholic. St. John's River, Fla. G. Brown Goode. 
ANIMAL RESOURCES AND FISHERIES OF UNITED STATES.

Haploidonotus grumniens, Raf.-Fresh-WATER DRUM.-Great Lakes and Mississippi Valley.

15701. Cast. Sandusky, Ohio. J. W. Milner. 1873.

1:26-127. Photographs. U. S. Fish Commission.

Liostomus obliquus, (Mitch.) De Kay.-SpoT._Cape Cod to Florida.

15816. Cast. Norfolk, Va. U. S. Fish Commission.

15817. Cast. June 10, 1873.

141. Photograph. U. S. Fish Commission.

56\%. Color sketch. Now York. Prof. Alex. Agassiz. Oct. 26, 1847.

Liostomus xanthurus, Lacep.-YELLOW-TAILED SPOT.-Southern Atlantic States.

142. Photograph. U. S. Fish Commission.

Bairdiella punctata, (Linn.) Gill.-SIlver-fish; Yellow TAIL.-Cape Cod to Florida.

143. Photograph. U. S. Fish Commission.

19060. Alcoholic. St. John's River, Florida. G. Brown Goode.

Sciaenops ocellatus, (Linn.) Gill.-Red Bass ; Spotted Bass.Cape Cod to Florida; Gulf of Mexico.

15463. Cast. Washington market. J. W. Milner.

15739. Cast. New York. E. G. Blackford.

128, 129, 130. Photographs. U. S. Fish Commission.

—. Oil painting. (J. H. Richard.)

Menticirrus alburnus, (Linn.) Gill.-Southerv Krvg-FISH.Cape Hatteras to Florida.

137. Photograph. U. S. Fish Commission.

19081. Alcoholic. St. John's River, Fla. G. Brown Goode.

Menticirrus nebulosus, (Mitch.) Gill.-Krra-FISH.-Cape Cod. to Florida.

16219. Cast. Wood's Holl, Mass. U. S. Fish Commission. July 27, 1875.

15579. Cast. New York market. E. G. Blackford. October 14, 1875.

15579. Cast. New York market. E. G. Blackford. October 14, 1875, 131, 132, 133, 134, 135, and 136. Photographs. U. S. Fish Commission. 508-9-10-11-12. Color sketches. (Richard.) U. S. Fish Commission.

Micropogon undulatus, (Linn.) Cuv. \& Val.-CroAKer.-Atlantic Coasts of America south of Cape Cod.

15845. Cast. Norfolk, Va. U. S. Fish Commission. June 19, 1873. 15810. Cast. Norfolk, Va. U. S. Fish Commission. July 18, 1873. 138, 139, 140. Photographs. U. S. Fish Commission. 19056. Alcoholic. St. John's River, Fla. G. Brown Goode. 


\section{GERIRIDA.}

Eucinostomus argenteus, B. \& G.-Cape Cod and southward. 16960. Alcoholic. Wood's Holl, Mass. U. S. Fish Commission.

Eucinostomus Lefioyi, Goode.-Bermuda Shad.-West Indian Fauna.

21358. Alcoholic. Bermudas. G. Brown Goode.

\section{PIMELEPTERIDA.}

Pimelepterus Boscii, Lacep.-BrfaAr.-West Indian Fauna and north to Cape Cod.

20844. Alcoholic. Newport, R. I. S. Powell.

20635. Alcoholic. Wood's Holl, Mass. U. S. Fish Commission.

21368. Alcoholic. Bermudas. G. Brown Goode.

\section{SPARIDAE.}

Lagodon rhomboides, (Linn.) Holbrook.-SAILOR's CHoICE.West Indian Fauna and north to Cape Cod.

21280. Alcoholic. St. John's River, Fla. G. Brown Goode.

Archosargus probatocephalus, (Walb.) Gill.-SHEEPSHEAD.Cape Cod to Florida; Gulf of Mexico.

10685. Cast. Washington market. J. W. Milner.

15825. Cast. New York market. E. G. Blackford. October 20, 1875.

15826. Cast. New York market. E. G. Blackford. October 14, 1875.

14880. Cast. Norfolk, Va. U. S. Fish Commission. July 11, 1872.

15818. Cast. New York. E. G. Blackford.

144, 145. Photographs. U. S. Fish Commission.

548. Color sketch. (Richard.) U. S. Fish Commission.

Stenotomus argyrops, (Linn.) Gill._ScUPPAUG; ScUP; PORGY.Cape Ann to Florida.

16035. Cast. Buzzard's Bay. U. S. Fish Commission. July 10, 1875.

10668. Cast. Wood's Holl, Mass. V. N. Edwards.

16209. Cast.

10601. Cast. Wood's Holl, Mass. V. N. Edwards.

146-47. Photographs. U. S. Fish Commission.

439. Color sketch. (Young.) (Richard.) U. S. Fish Commission.

Sargus Holbrookii, Bean.-ChARLESTON BREAM.-Carolinas.

20979. Cast. Charleston, S. C. G. Brown Goode.

Sparus aculealus, (Cuv. \& Val.) Gill.?-BASTARD SNAPPER.Southern Coast.

20981. Cast. Charleston, S. C. G. Brown Goode. 


\section{PRISTIPOMATIDAE.}

Hamylum arcuatum, Cuv. \& Val.-BLUE-CHECKED RED-MOUTH. -South Atlantic Coast of United States.

14907. Cast. Florida. E. G. Blackford.

Hamylum formosum, (Linn.) Cur.-SQUTREL RED-MOUTH.South Atlantic Coast of United States.

15846. Cast. Florida. E. G. Blackford.

HamyIum, sp.-South Atlantic Coast of United States.

15840. Cast. Florida. E. G. Blackford.

Hamylum chrysopterum, (Linn.) Cuv.? - YeLlow-Finned GrUNT.-South Atlantic Coast of United States.

15918. Cast. Florida. E. G. Blackford.

Haemylum elegans, Cuv. \& Val.-BLUE-STRTPED RED-MOUTH.South Atlantic Coast of United States.

15815. Cast. Florida. E. G. Blackford.

573. Color sketch. (Dall.) Florida. Prof. Alex. Agassiz. Alive in Boston Aquarial Garden. June, 1860.

574. Color sketch. (Burkhardt.) Bermudas. Prof. Alex. Agassiz. Alive in Barnum's Aquarium. Nov. 1862.

Hremylum arara, Poey?-ARARA RED-MoUth.-West Indian Fauna.

552. Water-color.sketch. (Burkhardt.) Florida. Prof. Alex. Agassiz. Alive in Boston Aquarial Garden. June, 1860.

Orthopristis fulvomaculatus, (Mitch.) Gill.-SPECKLED GRUNT.-South Atlantic Coast of United States.

15812. Cast. Norfolk, Va. U. S. Fish Commission.

15814. Cast. Norfolk, Va. U. S. Fish Commission.

15908. Cast.

Anisotremus virginicus, (Linn.) Gill.-South Atlantic Coast of United States.

15903. Cast. Florida. E. G. Blackford. April 16, $18 \% 4$.

148. Photograph. U. S. Fish Commission.

551. Color sketch. (Burkhardt.) New Providence. Prof. Alex. Agassiz; F. S. Shaw. April, 1861.

Lutjanus Blackfordii, Goode \& Bean.-RED SNAPPER.-West Indian Fauna and north to Sarannah Bank.

15700. Cast. New York market. E. G. Blackford. May 7, 1874.

12515. Cast. Washington market. J. W. Milner.

149. Photograph. U. S. Fish Commission. 
Lutjanus, sp.-SNaPPER.-West Indian Fauna and Southern Atlantic States.

15917. Cast. Florida. E. G. Blackford.

Lutjanus, sp.- - South Atlantic Coast of United States.

16641. Cast. Key West, Fla. E. G. Blackford.

Lutjanus caxis, (Bl., Schn.) Gill.-Gray SNAPPER.-West Indian Fauna and Southern Atlantic States.

18101. Alcoholic. Bermudas. G. Brown Goode.

Lutjanus Stearnsii, Goode \& Bean.-Gulf SNAPPER.-Gulf of Mexico.

21330. Cast. Pensacola, Fla. Silas Stearns.

Rhomboplites, aurorubeus, (Cuv. \& Val.) Gill.-Mangrove SNAPPER.-West Indian Fauna.

21224. Alcoholic. Charleston, S. C. C. C. Leslie.

21338. Alcoholic. Pensacola, Fla. Silas Stearns.

Dcyurus chrysurus, (Bl.) Gill._GoLden TaIL.-West Indian Fauna.

14905. Cast. New York market. Florida. E. G. Blackford. April 16, 1874.

150. Photograph. U. S. Fish Commission.

555. Color sketch. (Burkhardt.) New Providence. Prof. Alex. Agassiz; F. S. Shaw. April, 1861.

\section{CENTRA RCHIDAE.}

Eupomotis aureus, (Walb.) Gill \& Jordan.-SuN-FISH.-Fresh waters of Eastern North America.

14941. Cast. Washington market. G. Brown Goode. February, 1875.

151, 152. Photograph. U. S. Fish Commission.

505. Color sketch. (Richard.) U. S. Fish Commission.

Lepiopomus pallidus, (Mitch.) Gill \& Jordan.-BLUE-NosE BREAM.-Great Lakes and Southeastern United States.

18368. Alcoholic. St. John's River, Fla. G. Brown Goode.

Pomoxys nigromaculatus, (Les.) Girard.-Grass B $\Delta$ Ss.-Great Lakes, Mississippi Valley, and Southern Atlantic States.

10382. Cast. Norfolk, Va. Dr. H. C. Yarrow.

153, 154. Photograph. U. S. Fish Commission.

Ambloplites rupestris, (Raf.) Gill.-Rock BASS.-Great Lakes and Mississippi Valley.

15958. Cast. U. S. Fish Commission.

151. Photograph. U. S. Fish Commission. 
Micropterus pallidus, (Raf.) Gill \& Jordan.-LARGE-MrouTH BLACK BAss.-Great Lakes, Mississippi River and tributaries; Southern States; introduced northward.

10380. Cast. Norfolk, Va. Dr. H. C. Yarrow.

10668. Cast. Norfolk, Va. U. S. Fish Commission. Nov. 5, 1873.

10381. Cast. Norfolk, Va. Dr. H. C. Yarrow.

15880. Cast. Carrollton, Ky. J. W. Milner.

10380. Cast. Norfolk, Va. Dr. H. C. Yarrow.

155, 156. Photographs. U. S. Fish Commission.

Micropterus salmoides, (Lac.) Gill.-SMaLL-MoUthed BLACK BAss.-Great Lakes and Mississippi Valley; introduced eastward.

15297. Cast. Potomac River. Maj. Hobbs.

\section{PERCID A.}

Perca fuviatilis, L.-Yellow Perch.-Fresh waters of Eastern United States and Western Europe.

14976. Cast. Washington market. G. Brown Goode. Feb. 27, 1875.

167, 168, 169. Photographs. U. S. Fish Commission.

792. Color sketch. (Richard.) U. S. Fish Commission.

Stizostedium vitreum, (Mitch.) Jordan \& Copeland, (Val.) Cope. - Yellow PIKE-PERCH.-Fresh waters of Central United States.

15658. Cast. New York market. E. G. Blackford.

14862. Cast. Sandusky, Ohio. J. W. Milner. Oct., 1873.

611. Color sketch. (Roetter.) Sackett's Harbor, N. Y. Prof. Alex. Agassiz. Nov., 1868.

15658. Cast. New York market. E. G. Blackford. Nov. 5, 1875.

170, 171, 172, 173, 174. Photographs. U. S. Fish Commission.

793. Color sketch. (Richard.) U. S. Fish Commission.

Stizostedium canadense, (Smith) Jordan. - CANAdA PIKEPERCH.-St. Lawrence River to the Upper Missouri.

178. Photograph. U. S. Fish Commission.

15752. Cast. Ohio River. J. W. Milner.

15837. Cast.

175, 176, 177. Photographs. U. S. Fish Commission.

\section{SERRANID E.}

Epinephelus morio, (Cuv.) Gill.-RED-BELLIED SNAPPER.-West Indian Fauna and Southern Atlantic States.

12516. Cast. Washington market. J. W. Milner.

165. Photograph. U. S. Fish Commission.

Epimephelus, sp.-SNAPPER.-West Indian Fauna and Southern Atlantic States.

14923. Cast. Florida. E. G. Blackford.

Bull. N. M. No. $14-4$ 
Epinephelus Drummond-Hayi, Goode \& Bean.-STAR SNAPPER; HIND; JOHN PAW.-West Indian Fauna.

16795. Cast. South Florida. E. G. Blackford.

21255. Alcoholic. Pensacola, Fla. Silas Stearns.

—. Color sketch. Bermuda. Col. H. Drummond-Hay.

Epinephelus nigritus, Holbrook.-BLACK GROUPER.-Coast of Florida.

21239. Cast. Pensacola, Fla. Silas Stearns.

Epinephelus striatus, (Bloch.) Gill.-HAMLET; Grouper.West Indian Fauna.

18088. Alcoholic. Bermudas. G. Brown Goode.

582. Color sketch. (Burkhardt.) Bermudas. Prof. Alex. Agassiz. Alive in Barnum's Aquarium. Nov., 1862.

Epinephelus guttatus, (Gmel.) Goode.-Bermuda Hind.-West Indian Fauna.

18118. Alcoholic. Bermudas. G. Brown Goode.

587. Color sketch. (Burkhardt.) Bermudas. Prof. Alex. Agassiz. Alive in Barnum's Aquarium. Nov., 1862.

Trisotropis undulosus, (Cuv.) Gill.?-Rock Grouper.-Cape Hatteras to Florida; West Indian Fauna.

15462. Cast. Now York market. E. G. Blackford. June 14, 1875.

15881. Cást. New York market. E. G. Blackford. June 14, 1875.

794. Color sketch. (Richard.) U. S. Fish Commission.

Promicrops guasa, (Poey) Gill.-JEW-FISH; GuAsA.-West Indian Fauna.

15305. Cast. Key West. E. G. Blackford.

444. Color sketch. (Richard.) U. S. Fish Commission.

Centropristis atrarius, (Linn.) Barn.-SEA BAss.-Cape Cod to Florida.

10642. Cast. Wood's Holl, Mass. U. S. Fish Commission.

10597. Cast. Wood's Holl, Mass. U. S. Fish Commission. May 12, 1874.

15684. Cast. (Male.) Noank, Conn. U. S. Fish Commission. August, 1874.

15685. Cast. Wood's Holl, Mass. U. S. Fish Commission. September 2, 1875.

10667. Cast. (Female.) Wood's Holl, Mass. U. S. Fish Commission.

15963. Cast. Hog-fish Rocks, Va. U. S. Fish Commission. July 5, 1873.

157, 158, 159, 160, 161, 162, 163, 164, :81. Photographs. U. S. Fish Commission. 463-4 and 5. Color sketches. (Richard.) U. S. Fish Commission.

Diplectrum fasciculare, (Cuv. \& Val.) Holb.-SQUIRREL.Cape Hatteras to Florida; West Indian Fauna.

15844. Cast. New York. E. G. Blackford.

166. Photograph. U. S. Fish Commission. 


\section{LA B RA CIDAE.}

Roccus lineatus, (Schn.) Gill._STRIPED BASS; Rock-FISH.-St. Lawrence to Florida.

10664. Cast. (Female.) Potomac River. Dr. H. C. Yarrow.

15737. Cast. Wood's Holl, Mass. U. S. Fish Commission. May 27, 1873.

15725. Cast. Washington market. G. Brown Goode.

15706. Cast. New York. E. G. Blackford. Nov. 28, 1874.

185-186, 187. Photographs. U. S. Fish Commission.

782-3. Color sketch. (Richard.) U. S. Fish Commission.

Roccus chrysops, (Raf.) Gill.-White BASS.-Great Lakes and Mississippi Valley.

15807. Cast. New York market. E. G. Blackford. Oct. 7, 1875.

188. Photographs. U. S. Fish Commission.

503. Color sketch. (Richard.) U. S. Fish Commission.

Iorone americana,(Gmel.) Gill.-WHIte Perch.-Nova Scotia to Florida.

10748. Cast. Wood's Holl, Mass. U. S. Fish Commission.

10729. Cast. (Female.) Wood's Holl, Mass. U. S. Fish Commission.

10730. Cast. Wood's Holl, Mass. U. S. Fish Commission.

16618. Cast. Wood's Holl, Mass. U. S. Fish Commission.

179, 180, 181, 182, 183, 184. Photographs. U. S. Fish Commission.

766. Color sketch. (Richard.) U. S. Fish Cotumission.

\section{EPHIPPIID E.}

Parephippus quadratus, (Gun.) Gill.-Moon-FISH.-Cape Cod to Florida; West Indian Fauna.

14886. Cast. Norfolk, Va. U. S. Fish Commission. July, 1873.

14887. Cast. Norfolk, Va. U. S. Fish Commission. July, 1873.

15820. Cast. Norfolk, Va. U. S. Fish Commission.

196, 197. Photographs. U. S. Fish Commission.

\section{LOBOTID $A$.}

Lobotes surinamensis, Cuv. - TRIPLE-TAII FLASHER.-Cape Cod to Florida; West and East Indies.

15702. Cast. Wood's Holl, Mass. U. S. Fish Commission. August 28, 1873. 16202. Cast. New York market. E. G. Blackford. July 20, 1875. 201, 202. Photographs. U. S. Fish Commission.

\section{POMATOMIDA.}

\section{Pomatomus saltatrix, (Linn.) Gill.-BLuE-FISH.-Pelagic.}

15871. Cast. Wood's Holl, Mass. V. N. Edwards. June 11, 1873.

13166. Cast. Norfolk, Va. G. Brown Goode.

15753. Cast.

189, 190, 191, 192, 193, 194, 195, 386. Photographs. U. S. Fish Commission. 528-2-30. Color sketches. (Richard.) U. S. Fish Commission. 


\section{ELACATHDAE.}

Elacate camadus, (Linn.) Gill._Cobia ; Crab-eater.-Cape Cod to West Indies.

16250. Cast. New York market. E. G. Blackford. July 30, 1875.

14922. Cast. Point Lookout, Va. J. H. Skidmore. July 9, 1874.

198, 199, 200. Photographs. U. S. Fish Commission.

-

\section{PIRACANTHIDAE.}

Pseudopriacanthus altus, (Gill) Bleeker.-SHORT BIG-EYE.Cape Cod to Cape Hatteras.

203. Photograph. U. S. Fish Commission.

441. Color sketch. (Richard.) U. S. Fish Commission.

15583. Alcoholic. Wood's Holl, Mass. U. S. Fish Commission. Sept., 1875.

16954. Alcoholic. Wood's Holl, Mass. U. S. Fish Commission. 1876.

\section{ECHENEIDIDA.}

Leptecheneis naucrateoides, (Zuiew.) Gill.-REMORA; SUCKERFISH.-Coast generally.

16071. Cast. Wood's Holl, 'Mass. U. S. Fish Commission. Jnly 10, 1875.

16617. Cast. Wood's Holl, Mass. U. S. Fish Commission. Sept. 18, 1875.

16344. Cast. Wood's Holl, Mass. U. S. Fish Commission. Aug. 10, 1875.

206, 207, 208. Photographs. U. S. Fish Commission.

541-2-3. Color sketch. (Richard.) U. S. Fish Commission.

Remoropsis brachyptera, (Lowe) Gill.-SwORD-FISH SUCKER.

-Parasite of the Sword-fish (Xiphias gladius).

21693. Alcoholic. Sable l'd Bank. Capt. G. A. Johnson.

Rhombochirus osteochir, (Cuv.) Gill.-SPEAR-FISH SUCKER.Parasites of the Bill-fish (Tetrapturus albidus).

15842. Cast. Wood's Holl, Mass. U. S. Fish Commission.

209, 210, 211. Photographs. U. S. Fish Commission.

764-5. Color sketches. (Richard.) U. S. Fish Commission.

\section{SPIIYR AENIDAE.}

Sphyrana borealis, De Kay.-Northern BARRACUdA.-Cape Cod to Florida.

14978. Cast. Florida. E. G. Blackford.

204, 205. Photographs. U. S. Fish Commission.

407. Color sketch. (Richard.) U. S. Fish Commission. Probably identical with Sphyrona spet (Hauy) Goode, the common species of the Mediterranean. 
ANIMAL RESOURCES AND FISHERIES OF UNITED STATES.

Sphyraena picuda.-SOUTHERN BARRACUdA. - West Indian Fauna, \&c.

21886. Alcoholic. Bermudas. G. Brown Goode.

\section{PERCESOCES.}

\section{MUGILID $A$ E.}

Mugil limeatus, Mitch.-STRIPED Muldet.-Cape Cod to Florida; Gulf of Mexico.

15723. Cast.

212, 213, 214, 215, 216. Photographs. U. S. Fish Commission.

421. Color sketch. (Richard.) U. S. Fish Commission.

Mugil albula, Linn.-White Mullet.-Cape Cod to Florida (probably young of the preceding species).

420. Color sketch. (Richard.) U. S. Fish Commission.

21302. Alcoholic. Florida. G. Brown Goode.

\section{ATHERTNIDA.}

Chirostoma notatum, (Mitch.) Gill.-SILVER-SDEAS; FrIAR.Maine to Florida.

14930. Cast.

16612. Cast.

16620. Cast. Wood's Holl, Mass. U. S. Fish Commission.

380, 382. Photographs. U. S. Fish Commission.

518. Color sketch. (Richard.) U. S. Fish Commission.

Chirostoma californiensis, (Girard) Gill._"SMELT."-Coast of California.

506. Color sketch. (Richard.) U. S. Fish Commission.

16693. Alcoholic. San Francisco. Livingston Stone.

16693. Cast. San Francisco. U. S. Fish Commission.

\section{HEMIBRANCHII. \\ GASTEROSTEIDAE.}

Pygosteus occidentalis, (Cuv. \& Val.) Brevoort.-TEN-SPINED STICKLE-BACK.-Newfoundland to Cape Hatteras.

384. Photograph. U. S. Fish Commission.

644. Color sketch. (Burkhardt.) Prof. Alex. Agassiz.

Gasterosteus moveboracensis, Cuv. \& Val.-New YoRK STICKLE-BACK.-New Brunswick to Cape Hatteras.

644. Color sketch. (Burkhardt.) Prof. Alex. Agassiz. 
Apeltes quadracus, (Mitch.) Brev.-FouR-SPINEd STICKLE-BACK. -New Brunswick to Florida.

384. Photograph. U. S. Fish Commission.

644. Color sketch. (Burkhardt.) Prof. Alex. Agassiz.

Many other species of Gasterosteus are included in the series, which were not of sufficient importance to be enumerated.

\section{AUHASTOVIITDE.}

Aulostoma maculatum, Val.-TRUMPET-FISH. - West Indian Fauna.

568. Color sketch. (Burkhardt.) Prof. Alex. Agassiz.

\section{FISTULAREIDAE.}

Fistularia serrata, Cuv.-ToB.lcco-PIPE-FISH.-Cape Cod to Florida; West Indian Fauna.

16957. Alcoholic. Wood's Holl, Mass. U. S. Fish Commission. 1876.

\section{SYNENTOGNATHI.}

\section{BELONHDA.}

Belone longirostris, (Miteh.) Gill.-SILver GAR-FISH.-Cape Cod to Florida.

16555. Cast. Wood's Holl, Mass. U. S. Fish Commission. Sept. 21, 1875.

16423. Cast. Wood's Holl, Mass. U. S. Fish Commission. Sept. 6, 1875.

217. Photograph. U. S. Fish Commission.

563. Color sketch. Prof. Alex. Agassiz.

540. Color sketch. (Richard.) U. S. Fish Commission.

Belone latimanus, Poey.-Silver Gar-Fish.-Cape Cod to Florida.

16121. Cast. Wood's Holl, Mass. U. S. Fish Commission. July 15, 1875.

795. Color sketch. (Richard.) U. S. Fish Commission.

218. Photograph. U. S. Fish Commission.

Belone hians, Cuv. \& Val.-Bow-Mouthed GAR-FISH.-West Indian Fauna.

21810. Alcoholic. New York market. G. Brown Goode.

Belone Jonesii, Goode.-Hound-FIsH.-West Indian Fauna.

21392. Alcoholic. Bermudas. G. Brown Goode.

\section{SCOMBERESOCIDA.}

Exocatus exiliens, Gmel.-ButterFLy FLYING-FISH.-West Indian Fauna and north to Cape Cod.

21410. Alcoholic. Bermudas. G. Brown Goode. Mar., 1872. 
Exocotus noveboracensis, Mitch.?-BLACK-WINGED FLYINGFISH.-Cape Cod to Florida.

—. Alcoholic. Block Island, R. I. U. S. Fish Commission. Aug., 1874.

Exocotus Rondeletii, Cuv. \& Val.-Mediterranean and Atlantic. 21409. Alcoholic. Bermudas. G. Brown Goode.

Cypselurus furcatus, (Mitch.) Weinland.-BEARDED FLYINGFISH.-Atlantic.

21412. Alcoholic. Bermudas. G. Brown Goode.

Euleptor'hamphus longirostris, (Cuv. \& Val.) Gill._Cape Cod to Florida.

15648. Alcoholic. Newport, R. I. Mr. Brown.

Scomberesox scutellatus, Les.-HALF-BEAK; SKIPPER.-Nova Scotia to Florida.

13164. Cast.

410, 539. Color sketches. (Richard.) U. S. Fish Commission.

\section{HAPLOMI.}

\section{ESOCID AE.}

Esox americanus, Gmelin.-BrooK PICKEREL.-Massachusetts to Maryland.

17766. Alcoholic. Keeseville, N. Y. H. N. Hewitt.

796. Color sketch. (Richard.) U. S. Fish Commission.

493. Color sketch. Prof. Alex. Agassiz.

Esox reticulat us, Lesueur.-PICKEREL.-Atlantic slope, New England to Alabama.

15012. Cast. Washington, D. C. G. Brown Goode.

222. Photograph. U. S. Fish Commission.

758. Color sketch. U. S. Fish Commission.

619. Color sketch. (Roetter.) East Wareham, Mass. Museum of Comp. Zoology. Feb., 1869.

Esox Iucius, Linn.-PIKE.-Northern America, Asia, and Europe.

14876. Cast. Sandusky, Ohio. J. W. Milner. Oct. 25, 1873.

14875. Cast. Sandusky, Ohio. J. W. Milner. Nov. 3, 1873.

219. Photograph. U. S. Fish Commission.

618. Color sketch. (Roetter.) Museum of Comp. Zoology. Sackett's Harbor. Nov., 1869.

494. Color sketch. Prof. Alex. Agassiz.

Esox nobilior, Thompson.-MUSKELLUNGE (weight 37 pounds).Great Lakes and Southern British Provinces east of Rocky Mountains. 


\section{CYPIR INODONTHDAE.}

Cyprinodon variegatus, Lac.-SHORT CYPRINODON.-Cape Cod to Florida.

13986. Alcoholic. Noank, Conn. U. S. Fish Commission.

Fundulus pisculentus, (Mitch.) Val.-MuмmrcHoG.-Nova Scotia to Florida.

13970. Alcoholic. Noank, Conn. U. S. Fish Commission.

434, 797. Color sketches. (Richard.) U. S. Fish Commission.

Hydrargyra majalis, (Walb.) Val._MAY-FISH._Brackish waters;

Cape Ann to Cape Hatteras.

223-383. Photographs. U. S. Fish Commission.

13974. Alcoholic. Noank, Conn. U. S. Fish Commission.

434. Color sketch. (Richard.) U. S. Fish Commission.

\section{ISOSPONDYLI.}

\section{SYTODONTIDAE.}

Synodus fotens, (Linn.) Gill.-SNAKE-FISH.-Cape Cod to Florida.

16583. Cast. New York market. E. G. Blackford. Sept. 24, 1875.

424. Color sketch. (Richard.) U. S. Fish Commission.

\section{MICROSTOMIDAE.}

Mallotus villosus, (Müll.) Cuv.-CAPELIN.-Polar Seas and south to Nova Scotia.

3417. Alcoholic. Gross Water Bay. Dr. E. Coues.

Osmerus pacificus, (Rich.) -OULACHAN; CANDLE-FISH.-North Pacific.

20584. Alcoholic. Washington Ter. U. S. Fish Commission.

Osmerus mordax, (Mitch.) Gill._Syelt ; Frost-FISH._Nova Scotia to Cape Hatteras.

385. Photograph. U. S. Fish Commission.

507. Color sketch. (Richard.) U. S. Fish Commission.

13863. Alcoholic. Eastport, Me. U. S. Fish Commission.

Argentina syrtensium, Goode \& Bean.-WEstern ArGenTINE.-Deep-sea Fauna of Western Atlantic.

21624. Alcoholic. Sable Island Bank. Capt. J. W. Collins. 


\section{COREGONHDA.}

Coregonus clupeiformis, (Mitch.) Milner. - WHITE-FISH.Great Lakes and British America.

16741. Cast. Michigan.

14973. Cast. Ecorse, Mich. George Clark.

15741. Cast. Ecorse, Mich. George Clark.

14864. Cooperstown, N. Y. Elihu Phinney.

224, 225, 226, 227, 228, 229, 230. Photographs. U. S. Fish Commission.

Coregonus labradoricus, Rich.-LAKE WHITING.-Northern Lakes.

232. Photograph. U. S. Fish Commission.

16868. Alcoholic. Lake Winnepiseogee, Me. U. S. Fish Commission.

Prosopium quadrilaterale, (Rich.) Milner.-_"SHAD-WATTER." -Great Lakes and northward.

233. Photograph. U. S. Fish Commission.

12360. Alcoholic. Grand Lake, Me. U. S. Fish Commission.

Prosopium Couesii, Milner.-Chief Mountarn Lake WhiteFISH.-Upper Missouri Region.

14146. Alcoholic. Chief Mountain Lake. Dr. Elliott Cones, U. S. A.

Argyrosomus Artedi, (Les.) Hoy.-Herring WHITE-FISH.Great Lakes, etc.

235. Photograph. U. S. Fish Commission.

752. Color sketch. (Richard.) U. S. Fish Commission.

11195. Alcoholic. An Sable, Michigan. U. S. Fish Commission.

\section{SALVONIDA.}

Salmo salar, Linn.-SALMON.-Northern America and Europe.

14898. Cast. Bucksport, Me. Joseph Palmer. July 1, 1873.

16744. Cast. Bucksport, Me. C. G. Atkins. Nov., 1873.

16743. Cast. Bucksport, Me. C. G. Atkins. Nov., 1873.

10314. Cast. Bucksport, Me. C. G. Atkins. July 1, 1873.

239, 240, 241, 242. Photographs. U. S. Fish Commission.

415. Water-color sketeh. U. S. Fish Commission.

Salmo salar, var. sebago, Girard.-SEBAGo SALMON (land-locked.) -St. Croix River and Sebago Lake. Introduced into other lakes.

15467. Cast. Sysladobsis Lake, Me. "Dobsis Club," through Judge Harvey Jewell. June, 1875.

15977. Cast.

15978. Cast.

535-6. Color sketches. (Richard.) U. S. Fish Commission. 
Salmo fario, Linn.-Rrvir Trout.-Rivers of Europe.

252. Photograph. U. S. Fish Commission.

Oncorhynchus quimnat, (Rich.) Günther.-QUINNAT or SACRAMENTO SALMON.-Northwest Coast of America; south to California.

10340. Cast. New York market. E. G. Blackford.

10347. Cast. Sacramento River, Cal. L. Stone. March, 1873.

248, 249, 250, 251. Photographs. U. S. Fish Commission.

416. Color sketch. (Richard.) U. S. Fish Cominission.

Cristivomer namaycush, (Penn.) Gill \& Jordan.-Nanraycustr Trout; LAKE Trout.-Northern Lakes.

246, 247. Photographs. U. S. Fish Commission.

10312. Cast. 'Moosehead Lake, Me. E. M. Stillwell.

16670-71. Casts. Lake Winnepiseogee. U. S. Fish Commission.

463, 526-7. Color sketches. (Richard.) U. S. Fish Coinmission.

Salvelinus fontimalis, (Mitch.) Gill \& Jordan.-Brook Trout.Rivers and Lakes of British North America and of the northern parts of the United States and Appalachian Range.

16626. Cast. Wood's Holl, Mass. V. N. Edwards.

15961. Cast. Sysladobsis Lake, Me. "Dobsis Club," through Judge Harvey Jewell. June, 1875.

15728. Cast. New York market. E. G. Blackford. March 22, 1875.

10311. Cast. New York market. E. G. Blackford. March 22, 1875.

15470. Cast. Sysladobsis Lake, Me. "Dobsis Club," through Judge Harrey Jewell. June, 1875.

243, 244. Photographs. U. S. Fish Commission.

751. Color sketch. (Richard.) U. S. Fish Commission.

26792. Mounted. (Male.) Rangely Lake, Me. Geo. Shepard Page. Weight 10 pounds. The largest Brook Trout on record. Taken by Geo. Shepard Page in 1867. Transported alive in a box of water (which also contained a female trout weighing $8 \frac{1}{4}$ pounds) to Stanley, Morris Co., New Jersey.

Salvelinus oquassa, (Girard) Gill \& Jordan.-OQUassa Trout.Rangely Lake, Me., and vicinity.

245. Photograph. U. S. Fish Commission.

549. Color sketch. (Richard.) U. S. Fish Commission.

750. Color sketch. (Richard.) U. S. Fish Commission.

Thymallus tricolor, Cope.-Mrchigan GraYLING.-Northern portion southern peninsula of Michigan.

15226. Cast. Au Sable River, Mich. Fred. Mather. April 7, 1875.

236, 238. Photographs. U. S. Fish Commission. 


\section{ALEULIDAE.}

A Ibula vulpes, (Linn.) Goode.-LADY-FISH.-Pelagic; Tropical and Subtropical Seas.

255. Photograph. U. S. Fish Commission.

21859. Alcoholic. Wood's Holl, Mass. U. S. Fish Commission.

\section{HYODONTID $\mathrm{AE}$.}

Hyodon tergisus, Les.-MooN-EYE.-Great Lakes and Mississippi Valley.

15561. Cast. New York market. $\boldsymbol{E}$. G. Blackford. Nov. 15, 1875.

14863. Cast. Cincinnati, Ohio. J. W. Milner. Nov., 1873.

253, 254. Photographs. U. S. Fish Commission.

753. Color sketch. (Richard.) U. S. Fish Commission.

\section{ELOPID $A$.}

Elops saurus, Linn.-BiG-EYED HERRING.-Tropical and Subtropical Seas.

15824. Cast. New York market. E. G. Blackford. Oct. 11, 1875.

15821. Cast. New York market. E. G. Blackford. Oct. 11, 1875.

15823. Cast. New York market. E. G. Blackford. Oct. 11, 1875.

15822. Cast. New York market. E. G. Blackford. Oct. 14, 1875.

15744. Cast. New York market. E. G. Blackford. Oct. 14, 1875.

15824. Cast. New York market. E. G. Blackford. Oct. 11, 1875.

256. Photograph. U. S. Fish Commission.

772. Color sketch. (Richard.) U. S. Fish Commission.

Megalops' thrissoides, (Schn.) Günther.-TARPUM.-Cape Cod to Florida.

14924. Cast. New Jersey. E. G. Blackford. July 9, 1874.

398. Photograph. Newport, R. I. S. Powell. Aug., 1874.

\section{DUSSUMIERID $A$.}

Etrumeus teres, (DeKay) Brevoort.-Round HerRIng.-Cape Cod to Cape Hatteras.

20216. Alcoholic. Newport, R. I. S. Powel.

\section{CLUPEID $A$.}

Brevoortia tyranmus, (Latr.) Goode.-Menhaden; MossBUNKER ; POGIE.-Newfoundland to Gulf of Mexico.

10696. Cast. Wood's Holl, Mass. U. S. Fish Commission.

16313. Cast. Wood's Holl, Mass. U. S. Fish Commission. Aug., 1875.

257, 258, 259, 260, 386, 387. Photographs. U. S. Fish Commission.

564. Color sketch. Prof. Alex. Agassiz. 
Brevoortia patronus, Goode.-GuLF MENHADEN.-Gulf of Mexico.

892. Alcoholic. Brazos Santiago, Texas.

Alosa sapidissima, (Wilson) Storer.-SHAD.-Newfoundland to Florida.

10641. Cast. Potomac River. J. W. Milner. 1873.

10625. Cast. Potomac River, D. C. J. W. Milner.

14878. Cast. Connecticut River. E. G. Blackford. May 7, 1874.

261, 262, 263, 264, 265. Photographs. U. S. Fish Commission.

Opisthonema thrissa, Gill.-TuREAD HERRING.-West Indian Fauna and north to Cape Cod.

20218. Alcoholic. Newport, R. I. U. S. Fish Commission.

Pomolobus pseudoharengus,(Wilson) Gill.-ALEWTFE; FresHWATER HERring; GASPEREAU.-Newfoundland to Florida.

10622. Cast. (Female.) Wood's Holl, Mass: U. S. Fish Commission. 266, 267, 268, 269, 386. Photographs. U. S. Fish Commission.

457. Color sketch. (Richard.) U. S. Fish Commission.

Pomolobus mediocris, (Mitch.) Gill.-Mattawocon; Tamor Herring; Sea Shad.-Newfoundland to Florida.

10657. Cast. Potomac River. J. W. Milner. 1873. 269, 270, 271. Photographs. U. S. Fish Commission. 458, 771. Color sketches. (Richard.) U. S. Fish Commission.

Clupea harengus, Linn.-Herring; SEA HerRING.-North Atlantic.

399. Photograph. U. S. Fish Commission.

13855. Alcoholic. Eastport, Me. U. S. Fish Commission.

Clupea mirabilis, Girard.-Herring.-Coast of California.

605. Color sketch. Galians Id., Gulf of Georgia, W. T. Prof. Alex. Agassiz. June, 1859.

\section{DOROSOMIDA.}

Dorysoma Cepedianum, (Lac.) Gill.-MUD SHAD; WINTER SHaD.-Cape Cod to St. John's River, Fla.

14991. Cast. Potomae River. G. Brown Goode. March 1, 1875.

15695. Cast. Washington market. G. Brown Goode. Dec., 1874.

272, 273. Photographs. U. S. Fish Commission.

798. Color sketch. (Richard.) U. S. Fish Commission.

Dorysoma Cepedianum, var. heterurum, (Raf.) Jordan.OHio Gizzard SHaD.-Ohio River and Lower Mississippi.

20836. Alcoholie. Sarnia, Lake Huron. S. Wilmot. 


\section{ENGRAULIDIDAE.}

Engraulis vittata, (Mitch.) B. \& G.-ANCHovr.-Cape Cod to Cape Hatteras.

382. Photograph. U. S. Fish Commission.

14086. Alcoholic. Watch Hill, R. I., \&c. U. S. Fish Commission.

\section{EVENTOGNATHI.}

\section{CATOSTOMIDAE.}

Catostomus teres, (Mitchill) Les.-Common Sucker.-Eastern Northern America.

279. Photograph. U. S. Fish Commission.

18258. Alcoholic. Potomac River. U. S. Fish Commission.

Myxostoma macrolepidotum, (Les.) Jordan.-STRIPED SUCKER.-Mississippi Valley and Great Lakes.

15930. Cast. Washington market. J. W. Milner.

16786. Cast. Washington market. J. W. Milner.

16785. Cast. Washington market. J. W. Milner.

278. Photograph. U. S. Fish Commission.

Cycleptus elongatus, (Les.) Ag.-BLACK SUCKer.-Mississippi Valley.

16781. Cast. Ohio River. J. W. Milner. Nov. 5, 1875.

280. Photograph. U. S. Fish Commission.

Erimyzon sucetta, (Lac.) Jordan.-CHUB SUCKER.-Eastern United States.

281. Photograph. U. S. Fish Commission.

Erimyzon Goodei, Jordan.-Goode's SUcker.-Florida.

19071. Alcoholic. St. John's River, Fla. G. Brown Goode.

Bubalichthys bubalus, Ag.-BuFfaLo-FISH.-Mississippi Valley.

14883. Cast. Cincinnati, Ohio. J. W. Milner. Nov. 5, 1873.

Carpiodes cyprimus, (Les.) Ag.-CARP.--Eastern Ur.ited States.

10735. Cast. Potomac River, D. C. J. W. Milner.

16r80. Cast. Sandusky, Ohio. J. W. Milner. Nov. 3, 1875.

\section{CYPIRINIIDE.}

Ptychocheilus grandis, (Ayres) Girard._-"Prke."-Pacific Slope. 282. Photograph. U. S. Fish Commission. 
Notemigonus americanus, (Linn.) Jordan.-SHrNer.-Southern Rivers.

19063. Alcoholic. St. John's River, Fla. G. Brown Goode.

Notemigonus chrysoleucus, (Mitch.) Jordan.-SHINER.-Eastern Atlantic States.

435. Color sketch. (Richard.) U. S. Fish Commission.

Leuciscus pulchellus, Storer.

630. Color sketch. (Burkhardt.) New Bedford, Mass. Prof. Alex. Agassiz. 1861.

Carassius auratus, (Linn.) Bleeker.-GoLD-FISH.-Domesticated; native of China and Japan.

16667. Cast. Washington, D. C. J. H. Richard.

18290. Alcoholic. Ponds of Maryland. U. S. Fish Commission.

\section{ORDER NEMATOGNATHI.}

\section{SILURIDAE.}

Elurichthys marinus, (Mitch.) B. \& G.-Fork-TAILED CATFISH.-Cape Cod to Florida; Gulf of Mexico.

15575. Cast. New Bedford, Mass. U. S. Fish Commission. Oct. 11, 1875. 283, 284, 285. Photographs. U. S. Fish Commission.

522. Color sketch. (Richard.) U. S. Fish Commission.

Amiurus catus, (Linn.) Gill._HorN Pout._Eastern North America.

466. Color sketch. Prof. Alex. Agassiz. Natural size drawing by P. Roetter from a fresh specimen, East Wareham, Mass., Feb., 1869; weight, $1 \frac{1}{2}$ lbs. "S. T. Tisdale says he has seen the young of this species following the mother like a brood of chickens."-Ms. note.

Ichthalaurus furcatus, (C. \& V.) Gill.-ChANNEL CAT-FiSH.Mississippi Valley.

15690. Cast. Carrollton, Ky. J. W. Milner.

15787. Cast. Carrollton, Ky. J. W. Milner. Nov. 5, 1873.

Pelodichthys olivaris, (Raf.) Gill \& Jordan.-MuD CAT-FISH.Ohio Valley to Iowa and south.

15689. Cast. Carrollton, Ky. J. W. Milner. Nov. 5, 1875. 


\section{ORDER APODES.}

\section{CONGRIDA.}

Conger-oceanica, (Mitch.) Gill.-CONGER EEL.-Newfoundland to West Indies.

14873. Cast. Weight 11 lbs. Block Id., R. I. U. S. Fish Commission. Sept. 26, 1874.

14872. Cast. Block Island, R. I. U. S. Fish Commission. Sept. 26, 1874.

287. Photograph. U. S. Fish Commission.

\section{ANGUILLIDAE.}

Anguilla rostrata, (Les:)DeKay.-Connon EeL.-Eastern United. States.

15731. Cast. New York. E. G. Blackford. Aug. 26, 1874.

16392. Cast. New York. E. G. Blackford. Aug. 26, 1874.

16729. Cast. Potomac River. J. W. Milner.

16416. Cast. Wood's Holl, Mass. Wm. Palmer. Sept. 6, 1875.

10749. Cast. Wood's Holl, Mass. V. N. Edwards.

286. Photograph. U. S. Fish Commission.

480-81. Color sketches. (Richard.) U. S. Fish Commission.

773. Color sketch. Prof. Alex. Agassiz.

\section{VEMICHTHYIDA.}

Vemichthys scolopaceus? Rich.-SNIPE EEL.-Deep waters - of the Atlantic.

21195. Alcoholic. George's Bank. U. S. Fish Commission.

\section{SYNAPHOBRANCHIDA.}

Synaphobranchus pinmatus, (Gronow) Günther,-MADEIRA EEL.-Deep waters of the Atlantic.

21848. Alcoholic. Sable Island Bank. U. S. Fish Commission.

\section{ORDER CYCLOGANOIDEI.}

\section{AMIIDA.}

Amia calva, Linn.-MUD-FISH.-Central and Southeastern United States.

11134. Cast. Sandusky, Ohio. J. W. Milner.

16534. Cast. New York market. E. G. Blackford. Sept. 24, 1875.

288,289. Photograph. U. S. Fish Commission.

556. Color sketch. (Burkhardt.) Charleston, S. C. Prof. Alex. Agassiz. 1853. 


\section{ORDER RHOMBOGANOIDEI.}

\section{UEPIDOSTEID AE.}

Lepidosteus osseus, Linn.-Gar PIKE.-Mississippi Valley and Atlantic States south of Delaware River.

10736. Cast. Sandusky, Ohio. J. W. Milner.

10717. Cast. Sandusky, Ohio. J. W. Milner.

15366. Cast. Potomac River. J. W. Milner.

290, 291. Photographs. U. S. Fish Commission.

Lepidosteus platystomus, Raf.-ShorT-Nosed GAR PIKE.Great Lakes and streams south and west to the Rocky Mountains.

3241. Alcoholic. Cleveland, Ohio. Prof. Baird.

\section{ORDER SELACHOSTOMI.}

\section{POLYODONTIIDA.}

Polyodon folium, Lac.-PADDLE-FISH.-Fresh waters of Mississippi Valley.

14871. Cást. Cincinnati, Ohio. J. W. Milner. Nov. 5, 1873.

15475. Cast. Madison, Ind. George Spangler. June, 1875.

292. Photograph. U. S. Fish Commission.

\section{ORDER CHONDROSTEI.}

\section{ACIPENSERIDAE.}

Acipenser sturio, Linn.- SHARP-NOSEd SturgeON. - North Atlantic; ascending rivers.

15745. Cast. New York. E. G. Blackford.

14866. Casi. Wood's Holl, Mass. U. S. Fish Commission.

14877. Potomac River. J. W. Milner.

293, 294. Photographs. U. S. Fish Commissiou.

519. Color sketch. (Richard.) U. S. Fish Commission.

Acipenser brevirostris, Les.-SHORT-NOSED STURGEON.-Atlantic Coast of United States.

295, 296. Photographs. U. S. Fish Commission.

520. Color sketch. (Richard.) U. S. Fish Commission.

Acipenser rubicundus, Les.-LAKE STURGEON.-Great Lakes and south.

297, 298, 299, 300, and 301. Pliotographs. U. S. Fish Commission. 
ANIMAL RESOURCES AND FISHERIES OF UNITED STATES.

Acipenser maculosus, Les.-LONG-NOSED STURGEON.-Great Lakes and Western Rivers.

607-8. Color sketch. Huntsville, Ala. Prof. Alex. Agassiz. 1853.

Scaphyrhynchops platyrhynchus, (Raf.) Gill. - SHOVELNOSED STURGEON.-Mississippi Valley.

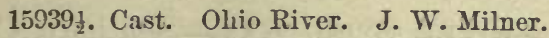

15939. Cast. Ohio River. J. W. Milner.

15476. Cast. Madison, Ind. George Spangler. June, 1875.

302, 303. Photographs. U. S. Fish Commission.

\section{ELASMOBRANCHIATES. ORDER HOLOCEPHALI. CWIMTERIDAE.}

Chimarea plumbea, Gill.-Brown CHMnkra.-Deep waters of Western Atlantic.

21904. Cast. Banquereau. Capt. Joseph W. Collins.

Hydrolagus Colliei, (Bennett) Gill.-PACIFIC CHncara.-Northwest coast of North America.

993. Alcoholic. Puget Sound. Dr. George Suckley.

\section{Order RAIA.}

\section{MYLIOBATIDAE.}

Myliobatis Fremenvillei, (Les.) Storer.-EAGLE RAY.-Cape Cod to Florida.

16603. Cast. Wood's Holl, Mass. U. S. Fish Commission. Sept. 23, 1875.

14417. Cast. Wood's Holl, Mass. U. S. Fish Commission.

306-319. Photographs. U. S. Fish Commission.

760. Color sketch. U. S. Fish Commission.

Myliobatis californicus, Gill.-CALIFORNIA STING RAY.-Coast of California.

16687. Cast. San Francisco, Cal. L. Stone.

320. Photograph. U. S. Fish Commission.

959. Color sketch. U. S. Fish Commission.

Rhinoptera quadriloba, (Les.) Cuv.-Cow-nosed RAY.-Cape

Cod to Florida.

304, 305. Photographs. U. S. Fish Commission.

Bull. N. M. No. $14-5$ 


\section{TRYGONID A.}

Trygon centrura, (Mitch.) Gill._STING RAY.-Cape Cod to Florida.

14920. Cast. Wood's Holl, Mass. U. S. Fish Commission. June, 1873.

14882. Cast. Portland, Me. Skillings.

324, 325, 326, 327, 328, 329. Photographs. U. S. Fish Commission.

Trygon Sabina, Lesueur.-Rrver Strng RAY.-Southern Coast entering rivers.

18068. Alcoholic. Lake Monroe, Fla. Prof. Baird.

Trygon hastata, (De Kay) Storer.-Syоoth Sting RAY.-Southern Coast.

21626. Skin. West Florida. Dr. J. W. Velie.

Pteroplatea maclura, Mull. \& Henle.-Butterfly RAY.-Cape Cod to Florida.

16319. Cast. Wood's Holl, Mass. U. S. Fish Commission. Aug. 5, 1875. 321, 322, 323. Photographs. U. S. Fish Commission.

\section{TORPEDINID E.}

Torpedo occidentalis, Storer.-TonPEDo; CrAMrP-FISH.-Cape Cod to Florida.

14912. Cast. Wood's Holl, Mass. U. S. Fish Commission. July 22, 1873. 14919. Cast. Wood's Holl, Mass. U. S. Fish Commission. July 5, 1873. 16665. Cast. Wood's Holl, Mass. U. S. Fish Commission. July 5, 1873. 330, 331, 332, 333, 334, 335. Photographs. U. S. Fish Commission.

\section{RAIID AE.}

Raia erinacea, Mitchill.-CLeAR-NOSED SKATE.-Nova Scotia to Florida.

343, 344, 345, 346. Photographs. U. S. Fish Commission.

14881. Cast. Portland, Me. U. S. Fish Commission.

10612. Cast. Wood's Holl, Mass. V. N. Edwards.

16508. Cast. Wood's Holl, Mass. V. N. Edwards. May 14, 1873.

336, 337, 338, 339, 340, 341, 342. Photographs. U. S. Fish Commission.

408, 409. Color sketches. (Richard.) U. S. Fish Commission.

761-2-3. Color sketches. U. S. Fish Commission.

768-9. Color sketches. U. S. Fish Commission.

774-5. Color sketches. Prof. Alex. Agassiz.

Raia ocellata, Mitchill. - Spotted Skate.-New England Coast. 19434. Alcoholic. Nahant, Mass. Mus. of Comp. Zoology.

Raia radiata, Donovan.-SPINY SKate.-Northern Atlantic.

19432. Alcoholic. Nahant, Mass. Mus. of Comp. Zoology.

Raia eglanteria, Lacep.-Eglantine SKate.-Cape Ann and southward.

19439. Alcoholic. S. Now England. Mus. of Comp. Zoology. 
Raia lavis, Mitch.-SHARP-NOSED SKATE.-Nova Scotia to Florida. 14904. Cast. (Young male.) Montauk Point, N. Y. U. S. Fish Commission. Aug. 1, 1874.

402. Color sketch. U. S. Fish Commission.

15704. Cast. (Young.) Noank, Conn. U. S. Fish Commission. Aug. 1, 1874. 15703. Cast. Noank, Conn. U. S. Fish Commission.

16658. Cast. (Young male.)

15707. Cast.

16659. Cast.

347, 348, 349, 350, 351. Photographs. U. S. Fish Commission.

\section{RHINOBATIDE.}

Rhinobatus productus, Girard.-LONG-NOSED SKATE.-Coast of California.

16704. Cast. San Francisco, Cal. L. Stone.

352. Photograph. U. S. Fish Commission.

\section{PRISTIDAE.}

Pristis antiquorum, (Linn.) Lath.-SAW-FISH. - Cape Cod to Florida; Tropical Seas.

12453. Stuffed skin. Florida. H. A. Ward.

\section{SQUATINIDA.}

Squatina Dumerili, Les.-MonK-FISH; FIDDLE-FISH.-Cape Cod to Florida; Temperate and Tropical Seas.

14890. Cast. Wood's Holl, Mass. V. N. Edwards. Sept. 1, 1873.

16410. Cast. Menemsha Bight, Mass. Jason Luce. Sept. 1, 1875.

353, 354, 355. Photographs. U. S. Fish Commission.

\section{ORDER SQUALI.}

\section{LAMINID A.}

Lamna cornubica, (Gmel.) Fleming.-PoRBEAGLE SHARK.Atlantic, Mediterranean, Japan.

21856. Alcoholic. Gloucester, Mass. U. S. Fish Commission.

Isuropsis Dekayi, Gill. (d. s.)-MACKEREL SHARK.-Newfoundland to Florida.

15949. Cast. Wood's Holl, Mass. V. N. Edwards. Sept. 20, 1873.

15973. Cast. Wood's Holl, Mass. V. N. Edwards. Dec., 1875.

446. Color sketch. (Richard.) U. S. Fish Commission.

Carcharodon Atwoodi, (Storer) Gill.-ATwOOD's SHARK; MANEATER.-Newfoundland to Florida.

- Jaws. 
Cynocephalus glaucus, (Linn.) Gill.-BLUL-HEADED SraRK.Atlantic.

19929. Alcoholic. Wood's Holl, Mass. V. N. Edwards.

\section{ODONTASPIDIDA.}

Eugomphodus littoralis, Gill.-SAND. SHarK.-Pelagic.

16647. Cast. Wood's Holl, Mass. U. S. Fish Commission. 16648. Cast. Wood's Holl, Mass. U. S. Fish Commission.

419. Color sketch. (Richard.) U. S. Fish Commission.

445. Color sketch. (Richard.) U. S. Fish Commission.

\section{ALOPECTDE.}

Alopias vulpes, (Linn.) Bon.-Thresher; SWINGLE-TAIL.-At. lantic and Mediterranean.

16256. Cast. Menemsha Bight, Mass. U. S. Fish Commission. July 30, 1875. 15733. Cast. Wood's Holl, Mass. U. S. Fish Commission.

417. Color sketch. (Richard.) U. S. Fish Commission.

\section{SPHYRNID IF.}

Sphyrna zygaena, (Linn.) Mull. \& Henle.-Hammer-HeAd SHARK. -Tropical and Subtropical Seas.

15833. Cast. Noank, Conn. U. S. Fish Commission.

360, 361, 362, 363, 364. Photographs. U. S. Fish Commission.

462. Color sketch. (Richard.) U. S. Fish Commission.

Reniceps tiburo, (Linn.) Gill.-SHovel-HeAd SHARK.-Atlantic and Western Pacific.

12;14. Cast.

—. Alcoholic. Beesley's Point, N. J. S. F. Baird.

\section{GALEORHINIDE.}

Eulamia Milberti, (Mull. \& Henle) Gill.-BLue SHarK.-Cape Cod to Florida.

15742. Cast. Wood's Holl, Mass. V. N. Edwards.

366, 357, 363, 359. Photographs. U. S. Fish Commission.

418. Color sketch. (Richard.) U. S. Fish Commission.

Eulamia obscurus, (Les.) Gill.-DUsKy SHARK.-Cape Cod to Florida.

16070. Cast. Wood's Holl, Mass. U. S. Fish Commission. July 10, 1875.

Isogomphodon maculipinnis, Poey.-SPOTTED-FIN SHARK.Tropical and Subtropical Seas.

356, 357, 358, 359. Photographs. U. S. Fish Commission.

425. Color sketch. (Richard.) U. S. Fish Commission.

16401. Cast. Wood's Holl, Mass. U. S. Fish Commission. 
Galeocerdo tigrinus, Mull. \& Henle.-Tiger SHARK.-Atlantic; Indian Ocean.

15740. Cast. Wood's Holl, Mass. V. N. Edwards. July 22, 1873. 16069. Cast. Buzzard's Bay, Mass. U. S. Fish Commission. 1875. 370, 371. Photographs. U. S. Fish Commission.

Mustelus canis, (Mitch.) De Kay.-SyоoтH DoG-FISH.-Cape Cod to Cape Hatteras.

14908. Cast. Norfolk, Va. U. S. Fish Commission. June 25, 1873.

14925. Cast. Wood's Holl, Mass. U. S. Fish Commission.

10734. Cast. Wood's Holl, Mass. U. S. Fish Commission.

10733. Cast. Wood's Holl, Mass. U. S. Fish Commission.

16649. Cast. (Male.). Wood's Holl, Mass. U. S. Fish Commission.

372, 373, 374, 375. Photographs. U. S. Fish Commission.

-. Color sketches. (Richard.) U. S. Fish Commission.

\section{GINGLYMOSTOMATIDAE.}

Ginglymostoma cirratum, (Gmel.) M. \& H.-NURSE SHARK.Tropical Atlantic.

16909. Alcoholic. Chesapeake Bay. Maryland Academy of Science.

\section{SPINACIDE.}

Squalus americanus, (Storer) Gill.-SPINED DoG-FISH.-New• foundland to Cape Hatteras.

16255. Cast. Martha's Vineyard. U. S. Fish Commission. July 30, 1875.

376, 377. Photographs. U. S. Fish Commission.

426. Color sketch. (Richard.) U. S. Fish Commission.

Centroscyllium Fabricii, (Reinh.) M. \&.H.-Greenland DoGFISH.-Deep waters of Western Atlantic.

21622. Cast. Lat. $42^{\circ} 52^{\prime}$ N., Lon. $63^{\circ} 50^{\prime}$ W. 220 to 260 fathoms. U. S. Fish Commission.

\section{SCYMNID $A$.}

Somniosus microcephalus, (Bloch.) Gill._SLEEPER SHARK.North Atlantic.

378, 379. Photographs. U. S. Fish Commission.

447. Color sketch. (Richard.) U. S. Fish Commission.

16630. Cast. Gulf of St. Lawrence. Renfrew \& Co. Nov. 20, 1875.

Centroscymmus cololepis, Bocage \& Capello.-BLAcK DoGFISH.-Deep waters of North Atlantic.

21621. Cast. Lat. $42^{\circ} 40^{\prime}$ N., Lon $63^{\circ} 50^{\prime}$ W. 220 to 260 fathoms. U. S. Fish Commission. 


\section{ECHENOREIINIDAE.}

Echinorhinus spinosus, (Gmel.) Delamoille.-SPINy SHaRK.North Atlantic.

21913. Cast. Provincetown, Mass. E. E. Small.

\section{MARSIPOBRANCHIATES. ORDER HYPEROARTIA. PRTROMYZONTIDAE.}

Petromyzon americanus.-Latrpere EeL. 489-90. Color sketches. Prof. Alex. Agassiz.

\section{ORDER HYPEROTRETI. MYXINIDIS.}

Myxine glutinosa, Linn.-HAG-FISH; SLIME-FISH.-North Atlantic.

21679. Alcoholic. Le Have Bank, N. B. U. S. Fish Commission.

VIII. LEPTOCARDIANS.

ORDER CIRROSTOMI.

\section{BRANCHIOSTOMIDE.}

Branchiostona Iubricum, Costa.-LANCELET.-Cosmopolitan. 21877. Alcoholic. Bermudas. G. Brown Goode. 


\title{
(THE CHASE ANI) THE FISHERIES.)
}

\section{MEANS OF PURSUIT AND CAPTURE. I. HAND IMPLEMENTS 0R TOOLS.}

\author{
* For striking.
}

\section{Unarmed clubs. ${ }^{1}$}

\section{Clubs.}

Salmon-clubs used by the Indians of the Northwest coast.

Hunting-clubs. ${ }^{1}$

Fishermen's clubs.

32717. "Halibut killer and gob-stick." Philip Merchant, Gloucester, Mass. A heavy club with which the fisherman kills the halibut by a blow upon the head. One end is sharpened for use in detaching hooks from the gullets of fish which have swallowed them.

\section{Armed clubs. ${ }^{1}$}

Stone-headed clubs. ${ }^{1}$

Clubs, armed with teeth or bone points. ${ }^{1}$

Clubs, armed with metal points. ${ }^{1}$

\section{Slumg-stones. ${ }^{1}$}

\section{Slung-shot. ${ }^{1}$}

\section{Straight knives.}

\section{SLUNG-WEIGHTS.}

Hunters' knives.

26152. Hunter's knife. 51-inch blade. John Russell Cutlery Co., Turner's

26153. Hunter's knife. 6-inch blade.

26154. Hunter's knife. 7 -inch blade.

26155. Hunter's knife. 8-inch blade.

26172. Hunter's knife. $5 \frac{1}{2}$-inch blade.

26173. Hunter's knife. 6-inch blade.

26174. Hunter's knife. $6 \frac{1}{2}$-inch blade.

26175. Hunter's knife. 8-inch blade.

26191. Hunter's knife. 5-inch blade.

26192. Hunter's knife. 6-inch blade.

26193. Hunter's knife. 7-inch blade.

26194. Hunter's knife. 8-inch blade.
[Falls, Mass.

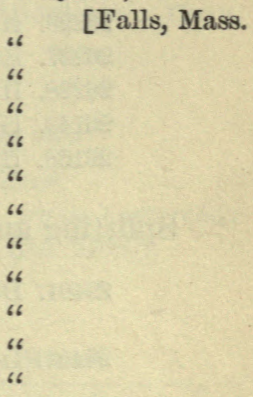




\title{
Straight knives.
}

\author{
Hunters' knives.
}

26220. Hunter's knife. 5-inch blade. John Russell Cutlery Co., Turner's

26221. Hunter's knife. 6-inch blade. 26222. Hunter's knifo. 7 -inch blade. 26223. Hunter's knife. 8-inch blade. 26224. Hunter's knife. 10-inch blade. 26145. Hunter's knife. $5 \frac{1}{2}$-inch blade. 26146. Hunter's knife. 6-inch blade. 26147. Hunter's knife. 7-inch blade. 26148. Hunter's knife, 8-inch blade. 26160. Hunter's knife. 5-inch blade. 26161. Hunter's knife. 6-inch blade. 26162. Hunter's knife. 7-inch blade. 26163. Hunter's knife. 8-inch blade. 26164. Hunter's knife. 9-inch blade. 26165. Hunter's knife. 10-inch blade. 26166. Hunter's knife. 11-inch blade. 26167. Hunter's knife. 12-inch blade. 26156. Hunter's knife. 5-inch blade. 2615\%. Hunter's knife. $5 \frac{1}{2}$-inch blade. 26158. Hunter's knife. 7-inch blade. 26202. Hunter's knife. 5-inch blade. 26203. Hunter's knife. 6-inch blade. 26204. Hunter's knife. 7-inch blade. 25205. Hunter's knife. 8-inch blade. 26203. Hunter's knife. 9-inch blade. 26207. Hunter's knife. 10-inch blade. 20208. Hunter's knife. 12-inch blade. i Falls, Mass.

Dudley hunters' knives.

26197. Hunter's knife. 5-inch blade. 26198. Hunter's knife. 6-inch blade. 26199. Hunter's knife. 7-inch blade. 26200. Hunter's knife. 9-inch blade.

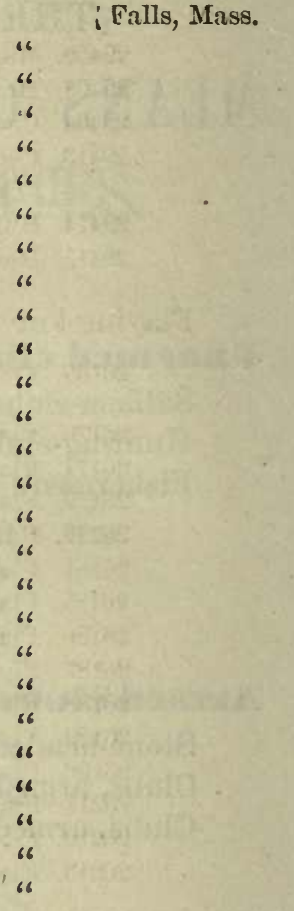

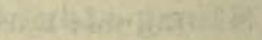

66

66

$6 s$

68

\section{Hunters' dirk-knives.}

26225. Hunter's knife (metal guard). 5-inch blade. 26226. Hunter's knife (metal guard). 6-inch blade. 26227. Hunter's knifo (metal guard). 7-inch blade. 26228. Hunter's knifo (metal guard). 8-inch blade. 26143. Hunter's knife (metal guard). 7-inch blade. 26168. Hunter's knife (solid guard). 7-inch blade.

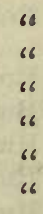

Splitting and ripping knives.

29401. Double-edged throating and ripping knife. A. McCurdy, Gloucester, Mass.

29403. Double-edged throating-knife (old style). G. B. Foster, Beverly, Mass.

29409. Throating or ripping knife. A. McCurdy, Gloucester, Mass.

29411. Throating or ripping knife. Capt. E. L. Rowe, Gloucester, Mass. 


\section{Straight knives.}

Splitting and ripping knives.

29416. Double-edged ripping-knifo (peculiar to coast of Maine). Wilcox, Crittenden \& Co., Middletown, Conn.

29402. Mackerel-splitting knife. A. McCurdy, Gloucester, Mass.

29408. Mackerel-splitting knife. Capt. Sam. Elwell, Gloucester, Mass.

29404, Codfish-splitting lnife. A. McCurdy, Gloucester, Mass.

29413. Cod or haddock ripping knife (old style). G. P. Foster, Beverly, Mass.

29414. Hake or haddock splitting knife. A. McCurdy, Gloucester, Mass.

29415. Haddock-ripping knifc.

\section{Flaying-knives, aboriginal and recent. ${ }^{1}$}

26169. Flaying-knife. 5-inch blade. John Russell Cutlery Co., Turner's

26170. Flaying-knife. 6-inch blade.

[Falls, Mass.

26171. Flaying-knife. 7-inch blade.

26179. Flaying-knife. 5-inch blade.

26180. Flaying-knife. 6-inch blade.

26181. Flaying-knife. 61-inch blade.

26185. Flaying-knife. 5-inch blade.

26186. Flaying-knife. 6-inch blade.

26187. Flaying-knife. 7-inch blade.

26188. Flaying-knife. 5-inch blade.

26189. Flaying-knife. 6-inch blade.

26190. Flaying-knife. 7-inch blade.

20211. Flaying-knife. 5-inch blade.

26212. Flaying-knife. 6-inch blade.

26213. Flaying-knife. $6 \frac{1}{2}$-inch blade.

$\begin{array}{ll}\text { "6 } & \text { [Falls, Ma } \\ 66 & 6 \\ 6 & 6 \\ 6 & 6 \\ 6 & 18 \\ 6 & 66 \\ 6 & 66 \\ 6 & 6 \\ 6 & 66 \\ 6 & 6 \\ 6 & 6 \\ 6 & 6 \\ 6 & 6\end{array}$

\section{Blubber-knives, Eskimos. ${ }^{2}$}

\section{Boarding-knives used by whalemen.}

Used in cutting the blubber into sections from the "blanket piece" or long strip which is peeled from the sides of the whale; for illustration of the manner of use see the model of whaler "cutting in the blubber."

256\%6. Boarding-knife. W. H. Cook \& Co., New Bedford, Mass.

"This knife has seen many years of service."-A. R. C.

26608. Boarding-knife, with sheath. A. R. Crittenden, Middlctown, Conn.

\section{Whalemen's boat-knives.}

Used to cut the harpoon-line when it gets tangled in paying out.

- Boat-knife (model). Capt. L. Howland, New Bedford.

This model in its sheath on the bulkhead of the rhalc-boat, ready for use, is shown in the model of a whale-boat (No. 24880).

Heading-knives.

32689. Halibut-heading Inife. Adolph Voss, Gloucester, Mass.

${ }^{1}$ A full series of Eskimo and Indian flaying-lknives is displayed in tho Ethnologic:al division.

${ }^{2} \mathrm{~A}$ series of these implements is exhibited in the Ethnological division. 


\section{Straight knives.}

Finning-knives.

29400. Halibut-finning knife. Alex. McCurdy, Gloucester, Mass.

29412. Halibut-finning knife. Capt. E. L. Rowe, Gloncester, Mass.

Chopping-knives.

29406. Bait-cleaver (used in halibut fishing). Alex. McCurdy, Gloucester, Mass.

32665. Cod-bait knife. Gloucester, Mass. U. S. Fish Commission.

32664. Bait-cleaver.

66 66

\section{Cheek-knives.}

29438. Codfish cheek-knife. Alex. McCurdy, Gloncester, Mass.

Throating-knives.

22669. Cod-throater (single edge). Gloucester, Mass. U. S. Fish Commission. 22670. Cod-throater (double edge).

Fish-knives (for general use).

26159. Fish-knife. Heavy. 12-inch blade. John Russell Cutlery Co., Turner's Falls, Mass.

26196. Fish-knife. Hook handle. 12-inch blade. John Russell Cutlery Co., Turner's Falls, Mass.

Scaling-knires.

26210. Saw-blade fish-scaling knife. John Russell Cutlery Co., Turner's Falls, Mass.

Sailors' and fishermen's sheath-knives.

Sailors' sheath-knives. Wilcox, Crittenden \& Co., Middletown, Conn.

29428. Sheath and belt, with "law-abiding" sheath-knife. First quality. 29426. Sheath and belt. Second quality.

29427. Sheath and belt, with "law-abiding" sheath-knife. Third quality. The "law-abiding" sheath-knife is round at the tip of the blade, which is also thick and dull.

\section{Hunters' sheath-knives.}

The hunting-knives enumerated above, manufactured by the John Russell Cutlery Co., and others like them, are usually provided with sheaths before they are used by hunters.

26665. Hunting-knife, sheath, and belt. Forest \& Stream Publishing Co. (Property of John A. Nichols, Syracuse, N. Y.)

Slivering-knives, used by fishermen.

These knives are used to slice the flesh from the sides of the menhaden used for bait. The slices thus prepared aro called "slivers," and are salted down

- in barrels to be used as baits for cod, halibut, and mackerel hooks, or are ground up in the bait-mills, forming "stosh" or "chum," a thick paste which is thrown over the sides of the mackerel-smacks to tole the fish to the surface. 


\section{Straight knives.}

Slivering-knives, used by fishermen.

29407. Slivering-knife. (Pattern first used by Cape Ann fishermen.) Geo. B. Foster, Beverly, Mass.

29399. Slivering-knife. (Cape Ann pattern.) Alex. MeCurdy.

29405. Slivering-knife. (Nantucket pattern.) Samuel Elwell,jr., Gloucester, Mass.

25\%64. Slivering-knife. Samuel Elwell, jr., Gloucester, Mass.

32666. Slivering-blade. Gloucester, Mass. U. S. Fish Commission.

\section{Flitching-knives.}

Used in slicing halibut into steaks or "flitches" in preparation for salting and smoking.

32;26. Shore flitching-knife. Gloncester, Mass. U. S. Fish Commission. 32690. Bank flitching-knife. Adolph Voss, Gloucester, Mass.

29410. Flitching-knife. Gloncester, Mass. A. R. Crittenden.

\section{Clam and oyster knives.}

26209. Clam-knife. John Russell Cutlery Co., Turner's Falls, Mass.

- Oyster-knife (model). See model of Chesapeake oyster-canoe (No. 25003).

\section{Net-makers' knives.}

These knives are without handles, and the heel of the short ( 2 inches long) round-pointed blade is curled so as to fit the finger like a ring.

29439. Net-mending knives (right-hand). Alex. McCurdy, Gloncester, Mass. 29440. Net-mending knires'(left-hand). Alex. McCurdy, Gloucester, Mass.

Mackerel-rimmers' fatting-knives or ploughs.

Used in creasing the sides of lean mackerel (Nos. 2 and 3 ) to cause them to resemble fat (No. 1) mackerel.

\section{Mackerel-plough. Edwin Blatchford.}

25769. Mackerel-plough. S. Elwell, jr., Gloucester, Mass.

25770. Mackerel-plough. S. Elwell,jr., Gloucester, Mass.

25771. Mackerel-plough. S. Elwell, jr., Gloucester, Mass.

25773. Mackerel-plough. Edward Davis.

25774. Mackerel-plough. Edward Davis.

25775. Mackerel-plough. (Used in 1860.) Mrs. Hannah M. Burt.

25720. Mackerel-plough. Central Wharf Co., Provincetown, Mass.

Splitting-knives.

Used in cleaning fish before salting.

32673. Mackerel-splitting knife. Gloucester, Mass. U. S. Fish Commission. 22667. Cod-splitting knife (curved).

22668. Cod-splitting knife (straight).

"6

66

Stone and bone knives used by Indians and Eskimos.

7224. Bone knife. Anderson River Eskimos, Fort Anderson, H. B. T. R. McFarlane. 


\section{Straight kmives.}

Stone and bone knives used by Indians and Eskimos.

16115. Bone knife. Magemut Eskimos, Nunivak Islands, Alaska. W. H. Dall.

2178. Bone knife. Eskimos.

1328. Bone knife. Eskimos.

Harpoon-knives.

16348. Harpoon-knife, with sheath. Magemut Eskimos, Nunivak Islands,

16110. Harpoon-knife, with sheath.

16105. Harpoon-knife, with sheath.

16103. Harpoon-knife, with sheath.

19382. Harpoon-knife, with slate blade.

[Alaska. W. H. Dall.

\section{Honey-knives.}

The thin blade bent at an angle to the handle.

26145. Honey-knife. John Russell Cutlery Co., Turner's Falls, Mass.

Skin scrapers and parers, used in preparing leather.

26144. Tanner's knife. 12-inch blade. John Russell Cutlery Co., Turner's

26195. Tanner's knife. 14-inch blade.

[Falls, Mass.

\section{Ares, proper.}

4. AXEs.

Head-axes for whalemen.

Used in cutting off head of whale.

25913. Head-axe. E. B. \& F. Macy, New Bedford, Mass.

Whalemen's boat-hatchets.

Used for cutting harpoon-line at the bow, when it becomes tangled.in "paying out."

24880. Boat-hatchet. (Model.) Capt. L. Howland, New Bedford, Mass. This implement in its place in the boat is shown in model of whale-boat.

26839. A boat-hatchet may be seen in its proper place in the bow of the large whale-boat.

\section{Cutting-spades.}

Whale-spades.

Cutting-spades.

Used in peeling the blubber from the carcass of the dead whale; for illustration see model of "whale-ship cutting in the blubber."

25679. Cutting-spade. E. B. \& F. Macy, New Bedford, Mass.

25003. Cutting-spade. J. H. Thomson, New Bedford, Mass. 
ANIMAI, RESOURCES AND FISHERIES OF UNITED STATES.

\section{Cutting-spades.}

Throat-spades, flat and round shank.

Used in eutting off the head of the whale.

25925. Throat-spade. E. B. \& F. Macy, New Bedford, Mass.

\section{Wide spades.}

Used in "blubber-room" for cutting blubber before mincing.

25629. Wide spade. E. B. \& F. Macy, New Bedford, Mass.

\section{Half-round spades.}

For cutting "blanket" piece, to allow blubber-hook to enter.

25927. Half-round spade. E. B. \& F. Macy, New Bedford, Mass.

\section{Head-spades.}

Used in cutting off the head of the whale.

25932. Head-spade. E. B. \& F. Macy, New Bedford, Mass.

Blubber-mincing spades.

For mincing blubber before trying out.

25912. Hand mince-knife. E. B. \& F. Macy, New Bedford, Mass.

\section{Chopping-knives.}

Used to chop clams for bait.

29489. Clam-chopper. William H. Hesbolt, Provincetown, Mass.

32676. Clam-chopper. Adolph.Voss, Gloucester, Mass.

Bait-mill knives.

Used on the rollers of bait-mincing machines; for mills see section C. 5 .

29417. Bait-mill knife. Provincetown pattern. William H. Hesbolt, Provincetown, Mass.

25715. Bait-mill knife. M. W. Grant, Wellfleet, Mass.

Ice-choppers.

Used in chopping ice for packing fish or bait.

32685. Ice-chopper. Adolph Voss, Gloucester, Mass.

Ice-chisels.

Used in cutting holes in the ice for fishing.

25888. Ice-chisel (nickel-plated). Bradford \& Anthony, Boston, Mass. 


\section{Thrusting spaARs AND PRODS.}

\section{Fishing-lances.}

Whale-lances.

Used by whalers to give the death-blow to the whale.

25678. Whale-lance with handle, ready for use. E. B. \& F. Macy, New Bedford, Mass.

25007. Whale-lance with handle, ready for use. J. H. Thomson, New Bedford, Mass.

Whale-lance, iron.

25611. Whale-lance. (Primitive model) used by New Bedford whalers. W. H. Cook \& Co., New Bedford, Mass.

Seal-lances.

10140. Head of lance (bone and iron). Eskimos of Northeast coast, southwest of King William's Land. Capt. C. F. Hall.

1117. Seal-lance. Eskimos of Arctic const, Anderson River, H. B. T. R. McFarlane.

\section{Fish-lances.}

29453. Sword-fish lance. Saml. Elwell, jr., Gloucester, Mass.

32703. Sword-fish lance. Vinald McCaleb. Gloucester, Mass.

25232. Sword-fish lance (with screw to fix folding handles). U. S. Fish Commission.

26519. Lance. Indians of the Northwest coast. J. G. Swan.

The tip of this lance is made from the horn of the mountain-goat (Mazama montana).

Whaleman's boat-spades (thick and thin).

Carried in boat to disable the whale by cutting its flukes.

25928. Boat-spade, with handle and warp complete, ready for use. E. B. \& F. Macy, New Bedford, Mass.

\section{Prodding instruments.}

Snow-probes.

Used by the Eskimos in probing the air-holes in ice and under the snow to detect the presence of seals.

10274. Bone probe. King William's Land. Capt. C. F. Hall.

10275. Bone probe.

10276. Bone probe.

2000. Bone probe. Northeastern Coast. S. F. Baird.

2179. Bone probe.

2180. Bone probe.

12181. Bone probe.

"6 66

${ }^{3}$ These probes are sometimes supplied with a detachable head. 
ANIMAL RESOURCES AND FISHERIES OF UNITED STATES.

\section{Prodding-instruments.}

Probing-awls.

Used in piercing the base of the brain in killing fish for the table.

29418. Large steel prod, snitable for large fish. A. R. Crittenden, Middletown, Conn.

\section{IMPLEMENTS FOR SEIZURE OF 0BJECT.}

*Scooping-instruments.

6. ScOOPS.

$\dagger$ For hand-use.

\section{Shovels.}

Clam-shovels.

-. ${ }^{1}$ Long-handled shovel. U. S. Fish Commission.

26716. ' ${ }^{1}$ Short-handled shovel. U. S. Fish Commission.

Oyster-shovels.

26717. (Model, with Chesapeake oyster-canoe, No. 25003). T. B. Ferguson, Maryland Commissioner of Fisheries.

Trowels used in taking burrowing shore animals.

-. Collector's trowel (flat). To be supplied.

- Collector's trowel (round).

Hand-scoops used in collecting mollusks.

- ' 'Spoon-scoop. U. S. Fish Commission.

Bait-ladles.

32652. "Bait-heaver" (straight). Gloucester, Mass. G. Brown Goode. 32653. "Bait-heaver" (one-sided).

Hand-dredges (used in collecting mollusks).

26718. Tin hand-dredge. U. S. Fish Commission.

\section{Pile-scrapers.}

26719. Frame of pile-scraper. U. S. Fish Commission.

${ }^{1}$ It is thought unnecessary to exhibit these familiar implements. 


\section{Armed leads.}

†f For use with sounding-lines. ${ }^{1}$

Common "deep-sea lead."

Deep-sea-sounding apparatus.

\section{Cup-leads. \\ Scoop sounding-machime.}

** Grasping-hooks.

7. Hooked INSTRUnents. (Those used with a single motion, that of hooking.)

\section{Single-pointed hooks.}

Gaff-hooks.

25495. Salmon-gaff hook and staff. Bradford \& Anthony, Boston, Mass.

2658. Gaff-hook. U. S. Fish Commission.

29388. Halibut-gaff. M. W. Grant, Welifleet, Mass.

32678. Halibut hand-gaff. Gloncester, Mass. G. Brown Goode.

32583. Halibut deck-gaff. " "

25935. Haddock hand-gaff. A. McCurdy, Gloucester, Mass.

29390. Haddock-gaff. M. W. Grant, Wellfleet, Mass.

25938. Codfish-gaff. Used in George's Bank fisheries. A. McCurdy, Gloucester, Mass.

25939. Dory cod-gafi. Used in shore fisheries. A. McCurdy, Gloucester, Mass.

2:934. Hand-gaff. Used in halibut fisheries. A. McCurdy, Gloucester, Mass. 29389. Cod-gaff. M. W. Grant, Wellfleet, Mass.

2518\%. Gaff-hook. Indians of Northwest coast. J. G. Swan.

26680. Gafí-hook. Property of J. H. Nichols, Syracuse, N. Y. Contributed by Forest \& Stream Publishing Co.

32716. "Pew." Used in handling fish on wharves and deeks. Capt. S. J. Martin, Gloucester, Mass.

32585. "Pew-gaff." Used in pitching fish from dories to vessels. Gloucester, Mass. G. Brown Goode.

32730. Fish-fork (three tines, short handle). Gloucester, Mass. G. Brown Goode. Used in pitching fish in a dory, or from hold of vessel.

32591. Halibut-cutter's hook. Used by the "header" in decapitating halibut. Gloucester, Mass. G. Brown Goode.

32684. Fish-fork (two tines). Gloncester, Mass. G. Brown Goode.

:2725. "Nape-boner" hook. Used in the preparation of boneless fish. Gloucester, Mass. G. Brown Goode.

Boat-hooks.

Arranged with "Accessories of fishing-boats," B. 48.

Rabbit and squirrel hooks, used by Indians.

-. Squirrel-hooks. Pi-Ute Indians. Sonthern Utah. J. W. Powell.

${ }^{2}$ Clam-hooks, hoes, and picks used in gatheringy shell-fish.

1 See exhibit of Navy Department.

:It is thought unnecessary to exhibit these familiar implements. 


\section{Single-pointed hooks.}

${ }^{1}$ Forks used in handling salted and dried fish.

Whalemen's hooks.

Blubber-hooks.

25930. Blubber-hook. For hauling small pieces of blubber. E. B. \& F. Macy. New Bedford, Mass.

26133. Blubber-hook. Alieut Eskimo. Nunivak Island, Alaska. W. H. Dall.

Blnbber forks and pikes.

25615. Blubber-pike. Used for tossing blubber into try-kettle. Humphrey S. Kirby, New Bedford, Mass.

25617. Blubber-pike. From the storeroom of a returned whaler. Humphrey .

S. Kirby, New Bedford, Mass.

Junk-hooks, etc.

For hauling heavy pieces of blubber.

25616. Gaff-hook. Used to haul blubber across the deck from chopper to try-kettle. Humphrey S. Kirby, New Bedford, Mass.

25916. Junk-hook. E. B. \& F. Macy, New Bedford, Mass.

${ }^{2}$ Lance-hooks.

\section{Many-pointed hooks.}

${ }^{2}$ Can-hooks.

${ }^{3}$ Grappling-irons.

Lip-hooks or grapnels, used by whalers.

25918. Whaler's grapnel. Used for towing whale to ship. E. B. \& F. Macy, New Bedford, Mass.

Line-hooks, used by whalers.

25924. Whaler's line-hook for catching line, \&c. E. B. \& F. Macy, New Bedford, Mass.

Clam-rakes.

29466. Clam-hoe. Provincetown style. Wm. H. Hesbolt, Provincetown, Mass.

29437. Hand-claw. Used for gathering "hen-clams" and "scallops." Wellfleet, Cape Cod, and coast of Maine. M. W. Grant, Wellfleet, Mass.

-. Clam-rake (model). Used in collecting the sea-clam (Mactra solidissima) on Nantucket Shoals. These clams are salted down and used as bait for cod, halibut, \&c. See with model of Nantucket dory (26257).

${ }^{1}$ It is thought unnecessary to exhibit these familiar implements.

${ }^{2}$ Arranged with boat fittings.

${ }^{3}$ Arranged with the anchors.

Bull. N. M. No. $14-6$ 


\section{Many-pointed hooks.}

Many-pointed fish-jigs.

29436. Mackerel-gaff. Used when the mackerel swim close in large shrals. M. W. Grant, Wellfleet, Mass.

29441. Mackerel-bob. Used when the mackerel are close to the vessel aud? in large schools. Wm. H. Hesbolt, Provincetown, Mass.

Oulachan rakes or spears.

Used by Indians of the Northwest coast in the capture of the oulachan or candle-fish (Osmerus pacificus).

- Oulachan rake or comb. Flathead Indians. J. G. Swan.

Squid-jigs.

25848. Squid-jig. George P. Steel, Provineetown, Mass.

25714. Squid-jig.

25776. Squid-jig. Gloueester style. A. R. Crittenden, Middletown, Conn.

29443. Squid-jig. Over fifty years old. Lemuel Cook, 2d, Provincetowu, Mass.

32721. Squid-jig. Capt. R. H. Hurlbert, Gloucester, Mass.

32722. Squid-jig.

" "6

25683. Squid-line and jig. Used in catching squid for bait. Bradford \& Anthony, Boston, Mass.

29447. Molds used in forming squid-jigs. John B. Parsons, Rockport, Mass.

Twisting-rods (used in drawing small mammals from their burrows).

- Twisting-rod. Virginia.

8. Barbed Implements. (Those used with two motions, the first that of thrusting.)

\section{Spears with fixed heads.}

Barbed spears (with single point).

25594. Crab-spear, used about Newport, R. I. J. M. K. Southwick, Newport, R. I.

25595. Flounder-spear. J. M. K. Southwick, Newport, R. I.

—. "Conch" harpoon. Used by Bahamians and fishermen of key West in the eapture of large fish. Dr. J. W. Velie, Chicago, Ill.

Eel-spears.

—. Eel-spear with six prongs for winter fishing. Lent by Bradfor! \& Au[thony, Boston, Mass.

25558. Eel-spear with ten prongs for winter fishing.

25557. Eel-spear for summer fishing.

25556. Dine fish-spears.

66

66

25224. Eel-spear, used in sonthern New England. U. S. Fish Commission.

25647. New Bedford cel-spear. H. S. Kirby, New Bedford, Mass.

25606. Eel-spear, Boston pattern. Used on Cape Cod. J. M. K. Southwick, Newport, R. I. 


\section{Spears with fixed heads.}

Aboriginal fish-spears.

7420. Head of fish-spear. Eskimos. Fort Anderson, Aretic coast. R. McFarlane.

2675. Heads of fish-darts. Eskimos. Mackenzie's River district. R. McFarlane.

7514. Head of fish-spear, made of elk-horn. Eskimos. Northwest coast. Geo. Gibbs.

2322. Head of salmon-spear. Indians. Fort Crook, Oreg. Lieut. John Feimer, U. S. A.

2628. Fish-dart heads. Indians. Columbia River. U. S. Exploring Expedition. Capt. C. Wilkes, U. S. N.

1439. Lance-head of bone. Indians. New Mexico. Licut. A. W. Whipple, U. S. A.

18933. Fish-spears. Sitka Indians. 'Sitka. J. G. Swan.

11429. Salmon-spears. Passamaquoddy Indians. Eastport, Me. E. Palmer. 10283. Salmon-spear. Eskimos. Igloolik. Capt. C. F. Hall.

2543. Fish-spear. Tschutschi Indians. South Pacific Exploring Expedition. Capt. John Rodgers, U. S. N.

23518. Three-pronged spear. Northwest coast. J. G. Swan.

Aboriginal bird and fish spears.

19517. Bird-spear. Eskimos. Greenland. Geo. Y. Nickerson.

10267. Bird-spear with throwing-stick. Arctic America. Smithsonian Institution.

15950. Fish-spear. Magemnt Eskimos. Nunivak, Alaska. W. H. Dall.

11358. Fish or bird spear. Eskimos. Bristol Bay, Alaska. Vin sent Colyer. 15689-90-91-93-94-95-96. Bird-spears. Eskimos. Nunivak Islands, Alaska, W. H. Dall.

7973-7997. Fish and bird spears. Mushegay Indians. Alaska. Smithsonian Institution.

\section{Spears with detachable heads.}

Lily-irons.

25230. Sword-fish lily-iron. Capt. John B. Smith. U. S. Fish Commission. 25645. Sword-fish dart and socket, peculiar to New Bedforl. A. R. Crittenden, Middletown, Conn.

32714. Sword-tish lily-iron. Adolph Voss, Gloucester, Mass.

32715. Sword-fish lily-iron.

"6 66

25208. Swordfish-dart head. Wilcox, Crittenden \& Co., Middletown, Conn.

—. "Turtle-peg" harpoon. Key West, Fla. Dr. J. W. Velie, Chicago, Ill.

Eskimo harpoons of stone, bone, and iron.

14255. Iron harpoon-head, with line of walrus hide. Eskimos. Smith Sound. Capt. C. F. Hall.

10120. Harpoon-head, brass and iron. Eskimos. Victoria Harbor. Capt. C. F. Hall.

9838. Harpoon-heads of bone and iron. Eskimos. Northeast coast. S. F. Baird. 


\section{Spears with detachable heads.}

Eskimo harpoons of stone, bone, and iron.

19522. Harpoon-head of stone and bone. Eskimos. Greenland Geo. Y. Nickerson.

10136. Head of walrus-harpoon. Eskimos. Igloolik. Capt. C. F. Hall. 10400. Head of seal-harpoon. Eskimos. Igloolik. Capt. C. F. Hall.

10407. Bone harpoon-head. Eskimos. King William's Sound. Capt. C. F. Hall.

10404. Part of aneient Innuit harpoon-head. Repulse Bay. Capt. C. F. Hall. 10273. Handle of whaling-harpoon made of bone and wood. Eskimos. Greenland. Smithsonian Institution.

19519. Handle of whaling-harpoon made of wood and bone. Eskimos. Greenland. Geo. Y. Nickerson.

10265. Whaling-harpoou. Eskimos. Northwest coast. Smithsonian Institution.

19518. Whaling-harpoon of recent manufacture, with head of bone and iron, handle of wood and iron, and seal-skin line. Eskimos. Greenland. Geo. Y. Niekerson.

565. Harpoon-head of bone and iron with walrus-hide line. Eskimos. Port Foulke. Dr. I. I. Hayes.

2186. Seal-harpoon head of bone and iron. Eskimos. Anderson River. R. McFarlane.

13140. Walrus-harpoon head of bone and iron, hide line. Innuit Eskimos. Greenland. S. F. Baird.

19376. Bene harpoon-head with hide line. Eskimos. Alaska. Rev. James Curley.

11618. Seal-harpoon head of bone. Eskimos. Nunivak Islands, Alaska. W. H. Dall.

15631. Miniature model of seal-harpoon. Eskimos. Alaska. H. W. Elliott. 1678. Miniature model of seal-harpoon. Eskimos. Alaska. W. H. Dall. 16120-21-23-25, 5606-7621. Seal-harpoon heads of bone and iron. Eskimos. Nunivak Islands, Alaska. W. H. Dall.

15619. Harpoon-head of bone. Eskimos. Alaska. H. W. Elliott.

2674. Seal-harpoon heads of bone. Anderson River Eskimos. Fort Anderson. R. MeFarlane.

$2092,2250,2817,3975,5815,7422,7440$. Seal-harpoon heads of bone and iron. Anderson River Eskimos. Mackenzie's River district. R.McFarlane.

- Indian harpoons of shell and iron. Whaling-harpoon, used by Makal Indians of Vancouver's Island and vicinity.

4131. Four models of whaling-harpoons, lines and throuts. Makah Indians. Neah Bay, Wash. J. G. Swan.

1869. Head of whaling-harpoon, with line. Makah Indians. Cape Flattery, Wash. Geo. Suckley.

This harpoon-head is made from the shell of a large species of Mytilus, and illustrates the methods of manufacture employed by Indians of the Northwest coast previous to the introduction of metal by the white man.

20896-7. Head of whaling-harpoon and line. Makah Indians. Sitka, Alaska. J. G. Swan.

This harpoon-head is construeted of sheet-iron and shows the method now employed in the manufacture of the weapons. The rope and covers are made from the bark of Thuja gigantea.

828. Head of whaling-harpoon with line. Makah Indians. Neah Bay, Wash. Ter. J. G. Swan. 


\section{Spear's with detachable heads.}

Eskimo harpoons of stone, bone, and iron.

1868. Head of whaling-harpoon with line. Makah Indiaus. Neah Bay, Wash. Ter. J. G. Swan.

26875-26825. Handles of whaling-harpoons. Makah Indians. J. G. Swan. 2530. Harpoon-darts. Eskimos. Alaska. North Pacific Exploring Expedition. Capt. John Rodgers.

16675. Harpoon-dart. Kotzebue Sound. W. H. Dall.

5775-6-7-9-80. Harpoon-darts. Sitka, Alaska. W. H. Howard. U. S. R. M.

\section{Harpoon-spears.}

6564. Head of barbed fish-dart, made of native copper. Eskimos. Sitka, Alaska. Dr. T. T. Minor.

9083. Head of barbed fish-dart, made of native eopper. Alaska. Lieut. F. W. Ring, U. S. N.

20653. Head of barbed fish-dart of native copper with line of twisted sinew. Alaska. Smithsonian Institution.

21413. Fish-spear with detachable barb. Hoochuon Indians. South Eel River, California. Stephen Powers.

Double-pronged spears with detachable heads. McCloud River Indians, Shasta Co., Cal. Livingston Stone. These spears are used in the capture of the Salmo quinnat. The handles are thirty feet in length. The barbs are made from the splint bones of deer. See No. 13743, below.

19046. Fish-spear with detachable barbs. Cooyunu Pi-Ute Indians. Pyramid Lake, Nerada. Stephen Powers.

23522. Two-pronged spear with detachable barbs. Indians of Northwest coast. J. G. Swan.

26826. Handle of spear similar to 23522, but longer. J. G. Swan.

23520. Spear with many-barbed detachable head and kelp line. Indians of Northwest coast. J. G. Swan.

13743. Points for salmon-spear made of the splint bones of the deer. McCloud River Indians. Shasta Co., Cal. Livingston Stone.

650. Harpoon-arrows with iron tips. Indians. Cape Flattery, Wash. Ter. Geo. Gibbs.

21308. Wooden barbs for fish-harpoon. Indians. Hoopah Valley, Cal. Stephen Powers.

2249. Head of fish-harpoon. Eskimos. Anderson River. R. McFarlane. 11356. Harpoon-dart with bladder-float. Nashegay Indians. Alaska. Dr. T. T. Minor.

9. ToNGs, \&c.

\section{†For hand-use.}

Tongs (with two handles).

Oyster-tongs and oyster-rakes.

26110. Oyster-tongs. S. Salisbury, Providence, R. I.

26109. Oyster-tongs. "

25205. Oyster-tongs. Wilcox, Crittenden \& Co., Middletown, Conn.

29111. Oyster-nippers. S. Salisbury, Providence, R. I. 
"Nippers"' (with cord and handle).

Snake-tongs.

Sponge-tongs.

Coral-tongs.

tf For use with sounding-lines.

"Clamms" for deep-sea soundings (forceps elosed by a weight)."

(Ross" "deep-sea clamms.")

(Bull-dog sounding-machine.)

$$
\begin{aligned}
& \text { *** Grasping-lines. } \\
& \text { 10. Nooses. } \\
& \text { † Stationary nooses. }
\end{aligned}
$$

\section{Jerk-smares.}

Bird-snares.

Fish-snares of wire, gut, hair, \&c.

†† Thrown nooses.

\section{Lariats and lassos.}

11344. Lariat of hide. Apache Indians. General M. C. Meigs, U. S. A. 8534. Lariat of hide. Sioux Indians. Nebraska. Dr. S. M. Horton, U. S. A. 1912. Lariat of hide. Sioux Indians. Upper Missouri River. Lieut. G. K. Warren.

6920. Lariat of hide. Comanche Indians. Fort Cobb, Ind. T. E. Palmer. 6921. Lariat of hide. Comanche Indians. Llano Estacado, Texas. E. Palmer.

5559. Lariat of hide. Apache Indians. E. Palmer.

7492. Lariat of moose-skin. Mackenzie River Indians. Fort Anderson. R. MeFarlane.

11206. Lariat of rope. Pi-Ute Indians. Southern Utah. Maj. J. W. Powell. 5558. Lariat of buffalo-hair. Apache Indians. E. Palmer.

7317. Lariat of buffalo-hair. Apache Indians. Maj. W. H. Mills, U. S. A. 9034. Lariat of buffalo-hair. Nez Percé Indians. Idaho. Dr. E. Storror. 6922. Lariat of buffalo-hair. Comanche Indians. Fort Cobb, Ind. Ter. E. Palmer.

\section{LOADED LINES. (Bolas.)}

Bird-slings (used by Eskimos).

19507. Bird-sling. Greenland. J. H. Clark. Smithsonian Institution. 9831. Bird-sling. Greenland. S. F. Baird. 66

7444. Bird-sling. McKenzie's River. Fort Anderson, H. B. T. R. MeFarlane.

9831. Bird-sling. Greenland. S. F. Baird.

7537. Bird-sling. Arctic coast. Fort Anderson, H. B. T. B. R. Ross.

\footnotetext{
'See exhibit of Navy Department.
} 


\section{****Entangling-lines.}

12. TANGLES.

The tangles are employed by naturalists for the purpose of gathering small spiny animals, such as sea-urchins and star-fishes, from the bottom at considerable depths. They adhere to the fibers of the spun-yarn in great numbers. It has been thought that this instrument might advantageously be employed in freeing oyster-beds from their worst enemies, the star-fish.

\section{Swab-tangles.}

Swab-tangles.

26844. Swab-tangle. U. S. Fish Commission.

(Dredge-tangles, used by English collectors.)

\section{Harrow-tangles.}

Harrow-tangles.

26845. Models of harrow-tangles. U. S. Fish Commission. Formerly used by the Fish Commission, now replaced by the wheel-tangles.

\section{Wheel-tangles.}

Wheel-tangles.

26846. Model of wheel-tangle. U. S. Fish Commission.

26848. Wheel-tangles. U. S. Fish Commission.

\section{MISSILES.}

* Simple missiles (those propelled by the unaided arm).

13. HURLED WEIGHTS.

Stomes and disks (thrown by the hand).

Weights (dropped from an elevation, dead-falls, not automatic).

\section{HURLED STICKS.}

\section{Straight sticks.}

Clubs used as missiles.

\section{Curved sticks.}

Throw-sticks, used by the Moqui Indians of New Mexico in hunting rabbits.

9543-4. Throw-sticks. Used in rabbit-hunting by Moqui Indians. New Mexico. Dr. Edward Palmer. 


\section{HuRLED SPEARS.}

\section{Darts and lances.}

See under "Lances and spears," above enumerated, many of which may be used as missiles.

* Centrifugal missiles. (Propelling power augmented by an artificial increase of the length of the arm.)

\section{SLINGS AND SPEARS THROWN BY STRAPS.}

\section{Slings.}

9532. Sling. Navajo Indians. Sunithsonian Institution. 17234. Sling. Indians. $66 \quad 66$

Spears (with straps).

\section{MISSILES PROPELLED BY "THROWING-STICKS."}

Spears (with throwing-sticks, used by Eskimos).

See above under "Bird and fish spears," particularly No. 10267, a spear with throwing-stick attached.

7899. Throwing-stick. Eskimos. Aleutian Islands. Dr. T. T. Minor. 7933. Throwing-stick. Eskimos. Kodiak.

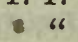
pedition. Capt. John Rodgers.

11346-47. Throwing-sticks. Yukon River, Alaska. Vincent Colyer. 15643. 1642-16243. Throwing-sticks. Eskimos. Nunivak Islands. W. H. Dall.

2267. Throwing-stick. Eskimos. Smithsonian Institution. 5774. Throwing-stick. Eskimos. Sitka. W. A. Howard, U. S. R. M. 20771. Throwing-stick. Eskimos. Sitka. J. G. Swan.

***Assiles propelled by a spring.-(Spring consisting of bent rod.)

\section{Bows.}

\section{Bows AND ARROWS.}

Simple bows.

(Cross-bows.)

(Ballistas.)

These articles are arranged with the Ethnological series, as are also the arrows, with the exception of a few forms peculiarly adapted to hunting.

\section{Arrows.}

\section{Hunting-arrows.}

11350-54. Bird-arrows. Eskimos. Bristol Bay, Alaska. Vincent Colyer. 16410-11-12. Bird-arrows. Eskimos. Nunivak Islands, Alaska. W. H. Dall. 
ANIMAL RESOURCES AND FISHERIES OF UNITED STATES.

\section{Arrows.}

Hunting-arrows.

8827-28-29-30. Bird-arrows. Eskimos. Alaska? Smithsonian Institution. 5602. Bird-arrows. Yukon River, Alaska. W. H. Dall.

15654. Hunting-arrows. Kodiak Indians. Alaska. W. H. Dall.

16413-14-15. Hunting-arrows with heads of bone and iron. Eskimos. Nunivak Islands, Alaska. W. H. Dall.

- Hunting-arrows with bone heads. Eskimos. Nunivak Islands, Alaska. Vincent Colyer.

Harpoon-arrows, used in fishing.

11348-52. Harpoon-arrows. Eskimos. Bristol Bay, Alaska. Vincent Colyer.

15677-15681-82. Harpoon-arrows. Eskimos. Nunivak Islands, Alaska. W. H. Dall.

19379. Harpoon-arrow. Eskimos. Alaska. Rev. J. Curley.

8005-6-9. Harpoon-arrows. Eskimos. Nushegay Indians. Dr. T. T. Minor.

\section{Accessories of bows and arrows.}

Holders.*

Quivers.*

Arrow-head pouches.*

\section{Implements of manufacture.}

Flint-chipping apparatus.*

Arrow-head sharpeners.*

Shaft-gauges.*

Cord-twisting apparatus.*

Shaft-polishers.*

Glue-sticks, used in fastening head of arrow.*

Arranged with the Ethnological series.

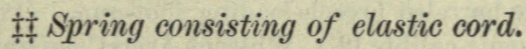

19. INDIA-RUBBER SLINGS.

Pea-shooters (used in killing birds).

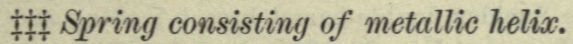

Spring-guns.

20. SPRING-GUNS.

**** Missiles propelled by the compression of air or water.

21. AIR-GUNS.

Blow-guns (missile propelled by the breath).

Blow-guns carrying arrows.

Blow-guns carrying balls. 


\section{Piston air-guns. Reservoir air-guns.}

Air-guns.

29535. Bedford Eureka air-pistol, with darts, slugs, and gun-rest. (Patented Dec. 21, 1875.) Eureka Manufacturing Company, Boston, Mass.

Air-gun canes.

\section{WATER-GUNS.}

Syringe-guns.

Humming-bird guns.

***** Fire-arms.

23. GUNS AND PISTOLS.

\section{Muzzle-loading arms.}

26714. Flint-lock gun (single barrel) old fashion. Smithsonian Institution.

809. Single-barrel shot (?) gun.

Given by Lord Melville to Sir John Franklin, who used it on his unfortunate expeditions in 1820,1821 , and 1822 , then given by Sir John to his interpreter, St. Germain, who sold it to Chief Factor Smith, of the Hudson Bay Co., who gave it to his son-inlaw, Chief Factor McPherson, from whom it was obtained by B. R. Ross, of the Hudson Bay Co.

\section{Breech-loading arms.}

25894. Six-shooting shot-gun. Colt's Fire-Arms Manufacturing Company, Hartford, Conn.

25895. Double-barreled breech-loading fowling-piece. E. Remington \& Sons, Ilion, N. Y.

25247. Double-barreled breech-loading fowling-piece. . Damascus steel, 12 gauge. Parker Bros., Mericlen, Comn.

25250. Single-barreled breech-loading shot-gun. (Patented May 26, 1874. Phœnix calibre 12.) Whitney Arms Company, Whitneyville, Conn.

§6574. Breech-loading gun. Clark \& Sneider, Baltimore, Md.

26573. Breech-loading gun.

"6 "6

29533. The Sneider patent double-barrel breech-loading shot-gun. Clark \& Sneider, Baltimore, Md.

29534. The Sneider double-barrel breech-loading shot-gun; solid tip grip. (Patented Dec. 22, 1868; April 7, 1874.) Clark \& Sneider, Baltimore, Md.

25896. Creedmoor rifle. E. Remington \& Sons, Ilion, N. Y.

- Mid-range rifle. Peabody \& Martin pattern (44 cal., 100 grs.), made by Providence Tool Co. Schuyler, Waltham \& Graham, New York.

25890. Sporting-rifle. King's improvement. (Patented March 29, 1866; October 16, 1860. Model, 1873. Calibre .14.) Winehester Repeating Arms, New Haven, Conn.

22202. Sharpe's rifle. (Patented April 1, 1866.) Manufacturers.

29289-311. Maynard's rifle with appurtenances. (Pistol grip, vernier rearsight. Front wind-gange sight and spirit-level; 32 inches, .4 calibre.) Massachusetts Arms Company, Chicopee Falls, Mass. 


\section{Breech-loading arms.}

29299. Shot-barrel for Maynard's rifle; 32 inches, .64 calibre. Massachusetts Arms Company, Chicopee Falls, Mass.

25873. Six-shooting rifle; 44-inch calibre. Colt's Fire-Arms Manufacturing Company, Hartford, Conn.

25889. Carbine. King's improvement. (Patented March 29, 1866; October 16, 1860. Model 1873. Calibre .44.) Winchester Repeating Arms, New Haven, Conn.

25248. Breech-loading sporting-rifle. (Patented October 17, 1866. Reissued June 25, 1872; Dec. 26,1865 . Reissued Oct. 1, 1867; May 15, 186t; ; July 16, 1872.) Whitney Arms Company, Whitneyville, Conu.

25249. Breech-loading sporting-rifle. Phœnix calibre, 44. Whitney Arms Company, Whitneyville, Conn.

25892. Six-shooting revolver. 45 calibre. (Patented Sept. 19, 1871; July 2, 1872.) Colt's Fire-Arms Manufacturing Company, Hartford, Conn.

\section{Whaling-guns.}

24986. C. C. Brand's improved whaling-gun. Patented June 22, 1852. For use with C. C. Brand's improved bomb-lance. 2498\%. Powder-flask with charger. 24988. Wad-cutter. 24989. Wad-cutter (inside). 24992. Prepared wads. 24990, 24991. Screw-drivers. C. C. Brand, Norwich, Conn.

24993-97. C. C. Brand's improved bomb-lance. Patented June 22, 1859. For use with C. C. Brand's improved whaling-gun. 2499\%. Explosled lance. 24998. Lance-hook (for drawing charge). C. C. Brancl, Norwich, Conn.

25251. E. Pierce's harpoon-gun. Patented 1865. U. S. Fish Commission.

26897. Cunningham \& Hogan's breech-loading bomb-gun, with explosive lances. William Lewis, Now Bedford, Mass.

\section{4. (ACCESSORY.) AMMUNITION AND ITS PREPARATION.}

\section{Explosives.}

Gunpowder.

Gun-cotton.

Percussion powder:

Caps.

Needle percussion.

Primers.

Wood powder.

Dynamite or giant-powder.

Nitroglycerine.

Dualine.

Lithofracteur.

Colonia powder.

Other explosives.

For obvious reasons this series could not be exhibited. 


\section{Missiles.}

Bullets.

(Accessory.) Bullet-molds.

29300. Pair of molds for conical and eylindrieal bullets. Massachusetts Arms Company, Chicopee Falls, Mass.

Shot.

- Series of samples of shot, sizes from No. 000 to No. 12. Thomas Sparks, Philadelphia, Pa.

Explosive bullets, shells, \&c.:

Bomb-lance.

\section{Wadding.}

Bulk wadding.

Prepared wads.

(Accessory.) Wad-cutters.

The articles of this class may be seen in connection with the ammunition series.

\section{Ammunition-measures.}

Measures.

$\left.\begin{array}{l}\text { Shot-measures. } \\ \text { Powder-measures. }\end{array}\right\}$ Attached to pouches and separate.

16190. Powder-charger. Nunivak Islands, Alaska. W. H. Dall.

2689. Gun-charger. Indians of Northwest coast. Captain Wilkes, U. S. N. U. S. Exploring Expedition.

Weighing scales.

\section{Prepared ammunition.}

Ball, shot, and wire cartridges.

25891. Card of rim-fire eartridges. Winchester Repeating Arms, New Haven, Conn.

29304. Ten metallic cartridge-shells, .4, for rifle. Massachusetts Arms Com. pany, Chicopee Falls, Mass.

29305. Ten metellic càrtridge-shells, .64, for shot-guns. Massachusetts Arins Company, Chicopee Falls, Mass.

\section{Methods of preparing cartridges.}

Loaders, crimpers, and cappers.

29303. Metallic loader for rifle-cartridge. Massachusetts Arms Company, Chicopee Falls, Mass. 


\section{Methods of preparing cartridges.}

Loaders, crimpers, and cappers.

29302. Rosewood loader for shot-cartridge. Massachusetts Arus Company, Chicopee Falls, Mass.

29308. Two rosewood loading-blocks. Massachusetts Arms Company, Chicopee Falls, Mass.

25897. Cartridge-loading machine. E. Remington \& Sons, Ilion, N. Y.

29306. Cartridge-capper. Massachusetts Arms Company, Chicopee Falls, Mass.

25. ACCESSORIES OF LOADING, CLEANING, AND REPAIRING, SIGHTING, AND TESTING FIRE-ARMS.

\section{Instruments for cleaning, loading, dxc.}

Rammers.

Swabs.

Charge-drawers-"worms"-and other loading tools.

These may be seen attached to the various wrappers.

29307. Wrench and cap-picker. Massachusetts Arms Company, Chicopee Falls, Mass.

29311. Rod and tip for cloth, plain. Massachusetts Arms Company, Chicopee Falls, Mass.

29310. Jointed rod and brush. Massachusetts Amns Company, Chicopee Falls, Mass.

29309. Screw-driver. Massachusetts Arms Company, Chicopee Falls, Mass.

7525. Gun-screw-driver. Apache Indians. Arizona. E. Palmer.

26695. Loading-tools. Property of J. A. Nichols, Syracuse, N. Y. Contributed by Forest \& Stream Publishing Company.

26696. Closer. Property of J. A. Nichols, Syracuse, N. Y. Contributed by Forest \& Stream Publishing Company.

29251. Oil-bottle, nickel (No. 1). Edwin W. Judge, New Haven, Conn. 29252. Oil-bottle, nickel (No. 2).

"

26698. Oil-can. Property of J. A. Nichols, Syracuse, N. Y. Contributed by Forest \& Stream Publishing Company.

\section{Sights, \&c.}

Muzzle-sights.

Slit-sights.

Globe-sights.

Peep-sights.

Breech-sights.

Plain-sights.

Graduating-sights.

Telescope-sights.

Levels, attached to guns.

Wind-gauges.

These may be seen attached to the gans. 


\section{Recoil-checks.}

25\%00. William D. Miller's patent recoil-check for shot-guns and rifles. (Patented Nov. 2, 1875, No. 52.) A. J. Norman, New York.

Advantages claimed for this arrangement are that it repels and neutralizes the reeoil, permits steadier aim, and insures increased range and greater penetration.

26. FOR CARRYING ARMS AND AMMUNITION.

\section{Ammunition-holders.}

Powder-horns:

Horns.

Flasks.

Canisters.

1910. Powder-horn. Sioux Indians. Upper Missouri River. Lieut. G. K. Warren, U. S. A.

1472. Powder-horn. Comanche Indians. General D. N. Couch, U. S. A.

16309. Powder-horn. Sitka, Alaska. W. H. Dall.

1909. Powder-horn and pouch. (Containing bullets, gun-flints, and arrowpoints.) Sioux Indians. Upper Missonri River. Lieut. G. K. Warren, U. S. A.

5520. Powder-horn. Papago and Apache Iudians. E. Palmer.

21672. Powder-horn and pouch. Yankton Sioux. Dakota. Army Medical Museum. Dr. J. T. Boughter.

26706. Cartridge-box. Property of J. A. Nichols, Syraeuse, N. Y. Contributed by Forest \& Stream Publishing Company.

26703. Cartridge-flask. Property of J. A. Nichols, Syracuse, N. Y. Contributed by Forest \& Stream Publishing Company.

7313. Powder-flask. Apache Indians. Major Mills, U. S. A.

13035. Powder-flask. Alieut Eskimos. Ounalashka. W. H. Dall.

16099. Powder-flask. Magemut Eskimos. Nunivak Islands, Alaska. W. H. Dall.

9290. Powder-flask. Alaska. Dr. A. H. Hoff, U. S. A.

5184. Powder-flask. Porterre Indians. Dr. J. T. Rothrock, U. S. A.

16292. Powder-flask. Kodiak Eskimos. Chirikoff. W. H. Dall.

\section{Shot and bullet holders.}

Pouches.

- Shot-pouch. Found in old house, Saint Regis, N. Y. R. B. Hough.

20673. Shot-pouch. Indians of the Northwest coast. Fort Simpson, B. C. . J. G. Swan.

9641. Bullet-pouch. Navajo Indians. E. Palmer.

11077. Bullet-poueh. Navajo Indians. Northwestern New Mexieo. Vincent Colyer.

2112. Bullet-pouch. Indians of Upper Missouri. War Department, U. S. A.

6199. Bullet-pouch aud belt. Delaware Indians. Arizona. E. Palmer.

2470. Bullet-poneh and belt. Indians of Missouri Valley. War Department, U. S. A.

5432. Bullet-pouch and belt. J. Varden.

26699. Ball-box. Property of J. A. Niehols, Syracuse, N. Y. Contributed by Forest \& Stream Publishing Company.

1935. Bullet-poueh and belt. Indian. 


\section{Shot and bullet holders.}

Cap-holders.

5525. Cap-case. Apache Indians. Arizona. E. Palmer.

26697. Cap-box. Property of J. A. Nichols, Syracuse, N. Y. Contributed by Forest \& Stream Publishing Company.

Pouches.

Boxes.

Cap-straps, used by Indians.

Cartridge-holders:

Pouches.

Boxes.

Belts.

Vests.

\section{Weapon-holders.}

Slings for arms:

Shoulder-slings.

Saddle-slings.

Holsters.

Belts:

Pistol-belts.

Racks and cases:

Gun-racks.

Gun-cases.

8546. Gun-case. Indians. Ogalalla, Nebr. Dr. S. M. Horton, U. S. A.

14849. Gun-ease. Indian. Colorado. Maj. J. W. Powell.

26705. Gun-case. Property of J. A. Nichols, Syracuse, N. Y. Contributed by Forest and Stream Publishing Company.

26704. Gun-case. Property of J. A. Nichols, Syraeuse, N. Y. Contributed by Forest and Stream Publishing Company.

\section{BAITED H0OKS. ANGLING-TACKLE.}

27. HOOKS WITH MOVABLE LINES.

\section{Tackle for surface-fishing.}

Fly-fishing tackle.

Salmon-tackle.

Trout-tackle.

Black-bass tackle.

Shad-tackle. 


\section{Tackle for surface-fishing.}

Trolling-tackle:

Trolling-tackle.

Whiffing-tackle.

Drailing-tackle.

Gangs of hooks for minnow-bait.

The parts of these gears may be seen in their proper places, with hooks, lines, \&c.

26683. Minnow-gang. Property of J. A. Nichols, Syracuse, N. Y. Contributed by Forest and Stream Publishing Company.

Surf-tackle for throwing and hauling.

Striped-bass tackle.

Red-fish or bass tackle.

Blue-fish tackle.

Tide-drailing tackle.

Pasque and Cuttyhunk bass-tackle.

24808-9. Blue-fish line. Rigged with eel-skin squids. J. M. K. Southwick, Newport, R. I.

24802-7. Blue-fish lines. Rigged with cloth squid., Block Island. J. M. K. Southwick, Newport, R. I.

\section{Tackle for fishing below the surface.}

Short hand-gear.

25684. Mackerel-lines and cleats. Bradford \& Anthony, Boston, Mass.

25940. Mackerel hook and line. A. McCurdy.

29293. "Otter," with line and flies attached. Used in lake and river fishing. William Morris, Lake City, Minn.

19047. Throw-line with minnow-hooks. Cooyuwee Pi-Utes. Pyramid Lake, Nevada. Stephen Powers.

Deep-sea gear.

25\%86. Hand-line gear for halibut and cod. Used in George's Banks fisheries. Alexander MeCurdy, East Gloncester, Mass.

25687. Gear, used by American fishermen on George's Banks. Bradford \& Anthony, Boston, Mass.

29471. Hand-line gear. Used in George's Banks cod and halibut fisheries. A. McCurdy, East Gloucester, Mass.

29483. Cod-fishing gear. Used from 1812-1830. Lemuel Cook, 2d, Province. town, Mass.

25686. Cod hand-line and gear. Used chiefly on Western and Grand Banks of Newfoundland. Bradford \& Anthony, Boston, Mass.

25685. Pollock line and gear. Bradford \& Anthony, Boston, Mass.

24810-11. Rigged tautog-lines. J. M. K. Southwick, Newport, R. I.

25665. Lines. Rigged for pond-fishing. Wm. M. Young, Philadelphia, Pa.

1140. Halibut-hook, with kelp line. Makah Indians. Puget Sound, W.

T. J. G. Swan. 


\section{Tackle for fishing below the surface.}

Deep-sea gear:

Flounder-gear.

Shark-gear.

Other bottom-gear.

Bobs :

Eel-bobs.

28. Hooks, WITH STATIONARY LINES.-SET TACKLE.

\section{Surface limes.}

Spilliards, or floating-trawl lines.

\section{Bottom-set lines.}

Trawl-lines, or bull-tows.

25688. Model of codfish-trawl, used by American fishermen on Western and Grand Banks of Newfoundland. Buoys, scale of one-sixth; anchors, scale of one-fifteenth. Bradford \& Anthony, Boston, Mass.

29469. Section (one-fifth) of trawl-line. Used in George's Banks codfisheries. A. R. Crittenden, Middletown, Conn.

6560. Trawl-line and hooks. Indians of Vancouver's Island. Dr. T. T. , Minor.

32705. One section or "skate" of a halibut trawl-line with (No. 32706) inner buoy with flag, (No. 32707) outer buoy with "black-ball," (No. 32708) buoy-line, and (No. 32709) anchor. Capt. Jos. W. Collins and Philip Merchant, Gloncester, Mass.

Set-traps.

25562. Pickerel-traps. With lines and flags for fishing throngh the ice. Bradford \& Anthony, Boston, Mass.

25563. Set of implements for smelt-fishing through the ice.

25667. Fishing-bows. W. M. Young, Philadelphia, Pa.

29. (ACCESSORY.) Parts AND aCCESSORIES OF ANGLING-APPARATUS AND OF HARPOON AND SEINE LINES.

Hooks (including a full series of unmounted hooks, of recent and aboriginal manufacture).

Plain hooks.

25682. The ten processes through which American hand-made fish-hooks pass from the wire to the finished hook. Made entirely by handlabor in the factory of J. W. Court, Brooklyn, N. Y. Brarlford \& Anthony, Boston, Mass.

25524. Double-refined, cast-stecl, tapered point; Virginia hooks, flatted, Nos. 10 to 1 and 1-0 to 3-0. American Needle and Fish-Hook Company, New Haven, Conn.

25535. Superfine cast-steel blackfish-hooks, japanned, flatted, Nos. 1 to 8 . American Needle and Fish-Hook Company, New Haven, Conn.

Bull. N. M. No. $14-7$ 


\section{Hooks (including a full series of unmounted hooks, of recent and}

Plain hooks. aboriginal manufacture).

25535. Eel-hooks, No. 6. American Needle and Fish-Hook Company, New Haven, Conn.

25640. Halibut-hooks, ringed; Nos. 1 to 3 . American Needle and Fish-Hook Company, New Haven, Conn.

25528. Cast-steel Kirby sea fish-hooks, flatted; Nos. 1 to 12. American Needle and Fish-Hook Company, New Haven, Conn.

25530. Cast-steel Kirby sea fish-hooks, ringed; Nos. 1 to 12.

25529. Superior cast-steel Kirby sea fish-hooks, galvanized, flatted; Nos. 1 to 8. American Needle and Fish-Hook Company, New Haven, Conn.

25522. Double-refined cast-steel Kirby river and trout fish-hooks, ringed; Nos. 1 to 12 and $1-00$ to $10-0$. American Needle and Fish-Hook Company, New Haven, Conn.

25523. Kirby river and trout fish-hooks, flatted, extra superfine; Nos. 1 to 12 and $1-0$ to $10-0$. American Needle and Fish-Hook Company, Now Haven, Conn.

25519. Superfine spring steel Kirby salmon, flatted; Nos. 12 to 3-0. American Needle and Fish-Hook Company, New Haven, Conn.

25520. Carlisle trout-hooks, flatted; Nos. 12-20. American Needle and Fish-Hook Company, New Haven, Conn.

25521. Carlisle trout-hooks, ringed; Nos. 8 to 3-0. American Needle and Fish-Hook Company, New Haven, Conn.

25516. Superfine cast-steel Limerick salmon, flatted; Nos. $1-0$ to 12 and 2-0 to 10-0. American Needle and Fish-Hook Company, New Haven, Conn.

25517. Superfine cast-steel Limerick salmon, ringed; Nos. 1-0 to 9 and 2-0 to 10-0. American Needle and Fish-Hook Company, New Haven, Conn.

25514. Double-refined cast-steel Limerick river and trout fish-hooks (spearpoints, flatted); Nos. 1-0 to 12 and 2-0 to 10-0. American Needle and Fish-Hook Company, New Haven, Conn.

25515. Double-refined cast-steel Limerick river and trout fish-hooks (spearhead points, flatted, shanks ringed); Nos. 1-0 to 12 and 2-0 to 10-0. American Needle and Fish-Hook Company, New Haven, Conn.

25518. Extra spring-steel Aberdeen trout-hooks, flatted; Nos. 8 to 4-0. American Needle and Fish-Hook Company, New Haven, Conn.

25525. Superfine spring-steel Kinsey trout-hooks, flatted; Nos. 6 to 16. American Needle and Fish-Hook Company, New Haven, Conn.

25591. Superfine steel Kinsey trout-hooks, ringed; Nos. 10 to 16. American Needle and Fish-Hook Company, New Haven, Conn.

25534. Cast-steel drop-point mackerel-hooks, large and small wire, flatted; Nos. $1 \mathrm{~A}$ to $5 \mathrm{~A}$, and $2 \mathrm{~B}$ to $4 \mathrm{~B}$. American Needle and Fish-Hook Company, New Haven, Conn.

25527. Superfine cast-steel J. P. cod-hooks, ringed; Nos. 1 to 8. American Needle and Fish-Hook Company, New Haven, Conn.

25526. Superfine cast-steel J. P. cod-hooks, flatted; Nos. 1 to 8. Amcrican Needle and Fish-Hook Company, New Haven, Conn.

25532. Central-draught codfish-hooks, eyed; Nos. 10 to 17. American Needle and Fish-Hook Company, New Haven, Comn.

25533. Double-refined east-steel, original, central-draught cod or mackerel hooks, ringed; Nos. 12 to 20. American Needle and Fish-Hook Company, New Haven, Conn. 
Hooks (including a full series of unmounted hooks, of recent and

Plain hooks. aboriginal manufacture).

25531. Donble-refined cast-steel, original, central-dranght cod or mackerel hooks, flatted. American Needle and Fish-Hook Company, New Haven, Conn.

25601. Cod-hooks. Used when fish rise to the surface. J. M. K. Southwick, Newport, R. I.

25538. Shark-hooks. Bradford \& Anthony, Boston, Mass.

29465. Shark-hooks. M. W. Grant, Wellfleet, Mass.

25648. Shark-hook. (Extraordinary.) A. R. Crittenden, Middletown, Conn.

29464. Ground-shark hook. Style used forty years ago. Elisha Cook, Provincetown, Mass.

25602. Dog-fish hook with chain. Used at Newport, R. I. J.M. K. Southwick, Newport, R. I.

25641. Dog-fish hooks, ringed. American Needle and Fish-Hook Company, New Haven, Conn.

29467. Horse-mackerel hook. John Thomas, Belfast, Me.

29505. Hooks, probably lost by a French fishing-vessel. Found on St. George's Banks on a piece of trawl; fished up by Geo. H. Lewis, Provincetown, Mass.

32732. French cod-hooks; taken from codfish on Jeffries Ledge. Capt. James Tarr, Gloucester, Mass.

32731. French cod-hook; taken from codfish in Salvages' Shoals, Cape Ann, in 1856. Capt. James Tarr, Gloucester, Mass.

20654. Wooden fish-hooks. Indians of Northwest coast. Bella Bella, B. C. J. G. Swan.

- Fish-hooks. Indians of Northwest coast of America. Straits of Fuca, Puget Sound. U. S. Exploring Expedition.

1051. Fish-hooks. Puget Sound. George Gibbs.

9765. Fish-hook. Wallapai Indians. E. Palmer.

5583. Fish-hook of wood and bone. Gens des Fous Indians. Yukon River, Alaska. W. H. Dall.

9807. Fish-hook and line. Chilkaht Indians. Alaska. Lient. F. W. Ring, U. S. A.

5590. Fish-hooks and sinkers. Premorska Indians. St. Michael's, Alaska. W. H. Dall.

19064. Fish-hooks. Cooyuwee Pi-Ute Indians. Pyramid Lake, Ner. Stephen Powers.

20651. Fish-hook. Bella Bella, B. C. J. G. Swan. Indian make.

9270. Halibut-hook. Alaska. Dr. Hoff, U. S. A. " "

- Halibut-hook. Sitka, Alaska. J. G. Swan. " "

9103-4. Halibut-hooks. Alaska. Lient. F. W. Ring, U.S. A. " "

1141. Butt-end of hemlock limb for making halibut-hook. Makah Indians. Puget Sound, W. T. J. G Swan.

16346. Halibut-hooks. Yakutat Eskimo. W. H. Dall.

2630. Fish-hook. Northwest coast of America. Capt. Chas. Wilkes, U. S.N. U. S. Exploring Expedition.

1324. Hooks and lines. Eskimo. Anderson River. C. P. Gaudet.

1989. Fish-hook. Aretic America. B. R. Ross.

5118. Fish-hook. Anderson River Eskimos. Mackenzie's River district. R. Kennicott.

5116. Fish-hook. Fort Anderson Eskimos. Mackenzin's River district. R. MacFarlane.

26822. Fish-line of kelp (Nereocystis), fish-hook, and bladder buoy. Makah Indians. Neah Bay. J. G. Swan. 
Hooks (including a full series of unmounted hooks, of recent and

Plain hooks. aboriginal manufacture).

9807. Fishing line and hook. Chilkaht Indians. Alaska. Lieut. F. W. Ring, U. S. A.

15630. Bone fish-hook with whalebone snood. Alaska. H. W. Elliott. 16315. Fish-hook. Sitka. W. H. Dall.

652. Halibut-hooks. Indians of Northwest coast of America. George Gibbs.

20656. Halibut-hooks. Indians of Fort Simpson, B. C. J. G. Swan. 15685. Fish-hooks. Eskimos. Poonook, Alaska. H. W. Elliott. 10142. Fish-hooks. Eskimos. Vietoria Harbor. Capt. C. F. Hall. 14280. Fish-hooks. Neah Bay, W. T. James G. Swan.

16116. Bone hook. Magemut Eskimos. Nunivak, Alaska. W. H. Dall. 16311. Fish-hooks. Nunivak Islands, Alaska. W. H. Dall.

1051. Fish-hooks. Capt. Chas. Wilkes, U. S. N. U. S. Exploring Expedition.

10219. Codfish-hook. Eskimos. Coast of Greenland. Capt. C. F. Hall. 2191-92. Fish-hooks of stone, bone, and iron. Fort Anderson Eskimos. Mackenzie's River district. R. Kennicott.

2093, 2248. Fish-hooks of bone and iron. Anderson River Eskimos. R. MacFarlane.

16311-12. Bone hooks and line spreaders. Thlinket Eskimos. Sitka, Alaska. W. H. Dall.

5118-7441. Hooks of bone and iron. Mackenzie's River Eskimos. R. MacFarlane.

32660. Smelt-spreader and hooks. Gloucester, Mass. G. Brown Goode.

Jigs and drails.

29448. Bass and bluefish drail. Elisha Cook, Provincetown, Mass.

29425. Bluefish-drail. Provincetown style. Lemuel Cook, 2d, Provincetown, Mass.

25555. Bluefish-drails. Bradford \& Anthony, Boston, Mass.

29485. Bluefish-drail. Used in Wellfeet, Mass., about 1820. Newell B. Rich, Wellfleet, Mass.

25555. Bluefish-drails. Bradford \& Anthony, Boston, Mass.

-. Bluefish-hooks. Collected by A. R. Crittenden, Middletown, Conn.

25550. Bluefish-drail. Bradford \& Anthony, Boston, Mass.

25771. Bluefish-drails. (Made in the form of a squid and very killing.) Peculiar to Provincetorn, Mass. Coleman Cook, Provincetown, Mass.

25553. Blnefish-drail. Wm. H. Young, Brooklyn, N. Y.

25669. Bluefish-drail. Peculiar to Hyannis, Mass. Freeman Hallett, Hyannis, Mass.

25671. Bluefish-drail. Peculiar to Chatham, Mass. Sanford Freeman, Norwichport, Mass.

25671 (?) Bluefish-drail. J. H. Bartlett \& Sons, New Bedford, Mass.

25537. Series of hollow bone bluefish-squids. Nos. 1 to 3. American Needle and Fish-Hook Company, New Haven, Conn.

25668. Bluefish-drail. Peculiar to Harwichport, Mass. Sanford Freeman, Norwich, Mass.

25708. Bluefish-drail. Central Wharf Company, Provincetown, Mass.

25598. Bluefish-drail. J. M. K. Southwick, Newport, R. I.

25670. Bluefish-drail. Made at sea from jaw-bone of sperm-whale (Physeter macrocephalus). J. H. Bartlett \& Son, Now Bedford, Mass. 
Hooks (including a full series of unmounted hooks, of recent and

Jigs and drails. aboriginal manufacture).

25669. Bluefish-drail. Peculiar to Hyannis, Mass. Freeman Hallett, Hyannis, Mass. When used, covered with an eel-skin.

25600. Weak-fish jigs. Used in Newport, R. I. J. M. K. Southwick, Newport, R. I.

9078. Metallic squid. Indians. Alaska. Lieut. F. W. Ring, U. S. A.

32657. Cahoon's improved trolling-hooks. (Patented March 24, 1874.)

Thomas J. Gifford \& Co., New Bedford, Mass.

12496. Mackerel-jigs. Cape Ann. J. P. Nason, Rockport, Mass.

32658. Mackerel-jig. Gloucester, Mass. G. Brown Goode.

29479. Mackerel-jig. John B. Parsons, Rockport, Mass.

32734. Mackerel-jigs. Used thirty years ago. A. McCurdy, Gloncester, Mass.

25599. Mackerel-jigs. J. M. K. Southwick, Newport, R. I.

25941. Mackerel-jigs. Used about the year 1840. Capt. Edward L. Rowe, Gloucester, Mass.

12495. Soapstone "jig" molds, No. 1. (Patented March 15, 1870.) Cape Ann. J. P. Nason, Rockport, Mass.

25780. Soapstone mackerel-jig mold. Capt. E. L. Rowe, Gloucester, Mass. 25781-2 Wooden, lead-lined, mackerel-jig molds.

25721. Mackerel-jig mold. (Patented March 15, 1870; J. P. Nason, No. 2.) Central Wharf Company, Provincetown, Mass.

32656. Mackerel-jig mold. Gloucester, Mass. G. Brown Goode.

32654. Mackerel-jig ladle. "6 66

32661. Mackerel-jig rasp. " "6 6

32662. Mackerel-jig file. " " 66

32663. Pewter for use in manufacture of jigs. Gloucester, Mass. G. Brown Goode.

29461. Codfish "trip" and "fly-jig." Styles nsed fifty years ago. Lemuel Cook, 2d, Provincetown, Mass.

25601. Codfish jig-hook. Used when the fish rise from the bottom. Massachusetts. A. R. Crittenden, Middletown, Conn.

Spoon-baits, plain and fluted.

25550. Fluted spoons for pickerel, bass, and trout. Manufactured by G. M. Skinner, Gananoque, Ontario. Patented United States and Canada, 1874. Bradford \& Anthony, Boston, Mass.

25550. Trolling-spoons. For bass and pickerel. Bradford \& Anthony, Boston, Mass.

25555. Bluefish-spoons. Bradford \& Anthony, Boston, Mass.

25550. Spinners. For pickerel, trout, and bass fishing. Bradford \& Anthony, Boston, Mass.

25549. Spoon-baits. For bass, pickerel, pike, and trout fishing (nickelplated). John H. Mann, Syracuse, N. Y.

25551. Spoon-baits. For bass, pike, pickerel, and trout (silver-plated). J. T. Buel, Whitehall, N. Y.

25552. Spoon-baits. For pike, pickerel, bass, trout, and bluefish. Wm. H. James, Brooklyn, N. Y.

25553. Spoon-baits. For pike, bass, pickerel, and trout fishing. Wm. H. James, Brooklyn, N. Y.

26793. Series of fluted trolling-spoons. D. M. Skinner, Gananoqne, Ontario, Canada.

26685. Spoon-hooks. Property of J. A. Nichols, Syracuse, N. Y. Contributed by Forest \& Stream Publishing Company. 
Hooks (including a full series of unmounted hooks, of recent and aboriginal manufacture).

Spoon-baits, plain and fluted.

26690. Trout-spoon. Property of J. A. Nichols, Syracuse, N. Y. Contributed by Forest and Stream Publishing Company.

25554. Spoon-baits. For pike, pickerel, bass, and trout. W. D. Chapman \& Son, Theresa, N. Y.

25666. Pearl minnows. W. M. Young, Philadelphia, Pa.

25550. MacHarg's pearl spoons. For pickerel, trout, and bass. Bradford \& Anthony, Boston, Mass.

Artificial flies on hooks.

32735. Bass-flies. Sara J. McBride, Mumford, N. Y.

32736. Trout-flies.

26105. Salmon-flies.

$\begin{array}{ll}66 & 66 \\ 66 & 66\end{array}$

32737. Artificial flies for salmon, trout, and bass. Bradford \& Anthony, Boston, Mass.

Note.-For convenience this entire collection is provisionally entered under a single catalogue number.

a. Peacock, with water-color sketch of original.

b. March Brown, with water-color sketch of original.

Body-Fur of the fox-squirrel's face ribbed over with olive silk. Tail-Two strands of brown feather of the wild mallard. Wings-From the side feather of the shoveller duck approaching the tail ; the light yeast-colored feather is the best, and if nicely tied must be an excellent fly. Legs-A grizzled cock's hackle, wound twice or thrice at the shoulder. For Pennsylvania, hooks Nos. 6 to 8; for New York, hooks Nos. 5 and 6 ; New England, hooks Nos. 4 and 5.

c. Great Red Spinner, with water-color sketch of original.

$d$. Water-cricket, with water-color sketch of original.

$e$. Great Dark Drone, with water-color sketch of original.

$f$. Cow-dung.

Body-Yellow mohair mixed with a little dingy brown fur from the bear. Wings-From the quill-feather of the curlew or whimbrel. Legs-Of a ginger-colored cock's hackle. For Pennsylvania, hooks Nos. 8 to 10; for New York, hook No. 8; for New England, hook No. 6.

g. Red Fly, with water-color sketch of original.

Body-The red part of squirrel's fur mixed with an equal quantity of claret mohair. Wings-The softest quill-feather of the pea-hen's wing. LegsClaret-colored hackle; clip some of the upper fibers off that the wings may lie flat. For Penusylvania, hook No. 6; for New York, hook No. 4; for New England, hook No. 3.

h. Blue Dun, with water-color sketch of original.

Body-Fur of a gray squirrel spun very thinly on fine yellow silk. Tail-Two fibers of a dun hackle. Wings-From a quill-feather of the bluo-jay. Legs-Two or three turns of a ginger-dun hackle at the shoulder helps to keep the wings upright. For Pennsylvania, hook No. 6; for Now York, hook No. 5; for New England, hook No. 4. 
ANIMAL RESOURCES AND FISHERIES OF UNITED STATES. 103

Hooks (including a full series of unmounted hooks, of recent and aboriginal manufacture).

32737. Artificial flies for salmon, trout, and bass-Continued.

i. Red Spinner, with water-color sketch of original.

Body-Bright brown silk ribbed, with fine gold twist. Tail-Two fibers of red cock's hackle. Wings-Upright from a mottled gray feather of the mallard stained a pale blue, the brighter in color the better. Legs-Plain red cock's hackle. For Pennsylvania, hook No. 6; for Now York; hook No. 5; for New England, hook No. 4.

j. Nicholson.

k. Black Dog.

l. Atkinson.

m. Policeman.

n. Claret Wasp.

o. Blue Wasp.

p. Wren-tail, with water-color sketch of original.

Body-Ginger-colored fur ribbed with gold twist. Wings-Feathers from a wren's tail; if these cannot be procured a small scapular feather of the woodcock makes a good imitation, and may be hackled with the same kind of feather. For Peunsylvania, hook No. 10; for New York, hook No. 8; for New England, hook No. 6.

$q$. Red Ant, with water-color sketeh of original.

Body-Peacock's herl tied with red-brown silk. Wings-From the quillfeather of the blue-jay. Legs-A small red cock's hackle.

r. Silver Horns, with water-color sketch of original.

8. Golden-dun Midge, with water-color sketch of original.

t. Sand-fly, with water-color sketch of original.

Body-Of the sandy-colored fur from the rabbit's neck or from the fox-squirrel spun on silk of the same color. Wings-From the whimbrel wing made full. Legs-From a light-ginger feather from the neck of a hen. For Pennsylvania, hooks Nos. 6 to 8; for New York, hooks Nos. 5 and 6; for New England, hooks Nos. 4 and 5.

u. Stone-fly, with water-color sketeh of original.

Body-Fur of the gray squirrel, when it is shortest is best, mixed with a little yellow mohair, leaving yellow about the tail. Tail-A strand or two of brown mottled feathers, say of mallard. Wings-From the soft inside feather of the pea-hen's wing. Legs-Blue-dun cock's hackle. For Pennsylvania, hooks Nos. 6 to 8; for New York, hooks Nos. 5 and 6; for New England, hooks Nos. 4 and 5.

r. Gravel-bed, with water-color sketch of original.

Body-Dark dun or lead-colored silk floss dressed rery fine. Wings-From a covert-feather of the woodcock's wing. Legs-A black cock's hackle, rather long, wound twice only round the body. For Pennsylvania, hooks Nos. 8 to 10; for New York, hooks Nos. 6 to 8; for New England, hooks Nos. 5 and 6. 
Hooks (including a full series of unmounted hooks, of recent and aboriginal manufacture).

\section{Artificial flies for salmon, trout, and bass-Continued.}

w. Grannum, with water-color sketch of original.

Body-Fur of a rabbit's face with a little fine green mohair worked in at the tail. Wings-From the inside wing-teather of a grouse. Legs-A palo ginger hen's hackle. For Pennsylvania, hooks Nos. 8 to 10; for New York, hooks Nos. 6 to 8; for New England, hooks Nos. 5 and 6.

$x$. Yellow Dun, with water-color sketch of original.

Body-Yellow mohair mixed with a little pale blue from a mouse or yellow floss silk with the least blue rabbit fur spun upon it. Wings-Upright, from the inside wing-feather of a mallard or summer duck. For Pennsylvania, hook No. 10; for New York, hook No. 8; for New England, hooks Nos. 5 and 6.

$y$. Iron-blue Dun, with water-color sketch of original.

$z$. Hawthorn, with water-color sketch of original.

Body-Black ostrich's herl. Wings-From the quill-feather of the English snipe. Legs-A black cock's hackle. For Pennsylvania, hooks Nos. 8 to 10; for Now York, hooks Nos. 6 to 8; for New England, hooks Nos. 5 and 6.

aa. Jenny Spinner, with water-color sketch of original.

ab. Dennison.

Body-Green floss silk ribbed with silver twist. Tail-Orange-tipped fibres of tippet, wood-duck, ibis, and green parrot. Legs-A golden yellow hackle. Wings-Of the following kinds: wood-duck, tippet, brown mallard, bustard, green parrot, blue and yellow macaw, with a few strands of red macaw; black ostrich head. Hooks Nos. 1, 2, and 3.

ac. Deacon.

Body-Bright yellow seal's fur ribbed with silver tinsel backed with gold twist. Tail-Sprigs of gray mallard and ibis. Legs-Bright yellow hackle. Wings-Strips of gray mallard dressed full; black ostrich head. Hooks Nos. 2 and 3.

ad. Montreal.

Body-Claret mohair ribbed with gold tinsel. Tail-Three of four fibres of scarlet ibis. Legs-Claret hackle. Wings-Brown turkey. Hooks Nos. 1, 2 , and 3.

ae. Rangely.

Body-Dark claret mohair ribbed with gold tinsel. Tail-Fibres of woodduck and ibis. Legs-Dark claret hackle. Wing-Strips of wood-duck mixed with sprigs of scarlet ibis. Hooks Nos. 1, 2, and 3.

af. Tinselled Ibis.

Body-Silver tinsel ribbed with gold twist. Tail-A slip of wood-duck mixed with ibis. Legs-A covert wing-feather of the ibis. Wings-Strips from the large covert-feather of the ibis (the wing may be varied, adding a slip of wood-duck on each side); black ostrich head. Hooks Nos. 1, 2, and 3. 
Hooks (including a full series of unmounted hooks, of recent and aboriginal manufacture).

32737. Artificial flies for salmon, trout, and bass-Continued.

ag. Lake George.

Body-Gold twist ribbed with silver twist. Tail-A small China topping. Legs-A bright orange hackle with a shoulder of bright claret. WingsTwo tippet feathers mixed with argus pheasant, brown mallard; black ostrich head. Hooks Nos. 1, 2, and 3.

ah. Chateaugay.

Body-Lemon-yellow floss ribbed with gold twist. Tail-A fuw fibres of brown mallard. Legs-A ginger-colored cock's hackle. Wings-Strips of shoveller duck mixed with fibres of argas pheasant.

ai. Yellow Drake.

Body-Yellow mohair ribbed with silver twist. Tail-Three filves of yellow macaw. Legs-Yellow hackle with two turns of ibis on shoulder. WingsStrips of gray mallard; black ostrich head. Hook No. 3.

aj. Richardson.

Body-A light-blue floss silk ribbed with silver twist. Tail-Three strands of brown mallard. Legs-Black cock's hackle. Wings-Strips of English blue-jay mixed with brown mallard. Hooks Nos. 3 and 4.

ak. Anthony.

al. Snow-fly.

an. Captain.

an. Combination.

Body-First half, yellow seal's fur; second half, red-claret seal ribled with silver tinsel (the fur to be picked out). Tail-A few fibres of gray mallard mixed with ibis. Legs-A natural red hackle dipped in yellow dye. Wings -A piece of the same kind of hackle with pale ibis strips. On each side a piece of gray mallard sufficiently large to make the wing full; black ostrich head. Hooks Nos. 1, 2, and 3.

ao. Silver Doctor.

Body-Silver tinsel ribbed with gold twist. Tail-China pheasant topping. Legs-A pale-blue hackle with a small teal or guinea-hen at the shoulder. Wings-Mixed fibres of wood-duck, brown mallard, guinea-hen, green parrot, blue macaw, teal, and bustard; black ostrich head. Hooks Nos. 2 and 3.

ap. Prouty.

Body-First joint, silver twist; second, black ostrich with three turns of the twist over it. Tail-Orange floss with a turn or two of twist, a topping mixed with fibres of English blue-jay. Legs-A yellow dyed list hackle wound over the ostrich. Wings-Strips of white swan dyed yellow. One each side a rib of teal-feather, red macaw feelers; black ostrich head. Hooks Nos. 2 and 3.

aq. Black Cricket.

ar. Grasshopper. 
Tooks (including a full series of unmounted hooks, of recent and aboriginal manufacture).

\section{Artificial flies for salmon, trout, and bass-Continued.}

as. Great Blow.

at. Cadis.

au. Murray.

Black silk floss ribbed with silver twist. Tail-A small feather from the neck of the scarlet ibis. Legs-A golden yellow hackle. Wings-Dark mottled turkey; black ostrich head. Hooks Nos. 1 and 2.

av. Round Lake.

aw. Nameless.

Body-Brown ostrich herl, ribbed with gold twist, tag orange floss. TailTwo or three short sprigs of yellow macaw. Legs-A small sooty orange hackle, wound from tag to shoulder. Wings-Alternate strips of brown peacock-wing feather and shoveller duck, with a sprig or two of wood-duck; peacock herl head. Hooks Nos. 1, 2, and 3 .

ax. Racquette.

Is made in two joints of black orange mohair with gold tinsel. Legs-A dyed black hackle wound from tail to head. Tail-Bright yellow toucan. Wings -A mixture of gold pheasant tail, argus, and teal. Hooks Nos. 1, 2, and 3.

ay. Priest.

$a z$. Francis Sykes.

ba. Duke.

bb. Dhoon.

bc. Dustin.

$b d$. Lascelles.

be. Snitching Sandy.

bf. Prouty.

bg. Grace.

bh. Powells.

bi. Hawthorne.

bj. Edmonson.

$b k$. Whitcher.

bl. Carshalton.

bm. Professor.

Body-Yellow mohair or silk floss ribbed with silver twist or tinsel. TailTwo or three strands of scarlet ibis-wing feathers. Wings-From the gray.

bn. Coughton.

bo. Alder.

bp. Channtry.

bq. Kingdom.

3r. Hoflan Fancy.

b8. Coachman.

Body-Peacock's herl. Wings-From a white hen's wing-feather, or a pigeonwing feather will answer the purpose. Legs-A red cock's hackle wound twice or thrice at the shoulder. For Pennsylvania, hooks Nos. 8 to 10 ; for New York, hooks Nos. 5 and 6; for New England, hooks Nos. 4 and 5. 
Hooks (including a full series of unmounted hooks, of recent and aboriginal manufacture).

32737. Artificial flies for salmon, trout, and bass-Continued.

bt. Willow.

bu. Prouty.

bv. Notion.

Body-First half gold twist, remainder brown mohair, with three turns of the twist over it. Tail-A topping mixed with blue kingfisher. LegsBrown hackle. Wings-Two tippet feathers mixed with argus pheasant, brown mallard, teal, China pheasant-tail feathers, blue and yellow macaw, with a blne kingfisher on each side of the wing; black ostrich head. Hooks Nos. 2 and 3.

bu. Louise.

Body-Brown mohair ribbed with gold twist. Tail-China feather topping. Legs-Reddish brown hackle, blne-jay on shoulder. Wings-Pheasant tippet feather and tail mixed with sprigs of green parrot, blue macaw, and kingfisher. Head-Orange mohair. Hooks Nos. 1 and 2.

bx. Round Lake.

Body-Orange and red claret merging into each other, silver tinselled. TailSprigs of gold pheasant tippet, blue macaw, and green parrakeet. Legs--. A claret hackle with a turn or two of orange on the shoulder. Wings-Two strips of brown turkey, with a small jungle-cock's feather on each side. Hooks Nos. 1, 2, and 3.

by. Nicholson.

bz. Our Pattern.

ca. Saranac.

Body-Claret floss silk ribbed with gold tinsel, backed with silver twist. Tail-China pheasant crest-feather. Legs-A claret hackle. Wings-Two China pheasant tippet feathers ou either side, a strip or two of brown mallard and argus pheasant; black ostrich head. Hooks Nos. 1-0, 2, and 3.

\section{cb. Long Tom of Long Lake.}

Body-Gray squirrel mixed with a little green mohair ribbed with silver tinsel. Tail-China pheasant crest-feather. Legs-A blue dun cock's hackle; at shoulder two or three turns of bright claret hackle. Wings-Strips of brown mallard mixed with strands of summer duck, peacock-wing, and upper coverts of the wild turkey, red macaw feelers; black plush head. Hooks Nos. 1, 2, and 3 .

cc. St. Regis.

Body-Cinnamon mohair ribbed with double gold twist. Tail-A strip of China pheasant tippet mixed with a few strands of bustard. Legs-A chestnut hackle with three turns or so of orange-dyed gninea-hen, small and short in the fibres. Wings-Strips of brown mallard, brown turker, English pheasant tail, and China tippet; black ostrich head. Hooks Nos. 1 and 2. 
Hooks (including a full series of unmounted hooks, of recent and aboriginal manufacture).

32737. Artificial flies for sàlmon, trout, and bass-Continued.

cd. No. 8.

Body-Three or four turns of mohair, rest of black mohair ribbed with silver tinsel and backed with gold twist. Tail-A small topping. Legs-A dyed black hackle and a shoulder of red claret. Wings-Mixed fibres of mallard, guinea-hen tail-feather over wing, two strips of dark turkey tipped with white. Hooks Nos. 2 and 3.

ce. Highlander.

cf. Lady of Mertoun.

Body-Water-rats fur ribbed with silver twist. 'Tail-A tip of eommon ostrich or molhair and a gold pheasant topping. Legs-Two or three turns of a small red lackle finished off with a black hackle. Wings-Strips of dark gray mallard. Head-Crimson ostrich or mohair. Hooks Nos. 1-0, 1, and 2.

cg. Toppy.

Body-Black mohair ribbed with silver tinsel. Tail-A topping tip crimson. Legs-A turn or two of red hackle, the rest black hackle. Wings-Black or brown turkey tipped with white. Head-Crimson. Hooks Nos. 1-0, 1, and 2.

ch. Sapper.

Body-Orange mohair ribbed with gold tinsel. Tail-Fibres of green parrot, guinea-hen, tippet feather, and ibis. Legs-Orange hackle, shoulder a dyed black hackle. Wings-Strips of peacoek-wing feather, brown mallard, green parrot, guinea-hen, gold pheasant tail, blue macaw feelers; black ostrich head. Hooks Nos. 1-0 and 1.

ci. Stephens.

Body-Brick-colored, silk ribbed with gold twist and blne tip. Tail-Gold pheasant topping. Legs-Hackle, same color as body. Wings-Gold pheasant tippet and slight mixture of mallard; black ostrich head. Hooks No. 1.

cj. Jock Scott.

Body-In two joints, gold-colored floss the lowest, and black floss the upper; from the joint are tied two short toncan points, and over the butts of them at the joints two turns of black ostrich. Tail-One gold pheasant topping and one Indian erow feather. Legs-Black hackle over the black joint and speckled guinea-hen at tho shoulder. Wings-A white tip turkey, slip in the middle fibres of bustard, teal, brown mallard, yellow, red, and green parrot, one topping over all; blue maeaw feelers. A kingfisher on either cheek; black ostrich head. Hooks Nos. 1-0, 1, and 2.

ck. Whitcher.

Body-Black mohair ribbed with silver, tip yellow silk. Tail-Gold pheasant topping. Legs-Black hackle. Wings-A mixture of mallard and hooded merganser; black ostrich head. Hooks Nos. 1 and 2. 
ANIMAL RESOURCES AND FJSHERIES OF UNITED STATES. 109

Hooks (including a full series of unmounted hooks, of recent and aboriginal manufacture).

32737. Artificial flies for salmon, trout, and bass-Continued.

cl. Nicholson.

Body-Blood-red mohair ribbed with gold tinsel. Tail-Sprigs of mallard and pheasant tippet feather. Legs-A blood-red and a dark-blue hackle wound on together. Wings-Brown mallard and blue macaw feelers; black ostrich head. Hooks Nos. 1 and 2.

cm. Caribou.

Body-Tip gold tinsel, tag golden-yellow silk, next a black silk joint, the rest of gray caribou. Legs-Gray hacklo with a claret on the shoulder. Tail-Gold pheasant topping. Wings-Turkey and mallard with sprigs of macaw and pheasant tippet feather; black ostrich head. Hooks Nos. 1-0, and 1.

cn. Moose.

Body-Yellow floss ribbed with silver tinsel. Tail-A China pheasant topping. Legs-A yellow hackle; shoulder hackle a guinea-hen. Wings-Two tippet feathers of the China pheasant with fibres of mallard wood-duck on each side; black ostrich head. Hooks Nos. 1, 2, and 3.

co. Moosehead.

Body-Deep claret mohair ribbed with gold twist. Tail-A topping. LegsA claret hackle with three turns of orange hackle at the shonlder. WingsStrips of brown mallard and tippet feather with red macaw feelers; black ostrich head. Hooks Nos. 1, 2, and 3.

cp. Fiery-brown.

Body-Fiery brown mohair ribbed with gold tinsel. Tail-A small topping mixed with wood-duck. Legs-A brown-red hackle. Wings-Brown mallard with a little wood-duck and golden pheasant neck-feather mixed; black head. Hooks Nos. 1, 2, and 3.

cq. Parson.

cr. Gold Wing.

c8. Gold Mallard.

ct. Kircudbrightshire.

cu. Eagle.

cv. Tartan.

$c w$. Last Fly.

cx. Atkinson.

cy. Strachan.

$c z$. Parson.

Body-Black mohair tipped with orange and ribbed with silver twist. TailA small topping. Legs-A black hackle. Wings-Brown turkey-tail; black head. Hooks Nos. 2 and 3.

da. Ross.

Body-Cinnamon-colored floss ribbed with gold twist. Tail-Sprigs of green parrot. Legs-A furnace hackle. Wings-Brown mallard mixed with peacock herl; black ostrich head. Hooks Nos, 1 -0 and 1. 
Hooks (including a full series of unmounted hooks, of recent and aboriginal manufacture).

32737. Artificial flies for salmon, trout, and bass-Continued.

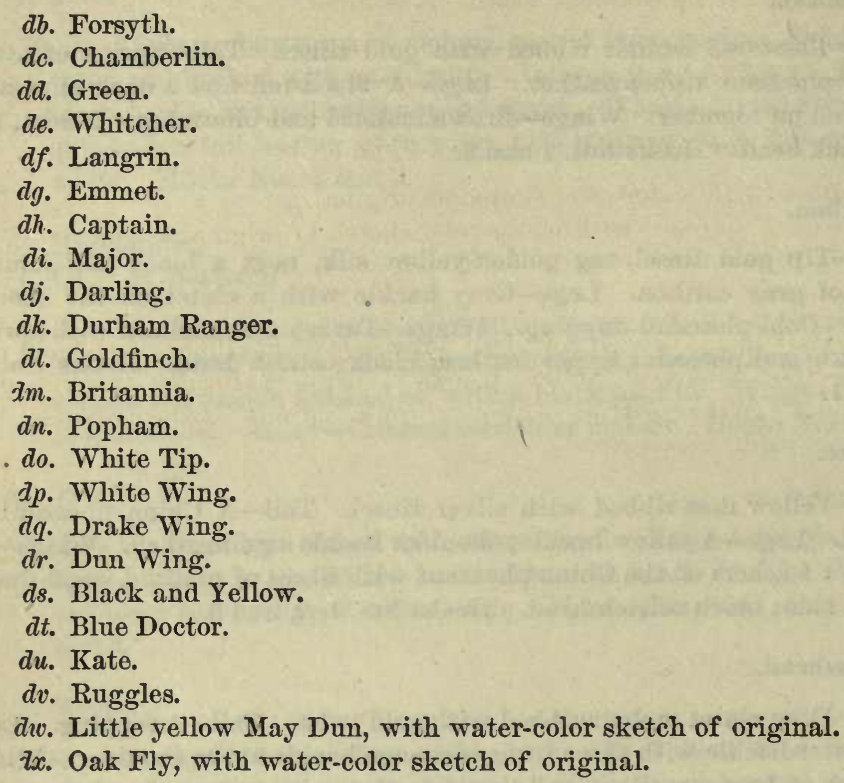

Body-Orange floss silk ribbed with ash-colored silk thread or a little floss, the ash-color to be shown well at the tail and shoulders. Wings-From a scapular feather of the woodcock. Legs-A furnace hackle or red cock's hackle with a black list up the middle. For Pennsylvania, hooks Nos. 8 to 10; for New York, hooks Nos. 6 to 8; for New England, hooks Nos. 5 and 6.

dy. Black Gnat, with water-color sketch of original.

Body-Black ostrich herl. Wings-From the quill-feather of the rice-bird or grakle. Legs-Black hackle. For Pennsylvania, hooks Nos. 10 to 12; for New York, hooks Nos. 8 to 10; for New England, hook No. 8.

$d z$. Fern Fly, with water-color sketch of original.

Body-Orange floss silk. Wings-From the quill-feather of the summerduck wing; the smaller-sized hooks can be dressed from the wing-feather of the blue-jay. Legs-A red cock's hackle. For Pennsylvania, hooks Nos. 8 to 10 ; for Now York, hooks Nos. 6 to 8; for New England, hooks Nos. 5 and 6.

ea. Yellow Sally, with water-color sketch of original.

Body-Any yellowish fur ribbed with yellow or apple-green silk. WingsFrom a wing-feather of a white hen or white pigeon stained pale yellow. Legs-A white cock's hackle stained in the same dyo. For Pennsylvauia, hooks Nos. 6 to 8; for New York, hooks Nos. 5 and 6; for New England, hooks Nos. 4 and 5. 
Hooks (including a full series of unmounted hooks, of recent and ąboriginal manufacture).

32737. Artificial flies for salmon, trout, and bass-Continued.

eb. Alder Fly, with water-color sketch of original.

Body-Peacock's herl. Wings-From a feather of a brown hen's wing. Legs-A red cock's hackle or a black cock's hackle will answer tolerably well. For Pennsylvania, hooks Nos. 8 to 10 ; for New York, hooks Nos. 5 and 6; for New England, hooks Nos. 4 and 5.

ec. Sky Blue, with water-color sketch of original.

ed. Little dark Spinner, with water-color sketch of original.

$e e$. Turkey Brown, with water-color sketch of original.

ef. Magalloway.

Body-Half black ostrich and half brown mohair ribbed with gold twist. Tail-Short fibers of yellow macaw. Legs-A furnace hackle of the shoulder. Wings-Strips of brown quill-feathers of the peacock; black ostrich head. Hook No..3.

eg. Bemis Stream.

Body-Chestnut mohair ribbed with gold tinsel. Tail-China pheasant topping. Legs-A chestnut hackle. Wings-Strips of brown peacock mixed with bustard. Hooks Nos. 1 and 2.

eh. Mooselocmaguntick.

Body-About equal parts mixed of gray squirrel's fur and pea-green mohair ribbed with gold twist. Tail-Four strands of argus feathers. Legs-A brown bittern hackle. Wings-Gray speckled turkey, white tipped (dye yellow), with a strip of argus feather on each side; green ostrich head. Hook No. 1.

ei. Molechunkemunk.

Body-Orange floss silk ribbed with gold tinsel, backed with silver twist. Tail-China pheasant topping. Legs-A furnace hackle. Wings-Brown mallard; black ostrich head.

ej. Willow Finch.

Body-Yellow seal's fur ribbed with silver twist. Tail-Sprigs of tippet feathers mixed with yellow macaw. Legs-A yellow hackle, at the shoulder a small guinea-hen stained yellow. Wings-Strips of swan feather dyed yellow with a spray of guinea-hen (tail-feather) dyed yellow; black ostrich head. Hooks Nos. 1, 2, and 3.

ek. Oquassac.

Body-Red claret mohair ribbed with pink floss. Tail-Yellow tag with pieces of argus and tippet feathers. Legs-A claret hackle. Wings-Strips from the quill-feather of the argus pheasant; black ostrich head. Hooks Nos. 1-0 and 1.

el. Welokennebago.

Body-2ued pig's hair ribbed with broad gold tinsel, backed with silver twist. Tail-A mixture of black turkey tipped with white and scarlet ihis. LegsScarlet hackle. Wings-Fibers of red macaw mixed with strips of black and brown turkey tipped with white; black ostrich head. 
Hooks (including a full series of unmounted hooks, of recent and aboriginal manufacture).

32737. Artificial flies for trout, salmon, and bass-Continued.

em. Capsuptuc.

Body-Silver tinsel ribbed with gold twist. Tail-Fibers of China pheasant tail mixed with guinea-hen and red macaw. Legs-A brilliant scarlet hackle. Wings-Mixed and to be made full. Two strips of brown turkey tipped with white-brown mallard, China pheasant tail and guinea-hen; black ostrich head. Hooks Nos. 1-0, 1, and 2.

en. Orange Grouse.

eo. Thunder and Lightning.

ep. Lough Gill.

eq. Lillie.

er. Black Ant.

es. Blue Blow.

et. Mare.

.eu. Hare's Ear.

ev. Ibis.

ew. Seth Green.

ex. Red Creeper.

ey. Turkey Brown.

ez. Queen of the Waters.

fa. Governor.

fb. White Miller.

fc. Lion.

$f d$. Water-witch.

fe. Atkinson.

ff. Our Own Pattern.

$f g$. Green Drake, with water-color sketch of original.

Body-Pale straw-colored floss silk ribbed fwith brown silk thread or floss; the extremities are of brown peacock's herl. Tail-Three rabbit's whiskers. Wings-Made from a mottled feather of mallard stained a pale yellowishgreen. Legs-A grizzled cock's hackle stained a yellowish-green in the same dye. For Pennsylvania, hooks Nos. 6 to 8; for New York, hooks Nos. 4 to 6 ; for New England, hooks Nos. 3 and 4.

fh. Gray Drake, with water-color sketch of original.

Body-The middle part of white floss silk ribbed with silver twist; the extremities of brown peacock's herl. Tail-Three rabbit's whiskers. WingsMade from a gray mottled feather of the mallard. Size of hooks same as green drake.

$f i$. Orange Dun, with water-color sketch of original.

This fly is equally attractive to trout, and is a prime favorite in its day-the end of June, July, and August. Body $\rightarrow$ Dark orange silk. Tail-Two fibers of brown mallard feather. Wings-From the quill-feather of the large red-crowned woodpecker. For Pennsylvania, hooks Nos. 6 to 8; for New York, hook No. 6 ; for New England, hooks Nos. 5 and 6.

fj. Green Mackerel, with water-color sketch of original.

$f k$. Brown Mackerel, with water-color sketch of original.

fl. Marlow Bux.z, with water-color sketch of original. 


\section{Fooks (including a full series of unmounted hooks, of recent and} aboriginal manufacture).

\section{Artificial flies for trout, salmon, and bass-Continued.}

fm. Pale Evening Dun, with water-color sketch of original.

$f n$. July Dun, with water-color sketch of original.

Body-Mole's fur and pale-yellow mohair mixed and spun on yellow sill. Tail-Two or three whiskers of a dark dun hackle. Wings-From the quill-feather of a blue-jay. Legs-Dark dun hackle. For Pennsylvanin, hooks Nos. 8 to 10 ; for New York, hooks Nos. 6 to 8; for New England, hooks Nos. 5 and 6.

fo. Gold-eyed Gange-wing, with water-color sletch of original.

fp. Butcher, No. 1.

$f q$. Blue Rauger.

fr. Black Ranger.

fs. Colonel.

ft. Children's Farlow.

fu. Candlestick Maker.

fv. Baker.

fio. Butcher.

$f x$. Namsen.

fy. Black and Teal.

fz. Guinea Hen.

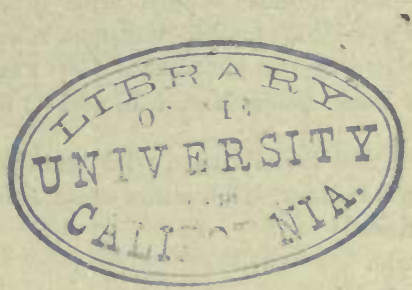

ga. Claret.

gb. Inquichin.

gc. Maxwell Ranger.

gll. August Dun, with water-color sketch of original.

Body-Brown floss silk ribbed with yellow silk thread. Tail-Two rabbit's whiskers. Wings-Feather of a brown hen's wing. Legs-A dark red hackle. For Pennsylvauia, hook No. 8; for New York, hook No. 6; for New England, hook No. 5.

ge. Orange, with water-color sketch of nriginal.

Body-Orange floss silk ribbed with black silk. Wings-Dark part of the blue-jay's wing. Legs-A rery dark furnace hackle. For Pennsylrania, hooks Nos. 8 to 10; for New York, hooks Nos. 6 to 8; for New Englapil, hook No. 6.

gf. Cinnamon, with water-color slietch of original.

Body-Fawn-colored floss silk ribbed with red silk thread. Wings-Feather of a jellow-brown hen's wing. Legs-A ginger hackle. For Pennsylvania, hook No. 8; for New York, hook No. 6; for New England, hook No. 6.

gg. Blue-bottle, with water-color sketch of original.

Body-Bright blue floss silk with a few turns of brown floss at the shoulder. Wings-From the quill-feather of a water-hen. Legs-Black hackle from a cock wrapped down the principal part of the body. For Pennsylvania, hook No. 8; for New York, hook No. 6; for New England, hook No. 5.

gh. Whirling-blue' Dun, with water-color sketch of original.

Body-Squirrel's red-brown fur mixed with yellow mohair. Tail-One or two whisks of a pale ginger hackle. Wings-From the quill-feather of a mallard. For Pennsylvania, hook No. 8; for New York, hook No. 8; for New England, hook No. 6.

Bull. N. M. No. $14-8$ 
Hooks (including a full series of unmounted hooks, of recent and aboriginal manufacture).

32737. Artificial flies for trout, salmon, and bass-Continued.

gi. Willow, with water-color sketch of original.

Body-Mole's fur mixed with a little fine yellow mohair. Wings-From the quill-feather of a water-hen or coot. Legs-A dark dun hen's-hackle. For Pennsylvania, hooks Nos. 8 to 10 ; for New York, hook No. 8; for New England, hooks Nos. 5 and 6.

gj. Snowy.

gk. Beauty Snow.

gl. Red Palmer, with water-color sketch of original.

Body-Red mohair ribbed with gold twist or tiusel. Legs-A blood-red cock's (saddle) hackle wrapper nicely over it, working the hackle closely together at the shoulder. For Pennsylvania, hooks Nos. 6, 8, and 10 ; for New York, hooks Nos. 4, 5, and 6; for New England, hooks Nos. 3, 4, and 5.

gm. Black and Red Palmer, with water-color sketch of original.

gn. Brown Palmer, with water-color sketch of original.

go. Furnace.

gp. Grizzle.

$g q$. Ginger.

gr. List.

g8. Soldier.

gt. White.

gu. Grizzle Peacock.

gv. Red.

gw. Black Peacock.

gx. Black.

gy. Brown Peacock.

gz. Scarlet.

25548. Salmon fly-book for carrying artificial flies.

25547. Trout fly-book for carrying artificial flies. Loaned by Bradford \& Anthony, Boston, Mass. (\$4.50.)

26677. Fly-book. Forest \& Stream Publishing Company. Property of J. A.

26678. Fly-book.

26679. Fly-book.

[Nichols, Syracuse, N. Y.

66

66

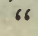

\section{Lines (twisted and plaited).}

Silk lines.

25633. Series of braided raw-silk lines. (50 yards; C to G.) G. H. Mansfield \& Co., Canton, Mass.

25632. Oiled, braided, raw-silk lines. G. H. Mansfield \& Co., Canton, Mass. 25628. XXXX silk fish-line. (50 yards.)

25629. XX silk fish-line. (50 yards.)

25634. Grass lines. Nos. 0, 1, and 3 cable, and 3 shroud. Bradford \& Anthony, Boston, Mass.

25635. Braided grass lines. Bradford \& Anthony, Boston, Mass. 


\section{Lines (twisted and plaited).}

\section{Linen lines.}

25626. Hard-braid linen lines. ( 1 to 5 ; 50 yards each.) G. H. Mansfield \& Co., Canton, Mass.

25631. Series of braided linen fish-lines. (50 yards.) G. H. Mansfield \& Co., Canton, Mass.

25612. Linen fish-lines. J. \& S. Allen, Walpole, Mass.

25613. Linen fish-lines. - a

25618. Linen fish-lines.

25637. Linen bass-line. (600 feet.) Bradford \& Anthony, Boston, Mass.

\section{Cotton lines.}

25619. Cotton fish-lines. (20 feet hank.) L. Crandall \& Co., Ashaway, R. I. 25620. Cotton fish-lines. 25621. Cotton fish-lines. (50 feet shroud, laid.) 66

25622. Cotton fish-lines. (14-fathom hawser.)

66 "6

26738. Fishing-line, No. 3. (Sea-Island fly-line.) J. W. Dresser, Castine, Me. 26733. Fishing-line, No. 5. 26743. Fishing-line, No. 5. (Golden mackerel, oiled.) " 26741. Fishing-line, No. 6. (Golden mackerel, oiled.) " 26735. Fishing-line, No. 6. 26744. Fishing-line, No. 7. (Golden mackerel, white.) " 26739. Fishing-line, No. 7. (White.) 26742. Fishing-line, No. 8. (Golden mackerel, oiled.) " 26740. Fishing-line, No.9. (Golden mackerel, oiled.) " 26734. Fishing-line, No. 9. $66 \quad 66$ $66-66$ 66

26745. Fishing-lines, No. 7, 8, and 9. (Sea-side cotton chalk-line, white.) J. W. Dresser, Castine, Me.

26736. Fishing-line, No. 10. (14 fathoms, hawser-laid.) J. W. Dresser, Castine, Me.

26732. Fishing-line, No. 11. (Bluefish.) (24 fathoms long, hawser-laid.) J. W. Dresser, Castine, Me.

25624. Tarred cotton fishing-lines. (25-fathom shroud.) L. Crandall \& Co., Ashaway, R. I.

25623. Cotton fishing-lines. (50 feet shroud, laid.) L. Crandall \& Co., Ashaway, R. I.

26016. Golden mackerel lines of assorted sizes. Made from pure Sea-Island cotton. J. W. Dresser, Castine, Me.

25625. Braided cotton fishing-lines. G. H. Mansfield \& Co., Canton, Mass. 25636. Sea-Island cotton mackerel-lines. Bradford \& Anthony, Boston, Mass. 2562\%. Water-proof braided fish-lines. (B to G.) G. H. Mansfield \& Co., Canton, Mass.

660. Fishing-line. Northwest coast of America. G. Gibbs.

Whalebone lines.

2193. Whalebone fish-line. Anderson River Indians. Anderson River. R. MacFarlane.

2197. Whalebone line with hooks. Eskimo. Anderson River. R. MaeFarlane.

2016. Whalebone line. Aretic coast. B. R. Ross. 


\section{Lines (twisted and plaited).}

\section{Hide lines.}

8787. Fishing-line made of seal-skin. Mahlemut Eskimo. W. H. Dall.

8785. Fishing-line made of seal-skin. Kaviakemut Eskimo. Grantley Harbor, Alaska. . W. H. Dall.

8786. Fishing-line made of seal-skin. Unaleet Eskimo. St. Michael's, Alaska. W. H. Dall.

16314. Harpoon-line. Nunivak Island, Alaska. W. H. Dall.

1561\%. Harpoon-line. Made of skin of joung walrus. Alaska. H. W. Elliott.

19376. Harpoon-line made of seal-skin. Rev. James Curly.

Bark lines.

20655. Fishing-line made of cedar bark. Bella Bella, B. C. J. G. Swan.

20888. Fishing-line made of spruce root-fibers. Hannegan Indians. Prince of Wales Islauds, Alaska. J. G. Swan.

26821. Harpoon-line, cedar bark. Makah Indians. J. G. Swan.

Kelp lines.

656. Fishing-lines of sea-weed. (Nereocystis lutkeana.) Northwest coast of America. G. Gibbs.

6561. Fish-line of kelp. (Nereocystis lutkeana.) With halibut-hooks. Haidah Indians. Prince of Wales Archipelago. Dr. T. T. Minor.

1052. Fish-line. (Nereocystis lutkeana.) Northwest coast. Lieut. J. W. White.

26818. Halibut-line of kelp. (Nereocystis lutkcana.) Makah Indians. Neah Bay, W. T. J. G. Swan.

26819. Fish-line of kelp with halibut-hooks. Clyoquot Indians. Vancouver's Island. J. G. Swan.

\section{(ACCESSORY.) APPARATUS FOR TWISTING LINES}

\section{Snoods, leaders, and traces.}

"Cat-gut" (sheep) snoods and leaders.

Silkworm-gut snoods.

Flax snoods.

Gimp snoods.

Wire snoods.

Hooks mounted on leaders.

25540. Kinsey trout-hooks. (Tied to gut.) Bradford \& Anthony, Boston, Mass.

25542. Aberdeen hooks. (Tied to gut.) Bradford \& Anthony, Boston, Mass.

25543. Hollow-point Limerick hooks. (Tied to double gut.) Bradford \& Anthony, Boston, Mass.

25544. Hollow-point Limerick hooks. (Tied to twisted gut.) Bradford \& Anthony, Boston, Mass.

25545. Hollow-point Limerick hooks. (Tied to gimp.) Bradford \& Anthony, Boston, Mass.

25546. Carlisle hooks. (Tied to gimp.) Bradford \& Anthony, Boston, Mass.

25539. Hollow-point Limerick trout-hooks. (Tied to gut.) Bradford \& Authony, Boston, Mass.

25541. New York bass-liooks. (Tied to gut.) Bradford \& Authony, Boston, Mass. 


\section{Sinkers.}

Sinkers and swivels.

-. Sinkers and swirels. For fishing-lines. Bradford \& Anthony, Boston, Mass.

25605. Series of sinkers used in fishing for cod and tautog. Newport models. J. M. K. Southwick, Newport, R. I.

25607. Hand-line sinkers. Rhode Island and Eastern Connecticut. A. R. Crittenden.

25716. Cod-line sinker. Central Wharf Company, Provincetown, Mass.

29456. Cod-lead mold. Used to make form in molding. John B. Parsons, Rockport, Mass.

15591. Sinker made of walrus ivory. Pornoox Eskimos, Alaska. H. W. Elliott.

Net-sinkers.

- Net-sinkers. Wilcox, Crittenden \& Co., Middletown, Conu.

29393. Net-rings or sinkers. Wilcox, Crittenden \& Co., Middletown, Conn.

29474. Primitive net-sinkers. Used in Wellfleet, Mass. Nerrell B. Rich, Wellfleet, Mass.

25800. Menhaden-net sinkers (old style). Formerly used about Beverly and Salem, Mass. George B. Foster, Beverly, Mass.

25603. Seine-sinkers. Newport model. J. M. K. Southwick, Newport, R. I.

\section{Spreaders.}

Chopsticks.

One-armed chopsticks or "revolving booms."

\section{cloats.}

Line-floats of wood, cork, and quill.

25661. Egg-shaped floats. Wm. M. Young, Philadelphia, Penn.

25662. Barrel-shaped floats.

25663. Snake-head floats.

25664. Quill floats.

$66 \quad 66$

$66 \quad 66$

$66-6$

Seine-floats of cork, wood, glass, and rubber tubing.

25597. Seine-corks. Used at Newport, R. I. J. M. K. Southwick, Newport, R. I.

Harpoon-floats of bladder, inflated skin, and wood.

20898. Seal-skin buoy. Sitka Alaska. J. G. Swan.

1035. Seal-skin buoy. Makah Indians. Puget Sound. J. G. Swan.

19515. Seal-skin buoy. North Greenland. G. Y. Nickerson.

26824. Seal-skin buoy. (Used in whale fisheries.) Clyoquot Indians, Vancouver's Island. J. G. Swan.

26823. Seal-skin buoy. (Used in whale fisheries.) Clyoquot Indians, Vancouver's Island. J. G. Swan.

20594. Seal's bladder buoy. Bella Bella, B. C. J. G. Swan.

827,4970 . Seal-skin huoy with rope. Makah Indians. Neeah Bay, Puget Sound, W. T. J. G. Swan.

Keg and other floats for lobster-pots, gill-nets, \&c.

Whale-line drag. 
29. (ACCESSORY.) ANGLING-APPARATUS.

\section{Reels.}

Simple reels for fly-fishing, with and without check.

25590. Brass fishing-reel. Plain, single, with ring. Bradford \& Anthony, Boston, Mass.

25589. Brass fishing-reel. Plain, single, with plate. Bradford \& Anthony, Boston, Mass.

25587. Brass fishing-reel. Plain, single, with stop and ring. Bradford \& Anthony, Boston, Mass.

25588. Brass fishing-reel. Plain, single, with stop and plate. Bradford \& Anthony, Boston, Mass.

25577. Hard-rubber fishing-reel, German-silver band. Rim very narrow, with leather case. Bradford \& Anthony, Boston, Mass.

25568. Hard-rubber salmon-fishing reel. German-silver rim. Bradford \& Anthony, Boston, Mass.

25581. Rubber trout-reel. (Fowler's patent.) Bradford \& Anthony, Boston, Mass.

25582. Orvis' patent fishing-reel. German silver, nickeled and perforated. Bradford \& Anthony, Boston, Mass.

25567. Fine click brass fishing-reel. (25 yards.) Bradford \& Anthony, Boston, Mass.

25586. Brass fishing-reel. Click, with plate. Bradford \& Anthony, Boston, Mass.

25585. Brass fishing-reel. Click, with ring. Bradford \& Anthony, Boston, Mass.

25575. German-silver trout-fishing reel. Click, with rim. Bradford \& Anthony, Boston, Mass.

25565. German-silver trout click fishing-reel. (150 yards.) Bradford \& Anthony, Boston, Mass.

25569. Hard-rubber trout-fishing reel. Click, German-silver rim.

25571. Hard-rubber trout-fishing reel. Click, plain rim. Bradford \& Anthony, Boston, Mass.

25579. Celluloid trout elick fishing-reel. Bradford \& Anthony, Boston, Mass.

25560. German-silver trout click fishing-reel. (60 yards.) Bradford \& Anthony, Boston, Mass.

25564. German-silver salmon-fishing reel, click. (4 $\frac{1}{2}$ inch.) Bradford \& Anthony, Boston, Mass.

Multiplying reels for bass-fishing, with and without check.

25580. Celluloid fishing-reel. Multiplying and click. Bradford \& Anthony, Boston, Mass.

25583. Brass fishing-reel. Multiplying, stop and ring. Bradford \& Anthony, Boston, Mass.

26688. Fowler reel. Property of J. A. Nichols, Syracuse, N. Y. Contrib-

26687. Fowler reel.

26686. Frankfort reel.

26689. Plain reel.

26916. Winans reel. J. Ross Winans, Baltimore, Md.

26666. Reel for trolling-line. Property of J. A Nichols, Syracuse, N. Y. Contributed by Forest \& Stream Publishing Company. 


\section{Reels.}

Multiplying reels for bass fishing, with or without check.

25574. German-silver fishing-reel. Multiplying; 25 yards. Bradford \& Anthouy, Boston, Mass.

25570. Hard rubber trout-fishing reel. Multiplying; 60 yards. Bradford \& Anthony, Boston, Mass.

25584. Brass fishing-reel. Multiplying stop and plate. Bradford \& Anthony, Boston, Mass.

25573. Brass fishing-reel. Multiplying drag; 60 yards. Bradford \& Anthony, Boston, Mass.

25572. German-silver fishing-reel. Steel pivot, multiplying drag, 300 yards. Bradford \& Anthony, Boston, Mass.

25578. Celluloid fishing-reel. With multiplying click and extra spool. Bradford \& Anthony, Boston, Mass.

Gunwale-winches.

Trawl-line rollers.

29432. Trawl-roller or hauler. Provincetown style. Andrew Kennedy, Provincetown, Mass.

29434. Trawl-roller or hauler. Cape Ann style. Samuel Elwell, jr., Gloucester, Mass.

29488. Trawl-roller and eye-plate. First used by Provincetown fishermen. Amasa Taylor, Provincetown, Mass.

29445. Improved trawl-roller and socket. Amasa Taylor, Provincetown, Mass.

25767. Trawl-roller. Used to haul in trawls over the sides of dory. Allen L. McDonald, Gloucester, Mass.

- Trawl-winch. Gloucester, Mass. G. Brown Goode.

Dredge-line rollers.

Seine-windlasses.

\section{Line-holders.}

Whaleman's line-tub.

88 F. C. Sounding-line reel. U. S. Fish Commission.

25009. Harpoon-line and tub. Used in whale-boat. J. H. Thomson, New Bedford, Mass.

Tub for trawl-line. (See under Trawl.)

Winders.

Spools.

25592. Crab-line reel. Used in Newport, R. I. J. M. K. Southwick, Newport, R. I.

Seine-reels.

\section{Rods.}

25511. Common rod. Three pieces; ash and hornbeam; brass mounting. Bradford \& Anthony, Boston, Mass. 


\section{Rods.}

25501. General fishing-rod. Nine pieces; German-silver mounting. Bradford \& Anthony, Boston, Mass.

25500. General fishing-rod. Six pieces; ash and lancewood; German-silver mounting. Bradford \& Anthony, Boston, Mass.

26890. Trunk-rod of greenheart; five-jointed, with extra fourth piece and tip, seven pieces in all; weight, $8 \mathrm{oz}$.; length, 11 feet 6 inche.3. Thaddeus Norris, Philadelphia, Pa.

25512. Gudgeon-rod. Three pieces; ash and hornbeam; brass mounting; common. Bradford \& Anthony, Boston, Mass.

25510. Common pickerel-rod. Four pieces. Bradford \& Anthony, Boston, Mass.

25509. Bait-rod for tront. Four pieces; common. Bradford \& Anthony, Boston, Mass.

25513. Jointed rod. Four joints, extra tips, tie guides; made of Calcutta bamboo; full mounted in brass. Bradford \& Anthons, Boston, Mass.

25508. Common bass-rod. Four pieces; brass miounted. Bradford \& Anthony, Boston, Mass.

25498. Light bass-rod. Four pieces; extra top ; ash and lancewood; German-silver monnting. Bradford \& Anthony, Boston, Mass.

25497. Bass-rod. Four pieces and extra top for sea-fishing; ash and laneewood; German-silver mounting; jeweled tip. Bradford \& Authony, Boston, Mass.

25496. Sea-bass rod. Ash butt joint, bamboo middle joint, lancewood stock; double guides, jeweled; German-silver mounting; jeweled tips. Bradford \& Anthony, Boston, Mass.

25499. Black-bass rod. Four pieces and two extra tops; split bamboo; German-silver mounting. Bradford \& Anthony, Boston, Mass.

25502. Fly-rod. Three pieces and extra top; cedar and split bamboo. Bradford \& Anthony, Boston, Mass.

25504. Fly-rod. Three pieces and extra top; extra middle joint; bamboo tip case; ash and lancewood; German-silver mounting. Bradford \& Anthony, Bostou, Mass.

25505. Fly-rod. Four pieces and extra top; ash and lancewood; Germansilver mounting. Bradford \& Anthony, Boston, Mass.

26887. Salmon-rod of greenheart, four-jointed in cedar case, with extra third piece and tip ; weight, $30 \mathrm{oz}$; length, 17 feet 3 inches. Thaddeus Norris, Philadelphia, Pa.

25503. Fly-rod for tront. Three pieces and extra top; split bamboo; German-silver mounting. Bradford \& Anthony, Boston, Mass.

25506. Trout-rod. Four pieces and extra top; ash and lancewood; Germansilver mounting; agate-lined tips. Bradford \& Antlony, Boston, Mass.

25507. Salmon-rod. Four pieces and extra tops ; bamboo top-case ; ash and lancewood; German-silver mounting. Bradford \& Anthony, Boston, Mass.

25887. The "Cold Brook," hollow, fly-rod. (Patented June 22, 1875.) J. L. Graves, Springfield, Mass.

25886. The "Cold Brook," hollow, salmon, bass, and angling rod. Nickelplated, with reel showing an attached line working. (Patented June 22, 1875.) J. L. Graves, Springfield, Mass. 


\section{Rods.}

The following are the advantages claimed by Mr. Graves for his new rods:

"1. The line is concealed and cannot be caught in underbrush or branches.

2. The strain on the rod is equalized through the entire length.

3. There is no friction through rings or guides except on the tip.

4. The strength of the rod is greatly increased.

5. The weight of the rod is diminished.

6. The wet line is not reeled up to decay.

7. The rod goes under the brush where the big trout lie.

8. It adds greatly to the comfort and pleasure of "the gentle art."'

26661. Plain fly-rod. Property of J. A. Nichols, Syracuse, N. Y. Contributed by Forest \& Stream Publishing Company.

26662. Bait-rod. Property of J. A. Nichols, Syracuse, N. Y. Contributed by Forest \& Stream Publishing Company.

20663. Bait-rod. Property of J. A. Nichols, Syracuse, N. Y. Contributed by Forest \& Stream Publishing Company.

25712. English fly-rods. Property of J. A. Nichols, Syracuse, N. Y. Contributed by Forest \& Stream Publishing Company.

26707. Rod-case. Property of J. A. Nichols, Syracuse, N. Y. Contributed by Forest \& Stream Publishing Company.

25882. Split bamboo trout-rod. $11 \frac{1}{2}$ feet. H. L. Leonard, Bangor, Me.

26660. Split bamboo rod. Property of J. A. Nichols, Syracuse, N. Y. Contributed by Forest \& Stream Publishing Company.

25888. Extra greenheart trout-rod; cedar case; three-jointed, with one extra middle and two extra tips, six pieces in all; weight, 8 oz.; length, 12 feet. Thaddeus Norris, Philadelphia, Pa.

26889. Rent and glued bamboo trout-rod in cedar case, with one extra middle and two extra tips, six pieces in all; weight, $8 \mathrm{oz}$; length, 12 feet. Thaddeus Norris, Philadelphia, Pa.

25883. Plain trout-rod of greenheart; three-jointed, with extra middle and tip, five pieces; weight, $8 \mathrm{oz}$.; length, _- Thaddeus Norris, Philadelphia, Pa.

25881. Split bamboo grilse-rod. 14 feet. H. L. Leonard, Bangor, Me.

25883. Split bamboo salmon-rod. 16 feet.

$$
\text { "6 }
$$

25884. Piece of bamboo. Showing spliting process in construction of rods. H. L. Leonard, Bingor, Me.

25885. Piece of bamboo. Showing gluing process in construction of rods. H. L. Leonard, Bangor, Me.

25491. Chapman's combiuation trolling-pole. Harpoon-line holder and cane. W. D. Chapman, Theresa, N. Y.

\section{Swivels.}

25\%98. Horn cod-line swivel. Mnch used in olden time by Grand and George's Banks fishermen. George B. Foster, Bererly, Mass.

25945. Cod-line swivel. Central Wharf Company, Glowcester, Mass.

2601\%. Cod-line gange-swirel. A. R. Crittenden, Middletown, Conn.

25944-6. Patent gange-swivel. Used in cod-fishing. Central Wharf Company, Gloucester, Mass.

29486. Cod-gange swivel. Showing mode of fastening. Lemuel Cook, 2d, Provincetown, Mass.

29487. Haddock-gange swivel. Showing mode of fastening. Lennuel Cook, 2d, Provincetown, Mass.

29392. Wood horse-swirel. Used on cod-line. Capt. E. L. Rorre, Gloncester, Mass. 


\section{Swivels.}

25942. Halibut-gange. Showing mode of fastening on the hook. A. R. Grittenden.

29457. Shark-hook swivel. Wileox, Crittenden \& Co., Middletown, Comn. 29395. Primitive trawl-buoy swivels. George B. Foster, Beverly, Mass.

29476. Halibut trawl-buoy swivel. Used by the George's Banks fishermen. Amasa Taylor, Provincetown, Mass.

29498. Trawl-buoy swivels. Alex. McCurdy, East Gloucester, Mass.

25187. Trawl-buoy rope swivel. Wilcox, Crittenden \& Co., Middletown, Conn.

25946. Trawl-buoy rope swivel. Central Wharf Company, Provincetown, Mass.

\section{Clearing-rings. \\ Disgorgers.}

29435. Trawl-sheave bushing. Samuel Elwell, jr., Gloucester, Mass.

—. Halibut " gob-stick." Philip Merchant, Gloucester, Mass.

\section{NETS.}

\section{ENTANGLING-NETS.}

Meshing-nets (entangling in meshes).

\section{$\ddagger$ Barrier-nets.}

Rabbit-nets, used by Indians of the Southwest.

14405-6-7-8-9-10-11-12-13-14-15-16-17-18-19-20-21. Small rabbit-nets. Pi-Ute Indians, Southern Utah. Maj. J. W. Powell.

14500. Small rabbit-net. Pi-Ute Indians, Southern Utah. Maj. J. W. Powell. 11245. Small rabbit-net.

12058. Small rabbit-net. 12051, 53. Large rabbit-net.

11247. Large rabbit-net. 14430-31. Large rabbit-net. 14401-2-3. Large bunt net (for rabbits).

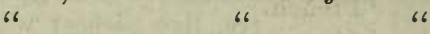

6

6"

66

66
66

66

66

66

66 19049. Rabbit-net. Cooyuwee Pi-Ute Indians, Southern Utah. Stephen Powers.

These nets are used largely in the capture of rabbits for food; they are stretehed in long lines by means of slender crotched sticks which support the upper edge. The chaparral is then scoured for miles by the Indiaus on horseback and on foot, and the rabbits, which are very abundant in the sage-brush, are driven into the meshes of the nets. The species thus captured are the sage-hare (Lepus sylvaticus var. artemisio), and the mule or jackass hare (Lepus callotis).

Bird mesh-nets.

Gill-net.

Gill-nets used in Great Lakes.

25\%51. Model of Lake Michigan gill-net. Scale: Depth, 1 inch to the foot; length, $\frac{1}{8}$ of inch to the foot. J. W. Milner.

The gill-netting in use on the Great Lakes is knit from linen thread, two and three ply (25-4, 2-cord, and 30-50,3-cord), from eleven to tweuty- 


\section{Meshing-nets (entangling in meshes).}

Gill-nets used in the Great Lakes.

two meshes in depth, 3 to 5 inch mesh. The nets when hung or mounted for use contain fiom one to three pounds of webbing, and range in length from 60 to 120 yards, and in depth from $4 \frac{1}{2}$ to 6 feet. They are set in gangs of from three to five nets, and three to five gangs are laid out in one setting usually by ail of sailboats or steamers. (See models of Mackinaw boat and lake gill-net steamer.)

For floating the upper line, round or octagonal floats of bark, or wooden pickets about two and one-half feet in length, are used. Sinkers are of lead or stone. The nets are set in from 20 to 100 fathonis of water, the lead-line resting upon the bottom. They are taken out once a week and dried.

They are used principally for the capture of the whitefish (Coregonus albus, \& c.), and the lake trout (Salmo namaycush), though most of the common lake fishes are taken in these meshes. Sea-Island cotton $(3,4,5$, and 6 thread) is being largely substituted for linen in their manufacture.

The weight of the twine preferred by fishermen varies in different localities, that used in Green Bay being the finest, that in Lake Erie next, then Lakes Michigan and Superior, and heariest in Lako Huron. Lake Ontario consumes about 5,000 pounds of netting annually, Erie 7,500, Huron 6,000, Michigan 20,000, Green Bay 2,500, and Lake Superior 5,000. The aggregate length of this netting is probably about 4,575,000 yards.

Sisco and herring gill-nets.

Used in the Great Lakes in the capture of the sisco (Salmo siscovet) and the lake herring (Argyrosomus clupeiformis).

* These nets are hung and set like the whitefish-nets previously described.

They are knit from linen thread (35-60, 2 -cord) 30 to 40 meshes in depth, and $2 \frac{1}{8}$ to 3 inch mesh. About 2,500 pounds are annually cousumed, chiefly about Sacket's Harbor, N. Y., and Lakes Huron and Michigan. (E. B. French.)

Anchored gill-nets.

Used on the coast from Cape Cod to Cape Hatteras in the capture of the bluefish (Pomatomus saltatrix).

* These nets are knit from cotton twines (12-18 thread. $\frac{1}{2}$ patent), and are 75 to 100 fathoms in length, and 80 to 200 meshes in depth, from $4 \frac{1}{2}$ to 6 inch mesh. They are heavily leaded and anchored with lead-line on the bottom, off-shore, in from 10 to 20 fathoms of water. They are chiefly used by New York fishing vessels; probably 1,000 or more are in use on the coast. In the winter season the fishing vessels follow the bluefish as far south as Cape Hatteras. (E. B. French.)

\section{Hook or trap gill-nets.}

Used on the coast of New Jersey in the capture of the Spanish mackerel (Cybium maculatum), \&e.

* These nets are peculiar in shape. They are straight nets, anchored in the form of an $L$ with a hook-like continuation, heavily leaded, and with anchors at the angles. They are knit from cotton twines (9-12 thread, $\frac{1}{2}$ patent), the outer end being of finer twine. Their length is about 100 fathoms, depth 75-100 meshes, 38 to 4 inch mesh. About 100 of these are in use on the coast, mostly between Sandy Hook and Barnegat Light. (E. B. French.)

\footnotetext{
* The nets belonging to this series are enumerated below, among Nos. 26848-26880.
} 


\section{ANIMAL RESOURCES AND FISHERIES OF UNITED STATES.}

\section{Meshing-mets (entangling in meshes).}

Salmon hook-gill-net of the Saint Lawrence.

\section{$\ddagger$ Drift-nets.}

\section{tThose drifting across the tide.}

\section{Shad gill-nets used in Southern rivers.}

26126, 26131-2. Model of shad gill-net. American Net and Twine Company, Boston and New York.

Used in rivers of the Atlantic coast.

These nets are knit of linen thread (22-50,3-cord, and 20-60, 2-cord). They range in length from 50 to 200 fathoms, and in depth from 25 to 90 meshes, 48 to 5 inch mesh. They are used exclnsively as drift-nets.

On the Connecticut River about 4,000 pounds of this netting are used annually. The average weight of a net is 30 to 40 pounds, its depth 45 to 50 meshes, $5 \frac{1}{4}$ to $5 \frac{1}{2}$ inches.

On the Hudson River about 7,500 pounds are annually used, fine threads (50-75,2-cord), 100 to 200 fathoms in length, and from 50 to 90 meshes in depth, $4 \frac{8}{4}$ to 5 inch, weight from 15 to 30 pounds to the net.

In the Delaware, Potomac, and Chesapeake 20,000 pounds are used, from 30 to 60 meshes in depth, and $5 \frac{1}{8}$ ( 30 to 40,2 -cord) length, 75 to 100 fathoms.

In the rivers of North Carolina nets are made from coarse twine (22-35,

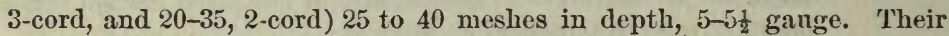
length is about 100 yards. About 25,000 pounds are used annually.

In the rivers of South Carolina the twine is slightly finer than in North Carolina (25-35, 3-cord), 25 to 60 meshes deep, the size otherwise about the same. 1,500 pounds are used annually.

In Georgia and Florida about 6,000 pounds are used. This netting is knit from linen thread (30-40,3-cord, and 25-35, 2-cord) 40 to 60 meshes in depth; $4 \frac{8}{4}$ to $5 \frac{1}{4}$ mesh. About 18 to 24 pounds are used in a net; its length 100 yards. (E. B. French.)

\section{Herring gill-nets.}

Used in Hudson and Delaware Rivers in capture of the alewife or herring (Pomolobus pseudoharengus).

* Knit from 30-40, 2-cord, thread, from 45 to 100 meshes in depth, $2 \frac{1}{2}$ to 3 inch mesh; about 13 pounds to a net on the Hndson and 6 to 7 pounds on the Delaware; the nets on the Hudson, 60 to 100 meshes, on the Delaware from 35 to $\mathrm{C} 0$. About 2,500 pounds used annually. (E. B. French.)

\section{Mullet gill-nets.}

Used principally on the Saint John's River, Florida.

Knit from coarse linen thread (16-25, 3-cord) and from 35 to 50 meshes in depth. The size of mesh varies with the season: in July $3 \frac{1}{2}$, August $3 \frac{8}{4}$, September 4 inch. The average length of the nets is 100 to 150 yards. About 1,500 to 2,000 pounds in nse on Saint John's River, and about 1,000 pounds of cotton $\left(\frac{12}{8}\right.$ and $\frac{12}{6}$ to $\left.\frac{22}{6}\right)$ nets on the Gulf coast from 30 to 40 meshes in depth, $3 \frac{1}{2}$ to $3 \frac{8}{4}$, not varying with scasons. (E. B. French.)

\footnotetext{
* The nets belonging to this series are enumerated below, among Nos. 26848-26880
} 
Meshing-nets (entangling in meshes).

Series of samples of gill-netting. American Net and Twine Company, Boston and New York:

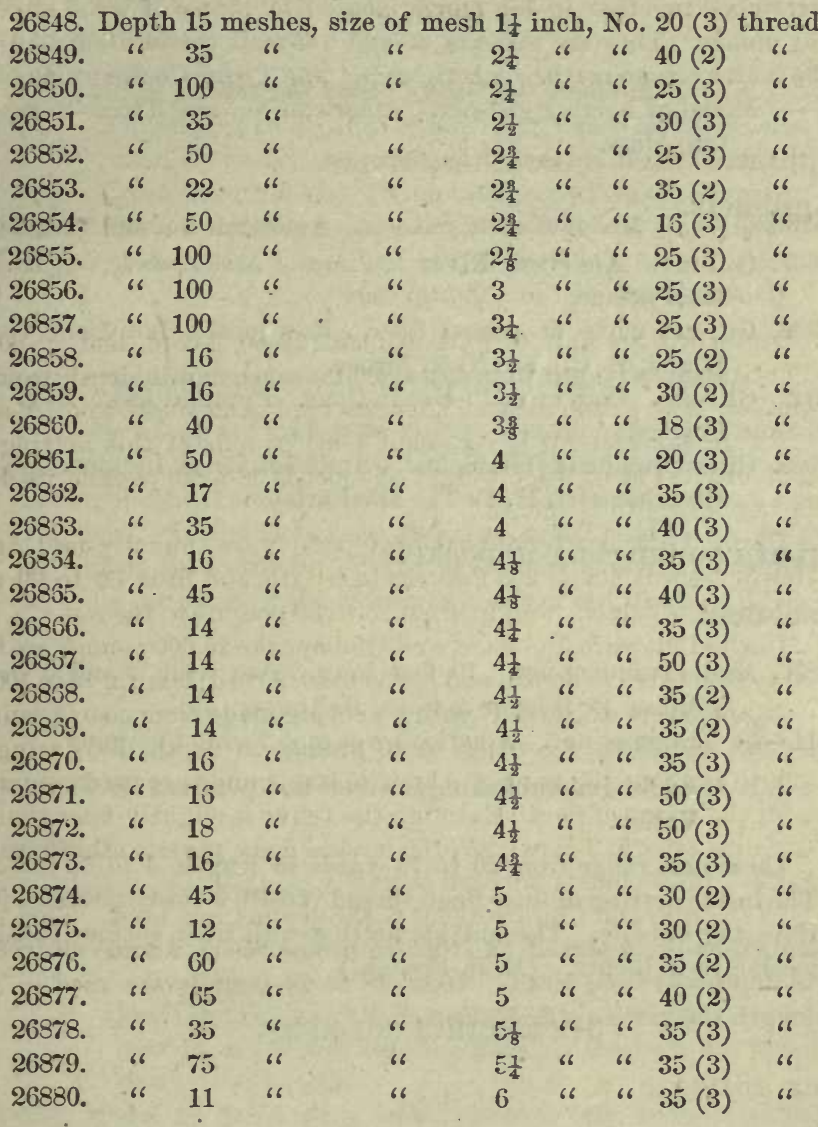

$\ddagger$ Drift-nets.

\section{† Those drifting across the tide.}

26135. One bale of brown gill-netting. American Net and Twine Company, Boston, Mass.

26139. One bale of white gill-netting. American Net and Twine Company, Boston, Mass.

\section{It Those drifting along the tide.}

Mackerel gill-nets.

Herring gill-nets.

26124-28-38. Herring gill-net. Used on the coast of Ner England and the Provinces in the capture of the herring (Clupea harengus). Amer. ican Net and Twine Company, Boston, Mass. 
Meshing-nets (entangling in meshes).

Herring gill-nets.

These nets are about 40 yards long and 150 meshes.in depth. They are stretehed together in big gangs, floated by pieces of wood and weighted by stones. They are made of 45 and 6 thread cotton from 14 to 20 yarn, $2 \frac{1}{2}$ inch average mesh. American Net and Twine Company, Boston, Mass.

- Model of herring gill-net. American Net and Twine Company, Boston, Mass.

Other gill-nets.

1667. Gill-net. Anderson River Eskimos. Anderson River, H. B. T. R. MacFarlane.

7962. Gill-net made of animal fiber. Kawquettle Indians. Vancouver's Island, B. C. Dr. T. T. Minor.

19043. Gill-net. Cooyumee Pi-Ute Indians. Pyramid Lake, Nev. Stephen. Powers.

4765. Gill-net made of "Babiche." Anderson River Indians. Mackenzie's River district, H. B. T. MacFarlane.

Pocket-mets (entangling in pockets).

Trammel-nets.

25270. Model trammel-net. 10 feet long, 2 feet wide, 2 and 5 inch mesh. William E. Hooper \& Sons, Baltimore, Md.

26118-29. Trammel-net. American Net and Twine Company.

Used for general fishing in rivers and ponds of Northern Mississippi Valley.

These nets range from 20 to 75 yards in length, 4 to $6 \frac{1}{2}$ feet in depth. The inside netting of finer linen thread (20-25, 3-cord), mesh 2-21, $\frac{1}{8}$ deeper than the outside. The outside netting-wall from cotton (15-21 thread), mesh 8 to 10 inches. (E. B. French.)

\section{Seines.}

\section{ENCIRCLING-NETS.}

Seines.

26134. Seven bales of brown seine-netting. Used for manufacture of pounds, traps, seines, fykes, \&c. American Net and Twine Company, Boston, Mass.

26139. Eighteen bales of white seine-netting. American Net and Twine Company, Boston, Mass.

Seal-seines.

17270. Seal-net made of sinew. Found wrapped about a mummy. Kagamil Island, Alaska. Alaska Commercial Company, San Franeiseo, Cal.

Manatee-seines.

Shad-seines.

Mullet-seines.

Menhaden-seines. 


\section{Seines.}

Bass-seines.

Bluefish-seines.

Capelin-seines.

Herring-seines.

26119. Model of herring-seine. Used on coasts of New England and the Provinces in capture of herring (Clupea harengus), and in the Hudson, Potomac, Delaware, and Chesapeake, and in North Carolina. Americau Net and Twine Company, Boston, Mass.

26127. Model of herring-seine. American Net and Twine Company, Boston, Mass.

\section{Shad-seines.}

These are used in the rivers of the Atlantic and Gulf coast.

These seines are knit from cotton thread. On the Connecticut River, the seines are of nine-thread twine, $5-5 \frac{1}{2}$ mesh; on the Hudson, the mesh is four inches, knit of six-thread twine in the wings and nine thread in the bunt. In the Delaware, Potomac, and Chesapeake, the mesh is $3 \frac{1}{2}$ to $4 \frac{1}{2}$ inches, the twine 12, 15, and 18 thread; in North Carolina, the mesh is $2 \frac{1}{2}$ to $3 \frac{1}{2}$ inches, and the cotton twine twelve-thread. (E. B. French.)

\section{Cod-seines.}

26137. Model of cod-seine. Used in Provinces in capture of cod (Gadus morrhua). American Net and Twine Compauy, Boston and New York. 30 to 40 feet deep. Mesh 5 inches, 18 to 21 thread, cotton.

Lance-bunts.

Baird collecting-seines.

26136. Baird net. Designed by Prof. S. F. Baird. Used by naturalists in collecting small fishes in brooks and ponds and in following behind large seines to secure the small species which escape through the meshes, six-thread coarse cotton. American Net and Twine Company, Boston, Mass.

26126. Model of Baird net. American Net and Twine Company, Boston, Mass.

Bait-seines.

26123, 26130. Model of minnow-seine. Used by amateurs in capture of minnow-bait. $\frac{1}{2}$ to $\frac{5}{8}$ inch mesh, six-thread cotton twine. American Net and Twine Company, Boston, Mass.

26121. Model of minnow-seine, with bag. Used by fishermen to secure bait for eel-pots. American Net and Twine Company, Boston, Mass.

26668. Minnow-seine. Property of J. A. Nichols, Syracuse, N. Y. Contributed by Forest \& Stream Publishing Company.

Other seines.

2232. Seine. Anderson River Eskimos. Mackenzie's River district. Robert MacFarlane.

2444. Seine made of "babiche." Tschutchi Indians. Capt. John Rodgers, U. S. N., North Pacific Exploring Expedition. 


\section{Seines.}

Other seines.

2445. Seine made of "babiche." Tschutchi Indians. Capt. John Rodgers, U. S. N., North Pacific Exploring Expedition.

2446. Hand-seine made of grass. Tsehntchi Indians. Capt. John Rodgers, U. S. N., North Pacific Exploring Expedition.

2447. Hand-seine made of grass. Tsehutehi Indians. Capt. John Rodgers, U. S. N., Nortli Pacific Exploring Expedition.

19234. Salmon-net. MeCloud River Indians. Shasta County, Cal. Livingston Stone.

20648. Salmon-net. Indians of Northwest coast. Fort Simpson, B. C. J. G. Swan.

2231. Hand-seine. Anderson River Eskimo. Mackenzie's River district, H. B. T. R. Kennicott.

21368. Fishing-net. Mado from fiber of milkweed (Asclepias sp.). Hoochnorre Indians. South Eel River, Cal. Stephen Powers.

7929. Fishing-net. Made from fibers of pineapple (Tillandsia sp.). Mirador, Mex. Dr. Sartorius.

897. Fishing-net made of willow bark. Kootchin Indians. Mackenzie's River district, H. B. T. R. Kennicott.

4883. Net made of "silkweed." Fort Crook Indians. Fort Crook, Cal. Capt. J. W. T. Gardiner.

\section{Hoop-nets.}

Handle, or dip nets.

Bull-nets (worked with ropes and blocks).

Scoop-nets (herring-nets, pound-scoops, car-scoops, \&c.).

25608. Bow of scoop-net. Used in dipping fish from smack's well. J. M. K. Southwick, Newport, R. I.

25165. Series of scoop-net hoops. Wilcox, Crittenden \& Co., Middletown, Conn.

83, F. C. Frame of dip-net. Used in Bay of Fundy herring fisheries. U. S. Fish Commission.

25229. Folding dip-net frame. U. S. Fish Commission.

26141. Dip-nets. American Net and Twine Conpany, Boston, Mass.

26141. Minnow dip-nets.

26141. Crab dip-nets.

"6 6

"6

\section{Landing-nets.}

25494. Jointed staff and folded net-ring. Bradford \& Anthonj, Boston, Mass.

25492. Nason's patent net-staff and ring. Flexible ring carried inside of staff. C. F. Nason, patent August 31, 1875. Bradford \& A thony, Boston, Mass.

25493. Nason's patent solid net-staff. With flexible ring. C. F. Nason, patent August 3, 1875. Bradford \& Anthony, Boston, Mass.

25235. Folding handles for dip-net or lance. U. S. Fish Commission.

25638. Braided linen landing-net (waterproofed). Bradford \& Anthony, Boston, Mass.

25639. Braided silk landing-net. Bradford \& Anthony, Boston, Mass.

658. Dip-net. Used in the capture of the oulachan (Osmerus pacificus). Northwest coast of America. G. Gibbs.

21725. Dip-net. Used by McCloud River Indians in fishing in small streams. Shasta County, Cal. Livingston Stone. 
ANIMAL RESOURCES AND FISHERIES OF IINITED STATES. 129

\section{Hoop-nets.}

Landing-nets.

26669. Landing-net. Property of J. A Nichols, Syracuse, N. Y. Contributed by Forest \& Stream Publishing Company.

26711. Landing-net. Property of J. A. Nichols, Syracuse, N. Y. Contributed by Forest \& Stream Publishing Company.

26664. Landing-net and rod. Property of J. A Nichols, Syracuse, N. Y. Contributed by Forest \& Stream Publishing Company.

Eskimo auk-nets.

15616. Bird-net frame. Alieut Eskimos. Alaska. Henry W. Elliott.

Baited hoop-net:

Crab-nets.

26591-2. Models of lobster-nets. Used on the coast of California. Johnson \& Young, Boston, Mass.

26801. Crab-nets. American Net and Twine Company, Boston and New York.

32710. Open cunner-net. Gloucester, Mass. G. Brown Goode.

32z11. Folding cunner-net.

66

\section{Trailing-nets.}

Trawls :

Beam-trawl.

(Otter-trawl.)

26882. Model of beam-trawl. American Net and Twine Company, Boston and New York.

32720. Model of beam-trawl. Made by J. G. Adam. U. S Fish Commission.

Dredges :

Flange, or ordinary dredge.

Rake-dredge.

Oyster-scraper.

(Coral-dredge.)

26140. Four brown dredge-nets. Oyster-dredging, \&c. American Net and Twine Company, Boston and New York.

Towing-nets :

Surface tow-nets.

25228. Towing-net frame. U. S. Fish Commission.

\section{Folding or jerk nets.}

Purse-nets :

Mackerel purse-seines (pursed by weight).

Menhaden purse-seines.

29357. Model of mackerel purse-seine. Ured on North Atlantic coast in capture of mackerel (Scomber seombrus). American Net and Twine Company, Boston, Mass.

Bull. N. M. No. $14-9$ 


\section{Folding or jerk nets.}

Menhaden purse-seines.

26, 120. Model of mackerel purse-seine. American Net and Twine Company, Boston, Mass.

These purse-seines range in length from 120 to 220 fathoms, and from

- 750 to 1,000 meshes in depth, reaching the depth of 20 to 30 fathoms of water. The average mesh is $2 \frac{1}{8}$ inches. They are made of fine Sea-Island cotton twine, and cost from $\$ 750$ to $\$ 1,500$ complete. About 300 are now in use on the coast of North America. The pursing weight varies from 100 to 150 pounds.

26122-26125. Model of pnrsc-seine. American Net and Twine Company, Boston, Mass.

90 to 150 fathoms in length, 300 to 650 meshes in depth, $1 \frac{8}{4}$ to $2 \frac{8}{4}$ fine Sea-Island twine. Wings, 9 to 12 ; bag, 15 to 21 , coarse.

25179. Snatch-block used in pursing-seine. Higgins \& Gifford, Gloucester, Mass.

25186. Ring or thimble for pursing-seine. Wilcox, Crittenden \& Co., Middletown, Conn.

\section{Cast-nets :}

Mullet cast-nets.

Pompano cast-nets.

Bait cast-nets.

25046. Casting-net. Diameter $4 \frac{1}{2}$ feet. William E. Hooper \& Sons, Baltimore, Md.

26799. Mullet cast-net. Diameter $5 \frac{1}{2}$ feet, $1 \frac{1}{2}$-inch mesh.

26800. Shrimp cast-net. Diameter $4 \frac{1}{2}$ feet, $\frac{8}{4}$-inch mesh.

Clap-nets for birds.

Rabbit spring-nets.

Spring-weirs (St. Lawrence).

Sieve-traps (for birds).

(Accessory.) Parts of nets and apparatus for manufacture.

Raw material of nets.

Babiche. (See under D. 20.)

Netting-fiber.

Netting-twine.

659. Netting-twine. Indians. Northwest coast of America. G. Gibbs. 14432. Fiber used for making nets. Pi-Ute Indians. Southern Utah. Maj. J. W. Powell.

29376. 38 bales of white netting-twine. American Net and Twine Company, Boston, Mass.

Samples of netting hung to lines. William E. Hooper \& Sons, Baltimore, Md.:

25048. 1-ineh mesh, 12 thread, 1 fathom long, 2 feet deep.

25049. 1

:5047. 1

25051. $1 \frac{1}{2}$

25050. :

"6

66

12 "6

$\begin{array}{lll}66 & 2 & 66 \\ 66 & 2 & 66 \\ 66 & 2 & 66 \\ 66 & 2 & 66\end{array}$


(Accessory.) Parts of nets and apparatus for manufacture.

Netting-needles.

Mesh-needles.

Hanging-needles.

Eskimo netting-needles.

25596. Seine-needle (home made). J. M. K. Southwick, Newport, R. I.

25593. Seine-needle.

"، "

25712. Seine-needle (called hanging-needle). N. H. Payne, Wellfleet, Mass.

-. Knitting-gauge. Used in regulating size of mesh. American Net and Twine Company, Boston and New York.

9839. Seine-needle. Eskimos. Northeastern America. S. F. Baird.

16202. Seine-needle. Magemut Eskimos. Nunivak Island, Alaska. W. H. Dall.

5613. Seine-needle of wood. Yukon River. W. H. Dall.

5614. Needle of bone. Norton Sound Eskimos. " "

$16170,16169,16166,16167,16168,16171,16196$. Seine-needles of bone. Magemut Eskimos. Nunivak Island. W. H. Dall.

1180. Seine-needle of wood. Chirikoff. W. H. Dall.

1315. Netting-needle. Eskimos. Smithsonian Institution.

9839. Seine-needle of bone. Eskimos of Northeastern America. S. F. Baird.

\section{TRAPS.}

32. Pen-TRAPS.

\section{Pocket-traps.}

Pitfalls :

Pits, covered.

Barrel-traps.

Jar mole-traps.

"Rabbit-tipe," used in England.

Salmon-baskets (Columbia River).

Salmon-weirs (Upper Columbia River).

River-weirs, with pockets :

Eel-traps.

Fish-slides:

Shad-slides, used in the rivers of North Carolina.

25830. Fish-slide. Used in James River, Virginia. Scale 1 inch to the foot. J. G. Adam.

25831. Fish-slide (with box). Used in rivers of Virginia. Scale 1 inch to the foot. J. G. Adam.

\section{Labyrinth-traps.}

Corrals.

Turkey-traps. 


\section{Labyrinth-traps.}

Weirs, or pounds.

12102. Bar-weir. Used in Bay of Fundy herring fisheries. Seale, 1 inch to 15 feet. Capt. W. S. Treat, Eastport, Me.

12101. Fish-weir. Used in Dennis River, Me. Seale, $\frac{1}{2}$ inch to the foot. Prof. S. F. Baird.

12106. Salmon-weir. Used in rivers of Maine. Dennis River. Scale, 1 inch to $8 \frac{1}{2}$ feet. Prof. S. F. Baird.

26833. Model of heart-weir. Ameriean Net and Twine Company.

25750. Model of pound-net. Used in Lake Miehigan. Scale, $3 \frac{1}{2}$ feet to 1 inch. Waukegan, Ml. D. D. Parmalee.

- Model of weir, or heart-net. Used on southern coast of New England. Scale, 1 inch to 8 feet. Spindel's Cove, Wood's Holl, Mass. Prof. S. F. Baird.

26731, 26746. Models of brush-weirs. Used in the Bay of Fundy in capture of herring (Clupea harengus). W. B. McLaughlin, Grand Manan, N. B.

25829. Model of fish-weir. Used by aborigines of Virginia in the fifteenth century: From figures in De Bry. J. G. Adam.

25820. Model of fish-trap. Valley of Yukon River. Scale, 1 inch to the foot. W. H. Dall.

\section{Funnel-traps.}

Fish-pots.

1754. Wicker fish-pot (model). Used in West Indies. 5 to 15 fathoms. Scale, 1 inch to the foot. H. O. Claughton, St. Martin's, W. I.

32738. Fish-pot (model). Bermudas. Scale of $\frac{1}{2}$. Made from wood of submerged cedar. G. Brown Goode.

\section{Lobster-pots.}

12100. Lobster-pot. Used in Bay of Fundy. 4 to 10 fathoms. Scale, inch to the foot. Prof. S. F. Baird.

24801. Lobster-pot. Used in Narragansett Bay, in 10 to 15 fathoms. Seale 3 inches to the foot. J. M. K. South wick, Newport, R. I.

29296. Model of Noank lobster-pot. G. L. Green, Noank, Conn.

29531. Lobster-pot net. Used on coast of New Jersey. American Net and Twine Company, Boston and New York.

26586-7-8-9. Models of lobster-pots. Used on the coast of New England. Johnson \& Young, Boston, Mass.

29363. Model of lobster-pot. N. C. Smith, Stonington, Conn.

Eel-weirs, with lẹaders.

Eel-pots, without leaders.

- Eel-pot. Used in Fisher's Island Sound, Conn. Scale, one-half. James H. Latham, Noank, Conn.

25015-16. Wicker eel-pot, two funnels, with leaders. Used about Martha's Vineyard, in 3 to 10 fathoms. Capt. Josiah Cleveland, maker, Vineyard Haven, Mass.

25014. Wieker eel-pot (three funnels). Used about Martha's Vineyard. Capt. Josiah Cleveland, maker, Vineyard Haven, Mass.

29530. Eel-pot net. Used on the coast of New Jersey. American Net and Twine Company, Boston and New York. 
ANIMAL RESOURCES AND FISHERIES OF UNITED STATES. 133

\section{Kabyrinth-traps.}

Eel-pots, without leaders.

25016. Leaders for eel-pot (Nos. 25014-15-16). Used in Martha's Vineyard. Capt. Josiah Cleveland, Vineyard Harbor, Mass.

26802. Basket eel-pot. American Net and Twine Company.

25018. Roots of young pine trees (Pinus strobus). Used in manufacture of eel-pots. Vineyard Haven, Mass. G. Brown Goode.

Barrel-pots for eels.

Set-nets.

32733. C. Set-net. Diameter of largest hoop, 15 inches. U. S. Fish Commission.

Fykes (set-nets with leaders).

25045. Fyke-net with wings. Diameter, 3 feet. Wm. E. Hooper \& Sons, Baltimore, $\mathrm{Md}$.

26113. Model of minnow-fyke. American Net and Twine Company, Boston

26114. Minnow-fyke.

“

[and New York.

26117. Minnow-fyke.

$66-6$

Bird-fyke.

26115, 26116. Model of bird-net. American Net and Twine Company, Boston and New York.

Bass-traps.

25704. Bass-trap. Used in Peconic Bay and Fisher's Island Sound. Scale, $\frac{1}{2}$ inch to the foot. Charles T. Potter.

\section{Door-traps.}

†Closed by the falling of a door.

Box-traps (figure 4).

25833. Horan's box-trap. Used in Philadelphia Zoological Gardens. Scale, one-half. Henry Horan.

25478. Box-trap. Used in capture of hares, possums, etc. Scale, one-half. T. N. Woltz.

Traps with hanging doors.

- Self-setting trap. Used in capture of muskrats, hares, \&c. Scale, one-half. Henry Horan.

25703. Self-setting trap. To be set in mouth of rabbit-burrow. Scale, onehalf. E. Herron.

Double box-traps.

25477. Double box-trap. Used in capture of hares, possums, \&c. Scale, one-half. T. N. Woltz. 


\section{ANIMAL RESOURCES AND FISHERIES OF UNITED STATES.}

\section{Door-traps.}

Spring-door traps.

t+ Closed by falling of whole trap.

Bowl-traps.

Cob-house bird-traps.

25659. Fall-trap. Used for partridges and other birds. Scale, one-half. T. N. Woltz.

25705. Fall-trap. Used in capture of partridges, \&c. Scale, one-half. Henry Horan.

Pigeon-nets.

t+t Closed by falling of tide.

Bar-weirs, arranged with the other weirs.

\section{Sheaf-traps.}

Sheaf-traps (New York Harbor).

\section{Noose-traps.}

\section{Clutthing-trapá.}

Snares:

Foot-path and barrier snares.

2033. Snare (made of sinew). Used in capture of lynxes, rabbits, \&c. Fort Resolution, H. B. T. R. Kennicott.

19063. Rabbit-snare. Coowoye Pi-Ute Indians. Pyramid Lake, Nevada. Stephen Powers.

25660. Spring-trap (model). Used in capture of hares, grouse, \&c. Scale, one-half. E. Herron.

25479. Spring-trap (model). Used for capture of hares, grouse, \&c. Scale, one-half. T. N. Woltz.

25832. Model of grouse-snare. Yukon River, Alaska. W. H. Dall.

Springes.

"Round mouse-traps."

\section{Jawed traps.}

"Steel traps:"

Newhouse traps.

25262. Newhouse trap. No. 0 for rats. Spread of jaws, $3 \frac{1}{2}$ inches; strong enough to hold muskrat. Oneida Community, N. Y.

25261. Newhouse trap. No. 1 for muskrats. Spread of. jaws, 4 inches; adapted to capturing the smaller fur-bearing animals. Oncicla Community, N. Y.

25260. Newhouse trap. No. $1 \frac{1}{2}$ for minks and fishers. Spread of jaws, 47 inches; strong enough to hold fox or fisher. Oneida Community, N. Y.

25259. Newhouse trap. No. 2 , for foxes. With double spring; spread of jaws, $4 \frac{7}{8}$ inches; strong enough to hold an otter. Oneida Community, N. Y. 
ANIMAL RESOURCES AND FISHERIES OF UNITED STATES. 135

\title{
Jawed traps.
}

"Steel traps:"

Newhouse traps.

25258. Newhouse trap. No. 3, for otters. Double spring; spread of jaws, $5 \frac{1}{2}$ inches. Oneida Community, N. Y.

25256. Newhouse trap. No. 4, for deer. Double spring; spread of jaws, $6 \frac{1}{2}$ inches. Oneida Community, N. Y.

25257. Newhouse trap. No. 4, for beavers. Double spring; spread of jaws, $6 \frac{1}{2}$ inches. Oneida Community, N. Y.

25255. Newhouse trap. No. 5, for bears. Spread of jaws, 11: inches; weight of each spring, 2 pounds and 10 ounces; weight of trap 17 pounds, suitable for taking the common black bear. Oneida Commnnity, N. Y.

25254. Newhouse trap. No. 6, for grizzly bears and moose. Spread of jaws, 16 inches; weight of each spring, 6 pounds and 10 ounces; weight of trap with chain, 42 pounds; made throughout, except the pan, of wrought iron and steel; strong enough to hold the moose or grizzly bear. Oneida Community, N. Y.

29250. Spring fish-trap. (Patented Dec. 9, 1856.) Edwin W. Judge, Now Haven, Conn.

Spring bird-nets.

(French bird-trap.)

13153. Spring bird-trap. Used in France. Dr. H. C. Yarrow, U. S. A.

\section{FALL-TRAPS.}

\section{Crushing-traps.}

Dead-falls.

Figure-four traps.

25749. Log dead-fall (model). Used in Mississippi Valley. Scale, 1 inch to the foot. Henry Horan.

15614. Fox-trap. Used by Mahlemut Eskimos. Henry W. Elliott.

\section{Piercing-traps,}

Spear-falls.

Mole-traps.

Harpoon-traps.

\section{Spring-hooks.}

Pickerel-hooks, arranged with other hooks.

\section{Cross-bow traps. Springaguns.}

35. Missille-TRAPS

36. AdHESIVE PREPARATIONS.

\author{
Bird-lime, \&c. \\ Hoods, boots, \&c.
}




\section{APPARATUS FOR WHOLESALE DESTRUCTION.}

\section{Food poisons. .}

\section{Poisons.}

Phosphorus poisons.

Strychnine.

Arsenic.

Corrosive sublimate.

Cyanide of potassium.

Opium poisons.

For obvious reasons this series is not exhibited..

\section{Blood poisons: Woorara.}

38. AsPHYXIATORS.

Apparatus for smoking out. (Apparatus for suffocating with fumes of sulphur:) Apparatus for drowning out.

39. TORPEDOES.

391. STOMACH-SPRINGS.

Eskimo whalebone springs (used for killing bears).

7442. Stomach-springs. Used by Eskimo in capturing bears, \&c. Fort Anderson, Aretjc coast. R. McFarlane.

\section{HUNTING-ANIMALS.}

Dogs.

40. HUNTING-MaMmILL.

Hunting-leopard (Cynailurus jubatus).

Weasels and ferrets.

Dtters.

41. ACGeissories to HUNTING-DOGS.

Dog-whips.

Dog-whistles.

29255. Dog-call (double). Edwin M. Judge, New Haven, Conn.

29256. Dog-cali.

29257. Dog-call.

29258. Dog-call.

29259. Dog-call.

66

$66 \quad 66$

$66 \quad 66$

$66-26$


ANIMAL RESOURCES AND FISHERIES

\section{Dog-whistles.}

29260. Dog-call. Edwin M. Judge, New Haven, Conn. 29261. Dog-call. 29262. Dog-call for whip. " 29254. Police-call. 29255. Railroad-call.

$\begin{array}{ll}\text { " } & \text { "6 } \\ \text { " } & \text { " } \\ \text { " } & \text { " }\end{array}$

\section{Dog-collars. \\ Dog-food. \\ Dog-carts. \\ Dog-muzzles.}

Falcoms.

42. HunTING-BIRDs.

\section{Dwis.}

Cormorants (Carbo sinensis). Used in fishing in China.

Hoods.

43. ACCESSORY TO HUNTING-BIRDS.

Perches.

Cormorant-collars.

44. Hunting-FISHES.

Remora (used in West Indies and Australia).

\section{DECOYS AND DISGUISES.}

\section{Natural baits.}

\section{BaIts.}

Flies and other insects. (This should include a collection of those insects which, as the favorite food of fishes, are imitated in making artificial flies.) Arranged with hooks. (See under 29 a.)

Worms.

Mollusks.

Salted baits (prepared).

Menhaden.

Herring.

Squids.

Clams, long.

Clams, hen.

Pea-roe of cod (used in French sardine-fisheries, and largely exported).

Grasshopper paste, used as a substitute for pea-roe.

Tolling baits, "stosh," \&c.

These articles, on account of their perishable nature, cannot well be exhibited. 
138 ANIMAL RESOURCES AND FISHERIES OF UNITED STATES.

\section{Natural baits.}

(Accessories.) Methods of preparing baits:

Bait-cutters.

Bait-mills.

Bait-ladles.

Wheelbarrows for bait-clams (Nantucket).

32740. Beach-cart. Nantucket, Mass. W. H. Chase, 2d.

Bait-boxes and cans.

25560. Five bait-boxes. Bradford \& Anthony, Boston, Mass.

26394. Bait-box. Forest \& Stream Publishing Company. Property of John

26633. Minnow-pail.

20̈692. Crab-can.

23691. Grasshopper-can.

[A. Nichols, Syracuse, N. Y.

Bait-needles.

\section{Artificial baits. ${ }^{1}$}

Trolling-spoons. ${ }^{1}$

Spinners. ${ }^{1}$

Squids and jigs. ${ }^{1}$

"Bobs," used in southern waters."

Artificial flies. ${ }^{1}$

\section{Accessories to artificial baits. ${ }^{1}$}

a. Fly-hooks. ${ }^{1}$

b. Raw materials for making artificial flies. ${ }^{1}$

c. Tools for making artificial flies. ${ }^{1}$

\section{Pastes.}

\section{Scent-decoys.}

DeCOYS.

\section{Sound=decoys.}

Animal-calls, whistles, \&c.

7452, 2149. Deer-call. Eskimos. Mackenzie's River district. R. MacFarlane.

2253. Decr-call. Eskimos. Mackenzie's River district. R. Kennicott.

Bird-calls.

26653. Turkey-call. Used in Illinois. J. W. Milner.

26654. Turkey-call. Used in Maryland. G. W. Woltz. 


\section{Sight-decoys.}

Living decoy animals and birds.

Decoy-dogs, used in hunting ducks.

Stool-pigeons.

Tame decoy-ducks.

Tame decoy-brants.

Imitations of animals and birds.:

Decoy-waders (carved in wood).

25042. Black-breasted plover (Squatarola helvetica). P. Brasher, Now York. 25041. Long-billed curlew (Numeneus longirostris).

"6 6

25043. Yellow-shanks (Gambetta flavipes).

$66 \quad 66$

Decoy-waders (stamped in tin).

25909. Black-breasted plover (Squatarola helvetica). Herman Strater \& Sons,

25908. Golden plover (Charadrius virginicus)

[Boston, Mass.

25906-7. Red-breasted snipe (Macrorhamphus grisens ?).

25910-11. Monstone (Strepsilas interpres).

These decoys are made hollow, stamped out in halves, hinged at. head and tail to open and nest together. One dozen ploverweigh 3 pounds, with box occupying a space of $8 \frac{1}{2}$ by 9 inches, 3 inches deep. Patented.

Decoy swimming-birds (made from the skins of birds).

7127. Skin of canvas-back duck (Fuligula vallisneria) stuffed with dry tule grass and fitted for decoy with strings and weights. Pi-Ute Indians. Robert Ridgway.

7128. Skin of red-head duck (Fuligula ferina, var. americana), fitted for use as. decoy. Pi-Ute Indians. Robert Ridgway.

7129. Same. Robert Ridgway.

4783. Same. Pi-Ute Indians. Carson Lake, Utah. Capt. J. H. Simpson. 19031. Skin of widgeon (Mareca americana), fitted for use as decoy. Cooyuwee Pi-Ute Indians. Pyramid Lake, Nevada. Nativename, Imoodoowe. Stephen Powers.

29532. Skin of a pin-tail duck (Dafila acuta), stuffed for use as a decoy. P. Louis Jouy, Washington, D. C.

Decoy swimming-birds (carved in wood).

25040. Brant (Bernicla brenta). P. Brasher, New York City.

25035. Mallard (Anas boschas). Henry A. Sterens, Weedsport, N. Y.

25242. " " " Male. John Krider, Philadelphia.

25241. " " " Female. "

29540. Black duck (Anas obscurus). Francis Burritt, South Norwalk, Conn. 25034. " " $\quad$ A. Stevens, Weedsport, N. Y.

26051. Pin-tail duck (Dafila acuta). John Krider, Philadelphia.

26054. Bald-pate duck (Mareca americana). Male. John Krider, Philadelphia.

$\begin{array}{llll}26055 . & 6 & \text { Female. " } \\ 25038 . & \text { " } & \text { " } & \text { P. Brasher, New York City. }\end{array}$

25031. Blue-wing teal (Querquedula discors). Henry A. Stevens, Weedsport, I. Y. 


\section{ANIMAL RESOURCES AND FISHERIES OF UNITED STATES.}

\section{Sight-decoys.}

Imitations of animals and birds:

Decoy swimming-birds (carved in wood).

25245. Blue-wing teal (Querqucrula discor8). Female. John Krider, Phila-

" [delphia.

$\begin{array}{llll}25246 . & \text { Male. } & 6 & 6 \\ \text { 25244. Green-wing teal (Nettion carolinensis). } & 6 & 6 & 66 \\ 66 & \text { Female. } & 6 & 66\end{array}$

25243. 2 " " 639 . Broad-bill duck (Fuligula marila). P. Bracher, New York City.

26058. " " " Male. John Krider, Philadelphia.

26059. " " " " "

29541. " " " Francis Burritt, South Norwalk,

[Conn.

25029. Scaup duck (Fuligula affinis). Henry A. Sterens, Weedsport, N. Y. 25032. Red-head duck (Fuligula ferina, var. americana). Henry A. Stevens,

26056.0 " "
$2605 \%$ "

25033. Canvas-back duck (Fuligula vallisneria). Henry A. Stevens, Weeds-

25037. 6 6 [port, N. Y.

25037.

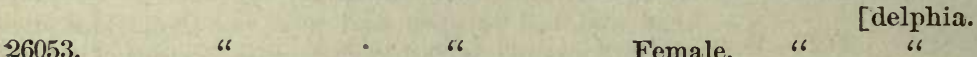

25036. Whistle-wing duck (Bucephala americana). Henry A. Stevens, Weedsport, N. Y.

25030. Butter-ball duck (Bucephala albeola). Henry A. Stevens, Weedsport, N. Y.

Decoy swimming-birds (stamped in tin, with wooden bottoms and head balance weights).

26047. Mallard (Anas boschas). Male. Herman Strater \& Sons, Boston. 25905. " " Female. " "

26048. Black duck (Anas obscura). Male. "6 "

26049. " " " " "

26045. Red-head duck (Fuligula ferina, var. americana). Male. Herman Strater \& Sons, Boston.

26046. Read-head duck (Fuligula ferina, var. americana). Female. Herman Strater \& Sons, Boston.

26043. Canvas-back duck (Fuligula vallisneria). Male. Herman Strater \&

26044. 66 " Female, " "

25901. Whistle-wing duck (Bucephala americana). Male. "

25902. " " " Female "

25903. Sheldrake (Mergus americanus). Male. "

25904. " " " " " " "

26702. Decoys. Property of J. A. Nichols, Syracuse, N. Y. Contributed by Forest \& Stream Publishing Company.

Imitations of fishes.

29366. Lure-fish. D. H. Fitzhugh, Bay City, Mich. Used in fishing through the ice for salmon-trout. 
ANIMAL RESOURCES AND FISHERIES OF UNITED STATES. 141

\section{Sight-decoys.}

Imitations of fishes.

29294. Lure-fishes. William Morris, Lake City, Mich. Used in fishing throngh the ice for pickerel.

These lure-fishes are used to decoy large fish under holes in the ice. so that they may be within reach of the spear.

Blanket decoy (for antelopes).

Lanterns and other apparatus for fire hunting and fishing.

Lanterns for still-hunting.

25238. Centennial dash-lamp. For sportsman's hunting-wagons. WhiteManufacturing Company, Bridgeport, Conn.

25239. Dash-lamp. Used for hunting and fishing. White Manufacturing Company, Bridgeport, Conn.

25236. Jack-lamp. For night-hunting and general camp uses. White Manufacturing Company, Bridgeport, Conn.

25240. Johnson's jack-lamp support. For night hunting and fishing. White Manufacturing Company, Bridgeport, Conn.

25237. Fishing-lamp. White Manufacturing Company, Bridgeport, Conn.

Lanterns for weequashing, or fire-fishing, for eels.

29365. Boat-lanterns. Used in bow of boat in weequashing or spearing eels by night. Southern New England, James H. Latham, Noank, Conn.

1210\%. Birch-bark used for torchlight fishing. Passamaquoddy Indians. Eastport, Me. Dr. E. Palmer.

32739. Torch for night fishing. Halifax, N. S. Capt. H. C. Chester.

\section{Movable covers.}

\section{Covers.}

Masks.

Deer heads and antelope heads.

8420. Antelope decoy. Made from head of prong-horn antelope (Antilocapra americana). Prescott, Ariz. Dr. E. Coues, U. S, A.

- Antelope decoy. Arizona. Dr. J. B. White, U. S. A.

5537. Deer decoy. Made from head of mule-deer (Cervus macrotis). Apache Indians. Edward Palmer.

Movable cop่ses.

Covers for hunters.

Covers for boats.

\section{Stationary covers.}

Hunting-lodges. 


\section{PURSUIT, ITS METHODS AND APPLIANCES.}

48. Methods of transportation.

\section{Personal aids.}

Snow-shoes.

Skates.

Alpenstocks and staves.

- Portable bridges.

\section{Animal equipments.}

Harness: ${ }^{1}$

Horse-trappings.

Dog-harness.

Girths, sinches.

Bits, cabrestos, spurs.

Saddles: ${ }^{1}$

Riding-saddles.

Pack-saddles.

Aparejos.

Riding-pads (for buffalo hunting).

Fur pack-saddle (Hudson's Bay Territory).

Vehicles: ${ }^{1}$

Deer-sledges.

Dog-sledges,

Wagons.

Dog-carts.

Fish-carts, used in Nantucket.

\section{Boats.}

Hunting-boats, fishing-boats:

Birch canoes.

Birch-bark canoes.

Used by Indians in hunting and fishing.

26615. Bark canoe. Passamaquoddy Indians. Eastport, Me. E. Palmer. 26614. Bark canoe. Sixteen feet long, thirty-seven inches wide. Montagnard Indians of Besamis. Labrador. R. H. Powell.

7630. Bark canoe. (Model.) Lower Ingalik, Alaska. W. H. Dall.

858. Bark canve. (Model.) Chippeway Indians, Athabasca and Great Slave Lakes. B. R. Ross.

2358. Bark canoe. (Model; scale, about 1 inch to foot.) Northeastern America. J. Varden. 


\section{Boats.}

Birch-bark canoes.

859. Bark canoe. (Model.) Slave Indians of Mackenzie's River. Fort Simpson, H. B. T. B. R. Ross.

641. Bark canoe. (Model.) Upper Columbia River. G. Gibbs. 1210\%. Birch-bark, used in manufacture of canoes. Passamaquoddy Indians. Eastport, Me. E. Palmer.

\section{Wooden sea canoes.}

Used by Indians of Northwest coast in hunting and fishing.

20592. Wooden canoe. Northwest coast. J. G. Swan.

13102. Wooden canoe. (Model.) Queen Charlotte Island. J. G. Swan.

2616. Wooden canoe. (Model.) Northwest coast. U. S. Exploring Expedition. Capt. Charles Wilkes, U. S. N.

20592. Wooden canoe. (Model.) Bella Bella, B. C. J. G. Swan.

2583. Wooden canoe. (Model.) Oregon. U. S. Exploring Expedition. Capt. Charles Wilkes, U. S. N.

1785. Wooden canoe. (Model). Northwest coast. Dr. George Suckley. 11082. Wooden canoe. (Model.) Alaska. Lieutenant Ring, U. S. N.

20895. Wooden canoe. (Model.) Haidah Indians. Prince of Wales Island, Alaska. J. G. Swan.

\section{Wooden canoes.}

Used by Indians of the Northwest coast in whaling and sea fisheries.

26785. Wooden canoe. (60 feet long.) British Columbia. J. G. Swan.

16269. Wooden canoe. (Model.) Sitka, Alaska. W. H. Dall.

21595. Wooden eanoe. (Model.) Alaska. Dr. J. B. White.

21594. Wooden canoe. (Model.) Alaska.

639. Wooden canoe. (Model.) North west coast. George Gibbs.

7285. Wooden canoe. (Model.) Neah Bay, Washington Territory. J. G. Swan.

16269. Wooden canoe. (Model, painted.) Ihliuket Indians. Sitka, Alaska. W. H. Dall.

640. Wooden canoe. (Model.) Northwest coast. George Gibbs.

18\%1. Wooden canoe. (Model.) Vancouver's Island. Dr. C. B. Kennerly.

811. Wooden canoe. (Model.) "6

26\%61. Wooden canoe. Model of Haidah canoe (with niasts and pushingsticks, for traveling, fishing, \&c.). Queen Charlotte Island. J. G. Swan.

26760. Wooden canoe. Model of Haidah canoe (for deep sea and war). Queen Charlotte Island. J. G. Swan.

200763. Wooden canoe. Model of wooden canoe (with masts, paddles, pushing-sticks, and ivory harpoons). J. G. Swan.

26762. Wooden canoe. Model of Cogwell canoe (for deep sea and war). Flathead Indians. J. G. Swan.

26\%8\%. Wooden canoe. British Columbia. J. G. Swan.

26786. Wooden canoe.

66

26785. Wooden canoe. Dug-out canoe (60 feet long). British Columbia. J. G. Swan. 


\section{ANIMAL RESOURCES AND FISHERIES OF UNITED STATES.}

\section{Boats.}

Kyaks or bidarkas.

Used by Eskimos of Arctic America in hunting and fishing.

2661\%. Kyak. (13 feet 9 inches long, 30 inches wide.) Northwest coast. Sitka, Alaska. William Burling.

14971. Kyak. (Model.) Alaska. W. H. Dall.

16275. Kyak. (Model.) Kodiak. - "

14971. Kyak. (Model, one hole.) Alaska. W. H. Dall.

21609. Kyak. (Model, one hole.) Alaska. Dr. J. B. White.

112\%. Kyak. (Model, two-hole.) Koloshes, Alentian Islands. Capt. J. R. Sands.

14970. Kyak. (Model.) Aleutian Islands. W. H. Dall.

21604. Kyak. (Model, 2-hole.) Alaska. Dr. J. B. White.

21605. Kyak. (Model, 3-hole.). Alaska. "

21610. Kyak. (Model, 3-hole.) Alaska. "

21606. Kyak. (Model, 4-hole.) Alaska. " "

8788. Kyak. (Model.) Unabeet Eskimo. Norton Sound, Alaska. W. H. Dall.

26618. Kyak. Eighteen fcet long, 22 inches wide. Greenland. Eskimo Joe.

562. Kyak. (Model.) East coast, Upernavik. Dr. Hayes.

14750. Kyak. (Model, with bird-spear, harpoon, and seal-skin float.) Eskimos, Tusiack, North Greenland. Prof. S. F. Baird.

2230. Kyak. (Model, with bird-spear, lances, and spear-rest.) Anderson River Eskimos. Mackenzie's River district. R. MacFarlane.

Umiaks or bidarras.

Used by Eskimos in whaling and sea fisheries.

1098. Umiak. (Model.) Fort Anderson, H. B. T. Robert MacFarlane:-

15618. Uniak. (Model of frame.) Saint Lawrence Island, Alaska. H. W. Elliott.

Indian raft-boats.

Used in hunting and fishing.

19028. Raft of tulé grass. (Model.) Pi-Ute Indians. Pyramid Lake, Nev. Stephen Powers.

Dug-out canoes.

Used by Indians of Pacific coast.

21358. Dug-out canoe. (Model.) Hoopah Indians, Trinity River, Cal. S. 21359. Dug-out canoe. (Model.)

[Powers.

Dug-out canoe.

Used in river fisheries of the Southern States.

25728. Dug-out canoe. (Model; scale, inch to foot.) Saint John's River, Florida. Francis C. Goode. 


\section{Boats.}

\section{Portable boats.}

29506. Hegeman portalle folding boat. Length, 10 feet; width, 3 feet. Hegeman Fortable Folding Boat Company, Ballston Spa, N. Y.

Directions for setting up boat:

1. Unfold the frame.

2. Place the knees and seats in position before fastening the bottomend section at the ends of the boat.

3. Fasten the bottom-end section to the ends of the boat by the thumb-screws.

4. Place on the canvas with the cords and tie in a single loop (or bow knot).

22218. Model of Colvin portable canvas boat. (Patented Oct. 6, 18r4.) R. A. Scott \& Co., Albany, N. Y.

"This boat consists of a canvas exterior made thoroughly water-proof by a preparation which preserves the strength of the canvas and prevents decay and oxidation. It is shaped like a canoe, sharp at both ends, and cuts the water handsomely. Along the sides and bottem are leather thongs, by which the boughs and limbs cut for frame can be lashed securely to the canvas, with the assistance of the four leather framing blocks or sockets (two for each end), which connect the stem and stern posts (or prow pieces) with the keelson, and it can be readily put together anywhere in the woods, no tools being required for the purpose, excepting such as are alvays carried by a party of sportsmen, or others, an ax or hatchet only being needed. The whole of it can be packed away in a spaco 24 inches long, 6 inches wide, and 3 inches thick. The size now made (No. 3), although but 12 feet long, will carry six men, or four men with their necessary baggage, and weighs but 12 pounds when rolled up. It has been tested in a heavy sea with a frame of green boughs cut only two hours before, and carried a weight of 700 pounds safely and easily."

25879-26-112. Model of Fenner's portable boat. With canvas bottom. C. A. Fenner, Mystic River, Connecticut.

One of these models is shown closed up in its case ready for transportation, the other set up for use.

\section{Canoes.}

\section{Paper canoe "Maria Theresa." N. H. Bishop, Lake George, N. Y.}

Designed by Rev. Baden Powell, of England; built by E. Waters \& Sons, of Troy, N. Y. Dimensions: length, 14 feet; beam, 28 inches; depth (amidship), 9 inches; weight of canoe, 58 pounds; weight of eanoeist, 130 pounds; weight of outfit, 90 pounds; total, 278 ponnds. Rowed by Mr. N. H. Bishop (from Troy, N. Y., 2,000 miles) while on his first geographical journey from the Gulf of Saint Lawrence to the Gulf of Mexico, 2,500 miles, during 1874 and 1875. Since the completion of the voyage all injuries the hull sustained were remedied by the sinple application of a sheet of paper and a coat of shellac varnish to the outside of the boat. When in use a piece of canvas covers the undecked part of the canoe and keeps the interior dry. Water-courses traversed by Mr. Bishop during 1874 and 1875: From Quebec, rivers Saint Lawrence and Richelieu,

Bull. N. M. No. $14-10$ 


\section{ANIMAL RESOURCES AND FISHERIES OF UNITED STATES.}

\section{Boats.}

Canoes.

Lake Champlain, and canal to Albany; the Hudson, Kill Von Kull, and Raritan rivers and canal, and the Delaware to Philadelphia; Delaware River and bay to Cape Henlopen, and interior salt-water passages on coast of Maryland and Virginia to Norfolk; the Elizabeth River and canal to Currituck Sound, Albemarle, Pamlico, Cove, Bogue, Stump, and other sounds, to near Wilmington, N. C.; Waccamau River to Georgetown, S. C.; by salt-water creeks, rivers, bays, and sounds along the coast of the United States to Florida; from Atlantic coast, via Saint Mary's and Suwannee rivers, to Gulf of Mexico.

26628. Rice Lake canoe. William English, Peterborongh, Ontario.

Coracles or skin boats.

9785. Skin boat. Hidatza (Gros Ventres) Indians. Fort Buford, Dakota. Dr. W. Mathews, U. S.A.

Whale boat (used in whale fisheries).

24880. Whale-boat. (Model, with all fittings; scale, 1 inch to foot.) Capt. L. Howland, New Bedford, Mass.

24868. Whale-boat. (Model.) C. H. Shute \& Son, Edgartown, Mass.

26839. Whale-boat, 35 feet long. Williams, Haven \& Co., New London, Conn.

This boat is mounted with all the gear used in the capture of the whale.

Seine-boat.

25827. Model of Capc Ann seine-boat. Higgins \& Gifford, Gloucester, Mass.

This model shows the fittings manufactured for seinc-boats by Wilcox, Crittenden \& Co., Middletown, Conn., to wit: cleat, stern-cap, snatchblock for pursing-seine, steering-oarlock with stern socket, socket used on side of stern for steering, davit-iron, tow-iron, tow-link and hook, belaying-pin, oar-holder, davit-guard and step-plate, breast-brace and eyeplate or oar-holder swivels, all of which are shown in their proper places by full-size models.

Dorys, sharpies, and dingies.

25657. Nantucket dory. (Model; scale, 1 inch to the foot.) William H. Chase.

Used in gathering clams for codfish-bait.

126r8. New England dory. (Models; scale, 1 inch to the foot.) Starling \& Stevens, Ferryville, Me.

13493. New England dory. (Model; scale, 1 inch to the foot.) Starling \& Stevens, Ferryville, Me.

Used in coast fisheries and bank eod fisheries.

24752. Connecticut sharpy. (Scale, 1 inch to the foot.) Capt. H. C. Chester, Noank, Conn. 
ANIMAL RESOURCES AND FISHERIES OF UNITED STATES. 147

\section{Boats.}

Italian fishing-boats.

Used in harbor fisheries of California.

22213. Italian fishing-boat. (Model; felucca rig.) San Francisco. Liv-

22214. Italian fishing-boat. '(Model; felucea rig.)

[ingston Stone.

22215. Italian fishing-boat. (Model; felucca rig.)

66

66

66

22217. Italian fishing-boat. (Model.) Chinese fishing-boat. San Francisco. Livingston Stone.

\section{Pinkies.}

25729. Martha's Vineyard pinkie-boat. (Model ; scale, $\frac{1}{2}$ inch to the foot.) William H. Chase.

Used in shore fisheries.

25898. Norman's Land pinkie-boat. (Model ; scale, inch to the foot.) Capt. William Cleveland, Vineyard Haven, Mass.

Used in cod and coast fisheries.

\section{Hunting-skiffs.}

Used for hanting and fishing in monntain lakes.

26621. Adirondack boat. Full size. Frederick D. Grares, maker, Boston, Mass.

25681. Adirondack boat. (Model; scale, $\frac{1}{2}$ inch to the foot.) Frederick D. Graves, maker, Boston, Mass.

Dimensions: 15 feet long, 3 feet 6 inches wide; weight, 75 to 80 pounds.

For the use of sportsmen this boat is claimed to excel, on account of its extreme lightness and durability, one man being able by means of a yoke to carry the same to any distance without fatigue. This boat is also adapted for family purposes, the patent rovlock enabling the most inexperienced rower of either sex to propel the boat with ease and perfect safety, and withont any possible chance of losing the oars.

25899. Ansable boat. (Model.) D. L. Fitzhugh, jr., Bay City, Mich.

Used in trout and grayling fishing, with well for live fish. Length; 16 feet; sides twelre inches high inside, 2 feet 10 inches wide on top, 2 feet 4 inches at bottom.

26624. Saint Lawrence boat. (Length, 19 feet; width, 43 inches.) Henry Sweetman, Clayton, N. Y.

Used in trolling in the Thousand Island region. Length, 19 feet; width, 43 inches.

25053. Alexandria Bay boat. (Model.) Cornwall \& Walton, Alexandria, N. Y.

Used for hunting and fishing in the Adirondacks and the Saint Lawrence.

Sea boats.

24999. New England surf-boat. (Model; scale, 2 inches to the foot.) Cragin \& Sheldon, makers, Boston, Mass.

Used in harbor, lake, and river fisheries.

25001. Whitehall boat (18 feet). (Model; scale, 2 inches to the foot.) Cragin \& Sheldon, Boston, Mass.

25000. Ship's yawl. (Model; scale, 2 inches to the foot.). Cragin \& Sheldon, Boston, Mass.

Carried by coasters and fishing smacks. 


\section{Boats.}

Sea boats.

22216. San Francisco yawl. (Model.) Livingston Stone.

Used by Italian fishermen on coast of California.

25028. Nantucket Harbor boat. (Model; scale, 1 inch to the foot.) W. H. Chase.

Used in harbor fishing.

\section{Oyster-canoes.}

25003. Chesapeake oyster-canoe (made from two logs). (Model; scale, 1 inch to the foot.) Major T. B. Ferguson, Maryland Fish Commission.

Used for oyster-raking in Chesapeake Bay.

25002. Chesapeake canoe-pungy. (Model; scale, 1 inch to the foot.) Major T. B. Ferguson, Maryland Fish Commission.

Used in oyster-dredging in Chesapeake Bay.

\section{Ducking-boats.}

25658. Egg Harbor boat. (Model; scale, inch to the foot. P. Brasker, New York City.

Used for hunting in marshes and bays.

26620. Cedar duck-boat "Central Republic." Built by Capt. George Bogart, surfman, Manahawken, Ocean County, New Jersey. Dimensions: 12 feet long, beam 3 feet 11 inches, depth 12 inches. N. H. Bishop, Lake George, N. Y.

This is the boat in which Mr. Nathaniel H. Bishop, of Lake George, Warren County, New York State, rowed from Pittsburg, Pa., via Ohio and Mississippi Rivers and the Gulf of Mexico (2,600 miles) to Cedar Keys, Fla., while on his second geographical expedition during 1875-76.

26623. New Jersey sneak-box. (Model; scale, 1 inch to the foot.) John D. Gifford, Tuckerton, N. J.

These boats are from twelve to fourteen feet in length; the shelving or sideboards on the stern of the boat are used to hold the decoys while the hunter rows to and from the shooting ground. Used by gunners on Barnegat and Little Egg Harbor Bays, New Jersey.

26622. Maryland ducking-sink. (Model; scale, 1 inch to foot.) J. G. Adam. Used by gunners on the Potomac River and Chesapeake Bay.

\section{- Cat-rigged fishing-boats.}

12099. Bay of Fundy cat-boat. (Model; scale, $\frac{1}{2}$ inch to the foot.) Captain Hallet, Eastport, Me.

Used ih herring fisheries.

25026. Martha's Vineyard cat-boat. (Model; scale, $\frac{1}{2}$ inch to the foot.) William H. Chase.

Used in coast fisheries.

29537. Providence River cat-boat. (Model; scale, inch to the foot.) J. M. K. Southwick, Newport, R. I.

These boats vary in length from 14 to $19 \frac{1}{2}$ feet, and cost from $\$ 225$ to $\$ 425$. Used by lobster fisheries and hook and line fisheries. Built by J. U. Stoddard.

26585. Two-masted cat-boat. (Model; scale, about $\frac{1}{2}$ inch to the foot.) Johnson \& Young, Boston, Mass.

Used in New England lobster fisheries. 
ANIMAL RESOURCES AND FISHERIES OF UNITED STATES. 149

\section{Boats.}

Schooner-rigged fishing-vessels.

26809. Noank lobster-boat. (Model.) Capt. H. C. Chester, Noank, Conn. 25825. Block Island boat. (Model; scale, $\frac{1}{2}$ inch to the foot.) Capt. H. C. Chester.

Used in cod fisheries and shore fisheries.

25730. Massachusetts schooner-smack. (Model; scale, $\frac{1}{8}$ inch to the foot.) William H. Chase, Boston, Mass.

Used in mackerel fisheries and winter oyster trade.

25731. Maine schooner-smack. (Model; scale, $\frac{1}{4}$ inch to the foot.) Capt. H. C. Chester.

Used in bank cod fisheries and eastern mackerel fisheries.

26536. Oyster-schooner. (Model; scale, 1 inch to the foot.) T. B. Ferguson, Maryland Fish Commission.

Used in oyster-dredging in Chesapeake Bay.

26584. Schooner-smack. (Model; scale, about $\frac{1}{2}$ inch to the foot.) Johnson \& Young, Boston, Mass.

Employed in the New England lobster fisheries.

25727. Noank well-smack. (Model; scale, $\frac{1}{2}$ inch to the foot.) H. C. Chester, Noank, Conn.

Supplies fresh fish to local markets and New Yorkiced-fish trade.

24883. Schooner-yacht. (Model; scale, $\frac{1}{8}$ inch to the foot.) William H. Chase. Used in pursuit of sword-fish and blue-fishing.

22220. Gloucester schooner-smack, style 1835. (Model.) M. M. McFadyn. First form of sharp-bowed schooner, out of which the present Gloucester schooner was developed.

22219. Old-fashioned topnıast schooner. (Model.) A. R. Crittenden.

26584. Schooner-smack. (Model; scale, about $\frac{1}{2}$ inch to the foot.) Johnson \& Young, Boston, Mass.

Used in the New England lobster fisheries.

Ships.

25726. Whaling-ship. (Model.) C. H. Shute \& Son, Edgartown, Mass.

Crew engaged in cutting in the blubber.

24881. Whaling-bark. (Model ; scale, $\frac{1}{6}$ inch to the foot.) U. S. Fish Commission.

Used in northern whale fisheries.

24882. Merchant ship. (Model; scale, $\frac{1}{8}$ inch to the foot.) U. S. Fish Commission.

Used in foreign trade.

\section{Boats of Great Lakes.}

26625. Mackinaw boat. (Model.) J. W. Milner.

Used in fisheries of the upper great lakes.

26626. "Norwegian boat" (Model.) J. W. Milner.

Used in Lake Michigan fisheries.

26790. Lake Erie pound boat. (Model.) J. W. Milner.

26627. Square-stern boat. (Model.) J. W. Milner.

Used in Great Lake fisheries.

\section{Steamers.}

25824. Menhaden steamer with seine-boats. (Model.) Joseph Lawler,

Bristol, Me.

Gill-net steamcr. (Model.) N. Crooks, Milwaukee, Wis. 


\section{Boats.}

Steamers.

25027. Gill-net steamer. (Model; scale, 1 inch to 5 feet 5 inches.) Used in Lake Miehigan fisheries.

25027. "Camel" floating-dock. (Model; scale, 1 inch to 5 feet 5 inches.) William H. Chase.

26808. "Camel" floating-dock. Model of steamship Cuba. Deposited by F. MeFadden, Philadelphia.

Built in 1842 for floating loaded ships over Nantucket bar.

\section{Apparatus accessory to rigging fishing-vessels.}

Blocks.

25821. Three single iron-sheaved, plain-hook tickle blocks. Walter Coleman \& Sons, Providence, R. I.

25820. Two double iron-sheaved, plain-hook tackle blocks. Walter Coleman \& Sons, Providenee, R. I.

25806. "Dead-eye" block. Used to secure the standing or fixed rigging to the hull of the vessel. Walter Coleman \& Sons, Providence, R. I.

25804. "Heart" block. Used to secure the standing or fixed rigging to the hull of the vessel. Walter Coleman \& Sons, Providence, R. I.

25805. "Bull's-eye". block. Used to secure the standing or fixed rigging to the hull of the vessel. Walter Coleman \& Sons, Providence, R. I.

25819. One single brass-sheaved, sister-hook tackle block. Walter Coleman \& Sons, Providence, R. I.

25152. Series of boat-blocks. Used on small fishing-boats around Cape Cod and Newport. Wilcox, Crittenden \& Co., Middletown, Comn.

25817. One single brass-sheaved, sister-hook tackle block. Walter Coleman \& Sons, Providence, R. I.

25818. One double iron-sheaved, sister-hook tackle block. Walter Coleman \& Sons, Providence, R. I.

25812. Round block. For jib-sheets and small craft. Walter Coleman \& Sons, Providence, R. I.

25816. Two double brass-sheaved, plain-hook tackle block. Walter Coleman \& Sons, Providence, R. I.

25815. Common iron sheave. Walter Coleman \& Sons, Providence, R. I.

25814. Plain brass sheave. Walter Coleman \& Sons, Providence, R. I.

25813. Patent brass-roller sheave. Walter Coleman \& Sons, Providence, R. I.

29444. Improved swivel-hook. For blocks and general nse. Daniel Walker, Providence, R.I.

Clews and hanks.

25139. Ship's clew for courses. Wilcox, Crittenden \& Co., Middletown,

25140. Earing-ring.

25141. Throat-ring.

25221. Sail-clew.

[Conn.

25135. Series of spectacle or fore-and-aft clews. With patent clew-thimbles. Wilcox, Crittenden \& Co., Middletown, Conn.

25136. Improved heart-clew. Wileox, Crittenden \& Co., Middletown, Conn. 25142. Tack-ring.

25137. Series of topsail clew-bows.

25128. Series of clew-bars.

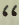

66

66
6. 
ANIMAL RESOURCES AND FISHERIES OF UNITED STATES. 151

\section{Apparatus accessory to rigging fishing-vessels.}

Clews and hanks.

29475. Clement's patent self-adjusting jib-hank. Wilcox, Crittenden \& Co., Middletown, Conn.

25143. Jib-head, with patent clew-thimble, used where the jib has been stretched too much; the jib is shortened at the head; and the jibhead is attached to the sail. Wilcox, Crittenden \& Co., Middletown, Coun.

25803. Jib-hank. Goes on jib-stay to hold the sail to it. Walter Coleman \& Sons, Providence, R. I.

25777. Wooden jib-hank. Samuel Elwell, jr., Gloucester, Mass.

25156. Series of single-stay jib-hanks. Wilcox, Crittenden \&. Co., Middle-

25157. Series of double-stay jib-hanks.

[town, Conn.

25215. Self-adjusting jib-hank for double stay. Clement's patent. Wilcox, Crittenden \& Co., Middletown, Conn.

25214. Patent self-adjusting jib-hank. Clement's patent. Wilcox, Crittenden \& Co., Middletown, Conn.

29460. Jib-sheet block (peculiar to Gloucester fishing-vessels). Samuel Elwell, jr., Gloucester, Mass.

25158. Pratt's patent jib-hank or yacht-jib. Wilcox, Crittenden \& C'o.,

25207. Hook-and-eye for bounet of jib. [Middletown, Conn.

Chocks.

29468. Line-chock for whale-boat. Provincetown style. William W. Smith, Provincetown, Mass.

25180. Line-chock for whale-boat. Wilcox, Crittenden \& Co., Middletown,

25216. Bow-chocks.

“

[Conn.

25195. Boat-chocks.

"6

66

\section{Boat-hooks.}

25926. Whalęr's large-ring boat-hook. E. B. \& T. Macy, New Bedford, Mass.

25614. Whale-boat boat-hook (peculiar to New Bedford). Humphrey S. Kirby, New Bedford, Mass.

25196. Series of wrought-iron boat-hooks. Wilcox, Crittenden \& Co.,

25200. Boat-hook for gunboat.

[Middletown, Conn.

25226. Boat-hook. U. S. Fish Commission (deposited).

25197. Double Navy boat-hooks with ball points. Wilcox, Crittenden \& [Co., Middletown, Conn.

25198. Series of Navy boat-hooks with ball points.

25199. Series of sharp-pointed boat-hooks.

66

Belaying-pins.

25161. Series of belaying-pins. Wilcox, Crittenden \& Co., Middletown,

25169. Belaying-pin for Cape Ann seine-boat. "

[Conn.

25766. Two belaying-pins. Samuel Elwell, jr., Gloucester, Mass. 


\section{Apparatus accessory to rigging fishing-vessels.}

Riggers' hooks.

25194. Deck or hammock hook. Wilcox, Crittenden \& Co., Middletown,

25195. Hammoek-hook.

"

[Conn.

25206. Series of riggers' sister-hooks. "

“

25145. Wide-mouthed single-hooks, or Cape Ann bonnet-hooks. Wilcox,

29478. Bonnet-hook and grommet.

[Crittenden \& Co., Middletown, Conn.

29452. Bonnet-hook-and-eye, for removing the jib. Wilcox, Crittenden \&

25155. Series of hooks and thimbles.

[Co., Middletown, Conn.

25943. Purrel hooks. S. Elwell, jr.

25144. Sister-hooks. Wilcox, Crittenden \& Co., Middletown, Conn.

25150. Sailmaker's bench-hook.

25149. Sailmaker's heaver.

66

25207. Hook-and-eye for bonnet of jib. " " "

25185. Hook-and-eye plate. " "

\section{Grommets.}

25116. Series of galvanized-iron sail-grommets (Wilcox's patent). Wilcox, Crittenden \& Co., Middletown, Conn.

25117. Series of brass sail-grommets (Wilcox's patent). Wilcox, Crittenden \& Co., Middletown, Conn.

25118. Series of brass grommets. Conical point, rolled rim. Wilcox, Crittenden \& Co., Middletown, Conn.

25119. Series of metallic grommets. First used in America. Wilcox, Crittenden \& Co., Middletown, Conn.

25120. Series of brass grommets. First patented in America. Wilcox, Crittenden \& Co., Middletown, Conn.

25121. Rope-yarn grommets (with rorked holes showing mode of use). Wilcox, Crittenden \& Co., Middletown, Conn.

25128. Series of light, galvanized grommet-rings. Wilcos, Crittenden \& Co., Middletown, Conn.

25129. Series of heavy galvanized sail-thimbles. Wilcox, Crittenden \& Co., Middletown, Conn.

25130. Series of heavy iron sail-thimbles (Navy pattern). Wilcox, Crittenden \& Co., Middletown, Conn.

25122. Galvanized-iron ring grommet, with worked holes showing mode of use. Wilcox, Crittenden \& Co., Middletown, Conn.

25123. Series of buntline leaders and earing grommets. Wilcox, Crittenden \& Co., Middletown, Conn.

25124. Series of eyelet grommets. Used to line worked holes and couplings to Wilcox's patent grommets. Wilcox, Crittenden \& Co., Middletown, Conn.

25125. Setting-die. Used for inserting eyelets. Wileox, Crittenden \& Co., Middletown, Conn.

25126. Cutting-punch. Used for cutting grommet-holes. Wilcox, Crittenden \& Co., Middletown, Conn.

25127. Series of heavy grommet-rings. Used for earings. Wilcox, Crittenden \& Co., Middletown, Conn.

25131. Series of light iron sail-thimbles. Wileox, Crittenden \& Co., Middletown, Conn. 


\title{
A pparatus accessory to rigging fishing-vessels.
}

Grommets.

25132. Series of throat-thimbles. Gloucester pattern. Wilcox, Crittenden $\&$ Co., Middletown, Conn.

25133. Series of reef-tackle or saddle-thimbles. Wilcox, Crittenden \& Co., Middletown, Conn.

25134. Series of brass sail-thimbles. Wilcox, Crittenden \& Co., Middle-

25152. Series of open or riggers' thimbles.

[town, Conn.

25153. Series of wire-rope thimbles.

16

$66^{\circ}-66$

\section{Anchors.}

25162. Boat-anchor. Wilcox, Crittenden \& Co., Middletown, Conn.

25163. Grappling-iron for dory.

\author{
" "6
}

25219. Wooden killick or coast anchor. H. C. Chester, Noank, Conn.

29249. Series of sailors' palms (from best to the poorest). Wilcox, Crittenden \& Co., Middletown, Conn.

29423. Sailor's palm (left hand). Wilcox, Crittenden \& Co., Middletown,

29424. Sailor's roping palm, A 1 (right hand). "6

29454. Snperior cast-steel sail-needles.

\section{Mast-gear.}

25802. Six "purrel trucks." Used on a rope around the mast to keep the gaff on the mast. Walter Coleman \& Sons, Providence, R. I.

25807. Mast-hoop. Used to hold the sail to the mast. Walter Coleman \& Sons, Providence, R. I.

25808. Lace trucks. Used on the foot of sail to attach it to the boon.

Walter Coleman \& Sons, Providence, R. I.

25159. Series of boat-mast hoops. Wilcox, Crittenden \& Co., Middletown, Conn.

25810. Mast-head truck. Used on top of mast to display bunting and signals. Walter Coleman \& Sons, Providence, R. I.

25811. Mast-head ball. Used on top of the topmast to display bunting and signals. Walter Coleman \& Sons, Providence, R. I.

29480. Mast-head gear for dory. Amasa Taylor, Provincetown, Mass.

29481. Mast and boom attachment for dory.

66

29484. Mast and gaff attachment for whale-boat (new style). Used by Provincetown whalers. Wilcox, Crittenden \& Co., Middletown,

25181. Mast-hinge for whale-boat. [Conn.

Leaders and foot-stops.

25604. Series of sail-leaches and boom foot-stops. Used by Newport smackmen. J. M. K. Southwick, Newport, R. I.

25193. Boom foot-stops. Wilcox, Crittenden \& Co., Middletown, Conn.

25181. Mast-hinge for whale-boat. " "

66

29450. Fair-leader. Used on the booms of Gloucester vessels. Samnel Elwell, jr., Gloucester, Mass.

29463. Patent topsail travelers. Used on square-rigged vessels. Wilcox, Crittenden \& Co., Middletown, Conn.

29449. Mast-hook clutch. E. A. Sawycr, Portland, Me. 


\title{
Apparatus accessory to rigging fishing-ressels.
}

\author{
Boat-builders' materials.
}

25170. Ring-bolts. Wilcox, Crittenden \& Co., Middletown, Conn.

25201. Series of screw eye-bolts.

25202. Series of screw ring-bolts.

25203. Series of ring-bolts.

25211. Common oval head elinch boat-nail. Wilcox, Crittenden \& Co.,

25212. Chisel-point clinch boat-nails.

[Middletown, Conn.

25213. Countersunk clinch boat-nails.

25220. Series of boat-rivets.

25223. Washers or clinch-rings for rivets.

25178. Stem cap for Cape Anu seine-boat.

25173. Davit-guard and step-plate for Cape Ann seine-boat.

25175. Eye-plate or oar-holder swivels for Cape Ann scine-boat. " "

25176. Gunwale supporter for Cape Ann seine-boat.

25173. Davit-guard and step-plate for Cape Ann seine-boat.

25174. Breast-brace for Cape Ann seine-boat.

25166. Davit-iron for Cape Ann seine-boats.

25167. Tow-iron for Cape Ann seine-boats.

25168. Tow-link and hook for Cape Ann seine-loat.

66
66
66
66
66
66
66
66
66
66
66
66
66

29482. Boom-rest or crotch-socket. Used on the taffrail of Cape fishingvessels when they are "laying to" on George's Banks. Theo. Brown, Wellfleet, Mass.

25204. Water-deck iron. Wilcox, Crittenden \&. Co., Middletown, Conn

\section{Rudder-fixtures.}

29496. "W. N. Clark's rudder-hanger." (Patented September 3, 186\%.) James B. Clark, Chester, Conn.

"Advantages claimed for this hanger: To ship the rudder one has only to enter the tongue (which has the rudder already attached) in the grooved plate from the top just far enough to get it steady, and then let it down, when it will go to its place without further eare. Hence arises the first great advantage which this hanger possesses over the old way, viz, the ease and dispatch with which the rudeler can be shipped under all circumstances.

Every boatman knows the trouble he has been to, at times, in trying to ship his rudder, while in a seawas, in the dark, or in muddy waier, when the eyes in the boat could not be seen; often being obliged to reach down with his hand to get the lower pintle entered.

From the quickness with which the rudder can be shipped, in any position of the boat, and under any circumstances, and its security when shipped, it must recommend itself for all life-boat purposes, where, in case of an emergency, time is of vital importance.

Another advantage is that with this hanger the rudder cannot of itself unship as has often been the case with the common hanger, when the boat has been left for a short time and the tiller worked out, thereby leaving the rudder free, by striking the bottom or anything sufficient to raise it three or four inehes, to unhinge and float away. As will readily be seen, this cannot get away until the rudder has risen the whole length of the tongue, which, of itself, won's never happen.

Again, with this hanger the rudder can bo shipped and unshipped while under full sail, thus making it very convenient for fishermen or 


\section{Apparatus accessory to rigging fishing-vessels.}

Rudder-fixtures.

any one sailing over a line or seine, as the rudder can be easily raised far enough to pass over and prevent a line getting caught between the rudder and boat, as would otherwise likely ensue, and when over, by simply letting down the rudder, it will go to its place again ready for use.

By this arrangement we are enabled to get the hinges further down on the rudder, thereby bringing the strain on both of them, while in the old way, the lower eye and pintle are so far from the bottom of the boat, in order to facilitate the shipping of the rudder, that this one has to bear nearly all of the strain." (W. N. Clark.)

25190. Rudder-gudgeons. Wilcox, Crittenden \& Co., Middletown, Conu. 25182. Rudder-braces for whale-boat. Wilcox, Crittenden \& Co., Middle-

25209. Series of common wrought-iron rudder-braces. 25189. Series of rudder braces.

[town, Conn.

25210. Rudder-braces for New Orleans cat-boat.

25183. Rudder-braces for metallic life-boat.

29472. Dory breast-hook and stern braces.

$66 \quad 66$

$66 \quad 66$

$66 \quad 66$

$66-66$

$66 \quad 66$

\section{Cleats.}

25779. Stay-sail snatch-cleat. Used by Gloncester fishing-schooners. Allen L. McDonald, Gloucester, Mass.

25809. Wooden cleats. Used to fasten ropes to. William Coleman \& Sons, Providence, R. I.

25218. Series of small eleats. Wilcox, Crittenden \& Co., Middletown, Conn. 2521\%. Small brass cleats.

"6 "6

25177. Cleats for Cape Ann seine-boat.

25191. Boat-cleats.

$66 \quad 66$

$66-66$

\section{Rowlocks.}

25088. Whale-boat rowlock. Wilcox, Crittenden \& Co., Middletown, Conn. 25086. Brass wash-streak rowlock.

"6

25113. Steering rowlock with stem socket for Cape Ann seine-boat. Wilcox, Crittenden \& Co., Middletown, Conn.

25114. Socket used on side of stern for steering. Used on Cape Ann seineboat. Wilcox, Crittenden \& Co., Middletown, Conn.

25085. Seine-boat rowlock. Wilcox, Crittenden \& Co., Middletown, Conu. 25070-72. Polished brass rowlocks. " "

66

25076, 25077. Polished brass rowlock used on gunning-skiff. Wilcox, Crittenden \& Co., Middletown, Conn.

25104-5 Galvanized socket rowlocks. Wilcox, Crittenden \& Co., Middle-

25082-3-4. Brass socket rowlocks.

[town, Conn.

25091-2-3. Plain brass patent swivel rowlock.

25094. Galvanized-iron patent swivel rowlock.

" 6 "

"6 6

25101. First patent swivel rowlock put in market. Wilcox, Crittenden \& Co., Middletown, Conn.

25079-80-81. Plain brass rowlock used on gunning-skiff. Wilcox, Crittenden \& Co., Middletown, Conn.

25106-7-8. Side-plate rowlock used on gunning-skiff. Wilcox, Crittenden \& Co., Middletown, Conn. 


\section{Apparatus accessory to rigging fishing-vessels.}

Rowlocks.

25188. Rowlock for dory. Showing new mode of fastening. Wileox, Crittenden \& Co., Middletown, Conn.

25765. Dory thole-pin rowlock. Samuel Elwell, jr., Gloucester, Mass.

25090. Gun-metal dory rowlock with Southwick's patent fastening. Wilcox, Crittenden \& Co., Middletown, Conn.

25100. Dory rowlock, showing patent mode of fastening. Wileox, Crittenden \& Co., Middletown, Conn.

26902. "Lyman's patent bow-facing rowing-gear." William Lyman, Middlefield, Conn.

This bow-facing, i. e., front view, rowing-gear is an invention which allows the rower to face forward instead of backward, pulling in the same manner as with the ordinary oars. This reverse movement is obtained by having the oar in two parts, each part having a ball-and-socket joint, which is attached to the wale of the boat by means of a slot and button, and the two parts connected by a rod (with hinged bearings) which crosses the wale of the boat.

The advantages claimed for this rowing-gear over the ordinary oar, are:

"1. The oarsman faces the direction in which he goes.

2. The arrangement of the levers is sueh that the oarsman applies his strength to the best mechanical advantage, enabling him to row faster and more easily than with any other oar.

3. During the stroke the bow of the boat is slightly raised by the motion of the rower instead of being lowered by his motion as in ordinary rowing.

4. The stroke is longer than with ordinary oars.

5. The oars can be closed up out of the way along the side of the boat without detaching them from the gunwale.

6. It is better from the fact that the blade of the oar is in front and can be seen at the beginning of the stroke, so that there is no difficulty in avoiding obstacles, and in a rongh sea there is little danger of "catching crabs."

7. With these oars the boatman makes no more effort in steering than in directing his course while walking, and this advantage lessens greatly the effort of rowing.

8. While rowing there is no noise from the bearings.

9. A pair of these oars weigh about 5 pounds more than the oars, but this additional weight has this advantage, that at the beginning and end of the stroke it helps to lower and raise the blade owing to the peculiar position of the oar.

10. When these oars are detached from the boat, no wood or iron projections are left on the wale of the boat, as in ordinary rowing-gear, and thus a serious inconvenience is obviated.

These oars can be attached to and detached from the boat very quickly and they can be closed up in a convenient form for carrying.

These several advantages, viz, the front view, the increased ease and speed in rowing, the raising of the bow instead of depressing it, the closing up of the oar out of the way while on the boat, the increasd facility in avoiding obstacles, the diminished effort of hand and eyes in steering, the rowing without noise, the better balance and swing of the oars, have commended this new gear to all who have tried it.

This gear can be attached to almost any boat, and is especially adapted to hunting, fishing, and all kinds of pleasure boating. 


\section{Apparatus accessory to rigging fishing-vessels.}

Rowlocks.

Almost any one (even if he has never rowed a boat) with an hour's practice can use these front view oars well; it being much easier to learn to ứse a pair of these oars than a pair of the back view oars." (William Lyman.)

28292. Frederick D. Graves's improved noiseless rowlock. Fred. D. Graves, Boston, Mass.

"The object of this invention is to improve the construction and operation of the class of rowlocks in such manner as, first, to insure the proper inclination of the blade of the oar, and prevent the liability of its catching the water when feathering in recovering, as well as to insure the proper position of the blade of the oar when making the stroke; secondly, to enable the outer end of the oar to be raised when it is being feathered, in order to prevent its contact with the water in rough weather. My improved rowlock, which is composed of an inclosing ring located on a pintle, and an inner ring inclosed by the ring and adapted to be partially rotated therein; the inside of the inclosing ring is provided with a groove which extends almost around it, its continuity being broken only by a stop. The pintle of the rowlock is inserted in a socket attached to the gunwale of the boat, the pintle and rowlock being adapted to turn freely in the socket. From the foregoing it will readily be seen that an oar pivoted in the inner ring is adapted to be partially rotated, in addition to its oscillating movements, so that when its stroke is completed it can be turned, so as to feather the blade in the recover stroke. The stop and shoulders of the inner ring are arranged in such mutual relation that the shoulder abuts against the stop, in feathering the oar, before the blade becomes horizontal in cross-section, so that the cross-section of the oar is necessarily inclined downward from its forward to its rear edge during the feathering stroke, this inclination of the blade preventing its forward edge from engaging with the water and overturning the rower, or, in other words, causing him to "catch a crab." This limitation of the oar in its rotation prevents awkward accidents in feathering, and enables an unskilled person to row with a considerable degree of certainty." (F. D. Graves.)

25098-9. Galvanized-iron patent swivel rowlock. Wilcox, Crittenden \&

25095. Galvanized-iron patent swivel rowlock.

25097. Galvanized-iron patent swivel rowlock. 25096. Galvanized-iron patent swivel rowlock. 25073-4-5. Polished brass patent swivel rowlock.

25102-3. Galvanized socket rowlock. [Co., Middletown, Conn.

25111. Countersunk rowlock. Used on Ohio River flat-boats. Wilcox, Crittenden \& Co., Middletown, Conn.

29459. Rowlock. Newport and Providence River style. Wilcox, Critten-

25087. North River pattern rowlock.

25089. East River pattern rowlock.

[den \& Co., Middletown, Conn.

"6"

"6 6

29319. Socket-joint rowlock. Frederick A. Gower, Providence, R. I.

"The socket-joint rowlock is intended to increase the speed and improve the convenience of racing boats. 'Its advantages have proved so easily apparent to oarsmen that there is little need of detailing its strong points, but the following are among its leading features: 


\section{Apparatus accessory to rigging fishing-ressels.}

Rowlocks.

Wabbling of the oar is wholly avoided. If the oar is a properly good fit, it will have less than $\frac{1}{4}$ inch of fore-and-aft motion in the lock.

"Catching erabs" is largely avoided by preventing the oar from jamming in the lock at the beginning or end of the stroke. If a "crab" should be eaught, the rowlock is not strained, and the oar can be recovered without stopping the boat.

A good grip of the water is assured to even the inexperienced oarsman by the shape of the back of the rowlock, which corresponds to that of the oar. The oar settles itself into the proper position on beginning the stroke.

Any length of reach may be taken by long-built men in going forward, avoiding an evil often complained of.

A space half as wide admits passage of the boat. Equipped with this rowlock a six or four oared shell passes through an opening the width of the outriggers. Crews rowing on narrow or bridged water will find this advantage worth the price of the rowlocks in a single season.

Uniting the rods at a single point brings the whole strength of the outrigger into play at every part of the stroke, and an outrigger thus made can hardly be demolished while the boat stands.

Any oars may be used if of recent pattern, $i . e$. , without the unsightly "bulge" on the loom. It is only necessary to make a slight change in the button, as described below.

Better time may be made. Experiments thus far indicate that the socket-joint rowlock is perceptibly speedier than the common pattern, by the stoppage of wabbling, and general smoothness of action.

Raising a rowlock with the common outrigger is a half hour's trouble with rusty nuts (one or two of which usually twist the bolt off in starting) and experimenting to get the right thickness of washers. With the socket-joint rowlock the same thing is done in two minutes by slipping half or three-quarters of an inch of washers on the shaft under the top rod.

Superior strength. The ordinary iron thole-pins are strong in one direction only; a backward or sidewise blow is likely to bend them. The supporting shaft of the socket-joint rowlock is equally strong all around and withstands a greater strain than the best oars made can apply to it. The whole rowlock is made of the best bronze-metal, which will not rust nor suddenly snap on a frosty morning. Under great mechanical pressure the lower part of the lock has been bent out nearly straight without breaking.

Minor conveniences continually appear in the use of this improvement. There is no wiring to do; no reaching out-board to ship oars; no wriggling the button through the rowlock; no getting grease on the oar-handle by passing through the rowlock; no "losing the button" outside the outrigger; no jamming the button between the thole-pins. When the outriggers are taken off the boat the rods turn on the shaft as a hinge and fold up into a compact bundle not easily bent out of shape nor injured. The rowlocks can be detached entirely, if desired, and each set of rods made into a package as easily carried as a walking-stick, while the rowlock may be put into the oarsman's eoat-pocket. Oarsmen having occasion to travel with boats by rail will appreciate this convenience.

This rowlock eaunot pretend to be a cheap contrivance; it is made of the best material, and requires expensive labor. Its first cost is more than that of the common pattern, but considering its advantages it will be found cheaper in the end." (F. A. Grower.) 
ANIMAL RESOURCES AND FISHERIES OF UNITED STATES. 159

\section{A pparatus accessory to rigging fishing-vessels.}

Rowlocks.

25185. Thole-pins for metallie life-boat. Wilcox, Crittenden \& Co., Middle-

25115. Whitehall pattern rowlock.

[town, Conn.

25112. Detroit or Lake Michigan rowlock.

6

"6

22227. "Acme" oarlock. Pattern invented 1876. "

25172. Oar-holder for Cape Ann seine-boat (old model). Higgins \& Gifford, Gloucester, Mass.

25171. Oar-holder for Cape Ann seine-boat. Wilcox, Crittenden \& Co., Middletown, Conn.

Oars.

25022. One pair white-ash oars (9 feet). R. T. Dodge, maker, Boston, Mass. 25021. One pair white-ash oars ( 6 feet).

25041. Pair white-ash oars (12 feet).

25011. Pair pine oars ( 8 feet).

25023. Pair white-ash oars ( 9 feet).

25012. Pair spoon oars (10 feet).

66 (6)

$66-20$

$66-56$

$66-66$

26811. Pair of oars ( 7 feet 8 inches). Waters \& Son, Troy, N. Y., makers; Delong \& Sons, Glens Falls, N. Y.

Paddles.

25020. White-ash paddles. R. T. Dodge, maker, Boston.

643. Indian paddles. Northwestern coast. George Gibbs.

644. Indian paddles. " "

645. Indian paddles. " " Cape Flattery. George Gibbs.

646. Indian paddles.

1790. Indian paddles.

Whaling.

1791. Indian paddles.

14284. Indian paddles.

14285. Indian paddles.

11471. Indian paddles. Fort Townsend, W. T. J. G. Swan.

11473. Indian paddles.

11474. Indian paddles.

66

66

66

66

66

11363. Indian paddles (for skin canoe used by Aleutians). Alaska. V. Colyer. 11369. Indian paddles (for skin or wooden eanoe).

11366. Indian paddles.

20902. Indian paddles (used by Trimsein Indians). Fort Simpson, B. C. 20903. J. G. Swan.

11434. Indian paddles. Passamaquoddy Indians, Eastport, Me. E. Palmer.

2652. Indian paddles. Northwestern coast. Exploring Expedition. Lieut. Wilkes, U. S. N.

2652. Indian paddles. Northwestern coast. Exploring Expedition. Lient. Wilkes, U. S. N.

26783. Whaling paddle. Makah Indians, Neeah Bay. J. G. Swan.

26781. Whaling paddle.

26782. Whaling paddle.

26780. Whaling paddle.

26779. Whaling paddle.

26778. Whaling paddle.

26777. Whaling paddle.

26776. Whaling paddle.

"6

66

66

66

66 
ANIMAL RESOURCES AND FISHERILS OF UNITED STATLS.

\section{Apparatus accessory to rigging fishing-vessels.}

Paddles.

$\begin{array}{lll}\text { 26775. Whaling paddle. Makah Indians, Neeah Bay. J. G. Swan. } \\ \text { 26774. Whaling paddle. } & \text { " } \\ \text { 26773. Canoe paddle. } & \text { " } & \text { " } \\ \text { 26772. Canoe paddle. } & \text { " } & \text { " } \\ \text { 26771. Canoe paddle. } & \text { " } & \text { " } \\ \text { 26770. Canoe paddle. } & \text { " } & \text { " } \\ \text { 26769. Canoe paddle. } & \text { " } & \text { " } \\ \text { 26768. Canoe paddle. } & \text { " } & \text { " } \\ \text { 26767. Canoe paddle. } & \text { " } & \text { " } \\ \text { 26766. Canoe paddle. } & \text { " Canoe paddle. } & \\ \text { 26765. Canoe paddle. } & \text { Made by Waters \& Son, Troy, N. Y.; De Long \& } \\ \text { 26810. Double paddle. Ma } & \end{array}$

Poles and pushing sticks.

15653. Bidarka pole. Nunivak, Alaska. W. H. Dall.

15653. Bidarka pole.

"6 "6

17443. Bidarka pole. Cave, Kagamil Island, Alaska. Alaska Commercial Company.

Candlestick.

Used in hold of vessel while storing fish.

32741. Candlestick. A. McCurdy, Gloucester, Mass.

32692. Candlestick or "Sticking Tommy." Gloucester, Mass. G. Brown Goode.

Fog-horns.

29382. Series of common reed fog-horns, Nos. 1, 2, 3, and 4. Wilcox, Crittenden \& Co., Middletown, Conn.

25783. Grand Bank fog-horn. Called by the fishermen "lipper" or "ripper." William H. Weston, Provincetown, Mass.

25281. The Anderson fog-horn. U. S. Fish Commission. (Deposited.)

\section{Deck-scrapers.}

25160. Series of ships' deck scrapers. Wilcox, Crittenden \& Co., Middletown, Conn.

Dory scoop.

25222. Dory scoop. S. Elwell, jr., Gloucester, Mass.

Flagging irons, \&c.

Used by mackerelmen of Capes Cod and Ann to separate barrel staves for the insertion of stems of flag to stop leakage.

29492-94. Flagging iron, hoop-drivers, and adze. M. W. Grant, Wellfleet, Mass.

Pump-bolt or toggle-pin.

Used on fishing-vessels of Cape Cod and Cape Ann.

23470. Pump-bolt or toggle-pin. Wilcox, Crittenden \& Co., Middletown, Conn. 
ANIMAL RESOURCES AND FISHERIES OF UNITED STATES. 161

\section{Apparatus accessory to rigging fishing-vessels.}

Pump box and haft for seine-boat.

29497. Pump box and haft for seine-boat. Andrew Kennedy, Provincetown,

29499. Pump box and haft for seine-boat.

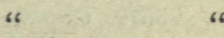

| Mass.

Bung-bucket or "water-thief."

25784. Bung-bucket or "water-thief." Wm. H. H. Weston, Provincetown, Mass.

Devil's claw.

Used to stop the chain when the windlass is wanted for other uses.

29442. Devil's claw. W. H. Hesbolt, Provincetown, Mass.

Box hook.

Used in closing boxes packed full of fish.

32680. Bilge hooks. Gloucester, Mass. G. Brown Goode.

:2695. Box hook or "devil's claw." Gloucester, Mass. G. Brown Goode.

\section{Barrel-lifters.}

Used for stowing away mackerel-kegs in holds of vessels.

29291. Barrel-lifters. Wilcox, Crittenden \& Co., Middletown, Conn.

32679. Chime barrel-hooks. Gloncester, Mass. G. Brown Goode.

Ice-hooks.

For lifting ice on vessel from wharf.

32674. Ice-hooks. Gloucester, Mass. G. Brown Goode.

Lance-hooks.

Fastened on side of whale-boat to hang lance on.

25919. Lance-hooks. E. B. \&. F. Macy, New Bedford, Mass.

Grappling gèar.

Used to recover lost trawls.

25936. Grappling gear. A. McCurdy, Gloucester, Mass.

Marline spikes.

29418. Marline spike or pricker. Used for splicing trawl-lines. Wilcox, Crittenden \& Co., Middletown, Conn.

29455. Marline spike. Made from the jawbone of sperm whale. Robert D. Baxter, Provincetown, Mass.

29419. Marline spike. Made from the jawbone of whale. Frank O. Blake, Portland, Me.

25147. Sailmakers' marline spike. Wilcox, Crittenden \& Co., Middletown,

25148. Sailmakers' marline pricker.

[Conn.

25164. Series of marline spikes.

25778. Fishermen's marline spike or trawl-line splicer. Alex. McCurdy, East Gloucester, Mass.

3ull. N. M. No. $14-11$ 


\section{Apparatus accessory to rigging fishing=vessels.}

Marline spikes.

25146. Series of hickory hand fids. Wilcox, Crittenden \& Co., Miduletown, Conn.

25672. Copper marline spike. Made at sea by Thomas Freeznan. Used for splicing trawl-lines. Sanford Freeman, Norwichport, Mass.

32693. Splicer. Gloucester, Mass. G. Brown Goode.

Rèst for harpoon, \&c.

11392. Rest for harpoon and bow and arrow. Aleutian Island. Vincent Colyer.

Used on deck of kyak.

Stretchers for kyak-line.

9836. Stretchers for kyak-line. Eskimos.

Stool.

3978. Stool. R. MacFarlane.

Used by Eskimos to stand on while watching for seal in water.

\section{Shelter.}

49. CAMP-OUTFit.

Lodges.

Tents.

Hunting-camps.

Hunters' houses.

Fishing-houses.

\section{Furniture.}

Hammocks.

Beds, couches, stretchers, and lounges.

Blankets (rubber and mackinaw), and fur robes.

Fuel.

Apparatus for kindling fire.

Lamps and lanterns.

Tools.

\section{Commissary supplies.}

Cooking apparatus, kettles, and stoves.

1. Commissary supplies.

29295. Portable camp-stove.

25689. Portable camp-stove.

H. L. Duncklee, Boston, Mass.

Open, showing ntensils, viz:

25690. Six tin plates.

25691. Six tin cups.

25692. Six-quart kettle.

25693. Eight-quart kettle.

25694. Stew-pan. 


\section{Commissary supplies.}

Commissary supplies.

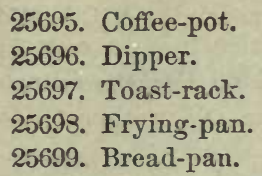

F. \& S. 60. Camp-stove and utensils. Property of John A. Nichols, Syracuse, N. Y. Contributed by Forest \& Stream Publishing Company.

26673. Coffee-heater. Property of J. A. Nichols, Syracuse, N. Y. Contributed by Forest \& Stream Publishing Company.

26713. Camp-stove. Property of J. A. Nichols, Syracuse, N. Y. Contributed by Forest \& Stream Publishing Company.

26843. Lehmen's patent folding camp-baker. Scoville \& Johnson, Marquette, Mich.

Table-furniture.

Preserved meats, \&c.

Canned meats.

24917. Fresh tomato soup. Wm. Underwood \& Co., Boston, Mass.

26649. Ox-tail soup (star brand). Portland Packing Company, Portland, Me. 24913. Fresh soup and bouilli. Wm. Underwood \& Co., Boston, Mass.

26648. Soup and bouilli (star brand). Portland Packing Company, Portland, Me.

24921. Mock-turtle soup. Wm. Underwood \& Co., Boston, Mass.

26641. Cumberland potted sansage (star brand). Portland Packing Company, Portland, Me.

24927. Ox-tail soup. Wm. Underwood \& Co., Boston, Mass.

24929. Original deviled ragout.

24928. Deviled tongue.

24930. Deriled ham.

"6 6

"6 "6

$66 \quad 66$

26645. Cumberland roast mutton (star brand). Portland Packing Company, Portland, Me.

24920. Fresh chicken. Wm. Underwood \& Co., Boston, Mass.

26640. Cumberland roast chicken (star brand). Portland Packing Company, Portland, Me.

24931. Deviled chicken. Wm. Underwood \& Co., Boston, Mass.

26646. Cumberland roast veal (star brand). Portland Packing Company, Portland, Me.

24916. Fresh mutton. Wm. Underwood \& Co., Boston, Mass.

26647. Cumberland roast beef (star brand). Portland Packing Company, Portland, Me.

24910. Beef à la mode. Wm. Underwood \& Co., Boston, Mass.

24911. Fresh mince-meat.

24915. Fresh veal.

66

26639. Champion shell-beans (star brand). Portland Packing Cornpany,

26638. Portland blueberries (star brand).

[Portland, Me.

22238. Fresh blueberries. Castine Packing Company, Castine, Me.

24919. Fresh beef. Wm. Underwood \& Company, Boston, Mass.

26637. Yarmouth sugar-corn. (Patented April 8, May 13 and 20, and August 26, 1862.) (Star brand.) Portland Packing Company, Portland, Me. 


\section{Commisgary supplies.}

Canned meats.

26652. Yarmouth succotash. Made from Yarmouth sugar-corn and champion shell-beans (star brand). Portland Packing Company, Portland, Me.

\section{Personal equipments.}

\section{Clothing.}

Hunting suits.

25555. Canvas hunting-coat. Property of J. A. Nichols, Syracuse, N. Y. Contributed by Forest \& Stream Publishing Company.

26558. Fur vest. Property of J. A. Nichols, Syracuse, N. Y. Contributed by Forest \& Stream Publishing Company.

26659. Buckskin coat. Property of J. A. Nichols, Syracuse, N. Y. Contributed by Forest \& Stream Publishing Company.

26670. Mole-skin pants. Property of J. A. Nichols, Syracuse, N. Y. Contributed by Forest \& Stream Publishing Company.

26671. Corduroy hunter's coat. Property of J. A. Nichols, Syracuse, N. Y. Contributed by Forest \& Stream Publishing Company.

26675. Corduroy hunter's pants. Property of J. A. Nichols, Syracuse, N. Y. Contributed by Forest \& Stream Publishing Company.

26676. Corduroy vest. Property of J. A. Nichols, Syracuse, N. Y. Contributed by Forest \& Stream Publishing Company.

26701. Chamois shirt. Property of J. A. Nichols, Syracuse, N. Y. Contributed by Forest \& Stream Publishing Company.

26594. Hunter's water-proof suit, with patent cartridge-holding vest. Geo. C. Henning, Washington, D. C.

This suit includes:

1. Pantaloons so made that they can be folded close to the legs.

2. Gaiters.

3. Vest with sleeves.

4. Reversible shooting-coat, with seventy-six receptacles for shell or cartridges so arranged as to permit them to be carried either end up, and secured from loss or from injury by rain, by means of the flaps which button over them. The coat is of the same shape before and behind, so that when the hunter exhausts his shells in front he can reverse the coat and have a fresh supply. There are eight pockets opening on the outside of the skirt, and two large game pockets on the inside arranged with openings in the bottoms for ventilation and drip.

5. A double-visored cap.

26710. Hunting-coat. Property of J. A. Niclols, Syracuse, N. Y. Contributed by Forest \& Stream Publishing Company.

Water-proof suits.

25656. Rubber hunting-coat. Property of J. A. Nichols, Syracuse, N. Y. Contributed by Forest \& Stream Publishing Company.

Oil-skin suit.

29543. Cape Ann coats. J. F. Carter, Gloucester, Mass.

29544. Cape Ann pants.

66 


\section{Clothing.}

Boots, moccasins, leggings.

26015. Fishermen's red cod boots. Jonathan Buck, Harwich, Mass.

26015. Fishermen's red-leather slippers. " " "

26014. Fishermen's black boots.

$66-66$

25823. Slippers made of sheep-skin, with the wool on the inner surface. Worn by fishermen inside of their boots. A. R. Crittenden, Middletown, Conn.

26671. Boot-packings. Property of J. A. Nichols, Syracuse, N. Y. Contributed by Forest \& Stream Publishing Company.

266z2. Moccasins. Property of J. A. Nichols, Syracuse, N. Y. Contributed by Forest \& Stream Publishing Company.

26708. Rubber boots. Property of J. A. Nichols, Syracuse, N. Y. Contributed by Forest \& Stream Publishing Company.

\section{Hats and caps.}

25\%22. Fisherman's eap, called "Russian cap." E. R. Cook, Provincetown, Mass.

26651. Hunter's rubber cap. Property of J. A. Nichols, Syracuse, N. Y. Contributed by Forest \& Stream Publishing Company.

29542. Series of sou'westers and oil-cloth hats (Cape Ann pattern). J. F. Carter, Gloucester, Mass.

Clothing for the hands.

25788. Pair of mittens. Called "Newfoundland cuffs" by fishermen. Peculiar to Gloncester. A. R. Crittenden, Middletown, Conn.

25790. Mackerel cots. Used on the fingers when taking mackerel by hook and line. Capt. Samuel EIwell, Gloucester, Mass.

25787. Pair of "hand-haulers." Used by fishermen off the Newfoundland Banks. Joseph Parsons, jr., East Gloucester, Mass.

25789. Pair of nipners; peculiar to Gloucester, Mass. Joseph Parsous, East Gloucester, Mass.

25718. Pair of nippers. Used by fishermen to protect the fingers while hauling in trawls. David Conwell.

25717. Pair of nippers. Central Wharf Company, Provincetown, Mass.

26709. Rubber gloves. Property of J. A. Nichols, Syracuse, N. Y. Contributed by Forest \& Stream Publishing Company.

Protection from insects:

Nets for beds and for face.

25700. Mosquito-net. Property of J. A. Nichols, Syracuse, N. Y. Contributed by Forest \& Stream Publishing Company.

Ointments (such as tar and sweet-oil).

Smudges (such as pyrethrum powder).

Shields, breastplates, and defensive armor.

\section{Trappings.}

Belts.

23565. Belt for sheath-knife. J. A. Nichols, Syracuse, N. Y. 


\section{Trappings.}

Cross-belts.

Game-bags.

26667. Game-bag. Property of J. A. Nichols, Syracuse, N. Y. Contributed by Forest \& Stream Publishing Company.

2523. Game-bag. Indians of Northwest coast. U. S. Exploring Expedition.

1473. Game-bag. Comanche Indians. Licut. D. N. Couch, U. S. A.

2023. Game-bag of knit leather thongs. Dog-rib Indians. Fort Simpson, B. C. R. R. Ross.

2047. Hunting-bag of "babiche." Fort Simpson, H. B. T. R. R. Ross.

2020. Hunting-bag made of "babiche." Dog-rib Indians. Fort Simpson, H. B. T. R. R. Ross.

2551. Hunting-bag of "babiche." Fort Rae Eskimos. Mackenzie's River district. Stratton Jones.

2498. Game-bag. Indians of Northwest coast. U. S. Exploring Expedition.

Wrist-guards.

6927. Wrist-guard. Used in shooting with the bow. Kiowa Indians. Fort Cobb, I. T. E. Palmer.

5520. Wrist-guard. Apache Indians. Arizona. E. Palmer.

\section{Dptical instruments, \&c.}

Snow-goggles.

1651. Snow-blind. Anderson River Eskimos. R. MacFarlane.

10292. Snow-goggles.

1650, 2147, 2157. Snow-goggles. Anderson River Eskimos. R. MacFarlane. 5589. Ingaleet Eskimos. Yukon River, Alaska. W. H. Dall.

5579. Mahlemut Eskimos. Lower Yukon, Alaska.

10200. Snow-goggles.

Telescopes.

Field-glasses, \&c.

Water-telescopes.

26884. Water-telescope. U. S. Fish Commission.

Used in examination of submarine objects.

\section{Compasses.}

26682. Hunter's compass. Property of J. A. Nichols, Syracuse, N. Y. Contributed by Forest \& Stream Publishing Company.

Scales.

26681. Scalcs. Property of J. A. Nichols, Syracuse, N. Y. Contributed by Forest \& Stream Publishing Company.

Game and fish baskets and slings.

Wallets for lines and other tackle. 
ANIMAL RESOURCES AND FISHERIES OF UNITED STATES. 167

\section{Medical outfit.}

Medicine-chests.

Hunter's and fishermen's flasks.

26684. Flasks. Property of J. A. Nichols, Syracuse, N.Y. Contributed by Forest \& Stream Publishing Company.

\section{Artificial lights.}

Lanterns for camp and ship use. ${ }^{1}$

Torches.

'See under Sight decoys above, p. 141. 


\section{SECTION C.}

\section{METHODS OF PREPARATION. \\ I. PREPARATION AND PRESERVATION OF FOOD.}

1. Preservation during life (see under E, 3 ).

2. Preservation of fresh meats.

\section{Refrigerators.}

Ice-boxes and refrigerators.

- Allegretti iceberg-refrigerator. Allegretti Refrigerator Company,

- Allegretti refrigerator show-case. $\left[\begin{array}{c}\text { [New York. } \\ \text { C }\end{array}\right.$

Banta refrigerator.

Banta horizontal refrigerator.

- Banta refrigerator show-caso. Process patented July 1, 1867. G. A. Banta, New York City.

—. Zero refrigerator. Alexander M. Lesley, New York.

Refrigerator-cars.

(Accessory.) The ice-trade:

Ice cutting and handling apparatus.

Methods of manufacturing artificial ice.

Ice-houses.

\section{Dther accessories of preservation.}

Meat-hooks.

Skewers, \&c.

Carving-tools.

\section{Preservation by drying.}

\section{Sun-drying apparatus.}

Beach dryers.

Flake-drying:

Newfoundland flakes.

Massachusetts flakes.

12495. Codfish-flake (with covers). Model. Coast of Maine. E. Skillings, Portland, Me. 


\section{Smoke-drying apparatus.}

Herring smoke-houses.

12105. Model of smoke-house used in preparation of herring (Clupea harengus). Lubec, Me. U. S. Fish Commission.

$12105 \frac{1}{2}$. Model of smoke-house used in preparation of salmon (Salmo salar). Lubec, Me. U. S. Fish Commission.

Halibut smoke-houses.

Sțurgeon smoke-houses.

Aboriginal drying-houses.

Methods of drying haliotis, used by the Indians of California.

\section{Preservation by CanNing aNd pickling.}

\section{Salting fish.}

Knives (see under B, 2).

Scaling apparatus.

20039. Kelsey \& Hosmer's fish-dresser. Sandusky, Ohio. Patented Sept. 15, 1873. Kelsey \& Hosmer, Sandusky, Ohio.

Tables, tubs, \&c.

Barrels.

25750. Model of D. D. Parmalee's Waukegan fishery. J. W. Milner.

This model shows in miniature all the apparatus employed in cleaning and salting down the lake whitefish.

(Accessory.) Salt:

Specimens of the salts used in preșerving fish.

Model of salt-mills used on Cape Cod in former days.

Extensively used in the first half of the present century in obtaining salt by evaporation of sea-water. Their remains are found on Cape Cod and Nantacket.

25\%06. Model of salt-works. Nantucket, Mass. W. H. Chase, $2 \mathrm{~d}$.

\section{Canning meats.}

Model of salmon-canning establishment.

Model of sardine-factory.

(Accessory.) Cotton-oil, and its manufacture.

Model of lobster-canning factory.

26583. Model of Johnson \& Young's lobster-house. Warren bridge, near Fitchburg depot. Johnson \& Young, Boston, Mass.

This model shows the factory with its vats for steaming the lobsters, the wharf, and the derricks used in handling the lobsters. It is accompanied by models of lobster-smack, and of the principal forms of lobster-nets; catalogued elsewhere.

Model of orster-canning factory. 


\section{Preparation of batts.}

Bait-mills, knives, choppers, \&c. (see, also, under B, 2 and 3). 26011. Voss' improved bait-mill. (Patented January 17, 1876.) A. Voss, Gloucester, Mass.

Bait-tubs, vats, \&c.

\section{MANUFACTURE OF TEXTILE, FABRICS, FELTS, AND STUFFINGS.}

6. Preparation of wool and hatr of mammals.

Preparation of wool cloths.

Washing.

Shearing.

Stapling or assorting.

Scouring.

Combing, carding, and plucking.

Spinning and reeling.

Weaving.

Fulling and teazling.

Cropping.

Pressing.

Weaving worsted cloths.

Felting and the hat manufacture.

Bowing.

Pressing.

Stopping.

Rolling off.

Shaping.

Preparation of curled hair for stuffings.

7. Preparation of whalebone.

Preparation of stuflings.

8. Preparation of featmers.

Preparation of down for stuffings.

- Preparation of feather fabrics.

Preparation of "brillantine." 
ANIMAL RESOURCES AND FISHERIES OF UNITED STATES. 171

Preparation of, or flocking for wall-paper, from refuse quills.

Preparation of fibers for manufacture of plush car, pets.

9. Preparation of silk of insects.

Preparation of silk of silk-worms.

Boiling the cocoons.

Reeling.

Spinning.

Dyeing.

Weaving.

10. Preparation of soft parts of other invertebrates.

Preparation of silk from byssus of Pinma.

Preparation of sponge stuffing.

\section{PREPARATION OF THE SKIN AND ITS APPEND- AGES.}

11. Currying of Leather.

Processes of currying.

Dipping.

Graining.

Scraping.

Dressing.

\section{Implements employed by curriers.}
"Head-knives,"
"Pommels,"
"Stretching-irons."
"Round-knives."
"Cleaners."
"Maces."
"Horses" or trestles.
"Dressers."
"Treading-hurdles."

Eskimo and Indian currying methods and implements.

Methods of dressing gut and sinew. 
172 ANIMAL RESOURCES AND FISHERIES OF UNITED STATES.

12. LEATHER DRESSING.

Processes of tanning leather.

Soaking.

Liming.

Tanning.

Processes of tawing or oil-dressing leather.

Soaking.

Liming.

Oiling.

Apparatus of leather-dressing, recent and aboriginal.

13. Fur-DREsSing.

Processes of fur-dressing.

Currying. (See under 12.)

Scouring.

Tanning.

Lustering.

Plucking and dyeing.

14. FeAtHer-DRESSING.

Method of preparing ornamental feathers.

Scouring.

Bleaching.

Washing.

Azuring.

Sulphuring.

Scraping.

Dyeing.

\section{(Art or plumagery $\bullet$ )}

15. MANUFACTURE OF QUILL ARTICLE:.

Manufactnre of quills for pens.

Sand-bath drying and steaming.

Polishing.

Dyeing.

Shaping.

Manufacture of tooth-picks.

Manufacture of floats and other articles.

Manufacture of quill brush-bristles.

16. HAIR AND WOOL WORK. 
ANIMAL RESOURCES AND FISHERIES OF UNITED STATES. 173

\section{PREPARATION OF HARD TISSUES.}

17. IVORY CUTTING AND CARVING.

Manufacture of handles, troinkets, billiand-balls, \&c.

Turning and sawing.

Polishing.

Bleaching.

Manufacture of organ and piamo keys.

Sawing.

Strip-sawing.

Polishing.

Bleaching. \&c.

Dther processes.

18. Preparation of horn and hoof. ${ }^{1}$

Steaming. ${ }^{x}$

Pressing. 1

19. Preparation of whalebone. ${ }^{1}$

Cutting and other processes. ${ }^{1}$

Planvfacture of whip-makers' stock and whips.

Manufacture of umabrella-maliers' bone.

Manufacture of noinhon=weavers' bone.

VIamufacture of hat amd bomet makers' bone.

Manuracture of suspender-matren's home.

Mamufacture of stock-makers' bone.

Manufacture or dress and stay makers' bone.

Manufacture or billiand-table cushiovs.

Manufacture of surgical instruments.

VIanufacture of whalebone brushes.

VIanufacture or nosettes, woven work, and thoinkets.

\footnotetext{
${ }^{1}$ These processes are illustrated in part by the specimens, showing the horn, whalebone, and tortoise-shell, in various stages of preparation, exhibited in Section D.
} 


\section{Other whalebore manufactures.}

20. Preparation of tortoise-Shell. ${ }^{1}$

21. Preparation of Fish-SCAle work.

22. Preparation of Nacre.

23. Preparation of coral.

24. Preparation of other hard tissues.

\section{OILS AND GELATINES.}

25. Extraction of WHALE-OIL (WITH MODELS OF TRY-WORKS, CLARIFYING-VATS, ETC.).

Preparation of body-oil.

Cutting in and stowing

Leaning and mincing.

Trying.

Bailing.

Cooling.

Barreling.

Refining.

\section{Preparation of head-oil.}

\section{Preparation of spermaceti.}

\section{Instruments amel appliances of rendering whale-oil.}

Boarding-knives. ${ }^{2}$

Leaning-knives. ${ }^{2}$

Mincing-horse and mincing-knives.

Mincing-tub.

Mincing-machine.

Blubber-fork. ${ }^{3}$

\footnotetext{
${ }^{1}$ These processes are illustrated in part by the specimens, showing the horn, whalebone, and tortoise-shell, in various stages of preparation, exhibited in Section D.

${ }^{2}$ Arranged with the knives.

'Arranged with the hooks.
} 
ANIMAL RESOURCES AND FISHERIES OF UNITED STATES. 175

\section{Instruments and appliamecs of rendering whalc-oil.}

Try-pots.

25013. Model of whaler's try-works. Capt. L. W. Howland, New Bedford, Mass.

This model is accompanied by miniature models of all the implements used in trying out the blubber, viz:
a. Fire-pike.
b. Stirring-pole.
c. Scrap-hopper.
d. Skimmer.
e. Bailer.
f. Cooler.
g. Deck-pot.
h. Casks.

26. Extraction OF OTHER MAMmal OILS.

27. EXTRACTION OF BIRD AND REPTILE OILS.

28. Extraction of FISH-OILS (WITH MODELS OF BOILERS, PRESSES, CLARIFYING-VATS, ETC.).

26899. Model of menhaden oil factory. Owned by Jos. Church \& Co. Joseph Lawler, Bristol, Me.

The factory is the most elaborate of the sixty or more on the coast of New England and the Middle States, and is 160 feet in length by 40 in width.

29. Ex'TRACTION OF GLUE, GELATINE, AND ISINGLASS.

\section{DRUGS, PERFUMES, AND CHEMICAL PRODUCTS.}

30. Manufacture of perfumes.

31. MANUfaCtURE OF IVORY-BlaCK.

32. MaNufaCture of prussiates.

33. Manufacture of murexides.

34. Preparation of cochineal colors.

35. MANUFACTURE OF INKS FROM ANIMAL SUBSTANCES.

36. Preparation of albumen.

37. MaNUfaCtuRE OF PEPSIN.

38. MaNUfaCtURE OF PHOSPHORUS.

39. Manufacture of sal ammoniac.

40. MaNufacture of ammonia.

41. ManUfaCture of albumen preparations.

42. MaNUfaCtuRE OF PROPYLAMTNE.

43. MaNUfaCture OF FORMIC $A$ CID.

44. Manufacture of carbazotates. 


\section{MANUFACTURE OF FERTILIZERS.}

\section{Preparation of guano.}

\section{Model of fish-guano works.}

Grinders and pulverizers.

Mixers.

25822. Model of guano-mixer. Patented April 27, 1867. Poole and Hunt, Baltimore, Md.

- This mixer is employed in the fish-guano works for the purpose of thoroughly mixing the fish-scrap with the mineral phosphates and sulphuric acid.

Guano in its various stages, with its ingredients, South Carolina phosphates, Navassa phosphates, scrap (crude and dried), sulphuric acid, kainite, screened and unscreened guano, and sea-weed used in preparation : a full series of these is exhibited in the case of Guanos.

\section{LIMES.}

46. BuRning OF LIME.

Mlodels of kilms for bunming shells.

\section{PRESERVATION OF THE ANIMAL FOR SCIENTIFIC USES.}

47. Apparatus for Making aND PReserving alCoholid SPECIMENS.

Tanks and jars.

Agassiz collecting-tank.

Army collecting-tank.

Museum storage-tar.k, Agassiz model.

Anatomical jars.

Self-sealing jars used in collecting.

Vials.

Syrimges for injecting.

Inflatable bags.

\section{Preservative mixtures.}

Alcohol.

Glycerine. 


\section{Preservative mixtures.}

Carbolic acid.

Chloral hydrate.

Picric acid.

Osmic acid.

\section{Labels.}

Metallic labels.

Parchment labels.

Indelible ink, pencils, \&c.

48. APPARATUS FOR PRESERVING AND MAKTIG SKELETONS.

\section{Preparation of the bones.}

Macerating-vats.

Boiling-vats.

Cleaning and bleaching preparation.

\section{Mounting of the bones.}

Scraping-tools.

Articuiatng-tools.

49. Apparatus FOR Making OASTS. MODHLING.

\section{Materials.}

Clays.

Plasters.

Glues.

Papier-maché and carton-pierre.

Gelatine.

Paraffine.

Collodion.

This apparatus and material is in constant use by the assistants in the National Museum and the Fish Commission. It is thought scarcely necessary to exhibit it.

\section{Frames and modeling tools.}

\section{Mlolds:}

Of plaster.

Of gelatine.

Of paper.

Of paraffine. 
50. APPARATUS AND METHODS OF IIAKING AND MIOUNTING SKINS.

\section{Tools.}

\section{TAXIDERMY.}

Flaying-tools.

Scraping-tools.

Taxidermists' tools for stuffing :

Forceps.

Pliers.

\section{Preservatives and insect-powders.}

Arsenic and arsenical soap.

Corrosive sublimate.

Salt, alum, \&c.

Persian insect-powder.

Tobacco, snuff, used as preservatives.

\section{Frames, dec.}

Wooden frames.

Wire frames.

Plaster model-bodies.

51. (ACCessory.) Photographic aNd other delineating APPARATUS.

\section{Photographic apparatus.}

Lenses.

Cameras and fittings.

Camera tripods and stands, with model.

Fish Commission stands.

- Model of Fish Commission camera-stand. U. S. Fish Commission. This stand is employed in taking photographs of large fishes. It enabling the photographer to operate his camera vertically.

Plates, and their results:

Wet plates.

Dry plates.

Dark closets.

Camera-obscuras.

Mechanical delineators.

Methods of heliotyping and engraving illustrations. 


\section{SECTION D.}

\section{ANIMAL PRODUCTS AND THEIR APPLICA- TIONS.}

I. FOODS.

\section{FOODS IN A FRESII CONDITION.}

This section includes specimens of the marketable animals in a fresh condition in refrigerators.

The following species of fish were exhibited in the Allegretti and Banta refrigerators in the Government building from May 10 to November 10, by Mr. E. G. Blackford, of New York City.

\section{Fishes (eastern coast):}

Rabbit-fish (Tetrodon laevigatus).

Bur-fish (Chilomycterus geometricus).

File-fish (Balistes capriscus).

Long-tailed file-fish (Alutera cuspicauda).

Orange file-fish (Ceratacanthus aurantiacus).

American sole (Achirus lineatus).

Flat-fish (Pseudopleuronectes americanus).

Flounder (Choenopsetta ocellaris).

Halibut (Hippoglossus vulgaris).

Pollack (Pollachius carbonarius).

Cod (Gadus morrhua).

Tom-cod or frost-fish (Microgadus tomcodus).

Haddock (Melanogrammus aglefinus).

Hake (Phycis chuss).

Striped sea-robin (Prionotus evolans).

Broad-fingered sea-robin (Prionotus carolinus).

Sea-raven (Hemitripterus americanus).

Wolf-fish (Anarrhichas lupus).

Tautog, or black-fish (Tautogà onitis), weight $22 \frac{1}{2}$ pounds.

Chogset or cunner (Tautogolabrus adspersus).

Parrot-fish (Pseudoscarus sp.).

Sergeant-major (Glyphidodon saxatilis).

Lump-fish (Cyclopterus lumpus).

Mackerel (Scomber scombrus). 
Fighes (eastern coast):

Bonito (Sarda pelamys).

Spanish mackerel (Cybium maculatum).

Cero (Cybium caballa).

Striped cero (Cybium regale).

Crevalle (Carangus hippos and Paratractus pisquetos).

Pompano (Trachynotus carolinus).

Big-eyed sead (Trachurops crumenophthalmus).

South Carolina rudder-fish (Seriola fasciata).

Silver-fish (Argyriosus vomer, \&c.).

Thread-fish (Blepharis crinitus).

Dolphin (Coryphoena Sueuri and C.punctulata).

Black rudder-fish (Palinurichthys perciformis).

Butter-fish (Poronotus triacanthus).

Short harvest-fish (Peprilus Gardenii).

Squirrel (Holocentrum sogo).

Squeteague (Cynoscion regalis).

Spatted squeteague or weak-fish (Cynoscion carolinensis).

Drum (Pogonias chromis).

Spot (Iiostomus obliquus).

Red-fish, or spotted bass (Sciaenops ocellatus).

King-fish (Menticirrus nebulosus).

Croaker (Micropogon undulatus).

Sheeps-head (Archosargus probatocephatus).

Scuppaug, or porgy (Stenotomus argyrops).

Grunts (Hoemylum arcuatum, \&c.).

Red snapper (Lutjanus Blackfordii).

Grouper (Epinephelus striatus, E. apua, \&c.).

Sea bass (Centropristis atrarius).

Striped bass or rock fish (Roccus lineatus).

White perch (Morone americana).

Moon-fish (Parephippus quadratus).

Triple-tail (Lobotes surinamensis).

Bluefish (Pomatomus saltatrix).

Cobia (Elacate canadus).

Sucker-fish (Leptecheneis naucrateoides).

Striped mullet (Mugil lineatus).

Silver gar-fish (Belone longirostris).

Skipper (Scomberesox scutellatus).

Salmon (Salmo salar).

Tarpum (Megalops thrissoides).

Menhaden (Brevoortia tyrannus).

Shad (Alosa sopidissima).

Alewife, or gaspereau (Pomolobus pseudoharengus).

Tailor herring (Pomolobus mediocris).

Herring (Clupea harengus). 
Fishes (eastern coast):

Mud shad (Dorosoma Cepedianum).

Sea cat-fish (Aelurichthys marinus).

Eel (Anguilla bostoniensis).

Sturgeon (Acipenser oxyrhynchus and A. brevirostris).

Spoonbill (Polyodon folium).

Ray, or skate (Raia sp.).

Spotted-fin shark (Isogomphodon maculipinnis).

Dog-fish (Mustelus loevis).

\section{Fishes (fresh waters):}

Burbot, or lawyer (Lota maculosa).

Fresh-water drum (Haploidonotus grunniens).

Small-mouthed black bass (Micropterus salmoides).

Large-mouthed black bass (Micropterus pallidus).

Rock bass (Ambloplites rupestris).

Sun-fish (Pomotis aureus).

Yellow perch (Perca flavescens).

Yellow pike-perch (Stizostedium americanum).

White bass, or striped bass (Roccus chrysops).

Lake pike (Esox lucius).

Masquallonge (Esox nobilior).

Pickerel (Esox reticulatus).

Brook trout (of eastern slope), (Salvelmus fontinalis).

Lake trout (Salmo confinis).

Salmon trout, or Mackinaw trout (Cristivomer namaycush).

Atlantic salmon (Salmo salar).

Sebago salmon (Salmo salar var. sebago).

White-fish (Coregonus albus).

Lake herring (Argyrosomus harengus and A. clupeiformis).

Michigan grayling (Thymallus tricolor).

Moon-eye (Hyodon tergisus).

Suckers (Catostomus teres and Ptychostomus aureolus).

Buffalo fish (Bubalichthys bubalus).

Shiner (Stilbe americana).

Catfishes (Amiurus catus, A. nigricans, \&c.).

Fishes (western coast):

Salmon (Salmo quinnat).

Mussels.

Clams.

Crabs.

Lobsters.

Squid. 


\section{FOODS: DRIED AND SMOKED.}

\section{Mammal preparations.}

Jerked bear-meat.

Jerked seal and walrus meat (Indian).

11435. Dried (jerked) flesh of harbor seal (Phoca vitulina). Prepared by the Passamaquoddy Indians. Eastport, Me. E. Palmer.

Jerked and smoked buffalo-meat.

14281. Dried (jerked) flesh of buffalo (Bison americanus), as prepared for hunters' use. Wyoming. F. V. Hayden, U. S. Geologist.

10917. Dried (jerked) flesh of buffalo (Bison americanus), Prepared by Sioux Indians. Army Medical Museum.

Dried and smoked beef.

Dried and smoked venison.

Hams of various kinds.

Jerked porpoise-meat (Indian).

11436. Dried (jerked) flesh of harbor porpoise (Phocaena brachycion). Prepared hy the Passamaquoddy Indians of Eastern Maine. Eastport, Me. E. Palmer.

Jerked squirrels and other small mammals.

Pemmican.

12238. Pemmican of dried flesh of buffalo (Bison americanus), with buffaloskin case. Prepared for hunters' use. Western Plains. Army Medical Museum.

Meat-biscuit, desiccated meat, meat extract (extractum carnis), desiccated and condensed milk, \&c.

29524. Valentine's preparation of meat juice. M. L. Valentine, Richmond, Va.

29525. Valentine's meat juice and glycerine. (Meat juice 1 part, glycerine 3 parts.)

29358. Condensed milk. The Gail Borden Eagle brand (made in 1876). New York Condensed Milk Company, New York.

29360. Borden's pure cocoa (in combination with refined sugar and Borden's condensed milk). New York Condensed Milk Company, New York.

29359. Borden's meat-biscuit (made in 1851). Composed of pure juce or extract of beef combined with wheat-flour. New York Condensed Milk Company.

29361. Borden's extract of beef (made in 1876). Prepared by the Borden Meat Preserving Company, Colorado County, Texas. Concentrated in vacuo. New York Condensed Milk Company.

(Borden's extract of beef consists of the juices of lean meat concentrated in vacuo at a low degree of heat, by which process it is claimed the burnt taste and smell, objected to in other beef extracts, are avioided.)

4915. Condensed raw beef (pulverized). Prepared by the National Proserving Company, Baltimore. 


\section{Mammal preparations.}

Sausages.

Cheese.

See in exhibition of Agricultural Department.

\section{Bird preparations.}

Jerked birds (Indian).

\section{Reptile preparations.}

Dried lizards (Indian).

\section{Fish preparations.}

Smoked halibut.

Dried cod, haddock, hake, \&c.

26750. Alden's vapor-cured, snow-flaked, fresh codfish. E. G. Blackford.

Dried and smoked mullet and roes.

Dried and smoked garfish, flying-fish, \&c.

Smoked herring, alewives, \&c., and their roes.

12130. Smoked No. 1 herrings (Clupea harengus). Eastport, Me. D. T. Odell.

12131. Smoked "Magdalena" herrings (Clupea harengus). Eastport, Me. D. T. Odell.

12129. Smoked "scaled" herrings (Clupea harengus). Eastport, Me. D. T. Odell.

26552-3-4. Smoked herring (Clupea harengus). Eastport, Me. Griffin Bros.

Smoked salmon, oulachan, white-fish, smelt, \&c., and their roes.

12121. Smoked white-fish (Coregonus albus). Lake Erie. Schacht \& Bros., Sandusky, Ohio.

11608. Smoked flesh of the quinnat salmon (Salmo quinnat). Prepared by the McCloud River Indians. Shasta County, California. Livingston Stone.

12122. Smoked sturgeon (Acipenser rubicundus). Lake Erie. Schacht \& Bros., Sandusky, Ohio.

19646. Dried flesh of trout (Salmo, sp.). Used as food by the Ahgy Pi-Uto Indians of Walker Lake, Nevada. Stephen Powers.

19353. Dried eggs of quinnat salmon (Salmo quinnat). Prepared by the McCloud River Indians. Shasta, Cal. Livingston Stone.

11049. Dried eggs of quinnat salmon (Salmo quinnat). Prepared for food by the Bannack Indians.

21716. Flour made from flesh of quinnat salmon (Salmo quinnat) by the McCloud River Indians of California. Livingston Stone.

21712. Basket of dried salmon (Salmo quinnat). Prepared for food by the McCloud River Indians. Shasta County, California. Livingston Stone.

25284. Dried flesh of salmon (Salmo, sp.). Prepared by the Sitka Iudians of Alaska. Alaska. J. G. Swan.

12132. Dried flesh of the quinnat salmon (Salmo quinnat). Used as food by the McCloud River Indians. California. Livingston Stone. 
184 ANIMAL RE'SOURCES AND FISHERIES OF UNITED STATES.

\section{Fish preparations.}

13752. Dried eggs of quinnat salmon (Salmo quinnat). Used as food by the McCloud River Indians. California. Shasta County, California. Livingston Stone.

21187. Eggs of "herring" (sp. incog.). Used as food by Sitka Indians. Collected by them upon branches of hemlock (Abies Mortcnsiana), planted in shallow water, upon the spawning grounds of the fish. Sitka, Alaska. J. G. Swan.

Smoked sturgeon.

Veziga, prepared from the notochord of sturgeon.

\section{Insects.}

Dried grasshoppers (Indian).

25314. Grasshoppers. Dried for food by the Indians of Southern California. E. Palmer.

\section{Worms.}

Dried worms (Indian).

\section{Mollusk preparations.}

Dried abalones (Haliotis) prepared by the California Chinese.

Dried siphons of Schizothcerus prepared by the Indians of the Northwest coast.

Dried slugs (Limax, \&c.), used by Indians.

\section{Radiate preparations.}

(Dried holothurians, "bêches de mer," used by Chinese.)

\section{Protozoans.}

("Mountain meal," a kind of infusorial earth, mixed with flour, and used as food in Lapland and China.)

3. FOODS: SALTED, CANNED, AND PICKLED.

\section{Mammal preparations.}

Salted buffalo-meat.

Salted beef. ${ }^{1}$

Salted deer, reindeer, elk.

Salted tongues of beef, buffalo, deer, horse. ${ }^{2}$

Salted pork. ${ }^{1}$

Canned milk of the various brands. 
ANIMAL RESOURCES AND FISHERIES OF UNITED STATES. 185

\section{Bird preparations.}

Canned turkey.

Canned meats.

24918. Fresh turkey (Meleagris gallopavo). Wm. Underwood \& Co., Boston,

24932. Deviled turkey (Meleagris gallopavo).

[Mass.

26644. Cumberland roast turkey (star brand). Portland Packing Company, Portland, Me.

Canned chicken.

Canned goose.

\section{Reptile preparations.}

Salted and canned turtles and turtle soup.

Canned frogs.

26751. Alden fresh green turtle. Prepared by Alden Sea Food Company. Sold by Lynn Manufacturing Company, New York. Presented by E. G. Blackford, New York.

\section{Fish preparations.}

Salted halibut, halibut fins, \&c.

25271. Preserved fresh halibut (Hippoglossus vulgaris). Wm. Underwood \& Co., Boston, Mass.

Salted cod, cod's tongues, sounds, and roe.

24923. Fresh codfish (Gadus morhua). Wm. Underwood \& Co., Boston, Mass.

25273. Fresh haddock (Melanogrammus aglefinus). "

Salted mackerel.

Salted Spanish mackerel.

26650. Fresh Seguin mackerel (star brand). Portland Packing Company, Portland, Me.

25855-60. Canned mackerel (Scomber scombrus). Kemp, Day \& Co., New York.

24922. Fresh mackerel (Scomber scombrus). Wm. Underwood \& Co., Boston, Mass.

Salted bluefish.

Salted pompano.

Salted sword-fish.

Salted mullets.

Salted salmon.

24924. Fresh salmon (Salmo salar). Wm. Underwood \& Co., Boston, Mass. 26557. Pickled salmon (Salmo).

26755. Fresh Columbia River salmon. Brookfield, Columbia River, W. T. J. G. Megler \& Co.

- Canned salmon. A. Booth \& Co., Chicago, Ill. 


\section{Fish preparations.}

Salted salmon.

26756. Fresh Columbia River salmon. Brookfield, W. T. J. G. Megler \& Co. 26757. Fresh Columbia River salmon. Brookfield, Columbia River, W. T. J. G. Megler \& Co.

26803. Spring salmon bellies (salted). Oregon Packing Company, Portland, Oreg.

26747. Cook's Culumbia River fresh salmon. Oregon Packing Company.

Canned menhaden, in oil, "American sardines."

16609. "American sardines." Prepared "à l'huile" from the menhaden (Brevoortia tyrannus). Amcrican Sardine Company, New York.

16702. Cornish sardines (à l'huile), first quality. Prepared by Fox \& Fryer, Falmouth and Nevagissy, Cornwall, from the pilchard (Clupea pilchardus).

16680. "American boneless sardines." Prepared in olive oil from the menhaden (Brevoortia tyrannus). Process patented May 21, 1872. American Sardine Company, New York.

15516. "Shadines." Prepared from the menhaden (Brevoortia tyrannus). Port Monmouth Fishery, New York. Hooper \& Coit, New York.

(Spiced lampreys) used in Europe.

Anchovy-sauce and "essence of anchovies."

Canned menhaden, in oil, "American club-fish."

Spiced menhaden, "ocean trout."

—. Ocean trout. Hoope \& Coit, Port Monmouth, N. J.

Salted herring.

26748. Quoddy River herring (salted). Griffin Bros., Eastport, Me. Presented by E. G. Blackford, New York.

Salted anchovies.

26565-68 3 "Krauter anchovies, Christiania." New York. Eagle Preserved 26571-72 Fish Company.

26559. Anchovies.

Canned herring, in oil, "Russian sardines."

26562. Russian sardines.

26563-26570. "Russische Sardinen." Adlerbrand. Prima qualitat. "Reval."

New York. Eagle Preserved Fish Company.

Caviare, prepared from roe of the various sturgeons.

12129. Caviare. Prepared from the eggs of the lake sturgeon (Acipenser rubicundus). Lake Erie. Schacht \& Bros., Sandusky, Ohio.

26558. Caviare.

26635. American caviare. Max Ams, New York.

26634. Prime Russian caviare. (Patented Nov. 9, 1875.) H. Dittman, Hamburg. Max Ams, New York. 


\section{Fish preparations.}

Pickled fish preparations.

26555. Pickled eels (Anguilla bostoniensis).

26633. American eels (pickled eels). Max Ams, New York.

26636. "Hamburger aale" (cans) (pickled eels). Max Ams, New York.

26630. "Hamburger aale" (pickled eels in jelly). Max Ams, New York.

26631. "Hamburger aale" (whole eels rolled and pickled with olives, capers, and mushrooms). Max Ams, New York.

26629. Hamburger aale (boxes). Max Ams, New York.

26632. Hamburger aale. G. Dittman, Hamburg. Max Ams, New York.

Extract of fish.

26749. Extract of fish. Made from the juices of the flesh of fishes (menhaden). S. L. Goodale, Saco, Me.

\section{Preparations of mollusks.}

Canned clams.

Canned Little Neck clams.

Canned scollops.

Cockles (Cardium edule), used in Europe as pickles and catsup.

See supplementary catalogue of Invertebrates.

\section{Gelatines.}

Mammal gelatimes (see, also, under 24)

Gelatines made from tanners refuse and from sinews.

Gelatines made from feet and hoofs.

Gelatines made from bone and ivory shavings.

\section{Bird gelatines.}

(Nests of esculent swallows (Calocalia esculenta, C. fuciphaga, C. indifica, \&c.), exported from Indian Archipelago to China.)

Fish gelatines or isinglass (see, also, under 24 ).

\section{Insect gelatine.}

Gelatine from cocoons of silk-worms.

\section{BAITS AND FOODS FOR ANIMALS.}

Prepared baits. (See under $\mathrm{B}, 45$ :)

\section{Food for domesticated amimals.}

Oil-factory scraps.

- Fish-scraps.

Cuttle-fish bone (see under 18). 


\section{CLOTHING.}

6. Furs (embracing the furs in their rough state (peltries), and in the various stages of preparation; also the manufactured articles, such as robes, rugs, cloaks, sacks, tippets, cuffs, muffs, hats, caps, gloves, trimmings, and linings).

\section{Mammal furs.}

Puma (Felis concolor), used for carriage-robes, rugs, \&c.

H. 67. Missouri. C. A. Herpich \& Co.

Ocelot (Felis pardalis) used for rugs.

12509. Texas. Smithsonian Institution.

Jaguar (Felis onca), used for rugs.

- Texas. Smithsonian Institution.

Cat (Felis domestica), used for robes and philosophical apparatus:

Black cat.

White cat.

Maltese cat.

Tortoise-shell cat.

H. 64. Natural. United States. C. A. Herpich \& Co.

H. 65. Dyed brown. United States. C. A. Herpich \& Co.

Canada lynx (Lynx canadensis), used for rugs and trimmings and dyed muffs, boas, \&c.

24754. Labrador. G. R. Renfrew \& Co., Quebec.

Bay lynx (Iynx rufus), used for rugs, and, when dyed, muffis and boas.

H. 61. Natural. Minnesota. C. A. Herpich \& Co.

H. 62. Dyed brown. Kansas.

H. 63. Dyed black.

"6

H. 59. Dyed black.

H. 60. Dyed brown.

6

6

- Eskimo dog (Canis sp.), used for rugs, \&c.

24756. Labrador. G. R. Renfrew \& Co., Quebec.

Wolf (Canis lupus), used for lining rugs and robes.

12508. Black variety.

H. 75. Gray variety. Kansas. C. A. Herpich \& Co.

24753. Labrador. G. R. Renfrew \& Co., Quebcc. 


\section{Mammal furs.}

Coyote or prairie-wolf (Canis latrans), used for rugs and robes.

H. 75. Colorado. C. A. Herpich \& Co.

1014. Smithsonian Institution.

Red fox (Vulpes fulvus) used for robes.

24757. Labrador. G. R. Renfrew \& Co., Quebec.

H. 34. Connecticut. C. A. Herpich \& Co.

H. 35. Indiana.

H. 3. Missouri.

Silver fox (Vulpes alopex, var. argentatus), used for muffs and trimmings.

24759. Labrador. G. R. Renfrew \& Co., Quebec.

Cross fox (Vulpes alopex, var. decussatus), used for robes and trimmingś.

24758. Labrador. G. R. Renfrew \& Co., Quebec.

H. 30. Montana. C. A. Herpich \& Co.

Arctic fox (Vulpes lagopus).

24760. Labrador. G. R. Renfrew \& Co., Quebec.

H. 29. White Aretic. C. A. Herpich \& Co.

H. 28. Blue Labrador.

Kit fox (Vulpes velox) used for robes, muffs, trimmings.

H. 37. Nebraska. C. A. Herpich \& Co.

Gray fox (Urocyon virginianus), used for robes, rugs, and linings.

H. 32. Michigan. C. A. Herpich \& Co.

H. 33. North Corolina.

American or Hudson's Bay sable (Mustela americana), used for cloaks, muffs, cuffs, boas, linings, \&c.

4393. Summer Arctic coast. . B. R. Ross.

10176. Alaska. Lieut. F. M. Ring.

4389. Aretic coast, B. R. Ross.

460. Fort Boise, M. T. Dr. Geo. Suckley.

24764. Orange. Labrador. G. R. Renfrew \& Co., Quebec.

24763. Silver. " " "

24762. Black. " " " "

H. 25. Labrador. Smithsonian Institution.

H. 25. N. W. coast. " " "

H. 26. Lake Superior. " " "

H. 27. Maine.

6 6

Fisher or pekan (Mustela Pennanti) used for linings; tails used for trimmings.

3230. Fort Crook, Oreg. Capt. Gardiner.

1008. Fort Dalles, Oreg. Dr. Geo. Suckley.

2000. Steilacoom, Wash.

1009. Fort Dalles, Oregon.

"

24761. Black. Labrador. G. R. Renfrew \& Co., Quebec. 


\section{Mammal furs.}

Ermine or weasal (Putorius erminea) of northern hemisphere, used for cloaks, linings, \&c.

24765. Labrador. G. R. Renfrew \& Co., Quebec.

H. 39. (5 specimens.) United States. C. A. Herpich \& Co.

Mink (Putorius vison), used for cloaks and muffs.

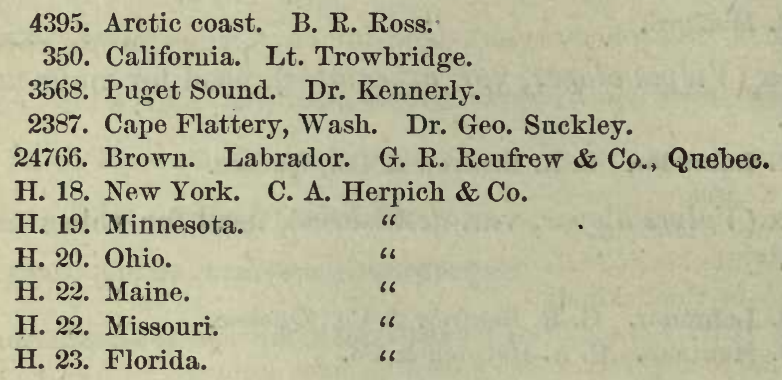

Wolverine (Gulo luscus), used for muffs, robes, linings.

24767. Labrador. G. R. Renfrew \& Co., Quebec. 11339. Filmore, Utah. Lieut. Geo. M. Wheeler. 4379. Fort Simpson, H. B. T. Robt. Kenuicott.

American badger (Taxidea americana), used for muffs and rugs.

26609. Southern Utah. U. S. Engineer Corps.

H. 70. United States. C. A. Herpich \& Co.

Skunk, Alaska sable (Mephitis mephitica), used for muffs, boas, \&c.

81. Washington, D. C. S. F. Baird.

H. 7. Black. Ohio. C. A. Herpich \& Co.

H. 8. Half-striped. Pennsylvania. C. A. Herpich \& Co.

H. 9. Striped. Connecticut.

H. 10. White. Missouri.

Striped skunk (Spilogale zorilla).

11136. Marsh Valley. Dr. F. V. Hayden.

Otter (Lutra canadensis), with specimens of the plucked and dyed fur, used for muffs, trimmings, \&c.

2803. White River. Puget Sound. Dr. George Suckley.

24768. Labrailor. G. R. Renfrew \& Co., Quebec.

25752. Dressed by G. C. Treadwell \& Co., Albany, N. Y.

25753.

25763.

،

H. 41. Natural. Maine. C. A. Herpich \& Co.

H. 42. Natural. Plucked. Canada. C. A. Herpich \& Co.

H. 43. Natural. Plucked and dyed. New York. C. A. Herpich \& Co. 
ANIMAL RESOURCES AND FISHERIES OF UNITED STATES. 191

\section{Mammal furs.}

Sea otter (Enhydra marina), used for muffs, gloves, collars, cuff's, trimmings.

12262. St. Paul's Island, Alaska. H. W. Elliott.

12265. 66 66 66 64

H. 44. California. C. A. Herpich \& Co.

H. 45. Silver tipped. California. C. A. Herpich \& Co.

Black bear (Ursus americanus), used for caps, rugs, muffs, robes, \&c.

24769. Labrador. G. R. Renfrew \& Co., Quebec.

247\%0. "6 "6

H. 75. Minnesota.

H. 76. Kansas.

H. 77. West Virginia.

12510. White bear (Thalarctos maritimus), used for rugs, robes; extensively by the Eskimos.

19904-5. Grizzly bear (Ursus horribilis), used for rugs, robes, trimmings.

12507. Raccoon (Procyon lotor), used for hats, linings:

H. 1. Natural. Northern New York. C. A. Herpich \& Co.

H. 2. Natural. Ohio.

H. 3. Natural. Virginia.

66

H. 4. Natural, plucked. Wisconsin.

H. 5. Djed black. Michigan.

66

H. 6. Dyed black and silver pointed. Michigan. C. A. Herpich \& Co.

Fur seal (Callirhinus ursinus) used for cloaks, hats, gloves, muffs, linings, trimmings, \&c.

12513-14-15-16-17-18. St. Paul's Island, Alaska. H. W. Elliott.

9526. Unplucked. Hutchinson, Kohl \& Co., San Francisco, Cal.

95:7. Unplucked. Alaska. Hutchinson, Kohl \& Co.

25\%5\%. Unplucked. Prybilov Islands, Alaska. Hutchinson, Kohl \& Co.

¿5758. London dye. Alaska. C. A. Herpich \& Co.

H. 93. " " "

2*233. Unplucked. Alaska. G. C. Treadwell \& Co., Albany, N. Y.

2:3234. Plucked. South Sea. "6

26610. Unplucked pelt of fur seal. Alaska.

26611. Plucked 6 . 66 66 .

26612. Plucked and dressed pelt of fur seal. Alaska.

26613. Plucked and djed pelt of fur seal. Alaska. Alaska Commercial Company.

Antarctic fur-seal (Arctocephalus aucklandicus), \&c.

25762. Dressed by G. C. Treadwell \& Co. Islos de Diego Ramires.

$25 \pi 61$.

25760 .

25759.

25756.

25755.

25754.

26804-5-6-7. Deposited by Duryea \& Hallet, Rahway, N. J.
Sonth Georgia Islands.

Staten Land, South Atlantic. South Shetland Islands.

$$
\text { "6 }
$$

66 


\section{Mamanal furs.}

Banded seal (Histriophoca equestris), used by Eskimos as fur.

7580. (Bag). Cape Romanzoff. W. H. Dall.

Square flipper seal (Erignathus barbatus).

12422. Labrador. Governor of Newfoundland.

Pacific hair seal (Phoca Richardi ?).

H. 89. White coat. Pacific. C. A. Herpich \& Co.

H. 90. White coat, silver pointed. Pacific. C. A. Herpich \& Co.

Hood or bladder-nose seal (Cystophora cristata).

12424. Young. Labrador. Governor of Newfoundland.

12425. Bedlamer (1 year old). Labrador. Governor of Newfoundland.

12423. Labrador. Governor of Newfoundland.

Harp seal (Pagophilus groenlandicus), with specimens of the white fur of the unborn cub and the blue fur of the young.

11828. Unborn. Newfoundland. Michael Carroll.

12427. Labrador. Governor of Newfoundland.

12421. Young. Labrador. Governor of Newfoundland.

12426. Bedlamer. "6 "6

13134. Sack made from white fur. Greenland. S. F. Baird.

Hair seal (Phoca vitulina), used for coats, caps, linings for shoes.

24771. Labrador. G. R. Renfrew \& Co., Quebec.

H. 91. Dyed black. Halifax. C. A. Herpich \& Co.

H. 92. Dyed brown. "6 "6

Bison, or buffalo (Bison americanus) used for rugs and robes.

H. 82. Full furred winter.

H. 83. Fall robe. Montana. C. A. Herpich \& Co.

H. 84. Summer robe. " "

H. 85. Indian painted. "

H. 86. Yearling calf. "6

66

H. 87. Medium calf. " "

H. 88. Small calf. "

Musk ox (Ovibos moschatus) used for robes, rugs, and trimmings.

12520. Hudson's Bay Territory.

12519. Calf. Hudson's Bay Territory.

Mountain sheep (Ovis montana).

H. 80. Montana. C. A. Herpich \& Co.

Antelope (Antilocapra americana).

H. 81. Indian Territory. C. A. Herpich \& Co. 
ANIMAL RESOURCES AND FISHERIES OF UNITED STATES. 193

\section{VII ammal Cüs}

Elk (Cervus canadensis), used for rugs and robes.

H. 78. Montana. C. A. Herpich \& Co.

Virginia deer (Cariacus virginianus).

12512. Virginia deer, used for trimmings and robes.

Black-tailed deer (Cariacus columbianus), used for robes and rugs.

11604-11605. Prepared by MeCloud River Indians, California. Livingston Stone.

3565. Puget Sound. Dr. Kennerly.

Mule deer (Cariacus macrotis), used for trimmings, robes.

H. 99. Montana. C. A. Herpich \& Co.

Woodland caribou (Tarandus.rangifer, subspecies caribou), used for rugs, robes, \&c.

24774. Labrador. G. R. Renfrew \& Co., Quebec.

Barren ground caribou (Tarandus rangifer, subspecies gronlandicus).

12363. (Albino.) F. Churchill, Hudson's Bay; W. W. Kirkby.

2050. (Young.) Robe from Mackenzie's River, H. B. T. R. Kennicott.

Moose (Alces malchis), used for rugs and robes.

247\%2. Labrador. G. R. Renfrew \& Co., Quebec.

Mole (Scalops and Condylura sp.), used for robes and garments.

H. 72. United States. C. A. Herpieh \& Co.

Woodehuck or siffleur (Arctomis monax) robes, exported to Europe as "white and gray weenusk."

24776. Labrador. G. R. Renfrew \& Co., Quebec.

H. 71. United States. C. A. Herpich \&. Co.

Marmot (Arctomys caligatus), used for robes and trimmings.

835. Robe. Indians of Rocky Mountains, west of Fort Good Hope, H. B. T. R. Kennicott.

Chinohilla (Chinchilla laniger) of South America, used for muffs, mantles, boas, cloak-linings, and trimmings.

H. 103. Real. Bolivia. C. A. Herpich \& Co.

H. 104. Bastard. Chili.

Parry's marmot (Spermophilus Parryi).

20793. Robe. Sitka, Alaska. J. G. Swan.

835. Robe. Indians of Rocky Mountains, west of Fort Good Hope, H. B. T. R. Kennicott.

Bull. N. M. No. $14-i 3$ 


\section{VIammal furs.}

Musquash (Fiber zibethicus), used for muffs, eapes, caps, and Imings and imitations of beaver fur.

24779. Labrador. G. R. Renfrew \& Co., Quebec.

24780. Black variety. Labrador. G. R. Renfrew \& Co., Quebec.

H. 12. Natural brown. Maine. C. A. Herpich \& Co.

H. 13. Natural brown. Indiana. " "

H. 14. Natural black. New Jersey. “

H. 15. Plucked and dyed. C. A. Herpich \& Co.

H. 16. Plucked and colored.

Neutria, or coypu (Myopotamus coypus), used for linings and muffs, and imitations of beaver.
H. 105. Plucked. Buenos Ayres.
C. A. Herpich \& Co.

Beaver (Castor canadensis), used for linings and muffs.

1230. Spotted albino. Bristol Bay, Alaska.

24777. American. Labrador. G. R. Renfrew \& Co., Quebec.

24778. " " " "

12506. White.

H. 46. Dyed and silver tipped. Hudson's Bay Territory. C. A. Herpich $\&$ Co.

H. 47. Dyed and silver tipped. Canada. C. A. Herpich \& Co.

H. 48. Dyed and plucked. Lake Superior.

H. 49. Natural. Lake Superior.

H. 50. Natural, in hair. Kansas.

66

"

6

Hare (Lepus, various species).

H. 58. United States. C. A. Horpich \& Co.

19615. Fur blanket. Pi-Ute Indians. Walker Lake, Nevada. Stephen Powers.

Rabbit, or cony (Lepus cuniculus), used for children's furs, and imitations of seal, beaver, \&c., exported largely to China.

H. 51. Dyed brown, sheared. United States.

H. 52. Natural blue.

H. 53. Natural white.

66

H. 54. Dyed black.

H. 55. Natural blue.

H. 56. Natural white.

66

66

66

H. 57. Gray. United States. C. A. Herpich \& Co.

Possum (Didelphys virginianus).

H. 17. Ohio. C. A. Herpich \& Co.

Mountain cat (Bassaris astuta).

H. 66. Montana. C. A. Herpich \& Co.

H. 11. Missouri. 
ANIMAL RESOURCES AND FISHERIES OF UNITED STATES. 195

\section{Bird furs.}

Loou (Colymbus torquatus).

1302. Used by Makah Indians in manufacture of robes. Nevah Bay, Washington Territory. J. G. Swan.

1296. Robe from down of. Neeah Bay, Washington Territory. J. G. Swan.

Swan's (Cygnus americanus) furs and swan's down trimmings.

H. 101. I. United States. C. A. Herpich \& Co.

H. 102. II.

"

66

Brown pelican (Pelecanus fuscus).

9559. Tiburon Islands, Sonora. E. Palmer.

Goose (Anser sp.).

H. 99. United States. C. A. Herpich \& Co.

H. 100. United States.

7. LEATHER. (See under 20.)

8. TeXtile FABRICS.

\section{Prepared from hair of mammals.}

Human hair used in manufacture of watch-chains.

Hair of bats used in felting and in plaiting ropes in Central America and tassels in New Caledonia.

Hair of raccoon used in felting (largely exported to Germany for the use of hatters).

Hair of weasels and sables used in felting.

Hair of fur seal woven with silk in the manufacture of shawls. Moose hair and its fabrics.

Ox and calf hair used in the manufacture of imitation woolen goods. Sheep's wool, with specimens of fleeces and stapled wools, fiom various breeds and localities, short-wool fabrics, broadeloths, merinoes, flannels, mouselins de laine, serges, tweeds, blankets, carpets, and tartans, worsted fabrics, stuffs, bombazines, canlets, shawls, plushes and velvets, hosiery, and yarns, felts, felt-cloths, and felt-hats.

Goats' wool with specimens of mohairs, cashmeres, plushes, velveteens, camlets, and shawls. (For manufactured wigs and perukes, see under 21.)

(Yak (Poëphagus grunniens) wool with specimens of yak-lace and other fabrics.)

(Camels' hair with specimens of fabries, plushes, felts, shawls, \&c.)

(Hair of llama, paco, guanaco, and vicugna, with specimens of alpaca, guanaco, and other fabrics, and umbrellas and other articles manufactured.) 


\section{Prepared from hair of mammals.}

Hair of horses used in weaving furniture-covers, crinoline-skirts, and bags for pressing oil.

Hair of buffalo used in plaiting ropes, lariats, \&c.

Fur of mole used in felting.

Beaver (castor) fur with specimens of the felt cloths, hats, dec.

(Neutria-fur used in felting and in the manufacture of hats.)

Musquash fur used in felting.

Possum hair with fabries of Indian and other manufacture.

Fur of rabbit and hare used in felting, with specimens of hats and cloths.

Whalebone fiber used in weaving eloth covers for telescopes, \&c.

\section{Prepared from feathers of birals.}

Cloths woven from feather (China).

Prepared from silk of insects. (This collection should include specimens of the cocoons, the raw silk, the spun silk, and of the various fabrics, plain and figured silks, satins and satinettes, shawls, damasks, brocades, crapes, and ribbons.)

Silk of common silk-worm (Bombyx mori).

Silk of Samia cecropia, Samia polyphemus, and other native American moths.

(Silk of exotic moths other than Bombyx mori, such as the tussah (Bombyx pernyi and Bombyx mylitta), the moonga (Saturnia assumensis), the joree (Bombyx religiosa), the ena or arindy (Bomby.x cynthia).)

Fabrics woven by the insects themselves, as Tinea padilla.

Silk of spiders.

\section{Prepared from byssus of mollusks.}

(Fabries woven from byssus of the wing-shell (Pinna nobilis) and other mollusks.) 


\title{
III. MATERIALS EMPLOYED IN THE ARTS AND MAN- UFACTURES.
}

\author{
Hard materials.
}

9. IVORY AND BONE.

\section{Irory of mammals.}

Tusks of walrus used for trinkets, handles, jewelry, buttons, paperknives, counters, \&c.

25656. Tusks of walrus (Rosmarus obesus). Alaska. C. H. Crandall.

15592. Commercial walrus ivory. Poonook, Alaska. H. W. Elliott.

16174. Teeth of young walrus (Rosmarus obesus). Used in making powder chargers. Nunivak Island, Alaska. W. H. Dall.

24819. Ivory of walrus in rough state. Joseph Shardlow, New York.

24887. Scrimshawed tooth of walrus (Rosmarus). (Figure of lady.) Geo. Y. Nickerson, New Bedford, Mass.

24886. Scrimshawed tooth of walrus (Rosmarus). (Figure of lady and horse.) Geo. Y. Nickerson, New Bedford, Mass.

26896. Scrimshawed tooth of walrus (Rosmarus Cookii). Repulse Bay. Capt. H. C. Chester, Noank, Conn.

25654. Harpoon head made at sea from walrus tusk. J. H Bartlett \& Sons, New Bedford, Mass.

2631. Handle of walrus ivory. Northwest coast, America. United States Exploring Expedition. Capt. Chas. Wilkes, U. S. N.

24815-6. Cane handles of walrus ivory. Joseph Shardlow, New York. 24812. Chain and cross of walrus ivory.

24814. Knobs of walrus Ivory.

24813. Scarf-slide of walrus ivory.

24817-18. Sword handles of walrus ivory.

248:20-21-22. Knife handles of walrus ivory.

24823. Crochet-needles of walrus ivory.

24824. Pool-balls of walrus ivory.

"6 "6

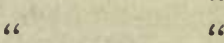

"6 6

6 6

6 6

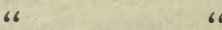

24825-6-7-8-9-30-31-32. Buttons and studs of walrus ivory. Joseph Shardlow, New York.

Teeth of bears, dogs, wolves, foxes, pecearies, and other large mammals, used as implements, arrow-tips, and ornaments, by Indians.

6226. Bear tecth (used as ormaments). Bloomfield, N. Y. Col. E. Jewett.

Elk ivory (used by Indians for ornamentation).

1874. Ivory of elk (Cervus canadensis). Yamp Utah Indians, Utah. Captain Gunnison, U. S. A.

Tusks of mammoth elephant (Elephas primigenius) from Northern America and Asia, with Eskimo carvings. ${ }^{1}$

15385. Tusk of mammoth. Alaska. J. G. Swan.

11041. Comb. Made from the ivory of fossil elephant. Saint Michael's, Alaska. W. H. Dall.

'An interesting series of aboriginal carvings from mammoth ivory is displayed in the Ethnological division; 


\section{Irory of mammals.}

\section{Teeth of peccary (Dicotyles sp.). ${ }^{1}$}

Ivory of narwhal (Monodon monoceros), used for canes.

- Tusks of narwhal. Greenland. U. S. Fish Commission.

13521. Cane made from tusk of narwhal. Eskimos of North Greenlanit. F. T. Commagere.

Teeth of sperm-whale (Physeter macrocephalus) and their application to the manufacture of balls, buttons, and trinkets.

25653. Teeth of sperm-whale. J. H. Bartlett \& Sons, New Bedford, Mass. 25710. Teeth of cow whale. Capt. Joseph Fisher, Provincetown, Mass. 25719. Teeth of sperm-whale. Andrew Kennedy, Provincetom, Mass. 24906-8. 'Teeth of sperm-whale, polished. J. H. Clark, Newport, R. I.

25709. Teeth of the cow whale (scrimshawed). Capt. Joseph Fisher, I :ovincetown, Mass.

7428. Tooth of sperm-whale. Scrimshawed with British coat of ains and female figure. J. Varden.

24905. Tooth of sperm-whale. Scrimshawed and mounted as watch cise, figure of American eagle. J. H. Clark, Newport, R. I.

24904. Tooth of sperm-whale. Scrimshawed with figure of crucifix and flowers. J. H. Clark, Newport, R. I.

24901. Tooth of sperm-whale. Scrimshawed with figure of whaling-ship. J. H. Clark, Newport, R. I.

24902. Tooth of sperm-whale. Scrimshawed with figure of America in colors. J. H. Clark, Newport, R. I.

24903. Tooth of sperm-whale. Scrimshawed with figure of girl daneingJ. H. Clark, Newport, R. I.

7659. Tooth of sperm-whale. Scrimshawed with this legend: "Taken * by $*$ the $*$ ship $*$ Montreal $*$ of $*$ London $*$ in $*$ the $*$ Pacitic * Ocean $*$ from *a $*$ one $*$ hundred $*$ barrel $*$ whale $*$ - $-*$ 1835 *." Mrs. Dove, Washington, D. C., 1842.

24888. Tooth of sperm-whale. Scrimshawed with figure of General Washington and American eagle. Geo. Y. Nickerson, New Berifo:d, Mass.

24889. Tooth of sperm-whale. Scrimshawed with figure of General Secrit and American eagle. Geo. Y. Nickerson, New Bedford, Mass.

7660. Tooth of sperm-whale. Scrimshawed with figure of pagoda. 8? Pacific Ocean. United States Exploring Expedition. Capt. Charles Wilkes, U. S. N.

25792. Tooth of sperm-whale (scrimshawed) Malcolm McFa!lyn, Gloncester, Mass.

24836. Balls turned from teeth of sperm-whale. Joseph Shardlow, New York.

Incisors of beaver (Castor canadensis) used by Indians for chisels, knives, and ornaments.

2684. Dice. Made from teeth of beaver. Oregon Indians. United States Exploring Expedition. Capt. Charles Wilkes.

Interesting applications of this material may be found in the Ethnological series. 


\section{Ivory of pentiles.}

Teeth of alligator used for jewelry, whistles, cane-handles, buttons, dic.

26895. Jewelry manufactured from teeth of alligator (Ailigator mississipiensis). E. F. Gilbert, Jacksonville, Fla.

An extensive trade in alligator teeth has sprung up within the last ten rears. Ten establishments in Eastern Florida are engaged in their manufacture into fancy articles.

\section{Ivory of fishes.}

Sharks' teeth used in arming weapons. ${ }^{1}$

Teeth of sharks and other fish used as trinkets.'

Jaws of the sleeper-shark (Scmniosus brevipinna) used for headdresses by Indians.

- Coronet of shark's teeth. Gulf of Saint Lawrence. G. R. Renfrew \& Sons, Quevec.

\section{Bone of mammals.}

Parts of splanchno-skeleton of feræe, used as charms.

- Os penis of raccoon, used as charn.

94і6. "Os mirabilis" of walrus. Alaska. Gen. Geo. H. Thomas, U. S. A.

Bones of bear and other large mammals, used by Indians for implements and as tablets for paintings. ${ }^{1}$

Bones of buffalo and of the domestic ruminants, used as substitute for ivory in the manufaeture of buttons, handles, combs, \&c.

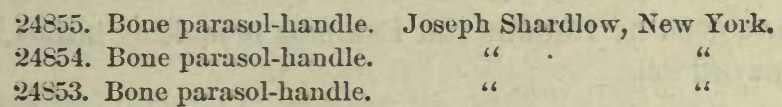

24852. Bone counters. Joseph Shardlow, New York.

24851. Bone shields. " " "

24850. Bone cribbage-pins. " " " "

24849. Bone dice. " " "

2484:-4-5-6-7-8. Bone brush-handles. Joseph Shardlow, New York.

24842. Bone martingale-rings.

2483\%. Bone napkin-rings.

24833-4-5-6. Bone parasol-handle.

"6 1 ".

19513. Bow. Made of bone. Greenland Eslimos. Geo. Y. Nickerson.

10:280. Bow. Made of bone. Eskimo. King William's Lant.

25673. Bone marlin-spike. Made at sea by Thomas Frecman. Used for splicing trawl-lines. Sanford Frecuan, Norwich, cr., $^{\prime}$, lass.

Sperm-whale jaw-bone, used for hamess-rings, martingales, \&c.

29:33-4-;-6-7-8-9-40. Parasol-handles mąde from sperm-whale's jaw. Harvey \& Ford, Philadelphia. 


\section{Bone of mammals.}

Sperm-whale jaw-bone, used for harness-rings, martingales, \&c.

29241. Paper-eutters, made from sperm-whale's jaw. Harvey \& Ford, Plhilalelphia.

24909. Chopping-knife. Made from jaw of sperm-whale. Prof. s. F. Baird.

25791. Sail-thimble. Made from bone of whale. J. W. Foster, Beverly, Mass.

25793. Seam-rubber. Used by sail-makers to rub along seams. Made from jaw-bone of sperm-whale. Frank Westerberger, Beverly, Mass.

25650. Sail-maker's hand-fid. Made at sea from jaw-bone of sperm-whale. A. R. Crittenden, Middletown, Conn.

25655. Saw-frame. Made at sea from bone of sperm-whale. J. H. Bartlett \& Sons, New Bedford, Mass.

25801. Pulley. Made from jaw-bone of sperm-whale. E. H. Cook, Provincetown, Mass.

25649. Pulley-block. Made at sea from jaw-bone of sperm-whale. A. R. Crittenden, Middletown, Conn.

25713. Seine-needle. Made from jaw-bone of sperm-whale. N. H. Payne, Wellfleet, Mass.

Horn-cores of ruminants, used in manufacture of assayers' cupels.

\section{Bone of birds.}

Bones of birds, used by Indians and Eskimos in making awls, needles, flutes, bird-calls, and dress-trimmings.

10333. Gambling-sticks. Made from bones of white crane. Mojave Indians. Dr. E. Palmer.

\section{Bone of fishes.}

Fish-bones, used by Indians and Eskimos in making implements. ${ }^{1}$

Bone of sword-fish.

25675. Shoemaker's tool. Made from sword of sword-fish (Xiphias gladius). Sanford Freeman, Norwichport, Mass.

Sharks' rertebræ, used for canes.

\section{Waste bone and ivory.}

Use in manufacture of bone-black, ivory-black, and bank-note ink (see under 29).

Use in manufacture of sizes and glues (see under 24).

Use in manufacture of gelatine for food (see under 4).

Use in manufacture of phosphorus, carbonate of ammonia (harts-

horn), and sal ammoniac (see under 30 ).

Use in manufacture of bone-charcoal for filters (see under 30 ).

Use in manufacture of paper.

Use of shavings in case-hardening gun-barrels and other fine steel. 


\section{Waste bone and ivory.}

10. Hons.

(Embracing the varieties of horn known to commerce, the split and pressed horns, and the various manufactured articles, such as jewelry, combs, and handles.)

Torn (employed as a material).

Horns of ox, sheep, and goat, used for handles, buttoms, combs, powder-flasks, cups, boxes, stirrups, spoons, and imitations of tortoise-shell, also "sensitive Chinese leaves," and formerly for transparent plates in lanterns and horn-hooks, for trumpets, and for finger-nails in lay figures.

2527\%. Cow's horns. Philip R. Woodford, Boston, Mass.

25274. Steer's horus. " " "

25276 . Bull's horus. "

Horn of buffalo, used like that of ox.

25278. Horns of buffalo bull. Philip R. Woodford, Boston, Mass.

25280. Horns of buffalo calf.

252\%9. Horns of buffalo cow.

"6 "6

"

8489. Spoon of buffalo horn. Assinaboin Indians. Fort Buford, Dakota Dr. J. P. Kimbail, U. S. A.

11030. Spoon of buffalo horn. Yellowstone Valley, Dakota. Lientenant Cusick.

Horn of musk ox (Ovibos moschatus).

11648. Arctic regions. Capt. C. F. Hall.

10389. Spoon made from horns of musk ox. Igloolik. Capt. C. F. Hall.

25:75. Ox horus. Philip R. Woodford, Boston, Mass.

Series of articles manufactured from horn. Geo. F. Lincoln, Leominster, Mass. :

29507. Horn as it comes from the press, cut out preparatory to making combs29508. Combs. Cut.

29509. Unfinished combs.

29510. Horn cut into small pieces for ase in manufacture of jewelry.

295\%1. Finished comb.

29502. Polished jewelry (uncolored).

Horn of mountain sheep and mountain goat, used by Aleutians in making spoons, bowls, and numerous other implements.

16809. Horus of mountain goat (Mazama montana). Used by Eskino for making horn spoons. Alaska. W. H. Dall.

20623-4. Spoon made from horn of mountain goat. Bella Bella Indians. J. G. Swan.

9278. Spoon made from horn of mountain goat. Alaska. A. H. Hoff, U. S. A. 
Horm (employed as a material).

Horns of Rocky Mountain sheep (Ovis montana).

704. Spoon made from horn of Rocky Mountain sheep. Northwest coast. George Gibbs.

20842. Spoon made from horn of Rocky Mountain sheep. Haidah Indians. Prince of Wales Island, Alaska. J. G. Swan.

14455. Spoon made from horn of Rocky Mountain shoep. Pi-Ute Indisns. Maj. J. W. Powell.

\section{Antlers.}

Antlers of deer, elk, and moose (stag horn), used in the manufacture of handles for instruments, trinkets, and buttons.

26229-2:-30. Carving from horn of deer (Cariacus virginianus). Harvey \& Ford, Philadelphia.

21312. Spoon carred fron antler of elk (Cervus canadensis). Hoopah Indians, California. S. Powers.

Antlers of deer, elk, moose, and nearly all species of ruminants, employed for ornamental purposes. (A series of these antlers is used in the decoration of the columns in the Government building.)

\section{Chemical and other applications.}

Purnt horn (corn: ustum) used in dentifrices.

Carbonate of aminonia (hartshorn), manufactured from deer horns.

(See under 30.)

11. Hoofs AND Claws, \&c.

(Embracing the commercial hoof, and the various stages of manufacture represented by specimens.)

\section{Hoofs.}

Hoofs of ox and bison, used in making buttons, combs, and handles.

23901. Conınercial hoof. Philip R. Woodford, Boston, Mass.

Series of articles made from hoof. Geo. F. Lincoln, Leominster, Mass. :

29516. Dust made from the hoof.

29517. Belt buckle.

- 29518. Martingale rings.

29519. Breastpin.

29520. Cross for neck wear.

29521. Breastpin.

Hoofs of horse, used like those of ox and bison.

Hoofs of inusk ox, deer, and antelope, used by Indians in ornamentation.

7443. Iloofs of musk ox. Used for trimming of garments by Eskimos Mackenzie's River. R. MacFarlane.

Feet of deer, used for knife-handles, stool-feet, \&c. 
ANIMAL RESOURCES AND FISHERIES OF UNITED STATES. 203

\section{Claws.}

Claws of bear, puma, wolf, \&c., used by Indians in ornamentation. (See Ethnological series.)

Human nails, used by Indians for ornamental trimming.

\section{Chemical application of hoofs and claws.}

Use in manufacture of prussiate of potash (see under 30 ).

Use in manufacture of glue (see under 24).

\section{BALEEN.}

\section{Whalebone in an unmanufactured state.}

14042. Baleen of humpback whale (Megaptera versabilis). Coast of California, 1873. C. M. Scammon.

12311. Bone of hunpback whale (Megaptera versabilis). Coast of California. C. M. Scammon.

13893. Baleen of humpback whale (Megaptera versabilis). Monterey, Cal. 1873. C. M. Scammon.

13019. Baleen of humpback whale (Megaptera versabilis). Monterey, Cal. 1872. C. M. Scammon.

12263. Baleen of humpback whale (Megaptera versabilis). San Luis, Cal. C. M. Scammon.

13020. Baleen of humpback whale (Megaptera versabilis). San Luis, Cal. C. M. Scammon.

13955. Baleen of sulphur-bottom whale (Sibbaldius sulfureus). Monterey, Cal. C. M. Scammon.

13981. Baleen of sulphur-bottom whale (Sibbaldius sulfurcvs). Monterey, Cal. C. M. Scammon.

12052. Bone of the California gray whale (Rhachianectes glaucus). Monterey, Cal. 1873. C. M. Scammon.

15402. Baleen. North Pacific. Capt. Henderson.

7494. Whalebone. Anderson River Eskimos. Mackenzie's River district. R. MacFarlane.

1108. Whalebone. Prepared by Anderson River Eskimos. MackenziogRiver district. R. MacFarlane.

1116. Whalebone. Anderson River Eskimos. Mackenzie's River district. R. MacFarlane.

2079. Whalebono. Aretic coast. R. MacFarlane.

24976. Whalebone fiber. Curled for bed-stuffing. J. A. Sevey, Boston, Mass.

24930. Whalebone. Prepared for whip-makers' use. J. A. Sevey, Boston, Mass.

24862. Whip with whalebone stock, knotted, inlaid with whale-tooth's ivory, handle wound with thin whalebone. American Whip Co., Westfield, Mass.

24950. Dress-bone. Whalebone prepared for dress-makers' use. J. A. Sevey, Boston, Mass.

24946. Whalebone. Prepared for suspender-makers' use. J. A. Sevey, Boston, Mass.

24945. Whalebone. Prepared for bonnet-makers' use. J. A. Sevey, Baston, Nass.

24941. Whatebone. Prepared for umbrella-makers' use. J. A. Sevoy, Boeton. Mass. 


\section{Whalebone in an unmanufactured state.}

24940. Whalebone. Prepared for parasol-makers' use. J. A. Sevey, Boston, Mass.

24951. Gross dress-bone. Whalebone prepared for dress-makers' use. J. A. Sevey, Boston, Mass.

24948. White dress-bone. Whalebone (white) prepared for dress-makers' use. J. A. Sever, Boston, Mass.

24978. Whalebone. Prepared for brush-makers' use. J. A. Sevey, Boston,

24942. Whalebone. Prepared for ribbon-weavers' use.

24943. Whalebone. Prepared for hat-makers' nse.

[Mass.

24944. Whalebone. Prepared for eap-makers' nse.

24947. Whalebone. Prepared for neck-stock-makers' use.

24952. Whalebone. Prepared for corset-makers' use.

$\begin{array}{cc}6 & \text { [Mass. } \\ 6 & 6 \\ 6 & 6 \\ 6 & 6 \\ 6 & 6\end{array}$

24949. Round dress-bone. Whalebone prepared for dress-makers' use. J. A. Serey, Boston, Mass.

24977. Whalebone fiber. J. A. Sevey, Boston, Mass.

24938. Whalebone cane. Black and white, twisted. J. A. Sevey. Boston,

24973. Whalebone boot-shanks.

2493\%. Whalebone tongue-serapers.

24933. W'halebone probang.

[Mass.

24935. Whalebone riding-whip, made of black and white whalebone, twisted. J. A. Sevey, Boston, Mass.

24934. Whalebove riding-whip. J. A. Sevey, Boston, Mass.

24937. Whalebone cane. Plain.

24936. Whalebone cane. Twisted.

24972. Whalebone graining-comb. Used by painters. J. A. Sevey, Boston,

24955. Whalebone probang.

24980. Whalebone caterpillar-brush.

24981. Whalebone shavings.

24933. Whalebone back-supporter.

24979. Whalebone flue-brush.

24975. Whalebone fiber shoe-brush.

24983. Whalebone. Sample.

24959. Whalebone divining-rod.

24958. Whalebone angling-rod tip

24955. Whalebone rosettes for harness.

24932. Whalebone landing-net rod.

24954. Whalebone hip busk bone.

24984. Whalebone. Price-list samples.

24970. Whalebone penholder. Black and white, twisted.

24961. Whalebone busk.

24934. Whalebone fore-arm bones. Artificial.

24968. Whalebone plait-raiser.

24939. Whalebone penholder.

24955. Manufactured corset, showing use of whalebone.

24953. Whalebone corset-clasps.

24960. Whalebone drill-bow.

24957. Whalebone billiard-cushion springs.

24971. Whalebone paper-cutter.

24985. Whalebone rule.

[Mass.

$\begin{array}{ll}66 & 66 \\ 66 & 66 \\ 66 & 66 \\ 66 & 66 \\ 66 & 66 \\ 66 & 66 \\ 66 & 66 \\ 66 & 66 \\ 66 & 6 \\ 66 & 66 \\ 66 & 66 \\ 66 & 66 \\ 66 & 66 \\ 66 & 66 \\ 66 & 66 \\ 66 & 66 \\ 66 & 66 \\ 66 & 66 \\ 66 & 66 \\ 66 & 66 \\ 66 & 66\end{array}$


ANIMAL RESOURCES AND FISHERIES OF UNITED STATES. 205

\section{Whalebone in an unmanufactured state.}

24860. Whalebone and rattan whip-stalk. Finished, ready for covering. American Whip Company, Westfield, Mass.

24858. Whalebone. As prepared for use in the whip. American Whip Company, Westfield, Mass.

24859. Whalebone and rattan. Fitted ready for sticking together for whipstalk. American Whip Company, Westfield, Mass.

24857. Whalebone. In rough state, as sold to whip manufacturers. American Whip Company, Westfield, Mass.

24982. Whalebone. Prepared for whip-makers' use (patent). J. A. Serey, Boston, Mass.

\section{TORTOISE-SHELL.}

Tortoise-shell (Eretmochelys squamata Linn.).

12357-8-9-90. Tortoise-shell (Eretmocholys squamata Linn.). Pacific hawk'obill turtle. Pacific coast.

24890. Commercial tortoise-shell. George Y. Nickerson, New Bedford, Mass. 26891. Tortoise-shell jewelry, \&c. Charles W. Kennard \& Co., Boston, Mass.:

Comb cut and polished.

Comb cut before polishing.

Brooch and ear-rings.

Sleeve-buttons.

Necklaco and locket.

\section{SCALES.}

Scales of fishes used in ornamental work, with specimens of flowers and other articles manufactured.

Fish-scale jewelry. F. C. Keergaard \& Co., Philarlelphia, Pa.:

25480. Scales of sheepshead (Avchosargus probatoccphalus).

25481. Scales of sheepshead (Archosargus probatocephalus). Prepared for use. 25482. Brooch and ear-rings. " " "

25483. Spray of flowers. " " "

254४4. Spray of flowers. " " " "

25485. Spray of flowers. " " "

25486. Spray of flowers. " " " "

2548\%. Spray of flowers (dyed). " " "

25488. Necklace and cross. " " " "

25489. Brooch andi ear-rings. " "

25490. Brooch and ear-rings (dyed) (Archosargus probatocephalus).

26892. Jewelry made from scales of mullet, drum, \&c. Mrs. C. E. Mott, Jacksomville, Fla.

(Pearl white, or essence d'Orient, prepared from scales of Alburnus lucidus and other Cyprinidae and Clupeida, used in making artificial pearls.) (See under 27.)

26893. Essence d'Orient. (Introduced for comparison.) Gustave Bossange, Paris. 


\section{Pearl.}

Pearls and nacre (embracing the pearl-yielding shells, with the pearls and the mother-o'-pearl in the rough state, with the manufactured buttons, handles, and jewelry, pearl-powder, inlaid work, and papier-maché, ornamented with mother-o'-pearl.

Top-shells (Turbinida), and their application to manufacture of shell-flowers.'

Tower-shells (Trochida). ${ }^{1}$

Ear-shells (Haliotidce), nsed in manufacture of buttons, handles, inlaid work, and pearl powder. ${ }^{1}$

Other gasetropods supplying nacre.'

Pearl-oysters (Aviculidoe), with pearls and nacre. ${ }^{1}$

River-mussels (Unionida), with pearls and nacre. ${ }^{1}$

Mussels, oysters, and other conchifers supplying pearls and nacre. ${ }^{1}$ Shells of nautilus and argonaut, prepared to exhibit their nacre. ${ }^{1}$

Ornamental pearl-work, imitating sprays of flowers, \&c. ${ }^{1}$.

Imitation pearls. ${ }^{1}$

\section{Cameo shell.'}

16. SHELL.

Shell of conch (Strombus gigas), and carvings. ${ }^{1}$

Shell of helmet (Cassis rufa, C. tuberosa, and C. madagascariensis), with carvings. ${ }^{1}$

\section{Shells uised for implements, dec. ${ }^{1}$}

Shells of Strombus, Triton, Dolium, Fusus, Murex, and Buccinum, used for fog-horns, lamps, vases, and ornamental borders in flowergardens. ${ }^{1}$

Shells of Busycon, Sycotypus, Mactra, \&c., used by Indians in manufacture of implements, with specimens of implements. ${ }^{1}$

Shells of Mactra, used for ladles, scoops, and spoons by fishermen. ${ }^{1}$ Shells of Tridacua, used for vases, fountains, and in the manufacture of handles and carvings. ${ }^{1}$

Shells of Pecten, Haliotis, Dentalium, Mercenaria, \&c., used by Indians for trimmings and ornaments. ${ }^{1}$

Shells of Pecten, used in making pin-cushions and purses. ${ }^{1}$

Shells of Mercenaria violacea, Purpura lapillus, and Buccinum undatum, used by Indians of eastern coast in manufacture of money, with specimens of wampum (with the modern wampum or shellbeads, manufactured for the Indian trade), and of the hyqua or Dentalium shells, employed in a similar manner by the Indians of the Pacific coast. ${ }^{1}$

Specimens of the cowry (Cypraea meneta), "live cowry" and dead cowry, used in African trade and for trimmings. ${ }^{1}$ 


\section{Shells used for implements, \&c.}

Shelli: of Cypraea, Rotella, Oliva, Turritella, Phasianella (Venetian shells), \&c., mounted as buttons and jewelry. ${ }^{1}$

Comrosition shell-work for box-covers and frames, made by gluing shells in mosaic. ${ }^{1}$

Calcined shells, used by dentifrice and porcelain makers. ${ }^{1}$ 'See, also, under 32.)

Cuttle-fish bone from Sepia officinalis, used as a pounce, as a dentifrice, as polishing powders, for taking fine impressions in counterfeiting, and as food for birds. ${ }^{1}$ (See, also, under D 5.)

Concretions from the stomach of Astacus, known as "crab's-eyes" and "crab-stones," and used as antacids."

Shell of king-erab (Limulus polyphemus), used as a boat-bailer.'

Opercula of mollusks, used as "eye-stones." "

\section{Coral.}

\section{Coral as a material.}

Red coral (Corallium nobilis), with specimens of the five commercial grades (1, froth of blood; 2, flower of blood; $3,4,5$, blood of first, second, and third qualities) of the white variety, and of the round beads, ncgligée beads, bracelets, pins, coronets, armlets, ear-rings, Se. ${ }^{1}$

White coral, Oculina, sp., used by jewelers. ${ }^{1}$

Madrepores and other showy corals, used for ornamental purposes. ${ }^{1}$

Horiny axis of black flexible coral (Plexaura crassa), used for canes and whips in the Bermudas. ${ }^{1}$

Axis of fan coral (Rhipidogorgia), used for skimmers and strainers in the Bermudas. ${ }^{1}$

Corci, used for building purposes. ${ }^{1}$

Coral rock of recent formation (Coquina), used in Florida in manufacture of ornamental vases and carvings. ${ }^{1}$

Calcined coral, used for dentifrices, as an antacid, \&c. ${ }^{1}$

Imitations of red coral in celluloid, rubber, and other substances. ${ }^{1}$

\section{INFUSORIAL EARTHS.}

Polishing powders (used for polishing metals, cabinet-ware, and stone).

Specimens of polishing slate, tripoli, and other foreign polishing powder. ${ }^{1}$

Specimens of American infusorial deposits. ${ }^{1}$ 


\section{In fusonial earths employed in manufactures.}

Infusorial earth, used in making window and plate glass. ${ }^{3}$ Infusorial earth, used in making soluble glass. ${ }^{1}$

Infusorial earth, used in making mortar. ${ }^{1}$

Infusorial earth, used in making molits for metal casting.

Infusorial earth, used in making filters. ${ }^{1}$

Infusorial earth, used in making dynamite. ${ }^{1}$

Infusorial earth, used in making fire-poof packing. ${ }^{k}$

Infuisorial earth, as an absorbent for oils and liquids. ${ }^{3}$

\section{OTHER MATERIALS FROM INVERTEBRATES.}

\section{From inasects.}

Brazilian diamond-beetles, used in jewelry.

Wings of beetles, used in embroidery.

\section{From echinoderms.}

Spines of echinoids, used for slate-crayons.

\section{Flexible materials.}

20. Leathers. (Embracing the hides in a rough state, in the various stages of dressing, and manufactured into shoe-leather, parchment, vellum, binders' leather, thongs, \&c.

\section{Leather prepared from mammal slkins.}

. Leather prepared from human skin.

260\%0. Boots made from skin of man. H. \& A. Mahrenholz, New York.

Sea-lion leather, used by Eskimos to cover bidarkas, and for garments and beds.

11371. Leather of sea-lion (Eumetopias stelleri). Used by Aleutian Islanders for mannfacture of canoe. Alaska. Vincent Colyer.

Walrus leather, used by Eskimos for harness, tables, thongs, sealnets, and for covering polishing-wheels.

15617. Harpoon-line of walrus leather. Alaska. H. W. Elliott.

Seal leather, used for fine shoes and in the manufacture of "patent leather," and by Eslimos for numerous purposes.

10186. Seal-skin bleached by hot water. Innuit Eskimos. Arctic Ocean. Capt. C. F. Hall.

1103. Seal-skin leather tanned by Eskimos. Mackenzie's River district. R. MacFarlane.

24785. Indian moccasins made from skin of seal (Phoca vitulina?) G. R. Renfrew \&: Co., Quebec. 


\section{Leather prepared from mammal skins.}

Bison leather (and buffalo leather, buff-leather).

25951. Imitation buckskin. Manufactured from skin of American bison (Bison americanus). Wilcox Tannery, Elk Connty, Pennsylvania. 25952. Collar leather. Manufactured from skin of American bison (Bison americanus). Wilcox Tannery, Elk County, Pennsylvania.

25954. Sole leather. Mannfactured from skin of American bison (Bison americanus). Wilcox Tannery, Elk County, Pennsylvania.

25953. Whang leather. Manufactured from skin of American bison (Bison americanus). Wilcox Tannery, Elk County, Pennsylvania.

Ox leather, with specimens of sole leather, split leather, grain leather, rawhide thongs, whips, leather belts and saddles, and of calf-skins, prepared for binders' and bootmakers' use, as Russia leather and vellum, and tawed, as parchment. ${ }^{1}$

Sheep leather, with specimens of binders' leather, imitation chamois leather, wash leather, buff leather, roan, imitation morocco and parchment, with vellum made from skins of dead-born lambs, and manufactured gloves, \&c. ${ }^{1}$

Goat leather, with specimens of shagreen leather, morocco leather, as used for linings, upholstery, bindings, and pocket-books, parchment, drum-heads, \&c., with kid leather, used in manufacture of shoes and gloves, under-clothing, and vellum made from skin of young kids, also skin bottles used in Asia. ${ }^{1}$

Horse and ass leather, used in manufacture of shagreen, sole leather, harness-leather, saddles, trunks, water-hose, pump-valves, military accouterments, ladies' shoe-uppers. ${ }^{1}$

8871. Tanned ox-skin, used for sole leather. Cheyenne Indians, Kansas. Dr. G. M. Sternberg, U. S. A.

Rawhide.

29549. Rawhide prepared for belting. Darrow Manufacturing Company. 29.546. Coil of rope. Made from rawhide. 29548. Basket.

29547. Doll's head.

29545. Powder-tlasks.

66

66

66
66

66

66

66

Deer leather, dressed as buff leather, chamois-imitation leather, Indian dressed (buckskin), and for the finer moroccos, also manufactured into gloves, gaiters, under-garments, polishers, \&c.

25232. Buck-tanned skin of mule deer (Cariacus macrotis). Indians.

6977. Leather from skin of deer (Cariacus macrotis?). Tanned by Caddo Indians. E. Palmer.

5554. Buck-tanned deer-skin (Cariacus macrotis). Apache Indians. E. Palmer.

14383. Buck-tanned skin of deer (Cariacus macrotis). J. W. Powell.

${ }^{1}$ In view of the extensive exhibition of leathers in the Shoe and Leather Building, no special effort has been made to complete this part of the collection.

Bull. N. M. No. 14-14 


\section{Leather prepared from mammal slinis.}

Deer leather, \&c.

6978. Buck-tanned skin of deer (Cariacus macrotis). Comanche Indians. E. Palmer.

11606. Buckskin (Cariacus columbianus). Dressed by McCloud Indians. Shasta County, California. Livingston Stone.

11605. Buckskin (Cariacus columbianus). Tanned by McCloud Indians. Shasta County, California. Livingston Stone.

11604. Buckskin (Cariacus columbianus). Tanned by MeCloud Indians. Shasta County, California. Livingston Stone.

8540. Buckskin for moceasins. Nebraska. Dr. S. M. Horton, U. S. A.

26885. Skin of Virginia deer (Cariacus virginianus). Seminole Indians of Florida. G. Brown Goode.

24800. Tanned skin of young Virginia deer (Cariacus virginianus). J. H. Henderson, Big Coon, Ala.

Moose leather in ordinary and buckskin finish.

24781. Moccasins made from skin of moose (Alces malchis). Huron Indians. G. R. Renfrew \& Co., Quebec.

24787. Rubber-sole moccasins made from skin of moose (dyed). G. R. Renfrew \& Co., Quebec.

24782. Indian moceasins made from skin of moose. Iroquois tribe. G. $R$. Renfrew \& Co., Quebec.

24773. Indian buck-tanned skin of moose (Alces malchis). Labrador. G. R. Renfrew \& Co., Quebec.

24786. Indian moceasins made from skin of moose. "Lady's size." G. R. Renfrew \& Co., Quebec.

838. Smoke-tanned skin of moose (Alces malchis). Slave (Lake?) Indians. R. Kennicott, Fort Liard.

Caribou leather in ordinary and buckskin fimish.

24775. Indian buck-tanned skin of caribon (Tarandus rangifer). Labrador. G. R. Renfrew \& Co., Quebec.

24783. Indian moccasins made from skin of caribou. "Man's size." G. R. Renfrew \& Co., Quebec.

24784. Indian moccasins made from skin of caribou. "Woman's size." G. R. Renfrew \& Co., Quebec.

Reindeer leather. ${ }^{1}$

836. Smoke-tanned skin of barren-ground caribou (Tarandus rangifer, subspecies grœnlandicus). Mackenzie's River district. R. Kennicott.

Elk leather in ordinary and buckskin finish.

8536. Elk-skin tanned with smoke. Nebraska. Dr. S. M. Horton, U. S. A.

Mountain-sheep leather.

8548. Buck-tanned skin of mountain sheep (Ovis montana). Nebraska. Dr. S. M. Horton, U. S. A. 


\section{Leather prepared from mammal skins.}

Series of different leathers illustrating the manufacture of gloves:

25286. Raw skin of "Maranham jack" deer (Cariacus sp.) from South America. S. G. Hutchinson \& Co., Johnstown, N. Y.

25287. Skin of "Maranham jack" deer, dressed by glove manufacturer, ready for cutting. S. G. Hutchinson \& Co., Johnstown, N. Y.

25288. Gloves manufactured from skin of "Maranham jack" deer. S. G. Hutchinson \& Co., Johnstown, N. Y.

25289. Raw skin of deer (Cariacus sp.). From Central America. S. G. Hutchinson \& Co., Johnstown, N. Y.

25290. Skin of deer dressed by glove manufacturers. Central America. S. G. Hutchinson \& Co., Johnstown, N. Y.

25291. Raw skin of mule deer (Cariacus macrotis). S. G. Hutchinson \& Co., Johnstown, N. Y.

25292. Skin of mule deer (Cariacus macrotis). Fat or liquor dressed. S. G. Hutchinson \& Co., Johnstown, N. Y.

25293. Skin of mule deer (Cariacus macrotis). Oil dressed. S. G. Hutchinson \& Co., Johnstown, N. Y.

25294. Gloves made from skin of mule deer (Cariacus macrotis). S: G. Hutchinson \& Co., Johnstown, N. Y.

25295. Raw skin of African "blees bok." S. G. Hutchinson \& Co., Johinstown, N. Y.

25296. Skin of African "blees bok" (dressed). S. G. Hutchinson \& Co., Johnstown, N. Y.

25297. Gauntlet gloves made from skin of African "blees bok." S. G. Hutchinson \& Co., Johnstown, N. Y.

25298. Raw skin of prong-horn or antelope (Antilocapra americana). S. G. Hutchinson \& Co., Johnstown, N. Y.

25299. Skin of prong-horn or antelope (Antilocapra americana). Dressed and colored. S. G. Hutchinson \& Co., Johnstown, N. Y.

25300. Gloves made from skin of prong-horn or antelope (Antilocapra americana). 'S. G. Hutchinson \& Co., Johnstown, N. Y.

25301. Raw skin of south American peceary (Dicotyles labiatus). S. G. Hutchinson \& Co., Johnstown, N. Y.

25303. Gloves made from skin of South American peceary (Dicotyles labiatus). S. G. Hutchinson \& Co., Johnstown, N. Y.

25302. Skin of South American peccary (Dicotyles labiatus). Dressed for glove manufacturer. S. G. Hutchinson \& Co., Johnstown, N. Y.

25304. Buck-tanned skin of sheep.

25305. Dressed skin of sheep, tanned like kid leather, but smoked instead of colored. S. G. Hutchinson \& Co., Johnstown, N. Y.

25306. Sheep-skin made into "kid leather." S. G. Hutchinson \& Co. Johnstown, N. Y.

25307. Gloves made from "kid-dressed" sheep-skin. S. G. Hutchinson \& Co., Johnstown, N. Y.

25308. "Kid"-dressed lamb-skin, ready for coloring. S. G. Hutchinson \& Co., Johnstown, N. Y.

25309. Lamb-skin "kid-dressed," colored. S. G. Hutchinson \& Co., Johnstown, N. Y.

25310. Gloves made from "kid-dressed" lamb-skin. S. G. Hutchinson \& Co., Johnstown, N. Y.

25311. Lamb-skin dressed in Germany. S. G. Hutchinson \& Co., Johnstown, N. Y. 


\section{Leather prepared from mammal skins.}

\section{Series of different leathers illustrating the manufacture of gloves.}

The following account of the glove trade in North America is from the pen of Mr. S. G. Hutchinson:

"The manufacture of gloves and mittens from leather was started in Fulton County, New York (according to best information), in the year 1809 , by people from Connecticut, who first engaged in the manufacture of tinware and in exchanging their tinware for the products of the country. They thus obtained deer-pelts, which they learned to tan according to the Indian process, and, using paper patterns, cut and made them into rough mittens and gloves. Subsequently they learned a better process of tanning, and also have made great improvements in manufacturing * gloves; and from apparently insignificant and accidental beginnings has originated an industry which is estimated to produce over $\$ 4,000,000$ worth of manufactured goods, and which business has never as yet been successfilly transplanted elsewhere.

"Tho skins used in the manufacture of gloves and mittens are the different varieties of deer-skins and sheep and lamb skins. The deer-skins are gleaned from the entire United States, Mexico, Central and South America, and Africa, and there is as much difference in the quality of the skins from the different countries as in the climate of the countries or localities from which they come. The heaviest and most valuable skins come from under the equator.

"Sheep-skins are extensively used in the manufacture of gloves as well as deer-skins. It is estimated that over 100,000 dozen are used annually. The quality of these varies as much as deer-skins, and depends as much upon the section of country from which they come, the coarsewool skins making the best leather. A part of the sheep-skins are dressed in a similar manner to the deer-skins, and are finished to resemble buckskin. Many sheep and lamb skins are by a very different process made into what is called kid leather, the lamb-skins, especially, making a very nice glove; in fact, some of the lined fur-trimmed gloves made from this kid leather excel any of foreign manufacture.

"To give a more definite idea of where the deer-skins come from, I will give a little item of statistics of arrivals of deer-skins at the port of New York in the years 1868 to 1872, inclusive:

\begin{tabular}{|c|c|c|c|c|c|}
\hline Whence. & 1868. & 1869. & 1870. & 1871. & 1872. \\
\hline 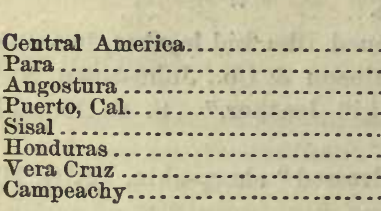 & $\begin{array}{r}\text { Pounds. } \\
254,200 \\
288,500 \\
100,000 \\
60,000 \\
105,000 \\
60,800 \\
30,000 \\
24,000\end{array}$ & $\begin{array}{r}\text { Pounds. } \\
249,000 \\
214,900 \\
89,600 \\
210,300 \\
62,000 \\
52,300 \\
26,700 \\
12,500\end{array}$ & $\begin{array}{r}\text { Pounds. } \\
252,900 \\
185,700 \\
173,000 \\
115,000 \\
84,000 \\
61,500 \\
19,000 \\
19,400\end{array}$ & $\begin{array}{r}\text { Pounds. } \\
230,700 \\
150,900 \\
157,500 \\
31,500 \\
67,700 \\
57,900 \\
19,500 \\
21,000\end{array}$ & $\begin{array}{r}\text { Pounds. } \\
249,000 \\
141,800 \\
65,000 \\
154,400 \\
125,500 \\
62,500 \\
21,000 \\
12,500\end{array}$ \\
\hline Total & 923,000 & 917,300 & 909,600 & 736,700 & 832,200 \\
\hline
\end{tabular}

"And to give you something of an idea of how these deer-skins are converted into leather ready for cutting into gloves, I will copy a poem written by Horace Sprague in 1859. However, the operation has been somewhat changed and much improved since:

"'And be it mine in brief to comprehend,

From the inception to the final end,

Through every process, how the routine moves

From unwrought hides to manufactured gloves. 


\section{Leather prepared from mammal skins.}

Scries of different leathers illustrating the manufacture of gloves:

First into vats, low sunken in the gronnd,

The rattling skins are thrown with husky sound,

And there for days are suffered to remain,

Until the water permeates the grain,

And their whole yielding form and texture make

Pliant and supple, fitting them to break.

Prone o'er the slanting beam the breaker plies,

With long two-handled knife, his energies

All the adhering flesh to clean away.

His is the hardest work and poorest pay.

Flesh-liming, or the hairing process called,

Is next in order and is next installed.

Upon the flesh-side of the broken skin

Quick-lime is spread and safely folded in;

Then in the soak or water vat,with care

'T is placed ten days for loosening the hair,

And when the beam and knife again are proved

The hairy coat is easily removed.

In lime-vats next the skins are put to lime;

From one to six weeks is the allotted time.

This process, perfected by low degrees,

Thickens the skins and smooths the surfaces.

Frizing requires the beam and knife again,

To share clean off the cuticle or grain.

Parching is used for heavy skins alone.

The meaning of the term is drying down;

Not in the fervors of the seorching sun,

But in the shade alone, ' $t$ is safely done.

A soaking then ensues until

They 're softer made and fitted for the mill.

Milling in order next succeeds, of course.

Placed in the stock, by steam or water foreo

The skins are briskly run six hours or more

To supple them and open every pore,

Then taken out to air. With oil imbued,

Replaced again, and milling is renewed.

Each half hour afterward alternately

They 're in the stocks or out to air and dry,

Until throughout the substance of the skin

The oil commingles with the gelatine

Or glue, and leares the other parts together

The true and gennine product we call leather.

The beam and scudding-knife again are plied

For scudding on the grain or facial side.

The mucous substance or reticular

Tissue of the skin is shaved off bare.

The process then, to perfect and to crown,

Requires a day at most for drying down.

Next in lye-liquor vats they're placed awhile,

In vulgar parlance, 'for to cut the ile';

But by the chymie law affinity

The oil gelatinous and alkali

Combine, without a figure or a trope,

And form the useful product we call soap.

A half hour in the stocks the skins being ran,

The soap washed out, and thus the scouring 's done.

To soften, to give shape, and natural size,

Duly the stacking process next applies.

Fast in the perch the pendent skin being placed,

Grasped by the hand and firmly shoulder-braced,

The arm-stake then is vigorously applied

To supple and extend the leathery hide,

While the knee-stake is more suitably found

Fitted to stretch and smooth the edges round.

Ocher with water mixed, when dried enough

And into square blocks fashioned, is called buff, 


\section{heather prepared from mammal skins.}

Series of different leathers illustrating the manufacture of glores.
Which by the hand is rubbed upon the skin.
Perch hung until the ocher's well wrought in
And deeply set, producing a soft, mellow,
Golden, enduring, inerasive yellow.
This buffing named. The process next to bring
The manufacture through is finishing.
A horizontal shaft, firm overlaid
With emery, and by machinery made
To turn, elaborates the skin placed on
To perfect smoothness, and the work is done.'

"The manufacture of the different kinds and styles of gloves is becoming divided up so that many of our leading manufacturers are making a specialty of some particular kind of gloves. Some make exclusively heavy buckskin gloves and mittens; others make exclusively sheep-skin gloves and gauntlets; others, lined kid gloves of various kinds and styles; others, unlined kid and antelope or castor gloves and ladies' gauntlets, thus enabling them to pay strict attention to their particular branch, and reaching the highest degree of perfection attainable at this age and stage of the business.

"Marked progress is yearly made in this industry, and it is predicted that in no distant future the finest gloves made in the world will be made here in the two villages of Johustown and Gloversville, N. Y."

Porpoise leather.

Beluga leather dressed as kid, sole, harness, velvet, plush, boot, mail-bag, belt, and patent (varnished) leather.

26018. Tanned skin of beluga (Delphinapterus catodon). G. R. Renfrew \& Co., Quebec.

26019. Lace leather, "Riviére du Loup en bas." Manufactured from the skin of beluga (Delphinapterus catodon), by the Gulf Porpoise Fishing Company.

Beaver leather, used in manufacture of saddles, shoes, gloves, and trunks.

Rat leather, used for thumbs of kid gloves.

Leather trimmings, used as stuffing for balls, \&c.

\section{Prepared from intestines of mammals.}

Parchment from viscera of seals, used by Eskimos for clothing, bags, and blankets.

6559. Intestine of seal. Used for waterproof clothing. Cook's Inlet. Dr. T. T. Minor.

5570. Intestine of seal. Used for waterproof clothing. Yukon River. W. H. Dall.

6559. Intestine of seal. Prepared and used for clothing. Dr. T. T. Minor. 20802. Prepared seal-gut for waterproof dresses. Sitka, Alaska. J. G. Swan. See also numerous garments of this material displayed in the Ethnological division. 


\section{Prepared from intestines of manmals.}

Leather from pharynx of seal and walrus, used by Eskimo for bootsoles.

Parchment from viscera of bears, used in Kamtchatka for masks and window-panes.

Viscera of ox, used in manufacture of gold-beaters' skin.

Bladders of animals, used for pouches, parchment, bottle and jar covers, and by Eskimo for oil-bottles.

Viscera of sheep, used in manufacture of "cat-gut," with specimens of whip-cord, hatters' cord, for bowstrings, clockmakers' cord, filandre, guitar, violin, and harp strings, angling-lines, \&c.

Viscera of hog, used as envelopes for minced meat, sausages, \&c.

Throat of sea-lion (Eumetopias Stelleri), dressed as parchment envelopes to preserve valuable papers.

20803. Sitka Indians, Alaska. J. G. Swan.

Sinews of sheep, deer, goat, buffalo, seal, walrus, and other animals, used in manufacture of threads, lines, nets, and snow-shoes, in strengthening bows, \&c.; the babiche of the Eskimos of the Northwest coast.

5185. Babiche. Siccanee Indians. British Columbia. J. T. Rothrock.

2034. Mackenzie's River. R. Kennicott.

849. Mackenzie's River.

842. Moose sinew. Fort Good Hope. Mackenzie's River. R. Kennicott. 2036. Sinews of moose and caribou. Fort Liard Indians.

66

5546. Deer sinew. Apache Indians. Dr. E. Palmer.

2200. Babiche. Undressed skin of mountain sheep.

843. Babiche from mountain sheep. Mackenzie's River. R. Kennicott.

1882. Bow covered with sinew of mountain sheep (Ovis montana). Digger Indians. California. Captain Gunnison, U. S. A.

24788. Snow-shoes made from sinew of caribou (man's size). G. R. Renfrew \& Co., Quebec.

24789. Snow-shoes made from sinew of caribou (woman's size). G. R. Renfrew \& Co., Quebec.

\section{Prepared from bird-skins (Eskimos).}

Eider leather. ${ }^{1}$

Auk leather. ${ }^{1}$

7453. Oil-bag. Made from skin of loon's foot. Fort Anderson. R. MacFarlane.

\section{Prepared from reptile skins.}

Alligator leather.

16810. Salted skin of alligator (Alligator mississippiensis). Upper Saint John's River, Florida. G. Brown Goode.

16810. Tanned skin of alligator. Upper Saint John's River, Florida. G. Brown Goode. 


\section{Prepared irom reptile skins.}

Alligator leather.

25283. Tanned skin of alligator (Alligator mississippiensis). Upper Saint John's River, Florida. G. Brown Goode.

24791. Tanned skin of alligator (Alligator mississippiensis). "Russet finish." Schayer Bros., Boston, Mass.

24796. Cigar-case, made from skin of alligator (Alligator mississippiensis). "Russet finish." Schayer Bros., Boston, Mass.

24792. Lady's satchel, made from skin of alligator (Alligator mississippien8is). "Russet finish." Schayer Bros., Boston, Mass.

24795. Match-case, made from skin of alligator (Alligator mississippiensis). "Russet finish." Schayer Bros., Boston, Mass.

24793. Slippers, made from the skin of alligator (Alligator mississippiensis). "Russet finish." Schayer Bros., Boston, Mass.

24794. Slippers, mado from skin of alligator (Aliigator mississippiensis). "Black finish." Schayer Bros., Boston, Mass.

26068. Riding-boots, made from skin of alligator (Alligator mississippiensis). H. \& A. Mahrenholz, Now York City.

\section{Rattlesnake leather.}

24797. Dressed skin of rattlesnake (Crotalus durissus). Big Coon, Ala. J. H. Henderson.

24799. Dressed skin of rattlesnake (Crotalus durissus). Big Coon, Ala. J. H. Henderson.

24798. Shoes made from skin of rattlesnake (Crotalus durissus). Big Coon, Ala. J. H. Henderson.

9043. Bow covered with skin of rattlesnake. Used by Flathead Indians. Fort Colville, W. T. Dr. J. T. Ghisslin, U. S. A.

Other snake leather.

26069. Boots made from skin of boa (Boa constrictor). H. \& A. Mahrenholz, New York.

\section{Prepared from fish-skins.}

\section{Leather prepared from scaled fish by Indians.}

16091. Salmon-skins dressed as leather and used in making waterproof shirts and boots by Magemut Eskimo. Nunivak Island, Alaska. W. H. Dall.

10347. Parky, or upper garment, made from the skin of codfish (q). Nunivak Island, Alaska. W. H. Dall.

Eel leather, made for pigtails, queues, flail-thongs.

Skins of eels (Anguilla vulgaris).

25285. Eel-skins. Market, Washington, D. C. G. Brown Goode.

These eel-skins are highly esteemed by the Virginia negroes as a cure for rheumatism.

Sturgeon leather.

26013. Tanned skin of sturgeon (Acipenser mibicundus). Wernich \& Wandel, Waukegan, IIl. 


\section{Prepared from fish-skins.}

Shark leather (shagreen used for coverings, and by the Alaska Indians for boot-soles). ${ }^{1}$

\section{Leather waste.}

Paper manufactured from waste.

Glue manufactured from waste. (See under 24.)

Prussian blue made from leather waste. (See under 30.)

\section{HAIR AND WOOL.}

\section{Hair used in weaving and felting. (See under 8.) Hair used for wigs and ornaments.}

Human hair as an article of commerce, with specimens of switches and wigs, and also of the trade imitations of hair in jute, horsehair, \&c.

Goat's wool as employed in manufacture of wigs and perukes.

Human scalp locks as Indian trophies. ${ }^{2}$

Scalps of animals as trophies. ${ }^{2}$

Hair and bristles used for brushes (embracing the commercial hair and bristles, assorted and unassorted, and specimens of the manufactured articles).

Hair of skunk, used for fine brushes.

29340. Gilders' and varnishers' brushes (black hair; flat). Miles Bros. \& Co.

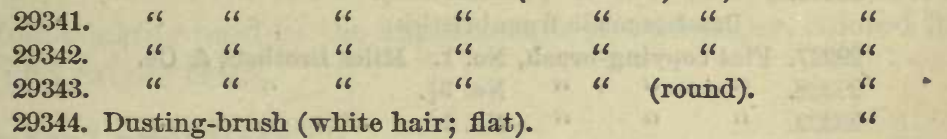

Hair of bear used for varnishing-brushes.

29338. Varnish or dusting brush. Miles Brothers \& Co.

29339. "Mottler" brush.

66

Hair of American badger used for fine shaving, graining, gilding, and dust brushes. ${ }^{3}$

Hair of American badger (Taxidea americana) adapted to the manufacture of brushes.

Hair of squirrel, especially the tail, used in making fine artists' pencils.

29320. "Camel's-hair" varnish-brush. French style. Miles Brothers \& Co. 29321. "Camel's-hair" coach-painters' color-brush. "6

\footnotetext{
${ }^{1}$ See garments in Ethnological series.

${ }^{2}$ See specimens in the Ethnological division.

${ }^{3}$ The badger-hair brushes sold in America are almost exclusively manufactnredefom the hair of the European badger. The hair of the American badger is quite ans well adapted to the purpose.
} 


\section{Hair and bristles used for brushes.}

Hair of squirrel, especially the tail, used in making fine artists, pencils.

29322. "Camel's-hair" varnish or copying brush. English style. Miles Brothers \& Co., New York.

29322. "Camel's-hair" gilders' brush. Miles Brothers \& Co., New York. 29324-5. "Camel's-hair" lacquering brush.

29326. "Camel's-hair" pencil, quill handles.

29353. Series of scrolling and ornamenting brushes. "

$\begin{array}{lll}66 & 66 \\ 6 & 66 & 1\end{array}$

These brushes are made chiefly from the tail of the gray squirrel (Sciurus carolinensis), and are known to the trade as "camel's-hair" brushes.

Bristles of hog and peccary used in making coarse brushes for varnishing, scrubbing, \&c.

26020. Series of bristles (black). B Nos. 1-12. William Wilkens \& Co.,

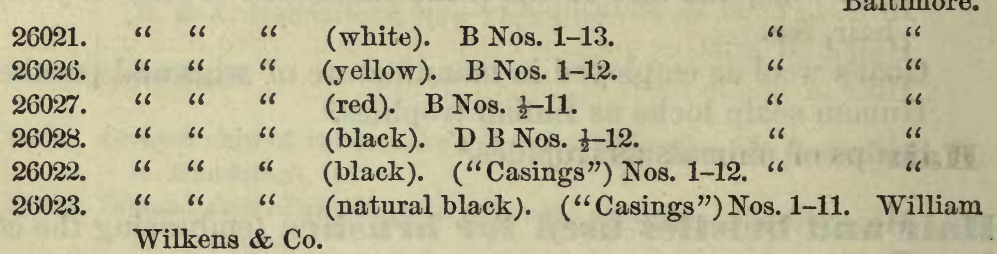

26024. Series of bristles (white). ("Casings") Nos.1-12. William Wilkens

$\begin{array}{llllll}26025 . & \text { " } & \text { " } & \text { " } & \text { (white). Medium stiff, Nos. 1-12. } \\ \text { 26029. } & \text { " } & \text { " } & \text { " } & \text { (union). } \\ 26030 . & \text { "William Wilkens \& Co. } & \text { " } & \text { " } & \text { (blue). } & \text { " } \\ 26031 . & \text { " } & \text { " } & \text { (unbleached). }\end{array}$

Brushes made from bristles:

29327. Flat copying-brush, No. 1. Miles Brothers \& Co.

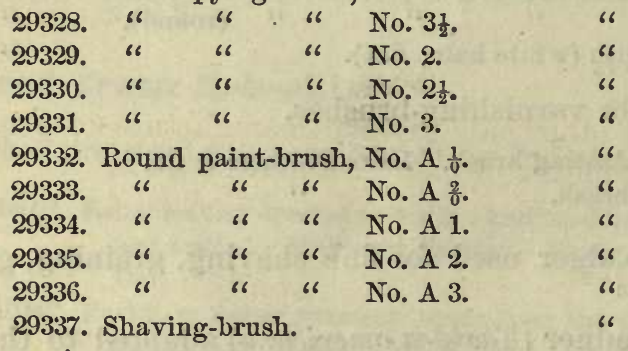

Sheep's wool (on skin) used for blackboard-rubbers. ${ }^{1}$

Hair of deer and antelope (on skin) used by Indians for hair-brushes. ${ }^{8}$

Deer-hair brushes.

Brushes made from white hair in tail of deer (Cariacus macrotis and $C$. virginianus):

29354. Flat brush. 1 inch Miles Brothers \& Co.

29355. " $1 \frac{1}{2}$ "

$29356 . \quad 2 \quad 2$ "

2935\%. Round brush.

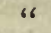

"6

66

6 
ANIMAL RESOURCES AND FISHERIES OF UNITED STATES. 219

\section{Hair and bristles used for brushes.}

Hair of horses, used for fly-brushes.

26032. Series of samples of horse-hair (dyed blue). William Wilkens \& Co. 26033. " " " " " " "

26034. " " " " " (dyed white). "

Ox-hair from the inside of cows' ears used for striping and lettering brushes.

29345-6-7-8-9-50. Fresco-painters' brushes, 1-6. Miles Brothers \& Co.

29351. Series of ox-hair striping-pencils, sold as camel's-hair pencils. Miles Brothers \& Co.

\section{Hair used in other manufactures.}

Bristles used in shoemakers' wax ends.

Bristles used in anatomical instruments.

Hair and bristles used in artificial flies. (See under B, 45.)

Hair of cattle used in strengthening mortar and plaster.

\section{Hair used for stuffing.}

Horse-hair, straight and curled, used for mattresses and cushions. Refuse hair of beaver and musquash, eut from felting-hair, used for cushions.

(Down of rabbits used for cushions.)

\section{Wool used as a medium for pigments.}

Wool-flocking used in the manufacture of wall-paper, colored felts, and rubber cloth.

\section{Chemical products.}

Refuse human and other hair used in manufacture of prussiate of potash, with specimens of manufactured product.

\section{Quils of mammals.}

22. QUILLS.

Quills of American hedge-hog used by Indians in embroidering.

\section{Quills of birds.}

Quills of swan and turkey for engrossing-pens.

Quills of goose and eagle for writing-pens.

Quills of crow and duck for fine pens.

Quills used in making tooth-picks, fishing-floats, color-bottles, pencil-handles, needle-holders, \&c. 
Feathers used for implements (including manufactured articles).

29528. Fan.

26595. Fan made from feathers of roseate spoonbill (Platalea ajaja). Mrs. C. E. Mott, Jacksonville, Fla.

26ะ97. Fan made from feathers of white tern (Sterna sp.). Mrs. C. E. Mott, Jacksonville, Fla.

26598. Fan made from feathers of white crane (Garzetta candidissima). Mrs. C. E. Mott, Jacksonville, Fla.

26599. Fan made from feathers of blue heron (Florida cœrulea). Mrs. C. E. Mott, Jacksonville, Fla.

26601-26605. Fan made from feathers of water-turkey (Plotus anhinga). Mrs. C. E. Mott, Jacksonville, Fla.

26602. Fan made from feathers of fish-crow (Corvus ossifragus) and blue herou (Florida corulea). Mrs. C. E. Mott, Jacksonville, Fla.

26603. Fan made from feathers of wood ibis (Tantalus loculator) and parakeet (Psittceus carolinensis). Mrs. C. E. Mott, Jacksonville, Fla.

26605. Fan from miseellaneous feathers. Mrs. C. E. Mott, Jacksonville, Fla. 26812. Domestic turkey-feather dusters. 5 sizes. Chicago Feather-Duster Company. Chicago, IIl.

Feathers used for plumes and ormaments (including plumes, head-dresses, cockades, hat and dress trimmings, \&c.)

26604. Bouquet made from feathers of Florida birds. Mrs. C. E. Mott, Jacksonville, Fla.

29529. Flowers made from feathers of Florida birds.

\section{Featheres used in other manufactures.}

Feathered arrow-shafts. (See under B, 18.)

Feathers used in making artificial flies.

Feathers used in manufacture of textile fabrics. (See under D, II, C.)

\section{Down of birds.}

Down of eider-duck used in bed-stuffing, with specimens of balls in which it is packed for transportation.

Down of other ducks.

Down of geese and swans used as stuffing for beds, and as electrical non-conductor in manufacture of philosophical instruments.

\section{Gelatime.}

\section{Gelatine and isinglass.}

Gelatine made from leather-shavings, bones, hoofs, and horns of bison, cattle, sheep, and other domestic animals, used in manufacture of glue, size, court-plaster, papier glacé for tracing, imitation glass, artificial flowers, and ornamental work, wrappings for confections, table-jelly (see under D 1), \&c. Glue.

25315. No. 1. Manufactured from horns and hoofs. Wm. H. Brown, Peabody, Mass.

25316. No. 2. Manufactured from horns and hoofs. Wm. H. Brown, Peabody, Mass. 


\section{Gelatine.}

Size, or frozen glue.

25317-18. "A. A. E." Manufactured from horns and hoofs. Wm. H. Brown, Peabody, Mass.

Gelatines made from bone and ivory shavings.

\section{- Bird gelatine.}

(Nests of esculent swallows (Calocalia esculenta, C. fuciphaga, C. indifica, \&c.) exported from Indian Archipelago to China.)

\section{Isinglass.}

Isinglass (ichthyocolla), made from air-bladders and skins of fishes and used in the manufacture of fine glues and sizes, adhesive and court plasters, diamond cement, imitation glass, and table-jelly and confectionery (see under D 1, D), in refining wines and liquors, in adulterating milk, in fixing the luster of artificial pearls, and in lustering silk rilbbons (embracing the dried bladders and the manufactured products) in their grades of "lyre," "heart-shaped," "leaf," and "book" isinglass.

Isinglass from sounds of cod and hake.

12123. Isinglass. (First quality.) Manufactured from sounds of cod, hake, \&c. Cape Ann. Cape Ann Isinglass and Glue Company, Rockport, Mass.

12124. (Second quality.) Manufactured from sounds of hake, cod, Sc. Cape Ann Isinglass and Glne Company, Rockport, Mass.

12126. Dried sonnd of cod (Gadus morrhua). Used in the manufacture of isinglass. George's Banks. Cape Ann Isinglass and Glue Company, Rockport, Mass.

12125. Dried sound of hake (Phycis chuss). Used in manufacture of isinglass. Bay of Fundy. Cape Ann Isinglass and Glue Company, Rockport, Mass.

16683. Sound of hake (Phycis chuss), used in the manufacture of isinglass. Portland, Me. H. Trefethern.

16684. Sound of hake (Phycis chuss), used in the manufacture of isinglass. Portland, Me. H. Trefethern.

25264. Isinglass. Manufactured from sounds of cod, hake, \&c. Cape Ann Isinglass and Glue Company, Rockport, Mass.

25263. Air-bladder of cod (Gadus morrhua), used in mannfacture of isinglass. Cape Ann Isinglass and Glue Company, Rockport, Mass.

25796. Isinglass made from skins of $\operatorname{cod}$ (Gadus morrhua). By a new method, by the Gloucester Isinglass and Glue Company. Wm. N. Le Paiz, agent, Boston, Mass.

25268. Air-bladder of "foreign crab" (species unknown), used in manufacture of isinglass. Cape Ann Isinglass and Glue Company, Rockport, Mass.

- Air-bladder of foreign "sea trout" (an unknown fish), used in tho manufacture of isinglass. East Indies. Cape Ann Isinglass and Glue Company, Rockport, Mass. 


\section{Isinglass.}

Isinglass from sounds of cod and hake.

25794. Prepared glue made from skins of cod (Gadus morrhua). By Gloucester Isinglass and Glue Company. Wm. N. Le Paiz, agent, Boston, Mass.

25797. "Court-plaster" glue made from skins of cod (Gadus morrhua). By the Gloucester Isinglass and Glue Company. Wm. N. Le Paiz, agent, Boston, Mass.

25795. Glue made from skins of cod (Gadus morrhua). By Gloucester Isinglass and Glue Company. Wm. N. Le Paiz, agent, Boston, Mass.

20744. Dried tongues of fish (probably cod), used by Sitka Indians in making glue. Sitka, Alaska. J. G. Swan.

Isinglass from the squeteague family (Scicenidae), principally used by confectioners.

25265. Air-bladder of "beluga" (an unknown sciænoid fish), used in the manufacture of isinglass. Cape Ann Isinglass and Glue Company, Rockport, Mass.

25269. Air-bladder of hake (Phycis chuss), used in manufacture of isinglass. Cape Ann Isinglass and Glue Company, Rockport, Mass.

25312. Air-bladder of sciænoid fish, known to the trade as "tongue." East Indies. Cape Ann Isinglass and Glue Company, Rockport, Mass.

25267. Air-bladder of squeteague (Cynoscion regalis), used in manufacturing isinglass. Cape Ann Isinglass and Glue Company, Rockport, Mass.

12127. Dried sound of squeteague (Cynoscion regalis), used in the manufacture of isinglass. Long Island Sound. Cape Ann Isinglass and Glue Company, Rockport, Mass.

Isinglass.

12120. Isinglass made from sonnd of lake sturgeon (Acipenser rwbicundus). Lake Erie. Schacht \& Bros., Sandusky, Ohio.

25. FleXible MATERIALS DERIVED From invertebrates. ${ }^{1}$

\section{Insect productions.}

Silk-worm "gut" used in making leaders for fish-lines. (Nest of Cayenne-ant (Formica bispinosa), used as a mechanical styptic.)

Spiders' web used as a mechanical styptic and for the cross-lines in optical instruments. (See, also, under D, 8).

Papier maché of hornets' nests used for gun-wadding.

\section{Mollusk productions.}

Byssus of mollusks (see under D, 8). 


\section{SPONGES. ${ }^{1}$}

Specimens of American commercial sponges (with the different grades, and bleached sponges).

(Specimens of Mediterranean sponges.)

Surgical apparatus, probangs, aurilaves, "sponge-tents," and other instruments manufactured.

Spongeo-piline used as a substitute for poultices.

Sponges used in stufing mattresses and cushions.

\section{Mammal oils.}

\section{OILS AND FATS.}

Bear-oil and bear-fat used as a cosmetic and in the manufacture of pomatums.

Dog-oil used in the manufacture of kid gloves.

Seal-oil, in its various grades, used for lubricating.

25059-60. Oil of seals (Cystophora, Pagophylus, Pusa, and Phoca, sp.). Newfoundland. Walter Grieve \& Co., St. John's, N. F.

25031-3. Oil of seals (Cystophora, Pagophilus, Pusa, and Phoca, sp.). J. Munn \& Co., Harbor Grace, N. F.

25979. Oil of harbor seal (Phoca vitulina). Capt. N. E. Atwood, Provincetown, Mass.

Sea-elephant oil.

25057. Oil of sea-elephant (Macrorhinus, sp.). Haven, Williams \& Co., New London, Conn.

25058. Oil of sea-elephant (Macrorhinus leonina). South Georgia Island. Haven, Williams \& Co., New London, Conn.

Sea-lion oil.

Manatee-oil.

Dugong-oil.

Oil and fat from domestic animals, (tallow, suet, lard, oil used in lamps, for lubricating, and neat's-foot oil used in dressing leather; also, manufactured into various substances (see D, 30), and tallow candles and night-lights.)

Oil from body of whales, grampuses, and porpoises used in the arts, for lubricating, painting, \&c.

25054. Oil of humpback whale (Megaptera, sp.). Atlantic Ocean. Haven,

Williams \& Co., New London, Conn.

25055. Oil of right-whale. Haven, Williams \& Co., New London, Conn.

25056. Oil of sulphur-bottom whale (Sibbaldius, sp.). Haven, Williams \&

Co., New London, Conn.

26038. Oil of beluga (Delphinapterus catodon). Renfrew \& Co., Quebec.

24894. Crude Arctic whale oil. George Delano \& Co.

24895. Bleached "winter" sperm-oil, from the sperm-whale (Physcter macrocephalus). George Delano \& Co., New Bedford, Mass.

${ }^{1}$ See under Part II of the present catalogue. 


\section{Mammal oils.}

Oil from whales and porpoises.

25743. Oil of grampus (Grampus griseus). Extracted by exposure to the sun. E. E. Small, Provincetown, Mass.

25067. Oil of grampus (Grampus griseus). Extracted by exposure to the sun. Capt. Caleb Cook, New Bedford, Mass.

25067. Double refined oil of grampus (Grampus griseus). Cape Cod. Capt. Caleb Cook, Provincetown, Mass.

25737. "Pressed" oil of grampus (Grampus griseus). E. E. Small, Provincetown, Mass.

25967. Oil of cowfish. Capt. N. E. Atwood, Provincetown, Mass.

25958. Oil of porpoise. Marvin Brothers \& Bartlett, Portsmouth, N. H.

25738. Oil of porpoise (Lagenorhynchus leucopleurus). Extracted by exposure to the sun. E. E. Small, Provincetown, Mass.

25974. Oil of porpoise (Delphinus erebennus?). Capt. N. E. Atwood, Provincetown, Mass.

12116. Oil of harbor porpoise (Phoccena americana). Prepared by the Passamaquoddy Indians. Eastport, Me. Dr. E. Palmer.

12115. Oil of harbor porpoise (Phoccena americana). Eastport, Me. Dr. E. Palmer.

26037. Oil of harbor porpoise (Phocana americana). Passamaquoddy Bay, Maine. George H. Peabody, Eastport, Me.

25739. Oil of snuffer (Phocana americana). Extracted by exposure to the sun. E. E. Small, Provincetown, Mass.

24893. Crude "body"-oil from sperm-whale (Physeter macrocephalus). George Delano \& Co., New Bedford, Mass.

26076. Oil of black-fish (Globicephalus intermedius). North American Oil Company, Wellfleet, Mass.

25741. Oil of black-fish (Globicephalus melas). E. E. Small, Provincetown, Mass.

25064. Refined oil of black-fish (Globicephalus intermedius). Cape Cod. Capt. Caleb Cook, Provincetown, Mass.

25065. Double refined oil of black-fish (Globicephalus intermedius). Cape Cod. Capt. Caleb Cook, Provincetown, Mass.

25977. Oil from body of black-fish (Globicephalus melas). Capt. N. E. Atwood, Provincetown, Mass.

Black-fish and porpoise-jaw oil used in lubricating fine machinery, watches, clocks, and guns, with specimens of blubber.

25742. Oil from head of black-fish (Globicøphalus melas). Extracted by exposure to the sun. E. E. Small, Provincetown, Mass.

25968. Oil from head of black-fish (Globicephalus melas). Sold as "porpoisejaw oil." Capt. Caleb Cook, Provincetown, Mass.

25984. Oil from head of black-fish (Globicephalus melas). Sold as "porpoisejaw oil." Capt. N. E. Atwood, Provincetown, Mass.

25969. Oil from jaw of porpoise. Capt. N. E. Atwood, Provincetown, Mass.

26035-6. Oil from head of harbor-porpoise (Phoccna americana). Passamaquoddy Bay. Geo. A. Peabody, Eastport, Me.

26075. Head-oil of black-fish (Globicephalus intermedius). North American Oil Company, Wellfleet, Mass.

26035. Jaw-oil of porpoise (Phoccena americana). Passamaquoddy Bay. G. A. Peabody, Eastport, Me.

25066. Jaw-oil of black-fish (Globicephalus intermedius). Cape Cod. Capt. Caleb Cook, Provincetown, Mass. 
ANIMAL RESOURCES AND FISHERIES OF UNITED STATES.

\section{Mammal oils.}

Black-fish and porpoise jaw oil, \&c.

26042. "Jaw-marrow" of black-fish (Globicephalus melas). E. E. Small, Provincetown, Mass.

25040. Blubber of black-fish and grampns (Globicephalus melas and Gramivis griseus). E. E. Small, Provincetown, Mass.

26041. "Melon" blubber of black-fish (Globicephalus melas). E. E. Snall, Provincetown, Mass:

25069. "Melon blubber" of black-fish (Globicephalus intermedius). Cape Cod. Capt. Caleb Cook, Provincetown, Mass.

Grampus-oil used for lubricating fine machinery.

25068. "Melon" blubber of grampus (Grampus griseus). Cape Cod: Capt. Caleb Cook, Provincetown, Mass.

25733. Oil from head of grampus (Grampus griseus). Extracted by exposure to the sun. E. E. Small, Provincetown, Mass.

Sperm-oil used in lamps, for lubricating, as an emollient in medicine, for lip-salves, and in the manufacture of spermaceti.

24892. Crude "head" sperm-oil from sperm-whale (Physeter macrocephalus). George Delano \& Co., New Bedford, Mass.

25745. Crude sperm-oil from sperm-whale (Physeter macrocephalus). E. E. Small, Provincetown, Mass.

Spermaceti, with specimens of candles.

24896. Plain refined spermaceti from sperm-whale (Physeter macrocephalus). George Delano \& Co., New Bedford, Mass.

24897. Spermaceti candles. George Delano \& Co., New Bedford, Mass.

Manufactured glycerines, used as a preservative and antiseptic, as a cosmetic, as an emollient, as a substitute for cod-liver oil, in the manufacture of nitro-glycerine, dynamite, dualine, lithofracteur, coloniamite, and other explosives, soap, \&c.

26798. Pure inodorous glycerine. Manufactured by H. Bower, Philadelphia. John Wyeth \& Bro., Philadelphia.

Manufactured stearines, with candles and other manufactured articles.

Soaps manufactured from mammal-oil, soda-soaps (hard, toilet, and resin soaps), potash-soaps (washing, shaving, and soft soaps), diachylon plaster, \&e.

Butter made from milk of cows, goats, and horses. Oleomargarines, with specimens of imitation butter.

Brains of buffalo used in tanning by Indians.

\section{Bird-oils.}

(Oil of petrels and other sea-birds used by Eskimos and in the Azores for lamp-oil.)

Bull. N. M. No. $14-15$ 


\section{ANIMAL RESOURCES AND FISHERIES OF UNITED STATES.}

\section{Bird=oils.}

Goose-oil used by watch-makers, and as an emollient.

Oil of pigeon (Ectopistes migratorius), used as food by Indians and frontiersmen.

\section{Reptile-oils.}

Alligator-oil manufactured in Florida.

24898. Oil of alligator (Alligator mississippiensis). Prepared by Col. L. A. Harden, Jacksonville, Fla. Dr. W. H. Babcock.

Turtle-oil made from turtle-eggs, used in dressing leather and in manufacture of soap.

Rattlesnake and other snake oils.

\section{Fish-oils.}

Sun-fish oil used by fishermen for cure of rheumatism.

25724. Oil from liver of sun-fish (Mola rotunda). Extracted by exposure to the sun. E. E. Small, Provincetown, Mass.

25959. Oil from liver of sun-fish (Mola rotunda). Marvin Brothers \& Bartlett, Portsmouth, N. H.

25966. Oil from liver of sun-fish (Mola rotunda). Capt. N. E. Atwood, Provincetown, Mass.

Oil from liver of the cod family.

25982. Oil from liver of cod-fish (Gadus morrhua), crude. Capt. N. E. Atwood, Provincetown, Mass.

25960. Liver-oil of cod-fish (Gadus morrhua). Marvin Brothers \& Bartlett, Portsmouth, N. H.

26550. Oil from liver of eod-fish (Gadus morrhua). Herbert M. Rodgers \& Co., 11 Fulton Market, New York.

26551. Oil from liver of cod-fish (Gadus morrhua). Herbert M. Rodgers \& Co., New York.

26707. Pure cod-liver oil. Prepared for medicinal use only, by Marvin Brothers, Portsmouth, N. H. John Wyeth, Philadelphia.

25985. Medicinal oil from livers of cod-fish (Gadus morrhua). Capt. N. E. Atwood, Provincetown, Mass.

25961. Stearine from liver-oil of cod-fish (Gadus morrhua). Marvin Brothers \& Bartlett, Portsmonth, N. H.

25970. Oil from liver of cusk (Brosmius vulgaris). Capt. N. E. Atwood, Provincetown, Mass.

25736. Oil from liver of hake (Phycis chuss). Extracted by exposure to the sun. E. E. Small, Provincetown, Mass.

25732. Oil from liver of haddock (Melanogrammus aglefinus). Extracted by exposure to the sun. E. E. Small, Provincetown, Mass.

25978. Oil from liver of haddock (Melanogrammus aglefinus). Capt. N. E. Atwood, Provincetown, Mass.

25971. Oil from liver of pollock (Pollachiuns carbonarius). Capt. N. E. At wood, Provincetornu, Mass.

25740. Oil from liver of poilock (Pollachiuus carbonarius). Extracted by exposure to the sun. E. E. Small, Provincetown, Mass. 


\section{Fish-oils.}

Herring-oil.

White-fish oil.

Sturgeon-oil.

Menhaden-oil used in currying leather, in rope making, for lubricating, for adulterating linseed-oil, as a paint-oil, and exported to Europe for use in the manufacture of soap and for smearing sheep.

26060. Oil of menhaden (Brevoortia tyrannus). Geo. W. Miles, Milford, Conn.

25744. Oil of pogie or menhaden (Brevoortia tyrannus), kettle-rendered. E. E. Small, Provincetown, Mass.

26077. Oil of pogie or menhaden (Brevoortia tyrannus). North American Oil Company, Wellfleet, Mass.

Oil of other fishes.

25973. Oil of horse-mackerel (Orcynus secundidorsalis). Capt. N. E. Atwood, Provincetown, Mass.

12117. Oil of herring (Clupea harengus). Capt. U. S. Treat, Eastport, Me. 12118. Oil from lake sturgeon (Acipenser rubicundus). Lake Erie. Schacht \& Bros., Sandusky, Ohio.

25980. Oil from liver of mackerel-shark (Isuropsis Dekayi). Capt. N. E. Atwood, Provincetown, Mass.

25975. Oil from liver of thresher-shark (Alopias vulpes). Capt. N. E. Atwood, Provincetown, Mass.

25956. Oil from liver of dog-fish (Squalus americanus). Marion Bros. \& Bartlett, Portsmouth, N. H.

25981. Oil from liver of dog-fish (Squalus americanus). Capt. N. E. Atwood, Provincetown, Mass.

25957. Oil from liver of skates (Raia laevis, \&c.). Marion Bros. \& Bartlett, Portsmouth, N. H.

2597. Oil from liver of cramp-fish (Torpedo occidentalis). Capt.N.E. Atwood, Provincetown, Mass.

25735. Oil from liver of cramp-fish (Torpedo occidentalis). E. E. Small, Prorincetown, Mass.

26978. Sword-fish oil. Capt. N. E. Atwood, Provincetown, Mass.

26979. Mackerel-oil.

26980. Skate-oil.

26981. Halibut-oil.

$66-66$

$66 \quad 66$

66

Oulachan oil used by Indians of Northwest coast for food and illumination.

Soaps made from fish-oil.

28. Perfunes.

\section{Nammal perfumes.}

Musk of musk-ox.

Musk of the musquash.

Castoreum of the beaver, including the various commercial grades, the Canadian, Hudson's Bay, and Russian castoreum, and specimens of castorine.

26037. Scent-glands of beaver (Castor canadensis). Nebraska. E. R. Squibb, M. D., Brooklyn, N. Y. 


\section{Mammal perfumes.}

Hyraceum of the daman (Hyrax capensis).

Ambergris of sperm-whale, with specimens of ambreine.

26894. Ambergris (commercial). Weeks Potter, Boston.

\section{Reptile perfumes.}

Musk of alligator.

Oil of hawksbill and loggerhead turtles, used in perfumery.

\section{Coloring materials.}

\section{Derived from mammals.}

Bone-black.

Ivory-black (noire d'ivoire), used in fine painting, and in the manufacture of bank-note ink.

Prussiates, prussian blue, ferrocyanide of potassium, made from hoofs and refuse human and other hair.

26093. Red prussiate of potassa (Potassium ferrocyanide). E. R. Squibb, M. D., Brooklyn, N. Y.

26094. Yellow prussiate of potassa (Potassium ferrocyanide). E. R. Squibb, M. D., Brooklyn, N. Y.

26794. Yellow prussiate of potash. Manufactured by H. Bower, Philadelphia. John Wyeth, Philadelphia.

Gall of animals used in dyeing.

Dung of animals used in calico-printing.

Hæmatin made from blood, and used in turkey-red dyeworks, and for the red liquor of printers.

Wool-flocking (see under D, 21).

\section{Derived from birds.}

Shell of eggs used for white pigment.

Series of murexides or purpurate of ammonia dyes, made from guano.

26065. Murexid. Prepared by E. Merck, Darmstadt. E. R. Squibb, M. D., Brooklyn, N. Y.

\section{Derived from fishes.}

Essence d'Orient, or fish-scale pearl, used as a pigment.

26893. Essence d'Orient. Introduced for comparison. Gustave Bossange, Paris.

(Gall of carp, used in Turkey as a green paint and in staining paper.)

\section{Derived from insects.}

(Cochineal dye, from Coccus cacti of Mexico, used in manufacture of rouge, of carmine, and lake pigments, and in coloring tinctures.)

26064. Honduras silver cochineal. E. R. Squibb, Brooklyn, N. Y. 


\section{Derived from insects.}

Canadian cochineal.

(Kermes and other cochineals of commerce, Coccus ilicis.)

Lac dye and lac lake, from Coccus lacca, C.polonicus, C. uva-ursi, and Ophis fabce.

Dye prepared from bed-bug (Cimex lectularius).

(Dye prepared from Trombidium, in Guinea and Surinam.)

Nut-galls produced by insects, and used in tanning for black dyes, for woolen cloth, silk, and calico, and in manufacture of ink and gallic and pyrogallic acid, employed in photography.

\section{Derived from mollusks. ${ }^{1}$}

(Sepia from Sepia officinalis.)

Purple dyes from gasteropods, Murex, Purpura, \&c.

Purple dyes from nudibranch mollusks.

30. CHEMICAL PRODUCTS AND AGENTS EMPLOYED IN ARTS AND MEDICINES.

\section{Derived from mammals.}

Secretion of skunk.

Album gracum of dogs used as a depilatory in tanning hides.

Albumen of blood, employed in sugar-refineries, in certain cements and pigments, and as an antidote and emollient.

Dung, used in calico-printing.

Gall of animals, used in mixing colors, in fixing the lines of crayon and pencil drawings, in preparing the surface of ivory for painting, in removing grease, and in medicine.

Pepsine and pancreatin, prepared from stomach of hogs and calves.

26796. Saccharated pepsin. John Wyeth \& Bro., Philadelphia.

26795. Pancreatin, saccharated.

66

66

25964. Saccharine pepsin. E. Schaffer, Lonisville, Ky.

25963. Dry pepsin (concentrated). E. Schaffer, Louisville, Ky.

25962. Pure pepsin. E. Schaffer, Louisville, Ky.

29262. Acid phospho-lactate or milk-phosphate. Prepared directly from milk, by Gail Borden \& Co. New York Condensed Milk Company, New York.

\section{Derived from insects.}

Coccinella, used as remedy for toothache.

(Trehala, made from nests of beetles (Larinas nidificans), of East Indies, and used for a substitute for tapioca.)

Formic acid.

Carbazotic acid and its derivatives, made from sewing-silk seraps, and used as a substitute for quinine. 


\section{Derived from insects.}

Beeswax, used in manufacture of candles, cerates, plasters, and artificial flowers, in modeling and casting, and in medicine.

Honey, used as a preservative, a food, and in medicine as an apefient and demulcent.

19076. Sugar made of cane-lice. Prepared by the Cooyuwee Indians, Pyramid Lake, Nevada. Stephen Powers.

(Wax, used in Chinese pharmacy, secreted by the Coccus pehlah.)

$\left(a^{\prime}\right.$. Manna from the Tamarix mannifera, used as food, and in medicine as a purgative.

$b^{\prime}$. Cedar manna from Mount Lebanon, from Pinus cedris.

$c^{\prime}$. Arabian manna, of Hedysarum alliagi.)

(Eye-powder, made by Chinese from the Telini fly (Mylabris cichorii). of India.)

\section{Derived from mammals.}

(Koumiss, a fermented liquor, prepared from mare's and cow's milk, and employed in medicines.)

Phosphorus, prepared from bones, with specimens of matches, vermin poisons, and other products.

Vaccine limph, derived from cows.

Ammonia, prepared from kones and horn.

Sal ammoniac, prepared from bones and dung.

Prussiates, prepared from hoof, horn, and leather waste, dried blood, hair, and wool, with specimens of blue cyanide of potassium. (See under Coloring Materials.)

Lime from bones and bone phosphates. (See, also, under 32.)

Punk and tinder, made from droppings of camel and bison.

Animal charcoal, used as a decolorizer.

\section{Derived from birds.}

Albumen of eggs, used in photography, in elarifying liquors, by physicians as emollients and antidotes, and by apothecaries in suspending oils and other liquids in water.

Egg-shells, employed as an antacid.

\section{Derived from reptiles.}

Crotalin of rattlesnake and copperhead.

(Scincus officinalis of Egypt, used by European practitioners as sudorific and stimulant.)

\section{Derived from fishes.}

Propylamine, made from fish-brine.

26066. Propylamine (manufactured by E. Merck, Darmstadt). E. R. Squibb, M. D., Brooklyn, N. Y. 


\section{Derived from fishes.}

(Intestines of grayling, used by Laplanders as a substitute for rennet.)

Skins of eels, used by negroes for rheumatism.

\section{Derived from insects.}

Vesicatory preparations from American beetles, Cantharis cinerea and $C$. vittata.

Vesicatory preparations derived from foreign beetles, cantharides or Spanish flies (Cantharis vesicatoria), and other species, and substitutes, Mylabris cichorii, Cercoma Schoefferi, Meloe, sp., var., \&c.

Vesicatory preparations from American spiders, such as Tegenaria medicinalis.

Gall-nuts, used in medicine (see under 29).

\section{Derived from crustacea.}

Salve-bug of fishermen of Banks (Caligus curtus), parasite on codfish.

Crabs' eves, or concretions from stomach of astacus, used as an antacid.

\section{Derived from worms.}

American leech (Macrobdella decora), used in surgery.

(European leech (Hirudo medicinalis), introduced into America.)

(African leech (Hirudo trochina), introdnced.)

Leeches used as barometers.

\section{Derived from mollusks.}

(Cuttle-fish bone of Sepia officinalis.) (See under D, III, H.)

Calcined shells, used for building-lime and in manufacture of dentifrices and enamel. (See under D, III, H.)

\section{Derived from radiates.}

a. Limes, derived from calcining coral and coral rock.

\section{Derived from protozoans.}

Burnt sponge, formerly used in medicine.

Infusorial earth and its applications. (See above under K.)

\section{Fertilizers.}

\section{Natural guanos.}

Bat guano from eaves.

Bird guano from oceanic islands. 


\section{Artificial guanos.}

Menhaden guano.

Series of preparations illustrating the manufacture of soluble Pacific guano. Soluble Pacific Guano Company, Wood's Holl, Mass. ${ }^{1}$

26104. Crude South Carolina phosphate. 25213, 26103. Crushed Sonth Carolina phosphates. 26102. Ground South Carolina phosphate. 26100. Crnde Navassa phosphate. Navassa Island, W. I.

26101. Sicily sulphur, used in mannfacture of sulphuric acid, used in factory.

26099. Stassfurth kainite, used in preservation of scrap.

26095. Crude menhaden scrap.

26097. Menhaden scrap, dried by the Hogle patent drying-machine. 26095. Soluble Pacific guano (unscreened).

26098. Soluble Pacific guano (screened).

\section{Other preparations. ${ }^{1}$}

26062. Island guano. Geo. W. Miles, Milford, Conn.

26061-3. Ammoniated bone superphosphate. Geo. W. Miles, Milford, Conn. 22246. Leopoldshall kainite. Winfield S. Dunan, Baltimore, Md.

Dried meat and blood.

Dried blood.

22239. Black dried blood. Contains 16 per cent. ammonia. Winfield S. Dunan, Baltimore, Md.

22240. Black blood-dust. Contains 12 per cent. ammonia. Winfield S. Dunan, Baltimore, Md.

22241. Red blood-dust. Contains 14 per cent. of ammonia. Winfield S. Dunan, Baltimore, Md.

22242. Mixed dried blood. Contains about 13 per cent. of ammonia. Winfield S. Dunan, Baltimore, Md.

22243. Blood, bone, and meat tankage. Contains about 9.50 per cent. of ammonia and 24 per cent. bone-phosphate of lime. Winfield S. Dunan, Baltimore, Md.

22244. Azotin. Contains about 14 per cent. of ammonia, and is made from what are known as "butcher's cracklings"-the grease having been pressed out, the scrap is dried and ground. Winfield $\mathrm{S}$. Dunan, Baltimore, Md.

22245. Sulphate of ammonia. Contains about 25 per cent. of ammonia. Winfield S. Dunan, Baltimore, Md.

Poudrettes.

Other animal fertilizers.

32. Limes. (See under 30.)

33. OTHER MATERIALS NOT MENTIONED.

${ }^{1}$ An elaborate model of the works of the Soluble Pacific Guano Company of Wood's Holl, Mass., and Charleston, S. C., is on exhibition in the grounds of the Exposition. 


\section{SECTION E.}

\section{PROTECTION AND CULTURE. \\ I. INVESTIGATION.}

\section{Methods of the United States Fish Commssion.}

\section{Methods of work.}

Apparatus for collesting specimens. (See under B.)

Apparatus for physical research.

Appliances for working up results.

This should include a model of coast laboratory with all its fittings.

Photographs.

401. Headquarters of the United States Fish Commission, Wood's Holl, Mass.

400. Little Harbor of Wood's Holl, Mass., with headquarters of U. S. Fish Commission.

399. Harbor of Wood's Hole, Mass., from the wharf of the Fish Commission laboratory.

398. Harbor of Wood's Holl, Mass., with U. S. Fish Commission fleet for 1871.

397. Village of Wood's Holl, Mass., with the Pacific Soluble Guano Company's Works.

404. Yacht "Mazeppa," employed in the service of the U. S. Fish Commission.

403. U. S. steamer "Blue Light" at the wharf of the U. S. Fish Commission, Wood's Holl, Mass.

402. Village of Wood's Holl, Mass, showing labopatory of U. S. Fish Commission.

\section{Results of work.}

1. Reports of the Cominission.

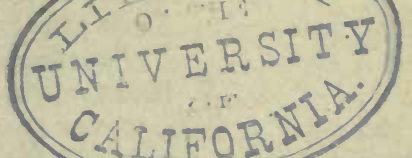

(Unted States Commission of Fismind Fishepus. Part I.-Report ON THE CONDITION OF THE SFA-FISHERIFS OF THE SOUTH COAST OF New Exglaxd in 1871 and 1Ej2. By Speneer F. Baird, Commissioner. With supplementary papers. Washington: Goverument Printing-Office. 1873. 8vo, xlvii, $852 \mathrm{pp} ., 40 \mathrm{pl}$., with 38 explanatory (to pl. 1-38). 1 folded map.)

I. Report of the Commissioner (S. F. Baird). pp. viixlvii. ${ }^{2}$

II. Gexeral play of ixquiries prosecuted. (1. MemORANDA OF INQUIRY RELATIVE TO THE FOOD-FISHES OF tHe UNITFD States. 2. QUESTIONS Relative to THE FOOD-FIsHes of THE UNited States.) pp. 1-6.

' The photographs here enumerated were on exhibition. Many others are in the possession of the Commission.

¿This portion, with general title-page (pp. i-xlvii), was issued in advance separately. 


\section{Results of work.}

1. Reports of the Commission.

(United States Commssion of Fisir and Fismeries. Part I.)

III. TESTIMONY IN REGARD TO THE PRESENT CONDITION OF THE FISHERIES, TAKEN IN 1871. pp. 7-72.

IV. SPECIAL ARGUMENTS IN REGARD TO REgULATING THE SEA-FISHERIES BY LAW. pp. 73-103.

V. REPORTS OF STATE COMMISSIONS IN REGARD TO REGULATING THE SEA-FISHERIES. pp. 104-124.

VI. Report of CONFErence of tile United States CoMMISSIONER WITH THE COMMISSIONERS OF RHODE ISLAND AND Massachusetts, held October 5, 1871. pp. 125-131.

VII. Draught OF LAW PROPOSED FOR THE CONSIDERation OF, AND ExaCtMENT BY, THE LEgislatures of MASSACHusetts, Rhode IslaNd, AND CoNnecticut. pp. 132-134.

VIII. MisceliaNeOUS CORRESPONDENCE AND COMMUNICATIONS ON THE SUBJECT OF THE SEA-FISHERIES. pp. 134-138.

IX. EUropean aUthorities oN THE SUBJECT OF REGULATING THE FISHERIES IBY LAW. pp. 139-148.

X. Notices IN REgard to TIE ABUNDANCE OF FISH ON THE New ENGLANd COAST IN ForMer times. pp. 149-17:.

XI. Statistics OF FISH AND Fisheries ON THE SOUTI SHORE OF NEW ENGLAND. pp. 173-181.

XII. SUPPLEMENTARY TESTIMONY AND INFORMATION RELATIVE TO THE CONDITION OF THE FISHERIES OF TIF SOUTH SIDE OF NEW ExGLAND, TAKEN IN 1872. pp. 182-195.

XIII. Pleadings before the sexate committee on fisileries of the Rhode Island Legislature, at its JANUARY SESSION OF 187\%. pp. 196-22\%.

XIV. NATURAL History OF SOME OF THE MORE IMPORTANT FOOD-FISHES OF THE SOUTII SHORE OF NEW ENGIAND, (viz: the Scup (Stenotomus argyrops), and the Blue-fisl (Pomatomus 8altatrix). pp. 228-252.

XV. DESCRIPTION OF APPARATUS USED IN CAPTURING FISH ON THE SEA-COAST AND LAKES OF THE UNITED STATES. pp. 253-274, with 19 (1-19) figs., and pl. (maps) xxxix and $\mathrm{xl}$, and large folded map.

XVI. List of Patents GRANTed BY the UNited Statts to THE END OF 1872 FOR INVENTIONS CONNECTED WITIY THE CAPTURE, UTILIZATION, OR CULTIVATION OF FISI AND MARINE ANIMALS. pp. 275-280.

XVII. LIST OF THE SEA-WEEDS OR MARINE ALGE OF TIIE SOUth COASt of New Exglaxd. By W. G. Farlow, M. D. pp. 281-294.

XVIII. REPORT UPON THE IYVERTEBRATE ANIMALS OF VINEYARD SOUND AND THE ADJACENT WATERS, WITH AN ACCOUNT OF tHE PHYSICAL CHARACTER OF THE REGION. By A.E. Verrill. pp. 295-778, with pl. i-xxxviii. 


\section{Results of work.}

1. Reports of the Commission.

(United States Commission of Fish and Fisheries. Part I.)

XIX. Catalogue of the fishes of the east coast of North Averica. By Theodore Gill. pp. 779-822.

XX. List of Fishes collected AT Wood's HoLl (between June 20 and October 4). By S. F. Baird. pp. 823-827.

XXI. Table of teniperatures of the Little Harbor,

WOOD'S HOLL, MASS., From JaYUARY 1, 1873, TO-

DECEMBER 31, 1873. pp. 828-831.

XXII. List of illustrations. p. 833.

XXIII. GeNeral INDEX. pp. 835-852.

United States Conmission of Fish and Fisheries. Part II.-Report OF THE COMMISSIONER FOR 1872 AND 1873. A.-INQUIRY INTO THE DECREASE OF FOOD-FISHES. B.-ThE PROPAGATION OF FOOD-FISHES iN. the waters of the United States. By Spencer F. Baird, Commissioner. With supplementary papers. Washington: Government Printing-Office. 1874.

Report of THE CoMmissioner. (Table of contents precedes report.) APPENDIX A.-THE FISHERIES OF THE GREAT LAKES AND THE SPECLESof Coregonus or Whitefish.

I. REPORTS ON THE FISHERIES OF THE GREAT LAKES; THE RESULT OF INQUIRIES PROSECUTED IN 1871 AND 1872. By James W. Milner. (Table of contents on p. 7\%.)

II. Miscellaneous votes aNd CORrespondence relaTIVE TO THE WHITEFISH. pp. 79-88.

Appendix B.-The Salmon and the Trout (species of the Salmo). p. 89.

III. ON the North American species of SALmox ANDTrout. By George Suckley, Surgeon United States Army (written in 1861). p. 91. Tabulated list of species, pp. 92-159.

IV. The Salion of the Davube, or the Hucho (Salmo hucho); AND ITS LNTRODUCTION LNTO AMERICAN WATERS. By Rudolph Hessel. p. 161.

V. IMPROVEMENT IN THE SALMON-FISHERIES OF SWEDEN. (Extract from the report of the Royal Swedish Intendant of Fisheries, 1868.) p. 166.

VI. REPORT OF OPERATIONS DURING 1872 AT THE UNITED. States hatching establishment on MCCloud. River, AND ON the CALIforvia SALMONide GENERALLY, WITH A LIST OF SPECIMENS COLLECTED. By Livingston Stoue.

A. Introductory remarks. pp. 168-174.

B. The Salmonidæ of the Sacramento River. pp. 175-197.

C. Catalogue of natural-history specimens collected on the Pacific slope in 1872, by Livingston Stone, for the United States Fish Commission.

VII. Notes on the Salmon of the Muramichu River. By Livingston Stone; p. 216. Fragmentary notes. p. 217.

VIII. The Salyonide of Eastern Manne, New Brunswick, Axd Nova Scotia. By Charles Lanman. pp. 219-225.

IX. ON the Salmon of Eastern North Averica, axd its. artificial culture. By Charles G. Atkins. (Table of contents on p. 336.) p. 226. 


\section{ANIMAL RESOURCES AND FISHERIES OF UNITED STATES,}

\section{Results of work.}

Reports of the Commission.

(United States Conmission of Fish and Fisheries. Part II.)

X. On the Salmox of Maine. By A. C. Hamlin. pp. $338-356$.

XI. The Lake Trouts. By A. Leith Adams, M. A., \&c. p. 357.

XII. ON the Speckled Trout of Utah Lake. By Dr. H. C. Yarrow, U. S. A., Surgeon and Naturalist, \&c. pp. 358-363.

XIII. Miscellaneous Notes AND CORRESPONDENCE RELATIVE to Salmon and Trout. pp. 364-378.

XIV. AdDITIONAL REPORTS RELATIVE TO THE HatCHING AND planting of the Plenobscot Salmon. p. 380.

A. New Hampshire. p. 380.

B. New Jersey. p. 381.

C. Pennsylvania. p. 382 .

D. Ohio. p. 382.

E. Wisconsin. p. 383.

Appendix C.-The Shad AND Alewife (species of Clupeida). p. 385.

XV. LETTERS REFERRING TO EXPERLMENTS OF W. C. DANIELL, M. D., in introducivg Shad into the Alabama RIVER. pp. $386,387$.

XVI. LETTERS REFERRING TO SHAD IN THE RIVERS TRIBUTARY to The Gulf of Mexico. pp. 388-391.

XVII. REPORT OF A RECONNAISSANCE OF THE SHAD-RIVERS soutil of the Potomac. By H. C. Yarrow, M. D. pp. 396-401.

XVIII. REPort on Shad-hatching operations. pp. 403-417.

XIX. Report oN tine propagation of the Shad (Alosa Sapidissma), AND ITS INTRODUCTION INTO NEW WATERS BY the United States Commissioner, in 1873. By James W. Milner. pp. 419-450.

XX. Notes on the NATURAL HISTORY OF tHe SHAD AND AlewiFe. pp. 452-462.

APPENDIX D.-Fish CULTURE (THE IIISTORY, THEORY, AND PRACTICE OF FISII-CULTURE). pp. $463,464$.

XXI. THE HISTORY OF FISH-CULTURE. p. 465.

A. The history of fish-culture in Europe, from its earlier record to 185. By Jules Haime. pp. $465-492$.

B. Report on the progress of pisciculture in Russia. By Theodore Soudakèvicz. pp. 493-512.

C. Report on the state of pisciculture in France and the neighboring countries. By M. BouchonBrandley, assistant secretary of the College of France. pp. 513-522.

D. The progress of fish-culture in the United States. By James W. Milner. pp. 52:3-558.

E. Alphabetical list of American fish-culturists and of persons known as being interested in fishculture. pp. 558-566. 


\section{Results of work.}

1. Reports of the Commission.

\section{(United States Commission of Fish and Fisheries. Part II.)}

XXII. Papers relativg to practical Fish-cUlture.

A. Method of treating adhesive eggs of certain fishes; especially of the Cyprinidæ, in artificial propagation. By Rudolph Hessel. pp. 567-5\%0.

B. On the so-called "dry" method of impregnating spawn. By Alexander Stenzel, inspector of fisheries in Silesia, Germany. pp. 571-574.

C. Fish-culture in salt or brackish waters. By Theodore Lyman, Fish Commissioner of Massachnsetts. pp. 5\%5-5\% .

D. Descriptions of improved apparatus in fish-hatching. pp. 578-587.

APPENDIX E.-OBSTRUCTIONS TO THE UPWARD MOVEMENT OF FISHES IN STREAMS, AND THE REMEDY. pp. 588, 589.

XXIII. Ox FISH-WAYS. By Charles G. Atkins. pp. 591-615.

XXIV. ON OBSTRUCTIONS TO THE ASCENT OF FISH IN CERTAIN RIVERS. p. $61 \%$.

A. Obstructions in the rivers of Maine. By E. M. Stillwell. pp. 617-621.

B. Obstructions in the tributaries of Lake Ch:ım. plain. By M. C. Edmunds. pp. 622-627.

C. Obstructions in some of the rivers of Virginia. By M. McKennie. pp. 628-629.

D. Character of the streams on the northern shore of Lake Michigan. By J. F. Ingalls. pp. 630-332.

E. Characters of some of the northern tributaries of Lake Michigan. By James W. Milner. pp. $632-634$.

Appendix F.-Natural History. pp. 635-636.

XXV. The Crustacea of the Fresh Waters of the UNited States. By Sidney I. Smith.

A. Synopsis of the higher fresh-water Crustacea of the Northem United States. pp. 637-657.

B. The crustacean parasites of the fresh-water fishes of the United States. pp. 661-665.

XXVI. SYNOPSIS OF THE NORTH AMERICAN FRESH-WATER Leeches. By A. E. Verrill. pp. 666-689.

XXVII. SKetch OP THE INVERTEBRate FAUNA OF LAKE SUPE. RIOR. By Silney I. Smith. pp. 690-706.

XXVIII. Food of Fresh-Water FIShes. By Sidney I. Smith. pp. $708-709$.

XXIX. Natural ANd economical history of the Gourami (Osphromenus goramy). By Theodore Gill. p. 710 .

A. Natural history. pp. 710-717.

B. The introduction and attempts to introdnce the gourami into foreign countries. pp. 718-723.

C. Rules for transportation and introduction. p. $72 \%$.

XXX. Notes on the Grayling (Thymallus) of North Auer. ICA. By James W. Milner. pp. 729-742

Appendix G.-Miscellateous Papers. p. 743. 


\section{Results of work.}

1. Reports of the Commission.

(Unted States Commission of Fish and Fisheries. Part II.)

XXXI. Temperature in the Gulf of Mexico, Fron records of the United States Cosst Survey. pp. 745-748.

XXXII. CORRESPONDENCE WITH CONPANIES RELATIVE TO FACIL ITIES IN TRANSPORTATION, ETC. pp. 749-756.

XXXIII. REPORTS OF SPECIAL CONFERENCES WITH AMERICAN Fish-Culturists' Association and State Connis'sIONERS OF Fisheries. p. 757.

A. Meeting at Boston, June 13, 1872. pp. 757-762.

B. Meeting at New York, October 17, 1872. pp.763-773.

XXXIV. Bibliography of Reports of Fishery Commissions. By Theodore Gill. pp. 764-773.

A. Names of Commissioners. p. 774.

B. Bibliography of reports. pp. 775-784.

List OF ILlustrations. pp. 785-790.

General INDEX. p. 791.

United States Commission of Fish and Fisheries. Part III.-Report OF THE COMmissIoNer FOR 1873-4 AND 1874-5. A.-INQUIRY INTO THE DECREASE OF THE FOOD-FISHES. B.-THE PROPAGATION OF FOOD-FISHES IN the waters of the United States. By Spencer F. Baird, Commissioner. Washington: Government Printing-Office. 1876.

APPENDIX A.-SEA-FISHERIES AND TIIE FISHES AND INVERTEBRATES USED AS FOOD.

I. Historical obSERVATIONS ON THE CONDITION OF THE FISHERIES AMONG THE ANCIENT GREEKS AND ROMANS AND THEIR MODE OF SALTING AND PACKING FISH. By J. K. Smidla. pp. 1, 2.

II. Statistics OF THE Most important Fisheries of the Nortil Atlantic. By Carl Dambeck. pp. 3-24.

III. ON the FISIIERIES OF NoRWAy. pp. 24-30.

IV. Statistical Data REgardiNG the SWEDish Fisheries. pp. 31-34.

V. ACCOUNT OF THE FISHERIES AND SEAL-HUNTING IN THE White Sea, the Arctic Ocean, and the Caspian SeA. By Alexander Schultz. pp. 35, 96.

VI. 'The Norwegian Herring-Fisheries. 'By A. J. Breck and A. Fadderdin. pp. 97-122.

VII. Preliminary Report for 1873-'74 on the Herrivg AND THE HERRING-FISHERIES ON THE WEST COAST OF Swedex. By Axel Vilhelm Springman. pp. 123-168.

VIII. The Halibut fisheries of the United States. By Lieut. P. De Broca. pp. 169-172.

IX. The fishing villages Shikikerstur aNd Skolterup, AND THE COLLECTION OF FISHING IMPLEMENTS EXhibited by THEM at ElsiNore, DenMaRK, DURING THE SUMMER OF 1872. pp. 173-182.

X. ON THE HerriNg AND ITS PREPARATION aS AN ARTICLE OF TRADE. By Hyalmar Widigner. pp. 183-192.

XI. New Contributions to the Herring question-The DISPUTE BETWEeN AXEL Back aNd Ossiay SARg REGARDING THE NORWEGIAN SUMMER HERRING- SARS' RECENT OBSERVATIONS AND HIS NEW THEORY ON THE MigRation OF tHe HERRING. pp. 193-194. 


\section{Results of work.}

1. Reports of the Commission.

(United States Comission of Fish and Frsheries. Part III.)

XII. ON THE SPAWNING AND DEVELOPMENT OF THE COD. FIsH. By Prof. C. O. Sars. pp. 195-222.

XIII. THE NorwegIAN LOBSTER FISHERY AND ITS HISTORY. By Axel Broeck. pp. 223-25\%.

Xiv. Transportation of Lobsters to California. pp. 253-25\%.

XV, ON THe ARTIFicial PROPAGATION OF THE LOBSTER. pp. 258-266.

XVI. ON THE Oyster INDUStries OF THE UNited States. By Lieut. P. De Broca. pp. 267-320.

APPENDIX B.-THE RIVER FISHERIES. pp. 321-322.

XVII. The propagation axd distribution of the Shad. pp. 323-350.

XVIII. Report of the Triana trip. By J. W. Milner. pp. 351-362.

XIX. ON THE TRANSPORTation OF SHAD FOR LONG DISTANCES. pp. 363-371.

XX. Report of operations in California in 1873. By Livingston Stone. pp. 372-42\%.

XXI. Hatching aNd distribution of Califorma Salmon. pp. 428-436.

XXII. REPORT OF OPERATIONS DURLNG 1874 AT THE UNITED STATES SALMON-HATCHING ESTABLISHMENT ON THE McCloud River, Californa. By Livingston Stone. pp. $437-476$.

XXIII. Correspondence relating to the SAN JoaquiN RIVER AND ITS FISHES. pp. 477-484.

XXIV. The Atlantic Salmox (Salmo Salar). By A. G. Atkins. pp. $485-539$.

APPENDIX C.-Fish-CULTCRE, RELATING MORE ESPECIALLY TO SPECIES of (Cyprinida). pp. 540.

XXV. Notes ox Pisciculture in Kiang Sr. By H. Kopsch. pp. $543-548$.

XXVi. ON the culture of the Carp. pp. 549-558.

XXVII. THE GoLd ORFe (Cyprinus orfus). pp. 559-562.

XXVIII. DIRECTIONS FOR USLNG TABLES FOR RECORDING THE PROPAGATION AND DISTRIBUTION OF FISH. pp. 563-568.

APPExdix D.-The REstoration, OF THE INLAND FISHERIES. pp. $569-5 \tilde{7} 0$.

XXIX. Fisheries AND fishing Laws in Austria and the World in general. By Carl Peyrer. pp. 571-680.

XXX. HOW CAN OUR LAKES AND PONDS BE STOCKED WITH FIsH IN THE ShORTEST POSSIBLE TIME? By Mr. Von dem Borne. pp. 681-684.

Appexdix E.-Natural History. pp. 685-686.

XXXI. Preliminary report on a Series of dredgrygs made ox the Uxited States Coast Survey steaner Bache in the Gulf of Mañe. By A. S. Packard, jr., M. D. pp. $687-690$.

XXXII. List of the Marine Alge of the United States. By W. G. Farlow. pp. 691-718. 


\section{Results of work.}

1. Reports of the Commission.

(United States Commission of Fish axd Fisheries. Pari III.)

XXXIII. SECTION ON THE ORgANS OF REPRodection AND THE FECUNDATION OF FISHES AND ESPECLALLY OF ENLS. By Dr. Syrski. pp. 719-734.

XXXIV. The food aNd Mode of LIVING of tue Salyox, TIIE: Trout, Axd the Sinad. By D. Barfurth. pp. 735-7:8.

United States Commission of Fisi and Fisheries. Part IV.-Report OF THE CoMmissioner For 1875-1876. "A.-INQUiRY INTO THE DECREASE. of the FoOD-Fishes. B.-THE propagation of FOOD-Fishes in the. waters of the United States. Washington: Government PrintingOffice. 1878. 8vo., pp. ix, 50, 1029, plates vi (Hist. of whale fishery).

I. Report of the Conmissioner.

A.-General considerations.

1. INTRODUCTORY REMARKS. p. 1.

B.-INQUIRY INTO THE DECREASE OF FOOD-FISHES.

2. INVESTIGATIONS AND OPERATIONS OF 1875. p. 4.

3. INVESTIGATIONS AND OPERATIONS OF 1876 . p. 7 .

C. -THE PROPaGation OF FOOD-FISHES.

4. General considerations. p. 8.

5. ACTUAL WORK OF PROPAGation OF FOOD-Fishes iN 1875 AND 1876. p. 20.

The shad. p. 20.

The California salmon. p. 21 .

The Atlantic salmon. p. 25.

The land-locked salmon. p. 25.

The white-fish. p. 26.

D. -TABLES.

The carp. p. 27.

TABLE 7.-HATChING AND DISTRIBUtiox OF FISII BY TIIE UNited States Fish Conyission from the BEGINNING OF ITS WORK IN 1872 TO THE SCMMER OF 1876. p. 28.

II.-APPENDIX TO REPORT OF COMMISSIONER.

APPENDIX A.-THE SEA FISHERIES.

I. History OF tHe AMERICAN WHALE FISHERY FROM: ITS EARLIEST INCEPTION TO THE YEAR 1076. By Alexander Starbuck.

APPENDIX B.-THE INLAND FISHERIES.

II. Fisheries of Chicago and vichity. Br E. W. Nelson. p. 783.

III. The salion fisheries of the Colvibia River. By Livingston Stone. p. 801.

IV. Notes oN SONE FISHERIES OF tIIE DelawaIE Rrver. By Dr. C. C. Abbott. p.825.

V. Method of PURIFYixg THE RESIDUUM OF GASWORKS BEFORE ALLOWING IT TO PASS OFF INTO THE Water. By J.R. Shotwell. p. 847.

VI. TABLES OF TEMPERATURES OF AIR AND WATER AT . SUNdRy Stations of the Uxited States Sigral Office, from March, 1874, to Febreary, 1875, AND Fron March, 1876, to February, 187\%, INCLUSIVE. p. 851 . 
ANIMAL RESOURCES AND FISHERIES OF UNITED STATES. 241

\section{Results of work.}

1. Reports of the Commission.

(United States Commission of Fish and Fisheries. Part IV.)

APPENDIX C.-THE PROPAGATION OF FOOD-FISHES.

VII. THE CARP AND ITS CULTURE IN RIVERS AND I.AKES, AND ITS INTRODUCTION INTO AMERICA.* By Rudolph Hessel. p. 865 .

VIII. THE PROPAGATION AND DISTRIBUtion OF SHAD. Jas. W. Milner. p. 901.

IX. ON THE COLLECTION OF EGGS OF SCHOOdIC SALMON IN 1875 AND 1876. By Charles G. Atkins. p. 910.

X. Operations on the McCloud River in salmonBREEDING IN 1875. By Livingston Stone. p.921.

Xi. Operations on the McCloud River in salmonBREEDING IN 1876. By Livingston Stone. p. 935.

XII. CORRESPONDENCE RELATING TO THE EXPORTATION OF Fish-Hatching apparatus to NeW Zealand, Germany, \&c. p. 959 .

ALPHABETICAL INDEX. p. 1025.

2. Collections. (See under A, V to VIII.)

\section{Photographs.}

See series of photographs and color-sketches of North American fishes.

Upwards of four hundred casts of coast and fresh-water species.

(See under A, V to VIII.)

\section{PROTECTIǪN.}

2. Preservation of gave, fish, etc.

* From man.

\section{Game laws.}

$$
\text { ** From artificial obstructions. }
$$

\section{Fish-ways.}

Gap fish-ways.

French, ditch, or "Cape Cod" fish-ways.

Oblique groove fish-ways.

Single groove.

15355. Model of fish-way. James D. Brewer, inventor, Muncy, Lycoming County, Pa.

15356. Model of fish-way. James D. Brewer, Muncy, Pa.

Bull. N. M. No. $14-16$ 


\section{Fish-ways.}

Step fish-ways.

Box or pool fish-ways.

25108. Model of fish-way. Jas. D. Brewer, Muney, Pa. Patented by Daniel Steck.

/ Steps contrived by arrangement of rocks and bowlders.

25701. Model of Duneanson fisli way. J. T. Rothe.

Inclined plane without steps.

29283. Model of old Pennsylvania fish-way. Built at Columbia, on the Susqhehanna River, in 1866. Designed by James Worral. Scale, $\frac{1}{8}$ inch to the foot. C. G. Atkins, Bucksport, Me.

29284. Model of old Pennsylvania fish-way. Bnilt at Columbia, on the Susquehanna River, in 1873. Designed by James Worral. Scale, $\frac{1}{8}$ inch to the foot. C. G. Atkins, Bucksport, Me.

With partitions at right angles.

¿9291. Model of rectangular return fish-way. Scale, $\frac{1}{4}$ inch to the foot. C. G. Atkins, Bucksport, Me.

Brackett's patent fish-way.

29285. Brackett's patent fish-way. Scale, $\frac{1}{4}$ inch to the foot. C. r. At.kins, Bucksport, Me.

303\%. Model of the fish-way at Holyoke, Mass., on the Connectiont River. Scale, $\frac{1}{8}$ of an inch to the foot $\left(\frac{1}{96}\right)$. C. G. Atkins.

This fish-way is on the Brackett plan. A submerged piece of colwork surmounted by a grating serves to turn the fish into the fish-way. It carries a column of water 2 feet wide and 2 feet deep which reaches the bottom with no perceptible increase in velocity, the current being less than 2 miles an hour. Height of the dam, 30 feet; length of the fish-way, 440 feet; the incline, 1 in 15.

\section{With oblıque partitions.}

29287. An adaptation of Foster's fish-way. Designed by C. G. Atkius, and built at Pembroke, Me. Scale, $\frac{1}{4}$ inch to the foot. C. G. Atkins, Bucksport, Me.

:9286. Model of Foster's fish-way. Invented by H. H. Foster, E. Machias, Me. Seale, $\frac{1}{4}$ inch to the foot. C. G. Atkins, Bucksport, Me.

29288. Model of oblique fish-way. Invented by Alfred Swazey, Bneksport, Me., in 1876. Seale, $\frac{1}{4}$ inch to the foot. C. G. Atkins, Bucksport, Me.

29289. Swazey's oblique fisli-way. Invented by Alfred Swazey, Bncksport, Me., in 1874. Scale, $\frac{1}{4}$ inch to the foot. C. G. Atkins, Bucksport, Me.

29290. Model of Swazey \& Atkins's fish-way. Invented by Alfred Swazey and C. G. Atkins, Bucksport, Me., in 1874. Scale, $\frac{1}{4}$ inch to the foot. C. G. Atkins, Bucksport, Me.

-. Model of the McDonald fish-way. M. MeDonald, Lexington, Va.

26939. No. 15. Model of the fish-way at Lawrence, Mass., on the Merrimack liver Scale, $\frac{1}{8}$ inch to the foot $\left(\frac{1}{96}\right)$. C. G. Atkins. 


\section{Fish-ways.}

With rectangular compartments.

2593\%. Model of rectangular compartment fish-way on the inclined-plane system, in an extended arrangement. Scale, $\frac{1}{2}$ inch to the foot $\left(\frac{1}{24}\right)$. C. G. Atkins.

Spiral fish-ways.

26949. No. 11. Model of rectangular compartment fish-way on the inclinedplane system, in spiral arrangement, devised by Charles G. Atkins, of Bucksport, Me., in imitation of Pike's spiral fish-way. Scale, $\frac{1}{2}$ inch to the foot $\left(\frac{1}{24}\right)$. C. G. Atkins.

This model represents a fish-way precisely the same capacity and slope, and adapted to a dam of the same height as No. 10, showing the great economy of space and material effected by the spiral arrangement. Further advantages of the spiral arrangement are the facility with which water can be admitted at different heights of the river, and contiguity of the outlet to the dam secured, so that the fish will readily find it.

26931. Model of Pike's spiral fish-way, devised by Hon. R. G. Pike, of Connecticut. Sale, $\frac{1}{2}$ inch to the foot $\left(\frac{1}{24}\right)$. C. G. Atkins.

The advantages of this, the first spiral arrangement invented in America, are the same as those claimed for that arrangement in Pike's spiral fish-way.

Moving float fish-ways.

26930. Model of Everleth's fish-way, derised by F. M. Everleth, M. D., of

Waldorboro', Me. Scale, $\frac{1}{4}$ inch to the foot $\left(\frac{1}{48}\right)$. C. G. Atkins.

The peculiarity of this fish-way is the movable attachment at the upper end, which, by its own buoyancy, rises and falls with the fluctuations of the river, thus insuring that the entrance shall always be at the right height to adnit the requisite quantity of water.

***From natural enemies.

\section{Apparatus for destroying injurious species.}

Oyster-bed tangles. (See under B, 12.)

\section{Tethers and hopples. \\ Cages and pens.}

Kennels for dogs, \&c.

Cages for animals.

Cages for birds.

Cages for insects.

5631. Cages for fire-flies. West Indies. Miss Septimia Randolph. 


\title{
Fish-cars and other floating cages for aquatic ani- mals.
}

29539. Model of fish-marketman's ear. For preservation of living fish. J. M. K. Southwick, Newport, R. I.

22221. Model of Providence River fish-car. These are towed by the smack, and as fast as fish are caught they are put into it, and so kept for Providence market. D. D. Almy.

29397. Model of Noank lobster-car. Capt. H. C. Chester.

29538. Model of fisherman's car for transporting living fish to market. J. M. K. Southwick, Newport, R. I.

26933. Model of a boat used in transporting living salmon at the United States salmon-breeding station at Bucksport, Me. Scale, 1 inch to the foot ( $\left.1_{2}^{\frac{1}{2}}\right)$. C. G. Atkins.

When in use the boat is depressed until full of water, a number of salmon, sometimes as many as 30 , are placed in it, and it is then towed after another boat, the motion insuring a constant change of water, which passes in at the forward ports and out at the after ports. The net and grating prevent the escape of the salmon, and the cloth shuts out the sight of any-

\section{Aquaria.} thing that might frighten them.

Globes.

Aquaria.

\section{Hives and other cages for insects.} Hive-boxes, troughs, \&c., for microscopists' use. Fish-ponds, fish-farms (morlels).

29278. Parlor trout-brook. Stone \& Hooper, Charlestown, N. H. 29380. Rearing-box. Stone \& Hooper, Charlestown, N. IH.

4. ENEMIES OF USEFUL ANIMIALS.

Intestinal worms and other internal parasites. ${ }^{1}$ Fish-lice, barnacles, and other external parasites." Predatory animals not elsewhere cxhibited. .

\section{PROPAGATION.}

\section{Propagation of mamials.}

\section{Methods of mink culture.} Methods of culture of domesticated animals.

\author{
6. Propagation of BIRDS.
}

\section{Methods of ostrich culture. Methods of culture of domesticated birds, fowls, \&e.}


ANIMAL RESOURCES AND FISHERIES OF UNITED STATES. 245

7. Propagation of reptiles.

\section{Methods of terrapin culture.}

8. Propagation of amphibians.

Methods of frog culture.

9. Propagation aNd culture of fishes. ${ }^{1}$

\section{Accessories of obtaining and impregnating ova.}

Pans, pails, \&c.

Strait-jackets used in spawning salmon.

Spawning-race (Ainsworth).

Roller spawning-screen (Collins).

Spawning-vat (Bond).

\section{Hatching-apparatus.}

26940. No. 19. Model of hatching-house at United States salmun-breeding station at Bucksport, Me. Scale, $\frac{1}{6}$ inch to the foot $\left(\frac{1}{48}\right)$. C. G. Atkins.

The hatching-troughs are arranged in sets of four across the building, and fitted with Brackett trays. The water enters them from a feed-trough along the side of the room and escapes by pipes through the floor.

Troughs :

Plain.

Gravel-bottomed.

With sieve-bottom trays.

26936. No. 20. Model of hatching-troughs and trays in use at the United States silmon-breeding stations at Bucksport and Grand Lake Stream, Me. Scale, full size. C. G. Atkins.

The eggs to be hatched are placed on the wire-cloth trays.

26935. Model of hatching-frame in use at Grand Lake Stream, adapted to use in a trough or in an open stream. Devised by C. G. Atkins. Scale, full size. C. G. Atkins.

The eggs are placed on all of the trays except the upper one. The interstices, though too small for the escape of the eggs, permit a change of water, and when the frame is shut it confines the trays securely in place.

26970. Model of hatching-apparatus for black-bass. John Roth, Duncannon, $\mathrm{Pa}$.

Brackett's.

Williamson's.

Clark's.

Vats or cases :

Holton's.

Roth's.

${ }^{1}$ Many of these articles cannot conveniently be exhibited. 


\section{Hatching-apparatus.}

Glass-grilled boxes (Coste's).

26995. Coste hatching-tray. Mrs. J. H. Slack, Troutdale, N. Y.

Jars and tin vessels.

22247. Shad-hatching ean. Invention of Fred. Mather. U. S. Fish Commission.

26909. Ferguson aquarium-jar. T. B. Ferguson, Baltimore, Md.

22250. Ferguson's fish-hatching can.

26998. Ferguson's hatehing jar.

"6 "6

Hatching-boxes (floating).

26903. Shad-hatching box. Seth Green's patent. U. S. Fish Commission.

26997. Shad-hatching box. Seth Green's patent. Seth Green, Rochester, N. Y.

26904. Shad-hatching box. Braekett's patent. U. S. Fish Commission.

26962. Shad-hatching box. Brackett's patent. E. A. Brackett, Winchester, Mass.

26905. Shad-hatching box (No. 2). Brackett's patent. U. S. Fish Commission.

26906. Shad-hatching box. Bryant's patent. U. S. Fish Commission.

26907. Shad-hatching box. Stillwell \& Atkins's patent. U. S. Fish Commission.

26908. Shad-hatching box. Bannister's design. U. S. Fish Commission.

26955. Hatching apparatus. N. W. Clark, Clarkston, Mich.

- Shad hatching-box (model). J. C. House \& O. A. McClain, Washington, D. C.

Adhesive eggs apparatus:

Vertical wire-cloth trays.

Hatching-basket.

26956. Salmon egg hatching-baskets. McClouc. River, California. Livingston Stone.

Brook-shanty (Furman's).

(Bay or cove barriers, Professor Rasch's.)

Accessories:

Tanks.

Nests.

Trays.

Grilles.

Gravel-filters.

Flannel screens.

Shallow troughs or tables (for picking eggs).

Egg-nippers.

26915. Wooden nippers. Fred. Mather, Honeoye Falls, N. Y.

25955. Brass egg-nippers. Frank N. Clark, Northville, Mich.

Cribbles.

Pipettes.

Skimmer-nets. 


\section{Hatching-apparatus.}

Accessories:

Feathering quills and brushes.

Rose-nozzles (for washing eggs).

Syringes, bulb, \&e.

Shallow pans.

Aerating-pipe.

\section{Transporting apparatus.}

Apparatus for transporting eggs:

Cans.

Case of eups (Wilmot's).

Case of eups (Clark's).

Case of trays (Clark's).

Moss-crates (Stone's).

25025. Moss-crates for transportation of eggs of Sacråmento salmon across the continent. Livingston Stone, Charlestown, N. H.

Apparatus for transporting fish:

Barrels.

Cans, plain.

26911. Milk-can, used in transportation. U. S. Fish Commission.

29377. Conical tank. Stone \& Hooper, Charlestown, N. H.

26910. Conical ean. Livingston Stone, Charlestown, N. H.

Cans with aerating accessories:

26914. Tank for ocean transportation. Invention of Fred. Mather. U. S. Fish :mmission.

29379. Trans „нr viug-tank. Stone \& Hooper, Chariestown, N. H.

26881. Transporting-can. C. W. Rogers, Waukegan, IIl.

26932. Model of box used in the transportation of living salmon at the United States salmon-breeding station at Bucksport, Me. Scale, 2 inches to the foot ( $\left(\frac{1}{6}\right)$. C. G. Atkins.

When in use the box is filled with water and from 5 to 7 salmon placed in it and carted a mile.

Slack's.

Clark's.

M. A. Green's.

Tanks, with attachment of band-wheel to car-axle (Stone's).

(Tanks, with Freiburg aerating apparatus.)

Aquarium-ear (Stone's).

Live-box (Atkins's).

Accessories:

Air forçe-pumps.

Siphon-tubes.

26912. Rubber siphon-tube. U. S, Fish Commission.

26913. Aerating-rose, with siphon. U. S. Fish Commission. 
248 ANIMAL RESOURCES AND FISHERIES OF UNITED STATES.

\section{Transporting apparatus.}

Accessories:

Bellows.

Dipping apparatus.

26934. Model of dipping-bag used instcad of a dip-net in handling salmon at the United States salmon-brecding station at Bucksport, Me. Scale, 1 inch to the foot $\left(\frac{1}{12}\right)$. C. G. Atkins.

10. Propagation of insects.

\section{Propagation of silk-worm.}

Specimens of plants used for food.

Model of house and its appliances.

\section{Propagation of cochineal insect. Propagation of bees.}

For hives see under E, 3.

11. Propagation of worms.

\section{Propagation of leeches.}

12. Propagation of mollusks.

\section{Methods of oyster culture.}

Stools for receiving spat, natural and artificial. Other apparatus.

13. Propagation of corals.

14. Propagation of sponges. 


\section{PART II.}

CATALOGUE OF ILLUSTRATIONS

OF THE

\section{ECONOMICAL INVERTEBRATES}

OF

THE AMERICAN COASTS.

BY

$$
\text { W. H. DALL. }
$$





\section{CATALOGUE OF ILLUSTRATTONS OF THE ECONOMICAL INVER- TEBRATES OF THE AMERICAN COASTS.}

\section{MOLLUSCA.}

\section{Mollusca cephalopoda.-SQUIDS AND CUTTLES.}

32905. Sepia "bone," or endosteum, in natural condition. East coast of the United States. Uses: Fed to cage-birds requiring lime.

32905a. Pounce: Powdered sepia-bone; used in rewriting over erasures to prevent blotting, in medicine as an antacid.

33005. Cuttle-tish (Octopus punctatus, Gabb). California to Alaska. Used for bait in the cod-fishery, and by the natives for food. W. H. Dall.

25972. Oil of squid (Ommastrephes illeccbrosa). Capt. N. E. Atwood, Provincetown, Mass.

\section{Mollusca gasteropoda.-SEA-Sirails, \&c.}

A. Useful :

\section{Used for food or bait:}

32885. Velvet chiton (Cryptochiton stelleri). Alaska to California. Indian food. W. H. Dall.

32886. Coat-of-mail shell (Katherina tunicata). Alaska to California. Indian food. W. H. Dall.

32883. Limpet (Acmaa testudinalis). Connecticut to Labrador. W. H. Dall. 32904. Western limpet (Acmeca patina). Alaska to California. W. H. Dall. 32880. Rockwinkle (Litorina subtencbrosa). Alaska to Oregon. W. H. Dall. 32882. Periwinkle (Purpura canaliculata). Alaska to California. W. H. Dall.

32884. Periwinkle (Purpura ostrina). California. W. H. Dall.

32903. Periwinkle (Purpura lapillus). Cape Cod to Labrador. W. H. Dall.

2. Useful by producing pearl-shell, \&c.:

32830. Turban-shell (Trochiscus norrissii). California: H. Hemphill.

32832. Top-shell (Pomaulax undosum), in uatural state. California. H. Hemphill.

32831. Top-shell, prepared to show pearly layers. California. H. Hemphill.

29301. Manufactured state of rarious kinds of American pearl-shells derived from gasteropods or sea-snails. Furnished by A. B. De Frece \& Co., 428 Broadway, New York.

32838. Sea-ears (Haliotis Kamchatkana), affording pearl-shell and food. Alaska. J. G. Swan. 
32890. Rough sea-ear (H. corrugata). Southern California. Used for pearlshell and for food. Specimen in natural condition. W. H. Dall.

- Rough sea-ear. Specimen ground and polished to show pearly layers. J. T. Ames.

32900. Red sea-ear or abalone (H. rufescens). Monterey, Cal. Used for pearl-shell and for food. Specimens in natural condition. $H$. Hemphill.

—. Red sea-ear. Polished specimen showing pearly layers. J. T. Ames.

—. Red sea-ear. Fleshy portion prepared and dried for food by California Chinese. Chinese market, California. H. Hemphill.

32823. White abalone (H. cracherodii), produeing pearl-shell and food. Natural state. California. Paul Schumacher.

32899. White abalone. Natural state. Monterey, Cal. H. Hemphill.

- White abalone. Polished to show pearly layers. Jas. T. Ames.

4792. White abalone. Polished specimens.

32821. Splendid sea-ear (H. splendens) affording food and pearl-shell. California. Paul Schumacher.

32893. Splendid sea-ear. Natural condition. Southern California. H. Hemphill.

- Splendid sea-ear. Polished to show pearly layers. J. T. Ames.

-. Splendid sea-ear. Young specimen polished. J. T. Ames.

29302. Manufactures of Haliotis shell, showing application in the arts. Furnished by A. B. De Freco \& Co., 428 Broadway, New York.

29248. Ditto. Parasol-handles. Furnished by Harvey \& Ford, Philadelphia, Pa.

\section{Afforling cameo and porcelain stock:}

6968. Cameo-shell (Cassis rufa), used for cameo cutting. Florida. Dr. Wm. Stimpson.

- Queen conch (Strombus gigas), exported to Liverpool in great numbers and ground up for making porcelain. ${ }^{1}$ West Indies.

\section{Used in Indian trade:}

2705. Hyqua shell (Dentalium indianorum), used in Indian trade. In this case the shells have been made into a belt by the purchaser. West coast of America. U. S. Exploring Expedition.

\section{Affording dyestuffs:}

32907. Sea-hare (Aplysia). Affording purple dye. Florida. F. B. Meek. 32896. Sea-hare. Specimen of the purple fluid. F. B. Meek.

32911. Purple shells (Phyllonotas radix). Ornamental and producing dye. Lower California. W. H. Dall.

32912. Purple shells (Phyllonotus bicolor). Used for ornaments and affording dye. West coast of America. W. H. Dall.

6. Affording bird-lime:

33080. Giant slug (Ariolimax columbianus), affords a thick tenacious slime, which is used by the Indians to lime humming-birds. California to Alaska. H. Hemphill.

\footnotetext{
1 The sea-ears and queeu conchs are also largely used in Indian trade in a manufactured state.
} 
B. Injurious:

1. By destroying food-producing mollusks or shell fish, such as clams, mussels, oysters, and razor-fish :

32850. Ribbon whelk (Fulgur carica). Florida. T. A. Conrad.

32859. Reversed whelk (Fulgur perversa). Carolinas. Dr. Wm. Stimpson.

32861. Hairy whelk (Sycotypus canaliculatus). Vineyard Sound. Dr. Wm.

Stimpson.

32864. Winged conch (Strombus alatus). Tampa Bay, Florida. T. A. Conrad. 32863. Thorny drill (Hemifusus bicoronatus). Tampa Bay, Florida. T. A. Conrad.

32835. Drill (Crosalpinx cinereus). Florida to Massachusetts Bay. W. H. Dall. 32975. Drill. South Norwalk, Conn. Hoyt Bros.

32837. Periwinkle (Purpura floridana). Barataria Bay, La. Gustar Kohn. 32892. Sea-snail (Lunatia Lewisii). Monterey, Cal. H. Hemphill.

32913. Sea-snail (Neverita recluziana). California. W. H. Dall.

27620. Sea-suail (Neverita duplicata). North Carolina. T. D. Kurtz.

32866. Sea-snail (Lunatia heros). Massachusetts Bay. C. B. Fuller.

2. Injurious by destroying vegetable substances and garden plants :

33088. Slug (Limax Hewstoni). Oakland, Cal. H. Hemphill.

\section{Mollusca acephala.-BIVALVE SHELLFISH.}

d. Producing food or used as bait.

* Oysters.

1. Series illustrating distribution and geographical varieties:

\section{Ostrea virginica, Gmelin.-EAST AMERICAN oysters.}

32784. Northern variety (O. borealis, Lam.) Prince Edward's Island. J.

W. Dawson.

32813. Nova Scotia. J. H. Willis.

32785. Shediac, New Brunswick. W. H. Dall.

33092. "Ponrrier Bed." Shediac, New Brunswick. G. F. Mathew.

33093. "Buctouche." Kent County, New Brunswick. G. F. Mathew.

32783. Miramichi River, New Brunswick. W. H. Dall.

3297\%. Indigenous oyster, now extinct. Shell-heaps. Damariscotta, Maine. Robert Dixon.

32978. Ditto. Shell-heaps. Sheepseot River, Maine. Robert Dixon.

32510. Indigenous oyster (var. borealis). Buzzard's Bay, Mass. Dr. Wm. Stimpson.

32814. Specimens showing color-bands. Rhode Island. General Totten.

Note.-The following series of oysters from the vicinity of New

York were furnished by Mr. B. J. M. Carley, orster-clealer, of Fulton Market, New York, through Mr. E. G. Blackford:

32790. "Greenwich." Greenwich, Conn.

32รr7. "Blue Point." Long Island, New York.

3:2ті9. "Lloyd's Harbor." Long Island, New York. 


\section{3z781. "Cow Bay." Loug Island, New York.}

3z791. "Glenwood." Glenwood, Long Island, New York.

32812. "Cove." Long Island, New York.

32920. "City Island." Loug Island Sound, New York.

32919. "Mill Pond." Cow Bay, Long Island, New York.

32778. "Shrewsburys." Shrewshury River, New Jersey.

33915. "Egg Island." Three years old. Morris Cove, Delaware.

33788. "Chesapeake" Crisfield, Mf. E. G. Blackford.

32976. Pokamoke, Virginia. E. G. Blackford.

NотE.-The following series from the waters of Virginia aud Maryland, all indigenous or "natural growths" as distinguished from "plants," were selected by Mr. G. W. Harvey, and furnished by Harvey \& Holden, oyster-dealers of Washington, D. C. :

33096. "St. Gerome River." Maryland.

33097. "Deep Creek." Eastern shore of Maryland.

33098. "Tangier Sound." Chesapeake Bay.

33100. "Little River." Western shore of Maryland.

33099. "Point Lookont Creek." Virginia.

33101. "Naswaddox." Eastern shore of Virginia.

33095. "Rappahannock." Rappahannock River, Virginia.

33103. "York River." York River, Virginia.

33104. "Cherrystones." Chesapeake Bay.

33102. "Presby's Creek." Presby's Creek, Virginia.

The following series from Florida were furnished by Kossuth Niles, U. S. N.:

32805. "Appalachicola Bay." Appalachicola Bay, Florida.

32806. "Cat Point." Same locality.

3280\%. - - Same locality.

32808. "Raccoou oysters." Appalachicola Bay, Florida.

The following series from the vicinity of New Orleans were selected by M. Zatarain, and furnished by W. Alex. Gordon, esq., of New Orleans, La. :

32800. "Timbalier Bay." Louisiana.

32801. "Southwest Pass." Louisiana.

32802. "Bayon Cook." Louisiana.

32803. "Four Bayous." Louisiana.

32804. "Grand Lake." Louisiana.

\section{Ostrea Iurida, Cpr.-West coAst oysters.}

32879. Natives. Crescent City, Cal. W. H. Dall.

32809. Natives. Shoalwater Bay, W. T. H. Hemphill.

32798. Natives. San Diego, Cal. H. Hemphill.

32798. Eastern oyster (O.virginica). Taken from Newark Bay, N. J., when a year old and planted in San Francisco Bay; showing two years' growth in California waters.

\section{Extra limital :}

32878. Fossil oyster from marine Tertiary beds near Vicksburg, Miss. Closely resembling the present English oyster.

32311. Fresh specimen, English oyster (O. edulis, Linn.). Introduced for comparison with the American fossil and recent:oysters. North Sea. Dr. Wm. Stimpson. 


\section{Series illustrating culture and individual rariations:}

\section{Dotrea virginica, Gmelin.-East American oysters.}

That portion of the series from South Norwalk, Conn., was furnished by Hoyt Bros. of that place, at the instance of James Richardson, esq. The portion of the series from the vicinity of New York was furnished by Mr. B. J. M. Carley through Mr. L. G. Blackford, of New York.

\section{a. Growth. 1-20 years old:}

32958. Young spat on various stools. South Norwalk, Conn. 3295\%. One year old. South Norwalk, Conn.

32967. Two to three years old. Natural growth. South Norwalk, Conn. 32968. Three to four years old. Natural growth. South Norwalk, Conn. 32955. "Cullers." Three to four years old. South Norwalk, Conn. 32962. Three years after transplantation. South Normalk, Conn. 32964. "Box." Four to six years old. South Norwalk, Conn. 32916. "Cullers." Three years old. Vicinity of New York. 32918. "Single extra." Four years old. Vicinity of New York. 327\%6. "Double extra." Vicinity of New York. 32917. "Box." Three years old. Vicinity of New York.

\section{b. Peculiarities of form and growth:}

32959. "Pinched" oyster from muddy bottom. South Norwalk, Comn. 32930. Showing effect of transplanting the "pinched" from a muddy to a hard bottom. South Norwalk, Conn.

32787. Form eaused by growing in a tideway. Vicinity of New York. 32786. Form caused by growing in still water. Vicinity of New York. 32974. Curious forms of shell. South Norwalk, Conn. 32782. Peculiar growth. Vicinity of New York. 32795. Specimens of peculiar form. Vicinity of New York. 32971. Natural growth on stone. South Norwalk, Conn. 32973. Natural growth on part of stone jug. South Norwalk, Conn. 32972. Natural growth on shells. South Norwalk, Conn. 329r0. Natural growth on bottle. South Norwalk, Conn. 32969. Natural growth on crab. South Norwalk, Conn. 32780. Illustrating methods of attachment. Vicinity of New York. 32914. Blue Point "seed." Long Island, New York. 32789. Rosette of oysters. Vicinity of New York. 32792. Shell growing on Mactra shell. Vicinity of New York. 32794. "Seed" on old rubber boot. Vicinity of New York. 32793. "Seed" growing on stone. Vicinity of New York. 32895. "Seed" on rubber shoe. Vicinity of New York. 32894. "Seed" on bone. Vicinity of New York. 32797. "Seed" on bark. Vicinity of New York. 32796. "Seed" on leather shoe. Vicinity of New York. 32932. "Seed" on old boot-leg. Vicinity of New York.

\section{c. Enemies and parasites:}

3292\%. Specimens injured by whelk. South Norwalk, Conn. 32929. Specimens injured by hairy whelk. South Norwalk, Conn. 
32928. Specimens perforated by "drill." South Norwalk, Conn.

32963a. Specimen injured by boring worm (an Annelid). South Norwalk, Conn.

32956. Specimens killed by star-fish. South Norwalk, Conn.

32963. Specimens showing ravages of Cliona or boring sponge. South Norwalk, Conn.

For commensal erab see Crustacea.

33092a. Lime derived from oyster shells. Use in medicine and as a fertilizer. Washington, D. C. W. H. Dall.

\section{*** Other bivalves.}

A. Affording or available for food or bait.

3288\%. Rock oyster (Placunanomia macroschisma, Desh.). Alaska to California. W. H. Dall.

32873. Scallops (Pecten irradians, Lam.). Long Island Sound. Dr. Wm. Stimpson.

32868. Great scallop (P. tenuicostatus, Migh.). Coast of Maine. C B. Fuller27523. Black mussel (Mytilus edulis, L.). Massaehnsetts Bay. Dr. Wm. Stimpson.

32857. Ditto. San Franciseo Bay, California. H. Hemphill.

32845. Ditto. Monterey, Cal. H. Hemphill.

32849. Ditto. San Diego, Cal. H. Hemphill.

32875. Grooved mussel (Modiola plicatula, Lam.). Nahant, Mass. Dr. Wm Stimpson.

32834. Ditto. (Modiola, sp.) Last Island, La. Gustav Kohn.

32858. Brown mussel (M. capax, Conr.). San Diego, Cal. H. Hemphill.

32876. Ditto. (M. modiolus, L.) Massachusetts Bay. Dr. Wm. Stimpson. 32897. Ditto. Massachusetts Bay. Dr. Wm. Stimpson.

- Ditto. Castine, Me. A: R. Crittenden.

32871. Giant cockle (Cardium magnum, Birn.). Tampa Bay, Florida. 'T. A. Conrad.

32851. Egg cockle (C. elatum, Sby.). Guaymas, west coast Mexico. Dr. Palmer.

32853. Nuttall's cockle (C. nuttallii, Con.). Banlinas, Cal. H. Hemphill. 32891. Ditto. Alaska. W. H. Dall.

32872. "Red edge" (Codakia tigcrrina, L.). Florida. Dr. Wm. Stimpson. 3287\%. Quahog-round clam (V. mercenaria, L.). Maine to Florida.

32862. Ditto. (Var. mortoni.) Maine to Florida. Dr. Stimpson.

32893. Ditto. Providence River, Rhode Island. Benj. Davis.

32819. Ditto. "Snubnosed" var. Fire Island. B. J. M. Carley.

32817. Ditto. Elongated var. Rockaway, N. J. B. J. M. Carley.

32838. Ditto. Barataria Bay, La. Gustav Kohn.

32818. Ditto. Deformed specimens. Long Island Sound. B. J. M. Carley.

- Ditto. Specimens of shell polished. Jas. T. Ames.

32889. "Hen elam" (Pachyderma crassatelloides, Conr.). California. W. H. Dall.

32843. "Round clams" (Saxidomıs aratus, Gld.). San Diego, Cal. H. Hemplill.

3286\%. "Painted clam" (Callista gigantea, Ch.). South Carolina.

32841. "Little Neck elams" (Chione succincta, Val.). San Diego, Cal. II. Hemphill.

32842. Ditto. (C. simillima, Sby.). San Diego, Cal. H. Hemplilll. 
32846. Ditto. (Tapes laciniata, Cpr.). San Diego, Cal. H. Hemphill.

32854. Ditto. (T. staminea, Conr.). Baulinas, Cal. H. Hemphill.

32844. Ditto. Tomales Bay, Cal. H. Hemphill.

32869. "Hen elam" (Mactra solidissima, Ch.). Massachusetts Bay. W. H. Dall.

32870. Ditto. Shells utilized for catch-alls. Newport, R. I. N. C. Peterson. 32888. Ditto. (M. falcata, Gld.). Alaska to California. W. H. Dall. 32826. "Gapers" (Schizotharus nuttalli, Con.). Oregon. J. G. Swan.

32852. Ditto. Baulinas, Cal. H. Hemphill.

32874. Salmon tellen (Macoma, sp.). Florida. T. A. Conrad.

32848. "Tellens" (M. nasuta, Conr.). San Francisco markets. H. Hemphill.

32847. "Flat clam" (Semele decisa, Cpr.). San Diego, Cal. H. Hemphill.

32909. "Razor-fish" (Solen ensis, L.). Cow Bay, New York. B. J. M. Carley. 32881. Ditto. (Siliqua patula, Dixon.) Alaska to California. W. H. Dall. 32955. "Soft-shelled clams" (Mya arenaria, L.). Cape Cod, Mass. E. G. Blackford.

32829. Ditto. Oyster Bay, L. I. E. G. Blackford.

32833. Ditto. Accidentally transplanted with young oysters to San Francisco Bay, where it now abounds greatly. Oakland, Cal. H. Hemphill.

33094. Ditto. Bay of Fundy, N. S. G. F. Mathew.

32850. Date-fish (Platyodon cancellatus, L.). Baulinas Bay, Cal. H. Hemphill.

32856. Ditto. (Zirphaca crispata, L.). Baulinas, Cal. H. Hemphill.

B. Useful or ornamental bivalves other than those affording food:

a. Pearl-producing.

1. River mussels:

26092a. River mussel affording pearl-shell, illustrating application of raw material. Cincinnati, Ohio. D. H. Shaffer.

26092. Carvings, from pearl-shell afforded by river mussels, for use as studs, buttons, pins, brooches, \&c. Cincinnati, Ohio. D. H. Shaffer.

26092b. Pearls derived from river mussels. Cincinnati, Ohio. D. H. Shaffer.

- A series of river mussels of various species, one valve polished, the other in its original condition in each case. Chicopee, Mass. Jas. T. Ames.

25986 to 26010. Another series, both valves polished, from Dr. C. A. Miller, Cincinnati, Ohio, comprising the following species:

Unio rugosus, Barnes.

alatus, Say.

ornatus, Lea.

verrucosus, Barnes.

gibbosus, Barnes.

rectus, Lam.

cylindricus, Say.

pyramidatus, Lea.

tuberculatus, Barnes.

siliquoides, Barnes.

circulus, Lea.

anodontoides, Lea.

pustulosus, Lea.

cuncatus, Barnes, \&.e., \&c.

Bull. N. M. No. $14-17$ 


\section{Marine pearl-shells:}

13507. American pearl-oyster ( $M$. fimbriata). Panama. Col. Jewett. 3624. Ditto. Illustrating formation of pearls. Panama. Col. Jewett. 32836. Ditto. Gulf of California. J. Xantus.

- Ditto. Polished shell. Chicopee, Mass. Jas. T. Ames.

32921. Ditto. Made into artificial fish-bait. Boston, Mass. Bradford \& Anthony.

32922. Ditto. Made into artificial minnow. Boston, Mass. Bradford \& Anthony.

- Series of buttons, studs, stopper-caps, \&c. Manufactured from, and showing application of American pearl-oyster shell. Furnished by A. B. De Frece \& Co., 428 Broadway, New York.

\section{b. Otherwise useful:}

32869. "Hen clam" (Mactra solidissima, Ch.). Shell used for scoops, milkskimmers, and boat-bailers. Painted inside and used for catch-alls.

29527. Basket. Made from Florida shells. E. F. Gilbert, Jacksonville, Fla.

22210. Basket. Made from Florida shells. Mrs. C. E. Mott, Jacksonville, Fla.

22209. Frame. Made from Florida sea-shells. Mrs. C. E. Mott, Jacksonville, Fla.

22211. Easter Cross. Made from Florida shells. Mrs. C. E. Mott, Jacksonville, Fla.

29526. Shell flowers. Made from Florida shells. E. F. Gilbert, Jacksonville, Fla.

26595. "Coquina." Miscellaneous species broken up and cemented by surf action into a natural conglomerate, used for building stone or for making a superior kind of lime. Saint Augustine, Fla. G. Browne Goode.

32839. "Cuneate clam" (Gnathodon cuneatus). Used largely for bait. Natural condition. Lake Pontchartrain, La. Gustar Kohn.

32840. Ditto. Semi-fossil (in shell-heaps), used for macadamizing roads. Lake Salvador, La. Gustav Kohn.

C. Injurious bivalves:

a. Destroying submerged timber:

\section{Specimens of wood showing ravages:}

32982. Ship-worm (Teredo sp.). Bangor, Me. (Brig H. B. Emory.) C. H. Parker.

32908. Ditto. In lignumvitæ wood. Gloucester, Mass. Samuel Elwell, jr. 33106. Ditto. (Teredo chlorotica, Gld.) Wood's Holl, Mass. Vinal N. Edwards.

33105. Ditto. (Xylotrya fimbriata, Jeffr.) Wood's Holl, Mass. Vinal N. Edwards.

32984. Ditto. (Teredo navalis? L.) New Haven, Conn. A. E. Verrill.

32902. Ditto. (Teredo sp.) Showing damage effected in white-pine wood in one year. Pier 44, North River, N. Y. W. T. Pelton.

32901. Ditto. Showing damage to hard-pine wood effected in one year. Charleston, S. C. W. T. Pelton.

32983. Ditto. Schooner Carrie Melvin; done in 6 weeks. Charleston, S. C. A. G. Hunt. 
32815. Ship-worm. (Teredo sp.). Gulf coast. Dewey. 32816. Ditto. Showing lining of tubes. Texas. Dr. Schott. 19405. Ditto. (Xylotrya sp.) Coast of Oregon. J. G. Swan.

D. Prepared foods:

* Specimens of various brands of canned, preserved, and pickled shell-fish in manufacturers' packages:

26579. Pickled oysters (Ostrea virginica). Blue Point. B. J. M. Carley.

26581. Pickled oysters (Ostrea virginica). Saddle Rocks. B.J.M. Carley, New York.

25835. Fresh Cove oysters (Ostrea virginica). Kemp, Day \& Co., New York. 25844-54. Fresh Cove oysters (Ostrea virginica). Kemp, Day \& Co., New York. 25861-3. Spiced Cove oysters (Ostrea virginica), hermetically sealed. Kemp, Day \& Co., New York.

26577. Pickled Little Neck clams (Mya arenaria). B. J. M. Carley.

26582. Pickled clams (Venus mercenaria). "Cow Bay." B. J. M. Carley.

26642. The Farmers' Old Orchard Beach clams (Little Necks, star brand). Portland Packing Company, Portland, Me.

26575. Pickled scallops (Pecten irradians). Oyster Bay. B. J. M. Carley.

26580. Pickled mussels (Mytilus edulis). East River, N. Y. B. J. M. Carley, New York.

25873. Scarboro' Beach clams (Venus mercenaria). Put np by Burnham \& Morrill, Portland, Me. Kemp, Day \& Co., New York.

25864-6. Orchard Beach elams (Venus mercenaria). Kemp, Day \& Co., New York.

25867-9. Little Neck elams (Mya arenaria). Kemp, Day \& Co., New York. 25870-2. Little Neck clams (Mya arenaria). Put up by Bogart \& Co., New York. Kemp, Day \& Co., New York.

24925. Little Neck clams (Mya arenaria). Wm. Underwood \& Co., Boston, Mass.

22235-6. Pickled Little Neck clans (Mya arenaria). Penobscot Bay. Castine Packing Company, Castine, Me.

26752. Alden's granulated clams. Prepared by Alden Sea-Food Company. Sold by Lyon Manufacturing Company, New York. Presented by E. G. Blackford, New York.

26753. Alden's granulated and concentrated clams (paper boxes). Prepared by Alden Sea-Food Company. Sold by Lyon Manufacturing Company, N.Y. Presented by E. G. Blackford, New York.

** Otherwise prepared.

5672. Dried siphons of Schizothorus Nuttalli. Prepared by the Puget Sound Indians, Wash. Ter. Dr. J. G. Suckley, U. S. Army.

\section{CRUSTACEA.}

\section{Crustacea phyllopoda.}

A. Useful; converted into fertilizers; carapax used as a scoop or boat-bailer:

2222. King crab, Horseshoe (Limulus polyphemus). Florida. F. B. Meek. 2223. Ditto. Male and female. Cape May C. H., New Jersey. Thos. Beesley.

2223. Ditto. Product “cancrine," prepared fertilizer. Cape May C. H., New Jersey. Thos. Beesley. 


\section{Crustacea isopoda.}

A. Useful; by removing wrecks or snags.

B. Injurious; by destroying submerged timber.

2286. Woodeatèr (Limnoria lignorum, White). San Diego, Cal. H. Hemphill.

2254. Ditto. New Haven, Conn. A. E. Verrill.

a. Wood showing ravages:

2240. Eastport, Me. U. S. Fish Commission.

2290. Wood's Holl, Mass. Vinal N. Edwards.

2221. San Diego, Cal. H. Hemphill.

\section{Crustacea stomatopoda.}

Available for food:

2253. Squill (Squilla empusa, Say). Long Island Sound. U. S. Fish Commission.

2268. Southern squill (Coronis glabriuscula, Stm.). Galveston, Texas. M. Wallace.

Crustacea decapoda.-LOBSTERS, SHRIMP, CRAWFISH, CRABS.

A. Useful; food-supplying:

2263. River shrimp (Palcemon sp.). New Orleans, La. Gustav Kohn. 2264. Ditto. (Pal. ohionis, Smith.) New Orleans, La. Gustav Kohn. 2269. Ditto. (Palcomon?) Isthmus of Panama. Dr. Bransford.

2252. Sea shrimp (Palcemonetes vulgaris, Stm.). Long Island Sound. U. S. Fish Commission.

2211. Shrimp (Pandalus Dana, Stm.), as dried for export by Californian Chinese. San Francisco, Cal. H. Hemphill.

2220. Ditto. (Hippolyte brevirostris, Dana.) San Francisco, Cal. H. Hemphill.

2219. Ditto. (Crangon franciscorum, Stm.) San Franciseo, Cal. H. Hemphill.

2251 Ditto. (Crangon vulgaris, Fbr.) New England coast. U. S. Fish Commission.

2267. River crawfish (Astacus oregonensis, Nutt.). California. J. R. Seupham.

2261. Ditto. (Cambarus Clarkii, Gir.) Now Orleans, La. Gustav Kohn. 2265. Ecrevisse (Cambarus affinis, Er.). Potomac River, Va. J. W. Milner. 2280. Lobster (Homarus americanus, Edw.). New York. E. G. Blackford. 2250. Ditto. Series showing young stages. Vineyard Sound, Mass. U. S. Fish Commission.

2241. Ditto. Young specimens, dry. Massachusetts Bay. U. S. Fish Commission.

2212. Ditto. Claws of extraordinary size. Massachusetts Bay. Amos Lawrence.

2213. Ditto. Remarkably abnormal claws. Newport, R. I. J. H. Clarke. 2214. Ditto. Noank, Conn. T. \& E. H. Potter.

—. Pincushion, showing applieation of lobster-claws. Wellfleet, Mass. Miss Anabel Stone.

2215. Prawn; Sea erawfish (Panulirus interruptus, Ran.). Santa Barbar: Cln:ancl, Cal. H. Hemphill. 
2248. Crab (Platyonichus ocellatus, Latr.). Vineyard Sound, Mass. U. S. Fish Conumission.

2256. Ditto. (Panopeus Herbstii, Edw.) New Orleans, La. Gustav Kohn. 2247. Ditto. (Carcinus manas, Leach.) New Haven, Conn. A. E. Verrill. 2243. "Soft-shelled" (in certain stages only) crab (Callinectes hastatus, Say). Vineyard Sound, Mass. U. S. Fish Commission.

2249. Ditto. Long Island Sound. U. S. Fish Commission.

2218. Kelp-crab (Episthus productus, Randall). Monterey, Cal. H. Hemphill.

2244. Crab (Cancer borealis, St.). Casco Bay, Maine. U. S. Fish Commission.

2242. Common crab (Cancer irroratus, Say). Casco Bay, Maine. U. S. Fish Commission.

2245. Ditto. Vineyard Sound, Mass. U. S. Fish Commission.

2217. Scalloped crab (Cancer antennarius, Stm.). San Francisco, Cal. H. Hemphill.

2216. Market crab (Cancer magister, Dana). San Francisco, Cal. H. Hemphill.

B. Commensal with other food supplies:

2266. Oyster-crab (Iinnotheres ostreum, Say). Commensal with all southern oysters and with northern-oysters in northern rivers where the southern oysters have been long planted. New York. E. G. Blackford.

2272. Ditto. Commensal on the western coast with Pachydesma and Mytilus californianus. San Diego, Cal. H. Hemphill.

C. Injurious by burrowing into and weakening levees and dams :

2261. Crawfish (Cambarus Clarkii, Gir. and most other species). New Orleans, La. Gustav Kohn.

2259. Fiddler-crab (Gelasimus pugnax, Smith). New Orleans, La. Gustav Kohn.

D. Prepared foods:

Canned lobster and crabs in manufacturers' packages:

25836-43. Canned lobster (Homarus americanus). Kemp, Day \& Co., New York.

22237. Canned lobster (Homarus americanus). Castine, Me. Castine Packing Company.

26643. Fresh star-lobster (star brand). Portland Packing Company, Portland, Me.

26651. Fresh star-lobster (star brand). Portland Packing Company, Portland, Me.

24926. Fresh lobster (Homarus americanus). Wm. Underwood \& Co., Boston, Mass.

25834. Canned lobster (Homarus americanus). Kemp, Day \& Co., New York. 24933. Original deviled lobster (Homarus americanus). Wm. Underwood \& Co., Boston, Mass.

26578. Pickled lobsters (Homarus americanus). Cape Cod. B. J. M. Carley, Now York.

26576. Pickled prawns. Savanuah, Ga. B. J. M. Carley. 


\section{Cirripedia.}

Injurious:

a. By dulling the edge of knives and spades employed in " cutting in" whale blubber:

2270. Whale barnacle (Coronula diadema, Lam.) on dried skin of "humpback" whale. New England coast. U. S. Fish Commission.

b. By obstructing the progression of vessels upon which they afĩx themselves:

2271. Barnacles (Balanus rugatus, \&e.). California. H. Hemphill.

\section{ANNULOSA.}

\section{Annelida.-WORMS AND LEECHES.}

A. Useful:

1. In surgery and medicine:

3226. Leech (Macrobdella decora, Verrill). New Haven, Conn. A. E. Verrill.

3227. Ditto. (Macrobdella sp.) Mountain Lake, Cal. H. Hemphill.

2. For bait in fishing:

3228. Earthworm (Lumbricus terrestris, L.). Washington, D. C. W. Palmer.

3229. Sea-worm (Nereis sp. ?). San Francisco, Cal. H. Hemphill.

3. For food:

19713. Dried worms (Ephydra sp.). Prepared for food by the Monachee PiUte Indians. Owen's Lake, Cal. Stephen Powers.

19714. Dried worms. Used in making soup by the Monachee Pi-Ute Indians. Owen's Lake, Cal. Stephen Powers.

B. Injurious:

1. By boring into and destroying oyster-shells:

32963a. Oyster-shell, showing ravages (of Heteronereis?). South Norwalk, Conn. Hoyt Brothers.

Note.-Insects and larvæ, commonly called worms, affecting chiefly agricultural interests, are not here included.

\section{RADIATA.}

Radiates.-SEA-URCHINS, STARFISH, CORALS, MEDUSAE, ETC.

$\mathrm{Y}$. B. Strictly ornamental corals and gorgonias, having no special useful application, have, for the same reasons which necessitated the exclusion of the solely ornamental shells, been here omitted.

A. Useful:

1. Food-producing:

3226. Trepang; Bêche-de-mer (Holothuria sp. ?). San Diego, Cal. II. Hemphill. 
3212. Sea-urchin (Strongylocentrotus drobachiensis). New England coast. U. S. Fish Commission.

3146. Ditto. (Toxopneustes sp.) Southern United States. Dr. William Stimpson.

3145. Ditto. (T. francisconım, Ag.) Alaska to California. F. Bischoff.

B. Injurious:

1. Destroying oysters, clams, \&c.:

3214. Starfish (Asterias vulgaris, Stm.). Portland, Me. U. S. Fish Commission.

3149. Ditto. (Ast. arenicola, Stm.) Massachusetts Bay. Dr. William Stimpson.

3213. Ditto. Long Island Sound. U. S. Fish Commission.

3150. Ditto. Sonth Norwalk, Conn. Hoyt Brothers.

3151. Ditto. In act of destroying oysters. South Norwalk, Conn. Hoyt Brothers.

2. By their urticating powers annoying bathers and "fouling" nets and fishing lines with slime-various Acalephs.

\section{PROTOZOA.}

Protozoans.-Sponges, ETC.

\section{Useful:}

1. For conveyance of fluids requiring an elastic and temporary menstruum, and as a detergent:

3210. Sponge (on bougie). Boston, Mass. J. A. Levey.

3206-9. Sponge (Spongia barbara, D. \& M.). Florida Keys and Bahamas. Isaacs \& Co., sponge-dealers, New York.

3205. Ditto. (Spongia graminea, Hyatt). (Prepared by cleansing for use.) Key West. Boston Soc. Nat. Hist.

3203-4. Ditto. (Dried in natural condition.) Key West. Boston Soc. Nat. Hist.

3152-3. \} Ditto. (S. dura, var. densa, Hyatt.) Florida Keys. Isaacs \& Co. 3154-66. Ditto. (S. dura, var. gravida, Hyatt.) Florida Keys. Isaacs \& Co.

3172. Ditto. Dried in natural state. (Aplysina aurca, Hyatt.) Bahamas. Boston Soc. Nat. Hist.

3168-71. Ditto. (Cleansed.) (S. dura, var. punctata, Hyatt.) Florida Keys. Isaacs \& Co.

3177. Ditto. (Dried in natural state.) (S. cerebriformis, Hyatt.) Key West. Boston Soc. Nat. Hist.

3173-76. Ditto. (Cleansed.) Key West and Bahamas. Isaacs \& Co. 3178-9. Ditto. (S. tubulifera, Lam.). Florida and Bahamas. Isaacs \& Co. 3180-85. Ditto. (S. tubulifera, var. rotunda, Hyatt.) Florida Keys and Bahamas. Isaacs \& Co.

3186. Ditto. (Dried in natural condition.) Florida Keys. Boston Soc. Nat. Hist. 
3189-90. Ditto. (Cleansed.) (S. tubulifera, var. disciformis, Hyatt.) Florida Keys and Bahamas. Isaacs \& Co.

3192-96. Ditto. (S. gossypina, D. \& M., var. hirsuta.) Florida Keys and Bahamas. Isaacs \& Co.

3197. Ditto. (S. gossypina, var. dendritica.) Florida Keys and Bahamas. Isaacs \& Co.

3198-3202. Ditto. (S. gossypina, var. porosa.) Florida Keys and Bahamas. Isaacs \& Co.

2. Useful as an elastic medium or absorbent:

3213a. Sponge prepared for use as lint in surgery. Wm. B. Moses, Washington, D. C.

3211. Ditto. For stuffing cushions and packing. Florida. Jas. Richardson.

3212a. Ditto. Prepared for stuffing cushions, mattresses, \&c. Florida. Wm. B. Moses, Washington, D. C.

Injurious:

1. By destroying oysters:

3215. Boring sponge (Cliona sulphurea, Verrill). Mature form, after oystershell has disintegrated. Vineyard Sound, Mass. U. S. Fish Commission.

32979. Boring sponge. Shells of Pecten showing ravages. Castine, Me. A. R. Crittenden.

32980. Ditto. Castine, Me. L. J. Heath.

32820. Ditto. Showing effect on oyster-shell. New York Bay. B. J. M. Carley.

3147. Ditto. Showing various stages in shell. Shrewsbury River, N. J. B. J. M. Carley.

\section{Rhizopods.}

Useful; the fossil forms being largely employed as a polishing powder under the name of "Tripoli" or "infusorial earth"; as a menstruum for nitro-glycerine, in the manufacture of dynamite and other explosives; and also in the manufacture of "stone china" and pottery. The valuable quality in nearly all cases is the contained silica.

\section{MISCELLANEOUS PRODUCTS OF SEA OR SHORE, NOT OF AN ANIMAL NATURE.}

\section{Plants:}

\section{a. Lichens:}

29316. Orchilla (Rocella tinctoria), in its natural condition as gathered from rocks and branches of plants. West coast of North America. W. A. Ross \& Bro., New, York.

29313. "Archil liquor," derived from Orchilla, and extensively used as a dyestuff. West coast of North America. W. A. Ioss \& Bro., New York. 


\section{ANIMAL RESOURCES AND FISHERIES OF UNITED STATES. 265}

29314. "Cudbear." Product of a lichen (Lecanora), extensively applied as a dye-stuff. Western coast of North America. W. A. Ross \& Bro., Nerr York.

\section{b. Algæ:}

\section{Having economical applications:}

\section{* Available as food.}

- Irish moss (Chondrus crispus, L.), affording gelatine. New England coast. Dr. W. G. Farlow.

- Western dulse (Schizymenia cdulis, Ag.). West coast United States. Rev. E. Hall.

- Dulse (Rhodymenia palmata, Grev.), used for food. New England coast. Dr. W. G. Farlow.

- Laver (Porphyra vulgaris, Ag.), used for food. New England coast. Dr. W. G. Farlow.

-. Badderlocks (Alaria esculenta, Grev.). Available for food. Cape Cod northward.

**Employed in the manufacture of fertilizers, iodine and bromine, or "artificial staghorn" (Laminaria) articles.

- Rockweed (Fucus vesiculosus, L. \& C.). New England coast. Dr. W. G. Farlow.

- Bull-head kelp (Nereocyslis Lütkeana, P.\& M.). Stems made by Indians into fishing-lines. Northwest coast of America. W. H. Dall.

- Specimens of lines made of this material. [See ethnological and fishing-implement series.]

29373. Devil's apron (Laminaria digitata), dried stems for making "tents." Newfoundland. Dr. E. R. Squibb.

29373a. "Sponge tents" used in surgery, made from dried Laminaria stems. 29373b. Paper-knife, made of "artificial staghorn" or dried Laminaria (longicruris), by J. H. Batehelder, Cambridge, Mass.

\section{Ornamental algæ:}

The following series, prepared by Dr. W. G. Farlow, comprises specimens collected by Mr. F. W. Hooper and Dr. Palmer, at Key West; by Dr. Farlow on the New England coast; by Prof. D. C. Eaton from various sourees; by A. R. Young, at New York; Mrs. A. S. Davis, at Cape Ann; Mrs. Beebe, at Gloncester, Mass.; Mrs. B. D. Halstead, at Swampseott; Mr. H. Averill, at New York; Dr. L. R. Gibbes, in South Carolina; Miss M. A. Booth, at Orient, L. I. ; and from California and Oregon by Dr. C. L. Anderson, Capt. I. Stratton, Rev. E. Hall, Mr. H. Hemphill, D. Cleveland, and Mr. W. H. Dall:

Amaxsia multifida, Lmx. Ḱey West.

DaSYa Gibbesir, Harr. Key West.

Dasya elegars, Ag. Chenille. Cape Cod.

Dasya ramosissima, Harv. Key West.

- Dasya Harveyi, Ashmead. Key West.

Dasya mollis, Hart. Key West.

Dasya mucronata, Harv. Key West.

Dasya Wurdemanxi, Bailey. Key West.

Dasya callithamion, Harv. San Diego. 
Dasya Tumanowiczi, Gatty. Key West.

DasYa Lophoclados, Mont. Key West.

Dasya Plumosa, Bail. and Harv. Santa Cruz, Cal.

Bostrychia Montagner, Harv. Key West.

Bostrychia calamistrata, Mont. Key West.

Bostrychia Moritziana, Mont. Florida.

Polysiphonia urceolata, Grev. Nahant, Mass. Var. formosa, New England.

Polysiphonia Havanensis, Mont. Var. Binneyi, Ag., Key West. Polysiphonia ferulacea, Ag. Key West.

Polysiphonia OlNeyi, Harv. Dough-balls. Long Island Sound. Polysiphonia HaRveYi, Bail. Nigger-hair. Wood's Holl, Mass. Polysiphonia elongata, Grev. Lobster-claws. Gay Head, Mass. Polysiphonia violacea, Grev. Wood's Holl, Mass.

Polysiphonia fibrillosa, Grev. Wood's Holl, Mass.

-Polysiphonia variegata, Ag. Wood's Holl, Mass.

Polysiphonia pennata, Ag. California.

Polysiphonia parasitica, Grev. California. Var. dendroidea, Ag., California.

Polysiphonia Baileyi, Ag. Pacific coast.

Polysiphonia PECTEN-VeNeris, Harv. Florida.

Polysiphonia ATronubescens, Grev. Wood's Holl, Mass.

Polysiphonia bipinnata, Post. and Rupr. West coast.

PoLYsiphonia Woodi, Harv. West coast.

Polysiphonia Nigrescens, Grev.

Polysiphonia fastigiata, Grev. Nahant, Mass.

Odonthalia aleutica, Ag. Oregon.

Odonthalia Lyalli, Harv. Neeah Bay, W. T.

Rhodomela larix, Ag. California.

RHODOMELA Floccosa, Ag. Aleutian Islands.

Rhodomela subfusca, Ag. Gloucester, Mass. Var. gracilis, samo limits.

Var. Rochei, Long Island Sound.

Digenia smplex, Ag. Key West.

Bryothamnion triangulare, Ag. Key West.

Bryothamnion Seaforthir, Ag. Florida.

Alsidium Blodgettir, Harv. Key West, Fla.

Acanthophora Thierir, Lmx. Florida to Brazil; Pacific Ocean.

ACANTHOPHORa Muscoides, Ag. Florida.

Chondria dasyphylla, Ag. Cape Cod.

Chondria striolata, Ag. (C. Baileyana, Mont.) Cape Cod.

Chondria tenuissima, Ag. Wood's Holl, Mass.

Chondria littoralis, Harv. Wood's Holl, Mass.

Chondria atropurpurea, Harv. Key West, Fla.

Laurencia Pinnatifida, Lmx. Pepper-dulse. California.

Laurencia virgata, Ag. California.

LAURENCIA OBTUSA, Lmx. Florida.

Laurencia implicata, Ag. Key West.

LaUrencia Cervicornis, Harv. Key West; San Diego, Cal.

Laurencia gemmifera, Harv.。 Florida.

laurencia papillosa, Grev. Florida.

Laurencia Paniculata, Ag. San Diego, Cal.

Crylocladia ovalis, Hook. (Lomentaria, Endl.) California.

Grinseldia Americanı, Harv. Wood's Holl, Mass.

Delesseria sinuosa, lmx. Gloncester, Mass.

Drlesseria querchoira, Bory. California. 
Delesseria alata, Linx. Gloucester, Mass.

Delesseria irypglossum, Larmx. Chleston, S. C.

Delesseria tenuifolia, Harv. Key West.

Delesseria involvexs, Harv. Key West.

Delesseria Leprieurir, Mont. New York.

Delesseria deciplens, Ag. West coast. Neeah Bay, W.T.

Nitophyllum pUnctatum, var. ocellatum, Grev. Key West.

Nitophyllum spectabile, Eaton, mss. California.

Nitophyllum laceratum, Grev. California.

Nitophyllum latissimum, Ag. California.

Nitophyllum AReolatum, Eaton, mss. California.

Nitophyllum (Neuroglossum) Andersonit, Ag. California.

Nitophyllum Ruprechtianum, Ag. West coast.

Calliblepharis ciliata, Kütz. Cape Ann, Mass.

Gracilaria multipartita, Ag. Var. angustissima, Harv. New York.

Gracilaria Cervicoris, Ag. Key West.

Gracilaria confervoides, Grev. Florida ; California.

Gracilaria armata, Ag. Key West.

Corallixa officinalis, L. Cape Ann. .

Corallina squamata, Ellis and Sol. San Diego, California.

JaNia Rubexs, Lmx. San Diego, California.

Jania Capillacea, Harv. Key West.

AMPHIROA Fragilissima, Lmx. Florida.

Astriroa NODUlosa, Kütz. Florida.

AMPHIROA DEBILIS, Küitz. Florida.

Amphuroa Californtca, Decaisne. West coast.

Melobesia farlxosa, Lmx. East coast.

Melobesia pustulata, Lmx. Wood's Holl, Mass.

LITHOTHAMNION POLYMORPHUM, Aresch. Eastport, Me.

Hildenbrandtia rosea, Kütz. Eastport, Me.

Gelidium corneum, Lmx. Florida; New Haven, Conn.

Gelidium Cartilagineum, Grev. San Diego, Cal.

Gelidium Coulteri, Harv. California.

Wurdemania Setacea, Harv. Key West.

Eucheuma istForme, Ag. Key West.

EucheUMa ACANTHOCLAduM, Ag. (Chrysymenia, Harv.). Key West. HyPNEA MUSCIEORMis, Lmx. Wood's Holl, Mass.

HYPNEA CORNuTA, Ag. Key West.

Rhodymenia palmata, Grev. Common dulse. Swampscott, Mass.

Rhodymenia palaietta, Grev. California.

Rhodymenia corallina, Grev. California.

Euthora Cristata, Ag. Gloncester, Mass.

Plocamium COccineum, Lyngb. Var. flexuosum. West coast.

Stenogramma ivterrupta, Mont. California.

Pikea Califorica, Harv. California.

Champla Parvula, Harv. Noank, Conn.

Lomentaria Barleyana, Farlow (Chylocladia, Harv.). New York Bay.

Lomentaria rosea, Thuret: Gay Head, Mass.

Rhabdonia tenera, Ag. (Solieria chordalis, Harv.) Wood's Holl, Mass.

Rhabdonia Coulteri, Harv. California.

Cordylocladia -conferta, Ag. San Diego, Cal.

Polyides rotundus, Ag. Cape Ann, Mass.

Peyssonnelia atro-purpurea, Crouan ?. Key West.

Nemalion multifidum, Ag. Watch Hill, R. I.

Scixaia Furcellata, Bivon. Gay Head, Mass. 
Lingora valida, Harv. Florida.

Liagora PiNNata, Harv. Florida.

Liagora pulverulenta, Ag. Key West.

Wrangelia penicillata, Ag. Key West.

Phyllophora Brodier, Ag. Long Island Sound.

Phyllophora membranifolia, Ag. Long Island Sound.

Gymogongrus Norvegicus, Ag. (inc. G. Torreyi, Ag.). Peak's Island, Me.

Gymnogongrus tenuis, Ag. California.

Gymnogongrus Griffithsi

GyMNOGONGRUS LINEARIS, Ag. California.

Airnfeltia gigartinoides, Ag. West coast.

Amnfeltia Plicata, Fr. Cape Ann, Mass.

Cystoclonium PURPurascens, Kütz. Block Island, New York.

Callophyllis variegata, Ag. California.

Callophyllis obtusifolia, Ag. San Diego, Cal.

Callophyllis discigera, Ag. California.

Gigartina acicularis, Lmx. Florida.

Gigartina Canaliculata, Harv. West coast.

Gigartina mamillosa, Ag. Portland, Me.; Santa Cruz, Cal.

Gigartina Micropirylla, Harv., and var. horrida. California.

Gigartina ranula, Ag. West coast.

Chondrus Crispus, Lyngb.' Irish moss. Cape Ann, Mass. Very common. Chondrus afrivis, Harv. California.

IRIDAEA LAMINARIOIDES, Bory. (including Iridaca minor and Iridoea dichotoma).

West coast.

Endocladia muricata, Ag. West coast.

Cryptonemia crenulata, Ag. Key West.

Chrysymenia halymenioides, Harv. Key West.

Chrysymenia uvaria, Ag. Key West.

Halymenia ligulata, Ag. Var. Californica; Santa Cruz, Cal.

Halymenia Floresia, Ag. Key West.

Prionitis lanceolata, Harv. West coast.

Prionitis Andersonir, Eaton, mss. Santa Cruz, Cal.

SchizYMeNiA EDUlis, Ag. Oregon.

SchizYMenia? Coccinea, Harv. Santa Cruz, Cal.

Grateloupia Gibbesir, Harv. Charleston, S. C.

Grateloupia Cutlerie, Kütz. Califormia.

Grateloupia filicina, Ag. Florida.

HaLOSACCION HYDROPIIORA, Ag. West coast.

Halosaccion fucicola, Post. and Rupr. West coast.

Halosaccion ramentaceum, Ag. Eastport, Me.

Spyridia aculeata, Kiitz. Florida.

SpYridia filamentosa, Harv. Wood's Holl, Mass.

Microcladia Coulteri, Harv. West coast.

Mrcrocladia Calmornica, Farlow. California.

Microcladia borealis, Rupr. West coast.

Centroceras clavulatum, Ag. Key West.

Centroceras Eatonianum, Farlow. West coast.

Ceramium nitrens, Ag. Key West.

Ceramum rubrim, Ag. East eoast.

Ceramium Deslongchampsir, Ch. Eastport, Me.

Ceramium diapianum, Roth. California.

Ceramium strictum, Harv. New England.

Ceramium Youngir, Farlow, mss. Canarsie, L. I.

Ceramiun tenuissimum, Lyngb. Key West. 
Ceramium fastigiatum, Harv. Southern New England.

Ceranium —. Key West.

Ptulota dexsa, Ag. California.

Prilota hypNoIdes, Harv. California.

Pтilota Plumosa, Ag. Var. filicina, west coast. Var. serrata. Eastport, Me., and Néeah Bay, W. T.

Pthlota elegaxs, Bonnem. New York.

Gloiosiphonia Capillaris, Carm. Cape Ann, Mass.

Crodania attenuata, J. Ag. Key West.

Griffithsia Bornettiana, Farl. Wood's Holl, Mass.

Callithamnion tetragonum, Ag. Orient, L. I.

Caluithamion Baileyi, Harv. New York.

Callithamion ptilophora, Eaton, mss. California.

Callithamniox Borreri, Ag. New Haven, Conn.

Callithannion BYssomeum, Am. Long Island Sound.

Callithamion corymbosum, Ag. Beverly, Mass.

Callithamion versicolor, Ag., var. seirospermum, Harv. New York.

Callithamion plumula, Lyngb. Gay Head, Mass.

Callithannion heterovorpilum, Ag., mss. California.

Callithamion Americanum, Harv. New York.

Callithamion Pylaisei, Mont. Gloncester, Mass.

Callithamion rloccosum, Ag. Var. pacificum, Harv. Neeah, Bay, W. T.

Callithamion Cruciatum, Ag. New York.

Callithanniox Lejolisia, Farlow, mss. San Diego, Cal.

Callithaminion Turvieri, Ag. New York.

Callithansion Rothil, Lyugb. New England coast.

Callitilamion rosium, Lyng. New York.

Porpiryra vulgaris, Ag. Laver. East coast.

Baygia fúscopurpurea, Lyngb. East coast.

Chantransia niflomescless, Thur. Gay Head, Mass.

Chantransia virgatela, Thuret. Portland, Me.

Erythrotrichia crranicola, Aresch. Cape Ann, Mass.

Padina payonia, Lmx. Peacoch's-tail. Key West, Fla.

Zonaria lobata, Ag. Key West.

Zonaria Flava, Ag. San Diego, Cal.

Taonia Schroderi, Ag. Florida.

Dictyota Fasciola, Lmx. Florida; Mediterranean Sea.

Dictyota dichotoma, D. C. Charleston.

Dictrota ciliata, Ag. Key West.

Dictyota Kextrir, Ag. San Diego, Cal.

Dictyota acutiloisa, Ag. Key West.

Sargassum vulgare, Ag. Atlantic Ocean.

Sargassum ibacciferum, Ag. Gulf-ioced. Gulf Stream.

Sargassum dentifollium, Ag. Key West.

Sargassum Agardianum, Farlow, mss. San Diego, Cal.

Turbinaria vulgaris, Ag. Key West.

Fucus fastigiates, Ag. West coast.

Fucus Disticries, $L$. ( $F$. filiformis, Gm.). Swampscott, Mass.

Fucus furcatus, Ag. Marblehead, Mass.

Fucus vesiculosus, L. Rock-vced. Swampscott, Mass.

Fucus seriatus, L. Nova Scotia.

Nereocystis Lütkraxa, Post. and Rupr. Greal bladder-wced. Monterey, Cal., and northward.

Alaria esculexta, Grev. Badderlccks. Henware. Cape Cod. 
Laminaria saccharuina, Lmx. Devil's apron; Kelp. New York, northward; west coast; Europe ; Japan?.

Laminaria longicruris, De la Pyl. Jevil's apron; Kelp. New England. Laminaria Flexicaulis, Le Jolis. Devil's apron; Kelp. New England. Agarum Turneri, Post. and Rupr. Sea-colander. Nahant, Mass. StILOPHORA RHIZODES, Ag. Vineyard Sound. Asperococcus sinuosus, Bory. Key West. Asperococcus echinatus, Grev. New England coast. Hydroclatmrus cancellatus, Bory. Noank, Conn. Ralfsia verrucosa, Areseh. Nahant, Mass. Chorda Filum, Staek. New York.

Chordaria flagellifolims, Ag. Eastport, Me. Chordaria abietina, Rupr. Santa Cruz, Cal. Chordaria divaricata, Ag. Gloucester, Mass. Castagnea virescens, Thuret. Wood's Holl, Mass. Leathesia tuberiformis, Gray. Wateh Hill, R. I. Elachista fucicola, Fr. New England.

Myrionema strangulans, Grev. Wood's Holl, Mass. Mrrionema Leclancheri, Harv. Gloucester, Mass. Cladostepirus spongiosus, Ag. Newport, R. I. Cladostephus verticillatus, Ag. Gay Head, Mass. Sphaceearia fusca, Ag. On Amiphiroa Californica, San Diego, Cal. Sphacelaria radicans, Ag. New England.

Ectocarpus firmus, Ag. (E. littoralis, Harv.). New England.

Ectocarpus Farlowir, Thuret. Peak's Island, Me.

Ectocarpus siliculosus, Lyugb. Charleston, S. C.

Ectocarpus viridis, Harv. Orient, L. I.

Ectocarpus fasciculatus, Harv. New England coast.

Ectocarpus granulosus, Ag. Santa Cruz, Cal.

Ectocarpus Hooperi, Harv. Greenport, L. I.

Desmarestia aculeata, Lmx. Eastport, Me.

Desmarestia viridis, Lmx. New York.

Desmarestia ligulata, Lmx. Monterey, Cal.

Punctaria latifolia, Grev., and var. zosterce, Le Jolis. Eastport, Me. Punctaria plantaginea, Grev. New England.

Phyllitis fascia, Ktz. Eastport, Me.

SCytosiphon lomentarius, Ag. Eastport, Me.

Caulerpa prolifera, Lmx. Florida.

Caulerpa Crassifolia, Ag., var. Mexicana. Florida.

Caulerpa plumaris, Ag. Florida.

Caulerpa Ashmeadi, Harv. Key West.

Caulerpa ericifolia, Ag. Florida.

Caulerpa cupressoides, Ag. Key West.

Caulerpa lanuginosa, Ag. Key West.

Caulerpa paspaloides, Bory. Florida.

Caulerpa clavifera, Ag. Florida.

Halimeda opuntia, Lmx. Florida.

Hadimeda tuna, Lmx. Florida.

Halimeda tridens, Lmx. Key West.

Udotea flabellata, Lmx. Key West.

Udotea conglutinata, Lmx. Key West.

Codium tomentosum, Stack. Florida; var. damacornis. West coast.

Chlorodesmis? Key West.

Bryopsis plumosa, Lmx. Eastern coast.

Bryopsis Hyproines, Lmx. Key West. 
Vaucheria pIloboloides, Thuret. Wood's Holl, Mass.

Dasycladus occinextalis, Harv. Florida.

Dasycladus Cla Vaformis, Ag. Key West.

Acetabularia crenulata, Lmx. Floridil.

Cymopolia barbata, Lmx. Key West.

Chamedoris axvulata, Mont. Key West.

Pexicillus dumetosus, Dne. Florida; West Indies.

Penicillus Capitatus, Lmx. Mermaid's shaving-brush. Florida.

Blodgettia ? CONfervoldes, Harv. Key West.

ANadyomene flabellata, Lmx. Key West.

Dictyosphairia favulosa, Dne. Key West.

Ascothamion Intricatum, Kütz. Key West.

ENTERoMorpha intestinalis, Link. New England.

Exteromorpha compressa, Grev. New England.

Exteronorpha clathrata, Grev. New England coast.

Ulva latissima, Linn. Sea-lettuce. New England coast.

Ulva fasdiata, Delile. California.

Cladophora membranacea, Ag. Key West.

Cladophora rupestris, L. Cape Ann, Mass.

Cladophora arcta, Dillw: Cape Ann, Mass.

Cladophora laxosa, Roth. Orient, L.I.

Cladophora uncialis, Fl. Dan. New England coast.

Cladophora latevirexs, Dillw. Key West, Fla.

Cladophora fracta, Fl. Dan. Eastern coast.

Chetomorpha Picquotiana, Mont. Cape Ann, Mass.

Chetonorpha melagonium, Web. and Mohr. Cape Aun, Mass.

Chetonorpha sutoria, Berk. Stonington, Conn.

Chetomorpha brachygoxa, Harv. Key West.

Chatomorpha tortuosa, Dillw. Eastport, Me.

Hormotrichum Younganum, Dillw. New England coast.

Lyxgbya majuscula, Harv. Cape Corl.

Lyngbya ferruglnea, Ag. New England coast.

LYNGBYA KÜTZUNGIANA, Thur. Eastern coast.

Calothrix confervicola, Ag. East coast.

Calothrix scopulorum, Ag. East coast.

Spherozyga Carmichaelit, Harv. Wood's Holl, Mass.

Petrocelis cruenta, Ag. Eastport, Me.

Spirulina texuissima, Kütz. Eastport, Me.

Chyoöspora fastigiata, Ag. San Diego, Cal.

Hormactis Farlowi, Bornet. East coast.

\section{Inorganic materials:}

-. Scouring-sand. Impure silex for domestic use. Alameda, Cal. H. Hemphill.

—. Glassmaker's-sand. Pure silex. Isle of Shoals, N.H. 
COMMERCIAL STATISTICS OF ANIMAL PRODUCTS IN THE UNITED STATES : A REVIEW OF A PORTION OF THE REPORT OF THE CHIEF OF THE BUREAU OF STATISTICS FOR THE FISCAL YEAR ENDING JUNE 30, 1877.

\section{BX G. BRowN GOoDE.}

The following review of the character and commercial values of animal products used or produced in the United States is intended to supplement and explain in part the preceding "Catalogue of the collection illustrating the animal resources of the United States," made under the direction of the United States National Museum for the International Exhibition of 1876. The statistics have been arranged with a view to a concise exhibition of the extent and location of the trade in all substances of animal origin. The classification is uniform with that employed in the catalogue.

An attempt is made to show-

1. The amount of imports, the countries from which the products are imported, and the ports through which the import entries are chiefly made.

2. The domestic consumption of foreign products. The table of imports entered into consumption is more detailed than any of the others, and from this have been taken many statements which were not elsewhere given, as, for instance, the amounts of coral, whalebone, chemicals, and specimens of natural history.

3. The exports of domestic products, the ports from which they were chiefly shipped, and the countries to which they are sent.

4. The statistics of foreign exports or of the exports of products not directly of domestic origin.

No account has been made of the indirect and transshipment trade.

\section{LIVING ANIMALS.}

The total value of living animals brought into the United States does .ot fall far below $\$ 2,200,000$.

The value of the miscellaneous importations of living animals is placed it $\$ 1,648,465$. Of this amount Quebec, Ontario, \&c., supply $\$ 1,452,457$, and Mexico \$129,897 (no doubt chiefly sheep), Nova Scotia and New Brunswick send $\$ 30,124$, Germany $\$ 13,262$, British Columbia $\$ 13,762$, England \$6,184. The remainder comes from the British East Indies $(\$ 1,389)$, Cuba (\$818), Brazil (\$133), Scotland, Honduras, Belgium, Chili, China, France, Guiana, Colombia, and Uruguay. The latter countries probably send chiefly animals for menageries and gardens.

Animals for breeding purposes are imported to the amount of $\$ 419,170$. The larger proportion $(\$ 291,960)$ comes from the British Provinces 
through the Lake ports. New York, with its extensive shipments from Europe, receives the next proportionate share $(\$ 111,501)$, then San Francisco $(\$ 4,708)$, Boston $(\$ 3,029)$, Baltimore $(\$ 2,113)$, Philadelphia (\$519), and New Orleans (\$200).

The teams of emigrants have the right of free entry. The yearly return of entries is placed at $\$ 26,070$. The greater proportion $(\$ 23,520)$ appears to come from the British Provinces through the Lake ports.

The imports of birds are valued at $\$ 109,879$. Of this amount, $\$ 71,989$ comes to New York, and consists principally, no doubt, of singing birds. The Provinces send $\$ 38,328$, probably, for the most part, fowls.

Leeches are imported to the amount of $\$ 4,227$. All come through New York, except $\$ 133$ worth through New Orleans.

The following table, compiled from the "Statement showing quantities and values of foreign merchandise entered into consumption in the United States during the fiscal year ended June 30, 1877, \&c." (No. 20, pp. 446-505), while it necessarily does not tally with the figures already given, is instructive, since it shows in fuller detail the numbers and character of the imports of foreign animals:

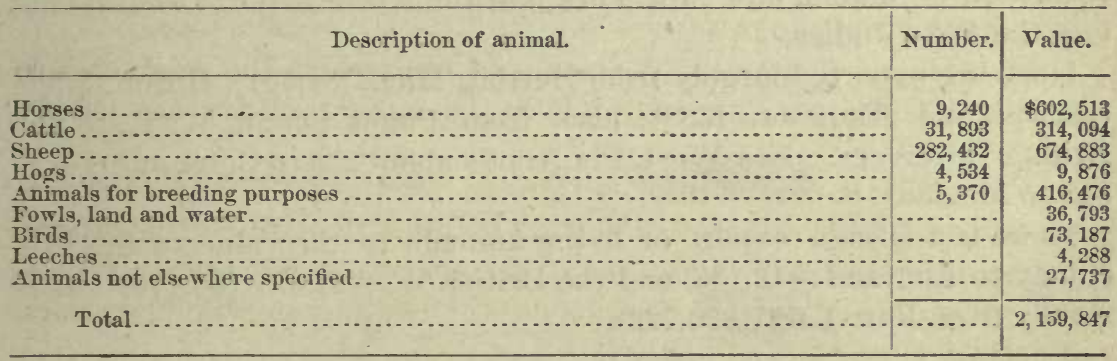

The domestic exports of living animals are valued at $\$ 3,306,308$, as shown in the following table:

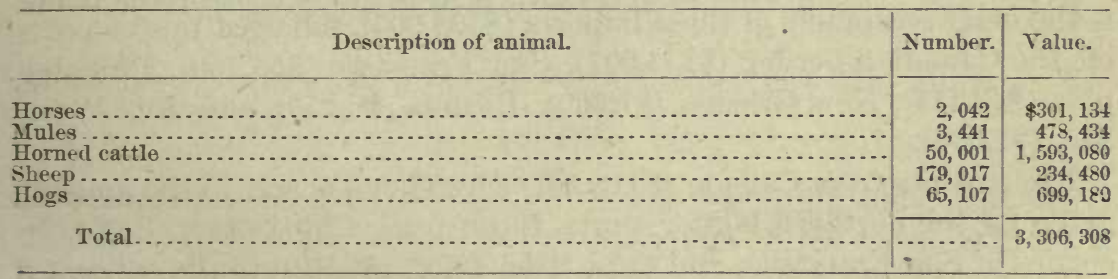

The largest number of horses is shipped from New York ( $72 \pi)$, next from Brazos de Santiago, Tex. (363), Minnesota (196), San Diego, Cal. (195), Corpus Christi, Tex. (82), Puget Sound, Washington (66), San Francisco (52), and Baltimore (53). The horses shipped from San Francisco are most valuable, being worth $\$ 500$ on an average; those from New York \$150; those from Texas \$40.

The principal exports of horses are to Mexico (603) chiefly from Texas, Quebec, Ontario, \&e. (391), the British West Indies and Honduras (232), Cuba (15i), and the French West Indies and French Guiana (129).

Bull. N. M. No. $14-18$ 
Mules are shipped in the largest numbers from New York $(2,058)$, New Orleans, La. (1,036), Brazos de Santiago, Tex. (116), Saluria, Tex. (92), and Galveston, Tex. (90). They are sent chiefly to the British West Indies and Honduras $(1,541)$, Cuba $(1,018)$, the French West Indies and Guiana (252), the Central American States (210), British Guiana (218), and Mexico (134).

Horned cattle are shipped chiefly from Texas $(20,396)$, Key West, Fla. $(9,071)$, Minnesota $(6,615)$, New York $(4,863)$, Huron, Mich. $(4,748)$, Boston (1,566), Philadelphia (700), Puget Sound, W. T. (611), Detroit, Mich. (543), and San Diego, Cal. (685). They are sent chiefly to Cuba $(27,388)$, Quebec, Ontario, \&c. (12,020), England (4,991), Liberia $(2,809)$, and to the British West Indies and Honduras $(1,741)$, the Bermudas taking a large share of the latter.

Sheep are sent principally from Texas $(108,74 \bar{\imath})$, Califoruia $(53,438)$, Washington Territory $(9,484)$, and New York $(4,744)$, and find their way mostly to Mexico (161,549), British Columbia $(9,484)$, British West Indies, $(2,299)$, England $(2,692)$, and Quebec, \&c. $(1,003)$. It is sufficiently evident that Texas and California send to Mexico, Washington Territory to British Columbia, and New York and the Atlantic ports to England and the West Indies.

Hogs are exported largely from Detroit, Mich. (34,504), Huron, Mich. (28,508), and Minnesota (339); also, from Puget Sound, W. T., to the British Provinces. Key West, Fla., sends about 230 to Cuba, and Texas 348 to Mexico.

There is a foreign export of living animals to the value of $\$ 22,970$, chiefly to England $(\$ 12,136)$ and the British West Indies $(\$ 8,176)$. It is chiefly from New York $(\$ 20,722)$.

\section{FOOD PRODUC'TS, EXCEPT FISH.}

The import entries of food products are placed at $\$ 724,452$. New York is the chief receptacle of these imports $(\$ 508,905)$, followed by the ports on the Canadian border $(\$ 173,007)$, San Francisco $(\$ 53,760)$, Philadelphia $(\$ 32,111)$, New Orleans $(\$ 7,400)$, Boston $(\$ 5,253)$, and Key West, Fla. $(\$ 2,336)$.

The receipts from Canada $(\$ 113,191)$ correspond nearly to the amount given for the northern border ports, those from China $(\$ 43,331)$ to the entries of San Franciseo, and those from Cuba $(\$ 2,846)$ to the entries of Florida. New York and Philadelphia receive nearly all the remainder, which is principally sent by Germany $(\$ 325,693)$, England $(\$ 65,164)$, Frunce $(\$ 63,119)$, Belgium $(54,537)$, the Netherlands $(\$ 40,145)$, Italy $(\$ 11,957)$, and Mexico $(\$ 2,679)$.

The total value of the import of honey is $\$ 61,205$, of which New York receives the principal share $(\$ 34,693)$, then New Orleans $(\$ 13,483)$ and Boston (\$8,019).

Sausages, sausage-skius, and Bologna sausages are imported to the 
value of $\$ 83,187$, of which New York receives over $\$ 50,000$ and New Orleans over $\$ 1,300$.

Condensed eggs come only to New York, which imports to the value of $\$ 2,509$.

Milk comes to the Lake ports to the value of $\$ 2,062$.

The quantities of each article entered into consumption are shown in the following table:

\begin{tabular}{|c|c|c|c|}
\hline Articles. & . & Amount. & Talue: \\
\hline Beef. & ...pounds.. & 213,909 & $\$ 15,34092$ \\
\hline Mutto & & & 2,41380 \\
\hline ( & ...................... pounds.. & 42,418 & 3,11170 \\
\hline 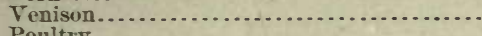 & & & $\begin{array}{r}82466 \\
33,02294\end{array}$ \\
\hline $\begin{array}{l}\text { Poultry } \ldots \ldots \ldots \ldots \ldots \\
\text { Salted tongues }\end{array}$ & & & $\begin{array}{r}33,02294 \\
11200\end{array}$ \\
\hline 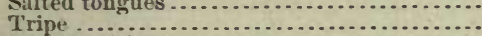 & & & $\ldots 11600$ \\
\hline Sausage-skins.................... & $\cdots$ & & 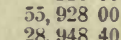 \\
\hline Bologna sausages.$\ldots \ldots \ldots \ldots \ldots \ldots \ldots \ldots$ & (nounds & 73 & $\begin{array}{l}28,94840 \\
14,19335\end{array}$ \\
\hline Prepared meats, game, and poultry, sealed or & insealed, in cans or otherwise... & & $\begin{array}{l}14,1933 \\
28,289 \\
20\end{array}$ \\
\hline 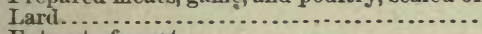 & ..................... pounds.. & 12,524 & 1,16674 \\
\hline $\begin{array}{l}\text { Extract of meat } \\
\text { Eqgs } \ldots\end{array}$ & doze & $5,048,900$ & $\begin{array}{r}38,12400 \\
617,64359\end{array}$ \\
\hline Eggs, condensed .......................... & (n) & & $\begin{array}{r}617,643 \\
1,87300\end{array}$ \\
\hline 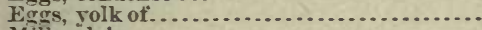 & ............... & & 20300 \\
\hline Milk, plain...$\ldots \ldots \ldots \ldots \ldots \ldots \ldots \ldots$ & (n) & ...... & $2,614 \quad 65$ \\
\hline Milk, condensed or preserved .............. & 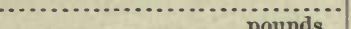 & $\cdots$ & $\begin{array}{r}2,79800 \\
464,00123\end{array}$ \\
\hline 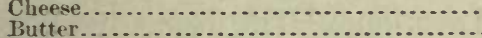 & 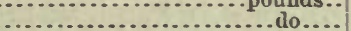 & 82,131 & $\begin{array}{rl}464,001 & 23 \\
17,231 & 00\end{array}$ \\
\hline Honey ..................................... & ........................... gallons.. & 27,017 & 16,47350 \\
\hline
\end{tabular}

The following tables show the imports of eggs by countries, and the corresponding entries by customs-districts.

\begin{tabular}{|c|c|c|c|c|c|}
\hline Conntries. & \multicolumn{2}{|c|}{ Eggs. } & Countries. & \multicolumn{2}{|c|}{ Eggs. } \\
\hline 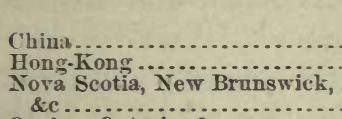 & $\begin{array}{r}\text { Dozens. } \\
126,800 \\
3,066 \\
948,703\end{array}$ & $\begin{array}{r}\text { Dollars. } \\
8,716 \\
183 \\
109,823\end{array}$ & 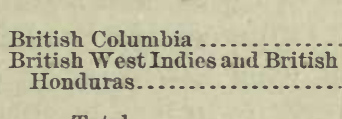 & $\begin{array}{r}\text { Duzens. } \\
100 \\
300\end{array}$ & $\begin{array}{r}\text { Dollars. } \\
6 \\
69\end{array}$ \\
\hline Quebec, Ontario, \&c ........ & $3,969,302$ & 498,825 & Total. & $5,048,271$ & 617,622 \\
\hline
\end{tabular}

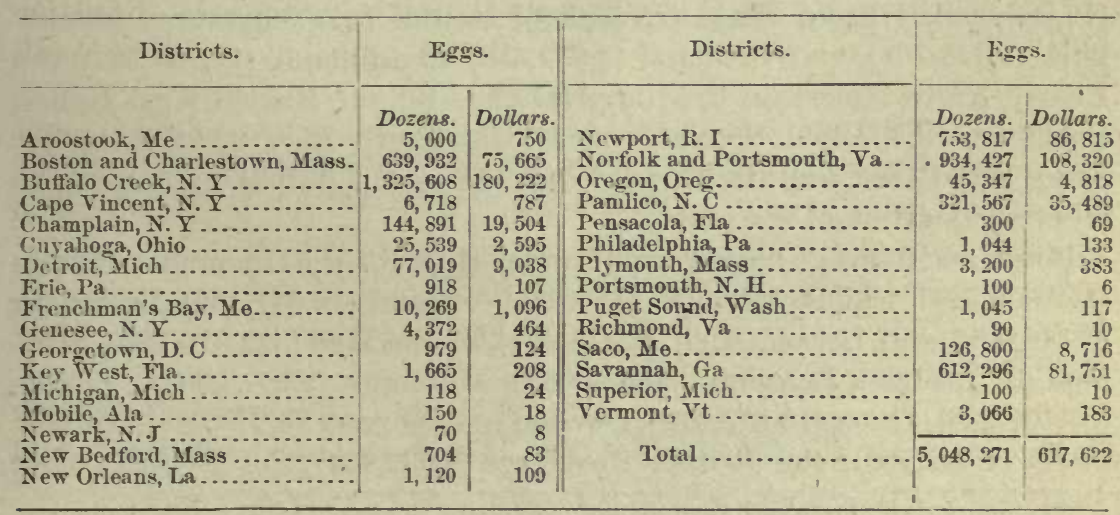


The amount of domestic exports is shown in the following table:

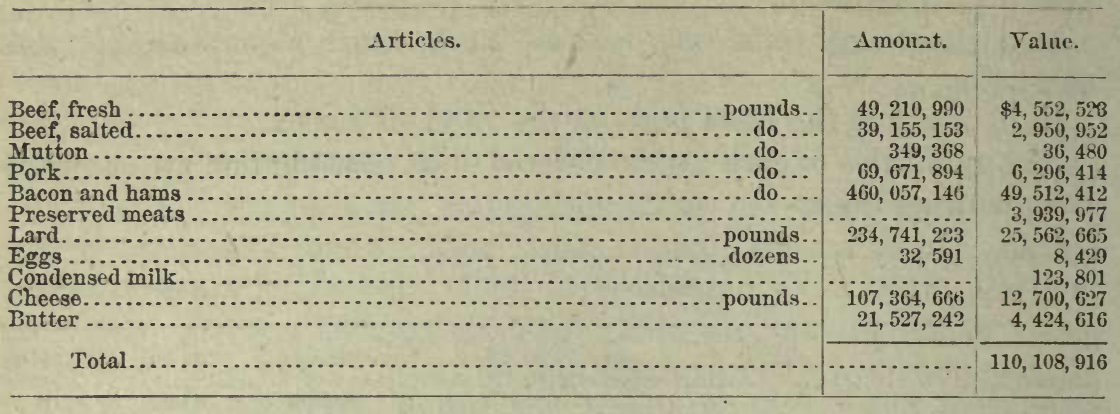

Fresh beef is shipped as follows:

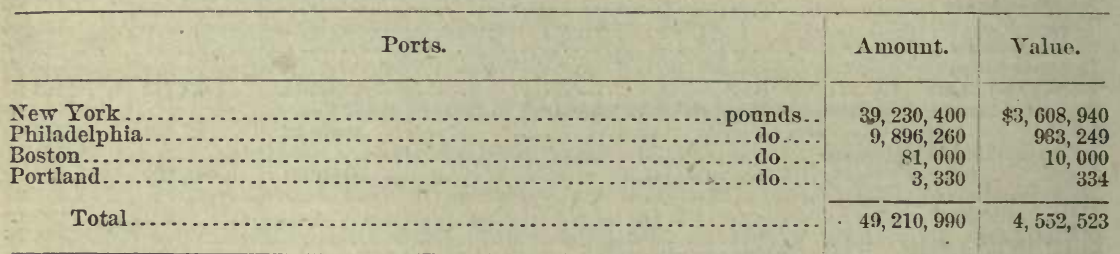

All the fresh beef goes to England and Scotland. The former receives $39,906,940$ pounds, valued at $\$ 3,614,779$, and the latter $9,304,050$ pounds, valued at $\$ 937,744 . .^{\prime}$

Salted beef goes principally from New York, Philadelphia, Boston, Baltimore, San Francisco, Portland, and Brazos de Santiago, Tex., and is sent to almost every country, England (19,727,882 pounds), Scotland $(5,887,774)$, the British West Indies $(2,774,804)$, Germany $(2,185,990)$, Nova Scotia and New Brunswick $(1,297,662)$, and British Guiana $(1,042,150)$ receiving the largest proportion.

Mutton goes from New York to England (219,928 pounds) and Scotland $(129,440)$.

Pork goes chiefly from New York (39,239,234 pounds), Boston $(10,763,062)$, Huron, Mich. $(7,748,660)$, Baltimore $(3,961,045)$, Philadelphia $(2,144,761)$, and Portland $(2,930,359)$ to England $(19,793,191)$, the British North American Provinces $(17,990,540)$, the British West Indian Provinces $(\$, 867,490)$, Scotland $(2,847,346)$, Porto Rico $(2,923,975)$, Germany $(1,251,166)$, and the Dutch West Indies $(1,126,169)$, as well as to all other quarters of the globe.

Bacon and hams go chiefly from New York (253,481,647 pounds), Boston $(112,656,704)$, Philadelphia $(72,738,161)$, Portland $(10,541,136)$, Baltimore $(6,146,098)$, and Huron, Mich. $(2,275,004)$, to England $(322,016,729)$, Scotland $(31,193,969)$, Belgium $(30,846,038)$, Germany $(23,715,093)$, France $(23,167,236)$, Cuba $(10,813,912)$, Sweden and Norway $(5,278,228)$, Netherlands $(4,442,709)$, the British Provinces $(3,632,464)$, the British West

${ }^{1}$ The Journal of the Royal Agricultural Society of England (1877) states the import of fresh beef from New York and Philadelphia in the first four months of 1877 $(22,812,123$ pounds) to have execerled tho whole import of the preceding year $(19,838,895$ pounds). 
Indies $(1,241,484)$, Spain $(1,004,849)$, and in smaller quantities to almost every other country.

Preserved meats go chiefly from New York $(\$ 3,066,538)$, Galreston, Tex. (\$359,063), Boston $(\$ 186,013)$, Oregon $(\$ 115,321)$, and San Francisco $(\$ 114,531)$ to England $(\$ 2,189,688)$, Scotland $(\$ 1,222,28 \tilde{5})$, Germany $(\$ 159,059)$, France $(\$ 126,619)$, and the British West Indies $(\$ 46,480)$.

Lard goes chiefly from New York $(166,924,25 j$ pounds), Boston $(29,380,349)$, Philadelphia $(11,682,146)$, Baltimore $(11,672,057)$, Portland $(7,744,890)$, and Huron, Mich. $(5,425,731)$, to England $(66,196,750)$, Scotland $(58,038,751)$, Belgium $(23,882,271)$, France $(23,788,669)$, Cuba $(21,665,367)$, Scotland $(8,096,852)$, British Provinces $(6,115,553)$, Netherlands $(5,597,166)$, United States of Colombia $(4,549,99 \tilde{5})$, Brazil $(4,267,310)$, Venezuela, Spanish Africa, Hayti, and numerous other countries.

Eggs go from New York (12,211 dozens), Washington Territory (8,9i1), and the Canadian boundary $(\mathbf{9}, 359)$ to the British Provinces $(\mathbf{1 8 , 8 9 5 )}$, England (4,200), and Porto Rico (9,024).

Condensed milk goes from New York $(\$ 94,246)$, San Francisco $(\$ 24,606)$, and Baltimore $(\$ 1,325)$ to the British possessions in Australasia $(\$ 37,509)$, England (\$30,727), Japan (\$12,984), British West Indies $(\$ 8,592)$, China $(\$ \$, 196)$, Cuba $(\$ 4,746)$, Brazil $(\$ 2,495)$, British Columbia $(\$ 2,46 \tilde{5})$, Central America $(\$ 1,754)$, and Hayti $(\$ 1,248)$.

Cheese goes chiefly from New York (103,251,661 pounds), Philadelphia $(1,456,868)$, Boston $(1,172,522)$, and Huron, Mich. $(1,116,320)$, to England $(95,571,379)$, Scotland $(1,100,099)$, and the English colonies, with small quantities to other countries.

Butter goes chiefly from New York (16,771,663 pounds), Boston $(2,284,619)$, and Philadelphia $(1,141,224)$ to England $(10,504,640)$, Scotland $(4,526,737)$, the British West Indies $(1,277,945)$, Scotland $(1,237,978)$, the British Provinces, Cuba, Porto Rico, Hayti, the Netherlands, Colombia, Venezuela, and the Danish West Indies.

The foreign exports of provisions amount to $\$ 64,478$, chiefly from $\mathrm{N} \in \mathrm{W}$ York to England, Cuba, Mexico, British Columbia, Central and South America.

\section{FISH.}

The quantity of fish imported not subject to duty is shown in the following table. The total value is $\$ 1,400,736$.

\begin{tabular}{|c|c|c|c|c|c|c|c|}
\hline \multirow{2}{*}{ Countries. } & \multicolumn{2}{|c|}{ Fresh, of all kinds. } & \multicolumn{2}{|c|}{ Herring, picklèd. } & \multicolumn{2}{|c|}{ Mackerel, pickled. } & \multirow{2}{*}{$\frac{\begin{array}{c}\text { All } \\
\text { other. }\end{array}}{\text { Dollaxs. }}$} \\
\hline & Pounds. & Dollars. & Barrels. & Dollars. & Barrels. & Dollars. & \\
\hline 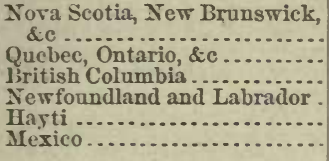 & $\begin{array}{r}4,584,678 \\
2,570,033 \\
1,270 \\
630,000 \\
\ldots \ldots \\
\end{array}$ & $\begin{array}{r}128,660 \\
94,780 \\
58 \\
12,600 \\
. . . . .\end{array}$ & $\begin{array}{r}49,033 \\
2,218 \\
\ldots \ldots \ldots \\
12,029 \\
\ldots . . . . . . . . . \\
\end{array}$ & 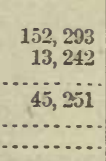 & $\begin{array}{r}43,053 \\
13\end{array}$ & 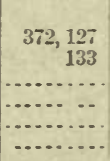 & $\begin{array}{r}312,047 \\
27,337 \\
\ldots . . . \\
180 \\
5703 \\
294\end{array}$ \\
\hline & $7,735,981$ & 236,098 & 63,280 & 210,786 & 43,066 & 372,260 & 540,300 \\
\hline
\end{tabular}


The remainder of the import subject to duty is shown in the next table. The total value is $\$ 1,054,748$.

\begin{tabular}{|c|c|c|c|c|c|c|c|}
\hline \multirow[t]{2}{*}{ Countries. } & \multicolumn{2}{|c|}{$\begin{array}{l}\text { Sardines and ancho- } \\
\text { vies, preserved in } \\
\text { oil or otherwise. }\end{array}$} & \multicolumn{2}{|c|}{ Herring, pickled. } & \multicolumn{2}{|c|}{ Mackerel, pickled. } & \multirow{2}{*}{$\frac{\begin{array}{c}\text { All } \\
\text { other. }\end{array}}{\text { Dollars. }}$} \\
\hline & Pounds. & Dollars. & Pounds. & Dollars. & Pounds. & Dollars. & \\
\hline $\begin{array}{l}\operatorname{lgium} . \\
\text { ina... }\end{array}$ & & $\begin{array}{l}20 \\
\ldots \ldots\end{array}$ & 167 & 2,368 & & & $\begin{array}{r}16 \\
47,089\end{array}$ \\
\hline Kon & (n......... & 685,164 & & & & & 761 \\
\hline nch Possessions.... & (n................ & $\begin{array}{r}080,104 \\
\ldots \ldots \ldots\end{array}$ & & & & & \\
\hline 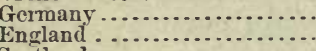 & n........... & $\begin{array}{r}5,266 \\
77,317\end{array}$ & $\begin{array}{r}4,726 \\
98\end{array}$ & $\begin{array}{r}61,676 \\
1,277\end{array}$ & & & $\begin{array}{l}7,098 \\
7,120\end{array}$ \\
\hline cotland....................... & & (........... & 49 & 698 & & & 169 \\
\hline 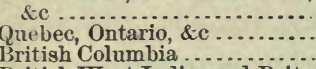 & & 6 & $\begin{array}{l}84 \\
24\end{array}$ & $\begin{array}{r}568 \\
35\end{array}$ & $\begin{array}{l}8 \\
6\end{array}$ & $\begin{array}{r}105 \\
43\end{array}$ & $\begin{array}{r}335 \\
19,691 \\
2,439\end{array}$ \\
\hline $\begin{array}{l}\text { 3ritish West Indies and Brit. } \\
\text { ish Honduras.............. }\end{array}$ & & & & & & & \\
\hline Jawaii $\ldots \ldots \ldots \ldots \ldots \ldots \ldots \ldots$ & (.............. & 969 & & & & $\begin{array}{ll} \\
\ldots \ldots \ldots \ldots\end{array}$ & $\begin{array}{r}35 \\
176\end{array}$ \\
\hline & ........... & & & & & 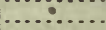 & 175 \\
\hline inds & $\ldots \ldots$. & 4,464 & 9.476 & 121,254 & & & 1,101 \\
\hline ain & & $\begin{array}{r}4,404 \\
42\end{array}$ & 8,460 & 121,204 & & & $\begin{array}{r}1,963 \\
63\end{array}$ \\
\hline & & 83 & 2 & 22 & & & 1,356 \\
\hline & & …. & 247 & 1,717 & & & 1,134 \\
\hline & |....... & 773,331 & 14,873 & 189,615 & 14 & 148 & 91,654 \\
\hline
\end{tabular}

The amounts of Canadian fish not liable to duty received in the various customs-districts are shown below:

\begin{tabular}{|c|c|c|c|c|c|c|c|}
\hline \multirow{3}{*}{ Districts. } & \multicolumn{7}{|c|}{ Fish, not of American fisheries. } \\
\hline & \multicolumn{2}{|c|}{ Fresh, of all kinds. } & \multicolumn{2}{|c|}{ Herring, pickled. } & \multicolumn{2}{|c|}{ Mackerel, pickled. } & $\begin{array}{c}\text { All } \\
\text { other; } \\
\text { not else- } \\
\text { where } \\
\text { speci- } \\
\text { fied. }\end{array}$ \\
\hline & Pounds. & Dollars. & Barrels. & Dollars. & Barrels. & Dollars. & Dollars. \\
\hline Baltimore, $\mathrm{Md} . . . . . \ldots \ldots \ldots$ & 1,500 & & 1,884 & 7,605 & & & \\
\hline Boston and Charlestown, Mass & 473,556 & 15,465 & 46,150 & 157,108 & 34,730 & 300,690 & 176,147 \\
\hline $\begin{array}{l}\text { Buffalo Creek, N. Y }, \ldots \ldots \ldots \ldots \\
\text { Cape Vincent, N. Y } \ldots \ldots \ldots \ldots\end{array}$ & $\begin{array}{l}378,869 \\
474,798\end{array}$ & $\begin{array}{l}13,154 \\
15,433\end{array}$ & 328 & 1,862 & & n.......... & \\
\hline hamplain, N. Y....... & 191, 033 & 14,338 & 84 & 524 & $\dddot{13}$ & 133 & 1,405 \\
\hline 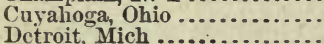 & $\begin{array}{r}12,720 \\
652,703\end{array}$ & $\begin{array}{r}509 \\
19,084\end{array}$ & & & & (n) & \\
\hline Erie, $\mathrm{Pa} . . . . . .$. & 5,400 & 227 & & & & & \\
\hline Gencsee, N. Y & 36,240 & 1,443 & & & & & \\
\hline $\begin{array}{l}\text { Gloucester, Mass } \\
\text { Huron, Mich .... }\end{array}$ & 46813 & 1924 & 1,010 & 2,010 & & & 12,199 \\
\hline $\begin{array}{l}\text { Huron, Mich ... } \\
\text { Key West, Fla. }\end{array}$ & 46,813 & & & 8,054 & & $\cdots \cdot$ & $\begin{array}{l}735 \\
258\end{array}$ \\
\hline Machias, Me....... & 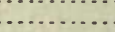 & & & & & & \\
\hline Marblehead, Mass . & (30 & & & 12 & 4 & 15 & \\
\hline $\begin{array}{l}\text { Minnesota, Minn .... } \\
\text { Newluryport, Mass }\end{array}$ & 200 & 10 & & & & & \\
\hline New York, N. Y .... & $2,610,000$ & 52,200 & 2,115 & 8,961 & 1,823 & 15,656 & 217,563 \\
\hline $\begin{array}{l}\text { Niagara, N. } \mathrm{Y} \\
\text { Oswegatchie, } \mathrm{N} . \mathrm{Y} . \ldots \ldots \ldots\end{array}$ & $\begin{array}{r}159,057 \\
6,800\end{array}$ & 7,561 & & & & & \\
\hline $\begin{array}{l}\text { Oswegatchie, } \mathrm{N} . \mathrm{Y} \ldots \ldots \ldots \\
\text { Oswego, N. Y . . . . . . . . }\end{array}$ & $\begin{array}{r}6,800 \\
184,244\end{array}$ & 7,471 & & & & & \\
\hline 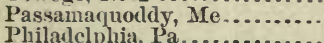 & $1,331,353$ & 63,844 & 6,726 & 9,885 & 4,974 & 44,031 & 55,320 \\
\hline Portland and Falmouth, $\mathrm{Me}_{\mathrm{e}}$ & 747,579 & 9,676 & 2,661 & 11,103 & 1,480 & 11,405 & 87,721 \\
\hline $\begin{array}{l}\text { Puget Sound, Wash ............ } \\
\text { Richmond, Va. }\end{array}$ & 1,270 & & & …..... & & & \\
\hline Salem and Beveily, Mass. & & & 510 & 810 & $\ddot{4}$ & 16 & 811 \\
\hline Sanclusky, Ohio & 212,540 & 3,545 & & & & & \\
\hline $\begin{array}{l}\text { San liral } \\
\text { Savanna }\end{array}$ & $\ldots . .$. & $\cdots$ & & & & & $\begin{array}{r}154 \\
50\end{array}$ \\
\hline Miel ...... & 118,614 & 2,459 & & & & & \\
\hline Vermon & 90,692 & 7,822 & 388 & 2,802 & & & 24,398 \\
\hline & & & & & & & \\
\hline & & & & & & & \\
\hline Total ......... & $7,735,981$ & 236,098 & 63,280 & 210,786 & 43,066 & 372,260 & 581,592 \\
\hline
\end{tabular}


The entries by customs-districts of fish not from Canada and dutiable are shown below:

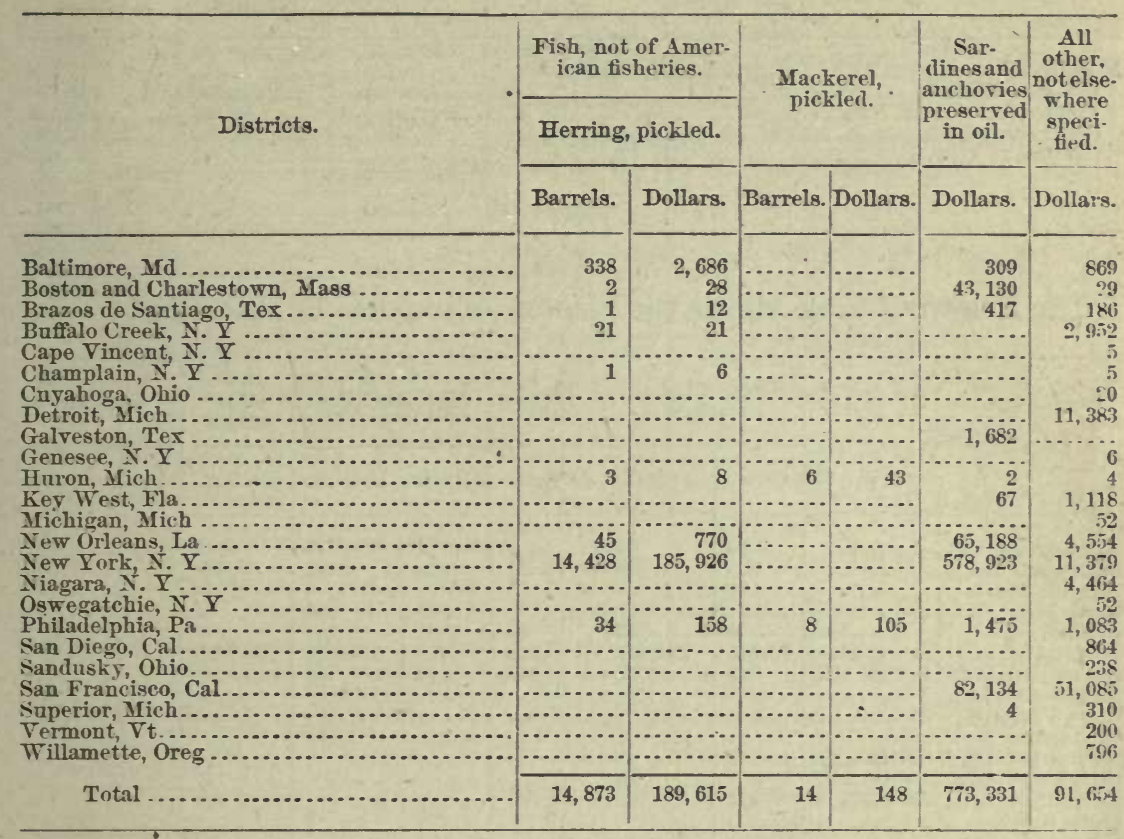

\section{The next table shows the amount of fish entered into consumption:}

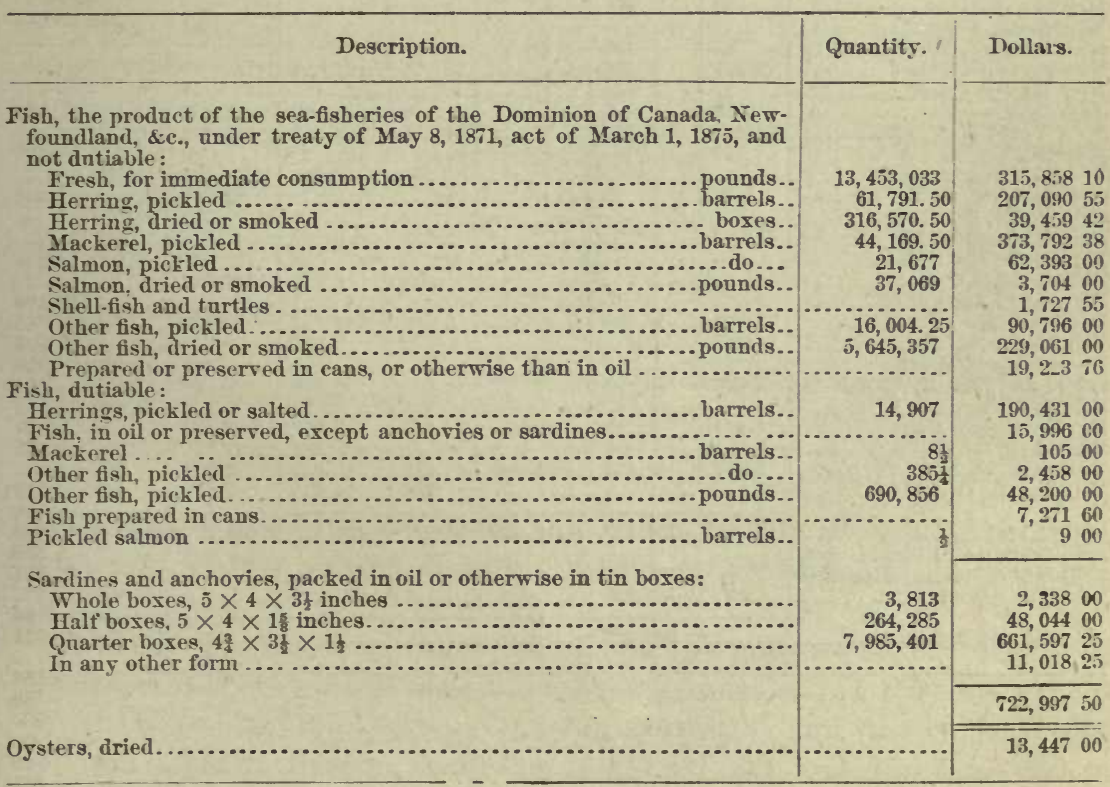


The following table shows the amount of domestic exports of fish:

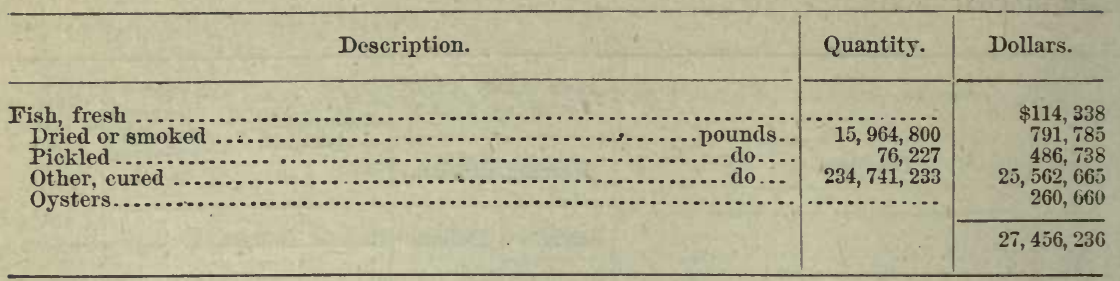

The following table shows the amount of exports by districts:

\begin{tabular}{|c|c|c|c|c|c|c|c|c|}
\hline \multirow{2}{*}{ Districts. } & \multicolumn{2}{|c|}{$\begin{array}{l}\text { Fish, dried or } \\
\text { swnoked. }\end{array}$} & \multirow{2}{*}{$\begin{array}{l}\begin{array}{c}\text { Fish, } \\
\text { fresh. }\end{array} \\
\text { Dollars. }\end{array}$} & \multicolumn{2}{|c|}{ Fish, pickled. } & \multirow{2}{*}{$\begin{array}{c}\begin{array}{c}\text { Fish, } \\
\text { other } \\
\text { cured. }\end{array} \\
\text { Dollars. }\end{array}$} & \multicolumn{2}{|c|}{ Oysters. } \\
\hline & Cwt.. & Dollars. & & Barrels. & Dollars. & & Bush. & Dolls. \\
\hline 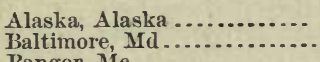 & $\begin{array}{r}13 \\
355\end{array}$ & $\begin{array}{r}66 \\
1,395\end{array}$ & & $\begin{array}{r}2 \\
670\end{array}$ & 4,745 & $\begin{array}{r}142 \\
31,521\end{array}$ & & 27,384 \\
\hline $\begin{array}{l}\text { Bangor, Me.......... } \\
\text { Bath, Me .......... }\end{array}$ & & & & 361 & 696 & 1,046 & & \\
\hline Belfast, Me & & & 84 & 42 & 258 & & & \\
\hline Boston and Charlestown, Mass & 78,815 & 349,408 & 222 & 26,150 & 171,078 & 117,225 & & 7,115 \\
\hline $\begin{array}{l}\text { Brazos de Santiago, Tex .... } \\
\text { Buffalo Creek, N. Y.......... }\end{array}$ & & $\begin{array}{r}362 \\
3 .+\ldots\end{array}$ & 143 & & 31 & 242 & & $\begin{array}{r}593 \\
2,239\end{array}$ \\
\hline Cape Vincent, N. Y............ & & & & & & 60 & & 3,987 \\
\hline Champlain, N. Y.... & & & & 100 & 1,000 & & & 14,443 \\
\hline Cuyahoga, Ohio..... & 1 & 15 & & & & 17 & & 50 \\
\hline Detroit, Mich....... & 312 & 1,260 & 2,071 & & & 5,021 & & 4,858 \\
\hline $\begin{array}{l}\text { Duluth, Minn ........ } \\
\text { Galveston, Tex..... }\end{array}$ & …. & ........ & & 1 & 7 & & & \\
\hline Genesee, N. Y ....... & & & & & & 13 & 467 & \\
\hline $\begin{array}{l}\text { Gloucester, Mass ... } \\
\text { Huron, Mich ...... }\end{array}$ & 90 & 200 & & 11,338 & 54,016 & $\begin{array}{r}391 \\
2491\end{array}$ & & \\
\hline Key West, Fla ..... & & & 60,200 & & & $\begin{array}{r}2,491 \\
13,547\end{array}$ & 468 & \\
\hline Machias, Me ${ }_{\text {Minuesota }}$ Minn & 98 & 187 & & & & 101 & & \\
\hline New Bedford, Mass........ & 67 & 329 & & & & 1,861 & 1,921 & 837 \\
\hline Newburyport, Mass .... & 2,371 & 9,796 & & & & & $\cdots$ & $\cdots$. \\
\hline Now Haven, Conn .......... & 27 & & & & & & & \\
\hline New Orleans, La. ............. & 36 & 195 & & & 68 & 2,193 & 39 & 10 \\
\hline $\begin{array}{l}\text { New York, N. Y. } \\
\text { Norfolk, Va................ }\end{array}$ & $\begin{array}{r}64,002 \\
\ldots \ldots\end{array}$ & $\begin{array}{r}368,779 \\
\ldots .\end{array}$ & & 24,357 & 188,415 & $\begin{array}{r}313,642 \\
19\end{array}$ & & $10.29 \pi$ \\
\hline Oregon, Oreg ................ & (n......... & $\cdots$ & & 299 & 2,709 & 693,125 & $\begin{array}{r}164,5.22 \\
320\end{array}$ & $\begin{array}{l}10,29 \\
\ldots \ldots\end{array}$ \\
\hline Oswegatchie, $\mathrm{N} . \mathrm{Y} . . . . .$. & 12 & 72 & & & & 2,582 & & \\
\hline Oswego, N. Y & -........ & -........... & & & & 500 & 21,914 & ...... \\
\hline $\begin{array}{l}\text { Passama } \\
\text { Pensaco }\end{array}$ & & & & $\begin{array}{r}2,312 \\
9\end{array}$ & $\begin{array}{r}6,000 \\
18\end{array}$ & 36 & 1,049 & 792 \\
\hline 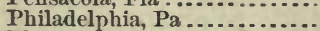 & & & & $\begin{array}{r}9 \\
333\end{array}$ & 2,415 & $\begin{array}{r}36 \\
191,442\end{array}$ & 1,049 & 192 \\
\hline Plymouth, Mass ............. & 1,500 & 6,000 & & & & & & \\
\hline Portland, Me & 2,590 & 10,845 & $\therefore . .$. . & 8,650 & 44,155 & 25,413 & 178 & \\
\hline $\begin{array}{l}\text { Providence, } \\
\text { Puget Sound, iVash ...... }\end{array}$ & 557 & 1,942 & & & 19 & 108 & 1,550 & \\
\hline Salem and Beverly, Mass & 5,643 & 20,085 & 27 & 461 & 2,960 & 82 & & \\
\hline $\begin{array}{l}\text { Saluria, Tex } \\
\text { San Francisco, Cal ............. }\end{array}$ & 448 & 3149 & & & & 066 & 1,009 & 31,343 \\
\hline Saran & & & & 527 & $\begin{array}{l}2,607 \\
211\end{array}$ & $1,066,430$ & & \\
\hline Vermont, Vt............... & 2,667 & 17,609 & 51,589 & 118 & 621 & 9,255 & 6,169 & \\
\hline Willamette, Oreg .............. & & & & 632 & 4,693 & 7,719 & 200 & \\
\hline Total ............ & 159,648 & 791,785 & 114,338 & 76,227 & 486,738 & $2,486,225$ & 260,620 & 45,361 \\
\hline $\begin{array}{l}\Delta \text { dditions to Niagara and } \\
\text { Vermont, taken from } \mathrm{Ca} \text { - }\end{array}$ & & & & & & & & \\
\hline & & & & & & & & 0,10 \\
\hline Grand total......... & & 980,936 & & & & & 431,230 & 48,523 \\
\hline
\end{tabular}


The following table shows the amounts of domestic exports of fish by countries :

\begin{tabular}{|c|c|c|c|c|c|c|c|}
\hline \multirow[t]{2}{*}{ Countries. } & \multicolumn{2}{|c|}{$\begin{array}{l}\text { Fish, dried or } \\
\text { smoked. }\end{array}$} & \multirow{2}{*}{$\begin{array}{c}\begin{array}{c}\text { Fish, } \\
\text { fresh. }\end{array} \\
\text { Dollars. }\end{array}$} & \multicolumn{2}{|c|}{ Fish, pickled. } & \multirow{2}{*}{$\begin{array}{l}\begin{array}{c}\text { Fish, oth- } \\
\text { er cured. }\end{array} \\
\text { Dollars. }\end{array}$} & \multirow{2}{*}{ Oysters. } \\
\hline & Cwt. & Dollars. & & Bairels. & Dollars. & & \\
\hline Argentine Republic.. & & & & & & & 812 \\
\hline Belgium ............. & & & & 6 & 60 & 779 & \\
\hline razil .... & & & & 50 & 541 & 309 & 1,841 \\
\hline Cential Am & 195 & 1,316 & & 121 & 857 & $5,0 \% 9$ & 240 \\
\hline & 䓅 & 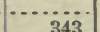 & & & & 3,4 & 2,555 \\
\hline $\begin{array}{l}\text { China ............... } \\
\text { Denmark ... }\end{array}$ & & & & 2,312 & 6,000 & & (n....... \\
\hline Danish Wrest Indies... & 170 & 624 & $\cdots$ & 395 & 2,302 & 2,489 & 402 \\
\hline France ................. & & & & 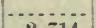 & & $43,36 \pi$ & 236 \\
\hline $\begin{array}{l}\text { French TWest Indies and French Guiana.- } \\
\text { French Possessions in Africa and adja- }\end{array}$ & 19,939 & 84,228 & 27 & 2,714 & 18,480 & 7,286 & 34 \\
\hline 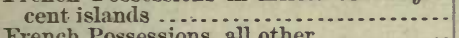 & & & & & & 612 & \\
\hline French Possessions, all other................. & $\begin{array}{l}22 \\
86\end{array}$ & $\begin{array}{r}163 \\
380\end{array}$ & ..... & 270 & 2,197 & $13,6.5$ & \\
\hline y. & $\begin{array}{r}86 \\
242\end{array}$ & $\begin{array}{l}350 \\
912\end{array}$ & $\cdots$ & 170 & 1,042 & 72,536 & $18,4: 0$ \\
\hline 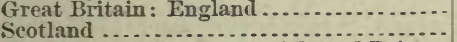 & 242 & & $\ldots .$. & $\begin{array}{r}746 \\
1,030\end{array}$ & $\begin{array}{l}4,151 \\
4,700\end{array}$ & $\begin{array}{r}1,587,457 \\
5,514\end{array}$ & $\begin{array}{r}118,6.34 \\
2, \cos \end{array}$ \\
\hline & & & & & & & 2, \\
\hline $\begin{array}{l}\text { Edward Island } \\
\text { Quebec, Ontario, Rupert's Land, and the }\end{array}$ & 9,592 & 41,352 & & 2,046 & 12,137 & 50 & 5,693 \\
\hline Northwest Territory............. & 2,992 & 18,900 & 53,660 & 219 & 1,628 & $21,7 \times 7$ & 56,516 \\
\hline diabrador & 87 & 696 & ....... & 2 & .16 & 2,453 & 1,849 \\
\hline $\begin{array}{l}\text { Newfoundland and Labrador } \\
\text { British West Indies and British Honduras }\end{array}$ & 5,084 & $\begin{array}{r}350 \\
-300\end{array}$ & $\cdots$ & & & 220 & \\
\hline 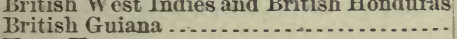 & $\begin{array}{r}5,084 \\
940\end{array}$ & 27,769 & $\begin{array}{r}86 \\
\end{array}$ & 5,540 & 33,066 & 25,289 & 1,491 \\
\hline (1) & 940 & $\begin{array}{r}4,886 \\
689\end{array}$ & 222 & 1,478 & 9,289 & 1,090 & 809 \\
\hline n Africa ............. & $\begin{array}{l}104 \\
815\end{array}$ & $\begin{array}{r}689 \\
3,474\end{array}$ & ...... & 81 & 866 & 291,606 & $\begin{array}{r}38 \\
183\end{array}$ \\
\hline ns in Anstralasia........ & & & & 626 & 4,652 & 207,463 & $33,14$. \\
\hline 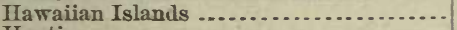 & 90 & 644 & ....... & 926 & 7,352 & 17,701 & 2,992 \\
\hline 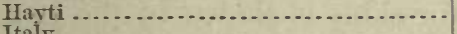 & 62,387 & 372,025 & ....... & 29,737 & 225,949 & 31,344 & 482 \\
\hline (n) & 10 & 60 & ........ & ........... & $-\ldots . . . .$. & & \\
\hline ( & $\begin{array}{r}55 \\
371\end{array}$ & 406 & ........ & $\cdots$ & & 2,523 & \\
\hline (n) & $\begin{array}{r}371 \\
42\end{array}$ & 1,238 & Fin & 430 & 3,117 & 3,048 & \\
\hline nds & 42 & 443 & 143 & 4 & & 5,967 & 3,49 \\
\hline $\begin{array}{l}\text { Netherlands } \\
\text { Dutch West Indies. }\end{array}$ & & & ...... & & $\begin{array}{r}56 \\
11\end{array}$ & & \\
\hline 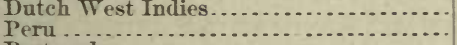 & $\begin{array}{r}24,994 \\
72\end{array}$ & 77,818 & .... & 2,102 & 11,416 & $\begin{array}{r}3,435 \\
14,315\end{array}$ & 43 \\
\hline Portugal & 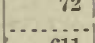 & 310 & & 1 & 10 & $\begin{array}{r}14,315 \\
20\end{array}$ & \\
\hline Azore, Macleira, and Cape Verde Islands. - & 611 & 3,295 & & 13 & 141 & 360 & \\
\hline 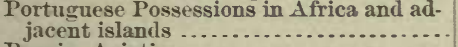 & 22 & 90 & & & & & \\
\hline 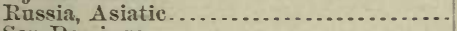 & & & & & & 27 & \\
\hline 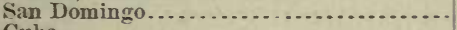 & 3,490 & 19,503 & & 2,112 & 16,534 & 6,757 & \\
\hline Cuba ............................. & 18,483 & 87,687 & 60,200 & 588 & 5,146 & 65,491 & 3,905 \\
\hline $\begin{array}{l}\text { Porto Rico } \\
\text { Spanish Possessions in Africa and adja- }\end{array}$ & 5,729 & 24,077 & ........ & 1,258 & 8,137 & 8,112 & \\
\hline & & & & & & 384 & \\
\hline Sweden an & $\begin{array}{r}196 \\
1,997\end{array}$ & 12,760 & & 20,516 & 101,492 & $\begin{array}{r}4,400 \\
13,980\end{array}$ & \\
\hline tes of Colombia. & 1,996 & 12,142 & & 715 & 5,232 & $\begin{array}{r}13,980 \\
1,117\end{array}$ & \\
\hline 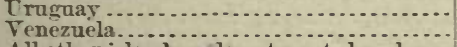 & 710 & 5,160 & & 13 & 129 & $\begin{array}{l}1,117 \\
7,256\end{array}$ & 1,38 \\
\hline 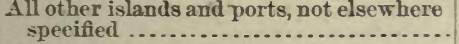 & 5 & 33 & & & & 4,551 & \\
\hline T & 159,648 & 785 & 144,138 & 76,227 & 486,738 & $2,486,225$ & \\
\hline Additions taken from Canadian reports - & & & & ............ & & & \\
\hline Granc & &, 936 & & & & & 431,23 \\
\hline
\end{tabular}

One thousand nine hundred and three barrels of pickled herring, valued at $\$ 9,088$, passed through Boston to Sweden and Norway as a foreign export.

Miscellaneous fish to the value of $\$ 32,120$ goes as foreign export to England $(\$ 22,098)$, Nova Scotia and New Brunswick $(\$ 5,795)$, the French West Indies $(\$ 3,932)$, Quebec, Ontario, \&c. (\$215), and Australasia (\$80). Of this amount Boston sends the most $(\$ 31,905)$ and Portland the remainder (\$215). 


\section{The following table shows the foreign exports of fish:}

\begin{tabular}{|c|c|c|c|c|}
\hline \multirow{3}{*}{ Countries. } & \multicolumn{4}{|c|}{ Fish, not of American fisheries. } \\
\hline & \multicolumn{2}{|c|}{$\begin{array}{l}\text { Herring, } \\
\text { pickled. }\end{array}$} & $\begin{array}{l}\text { Sardines ant } \\
\text { anchovies, } \\
\text { preserved in } \\
\text { oil. }\end{array}$ & $\begin{array}{l}\text { All other, not } \\
\text { elsewhere } \\
\text { specified. }\end{array}$ \\
\hline & Barrels. & Dollars. & Dollars. & Dollars. \\
\hline Central American States. & & & 1,296 & \\
\hline China ${ }_{\text {Franes }}$ & & & j8i1 & 805 \\
\hline 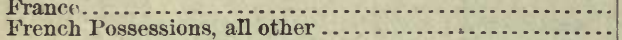 & $\because$ & & $\begin{array}{r}1,811 \\
630\end{array}$ & $\begin{array}{r}2,033 \\
7\end{array}$ \\
\hline Germany $\ldots \ldots \ldots \ldots \ldots \ldots \ldots \ldots$ & & & ........ & \\
\hline 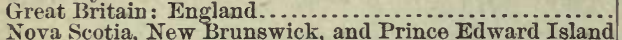 & & & & 33,956 \\
\hline Quebec, Ontario, Manitoba, Fupert's Land, \&c.......... & & & $\begin{array}{r}193 \\
16,930\end{array}$ & 666 \\
\hline British Columbia $\ldots \ldots \ldots \ldots \ldots \ldots \ldots \ldots$ & .......... & $\cdots$ & 288 & 529 \\
\hline $\begin{array}{l}\text { British West Indies and Honduras } \ldots \ldots \ldots \ldots \ldots \ldots \\
\text { British Possessions : Hong-Kong } \ldots \ldots \ldots \ldots \ldots\end{array}$ & $\cdots$ & & 187 & \\
\hline $\begin{array}{l}\text { British Possessions : Hong-Kong ............. } \\
\text { British Possessions in Australasia......... }\end{array}$ & & & $\cdots .$. & $\begin{array}{r}470 \\
4333\end{array}$ \\
\hline Hawaiian Islands .................................. & & & & $\begin{array}{r}4,333 \\
95\end{array}$ \\
\hline 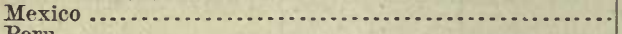 & 2 & 22 & 2,366 & 181 \\
\hline Peru Domingo & $\cdots$ & $\cdots \ldots$ & 591 & 473 \\
\hline Cuba & & & 25 & 91,489 \\
\hline Tnited States of Colombia ............................. & & & 56 & 133 \\
\hline Venezuela ................... & & & 477 & \\
\hline Total....... & 2 & 22 & $\cdot 24,780$ & 135,854 \\
\hline
\end{tabular}

\section{FURS.}

The value of the import of undressed fur-skins is shown in the next tahle:

\section{Imports of fur-skins undressed.}

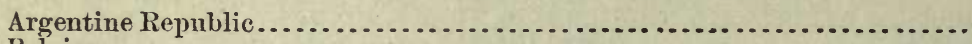

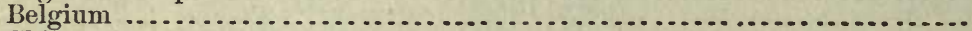

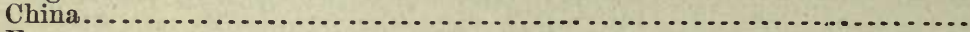

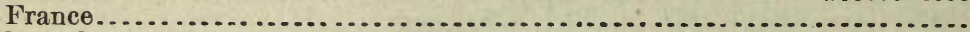

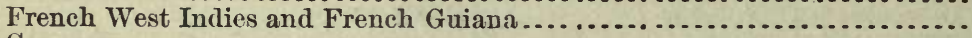

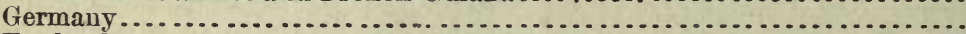

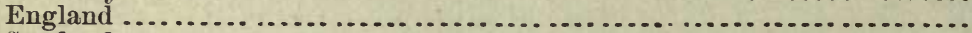

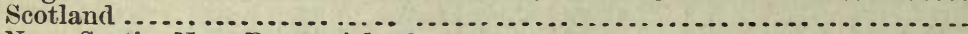

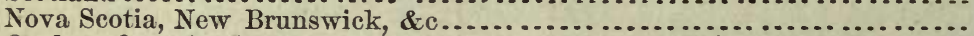

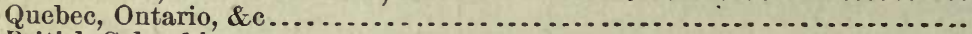

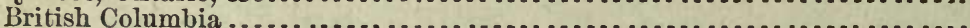

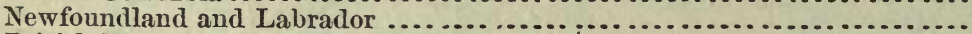

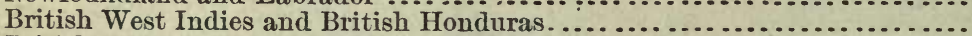

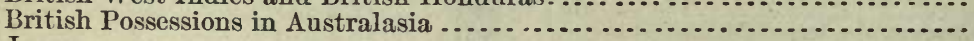

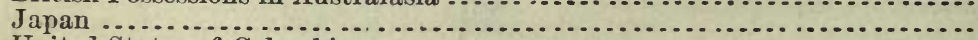

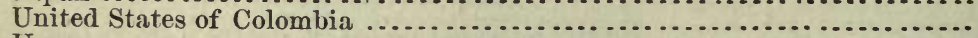

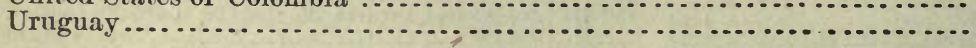

Total.

The value of the imports of furs and dressed fur-skins is shown in the following table:

Eingland

France.

Germany .................

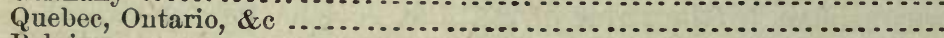

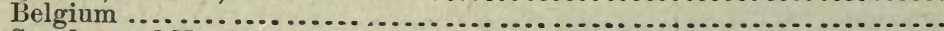

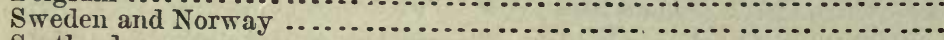

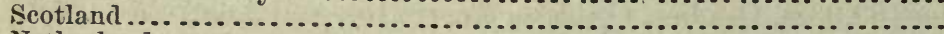

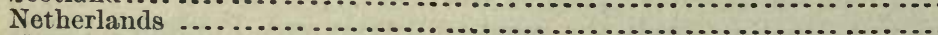

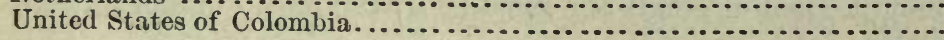

Carried forward.
$\$ 38,026$

2, 082 77

2, 696

204

82,044

359,351

1, 922

3,435

789,591

162, j58

72

114,657

$4,0=6$

134

$1,561,666$
$\$ 1,085,376$ 781,769 :378, 643

76,694

$60,7<1$

8,252

5,538

3, 319

375 
Brought forward

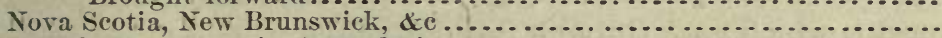

British Possessions in Anstralasia ................................

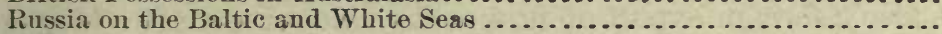

China ....................................................

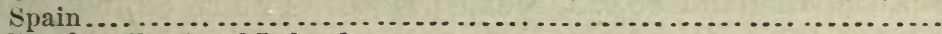

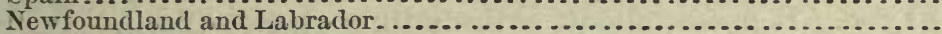

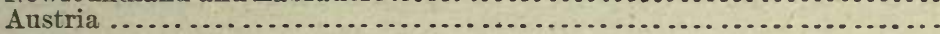

British West Indies and British Honduras ..............................

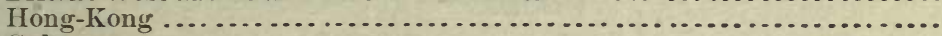

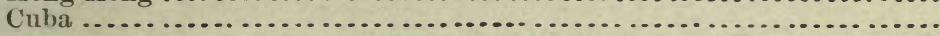

Total

Furs are imported chiefly to New York $(\$ 2,142,947)$, Philadelphia $(\$ 93,713)$, Boston $(\$ 72,625)$, Montana and Idaho (from the Hudson's Bay Territory, of course) $(\$ 69,051)$, and Sản Francisco $(\$ 11,874)$.

The value of fur-skins and furs entered into consumption is shown in the following table:

Fur-skins of all kinds, not dressed in any manner ............. \$1,544, 89389 Furs, and manufactures of:

Dressed, on the skin.........

$1,044,93023$

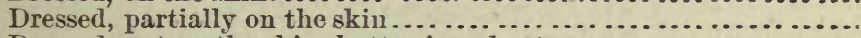

Dressed, not on the skin, hatters', and others..................

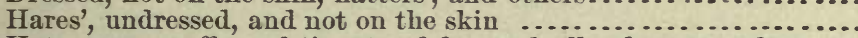

Hats, caps, muffs, and tippets of fur, and all other mannfactures of fur, or of which fur shall be the component of chief value...

Total

Sheep and lamb skins tanned with the wool on are imported to the Lake ports to the amount of $\$ 22,232$.

The domestic export of furs amounts to $\$ 3,836,579$. The amount of this export, by customs-districts, and by countries, is shown in the following table:

\begin{tabular}{|c|c|c|c|}
\hline Districts. & $\begin{array}{l}\text { Furs and } \\
\text { fur-skins. }\end{array}$ & Countries. & $\begin{array}{l}\text { Furs and } \\
\text { fur-skins. }\end{array}$ \\
\hline 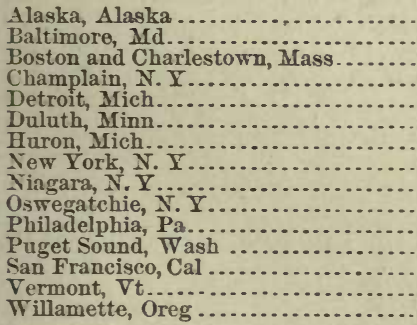 & $\begin{array}{r}20,900 \\
16,300 \\
138,468 \\
28,640 \\
829 \\
16 \\
600 \\
2,77,050 \\
210 \\
1,728 \\
757,986 \\
16,707 \\
29,337 \\
21 \\
10\end{array}$ & 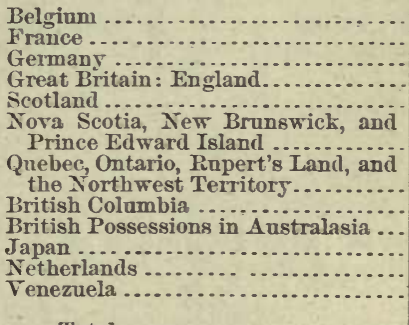 & $\begin{array}{r}605 \\
8,397 \\
1,099,380 \\
2,606,253 \\
2,200 \\
1,250 \\
32,044 \\
37,617 \\
200 \\
437 \\
200 \\
219\end{array}$ \\
\hline 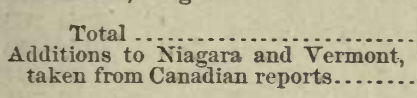 & $\begin{array}{r}3,788,802 \\
47,777\end{array}$ & $\begin{array}{l}\text { Total } \\
\text { Additions taken from Canadian re- } \\
\text { ports }\end{array}$ & $\begin{array}{r}3,788,802 \\
47,777\end{array}$ \\
\hline Grand total................. & $3,836,579$ & & \\
\hline
\end{tabular}

Fur-skins, undressed, are sent as foreign exports to the amount of $\$ 118,089$ : to England $\$ 105,020$, Germany $\$ 9,214$, France $\$ 3,227$, and 
284 ANIMAL RESUURCES AND FISHERIES OF UNITED STATES.

Hong-Kong \$625. All passes through New York, except the HongKong shipment, which goes through San Francisco.

There is also a foreign export of furs to the value of $\$ 52,199$ : to Quebec, \&c., $\$ 37,518$, England $\$ 8,025$, Mexico $\$ 2,667$, France $\$ 2,136$, and Germany $\$ 1,296$. It passes almost entirely through New York.

WOOL.

The importation of unmanufactured wool amounts to $42,171,192$ pounds, valued at $\$ 7,156,944$. The value of manufactures of wool (exclusive of hats) is $\$ 25,601,922$. The details of this importation are given below: 
ANIMAL RESOURCES AND FISHERIES OF UNITED STATES. 285

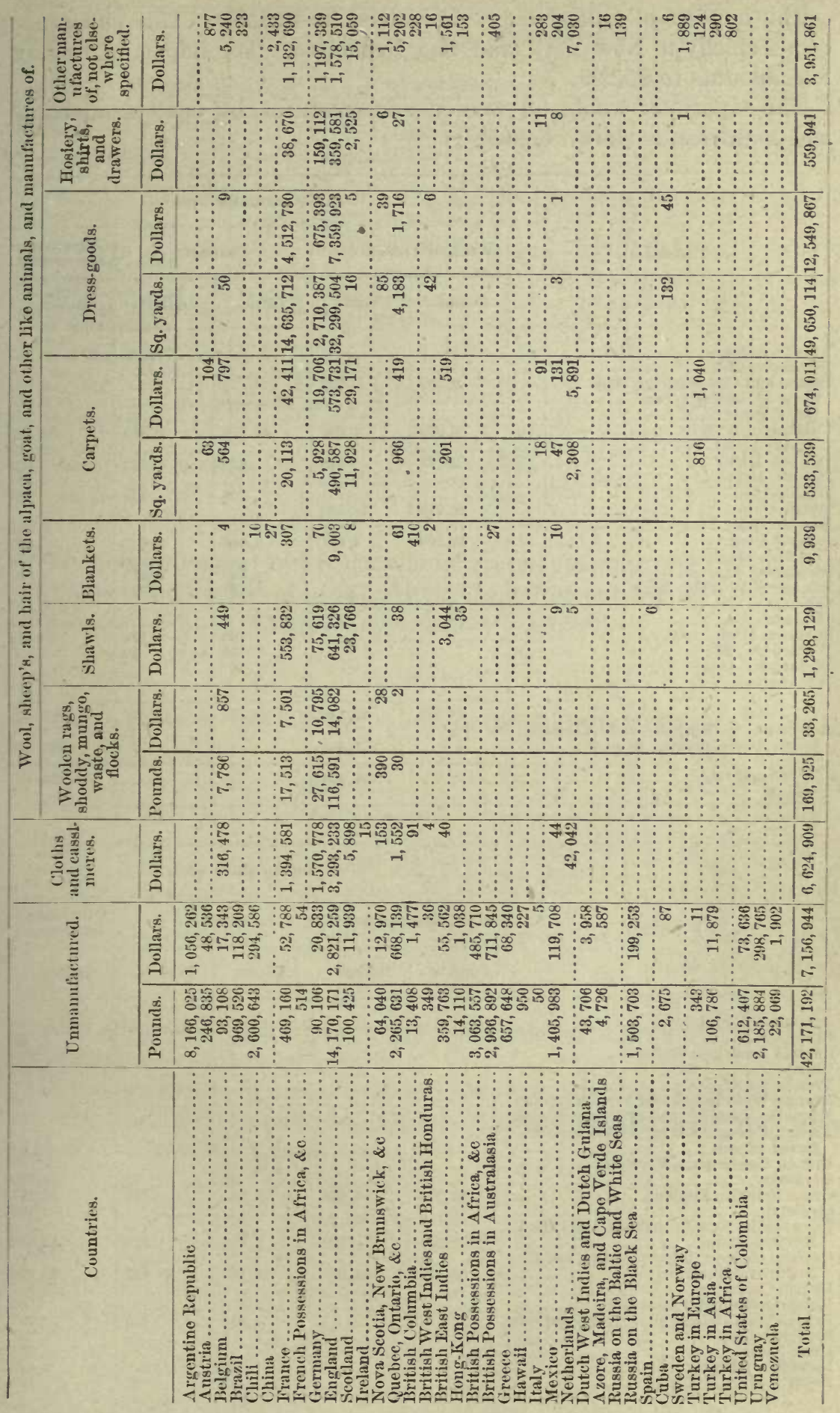


The imports of adhesive felt are valued at $\$ 28,273$. This substance comes chiefly to New York and San Franciseo. The import of roofing felt amounts to $\$ 5,299$.

The exports of wool and woolen manufactures, by customs-districts and countries, is shown below:

\begin{tabular}{|c|c|c|c|c|c|}
\hline \multirow{3}{*}{ Districts. } & \multicolumn{5}{|c|}{ Wool, and manufactures of. } \\
\hline & \multicolumn{2}{|c|}{ Wool, raw and fleece. } & \multicolumn{2}{|c|}{ Carpets. } & \multirow{2}{*}{$\frac{\begin{array}{l}\text { Other manu- } \\
\text { factures of. }\end{array}}{\text { Dollars. }}$} \\
\hline & Pounds. & Dollars. & Yards. & Dollars. & \\
\hline \multicolumn{6}{|l|}{$\begin{array}{l}\text { Alaska, Alaska ......... } \\
\text { Baltimore, Md........ }\end{array}$} \\
\hline $\begin{array}{l}\text { Baltimore, Md ....................... } \\
\text { Boston and Charlestown, Mass. }\end{array}$ & 2,505 & 762 & .............. & & \\
\hline $\begin{array}{l}\text { Boston and Charlestown, Mass.. } \\
\text { Brazos de Santiago, Tex......... }\end{array}$ & $\begin{array}{c}2,505 \\
\cdots \ldots . .\end{array}$ & 702 & (4 & .... & 3,922 \\
\hline & 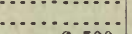 & & & & $\begin{array}{r}3,456 \\
365\end{array}$ \\
\hline 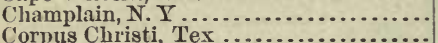 & 6,500 & 1,900 & 14,570 & 9,875 & 82,327 \\
\hline Detroit, Mieh................... & 2,175 & 870 & 420 & 462 & $\begin{array}{r}2,625 \\
490\end{array}$ \\
\hline Dulutb, Minn...$\ldots \ldots \ldots \ldots \ldots \ldots \ldots \ldots$ & 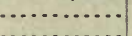 & & & & 455 \\
\hline $\begin{array}{l}\text { Machias, Mo } \\
\text { Miami, Ohio } \ldots \ldots \\
\text { M }\end{array}$ & 58,219 & 18,293 & 100 & 125 & 225 \\
\hline Nowburyport, Mass ...................... & ........ & & & & 1,981 \\
\hline $\begin{array}{l}\text { Oregon, Oreg } \\
\text { Portland, Me }\end{array}$ & 10,200 & 4,621 & 1,404 & 1,407 & 91,310 \\
\hline $\begin{array}{l}\text { Portland, } \\
\text { Richmond, } V \mathrm{a}\end{array}$ & …........ & $\cdots$. & 4,345 & 3,475 & $\begin{array}{r}20,984 \\
6,982\end{array}$ \\
\hline Salem and Beverly, Mass .............. & ............ & ….... & 2,480 & 829 & 19,255 \\
\hline $\begin{array}{l}\text { San Diego, Cal } \ldots \ldots \ldots \ldots \ldots \ldots \ldots \\
\text { Savannah, Ga. }\end{array}$ & & & . & 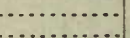 & $\begin{array}{r}6,293 \\
924\end{array}$ \\
\hline $\begin{array}{l}\text { Savannah, Ga } \\
\text { Superior, Mieh }{ }^{\prime} \ldots \ldots \\
\end{array}$ & & & 130 & 174 & 19,379 \\
\hline Waldoboro', Me & (n) & & 30 & 30 & 8,135 \\
\hline Willamette, Oreg . ....................... & ............. & & .... & ....... & 23 \\
\hline 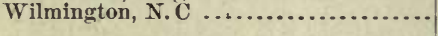 & (............ & & & & 1,241 \\
\hline Total $\ldots \ldots \ldots \ldots \ldots \ldots \ldots \ldots \ldots \ldots \ldots \ldots \ldots \ldots \ldots$ & 79,599 & 26,446 & 23,479 & 16,377 & 275,460 \\
\hline $\begin{array}{l}\text { Additions to Niagara and Vermont, } \\
\text { taken from Canadian reports ......... }\end{array}$ & & 670,008 & & & 161,106 \\
\hline Grand total ......... & ........... & 696,454 & & & 436,566 \\
\hline
\end{tabular}

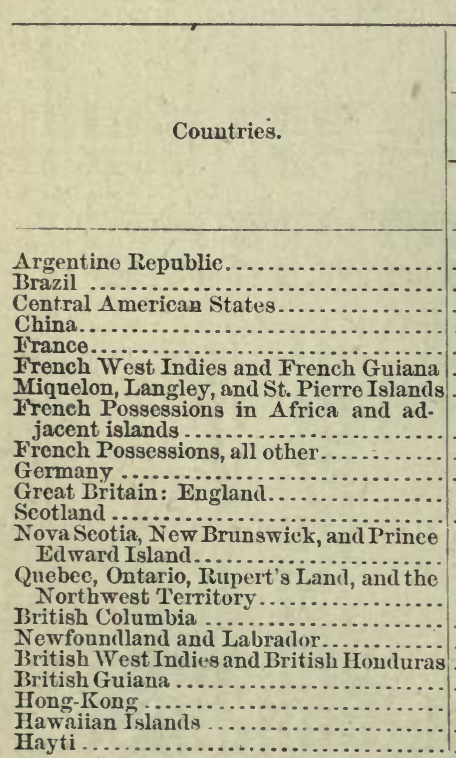

Wool, and manufactures of.

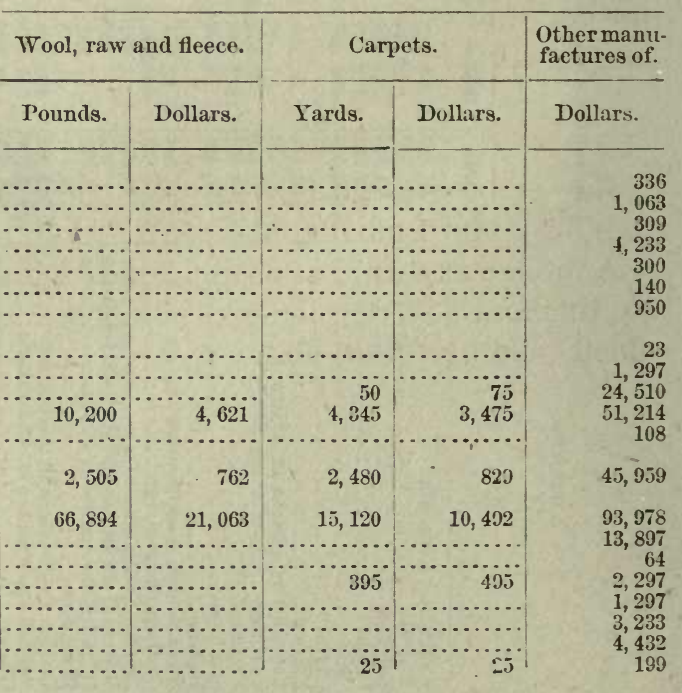




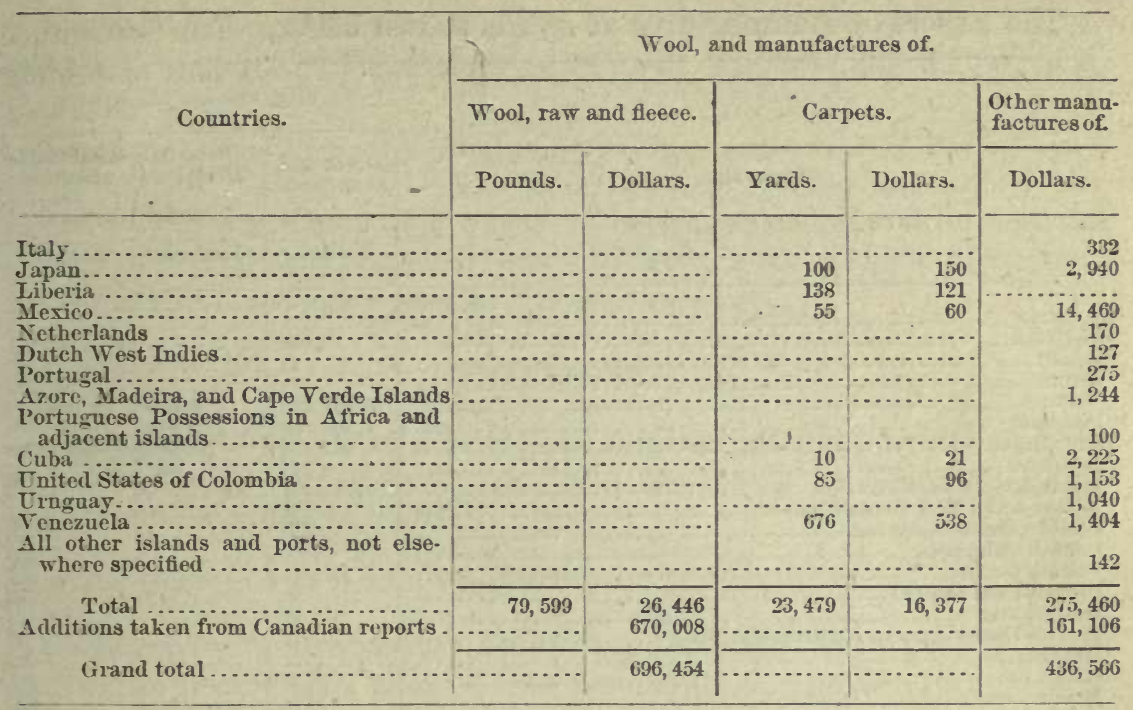

The foreign export of woolen manufactures amounts to $\$ 373,753$, that of unmanufactured wool to $\$ 472,519(3,088,957$ pounds), chiefly to Canada $(\$ 445,134)$, France $(\$ 23, \$ 35)$, and England $(\$ 3,550)$.

SILK.

The imports of raw silk are shown in the following table:

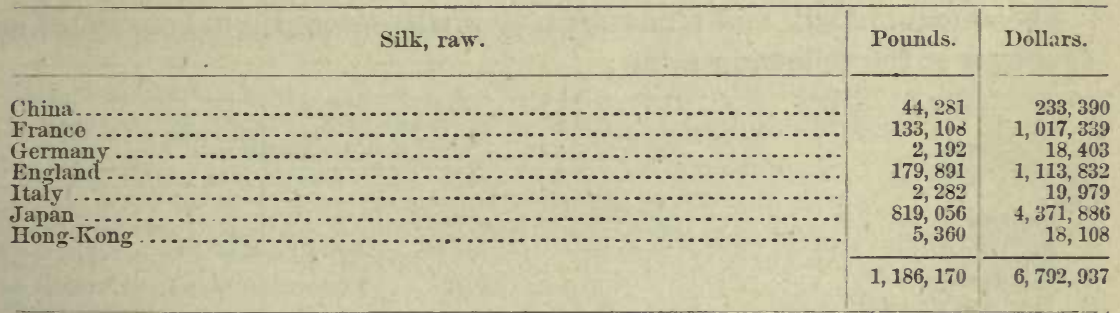

Raw silk comes entirely to San Francisco (861,166 pounds), New York (324,328), and Philadelphia (676).

$\Lambda$ foreign export of raw silk $(38,515$ pounds), valued at $(\$ 209,709)$, goes to England (37,018 pounds), France (1,000), and Quebec. It passes rhiefly through New York. 
The import of manufactures of silk is shown below :

\begin{tabular}{|c|c|c|c|}
\hline \multirow{3}{*}{ Countries. } & \multicolumn{3}{|c|}{ Silk, manufactures of. } \\
\hline & $\begin{array}{l}\text { Dress and } \\
\text { piece goods. }\end{array}$ & Hosiery. & $\begin{array}{l}\text { Otherman- } \\
\text { ufactures } \\
\text { of. }\end{array}$ \\
\hline & Dollars. & Dollars. & Dollars. \\
\hline ustria & & & \\
\hline Belgium..... & 9,000 & 10 & 44,217 \\
\hline Brazil ........................ & 11 & & \\
\hline 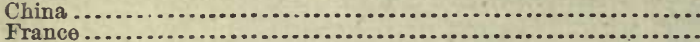 & $10,608,762$ & $\dddot{3} 060$ & $\begin{array}{r}80,24 ! \\
2,098,17\end{array}$ \\
\hline Germany...................... & $4,169,604$ & 39,861 & $\begin{array}{l}2,098,17 \\
1,178,26\end{array}$ \\
\hline England..................... & $1,667,826$ & 35,559 & $1,567,508$ \\
\hline $\begin{array}{l}\text { Scotland } \ldots \ldots \ldots \ldots \ldots \ldots \ldots \ldots \ldots \\
\text { Ireland } . . . \ldots \ldots \ldots \ldots \ldots \ldots \ldots\end{array}$ & 9,247 & 450 & 5,975 \\
\hline 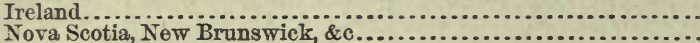 & $\cdots$ & (............. & $\begin{array}{r}312 \\
57\end{array}$ \\
\hline Quebec, Ontario, \&o ................... & 610 & $\cdots$ & 2,273 \\
\hline British Columbia............. & 6 & 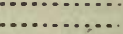 & 160 \\
\hline 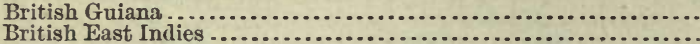 & & & 23 \\
\hline 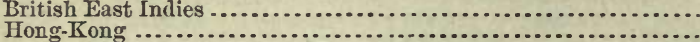 & $\begin{array}{l}82 \\
37\end{array}$ & …......... & $\begin{array}{r}88: \\
4.518\end{array}$ \\
\hline 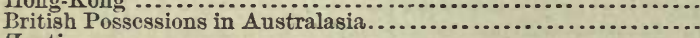 & 37 & $\cdots .$. & 4,518 \\
\hline 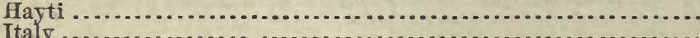 & $\ldots$ & 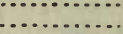 & \\
\hline n & 329 & (n) & 411 \\
\hline 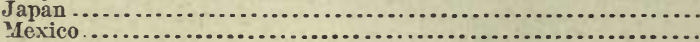 & $\begin{array}{r}174 \\
4\end{array}$ & (n............ & 8,925 \\
\hline Netherlands & 284,235 & & 6,531 \\
\hline 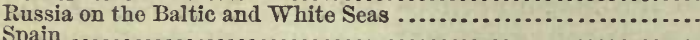 & $\ldots \ldots$ & (n) & 544 \\
\hline Spain & $(\cdots, \ldots+\ldots$ & & 127 \\
\hline $\begin{array}{l}\text { Puba } \\
\text { Porto }\end{array}$ & 68 & …........ & 278 \\
\hline Sweden and Norway & 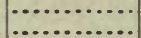 & (n............ & $\begin{array}{l}24 \\
64\end{array}$ \\
\hline 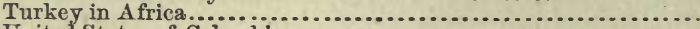 & & & 359 \\
\hline 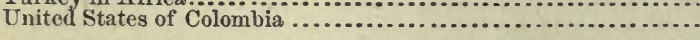 & 82 & $h^{2}$ & 10 \\
\hline Total........ & $16,750,826$ & 78,940 & $5,000,393$ \\
\hline
\end{tabular}

Almost the entire imports of this class come to New York.

The amount of silk and manufactures of silk entered into consumption is shown in the following table:

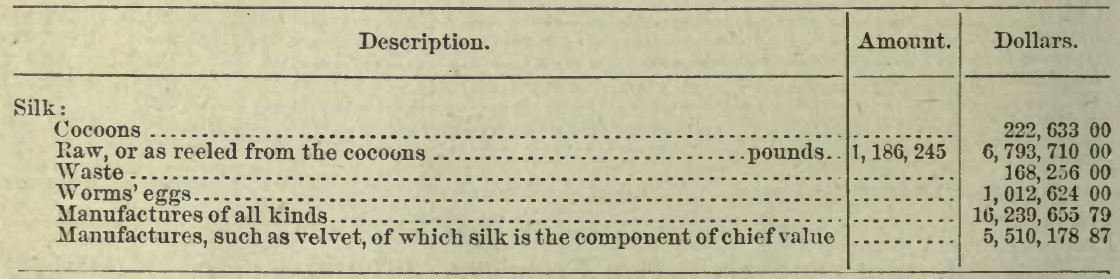

The import of silk waste amounts to $\$ 166,646$. New York receives $\$ 84,414$; San Francisco, $\$ 81,232$.

The import of silk-worm eggs and cocoons amounts to $\$ 1,235,283$. San F'rancisco receives $\$ 10,818,447$; New York, $\$ 216,836$.

The foreign export of silk manufactures amounts to $\$ 199,593$.

\section{IVORY.}

The amount of ivory and manufactures of ivory entered into consumption is shown in the following table:

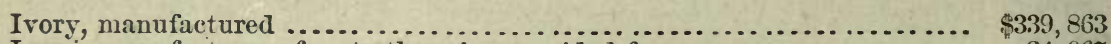
Ivory, manufactures of, not otherwise provided for ................. 34,067 Irory or bone dice, draughts, chess-men, chess-balls, and bagatelle-balls... 2,236 
The total import of ivory amounts to $\$ 379,402$. New York receives $\$ 333,727$, Boston $\$ 21,938$, Baltimore $\$ 20,043$, Philadelphia $\$ 2,749$, San Francisco $\$ 965$.

\section{HORN.}

The total value of the importation of horns, horn-tips, and horn-strips is $\$ 285,368$, of which $\$ 240,487$ eomes to New York, $\$ 35,352$ to Boston, $\$ 4,720$ to the Lake ports, and $\$ 4,119$ to Baltimore.

\section{WHALEBONE.}

Unmanufactured whalebone entered into consumption to the amount of 1,880 pounds, valued at $\$ 1,379$. The consumption of manufactured whalebone is valued at $\$ 851$.

\section{SHELL.}

Shells of every description, including, doubtless, both tortoise shell and shells of mollusks, entered into consumption, $\$ 162,768.76$.

\section{CORAL.}

Unmanufactured coral entered into consumption to the amount of \$718.14; coral cut or unmanufactured to the amount of $\$ 28,649$.

\section{LEATHER.}

The following table shows the amounts and values of leather and leather articles entered into consumption:

Hides and skins:

Goat-skins, Angorn, and sheep-skins, with the wool on (less the value of the wool) .......................................

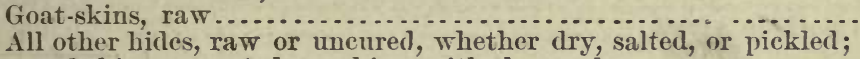

and skins, except sheep-skins, with the wool on

Leather, tanned, not manufactured .............................

Manufactures of leather.................................

Parchment

Preparations of viseera:

Manufactures of bladders

Gold-beaters' molds and skins:

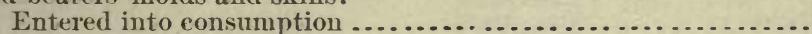

Imported (this whole import comes to New York) ...........

Sinews, nerves, \&c., erude ...............................

Catgut and whipgut ummanufactured, catgut strings and gutcord for musieal instruments, also gut and wormgut for whip aud other cords, entered into consumption

The total entry of eatgut strings amounts to $\$ 146,210$. Of this, New York receives $\$ 117,952$, Baltimore $\$ 12,218$, San Francisco $\$ 5,635$, Boston $\$ 5,411$, New Orleans \$2,898, and Philadelphia \$1,644.

Wool pelts, less the value of the wool, are imported to the value of \$8,736. This import is entered entire at Boston. 


\section{HIDES $\triangle$ ND SKINS.}

\section{The following shows the value of importations of hides and skins:}

Argentine Republic ...................................... Austria

Belgium

Brazil

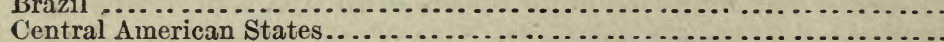

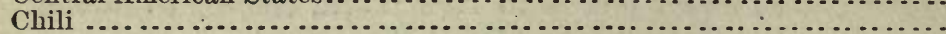

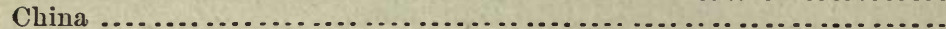

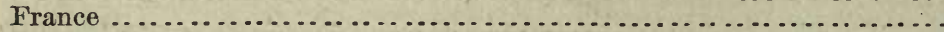

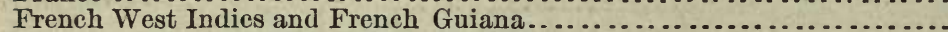

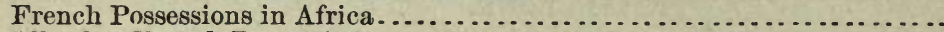

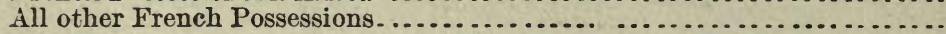

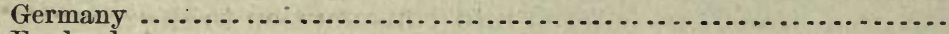

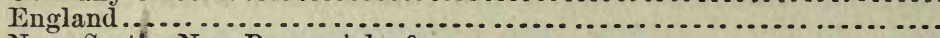

Nova Scotlo, New Brunswick, \&c................................

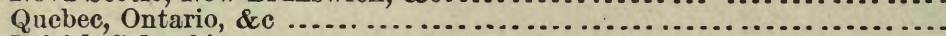

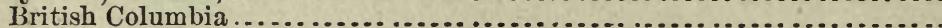

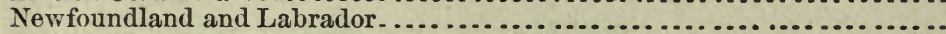

British West Indies and Honduras . . . . . . . . . . . . . . . . . . . . . . . . . . .

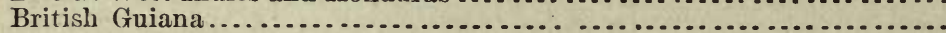

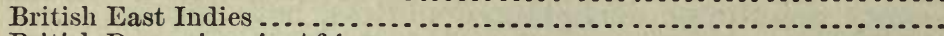

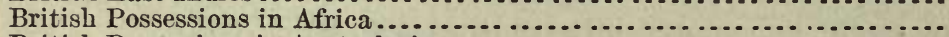

British Possessions in Australasia . . . . . . . . . . . . . . . . . . . . . . . . . . . .

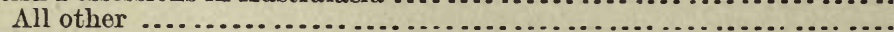

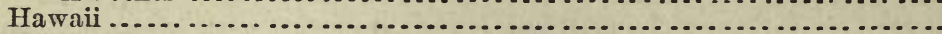

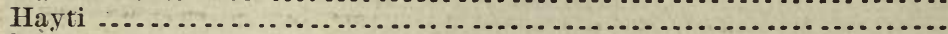

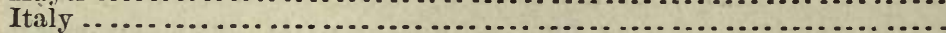

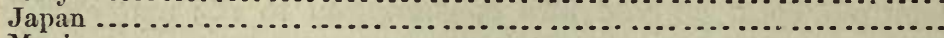

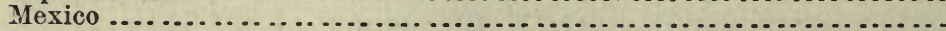

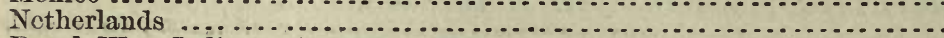

Ditch West Indies and Dutch Guiana................................

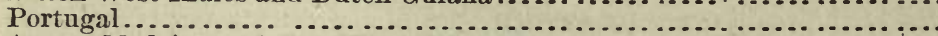

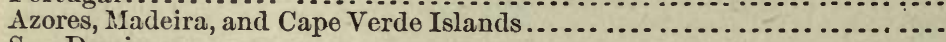

San Domingro

Cuba

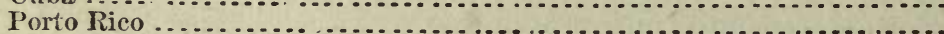

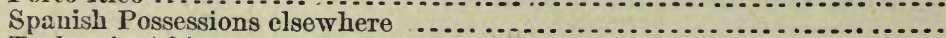

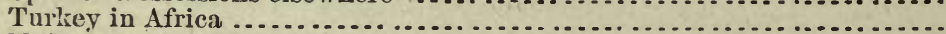

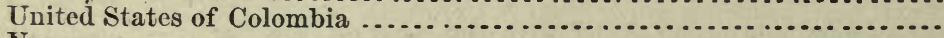

Uruguay

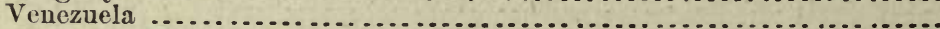

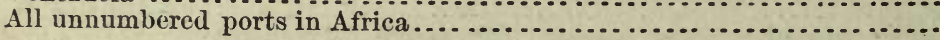

$\$ 2,071,161$

26,846

513,677

$\mathbf{1}, \mathbf{1 3 8}, 819$

43,716

10,921

822

237,777

3,543

36,595

1,972

234,153

1, 988, 186

14,303

493, 530

23,288

2,327

17,577

808

$1,272,617$

154,746

627

25,364

50,861

7,219

679

121

$1,529,702$

126,857

93,778

23,467

48,122

19,977

65,783

13,826

14,679

562

$1,033,079$

$1,790,057$

703,694

126,863

$14,963,701$

The next table shows the ports at which hides and skins are entered by the importers :

\begin{tabular}{|c|c|c|c|}
\hline Districts. & $\begin{array}{l}\text { Hides and } \\
\text { skins, other } \\
\text { than furs. }\end{array}$ & Districts. & $\begin{array}{l}\text { Hides and } \\
\text { skins, other } \\
\text { than furs. }\end{array}$ \\
\hline 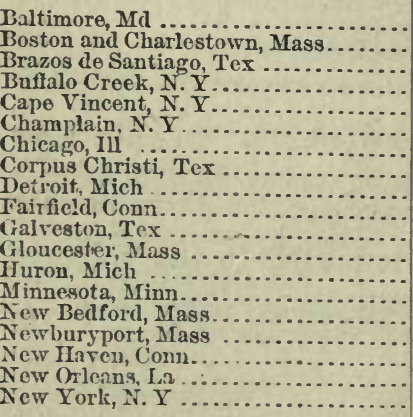 & $\begin{array}{r}\$ 184,422 \\
3,498,294 \\
607,139 \\
105,482 \\
22,623 \\
7,129 \\
690 \\
157,135 \\
49,919 \\
251 \\
7,359 \\
80 \\
11,533 \\
4,305 \\
20,065 \\
7,337 \\
87 \\
66,879 \\
9,326,876\end{array}$ & 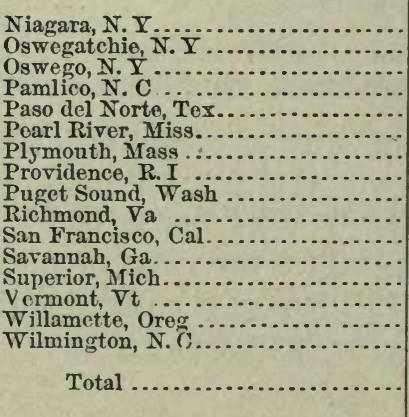 & $\begin{array}{r}\$ 92,891 \\
80,309 \\
5,829 \\
238 \\
9,261 \\
471,104 \\
9 \\
778 \\
25,897 \\
45 \\
26 \\
86,446 \\
191 \\
68 \\
111,979 \\
1,025\end{array}$ \\
\hline
\end{tabular}


The next table shows the importation of manufactured leather and articles made therefrom:

\begin{tabular}{|c|c|c|c|c|c|}
\hline \multirow{3}{*}{ Conntries. } & \multicolumn{5}{|c|}{ Leathcr, and manufactures of. } \\
\hline & \multicolumn{2}{|c|}{ Leather of all kinds. } & \multicolumn{2}{|c|}{$\begin{array}{l}\text { Gloves of kid, and all } \\
\text { other of skin or } \\
\text { leather. }\end{array}$} & \multirow{2}{*}{$\begin{array}{c}\begin{array}{c}\text { Other manu- } \\
\text { factures of. }\end{array} \\
\text { Dollars. }\end{array}$} \\
\hline & Pounds. & Dollars. & Doz. prs. & Dollars. & \\
\hline Anstria.. & 36 & 49 & & 290 & \\
\hline Belgium. & 5,374 & 7,007 & 6,377 & 41,024 & 482 \\
\hline Braz & 195 & 130 & & & 104 \\
\hline Dhina & 623 & $\begin{array}{r}42 \\
9\end{array}$ & & (n) & 7,255 \\
\hline France $\ldots . .$. & $4,633,915$ & $3,095,685$ & 231,093 & $1,356,022$ & 142,501 \\
\hline Germa & 658,708 & 442,568 & 258,870 & $1,196,109$ & 126,119 \\
\hline Jing] & $1,199,696$ & 778,065 & 99,063 & 543,517 & 242,549 \\
\hline Scotle & 382 & 255 & 47 & 319 & 722 \\
\hline d $\ldots$. & …....... & $\ldots \ldots \ldots$ & & $\cdots \cdots$ & $\begin{array}{r}100 \\
1088\end{array}$ \\
\hline $\begin{array}{l}\text { Nova Scotia New Brunswick, \&c... } \\
\text { Ouebec, Ontario, \&c.............. }\end{array}$ & 583,873 & 82,854 & $\begin{array}{r}2 \\
12\end{array}$ & $\begin{array}{r}9 \\
105\end{array}$ & $\begin{array}{r}1,088 \\
10,948\end{array}$ \\
\hline British Columbia & & & & & 70,700 \\
\hline West Indies and British Honduras & & & & & \\
\hline East Indies $\ldots \ldots \ldots \ldots \ldots \ldots$. & 354,143 & 176,193 & 4........... & (............. & 759 \\
\hline British Possessions in Africa, \&c ........ & 12 & 15 & ….......... & .............. & $\begin{aligned} 50 \\
177\end{aligned}$ \\
\hline $\begin{array}{l}\text { British Possessions in Australasia } \ldots \ldots \ldots \\
\text { Hawaii } \ldots \ldots\end{array}$ & 480 & & $\cdots$ & $\cdots$ & $\begin{array}{r}177 \\
7\end{array}$ \\
\hline - & 1,821 & 1,214 & & & \\
\hline n...................... & 1,963 & 1,3 & 310 & 1,333 & 119 \\
\hline Japan & & & & $\cdots \cdots$ & \\
\hline $\begin{array}{l}\text { Mexico } \ldots{ }^{\prime} \\
\text { Netherland } \ldots \ldots\end{array}$ & $\begin{array}{l}2,785 \\
1,533\end{array}$ & & $\begin{array}{r}16 \\
1\end{array}$ & 93 & 1,242 \\
\hline Madeira and Cape Verde Islands. & & & & & \\
\hline Russia on the Baltic and White Seas.... & 400 & 465 & & & 427 \\
\hline 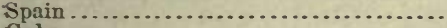 & & & 16 & & \\
\hline (1)..... & 424 & 283 & ............ & $\cdots$ & 112 \\
\hline Africa & & & & & \\
\hline of Colombia................ & 805 & 162 & & & 201 \\
\hline$\ldots \ldots \ldots \ldots \ldots \ldots$ & 115 & 12 & & & \\
\hline Venezuela. & 55 & 42 & & & 31 \\
\hline Total & $7,447,423$ & $4,589,713$ & 595,862 & $3,128,919$ & 597,014 \\
\hline
\end{tabular}

The exports of leather are as follows:

\begin{tabular}{|c|c|c|}
\hline . & Quantity. & Vulue. \\
\hline 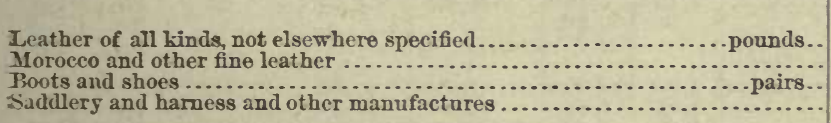 & $25,122,936$ & $\begin{array}{r}\$ 2,480,427 \\
6,016,373 \\
1,280,225 \\
414,630 \\
456,073\end{array}$ \\
\hline Total. & & $10,647,728$ \\
\hline
\end{tabular}

The foreign exports of hides and skins amount to $\$ 44,415$. This export is made from New York and Boston to France $(\$ 13,976)$, Nova Scotia and New Brunswick (\$12,068), England $(\$ 10,668)$, and Germany $(\$ 7,515)$. That of leather amounts to $\$ 106,762(382,765$ pounds), chiefly to England and Canada; of leather gloves $\$ 13,372$ (2,286 dozen pairs), chiefly to Canada and France; and other manufactures, $\$ 17,857$, to British Columbia, Scotland, Mexico, England, Canada, and France. 
The tables below show the amounts of exports by countries and by districts :

Leather, and manufactures of.

Countries.

Argentine Republic

Belgium

Brazil

C.......................

China

anish West Indies..............

French West Indies and French Guiana ...........................

Miquelon, Langley, and St. Pierre

Islands ................................ adjacent islands.................. French Possessions, all other .......

Germany .......................

Great Britain: England............

Scotland

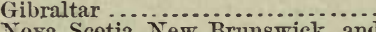
Prince Edward Island ...........

Quebec, Ontario, Rupert's Land, and the Northwest Territory ..........

British Columbia.

Newfoundland and Labrador.......

British West Indies and British Honduras

British Guiana..................

Hong-Kong .

British Possessions in Africa.....

British Possessions in Australasia .

Hawaiian Islands . . . . . . . . . . . . . .

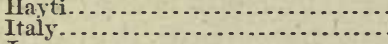

Japan.

Liberia ......

Mexico

Netherlands .........................

Duteh West Indies................

Peru

Portugal .

Azore, Madeira, and Cape Verde Islands

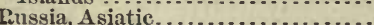

San Domingo ....................

Cnba

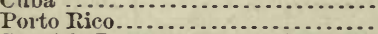

Spanish Possessions in Africa and

adjacent islands.................

Sweden and Norway ................

Turkey in Europe

Turkey in Asia

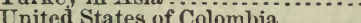

Uruguay .

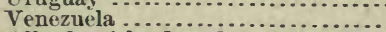

All other islands and ports, not else-

where specified ..................

Total

Adritions taken from Canadian re ports..........................

Grand total

\section{Leather, and manufactures of.}

\begin{tabular}{|c|c|c|c|c|}
\hline Boots and shoes. & $\begin{array}{l}\text { Leather of all kinds, } \\
\text { not elsewhere speci- } \\
\text { fied. }\end{array}$ & $\begin{array}{l}\text { Moroceo, } \\
\text { and other } \\
\text { fine. }\end{array}$ & $\begin{array}{c}\text { Sad- } \\
\text { dlery } \\
\text { and } \\
\text { harness. }\end{array}$ & $\begin{array}{l}\text { Manu- } \\
\text { factures } \\
\text { of, not } \\
\text { else- } \\
\text { where } \\
\text { speci- } \\
\text { fied. }\end{array}$ \\
\hline
\end{tabular}

Pairs. Dollars.

\begin{tabular}{r|r}
144 \\
\hdashline$\ldots \ldots 38$ \\
11,782 & 10 \\
\hline
\end{tabular}

1,357

75 ....

8,961

..........

4,103

18,938

1,153

........

41,091

18,074

17,896

240

56,093

370
478

472
398

21,188

12,165

638

2,453
38,793

2,198
4,473

4,473

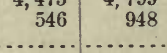

2,231

1,327

7,712

3,958

2,403

6, 723

25,797

1,756

4,910

48,723

33,890

31,294

500

66,633

462

179

1,313

702

13,670

1,262

4,584

53,383

5,662
2,683

4,799

3,064

2,642

8,962

4,785
622

....................

...............

$15,625 \quad 24,914$

$424 . \cdots 332$

744

$\overline{300,484} \overline{414,630}$

....... 133, 842

548,472
Pounds.

Dollars.

Dollars. Dollars. Dollars.

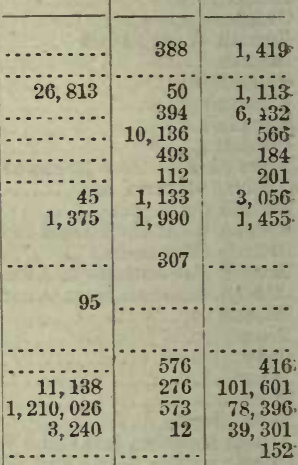

8,279

20,620 .

6,336 .

2. 501

153,261
152,796

7,740

32,416

8,630

5,719

15,973

9,176

3. 310

325,698

.........

4,077
194,291

16,668

8,992

2,152

4,430
4,360

2,428

127

1,100
71,953

5,342

4,009

7,599

1,285

2, 139

3,316

5,302 .

149

$5 \mathrm{2}$

7,953

17,685

7,841

1,097

2,962

i. 675

1,675
64,330
4,253

.................

.........

2,518

3,867

280

519

9,421

.................

4,446

977

1,217

8,019 .

5,231

453.

7,588

144

8,010

16,766

1,824

1,007

750

313

1,033

19,056

949

264

5,268

80

2, 519

2,255

4,630

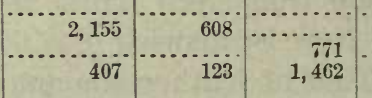

.

\begin{tabular}{|c|c|c|c|c|}
\hline $\begin{array}{l}25,122,936 \\
\ldots \ldots \ldots \ldots .\end{array}$ & $\begin{array}{l}6,016,373 \\
\ldots \ldots \ldots\end{array}$ & $1,280,225$ & $\begin{array}{l}94,085 \\
\ldots . . .\end{array}$ & $\begin{array}{l}361,988 \\
380,312\end{array}$ \\
\hline$\ldots$ & & & & 742,300 \\
\hline
\end{tabular}




\begin{tabular}{|c|c|c|c|c|c|c|c|}
\hline \multirow{3}{*}{ Districts. } & \multicolumn{7}{|c|}{ Leather, and manufactures of. } \\
\hline & \multicolumn{2}{|c|}{ Boots and shoes. } & \multicolumn{2}{|c|}{$\begin{array}{l}\text { Leather of all kinds, } \\
\text { not elsewhere speci. } \\
\text { fied. }\end{array}$} & \multirow{2}{*}{$\begin{array}{c}\text { Morocco, } \\
\text { and other } \\
\text { fine. }\end{array}$} & \multirow{2}{*}{$\begin{array}{c}\text { Sad- } \\
\text { dlery } \\
\text { and } \\
\text { harness. }\end{array}$} & \multirow{2}{*}{$\begin{array}{l}\text { Manu- } \\
\text { factures } \\
\text { of, not } \\
\text { else- } \\
\text { where } \\
\text { speci- } \\
\text { fied. } \\
\text { Dollars. }\end{array}$} \\
\hline & Pairs. & Dollars. & Pounds. & Dollars. & & & \\
\hline $\begin{array}{l}\text { Alaska, Alaska } \\
\text { Baltimore, Mrd. }\end{array}$ & 3,599 & 6,120 & $\begin{array}{r}50 \\
516,145\end{array}$ & 202,137 & 441 & 1,530 & 1,370 \\
\hline Bangor, Me & 63 & 60 & .............. & & $4+1$ & 1,050 & $1,3,0$ \\
\hline $\begin{array}{l}\text { Boston and Charlestown, Mass. } \\
\text { Brazos de Santiago, Tex....... }\end{array}$ & 25,585 & 33,433 & $3,312,403$ & 666,173 & $1,119,981$ & 5,040 & $26,8 \leq 1$ \\
\hline $\begin{array}{l}\text { Brazos de Santiago, Tex........ } \\
\text { Baffalo Creek, } \mathbf{Y} . \mathbf{Y} . . . . . . . . .\end{array}$ & 25,823 & 32,218 & 125 & 27 & & 1,233 & 153 \\
\hline Cape Vincent, $N$ & 75 & 109 & & & & & 1,934 \\
\hline Champlain, N. Y.... & 1,650 & 1,658 & 57,566 & 16,639 & .... & 234 & 3,316 \\
\hline Corpus Christi, Tex. & 8,457 & 14,976 & 95 & $\begin{array}{l}90 \\
21\end{array}$ & & 550 & 341 \\
\hline $\begin{array}{l}\text { Cnyahoga, Ohio..... } \\
\text { Detroit, Mich ....... }\end{array}$ & 1,444 & 3,342 & & & & 702 & 4,078 \\
\hline $\begin{array}{l}\text { Duluth, Minn .......... } \\
\text { Erie, Pa........... }\end{array}$ & …..... & (........... & 60 & 16 & & & \\
\hline 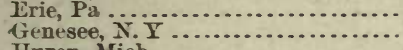 & 72 & 145 & 905 & 250 & & 808 & \\
\hline $\begin{array}{l}\text { Huron, Mich......... } \\
\text { Key West, Fla....... }\end{array}$ & & & & & & $\cdots$ & 662 \\
\hline Machias, Me.......... & & & 50 & & & & \\
\hline Minnesota, Minn ................. & 3,286 & 4,708 & 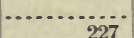 & & & 4,739 & \\
\hline $\begin{array}{l}\text { New Bedford, Mass ................ } \\
\text { New Haven, Conn ............. }\end{array}$ & (n........... & . & 227 & 62 & $\begin{array}{l}\cdots . . \\
\cdots . .\end{array}$ & (n) & 5,268 \\
\hline New London, Conn .. & & & 280 & $1 i 2$ & $\cdots$. & 375 & 0,208 \\
\hline New Orleans, La..... & 4,288 & 4,068 & 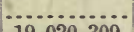 & 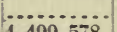 & & 170 & 232 \\
\hline $\begin{array}{l}\text { New York, N. } \mathbf{Y} \ldots \ldots \ldots \ldots \\
\text { Niagara, } \mathbf{N} . \mathbf{Y} \ldots \ldots \ldots \ldots\end{array}$ & 129,857 & 167,856 & $\begin{array}{l}19,020,309 \\
\ldots . . . \ldots . . . .\end{array}$ & \begin{tabular}{l}
$4,499,578$ \\
\hdashline$. \ldots . \ldots . .$.
\end{tabular} & $\mathbf{1 5 9 , 5 0 6}, 175$ & $\begin{array}{l}44,305 \\
60\end{array}$ & $\begin{array}{r}2 \pi 4,390 \\
140\end{array}$ \\
\hline 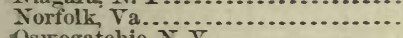 & $\cdots$ & & ......... & (n) & & & 144 \\
\hline $\begin{array}{l}\text { Oswegatchie, } \mathrm{N} . \mathrm{Y} \ldots \ldots \ldots \ldots \ldots \ldots \\
\text { Oswega } \mathrm{N} . \mathrm{Y} . \ldots \ldots \ldots \ldots\end{array}$ & 3,755 & 3,013 & 5,065 & 1,535 & .... & -.. & 4,628 \\
\hline 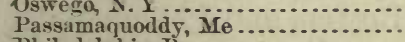 & 26,828 & 30,021 & & & & 2,418 & 5,192 \\
\hline 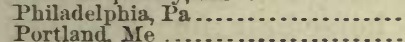 & 2,116 & 3,126 & $1,736,280$ & 518,679 & & 522 & 689 \\
\hline 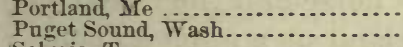 & 25 & 87 & & & & 264 & $\begin{array}{l}890 \\
862\end{array}$ \\
\hline 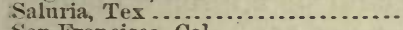 & 3,119 & 4,279 & & & 102 & 140 & \\
\hline San Francisco, Cal .................. & 49,515 & 80,915 & 445,571 & 103,103 & $\cdots$ & 30,248 & 24,851 \\
\hline 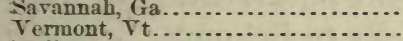 & $\begin{array}{l}3,135 \\
7,792\end{array}$ & $\begin{array}{r}3,581 \\
20,915\end{array}$ & 27,665 & 7,895 & & 368 & 3,268 \\
\hline 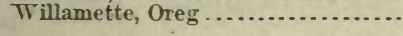 & & . & & ............ & ............. & 314 & ......... \\
\hline Total ... & 300,484 & 414,630 & $25,122,936$ & $6,016,373$ & $1,280,225$ & 94,085 & 361,988 \\
\hline $\begin{array}{l}\text { Additions to Niagara and Vermont, } \\
\text { taken from Canadian reports...... }\end{array}$ & & 133,842 & & & & & 380,312 \\
\hline Grand total. & & 548,472 & & & & & 742,300 \\
\hline
\end{tabular}

\section{HAIR.}

The amounts of hair and manufactures of hair entered into consumption are shown in the following table:

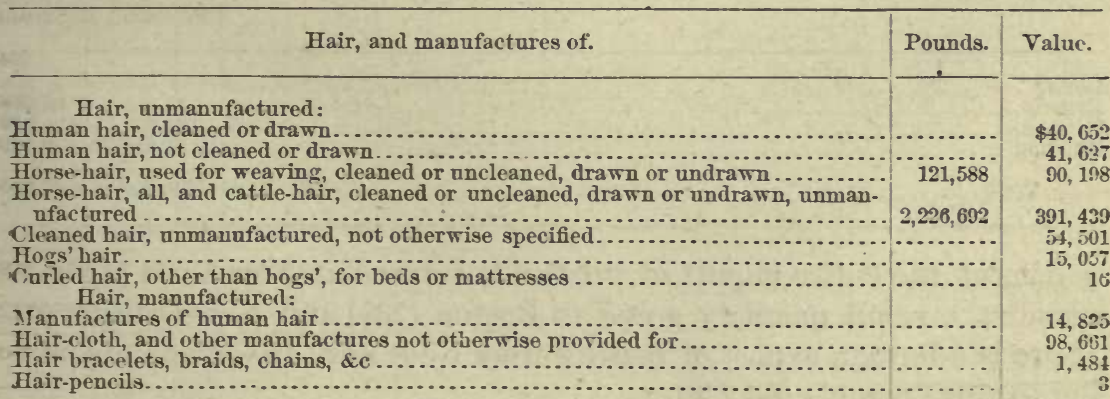

Total. 


\section{ANIMAL RESOURCES AND FISHERIES OF UNITED STATES.}

The imports of hair, by countries, are as shown below:

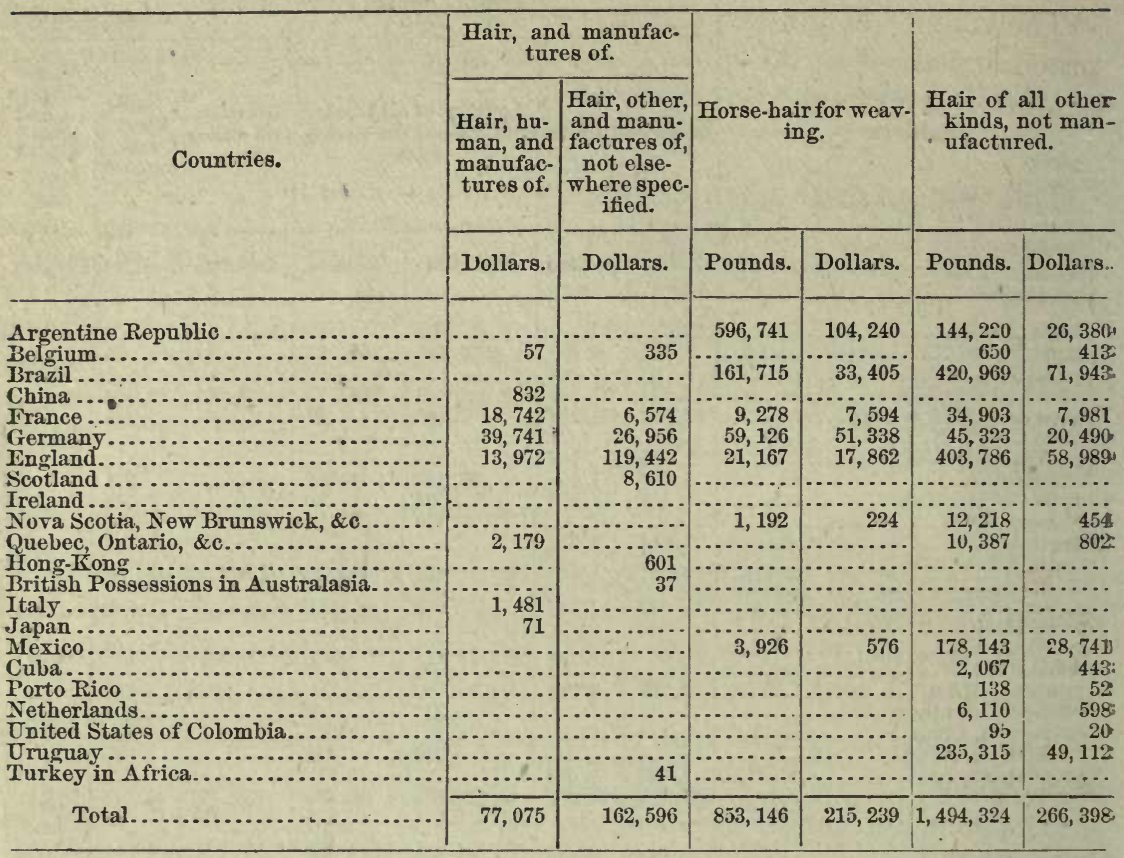

The imports are made chiefly to New York, Boston, and Philadelphia: 'Twenty-one thousand and three pounds of horse-hair for weaving, valued at $\$ 4,201$, pass through Boston to England as a foreign export; also manufactures of human hair to the value of $\$ 19,329$, chiefly to England, and other hair manufactures $(\$ 3,597)$ chiefly to Belgium.

\section{BRISTLES.}

The amount of bristles entered into consumption is placed at 353,287 pounds, valued at $\$ 545,011$. The imports of bristles by countries is shown below:

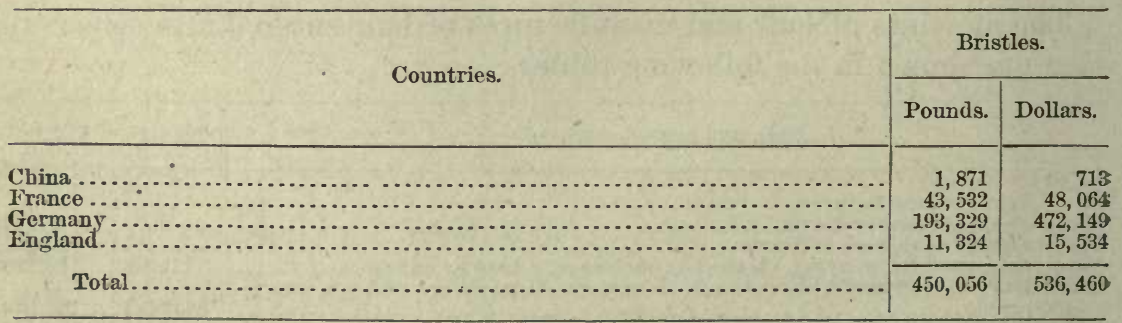

Almost the entire import of bristles is entered at New York $(449,910$ pounds), a small quantity going to Boston (137) and New Orleans (9). There is a foreign export of bristles from New York to Canada amounting to 4,642 pounds $(\$ 3,236)$. 


\section{QUILLS.}

The amount of quills entered into consumption, prepared and unprepared, is valued at $\$ 1,051$. The value of toothpicks entered into consumption is $\$ 15,441$.

\section{FEATHERS.}

The value of feathers entered into consumption is shown below:

Feathers and down for beds and feather-beds .................... \$12,531 50 Oruamental feathers, ostrich, vulture, cock, \&c., crude............... 634,45020 Feathers, dressed, colored, or manufactured ..................... 15, 35200

The total entries of feathers amount to $\$ 11,313$, of which New York receives $\$ 10,431$, and San Francisco $\$ 727$, with trifling entries at other ports. There are also feather-beds to the value of $\$ 1,404$, coming chiefly to New York and Philadelphia.

\section{GLUE AND GELATINE.}

The import of hide-cuttings for glue-stock amounts in value to $\$ 320,722$, of which New York receives $\$ 163,593$, Boston $\$ 156,448$, and Baltimore $\$ 681$. Hoofs and other glue-stock of that description are valued at $\$ 10,650$, of which $\$ 10,188$ comes to the Lake ports.

The import of common glue amounts to $1,112,527$ pounds, valued at $\$ 26,345.60$.

The consumption of gelatine and similar products, of which a portion is probably of regetable origin, is valued at $\$ 90,971$.

Isinglass or fish-glue entered into consumption to the value of $\$ 32,236$ (75,267 pounds).

The total import of fish sounds and glue is given at $\$ 16,125 ; \$ 11,727$ comes to Boston, and $\$ 4,398$ to other ports.

Glue is exported to the amount of $\$ 1,685$ pounds, valued at $\$ 16,069$.

\section{SPONGES.}

The total import of sponges is valued at $\$ 91,742$. New York receives $\$ 74,524$, Philadelphia $\$ 2,452$, and San Francisco $\$ 1,693$.

$$
\text { OILS, FATS, AND SOAPS. }
$$

The following quantities entered into consumption:

\begin{tabular}{|c|c|c|}
\hline Oils. & Amount. & Dollars. \\
\hline 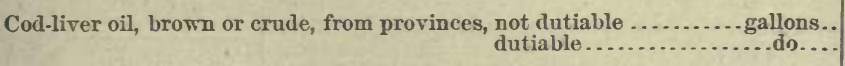 & $\begin{array}{c}129,263 \\
13,732\end{array}$ & $\begin{array}{l}81,60700 \\
15,43400\end{array}$ \\
\hline Total .... & 142,995 & 97,04100 \\
\hline Cod-liver oil, refined, medicinal ........... & $\ldots \ldots \ldots \ldots$ & 17,29000 \\
\hline $\begin{array}{r}\text { Whale or fish oil from provinces, not duitable } \ldots \ldots \ldots \ldots \ldots \ldots \ldots \ldots \ldots \\
\text { dutiablo } \ldots \ldots \ldots \ldots\end{array}$ & $\begin{array}{l}19,620 \\
26,711\end{array}$ & $\begin{array}{l}10,98200 \\
11,23700\end{array}$ \\
\hline Total.. & 46,331 & 22,21900 \\
\hline $\begin{array}{l}\text { Neat's-foot, and all animal, not otherwise provided for................ gallons.. } \\
\text { Seal } \\
\text { Tallow } \ldots \ldots\end{array}$ & $\begin{array}{l}2,597.50 \\
410 \\
25,522\end{array}$ & $\begin{array}{r}1,12403 \\
8000 \\
1,93800\end{array}$ \\
\hline . & $\ldots \ldots \ldots \ldots$ & 2,14203 \\
\hline
\end{tabular}




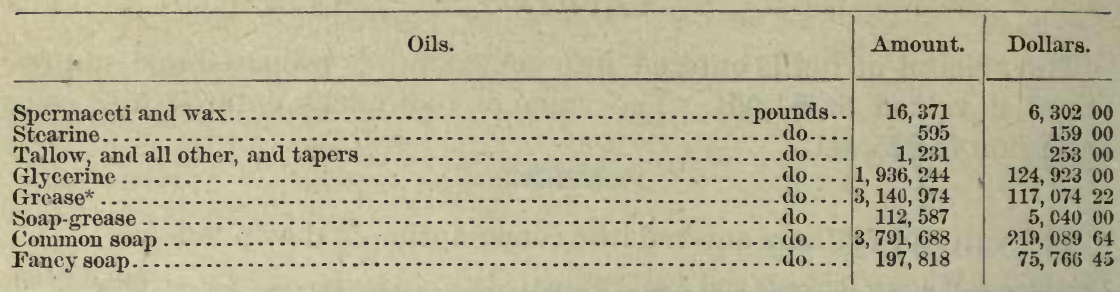

* The total import of grease amounts to $\$ 116,070$; New York receires $\$ 58,340$, Boston, $\$ 56,057$.

Soap-grease is imported to the value of $\$ 5,384$. Boston receives $\$ 2,384$, New York $\$ 1,469$, the Lake ports $\$ 894$, and Philadelphia $\$ 637$.

The total import of sperm oil is $\$ 5,590$, all coming to San Francisco.

The next table shows the exports of oils and fats:

\begin{tabular}{|c|c|c|}
\hline Oils, fats, \&c. & Amounts. & Dollars. \\
\hline 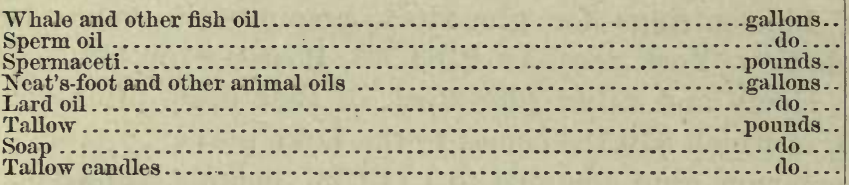 & $\begin{array}{r}1,026,038 \\
634,991 \\
153,552 \\
19,932 \\
349,429 \\
91,472,803 \\
1,616,163 \\
\end{array}$ & $\begin{array}{r}442,165 \\
879,865 \\
41,027 \\
19,720 \\
281,551 \\
7,883,616 \\
233,634 \\
638,952\end{array}$ \\
\hline Total................ & & $10,820,530$ \\
\hline
\end{tabular}

There is a foreign export of whale and other fish oils, apparently from the British Provinces through Boston to Belgium; this amounts to 43,103 gallons, valued at $\$ 26,669$. A small foreign export of dutiable oils of this description goes to Quebec, Ontario, \&c. (1,459 gallons), the British West Indies (236), and Brazil (10). This whole export amounts to 1,705 gallons, valued at $\$ 794$. It passes through Boston (1,365 gallons) and New York (340).

The imports of whale and fish oil by countries and by districts are shown below:

\section{Countries.}

\begin{tabular}{|c|c|}
\hline Gallons. & Dollars. \\
\hline $\begin{array}{r}130,562 \\
2,142 \\
6,004\end{array}$ & $\begin{array}{r}79,403 \\
1,339 \\
3,346\end{array}$ \\
\hline 138,708 & 84,088 \\
\hline $\begin{array}{r}2,745 \\
4,128 \\
11,164 \\
10,945 \\
450 \\
2,554 \\
2,609 \\
4,767 \\
12,400 \\
120\end{array}$ & $\begin{array}{r}2,814 \\
3,672 \\
21,604 \\
4,447 \\
161 \\
837 \\
1,070 \\
5,377 \\
3,941 \\
92\end{array}$ \\
\hline 51,88 & 44,015 \\
\hline
\end{tabular}

\begin{tabular}{|c|c|c|}
\hline \multirow{2}{*}{ 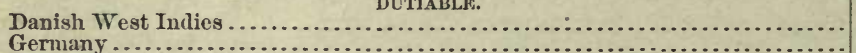 } & & \\
\hline & 2,745 & 2,814 \\
\hline 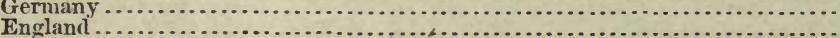 & $\begin{array}{r}4,128 \\
11,164\end{array}$ & $\begin{array}{r}3,672 \\
21,604\end{array}$ \\
\hline British Columbia .................... & $10,94.5$ & 4,447 \\
\hline 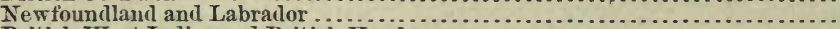 & 450 & 161 \\
\hline British West Indies and British Honduras ....................... & 2,554 & 837 \\
\hline 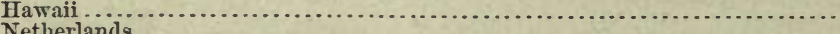 & 2,609 & 1,070 \\
\hline 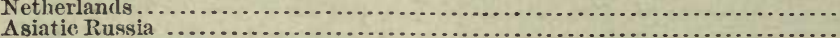 & $\begin{array}{r}4,767 \\
12,400\end{array}$ & 5, 378 \\
\hline Sweden and Norway ............ & 120 & 92 \\
\hline Total: & 51,882 & 44,015 \\
\hline
\end{tabular}




\begin{tabular}{|c|c|c|c|c|}
\hline & \multicolumn{2}{|c|}{ FREE. } & \multicolumn{2}{|c|}{ DUTLABLR. } \\
\hline \multirow[t]{2}{*}{ Districts. } & \multicolumn{2}{|c|}{$\begin{array}{l}\text { Whale and fish, not } \\
\text { of American fish- } \\
\text { eries. }\end{array}$} & \multicolumn{2}{|c|}{$\begin{array}{l}\text { Whale and fish, not } \\
\text { of A merican fish. } \\
\text { eries. }\end{array}$} \\
\hline & Gallons. & Dollars. & Gallons. & Dollars. \\
\hline 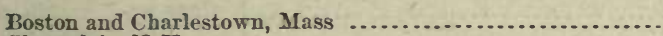 & 82,007 & 45,782 & 2,570 & 771 \\
\hline 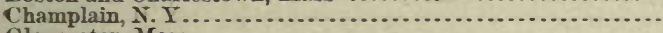 & 72 & 97 & ........... & ........... \\
\hline 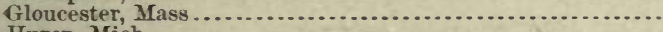 & 1,360 & 593 & -.......... & $\ldots \ldots \ldots$ \\
\hline Huron, Mich & 2, 070 & 1,242 & - . & ........... \\
\hline 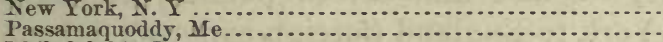 & $\begin{array}{l}40,680 \\
10,160\end{array}$ & $\begin{array}{r}31,870 \\
3,480\end{array}$ & $\begin{array}{r}23,238 \\
\ldots\end{array}$ & $\begin{array}{r}33,694 \\
\ldots . . . . . . .\end{array}$ \\
\hline 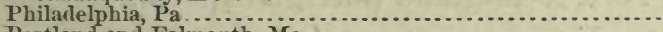 & $\ldots \ldots$ & $\ldots \ldots+\cdots$ & 120 & \\
\hline 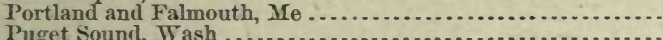 & 2,090 & 895 & $\cdots$ & $\cdots$ \\
\hline 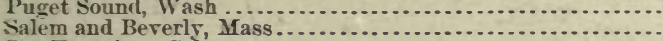 & 269 & 129 & $\begin{array}{r}4,535 \\
\ldots \ldots\end{array}$ & $\begin{array}{l}1,801 \\
\ldots \ldots\end{array}$ \\
\hline 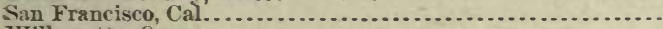 & ............ & & 18,821 & 6,483 \\
\hline 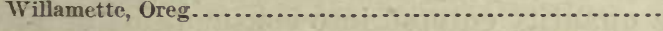 & .......... & & 2,598 & 1,124 \\
\hline Total . . & 138,708 & 84,088 & 51,882 & 44,015 \\
\hline
\end{tabular}

\section{PERFUMERY MATERIALS.}

The next table shows the quantity entered into consumption of materials used by perfumers:

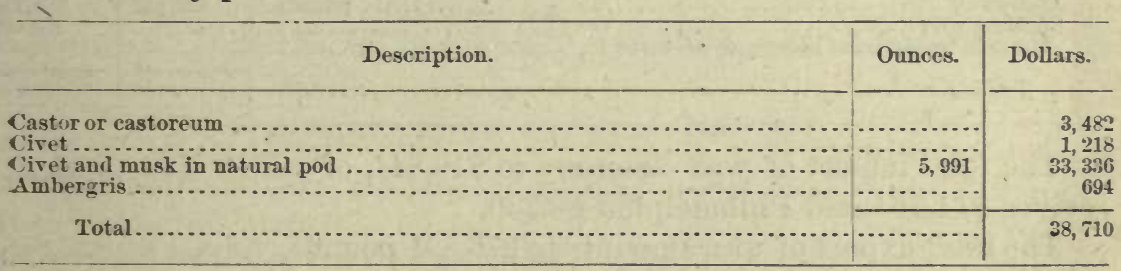

\section{COLORING MATERIALS.}

The next table shows the quantity entered into consumption of substances used by color-makers :

\begin{tabular}{|c|c|c|}
\hline Description. & Pounds. & Dollars. \\
\hline 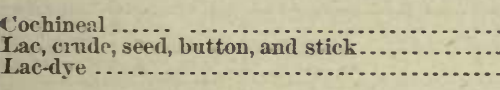 & $\begin{array}{r}1,304,370 \\
47,063 \\
454,781\end{array}$ & $\begin{array}{r}648,621 \\
9,592 \\
26,243\end{array}$ \\
\hline Total.......... & .... & 674,456 \\
\hline
\end{tabular}

The total import of cochineal is $1,324,165$ pounds, valued at $\$ 649,325$.

The next table shows the quantity of cochineal imported, by coumtries:

Imports of cochineal.

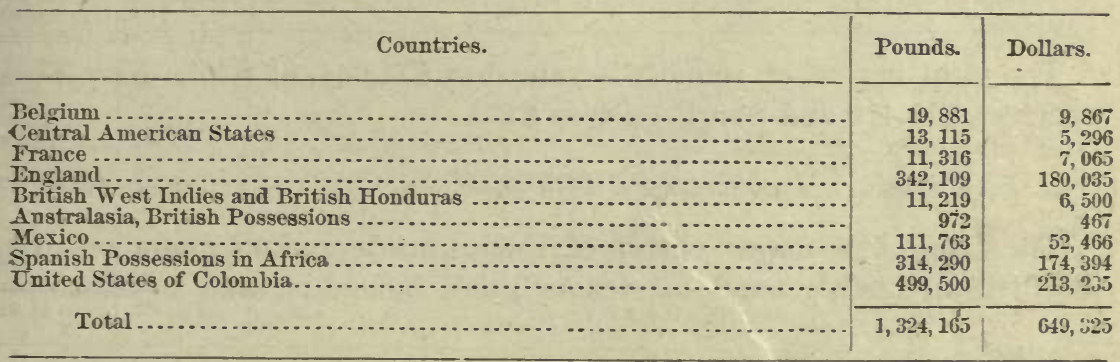


The next table shows the quantity of imports by customs districts:

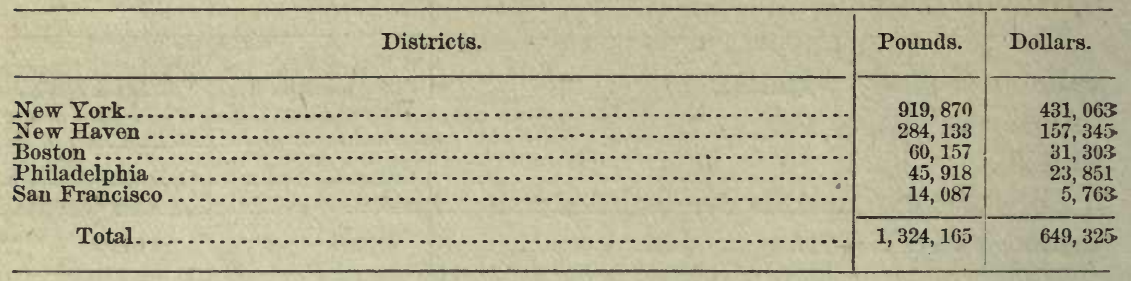

In addition to the above, we find that 66,986 pounds, valued at $\$ 52,938$, pass through New York to England (foreign exports).

WAX.

The next table shows the quantity entered into consumption of wax and manufactures thereof.

\begin{tabular}{|c|c|c|}
\hline Description. & Amount. & Dollars. \\
\hline 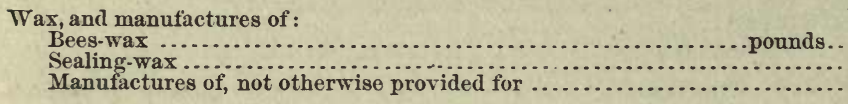 & 19,687 & $\begin{array}{l}3,198 \\
3,088 \\
6,356\end{array}$ \\
\hline Total....... & & 12,553 \\
\hline
\end{tabular}

The total import of wax amounts to $\$ 16,844$, of which New York receives $\$ 11,764$ and Philadelphia $\$ 3,330$.

The total export of wax amounts to 276,891 pounds, valued at $\$ 22,876$.

The total export of bone-black, ivory-black, and lamp-black (the latter not of animal origin), amounts to 515,488 pounds, valued at $\$ 22,876$.

CHEMICAL PREPARATIONS, MEdicines, ETC.

The following table shows amounts entered into consumption:

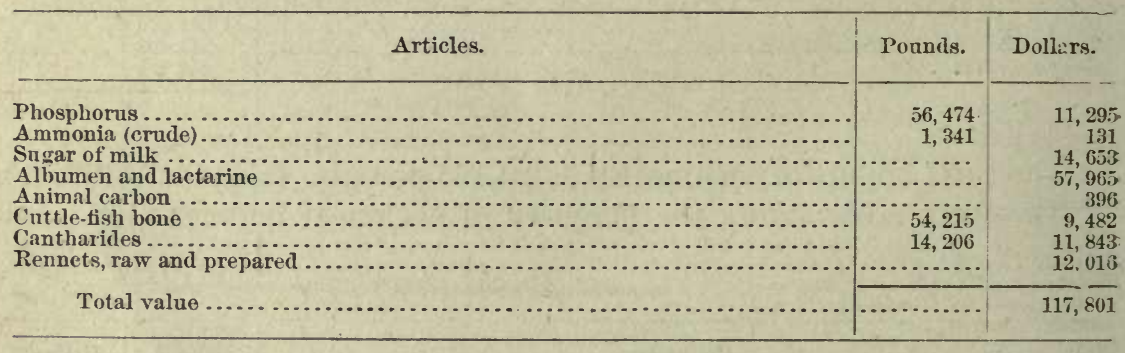

The total import of rennets is valued at $\$ 11,944$, of which New York receives $\$ 11,470$ and San Francisco $\$ 398$.

BONES.

The value of the import entries of "bones, crude, and not manufactured, burned, calcined, ground, or steamed, and bone-dust and bone-ash for 
the manufacture of fertilizers," is placed at $\$ 82,882$. The amount entered into consumption is $\$ 56,935$.

The principal import is through the Lake ports, which enter to the value of $\$ 52,469$. Baltimore, the seat of many extensive fertilizer factonies, receives to the value of $\$ 23,857$, New York $\$ 4,937$, and Boston $\$ 1,475$.

The total export of bones and bone-dust amounts to 7,072,000 pounds, valued at $\$ 121,493$.

\section{GUANO AND OTHER FERTHLIZERS.}

The import entry of guano, except from bonded islands, is placed at 25,482 tons, valued at $\$ 873,790$.

The export of guano amounts to 954 tons, valued at $\$ 41,530$. 2,757 tons, valued at $\$ 77,190$, goes as a foreign export to Ireland (1,537 tons), England (680), and Cuba (535). It passes through Petersburg, Va. (1,437 tons), Beaufort, S. C. (779), and New York (541).

Other fertilizers are imported to the value of $\$ 157,471$. Of this. amount Baltimore receives $\$ 48,230$, New York $\$ 18,897$, Philadelphia $\$ 9,613$, and other ports $\$ 80,647$.

Manures, probably mostly animal, are exported, to the value of $\$ 1,076,602$.

\section{SPECIMENS OF NATURAL HISTORY.}

The following entered into consumption :

Specimens of natural history, botany, and mineralogy for cabinets, \&c., and

not for sale .....................................................

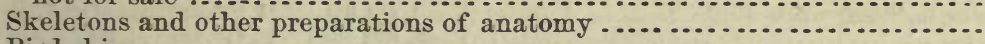

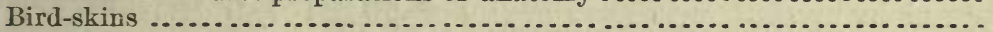

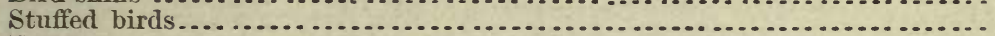

Fossils

Total

17,714

The following table shows the countries from which guano is imported:

\begin{tabular}{|c|c|c|c|c|c|}
\hline \multirow{2}{*}{ Countries. } & \multicolumn{2}{|c|}{$\begin{array}{l}\text { Guano (except from } \\
\text { bonded islands). }\end{array}$} & \multirow{2}{*}{ Countries. } & \multicolumn{2}{|c|}{$\begin{array}{l}\text { Guano (except from } \\
\text { bonded islands). }\end{array}$} \\
\hline & Tons. & Dollars. & & Tons. & Dollars. \\
\hline 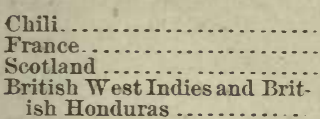 & $\begin{array}{r}1,832 \\
16 \\
4 \\
615\end{array}$ & $\begin{array}{r}55,139 \\
790 \\
317\end{array}$ & 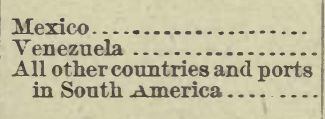 & $\begin{array}{r}18,481 \\
4,463 \\
1\end{array}$ & $\begin{array}{r}741,124 \\
65,276 \\
12\end{array}$ \\
\hline 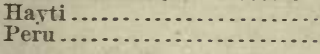 & $\begin{array}{r}100 \\
70\end{array}$ & $\begin{array}{r}3,178 \\
143\end{array}$ & Total ... & 25,582 & 873,390 \\
\hline
\end{tabular}

Guano is brought chiefly to New York (16,738 tons), Baltimore $(7,732)$, Philadelphia (673), Norfolk (300), San Francisco (122), and New Orleans $(16)$. 


\section{ANIMAL RESOURCES AND FISHERIES OF UNITED STATES.}

The two following tables show the aggregate imports and exports for the years 1875,1876 , and 1877 .

Net imports.

\begin{tabular}{|c|c|c|c|}
\hline Articles. & 1875. & 1876. & 1877. \\
\hline Living animals . & $\$ 2,062,542$ & $\$ 1,715,264$ & $\$ 1,625,495$ \\
\hline Fish....$\ldots \ldots \ldots \ldots \ldots$ & $2,802,395$ & $2,520,238$ & $2,253,620$ \\
\hline Hides, skins, furs undressed, hair, \&c ........ & $20,541,768$ & $15,185,194$ & $16,840,299$ \\
\hline Furs & $2,987,865$ & $2,881,329$ & $2,348,380$ \\
\hline Wool, unmanufactured.. & $10,379,438$ & $7,929,139$ & $6,684,425$ \\
\hline manufactures of. . & $44,216,371$ & $32,607,152$ & $25,328,169$ \\
\hline Silk, raw................ & $4,471,396$ & $5,405,608$ & $6,583,228$ \\
\hline manufactures of .......... & $24,107,665$ & $23,487,418$ & $21,630,566$ \\
\hline Leather and manufactures of . . . . . . . . . . . . . . . . & $10,166,909$ & $8,208,150$ & $8,117,655$ \\
\hline Hair manufactures............................ & 879,419 & 348,621 & 216,745 \\
\hline Oils, animal and vegetable $\ldots \ldots \ldots \ldots \ldots \ldots \ldots \ldots$ & $1,906,949$ & $1,508,387$ & $1,699,829$ \\
\hline \multirow{3}{*}{ Provisions not included................................ } & 525,667 & 704,818 & 796,200 \\
\hline & & .... & \\
\hline & $\$ 125,048,384$ & $\$ 102,500,718$ & $\$ 94,124,611$ \\
\hline
\end{tabular}

Net exports.

\begin{tabular}{|c|c|c|c|}
\hline Articles. & 1875. & 1876. & 1877. \\
\hline Living animals .......... & $\$ 2,672,505$ & $\$ 2,436,287$ & $\$ 3,325,203$ \\
\hline $\begin{array}{l}\text { Provisions: } \\
\text { Meats ....... }\end{array}$ & $39,217,176$ & $49,592,834$ & $67,288,758$ \\
\hline Butter and cheese & $15,166,599$ & $13,379,579$ & $17,125,243$ \\
\hline Eggs and condensed milk ....................... & 132,308 & 126,849 & 132,230 \\
\hline Fish $\ldots \ldots \ldots \ldots \ldots \ldots$ & $3,165,065$ & $3,715,184$ & $4,139,706$ \\
\hline 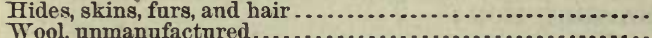 & $9,555,747$ & $7,615,565$ & $6,607,716$ \\
\hline 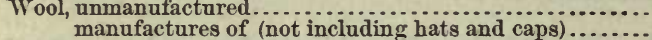 & 154,401 & $\begin{array}{r}13,840 \\
336,389\end{array}$ & $\begin{array}{r}26,446 \\
291,837\end{array}$ \\
\hline $\begin{array}{l}\text { Leather and manufactures of (inclnding trunks)............. } \\
\text { Oils and fats : }\end{array}$ & $7,438,192$ & $10,142,576$ & $8,298,383$ \\
\hline 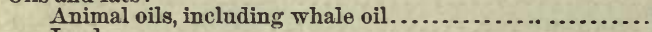 & $1,420,324$ & $1,975,972$ & $1,623,301$ \\
\hline 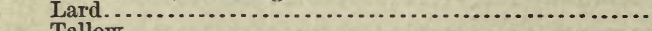 & $22,900,522$ & $22,429,485$ & $25,562,665$ \\
\hline 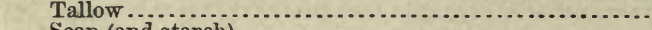 & $5,692,203$ & $6,734,378$ & $7,883,616$ \\
\hline 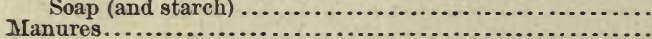 & $\begin{array}{r}1,136,173 \\
616,376\end{array}$ & $\begin{array}{l}1,209,695 \\
922,221\end{array}$ & $1,093,234$ \\
\hline & & & \\
\hline Total & $\$ 109,330,345$ & $\$ 120,630,859$ & $\$ 144,516,470$ \\
\hline Annual average for three jears. & & & \\
\hline
\end{tabular}




\section{INDEX OF OBJECTS.}

$\Delta$.

Abalones

Abeona Trowbridgii .

Aboriginal bird-spears

drying-houses .................

fish-spears

Alusorbent, Infusorial earth for.

Acanthophora muscoides

$$
\text { Thierii }
$$

Acanthurus chirurgus

$$
\text { nigricans }
$$

Accessories, hatching

of bows and arrows...........

of obtaining and impregnating

to artificial baits ..............

to hanting-birds ..............

to hunting-dogs .

Acetabularia crenulata

Achirus lineatus

Acid, Carbazotic.

$$
\text { Carbolic }
$$

Formic

Osmic.

Picric.

Acipenser brevirostris

maculosus...

rubicundus

sturio

Acipenseridre

Adhesiro eggs apparatus................ preparations.

Elurichthys marinus

African leect

Agaphelinæ

A gaphelus gibbosus....................

A garum Turneri

Agassiz collecting-tank.................

Agonidre ...............................

Ahnfeltia gigartinoides .................. plicata......................

Aids, Personal .........................

Air force-pumps.........................

Air-gun canes .........................

dir-guns .............................

Piston.........................

Feservoir ......................

Alaria esculenta.

Alaska Sable.

Albicore

Albula ralpes.

Albulida.
Page.

184
Page.

Preparation of ................ 175 preparations, Manufacture of.... 175

Album græcum of dogs ................ 229

Alces malchis ......................... T

Alcohol ............................... 176

Alcoholic specimens.................. 176

Alewife............................. 60

Alewires, Smoked................... 183

Algæ................................. 265

for "artificial staghorn" .......... 265

for fertilizers....................... 265

as food .......................... 265

for manufacture of bromine........ 265

for manufacture of iodine.......... $\quad 265$

Ornamental ...................... 265

Alligator ............................ 21

mississippiensis ............... 21

leather .......................215-216

Musk of...................... 228

Teeth of ..................... 199

Turtle........................ 22

Alligator-oil ......................... 226

Alopecidæ........................... 68

Alopias vulpes ........................ 68

Alosa sapidissima ..................... 60

Alpenstocks ........................ 142

Alcidinm Blodgettii................... 266

Alum, \& .......................... 178

Alutera cuspicauda ................. . $\quad 25$

Amber-fish ............................... 43

Ambergris, Imports of .................. 298

of sperm-whale .............. 228

Ambloplites rupestris.................. 48

Ambreine .......................... 228

American Badger ...................... 4, 190

Beaver...................... 17

Buffalo ...................... 7

Club-fish................... 186

Elk ......................... 8

Ieech...................... 231

Miller's Thumb................ 34

Sable ........................ 189

Otter....................... 4

Sardines .................... 186

Sole ........................ 26

Amia calra......................... 63

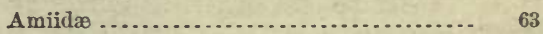

Amiurus catus ........................ 62

Amansia multifida..................... 265

Ammodytes americanus................ 31 
Ammodytidæ ..................... Page.

Ammonia.......................... 230, 299

Carbonate of .................. 202

Purpurate of .................. 228

Manufacture of................. 175

Anmunition (its preparation)............ 91

Prepared...................

holders.

measures ....................

Amphibians, Propagation of................

Amphiroa Californica

". fragillissima...................

nebilis .......................

nodulosa

Amphistichus argenteus

$$
\text { similis. }
$$

Anacanthini similis...................

Anadyomene flabellata

Anarnacinæ..........................

Anarnacus semijunctus ..................

Anarrhichadidæ.........................

Anarrhichas lupus . . ..................... vomerinus ..................

Anatomical instruments, Bristles for....... jars........................

Anchored gill-nets.......................

Anchors.

Anchovies, Essence of.

Preserved exports of

Preserved imports of............

Salted.

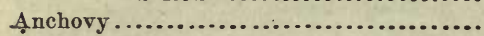

sauce............................

Ancylopsetta quadrocellata................ Angel-fish.

Angel-fish, Black.........................

Angler .

Angling-apparatus, Accessory .............

Parts and accessories of

Angling-tackle .........................

Anguilla rostrata .........................

Anguillidx............................

Animal charcoal..........................

equipments ......................

fertilizers, Other.................. 232

for scientific uses, Preservation of .176-178 products and their applications . 179-187, 273 scalps........................ $\quad 217$

calls, whistles, \&c.............. 138

Animals and birds, Imitations of ...........139-140

Bladders of................... 215

breeding, Foreign imports of ...... 274

Cages for..................... 243

decoy, Living .................. 139

domesticated, Culture of ......... 244

Dung of, used in calico-printing ... 228

Food for...................... 187

Gall of, for dyeing.............. 228

Hunting..................... 136

Predatory, notelsewhere exhibited. 244

useful, Enemies of.............. 244

A nisotremus virginicus ................. 47

Anuelida............................ 262

Annulosa.......................... 262

Autarctic Fur-seal ......................
Antelope (Arctiloce.

192

Hair of (on skin) .............. 218

heads, Masks for .............. 141

Hoofs of..................... 202

Proghorn...................... 7

Antennariidæ $\ldots \ldots \ldots \ldots \ldots \ldots \ldots \ldots \ldots . . . \ldots \ldots$

Antilocapra americana ................. 7

Antilocapridæ........................ 7

Antilopinæ.......................... 7

Antlers ........................... 202

of deer....................... 202

of elk......................... 202

of moose....................... 202

Aparejos .......................... 142

Apeltes quadracus ...................... 54

Apodes ............................. 63

Apparatus accessory to rigging fishing-ves-

sels .....................150-162

Adhesive eggs............... 246

Angling (accessorv) .......... 118

Angling, Parts and accessories of $\quad 97$

Cooking .................... 162

Cord-twisting................. 89

Deep-sea-sounding ............ 80

Dipping .................... 248

Flint-chipping ................ 89

for collecting specimens ........ 233

for destroying injurious species. 243

for drawing out............... 136

for ice-cutting ................ 168

for kindling fire ............ 162

for making and preserving alco-

holic specimens ............. 176

for making and mounting skins. 178

for making carts............... 177

for mannfacture of nets (acces-

sory) ..................130-131

for physical research .......... 233

for preserving and making skele-

tons .................... 177

for smoking out.............. 136

for suffocating with fumes of sulphur.................... 136

for transporting eggs .......... 247

for transporting fish .......... $\quad 247$

for twisting lines ............ 116

for wholesale destruction ....... 136

Hatching $. \ldots \ldots . . . \ldots \ldots \ldots \ldots . .245-247$

of leather-dressing, recent and

aboriginal ................. 172

Photographic (accessory)....... 178

Scaling ................... 169

Smoke-drying................. 169

Sun-drying ................ 168

Transporting ................ 247

Appliances for working up results......... 233

of pursuit ................. 142

Applications of animal products.........179-187

Aquaria ............................. 244

Aquarium-car (Stone's) ................. 247

Aquatic animals, Fish-cars for ........... 244

Floating cages for....... 244

Arabian manna...................... 234

Arara, Red-mouth.................... 47

Archosargus probatocephalus ........... 46 


\begin{tabular}{|c|c|}
\hline & Page. \\
\hline Aretic Fox........ & 189 \\
\hline Arctomys caligatus ....... & 16 \\
\hline " flaviventer $\ldots . . . \ldots \ldots \ldots \ldots \ldots$ & 16 \\
\hline $\operatorname{monax} \ldots \ldots \ldots \ldots \ldots \ldots \ldots \ldots$ & 16 \\
\hline Argentina syrtensium..... & 56 \\
\hline Argentine, Western....... & 56 \\
\hline Argyreiosus vomer....... & 41 \\
\hline Argyrosomus Artedi ...... & 57 \\
\hline Armadillo ................ & 20 \\
\hline Arnied clubs .............. & 71 \\
\hline leads......... & 80 \\
\hline Armor, Defensive.......... & 165 \\
\hline Arms, Breech-loading ...... & 90 \\
\hline Fire $\ldots \ldots \ldots \ldots$ & 90 \\
\hline Muzzle-loading ...... & 90 \\
\hline Army collecting-tank .................... & 176 \\
\hline Arrow-head pouches ..................... & 89 \\
\hline sharpeners............ & 89 \\
\hline Arrows ...... $\quad \ldots . . .$. & 88,89 \\
\hline Arrow-shafts, Feathered ................. & 220 \\
\hline Arrows, Harpoon (used in fishing)........ & 89 \\
\hline Hunting....... & 88,89 \\
\hline
\end{tabular}

Arsenic 136,178

Arsenical soap .......................... 178

Articulating-tools ..................... 177

Artificial baits ........................ 138

(accessories to) $\ldots \ldots \ldots \ldots \ldots .6138$

flies ..................... 138

for bass .................102-114

for salmon ...............102-114

Feathers used for ......... 220

Hair and bristles for (see under

B 45) .................. 219

on hooks ................ 102

Raw material for making .... 138

Tools for making............ 138

guanos ...................... 232

ice, Methods of manufacturing.... 168

lights ...................... 167

staghorn, Algæ used for ......... 265

Art of plumagery .................... 172

Arts and manufactures, Materials employed

in ....................... 197-232

medicines, Chemical products and

agents used in...............229-231

Ascothamnion intricatum ............... 271

Asperococcns echinatus ................. 270

"Asperocens................. 270

Asphyxiators ......................... 136

Aspidonectes ferox

$$
\text { spinifer . }
$$

Aspidophoroides monopterygius..............

Ass leather

Astacus, Concretions from stomach of......

$\Lambda$ stroscopus anoplus

Atherinidaæ

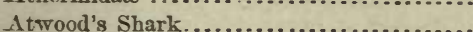

Andubon's Hare

Ank leather.

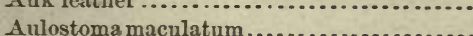

Aulostomidæ .

Anrilares

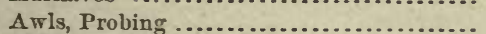

Axes ...................................

A zuring.

\section{B.}

l'age.

Babiche (see under D 20).

Bacon and hams, imports and exports .....270-277

Bachman's Hare........................ 19

Badger, American ..................... 4

Hair of ............... 217

Bags, Game......................... 166

Inflatable..................... 176

Bailing ............................. 174

Baird collecting-seines.................. 127

Bairdiella punctata.................... 45

Baird's Hare .......................... 19

Porpoise...................... 10

Bait, Sea-snails usèd for ................ 251

seines .......................... 127

boxes ........................ 138

Bivalve shell-fish for............... 253

cans ............................ 138

cast-nets...................... 130

clams, Wheelbarrows for ........... 138

cutters.......................... 138

Baited hooks ......................... 95

hoop-net ........................ 129

Bait-ladles......................... 79,138

Bait-mills .......................... 138

Bait-mill knires ...................... 77

Bait-mills, knives, choppers, \&c............ 170

Bait-needles .......................... 138

Baits ................................. 187

Artificial ........................ 138

Methods of preparing (accessories) ... 128

Natural........................137-138

Preparation of .................... 170

Prepared (see B. 45) ................ 187

Salted ......................... 137

Tolling ........................... 137

Spoon, plain and fluted ............101-102

Balæna mysticetus ..................... 13

Balænidæ............................ 13

Balænoptera Davidsonii ................. 13

" rostrata................... 13

Balanopteridæ.......................... 12

Balænopterinæ....................... 12

Baleen ............................... 203

Balistes capriscns ...................... 25

" ringens....................... 24

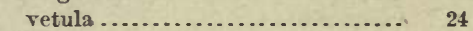

Balistidæ............................. 24

Ball, shot, and wire cartridges............ 92

(Ballistas) ........................... 88

Banded Rock-fish ..................... 35

Rudder-tish ..................... 43

Seal $\ldots . . \ldots \ldots \ldots \ldots \ldots \ldots \ldots \ldots \ldots .6,6,192$

Bangia fuscopurpurea................. 269

Bank-note ink ....................... 200

Banta refrigerator, Horizontal............. 168

Barbed implements................... 82 spears........................ 82

Bark lines........................ 116

Barnacles ............................ 244

Barracuda, Northern ................. $\quad 52$

Southern ................... 53

Barreling ........................... 174

Barrel-lifters ......................... 161 
Barrel-pots for eels................... Page.

Barrels ..............................169, 247

Barrel-traps .......................... 131

Barren Ground Caribou ................. 8, 193

Barrier-nets . ........................... 122

Barrier-snares ......................... 134

Barriers, Bay or cove (Rasch's) ........... 246

Bar-weirs .......................... 134

Basket-hatching....................... 246

Baskets, Game and fish ................ 167

Salmon (Columbia River).......... 131

Bass, Artificial flies for ................ 102-114

Grass $\ldots \ldots \ldots \ldots \ldots \ldots \ldots$
Red $\ldots \ldots \ldots \ldots \ldots \ldots \ldots$

Rock ............................

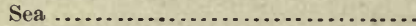

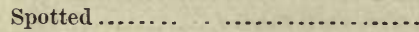

Striped ...........................

White ............................

fishing, multiplying reels for ....

tackle .......................... 96

traps............................ 133

Bastard Snapper ...................... 46

Bat guanc ............................. 231

Batrachidr......................... 32

Batrachus tau ........................... 32

Bat, Sea ............................... 23

Bats, Hair of ........................ $\quad 195$

Bay or cove barriers (Rasch's)............. 246

Lynx (Lynx rufus) ................... 188

Porpoise........................ 11

Beach-dryers .......................... 168

Beak, Half. .......................... $\quad 55$

Beam-trawl ........................ 129

Bear, Black ....................... 5,191

Bones of, \&e.................... 199

Claws of ......................... 203

Grizzly......................... 4

Hair of........................ 217

Polar............................. 5

White ...........................

Bearded Flying-fish.

Bear-fat

meat, Jerked...

oil

Bears, Teeth of ........................

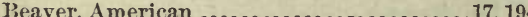

Castoreum of.................................

Fur of (castor) .................. 196

Incisors of .................... 198

leather ...............................

Bed-bug dye............................ $\quad 229$

Beds ................................. 162

Nets for .......................... 165

Beef, Imports and exports of. .............276-277

Dried, smoked, and salted ............ 182-184

Bees, Propagation of .................... 248

Beeswax ............................230, 299

Beetles, \&c., Vesicatory preparations from.. 231

Wings of....................... 208

Belaying-pins ........................ 151

Bellows ............................. 248

Belone hians......................... 54

Jonesii .

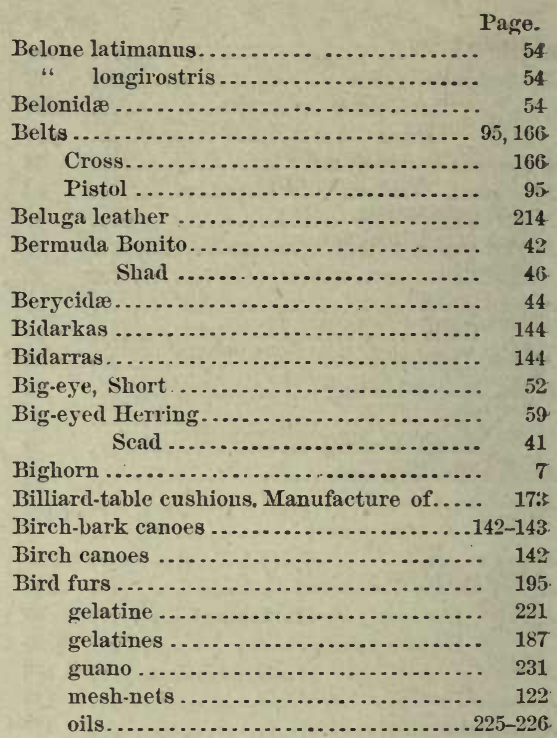

Extraction of ................. 175 .

preparations ...................... 183-185.

Bird-calls.......................... 138

Bird-fyke............................ 133

Bird-lime, \&c ... ...................... 135-25:.

Birds, Bone of ....................... 200

Cages for ....................... $\quad \mathbf{8 4 3}$

Chemical products from............ 230

Coloring from.................... 228 .

domesticated ..................... 244

Down of ....................... 220 .

Foreign imports of............... 274

Jerked........................... 184

Propagation of .................... 244

Quills of ...................... 219

Bird-hunting .......................... 137

Bird-skins, Leather prepared from........215-300

Bird-slings (used by Eskimos) ........... 86 .

Bird-snares ........................... $\quad 86$

Bird-spears, Aboriginal .................. 83

Bison dmericanus .................... 7,192

Hoofs of......................... 202

leather ........................ 209

Bits ................................ 142

Bivalves, Other, for food .................256-25t

Bivalve shellfish ..................... 253

for bait................ 253

for food ................. 253

Bivalves, Injurious ......................258-259

Prepared foods of.............. 259.

Pearl-producing................ 257

Useful or ornamental, other than

for food ..................... 257

useful, Otherwise............... 258

Black Angel-fish ...................... 39

Bear.......................... 5, 191

Cat ............................. 188

Doctor-fish ...................... 38

Dog-fish ...................... 69 
Page.

Black Grouper

Rat.

Rudder-fish

Sucker .

Bass, Large-mouth.

Small-monthed -...........

Black-bass tacklo.

Black-eared, Rockfish

Black-fish .

Black-headed Rockfish ..................

Black-tailed Deer (Cariacus columbianus) .. 193

Black-winged Flying-fish ................ 55

Bladders of animals .................... 215

Blanket decoy (for antelopes)............ 141

Blankets, Imports of .................... 286 (rubber and mackinaw) .......... 162

Bleaching ...........................172-173 preparation, ................... 177

Blepharichthys erinitus ............... 42

Blocks ............................... 150

Blodgettia........................... 271

Blood, Albumen of ...................... 229

Hrematin ...................... 228

poisons ......................... 136

Blow-guns (arrows). (balls) .

(by the breath)

Blubber-fork

Blubber-forks

Blubber-hooks

Blubber-knives

Blubber-mincing spades

Blubber-pikes

Blue Hake.

Parrot-fish

Shark .

Blne-checked Red-month

Blue-fish ...............................

Salted ....................... 185

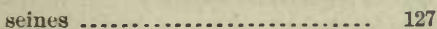

tackle ......................... 96

Blue-headed Shark .................... 68

Blue-nose Bream ....................... 48

Blue-striped Red-mouth ................. 47

Boarding-knires........................73, 174

Boat-builders' materials ................... 154

Boat-hooks .............................80, 151

Boats ................................142-150

Covers for ...................... 141

Dueking........................... 148

Boat-seine, I'ump-box and haft for.........146, 161

Boats, Fishing .......................... 142

fishing, Cat-rigged .............. 148

Hunting ...................... 142

Italian fishing.................. 147

of Great Lakes ................. 149

Portable ......................... 145

Sea........................... 147-148

Skin ......................... 146

Whale ......................... 146

Bobs ..................... 138

Eel ............................. 97

Body-oil, Preparation of ................. 174

Boiling cocoons.

171

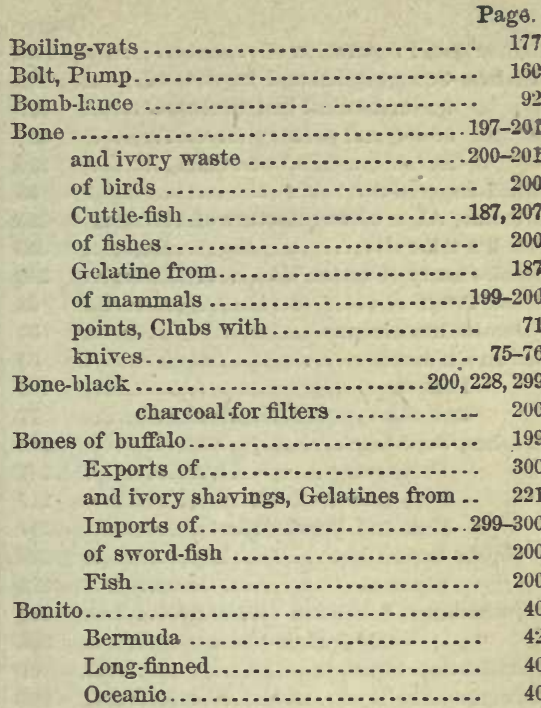

Booms, revolving ..................... 117

Boots and shoes ...................165, 292-293

Bostrychia calamistrata ................. 266

Montagnoi................. 266

Moritziana ................... 266

Bottle-head Whale ...................... 12

Bottom-set lines....................... 91

Bovidæ............................... T

Bovinæ............................... 7

Bowhead Whale ...................... 13

Bowing ........................... 170

Bowl-traps ............................ 134

Bow-monthed Gar-fish................. 54

Bows and arrows ...................... 88

Cross ............................ 88

Simple....................... 88

Boxes ............................... 95

Bait ........................... 138

Glass-grilled (Coste's)............... 246

Hatching (floating) ............... 246

Ice ........................... 168

Box fish-ways ....................... 242

Box-hook............................. 161

Box, Live (Atkins's) ................... 247

Box traps ............................ 133

Braekett's patent fish-ways.............. 242

troughs ..................... 255

Brains of buffalo used in tanning......... 225

Branchiostoma lubricum................. 70

Branchiostomidæ...................... 70

Brazilian diamond-beetles................ 208

Bream.............................. 46

Blne-nose...................... 48

Charleston....................... 46

Breastplates......................... 165

Breech-loading arms.................... 90-91

Breech-sights ........................ 93

Brevoortia patronns.................... 60

tyrannus................... 59

Bridges, Portable...................... 142

Brill................................ 28 
Brillantine, Proparation of

Bristles, Consi raption and imports of .......

for aratomical instruments ......... of hog and peccary ................

for shoemakers' wax-ends .........

Broad-fingered Sta robin ..................

Bromine, Algæ in manufacture of...........

Brook Pickerel.

Brook-shanty (Furman's).

Brook Trout.

Brosmins americanus.

Brown Chimæra.

Pelican - . .

Rat

Brushes, Deer-hair

Feathering

ering ................

from hair of skunk...............

Hair and bristles for.............

Bryopsis hypnoides.

plumosa ........................

Bryothamnion Seaforthii ................... triangulare ..................

Isubalichthys bubalus ....................

Buscinum, Shells of ..................... 206

Buffalo, American....................... 7, 192

Bones of ...................... 199

Brains of, used in tanning......... 225

Horn of........................ 201

Sinews of....................... 215

fish .......................... 61

hair .......................... 196

leather ...................... 209

meat, Salted .................... 184

Bulk-wadding .......................... 92

Bull-dog sounding-machine ................ 86

Bullet-holders ........................ 94-95

Bullet-molds . .......................... 92

Bullets........... 92

shells, \&c. (explosive)............ 92

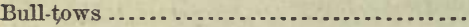

Bung-buckets ...........................

Bunts, Lance.

Burbot.

Bur-fish

Burning of lime

Bilns for.........

Burnt horn

$$
\text { sponge }
$$

Busycon Shells of.

Butter, Exports and imports of

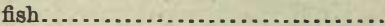

from milk of cows................

Butterfly, Flying-fish.

$$
\text { Ray }
$$

Byssus of mollusks....................... of mollusks, Fabrics from .......... of wing-shell (Pinna nobilis) .......

\section{C.}

Cabreo.

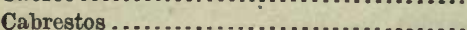

Cages ..................................

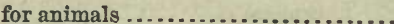

for birds..

for insects.
Calcined coral

shells....................... 207, 231

California Gopher ..................... 17

Gray Squirrel................. 14

Ground Squirrel............... 15

Hare ...................... 19

Spotted Sole.................. 28

Sting Ray ..................... 65

Calliblepharis ciliata................... $\quad 267$

Callirhinus ursinus...................... 5

Callithamnion Americanum ............... 269

Baileyi.................. 269

Borreri . ................... 269

byssoideum ............... 269

corymbosum .............. 269

cruciatum ................. 269

floccosum ................. 269

heteromorphum.......... 269

Lejolisia ................... 269

plumula .................. 269

ptilophora................ 269

Pylaisæi .................. 269

roseum.................... 269

Rothii................... 269

tetragonum ................ 269

Turneri .................. 269

versicolor................. 269

Callophyllis discigera ................... 268

" obtusifolia................. 268

variegata.................. 268

Calothrix confervicola................... 271

scopulorum.................. 271

Calls, Animal, whistles, \&c ............. 138

Bird ............................... 138

Camel's hair........................... 195

Cameo, Sea-snails for................... 252

shell ............................ 206

Camera-obscuras ....................... 178

Cameras and fittings ................. 178

Camera tripods and stands................ 178

Camp outfit ............................ 162

Camp, Hunting ....................... 162

Canada Lynx .......................... 198

Pike-perch ...................... 1i

Canadian cochineal...................... 229

fish ......................... 279

Candle-fish ............................ 56

Candles, tallow, Exports of.............. 297

Candlestick ............................. 160

Canes, Air-gun ........................... 90

Can-hooks............................ 81

Canisters............................... 94

Canned chicken ......................... 188

clams ......................... 187

food .......................... 184

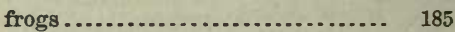

goose......................... 185

herring.......................... 186

lobster and crabs................. 261

Little Neck clams ................ 187

meats .......................163, 164, 185

menhaden ...................... 186

milk .......................... 184

scollops ......................... 187

turkey ..................... 185 
Page.

Cannid tartle

Canning factory, Model of lobster.

Model of ojster

meats

Preservation by salmon, establishment, Model of . 169

Canoes Birch

145,146

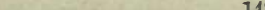

Birch-bark ......................142, 143

Dug-out ...................... 144

Oyster........................... 148

Wooden.......................... 143

Cans

Clark's $-2=0$

Green's

Plain.

Slack's

Bait.

Cantharides, Imports of.

(o...........

"Cape Cod" fish-ways.

Capelin

Capelin-seines

Cap-holders

Cappers

Caps

Cap straps.

Carangidæ

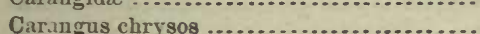

$$
\text { hippos. }
$$

Car-aquarium (Stone's)

Carassins auratus .

Carbazotates, Manufacture of ............

Carbazotic acid ...........................

Carbolic acid.

Carbonate of ammonia (hartshorn) (see un-

(k) 30)

Carbon, animal, Imports of................

Carcharodon Atwoodi.

Carding

Cariacus columbianus................

macrotis .......................

virginianus...

Caribou, Barren Ground........... 8,193

leather......................... 210

Woodland.........................

Woodland

Carp

Gall of

Carpets, Imports of

Carpiodes cyprinus

Cars, Refrigerator.

Carton-pierre.

Cart ridge-holders

Cartridges, Ball, shot, and wire.

Methods of preparing

Carts, Dog

(........ 92-93

Carving, Irory $\ldots$

Carving-tools ............................ 168

Case of cups (Clark's).................. 247

(Wilmot's) ................. 247

Case of trays (Clark's) ................. 247

Cases
Page.

Cast-net ...--r.

Castor canadensis ...................... 17

Castoreum of beaver ..................227, 298

Castoridæ .............................. 17

Castorine............................. 227

Casts, A pparatus for making............ 177

Casts of fishes .......................... 241

Cat (Felis domestica) ................... 188

Black ......................... 188

Maltese $\quad \ldots \ldots \ldots \ldots \ldots \ldots \ldots \ldots . \ldots . \ldots . \ldots 188$

Tortoise-shell ...................... 188

White .......................... 188

Catalogue of illustrations of invertebrates of

American coasts....................... 251

Cat-fish, Fork-tailed ..................... 62

Mnd........................... 62

"Cat-gut" snoods and leaders .............. 116

Catostomidæ .......................... 61

Catostomus teres........................ 61

Cat-rigged fishing-boats ................. 148

Cattle, Foreign imports of.............. 274

Cattle, Hair of . ......................... 219

Caulerpa Ashmeadii.................... $\quad 270$

clavifera .................... 270

crassifolia.................... 270

cupressoides .................... 270

ericifolia ...................... 270

lanuginosa ..................... 270

paspaloides .................... 270

plumaris ...................... 270

prolifera ....................... 270

Caulolatilus microps ..................... 44

Caviare ............................. 186

Cedar manna (Pinus cedrus) ............. 230

Centrarchidæ ......................... $4 \varepsilon$

Centroceras clavulatum ................. 260

Eatonianum ................ 268

Centropristis atrarius .................. $\quad 50$

Centroscyllium Fabricii . ............. 65

Centroscymnns cœlolepis ................ 69

Ceramium Deslongchampsii.............. 268

diaphanum ................... 268

fastigiatum................... 269

nitens ..................... 268

rubrum................... 268

strictum .................... 268

tenuissimum ................. 268

Youngii .................... 268

Ceratacanthns aurantiacus .............. 25

Cero ............................... 41

Spotted.......................... 41

Cervidæ............................. 7

Cerrus canadensis ...................... \&

"dama ....................... g

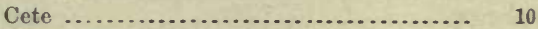

Chænopsetta dentata................... 27

oblonga .................... 27

ocellaris ................... 27

Chætodontidæ.......................... $3 \varepsilon$

Chætomorpha brachygona............... 27]

melagonium ............... 271

Picquotiana.............. 271

sutoria ................... 271 
C Page.

Chretomorpha tortuosa.................. 371

Chamædoris annulata.................. 271

Champia parvula...................... $\quad 267$

Channel Cat-fish........................

Chantransia efflorescens.................. virgatula.................. 269

Charcoal, Animal....................... 230

Charge-drawers .......................... 93

Charleston Bream ..................... 46

Checks, Recoil ....................... 94

Cheek-knives.......................... 74

Cheese...........................183, 277, 276

Chelonia mydas .

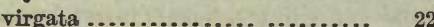

Cheloniidæ

Chelydra serpentina

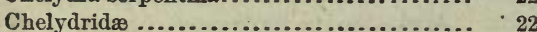

Chemical application of hoofs and claws ..203-205 preparations, Consumption of .... 299 products ....................175, 219 products and agents in arts and medicines ...................229-231 products from birds ............. 230 products from crustacea ........ 231 products from fishes............230-231 products from insects...........229-231 products derived from mammals. 229-230 products from mollusks . products from protozoans ......... products from radiates ........... products from reptiles............ products from worms............

Chests, Medicine......................

Chickaree

Chicken, Canned........................

Chief Mountain Lake White-flsh.

Chilichthys turgidus

Chilomycterus fuliginosus

Chimæra, Brown geometricus................ Pacific......................... plumbea......................

Chimæridæ

Chinchilla (Chinchilla laniger).............

Chipmunk

Chirostoma californiensis. notatum

Chirus constellatus guttatus pictus.

Chloral hydrate

Chlorodesmis (?)

Chnoöspora fastigiata .....................

Chocks...............................

Chœrojulis radiatus

Chogset

(n.....................

Choker, Hog

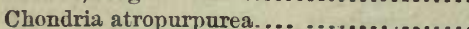
dasyphylla ..................... littoralis . striolata.................................

tenuissima $. . . . . . . \ldots \ldots \ldots . . . . .$.

Condrostei

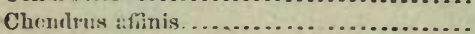

Chondrus crispus ..................... $\quad 268$

Chopping-knives ...................... 74-77

Chopsticks.......................... 117

Chorda filum ......................... $\quad 270$

Chordaria abietina .................... $\quad 270$

" divaricata ................... 270

Chrysymenia halymenioides............. 270 uvaria.................... 268

Chub Sucker ........................ 61

Chulocladia ovalis........................ 260

Ciliata argentata ...................... 30

Cirripedia, injurious.................. 202

Cirrostomi ........................... $\quad 70$

Civet, Imports of...................... 297

Cladophora arcta..................... 271

" $\quad$ fracta...................... 271

، lætevirens................ 271

" lanosa.................... 271

" membranacea.............. 271

" rupestris ................... 271

uncialis .................... 271

Cladostophus spongiosus............... 270 verticillatus .............. 270

Clam-hooks, hoes, and picks............. 80

Clam-knives..........................

Clam-rakes.......................... 81

Clam-shovels ........................ 79

Clams................................ 86

Canned ....................... 187

Deep-sea....................... 86

Hen .......................... 137

Little Neck, Canned.............. $18 \mathrm{~T}$

Long ......................... 137

Clap.nets for birds .................... 130

Clark's cans ....................... 247

troughs ........................ 245

Claw, Devil's .......................... 101

Claws ............................ 203

of bear......................... 203

of puma ......................... 203

of wolf......................... 203

Clays ............................. 177

Cleaners............................. 171

Cleaning fire-arms..................... 93 preparation................... 177

Clearing-rings.......................... 122

Clear-nosed Skate ...................... 66

Cleats............................... 155

Clews .................................150, 151

Closets, Dark....................... 178

Clothing ....................164, 165, 188-196

Feathers for .................... 219

for hands....................... 165 .

Cloths woven from feather.............. 196 \&c., Imports of.................... 286

Club-fish, American.................. 186

Clubs, Armed ........................ 71

(as missiles) .................... 87

with bone-points ................ $\quad 71$

Fishermen's.................... 71

Hunting .....................

with metal points ............... 71

Salmon ........................ $\quad 71$

Stone-headed................... 71 


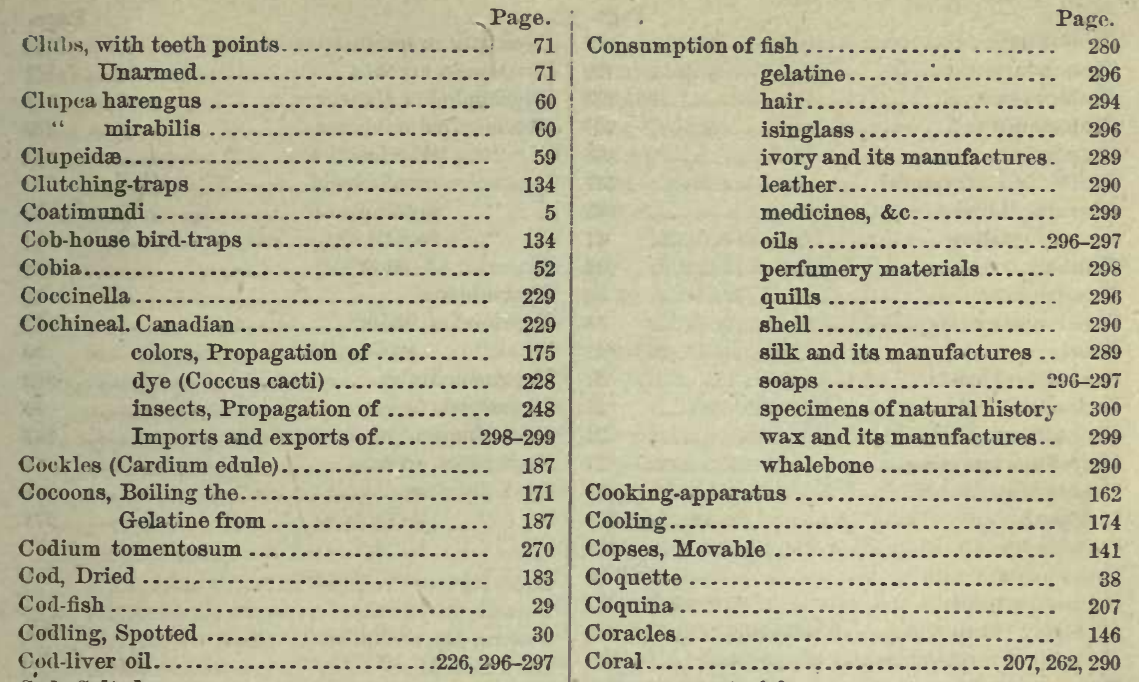

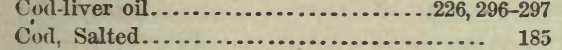

Tom ............................. 29

Cod-seines.......................... 127

Cods' tongues ......................... 185

Collars, Cormorant ...................... 137

Dog ........................ 137

Collecting-tank, Army.................. 176

Collections............................ 241

Collodion........................... 177

Colonia powder......................... 91

Coloring from birds .................... 228

fishes $\ldots \ldots \ldots \ldots \ldots \ldots \ldots . . .228$

insects ..................228-229

mammals................ 228

mollnsks ................. 229

materials ...................228-229, 298

Columbia Black-tailed Deer .............. 9

Combing ............................. 170

Commercial statistics of animal products in

the United States ..................... 273

Commissary supplies .....................162-164

Common Eel.......................... 63

Flounder.................... 27

Mouse....................... 17

Porpoise...................... 10

Seal ......................... 5

Silk-worm, Silk of .............. 196

Skunk ...................... 4

Sucker....................... 61

Compasses............................. 166

Composition shell-work .................. 207

Conch shell (Strombus gigas)............ 206

Condylura cristata .................... 14

Conepatus mapurito.................... 4

Conger Eel.......................... 63

Congridæ............................ 63

Consumption of bristles ................ 295

chemical preparations...... 299

coral ................... 290

coloring materials......... 298

fats .................296-29i

leathers................. 296

as a material

Fan ............................ 207

for building ..................... 207

Calcined.......................... 207

Preparation of .................... 174

Red ............................ 207

imitations of $\ldots . . \ldots \ldots \ldots \ldots \ldots . .207$

White....................... 207

Coral-dredge $. . . \ldots \ldots \ldots \ldots \ldots \ldots \ldots \ldots \ldots . .129$

Coral-rock............................ 207

Corallina officinalis..................... $\quad 267$

squamata.................. 267

Corals, Propagation of.................. $\quad 248$

Coral-tongs.......................... 86

Cordylocladia conferta.................. 267

Cord-twisting apparatus ............... . 89

Coregonidæ ....................... 57

Coregonus clupeiformis ................. 57

labradoricus ................. 57

Cormorant collars ...................... 137

Cormorants ........................... 137

Corrals ................................. 131

Corrosive sublimate .................... 136, 178

Coryphæna punctulata ................. 43

Coryphænidæ ........................ 43

Cotlidæ.............................. 34

Cotton lines ........................... 115

Cotton-oil and its manufacture (accessory).. $\quad 169$

Cottus grœnlandicus .................... 34

" Mitchilli........................ 34

octodecimspinosus................. 34

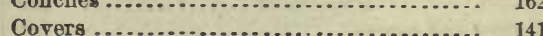

for boats ....................... 141

for hunters...................... 141

Movable ...................... 141

Stationary.................... 141

Cow-fish .......................... 10, 11, 24

Cow-nosed Ray......................... 65

Cowry, Specimens of (Cypræa moneta) ..... 206

Coyote ............................ 189 
Page.

Crab-eater.

Crab-nets.

Crabs' eyes 52

Crab-stones

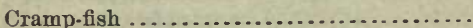

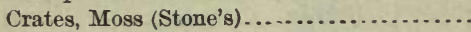

Crevallé, Horse

$$
\text { Yellow. }
$$

Cribbles.............................. 246

Crimpers.............................. 92-93

Cristivomer namaycush .................

Croaker ...............................

Crocodile, Florida ......................

Crocodilia .............................

Crocodilidæ ...........................

Crocodilus americanus...................

Cronania attenuata ......................

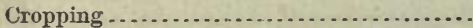

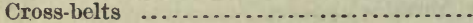

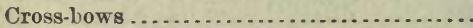

Cross-bow traps .........................

Cross fox (Vulpes alopex decussatus) .......

Crotalin of rattlesnake and copperhead.....

Crow, Quills of .........................

Crashing-traps

Crustacea

Chemical prodlacts of

Chemical prodacts of.............

decapoda

decapoda injurious ...............

isopoda injurious...............

isopoda, nseful.

phyllopoda, useful ...............

stomatopoda for food ............

Cryptacanthidæ

Cryptacanthodes inornatus ................

maculatns ................

Cryptonemia crenulata ...................

Cnckold ...............................

Culture and protection ..................

Culture of fishes ......... 245-247

Cunner................................ 36

Cup-leads .............................

Cups, Case of (Wilmot's).

Curriers, Implements employed by.........

Carrying

of leather.......................

methods of the Eskimo and Indian

Curved sticks

Catters, Bait

Catters, Wad

Cutting and other processes................

Cutting in and stowing.

Cutting, Ivory

Cutting-spades.

Imports of............... 299

Cuttles and squids

Cusk.

Cyanide of potassium

Cybium caballa.

maculatum .....................

regale

Cycleptus elongatus.

Cycloganoidei

Cyclopteritio

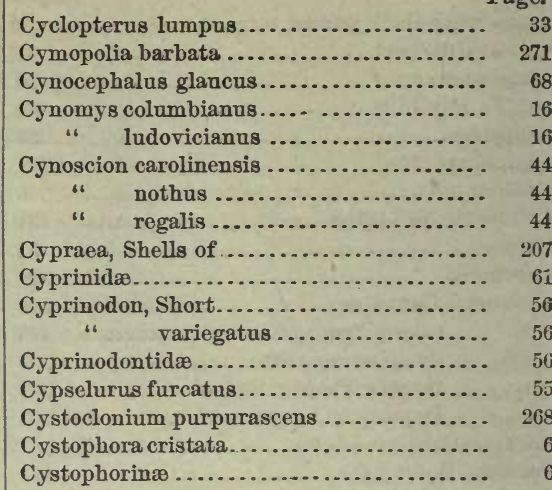

\section{D.}

Dactylopterus volitans .................. 33

Damalichthys vacca.................... 37

Daman, Hyracenm of.................. 228

Dark closets......................... 178

Darts and lances ....................... 88

Dasya callithamnion ................... 265

" elegans ......................... 265

" Gibbesii ........................ 265

" Harveyi ......................... 265

" lophoclados..................... 266

" mollis.......................... 265

" mucronata..................... 265

" plumosa ........................ 266

"ramosissima ..................... 265

4 Tumanowiegi .................... 266

"Wurdemanni .................... 265

Dasycladus clavæformis ............... 271 occidentalis................. 271

Dásypodidæ......................... 20

Dead-falls ............................ 135

Decapterus macarellus ................. 42 punctatus.................. 42

Deck-scrapers ....................... 160

Decoy animals and birds, Living.......... 139

blanket (for antelopes) ............ 141

swimming-birds (carved in wood) ... 139

swimming-birds (from bird skins) ... 139

swimming-birds (in tin with wooden

bottoms, \&c.).................. 140 brants, Tame ................... 139

dogs used in hunting ducks . ....... 139

dacks, Tame .................... 139

Decors........................ 137, 138-141

Scent ....................... 138

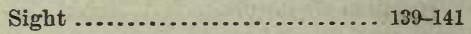

Sound........................ 138

Decoy-waders (carved in wood) ............ 139

(stamped in tin)........... 139

"Deep-sea clams," Ross.................... 86

gear ......................... 96-97

Deer, Black-tailed (Cariacas columbianus).. 193

Hair of (on skin) ................. 218

heads, Masks for ................ 141

Hoofs of..................... 202

Salted $\ldots \ldots \ldots \ldots \ldots \ldots \ldots \ldots \ldots . \ldots \ldots \ldots$

Sinews of....................... 215 
Page.

Deer, Virginia (Cariacus virginianus) .....8, 9, 193

Deer-hair brushes ..................... 218

Deer-leather..........................209-210

Deer-sledges......................... $1_{2}$

Defensive armor........................ 165

Delesseria alata ......................... 267

decipiens.................... 267

hypoglossum ................ 267

involvens..................... 267

Leprienrii .................... 267

quercifolia................... 266

tenuifolia...................... 267

Delineating apparatus, Other............. 178

Delineators, Mechanical ................ 178

Delphinapterinæ ........................

Delphinapterns catodon

Delphinidæ.

Delphininæ

Delphinus Bairdii

bombifrons..

Dentalium, Shells of .......................

Deposits, infusorial, Specimens of..........

Desiccated meat........................ milk ..........................

Desmarestia acnleata.................... ligulata.

viridis

Destroying injurious species, Apparatus for.

Detachable-head spears.

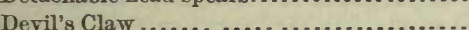

Diamond-back Terrapin ..................

Diamond-beetles, Brazilian

Dicotyles torquatus

Uicotylidæ.

Dictyasy hria favulosa.

Dictyota acutiloba.......................

ciliata..........................

dichotoma

fasciola .......................

Kunthii.......................

Didelphidæ

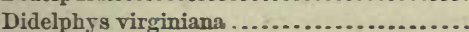

Digenia simplex.

Dingies. .

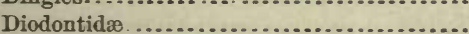

Diplectrum fasciculare ....................

Dip-nets .

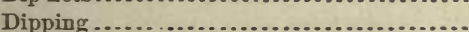

Dipping apparatus

Disgorgers

Disguises.

Disks (thrown by ham

Disks (thrown by hand) ....................

Ditch fish-ways...........................

Doctor-fish .............................

Dog-carts ...........................137, 142

Dog-collars ........................... 137

Dog, Eskimo ........................... 188

Black .............................

Greenland

Prairio

Sea...............................

Short-tailed Prairio

Smooth .

Spined ...........................

vos-food

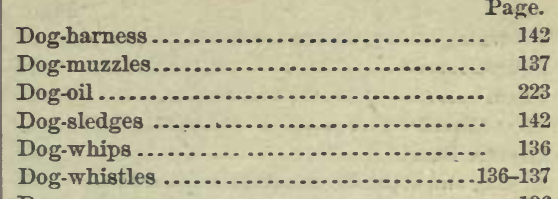

Dogs ................................ 136

Album græcum of ................ 229

Kennels for, \&c ................... 243

Teeth of ......................... 197

Decoy, used in hanting ducks....... 139

Dolium, Shells of ....................... 206

Dolphin ............................ 43

Small-spotted ................... 43

Domestic animals, Oil and fat from........ 223

Domestic exports ..................... 277

Domesticated animals, Food for........... 187

Door-traps ...........................133-134

Dorosomidæ .......................... 60

Dorys ............................. 146

Dory scoop .......................... 160

Dorysoma cepedianum.................. 60

Double box-traps ...................... 133

Down of birds ........................... $\quad 220$

of geese ....................... 220

of eider-dack ..................... 220

of rabbits......................... 219

for stuffings, Preparation of......... 170

of swans ....................... 220

Drag whale-line ....................... 117

Drailing-tackle......................... 96

Drails .............................. 100-101

Drawers, Charge ....................... 93

Dredge, Coral.......................... 129

Ordinary ..................... 129

Dredge-line rollers ...................... 119

Dredge-rake.......................... 129

Dredges .............................. 129

Hand ......................... 79

Dredge-tangles ........................ 87

Dress-goods, Imports of................. $280^{\circ}$

Dress and stay maker's bone, Manufacture

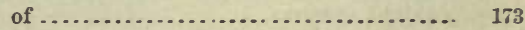

Dressers .............................. 171

Dressing .............................. 171

Dressing, Feather ..................... 172

Dressing fur, Process of ................. 172

gut and sinew, Methods of....... 171

leather...................... 172

Dried abalones (Haliotis) ............... 184

cod ............................ 183

grasshoppers ................... 184

holothurians .................... 184

lizards ........................ 183

meat and blood, Guano from ........ $\quad 232$

mullet........................... 183

siphons (Schizothœrus) ............ 184

slugs $(\operatorname{Limax}, \& c$.$) ................. 184$

worms .......................... 184

Dried and smoked beef ................. 182

flying-fish ............ 183

foods ..................182-184

$\begin{array}{ll}\text { garfish } \ldots \ldots \ldots \ldots \ldots \ldots \ldots & 183 \\ \text { roes ..................... } 183\end{array}$

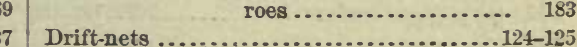




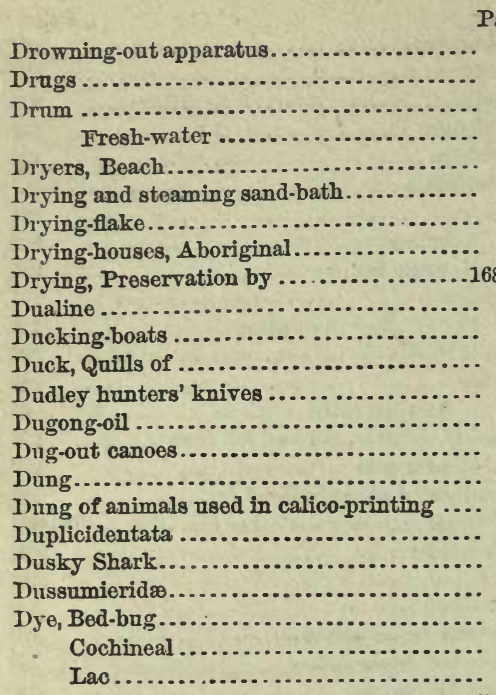

Dyeing

Dye-stuffs, Sea-snails for..................

Dyes from gasteropods (Murex, Purpura, \&Co.)

Dres from nudibranch mollusks............ from trombidium ...................

Dynamite .

Infusorial earth for ................ E.

Eagle, Quills of. Ray

Earth, Infusorial

Earths, Infusorial.

Eater, Crab.

Echeneididæ

Echinoderms .

Echinorhinidæ

Echinorhinus spinosus

Ectocarpus Farlowii.

\begin{tabular}{|c|c|}
\hline “" & fasciculatus ..................... \\
\hline "“ & 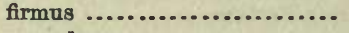 \\
\hline "6 & granulosus .................... \\
\hline “ & Hooperi ........................ \\
\hline “ & siliculosus..................... \\
\hline " & viridis.. \\
\hline
\end{tabular}

Edentata

Eel-bobs

Eel, Common.

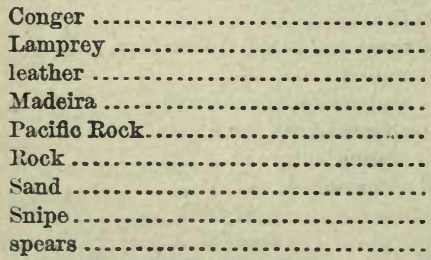

skins of (Anguilla vulgaris) .........216, 231

Ecl-pots without leaders.

Eel-pout.
Page.

136

1

\section{OBJECTS}

Page.

Eel traps.............................. 131

Eel-weirs with leaders................. 132

Egg-nippers.......................... 246

Eggs, Albumen of..................... 230

Exports and imports of .............276-277

Egg-shells........................... 230

Eggs, Shell of ......................... 228

Yolk of .......................... 276

Eglantine Skate...................... $\quad 66$

Ehinoids, Spines of..................... 208

Eider-duck, Down of .................. 220

Eider lcather........................ 215

Elachista fucicola ...................... 270

Elasmobranchiates...................... 65

Elecate canadus....................... 52

Elecatidæo........................... 52

Elephant, Sea ........................ 6

Elephant-seal.......................... 6

Elk, American ........................ 8, 193

Antlers of....................... 202

ivory ........................ 197

bather.......................... 210

Salted........................... 184

Elopidæ............................ 59

Elops saurus ......................... 59

Embiotoca Jacksoni ..................... $\quad 37$

Webbi..................... 37

Embiotocidæx......................... 37

Emydidæ............................ 21

Ena or arindy, Silk of (Bombyx cynthia) ... 196

Encircling-nets........................ 126

Endocladia muricata ................... 268

Enemies of useful animals................ 244 and parasites of Amcrican oysters . 255-256

Engraulididæ ......................... 61

Engraulis vittata...................... 61

Engraving illustrations, Methods of ........ 178

Enhydra marina....................... 4

Enhydrin $x . . . \ldots \ldots \ldots \ldots \ldots \ldots \ldots \ldots . . . \ldots \ldots$

Entangling-lines ...................... 87

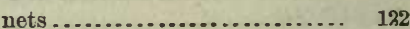

Enteromorpha clathrata................ 271 compressa................ 271 intestinalis ............... 271

Ephippiidæx ........................ 51

Epinephelus ....................... 49

Drummond-Hayi............ 50

guttatus.................. 50 morio..................... 49

nigritus .................. 50

striatus.................. 50

Equipments, Animal .................. 142 Personal......................164-167

Erethizon dorsatus (var. epixanthus) ....... 18

" dorsatus (var. dorsatus)......... 18

Eretmochelys imbricata ................. 22 squamata................. 22

Erignathus barbatus ................... $\quad 6$

Erimyzon Goodei........................ 61

sucetta ..................... 61

Ermino or weasel (Putorius erminca) ...... 190

Erythrotrichia ceramicola ................ 269

Eschrichtius robustus.................. 12

Eskimo and Indian currying methods ...... 171 auk-nets ...................... 129 
Eskimo $\operatorname{Dog}$ (Canis) .................... Page.

harpoons (stone, bone, iron) . ...... 83-85 netting-needles ................. 131 whalebone springs ............... 136

Erocid .

Esox americanus ........................ Jacius ........................... nobilior.......................... reticulatus.

Essence of anchovies"

Essence d'Orient.

Etrumeus teres.

Eubalæna cisarctica.

Cullamach................... 13

Euchalarodus Putnami .................... 26

Eucheuma (?) acanthocladum .............. 267 isoforme.................... 267

Eucinostomus argentens ................. 46 Lefroyi................... 46

Eugomphodus littoralis ..................

Eulamia Milberti.

obscurus ...............................

Eulcptorhamphus longirostris.............

Eumesogrammus subbifurcatus ............

Eumetopias Stelleri .....................

Eupomotis aureus......................

European Leech (Hirudo medicinalis) ......

Enthora cristata.......................

Eventognathi .........................

Exocœtus exiliens ....................... noveboracensis ................ Rondeletii .....................

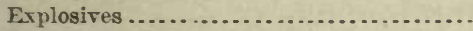

Exports, Aggregate net, for 1875-77 ...... of anchovies, preserved, Foreign . of living animals, Domestic..... 274-275 Net ......... 301 of bacon and hams............. 277 of beef, fresh ................. 277 salted .................. 277 of bone-black, \&c.............. 299 of bones, \&c ................. 300 of boots and shoes............. 292-293 of butter ................... 277 of tallow candles ............... 297 of carpets, woolen ..............28i-288 of horned cattle ............... 274 of cheese ....................... 277 Domestic .................... 277 of fish ............... .281-282 by countries..... 282 of furs, by districts and countries

of eggs ........................... of fish, cured .................... dried or smoked ........... by districts ............... fresh ................... pickled ................... Net.

of food products, except fish.....277-278

Foreign, of fish ................ 283 of píckled herring ....... 283 of fish-oils ............. 297 of sardines, preserved.... 283
Exports, Fo:cign, of silk manufactures ..... 289 of fur-skins...................281-28; of guano and other fertilizers..... 300 of hides and skins.............. 292 \&c., Net...... 301 of hogs...................... 274 of horses ..................... 274

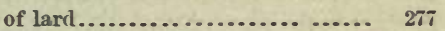
of leather......................292-294 and its manufactures, by districts............. 294 and its manufactures, by countries............ 293

Net, of leather, \&c ............. 301 of manures ................ 301

of meats, preserved.............. 277 of milk, condensed ............. 277 of morocco and other fine leather.292-293 of mules........................ $2 \pi 4$

of mutton ..................... 277 of lard-oil ...................... 297

of neat's-foot oil, \&c ............. 297 of oils and fats..................297-298 of oysters .................... 281 of sperm-oil .................... 297 of whale and fish oil............ 297 Net, of oils and fats ............. 301 of pork....................... 277 Net, of provisions ............... 301 of sheep ..................... 274 of saddlery, harness, \&c .........292-293 of silk, raw.................. $\quad 289$ of soap ...................... 297 of spermaceti.................. 297 of tallow ...................... $\quad 297$

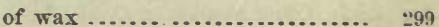
of woolen manufactures .........287-288 Net, of wool, \&c............... 301 of wools, \&c., by districts and coun-

tries .....................28i-288

External parasites...................... 244

Extra limital oysters .................. 254

Extract of fish .......................... 187

of meat, and imports of ..........182, 276

Extraction of bird-oils .................. 175

of fish-oils ................... 175

of gelatine ................... 175

of glue ................... 175

of isinglass .................. 175

of other mammal oils........... 175

of reptile-oils................. 175

of whale-oil (with models) .....174-175

Eye goggle ........................... 41

Moon ............................ 59

powder ......................... 230

F.

Fabrics, feather, Preparation of.......... 170

Mannfacture of ...............170-171

Textile........................ 195

Face, Nets for $\ldots \ldots \ldots \ldots \ldots \ldots \ldots \ldots \ldots \ldots \ldots . \quad 165$

Factory, lobster-canning, Model of......... 169

Falcons .............................. 137

Fallow Deer ......................... 9

Falls. Dead ............................ 135 
Page.

Falls, Spear ........................ 135

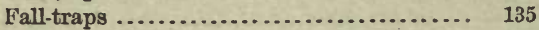

Farms, Fish (models).................. 244

Fat, Bear........................... 223

Fats, Consumption of....................296-297

Imports of. ......................296-297

and oils .........................223-227

Feather-dressing ....................... 172

Feather-fabrics, Preparation of........... 170

Feathered arrow-shafts................. 220

Feathering brushes ..................... 247

quills..................... 247

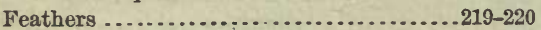

for artificial flies............... 220

of birds, Prepared from...........

Consumption of.................

for clothing .....................

Implements for ..................

Imports of .....................

nsed in other manufactures.......

ornamental, Method of preparing. .

for ornaments.

for plumes ......................

Preparation of .................

for textile fabrics ................

Feet of deer.

and hoofs, Gelatine from .............

adhesive, Imports of .................

Felting...

Hair used in

Felts, Manufacture of ..................170-171

Ferrets............................. 136

Ferrocyanide of potassium ............... 228

Fertilizers......................... 231, 232

Algæ for ................... 265

Other animal ................ 232

Manufacture of................ 176

Fiber-netting......................... 130

Fiber, Whalebone..................... 196

zibethicus........................ 18

Fibers for manufacture of plush carpets.... 171

Fiddle-fish ............................

Field-glasses, \&c .......................

Figure-four traps......................

File-fish ..............................

Long-tailed .....................

Orange ..........................

Spotted.........................

Storer's.........................

Filters, Infusorial earth for............... gravel ..........................

Finback Whale

Finner, Oregon.

Finning-knives ........................

Fire-arms

Cleaning (accessories) ...........

Loading (accessories) ............

Repairing (accessories) ..........

Fire hunting and fishing, Lanterns, \&c., for .

Fire-proof packing, Infusorial earth for.....

Fish, Canadian, not liable to duty............

Commission, United States, Methods of ..............................

Commission stands .................

Consumption of $. . . \ldots \ldots \ldots \ldots \ldots . .$.
Fish, cured, Exports of

Page.

Domestic exports of ................281-282

Domestic exports, by countries ....... 288

dried or smoked, Exports of ......... 281

Exports, by districts... ............ 281

Extract of ....................... 187

Foreign exports of............... 283

fresh, Exports of .................. 281

gelatines (see 24) .................. 187

Imports of . . .....................278-280

Imports of fresh.................. 278

Net exports of $. . . \ldots \ldots \ldots \ldots \ldots \ldots . .301$

Net imports of .................. 301

pickled, Exports of .............. 281

Fish-bones ........................ 200

Fish-cars for aquatic animals ............. $\quad 244$

Fish-carts (used in Nantucket) ............ 142

Fishermen's club .................... 71

flasks...................... 167

sheath-knives .............. 74

Fisher or pekan (Mustela Pennanti) ....... 189

Fishes............................ 23

Chemical products from ........... 230-231

Coloring from .... ............... 2:8

Culture of . . . . . . . . . . . . . . . . . . 245-247

Hunting...................... 137

Imitations of ...................140-14t

Irory of ..................... j99

Propagation of . . . . . . . . . . . . . 245-247

Scales of ...................... 205

Fish-farms (models).................. 244

Fish-guano works, Model of .... ........ 176

Fishing-boats ....................... 142

Fishing-houses ........................ 162

Fishing-lances...................... 78

Fish-jigs, Many-pointed ... ............ 82

Fish-knives .......................... 74

Fish-lances .. ...................... $i 8$

Fish-lice........................... 244

Fish-oils ..............................226-227

Extraction of ................ 175

Soaps from .................. 227

Fish-ponds (models) .................... 244

Fish-pots ............................ 132

Fish-preparations ....................183-18i

Fish-salting ......................... 16!

Fish-scale pearl..................... 228

Fish-scale work, Preparation of........... 174

Fish-scraps ........................ 187

Fish-skins, Leather prepared from........216-217

Fish-slides .......................... 131

Fish-snares (wire, gut, hair, Sc.) .......... 86

Fish-spears, Aboriginal ................ 83

Fish-spike.......................... 39

Fish-way, Brackett's patent ............. 24 ?

Fish-ways..........................241-243

Box ......................

"Cape Cod" .................. 241

Ditch....................... 241

French .................... 241

Gap ....................... 241

Mooring-float................. 243

Pool ....................... 242

Oblique groove............... 241

Singlo groove................ 241 
Page.

Fish-ways, Spiral. Step

Fistularia serrata

Fistulariidæo

Fixed-head spears.

Flagging-irons, \&c.

Flake-drying . .............................

Flakes, Massachusetts.

Newfoundland

Flange ...............................

Flannel screens

Flasks

Hunter's and fishermen's...........

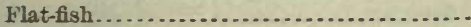

Putnam's........................

Flax snoods

Flaying-knives

Flexible

from invertebrates.......

Flies, Artificial........................ 138

for bass.................102-114 on hooks.................. 102

and other insects ................. 137

Artificial, for salmon ...............102-114 trout ...............102-114

Flint-chipping apparatus................ 89

Flitching-knives ....................... 75

Floating-eages for aquatic animals......... 244

Floating trawl-lines ..................... $\quad 97$

Floats ............................... 117

Harpoon .........................

Keg ..............................

Manufacture of, \&o ................

Seine

Flocking for wall-paper from refuse quills..

Flocking-wool..........................

Florida Crocodile.

Gopher-tortoise

Salamander

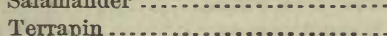

Flounder, Common.......................

Four-spotted...............

Pole.........................

Rough ......................

Rusty.

Smooth-back ..................

Southern .....................

Watery

Winter.

Flying-fish ,

Black-winged .................

Butterfly .....................

Dried and smoked..............

Flying Gurnard

Fly-fishing, Simple reels for ..............

tackle

hooks

Fog-horns

........................... 138

Folding nets. . . . . . . . . . . . . . . . . . . . . 129-130

Food, Algæ used for..................... 265

for animals .................... 187
Food, for domesticated animals........... 187

Bivalve shell-fish for.............. 253

Bivalves for .......................256-257

Lobsters, shrimp, crawfish, crabs, for .260-261 products, except fish, Exports of . ... 277-278 products, except fish, Imports of ....275-276 poisons .......................... 136

Preparation of ................... 168-170

Preservation of ....................168-170

Sea-snail used for ................. 251

Foods............................... 179-187

Canned ........................... 184

Dried and smoked .................182-184

In a fresh condition ................. $\quad 179$

Pickled ........................... 184

Salted, canned, and pickled ..........184-187

Foot-path snares ........................ 134

Foot-stops.......................... 183

Forceps .............................. 178

Force-pumps, Air .................... 247

Foreign animals, Imports of .............. 274

Fork, Blubber ......................... 174

Forks ................................ 81

Fork-tailed Catfish ..................... 62

Formic acid ........................... 229

Fossils ... Manufacture of ................ $\quad 175$

Four-bearded Rockling .................. 30

Four-spined Stickle-back ................. 54

Four-spotted Flounder ................. 27

Fowls, foreign, Imports of .............. 274

Fox, Aretic (Vulpes lagopus) .............. 189

Cross (Vulpes alopex decussatus)...... 189

Gray (Urocy on virginianus) ........... 189

Kit (Vulpes velox) ................. 189

Red (Vulpes fulvus) ................. 189

Silver (Vulpes alopex argentatus) ...... 189

Squirrel .......................... 14

Foxes, Teeth of........................ 197

Frames ........................... 177-178

Wire........................ 178

Wooden........................ 178

French bird-trap ...................... 135

fish-ways....................... 241

Fresh-water Drum ...................... 45

Herring.................. 60

Friar ................................. 53

Frog culture, Methods of................ 245

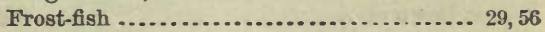

Frozen glue ........................... 221

Fucns distichus ....................... 269

" fastigiatus......................... 269

" furcatus.......................... 269

serratus......................... 269

vesiculosus...................... 269

Fuel.................................. 162

Fulling............................... 170

Fundulus pisculentus .................. 56

Funnel-trap ............................ 132

Fur of beaver (castor) ................. 196

Fur of hare ............................ 196

of mole........................... 196

of musquash....................... 196

pack-saddle (Hudson's Bay) .......... 142 


\begin{tabular}{|c|}
\hline Page. \\
\hline Fur of rabbit ................. \\
\hline Fur-dressing, Processes of.......... \\
\hline Fur-skins, Exports of............... \\
\hline Imports of ........... \\
\hline 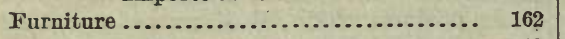 \\
\hline Furniture-table $\ldots \ldots \ldots \ldots \ldots \ldots \ldots \ldots \ldots \ldots \ldots \ldots \ldots$ \\
\hline Fur-robes $\ldots \ldots \ldots \ldots \ldots \ldots \ldots \ldots \ldots \ldots \ldots \ldots \ldots \ldots \ldots \ldots \ldots \ldots \ldots, 188,195$ \\
\hline Fur-seal ............. \\
\hline Antaretic....................... \\
\hline Hair of ......................... \\
\hline
\end{tabular}

Furs, Bird

Domestic exports of, by districts and countries....................... 284

Imports of ......................283-284

Net imports of.................... 301

Fusus, Shells of ........................ 206

Fyke-bird ............................ 133

Fykes (set-nets with leaders)............. 133

G.

Gadidæ

Gadus morrhua.

Gaff-hooks

Galeocerdo tigrinus

Galeorhinidæ.

Gall of animals

of animals for dyeing . ................ of carp.

Gall-nuts.

Galls, Nut

Game and fish baskets....................

fish, \&c., Preservation of............

laws

Gangs of hooks for minnow-bait............

Gar-fish, Bow-mouthed ....................

Dried and smoked...............

Silver .........................

Gap fish-ways ..........................

Gar Pike ..............................

Short-nosed....................

Gaspereau.

Gasteropods, Dyes from (Murex, Purpura, \&c.)

Gasterosteidæo.

Gasterosteus noveboracensis . . .

Gear, Bottom

Deep-sea

Gecse, Down of.

Imption of $\ldots \ldots \ldots \ldots \ldots . . .22,177,296$

Imports of ..................... 296

and isinglass .................. 220

Bird.......................... 221

Bone ......................... 187

from cocoons .................... 187

Extraction of.................. 175

for food (see under 4)........... 200

from feet and hoofs............... 187

Insect...................... 187

from ivory shavings............. 187

from leather shavings, \&c ........ 220

Molds of .......................

and oils..........................

Bird.

Page.

of fish (see 24)................ 187

Mammal (see 24).............. 187

from sinews .................. 187

from tanner's refuse ............. 187

Gelidium cartilagineum ............... 267

" corneum....................... 267

Coulteri..................... 207

Geomyidæ........................ 17

Geomys bursarius ..................... 17

“ castanops.................... 17

" tuza ........................ 17

Gerridæ.......................... 46

Ghost-fish .......................... 31

Giant-powder ...................... 91

Gigartina acicularis .................... 268

canaliculata ............... 268

mamillosa..................... 268

microphylla................. 268

“ radula ..................... 268

Gill-net ............................ 122

Gill-nets used in Great Lakes . . . . . . . . . . . 122-123

Gimp snoods ....................... 116

Ginglymostoma cirratum.............. 69

'Ginglymostomatidæ................... 69

Girths........................... 142

Glass-grilled boxes (Coste's)............. 246

Glires ............................. 14

Globes............................. 244

Globe-sights......................... 93

Globicephalinæ...................... 11

Globicephalus intermedius ............. 11

Scammoni................ 11

Gloiosiphonia capillaris ................ 269

Gloves, Leather for manufacture of........211-214 skin, kid, \&c., Imports of......... 292

Glue .............................. 220

Exports and imports of .............. 296

Extraction of ...................... 17.;

Frozen ....................... 221

made from waste.................. 217

Manufacture of.................... 203

Glues ............................. 177

Glne-sticks ......................... 89

Glutton ........................... 4

Glycerine ......................... 176

Imports of .................. 297

Glycerines, Manufactured............... 225

Glyphidodon saxatilis................. $\quad 37$

Glyptocephalus cynoglossus............. 27

Goat, Horn of ..................... 201

leather......................... 209

Mountain ..................... T

Sinews of ........................ 215

Goat's wool (for wigs, \&c.)..............195, 217

Goggle-eye ......................... 41

Goggles, Snow...................... 166

Golden Tail ........................... 48

Gold-fish .......................... 62

Goode's Sucker....................... 61

Goose (Anser sp.)..................... 195

Canned....................... 185

Fish ............................ 23

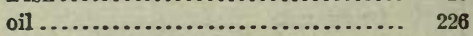

Quills of ..................... 219 
Gopher, California

Gray ...........................

Pocket..........................

Pouched.

Small-footed Pouched.

Striped -

Texas Pouched ..................

Yellow

Gopher-tortoise, Florida

Gracilaria armata

cervicornis .....................

confervoides...................

multipartita ...................

Graduating-sights .

Graining

Grampus

griseus

Mottled

Stearnsii

White-headed

Grampus-oil

Grapnels

Grappling-gear .......................

irons

Gräsö Whale.

Grasping-hooks

Grass Bass . .

Grasshopper paste

Grasshoppers, Dried .....................

Grateloupia Cutleriæ.

filicina ....................

Gibbesii....................

Gravel-bottomed troughs................ filters ..........................

Gray Fox (Urocyon virginianus) .......... Gopher..........................

Grayling, Intestines of .................. Michigan .....................

Gray Rabbit.

Seal

Snapper ............................

Squirrel

Whale.

Great Lakes, Boats of .

Grease, Imports of .

Greenland Dog-fish.

Seulpin ......................

Turbot

Green Turtle

Green's cans ............................

Griffithsia Bornettiana

Grilles

Grinders ................................

Grindle.

Grinnellia, Americana....................

Grizzly Bear ............................

Grommets

Grouper............................ 50

Black ....................... 50

Rock ......................... 50

Growth of East American oysters......... 255

Grunt, Speckled....................... 47

Yollow-finned.................... 47

Guanaco hair.......................... 195

Guano and other fertilizers, Exports of.... 300
Page.

Guano and other fertilizers, Imports of..... $\quad 300$

Net imports of.................... 301

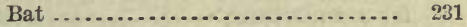

Bird............................ 231

from dried meat and blood.......... 232

Menhaden...................... 232

Pacific, preparations illustrating.... 232

Preparation of ................... 176

Guanos, Artificial ..................... 232

Natural ....................... 231

Guards, Wrist........................ 166

Guasa.............................. 50

Gulf Menhaden ........................ 60

Snapper....................... 48

Gulo luscus .......................... 4

Gun-cases ........................... 95

Gun-cotton.......................... 91

Gunpowder....................... 91

Gun-racks ........................... 95

Guns, Humming-bird.................... 90

Guns and pistols ..................... 90,135

Gunwale winches ..................... 119

Gurnard, Flying ...................... $\quad 33$

"Gut," Silk-worm ..................... 222

Gymnogongrus Griffithsiæ .............. 268

linearis.................. 268

Norvegicus .............. 268

tenuis................... 268

H.

Haddock ..............................29, 183

Norway..................... 34

Hæmatin from blood ................... 228

Hæmylum ........................ 47

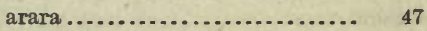

arcuatum .................. 47

chrysopterum ................. 47

elegans.................... 47

formosum .................. 47

Hag-fish .............................. 70

Hair of American badger (Taxidea Americana) .......................... 217

of Antelope (on skin) ............... 218

bracelets, \&c., Imports of .......... 294-295 and bristles for artificial flies (see un-

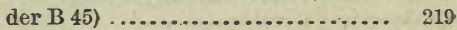

and bristles for brushes ............217-219

of bats ........................... 195

of bear.......................... 217

Buffalo......................... 196

Camel's ........................... 155

Cattle............................ 219

Consumption of ................... 294 cloth, Imports of . . . . . . . . . . . . . ...294-295 curled, for mattresses, Imports of ...294-295 of deer (on skin) ................. 218 for felting (see under 8) ............ 217

Fur-seal......................... 195

Guanaco ........................ 195 hog's, Imports of .................. 294-295 Horse .......................... 196-219

Human. .......................... 195 human, Imports of .................294, 295 Human, for commerce.............. 217 human, Refuso of, \&c ............. 219 
Page.

Hair, Imports of.....................295-301

Llama .......................... 195

for manufactures...................219, 294

manufactured, Imports of ...........294-295

Moose......................... 195

for ornaments .................... 217

Ox and calf.................... 195

Paco ............................ 195

pencils, Imports of ..............294-295

Possum ........................ 196

of raccoon........................ 195

Refuse ......................... 219

Sable's ........................ 195

Seal (Phoca vitulina).............. 192

of squirrel ..................... 217-218

for stuffing. ..................... 219

Tail ............................. 39

nnmanufactured, Imports of. . ....... 294-295

Vicugna $\ldots \ldots \ldots \ldots \ldots \ldots \ldots \ldots \ldots . . \ldots \ldots$

Weasel's ........................ 195

for weaving..................... 217

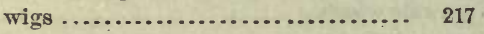

and wool $\ldots \ldots \ldots \ldots \ldots \ldots \ldots \ldots \ldots . . \ldots \ldots$

work .......................... 172

Hairv Box-fish ........................ 24

Hairy-tailed Mole ....................... 14

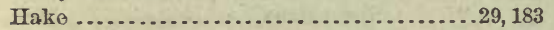

Blue ................................

Long-finned......................

Silver...

Squirrel...

Halatractus zonatus . ....................

Half-beak

Half-round spades

Halibut

fins, \&c

Smoked

smoke-houses....................

Halimeda opuntia

tridens...................

tuna.

Haliotis, Methods of drying .

Shells of .

Haloporphyrus viola

Halosaceion bucicola

bucicola......................

hydrophora...................

Halymenia Floressia

ligulata.

Hammer-head Shark.

Hammocks

Hams, Kinds.

Hand-dredges.

Hand-gear, Short

Hand-implements

Handle-nets

Handles, trinkets, billiard balls, \&ce, Man

facture of ...........................

Handling apparatus for ice ................

Hand-scoops

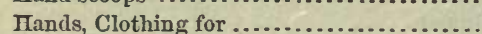

Hanging-needles........................ 131

Hanks............................ 150, 151

Haplodontia leporina ...................

16
Haplodontidæ

Haploidonotus grunniens

Haplomi ............................ 55

Harbor Seal ......................... 5

Hard materials ....................... 197-207

Hard tissues, Preparation of ............ $173-174$

Hare .................................. 194

Audubon's ....................... 19

Bachman's ....................... 19

Baird's ......................... 19

California ........................ 19

Fur of........................ 196

Jackass ......................... 19

Northern....................... 18

Polar........................... 18

Prairio ......................... 19

Red ............................. 19

Trowbridge's.................... 20

Virginia........................ 18

White............................ 18

Harness ............................. 142

Harness, Dog........................ 142

Harpe rufus ......................... $\quad 36$

Harpoon-floats of bladder, skin, and wood .. $\quad 117$

Harpoon-lines .......................... 97

Harpoon, Rest for, \&c ................. 102

Harpoon-arrows ...................... 89

Harpoon-knives ....................... $\quad 76$

Harpoons, Eskimo .................... 82

Harpoon-spears........................ 85

Harpoon-traps......................... 135

Harp Seal (Pagophilus grøenlandicus) ..... 6, 192

Harris's Ground Squirrel ................ 15

Harrow-tangles....................... 87

Hartshorn (see 30) ...................... 202

Harvest-fish ......................... 43

Short.................... 44

Hat and bonnet makers' bone, Manufacture

of.................................. 173

Hatehets, Whalemen's boat............. $\quad 76$

Hatching accessories ..................... 246-248

apparatus ....................24, $=47$

Hatching-basket ..................... 246

Hatching-boxes (floating) .............. \$46

Hat manufacture ....................... 1,0

Hats ............................. 165

Hawksbill Turtle, Oil of................. 228

Hawksbill Turtle..................... 22

Head-axes for whalemen................ $\quad 76$

Heading-knives ....................... $\quad 73$

"Hearl-knives" .......................... 171

Head-oil, Preparation of................. 174

Head-spades........................... 77

Hedge-hog, American, Quills of .......... 219

Heliastes insolatus .................... $\quad 37$

Heliotyping illnstrations, Methods of...... 178

Helmet shell (Cassis rufa, \&c.) ........... 206

Hemdurgan .......................... 84

Hemibrauchii ........................ 53

Hemitripteridæ ..................... 34

Hemitripterus americanus.............. 34

Herring ............................60, 137

Big-eged..................... 59

Canned ....................... 180

Fresh-water .................... 60 


\section{INDEX OF OBJECTS.}

Page.

Herring gill-nets

pickled, Foreign exports of ........ 283 Imports of ..............278-279

Round ........................ 59

Salted ......................... 186

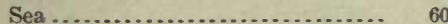

Smoked....................... 183

smoke-houses................... 169

Tailor .......................... 60

Thread .......................... 60

White-fish..................... 57

Herring-Hog ........................ 11

Herring-seines ........................ 127

Hesperomys leucopus ................. $\quad 17$

Heterosomata ........................ 26

Hide-lines ............................ 116

Hind .................................. 50

Hides and skins, Exports of .............. 292

Imports of.............. 291

skins, \&c., Net exports of.......... 301

imports of .......... 301

Hildenbrandtia rosea .................. 267

Hippocampidø .......................... • 25

Hippocampus antiquorum ................ 25

Hippoglossoides limandoides ............ $\quad 27$

Hippoglossus americanus................ 27

Histiophorus americanus ............... $\quad 39$

Histriophoca equestris ...................

Hives (see under E 3).

Hog and peccary, Bristles of

Choker -

Herring ...........................

$\nabla$ iscera of ..........................

Hogs, Exports of ........................

Foreign imports of..................

Holacanthns ciliaris .....................

tricolor .......................

Holer notus pulchellus ....................

" rhodoterus..................

Holocentrum $80 \mathrm{go}$.......................

Holocephali .

Holothurians, Dried

Holsters.

Holton's vats

Honey.

Honey-lonires

Hoorled Seal............................

Hoorl or Bladder-nose Seal (Cy'stophora cistata

Hoods ....

Hoofs and claws of antelope ..................... 202 of bison ....................... 202 of deer ......................... 202 of horse ......................... $\quad \mathrm{2n}_{2}$ of musk ox...................... 202

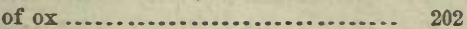

Hook-box

Hook gill-nets..

Hooked instruments
Hooks with artificial flies. Page.

Baited ............................ 95

Blubber........................ 81

Boat $\ldots \ldots \ldots \ldots \ldots \ldots \ldots \ldots \ldots \ldots \ldots \ldots, 150$

Can ............................. 81

Clam.......................... 80

Fly ......................... 138

Gaff.......................... 80

Grasping...................... 80

Ice............................ 161

Junk, \&c...................... 81

Lance........................ 81, 161

Lip .......................... 81

Many-pointed ................... 81-82

Meat......................... 168

for minnow bait, Gangs of.......... 96

mounted on leaders .............. 116

with movable lines ................ 95

Pickerel ......................... 135

Plain.......................... $97-100$

Rabbit......................... 80

Riggers' ........................ 152

Single-pointed.................... $80-81$

Spring ....................... 135

Squirrel........................ 80

with stationary lines............. 97

Unmounted, recent and aborigiras...97-114

Whalemen's ...................... 81

Hoop-nets .............................128-129

Hopples ............................... 243

Hormactis Farlowi ..................... 271

Hormotrichnm Younganum .............. 271

Horn ... ........................... 201

Burnt .......................... 202

of buffalo ....................... 201

of goat......................... 201

Imports of...................... 290

and hoof, Preparation of. ............173-174

as material ........................ 202

of mountain goat.................. 201

of mountain sheep ................ 201

of musk-ox (Ovibos moschatus) ...... $\quad \Sigma 01$

of Rocky Mountain sheep ............ 202

Pout ............................ 62

Horn-cores of ruminants................. 200

Horned cattle, Exports of ............... 274

Horns ................................ 04

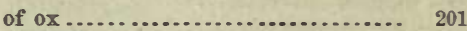

of sheep ........................ 201

Horse Crevallé .......................... 42

Hoofs of ........................ 202

leather......................... 209

Mackerel ........................ 40

Horse-fish ............................. 25

Horse-hair............................ 219

Horses, hair of .........................196, 219

Imports and exports of............ 274

or trestles...................... 171

Horse-trappings ...................... 142

Hosiery, \&c., Imports of................. 286

Hound-fish ......................... 54

Houses, Fishing ........................ 162

Hunters'....................... 162

smoke, Herring ................. 169

Human hair ......................... 195 


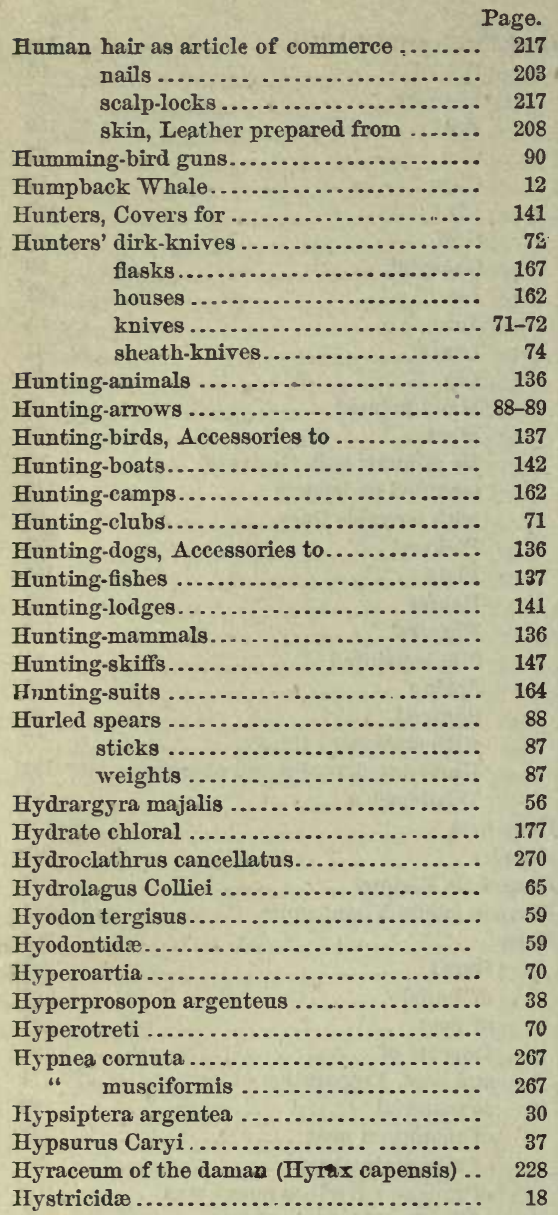

I.

Icc-boxes........................... 168

Ice-chisels............................ 77

Ice-choppers ........................ $\quad 77$

Ice-cntting apparatus .................. 168

Ice-handling apparatus ................. 168

Ice-hooks ............................ 161

Ice-houses............................ 168

Ice-trade (accessory) .................. 168

Ichthælurus furcatus.................... 62

Imitation pearls ...................... 206

Imitations of animals and birds...........139, 140

of fishes....................140, 141

Implements, Barbed................... 82

employed by curriers ........ 171

Feathers for ............... 210

Hand ................... 71

of manufacture.............. 89

for scizure of object. .......... 79

Shells used for .............206, 207

Imports, aggrégate, Net, for 1875-1877..... 301 of albumen and lactarine ........ 298
Page.

Imports of ambergris.................. 298

of ammonia .................... 299

of anchovies, preserved .......... 279

of living animals ............... 273

Net, of living animals ........... 301

of bacon and hams.............. 276

of blankets.................... 286

of beef ........................ 276

of beeswax ................... 299

of cuttle-fish bone............... 299

of bones, \&c....................299-300

of bristles, by countries .......... 295

of bntter ...................... $\quad 276$

of Bologna sausages............. 274

of Canadian fish ................ $\quad 279$

of cautharides................... $\quad 299$

of carbon, animal................ 299

of carpets .................... 286

of castoreum or castor........... 298

of cheese ....................... 276

of cloths and cassimeres .......... 286

of civet....................... 298

of cochineal .................... 298

by countries and dis-

tricts .............298-299

of foreign animals ............... 274

Foreign, of breeding animals ..... 274 of animals not specified .. 274

of birds ............... 274

of cattle.............. 274

of dress-goods .................. 286

of eggs ........................ 276

of eggs, condensed............... 276

of eggs, yolk of ................. 276

of fats........................296-297

of feathers .................... 296

of felt, adhesive ................ 287

of fish .........................278-280

of all other fish................278-279

Net, of fish ................... $\quad 301$

of food products, except fish . .....275-276

Foreign, of fowls ............... 274

Net, of furs ................... 301

of fur-skins.....................283-284

of gelatine. ................... 296

of glores of kid skiu, or leather... . 292

of glue ...................... 296

of glycerine .................. 297

of grease .................... 297

Net, of guano ................ 301

of guano and other fertilizers ...... 300

of hair-cloth... ...............294-295

of horse hair..................294-295

of hair, unmanufactured . . . . . . 294-295

Foreign, of hogs. .............. $27 t$

of horses.............. 274

of ivory .................... 290

Foreign, of leeches ............. $27 t$

sheep.............. 274

of hair........................ 29

Net, of hair, \&c ............... 301

of hair, curled, for mattresses ....294-295

of hair-pencils..................294-295

of hair, human .................294-295

of herring, pickled ............278-270 
Page.

Inports of hides and skins .............. 291

of hair bracelets, \&c............294-295

Net, of hides, skins, \&c ......... 301

of hog-hair ....................294-295

of honey...................... 276

of horn, \&c .................. 290

of hosiery, \&c................. 286

of lac, \&c................... 298

of lac-dye....................... 298

of 'sad....................... 276

of leather...................... 290

Yiet, of leather, \&c .............. 301

of mackerel pickled .............278-279

of manufactured leather, \&c....... 292

of extract of meat............... 276

of prepared meats, game, \&c ...... 276

of milk, condensed or preserved ... $\quad 276$

of milk, plain................... 276

of cod-liver oil.................296-297

of neat's-foot oil, \&c.............296-297

of whale or fish oil................296-297

of oils ........................ 296-297

Net, of oils ................... 301

of fish-oils, by conntries and dis-

tricts.

297-298

of phosphorus................... 299

of pork ........................ 276

of poultry .................... 276

Net, of provisions not specified.... 301

of rennets . ...................... 299

of sardines, preserved .......... 279

of sausage-skins ................. 276

of seal-oil. . . . . . . . . . . . . . . . . 296-297

of shawls..................... 286

of silk hosiery.................. 289

of silk dress-goods............... 289

of other silk manufactures........ $\quad 289$

of silk manufactures by conntries.. $\quad 289$

of silk, raw . . ...................288-289

Net, of raw silk ............... 301

of soap, common................ $\quad 297$

of soap, fancy .................. 297

of soaps ..................... 296-297

of spermaceti and wax............ 297

of sponges...................... 296

of sugar of milk ................. 299

of tallow ......................296-297

of tongues, salted .............. 276

of tripe....................... 276

of venison ..................

of wax......................... 299

of wax manufactures not specified. . $\quad 299$

of sealing-wax.................. $\quad 299$

Net, of wool................... 301

of woolen manufactures not else-

where specified................ 286

of woolen rags, shoddy, \& c....... 286

of wool pelts................... 290

of wools, \&c...................285-286

of wools uxmanufactured......... 286

Incisors of beaver..................... 198

Indelible ink, pencils, \&c............... 177

India-rubber slings.................... 89

Indian raft-boats .......................

tracle, Sna-snails used in

\section{Bull. Y. YT. Yo. 14}

Page.

Inflatable bags ....................... 176

Infusorial deposits, Specimens of......... 207

earth for absorbents ............ 208

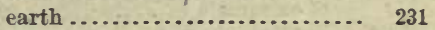

earth for dynamite............. 208

earth for fire-proof packing...... 208

earth for filters................ 208

earth for soluble glass .......... 208

earth for molds for metal casting. 208

earth for making mortar ....... 208

earths .......................207-208

earths emplosed in manufacture. 208

earths for window and plate glass...................... 208

Injecting-syringes...................... 176

Injurious bivalves .......................258-259

sea-snails................... 253

Ink, indelible, pencils, \&c .............. 177

Inks from animal substances, Manufacture

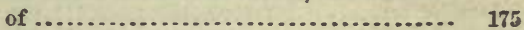

Iodine, Algæ used in manufacture of....... 265

Inorganic materials ................... 271

Insect gelatine ....................... 187

Insectivora............................. 13

Insect productions ..................... 222

powder........................ 178

Insects...............................184, 208

Cages for.....................243-244

Coloring from ..................228-229

Hives for....................... 244

Chemical products from...........229-231

Propagation of .................. 248

Protection from .................. 165

Instruments for cleaning, loading, \&c ...... 93

Hooked .................. 80

Optical, \&c.................166-167

Prodding.................. 78-79

Scooping .................. 79

Internal parasites ....................... 244

Intestinal worms..................... 244

Intestines of grayling .................. 231

of mammals, Leather prepared

from ......................214-215

Inrertebrates, Flexible materials from.... 222

Other materials from........ 208

Inrestigation......................... 233

Iridæ laminarioides..................... 268

Irons, Flagging, \&c................... 160.

Grappling ..................... 81

Lily ......................... 83

Isiuglass $\ldots \ldots \ldots \ldots \ldots \ldots \ldots \ldots \ldots \ldots . \ldots \ldots \ldots, 221-222$

from air-bladders, \&c. (ichthyo-

colla) ....................... 221

and gelatine................... 220

Consumption of ................ 296

Extraction of ................... 175

from sounds of cod and hake.....221-222

from squeteague (Sciænidae) ....... 222

Isogomphodon maculipinnis.............. 68

Isospondyli .......................... 56

Isaropsis Dekayi.................... 67

Italian fishing-boats.................... 147

Irory.............................197-199

Irory-carving ........................ 173

Irors-entting......................... 173 


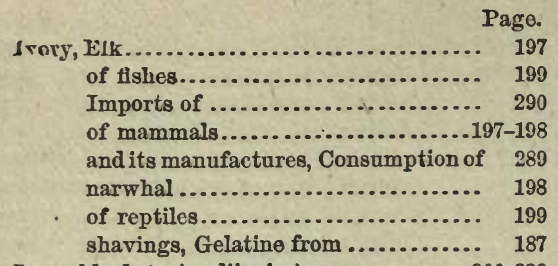

Ivory-black (noire d'ivoire)...............200, 228 Manufacturing of............ 175

\section{J.}

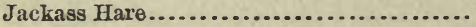

Jacket, Leather

Jack Rabbit.

Jania capillacea

$$
\text { rubens. }
$$

Jaguar

Jar mole-traps

Jars.

Anatomical

Self-sealing, used in collecting.

Juw.bone, Sperm-whale .

Jawed traps.

Jaws of sleeper shark.

Jerked bear-meat

\section{birds}

and smoked buffalo-meat..........

porpoise-meat

seal and walrus meat............. 182

squirrels and other small mammals.

Jerk-nets. snares

Jew-fish.

Jigs .

Jigs, Squid

John Paw (fish)

Joree, Silk of.

Junk-hooks 129-130

86

50

100-101

82,138

50

196

81

K.

Kog-floats for lobster-pots, gill-nets, \&c .... Kelp-Jines............................ Kennels for dogs, \&c..

Kermes (Coccus ilicis) ...................

Kettles.

Killer.

Kilmagore.

Kin

King-fish .

Kit-fox (Vulpes velox) ....................

Knives

Bait-mill .........................

Blubber........................

Boarding ........................

Bone.

Cheek

Chopping

Clam

Dudley hunters'

Finning

Tish

Fishermen's sheath

Flaying.
Knives, Flitching

Pago.

Harpoon ....... 76

Heading ........................ 73

Honey ....................... 76

Hủnters'....................... 71

Hunters' dirk.................. 72

Hunters' sheath ................ 74

Canning ....................... 174

Mackerel-rimmers' fatting........ 75

Mackerel-rimmers' ploughs........ 75

Mincing ...................... 184

Net-makers' ................... 75

Oyster........................ 75

Ripping ...................... $72-73$

Sailors' shcath .................. 74

Scaling ........................ 74

Slivering ..................... 74-75

Splitting....................72-73,75

Stone........................ $75-76$

Straight ..................... $71-76$

Throating ..................... 74

Whalemen's boat ............... 73

Kogia Floweri ....................... 12

Kogiinæ............................ 12

Konmiss .......................... 230

Kyaks.............................. 144

L.

Labels............................. 177

Metallio........................ 177

Parchment ..................... 177

Labracidæ .......................... 51

Labridæ............................ 36

Labyrinth-traps ......................131-133

Lao, \&c., Imports of..................... 298

Lac-dye (Coccus lacca) ...................229, 298

Lachnolæmus falcatus................. $\quad 36$

Lactophrys trigonus.................... 24

Ladles-bait .......................... 79,138

Lady-fish.......................... 36,59

Lagenorhynchus gubcrnator ............ 10

leucopleurus............ 10

obliquidens............. 10

perspicillatus............ 10

thicolea............... 11

Lagodon rhomboides ................... 46

Lake Sturgeon ....................... 64

Trout ........................... 58

Whiting......................... 57

Laminaria flexicaulis.................. 270

longicruris ................... 270

saccharina .................. 270

Lamna cornubica...................... 67

Lamnidæ............................ 67

Lamprey Eel .......................... $\quad 70$

Lampreys, Spiced .................... 186

Lamps .............................. 162

Lance, Bomb......................... 92

Lance-bunts......................... 127

Lance-hooks........................81, 161

Lancelet ............................. 70

Lances, Fish ....................... 78

Fishing...................... 78

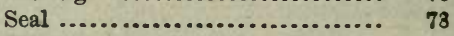

Whale......................... 78 
Landing-nets $\ldots \ldots \ldots \ldots \ldots \ldots \ldots \ldots \ldots \ldots \ldots . .128-129$

Lanterns .............................. 162

for camp and ship ............. 167

for fire hunting and fishing ....... 141

for still hunting ............... 141

for weequashing or fire-fishing.... 141

Lard-oil exports and imports ..........276-277, 297

Large-mouth Black Bass ................. $\quad 49$

Lariats.............................. 86

Lassos................................ 86

Latilidre............................. 44

Laurencia cervicornis

implicata....................

obtusa

paniculata......................

papillosa..................

pinnatifida...$\ldots \ldots \ldots \ldots \ldots \ldots$

virgata...................... 266

Laws, Game........................ 241

Leaders .............................116, 153

Hooks mounted on.............. 116

Leads, Armed

Leads, Cup

Leaning-knives

Leaning and mincing.

Leather.

Alligator.

Ass ......................... 209

Ank ......................... 215

Beaver......................... 214

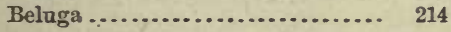

Bison......................... 209

Buffalo ......................... 209

Caribou ....................... 210

Consumption of ................ 290

Currying of ................... 171

Deer .........................209-210

dressing...................... 172

dressing apparatus, recent and aboriginal

Eel......................... 216

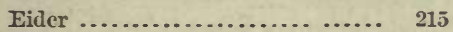

Elk ....................... 210

Exports of ...................292-294, 301

Goat ......................... 209

Horse ...................... 209

Imports of.....................290, 301

Jacket

and its manufactures, \&c. (exports

and imports) .................292-294

Mountain-sheep ................ 210

Moose........................ 210

Ox ........................... 209

from pharynx of seal and walrus .. $21 \overline{5}$

Porpoise....................... 214

prepared from bird-skins ........ 215

prepared from fish-skins.........216-217

prepared from human skin........ 208

prepared from intestines of mam.

mals ......................214, 215

prepared from mammal skins ....208-214

prepared from reptile skins.......215-217

prepared from scale-fish .......... 216

flat ........................ 214
Leather, Rattlesnake ................... 216

Reindecr................... 210

Seal .......................... 208

Sea-Lion ..................... 208

Shark ....................... 217 shavings, \&c., Gelatine made from . 220

Sheep ........................ 208

Other snake................... 216

trimmings.................... 214

Walrus I........................ 208

Waste....................... $2: 17$

Leatherback Turtle ...................... 22

Leathers ............................ 208

for manufacture of gloves .......211-214

Leathesia taberiformis ................... 270

Leech, African (Hirudo trochina) ........... 231

American (Macrobdella decora) ..... 231

European (Hirudo medicinalis) ...... 231

Leeches as barometers................... 231

Foreign imports of............... 274

Propagation of.................. 248

and worms, Injurious and useful ... $22_{2}$

Leggings........................... 165

Lenses ................................ 178

Leopard-hunting ...................... 136

Leopard Seal ......................... 6

Lepidosteidæo........................... 64

Lepidosteus osseus...................... 64

platystomus................ 64

Lepiopomus pallidus ................... 48

Leporidæ........................... 18

Leptecheneis naucrateoides............... 52

Leptocardians . ...................... 70

Lepus americanus (var. americanus)....... 18

americanus (var. Bairdii) ........... 19

americanus (var. virginianus) ........ 18

americanus (var. Washingtonii) ...... 19

aquaticus ...................... 20

Bachmani . ..................... $\quad 19$

californicus .................... 19

callotis ......................... 19

campestris ....................... 19

palustris ....................... 20

sylvaticus...................... 19

sylvaticus (var. Andubonii) .......... 19

sylvaticus (var. Nuttalli) ........... 20

timidus (var. arcticus) ............ . 18

Trowbridgii...................... 20

Leuciscus pulchellus .................. 62

Leucorhamphus borealis ................ 10

Levels (attached to gans) ............... 93

Liagora pinnata....................... 268

pulverulenta................... 268

valida ......................... 268

Lice, Fish ......................... 264

Lichens ............................... 264

Lifters, Barrel .......................... 161

Lights, Artificial ..................... 167

Lily-irons ............................. 83

Lime ............................... 230

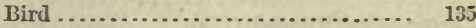

Burning of...................... 176

Limes ...........................176, 231, 232

Liming ........................... 172

Limph, Vaccine..................... 230 
Line-floats of wood, cork, and quill.......... 117

Line-holders............................ 119

Line, kyak, Stretchers for .............. 162

Linen lines ......................... 115

Lines, Bark......................... 116

Bottom-set........................

Cotton..........................

Floating-trawl...................

Harpoon .......................

Hide............................

Kelp.

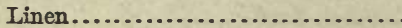

Loaded ...........................

(Plaited) $\ldots . . . . . . . . . . . .114-116$

Seine .......................... 97

Silk........................... 114

Surface......................... 97

Trawl ........................ 97

(Twisted) .....................114-116

Twisting apparatus for ............ 116

Wallets for, and other tackle........ $\quad 167$

Ling.

Whalebone......................

Lion, Sea

Liostomus obliquas......................

$$
\text { xanthurus. }
$$

Liparididæ ..........................

Liparis lineata.........................

Montagui.......................

Striped...

Lip-hooks

Lithofracteur

Lithothamnion polymorphum .............

Little Striped Skunk

Little Tunny .

Live-box (Atkins's) .......................

Live-boxes, troughs, \&c., for microscopists' use.

Living animals, Exports of

274-275, 301

Imports of ...............273, 301

decoy animals and birds........... 139

Lizards, Dried .......................... 183

Llama hair .......................... 195

Loaded lines ........................ 86

Loaders ............................... 92-93

Loading fire-arms....................... 93

Lobotes surinamensis ................... 51

Lobotidæ............................ 51

Lobsters, crabs, shrimp, \&c ..............260-261

Lobster-pots........................ 132

Lodges .............................. 162

Hunting $. . . \ldots \ldots \ldots \ldots \ldots \ldots \ldots . . \ldots \ldots$

Loggerhead Turtle..................... 22 turtle oil ................... 228

Lomentaria Baileyana .................... 267 rosea...................... 267

Lopg-finned Bonito..................... $\quad 40$ Hake...................... 30

Long-nosed Skato.................... 67 Stargeon...................... 65

Long-tailed File-fish..................... 25

Loon (Colymbus torquatus) ............. 195

Lophiidæ............................ 23

Lophius piscatorius ................... 23

Lophobranchii........................ 25
Page.

Lota maculosa.

Lounges............................. 162

Lump-fish .......................... 33

Lustering ............................. 172

Lutjanus Blackfordii .................. 47

caxis ........................ 48

Stearnsii..................... 48

Lutra canadensis....................... 4

Lutrinæ ............................. 4

Lycodidæ ............................ 31

Lyngbya ferruginea................... 271 Kützungiana ................. 271 majuscula .................... 271

Lynx, Bay (Lynx rufus)................. 188 Canada (Lynx canadensis) ......... 188

\section{M.}

Macerating-vats...................... 177

Maces............................. 171

Machine, Mincing ..................... 174

Mackerel............................ 40

gill-nets ................... 125

Horse ...................... 40

pickled, Imports of . . . . . . . . . . $278-279$

purse-seines .................. 129

Salted ...................... 185

Spanish..................... 41

Yellow ...................... 42

Scad ........................ 42

Shark........................ 67

Midge ...................... 30

Mackerel-rimmers..................... 75

Mackinaw blankets ................... 162

Macrochelys lacertina.................. 22

Macrorhinus angustirostris.............. $\quad 6$

Macruridæ........................... 28

Macrurus Bairdii.................... 29

rupestris..................... 28

Mactra, Shells of ...................... 206

Madeira-eel........................... 63

Madrepores ........................ 207

Malacoclemmys palustris................. 21

Mallotus villosus ...................... 56

Maltese Cat ......................... 188

Malthe cubifrons....................... 23

" vespertilio...................... 23

Maltheidæ......................... 23

Mammal furs...........................188-194

gelatines...................... 187

oils .........................223, 225

oils, Extraction of other ......... 175

perfumes ......................227-228

preparations ..................182-184

skins, Leather prepared trom......208, 214

Mammals, Bone of......................199-200

Coloring from ............... 228

Hunting ................... 136

Ivory of. .................197-198

Prepared from hair of ......... 195

Chemical products derived from. 229-230

Propagation of ............... 244

Quills of ................... 219

Mammoth Elephant (Elephas primigeniad) . $\quad 197$

Manateo.............................. 


\begin{tabular}{|c|c|}
\hline & Page. \\
\hline Manatee-oil................................ & 223 \\
\hline 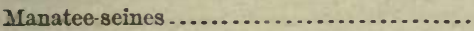 & 126 \\
\hline 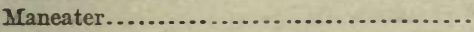 & 67 \\
\hline Mangrove Snapper .................... & 48 \\
\hline Manna (Tamarix mannifera) ............ & 230 \\
\hline Arabian $\ldots . . . . . .$. & 230 \\
\hline Cedar (Pinus cedrus)...$\ldots \ldots \ldots$ & 230 \\
\hline Many-pointed fish-jig...................... & 82 \\
\hline hooks...................... & $81-82$ \\
\hline Manufacture of albumen preparations .... & 175 \\
\hline
\end{tabular}
of oammonia ............... 175 of billiard-table cushions..... 173 of carbazotates............... 175 of dress and stay makers' bono..................... of fabrics.................170-171 of felts ...................170-171

of floats, \&c.............. 172 fertilizers................. 176 of formic acid ................ 175 of handles, trinkets, billiardballs, \&c................. 173

of hat and bonnet makers' 172 bone .................. 173 of hair .................... 294 of ink from animal substances 175 of ivory-black ............... 175 of murexides................ 175 of organ and piano keys...... 173 of pepsin.................. 175 of perfumes ................ 175 of phosphorus............. 175 of propylamine............ 175 of prussiates................ 175 of quill articles............. 172 of quill brush-bristles....... 172 of quills for pens............ 172 of ribbon-weavers' bone...... 173 of rosettes, woven work, trin-

kets, \&c............... 173

of sal ammoniac............ 175 of stock-makers' bone........ 173 of stuffings.................. 170-171 of surgical instruments ...... 173 of suspender-makers' bone... 173

Textile.................170-171

of toothpicks .............. 172 of umbrella-makers' bone .... 173 of whalebone brushes........ 173 of wool ...................286-288 of whip-makers' stock and whips.

Manufactured leather, Exports of .......... glyeerines................. stearines

Manures, Exports of. Marine pearl-shells

Marmot (Arctomys caligatus)

Northwestern ..................... Parry's.

(Spermophilus Parryi).....

Yellow-footed .................. Marsh Rabbit ......................... Marsipobranchiates ..................... Masks.
141

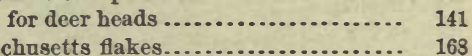

$\begin{array}{lll}\text { Massachusetts flakes..................... } & 168 \\ \text { Mast-gear ............................... } & 153\end{array}$

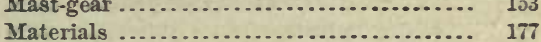

Boat-builders' ................. 154

Coloring......................228-229 employed in arts and manufac-

tures.....................197-232

Inorganic .................... 271

not mentioned.................... $\quad 232$

Mattawoeca.......................... 60

Mazama montana...................... 7

May-fish ............................. 56

Means of pursuit and capture ............. 71

Measures.............................. 92

Ammanition ................... 92

Powder ....................... 92

Shot.......................... 92

Meat-biscuit............................ 182

Meat, buffalo, Jerked and smoked ......... 182

Desiccated ........................ 182

Extract (extractum carnis) ......... 182

Jerked seal and walrus ............ 182

porpoise, Jerked ................... 182

Meat-hooks ........................... 168

Meats, Canned.....................163-164, 185

Canning ........................169-170

prepared, game, \&c., Imports of.... 276

Preservation of ...................168-170

Preserved, \&c.....................163, 277

Mechanical delineators................... 178

Medical ontfit......................... 167

Medicine-chests........................ 167

\&c., Consumption of............. 299

Medregal........................... 42

Medusæ.............................. 262

Megalops thrissoides ..................... 59

Megaptera osphyia.................... 12

versabilis ................... 12

Megapterinæ......................... 12

Mrelanogrammus $x$ glefinus ............... 29

Melobesia farinosa ....................... 267

pustulata .................... 267

Menhaden ............................59-137

Canned ....................... 186

guano ....................... 232

Gulf ........................ 60

oil .......................... 227

purse-seines .................129-130

seines ...................... 126

Spiced........................ 186

Menticirrus alburnus.................... 45

nebulosus.................. 45

Mephitis mephitica..................... 4

Mercenaria, Shells of ..................... 206

"6 violacea, Shells of............. 206

Merluciidæ........................ 30

Merlucius bilinearis .................... 30

Meshing-nets...........................122-126

Mesh-needles......................... 131

Mesoplodon Sowerbiensis ............... 12

Metallic labels ........................ 177

Metal points, Clubs armed with .......... 71 
Methods of culture of domesticated animals, \&c.................... 244 of dressing gut and sinew....... 171 of United States Fish Commission 233 of frog culture................ 245 of drying haliotis ............... 169 of heliotyping and engraving .... 178 of manufacturing artificial ice ... 168 of mink culture................ 244 of oyster culture............... 248 of ostrich culture............. 244 of preparing baits (accessories) .. 138 of preparing cartridges .......... 92-93 of preparing ornamontal feathers $\quad 172$ of pursuit and appliances.......142-167 of terrapin culture............. 245 of transportation . . . . . . . . . . . 142-162 of work..................... 233

Metrogaster aggregatus.

Mexican Ground Squirrel

Skunk ........................

Michigan Grayling.....................

Microcladia borealis ....................

Californica ..................

Coulteri ....................

Microgadus proximus tomcodus

Micropogon undulatns

Micropterus pallidus

Microstomidœ salmoides

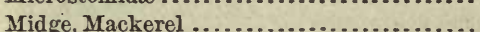

Milk, Canned.

Desiccated ...................... 182

Exports and imports of............276, 277

Mills, Bait, knives, choppers, \& c ............138, 170

Mincing and leaning.

Mincing.horse $\ldots$

Mincing-knives ..........................

Mincing-machine.

Mincing-tub. culture, Methods of.

Missiles propelled by "throwing-sticks" . Missiles

Missile-traps.

Missouri Striped Squirrel ................ 15

Mixers .............................. 176

Mixtures, Preservative ..................176-177

Moccasins ........................... 165

Model-bodies, Plaster................... 178

Model of fish-guano works ............... 176 of lobster-canning factory .......... 169 of oyster-canning factory ........... 169 of propagating-house, \&c........... 248 of salmon-canning establishment .... 169

Modeling of sardine-factory ...................

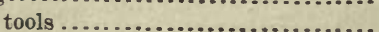

Models of kilns for burning shells.......... of salt-mills .....................

Mola rotunda.......................... Molds.

Bullet.

of gelatine
Molds for metal-casting, Infusorial earth for.

Page.

of paper ...................... 177

of paraffine..................... 177

of plaster..................... 177

Mole (Scalops and Condylura sp.) ......... 193

Fur of........................ 196

Hairy-tailed .................... 14

Oregon ........................ 14

Silvery....................... 13

Star-nosed...................... 14

traps.......................... 135

Molidø .......................... 23

Mollusk preparations .................. 184

Mollusca............................ 251

acephala.................... 253

cephalopoda.................. 251

gasteropoda .................. 251

Mollusk productions .................... 222

Mollusks.......................... 137

byssus ........................ 222

Coloring from................ 229

Opercala of. .................. 207

Preparations of ................ 187

Chemical products from ......... 231

Propagation of................ 248

Molva vulgaris .......................... $\quad 30$

Monk-fish .......................... 67

Monodon monoceros.................. 10

Moon-eye........................... 59

Moon-fish ............................ 51

Moonga, Silk of (Saturnia assamensis)..... 196

Moose.............................. 7

(Alces malchis) ................... 193

Antlers of...................... 202

hair............................ 195

leather........................ 210

Morocco and other fine leather, \&c., Exports

of ................................292-293

Morone americana..................... 51

Mortar, Infusorial earth for ............. 208

Mossbunker........................... 59

Moss crates (Stone's) ................... 247

Moths, Exotic silk of ................... 196

Mottled Grampus ...................... 11

Mountain Cat (Bassaris astuta)............ 194

Goat....................... 7

goat, Horn of................ 201

meal........................ 184

Sheep (Ovis montana)......... 7, 192 sheep, Horn of................ 201

sheep leather ............... 210

Mounting of the bones................. 177

Monse, Common....................... 17

White-footed ...................... 17

Mouse-fish ......................... 23

Movable copses ........................ 141

covers ......................... 141

Moving float fish-ways.................. 243

Mnd Catfish........................... 62

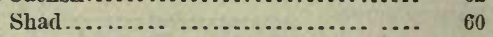

Mud-fish ........................... 63

Mugil albula ........................ 53

"lineatus. ......................... 53

Mugilida........................... 53

Mule Deer (Cariacus macrotis) .......... 9, 193 


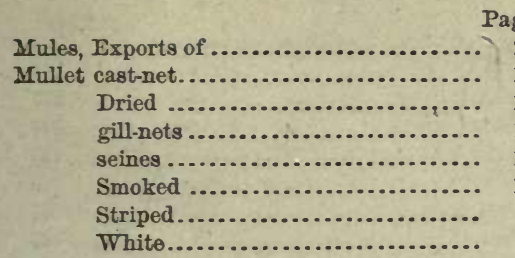

Mullets, Salted ......................... 185

Multiplying reels for bass-fishing..........118-119

Mummichog............................ 56

Murænoides mucronatus ................ 32 " ornatus .................... 32

Murexides ............................ 228

Manufacture of.............. 175

Murex, Shells of....................... 206

Mruridro................................ 17

Mus decumanus...................... 17

Museum storage-tank, Agassiz model....... 176

Musk of alligator......................... 228 of musquash ..................... 227 of musk-ox ....................... 227 rat.............................. 18

Musk-ox (Ovibos moschatus) ............. 192 Hoofs of ........................ 202

Horn of (Ovibos moschatus)..... 201

Musk of...................... 227

Muskellunge .......................... 55

Yus musculus........................... 17

"rattus ........................... 17

Musquash (Fiber zibethicus) ............. 194

fur .......................... 196

Musk of ....................... 227

Mussels, oysters, \&c..................... 206

River (Unionidæ) ...............206, 257

Mustelus canis ......................... 69

Matton, Exports and imports of..........276-277

Muzzle-loading arms.................... 90

Muzzles, Dog......................... 137

Muzzle-sights .......................... 93

Myliobatidæ ........................... 65

Myliobatis californicus .................. 65

Fremenvillei................. 65

Myrionema Leclancherii................. 270

“ strangulans ................... 270

Myxine glutinosa......................... 70

Myxinidæ ............................ 70

Myxostoma macrolepidotum.............. 61

Myzopsetta ferruginea................... $\quad 26$

\section{N.}

Nacre ................................ 206

Preparation of ................... 174

Naits, Human ......................... 203

Naked Stargazer .......................... $\quad 32$

Namajcush Trout....................... 58

Narwhal .............................. 10 Ivory of (Monodon monoceras) ... 198

Nasua fusca............................ 5

Natural baits............................137-138 guanos ........................ 231

Nautilus and argonaut shells............. 206 Teat's-foot oil, \&c., Exports and imports of.296-297

Needle percussion..

Needles, Bait.
Page.

Needles, Hanging ....................... 131

Mesh ....................... 131

Netting...................... 131

Nemalion multifidum................... 207

Nematognathi.......................... 62

Nemichthyidæ...................... 63

Nemichthys scalopaceus.................. 63

Neotomacinerea......................... 18

floridana ...................... 18

Nereocystis Lutkeana................... 269

Nest of Cayenne ant (Formica bispinosa)... 222

Yests .............................. 246 of esculent swallows............... 187

Yet, Gill .............................. 122

gill, Salmon hook .................. 124

hoop, Baited....................... 129

Net-makers' knives...................... 75

Net-sinkers .......................... 147

Nets.............................. 122

Barrier........................ 122

for beds......................... 165

Bird spring ...................... 135

Cast .............................. 130

cast, Bait ......................... 130

cast, Mullet ........................ 130

cast, Pompano ..................... 130

Clap, for birds .................... $\quad 130$

Crab .............................. 129

Dip ............................. 128

Drift...........................124-125

Encircling ......................... 126

Entangling ...................... 122

Eskimo ank....................... 129

Face............................. 165

Folding ...........................129-130

gill, Anchored......................122-123

gill, Herring . . . . . . . . . . . . . . . . 123, 125-126

gill, Hook ......................... 123

gill, Mackerel ....................... 125

gill, Mrullet......................... 124

gill, Other.......................... 126

gill, Shad, used in Sonthern river ..... 124

gill, Sisco ........................... 123

gill, Trap......................... 123

Handle............................. 128

Hoop ...........................128-129

Jerk .............................129-130

Landing...........................128-129

mesh, Bird ........................ 122

Meshing ..........................122-126

Parts of, for manufacture (accessory) .130-131

Pigeon ........................... 134

Pocket.......................... 126

Purse ............................ 129

Rabbit........................... 122

Raw material of................... 130

Skimmer......................... 246

Spring rabbit ........................ 130

Set ............................ 133

Towing ............................ 129

Tow surface ....................... 129

Trailing......................... 129

Trammel......................... 126

Netting-fiber ............................. 130

Netting, gill, Samples.................. 125 
Netting hung to lines, Samples of ......... 130

Netting-needles ......................... 131

Netting-twine ......................... 130

Neutria, or coypu (Myopotamus coypus) ... 194 fur.......................... 196

Newfoundland flakes ................... 168

Newhouse traps ....................... 134-135

New York Sticklc-back .................. 53

Nippers ............................ $\quad 86$

Nippers, Egg........................ 246

Nitophyllum (Neuroglossum) Andersonii... 267 areolatum................. 267 laceratum................. 267

latissimum................. $\quad 267$

punctatum................. 267

Ruprechtianum.............. 267

spectabile ................... $\quad 267$

Nitroglycerine .........................

Nooses ...............................

Noose-traps .............................

Northern Barracuda.....................

Hare

Northwestern Marmot.

Norway Haddock

Notemigonus americanus

$$
\text { chrysoleucus }
$$

Nozzle-rose (for washing eggs) ............

Nudibranch mollusks, Dyes from

Nurse Shark

Nut-galls

\section{0.}

Oars

Oblique groove fish-ways

Obscuras, Camera.

"Ocean Trout"

Oceanic Bonito

Ocelot (Felis pardalis)

Octariidæ

Ocyurus chrysurus.

Odontaspididæ

Odonthalia aleutica

$$
\text { Lyallii. }
$$

Ohio Gizzard Shad

Oil, Alligator.

Bear .............................

Black-fish ........................224-225

Cod-liver .............................

Cotton, and its manufaeture............

Dog...............................

Dugong.............................

factory scraps......................

and fat from domestic animals .........

Groose...............................

Grampus .........................

of hawksbill turtle ...................

Herring.............................

Loggerhead-turtle ..................

Manateo :.............................

Menhaden ...............................

of petrel and other sea birds............ 225

of pigeon (Ectopistes migratorius) ...... 226

Porpoise-jaw.........................224-225

of rattlesnake, \&c ................. 226

Seal ..................................
Oil Sea-elephant Page.

Sea-lion ............................ 223

Shark-lirer...................... 227

Skate-liver........................ 227

skin suit......................... 165

Sperm .......................... 225

Sturgeon ........................ 227

Sun-fish ........................... 226

Oulachan ....................... 227

Turtle............................. 226

from whales, \&c ....................223-324

White-fish ....................... 227

Oiling ................................ 172

Oils, Bird ...........................225-226

Consumption of ...................296-297

and fats................223-227, 297-298, 301

Fish .....................226-227, 297-298

and gelatines .................... 174

Imports of . ...................296-297, 301

Mammal ..........................223-225

Reptile .......................... 226

Ointments (as tar and sweet-oil)........... 165

Oldwife .............................. 24

Oleomargariues ....................... 225

Oligoplites occidentalis................... 43

Oliva, Shells of ........................ 207

Onchorhynchus quinnat................ 58

One-armed chopsticks .................. 117

Onion-fish ............................. 28

Opercula, Mollusks of................. 207

Ophidiidæ............................ 31

Ophidium marginatum ................... 31

Opisthonema thrissa ..................... 60

Opium poisons......................... 130

Optical instruments, \&c................16G-167

Oquassa Trout ....................... 58

Orange File-fish ....................... 25

Orca atra............................. 11

" gladiator.......................... 11

Orcynus alalonga....................... 40

" " alliteratus....................... 40

266 " "argenti vittatus ................ 40

266 " " pelamys......................... 40

60 " secundi dorsalis ................. 40

Oregon Finner ...................... 13

Mole .......................... 14

Organ and piano keys, Manufacture of .... 173

Ornamental algæ....................... 265 pearl-work ................ 206

Ornaments, Feathers for ................ 220

Hair used for .............. 217

Orthropristis fulvomaculatus............ 47

Osmerus mordax ...................... 56

pacificus....................... 90

Osmic acid .......................... 177

Ostraciidæo .......................... $\quad 24$

Ostracium quadricorne $\ldots . . . \ldots \ldots \ldots \ldots \ldots . . . . .24$

triquetrum ................... 21

Ostrea lurida......................... 254

"6 virginica. .........................253-25.5

Ostrich culture, Methods of ............. 244

Other accessories of preservation.......... 168 apparatus .......................... 248 explosives ....................... 91 gill-nets ....................... 120 
Page.

Other materials not mentioned seines. snake leather

127-128

Otter, American.

(Lutra canadensis)................ 190

Sea (Enhydra marina) ............. 41, 91

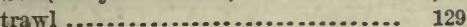

Otters ............................... 136

Oulachan.............................. 56

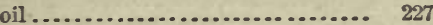

rakes .......................... 82

Smoked......................... 183

spears .

Outfit, Camp.

Medical

Ova, Accessories of obtaining and impreg. nating.

Ovibos moschatus

Ovinæ

Ovis montana ...........................

Owls

Ox and calf, Hair of .....................

hair

Hoofs of

Horns of

leather.

Viscera of

Ox, Musk (Ovibus moschatus) .............

Oyster-bed tangles ........................

Oyster-canoes ..............................

Osster-culture, Methods of .................

Orster-fish

Orster-knives ..............................

Oyster-rakes

Oyster-scraper

Oyster-shovels

Oyster-tongs

Oysters

East American ..................253, 254

Exports of...................... 281

Extra limital ..................... 254

Pearl (Aviculidæ) ................ 206

West Coast. .......................

P.

Pacific Chimæra..........................

Hair Seal (Phoca Richardi ?) ........ Green Turtle ...................... guano, Preparations illustrating .... Hawkbill Turtle ..................

Rock Eel

Right Whale........................

Pack-saddle fur (Hudson's Bay Territory)..

Pack-saddles ......................

Paddle-fish . .

Paddles .............................

Padina pavonia........................... 269

Pads, Riding (for buffalo-hunting) ......... 142

Pagonias chromis ..........................

Pagophilus grønlandicus...................

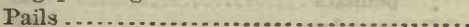

Palinurichthys perciformis...............

Palometta.

Pancreatin

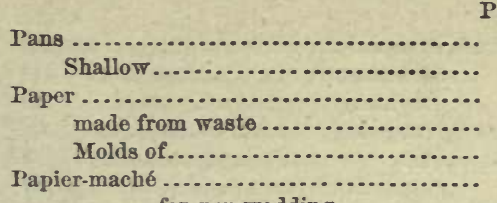

for gun-wadding............. 229

Paraffine ............................. 177

Molds of ..................... 177

Parasites, External ...................... 244

Internal ...................... 244

Paratractus pisquetus ................... 41

Parchment labels........................ 177

from viscera of bears ........... 215

from viscera of seals........... 214

Parephippus quadratus.................. 51

Parophrys vetulus ...................... 28

Parrot-fish ............................... 35

Blne ........................ 36

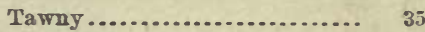

Parry's marmot (Spermophilus Parryi)..... 193

Parts of splanchno-skeleton ............... 199

Pastes............................... 138

Paw, John.............................. 50

Pea-roe of $\operatorname{cod}$........................... 137

Pea-shooters .......................... 89

Pearl................................... 206

oysters (Aviculidæ).................. 206

prodncing bivalves.................. 257

shell, Sea-snails for.................. 251

shells, Marine.................... 258

White............................ 205

work, Ornamental .................. 206

Peccaries, Teeth of...................... 197

Peccary .............................. 9

Teeth of ........................ 198

Pecten, Shells of......................... 206

Peculiarities of form of East American oysters................................ 255

Pediculati ............................. 23

Peep-sights ........................... 93

Pelican, Brown (Pelecanus fuscus) ........ 195

Piline, Spongeo......................... 223

Pelodichthys olivaris................... 62

Pemmican.............................. 182

Penicillus capitatus ..................... 271

192 " dumetosus.................... 271

22 Pens.................................. 243

232 Pen-traps ............................ 131

Peprilus Gardenii ..................... 44

Pepsin, Manufacture of ................. 175

Pepsino ............................. 229

Perca fluviatilis ....................... 49

Percesoces ............................... 53

Perch ......................... 37

Red ............................. 34

Striped .............................. 37

White ............................. 51

Jellow ........................... 49

Perches .................................. 137

Percidæ.................................. 49

Percussion needle ...................... 91

\begin{tabular}{r|r|r}
43 & powder .......................... \\
39 & Perfumery materials, Consumption of...... & 298
\end{tabular}

229 Perfumes .................................... 227 
Page.

Perfumes, Mammal.................... 227-228 Manufacture of ............... 175 Reptile.................... 228

Persian insect-powder.................. 178

Personal aids......................... 142 equipments ...................164-167

Petrel, \&c., Oil of ...................... 225

Petrocelis eruenta....................... 271

Petromyzon americanus ................. $\quad 70$

Petromyzontidæ....................... $\quad 70$

Peyssonnelia atro-purpurea ............. 267

Phanerodon furcatus ................... $\quad 37$

Phasianella, Shells of ................... 207

Phocæna brachycion ..................... lineata........................ vomerina

Phoca Richardsii.

$$
\text { vitulina }
$$

Phocidæ.

Phocinæ

Phosphorus

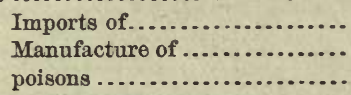

Photographic apparatus (accessory).

Photographs.

Phycis Chesteri

chuss.

tenuis

Phyllitis fascia.

Phyllophora membranifolia.

Brodlæi .

Physeteridæ

Physeterinæ

Physeter macrocephalus

Pickerel.

Brook

hooks

Pickled fish, Preparations of foods

Pickling, Preservation by

Picric acid

Piercing-traps.

Pierre-carton

Pigeon-nets ...........................

Pigeon, Oil of

Pigeons, Stool

Pigments, Wool used as medium for........

Pigmy Sculpin

Pig, Snuffing

"Pike"

Pike, Blubber

Pike, Gar

Pike-perch, Canada

Yellow

Pikea Californica.

Pile-scrapers.

Pimelepteridæ

Pimelepterus Boscii .

Pinkies...

Pinnipedia

Pins, Belaying

Pin, Toggle...

Pipe, Aerating.
Pipe-fish $\ldots \ldots \ldots \ldots \ldots \ldots \ldots \ldots \ldots \ldots \ldots, 25$

Pipettes............................. 246

Pistol-belts........................... 95

Pistols and guns........................ 90

Piston air-guns....................... 90

Pitfalls............................ 131

Pits, Covered......................... 131

Plain hooks ........................ 97-100

sights .......................... 93

troughs......................... 245

Plaited lines............................114-116

Plants .............................. 264 for food, Specimens of............. 248

Plaster model-bodies .................... 178 molds ......................... 177

Plasters.............................. 177

Plates, Wet and dry.................... 178

Platichthys stellatus ................... 28

Plectognathi .......................... 23

Pleuronectes glaber ..................... 26

Pleuronectidæ....................... $\quad 26$

Pliers ................................ 178

Plocamium coccineum.................. 267

Plucking .............................170, 172

Plumagery, Art of...................... 172

Plumes, Feathers for.................. $\quad 220$

Pocket Gopher....................... 17

Pocket-nets ............................ 126

Pocket-traps ........................... 131

Pogie............................. 59

Poisons.............................. 136

Blood ........................ 136

Food ......................... 136

Phosphorus ..................... 136

Opium ....................... 136

Polar Bear............................ 5

Hare ........................... 18

Pole Flounder ......................... 27

Poles.............................. 160

Polishers, Shaft ........................ 89

Polishing..............................

powders .................... 207

Pollachius carbonarius .................. 29

Pollack............................... 29

Polyides rotundus........................ 267

Polyodon folium.......................... 64

Polyodontidæ ......................... 64

Polysiphonia atrorubescens .............. 266 Baileyi.................... 266

bipinnata.................. 266

elongata .................... 266

fastigiata................... 266

ferulacea ................... 266

fibrillosa .................. 266

Havanensis ............... 266

Harveyi................ .... $\quad 266$

nigrescens................. 266

olneyi..................... 266

parasitica .................. 266

pecten-veneris............... 266

pennata ................. 286

urceolata .................. 266

variegata ................ 288

violacea ................... 266 
Page.

Polysiphonia Woodii .

Pomacanthus arcuatus

Pomacentridæ

每ostictus

Pomatomidæ

Pomatomus saltatrix ....................

"Pommels".............................

Pomolobus mediocris .................... psendoharengus ...............

Pomoxys nigromaculatus................

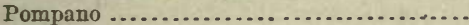
cast-nets ...................... 130

Salted......................... 185

Short ....................... 42

Ponds, Fish (models).................. 244

Pool fish-ways....................... 242

Porbeagle Shark ....................... 67

Porcelain stock, Sea-snails for............ 252

Porcupine, White-haired................. 18

Yellow-haired ................ 18

Porgy ............................... 46

Spanish........................ 36

Porichthys notatus...................... $\quad 32$

Pork, Exports of ....................... $\quad 277$ Imports of ...................... 276

Salted ......................... 184

Poronotus triacanthus.................... 43

Porphyra vulgaris...................... $\quad 269$

Porpoise............................... 10-11

Baird's ..................... 10

Bay ........................... 11

Common..................... 10

leather....................... 214

Right-whale.................. 10

Skunk........................ 10

Sperm-whale................ 12

Striped ..................... 10,11

jaw oil .......................224-325

Portable boats.......................... 145 bridges........................ 142

Possum (Didelphys virginianus) ............20, 194 hair.......................... 196

Potassium, Cyanide of .................. 136

Ferrocyanide of................ 228

Pots, Barrel for eel ..................... 133

Eel, without leaders ................132-133

Fish ............................. 132

Lobster........................ 152

Try ............................. 175

Pouched Gopher ...................... 17

Pouches, Arrow.head..................89, 94-95

Poudrettes ............................. 232

Poultry, Imports of...................... $\quad 276$

Pout Eel ............................. 31

Horn.

Powder, Colonia

Giant.

Percussion

Pyrethrum

Wood.

Powder-horns

Powder-measures

Powders, Insect .

Polishing

Prairie Dog
Page.

19

15

Wolf............................ 189

Predatory animàls not elsewhere exhibited. 244

Preparation of albumen ................. 175

of baits.................... 170

of body-oil.................. 174

of the bones ................. 177

of "brillantine"............. 170

of cochineal colors........... 175

of coral..................... 174

of feathers ................. 170

of fibers for manufacture of

plush carpets............... 171

of fish-scale work ............ 174

of food ....................168-170

of guano.................... 176

of curled hair for stuffing ...... 170

of horn and hoof..............173-174

of other hard tissues.......... 173-174

tortoise shell ............... 174

of silk from byssus of pinna... 171

of silk of insects ............ 171

of silk of silk-worms ......... 171

of the skin and its appendages. 171-173

of nacre .................... 174

of spermaceti................ 174

of sponge stuffing............. 171

of soft parts of other inverte-

brates ................... 171

of head oil.................. 174

of stuffings ................. 170

of whalebone............170, 173-174

of wool-cloths .............. 170

of wool and hair of mammals. . 170

Preparations, Adhesive................. 135

Bird......................183, 185

Fish..................183, 185, 187

Mammal ..................182, 184

of mollusks................184, 187

of pickled fish............... 187

Radiate ................... 184

Reptile..................183, 185

Prepared ammunition ..................... 92

wads ........................ 92

Preservation, Accessories of ............. 168

of the animal for scientific

uses....................176-178

by canning ...............169-170

by drying..................168-170

of meats ..................168-170

of food ...................168-170

of game, fishes, \&c.......... 241

by pickling.................169-170

Preservations ........................ 178

Preservative mixtures.................. 176-177

Preserved meats, \&c.................... 163

Preserving fish, Specimens of salts used

in .................................. 169

Pressing ...............................170-173

Priacanthidæ........................ 52

Primers ............................... 91

Prionitis Andersonii.................... 268

lanceolata...................... 268

Prionotus carolinus ..................... 33 


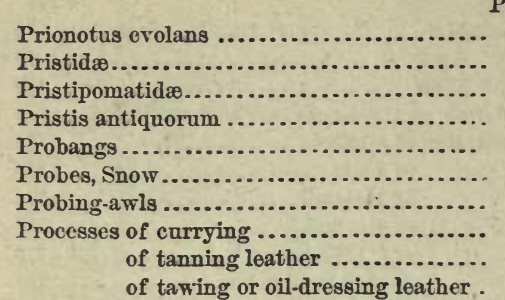

Procyonidio.

Procyon lotor.

Prodding-instruments .................... 78-79

Productions, Insect..................... 78

Mollusk.................... 222

Products, Chemical ..................... 219

Proghorn Antelope......................

Promicrops guasa ......................

Propagating-house, Model of, \&c...........

Propagation

of amphibians ................

of bees ......................

of birds

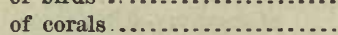

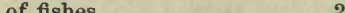

of

insect............. 248

of insects................... 248

of leeches ................... 248

of mammals ................. 244

of mollusks.................. 248

of reptiles ................... 245

of silk-worm ................ 248

of sponges................... 248

of worms .................. 248

Propylamine ........................... 230

Manufacture of ............. 175

Prosopium Conesii ....................... quadrilaterale .................

Protection...

and culture.....................

from insects .

Protozoans . 184,263

Chemical products from........ 231

Injurious .................... 264

Useful.......................263-264

Provisions, meats, butter, cheese, eggs, \&c.,

Net exports of ..................

not included, Imports of.........

Prussian blue ..........................

blue made from leather waste (see nuder 30 ) ..................

Prussiate of potash (see under 30.) .......... Prussiates.

Manufacturo of ................ 175 $.228,930$

Psettichthys melanostictus ............... 28

Pseudemys concinna. mobiliensis . rugosa....

Pscuiloplenronectes americanus ............ Pseudopriacanthus altus

Pseudoscarus cœruleus.

Pterophryne histrio
Ptil

tilota elegans

Page.

" hypnoides ........................ 269

plumosa ..................... 269

Ptychocheilus grandis.................. 61

Pulverizers......................... 176

Puma (Felis concolor) .................. 188

Claws of ...................... 203

Pump-bolt........................... 161

Pump box and haft for seine-boat ......... 161

Punctaria latifolia.................... 270

" jlantaginea................... 270

Punk............................. 230

Purpura lapillus shells.................. 206

Purpurate of ammonia dyes.............. 228

Purse-nets ............................ 129

Pursuit, methods and appliances........... .142-107

Pusa gryphus .......................... 6

Pushing-sticks .......................... 160

Putnam's Flat-fish...................... $\quad 26$

Pygostensoccidentalis................... 53

Pyrethrum powder.................. 165

\section{Q.}

Quill articles, Manufacture of............ 172 brush-bristles, Manufacture of....... $\quad 172$

Quills .............................. 219 of American hedge-hog ............ 219 of birds.......................... 219

Consumption of.................. 296 of crow.......................... 219 of duck........................ 219

of eagles........................ 219

Feathering ..................... 247

of goose ...................... 219

of mammals ..................... 219

for pens, Manufacture of ........... 172

of swan ......................... 219

for tooth-picks, \&c................ 219 of turkey......................... 219

Quinnat .............................. 58

Quivers ............................ 89

$\mathrm{R}$.

Rabbit or Cony (Lepus cuniculus) ......... 194

Fur of ....................... 196

Gray ........................... 19

hooks ........................ 80

$\begin{array}{lll}\text { Jack ............................. } 19 & 19\end{array}$

Marsh .......................... 20

nets......................... 122

Sage ............................ 20

spring-nets...................... 130

tipe used in England ............. 131

Water ........................... 20

White......................... 18

Rabbit-fish $\ldots \ldots \ldots \ldots \ldots \ldots \ldots \ldots \ldots \ldots . . \ldots, 24$

Rabbits, Down of...................... 219

Raccoon ............................ 5

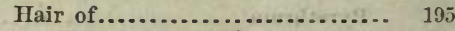

Race-spawning (Ainsworth)............. 245

Racks ............................... 95

Gun ......................... 95

Radiata.............................. 262

preparations .................... 184

Radiates.......................... 262 
Page.

Radiates, Chemical products from......... 231 Injurious.................... 263

¿seful......................... 263

Raft-boats, Indian ..................... 144

Paft of tulé grass...................... 144

Raire

Raia eglanteria

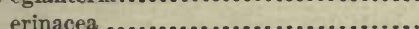

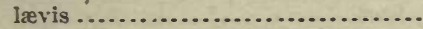

ocellata

radiata.

Raiidæ

Rake-dredge

Rakes, Clam.

Oulachan ........................ Oyster.

Ralfsia verrucosa.

Rammers

Rat, Black

Brown

Florida

leather

Mrusk

Rocky Mountain ...................

Tood.

Rattlesnake leather

Raven, Sea.

Pav material fo.......................... material of nets ......................

Rawhide.

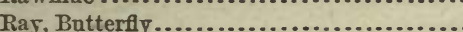

Cow-nosed

Eagle.

Sting.

Recoil-checks

Red Bass

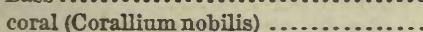

Fox (Vulpes fulvus) .

Hare.

Perch

Snapper ...........................

Squirrel

Red-bellied Snapper .

Red-fish tackle

Terrapin .....................

Rell-month, Arara

Blue-checked .................

Blue-striped.

Squirrel.

Reels ...............................118-119

Multiplying ......................118-119

Seine......................... 119

Simple ....................... 118

Reeling .............................170-171

Refining............................. 174

Refuse hair.......................... 219

human and other hair............ 219

Refrigerator, Banta.................... 168

Refrigerator-cars ....................... 168

Refrigerators........................ 168

Reinileer leather ..................... 210

Salted ...................... 184

Reinhardtius hippoglossoides ........... 28

Remora .............................52, 137

Remoropsis brachyptera
Rendering whale-oil, Instruments and appli-

ances of ............................174-175

Reniceps tiburo .......................... 68

Rennets, Imports of ................... 299

Repairing, sighting, and testing fire-arms .. $\quad 93$

Reptile oils......................... 226

Extraction of ............... 175

perfumes ....................... 228

preparations ....................183-185

skins, Leather prepared from .....215-216

Reptiles............................ 21

Chemical products from .......... 230

Ivory of .................... 198

Propagation of ................. 245

Reports of the U.S. Fish Commission .....233-237

Research, Apparatus for physical ......... 233

Reservoir air-guns. ..................... 90

Rest for harpoon, \&c ................... 162

Results, Appliances for working up ........ 233

of work of U. S. Fish Commission...233-241

"Revolving booms".................... 117

Rhabdonia Coulteri .................... 267

tenera ..................... 207

Rhodymenia corallina .................... 267

palmata ................... 267

Rhachianecles glaucus .................. 112

Rhachochilus toxotes................... 38

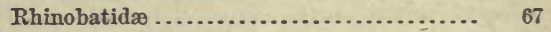

Rhinobatus productus.................. 67

Rhinonemus caudacnta.................. 30

Rhinoptera quadriloba .................. 65

Rhodomelia floccosa.................... 266

larix........................ 266

subfusca.................... 266

Rhombochirus osteochir................. 52

Rhomboganoidei ....................... 64

Rhomboplites aurorubeus ............... 48

Rhombus læris....................... 28

maximus.................... 28

Rhyzopods, Useful ....................... 264

Ribbon-weavers' bone, Manufacture of ..... 173

Riding-pads (for buffalo hunting).......... 142

Riding-saddles ...................... 142

Rigger's hooks ....................... 152

Rigging fishing-vessels, Apparatus accessory

to .................................. 150-162

Right Whale ......................... 13

Right-Whale Porpoise.................... 10

Ringed Ground Squirrel.................. 16

Rings, Clearing...................... 122

Ripping-knives...................... $72-73$

River-mussels (Unionidæ) ................206, 257

River-weirs, with pockets................ 131

River Sting Ray...................... 66

Trout.......................... 58

Robes, Fur........................ 162

Robin, Round....................... 42

Roccus chrysops....................... 51

lineatus ....................... 51

Rock Bass.......................... 48

Eel ............................. 32

Grouper ....................... 50

Trout ......................... 35

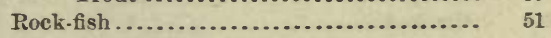

Banded.................... 35 
Rock-fish, Black-eared ..................... Page. Black-headed .................. 35

Rosy....................... 34

Rockling, Four-bearded................. $\quad 30$

Rocky Mountain Rat.................. 18

sheep horn ............ 202

Rods .................................119-121

Rods, Twisting ........................ 82

Roe ................................ 185

Roes, Dried and smoked ................. 183

Roller, Spawning-scrcen (Collins)......... 245

Rollers, Dredge-line................... 119

Trawl-line.................... 119

Rosmaridæ.......................... 6

Rosmarus Cookii ...................... 6

obesus ...................... 6

Rose-fish ............................. 34

Rose-nozzles (for washing eggs) .......... 247

Rosettes, woven work, and trinkets, Manu-

facture of .

Rosy Rock-fish . ........................

Rotella, Shells of . . . . . . . . . . . . . . . . . . . .

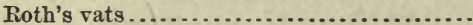

Rough Flounder.......................

Round Herring......................... mouse-traps .....................

Robin ............................

"Round-Knives"........................

Round-tailed Ground Squirrel .

Rowlocks...........................155-159

Rubber blankets..................... 162

Rudder-fish, Banded

Black..................... 43

43

Rudder-fixtures ........................154-155

Ruminants, Horn-cores of .............. 200

"Russian sardines"..................... 186

Rusty Flounder ...................... 26

\section{S.}

Sable, American, or Hudson's Bay (Mustela Americana)

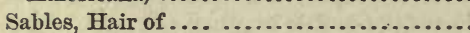

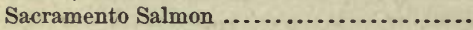

Saddlery, harness, \&c., Reports of..........292-293

Saddle-slings......................... 95

Saddles.............................. 142

Pack....................... 142

Riding ........................ 143

Sage Rabbit........................ 20

Sail-fish .... ......................... 39

Sailor's Choice ........................... 46

Sailors' sheath-knives ................... 74

Salamander, Florida.................... 17

Sal ammoniac (see under 30)............200, 230

Manufacture of ............ 175

Salmo fario......................... 58

Salmon ............................. 57

Artificial flies for ................102-114

baskets (Columbia River).......... 131

hook-gill-net.................. 124

Sacramento................... 58

Salted .........................185-186

Sebago ....................... 57

Smoked..................... 183

Salmon-clubs.

OBJECTS.

Salmon-tacklo

Salmon-weirs (Upper Columbia River) ....

Salmonidæ......................... 57

Salmo salar........................ 57

Salt ................................. 178

(accessory) ....................... 169

Salted anchovies....................... 186

baits (prepared) ................. 137

beef........................... 184

bluefish ....................... 185

buffalo meat..................... 184

cod............................ 185

deer......................... 184

elk.......................... 184

foods........................... 184

halibut....................... 185

herring......................... 186

mackerel........................ 185

mullets........................ 185

pompano....................... 185

pork ......................... 184

reindeer...................... 184

salmon .......................... 185, 186

Spanish mackerel ............... 185

sword-fish..................... 185

tongues of buffalo, deer, horse...... 184

turtle .......................... 185

Salting, Fish ........................ 169

Salt-mills, Models of (Cape Cod)........... 169

Salts, Specimens of, used in preserving fish. $\quad 169$

Salve-bug ........................ 231

Salvelinus fontinalis ................. $\quad 58$

oquassa ..................... 58

Samia cecropia, Silk of ................... 196

polyphemus, Silk of .............. 196

Samples gill-netting..................... 125

of netting hung to lines......... 130

Sand-bath drying and steaming. .......... 172

Sand Dab........................... $\quad 27$

Eel ........................... 31

Shark .......................... 68

Sarda pelamys........................ 40

Sardine-factory, Model of................ 169

Sardines, American...................... 186

preserved, Foreign exports of..... 283

preserved, Imports of. .......... $\quad 279$

Russian ..................... 186

Sargassum Agardianum .................. 269

bacciferum................. 269

dentifolium .................... 269

vulgare.................... 269

Sargus Holbrookii..................... ๑46

Sarothrodus capistratus................. 38

maculocinctus.............. 39

Sance, Anchory...................... 186

Sausages ........................... 183

Sausages, Bologna, Imports of............ 276

Ssusage-skins, Imports of ............... 276

Saw-fish............................ 67

Sawing............................... 173

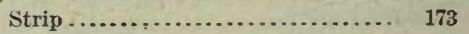

Says' Striped Squirrel.................. 15

Scabbard-fish......................... 39

Scad, Big-eyed........................ 41

Mackerel...................... 42 
Page.

Scales ...............................166, 205

of fishes......................... 205

Weighing....................... 92

Sealed fish, Leather prepared from ......... \&16

Scaling apparatus ...................... 169

Sealing-knives........................ 74

Scalp-locks, Human................... 217

Scalops aquaticus..................... 13

argentatus...................... $\cdot 13$

Scalps of animals....................... 217

Scapanus Breweri ....................... 14

Townsendii .................... 14

Scaphyrhynchops platyrhynchus.......... 65

Scarida............................ 35

Scarus Albildgaardii................... 35 radians.......................... 36 squalidus ....................... 35

Secnt-decoys ........................ 138

Schizymenia (?) coccinea.................. 268 edulis.................... 268

Schooner-rigged fishing-vessels........... 149

Sciaenidre .......................... 44

Sciaenops ocellatus .................... 45

Seiurus hudsonius ...................... 14

Seinaia furcellata...................... $\quad 267$

Scincus officinalis of Egypt ............. $\quad 230$

Seiuridre........................... 14

Sciurus Abertii...................... 14 carolinensis ................... 14 cinereus...................... 14 fiossor .......................... 14

Scollops, Canned....................... 187

Scomberesocidæ...................... 54

Scomberesox scutellatus................. 55

Scomber scombrus..................... 40

Scombridæ ........................ 40

Scoop, Dory ......................... 160

Sounding-machine............... 80

Scooping-instruments ................... $\quad 79$

Scoops ................................ 70

Hand ...................... 79

Scorpænidæ ......................... 34

Sconring ............................170-172

Scragg Whale......................... 12

Scraper, Oyster........................ 129

Scrapers, Deck ........................ 160

and parers, Skin ............... 76

Pile ........................ 79

Scraping ..............................171-172

Scraping-tools .........................177-178

Seraps, Fish ......................... 187

Oil-factory..................... 187

Screens, Flannel ...................... 246

Sculpin.

Greenland

Pigmy..........................

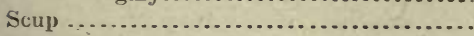

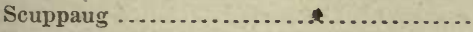

Scyunnidæ............................

Scytosiphon lomentarius.................

Sea Bass...............................

Bat...................................

Dog

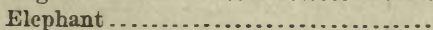

Herring
Sea Lion ........................ Page.

lion, Throat of .................... 215

Otter........................... 4, 191

Raven............................. 34

Robin, Broad-fingered ............... 33

Robin, Striped.................... $\quad 33$

Shad ............................. 60

Snail ............................... 33

Sea-boats ............................147-148

Sea-elephant oil ....................... 223

Sea-horse ........................... 25

Sea-lion leather....................... 208

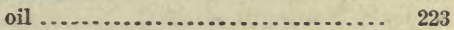

Sea-snails ............................ 251

for bait .................... 251

for cameo .................... 252

for food..................... 251

for dye-stuffs ................. $\quad 252$

Injurious ..................... $\quad 253$

for pearl-shell, \&c............. 251

for porcelain stock............ 252

used in Indian trade ........... 252

Sea-urchins.......................... 262

Seal, Banded ......................... 6, 192

Common ......................... 5

Elephant........................ 6

Fur ........................ 5, 191

Gray ........................... 6

hair (Phoca vitulina) ................ 192

Harbor ......................... 5

Harp ............................. 6, 192

Hood or Bladder-nose ............... 192

Hooded........................... 6

lances......................... 78

leather.......................... 208

Leopard......................... 6

oil............................... 233

oil, Imports of....................296-297

Pacific Hair ...................... $\quad 192$

seines.......................... 126

Sinews of ........................ 215

Square-flipper.................... 6, 192

Walrus, leather from pharynx of...... 215

Sealing-wax, Imports of ................. 299

Sebago Salmon ....................... 57

Sebastes marinus...................... 34

viviparus....................... 34

Scbastodes pancipinis ...................

Seliastomus auriculatus ................. $\quad 35$

elongatus.................... 35

fasciatus.................... 35

rosaceus.................... 34

Sebastosomus melanops .................. 35

Secretion of skunk.................... 229

Seine, Boat .......................... 146

floats of wood, cork, glass, and rubber. 117

lines ........................ 97

reels ........................... 119

Seines.............................. 126-128

Baird collecting ................ 127

Bait ........................... 127

Bass.......................... 127

Bluefish ....................... 127

Capelin........................ 127

Cod............................ 127 


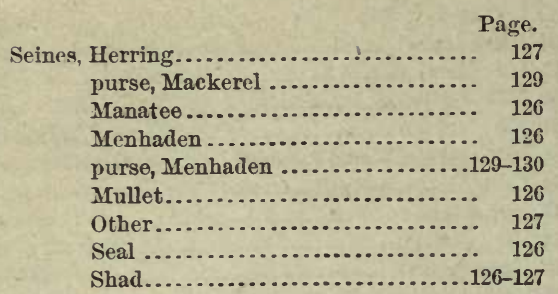

Seine-windlasses 119

Selachostomi.

Self-sealing jars used in collecting.

Sepia, from Sepia officinalis. .

Sergeant Major.

Seriola Lalandii . . . . . . . . . . . . . . . . . . . .

Serranidæ

Set-nets ...

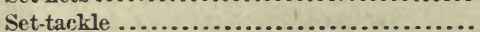

Set-traps ..............................

Sewellel

Shad.

Bermuda .......................... gill-nets used in Sonthern rivers ...... Mad.

Ohio Gizzard .......................

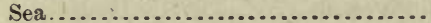

seines .126-127

slides

tackle.

Winter.

"Shad-waiter".

Shaft-ganges -.....

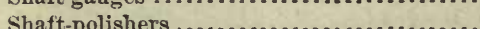

Shanty, Brook (Furman's) ............. 246

Shaping ..........................170-172

Shark, $\Delta$ twood's...................... 67

Blue.............................

Blue-headed.

Dusky ...........................

gear.............................

Hammer-head .....................

leather ...........................

Mackerel..........................

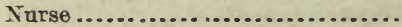

Porbeagle ........................

Sand $\ldots \ldots \ldots \ldots \ldots \ldots \ldots \ldots \ldots \ldots \ldots$

Shovel-head

Sleeper.

Sleeper, Jaws of (Somniosa brevipinna)

Spiny.

Spotted-fin

Teeth of.

Tiger.

Shark-liver oil.

Shark's vertebræ

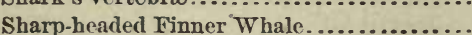

Sharpies ..............................

Sharp-nosed skate.

$$
\text { Sturgeon }
$$

Sharpeners, Arrow-head................... Shavings used in case-hardening gun-barrels, \&c.

Shawls, Imports of $\ldots . \ldots \ldots \ldots \ldots \ldots \ldots . . . . . .$.

Sheaf-traps.

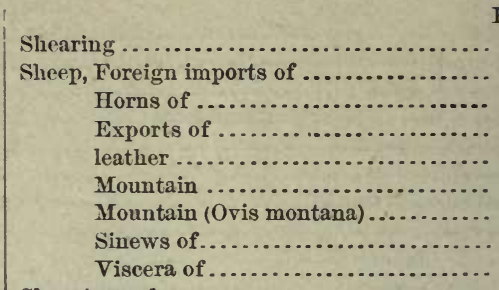

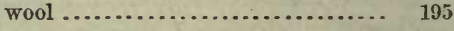

Sheepshead (on skin) .................... 218

Shell ................................. 200

Cameo.......................... 206

Conch (Strombus gigas) ............ 206

Consumption of.................... 290

of eggs........................ 228

fish, Bivalve...................... 253

helmet (Cassis rufa, \&c.) ............ 206

of king-crab.................... 207

Shells of Buccinum .................... 206

of Buccinum undatum ........... 206

of Busycon................... 206

Calcined......................207, 231

of Cypraea .................... 207

of Dentalium.................... 206

of Dolium ...................... 206

Ear (Haliotidæ) ................ 206

Egg ......................... 230

of Fusus ....................... 206

Implements used for..............206-207

of Haliotis .................... 200

of Mactra ...................... 206

of Mercenaria .................. 206

of Mercenaria violacea ............ 206

of Murex........................ 206

of nautilus and argonaut ......... 206

of Oliva ....................... 207

of Pecten ...................... 206

of Phasinella..................... 207

of Purpura lapillns............... 206

of Rotella ........................ 207

of Strombus.................... 206

of Sycotypus.................. 206

of Tridacua ..................... 206

of Triton ....................... 206

of Turritella .................... 207

Shells, Top (Turbinidæ) ................ 206

Shells, Tower (Trochidæ) ................ 206

Shell, Tortoise (Ersemochelys squamata) ... 205

Shell-work, Composition .................. 207

Shelter ............................ 162

Shiells ............................. 165

Shiner............................. 62

Shoemakers' wax-ends, Bristles for......... 219

Shoes, Snow ........................ 142

Shooters, Pea........................ 89

Short Big-eye........................ 52

Cyprinodon ..................... 56

hand-gear...................... 90

Harvest-fish ..................... 44

Pompano....................... 42

Short-nosed Gar Pike................... 64

Sturgeon .................. 64

Short-tailed Prairie Dog................ $\quad 16$ 
Shot

Page.

Shot-holders

94-95

Shot-measures

shot, Slung

Shoulder-slings

Shovel-head Shark.

Shovel-nosed Sturgeon

Shovels.

Clam

Oyster.

Showt'l.

Sibbaldins borealis

" $\quad$ sulfureus ....................

Sight-decoys

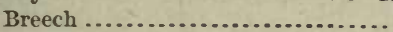

Globe...........................

Graduating.......................

Muzzlo.

Peep

Plain

Slit.

Telescope .......................

Silk from byssus of Pinna, Preparation of. .

dress-goods, Imports of

of ena or arindy

Exports of raw.

hosiery, Imports of .................

Imports of raw ................... 288-289

of insects, Prepared from.............. 196

of insects, Preparation of.............. 171

of joree (Bombyx religiosa)........... 196

lines............................. 114

and its manufactures, Consumption of. 289

manufactures, Foreign exports of......

other manufactures of, Imports of ......

other manufactures, Imports of, by

countries ..........................

of moonga............................

of exotic moths......................

raw, Net imports of ..................

of Samia cecropia ....................

of Samia polyphemus.................

of silk-worms, Preparation of .........

of spiclers ...........................

of tussah (Bombyx pernyi) .............

of common silk-worm (Bombyx mori)..

Silk-worm gut ........................

Silk-worm-gut snoods ...................

Silk-worm, Propagation of.................

Siluridæ

Silver Fox $(\nabla u l p e s$ alopex argentatus ........

Fish............................

Gar-fish . ... .....................

Hake ... ........................

Squeteague.

Silver-sides.

Silvery Mole .

Simple bow

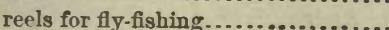

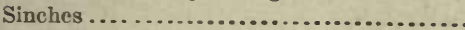

Sinews of buffalo.........................

of deer

Gelatines from ...................

Bull. N. M. No. 14
Page.

Sinews of goat....................... 215

of seal......................... 215

of sheep...................... 215

of walrus........................ 215

Single-groore fish-ways .................. 247

Single-pointed hooks ................. $80-81$

Sinkers............................... 117

Sinkers, Net......................... 117

Siphons, Dried ....................... 184

Siphon-tubes .......................... $24 \pi$

Sirenia ............................... 9

Sisco gill-nets ......................... 123

Size ................................ 221

Sizes and glues (sce under 24) ............ 200

Skate, Clear-nosed ..................... 66

Eglantine ....................... 66

Long-nosed ..................... 67

Sharp-nosed.................... 67

Spring .......................... 66

Spotted ......................... 66

Skate-liver oil ......................... 227

Skates .............................. 142

Skeletons, \&c....................... 300

Apparatus for making .......... 177

Skiffs, Hunting ........................ 147

Skimmer-nets ........................ 246

Skin and its appendages, Proparation of ...171-173

boats ............................ 146

of Eels......................... 231

Skins, Apparatus for making and mounting. $\quad 178$ of eel (Anguilla vulgaris)........... 216

Skin scrapers and parers ................ $\quad 76$

Skipper............................. 55

Skunk, Alaska Sable................. 190

Common ....................... 4

Hair of, for brushes ..............217-219

Little Striped ................... 4

Mexican........................ 4

Porpoise ......................... 10

Secretion of ..................... 229

Striped (Spilogale zorilla) ........ 190

White-backed ..................... 4

Slack's cans........................... 247

Slate, Polishing of...................... 207

Sledges, Deer ........................ 142

Dog......................... 142

Steeple Shark ......................... 69

Slides, Fish ......................... 131

Shad .......................... 131

Slime-fish ........................... $\quad 70$

Slings .............................. 167

for arms ........................ 95

Bird (used by Eskimos)............ 86

India-rubber..................... 89

Saddle......................... 95

Shoulder...................... 95

and spears thrown by straps........ 88

Slit-sights ........................... 93

Slivering-knives..................... $74-75$

Slugs, Dried (Limax, \&c)................. 184

Slung-shot ......................... 71

stones ........................ 71

weights ........................ 71

Small-footed Pouched Gopher ............ 17 
Page.

Small-mouthed Black Bass ................ Small-spotted Dolphin....................

'Smelt'

Smelt, \&c ...........................

Smoked alewives

halibut

herring

mullet ..........................

oulachan........................

salmon .........................

sturgeon

white-fish

Smoke-drying apparatus .................

Smoking-out apparatus.

Smoke-houses, Halibut.

(n...........

(n)..................

Smooth-back Flounder ...................

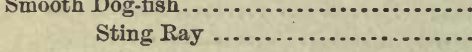

Smudges

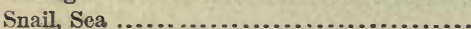

Snails, Sea............................

Snake-fish

Snake-tongs ..........................

Snapper

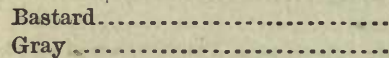

Gulf ..........................

Mangrove

Red.

Red-bellied

Star

Snapping Tortoise

Snares

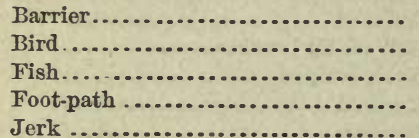

Snipe Eel...............................

Snoods ...............................

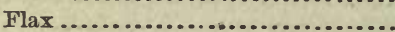

Silkwrorm-gut

Wire

Snow-goggles .......................... 166

probes ......................... 78

shoes .......................... 142

Snuffing Pig............................ 11

Soaking ............................. 172

Soap, Arsenical ....................... 178

common, Imports of................ 297

Exports of ..................... 297

fancy, Imports of.................. 297

Soaps, Consumption of ...................296-297

from fish-oil ................... 227

Imports of .....................296-297

from mammal oil ................. 225

Soft parts of other invertebrates, Prepara. tion of.

225

Soft-shell Turtle.........................

Sole ................................ 26, 28

American........................ $\quad 26$

Spotted California ................. 28
Solea vulgaris $\quad$ Page.

Soleidæ

Soluble glass, Infusorial earth for ........ 208

Somniosus microcephalus ............... 69

Sonora Ground Squirrel ................. 16

Sound-decoys......................... 138

Sounding-machine, Bull-dog............ 86

Scoop ................. 80

Sounds.............................. 185

of cod and bake, Isinglass from...221-222

Southern Barracuda...................... 53

Flounder..................... 27

King-fish ................... 25

Sowerby's Whale...................... 12

Spades, Blubber-mincing............... $\quad 77$

Cutting..................... 76-77

Head ........................ 77

Half-round .................... 77

Throat ....................... 77

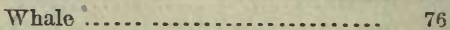

Whaleman's boat................ 78

Wide.......................... $7 \overline{7}$

Spanish Lady-fish ...................... $\quad 36$

Mackerel ...................... 41

mackerel, Salted................ 185

Porgy ....................... 36

Spargis coriacea....................... 22

Sparidæ............................ 46

Sparus aculealus ..................... 46

Spat, Stools for receiving natural and artif. cial.

Spawning-race (A insworth) 248

Spawning salmon, Strait-jacket for ......... 245

Spawning-screen roller (Collins).......... 245

Spawning-vat (Bond) .................. 245

Spear-falls ............................. 135

Spear-fish Sucker.................... 52

Spears, Barbed ....................... 82

Detachable-head ................. 83-85

Eel......................... 82

Fixed-head ..................... 82

Harpoon................. .85

Hurled ...................... 88

Oulachan ...................... 82

(with straps) .................. 88

(with throwing-sticks) .......... 88

Thrusting..................... 78

Species of fish exhibited in the Allegretti and

Banta refrigerators in Government build-

ing, May 10 to November 10 ...........179-181

Specimens of American commercial sponges 223

Apparatus for collecting ........ 233

of Cowry (Cypreæ moneta) ...... 206

of Mediterranean sponges....... 223

of natural history, Consumption of ....................... 299 of plants for food ............. 248

Speckled Grant........................ 47

Sperm Whale ........................ 12

Ambergris of............... 228

jaw-bone ..................199-200

Teeth of (Physeter macrocephalus) .................... 198

Sperm-oil ........................... 225 


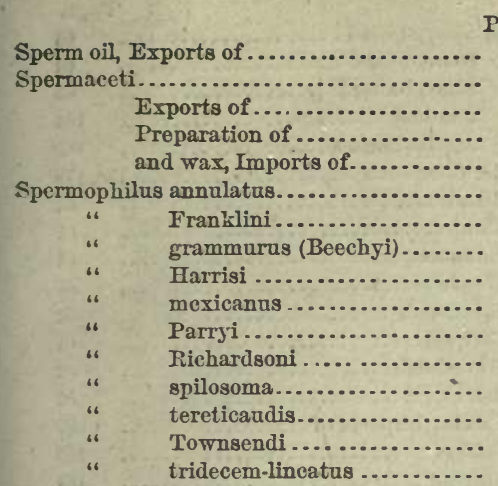

Sphacelaria fusca..........................

radicans .....................

Sphærozyga Carmichaelii................... Sphargididæo

Sphyræna borealis.

“ picuda .......................

Sphyrænid (?) .........................

Sphyrna zygæna..........................

Sphyrnidæ

Splced lampreys

$$
\text { menhaden }
$$

Spiders, Silk of web

Spike-fish

Spike-tail ............................

Spikes, Marline ..........................161-162

Spiiliards ............................. 97

Spilogale zorilla...................... 4

Spinacidær........................... 69

Spined Dog-fish ..................... 69

Spines of echinoides................... 208

Spinners ............................ 138

Spinning ...........................170-171

Spring Shark........................ 70

Skate......................... 66

Spiral fish-ways ....................... 243

Spirulina tenuissima.................. 271

Sponge, Burnt........................ 231

"Sponge-tents" ........................ 223

Sponge-tongs.......................... 86

Sponges, \&c............................263-264

American commercial, Specimens of...........................

Imports of........................

Mediterranean, Specimens of ......

Propagation of..................

Spongeo-piline.

Spoon-baits, plain and fluted .................101-102

Spoons, trolling........................ 138

Spools................................ 119

Splanchno-skeleton of feræ, Parts of ........ 199

Splitting-knives.................... 72-73, 75

Spot............................... 45

Yellow-tailed.................... 45

Spotted Bass .............................. 45

Cero .......................... 41

Codling .........................

File-fish

Sole, California
Spotted Skate ...................... Page.

Squeteague................... 44

Turbot....................... 27

Wry-mouth .................... 31

Spotted-fin Shark..................... 68

Spreaders.......................... 117

Spring bird-nets...................... 135

Spring-door traps..................... 134

Springes ........................... 134

Spring-gans ............................ 89, 135

Spring-hooks ........................ 135

Springs, Stomach .................... 136

Spring-weirs (St. Lawrence).............. 130

Spurs :........................... 142

Spyridia aculeata..................... 268

filamentosa.................. 268

Squali.............................. 67

Squalus americanns ................... 69

Square-flipper Seal (Erignathus barbatus).. 6, 192

Squatina Dumerili...................... 67

Squatinidø......................... 67

Squeteague........................... 44

(Sciænidæ), Isinglass from ..... 222

Silver.................... 44

Spotted ................... 44

Squids ............................. 137

and cuttles ...................... 251

and jigs ......................... 82,138

Squirrel ............................ 44, 50

California Gray ................. 14, 15

Fox........................ 14

Gray........................ 14

Hair of . . . . . . . . . . . . . . . $217-218$

Harris' Ground................. 15

Mexican Ground ................ 15

Missouri Striped ................ 15

Prairie....................... $\quad 15$

Red........................... 14

Red-mouth................... 47

Ringed Ground ................. 16

Round-tailed Ground............. $\quad 15$

Townsend's Ground............... 16

Tuft-eared .................... 14

Say's Striped..................... 15

Sonora Ground................ 16

Squirrel Hake........................ $\quad 29$

Squirrel-hooks....................... 80

Squirrels, Jerked, and other small mammals. $\quad 182$

Stands, Fish Commission................ 178

Stapling............................ $\quad 170$

Star-fish ........................... 262

Stargazer, Naked ....................... 32

Star-nosed Molo........................ 14

Star Snapper........................ 50

Stationary covers ...................... 141

Staves ................................ 142

Steamers............................149-150

Steaming............................. 173

Stearine, Imports of .................... 297

Stearines, Manufactured ................. 225

"Steel traps" ............................134-135

Stenogramma interrupta ................. 267

Stenotomus argyrops ................... 46

Step fish-wars....................... 242

Stephanolepis setifer.................. 25 
Steps, by arrangement of rock and bowlders Stichæidæ

Stichæus punctatus.

Stickle-back, Four-spined.

$$
\text { New York }
$$

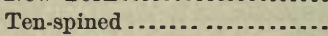

Sticks, Curved

Glue (for fastening arrow-head) .....

Hurled .

Pushing .........................

Straight. ........................

Throw

Still-hunting, Lanterns for

Sting Ray

\section{California.}

River.

Smooth

Stizostedium canadense

$$
\text { vitrenm }
$$

Stock-makers' bone, Mannfactno of .....

Stomach-springs.

Stone-headed clubs.......................

Stone knive

Stones (thrown by hand) Slung

Stool .

pigeons ..............................

Stools for ojster spat....................

Stopping

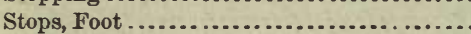

Storage-tank, museum, Agassiz model......

Storer's File-fish

"Stosh".

Stoves...................................

Stowing and cutting in

Straight knives.

sticks ........................

Strait-jacket for spawning salmon..........

Straps, Cap.............................

Stretchers .............................

for kyak-line

"Stretching-irons".

Striped Bass.

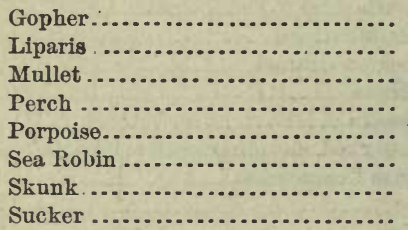

Sucker ...........................

Striped-bass tackle.

Strip-sawing..

(n).......

Strychnine.

Stuffed birds ................................

Stuffing, Hair for ......................... sponge, Preparation of

Page.

Stuffings, Manufacture of .

Preparation of ..................

Sturgeon, Lake.......................... Long-nosed .................... leather....................... oil.

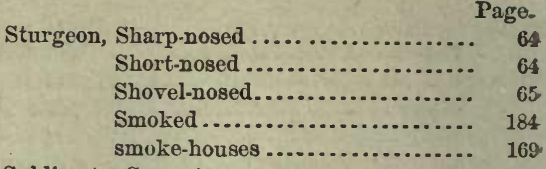

Sublimate, Corrsive ...................136, 178

Sucker, Black ......................... 61

Chub........................... 61

Common.......................... 61

Goode's ....................... 61

Spear-fish ....................... 52

Striped........................ 61

Sword-fish..................... 52

Sucker-fish ............................ 52

Sugar of milk, Imports of ................ 299

Suit, Oil-skin ........................... 165

Suits, Hunting ........................ 164

Water-proof ..................... 164

Sulphur-bottom Whale................ 13

Sulphuring ............................ 172

Sun-drying apparatus ................... 168

Sun-fish ............................ 23, 48 oil ............................ 226

Supplies, Commissary ..................... 162-164

Surface lines ......................... 97

tow-nets ....................... 129

Surf-tackle for throwing and hauling ...... $\quad 96$

Surgical apparatus ..................... 223 instruments, Manufacture of ..... 173

Suspender-maker's bone, Manufacture of ... 173

Swabs............................. 93

Swab-tangles .......................... 87

Swallows, esculent, Nests of .............. 187

Swan (Cygnus americanus) .............. 195 .

Quills of ......................... 219

Swans, Down of ........................ 220

Swell-fish ............................ 24

Swimming-birds, Decoy (carved in wood)... 139

Swingle-tail ............................ 68

Swivels ..........................117, 121-122

Sword-fish ........................... 39

Bone of...................... 200

Salted ...................... 185

Sucker ...................... 52

Sycotypus, Shells of .................... 206

Synaphobranchidæ.................... 63

Synaphobranchus pinnatus............... 63

Synentognathi ........................ 54

Syngnathidæ ......................... 25 .

Syngnathus Peckianus ................... 25

Synodontidæ .......................... 56

Synodus fotens ........................ 56 .

Syringe.guns ............................ 90

Syringes .......................... 247

for injecting ................. 176 .

T.

Table-furniture........................ 163

Tables............................. 169

Tackle, Angling ...................... 95

Bass .......................... 96

Black-bass ................... 95 .

Bluefish........................ 96 .

Drailing....................... 96

Fly-fishing $\ldots \ldots \ldots \ldots \ldots \ldots \ldots \ldots . .65$ 
Page.

Tackle for fishing below surface........... 96-97

Pasque and Cuttyhunk bass........

Red-fish........................

Salmon

Shad

Set............................

Striped-bass ...................

Surf.......................... 96

for surface-fishing............... $95-96$

Tide-drailing ................... 96

Trolling ......................... 96

Trout ...........................

Whiffing

Tæniotoca lateralis

Tail, Golden

Tail, Hair.

Tailor Herring

Tail-spike

Tallow, Exports of Imports of

6

Te

Talpidæ 296-297

Tame decos-brants decoy-ducks ........................

Tamias quadrivitattus.

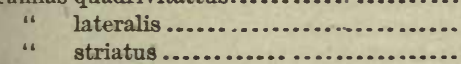

Tangles

\begin{tabular}{|c|c|}
\hline Dredge & \\
\hline Harrow ... & \\
\hline & 87 \\
\hline $\begin{array}{l}\text { Oyster-bed (see under B 12). } \\
\text { Swab. }\end{array}$ & 243 \\
\hline Swab .............................. & 87 \\
\hline 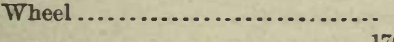 & 87 \\
\hline
\end{tabular}

Tanks.............................176, 246 with Freiburg aerating apparatus ... $\quad 247$ (Stone's)

Tanners' refuse, Gelatines from .............

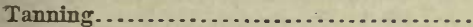
leather, Processes of..............

Taonia Schrœderi

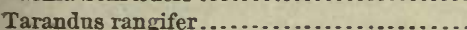
rangifer (grœnlandicus) ..........

Tarpum ..............................

Tar and sweet-oil ointments ..............

Tatusia septem-cinctns.................

Tautog...

Tantoga onitis.

Tantogolabrus adspersus..................

Tawing or oil-dressing leather, Process of ..

Tawny Parrot-fish .

Taxidea americana .......................

Taxidermist's tools for stuffing .............

Taxidermy

Teazling

Teeth of alligator........................

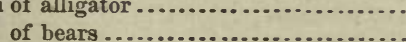

of $\operatorname{dog}$............................

of foxes ...........................

of peccaries ........................

of peccary (Dicotyles sp.) ...........

point clubs .........................

of shark.

of sperm-whale (Physeter macrocepl-. alus)

of wolres.

Teleocephali

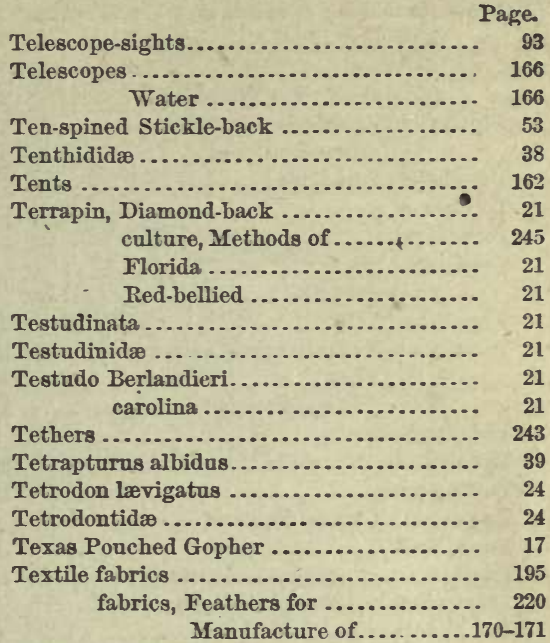

Thalarctos maritimus .................. 5

Thalassochelys caonana................. 22

The chase and the fisheries.............. 71

The Fish Commissioner, Reports of .......233-237

Thief, Water........................ 161

Thomomys clusius .................... 17

talpoides ..................... 17

Thread-fish.......................... 42

Thresher............................. 68

Throating-knives ...................... 74

Throat of sea-lion ..................... 215

Throat-spades......................... 77

Throw-sticks........................ 87

Thrusting prods....................... $\quad 78$

spears....................... 78

Thumb, American Miller's............... $\quad 34$

Thyınallus tricolor ..................... 58

Tide-drailing tackle .................... 96

Tiger shark .......................... 69

Tinder .............................. 230

Tin ressels .......................... 246

Tipe, Rabbit........................ 131

Toad-fish ............................. 32

Tobacco-pipe Fish...................... 54

Tobacco, snuff, used as preservatives ....... 178

Toggle-pin ........................... 161

Tolling-baits ........................ 137

Tom Cod ........................... 29

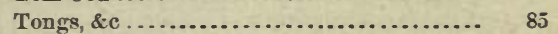

Coral......................... 86

Oyster ........................ 85

Snake......................... 86

Sponge......................... 86

(two handles) ................... 85

Tongues, Cod's ......................... 185

Salted, of buffalo, deer, horse..... 184

salted, Imports of .............. 276

Tools ................................. 162, 178

Articulating ................... 177

Carving.......................... 168

Flaying.......................... 178

Hand .......................... 71 
Tools for making artificial flies........... 138

Modeling ...................... 177

Scraping......................177-178

for stafting, Taxidermists' ......... 178

Tooth-picks, Quills used in making ......... 219

Manufacture of............. 172

Top-shells (Turbinidæ) ................ 206

Torches ............................ 167

Torpedinidæ.

Torpedo occidentalis

Torpedoes ............................

Tortoise-shell (Eretmochelys squamata) ....

Cat........................

Preparation of

Tortoise, Snapping

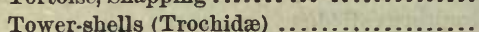

Towing-nets.

Townsend's Ground Squirrel

Tows, Bull .

Traces.

Trachurops crumenophthalmas ...........

Trachynotus carolinus.

ovatus ......................

Trade, Ice (accessory)

Trailing-nets

Transportation, Methods of.....

Transporting apparatus of..............142-102

eggs, Apparatus for.......... 247

fish, Apparatus for .......... 247

Trap, bird, French ................... 135

Trap gill-nets ........................ 123

Trap-funnel .......................... 132

Trappings........................... 166

Horse $\ldots \ldots \ldots \ldots \ldots \ldots \ldots \ldots \ldots .142$

Traps .............................. 131

Barrel ......................... 131

Bass ........................ 133

Bowl......................... 134

Box........................... 133

Clutching..................... 134

Cob-house bird.................. 134

Cross-bow....................... 135

Crushing...................... 135

Door.........................133-134

Double box ..................... 133

Eel .......................... 131

Fall......................... 135

Figure-four................... 135

with hanging doors ............... 133

Harpoon ....................... 135

Jawed .............................134, 135

Labyrinth .................... 131-133

Missile......................... 135

Mole............................. 135

mole, Jar....................... 131

Newhouse.....................134, 135

Noose.......................... 134

Pen .......................... 131

Piercing ....................... 135

Pocket......................... 131

Set......................... 97

Sheaf .......................... 134

Sieve (for birds) ............... 130

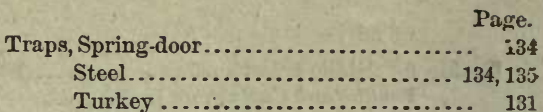

Trawl-line rollers...................... 119

Tub for (see under Trawl.)

Trawl-lines......................... 97

Trawl, Beam ........................ 129

(Trawl, Otter) ......................... 129

Trawls ............................. 129

Trays ............................ 246

Case of (Clark's) .................. 247

Troughs with sieve-bottom ......... 245

Vertical wire-cloth.................. 246

"Treading hurdles" .................... 171

Trehala............................ 229

Trichechidæ........................ 9

Trichechus manatus................... 9

Trichiuridæ....................... 39

Trichiurus lepturus ................... 39

Trichodiodon pilosus .................... 24

Tridacua, Shells of... ................. 206

Triglidæ............................ $\quad 33$

Trimmings, Leather .................... 214

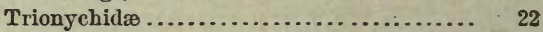

Tripe, Imports of ..................... 276

Triple-tail Flasher..................... 51

Tripods and stand, Camera with model ..... 178

Tripoli; \&c ........................ 207

Trisotropis undulosus.................. 5

Triton, Shells of .................... 206

Trolling-spoons...................... 138

Trolling-tackle ........................ 96

Trombidium dy $\theta . \ldots \ldots \ldots \ldots \ldots \ldots \ldots \ldots . .229$

Troughs.............................. 245

Brackett's..................... 245

Clark's ........................ 245

Gravel-bottomed ............... 245

Plain.......................... 245

with sieve-bottom trays ......... $\quad 245$

or tables (for picking eggs) ........ 246

Williamson's ................... 545

Trout, Artificial flies for................ 102-114

Brook .......................... 58

Lake ........................... 58

Namaycush.................... 58

Ocean .......................... 186

Oquassa ......................... 58

River........................ 58

Rock ......................... 35

tackle ......................... 95

Trowbridge's Hare .................... 20

Trowels .............................. 79

Trumpet-fish .......................... 54

Trunk-fish ......................... 24

Trygon centrura ...................... 66

" hastata....................... 66

" Sabina ....................... 66

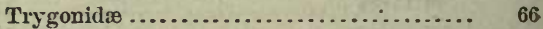

Trying .................................. 174

Try-pots............................ 175

Tubes, Siphon ....................... 247

Tub, line, Whaleman's.................. 119

Tubs, \&c ............................. 169

Tubs, Bait, vats, \&c.................... 170

Tub, Mincing........................ 174 
Page.

Tub for traw-line (seo Trawl)

Tuft-eared Squirrel

Tulé grass, Raft of

Tunny

$$
\text { Little. }
$$

Turbinaria vulgaris

Turbot

Greenland

Spotted

Turkey, Canued

$$
\text { Quills of }
$$$$
\text { traps. }
$$

Turning

Turritella, Shells of.

Tursiops erebennas

$$
\text { Gillii . }
$$

Turtle, Alligator.

Canined

Green.

Hawksbill

Leatherback

Loggerhead

oil

Pacific, Green

Pacific, Hawksbill .................

Salted .

Soft-shell .........................

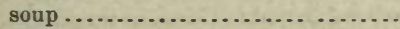

Tusks of mammoth elephant (Elephas primigenius)

of walrus...........................

Tassah, Silk of (Bombyx pernyi) ............

Twine, Netting.

Twisted lines.

Twisting-rods

\section{U.}

Udotea conglutinata

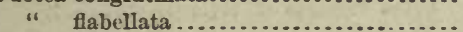

Ulva fasciata.

" latissima

Umbrella-makers' bone, Manufacture of...

Umiaks

Unarmed clubs

Uranidea riscosa .........................

Cranoscopidø...........................

Urgulata

Urophycis regius

Ursidæ

Ursus americanus

" horribilis

\section{$\nabla$.}

Vaccine limph.

Vat, Spawning (Bond)

Vats

Boiling.

Holton's

Macerating ............................

Roth's

Vaucheria piloboloides ......................

Vehicles.

Venison, Dried and smoked. Imports of
Veb, Spider

Weequashing or fireseshing, Lanterns for.-.

Weighing-scales

Weights (dropped).

Hurled .........................

Slung

Weirs, Bar....

.................. 134

Eel, with leaders................. 132

or pounds...................... 132

River, with pockets ............... 131

Salmon (Upper Columbia River).... 131

Spring (St. Lawrence) ............. 130

West coast ojsters...................... 254

Western Argentine ..................... 56
Page.
200

246

149

246

95

184

195

193

215

215 


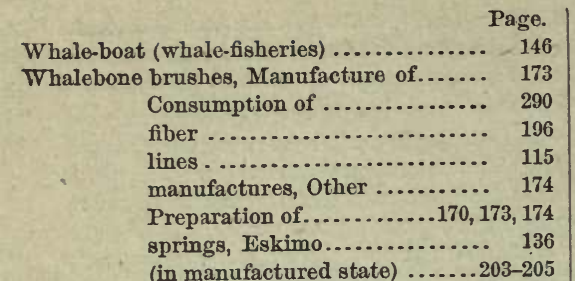

Whale, Bottle-head..................... 12

Bowhead ....................... 13

Finback..................... 12-13

and fish oil, Exports and imports of. 296-297

Gräsö ......................... 12

Gray ......................... 12

Humpback .....................

Pacific Right....................

Porpoise Sperm

Right.

Scragg

Sharp-headed Finner ..............

Sowerby's.

Sperm.

Sulphur-bottom

White.

Whale-lances.

Whale-line drag. ..........................

Whale-oil, Instruments and appliances of rendering.................174-175

Retraction of (with models) ....174-175

Whale-spades ........................ 76

Whalemen's boat-spades................. 78

tub, line.................. $\quad 119$

boat-hatchets.............. 16

boat-knives ................. 73

hooks................... 81

Whaling-guns ........................ 91

Whales, \&c., Oil from .....................223-224

Wheelbarrows for bait-clams............. 138

Wheel-tangles........................ 87

Whiffing-tackle ....................... 96

Whip-makers' stock and whips, Manufac-

ture of

Whips, $\operatorname{Dog} \ldots \ldots \ldots \ldots \ldots \ldots \ldots \ldots \ldots \ldots \ldots . . . \ldots 126$

Whistles, Dog.......................136-137

White-backed Skunk.

White Bass

Bear...........................

Cat..............................

coral (Oculina) ......................

Hare ...........................

Mullet.

Pearl

Perch ...........................

Rabbit

Whale.

White-fish.

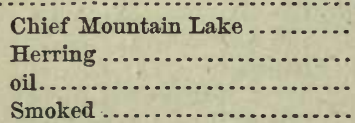

White-footed.Mouse

White-haired Porcupine

White-headed Grampus

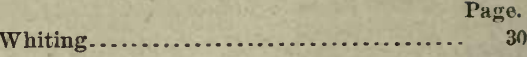

Lake....................... 57

Wholesale destruction apparatus......... 136

Wide spades ......................... 77

Wigs, Hair used for ................... 217

Williamson's tronghs.................. 245

Winches, Gunwale ..................... 119

Winders ............................. 119

Wind-gauges ......................... 93

Windlasses, Seine .................... 119

Window and plate glass, Infusorial earths

for .............................. 208

Wings of beetles....................... 208

Wing-shell, Byssus of (Pinna nobilis) ...... 196

Winter Flounder..................... $\quad 26$

Shad ........................... 60

Wire frames .......................... 178

snoods........................... 116

Wolf (Canis lupus) .................... 188

Claws of......................... 203

Wolf-fish............................ 32

Wolverine (Gulo luscus) .............. 4, 190

Wolves, Teeth of...................... 197

Woodchuck or Siffleur (Arctomys monax)...16, 197

Wooden canoes........................ 143 frames....................... 178

Woodland Caribou (Tarandus rangifer) .... 8, 193

Wood-powder .......................... 91

Wood Rat............................ 18

Wool as medium for pigments............ 219

cloths, Preparation of ............ 170

Exports of. ..................287-288, 301

flocking.........................219, 228

Goat's (for wigs, \&c.) ...............195, 217

and hair........................ 217

Imports of ................... 285-286, 301 and hair of mammals, Preparation of. 170

pelts, Imports of ................. $\quad 290$

Sheep's......................... 195

Sheep's (on skin) ................ 218

work .......................... 172

Woolen carpets, Exports of ................ 287-288

Woorara........................... 136

Work, Results of, United States Fish Com-

mission.............................233-241

Worms ................................... 184

Dried......................... 184

Intestinal..................... 244

and leeches, injurious............. 262

and leeches, useful................ 262

Chemical products from ........... 231

Propagation of ................. 248

"Worms" and other loading tools......... 93

Worsted cloths, Weaving................ 170

Wrangelia penicillata ................... 268

Wrist-guards........................ 166

Wry-mouth, Spotted .................. 31

Wurdemannia cetacea.................. 267

$\mathbf{X}$

Xiphias glndius $\ldots \ldots \ldots \ldots \ldots \ldots \ldots \ldots \ldots . . . \ldots \ldots$

Xiphidiontidr......................... 32

Xiphiidæ.......................... 39 


\section{INDEX OF OBJECTS.}

Y.

Yak (Poëphagus grunniens) Yellow Crevallé

Gopher ......

Mackerel

Perch................................

Pike-perch

Tail Yellow-finned Grunt

Yellow-footed Marmot.

Yellow-haired Porcupine
Page. 195

, 41

16

42

49

49

45

47

16

18
Yellow-tailed Spot

$\mathbf{z}$.

Zalophus Gilliespii

Ziphiidæ

Ziphiinæ

Zoarces anguillaris .........................

Zonichthys fasciatus

Zonich flava 269

" lobata............................. 269

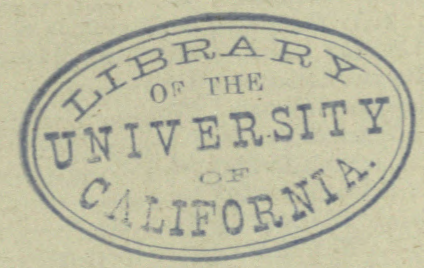





\section{INDEX OF CONTRIBUTORS.}

$A$

Abbott, Dr. C. C

Abert, Lieutenant J. T

Academy of Natural Sciences

Adam, J. G

Adams, A. Leith ..................... 236

Agassiz, Alexander, 24, 26, 28, 41, 44, 45, 47, 50

$53,55,59,60,62,63,65,66,70$

Aiken, C. E $.4,7,14$

Alaska Commercial Company ......5-6, 126, 160, 191

Allegretti Refrigerator Company.......... 168

Allen, J. \& S . . ....................... 115

Almy, D. D........................ 244

Alvord, F. W....................... 146

American Needle and Fish-Hook Company..97, 98,

99,100

American Net and Twine Company...125, 126, 127,

$128,130,131,132,133$

American Sardine Company.............. 186

American Whip Company................203, 205

A mes, James T . . . ..............252, 256, 257, 258

Ams, Max..........................186, 187

Anderson, Dr. C. L ..................... 265

Armitage, J ........................... 7

Army Medical Museum ................. 182

Atkins, C. G..........57, 235, 237, 239, 241, 242, 243,

$244,245,247,248$

Atwood, Capt. N.E...........223, 224, 226, 227, 251

Averill, H.......................... 265

B.

Babcock, Dr. W.H.................. 226

Baird, S. F.......11, 14, 17, 21, 22, 24, 27, 28, 40, 64, 66 , $68,78,83,84,86,131,132,144,190,192,200,235$

Baker, Captain

Banta, G. A ..... 168

Barber, J. C........................... 8

Barfurth, D .......................... 240

Barnston, J .......................... 8

Barnum, P.T......................... 9

Barry, Rev. A. C........................ 14

Bartlett, J. H., \& Sons ............100, 197, 198, 200

Batchelder, J. H..................... 265

Batty, J. H....................... 14, 16

Baxter, Robert D ...................... 161

Bean, Tarleton H. . .................. 22, 26

Beckwith, E. G..................... 15

Beebe, Mrs........................... 265

Bersley, Thomas ...................... 259

Bell, J. G.........................14, 18, 19

Bergland, Lieutenant. .................. $\quad 10$

Biddle, Henry J ...................... 7

Bischoff, F ........................15, 16, 263

Bishop, $\mathrm{N}$. H ........................145, 148

Black ford, E. G..........253, 254, 255, 257, 259, 260

Boardman, G. A ...................... 7,14

Booth, Miss M. A ...................... 265

Boston Society Natural History .......... 263
Page.

Botteni, Mr...........................

Bowchon, Brandley ..................... 236

Boughter, Dr.J.T................... 94

Bowman, J.S....................... 9

Bossange, Gustave .................. 205, 228

Brackett, A. G...................... 8, 16

Brackett, E. A....................... 246

Bradford \& Anthony....77, 80, 82, 96, 97, 99, 102,114, $116,120,128,138,258$

Brand, C. C......................... 91

Bransford, Dr ........................ 260

Brasher, P........................139, 140, 148

Breck, A. J......................... 238

Brewer, James D.................... 241, 242

Broeck, Axel ........................... 239

Brown, Theo .......................... 154

Brown, William H. ................... 220, 221

British Museum ........................ 23

Buck, Jonathan ........................ 165

Buel, J. T............................. 101

Burling, William ........................ 144

Burritt, Francis .....................139, 140

Burt, Hannah, Mrs .................... 75

C.

Carley, B. J. M .............256, 257, 259, 261, 264

Castine Packing Company................ 261

Central Wharf Company ...75, 100, 101, 117, 121, 122,

165

Chapman, W. D....................... 121

Chapman, W.D., \& Son .................. 102

Chase, W. H............138, 146, 147, 148, 149, 150, 169

Chester, Capt. H. C ............146, 149, 153, 197, 244

Chicago Feather-Duster Company......... 220

Churchill, General S ..................... 7

Clark, Frank N........................ 246

Clark, George ........................ 57

Clark, James B ....................... 154

Clark, J. H . . .................... 86, 198, 260

Clark, N. W ........................ 246

Clark \& Sneider......................... 90

Claughton, H. O ..................... 132

Cleveland, D.......................... 265

Cleveland, Capt. Josiah..................132, 133

Cleveland, William.................... 147

Coleman, Walter......................151, 153

Coleman, Walter, \& Sons................ 150

Coleman, William .................... 155

Colt's Fire-Arms Manufacturing Company - 90, 91

Collins, Jos. W.....................30,56, 65, 97

Collins, W. O......................... 9

Colyer, Vincent..........83, 88, 89, 94, 159, 162, 208

Commagére, F. T...................... 198

Carter, J. F ........................ 165

Carroll, Michael....................... 192

Castine Packing Company ............... 164

Cape Ann Isinglass and Glue Company ...221, 222 
Page.
Page

Conrad, T. A .......................253, 256, 25

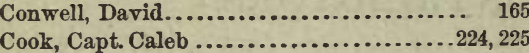

Cook, Coleman ....................... 100

Cook, Elisha ..........................99, 100

Cook, E. H ......................... 200

Cook, Lemuel .................82, 96, 100, 101, 121

Cook, W. H ........................ 73, 78

Cooper, J. G........................ 19

Copley, C .........................23, 31

Couch, Lient. D. N ...............19, 94, 147, 166

Cones, Dr. Elliott ...........7, 9, 16, 19, 56, 57, 141

Cragin \& Sheldon ...................... 147

Crandall, C. H.......................... 197

Crandall, L., \& Co..................... 115

Crittenden, A. R ......75, 79, 82, 83, 97, 99, 101, 117, $122,149,165,200,256,264$

Crnok, E. R......................... 165

Crooks, N........................... 149

Culbertson, T ......................... 9, 19

Curley, Rev. James..................84, 89, 116

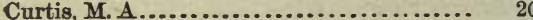

Cusick, Lieutenant..................... 201

\section{D.}

Dall, W. H ..6, 8, 10, 12, 76, 81, 83, 85, 88, 89, 92, 94, 99, $100,115,131,132,134,142,144,160,166,192$, $197,201,214,216,251,252,254,256,257,265$

Daniell, W. C........................ 236

Darrow Manufacturirig Company ......... 209

Davis, Mrs. A.S...................... 265

Davis, Benjamin ...................... 256

Davis, Edward ........................ 75

Dawson, J. W .......................... 253

De Frece, A. B., \& Co ...............251, 252, 258

Delano, George, \& Co ................223, 224, 225

Delong \& Sons ........................159, 160

Dewey ............................... 259

Dixon, Robert........................ 253

"Dobsis Club," through Judge H. Jewell...

Dodd, P. W

Dodge, R. T

Downes, A.

Downes, John

Dove, Mrs.

Dresser, J. W

Drexler, C .

Duncklee, H. L ...................... 162

$\ldots \ldots \ldots \ldots \ldots \ldots \ldots \ldots \ldots \ldots \ldots \ldots \ldots \ldots \ldots \ldots \ldots \ldots \ldots, 13,14,16$

E.

Eagle Preserted Fish .................. 186

Eaton, Prof. D. C...................... 265

Edmunds, M. C....................... 237

Edwards, V. N ...10, 11, 23, 24, 27, 30, 41, 46, 51, 58, 63, $66,68,69,258,260$

Elliott, H. W ....5, 84, 100, 116, 117, 129, 135, 144, 191, 197,208

Elwell, Samuel, jr....73, 75, 78, 119, 122, 151, 153, 156, $160,165,258$

Emory, Maj. W. H.

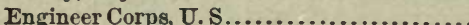

Eskimo Joe

Eureka Manufacturing Company
Evans, John ........................

Exall, G........................... 13

Exploring Expedition U.S.....22, 99, 100, 166, 252

F.

Fadderdin, A....................... 238

Fairie, James........................ 20

Falls, A. J ......................... 14

Farlow, W. G....................234, 239, 265

Feiner, Lieut. John ................... 83

Fenner, C. A......................... 145

Ferguson, S. W ....................... 22

Ferguson, Maj. T. B..............79, 148, 149, 246

Fish Commission, U.S.. 5, 10, 13, 23, 37, 39, 49, 51, 70,

$74,75,78,80,82,83,87,91,119,128,129,133,141$,

$149,151,160,166,169,178,198,246,247,260,264$

Fisher, Capt. Jos..................... 198

Fitzhugh, D. H ...................... 140

Fitzhugh, D. L..................... 147

Forest and Stream Publishing Company.. 74, 80, 93,

$96,101,102,114,118,121,127,129,138,140,163,167$

Foster, George B .........72, 73, 75, 117, 121, 122, 200

Freeman, Sanford...............100, 162, 199, 200

French, E. B..................123, 124, 126, 127

Fuller, C. B........................253, 256

Fuley, Col. J........................... 9

\section{G.}

Gabb, W. M........................

Gardiner, Capt. J. W. T.................128, 189

Gaudet, C. P......................... 99

Ghisslin, Dr. J. T....................... 216

Gibbes, Dr. L. R.................... 265

Gibbs, Theo ....4, 83, 85, 99, 100, 115, 128, 130, 143, 202

Gifford, John D....................... 148

Gifford, Thomas J ...................... 101

Gilbert, E. F........................... 258

Gilliss, J. M......................... 9

Gill, Theo...................... 32, 235, 238

Gilpin, Dr. Bernard................... 7

Goodale, S. L......................... 187

Goode, 1. C..........................21, 144

Goode, G. Brown....17, 19, 21, 24, 25, 38, 42, 44, 46, 48, $50,51,53,55,60,62,70,79,80,101,119,129$,

$132,133,160,161,210,215,216,258,273$

Gordon, W. Alex..................... 254

Government of Newfoundland.............. 6

Governor of Newfoundland ............. 192

Gower, F. A ........................ 157

Grant, M. W.................77, 80, 81, 82, 99, 160

Graves, F. D....................... 157

Graves, Frederick.................... 147

Graves, J. L........................... 120

Green, G. L......................... 132

Green, Seth ........................ 246

Grieve, Walter \& Co .................... 223

Griffin Bro ........................... 183.

Grower, F. A........................ 159

Gulf Porpoise Fishing Company ........... 214

Gunnison, Captain...................197, 215

H.

Haime, Jules ........................ 236

Haldeman, Prof. S. S................... $\varepsilon$

Hall, Capt. C. F .............78, 83, 84, 100, 201, 268

Hall, Rev. E........................ 


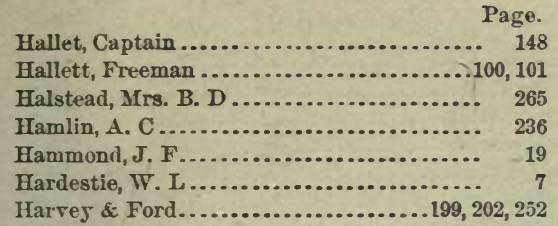

Harvey \& Holden ...................... 254

Harrey, Rev. M ....................... 6

Haven, Williams \& Co.................. 223

Hay, E. B. \& F......................... 77

Hay, Col. H. D ........................ 50

Hayden, F. V ...................7, 8, 17, 19, 190

Hayes, Dr ........................6, 8, 84, 144

Heath, L. J ........................... 264

Heerman, Dr. A. L .................... 14, 15

Hegeman Portable Folding Boat Company.. 145

Hemphill, H ......251, 254, 256, 257, 260, 262, 265, 271

Henderson, J. H....................203, 210, 216

Henman, $J$............................ 14

Henning, Geo. C....................... 164

Henry, T. C ......................... 16

Herpich, C. A., \& Co......................188, 195

Herron, E ............................. 133, 134

Hesbolt, Wm. H.................77, 81, 82, 161

Hessel, Rudolph........................ 235, 237

Hessel, Rufus ........................ 241

Hewitt, H. N . . . . . . . . . . . . . . . . . . 55

Higgins \& Gifford .....................130, 146, 159

Hitchcock, G. N....................... 22

Hoff, Dr. A. H...................94, 99, 201

Hooper \& Coit ........................... 186

Hooper, F. W .......................... 265

Hooper, Wm. E., \& Sons ..............126, 130, 133

Horan, Henry . ....................133, 134, 135

Horton, Dr. S. M . . . ................86, 95, 210

Hough, R. B ....................... 94

House, $J . C . . . \ldots \ldots \ldots \ldots \ldots \ldots \ldots \ldots \ldots .246$

Howard, W. A........................ 88

Howard, W.H ......................... 85

Howland, Capt. L ................73, 76, 146, 175

Hoy, Dr. P. R. . . . . . . . . . . . . . . . . . . . 14-15

Hoyt Bros........................252, 253, 263

Hunt, A. G ......................... 258

Hurlbert, Capt. R. H ................. 30,82

Hutchinson, S. G., \& Co................ 211

Hutchinson, Kohl \& Co ................ 131

\section{I.}

Ingalls, J. F.

Isaacs \& Co 263,264

\section{J.}

Jack, Mr.

James, William H...................... 101

Janney, $N$

Jeffries, Dr

Jenkins, A. R.

$.32,36,39$

Jenks, J. W. P.

14

Jewell, Judge

18

Jewett, Col. E..........................197, 258

Jones, J. M.

Jones, Stratton

John Russell Cutlery Company.
Johnson, F. H

Page.

27, 29, 32, 34

Johnson, Capt. G. A..................... 52

Johnson \& Young................129, 132, 148, 169

Jouy, P. Louis......................... 139

Judge, Edwin M ..................... 137

Judge, Edwin W...................... 93

$\mathbf{K}$

Keergaard, F. C., \& Co.................. 205

Kelsey \& Hosmer ....................... 169

Kemp, Day \& Co.....................185, 259, 261

Kennedy, Andrew.................119, 161, 198

Kennerly, Dr................ 9, 19, 143, 190, 193

Kennicott, R..........18, 99, 100, 128, 134, 138, 190 ,

$193,210,215$

Kennard, Charles W ................... 205

Kent, D. F ............................ 13

Kimball, Dr. J. P........................ 201

C. J. King ............................. 18

King, Lieut. F. W ..................... 85

King, W. S ........................... 15

Kirby, Humphrey S................81, 82, 151

Kirkby, W. W ...................... 193

Kirtland, Dr. J. P..................... 14

Knox, S. R ............................ 39

Kohn, Gustav.............21, 253, 256, 258, 260, 261

Kopsch, H........................... 239

Krider, John .........................139, 140

Kartz, T. D ......................... 253

L.

Laing, J. M.......................... 23

Lanman, Charles ....................... 235

Le Paiz, William N.....................221, 222

Laszlo, C. H ............................. 20

Latham, James H ..................43, 132, 141

Lawler, Joseph ........................149, 175

Lawrence, Alfred........................ 10

Lawrence, $A$ mos ..................... 260

Leavenworth, J. H..................... 8

Leib, T.............................. 32

Leonard, H. L ....................... 121

Lesley, A. M........................... 168

Leslie, C. C .............................. 48

Levey, J. A.......................... 263

Lewis, George H ........................ 99

Lewis, William ........................ 91

Lincoln, George F ......................201, 202

Liverpool Free Public Musenm ............ 29, 30

Lnce, Jason ............................. 67

Lyman, Theodore...................... 237 .

Ljman, William ........................ 156

M.

Macy, E. B. \& F ................76, 78, 81, 151, 161

Mahrenholz ..........................208, 216

Mann, John H ........................ 101

Mansfield, G. H. \& Co.......................114, 115

Marcy, Captain....................... 19

Martin, Capt. S. J....................... 89

Marvin Bros. \& Bartlett................ 226, 227

Massachusetts Arms Company........90, 91, 92, 93

Mather, Fred........................30, 58, 246

Mathew, G. F ........................ 253

Mathews, Dr. W..................... 146 
Page.

McCaleb, Vinald........................ ${ }_{78}$

McClain, A. O ...................... 246

MrCurdy, Alex....72, 75, 80, 96, 101, 122, 160, 161, 162

McDonald, M...................... 242

McDonald, Allan L...................119, 155

McFadden, F.......................... 150

McFadyn, Malcolm ......................149, 198

MacFarlane, R......6, 16, 75, 83, 86, 99, 100, 115, 126, $127,136,138,144,162,166,202,203,208,215$

McFarlane, R R

McKennie, M

McLanghlin, W. B.................... 132

McLeod, Rev. R. R...................... 8

Maryland Academy of Science ............ 69

Meek, F. B ............................252, 259

Megler, J. G., \& Co.....................185, 186

Meigs, General M. C...................... 86

Merchant, Philip ....................71, 97, 122

Merrill, Dr. J. C . ..................... 5, 21

Middleton, Carman \& Co ................ 28

Miles, George W ........86, 94, 217, 218, 219, 227, 232

Miller, Dr. C. A........................ 257

Milner, J. W......21, 45, 59, 60, 65, 122, 138, 149, 169,

$235,237,239,241,260$

Minor, Dr. T. T..

$4,85,88,89,97,116,126,214$

Möllhansen, H. B

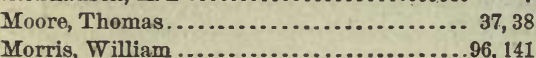

Moses, William B ....................... 264

Mott, Mrs. C. E ...................205, 220, 258

Munn, J., \& Co.......................... 223

Museum of Comparative Zoology ........ 55, 66

N.

Nason, J.P

101

National Institution.....................4, 5, 12

National Preserving Company............. 182

Nelson, E. W ............................ 240

Newberry, J.S......................4, 9, 19, 20

Nichols, J. A........................ 94, 95

Nickerson, George Y..10, 83, 84, 117, 197, 198, 199, 205

Niles, Kossuth ....................... 254

Norman, A.J ......................... 94

Norris, Thaddeus .......................120, 121

North American Oil Company.............224, 227

North Pacific Exploring Expedition.......127, 128

New York Condensed Milk Company ......182, 229

0.

Odell, D. T

Onion, J.S

P.

Packard, A. S., jr

Page, G. S.

Palmer, E. $9,20,57,63,83,86,87,93,95,99$, $141,143,159,166,182,184,195,200$, $209,210,215,224,256,265$

Palmer, Joseph

Palmer, W

Parker Brothers

Parker, C. H.

Parmalee, D. D

Parsons, Jos., jr.................82, 101, 117, 165

Payne, N. H 131,200
Page.

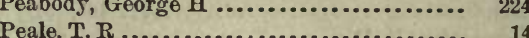

Pelton, W.T ......................... 258

Peterson, N. C......................... 257

Peyrer, Carl ........................... $\quad 239$

Pollard, R. O ........................ 18

Poole \& Hunt........................... 176

Pope, Capt. J ........................... 4

Portland Packing Company........163, 164, 185, 186,

259,261

Potter, T. \& E. H......................... 260

Potter, Charles T ......................44, 133

Potter, Weeks .......................... 228

Powell, Maj. J. W.....80, 86, 95, 122, 130, 142, 202, 209

Powell, $\mathrm{S} \ldots \ldots \ldots \ldots \ldots \ldots \ldots \ldots \ldots \ldots \ldots . . . \ldots 42,46,59$

Powers, Stephen.85, 96, 99, 122, 126, 128, 134, 139, 144,

$183,194,202,230,262$

Phinney, Elihu....................... 57

Platt, W. B........................... 16

Prior, William, jr., \& Co ................. 30

Putnam, F. W........................ 26

\section{R.}

Randolph, Septimia, Miss................ 243

Remington \& Sons, E.................. 90, 93

Renfrew, G. R .................191, 192, 194, 199

Renfrew, G. R., \& Co....10, 69, 188, 189, 190, 193, 208 ,

$210,214,215,223,229$

Rich, Newell B .................... 100, 117

Richard, J. H....................... 45, 62

Richardson, James ................255, 256, 264

Ridgway, Robert ................13, 15, 22, 139

Ring, Lieut. F. M . .................99-101, 143, 189

Rodgers, Herbert M., \& Co .............. 226

Rodgers, Capt. John ..................83, 85, 88

Rogers, C. W......................... 247

Ross, B. R ......4, 15, 86, 90, 99, 115, 142, 143, 189, 190

Ross \& Hardesty ....................... 18

Ross, R. R .......................... 166

Ross, W. A., \& Bro .......................264, 265

Roth, John ......................... 245

Rothe, J. T............................ 242

Rothrock, J.T.......................94, 215

Rowe, Capt. E. L ................72, 74, 101, 121

S.

Salisbury, $\mathrm{S}$.......................... 85

Samnels, E ......................... 19, 20

Sars, Prof. C. 0 ......................... 239

Sartorins, Dr .......................... 128

Sawyer, E. A ........................ 153

Scammon, Capt. C. M...........6, $8,10,11,13,202$

Schacht \& Bros ....................183, 186, 222, 227

Schaffer, E ......................... 229

Schayer Bros............................ 216

Schott, Dr............................ 259

Schultz, Alexander.................. 238

Schumacher, Paul ....................... 252

Scott, A. R., \& Co....................... 145

Scoville \& Johnson ........................ 163

Scupham, J.R....................... 260

Sevey, J. A.......................203, 204, 205

Sibley.............................. 44

Simpson, Capt. J. H..................16, 19, 139

Shaffer, D. H ........................ 257

Shardlow, Joseph.................197, 198, 199 


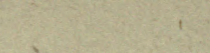

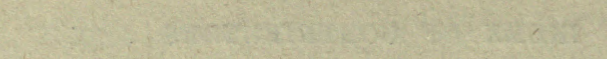

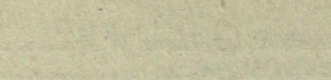


Department of the Interior:

U. S. NATIONAL MUSEUM.

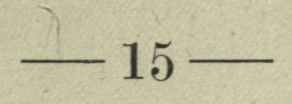

\title{
BULLETIN
}

OF THE

\section{UNITED STATES NATIONAL MUSEUM.}

\author{
No. 15 .
}

PUBLISHED UNDER THE DIRECTION OF THE SMITHSONIAN INSTITUTION

WA SHINGTON:

GOVERNMENT PRINTING OFFIOE.

1879 . 


\section{A D VERTISEMENT.}

This work is the fifteeenth of a series of papers intended to illustrate the collections of Natural History and Ethnology belonging to the United States, and constituting the National Museum, of which the Smithsonian Institution was placed in charge by the act of Congress of August 10, 1846.

It has been prepared at the request of the Institution, and printed by authority of the honorable Secretary of the Interior.

\section{SPENCER F. BAIRD,} Secretary of the Smithsonian Institution.

SMrthisonian Institution,

Washington, April 15, 1879. 


\section{CONTRIBUTIONS}

TU THE

\section{NATURAL HISTORY}

\section{ARCTIC AMERICA,}

MADE IN CONNECTION WITH

THE H0WGATE POLAR EXPEDITION, 1877-78,

$$
\text { BY }
$$

\section{LUDWIG KUMLIEN,}

NATURALIST OF THE EXPEDITION.

WASHINGTON :

GOVERNMENT PRINTING OFFIOE. 1879 . 


\section{TABLE OF CONTENTS.}

Introduction. By LuDwrg KuMLIEN ........................ 5

EthNoLOGY. By LUDWIG KUMIIEN ............................ 11

Mammals. By Ludwig Kumlien .............................. 47

Birds. By Ludwig Kumuden ................................. $\quad 69$

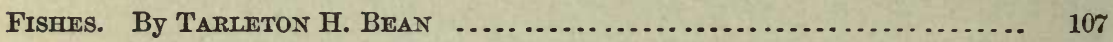

Crustace. By S. I. Smith .................................... 139

ANNELIDES. BУ A. E. VERRHL................................. 141

Mollusks. By W. H. DaLL................................ 145

Molluscond. By A. E. VerrmL ............................. 147

RADiates. By A. E. VerriLL................................. 151

Insects: Diurnal Lepidoptera. By W. H. Edwards ................. 155

Insects: Hymenoptera, Nocturnal Lepidoptera, Diptera, Coleoptera,

NeUroptera, aNd AraChNida. By S. H. SCUdDER AND others.......... 159 Plants. By Asa Gray ....................................... 163

Lichens. By EdWARd TuCKERMAN ............................ 167

ALGA. By W. G. FARLOW ...................................... 169

MINERALS. By F. M ENDLICH ................................. 171 


\section{INTRODUCTION.}

\section{Bx Ludwig KumLien.}

The vessel conveying the Howgate preliminary Polar Expedition was the "Florence" of New London, Conn. She is a fore-and-aft schooner of fifty-six tons, and was built in Wells, Me., in 1851, for mackerel, and was subsequently used as a sealer in the southern seas.

Although a staunch and fair sea-boat, as far as her diminutive dimensions could allow, a less suitable vessel for the purpose could hardly have been chosen. To say that she was too small for thorough scientific work covers the ground, but quite fails to convey a proper idea of what drawbacks all scientific labors were subjected to on this account.

The schooner was fitted out in New London, and sailed on the morning of August 3, 1877, unfortunately at least two months later than desirable, had her object been purely scientific.

The primary object of the expedition, by Captain Howgate's order, was to collect material, skins, skin clothing, dogs, sledges, and Eskimo, for the use of a future colony on the shores of Lady Franklin Bay. The secondary object of the expedition was scientific work; and, thirdly, whaling was to be one feature of the cruise.

So far as the primary object is concerned, the expedition was as successful as could be expected: a large amount of skins was collected and made into clothing; the services of sixteen Eskimo were secured, who were willing to accompany the coming steamer northward; nearly thirty dogs were secured, and several good sledges, with an ample supply of whales' jaw-bones for shoeing the runners for some years.

As has been stated by Captain Howgate, "the peculiar nature of her mission lifted the enterprise from the level of an ordinary whaling royage to the higher plane of geographical discovery." Every one, except the scientists, had a "lay" in the voyage; and, so far as the crew was concerned, their "lay" was to be their only remuneration; as a uatural consequence, whaling became the primary object to them. The expedition was also fairly successful in this direction.

As far as the scientific work is concerned, some valuable work was 
done, especially by Mr. Sherman in meteorology; still, nearly all the scientific labors were prosecuted under very discouraging conditions. The lack of any place to work in save a snow-hut on shore, in which neither sufficient light nor heat was to be obtained, rendered it very difficult to prosecute certain investigations. The late date of sailing and the early departure from the winter harbor deprived us of the most interesting and profitable season for scientific research.

The outward trip presented nothing to break the usual monotony of a long sailing voyage: fogs and light winds prevailed till off the north of Resolution Island, when a strong northeast gale was encountered. The schooner was heavily loaded and poorly trimmed, so that some uneasiness for safety was naturally felt, especially as we were close inshore among icebergs and rocks, in a thick fog and on an unknown coast. One boat was stove in and a few barrels of provisions washed from deck; otherwise no damage was done.

The first anchorage was in Niantilic Harbor, on the western shore of Cumberland Sound, September 12, forty-one days after. leaving New London. Some natives were secured here, to assist in whaling; and all their worldly possessions, including dogs, sledges, boats, \&c., were taken upon the decks, and the schooner weighed anchor and started for the opposite side of the sound. A short stay was made at the Kikkerton Islands, and on the 6th of October the Florence dropped anchor in the little harbor of Annanactook, at about lat. $67^{\circ} \mathrm{N}$., long. $68^{\circ} 50^{\prime} \mathrm{W}$.

Arrangements were at once begun by Mr. Sherman and myself to erect a shelter that would serve for an observatory and general working-place; an eminence on a little rocky islet in the harbor was chosen for this purpose, and our tent raised. Instrument-shelters were erected, and the meteorological work began in earnest.

As soon as the snow became compact enough, we engaged the Eskimo to build a snow-house for us, in which our tent served as a lining.

It was often difficult to get from the ship to the shore on account of the ice or unusually stormy weather.

We improved every opportunity at this late day to secure specimens; but as the ice soon formed over the sound, our endeavors were far from satisfactory, especially as we were unable to procure a boat with any degree of certainty, as they had to be kept in readiness for whaling.

The winter was spent by Mr. Sherman in taking observations; and to judge from the manner in which he assiduously applied himself to his work, night and day, through all weathers and under the most discour. 
aging circumstances, the results of his labors cannot fail to be very valuable and do justice to Mr. Sherman's indefatigable perseverance and scholarly attainments. We spent our time in procuring and taking care of specimens, as well as taking our "watch" at the observatory when not too busy with other work.

From our peculiar surroundings and the isolation to which we were necessarily subjected, we lost much of our wonted enthusiasm during the long, dreary winter, and found rest only in continual work.

The spring of 1878 was stormy and backward, and the prevalence of southerly gales kept the ice closely packed about us till the fore part of July. This treacherous condition of the ice, and early departure from the winter harbor, robbed us of any opportunity to prosecute extended researches, except in the immediate vicinity of the harbor; thus the most valuable season was completely lost to us.

The Florence left her winter harbor on the 6th of July, Laving all the collected material for the future Arctic colony stored in her hold, and sixteen Eskimo and twenty-eight dogs on deck.

In the unnecessary haste of departure many valuable preparations had to be abandoned for want of time to get them aboard, as well as space to store them.

Short stoppages were made at two or three points on the outward passage from the sound, and on the 19th of July we rounded Cape Mercy and took the pack-ice of Davis Straits. It was on this day that the schooner received the bump which afterwards cost us so much trouble and anxiety.

The pack proved to be quite loose, but extensive, and the floes rather small, but the winds were invariably contrary and quite stiff; and the almost impenetrable fog made the navigation dangerous and tedrous; we were often obliged to tie up to a floe and await a "lead" in the pack, or the lifting of the murky fog veil.

Godhavn Harbor, Disko Island, Greenland, was reached on the 31st of July. We were all in high spirits in anticipation of news from home, if not the presence of the expected expedition steamer. Of course the double disappointment was sorely felt.

The advent of the expedition was awaited with great anxiety, more especially as no word had been sent us via Denmark, so we naturally concluded the vessel or vessels were belated from some cause; but when three weeks of waiting brought us no news, the anchor was weighed, and the Florence put on a course for Cumberland once more, to returu the Eskimo and their effects to their country. 
During our sojourn in Godhaven every attention was paid to our comfort by the highly enlightened Danes resident there, and these three short weeks were to us the most enjoyable of the whole cruise. We pursued our scientific labors here as elsewhere when an anchorage was made, but in this case had the misfortune of being on an old and wellrorked field.

On the evening of the $22 \mathrm{~d}$ of August, the Florence left Godhaven and sped on a southerly course, with a fair north wind; this soon veered to ESE. and blew a gale. For four days the schooner lay hove-to under close-reefed storm-sail, while the hatches were battened down over the poor natives in the hold. We were entirely at the mercy of the elements and drifted with the sea. An impenetrable fog, with heavy rain, continued the whole time, and we were drifting among hundreds of icebergs, but luckily did not come in contact with any.

On the 27th land was sighted on our starbeard quarter, and subsequent observations proved us to be in the mouth of Exeter Sound! We had drifted completely across Davis Straits.

On the 31st of August we again anchored at Niantilic, and most will. ingly landed our passengers and all their goods, and enjoyed a few days of rest,-rest from the howling of wind and wave and from the far less musical squall of the juvenile Eskimo and the fiendish howls of the dogs. We could also enjoy the luxury of clean and free decks once more, the first time since June.

On the 12th of September willing hands headed the Florence for home, very glad indeed to near the long-wished-for shores of the United States, hut little dreaming of the terrible passage we were about to encounter.

We started with a fair free wind, which soon increased to a gale; and as the cize of the schooner forbid scudding with more than a whole sail breeze, we were obliged to heave-to for two days. From this time till the 26th, when we made St. John's, Newfoundland, we were in a continual gale nearly the whole time. At the commencement of each storm, and they followed one another in quick succession, we made a fair run for a few hours, and then hove-to till the storm abated.

On the 11th of October, the Florence left St. John's, Newfoundland, for the United States. The passage was one of unusually severe weather: one storm followed an other before the sea could go down, and to add to our misery the schooner sprang a leak on the evening of the 19th, while carrying a good deal of canvas, with stiff free wind and heavy 
head sea. We were somewhere off Sable Island at the time, our exact bearings being unknown to us. The pumps were kept manned, and diligent search made for the leak, but without avail. Such a condition of affairs cast a shadow of gloom over the whole company: our provisions gone, ship leaking badly, and not knowing at what moment it might gain on us; the elements in all their fury let loose, so that we were entirely in their power, drifting helplessly at the mercy of raging billows, without knowledge of our position within a hundred miles. On the evening of October 25, Thatcher's Island lights were sighted, and the Florence seemed to have become animated, for with a fair NW. breeze she sped like a thing of life, and before midnight we saw the reflected. lights of Boston on the clouds, and the next morning dropped anchor in Provincetown, Mass. Provisions were secured and some slight repairs made.

On the morning of October 30, the Florence lay alongside of the same dock she had left fifteen months before, every man brought back alive and wen. 



\section{ETHNOLOGY.}

\section{FRAGMENTARY NOTES ON THE ESKIMO OF CUMBERLAND SOUND.}

By Ludwig Kumlies.

The Cumberland Straits, Sound, Gulf, or Inlet, extends from abont lat. $65^{\circ} \mathrm{N}$. to lat. $67^{\circ}+\mathrm{N}$. It is the Cumberland Straits of Baffin, its original discoverer at the end of the sixteenth century; the Hogarth Sound of Captain Penny, who rediscovered it in 1839; and the Northumberland Inlet of Captain Wareham in $\mathbf{1 8 4 1 .}$

During the last quarter century it has often been visited by Scotch and American whalemen, ships frequently wintering on the southwest. eru shores.

It is at present unknown if it be a sound or gulf; it is generally considered as a gulf, but some Eskimo say that the Kingwah Fjord, one of the arms extending to the NE., opens into a large expanse of water, to them unknown. Icebergs are also sometimes found in this fjord that, from their positions, seem to have come from the northward, and not from the south.

The eastern shore of this sound forms the western boundary of that portion of Cumberland Island which lies between its waters and Davis Straits, and known as the Penny Peninsula.

In about lat. $66^{\circ} \mathrm{N}$. the Kingnite Fjord extends from the sound in an ENE. direction, and nearly joins Exeter Sound from Davis Straits; they are separated only by a portage of a few miles. The Cumberland Eskimo make frequent excursions to the eastern shore via these fjords, but seem to have extended their migrations but a short distance northward, finding Cumberland Sound more to their tastes.

The width of Cumberland Sound opposite Niantilic is about thirty miles, possibly its widest part. It is indented by numerous and large fjords, few, if any, of them having been explored ; many islands are scattered along both shores, and in some instances form quite considerable groups.

The present Eskimo are few in numbers. We would estimate the entire population, men, women, and children, on both sides of the sound, 
from Cape Mercy on the east to Nugumente on the west, not to exceed four hundred individuals. It is certain that within the last thirty yecrs the mortality has been very great among them; even the whalemen remark an astonishing diminution in their numbers at the present day, as compared with twenty years ago.

Numerous traditions exist among them of the time when they warred with other tribes, and old men, now living, have pointed ont to us islands that were once the scene of hattles, where the besieged party was starved into submission by their enemies. Áccording to the usual story, the hurling of stones was one of the most effective and common modes of warfare; this was especially the case when one party could get upon a ledge above the other. At the present day they are peaceful and quiet, have no recognized leader, and no desire to fight, even if their numbers would permit of it.

As the story goes, the present population were the victors in those fights, and took posmession of the country they now inhabit. Some say they came from the northwest, and found another tribe, which they overcame and drove away. Their stories on this subject vary, and sometimes with this unusually interesting tradition, as well as many others, they get events of a very recent date hopelessly mixed up with the rest; and it is no unusual instance to find that some whaler with a good imagination has supplied and restored lost portions of the narrative, to their entire satisfaction; but these restorations are chiefly remarkable for their utter disregard of truth or possibility.

The following tradition is a translation from one of the most reliable natives we became acquainted with:

"A long time ago (tichemaniadlo)* other Innuits (Eskimo) were found here; they were called "Tunak"; $\dagger$ they were very strong, ver'y large, and had short legs and large arms; they had very wide chests. Their clothes were made of bear skins, and their knives from walrus tusks. Did not use bows and arrows, but only the harpoon-lance; they harpooned the reindeer in the water, from their kyacks; used very large kyacks. The

\footnotetext{
*Here arises a great difficulty: tichemani signifies a long time, i.e., it may be any-
} where from a week to a year; tichemaniadlo is a very much louger period, generally conceded to antedate the advent of the whites; at least, this was the only example we could bring up which they could understand, except their own ages, which we could ascertain with less certainty. When a very long period (as in this case) is represented. as having intervened, they repeat tichemaniadlo several times, but how much time is added by each repetition we are unable to say.

+Variously pronounced, "Tunare," "Tumnuk," or "Tunnak." 
Tunuks made houses out of stone.* They were able to lift large stones. We were afraid of them; we fought with them and killed them. They (the Tunuks) came in the first place from Greenland.t The women made clothes from their own hair. They had no dogs at that time, but they made sledges and harnesses, and finally (witchou = by and by) put the harnesses on three rocks, one white, one red, and one black; they then called, and when they looked they found the stones had been transformed into dogs. After a time they got plenty dogs; then they went about more. 'The present Eskimo could not understand their language. They lived to a greatage (E. tukercouk nami=did not die!). Far to the west some Eskimo lately saw some Tunuks; they had bear-skin clothing. In the Tunuks land (where?) the musk ox (oming muk), bear, and seals are abundant. They build walls of stones on the land, and drive the reindeer into ponds, and catch them in kyacks. They have a large, long callytong (coat, or jumper jacket) that they fasten down around them on the ice while they are watching a seal's hole; underneath this

* Vide sketch of foundation, No.1. Stone foundations of a somewhat peculiar pattern are found in many of the larger fjords. The subject of the sketch was about fourteen feet in its greatest diameter (the larger enclosure) inside; the smaller one about ten feet. The arrangement is much the same as the Eskimo use at the present day, a raised platform in the end opposite the entrance for a sleeping and general lounging place, and two smaller platforms on either side, where the lamps are kept, and where the garbage accumulates.

These foundations are now mere ruins. Some of the stones in the walls are so large that it must have required the united efforts of several men to place them in position. 'The stones gradually diminish in size from the foundation upward. Standing walls are from two to three feet high, and might have been a foot higher, to judge from the loose stones lying about. There was probably a frame-work of whale ribs, over which the seal-skin covering was spread.

On the north side of this foundation were seven kyacks, built of small stones; they lie parallel to each other, and are from ten to fifteen feet in length; they are built of a single row of stones, and only one tier high. These are said to indicate the number of inmates that have died. They appear to ns more like the work of children. In the lamp-places we found the remains of Pagomys foetidus (abundant), Phoca barbata, Cistophora cristata, Trichechus rosmarus, Ursus maritimus (the three last-named species occur now only as stragglers in the vicinity), Rangifer tarandus, Beluga catodon, Larus - , and Somateria —_ (mollissima, probably). Other bones are found, but not recognizable from decay. Wo implements were found except a stone skin-scraper. The present Eskimo say these stone foundations were made by the Tunuks. They are found in various out-of-the-way places, especially in the greater Kingwah Fjord.

tAbout twenty years ago, a man and women (Greenlanders) landed near Cape Mercy, having got adrift on a piece of ice on the Greenland coast. From this occurrence we coujecture that the story has received a modern addition. 
$g$-rment, on the ice, they place a lamp; over this lamp they cook meat. Their eyes are sore all the time. We are afraid of them; do not like them; glad they hare gone away."

This tradition differs somewhat in the particulars when told by differ«nt individuals, but the main points are essentially the same. Many will not tell it all; some, only parts of it. The ridiculous story about the dngs is firmly believed by the present Eskimo as the origin of these animals.

That the Tunuks have been seen of late years in the west is not improbable, - that is, natives, different in dress and stature; but they were most likely the tribe known as the Pelly Bay Eskimo from the north shores of Hudson's Straits and from Fox Channel, they being larger and more robust than the Cumberland Eskimo of the present day. It is certain that since the whalers have begun coming among the Cumberland Eskimo, and introduced venereal diseases, they have deteriorated very much. They now almost depend upon ships coming, and as a consequence are becoming less'expert hunters, and more careless in the construction of their habitations, which are merely rude temporary shelters made at a few minutes' notice. Great suffering often ensues from living in these miserable huts. The seal skin that should have gone to repair the tent is bartered to the whalemen for a little tobacco, or some valueless trinket, which is soon thrown aside. The men are employed to catch whales, when they should be hunting in order to supply the wants of their families; and the women, half clad, but sporting a gaudy calico gown, instead of their comfortable skin clothes, and dying of a quick consumption in consequence, when they should be repairing garments or preparing skins, are loafing around the ships, doing nothing for themselves or any one else.

The Cumberland Eskimo of to-day, with his breech-loading rifle, steel knives, cotton jacket, and all the various trinkets he succeeds in procuring from the ships, is worse clad, lives poorer, and gets less to eat than did his forefathers, who had never seen or heard of a white man.

There is a practice among them that is probably of long standing, and is regularly carried out every season, of going into the interior or up some of the large fjords after reindeer. They generally go during the months of July and August, returning in September, to be on hand when the fall whaling begins. The purpose of this reindeer hunt is to procure skins for their winter clothing. Nearly all return to the sound to winter. They have regular settlements, which are hardly ever entirely deserted 
at any season. The principal ones are known as Nugumeute, Niantilie, Newboyant, Kemesuit, Annanactook, Oosooadluin, Ejujuajuin, Kikkerton, and Middliejuacktuack Islands, and Shaumeer, situate at different points on both sides of Cumberland Sound. During the winter they congregate at these points in little villages of snow-huts.

The present principal headquarters are at the Kikkerton Islands, or at Niantilic, according to which point the whalers winter. The old harbor of Kemasuit, once the winter harbor of whalers and a favorite resort of the Eskimo, is now deserted, except by a few superannuated couples, who manage to catch enough seal to live on.

As a rule, the present race is of short stature, the men from five feet three inches to five feet six. There are some exceptions, but they are in favor of a less rather than a greater height. The women are a little shorter. The lower extremities are rather short in proportion to the body, and bow-legs are almost the rule. This probably arises from the manner in which the children are carried in the mother's hood, as well as the early age at which they attempt to walk. The habit of sitting cross-legged may also have a tendency to produce this deformity. Their hands and feet are small and well formed. Their hands are almost covered with the scars of cuts and bruises. It seems that in healing the injured part rises, and is always afterwards disgustingly prominent. There is a great variation in the color of their skin, and a description that would answer for one might not apply at all to another. Even among those that are of pure breed there are some whose skins are no darker than a white man's would be if subjected to the rigors of wind and cold, and the never-removed accumulation of soot and grease. Others again seem to have been "born so." The children, when young, are quite fair. The eyes are small, oblique, and black or very dark brown. The hair is black, straight, coarse, and very abundant. It is rarely wavy or curly among the full-blooded Innuits.

There are, of course, exceptions to the above in cases of half-breeds. Their faces are broad and flat, with rather large lips and prominent cheek-bones.

Infanticide is not practiced among the Cumberland Eskimo at the present day. I have learned from some of the most intelligent that this barbarous custom was in vogue in former times, however. Among the natives of Repulse Bay and those living on the north shores of Hudson's Straits, it is practiced to a considerable extent, especially with the tribe known as the Pelly Bay natives. The practice is confined almost en- 
tirely to female children, the reason being, they tell us, that they are unable to hunt, and consequently of little account. It seems to have been referable to the same cause among the Cumberland Eskimo. Their intercourse with the whites seems to have modified some of the most barbarous of their primitive habits.

Twins are not common, and triplets very rare. The males outnumber the females. Infanticide may, to some extent, be the cause; but lung diseases, which are alarmingly prevalent, seem more fatal to the women than to the men.

Children are often mated by the parents while they are still mere infants. There is such an extreme laxity of morals that the young women almost invarialy become wives only a short time before they are mothers.

It is impossible to say at what age the women cease to bear children, as they have no idea of their own age, and few are able to count above ten. Puberty takes place at an early age, possibly at fourteen with the female. They are not a prolific race, and it is seldom a woman has more than two or three children, and often only one, of her own; still many, or almost all, have children; but inquiry will generally dirulge the fact that some of the children have been bought. Almost every young woman has or has had a child, but the identity of the father is in no wise necessary in order to insure the respectability of the mother or child. Such children are generally traded or given away to some elderly couple as soon as they are old enough to leave the mother. The foster-parents take quite as good care of such adopted children as if .they were their own.

So far as we could learn, they do not generally practice any rites or ceremonies of marriage. The best hunter, or the owner of the largest number of dogs and hunting-gear, will seldom have any difficulty in procuring the woman of his choice for a wife, even though she has a husband at the time. It is a common practice to trade wives for short periods or for good. They appear to have marriage rites sometimes, but we could induce no one to tell us, except one squaw, who agreed to, but only on condition that we became one of the interested parties and she the other. This was more than we had bargained for, and, although generally willing to be a martyr for the cause of science, we allowed this opportunity to pass without improving it.

Monogamy is at the present time the most prevalent. Polygamy is practiced only in the case of a man being able to provide for two or more wives. Three, and even four, are known of, but rare. Neither do two 
or three wives in one hut make an altogether harmonious household; but all little difficulties are generally settled by the husband, in a manner better calculated to insure reverence to masculine strength than respect for superior intelligence.

The scarcity of women at present in proportion to the men makes polygamy a luxury only to be indulged in by the wealthy. Divorce, if it can be ealled by that name, is very frequent among them. All that is needed is that the husband tires of his wife, or knows of a better one that he is able to procure. Neither does it seem to trouble the woman much: she is quite sure to have another offer before long; and a change of this kind seems to benefit both parties. One rather remarkable and very laudable practice among these people is the adoption of young children whose parents are dead, or, as often happens, whose mother is the only recognized parent. Orphans, so to speak, are thus twice as common as among civilized nations. These children, whether bought or received as a gift, are always taken as good care of as if they were their own, especially if they are boys.

Among the Eskimo employed by the Florence was a family that had two children, who passed for brother and sister. One, the boy, was a nephew of "Eskimo Joe," of Polaris fame. He had been bought from the Hudson's Straits Eskimo, some two hundred miles to the south. He was a perfect little satan; and, though he gave us much annoyance, he was a nerer-failing source of amusement to us all. The girl, again, was a native of Exeter Sound, on the west coast of Davis Staits; still, both were considered as their own children, and well cared for.

Half-breeds are said to be of more irritable temperaments, and less able to bear exposure and fatigue, than the full-blooded Eskimo.

The food of the Cumberland Eskimo consists entirely of flesh, and in most sections of the sound of Pagomys foetidus. In fact, this animal is their principal dependence for food, fuel, clothing, and light. The Eskimo will eat a few of the berries of Vaccinium uliginosum and Empetrum nigrum, the roots of Pedicularis, and occasionally a little Fucus vesiculosus in winter, but this constitutes a very small and unimportant part of their food.

As soon as the ice has fairly left the somnd, the Eskimo hunter leaves the winter encampment, with his family and such portions of his housebold goods as will be needed, and takes a tour inland or up some of the large fjords after reindeer. The larger part of his possessions, including sledge, dogs, harnesses, winter clothing, \&c., he secretes among the rocks in some unfrequented spot. His dogs are put on some little rocky islet, Bull. Nat. Mus. No. 15 2 
to shitt tor themselves. They eke out a scanty subsistence by making good use of their time at low tide, Cottus scorpius constituting the greater part of their food at this season.

There are at present so many whaleboats owned by these Eskimo, that they experience little difficulty in making quite extensive cruises, three or four families constituting a boat's erew. They will load a whaleboat to within an inch or two of the gunwale, and then set out for a few weeks of enjoyment and abundance. The squaws do the rowing and the "captain" stands majestically in the stem with the steering oar, while the rest of the men are either asleep or on the lookout for game. The eargo consists of their tent-poles, the skin-tents, pots, and lamps, with sundry skin-bags containing the women's sewing and skimning utensils. Their hunting-gear, of course, forms a quite conspicuous portion of the contents of the boat. Very few there are at present who have not become the possessors of a half-barrel, and this ressel occupies a conspicuous place in the boat, and is almost constantly receiving additions of animal matter in some shape; a fer young eiders or gulls will soon be covered up with the intestines of a seal and its flesh. From this receptacle all obtain a piece of meat whenerer they feel hungry. This ressel is never emptied of its contents, except by accident or when scarcity of material forbids its repletion; and, as the temperature at this season is well up in the "sixties" during the day, this garbage heap becomes so offensive as to be unbearable to any one but an Eskimo.

They proceed at a very leisurely rate, rowing for a few minutes and then stopping for a time, chatting, smoking, or eating. When they feel tired they haul up on the rocks and have a sleep, and then resume the journey in the same vagabond manner. If, while thus cruising, any live creature that they think there is any possibility they can capture comes in sight, all hands become animated, the oars are plied with redoubled energy, guns and spears are in readiness, and every one is eager for the sport. Hours are often consumed in chasing half-grown duck or young loon, which when procured is but a bite; but the fun of the chase seems to be the principal object, and they enjoy it hugely. Thus they journey till they reach some suitable locality, when the boat is unloaded, the toopiks raised, the lamps put in their places, and all is ready for a grand hunt. The men divide and scatter over the mountains, leaving the camp in charge of the women and children ; these busy themselves by liunting for and destroying every living creature that they can find.

On the return of the hunters, who perchance have brought some skins and a hmm of venison, there are joyous times in cann,; the meat is dis- 
posed of first, and then the younger people engage in various games, while the older ones gather around some aged crone, who excitedly recounts the hunts of her girlhood days, plentifully intermixing stray portions of the old sagas and legends with which her memory is replete. Thus they live from day to day, the men hunting and the women stretching the skins, till the season comes around when they must return to the coast. Happy, contented, ragabond race! no thoughts of the morrow disturb the tranquillity of their minds.

When a deer is killed any distance from camp, the meat is cached, with the intention of returning after it in winter; but with what the wolves and foxes devour and what the Eskimo never can find again, very little is brought back.

Many have now firearms of some pattern or other; and though they will hunt for a ball that has missed its mark for half a day, they do not hesitate to fire at any useless creature that comes in their way. Those that have no guns use bows and arrows made from reindeer antlers. Sometimes the deer are driven into ponds, and eren into the salt water, and captured in kyacks with harpoons.

They have an interesting custom or superstition, namely, the killing of the evil spirit of the deer; some time during the winter or early in spring, at any rate before they can go deer-hunting, they congregate together and dispose of this imaginary evil. The chief ancoot, angekok, or medicine-man, is the main performer. He goes through a number of gyrations and contortions, constantly hallooing and calling, till suddenly the imaginary deer is among them. Now begins a lively time. Erery one is screaming, running, jumping, spearing, and stabbing at the imaginary deer, till one would think a whole mad-house was let loose. Often this deer proves very agile, and must be hard to kill, for I have known them to keep this performance up for days; in fact, till they were completely exhausted.

During one of these performances an old man speared the deer, another knocked out an eye, a third stabbed him, and so on till he was dead. Those who are able or fortunate enough to inflict some injury on this bad deer, especially he who inflicts the death-blow, is considered extremely lucky, as he will have no difficulty in procuring as many deer as he wants, for there is no longer an evil spirit to turn his bullets or arrows from their course.

They seldom kill a deer after the regular hunting season is over, till this performance has been gone through with, even though a very good opportunity presents itself. 
Salmo salar, and one other species of Salmo that I could not procure enough of to identify, are caught to some extent in June and September in some of the larger fjords; they are mostly caught with a spear, but sometimes with a hook. (For description vide under hunting-gear, \&c.)

When these fish are caught, they are put into a seal-skin bag, and it remains tied up till the whole becomes a mass of putrid and fermenting fish, about as repulsive to taste, sight, and smell as can be imagined. Cottus scorpius, which contributes so largely towards the Greenlander's larder, is not utilized by the Cumberland Eskimo, except in eases of a scarcity of other food supplies; the fish is abundant in their waters, however, and fully as good eating as they are on the Greenland coast.

Birds and their eggs also contribute towards their sustenance in season; they are extremely fond of eggs, and devour them in astonishing quantities.

The "black skin" of the whale, called by them mulituk, is esteemed the greatest delicacy. When they first procure a supply of this food, they almost invariably eat themselves sick, especially the children. We found this black skin not unpleasant tasting when boiled and then pickled in strong vinegar and eaten cold; but the first attempts at masticating it will remind one of chewing India rubber. When eaten to excess, especially when raw, it acts as a powerful laxative. It is generally eaten with about half an inch of blubber adhering.

The greater portion of their food is eaten raw, especially in winter. When they cook at all, they only "simmer" it over their lamps in a pot of soapstone. These pots are from eight to twenty inches in length, usually about sixteen inches, and though of variable patterns, the length is generally three times the width or depth. Among such Eskimo as are able to procure old cast-away meat-cans from around the ships, tin has superseded the soapstone both for lamps and boiling-pots.

In summer, especially when on hunting excursions, they very often "fry" meat by making a little fireplace of stones, and laying a flat piece of stone on the top. The opening to receive the fuel supply is to windward. For fuel at such times they use Cassiope tetragona and Ledum palustre; these shrubs make a quick and very hot fire. It would be comparatively an easy task for these people to gather enough Cassiope tetragona during the summer to burn during the coldest weather, and not rely wholly upon blubber.

When the Eskimo have been simmering meat, especially seal, in their boiling-pots, they pour off the liquar and mix it with about an equal 
quantity of blood; this makes a thick and rather greasy soup that must be quite nourishing; the children are very fond of it. It seems possible that from this dish has originated the popular error that these people drinti oil, a notion that is simply preposterous.

I found among some of these people a little spoon, or rather a miniature scoop, made of ivory, which they used to drink the soup with; it appears to be an old utensil, now fast going out of use, for they can now procure tin mugs. A reindeer's rib, pointed at one end, is used to fish up the meat with, and sometimes to convey it to the mouth. These instruments are found in the graves, but seem to be but little used at the present day.

When a seal is brought to the encampment, especially if they have not been plenty for some days, all the villagers are invited to the hut of the lucky hunter, and the seal is soon dispatched. A couple of the younger men skin the aniral and distribute the pieces to the assembled company as fast as needed. The testicles, being considered as the choicest titbit, are usually handed over to the hostess; the spinal cord is also rated as one of the choicest portions of the animal. During these feasts they gorge themselves to their utmost capacity, and are in good humor and hilarious. Though there may be ever so poor prospects to procure more food for the morrow, this does not deter them from gluttonously devouring the last morsel, and then go on allowance till they can get a fresh supply. I have seen them thus gorge themselves, and then lie down to sleep with a piece of seal meat by their side, which they attacked every time they awoke.

The intestines of birds, notably Lagopus and Somateria, are looked upon as choice parts, and birds brought to the encampment are generally "drawn" by the hunters. The fatty excrescence at the base of the upper mandible of the male Som. spectabilis is too great a temptation for them. It was with great difficulty that we could induce them to bring these birds to camp without having them thus mutilated.

Since whalers began to cruise in the Cumberland waters, they have found that it is decidedly to their advantage to hire boats' crews of natives to assist in the capture of whales. They make good whalemen. When such crews are seçured, they wisely count in all of their family in tho bargain, so that to secure the services of a erew of seren men one must feed thirty or more. While working for whalers, these Eskimo depend almost wholly on the ship for their food supply; as a consequence, they are fast becoming poor hunters, and prefer to lounge around a vessel 
and pick up such scraps as offer themselres rather than to strike out for themselves and live independently and in comparative plenty.

As to meals, or regular meal-times, they eat when hungry, if they have anything. They always eat in the morning before going out to hunt; but the principal meal is in the evening, on their return. When supplied with rations by the ships, they often have their regular meals aboard; but this does in no wise hinder them from taking their usual evening allowance of raw meat when ther return to their huts.

That the Eskimo possess considerable powers of abstinence cannot be disputed; but it is not so remarkable after all, for they certainly have had ample experience in this direction. That they are able to bear temporary or sustained exertion better than the whites is doubtful. They are acclimated and have clothing suited to the climate, and readily adapt themselves to the rude shelter of a snow-bank, if necessary; but give a healthy white man as good clothes, and he will stand as much fatigue, and perhaps more.

While hunting with the Eskimo, we often had our nose and face frozen, when it did not seem to affect the Eskimo in the least; but when it came to a tramp through the snow all day long, few of them would stand it any better than we could.

Some have judged their powers of endurance from the manner in which they will follow their game; but it seems to us it is rather their wonderful patience, for we have known them to follow animal tracks for a whole day, when we confess we could not discover the faintest trace of a track, except at long distances apart. They will discover any traces of animals on the snow that a white man would pass by and not notice. When traveling either on the ice or water, they make the journey by short, easy stages, stopping as soon as they feel the least tired, and recruiting; if they were required to walk a given distance, as on a regular march, they would give out.

The Cumberland Eskimo are known to make better and more beautiful clothing than the tribes of Northern Hudson's Bay and Straits. During the summer, and, in fact, at all seasons, except when the weather is very severe, the outer garment of the men is made from the skins of adult-or, more properly speaking, yearlings, as they are the bestPagomys foetidus. In very cold weather, they betake themselves to deerskin clothing; but as these clothes are less strong than the seal-skin, they make the change as soon as the weather permits. The women wear the deer-skin clothes much later in the season than the men; their dress 
is also made of the same kind of seal, unless they are fortunate enough to procure Callocephalus vitulinus, which skins are so highly prized that they use thein even though there is only sufficient for a part of the fronts of their jackets.

Both the men and women wear a garment the exact duplicate in shape under the outer one; this garment is made either from the young seal in the white coat or of reindeer.

The coat of the men does not open in front, but is drawn on over the head like a shirt, and has a hood that fits the head snugly, while the woman's hood is large and loose, and the jacket is quite loose-fitting, so as to receive the child, which is always carried in the hood. The woman's jacket further differs from the men's in being shorter in front, and ending in a rounded point, while behind it reaches quite to the ground in the form of a lance-shaped train. This appendage is caught up in the same manner as the fashionable train of the present day among civilized nations, when the condition of the ground is unfavorable for its trailing. After all, is not this fashion borrowed from the Eskimo? There is often an approach towards this prolongation in the men's jackets, especially when made of deer skin, but nerer so long as on the woman's. Neither do little girls have a long train to the jacket; but as soon as they arrive at the age when they are no longer looked upon as children, they learn to imitate their mothers. There are nerer any pockets in the jackets of either sex, the hood serving for this purpose.

The pants of the men are made from the same material as the coat, with the exception that the young seal in the white coat is often used for the outer as well as the inner garment. The pants reach only to the upper part of the pelvis, and are kept up by means of a string around the body. They reach a little below the knee, where they are met by the boots. When made of deer skin, they are usually ornamented by fringes of cut skin around the lower edges.

The women's pants differ from the men's in being composed of two separate pieces, the lower reaching. from a little below the knee to the middle of the thigh, and are kept in place by a string which runs to the upper edge of the other portion. The lower portion of these pantaloons is removed while they are at work in their igloos, and the bare thigh used, as a board would be, to lay the seal skin on while cleaning the blubber from it. The women have the habit of thrusting their hands between the upper and lower pantaloons the same as we do in a pocket; in fact, they use this space as a sort of pocket.

Little girls wear their breeches like the men till they get to be ten or 
twelve years of age. Very small children are dressed in a fawn-skin jacket without attached hood; but their heads are, nevertheless, well bundled up in a double fawn-skin hood that fits the scalp closely. This hood is never removed, except perchance by accident, till the child outgrows it. The lower extremities are usually not clad at all.

The children are carried on the mother's back inside her jacket. The cut of the jacket is such that the child goes down as far as the mother's waist, when the closeness of the jacket prevents it going any farther. The hood allows the child freedom for its arms and head, but the legs are cramped underneath its body, and this is probably one cause of bow-leggedness and possibly the shrmtness of the lower extremities. I have seen the Eskimo mother, with a child fast asleep in her hood, building a toopik. This work often necessitated her stooping over so much as to seemingly endanger the dumping of the infant over her head on the ground; still, it did not seem to inconvenience the child in the least, as it slept soundly through the whole proceeding.

The kámik, or, as generally pronounced, kumming, or boots, are principally made from the skins of adult Pagomys foetidus, with the hair off, the soles being made from the skin of Phoca barbata. For winter wear a very beantiful and serviceable boot is made from the skin of reindeer legs sewed together lengthwise; they are used only in dry snow, being quite useless when the snow is wet. Another style of boot is to have the leg of netsick skin, but with the hair on. These boots reach nearly to the knee, and are kept in place by means of a string around the top, and also secured by a seal-skin cord passing over the instep and around the heel. They are generally sewed with sinews from reindeer; but for boots the sinews from the dorsal vertebræ of Beluga catodon are preferred when they can be procured.

The stocking worn next to the foot is of heavy reindeer skin, the hair side next the foot; they reach above the knee. Over the stocking is worn a sort of slipper made from the eider-duck. The bird is skinned by making an incision on the back near one wing; through this opening the body is removed. The skin is cleaned of the fat by the Eskimo's teeth, and the skin farther prepared by chewing it. The tail-feathers are removed, and this end becomes the toe of the slipper, the feather side being worn inside. Its upper edges are bound with some kind of skin to give it additional strength, and if the entire slipper is covered with cloth will last a long time. They are very warm and comfortable. Larus glaucus is often used for this purpose. For children they use Uria grylle and Rissa tridactylus skins. Over all this is worn another slipper 
made from the netsick skin, with the hair on, and the hair side worn outward and the hair pointing from the toe backwards. This very much facilitates the drawing on of the boot.

For summer wear the young of the netsick in the roolly coat is substituted for reindeer for the stockings. Dog skin is also sometimes used for stockings, but not so eommonly among the Cumberland Eskimo as amoug those of Hudson's Straits, who use dog skins for pants as well as stockings.

All the clothing is sersed with sinews, reindeer or white whale. The reindeer sinews are dried in bulk as they come from the animal, and are split off as needed. The fibres are separated as fine as necessary, and then drawn quickly between the teeth to secure a more uniform size. The women all sew towards themselves, using the thimble on the first finger; they seldom use but one kind of seam; the edges of the skin are carefully matched together, and joined by sewing over and over the overcast seam. Their thimbles (called tikik, also signifies first finger) are made from the skin of Phoca barbata; in shape they are merely an oblong piece suficiently large to cover the point of the finger. A rim is cut around the outside erlge for about one half its length ; this forms a sort of loop under which the finger is passed, and in this manner it is kept in place. We found this style of thimble much more convenient than the metal one of the usual form.

Very few of the Cumberland Eskimo at the present day use anything but steel needles, or bone ones made after the same pattern. We have seen an instrument said to have been used as a needle that is considerably different from anything we ever saw before. An Eskimo brought it to us, and wanted a hatchet in exchange. We thonght it certain he would return and offer to trade at our terms, but he did not, and we never saw him again. This tool was almost exactly like an awl in shape, but had an eye near the point. They must have had to thread this instrument for each stitch. The needle part was apparently of deer horn and the handle of walrus irory.

The farorite and principal tool of the women is a knife shaped like an ordinary mincing-knife. Nearly all the Cumberland Eskimo have now procured iron enough from some source or other so that ther ean hare an iron knife of this pattern. Before they could procure enough iron, they made the knife of ivory, and merely sank flakes or pieces of iron into the edge, in the same manner as the natives of North Greenland do at the present time. This same practice of sinking iron flakes into the 
edge was also used on their large skinning-knives, which were made from a walrus tusk, and much after the pattern of an ordinary steel butcherknife. Some of these ivory knives have no iron in them; but at the present time they are used principally, if not entirely, for cutting snow and removing ice from their kyacks.

The women seldom use any other kind of knife than such as just de. scribed. With them they remove the blubber from the skins, split skins, cut up meat, and when sewing this instrument is used instead of scissors. They begin a garment by sewing together two pieces of skin and shaping them as they go along by means of the knife, cutting for an inch or two and then sewing. They always push the knife from them when working it.

Tattooing does not seem to be as prevalent now as formerly, for it is mostly on the aged women that one finds it at present. The markings resemble India ink in appearance, and are done with gunpowder at present. Still, some use the old method, by taking the juice of Fucus resiculosus L. (or a closely allied species), and some small algæ that apparently contain a good deal of iodine, and mixing with lampblack.

Instances came under our observation of people of apparently great age,--say seventy years and over, to judge from appearances; they had gray hair (a rare thing among the Eskimo), and were nearly blind; the women had the teeth worn close to the gums by chewing skins.

It is impossible to arrive at any definite conclusion regarding their age, as they keep no record of time and cannot refer to any past event by any means of notation. We could not learn of the rudest attempt at picture-writing or hieroglyphics; and, as they possess no records whatever, their traditions are handed down from generation to generation without being fixed by any means which allow even an approximate estimate of their growth and prosperity.

Most of them are unable to count beyond their ten fingers, and many are unable to go over six; some, again, are said to have names for numbers to twenty, but they are few. The numerals are differently pro- nounced, and we found difficulty in getting one sufficiently conversant with them to give us the numerals to ten.

One $=$ Atáusa, or atausat.

Two $=$ Mócho .

Three=Pingasuit, or pingasat .

Four=Séseminé, or sesemat.

Five=Tódlimené, or tódlimát. 
Six $=$ Aúkbinigan .

Seven=Pingashuing (?).

Eight $=$ Aukbinigan-machoni (6 and 2).

Nine= Schischimani $(?$ ? ?)

Ten $=$ Korcolin .

Above ten they are said to count their toes and take ten and one, ten and two, \&c.; but we were unable to find one who knew their names. They will tell you they have eaught seals or birds up to six, but if more they generally put it amashuadly (a good many), which may be any number from seven upwards.

In the treatment of the sick they are very superstitious, and in fact they resort almost entirely to their ancoot, angekoks, or medicine-men.

The following is a Greenlander's legend that proposes to give a reason why people die: "The cause of people's dying is laid to a woman, said to have discoursed thus: 'Let the people die gradually, otherwise they will not have room in the world."

Others relate it in this manner: "Two of the first people quarreled. One said: 'Let it be day and let it be night, and let the people die.' The other said: 'Let it only be night and not day, and let the people live. After a long wrangle it came to pass as the first had said."

It is interesting that this same curious legend exists among the Eskimo of Cumberland Sound; they say though that "those who quarreled finally arranged matters and had both entire day and entire night at the different seasons, so that both parties might be suited."

The lungs of Lepus glacialis are considered as a sure cure for boils and all manner of sores; they draw, they say, and their manner of applying them is the same as we would a poultice. They must be applied as soon after the animal's death as possible, and while they are yet warm.

In cases of scurry they never use Cochliaria, but the stomach of a freshly killed reindeer, with the vegetable contents, instead. If the scurry patient be very bad, the limbs are bound with pieces of the deer's stomach, whale or seal's blubber, or any kind of fresh meat. If a whale can be eaught at such a time, the patient is sometimes bodily shored into the carcass, or the lower extremities only are sunken into the flesh.

The most prevalent disease among them seems to be lung disease; it is alarmingly common, and consumption probably kills more than all other diseases combined.

The whalemen have introduced venereal diseases among them, which have spread at a terrible rate, and devastate the natives almost like a pest. 
I could not learn that they have any knowledge of the medical properties of any plant or shrub. Some of the coarser kinds of alyce are procured at low tide from the cracks in the ice, and eaten raw, but only because they are fit to eat, they say; the roots of Pedicularis are also sometimes eaten.

When the women are about to be confined they are placed in a small snow-hut, if it be winter, and in a little skin tent, if summer, by themselves. Their only attendant is a little girl, who is appointed by the head ancoot of the encampment. A little raw meat-deer, if they have it-is put into the hut with her, and she is left to give birth to the child as best she can. The reason she is removed from her tent is, that should mother or child die in the tent nothing pertaining to the equipment of the establishment could ever be used again, not even the tent-covering or the husband's hunting-gear. In some instances they are obliged to modify this custom somewhat. We have known them to cut the tentcover about two feet from the ground all around and use the upper portion. A man's wife accidentally shot herseif in her igloo, but the gun was too great a sacrifice; he used it, but the rest of his household effects were left to waste away where they lay. We knew of another instance where the tent-poles were brought into use again in the course of a year after a death had occurred beneath them.

As soon as the mother with her new-born babe is able to get up and go out, usually but a few hours, they are taken in charge by an aged female ancoot, who seems to have some particular mission to perform in such cases. She conducts them to some level spot on the ice, if near the sea, and begins a sort of march in circles on the ice, the mother following with the child on her back; this manœurre is kept up some time, the old woman going through a number of performances the nature of which we could not learn, and continually muttering something equally unintelligible to us.

The next act is to wade through snow-drifts, the aged ancoot leading the way. We have been informed that it is customary for the mother to wade thus bare-legged, but (whether from modesty or the temperature of $-50^{\circ} \mathrm{F}$. we eannot say) on some occasions this part of the performance is dispensed with.

When a sick person gets so far gone that they deem recovery improbable, he is removed from the hut, and either dragged out upon the rocks to die, or a little snow shelter may be constructed for him, and some scraps of raw meat thrown in to him. Usually such proceedings are apt 
to end fatally o the patient, even though his ailment might not have been so dangerous had proper care been taken. We kuow of one instance where a man was thus put out to die seven different times; but he recovered and crawled back to his igloo, and looks now as if he was good for a number of years yet. Stories are common of how aged and infirm people are put out of the way by the younger ones, to rid themselves of a useless burden; but of this we know nothing from personal observations, or from reliable sources.

Occasional instances of suicide happen, generally when the person is afflicted with some incurable disease. Hanging seems to be the favorite mode of killing themselves.

The ancoot's manner of operating is various, and almost every one has some method peculiar to himself. We could get but a glimpse of some of them, as they are averse to having a white man witness their performances, and we had the greatest difficulty in getting any one to explain to us their meaning. The following legend is supposed to give the directions for becoming an ancoot; it is interesting that this legend does not differ essentially from the Greenlander's. (Vide Grœnlands nye Perlustration, Eller Naturel-Historie, Hans Egede, 1741.)

We would here add that those who become ancoots are only such as are naturally possessed of a more penetrating mind than their fellows, generally the biggest rascals in the encampment, who seldom pay any attention to what is right or just, but ply their vocation so as to win for themselves renown among their fellows, and possess themselves of any coveted article as remuneration for their services.

\section{The manner in which one may become an ancoot, or angekok.}

Any one wishing to become an ancoot must go away a long distance from where there is any other person. Then he must find a large stone, and seat himself by it, and call on Torngarsuk.* This spirit will then make himself present to him. The would-be ancoot will at first be very much frightened at the arrival and appearance of this spirit, so much so that he is seized with severe pains, and falls down and dies, and remains dead for three days. Then he comes to life again, and returns home a very wise man.

* Torngarsuk of the natives of South Greenland, and Tornarsuk of North Greenland, is the highest oracle, the master spirit of these people. There are many spirits of less power, called Tornat; these cau be seen only by the angekoks, after their meeting with Torngarsuk. It appears that this word signifies the greatest spirit of Good, as well as of Evil. They now call the Devil Torngarsuk, and in their ancient belief their God, so to speak, the same. 
An ancoot's duty is, first, to mutter over the sick, that they may become well again; secondly, he will talk with Torngarsuk, and get information from him as to how he must manage so that they will have success in their undertakings; thirdly, of him he learns if any one is about to die, and what the cause is, or if some unusual death or misfortune is about to occur to the people.

Their derotion and belief in the ancoots are unlimited; they can nerer be induced to trespass on the commands or disbelieve the prophecies of these important personages. When one has been a very successful ancoot for a long time he may become a great ancoot; this necessitates a period of fasting, and then, as the story goes, an animal they call amarook (the same word is used for wolf, and for an animal which is probably mythical, unless it can be a Gulo) comes into his hut and bites the man, who immediately falls to pieces; his bones are then conreyed to the sea, where he lives for some time as a walrus; he finally returns among his people, a man in appearance, but a God in power.

If the prophecy of an ancoot does not come to pass as he had said it would, any phenomenon of nature, as a halo, corona, aurora, \&c., is sufficient to have broken the spell, and the ancoot loses nothing of his reputation by the failure, for it is then believed that the measure, whatever it might have been, was not pleasing to Torngarsuk.

The people come to these soothsayers after all manner of information. We knew of one case where a young woman asked an ancoot if her yet unborn child would be a boy or girl. He retired outside the hut for a few moments, and when he returned he said it would "be a boy"; but he adds, "If it is not a boy, it will be a girl"! For this valuable information he charged three seal-skins and a knife. As a general thing, the ancoots are paid according to their reputation; still, it is very seldom they refuse to give them what they ask for in return for their valuable services.

They seem to hare an idea of a future state, but what we denominate as the region down below they consider as the best place. In Egede's Gronlands nye Perlustration, year 1741, is giren a legend which is almost exactly the same as one that is found among the Cumberland Eskimo at the present day. But Egede says, in the Danish translation, "Himmel," heaven, as though this was the equivalent for the Greenlander's word; the Eskimo of Cumberland say "topani," which means simply "up." They do not distinguish any difference in the soul's condition after death, or rather of the two places where they expect to live 
hereafter; one differs from the other only in this wise, that if death is caused by certain means they go to the one, and if they die a natural death they go to the other.

The following is their idea of the future: "In the spirit-land all will have it as good as or better than they had it on earth." Yet they designate two places where the soul goes after death, viz: "Some go up; others far down into the earth." But the lower place is considered preferable. This is described as a beautiful land, with everlasting sunshine, where the seal and reindeer abound in fabulous quantities, and food is consequently abundant. To this latter place go only such as are killed by other Eskimo, women who die in childbirth, such as drown in salt water, and whalers; they think, this being the better place, it is a sort of recompense for the suffering they underwent on earth; all the rest go up.

In this connection we will mention that the Cumberland Eskimo think the aurora borealis is the spirits of dead Eskimo dancing and having a good time generally. It has even considerable influence over them, and they are well pleased to see a bright aurora. The Greenlanders, on the other hand, say it is the spirits of dead Eskimo fighting.

We have been told by some that those who hunt in the kyack and get lost or driven upon the ice or some uninhabited island are supplied with food from these regions; that is, living game is thrown in their way for them to capture, so they will not starie. This is firmly believed by them.

Unlike the Greenlanders, the Cumberland Eskimo of the present day hare no permanent habitations. They may lire at the same locality for several winters in succession, but each year construct a new snow-house. The Greenlander has a permanent sod or stone hut, and lives in tents only while away hunting. The Cumberland natives live in snow-houses from the time the snow gets firm enough to be fit to build with till it melts, in June. They generally begin the construction of the snow-house, or igloe, in the latter part of October. A place is chosen which is sheltered from the north, under the lee of a rock, if possible, and where there is a considerable depth of snow. They begin by treading a circular space about sixteen feet in diameter; on this they keep piling snow and stamping it down as hard as possible till the whole mass is a raised platform as hard as ice. They then cut out a square block from the middle, abont eighteen inches deep. After this block is removed they have a chance to cut others from around the sides, and this space is enlarged till it becomes of the desired dimensions. The sleeping platform is left as they finished treading it, no blocks being cut from this portion; it 
also serves to stand on while constructing the wall, which is always done from the inside, the builder being furnished with fresh snow-blocks from the outside when his supply gives out. The wall is built in a spiral form, so that, if viewed from above, it would have the appearance of a conical coil.

The only tools used in building are a saw, if they can get it, for sawing out the blocks, and a long knife, made from a walrus tusk, for trimming them into shape. In cutting and fitting the blocks of snow, they show skill and ingenuity, so that they make as perfect an arch as the best mason. When the hut is done, or rather enclosed, there is neither door nor window, and the builder is a prisoner. A door, however, is soon made, but at the opposite end from where the entrance is to be; through this aperture the women and children begin dragging in the "furniture," while the men "chink" up the places where the blocks join each other. The structure is so strong that it readily bears a man's weight on the top. When everything is ready inside and out, the lamps are lit; sometimes more than the usual number are procured, and trimmed to burn as brightly as possible; the heat begins to melt the inner surface of the structure, but it soon freezes and forms quite a coating of ice; this, of course, adds considerably to the strength of the building. The inside is now lined with the seal-skin tent of their summer toopiks, fastened up all around the sides and top by means of small pegs of wood or bone. A window is cut through the wall over the entrance-way, facing the south; it consists of a half-moon-shaped bow of whalebone, over which are stretched the intestines of Phoca barbata, sewed together lengthwise. This window admits the light quite well.

The entrances are long, low structures, sometimes only two, often four or eren five. They gradually diminish in size from the igloo, but each one has a door, which is so low and narrow that a large person is unable to get through them, even on hands and knees. The door to the hut proper is barricaded at night with a slab of ice or the scapula of a whale. Ice is also sometimes substituted instead of seals' intestines for the window. On either side of the entrance-ways, the dogs are allowed to lie, but never inside the dwelling apartment.

About one-half of the floor at the end opposite the entrance-way is from one to two feet higher than the rest. On this platform they keep all their skins, and it is used for a general lounging and sleeping place. On the top of the snow they lay a coating of Cassiope tetragona, or something of this sort, and neatly spread the skins over it. One can see at. 
almost any time an impish-looking head, covered with a thick nat of tangled black hair, plentifully powdered with reindeer-hair of various lengths and colors, protruding from among the pile of skins. The whole family crowd together on this platform, like so many pigs. The lamps are kept burning day and night, and the woman's place is directly in front of them on the sleeping-platform. Here they sit cross-legged and work. Back of the lamps and around them they pile up their meat. This accumulation of garbage is only cleaned out when it becomes necessary to make room for a fresh supply. This pile of putrifying flesh soon becomes extremely offensive both to sight and smell. Meat is sometimes brought in the huts that is already spoiled, even though the temperature may be 50 degrees below zero. This often happens with deer. We think the cause may be that the body of the animal immediately freezes on the outside and forms a coating of nen-eonducting ice, which prevents the escape of gas, which instead permeates the tissues. If the animal is disemboweled as soon as killed, it does not happen. Several earcasses, still warm, are often piled one upon the other, and the animal heat is probably sufficient to start decomposition before the mass freezes.

Around the lamps lie the bones they have picked the meat from, and such other parts as are discarded in time of plenty. This rubbish is not. thrown out, but rooted among after a fresh supply, as it is needed.

Nearly every igloo has a little addition on one side, with an opening to it from the inside of the main hut. In this they keep their deer-skin clothes when not in use, and also an extra blubber supply. Over the lamp is hung a half-moon-shaped frame of whalebone, with seal-skin thongs drawn tightly across. On this they put their foot-gear to dry during the night.

When the snow begins to melt, and their igloos tumble, they have a sad time for a few dass. The skin-tent, or toopik, must now be brought into requisition and do service alone. For the toopik they select a flat rock, from which the snow has melted, and by means of two sets of poles, those for the front end of the structure the shortest, and lashed together at the top, like an Indian wigwam, with a ridge-pole between them. Over this the skin cover is spread, and secured to the rock by means of stones laid on the lower edge. All the after portion of this tent is made from seal-skin, with the hair on, on the back generally a large male Pagophilus gronlandicus. The forward part is made from what they term mamma; which is prepared from the skins of the netsick in the following manner: After the blubber has been removed in the usual Bull. Nat. Mus. No. 15-3 
way (the skins of pregnant females and those suckling young are the best), they split the skins, or rather remove a membrane that lies between the blubber and the skin proper. The splitting is done with the womau's knife. 'The skin is laid upon a flat surface and the knife pushed away from the operator. When the mamma is removed from the skin it is treated in the same manner as the skins, stretched, and dried in the sun. It is tough and transparent, and, being rery oily, does not easily get saturated with water.

When the toopik is about to be raised, the skin covering is first stretched out upon the rock, and the poles are pushed underneath, and then raised up, stretching the cover as tightly on the poles as possible. The toopik is earried with them when they go hunting in summer.

Such habitations are of variable dimensions, regulated by the number of occupants somewhat, but more by the industry of the hunter and the economy of his wife, for the skins need repairing very often; and, as a consequence, many of the more shiftless natives have extremely poor shelters, patched up with dog and bear skin and old cast-away pieces of canvas, which they have paid well for in serviceable seal-skins.

Their greatest concern is to procure the poles. At present many get broken oars, lance-poles, \&e., from the whalers; but still, ingeniously lashed together, bone supports for the tent are yet found among them. The inside arrangement of the toopik does not differ essentially from that of the igloo, except it may be a little nastier as a rule and smell a trifle stronger. Sometimes whale-ribs are made use of instead of poles, and are very ingeniously lashed together. These were more in vogue formerly, before they could procure poles from the ships.

We think they were perhaps less nomadic in past times, as there are still extant sod foundations, which were no doubt used as permanent abodes.

At the present day, so many of the Cumberland Eskimo have procured some kind of firearms that their primitive modes of hunting and their hunting implements have, to a great measure, been modified, and even in some instances altogether lost. Bows and arrows are fast becoming an institution of the past; they do not now rely on them for killing reindeer as they did at one time. Bows and arrows are found around the settlements, broken and out of repair; the arrows, of different kinds, lying about unused, or doing service as some other tool. The children all have bows and arrows; but they seldom kill larger game than snowbirds and lemmings. 
Of prime importance to the Eskimo is his unang, or spear. - At the present day, the sealing spear is often made from an old whale-lance, having a wooden handle and an iron harpoon-head (vide sketches). The socket of the lance is put on the opposite end of the handle, and is used for a variety of purposes. This kind of spear is very useful to the Eskimo in catching the seals in their atluks through the ice. They are extremely expert in the use of this weapon, and possess such marrelous patience that they will stand by a seal's atluk all day awaiting the return of the animal.

This spear is carried on all occasions wherever they go and whatever kind of game they pursue. The opposite end of the spear from which the harpoon is fastened is also their principal tool in building fox-traps of ice, eutting down hummocks so as to get their sledges over the shoreice, \&c. Not the least important use of this instrument is to sound the ice with it. In traveling they very often come to places where the rapid running tide has worn the ice very thin, and by means of this spear they carefully feel their way along. They will even cross on a floe that is completely rotten by feeling around till they get upon a more solid spot and then advancing. They are very much averse to getting into the water, as none of them are able to swim.

The harpoon-head used with this spear is made of iron, and is about three and a half inches in length and one inch between the outside tips of the barbs. They manufacture them entirely by filing, and will sit and file for many days till they get the instrument in the desired form.

For whales and walrus they use a much different weapon, the same, we imagine, as they used before the whites came among them. It is a large, awkward, bulky-looking affair, with a shaft made from the horn of Monodon monoceros, or from parts of a whale's jawbone, ingeniously lashed together, when wood is not procurable. Some have the handle composed of as many as eight to a dozen pieces, beautifully and compactly lashed together, till the whole is as firm as though it were composed of a single piece.

Although such large spears were not rare among these natives, we found difficulty in getting them to part with them. A favorite harpoonhead is also hard to procure, though they may not have used it for years. Some considerable value seems to be attached to these old implements, especially if they have been successful with them in former times. We depend more upon the illustration here given of this spear than upon the choice of words. Their old harpoon-head for seals was probably 
of the pattern here figured. This specimen is from a grave at Exeter Sound, and greatly resembles in pattern the iron seal harpoon-hearls of the present day. Others were made like the walrus harpoon, but having barbs, instead of being iron-tipped. A very ingenious contrivance about these old spears is the perfect ball-and-socket joint which unites the eeheemung, or bone portion (on which the harpoon is placed), with the shaft. The shaft, if made of wood, has a bone tip, which is cupped to receive the rounded end of the echecmung; they are kept in place by two thongs of seal-skin, which makes it sufficiently firm to use, but at the same time will allow the eeheemung to double upon the shaft without breaking when an animal is struck.

As before mentioned, so few bows and arrows are now in use that it is almost impossible to procure a bow and set of arrows that are actually or have been in use. In the following illustration, no less than eight different patterns of arrows are represented. We have derived our information from various sources besides our own observations. We had instructed some of the most intelligent Eskimo to make for us wooden models of all the different kinds of arrows that they ever knew were in use. So far as we were able to procure or see the original, these models were faithfully and well executed, and leaves us no reason to think that they in any instance imposed upon us. Some of the arrows we have seen in the possession of sailors that had bartered for them for a mere song, but would not trade them to us, under the impression that they would bring fabulous sums in the States. They now probably adorn some third-rate gin-shop.

Of the arrows figured, No. 1 is made from reindeer antlers, with short wooden shaft, an old and very common form of arrow. No. 2 is perhaps still older. This is also made of reindeer horn. It is more common on the Greenland coast than among the Cumberland Eskimo. No. 3 is the only one of the kind I saw, and this I was unable to procure; the head was of flint, and the next piece of bone, with the wooden shaft lashed in two places, showing probably a scarcity of wood. No. 4 was a rare (?) form of arrow among the Cumberland Eskimo. The head was made of stone, with the forward portion of the shaft of bone and the rest of wood. No. 5 was iron-tipped, a favorite pattern when iron was scarce. No. 7 is now the style used by the children, and was probably the next pattern suggested after No. 5, as any pointed piece of iron can be utilized for this form of arrow. No. 6 has a lance-shaped and somewhat elongated iron head; such arrows were made only when they could get a considera- 
ble iron supply. No. 8 is bone-tipped. I could not learn why the point should be so bent, but many had them so, and even preferred it. All their arrows were lashed with finely separated deer sinews. The feathervanes were nearly always made from the primaries of Strix scandiaca or Graculus carbo. The arrows were all short; in fact, their length depended somewhat on the wood supply. We were unable to find but a single specimen of flint arrow-heads in the graves.

The bow is made from reindeer antlers; these are split, using only one of the halves in the construction of the bow. It is always made in three pieces, ingeniously lashed together. On the back of the bow are three or more strings, made like the bow-string; these are fastened at both ends of the bow, and also securely at the middle of the back. This of course gives additional strength to the affair, and is a convenient place to carry an extra string. The bows are very short, often not more than thirty inches. Not every Eskimo is able to manufacture his own bow; but each encampment has generally at least one skilled mechanic, who supplies the rest.

Bows and arrows were principally used in the capture of the reindeer, hare, and birds, seldom seals. These bows are surprisingly elastic, and the Eskimo are able to use them with wonderful dexterity. In shooting this weapon, the string is placed on the first joint of the first and second fingers of the right hand.

Another Eskimo implement fast going out of use is the kakivak, or salmon spear. A glance at the figure will give a better idea of this instrument than we can express in words. The two outside tines are each about seven inches in length, and are made of reindeer antlers. Near the tip and curving inward is a tooth-like prong about one and threefourths inches in length. The points of these teeth come to the end of the middle tine, which is abont six inches in length, perfectly straight, and made from walrus ivory. The three tines are securely lashed to a piece of the jaw-bone of the whale, of varying length, sometimes only a foot, but often two or three feet. When the bone shaft is too short to use, they generally have a short wooden handle lashed to it to make it the desired length. The two ontside tines of this spear are very elastic, and spring out when a fish is struck, but close again when the body of the fish has passed beyond the tooth points which project inward. It is thus impossible for it to escape, the central tine having entered the body.

Another instrument, generally used in connection with the kakivak, is 
the aják-kaljijjak, or ivory fish-bait. It is about four inches in length, and is made to look as much like a fish as possible. A line is passsed through the middle of the back, and is fastened on the belly; here is a small ivory hook that reaches from an inch to two inches below the fish. The principal use of the ajakkaljujak is not, however, to hook fish, but to lure them within reach of the spear. The Eskimo takes his ivory fish and bobs it up and down in the water, generally in a tide crack or a hole in the ice on purpose, and watches till he spies a fish making for it. He then gently begins to haul in on his line, if the fish follows the lure, till it is within reach of his spear; sometimes a greedy fish will swallow the bait and get eaught with this primitive gear. At the present day they seldom use this implement. Iron fish-hooks are supplied them from the ships; but they are poor fishermen compared with the Greenlanders.

One little implement of comparatively insignificant importance seems not to have been superseded by any modern substitute as yet. It is the kadjuk, a small piece of ivory of different shapes, used to insert in the lips of the seals while dragging them over the ice. We have given illustrations of the principal patterns we found in use. No. 8 is the same as No. 7 when seen from the top. This is a very ingenious piece of work. The main body of the piece is hollow, and the portion No. 11 has a head which prevents it pulling through, but at the same time turns freely, and prevents the line from twisting when the seal turns over. It is so well made that the inside piece cannot be got through any of the openings. No. 3. is No. 2 seen from the top. No. 10 is sometimes used as a part of the clasp on the sealing line. Nos. 1, 4, and 9 are the commonest patterns. No sealer's line is without one or more of these implements of some pattern or other; they are all made from walrus ivory.

Of prime importance to the Eskimo hunter is his hook for catching the young seal. Here again their old pattern has been modified by their contact with the whites. A glance at the aocompanying figures will sufficiently explain the shape of these implements. The upper figure represents the ancient pattern; it was found in a grave in the Greater Kingwah Fjord, but so much decayed as to fall to pieces when handled; the hook part was made from a portion of a reindeer's antler, with a small barb cut near the point. Its resemblance to the iron hook of the present day is very apparent.

The sealing hook of the present day is made generally from a discurded whale lance; the handle is a light wooden shaft about tive feet in length. 
This instrument is used only to eatch the young of Pagomys foetidus, while they are still in the white coats; they are caught either while lying beside the athut on the ice or while still in the snow-burrow. When an Eskimo sees a young seal on the ice, he begins to make his way cautiously toward it, stopping frequently, and giving the animal ample opportunity to satisfy its curiosity. The seal will work its head and fore part of the body in a jerky, awkward manner, and keep edging nearer and nearer to its atluk; the Eskimo watches every movement of the seal, and knows just the proper moment to advance a step or two and then stop. This manœurre is kept up till he gets near enough to reach the seal with his hook. He then makes a quick jump, at the same time striking the hook into the animal. Sealing among the Cumberland Eskimo is sufficiently described under our notes on Pagomys foetidus, in the report of the mammals, for us to leave it out of this paper.

When a seal-skin is about to be prepared for drying, the blubber is first removed somewhat roughly; the skin is then laid on a board, and with the woman's knife the membrane underneath the blubber is separated from the skin. The knife must be rery sharp to do this successfully. The operators always push the knife from them; it takes considerable experience in order to do the job well. When all the blubber is removed, which will take three or four hours of faithful work, the skin is taken outside, and by means of the feet is rolled and rubbed around in the snow for some time, and by this process they succeed in removing every trace of grease from the hair. When thoroughly washed, the skin is put upon the stretchers, if it be winter, to dry; these stretchers are merely four poles, which are lashed together at the corners like a quiltframe, the proper distance apart to suit the size of the skin. The skin is secured in place by seal-skin thongs passed through little slits along its edges and made fast to the poles. When the skin is properly stretched upon the frame, it is put above the lamps inside the snow-hut to dry. As the sun gets higher and begins to have some effect, the skins are stretched, flesh side up, on the southern slopes of snow-banks, and are secured by means of wooden or bone pegs about a foot in length. As the season advances and the snow melts they begin to stretch the skins upon the ground by means of the before-mentioned pegs. The skins are not allowed to rest upon the ground, but are raised a few inches to allow the air to circulate underneath. Skins dry very fast when exposed in this manner.

The first days of spring are always a busy time with the Eskimo 
romen. One thing is, they get more freshly killed skins to prepare, and then they generally have a surplus stock of the winter's catch which they could not take care of by the slow process of drying over the lamps in the huts during winter. The skins of the young in the white coats are dried in some.considerable quantities, as it takes about fifteen to make a single suit of clothes, and many have double suits made from this material. They have no idea of any tan, and prepare the skins merely by rubbing them with their skin-scraperș.

We insert a sketch of a very old skin-scraper, such as are now found only in the old graves. It is made of stone, with a wooden handle, which is fastened to the stone by means of a strip of whalebone. Another and later pattern is made from the scapula of a reindeer. A better idea of its make can be got from the sketch than by a description. Such scrapers are still in use, but serve as a sort of auxiliary to a scraper made from a tin can, resembling a little scoop in shape, and having a wooden handle. This is the style of scraper made at the present day, and is by far the most effective instrument of the three. The manner of using these scrapers is to take the skin firmly in the left hand and putting the knee or foot upon the lower part of it holding it securely, while the scraper is worked with the right hand, pushing downward with some force. If the skins are very dry, when they begin they are somewhat softened by rubbing with the hands, or eren chewing the most stubborn parts. They continue using these tools upon a hide till it gains the desired pliability. All the work of stretching, drying, cleaning, washing, and softening the skins falls upon the women.

The skins of Phoca barbata are stretched on a frame like those of the netsick, but not till the hair has been removed. The cutting of the hair is one of the nastiest and most disgusting sights one can imagine. It generally falls to the lot of some old woman to do this. The skins are allowed to lie and become somewhat putrid, a portion of the blubber remaining on. The only tool used is the woman's knife before mentioned. When about to clean one of these skins, the squaw takes off her boots, stockings, and pantaloons, and, tucking her feet under her body, lays this dirty, bloody, greasy, stinking skin on her bare thigh, the flesh side down. She then pushes the knife against the hair, cutting, or rather shaving it off. As her hand becomes too oily to hold on to the skin, she puts her fingers into her mouth, and thus cleans them. When properly cleaned, it is dried in the manner already spoken of, except that the back and belly of the animal are dried separately, as the skin is different on those por- 
tions of the body, and would dry unevenly. When dry, it is almost as stiff and hard as a board. This skin is used mainly for the soles of boots; the pattern is eut from the hide, and then chewed till it becomes suffieiently softened to sew. This last operation is also mainly performed by the old squars. When they are too old to sew, they become orjook chewers as the last resort, and when their teeth fail them they are better off in the grave.

Seal-skins are also manufactured into drinking cups; such cups generally have a depth and diameter of about three inches. A short, straight piece of bone, mostly the humerus of a gull or duck, is sewed into the upper rim on one side, projecting outside about two inches and a half; this serves for a handle. The hair side of the skin is used for the inside of the vessel. Larger vessels, somewhat resembling a small sack, were used to carry water in at their encampments; but when out traveling, they mostly carry their water supply in a seal's stomach, prepared for the purpose.

We would naturally expect these people to be very expert in making various devices for capturing their game in traps or snares. This does not seem to be the ease, however. They make a fox-trap, which is nothing more than a little round hut of ice, with a hole in one side just large enough for the fox to crawl into. Inside the hut is a large slab of ice, which rests horizontally upon a-small upright piece of ice; the end of the upright rests on the bait, and when the fox pulls at the meat he draws the upright down, and the ice slab falls upon him and he is a sure prisoner.

Another manner of eatching foxes is to make an ice house much larger, so high that a man can readily stand up in it. A small funnelshaped hole, just large enongh to admit the fox, is made at the top of the structure, and the bait is hung inside just out of his reach. The fox will work a long time trying to secure it, and finally crawl in and jump down upon the floor of the hut, but then he is unable to get out again.

A sort of snare is sometimes made for hares. It is nothing more than a seal-skin line, with a number of slip-nooses upon it; this is laid across the runs of the animals, or upon their feeding-grounds. They are often canght in this manner; but the foxes are generally the only ones benefited by the capture; all that the Eskimo finds is a little hair and a few bones the next morning.

Birds are sometimes snared in about the same manner, except that 
they use finely braided deer sinews for the snares, instead of seal-skin. They take a good many eiders on their nests in this manner.

When traveling over the frozen wastes in winter they use snow-shoes. These are half-moon-shaped, of whalebone, with seal-skin thongs tightly drawn across. They are about sixteen inches long. Another pattern is merely a frame of wood, about the same length, and eight or ten inches wide, with seal-skin thongs for the foot to rest on. As their dogs' feet often get rery sore while traveling on crusty snow, they make them little moccasins of seal-skin to protect the feet.

Nearly all the Eskimo become snow-blind in spring, though they use eye-blinkers of wood. These are only a piece of wood fitting closely over the eyes, and having a horizontal slit about one-sixteenth of an inch wide; it affords a good deal of protection to the eyes, but they are generally not put on till the condition of their eyes forbids them going without. Some eye-blinkers of bone were found in a grave; they were apparently very old, and of a different pattern, but so much decayed as not to admit of handling.

All the Cumberland Eskimo of the present, day have sledges of wood. This has either been bartered from the whalemen or secured from the wrecks of ships. There are, nevertheless, some remains occasionally found of sledges that were composed entirely of bone, whales' jaw-bone apparently. They were made in many pieces, and ingeniously lashed together. All their sledges of the present day are shod with bone, and when about to undertake a journey they pour warmed blood upon the under surface of the bone shoeing; some use water, but this does not last nearly so long as blood, and is more apt to chip off. This coating makes a very smooth surface, and also protects the runners. All their sledges have a sort of upright on the back end. This is nothing more than a deer's head, with the antlers attached, the antlers being lashed on the top edge of either runner. This serves for a variety of purposes, and is very handy indeed.

The kyack of the Cumberland Inuit does not seem to have undergone any change in pattern since the whites came among them. Still, these craft are extremely rude and bulky, compared with the Greenlanders' kyack; neither do they compare with the Greenlanders in expertuess in its use. These kyacks are mostly so large that they would readily carry two persons, and quite heavy. They do not earry so much gear upon their kyacks as the Greenlanders; the seal spear, walrus spear, and bird spear, with their respective lines, are about all, unless they are after some 
special kind of game, as, for instance, bears; then they carry a bear lance, which, however, does not materially differ from the whale lance. The omiak, or woman's skin boat, is now rare among them, as they are able to procure whale-boats from ships, and one boat will accommodate several families. Some of these boats still exist in the vicinity of Nugumeute and farther south. It required about fifteen skins of Phoca barbata to construct one, and several years' accumulation of drift-wood.

It seems very probable that before the advent of whalemen they practiced a great many rites aud ceremonies, many of which are now obsolete, or exist only in tradition. Sometimes one of these old customs will be repeated, but, as a general thing, not in the presence of a white man, if they can help it.

One of these customs, which possesses a good deal of interest, is their manner of greeting a stranger. When a stranger arrives at an encampment, and is personally unknown to all or the major portion of the inhabitants of the village, he receives an introduction after the following manner: The villagers (the men) form themselves into a single rank, all of them, with the exception of the stranger and the head ancoot of the village, having hare-skin mittens on; they then begin a monotonous singing chant, keeping time with their arms, swinging them in front, raising the hand as high as the shoulder, with arm slightly bent, and then describing a half circle by lowering the hands as far as the abclomen. Finally, the ancoot and the stranger step out from the ranks and face one another. Both have mittens of seal-skin. The stranger complacently folds his arms over his breast, and inclines his head to one side, so as to fully expose liis cheek, while the ancoot deals him at terrible blow on it, sometimes felling him to the grouncl. The two actors now change parts, and it becomes the stranger's turn to strike, which he does with a vengeance; the two then kiss each other, and the ceremony is over. The stranger is now duly initiated to share in any and all their eustoms, and due hospitality is shown him by all. Among his privileges he can also choose for himself a wife during his sojourn.

Another custom, which was once very popular, is the following: An ancoot dresses himself up in the most hideous manner, having several pairs of pants on, among the rest, and a horrid-looking mask of skins. The men and women now range themselves in separate and opposite ranks, and the ancoot takes his place between them. He then picks out a man and conducts him to a woman in the opposite ranks. This: couple then go to the woman's hut and have a grand spree for a day 
or two. This manner of proceeding is kept up till all the women but one are disposed of. This one is always the ancoot's choice, and her he reserves for himself. The people thus assembled are, of course, all well known to him, and he understands pretty well how to mate them so as to meet general approbation.

When the women have their monthly courses, they will not work, nor visit the ship, or even each others' huts.

The dead are generally covered with a little pile of stones, so arched over as to form a sort of tomb. It is also quite common at the present time to leave the dead fully exposed upon the rocks. All the Eskimo have a great horror of handling a corpse, so that when a person is very sick he is carried out to die, and where be lays the stone pile is erected around him. The hunting implements and many of the valuables of the deceased are put by him; such things as he will need for a long time inside, and the rest outside of the grave. We have found in one grave the skeletons of two dogs, remains of a sledge, whip, \&c., and the partial skeleton of a Pagomys foetidus. The right femur of the Eskimo skeleton in the grave was deformed, and had the appearance of having been broken and allowed to grow together without setting. He was probably lame during life, and the dogs and sledge had been given him in order to facilitate his traveling to the happy hunting-grounds. In another grave we discovered portions of a kyack. That decayed bow and arrows, spears, and all their hunting implements, were at one time plenty in graves, is very apparent; but of late years they have so amended this usage that it is no longer necessary for the articles to remain very long, so they are taken out and used by the relatives. In very recent graves we found tin cups and pots, knives, and even one fork and spoon, comb, pieces of cloth, needles, thread, thimble, and in one a photograph and a Harpers Weelly newspaper, tub for meat, \&c.; in fact, all the equipments and treasures of the deceased. The more valuable of these articles were outside, and would undoubtedly soon have been appropriated by the relative's. This is the reason that so little is found in graves at the present day. In the old graves the wood and bone implements seem to decay very fast, and can seldom be handled without falling to pieces. All the graves contain entire or partial skeletons of some animal or bird, mostly the netsick seal. This was put in for food, undoubtedly. Very few graves contain the perfect skeleton of the inmate. The dogs, wolves, and foxes despoil the graves, and scatter the bones in every direction. It is seldom that these tombs are so well constructed that the dogs cannot tear them down. 
As a rule, they are not kind to the aged or feeble. We know of ono instance where an old cripple, who had no one who would recognize his authority, was obliged to go sealing for himself. He had but one dog, and no sled; so, taking a seal-skin and allowing the dog to drag it, he was conveyed to the sealing-ground on this novel conveyance. There were every day large sleds leaving the encampment, but no one offered to help the old man, as there was no prospect of his being able to reciprocate the favor.

Among their many superstitious notions, the wearing of charms about the person is one of the most curious. These are called amgoouk, or amusit, and may be nothing but pieces of bone or wood, birds' bills or claws, or an animal's teeth or skin. To these charms they attribute supernatural powers, and believe them to be able to keep the wearer from sickness or misfortune. It is a common custom for the wife to throw a piece of seal's blubber on her husband's kyack when he is about to go hunting; this will give him success. Little strips of deer-skin are hang about the person in different places to insure success in some undertaking or to ward off some misfortune, real or imaginary. We discovered one of these charms, which seemed to possess unusual interest. It was worn by a little girl about eight years old. She had a small envelope of seal-skin that was worn on the back of her inside jacket. We succeeded in bribing her grandmother to show us the contents of the envelope, which proved to be two small stones, the one a bluish flint, the other apparently meteoric iron. The tradition connected with these stones, the grandmother said, is that a very long time ago an Eskimo, from whom she was a lineal descendant, had discovered the iron, and had picked up a stone to break a piece off and take home with him; but when he struck the iron fire flew from it, and he soon learned how to make use of this accidental discorery, and became a great man among the people. At this point we lost the thread of the old woman's narrative, and all we could further learn was that these two small pieces had been preserved in the family for successive generations, and were inherited by her from her mother, and that she had now given them to her grandchild, the child's mother being dead. The child will in turn give it to her children. She thought this charm of inestimable value, and could not be induced to part with it, for, she said, "No one has yet died while wearing this charm."

Another charm of great value to the mother who has a young babe is the canine tooth of the polar bear. This is used as a kind of clasp to 
a seal-skin string, which passes around the body and keeps the breasts up. Her milk supply cannot fail while she wears this.

Many of the ancoots by long practice become quite competent jugglers, and often take advantage to show off their powers to the edification of their friends. A common trick with a full-fledged ancoot is to come suddenly into a hut with a harpoon toggled on his breast, and the handle sticking in his back, the wound bleeding profusely. Such demonstrations make a lasting impression upon the minds of those who witness it, and it becomes no less marvelous when they see that he survives, without even a mark after the wound.

A very interesting legend is one which they tell as to the origin of man, as regards creation, and the beginning of all things. They say it came so of itself. Of the creation of man they say: In the beginning there grew up from the earth a man; he got a wife from one of his thimbs (!), and from this pair the race has originated. But the whites, whom they call cablunet, or codlunak, they have sprung from dogs. An Eskimo woman at one time gave birth to human beings and dogs. These latter she put in an old boot, and threw them out into the sea, saying, "Go hence, and become white people." From this they say whites live on the sea, and their ships are like the Inuits' boots, round at both 


\section{MA M M A LS.}

FRAGMENTARY NOTES. ON THE MAMMALIA OF CUMBERLAND SOUND.

BY Ledwig KemLin:

The following list coutains little else than fragmentary notes on such species as I procured, or with certainty identified, during my short sojourn in the northern waters of Cumberland Sound (the Hogarth Sound of Penny), at about lat. $67^{\circ} \mathrm{N}$.

The region about our winter harbor was marvelously barren, and very few mammals are found there. Its location is such that many of the species that frequent the southern waters are seldom found about Annanactook, as it is so far "inland." It is a rarity for a bear to stray up the sound any distance, and some of the seals and most of the cetaceans are only of irregular occurrence.

Near the southern entrance of the sound, however, the harp seal, polar bear, walrus, and many of the cetaceans, are regular visitors. I have not the least doubt that many cetaceans are found in these waters that I lid not see. Should I place confidence in the information of whalemen regarding whales, I could easily make out many species, and some very marvelous ones; but my experience has been that whalemen generally are not to be relied upon in this matter, as they confound species to such a degree that one can never unravel the snarl, and their own peculiar nomenclature makes matters worse instead of better.

My stay was also much too short for anything like a satisfactory investigation of certain interesting problems. I was even obliged to leave some valuable skeletons, and could have procured many more had there been any place to stow them away on shipboard.

There seems to be a prevalent belief among the Eskimo, as well as the whalemen, that the mammals have disappeared from this section of country at a wonderful rate within the last few years. I found the remains of Trichechus rosmarus, Cistophora cristata, and Ursus maritimus in the ancient kitchenmiddens in Kingwah Fjord, in localities where these animals occur at the present day only as rare stragglers. It is hardly probable that such large animals could have been brought any distance, 
so they must at a comparatively recent date have been found in the immediate vicinity. I could find no trace of the musk-ox, or any Eskimo that had seen one; but almost any of them conld describe the animal very intelligently, and would tell you they are found far to the north. The Eskimo name for this animal, "omingmuk," is by no means a rare name among them, and it is possible that they were once found on Cumberland Island, but are now extinct, as other species are in a fair way of becoming.

The vicinity of the Kikkerton Islands offers many advantages to : naturalist; it is now a permanent whaling station, and a person coul 1 at any time secure the valuable assistance of natives, besides having ample conveniences for drying, stowing, \&c. It would be comparatively easy to secure a good skeleton of an adult right whale at this place if a person went about it in the proper manner. Almost any of the smaller cetaceans, and all the seals, adult, young, and foetal, could be secured at a very trifling outlay of presents to the Eskimo.

\section{Ursus maritimus, Linné.}

"Nannok," Cumberland Eskimo.

It is a rare occurrence to find a bear any distance up Cumberland Sound; they are common about Cape Mercy, Shaumeer, and Nugumeute, but seldom stray above Niantilic, or the Kikkerton Islanils. Below Niantilic, on the southern side of Bear Sound, in the vicinity of what the Eskimo call Okaglik and Kokaluyah, they are quite plenty. Many are captured here every year, especially in spring, by the Eskimo, who fearlessly attack them in their frail kyacks, but are afraid of them on the ice or land. From Nugumente to Hudson's Straits they appear to be even more plenty, and westward, in the northern waters of Hudson's Bay, whalemen often procure twenty or more skins in a season.

In October, 1877, an enormous female with two cnbs paid the Eskimo eneampment, at the Kikkerton Islands, a visit. They swam orer the Salmon Fjord, probably scenting a dead whale that was on the beach near the huts. The bears made a lively time arnong the huts, and a considerable ontlay of ammunition and dogs was made before they were finally eaptured. There were abont two hundred dogs and half as many natives, besides the crews of two whalers; all this motley crowd made war on the bears; one of the whaling, eaptains, a little braver than the rest, got too close to the old bear, and she dealt him a blow which knocked his gun many feet into a snow-bank; she then began to make way with him, but was prevented by the Eskimo and dogs. A joung Eskimo was 
served in a similar manner, but sustained quite serious injuries. Great consternation and fear prevailed among the women and children, and that memorable night, when the nannokes besieged their quiet camp, was long a lively topic of conversation.

When the Florence took the pack-ice off Cape Mercy, a huge male was suddenly espied alongside, but he did his best to get away as fast as possible; a boat was lowered and his capture was as devoid of excitement as the killing of a sheep in a barn-yard. We had at this time sixteen Eskimo and thirty dogs on deck, and the greater portion of the meat was utilized as food by one or the other without any symptoms of poisoning. During the season that Pagomys foetidus have their young, the bears begin to wander up the fjords in search of them, and are at this time often found a considerable distance from the open water.

In and about the old stone-hut foundations in the neighborhood of Annanactook I found the remains of bears. There is a story among the Eskimo that the bear, walrus, and hooded seal were once plenty there, but for some cause do not now frequent the locality. A very young cub skin was secured in April by a Shaumeer Eskimo. The vicinity of Cape Mercy is one of the most frequented localities for bears; here they come down on the pack-ice with the current from the north. Eskimo from the region northward in Cumberland are in the habit of coming here to hunt them.

\section{Vulpes lagopus, Linné.}

"Touyunaik," Cumberland Eskimo.

The Arctic fox is quite common on both sides of Cumberland in all suitable localities. During the winter they often fare badly, and become quite impudent when pressed by hunger, even coming upon the schooners' decks at night. They were a source of annoyance as well as amusement to us around our observatory. We were not the fortunate possessors of enough glass to let the light in through the wall of snow that surrounded our tent, so we had recourse to oiled sheeting stretched over the aperture, borrowing the idea from the Eskimo window of seal intestine. But as we had no dogs about our snow-house, the foxes became so bold during the long cold nights of winter that they often came and sat around the storepipe that projected through the roof of the hut. Our cloth windows had to be repaired very often, as they would tear them down and eat them for the oil the cloth contained. It was almost impossible to eatch them with a steel trap. I tied the bait underneath the tongue, and carefully placed the trap in a little excavation in the Bull. Sat. Mus. No. 15 
snow, and covered the whole with snow; but they dug beneath the trap, and secured the bait from below, often even without springing the trap. With an ice trap made after the Eskimo pattern I was more successful.

As soon as the seals begin pupping, the foxes fare better; this season is in fact the grand banqueting time for these animals, after the long sufferings and privations of winter. At this season (March, April, and May), they destroy a great many young seals. I have often found the remains of the seals so well skinned and cleaned that it seems impossible it could have been done by an animal. They begin by biting the skin around the mouth, and drawing the entire animal through the aperture, and turning the skin inside out; even the flippers are drawn through to the nails, and every vestige of the meat removed. Nor is the skin bitten in the least, althongh it is finely cleaned of all the fat. But the most remarkable part of all is, that the skeleton remains intact and finely cleaned. When the Eskimo find such skins, they always make use of them, as they are quite as well skinned as if they had done it themselves. The white variety appears to be much more abundant than the blue. According to the Eskimo, the two varieties interbreed, and the young are sometimes dark and both parents white, and vice versa. During the winter months they congregate in considerable numbers abont any carcass, especially a whale, and get themselves thoroughly begrimed with grease.

It often happens that some venturesome fellow succeeds in getting upon the ducks' island, in breeding time, by means of the ice, and is left there; but when the birds leave he gets enough shell-fish, \&c., at low-water to live on till the ice makes. If they are a short distance from the mainland or from other islands, they do not hesitate to take to the water.

\section{Canis familiaris, Linné, var. borealis.}

"Kidmik," or "Mikkie," Cumberland Eskimo.

As might be expected, the dogs of the Cumberland Eskimo are afflicted with the much dreaded rabies. I paid considerable attention to the subject, in hopes of being able to throw some light on the cause of this disease, but, like many others before me, with little success. In the first place, so far as the dogs about our winter harbor were concerned at least, there are other causes besides the so-called hydrophobia that lessens their ranks, thongh when a dog dies this is always the cause assigned. Some of the best dogs that died at Annanactook during the winter of 1877-78 died from injuries inflicted on the head by a club in the hands 
of their masters. After these dogs were disabled they wandered about the settlement staggering and howling, and were to all appearance bona fide victims of hydrophobia; but on dissection it was only too plain what the matter was. Many of the dogs are so overworked and so illy treated that they could not survive the repeated injuries inflicted upon them if they were as strong again.

The Eskimo have the habit of putting a slut in heat on ahead as leader, as by this method they considerably accelerate the movements of the rest of the team, and save themselves some extra labor; but these dogs often prove themselves too eager, and rupture blood-ressels. I have seen such cases where the dog romited clear blood, and also discharged it copiously through the anus; such cases survive but a few days generally. Again, many young dogs are taken from the mother long before they are prepared by nature to shift for themselves. I have positive evidence of this being a prolific cause of so many young dogs dying. Of all the dogs that died at Annanactook, at least four-fifths of the adults were males, and the greater number of these died about the time the females were in heat.

I was very much interested to see if the theory that hydrophobia is prevalent only in countries where the females are subjected to indiscriminate slaughter, or animal instinct thwarted or perverted under the ban of an ignorant and false modesty, would work here, instances being cited of Turkey and other countries, where the dog is held sacred and allowed to run at large, that hydrophobia is unknown. According to the theory, then, that its origin is always the result of unrequited affection, we should not find this disease among the Eskimo dogs, where it may reasonably be expected that nature has allowed the proper proportion of the sexes and man does not interfere; but here is the point: Has the Eskimo dog unrestrained freedom to follow the instincts of his animal nature? We answer, $\mathrm{By}$ no means. To be sure, there are plenty of females, but they are appropriated by such dogs as possess the greatest strength; the females go to them, and the weaker dogs are given the cold shoulder. As a general thing, the possession of a slut is a disputed point, which ends in a hard fight between the dogs; but there is no further question after the battle, and the vanquished dog has to bear a double disappointment; this he seems unable to do, and worries himself into a melancholy that soon takes the form of the so-called hydrophobia.

I carefully watched a team of three dogs that I often went sealing with; one was a fomale and two were males; the slut seemed to be ap- 
propriated by one of the dogs without question, till one day a strange dog from another settlement was added to the team. The possession of the slut now became the cause of a series of severe fights, which ended in favor of the strange dog, which immediately became the guardian of the slut. The beaten dog began to lag and droop, and in a few days was dead, having gone through all the stages of hydrophobia to all appearance.

This was not the only instance of a similar nature that came under my observation; still I do not wish to be understood that I place unshaken faith in this theory. I had too short a time for observation, and too few examples to warrant me in making generalizations on these data; but I think it well worth the time for any one who does get the opportunity not to overlook these facts. I dissected a number of the male dogs that died from the rabies, but I never could detect any of the organs diseased except the penis, testicles, and sometimes the kidneys. Why this should be the ease I am at a loss to say. There is one other theory that may throw some light on the subject, viz, the constant interbreeding of the dogs. I have known of instances where a dog had possession of the mother and her yearling whelps, all, mother included, of which he was father to. It is certain that the progeny resulting from such connections are very inferior, and tend toward degenerating the race. It often happens that female dogs cohabit with wolves, the dog being driven off by the superior strength of the wolf. This progeny again is characterized by superior strength and great powers of endurance, and is less apt to suffer from disease.

It sometimes happens, the Eskimo tell me, that a family goes into the interior and remains for a year or more, but seldom loses any dogs by disease; they have an idea that the salt-water has something to do with their dogs dying, for they say they do not die when they live away from it. It does not seem probable, however, that the disease would prove contagious, assigning either of the above causes for its origin.

Again, is it positively known that the disorder is not communicable by bite? I am by no means sure of this. The Eskimo always carefully get out of the way of dogs afflicted in this manner, and they told me that if one of the sick dogs bit me I would get the same disorder. This information may have been imparted to them by whalemen, however.

4. Canis occidentalis, var. griseo-alba, $\mathrm{Bd}$.

"Amarook" (?), Cumberland Eskimo.

Wolves are frequently seen during the winter months on both shores of Cumberland; their principal resorls, however, are further inland, 
where the reindeer herds abound. It often happens that the Eskimo dogs and wolves interbreed; the female dog is especially liable to cohabit with a wolf, and the progeny are considered much superior beasts, but are very hard to manage. I have seen Eskimo dogs that corresponded hair for hair with the Arctic wolf.

The Eskimo say there are packs of $\operatorname{dogs}$ now in some localities that have run wild, and in all probability returned to the original wolf type. There are stories of some kind of animal, that from the description giren by some may be a Gulo, but others say it is only the common dog; such animals are always reported from the interior.

It is said that the female wolf is considerably fleeter than the male, being longer-bodied. The females, the Eskimo say, always distance the males in the chase after the reindeer, and generally succeed in killing the deer before the male comes up.

\section{Mustela erminea, Linné.}

Two specimens, procured in the Kingnite Fjord, one in the summer and one in the winter fur. Appears to follow the lemming in their migrations; is nowhere abundant in Cumberland, and even unknown to some of the Eskimo. Said to be able to capture the hare and ptarmigan by attaching itself to some vital part and not loosening its bold till the victim is dead. I am rather skeptical on this, howerer. Still, the Eskimo say they have seen them do it, and it really puzzles me to tell what else they should live upon during winter, as they do not hibernate.

6. Myodes torquatus, (Pall.) Keys. \& Blas.

"A wingak," Cumberland Eskimo.

I procured but a single specimen of the lemming; this was caught near Cape Mercy. They may yet be common somewhere along the sound, as I saw traces in different places where we stopped. According to the Eskimo, they are getting less common every year. Whalemen have told me that twenty years ago some ships procured as many as four hundred skins at Niantilic, in the spring, from the young Eskimo, who killed them with bows and arrows. From what I could learn of the Eskimo, the lemming is rery irregular in its migrations, appearing in great numbers at one place, and then disappearing for many years.

7. Lepus glacialis, Leach.

"Okoodlook," Cumberland Eskimo.

Common in all suitable localities. Many do not undergo any change of color during summer, and I doubt if it be more than partial change 
with any. I have seen pure white specimens during all the summer months, and occasionally one about half-gray. The Eskimo firmly believe that the lungs of the hare applied fresh to a boil or sore of any kind is a sure cure. The specimens I examined in Cumberland were much smaller than Greenland specimens.

\section{Rangifer tarandus, (Linn6) Bd.}

"Tuktoo," Cumberland Eskimo.

The reindeer are found in considerable numbers on both sides of Cumberland Sound, but by far the greater number on the western shore. It is no rare instance to find them during the summer months on the seacoast; they seem to delight in feeding upon the fuci exposed at low tide. In winter they retire to the larger valleys and go farther inland, being seldom seen on the coast at this season of the year.

The Eskimo go reindeer-hunting every summer, commonly during the months of July, August, and September. At this season they make quite extensive excursions inland, where the deer are more abundant and much more easily procured. Within the last few years they are reported as less common on the Penny Peninsula; but I hear of no apparent diminution in their numbers to the west and southwest, especially toward Lake Kennedy, where they are reported as very abundant.

Before the introduction of firearms among the Eskimo by the whalemen, they took advantage of the habits of the deer in coming down to the coast, and drove them into the water, where they were easily captured with a kyack. The Eskimo bring the skins back with them to their winter encampment, having cached the meat for the ostensible purpose of returning for it in winter. This seldom happens, however, and the wolves generally make way with it. It is said that when a herd is first approached by a hunting party that has been living on the seacoast, they scent them a long way off, but that they soon lose this power; the fact being, I take it, that the peculiar odor of the salt-water has left the Eskimo. During the winter they herd together in large droves, and when a suitable valley is found paw up the snow for a considerable extent, till it looks as if a herd of swine had been rooting in the snow. These droves are continually beset by packs of wolves, which keep a vigilant watch for any that unluckily stray out of the herd, for such a one is immediately attacked and run down. It is seldom, however, that the wolves can do much damage to the herd when they keep together, as they form a cir cle, with the weaker ones in the centre, and can thus keep the wolves at bay. 
9. Callocephalus vitulinus, (Linné) F. Cuv.

"Kassigiak," Cumberland Eskimo.

The so-called "fresh-water seal" of the whalemen is one of the rarer species in the Cumberland waters. They are mostly met with far up the fjords and in the fresh-water streams and ponds, where they go after salmon. They are rather difficult to capture, as at the season they are commonly met with there is so little blubber on them that they sink when shot. The skins are highly prized by the Eskimo women for their jackets, and if they do not have enough for the entire garment will use what they have, always putting it within the most convenient sight of the wearer. It is said by the Eskimo that the young remain in the white coat but three or four days, differing greatly in this respect from Pagomys fotidus. Neither do they make an excavation underneath the snow for the reception of the young, like the above-mentioned species, but pup later in the season, on the bare ice, fully exposed. The adult males often engage in serere combats with each other. I have seen skins so scratched up that they were nearly worthless; in fact, the Eskimo consider a "kassiarsoak" (a very large kassigiak) as having an almost worthless skin, and seldom use it except for their skin tents. The skins of the young, on the contrary, are a great acquisition. It is said, possibly with a shade of exaggeration, that the affections of the Eskimo damsel can be secured by a present of kassigiak skins, when all ordinary means of persuasion have failed to move her.

10. Pagomys fœtidus, (Fab.) Gray.

"Netsick," adults generally; "Tigak," adult males; "Netsiavik," young after shedding and till one year old; "Ibeen," young in white coats, of the Cumberland Eskimo. "Pickaninny pussy," young, pigeon-English of the whalers.

This seal is very common in all the fjords and bays from Hudson's Straits northwad along Cumberland Island to the extreme head of Cumberland Sound, on all the outer islands about Cape Mercy, and on the west coast of Davis Straits. I have seen skins from Lake Kennedy that I could not distinguish from those found in Cumberland Sound. This seal was never noticed but a few miles from land; was not met with in the pack-ice, nor on the Greenland coast except far up the fjords. This was in July and August; but I am informed that they become more common toward autumn, and are found in considerable numbers some distance from land; they are less common here, howerer, than on the west coast.

It was a source of great curiosity to the Greenlanders to see the 
clothing of the Cumberland Eskimo made from the skins of the joung seal; they at first mistook it for bear. I was informed that, in the vicinity of Disko at least, they never procure enough of the skins of the young in the white coat to use them for clothing to any extent.

In the Cumberland waters they are resident, and do not migrate at all unless much disturbed, and then they merely seek a more secluded locality. On the Greenland coast they appear to migrate up the ice fjords in summer, but to be more generally distributed at other seasons.

The netsick shows a decided predilection for the quiet still bays and fjords, seldom venturing far from land. They are the only seal caught through the ice in winter, and are consequently the chief and almost sole dependence of the Eskimo for food, fuel, light, and clothing.

The skins of the adults are made into summer clothing, while the young are in great demand for under-garments and for trousers. Children often have entire suits of the young in the white coats; such clothing looks very beautiful when new, but it is new but a few days, and after this it is repulsive enough. The females were found enceinte in the latter part of October, and a fotus nearly rearly for birth was taken from the uterus January 16. It was two feet from the end of nose to the end of hind flippers. It was so doubled in the uterus, however, as to occupy a space hardly a foot in length; the hind flippers were turned forward on the tibix, the fore flippers hugged the sides, and the head bent over on the neck and inclined to one side.

In a large fjord known as the Greater Kingwah the tide runs so swiftly at one locality that it never freezes for a space varying from ten to one hundred acres. Here the netsick gather in considerable numbers all winter, and it is a favorite resort for such Eskimo as are fortunate enough to possess a gun. Being but a few miles from our winter harbor, there were almost daily excursions to these tide rifts by our Eskimo hunters. After the 1st of March very few pregnant females were killed at this place, they having by this time chosen the localities for having their young. Those killed after this date were all adult "tigak," or old stinking males.

It was interesting that the young-yearlings and some two-year olds, such as had not yet arrived at maturity-were seldom, if ever, killed in this open water, but lived in colonies by themselves. When an Eskimo finds a number of atluks (breathing-holes) near together, he always marks the place by raising little mounds of snow near the holes, for he knows that here is a colony of young animals, which have better skins and 
meat than the old ones, and are moreover much easier to capture. I have counted nearly seventy of these atluks on a space of two acres.

When a pregnant female has chosen the place where she is to hare her young, she makes an excavation from six to ten feet in length under the snow, and from three to five feet wide, the height varying with the thickness of the snow covering. The atluk is at one, extremity of this excavation, and in such a position that it is always a ready channel of retreat in case of danger.

The first young found in the Upper Cumberland waters was during the early days of March; still I have taken a fotus from the mother in the middle of April. The most profitable time for hunting the young seal is during the month of April; after this date they have shed so much that the skins are nearly worthless till the hispid hair has got to be of the proper length, when they are considered as the prime article, and second only to the young of Callocephalus vitulinus in quality.

The first young one I procured that had begun to shed was April 15. I have seen examples that were nearly or quite destitute of the white coat, but still not having the next coat in sight. Such specimens on close examination will be found to have a very fine coat of the new hair, but so short as not to be perceptible except on close examination, still showing the exact location and distribution of the dark and light markings; the slin at this time is very black, and often much scratched up, probably by the mother in trying to make the young one shift for itself. I often examined the stomachs of young as well as adults, but till after they had begun shedding the white coat, and were, in all probability, 25 to 30 days old, I found nothing but the mother's milk. After they begin to shift for themselves, their food, for a time at least, consists of Gammari of different species.

Before the young shed the white coat, they are from 23 to 36 inches from the nose to end of flippers; the average the season through, from a good series of measurements, was about 30 inches. They are very variable in color; some are pure white; others very white on the lower parts, but more or less dusky on back; others again are a fine strawyellow, with the same dusky variation as in the white ones. The yellow is also variable in the intensity of shade. Rarely some are found that are quite dusky all over, especially on the head and back; these are generally small and scrawny individuals. The hair is also quite as variable in texture as in color. In some it is fine, long, and woolly (mostly in the pure white examples). In others it is straight or wavy, while 
some have short and quite hispid hair. They weigh at birth from four to six and one-half pounds, but grow at an astounding rate, becoming exceedingly fat in a few days. The blubber on the young a few days old is almost white and thickly interspersed with blood-vessels; it is not fit to burn. There is usually but one young at a birth; still twins are not of rare occurrence, and one instance came under my observation where there were triplets, but they were small, and two of them would probably not have lived had they been born. The season for hunting the young at lat. $67^{\circ} \mathrm{N}$. begins about the middle of March and continues until the latter part of April. The first two weeks of April are the most productive, as later the hair is apt to be very loose, and many even have large bare patches on them.

When the season fairly opens, the Eskimo hunter leaves the winter encampment with his family and dog-team for some favorite resort of this seal; he soon constructs his snow-hut, and is as well settled as if it had been his habitation for years, for the seals he catches bring him and his family food and fuel, and snow to melt water from is always plenty, so that his wants are easily supplied, and he is contented and happy.

The manner of hunting the young seal is to allow a dog to run on ahead of the hunter, but having a strong seal-skin line about his neck, which the Eskimo does not let go of. The dog scents the seal in its excavation, which could not have been detected from the outside by the eye, and the hunter, by a vigorous jump, breaks down the cover before the young seal can reach its atluk, and if he be successful enough to cut off its retreat, it becomes an easy prey; otherwise he must use his sealing-hook very quickly, or his game is gone. It sometimes happens that the hunter is unfortunate enough to jump the snow down directly over the hole, and gets a pretty thorough wetting. The women often take part in this kind of sealing, and many of them are quite expert. The children begin when they are four or five years old. The teeth and flippers of their first catch are saved as a trophy and worn about the little fellow's neck. The next year when he begins, this will give him good luck, they think.

There exists a eonsiderable spirit of rivalry among the mothers as to whose offspring has done the best, size, \&c., considered. This runs to such a high pitch that I have known some mothers to catch the seal, and then let her child kill it, so as to be able to swell the number of his captures. 
Some of the Eskimo hunters belonging to the Florence brought as many as seventy at one load. They were kept frozen, and we almost lired on the meat during the season, and learned to like it very much.

Some of the hispid seals pup on the ice without any covering whatever. Six instances of this nature came under my observation, and they were all young animals. The young exposed in this manner almost always fall a prey to foxes and ravens before they are old enough to take care of themselves.

As the season advances and the joung begin to shed their coats, the roof of their igloo is often, or perhaps always, broken down, and the mother and young can be seen on sunny days basking in the warm sunshine beside their atluk. The mother will take to the water when the hunter has approached within gunshot, and leave the young one to shift for itself, which generally ends in its staring leisurely at the hunter till suddenly it finds a hook in its side; a stout seal-skin line is then made fast to its hind flippers, and it is let into the atluk; it, of course, makes desperate efforts to free itself, and is very apt to attract the attention of the mother if she is anywhere in the vicinity. The Eskimo carefully watches the movements of the young one, and, as soon as the mother is observed, begins to haul in on the line. The old one follows nearer and nearer to the surface, till at last she crosses the hole at the proper depth, and the deadly harpoon is planted in her body, and she is quickly drawn out. If the mother has seen the hunter approaching the atluk, howerer, she will not even show herself. I have never known of an instance where they have attempted to defend their offspring from man. I once saw a raven trying to kill a young seal while the mother was making frantic but very awkward attempts to catch the bird in her mouth. When the young first assume the coat of the adults (about the time the ice begins to loosen), they seem possessed of a vast amount of curiosity, and while swimming near the land, as they almost always do, can be lured within gunshot by whistling or singing. They would often play about the schooner, diving underneath and coming up on the opposite side, apparently enjoying it hugely. They delight to swim among the pieces of floating ice in the quiet bays. The young and yearlings of this species are often found together in small bands. The adult females wrill average four feet and a half to the end of the flippers. Surih specimens are probably from four to seven years old; the males are a little larger. There is great variation in the skulls, but the sexes can readily be distinguished by the skull alone, the males having a longer and narrower head, with the ridges more prominent. 
It is ouly the adult males (called "tigak," stinker, by the Eskimo) that emit the horribly disagreeable, all-permeating, ever-penetrating odor that has suggested its specific name. It is so strong that one can smell an Eskimo some distance when he has been partaking of the flesh. They say it is more nourishing than the flesh of the females, and that a person can endure great fatigue after eating it. If one of these tigak comes in contact with any other seal meat, it will become so tainted as to be repulsive to an educated palate; even the atluk of the tigak can be detected by its odor.

There is sometimes caught a hairless variety of this seal that the Eskimo call "okitook." I have seen one such skin. It had a few fine curly hairs scattered over it, but they were very different in texture from the ordinary hair. I do not know if the specimen otherwise differed from the ordinary seal. The food of the adults consists largely of different species of crustaceans, and during winter especially they subsist to a considerable extent upon fish. I have found in them the remains of Cottus scorpius, C. groenlandicus, Gadus ogac (commonly), and Liparis vulgaris. During the time the adults shed for nearly a month previous I could detect nothing but a few pebbles in their stomachs. They become poor at this time, and will sink when shot in the water. The milk is thick and rich, and is sometimes eaten by the natives. The excrement looks like pale, thickly clotted blood.

There are sometimes found albinos, of which the Eskimo tell marvelous stories, one being that when they rise to breathe in their atluks they come stern first, and, in fact, they think such animals have their breathing apparatus on the posterior end of the body. I imagine this originated from a native once harpooning an albino in its atluk and finding his harpoon fastened in one of the hind flippers.

Toward spring, when the sun is shining brightly, these seals can be seen in all directions basking on the ice. They are to all appearance asleep, but manage to wake up regularly every few minutes to make sure that there is no danger about. At this season it is a favorite method of the Eskimo to hunt them by crawling flat on his belly toward the seal, and when discovered to imitate the movements of the animal, anu to advance only when the seal looks in the opposite direction. In this manner-they often approach so close as to be able to push them away from their atluks. This seal is of some commercial importance. The Scotch whafiers often buy from the natives during the winter a thousand skins. Tl 1 ese are brought with the blubber, and often cost the pur- 
chaser not over 3 to 7 cents, and this mostly in tobacco, trinkets, or ship stores. To encourage them to procure more skins, they are furnished with a cheap breech-loading gun and a few hundred cartridges, which they soon waste, and then their guns are of course worthless. At the rate both young and adults are slaughtered at the present day, they will soon become so scarce that there will not be enough to supply the wants of the natives.

\section{Pagophilus grœnlandicus, (Mïll.) Gray. \\ "Kiolik," Cumberland Eskimo.}

The saddle-back is of frequent occurrence about the southern waters of Cumberland Sound in spring and autumn. It is rather rarely found singly, but generally in considerable schools. They are even occasionally found as far up the sound as Annanactook, but mostly the young. Their procreation is unknown to the Cumberland Eskimo. A few schools were noticed at different times during September, 1877, and October, 1878, from the islands off the middle Labrador coast to Cumberland, at times at considerable distances from land. Every Eskimo who can secure it will have an adult male kiolik skin on the back of his toopik. The skins are here never used for clothing, the hair being too short and thin. They disappear from Cumberland when the ice makes, and return again in spring with open water, but stay only a short time. The flesh is much inferior to the netsick.

12. Phoca barbata, O. Fab.

"Ogjook," Cumberland Eskimo; "Oo-sook," Greenlanders.

This seal was first noticed a little to the sonthward of Cape Chidly, and thence northward to our winter harbor in about lat. $67^{\circ} \mathrm{N}$. According to the Eskimo they are the most common about Cape Mercy, Nugumeute, and the southern Cumberland waters, where they remain the year around, if there is open water. They remain in the sound only during the time there is open water, as they have no atluk.

On the rest coast of Davis Straits they are not rare, but are said by whalemen to diminish in numbers above lat. $75^{\circ} \mathrm{N}$. They appear to be more common on the southern shores of the west coast of Davis Straits than on the northern, so that the natives go southward some distance to secure the skins. Was noticed among the pack-ice in Davis Straits in July and August.

The ogjook delights in basking upon pieces of floating ice, and generally keeps well out at sea. I have never seen any numbers together, but almost always singly. The old males do not seem to agree well, and 
often have severe battles on the ice-floes when they meet. They use the fore flippers, instead of the teeth, in fighting.

In Cumberland they begin working northward as fast as the floe edge of the ice breaks up, arriving in the vicinity of Annanactook about the latter days of June. In autumn they move southward as fast as the ice makes across the sound, always keeping in open water. They are seldom found in the smaller fjords or bays, but delight in wide expanses of water. They dive to great depths after their food, which is almost entirely crustacea, mollusks, and even clams of considerable size. This seal has a habit of turning a summersault when about to dive, especially when fired at; this peculiarity, which is not shared by any other species that I have seen, is a characteristic by which it may be distinguished at a considerable distance. During May and June they crawl out upon an ice-floe, to bask and sleep; at such times they are easily approached by the Eskimo in their kyacks and killed. An adult will often measure ten feet between the two extremes. The color is rariable; the tawniness more or less clouded with lighter or darker markings irregularily dispersed. By July some of them become almost naked. At this season their stomachs contained nothing but stones; some of them nearly of a quarter pound weight. They seem to eat nothing during the entire time of shedding, probably six weeks. Certain it is they lose all their blubber, and by the middle of July have nothing but " whitehorse," a tough, white, somewhat cartilaginous substance, in place of blubber. At this season they sink when shot. Some specimens were procured that had scarcely any teeth at all, and in many adults the teeth can almost be plucked out with the fingers. The young are born upon pieces of floating ice, without any covering of snow. The season of procreation is during the fore part of May. After the young have shed their first woolly coat (which they do in a few days), they have a very beautiful steel-blue hair, but generally so clouded over with irregularly dispersed patches of white that its beauty is spoiled.

A fœetus was procured near the Middliejuacktwack Islands April 28. Its extreme length was four feet seven inches.

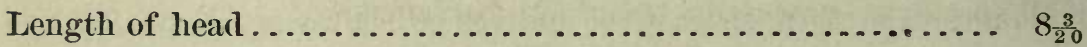

Width of muzzle .............................. 4.5

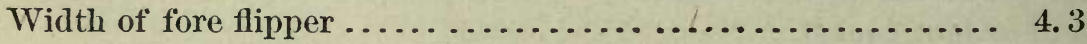

Length of fore flipper to end of nails................. $7 \frac{3}{20}$

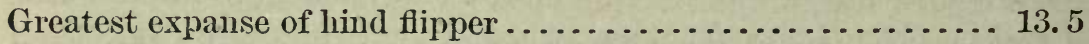

Length of hind flipper ........................... 12

From end of nose to eye $\ldots \ldots \ldots \ldots \ldots \ldots \ldots \ldots \ldots \ldots \ldots \ldots, 3.2$

Distance between eyes .......................... 3.50 
Color uniform grizzly mouse-color, with a tinge of olive-gray. Muzzle, crown, and irregular patches on back and fore flippers white. From nose to eyes a black line crossing the head back of the eyes, forming a perfect cross. Nails horn-blue, tipped with white. Iris dark brown. Nose black. Muzzle wide; lips full and fleshy, giving the animal a bull-dog expression. Body long and slender. Beard pellucid, abundant, white, stout, the bristles growing shorter from the eye toward the nostrils. Hind flippers large and heary, looking disproportionate. The hair rather short, but fine and somewhat woolly. There was interspersed another kind of hair, stiff and of a steel-blue; the next coat, I take it.

The Eskimo are firm in the belief that the ogjook sheds its first coat within the uterus of the mother. In this instance there was certainly plenty of loose hair in the uterus; but the specimen had been dragged some miles in its envelope over the rough ice, and banged around considerably, besides having been kept three or four days in an Eskimo igloo among a heap of decaying garbage, so it is not to be wondered at if the hair was loose. There was little blubber on the specimen, and this was thickly interspersed with blood-ressels. The intestines toward the anus were filled with dung. The kidneys were very large, the heart remarkably so. The cartilaginous prolongation of the thorax, so prominent in Pagomys fotidus, is wanting in this species.

The ogjook is of great value to the Eskimo, who prize the skins very highly. All their harnesses, sealing-lines, \&c., are made from the raw skins; besides this, they make the soles of their boots, and sometimes other portions of their dress, from the skin. In such localities as the whalemen do not visit, and the natives are obliged to construct skin boats, this seal is in great demand. It takes fifteen skins for an ominak, or skin boat, and these skins require renewing very often. The skin of the back and belly dries unerenly, so the Eskimo skin the animal by cutting it longitudinally along both sides, and drying the skin of the upper and lower parts separately. It is a prevalent belief among whalemen that seals' livers, and more especially those of this species, are poisonous; but I am inclined to rate this as imagination. We ate the livers of all species we procured without any bad effects.

13. Trichechus rosmarus, Linn6́.

"Awouk" and "Ivik," Cumberland Eskimo.

The walrus is quite common about Cape Mercy and the southern waters of Cumberland, but at the present day rarely strays far up the sound. Their remains, however, are by no means rare, even in the Greater King- 
wah, and many of the old Eskimo hut foundations contain the remains of this animal. The Eskimo say they got mad and left; certain it is they are found around Annanactook only as stragglers at the present day. Considerable numbers were observed on pieces of floating ice near Cape Mercy in July. About Nugumeute they are largely hunted by the Eskimo living there. The Eskimo say the tusks of the male always bend outward toward the tips, while those of the female bend inward.

\section{Cistophora cristata, (Erxleb.) Nilss.}

The bladder-nose appears to be very rare in the upper Cumberland waters. One specimen was procured at Annanactook in autumn, the only one I saw. The Eskimo had no name for it, and said they had not seen it before. I afterward learned that they are occasionally taken about the Kikkerton Islands in spring and autumn. I found their remains in the old kitchenmiddens at Kingwah. A good many individuals were noticed among the pack-ice in Davis Straits in July.

\section{CETACEA.}

\section{Balæna mysticetus, Linné.}

"Akbik," Cumberland Eskimo.

Also called "Pumah." I think the word had its origin in this wise. When whalemen first began to cruise in these waters, few, if any of them, had a knowledge of the Eskimo language, and, to make the natives understand what they were after, imitated the spouting of the whale by blowing. 'This was soon taken up by the Eskimo as the "codlunak" (white man's) word for whale, and soon came into general usage, and thus one of the first words was made that now constitutes a part of the pigeon-English of the whalemen's jargon.

The Cumberland Sound, or Hogarth Sound of Penny (Northumberland Inlet of Wareham in 1841), has been renowned among Scotch and American whalemen for more than a quarter of a century as a favorite resort of the right whale, and one of the most profitable whaling stalions on the globe. But this locality, like all others, has been so thoroughly hunted nearly every season for a number of years that it no longer sustains its pristine renown as a profitable whaling ground.

So many ships were sometimes found here at one time that there arose a great spirit of strife among the crews as to which vessel would procure the most whales, and as a consequence whales were struck when there was but the slightest chance of securing them, and the line had to be cut to set them free. Such whales in all probability die, but not before 
they have succeeded in permanently frightening others, which, instead of seeking the upper waters of the sound for a few weeks' quiet feeding, strike out and are seen no more.

Instead of allowing these animals to go up the sound, and find their favorite feeding grounds, they are attacked and chased as soon as they show themselves at the mouth of the sound. In fact, they have been so persistently persecnted that now very few pass up above Niantilic or the Kikkerton Islands.

The fall whaling begins late in September and continues till the ice makes across the sound. The whaling at this season is attended with great danger and hardships to the crews, and it is while prosecnting this fall "fishing" that the foundation to many a stubborn case of scurvy is laid.

The spring whaling begins generally in March or April, and continues along the floe edge until July, when the ice has left the sound.

The Eskimo from the southern part of the sound and along the coast from Nugumeute to Hudson's Straits report whales as found in those localities all winter; it is then quite probable that they reproduce on these coasts during the latter part of winter.

According to Eskimo tradition, these animals were once very abundant in the Cumberland waters, and their remains now bleaching on the rocky shores faithfully testify to this fact.

Of late years, whalers frequenting Cumberland Sound have been in the habit of employing natives to catch whales, supplying them with boats and all necessary equipments. It is needless to say that they are more successful than the whites in this hunt.

With their own primitive gear, the Eskimo seldom attacked a large whale; but yearlings were frequently caught. I was presented with a harpoon-head by the captain of a Peterhead whaler, that had been taken out of a very large whale caught near the Kikkerton Islands; it was imbedied in the muscles, so that the whale must have been struck while it was quite small in order that the harpoon should have pierced through the blubber. The weapon is, moreorer, of a pattern which the Eskimo I showed it to say they never saw before; but I must confess I can see but a very slight difference in it from those in use at the present day.

The "black skin," called "muktuk" by the natives, is considered as a great delicacy; when they have not eaten of this food for some time, and then get an opportunity to indulge to their heart's content, they eat till they can hardly move.

Bull. Nat. Mus. No. $15-5$ 
2. Physalis antiquorum, Gray.

Razor-back of whalers.

I cannot positively assert that the razor-back frequents the Cumberland waters to any great extent; in fact, I somewhat doubt if it does, one reason being possibly the scarcity of fish. I have seen it north of Hudson's Straits and about Cape Mercy, as well as on the Greenland coast in Disko Bay.

\section{Megaptera longimana Gray.}

Hump-back of whalers.

I could not ascertain that this whale is common in Cumberland at any season. It frequents the southern waters, but is little troubled by the whalers. The Eskimo do not seem to have a very clear idea of it.

4. Orca gladiator, (Bonn.) Sund.

"Killer" of whalers.

The killer is a very common whale in the Cumberland waters. They arrive with the white whales, which they follow up the fjords. Many thrilling stories are told by the Eskimo as well as whalemen of desperate fights between this animal and other whales. The Eskimo are rather afraid of it, especially the solitary kyacker. I have known the white whales to come in close proximity to the ship and lie along her sides, when they were pursued by these voracious sea-wolves.

\section{Phocæna communis, Brooks.}

The porpoise is by no means rare, especially in the southern waters during spring and autumn. I neither saw nor heard of them in the vicinity of Annanactook.

\section{Beluga catodon, (Linné) Gray.}

White fish, or White whale, of whalcrs. "Killeluak," Cumberland Eskimo.

The white whales begin to work up the sound as soon as the ice begins to loosen. They become very abundant, especially in the Great Kingwah Fjord. In July many hundreds repair to the sand-beaches of this fjord, and some whalers have attempted to eatch them in nets, but with indifferent success. They are sometimes driven up into shallow water at flood tide, and by the receding of the water many are left high and dry. It is a question of interest what they go into this fjord after. It is not to have their young, as they are already with the mothers; nor does it seem to be after food, as little or nothing is found in their stomachs at this time. One thing 1 noticed, when they go up the fjord they have a ragged appearance and dirty color, and, according to some whalemen, 
are covered with parasites; but after they have been rolling and rubbing themselves on the sand-beaches for a few days they look much smoother and their color is a creamy white. The Eskimo say the males and females keep separate, but I do not think there is much truth in this statement. Some think they go on these shoals to avoid the attacks of the killers, which play sad havoc among them outside, but do not follow them into shallow water; but if this were the reason, they would take refuge in any small bay or inlet, and not choose this particular fjord year after year. I found no external parasites, but the internal ear cavity was nearly filled with worm-like animals nearly two inches long. They were firmly attached by one end, and stood erect, having somewhat the appearance of very coarse hairs. While migrating into the sound they always keep just at the floe edge, and if the ice is broken do not seem to like getting among it. In the winter of 1876-77, a couple got belated and froze up in the Kingwah tide rifts. They were harpooned by the Eskimo in January. A considerable number of these whales are caught by the Eskimo from their kyacks.

7. Monodon monoceros, Linné.

Narwhal of whalemen. "Killeluaksuak," Eskimo.

By no means abundant, but of regular occurrence in spring and autumn. These whales give the Eskimo much trouble to capture, on account of their agility. The horn is often used for the handle of the harpoon, and for various other purposes where wood is scarce. 



\section{BIRDS.}

BY Ludwig KumLien.

The following list is of necessity fragmentary and very incomplete from various reasons. In the first place, the expedition did not arrive at the proposed winter-quarters until October, when the weather had become so inclement that most of the birds har gone southward. During the brief stops that were made at different harbors in the autumn of 1877 , I was often obliged to remain on shipboard for want of a boat, instead of cruising about, as I would otherwise have done. Of course I often went out with the Eskimo; but as they were looking for whales and seals, I got only such birds as accidentally came in our way. In the spring, the schooner was under weigh before the birds had fairly begun nesting. The last three weeks of our sojourn in the winter harbor I was prevented from making any explorations, except in the immediate vicinity of the harbor, on account of the ice, which was driven northward by the long-continued southerly gales. This ice formed so perfect a barrier about us that we could not get out of the harbor, and to have ventured among it with a boat when the strong currents were whirling and crashing it in every direction would have been a piece of foolhardiness that could but have resulted disastrously.

There is no point on either side of Cumberland Gulf or Sound that is less suitable for a naturalist than was Annanactook Harbor. It is formed by a cluster of small rocky islands, the outermost of a large group lying between the Greater and Lesser Kingwah Fjords. The nearest point to the mainland from the harbor was about nine miles. There were extensive valleys, with large grassy flats and sandy beaches, much frequented by different kinds of birds, both for feeding and breeding grounds.

When the season was so far advanced that these places became the resorts of birds, I seldom got an opportunity to go on a cruise, for with the inclemency of the weather, the uncertainty of procuring a boat, and the treacherous condition of the ice, it was almost sure that one or the 
other of these drawbacks would indefinitely postpone a contemplated journey. At this time I had the use of but one hand, and could not manage a kyack.

All the islands in the vicinitry of Annassactook are rocky-solid rock; in fact-with extremely scanty regetation. The shores are generally steep bluffs, and very little beach is exposed at low tide. A few miles up the Greater Kingwah, however, are very extensive beaches, and thither all the waders congregated as soon as the ice began to loosen from the shores. After leaving our winter harbor, the Florence made brief stops at different points, but for such short periods that it gave me very little time for explorations.

After our arrival on the Greenland coast I received very great assistance from Governor Edgar Fencker and lady, of Godhavn, through whose kindness I procured many valuable specimens. I can never forget the kindness and unbounded hospitality of this educated and refined gentleman and enthusiastic naturalist.

To Inspector Krärup Smitz and lady, of Godhavn, I am under very great obligations, not alone for the valuable donations of interesting Eskimo implements, but for their untiring zeal in making our sojourn as pleasant as possible, and the ready and entertaining information on many little known subjects pertaining to Arctic matters.

I was not a little surprised, as well as delighted, to find in Governor Fencker a person perfectly familiar with the birds of North America as well as Europe. During his eleven years' residence in Northern Greenland he has, of course, added much to the knowledge of Arctic ornithoiogy, and I was pleased to learn that he contemplated giving the world the benefit of his observations in an illustrated work on the birds of Greenland. Such a work, embellished with his superb drawings, cannot fail to rank very high among the ornithological literature of the age.

I have not the least doubt that future explorations in Cumberland waters will yield a much richer harvest than I gathered. Many species will be added, especially if the Lake Kennedy region is visited in summer.

For the benefit of any future explorer who may visit this section of country I will give what appears to me the best route and manner of reaching Lake Kennedy. A person wintering in Cumberland will be very apt to be stationed either at Niantilic on the western shore, or the Kikkerton Islands on the eastern, a little farther to the north. These points are favorite resorts for Eskimo in winter, and hunting parties 
leave both settlements ior the interior every summer, so there would be no difficulty in securing Eskimo guides and assistants, who are absolutely necessary to the success of such an enterprise. Good strong dogteams, to carry boats and all the required equipments, can be secured from the Eskimo, they driving their own teams.

The start should be made in May, and the course up the so-called "Mollu Keitook" fjord that opens into the gulf about forty miles north of the Kikkerton Islands on the western shore. This fjord can at this season be traveled with ease with sledges its entire distance-about ninety miles. During this stage of the journey the Eskimo could secure enough seal in the fjord for both man and beast. When the inland country was reached, reindeer would make a very acceptable substitute. But this supply should in no wise be solely depended upon. When the head of the fjord is reached there will be found a fresh-water stream, the eastern exit for the Kennedy Lake waters. This stream should be followed to the lake. If it be late in the season, a whale-boat may be taken up the stream with comparative ease. There are some places where the stream runs in narrow gorges, but the surrounding country offers suitable places for a portage over such points, into the numerous lake-like expansions that will be met with. If it be in May there will be found an abundance of snow for traveling with sledges on the land, and the comparatively level character of the country, which becomes more strikingly so as one nears the lake, will present but few obstacles to a good dogteam.

A light canvas tent should be a part of the equipment. While the snow lasted this could be inclosed within a wall of snow, and later be made very comfortable with a stone wall.

The lake abounds in numerous small islands, has sandy as well as grassy beaches, and is a favorite resort for myriads of waterfowl. It is so large that one cannot see across it. Its location is probably between the 66th and 67th parallels of north latitude. Salmon are abundant in its waters, and a seal that, from the skin, I could not distinguish from Pagomys foetidus, abounds in considerable numbers. The vicinity is the farorite feeding-ground of immense herds of reindeer. Wolves and foxes are very numerous, and among the Eskimo there is mention of an animal that from their descriptions and drawings seems to be a Gulo.

Fossils (Silurian) seem to be very abundant, and petrifactions marvelously perfect abound in the lowlands. The surrounding country has much the general aspect of a high northern prairie, being quite flat and 
sustaining a good growth of grass and plants. The ascent to the Cumberland coast on the east and the Fox Channel on the west is so gradual that it is hardly perceptible, the coast-line in both instances being precipitous. This is especially true of the western slope, where it is so gradual that it is with the greatest astonishment one suddenly finds himself on the summit of an enormous eliff, with the breakers of Fox Channel dashing on the rocks below him and an expanse of water stretching to the westward as far as the eye can reach.

The western outlet of the lake is larger than the eastern, and is said to empty through a deep gorge near Point McDonald.

A far less satisfactory time to go is after the breaking-up of the ice. There is no doubt it could be performed with less labor and fatigue at this time, but for the naturalist the best season would be over.

When the collections are ready, they can be safely cached till winter, and brought down in comparative safety on dog-sledges. A very interesting station for a naturalist would be near the mouth of the gulf, in the vicinity of the Kikkerton Islands; at this place there would be open water in April or May, and many valuable birds could be secured before they scatter over the country to breed. When the birds arrive at Annanactook, the season is already so far advanced that they immediately begin nesting. I have concluded to retain in the present list many species on very slight evidence in the hope that it may in some degree assist future explorers and put them on the lookout for some species that might otherwise escape their notice.

The birds do not congregate in large numbers on the islands in Cumberland to breed, the way they do to the sonthward and on the Greenland coast. There is an exception with Somateria mollissima. Some species that breed by myriads two hundred miles to the southward, and are equally numerous on the coast of Greenland to $73^{\circ} \mathrm{N}$. lat., are found only as occasional stragglers in the Cumberland waters.

Some idea of the barrenness of the islands around Annanactook may be arrived at from the fact that from October to July one hare and two ptarmigans were brought in, and there were twelve Eskimo that hunted the greater part of the time, and I was out on every occasion when I thought it at all likely that such game couid be procured. Scotch whalers have told me that near Nugumeute they have had as high as two hundred ptarmigans during the winter, and hares in abundance.

I have added the Eskimo names of the birds in such instances as I could do so with certainty. The Greenlanders' names are often quite 
different from the Cumberland Sound Eskimo; these have also been added. These names will be of use to any one visiting this region not conversant with the Eskimo language.

1. Turdus aliciæ, Bd.

One specimen caught on shipboard off the coast of Newfoundland, October 22, 1878.

2. Saxicola œnanthe, Bechst.

Breeds along both shores of Cumberland and on the west coast of Davis Straits, but rare.

One of the commonest land birds on Disko Island, Greenland, and around Disko Bay, both on the islands and mainland. I showed specimens to Eskimo from Nugumeute and Frobisher Straits, and they instantly reeognized them and said they breed there, but are not plenty.

3. Anthus ludovicianus, Bechst.

Kung-núk-took, Cumberland Eskimo.

The first specimens were seen in the spring at Annanactook Harbor on the 30th of Nay. There was no bare ground; but they frequented the tide-rifts at low water, searching after small marine animals.

It looked very strange to see this bird running about among the stones and in the water like a Cinchus. I examined the stomachs, of specimens killed in these localities, and found them to contain Gammarus, Lamodiportia, Caprella, and a few small mollusks! There can be no doubt that they were feeding on this food from necessity, and not choice, for there was no bare ground and no insects at this time. During the first of June we had the severest snow-storm of the season, and I think most of them perished. They would come around the observatory and shelter themselves as best they could. They were so far reduced that they were easily caught with the hand.

In autumn they leave for the south about the middle of September. At this season, besides their diet of insects, they feed on the berries of Empetrum nigrum and Vaccinium uliginosum. During summer their food consists almost entirely of insects, largely of dipterous larvæ, which they procure among the carices around the fresh-water ponds. At Annanactook they began building about the 20th of June. The nest was always placed deep in a rock crevice, so far in, in fact, that I could not secure any of the nests I found. On the Greenland coast, especially in the vicinity of habitations, they often build in a tussock, much iike a sparrow; but there the ravens are not so numerous or destructive to birds and eggs as in Cumberland. 
They practice every artifice to decoy an intruder from the vicinity of the nest-shamminglameness, and uttering the most plaintive cries ; flitting from crag to crag before the pursuer till they have led him far beyond the nest, when suddenly they seem to have recovered, and take longer flights, till at last they jump up very smartly and fly away apparently highly elated at the little ruse they have so successfully practiced.

This little bird is considered a great enemy by the Eskimo. They say it warns the reindeer of the approach of the hunter, and, still worse, will tell the reindeer if it be a very good shot that is in pursuit, that they may redouble their efforts to escape. The Eskimo never lose an opportunity to kill one of these birds. I have seen one with a rifle wasting his last balls in vain attempts to kill one when he knew that there was a herd of reindeer not more than a quarter of a mile away. They are generally distributed on both sides of Cumberland Sound and the west shores of Davis Straits to lat. $68^{\circ} \mathrm{N}$. at least, but nowhere very abundant. Toward autumn they become more or less gregarious, and seem to migrate along the seashore.

\section{Sitta carolinensis, L.}

Caught on shipboard off the coast of Newfoundland October 22.

5. Dendrøca coronata, (L.) Gray.

A single example, an adult male, in Godhavn Harbor, Greenland, July 31, 1878.

6. Siurus nævius, (Bodd.) Coues.

Caught on board the Florence in Straits of Belle Isle, August 18.

7. Tachycineta bicolor, (Vieill.) Cab.

A couple of these swallows followed the sehooner for two days in succession off Belle Isle, in August, 1877. Where were they during the night?

\section{Pyrrhula $\square$ ?}

July 19, 1879, while hunting among the mountains near Oosooadluin Harbor, in the northern waters of Cumberland, my attention was called by a bird whistling somewhat like Ampelis garrulus, but louder and clearer. I soon discovered it flitting among some small willows on the grassy ledges of a perpendicular cliff about 1,500 feet above tide-level. I could not scale the cliff, and had to content myself by watching it. It was apparently nesting among the willows, but kept continually just 
out of range. At the time I pronounced it undoubtedly the female of Pyrrhula europea, which it resembled very much indeed, but now I incline to the belief that it was more likely the male of Pyrrhula cassinii, and that the female was sitting. I made a life-size drawing of it, and showed it to all the Eskimo in the vicinity. None could recognize it; but some said they had seen such a bird at Lake Kennedy, but that they were "tummumik abertook," all red. This may have been Pinicola enucleator, Carpodacus purpureus, or Pyrrhula europea, as I doubt not but the last species would be called "all red" by an Eskimo. The red part would certainly make the most lasting impression on his mind. I tried for some hours to procure this bird, but at last it flew over a ravine that I could not cross. I never got an opportunity to revisit the locality, and this interesting discovery had to be left unsettled. The bird was apparently slate-colored on the breast, the upper and lower tail-coverts conspicuously white, the top of head and throat much darker than the back. The flight was undulating. It kept whistling almost constantly, which led me to think it was a male bird.

9. Carpodacus purpureus, (Gm.) Gray.

During a dense fog, September 1, 1877, off Resolution Island, north of Hudson's Straits, one of these birds was caught on board the Florence. The Eskimo describe a bird about the size of the purple finch that occurs in the interior, and is "all red." Such information is, however, in no manner reliable, as "abertook" may be any color from umber to vermilion, and "all," especially when it comes to red, may be but a small part of the plumage.

10. Loxia leucoptera, (Wils.).

Caught on board the schooner in a fog off Bonne Bay, Newfoundland, August 15, 1877. Very common in the low pines at the head of Conception Bay, Newfoundland, October, 1878.

11. İgiothus linaria, (L.) Cab.

"Anarak," Cumberland Eskimo. "Orpingmatook," Greenlanders.

Arrive in Cumberland as soon as the snow begins to disappear from the mountain sides. I found them about Niantilic and the Kikkerton Islands in September and October, but very few at our winter harbor. They are now common from Nugumeute to Hudson's Straits, and inland toward Lake Kennedy. Wherever there is a valley with any considerable vegetation, especially low willows, they are almost sure to be found. Observed abundantly on Disko Island, Greenland, where I found half- 
fledged young in the last days of July. The nest here was built in small willows, like a Chrysomitris. Although they seemed to be migrating in October, I did not see any flocks, but only a few straggling individuals. They seem to wander from the land very often in fogs. I have counted a dozen or more in the rigging at one time from Hudson's Straits to Niantilic. Off Kikkertarsoak Islands, on the Labrador coast, as much as one hundred miles from land, these birds came aboard of the schooner in a gale. They were all young birds.

12. Aggiothus holbölli, Reinhdt.

A large linnet was caught in a thick fog in Grinnell Bay, September 3,1877 . It measured 6.25 inches in length. The specimen was "picked" by one of the ship's company while I went down into the cabin after my skinning tools. The body (without feathers) was preserved in alcohol, and Mr. Ridgway pronounces it $\mathscr{E}$. holbölli. It was the only specimen I procured that differed in the least from a typical linaria.

13. Chrysomitris tristis, (L.) Bp.

An adult male caught on shipboard, August 22, 1877, off Cape Mugford, Labrador.

14. Plectrophanes nivalis, (L.) Meyer.

"Kopernúak," Cumberland Eskimo. " "Kopanauarsuk," Greenlanders.

The first snowbird seen at our winter harbor was April 5, an adult male. The weather was quite severe, and there was no bare ground. It staid about the ressel some days, gleaning a scanty subsistence from the cook's rubbish pile. After this date I saw none until May 8. They then began to appear around the Eskimo encampments, and were in full song, and a very beautiful song they have. Never did I so enjoy a bird's song as I did their lively ditty after the long, silent, dreary winter. By the 13th five pair had arrived in the neighborhood, and the males seemed to try and outdo each other in their efforts to bè musical. Such companions were they for me that I had no heart to destroy them, much as I wanted specimens in full plumage. The young Eskimo had no such scruples, however, and supplied me with specimens killed with their bows and arrows.

By the last days of May they had paired and chosen their breedingplaces. The first eggs were procured June 20. The nests are very often in such deep fissures in the rocks that it is impossible to get at them. They are obliged to hide away their nests in this manner to escape the ravens. One of the most favorite positions for the nest is inside of an 
Eskimo grave; i. e., inside the stone cairn that they erect over the body. I have even seen a nest built in an Eskimo cranium. The nest is large and bulky, nearly the entire structure being composed of Poa arctica and other grasses, and invariably lined with feathers or hair. One nest, found July 11, that contained small young, was thickly lined with the hair of Vulpes lagopus. Some contain only feathers; others both hair and feathers. The number of eggs in all the nests I found was six. They present an almost endless variation in size and coloration, great difference being observable even in the same nest.

The snow bunting is generally distributed on both sides of Cumberland, but is nowhere abundant. Almost any locality is suitable, but I doubt if the food supply would be sufficient if they did not scatter well over the country. They are very common on Disko Island and around Disko Bay. Half-fledged young were taken near Godhavn August 2. The first plumage of the young is a uniform ashy gray. The food of the snowbird in summer consists largely of aquatic dipterous larvæ. For these they are constantly searching among the grass at the edges of fresh. water ponds. During the autumn they feed mostly on various kinds of seeds. They are very fond of the berries of Empetrum nigrum and Vaccinium uliginosum. As soon as the young are full-grown, they begin to congregate in small loose flocks, and move sonthward with the first snows of September. The young have by this time become lighter in plumage, and the russet wash begins to appear on the head and neck. They were often seen on board the schooner on the passage, at one time tioo hundred miles at sea, off Cape Chidly. There seems to be a striking difference in the size between Greenland and Alaskan specimens, the latter being the larger.

15. Plectrophanes lapponicus, (L.) Selby.

"Kióligak," Cumberland Eskimo. "Narksormutak," Greenlanders.

Not nearly so common as the preceding in Cumberland. In the autumn of 1877, I found a good many in the vicinity of Niantilic, but nowhere else; saw no males in the breeding plumage after September. During the summer of 1878 , I procured one single specimen in June. I think they breed in the interior on the level land, and do not frequent the sea-coast so much as $P$. nivalis. I found them very common on Disko Island, and procured eggs and young in July and August. Their food at this time seemed to be entirely dipterous larvæ, for which they searched about fresh-water pools. In autumn they feed on seeds and berries. Many lit on the schooner during fogs and storms all the way 
from Cape Chidly to Niantilic. According to the Eskimo they are more common than nivalis from Nugumeute southward and in the interior. There appears to be quite a marked difference in specimens from Greenland and from Alaska, and a comparison of a large series may give some interesting results. The Eskimo say they will eat blubber and meat if their food gets covered by snow. I have seen a specimen that was so covered with some oily substance that the feathers on the breast and belly were matted together. I am told by Nugumeute Eskimo that in summer the males "akapok amasuit" (talk a great deal). From this I infer that they are probably lively songsters during the breeding season.

16. Junco hyemalis, (L.) Scl.

Once obtained on shipboard off Belle Isle, October, 1878.

17. Scolocophagus ferrugineus, (Gm.) Sw.

Caught on shipboard during a gale off the north coast of Newfoundland, October, 1878.

18. Corvuss corax, Linné.

"Tudlúak," Cumberland Eskimo. "Kernetook," Greenlanders; but also called "Tulluak."

The raven is extraordinarily common on both shores of Cumberland and on the eastern shore of the Penny Peninsula. In winter they congregate about the Eskimo encampments, where they can almost always get dead dog, if nothing more. All the specimens collected by me in Cumberland are of remarkable size, much larger than any I ever saw on the Greenland coast. The same was remarked by Governor Fencker, of Godhavn, who said he never could see any reason why the American raven should be called a variety of the European till he saw my specimens from the western coast of Davis Straits.

When the raven gets closely pressed by hunger, he will attack almost anything but man. Young reindeer fall an easy prey to them. When they attack a young deer, there are generally six or seven in company, and about one-half the number act as relays, so that the reer is given no rest. The eyes are the first parts attacked, and are generally speedily plucked out, when the poor animal will thrash and flounder about till it kills itself. In the capture of the young of Pagomys foetidus they evince a considerable degree of intelligence. I have, on different occasions, witnessed them capture a young seal that lay basking in the sun near its hole. The first manœuvre of the ravens was to sail leisurely over the seal, gradually lowering with each circle, till at last one of them 
suddenly dropped directly into the seal's hole, thus cutting off its retreat from the water. Its mate would then attack the seal, and endeavor to drag or drive it as far away from the hole as possible. The attacking raven seemed to strike the seal on the top of the head with its powerful bill, and thus break the tender skull. In two instances I allowed the combat to proceed until the seal was killed, and then drove the ravens away. I found no marks on the seal, except the blows on the head, which had fractured the skull in two places.

December 13, 1877, I witnessed a rery amusing chase after a Lepus glacialis. There were two ravens, and they gave alternate chase to the hare. Sometimes the raven would eatch the hare by the ears, and hare and raven would roll down the mountain side together thirty or forty feet, till the raven lost his hold, and then its companion would be on hand and renew the attack. They killed the hare in a short time, and immediately began devouring it.

They are extremely destructive to the eggs and young of all birds that have an open nest. They breed so early in the season that the young are fully fledged by the time the eiders begin laying, and the entire raven family then take up their abode on the duck islands, and gorge themselves with eggs and young. Nor is it only the eggs they eat, but their mischievous nature must out, and I have seen them drive the duck from her nest and deliberately break the eggs.

The Eskimo accuse the raven of warning the deer of the approach of the hunter by a pecnliar croak not uttered at other times. This helps to add odium to their not over-enviable reputation. They are constant attendants of the Eskimo while seal-hunting. If the hunter procures more seal than he can take back with him, he will cover them with snow and return for them; but the operation has been watched by the black robbers from the neighboring clift's, and a good number of them are soon made acquainted with the discovery, and as soon as the Eskimo is gone the seal is exhumed and soon reduced to the mere skeleton. I tried on sereral occasions to catch them by baiting a hook with a piece of meat, and carefully concealing the string in the snow. They took hold of the meat very cantiously, and lifted it till they saw the string, and then flew away in great haste.

During the winter, while making skeletons, I used to throw the refuse outside of the observatory; and I have repeatedly watched the ravens sit around and wait till I went to dinner, about $3.30 \mathrm{p} . \mathrm{m}$. It was then, of course, quite dark; but as soon as I left the hut they came and got their meal, but were extremely cautions, often turning the pieces over 
many times before they swallowed them, and even throwing and tossing them, to be sure that there was no trap about it. Some pieces that looked suspicious they would not eat, but walked around them and turned them over, but could not be convinced that there was not some trickery about them. I have often found them hunting about the observatory after some stray scraps, even on my return from dinner, when it was so dark that I could not see them but a few feet away. On moonlight nights I have known them to make visits to the rubbish pile outside our observatory; but such cases are rare, and only at the season when they cannot get any food without the greatest difficulty. At Annanactook Harbor they began building as early as March 20, but I saw some carrying pieces of skin and hair from the Eskimo encampments many days earlier than this, and when we had a temperature of $-40^{\circ}$ Fahr.

They nest only on the south side of the highest and most inaccessible cliffs, so the nest can seldom be reached. I examined one nest built on a little shelf of a high cliff. It was composed almost entirely of pieces of Eskimo skin clothing, among which were scattered the larger wingbones of gulls, the larger primaries of several species of birds, twigs of salix, \&c. The inside had a good lining of Poa alpina, and a considerable quantity of reindeer, fox, and dog hair, the whole presenting a very cozy appearance indeed. As soon as the seals begin to pup under the snow on the ice, they follow the foxes, which find the seal and drag them out. Now the ravens can fare well on the leavings. The Eskimo firmly believe that it does not hurt the ravens' eggs to freeze. 'They say the shell cracks, but the inner membrane is very thick and tough. I found that the Scoteh whalers are also of this opinion, some positively asserting that they had known frozen ravens' eggs to hatch!

The young are full-fledged by the latter part of May. During the autumn months they feed largely on the berries of Vaccinium uliginosum and Empetrum nigrum. I have often observed them fishing at low tide among the stones. I killed a couple to ascertain the nature of the food they got. I found it to be Cottus scorpius and Liparis vulgaris?, with a few small crustaceans.

They are resident in Cumberland the entire year, but appear more numerous in winter, from their habit of staying about the Eskimo encampments.

The raven is considered as worse than useless by the Eskimo. They make no use of them except to wipe the blood and grease from their hands and face with the feathers. 
19. Empidonax flaviventris, $B d$.

Taken at sea off Cape Farewell, Greenland, September, 1878. This is, I think, the first recorded instance of its occurrence in Greenland.

20. Brachyotus palustris, (Bechst.) Gould

"Sutituk" (?), Greenlanders.

Apparently rare. Found breeding in the Kingnite Fjord in the Penny Peninsula ; also in the Greater Kingwah. Probably will be found more common in the interior toward the southwest in Hall's Land, if it be the species described to me by Eskimo from there. They say it nests underneath an overhanging shelf of rock on or near the ground. Appears to be rare on the coast of Greenland. Is found as far north as $70^{\circ} \mathrm{N}$. lat.

21. Nyctea scandiaca, (L.) Newt.

"Opigjuak," Cumberland Eskimo. "Opik" and "Opirksook," Greenlanders.

I. was very much surprised not to find this owl more common. At the Kikkerton Islands and up Kingnite Fjord were the only localities where I met it on the west coast. From Hudson's Straits to Nugumente, in Hall's Land, it is more common, probably on account of the greater abundance of hares and ptarmigans in this region. It probably breeds on the Hunde Islands in Disko Bay, and on the "islands" (the rocks projecting through the glacier) in the glacier on the mainland, to the eastward of Rittenbenck, Greenland. They are by no means strictly nocturnal. I have seen them chasing ptarmigan at midday in October, when the sun was shining brightly. I have seen them coursing along the shore at low tide, apparently fishing; but whether they were hunting for snipe or fish I am unable to say, as they were so shy that I could not get within rifle range of them. The primaries are highly prized by the Eskimo for their arrows. These birds migrate to the southward about the same time as the majority of the waterfowl.

22. Falco candicans, Gm.

"Kirksoveasuk," Greenlanders.

During the whole year's collecting on Cumberland Island I saw but one single specimen, late in November, 1877. He was beset by a large concourse of ravens that were teasing him, as the jays do hawks and owls at home. According to the Cumberland Eskimo, they are very rare, and seldom seer except in winter. Many do not know them at all. On Disko Island, especially in the Godhavn district, they are common and resident. These hawks seem to prefer nesting in the vicinity of "bird rocks," where they can procure plenty of birds with very little

Buil. Nat. Mus No. $15-6$ 
trouble. In winter they subsist wholly on ptarmigans and hares. Governor Fencker, during his long residence in Northern Greenland, has had good opportunities for studying this bird, and he thinks there is but one species inhabiting the country, having known of instances where the parents of a nest represented the two extremes of plumage. Nor does the difference seem to be sexual, seasonal, or altogether dependent upon age, but more probably partaking of that remarkable phenomenon familiar in Scops asio.

During my frequent excursions about Disko Island I often had an opportunity of witnessing this hawk preying upon jaegers, kittiwakes, \&e., but was surprised that they are not possessed of swifter flight. A duck hawk would have made a short job of eatching a kittiwake that one of these hawks followed till he fairly tired the bird out. Their success seems to depend more upon a stubborn perseverance than alacrity of flight. The flesh of the young birds is by no means despicable food, and is highly prized by the Danish colonists.

23. Falco communis, Gm.

A regular breeder in Cumberland. Usually found about the Eider Islands. Procured nearly full-fledged young in August that were taken from the nest on a high cliff in the Greater Kingwah Fjord.

24. Astur atricapillus, (Wils.) Jard.

A single specimen, at Niantilic, September 19, 1877.

25. Haliaëtus albicilla, Liuné.

"Netkoralik," Greenlanders.

I saw this eagle at American Harbor, in October, 1877, at two different times. In the spring of $1878 \mathrm{I}$ often noticed a pair that finally built a nest on a high but not inaccessible cliff in Kingwah Fjord. I could have shot the birds, but waited until I shonld be able to procure the eggs, and then get the birds. Unfortunately the wind set in from the south, and I could not get near the place on account of ice till the Florence set sail for the Greenland coast. Enough was ascertained, however, to show that this bird does breed on the western shores of Davis Straits, although probably sparingly. On the coast of Greenland it is by no means uncommon. Eggs were procured from Clausharn through the kindness of Governor E. Fencker.

26. Lagopus albus, (Gmel.) Aud.

"Akagik" (both species), Cumberland Eskimo.

Very few ptarmigan were found about our winter harbor; but, from the Eskimo accounts, they are quite common in the larger valleys, where 
there is a ranker growth of willows. The stomachs of those I examined of this species contained willow buds and small twigs. From Nugumeute southward and westward in the interior they are abundant dccording to the Eskimo stories, but which species is of course impossible to say. They begin to change color as soon as the snow commences to melt, in lat. $67^{\circ} \mathrm{N}$. about the middle of May. This change in plumage is more tardy as one goes farther north. I was informed by intelligent Greenlanders that north of Upernavik, near the glacier, they had found ptarmigans nesting, and that the male was in perfect winter plumage. This was probably $L$. rupestris. If this be true, it is possible that in sections where much snow remains during the summer the change is very late, or, perhaps, does not occur at all.

27. Lagopus rupestris, (Gmel.) Leach.

"Akagik," Cumberland Eskimo. "Akeiksek," Greenlanders.

I am unable to throw any light on the distribution of these birds in Cumberland, as I was unable to procure but a single specimen of this species and two of the preceding. The crop was crammed full of sphagnum moss.

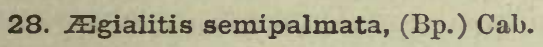

"Koodlukkáleak," Cumberland Eskimo.

Arrived at Annanactook about the middle of June. By no means rare. Breeds on the mossy banks of fresh-water ponds along both the Kingwah Fjords, as well as other localities in Cumberland. It seems remarkable that the Cumberland Eskimo should discriminate between this and the following species, when they confound all the larger gulls under one name. They told me that $A$. hiaticula was larger, flew faster, and had a stronger voice than semipalmatus!! All of which is true. The condition of the ice at the time these birds were nesting kept me from visiting their breeding-grounds, although but a few miles away. They migrate southward as soon as the fresh water is frozen.

29. Ifgialitis hiaticula, (L.)

"Tukagrajok," Greenlanders.

I am not aware that this species has hitherto been introduced into the North American fauna, though long knowu as a common bird on the Greenland coast, where $A$. semipalmata is rare. It is apparently more common than the preceding in Cumberland. Arrives about the same time, and breeds in similar localities. Very common about Disko Island, Greenland, where young birds were procured. This bird is readily distinguishable from $\not E$. semipalmata by its greater size and more 
robust form, in having a white patch above and behind the eye, and much wider pectoral band; it will also be found that only the outer and iniddle toes are united by a web.

30. Strepsilas interpres, (L.) III.

"Telligvak," Greenlanders.

Common about Disko Bay, Greenland, and northward to $73^{\circ} \mathrm{N}$. lat. at least. Breeds on the Green, Hunde, and Whale Islands in Disko Bay. They nest among the Sterna arctica, and it is impossible to distinguish between the eggs of the two species. Not observed in Cumberland Sound, nor on the east coast of the Penny Peninsula; still, the bird was instantly recognized by the Cumberland Eskimo, when they saw it on the Greenland coast, and they had the same name for it as the Greenlanders.

\section{Recurvirostris americana, Gm.}

I enter this bird on my list on Eskimo authority,-poor authority, it is true, but I have in my possession a drawing, made by a wild Eskimo, that is so unmistakably this bird that $I$ do not hesitate to accept it, especially when he gave me a perfect description, and that without any attempt on my part to draw him out. He says he saw them for the first time in the summer of 1877 , while reindeer hunting, south of Lake Kennedy.

\section{Lobipes hyperboreus, (L.) Cuv.}

"Shatgak," Cumberland Eskimo.

Arrives in Cumberland in June. Large flocks were repeatedly seen going to and coming from their breeding-grounds in Kingwah Fjord. Not nearly so common in Cumberland as the following species. The remarks on the habits of $P$. fulicarius as observed by me will apply to this species only in part. I have seen them as far south and farther north, and nearly as far from land, as the following species, but only a few individuals. They seem to prefer the shore more, are often noticed running about on the ice-cakes, and when they see anything in the water they want jump in after it. Breed plentifully on the islands in Disko Bay and around Upernavik; on these islands they nest among Sterna macrura, on the rocks; in Cumberland, around fresh-water ponds, on grassy banks. They are apparently less gregarious than $P$. fulicarius, and prefer the smaller bays to the more open and boisterous waters. I have often seen a whole flock alight on the drift-ice and feed by jumping into the water after the food when seen; but fulicarius would have lit in the water in the first place. Eggs were procured on the Green Islands in Disko Bay. 
33. Phalaropus fulicarius, (L.) Bp.

"Shatgak," Cumberland Eskimo. "Whale-bird," or "Bowhead Bird," of whalemen.

These birds were met with at great distances from land. The first seen on our outward passage was on August 4, 1877, in lat. $41^{\circ} \mathrm{N}$., long. $68^{\circ} \mathrm{W}$.; here large flocks were met with. As we proceeded northward, their numbers increased till we reached Grinnell Bay. Off the Amitook Islands, on the Labrador coast, two hundred miles from the nearest land, I saw very large flocks during a strong gale. Hardly a day passed but some were seen, either flying about in a rapid and vigorous manner, often rising to a considerable height, and then suddenly darting off in the direction of a spouting whale, or swimming about with that grace so eminently characteristic of the phalaropes. They follow the whales, and, as soon as a whale is seen to blow, immediately start for him, as a quantity of marine animals are always brought to the surface.

Very few were seen north of Frobisher Straits, for the weather by this time had probably become too severe for them, and I think the birds seen on the passage were migrating southward. I am more inclined to think so, as the next year, in going over nearly the same route a month later, very few were seen. They arrive in Cumberland with the breaking-up of the ice, and from this time till they begin breeding are seldom seen on the shore, but cruise out in the sound. Whalemen always watch these birds while they are wheeling around high in the air in graceful and rapid circles, for they know that as soon as they sight a whale blowing they start for him, and from their elevated position they can of course discern one at a much greater distance than the men in the boat. I doubt if it be altogether the marine animals brought to the surface by the whale that they are after, for if the whale remains above the surface any length of time they always settle on his back and hunt parasites. One specimen was brought me by an Eskimo that he had killed on the back of an Orca gladiator; the œsophagus was fairly crammed with Larnodipodian crustaceans, still alive, although the bird had been killed some hours; they looked to me like Caprella phasma and Cyamus ceti. According to the Eskimo who killed it, the birds were picking something from the whale's back. I have often seen them dart down among a school of Delphinapterous leucas and follow them as far as I could see. On one occasion a pair suddenly alighted astern of my boat, and were not three feet from me at times; they followed directly in the wake of the boat, and seemed so intent on picking up food that they 
paid no attention whatever to us. They had probably mistaken the boat for a whale.

They are without doubt the most graceful of all birds on the water, so light and buoyant that they do not seem to touch the water. While swimming, they are continually nodding the head and turning from one side to the other. They have greater powers of flight than either hyperboreus or wilsoni, and fly much more swiftly. In Cumberland, as well as on the Greenland coast, they nest with hyperboreus.

Governor Fencker tells me they are not found as far north as hyperboreus; probably few breed above $75^{\circ} \mathrm{N}$. lat. Are common on the outlying islands between Nugumeute and Hudson's Straits. About the entrance of Exeter Sound, on the east coast of Penny Peninsula, are some islands which the Eskimo call "Shatgak nuna"-Phalaropes land-so they are probably very common there.

When they begin nesting they live more on shore, and probably get their food along the beaches at low tide. There is great variation in plumage, even among the apparently adult birds, in spiring. I think it quite probable that they do not attain their full plumage the first year.

34. Tringa minutilla, Vieill.

Noticed in Niantilic, September, 1877, and in Disko Fjord, Greenland, August, 1878.

\section{Tringa fuscicollis, Vieill.}

Breeds in Kingwah and Kingnite Fjords, and probably in other suitable localities on both shores of Cumberland Sound. Considerable numbers were observed along the beach near Nuboyant, on the west shore, in July; they were in all probability breeding. We were cruising close to shore, but I could not land.

\section{Tringa maritima, Brünn.}

"Sigereak," Cumberland Eskimo. "Sarbarsook," Greenlanders.

The purple sandpiper is the first wader to arrive in spring and the last to leave in autumn. The 4th of June is the earliest date I met them at Annanactook; this was during a heavy snow-storm, and the earliest date possible that they could have found any of the rocks bare at low tide. The flock lit on the top of one of the small islands in the harbor, and sheltered themselves from the storm by ereeping behind and underneath ledges of rocks; they then huddled together like a flock of quails in winter. I have often noticed the same habit with them in late autumn, while they were waiting for low tide. They remained in the vicinity of Annanactook till November,- as late as they could find any exposed 
shore at low tide; were very common in all the localities that I visited on Cumberland Island. Saw a good many on the Greenland coast. It is said that some remain in the fjords of South Greenland all winter.

They seem completely devoid of fear, and can almost be caught with the hands. Although such lovers of the rocky sea-shore, they nest on the borders of fresh-water lakes. Hundreds were breeding a few miles from our winter harbor, but it was impossible to reach the mainland on account of the treacherous condition of the floating ice. The specimens collected by me on Cumberland Island differ so much from the Alaskan, that I conjecture the probability of a western variety when a series can be brought together for comparison.

By the latter days of June very few were to be seen on the sea-shore, they having gone inland to breed.

They appear very sociable, and when a large flock is together they keep up a lively twitter, by no means unpleasant. As the breeding season approaches, the males have a peculiar cry, resembling somewhat that of Actiturus bartramius, but lower and not so prolonged. When this note is uttered they assume a very dignified strut, and often raise the wings up over the back and slowly fold them again, like the upland plover. After the breeding season commences very few are seen on the sea-shore till the young are full-grown. They are somewhat crepuscular in their habits.

37. Tringa subarquata, (Gould) Temm.

Not uncommon in North Greenland. Eggs were procured at Christianshaab, Greenland, throngh the kindness of Governor Edgar Fencker. Not obserred on any part of Cumberland that I visited.

38. Tringa canutus, Liunć.

A small flock lit on the schooner's deck in November after the harbor was frozen over. Saw none in the spring or summer. Seem to be quite common in North Greenland, but probably do not nest south of lat. $70^{\circ} \mathrm{N}$.

39. Calidris arenaria, Linn.

One small flock in September, 1877, at Niantilic; no specimens were procured.

40. Limosa hudsonica, (?) (Lath.) Sw.

Two godwits were seen near Cape Edwards, on the west coast of Cumberland Sound, in September, 1877, but I could not, with certainty, ascertain the species. 
41. Totanus melanoleucus, (Gm.) Vieill.

A single specimen on Arctic Island, Cumberland Sound, September $14,1877$.

42. Numenius borealis, (Forst.) Lath.

A few flocks seen passing northward up Kingwah Fjord in June. One specimen procured. Not noticed in autumn. Well known to the Cumberland Eskimo.

43. Grus —? (probably fraterculus).

Quite common in some localities. Breeds in Kingwah and Kingnite Fjords in Cumberland, in Exeter Sound, and Home Bay on the west coast of Davis Straits. Common, especially during spring, at Godhavn.

\section{Cygnus —?}

Swans occasionally occur in the Southern Cumberland waters; but the species is uncertain, as I could not procure a specimen. Said to be of regular occurrence in the Lake Kennedy region.

45. Anser albifrons, var. gambeli, (Hart.) Coues.

Not observed in any numbers about our winter harbor, but undoubtedly occurs in abundance on the fresh-water lakes. This is probably the goose that the Eskimo take in such great numbers at Lake Kennedy, where they drive them towards the sea-coast while they are in inoult. Are common on the Greenland coast to $72^{\circ} \mathrm{N}$. lat., and probably much farther. Large flocks were met with on the pack-ice in the middle of Davis Straits, July 24, 25, and 26. Eggs were procured in the Godhaven district in Greenland. The skin of the breast is sometimes used by the Eskimo for under-garments.

\section{Anser hyperboreus, Pall.}

Appears to be rare and migratory in the Cumberland waters. Saw a few specimens in early spring and late autumn.

47. Branta hutchinsii, Sw.

A single specimen procured June 10 in Kingwah Fjord. The Eskimo who killed it said he has seen many to the southward of Nugumeute. Saw no Canada geese at any time during my stay.

\section{Anas boschas, Linn.}

"Kaertooluk," Greenlanders.

Not observed in Cumberland, and unknown to the Eskimo. Not rare on the Greenland coast as far north as Upernavik. The flesh of this duck on the coast of Greenland is scarcely fit to eat, being almost as rank as a loon's. 


\section{Bucephala —?}

Flocks of whistlers were observed on three occasions in May; but I could not with certainty identify the species, as none were killed. $B$. islandica is quite common in the Godharn district on the coast of Greenland; breeds near Christianshaab.

50. Histrionicus torquatus, (Linn.) Bp.

"Tornauiartook," Greenlanders.

Three examples seen, and one killed at Annanactook. Not uncommon in the Godhavn district on the Greenland coast.

51. Harelda glacialis, (Linn.) Leach.

"Agingak," Cumberland Eskimo. "Aglek," Greenlanders.

Arrived at the head of Cumberland during the latter days of May. As soon as there was extensive open water they became quite numerous, and their loud and incessant cries could be heard at any hour out of the twenty-four. They nest on the small rocky islands, especially about the Greater Kingwah Fjord, but singly, and not in colonies. They are gregarious when they first arrive, but soon pair and scatter. Common on the whole Greenland coast, and breed far to the north. These ducks are the noisiest birds for their size I have ever met. During the breeding plumage, scarcely any two males can be found that are precisely alike.

52. Polysticta stelleri, (Pall.) Eyton.

A beautiful adult male was shot in Disko Fjord in August, 1878. The specimen is now in the collection of Governor Edgar Fencker of Godhavn. During the time we were blockaded by the ice-jam at Annanactook Harbor, in Cumberland, I saw three or four of these eiders. At one time a superb specimen sat for hours on a cake of ice but a short distance from the ship; but I could not reach it on account of the breaking ice. I watched him a long time with a good glass, and there is no question of its identity. In late autumn I saw some that $I$ think were of this species.

53. Somateria mollissima, (Linn.) Leach.

"Metuk," Cumberland Eskimo. "Mettek" and "Amaulik," Greenlanders.

This eider is one of the commonest birds in Cumberland, and the only species that congregates together in any considerable numbers to breed. They are at all times gregarious. The old males separate from the females and young as soon as the breeding season is over, and assemble by themselves in large flocks. They also migrate southward much 
earlier than the females and young. During the autumn of 1877 we procured about serenty of these birds; but not a single adult male was shot or even seen. They were met with in large flocks at sea off the outer islands on the east coast of Hall's Land; here I also remarked that they seemed to be all males. As soon as there is any open water they are found in spring; still they were not common at Annanactook till the latter days of May. Eskimos from the south reported them on the floe edge near Niantilic early in May, and I saw a few on an iceberg near the Middliejuacktwack Islands on the 30th of April. They can stand almost any temperature if they can find open water. I saw one adult male in the tide rifts of the Greater Kingwah in January. The day I saw him it was $-50^{\circ} \mathrm{F}$; ; but he proved too lively for me. The Eskimo could have procured him on different occasions; but they had some superstitious notion regarding so unusual an occurrence, and would not kill it.

In the fall of 1877 I often found broods still unable to fly, though more than three-fourths grown, as late as the middle of October. Small flocks continued about the open tide-holes till November 17. At this. date I killed six young males; the temperature was $-70 \mathrm{Fah}$. They had at this time about fifty miles to the open water.

Their food in antumn consists almost entirely of mollusks. I have taken shells from the osophagus more than two inches in length; from a single bird I have taken out forty-three shells, varying from onesixteenth to two inches in length. The adult birds in spring did not seem to be quite so particular; in them I found almost all the common forms of marine invertebrates, and sometimes even a few fish (Liparis, and the young of Cottus scorpius).

By the first week of June they were abundant; enormous flocks would congregate on an ice-field and hold high carnival. I have watched such gatherings with a great deal of interest. When thus assembled, some old veteran would make himself conspicuous, and jabber away at a terrible rate, often silencing the greater portion of the rest, who appeared to listen for a short time, when the entire crowd would break out, each one apparently expressing his or her opinion on the subject. There always seemed to be the best of good feeling in those meetings, however, and all points were apparently settled to every one's satisfaction. I have often lain behind a rock on their breeding-islands and watched them for a long time. On one occasion we disturbed a large colony, and the ducks all left the nests. I sent my Eskimus away to another island, 
while I remained behind to see how the ducks would act when they returned. As soon as the boat was gone they began to return to their nests, both males and females. It was very amusing to see a male alight beside a nest, and with a satisfied air settle himself down on the eggs, when suddenly a female would come to the same nest and inform him that he had made a mistake, - it was not his nest. He started up, looked blankly around, discovered his mistake, and with an awkward and very ludicrous bow, accompanied with some suitable explanation, I suppose, he waddled off in search of his own home, where he found his faithful mate installed. Now followed an explanation that seemed to be hugely enjoyed by all in the vicinity. A pretty lively conversation was kept up, probably on the purport of our visit, as they seemed much excited. I could spare no more time to watch them, and crept out from my hidingplace into full view of all, and a look of greater disgust and astonishment than these birds gave me is difficult to imagine; they evidently regarded such underhand work beneath the dignity of a human being, and probably rated me worse than a gull or raven. So sudden and unexpected was my appearance that many did not leave their nests, but hissed and squaked at me like geese; these same birds left their nests before when the boat was within a quarter of a mile of the island.

The first eggs were procured June 21. The islands on which they nest are but small barren rocks, of an acre or less in extent, and often but a few feet above high tide-mark. There are a few patches of Poa arctica and Cochlearia officinalis seattered about, and these contain the greater number of nests. Each nest has a little circle of green sod about it, which is manured every year and becomes quite luxuriant. These mounds are sometimes a foot high and as much in diameter, having been used as a nest for many years in succession. Very little repairing is necessary to fit the nest for the reception of the eggs,-merely a little grass or moss. But little down is used till the full complement of eggs is laid. The nests are often so close together that it is impossible to walk without stepping on them. A nest seldom contains more than five eggs, often three or four, and I never saw as many as six but twice.

The principal breeding-places in Cumberland are between lat. $66^{\circ}$ and $67^{\circ} \mathrm{N}$. The lower of these places is about ten miles off shore from Mallukeitu; the greatest number of birds nest here. The seren islands to the northward about twenty-five miles are favorite resorts; also the small islands to the SE. of Annanactook. There is also a group known 
to the Eskimo as the "Shutook" Islands, in the Greater Kingwah, where I found them extremely abundant. In the Mallukeitu Fjord, according to the Eskimo, is another very much frequented breeding-place, but I did not visit it.

Thousands of eggs could be gathered on these rocks during the latter part of June and the first three weeks of July. It seems to me that it would pay whalemen to gather the down which can here be secured in great quantities. The islands are so close together that they could all be worked within two days of each other. There are a great many immature birds, both male and female, that do not breed; they assemble in large flocks, and are often met with at considerable distances from land. I have found such flocks commonly in Cumberland, on the west coast of Davis Straits and Baffin's Bay, and on the Greenland coast abundantly. Many large flocks were seen in the middle of Davis Straits, among the pack-ice, in the latter part of July. During the first days of August I saw immense flocks of eiders on the western end of Disko Island, all males, flying southward. The specimens collected by me in Cumberland present certain striking and remarkable points of difference from specimens from the South Labrador and Newfoundland coasts, especially in the form and size of bill. I had prepared a series of skulls, selected from over two hundred birds, that was calculated to show the variation among them; but, unfortunately, they were among the specimens that I had to leave behind, in the unnecessary haste of our departure, of which I was given but a few hours' warning.

These ducks are of great use to the Eskimo; their eggs are eagerly sought after and devoured in astonishing quantities. The birds themselves constitute a good portion of their food at certain times, and the skins are used for a portion of their foot-gear in winter, and sometimes for clothing. We found the flesh of the young in autumn very acceptable indeed; but the adults in spring were rather rank. Some specimens were procured that weighed over five pounds. They become extremely fat by the end of June; and when an Eskimo can get a number, he will eat little else but the fat. I was often saved much labor by having them remove the fat from the skins, which they did with their teeth, and much more effectually than I could have done it with a knife. These birds suffer much from the depredations of gulls and ravens. Larus glaucus even nests among the ducks, and the ravens live off the eggs and ducklings the entire season. 
54. Somateria spectabilis, (L.) Boie.

"Kingalalik," Cumberland Eskimo. "Siorakitsook" and "Kingalik," Greenlanders.

The king eiders were not noticed till the 20th of June. I saw a few large flocks at different times during spring; but there were a hundred mollissima to one spectabilis. They appear to keep by themselves, and not to mix with mollissima, at least during the breeding season. I never saw any on the eider islands. The Eskimo say that some years they are very plenty and others very few are found. One Eskimo told me that he once found them nesting in great numbers some distance up the Greater Kingwah, but not in company with the common eider. They arrive later and leave earlier than mollissima. In July I saw many of these ducks, males and females, about America Harbor. The sexual organs of those I procured were not developed, and they were all in the plumage of the female. I suspected them to be such birds as were thached very late the preceding season. Saw a great many in the same plumage on the west coast of Davis Straits and around Disko Island; many of the males seemed to be assuming the plumage of the adult. Governor Fencker told me that there were always a good number of these birds around in summer that did not breed. Many flocks of male birds were noticed west of Disko, all flying southward. Governor Fencker has procured identified eggs of this duck at Upernavik by shooting the parent on the nest. They are very common around Disko, but breed farther north. I shot a half-grown young in Kingwah Fjord in October, 1877. The lump of fat at the base of the bill of the adult males is esteemed a great delicacy with the Eskimo, and it is very seldom they bring one back that does not have this choice tit-bit removed.

\section{Edemia —?}

From the Middle Labrador coast north to lat. 670, I saw at different times large scoters, but could not identify the species.

I will here make mention of a duck that I saw on two or three occasions. It seemed to have the size and general make-up of a scoter, but had much white on the scapulars and about the head. A duck was winged by one of the ship's officers; he said it had a white ring around the neck and the rest of the body was nearly all black. The bird that I saw was unknown to me; it may possibly have been the Camptolacmus labradorius. I find in my notes that the first one I saw was pronounced a partially albino scoter; but, seeing more just like it, I gave this theory up. 
56. Mergus serrator, Linné.

"Pye," or "Pajk," Cumberland Eskimo and Greenlanders.

A regular breeder in Cumberland, but not very common. Nests on the perpendicular faces of high cliffs. Found on the Greenland coast to $73^{\circ} \mathrm{N}$. lat. at least, and probably farther. Begins nesting in Cumberland about July 1.

\section{Sula bassana, Briss.}

Noticed at different times from Beaver Island, Nova Scotia, to lat. $65^{\circ} \mathrm{N}$., most numerously in the Gulf of St. Lawrence and the South Labrador coast. Not observed in Cumberland.

58. Graculus carbo, Linné.

"Okaitsok," Cumberland Eskimo and Greenlanders.

A regular breeder in Cumberland; did not appear to be common, but the Eskimo say that some years they are quite plenty. The primaries were formerly in great demand for their arrows.

59. Buphagus skua, (Brünn.) Coues.

"Sea-hen" of whalemen.

One specimen procured at sea, lat. $41^{\circ} \mathrm{N}$., long. $68^{\circ} \mathrm{W}$., Atlantic Ocean. Others were seen at the time. Appears to be of frequent occurrence on the George's, Newfoundland, and Nova Scotian banks in winter. Seeu near Lady Franklin Island, north of Hudson's Straits, in September; they then had young ones on the rocks.

60. Stercorarius pomatorhinus, (Temm.) Vieill.

"Ishungak," Cumberland Eskimo and Greenlanders.

These birds were first observed at Bonne Bay, Newfoundland, August 16. From this point northward to $710 \mathrm{~N}$. they were common at nearly all points, and from Belle Isle to Hudson's Straits they were abundant. They nest about Nugumeute and Grinnell Bay, but not in Cumberland Sound. On the western shore of Davis Straits they are common, and nest at the mouth of Exeter Sound and at Shaumeer. I have, however, nowhere found them so very common as on the southern shores of Disko Island; at Laxbught and Fortuna Bay there must have been many hundred pairs nesting. Their breeding-place was an inaccessible cliff, about half a mile from the seashore. The greater number of the birds nesting here were in the plumage described in Dr. Coues's monograph of the Laride as the nearly adult plumage; but there were also a good many birds that were unicolored blackish brown an over, but with the long vertically twisted tail-feathers. That these were breeding I think there can be no doubt, as I saw them carrying food up to 
the ledges on the cliff, for the young I suppose. They were very shy at Disko, and the greatest cantion was required to shoot them. I shot none, even in full plumage, that did not have some white on at least one of the tarsi. They live to a great extent upon the labors of the kittiwake, though they do not hesitate to attack Larus leucopterus and even glaucus. They are destructive to young birds and eggs. It is a common sight to see fire or six after one gull, which is soon made to disgorge, and then the jaegers fight among themselves for the morsel, which often gets lost in the mêlée. Eggs were procured at Claushavn, Greenland; the nest contained three eggs.

61. Stercorarius parasiticus, Brünn.

"Ishungak," Cumberland Eskimo and Greenlanders.

This species seems to have the same general distribution as the foregoing, but, so far as my observations went, far from as common. Eggs were obtained from the Waigat Straits. They do not breed in Cumberland Sound; in fact, I rarely saw one in the Cumberland waters. This species seems to depend on Rissa tridactyla for the greater part of its food.

62. Stercurarius buffoni, (Boie) Coues.

"Ishungak," Cumberland Eskimo and Greenlanders.

A very few of these birds visited the upper Cumberland waters in Jurie, and soon disappeared. I doubt if they breed there. I saw but very few in all the localities I visited. Seems to be more common on the east than on the west coast of Davis Straits. One fine specimen was found lead on the ice, with a vorought-iron nail three inches in length in the esophagus. The nail had probably fallen out of a whale-boat that had been dragged over the ice, and the bird had mistaken it for a fish. This species has probably the most northerly range of any of the jaegers. Breeds in the Waigat Straits and about Omenak on the Greenland coast. Said by the Eskimo to be the first to return in the spring. They certainly were the first to visit Annanactook.

63. Larus glaucus, Brünn.

"Nowgah," Cumberland Eskimo. "Naga," Greenlanders.

This gull is the first bird to arrive in spring. In 1878 they made their appearance in the Kingwah Fjord by the 20 th of April. It was still about serenty miles to the floe edge and open water; still they seemed to fare very well on the young seals. Many are caught by them, and those partially devoured by foxes are carefully cleaned of every vestige of flesh. At this season, the Eskimo delight in capturing them in various ways. One of the most popular is to build a small snow-hut on the ice in a locality 
frequented by the gulls. Some blubber or scraps of meat are exposed to view on the top, and seldom fails to induce the bird to alight on the roof of the structure. This is so thin that the Eskimo on the inside can readily see the bird through the snow, and with a quick grab will break through the snow and eatch the bird by the legs. Some use a spear, thrusting it violently through the roof of the hut. Many are killed by exposing pieces of blubber among the hummocky ice and lying concealed within proper distance for bow and arrow practice.

By the middle of May they had become very abundant about Annanactook; still, there was no open water within fifty or sixty miles. These were all adults in full plumage; saw no immature birds till July. They settle on ice around the Eskimo encanıments, and even on the rocks in close proximity to the huts. During this season they keep up an almost constant screaming at all hours of the day and night.

May 24, I noticed a couple of pairs building. I think this is the earliest date they would begin nidification at this latitude. June 4, I saw a few $L$. glaucus among a large flock of Som. mollissima that were diving for food outside the harbor in a small lead in the ice. As soon as the duck came to the surface, the gull attacked it till it disgorged something; which was immediately gobbled up by the gull. The gull picked several times at what was disgorged, which leads me to the belief that the food was small crustaceans. This piratical mode of living is very characteristic of Larus glaucus. At this season of the year there was so little open water in the vicinity that they would have had great difficulty in procuring any food therefrom themselves. I have taken the eggs by June 8, when there was more than a foot of newly fallen snow on the rocks; but the greater number do not nest within two weeks of this time.

A great many of these birds nest in Cumberland on what the Eskimo call "Nawyah nuna"-land of the Glaucous Gulls. This is an enormous cliff about one and one-half miles in length and over 2,000 feet in height, and nearly perpendicular. This cliff is about four miles from the seashore to the ENE. of America Harbor. Many hundreds of nests are scattered about on the little projecting shelves of rock, and the birds sitting on them look like little bunches of snow still unmelted on the cliff. The ascent to this locality is very laborious; but the marvelous beanty of the place will well repay any future explorer to visit it, for the plants that grow in such rich profusion at the base of the cliff, if nothing more.

This is the most common gull in Cumberland during the breeding season. I did not see any sonth of Resolution Island in September and 
in October, but a very few as far south as the Kikkertarsoak Islands on the Labrador coast. They are far less common on the Greenland coast than $L$. leucopterus, while in Cumberland it is just the opposite. Eskimo from Cape Mercy tell me they are found all winter off the cape and about Shaumeer. A single specimen staid in the tide-rifts of the Greater Kingwah during the winter of $187 i-78$. In autumn they remain in the upper Cumberland waters as long as they continue open.

I have examined some nests that were built on the duck islands, always on the highest eminence; the structure seemed to have been used and added to for many years in succession, probably by the same pair. In shape they were pyramid-formed mounds, orer four feet at the base and about one foot at the top, and nearly two and a half feet in height. They were composed of every conceivable object found in the vicinity, grass, sea-weed, moss, lichens, feathers, bones, skin, egg-shells, \&c. The normal number of eggs is three, but often only two are found. Have taken the downy young in the latter part of June. I had an opportunity of seeing how these young hopefuls are instructed in eggsucking. The parent carried a duck's egg to the nest and broke a hole in it, and the young one just helped himself at his leisure. After the young are full-fledged, these birds are eminently gregarious, and are often seen feeding in considerable flocks. The flesh is highly esteemed by the Eskimo; we found the young by no means despicable food.

The Eskimo use the skin with the feathers on for a part of their winter's foot-gear. They are extraordinarily greedy and roracious; nothing in the animal kingdom seems to come amiss to them. I have seen a half dozen tugging at an Eskimo dog skin; but this proved too much for them, though they made desperate attempts to get off some small pieces, which they would have eaten had they succeded. Eggs, young or disabled birds, fish, and crustaceans are their common fare. They are also very fond of feeding upon seal carcasses. The first plumage of the young is much lighter than that of a yearling bird. This is just the opposite of $L$. leucopterus, they being the darkest when young. The young of $L$. glaucus gets darker in autumn, but when first fully fledged resembles more the bird of two years, except that there is no trace of blue on the mantle, and they have somewhat darker primaries.

64. Larus leucopterus, Faber.

"Nowyah," Cumberland Eskimo. "Nayangoak," Greenlanders.

The Eskimo do not distinguish between $L$. glaucus, leucopterus, glaucescens, and argentatus; they are all "nowyah"; in fact, I am led to Bull. Nat. Mus. No. $15 \longrightarrow 7$ 
think it a sort of general term as they use it,-something like "gull." This species is far less common in Cumberland than glaucus. On the Greenland coast it is the most common gull, except Rissa tridactyla. My opportunities for studying leucopterus were not very extensive, and my conclusions may be too hasty; but still it is worth while for others that may get better opportunities, to observe if the following points of difference are constant:

First. Leucopterus, 24 inches or less ; glaucus, 27 to 32 inches.

Second. Tarsus and toes of leucopterus in fully adult birds often orangered, and not flesh-colored as in glaucus.

Third. Ring around the eye in leucopterus flesh-colored; in glaucus, reddish purple.

Fourth. Young of glaucus in first plumage as light as the bird of the second year; the young of leucopterus nearly as dark as the young of glaucescens. The bill is also weaker and thinner than in glaucus.

- Governor Fencker says he has often had birds that answered nearly to the description of $L$. hutchinsii, but with chrome-yellow bill, with vermillion spot, and not flesh-colored, with dusky tip; these birds were always found to measure less, however, than the average glaucus, which is directly the opposite of my experience with hutchinsii. There may be a gradation between the two species as far as regards size; but the above cited points of difference have proved good so far as my observations have gone. They mix indiscriminately with glaucus at all times, but are always readily distinguishable by their smaller size. Eggs were procured at Claushavn, Greenland, which are indistinguishable from those of glaucus except in size. A fine specimen, a full-fledged young, was secured on the Hunde Islands, Disko Bay, that had four feet, the second pair growing out of the knee-joint in front.

\section{Larus glaucescens, Licht.}

"Nowyah," Cumberland Eskimo.

So far as I an awware this is the first instance on record of this bird being taken on the Atlantic coast. They are quite common in the upper Cumberland waters, where they breed. Arrived with the opening of the water and soon began nesting. The nest was placed on the shelving rocks on high cliffs. Two pairs nested very near our harbor; but the ravens tore the nest down and destroyed the eggs.' Only a single well-identified egg was secured. This gull is unknown to Governor Fencker on the Greenland coast. They remained about the harbor a great deal, and were often observed making away with such scraps as 
the cook had thrown overboard; were shy and difficult to shoot. Fullgrown young of this species ivere shot in the first days of September; these were even darker than the young of $L$. argentatus, the primaries and tail being very nearly black.

66. Larus marinus, Linn.

"Nayarlluk," Greenlanders.

Observed in Cumberland only in late autumn; cannot ascertain that they breed there; quite common on the Greenland coast form $63^{\circ}$ to $70^{\circ}$ N. lat. Abundant in October on the South Labrador coast and Newfoundland. Hundreds daily frequent St. John's Harbor, Newfoundland.

67. Larus argentatus, Brünn.

"Nowyah," Cumberland Eskimo.

Not uncommon in Cumberland, and breeds to lat. $67^{\circ} \mathrm{N}$. A mere straggler on the Greenland coast. Specimen shot June 20 in Cumberland contained ova as large as buckshot.

68. Pagophila eburnea, Gm.

"Nayauarsuk," Greenlanders.

Very common in Kingwah Fjord and vicinity just before it froze up, for a few days only. None seen in spring. Does not breed in Cumberland. By no means common on the Greenland coast. The food of those I examined consisted of small crustaceans. I saw one trying to swallow the ving of a Som. mollissima that the cook had thrown orerboard, when I shot it. The wing was so lodged in the œsophagus that it would certainly have choked the bird had it not disgorged. Those that visited our neighborhood seemed to have a very decided preference for meat. I once saw three or four alight on a seal that had just been killed, and attempt to get at the flesh. They are easily decoyed within shot by strewing pieces of meat on the ice. Were one of the most abundant and greedy birds around a whale carcass that had been killed in the vicinity. The specimens I procured that were nearly in adult plumage had a greenish yellow bill at base and bright yeilow tip, with no dusky markings; the younger birds only had the bill clouded with dusky. There appears to be a marked difference in the size of the sexes, the female being one to two inches shorter than the male.

69. Rissa tridactyla, Linn.

"Nowaváh" (Little Nowyah), Cumberland Eskimo. "Tattarat," or"Tatarak," Greenlanders and Eskimo about Frobisher Straits.

The kittiwake was first noticed in the Straits of Belle Isle, on our outward passage, the 18th of August, 1877. From this point northward 
they were with us constantly, if we were near land or far out at sea, in storm or calm, fog or snow; no day-scarcely an hour-but some of these interesting birds were-our companions; often a few individuals only, at other times flocks of many hundreds or even perhaps thousands on the islands of the north Labrador coast. In Cumberland they are by far the most common gull, and in fact the most abundant species in fall, but so far as I could learn do not breed there. From September till the ice covered the water they were extraordinarily abundant, congregating in immense flocks. When the tide runs strong they follow the stream for many miles in regular order, about half their number constantly dipping into the water, while the rest fly on ahead a few feet; while thus feeding they remind one of a flock of passenger-pigeons feeding in a grain-field. The food obtained at such a time is mostly small crustaceans.

When a good feeding-place is found, the whole flock settles down, and so close together that almost any number ean be shot. The jaegers are always on the alert for such flocks, and when they get near the gulls, they all foolishly take wing, when the jaeger singles out a likely looking subject, which is soon made to disgorge. The flock soon settles again, and the same manœurre is repeated.

I did not see a single kittiwake in the upper Cumberland waters during spring or summer, where there were thousands the previous autumn. A very few immature birds were noticed on an iceberg, July 18, near Cape Mercy; but these were all I saw till nearing the Greenland coast, where they are more common still. The flesh is highly esteemed by the Danes resident on the Greenland coast; in fact, they form no in. considerable portion of their meat supply during the latter part of July and August and September. We found the flesh of the young quite acceptable.

A few young birds were observed along the east coast of the Penny Peninsula as far as Exeter Sound, and in the pack-ice an occasional specimen was seen; but when nearing the coast of Disko their numbers increased to thousands. They followed the schooner constantly from this point till we got to the southern shores of Newfoundland, where few were seen.

Among the specimens collected by me were some that had scarcely any hallux, while in others it was as well developed as in any gull, and having a perfect nail. There is also every gradation between the two.

I saw a gull a little larger than trilactyla, in Godhavn Harbor, one day; it had a black head. The same afternoon Governor Fencker saw 
it in front of one of the Eskimo huts, feeding from a pile of garbage; he also failed to secure it. The bird looked to me like an adult $L$. frankilini, a bird not hitherto taken up as belonging to the Greenland fauna.

70. Xema sabinii, (Sab.) Leach.

On the 6th of October, 1877, on the passage from the Kikkerton Islands northward, a pair of these birds kept close to the stern of the schooner for many miles. I could easily have shot them, but it would have been impossible to procure them had I done so. Saw no others at any time.

\section{Sterna macrura, Naum.}

"Emukitilak," Cumberland Eskimo and Greenlanders.

On the 19th and 20th of June there were thousands of these birds about Annanactook Harbor, but this was also the only time I saw any. The Eskimo say they breed on the Seven Islands in Cumberland some years. They were first noticed in the Gulf of Saint Lawrence in August. From this point they seemed more or less common along the entire Labrador coast and the islands north of Hudson's Straits, but not in Cumberland. On the Greenland coast they are abundant, in suitable localities, to lat. $73^{\circ} \mathrm{N}$. In Disko Bay they are very common, and breed by thousands. They begin migrating southward during the latter days of August, when the young are large enough to take care of themselves. Appeared to be plenty at the month of Exeter Sound, where "kaplin" are very abundant.

72. Fulmarus glacialis, Leach.

"Oohudluk," Cumberland Eskimo. "Kakordluk" (white) and "Igahsook" (dark), Greenlanders.

On our outward passage these birds were first noticed off Belle Isle, August 20. From this point northward their numbers increased; they were everywhere close in shore and far out at sea, at all times and in all weather. Nearly all the Fulmars I saw in the autumn of 1877 were light-colored; saw none so dark as I did in the spring. They were very common in Cumberland till the middle of October. Were especially abundant off shore, Cape Chidly, Resolution Island, Grinnell Bay, and Frobisher Straits, during the latter part of August, September, and fore part ef October. These were white with a pearly grey mantle and bright rellow bill. I also procured a few that were ashy; these I presumed wcre young birds; but in July, 1878, I found a few of these dark-colored ones, darker than any I ever saw in fall, breeding near Quickstep Harbor, 
in Cumberland, on some small rocky islands. When fresh these darkcolored birds have a bright olive-green gloss, especially apparent on the neck and back. The bill is shorter, stouter, and thicker, dusky brown instead of yellow. On Blue Mountain, Ovifak, Greenland, these birds breed by myriads to the very summit of the mountain, about 2,000 feet. Here I could see but few darli birds; even the full-fledged nestlings were white.

In Exeter Sound and to the northward along the west shores of Davis Straits and Baffin's Bay, the dark variety seems to predominate. Near Cape Searle they are extraordinarily abundant, breeding by thousands on the Padlie Island, and they are so tame about their nesting-places that they can be killed with a stick. The eggs, even after being blown, for many months still retain the musky odor peculiar to the birds. Perfectly fresh eggs are quite good eating, but if a couple of days old the musky odor has so permeated them, even the albumen, that they are a little too much for a civilized palate.

So far as my observations went, more dark birds were seen in spring than in fall, so the dark plumage cannot be characteristic of the young.

The mollimoke is one of the greediest of birds. I have seen them feeding on the carcass of a whale, when their looks and actions were per. fectly those of a vulture,-completely begrimed with blood and grease, and so full that they could not take wing. I found great difficulty in procuring white specimens that were not more or less daubed over with "gurry," especially about the head and neck. These birds possess extraordinary powers of flight, and are marvelously graceful on the wing, rising with the billow and again settling into the trough of the sea without any apparent motion of the wings.

73. Cymochorea leucorrhoa, Coues.

Noticed sparingly about Cape Mercy and Exeter Sound. Two specimens seen in Disko Fjord in August, when they were probably nesting. Far less common on the passage southward than the following.

74. Oceanites oceanica, Keys.

Traced as far north as Resolution Island on our outward passage; on tie homeward, first seen about one hundred miles south of Cape Farewell.

75. Puffinus kuhli, (Briss.) Boie.

Common from Belle Isle to Grinnell Bay. Not observed in Cumber. land, on the Greenland coast. 
76. Puffinus major, (Briss.) Faber.

Abundant from Belle Isle to Resolution Island. Not observed in Cumberland.

77. Colymbus torquatus, Linn.

"Toodlik," Cumberland Eskimo and Greenlanders.

Quite common in Cumberland, where it breeds. Saw no mpecimens that approached the variety adamsi.

78. Colymbus arcticus, Linn.

"Codlulik," Cumberland Eskimo.

Not common, but breeds in Kingwah Fjord. First specimen shot June 24. Saw a few in autumn near Grinnell Bay. Not found in North Greenland according to Governor Fencker.

79. Colymbus septentrionalis, Linu.

"Kuksuk," Cumberland Eskimo. "Karksauk," Greenlanders.

Very common in all the localities visited by me. Begins nesting in the upper Cumberland waters in the latter part of June. The nest is placed on the low rocks with very little grass and moss beneath the eggs. They are very noisy, especially during the mating season. Do not leave as long as there is open water.

80. Utamania torda, Leach.

" Akparnak," Greenlanders.

Was seen on many occasions and often in close proximity to the ship from the outer islands of the Middle Labrador coast to Frobisher Straits. They were often noticed considerable distances from land. Are not found in Cumberland, but by no means rare on the entire west coast of Greenland to latitude $69^{\circ} \mathrm{N}$. Off the North Labrador coast I noticed on several occasions a small auk (?) intermediate in size between Mergulus alle and Uria grylle, with much the same pattern of coloration as the former, but with tufts or plumes of white feathers on the head. I saw some with single young, and at one time killed three at a single discharge; but the ship was under such headway that the sailor stationed on the waist could not reach them with his pole and net. The bird is entirely unknown to me, but I suspect it will be found to be one of the small auks hitherto supposed to belong only to the North Pacific.

81. Fratercula arctica, (L.) Ill.

"Killaugak," Greenlanders.

Observed abundantly in the Gulf of St. Lawrence, and thence northward to Hudson's Straits. Not known to the Cumberland Eskimo; but common on the Greenland coast to $70^{\circ} \mathrm{N}$. at least. Breeds plenti- 
fully on the Hunde and Green Islands in Disko Bay, where eggs were procured. There seems to be no appreciable difference in Gulf of St. Lawrence specimens and those from North Greenland except in size.

82. Mergulus alle, $\mathrm{L}$.

"Kaerrak," Greenlanders.

Common on the north coast of Labrador, off Resolution Island, Grinnell Bay, and Frobisher Straits, but did not see any in Cumberland. I showed specimens to the Eskimo, and they called it a young "akpa" (Lomvia arra). So I presume the bird is very rare, if found at all, in the Cumberland waters. Still they are abundant off Exeter Sound and to the northward on the west coast of Baffin's Bay. Governor Fencker says they nest to latitude $78^{\circ} \mathrm{N}$., and perhaps farther. Nest abundantly on the Whale Islands in Disko Bay. I procured young off Resolution Island in the fore part of September. They were very common among the pack-ice in Davis Straits during July. Often a considerable number would be seen sitting on the ice. They seem devoid of fear. I have caught them from the schooner's deck with a net on the end of a pole while they were swimming alongside.

83. Uria grylle, (L.) Lath.

"Pesholak," Cumberland Eskimo. "Serbek," or "Sergvak," Greenlanders.

Was first observed off Resolution Island in the first days of September, 1877. They were then busily engaged fishing and carrying the fish sp the cliffs to the young, which were not yet in the water. They are most expert divers and are often seen fishing where there is a considerable depth of water. I once shot an adult female that was carrying a little Morrhua 7 inches in length up to her young. This was on the 19th of September, and the young were not more than three-fourths grown at this date. I visited no locality either on Cumberland or on the GreenIand coast where this bird was not abundant. Some sections are of conrse more suitable than others, and here they are very numerous. They began to change into the winter plumage in the latter part of September. Some of the earlier-hatched young were much earlier than this, but the adults were not in perfect winter dress till the middle of October. They remained about our winter harbor as long as there was open water, and even one or two staid in the Kingwah rifts all winter. In spring they returned as soon as there was open water. About the Southern Cumberland waters some remain all winter,-the Eskimo say only the young birds. At Annanactook Harbor they began nesting about June 25 . The normal number of eggs is two; very rarely 
three are found. Always nest in crevices and fissures of cliffs, where it is often extremely difficult to get at them. They are very tame; but it is next to an impossibility to shoot one on the water if the bird is watching you, for they dive quite as quickly as a loon. I have seen three entirely black specimens, which I considered to be $U$. carbo. One was procured in Cumberland, but was lost, with many others, after we arrived in the United States. I have examined specimens of carbo since in the Smithsonian collection, and my bird was nothing but a melanistie specimen of $U$.grylle. I also have seen an albino specimen.

'There were a few birds in an air-hole in the ice near our harbor in the latter days of June that to all appearance resembled the autumn plumage of the young; but the ice was too treacherous for me to venture out, so I sent an Eskimo. He returned and reported them "Kanitucalo pechulak" (very near a Guillemot). But if he meant that they were in imperfect plumage or another species closely resembling grylle, I could not make oat. He conld not get close enough to the air-hole to proeure the specimen he killed, and I never saw or heard anything more of them.

\section{Lomvia arra, Brandt.}

"Akpa," Cumberland Eskimo and Greenlanders.

I had hoped to be able to throw some light on the subject of the relationship of the Murres, but I find my material corresponds with my opportunities for observation-very poor and uisatisfactory. I first met these birds in numbers off the coast of Resolution Island, but many were seen farther south. About Grinnell Bay and Frobisher Straits they are common even as far as the mouth of Cumberland, but apparently quite rare in the waters of that sound The Eskimo say they formerly bred in great numbers on the Kikkerton Islands; but they have now apparently abandoned them. There are large breeding-places about Cape Mercy and Walsingham, the largest "rookery" being on the Padlie Islands in Exeter Sound. On the Greenland coast they are very abundant, breeding by thousands in many localities. Observed plentifully in the pack-ice in July. All the specimens collected by me were typical arra. I procured but one single troile. The var. ringvia, Briinn., Gorernor Fencker has not met during eleven years' collecting on the Greenland coast; and var. troile appears to be far from common. There is a remarkable variation in the distribution of the dark color, some being white on the throat quite to the bill, and again 1 have seen specimens entirely black. The dark markings on the eggs of $L$. arra and troile, as well as $A$. torda, can readily be obliterated with luke-warm water. 


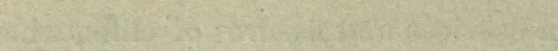

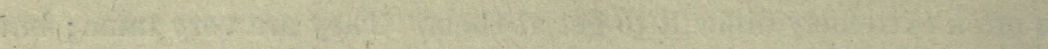
S.

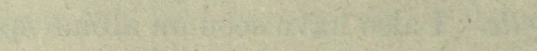

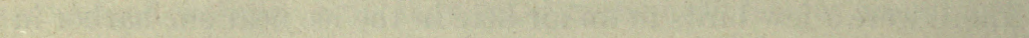

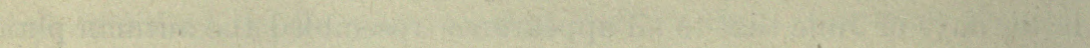

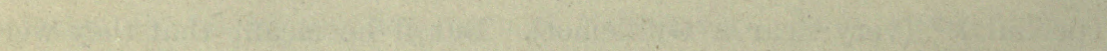

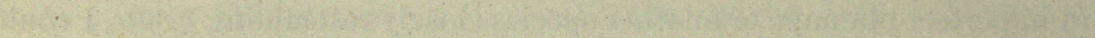

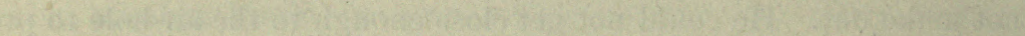

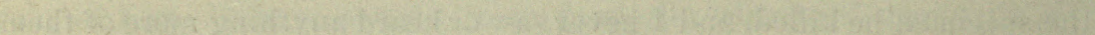
(6)

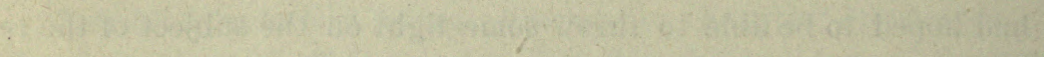

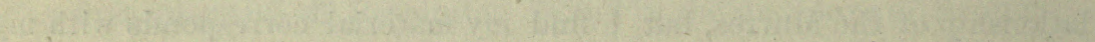

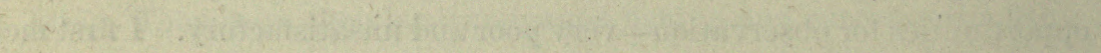

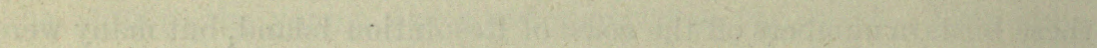

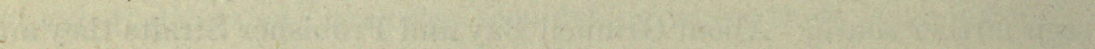

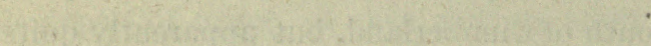

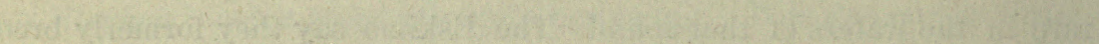

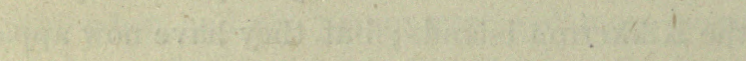

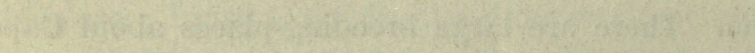

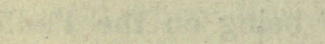

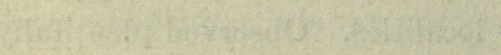

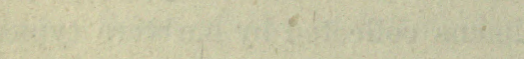

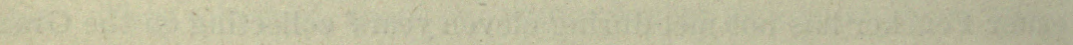

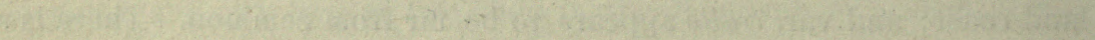

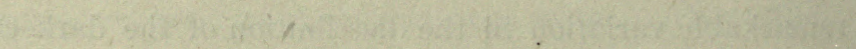

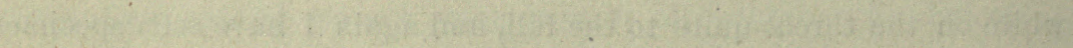

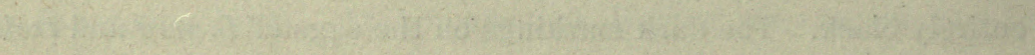

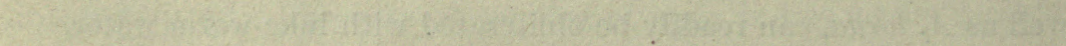




\section{FISHES}

COLLECTED IN CUMBERLAND GULF AND DISKO BAY.

By Tarletox H. Beax.

The collection of fishes made by Mr. Kumlien embraces ten species, as follows :

1. Boreogadus saida.

2. Gadus ogac.

3. Gymnelis viridis.

4. Liparis vulgaris.

5. Cyclopterus lumpus.

6. Cottus scorpius.

7. Cottus scorpius sub-species grönlandicus.

S. Cottus scorpioides.

9. Gymnacanthus pistilliger.

10. Gasterosteus pungitius sub-species brachypoda.

With these I have combined several species collected by Lieut. W. A. Mintzer, U. S. N., in Cumberland Gulf in 1876, the two following being additions to Mr. Kumlien's list:

11. Lycodus mucosus.

12. Salvelinus Naresi.

Besides giving a report upon these twelve species recently obtained by the United States National Museum, I have made a list of the species recorded from Northeastern North America, which is by no means complete, but is as nearly so as the limited time allowed me for searching would permit. Of course there are many Greenland species which we may be sure are found also on our northeastern coast, but we have as yet no positive evidence of their occurrence.

The additions to our collections and to our knowledge of the species made by Mr. Kumlien are by far the most important contributions from the region in question hitherto received by the museum, and that excellent naturalist deserves hearty acknowledgments for the raluable material which he has secured in the face of great obstacles. Two of the species taken by him have not before been recorded from the northeast 
coast-Cottus scorpius and Gasterosteus pungitius sub-species brachypoda. Many of the others are extremely rare in collections.

- Lieutenant Mintzer's collection also, though small in the number of species, is rich in interest, and has greatly extended our acquaintance with some of the rarest of northern forms.

\section{Family, PLEURONECTID Ȧ.}

\section{Pleuronectes Franklinii Günther.}

Pleuronectes Franklinii Güntr., Cat. Fish. Brit. Mus., iv, 1862, p. 442.

Pleuronectes (Rhombus) glacialis RICIr., F. B. A., ii:, 1836, p. 258.

Platcssa glacialis Rich., Voy. Herald, Fishes, 1854, p. 166, pl. xxxii.

Richardson records the species from Bathurst's Inlet (670 $40^{\prime}$ N., $109^{\circ}$ W.); Dr. Giinther has Aretic American specimens from Dr. Rae and the Haslar collection. Judging from the descriptions given by Richardson and Guinther, Pleuronectes Franklinii is very closely related to $P$. glaber (Storer) Gill.

\section{Hippoglossus vulgaris Fleming.}

Halibut Kumles, in lit. Feb. 16, 1879.

Mr. Kumlien writes me, that " in February a large halibut was caught in a seal breathing-hole by an Eskimo, but it was something entirely un. known to them."

It may be that this was not Hippoglossus vulgaris, but Platysomatichthys. hippoglossoides (=Reinhardtius hippoglossoides (Walb.) Gill).

\section{Family, GADID $\nexists$.}

3. Boreogadus saida (Lepech.) Bean.

Gadus fabricii RicH., Faun. Bor. Amer., 1836, p. 245: Güsther, Cat. Fishes Brit. Mus., iv, 1862, p. 336.

Borcogadus polaris GiLL, Cat. Fishes E. Coast N. A., 1873, p. 17.

21746. (310.) Annanactook, Cumberland Gulf, A. L. Kumlien. D. 14, 18, 18. A. 21, 19. P.17. V.6. Length 250 millimetres.

The inequality of the caudal lobes mentioned by Gill* is evident in this example; the length of the upper lobe, measured from the origin of the middle caudal rays, is 31 millimetres, of the lower lobe 27 . The outline of the lower lobe is decidedly convex below. The middle caudal rays, instead of pursuing the horizontal of the median line of the bodr, are slightly raised, giving the fin a peculiar shape, which may perhaps be due to outside circumstances, or may be characteristic of the adult.

* Proc. Acad. Nat. Sci. Phila. 1863, p. 233. 
The inequality of the lobes and the singular shape are not present in the smaller individuals referred to below.

Mr. Kumlien sent the following notes of color: "Brassy red; belly white; eye red. Fins dark purple brown." A sketch of this specimen by Mr. Kumlien has the caudal lobes equal.

21747. (481.) Kingwah Fjord, Cumberland Gulf, A. L. Kumlien. D. 13, -, 20. A. 16,21. V.6. Length 180 millimetres.

"Found on a seal-hole. Iris silvery white. Fins dark purple brown. Belly and lower parts silvery. Back brassy olive brown."-Kumtien.

21748. (85\%.) Head of Cumberland Gulf, A. L. Kumlien. D. 13,16, 20. A. 19, 21. P. 19. V.6. Length 160 millimetres.

"Dark brassy red, becoming blue-black on head. Silvery white on belly. Pectorals white. All the rest of the fins dark purple-blue."Kumlien.

21753. (369.) Cumberland Gulf, Jan. 2, 1878, A. L. Kumlien. Length 112 millim.

"The principal food of Pagomys foetidus at this season."-Kumlien.

I have followed the lead of Malmgren* and Collettt in employing the name Gadus saida Lepech. Professor Collett has made a direct comparison of examples of this form of cod from Archangel, Greenland, Spitzbergen, and Nora Zembla, and he believes the polaris of Sabine, 1824, Fabricii of Richardson, 1836, and agilis of Reinhardt, 1838, to be identical with G. saida. The only difference that he observed is that individuals from the White Sea hare, as a rule, darker fins than the rest, which he justly attributes to a difference in the surroundings of the bottom in the different places. They agree in squamation, structure of the teeth, position of the anus, and in every particular of the structure of the body so completely that they cannot possibly be separated.

4. Pollachius carbonarius (Linn.) Bon.

Merlangus carbonarius Rich., Last of the Arctic Voyages, 1855, p. 375.

Richardson records the species from Davis Strait.

5. Gadus morrhua Linn.

Gadus morrhua Rrcr., F. B. A., iii, 1836, p. 243.

Richardson states that Davis observed many cod in the possession of the Eskimo who live between Cape Raleigh and Cumberland Strait.

* Öfv. Kgl. Vet. Akad. Förh. 1864, p. 531.

†Christiania Vid. Selsk. Förh. No. 14, 1878, (p. 80).

$\ddagger$ Men iövrigt stemme de i Skjælbeklædning, Tandbygning, Stillingen af Anus og i ethrert Punkt af deres Legemslbygning saa fuldkommen overens, at nogen Adskillelsa mellem den ikke er mulig.-Collett, 7 . $c$. 
6. Gadus ogac Rich.

Gadus ogae RICH., Faun. Bor. Amer., iii, 1836, p. 246.

Gadus ovak RHDT., Vid. Selsk. Naturvid. og Math. Afh., deel vii, 1838.

Gadus ogat Kröyer, Voy. en Scand., \&c., pl. xix.

21723. (1417.) के Godthaab, Greenland, August 11, 1878. D. 13, 19, 22. A. 22 , 21. V. 6. Length of specimen 330 millimetres.

A black spot on the second dorsal, $\frac{2}{3}$ as long as the eye, between the thirteenth and fifteenth rays.

21724. (1418.) \& Godthaab, Greenland, August 11, 1878. D. 14, 18, 20. A. 20, 18. V. 6. Length of specimen 359 millimetres.

The lateral line shows an interruption, measuring 22 millimetres on the left side, the right being normal. The first portion of the lateral line ends at the vertical through the interspace between the first and second dorsals; the second portion begins at the vertical let fall from the sixth ray of the second dorsal.

21725. (1419.) $\subsetneq$ Godthaab, Greenland, August 11, 1878. D. 14, 17, 18. A. 19, 20. V. 6. Length of specimen 300 millimetres.

Richardson records this species at Cape Isabella, Peninsula of Boothia.

Gadus ogac Rich., may be only a variety of $G$. morrhua Linn., as claimed by Dr. Günther; but after examining many specimens of the latter species and comparing them with Mr. Kumlien's examples, I prefer to consider these distinct from $G$. morrhua and identical with Richardson's species. It may be that a larger series would lead me to the same conclusion reached by Dr. Günther. I have studied all the common cod in the United States National Museum, a very large series, recently increased by the addition of a monster weighing 100 pounds, and find that Gadus ogac is distinguished from G. morrhua by several important characters, among which are (1) a more slender caudal peduncle; (2) a longer barbel; (3) a larger eye; (4) a greater distance between the eyes; (5) a longer pectoral; and (6) the more advanced position of the ventrals. These differences may be seen in the tables of measurements, in which are given the proportions of parts of the body in hundredths of the total length without the caudal.

The general color of Mr. Kumlien's specimens is very dark brown, and the sides are marbled with white. 
FISHES.

Table of Measurements.

Species, Gadus ogae Rích.

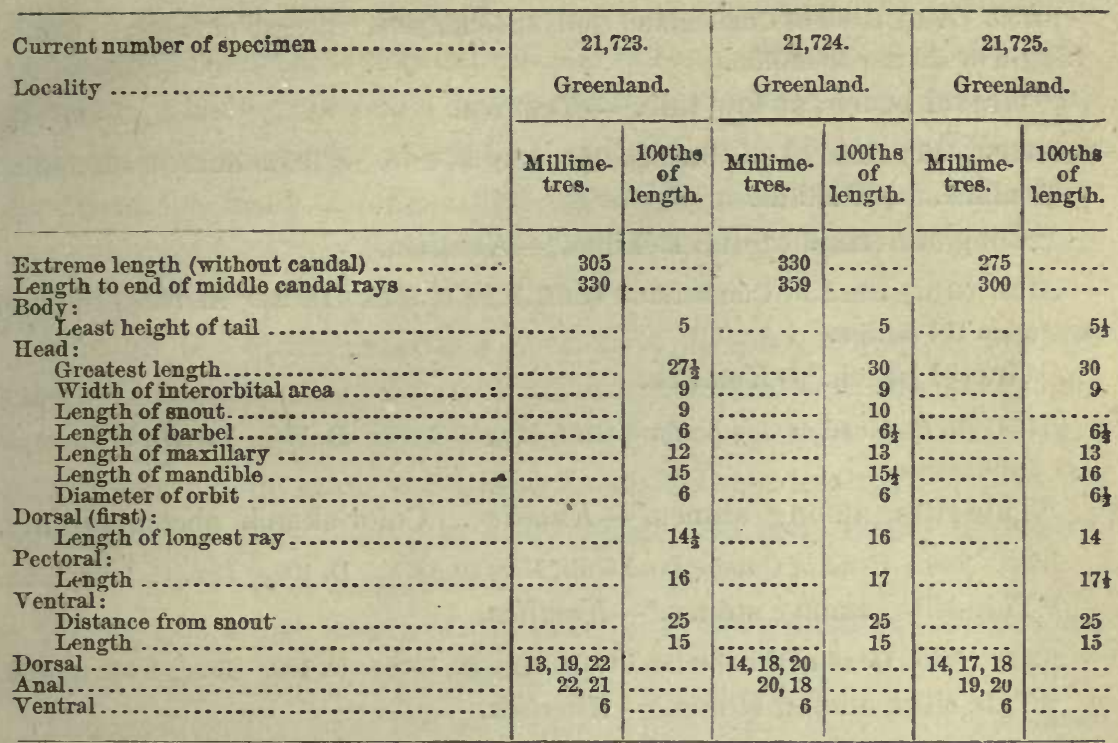

Table of Measurements-Continued.

Species, Gadus morrhua Linn.

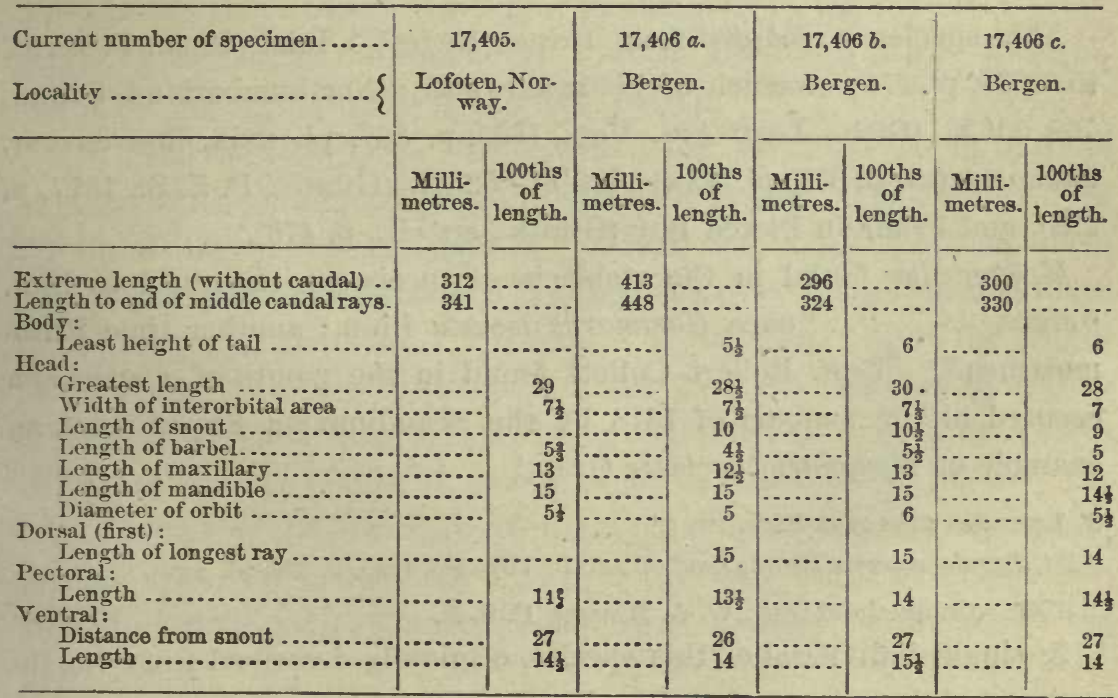




\section{Family, LYCODIDAs.}

7. Gymnelis viridis (Fabr.) Rhdt.

21739. (726.) Head of Cumberland Gulf, June 13, 1878. Length of longer 63 millim. Length of shorter 59 millim.

"Gravel beach, at low tide."-Kumlien.

21749. (648.) Head of Cumberland Gulf, May 30, 1878. a, 109 millim. b, 103 millim. $c, 65$ millim. $d, 60$ millim.

"Coogjannernak of the Eskimo."-Kumlien.

21757. (661.) Head of Cumberland Gulf, June 6, 1878. D. 95. A. 77. Length of specimen 104 millim.

"Gravel beach."-Kumlien.

21758. (647.) Head of Cumberland Gulf, May 30, 1878. D. 105. Length of example 147 millimetres.

"Tide-rifts, among stones."-Kumlien. Color-sketch accompanying. 21759. (646.) Head of Cumberland Gulf, May 30, 1878. D. 102. Length 142 millim. "Tide-rifts, among stones."-Kumlien.

21760. (645.) Head of Cumberland Gulf, May 30, 1878. D. 100. Length 142 millim. "Tide-rifts, among stones."-Kumlien.

21999. (86.) Niantilic, Cumberland Gulf, August, 1876. W. A. Mintzer, U. S. N. $a$, 210 millim. b, 176 millim.; D. ca. 95 ; A. 77; P. $13 . \quad$ c, 175 millim. ; A. 75; P. 12. d, 124 millim.; A. 78 ; P. 13.

"Found between high and low water mark."-Mintzer.

This species is recorded from Prince Regent's Inlet (Rich., F. B. A., iii, 1836, p..271; stomach of kittiwake gull); Northumberland Sound, $76053^{\prime}$ N. (Rich., Last Arc. Voy., 1855, p. 367, pl. xxix, and as var. unimaculatus, p. 371, pl. $\mathrm{xxx}$ ); lat. $81052^{\prime}$ N. (Giinth., P. Z. S., 1877, p. 293), and Franklin Pierce Bay (Guinth., op. cit., p. 476).

Kröyer has found in the stomachs of specimens examined by him, "crabs . . . once Gammarus locusta Linn.; another time Ento. mostraca."* Prof. Robert Collett found in the mouth of a specimen secured in the summer of 1878 by the Scandinavian Expeditions, an example of Modiolaria lovigata Gray.†

\section{Lycodes mucosus Rich.}

Lycodes mucosus RIcr., Last of Arctie Voyages, 1855, p. 326, pl. xxvi.

16930. Cumberland Gulf, W. A. Mintzer, U. S. N.

A single individual of this species, originally described from Northumberland Sound, was found by Lieutenant Mintzer, and presented by him to the United States National Museum. From the appearance of the specimen it must have been picked up dead; but it is in a good state 
of preservation. As there is little on record concerning the speciss, and the example under consideration is much larger than the types, and, while it agrees in all important particulars with Richardson's description and figure of $L$. muscosus, still shows some differences in the measurements, I have drawn up a description and prepared an accompanying table of measurements. It will be observed that in Lieutenant Mintzer's specimen the head is longer and wider and the height and width of body slightly less than in the types, which rariations may be accounted for by the difference in size.

Like all the other described species of Lycodes, except $L$. paxillus Goode \& Bean, of which I have knowledge, the width of the body at the vent is very much less than just behind the pectorals, and the height of the borly at the same point is also considerably less than it is in the anterior part of the body; in other words, the body tapers decidedly, and the tail is much compressed.

Description.-The length of the example is 430 millimetres (17 English inches). Scales are entirely wanting.

The greatest height of the body (at the pectorals) is contained 8 times and its greatest width (just behind the pectorals) 9 times in the total length. The width at the rent is contained 8 times in the length of the head, and twice in the length of the longest dorsal ray. The height at the ventrals about equals the height of the body at the pectorals. The height of the body at the rent equals half the greatest width of the head, and is contained $11 \frac{1}{2}$ times in the total length.

The head is very large, its length being $\frac{7}{25}$ of the total, and its greatest width contained $5 \frac{3}{4}$ times in the whole length. The distance from the tip of the snout to the nape is $\frac{1}{5}$ of total length, and $\frac{4}{3}$ of the length of the mandible. The distance between the eyes is contained 6 times in the length of the head. The length of the snout is $\frac{1}{3}$ of the length of the head. The nostrils are much farther from the eyes than from each other, their distance from the eyes being contained $4 \frac{1}{3}$ times in the length of the head. The length of the upper jaw is contained $6 \frac{1}{4}$ times in the total length ; of the lower.jaw, 62 times ; the upper jaw slightly exceeding the mandible in length. The eyes are very small, close together, and high, their long diameter being equal to $\frac{1}{11}$ of the length of the head.

The distance from the tip of the snout to the beginning of the dorsal fin is contained $3 \frac{1}{4}$ times in the total length. The first ray of the dorsal is contained $5 \frac{3}{5}$ times in the length of the head, and the longest, 4 times.

The distance of the anal from the snout is $\frac{11}{2} \frac{1}{0}$ of the total length and Bull. Nat. Mus. No. $15 \longrightarrow 8$ 
almos equals twice the distance of the pectoral from the snout. The first anal ray is contained $9 \frac{1}{3}$ times in the length of the head, the longest $4 \frac{1}{3}$ times. The vent is nearly in the middle of the total length.

The distance from the tip of the snout to the base of the pectoral is contained $3 \frac{1}{2}$ times, and the length of the pectoral $6 \frac{2}{3}$ times in total length. The length of the pectoral equals that of the mandible, and only slightly exceeds one-half of the length of the head.

The distance of the ventral from the tip of the snout equals the length of the head. The length of the ventral equals the long diameter of the eye.

Radial formula.-D. (including half of candal) 90 ; A. (including half of caudal) 71 ; P. $18 ;$ V. 3.

Colors.-These agree, in the main, so closely with Richardson's description of them, that it is unnecessary to say more than that the cross. markings are faint and narrow.

The gape of the mouth is very wide. The character and arrangement of the teeth agree perfectly with the original description.

Table of Measurements.

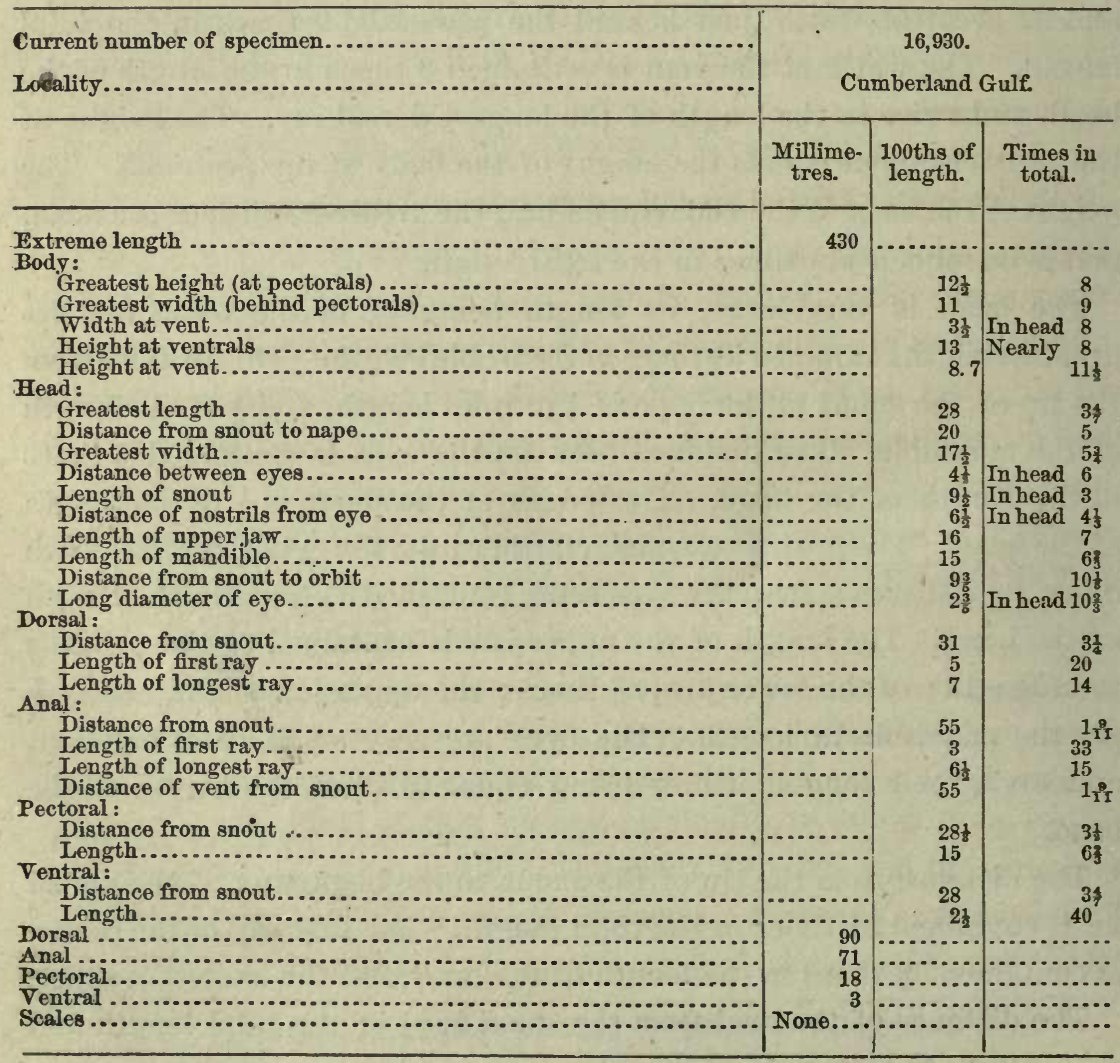


9. Iycodes polaris (Sabine) Rich.

Blennius polaris SaBIxE, App. Parry's First Voy., p. cexii.

Lycodes polaris RrcH., Last Are. Voy., 1855, p. 362.

Described from North Georgia, lat. $75^{\circ} \mathrm{N}$., long. $110^{\circ} \mathrm{W}$. Recorded, also, from the west side of the Peninsula of Boothia by Capt. J. C. Ross.

10. Uronectes Parryi (Ross) Günther.

Ophidium Parrii Ross, in Parry's Third Voy., App., p. 109; Polar Voyage, p. 199.-Rrch., F. B. A., iii, 1836, p. 274.

Discovered in Baffin's Bay and Prince Regent's Inlet. Observed near Felix Harbor, ejected by a glaucous gull.-Rich., $l_{\text {. }}$.

Family, STICHAID A.

11. Centroblennius nubilus (Rich.) Gill.

Lumpenus nubilus RIcH., Last Arc. Voy., 1855, p. 359, pl. xxviii.

This species was described from Northumberland Sound, lat. $76^{\circ} 53^{\prime} \mathrm{N}$.

\section{Family, ZIPHIDIONTID必.}

12. Murænoides fasciątus (Schn.) Gill.

Gunnellus fasciatus RicH., Last Arc. Voy., 1855, p. 35\%, pl. xxvii.

Richardson records the species from Northumberland Sound.

Family, CYCLOPTERIDA.

13. Eumicrotremus spinosus (Fabr.) Gill.

Cyclopterus spinosus GüNTH., P. Z. S., 1877, ṕp. 293, 476.

Günther has examined specimens from Franklin Pierce Bay.

14. Cyclopterus lumpus Linn.

21726. (1411.) Godthaab, Disko Island, Greenland.

Mr. Kumlien brought down a single specimen 430 millimetres in length, and furnished the following notes of color: "Varying shades of dusky olive green. Dorsal light. Belly nearly white. Tris umber."

Family, LIPARIDID丑.

15. Liparis vulgaris Fleming.

Liparis lineata (LEP.) KRörer, Nat. Tidsskrift, ii, 2, p. 284 ; iii, 1, p. 244 ; Voy. en Scand., \&c., pl. xiii, fig. 2.

Liparis lineatus CoLLeTt, Christiania Vid. Selsk. Forh. 1878, No. 14, (p. 32).

21762. (657.) Annanactook, Cumberland Gulf. D. 42. A. II, 34. P. 35. C. 11. Taken in " 7 fathoms. Nee-fitz-shak of the Eskimo."-Kumlien.

21763. (859.) Head of Cumberland Gulf, June 29, 1878. (a) D. 19, 23; A. 34.

(b) D. 19,21 ; A. 35 .

"Fastened to kelp in 7 fathoms." - Kumlien.

21764. (860.) Annanactook, Cumberland Gulf, June 29, 1878.

"Fastened to kelp."-Kumlien. 
21765. (858.) Head of Cumberland Gulf, June 29, 1878. D.41. A.34. P.34. C. 10. "Fastened to kelp in 5 fathoms."-Kumlien.

21752. (573.) Annanactook, Cumberland Gulf.

Referred doubtfully to $L$. vulgaris. The specimen is young and in bad condition. It was taken in 9 fathoms.

Richardson (F. B. A., iii, 1836, p. 263) mentions this species from the west side of Davis Strait in lat. 700, and from Regent's Inlet.

Professor Collett found the alimentary canal of one of his specimens filled with small amphipods, one of them being Caprella septentrionalis Kr., together with many individuals of Protomedeia fasciata Kr.*

16. Liparis Fabricii Kröyer.

Liparis Fabricii GÜNTHER, P. Z. S., 1877, pp. 294, 476.

Dr. Guinther has examined specimens collected in Discovery Bay and Franklin Pierce Bay.

Family, AGONID ze.

17. Aspidophoroideś monopterygius (Bloch) Storer.

Aspidophoroides monopterygius GÜNTH., P. Z. S., 1877, p. 295.

A young individual was taken in 30 fathoms, lat. $65^{\circ} \mathrm{N}$., long. $53 \circ \mathrm{W} .-$ Günther, $l$. c.

\section{Family, COTTID王.}

18. Cottus scorpius Linn.

21989. (151.) \& Niantilic Harbor, Cumberland Gulf, A. L. Kumlien.

21742. (180.) ¿ Niantilic Harbor, Cumberland Gulf, A. L. Kumlien.

Mr. Kumlien collected this individual on the 25th of September, 1877, at which time its colors must have been exceedingly brilliant, judging from the traces which still remain. He states in his notes, that it lives "among the rocks at the bottom, feeding largely on crustacea and mollusks." Cottus scorpius, and the sub-species grönlandicus, but especially the latter, formed an important part of the food supply of the expedition.

These specimens of Cottus scorpius are clearly identical with Scandinavian examples of the same species, as may be seen from the tables of measurements which follow. In all the tables it must be remembered that the unit of length is the total length without candal. So far as I know, the true Cottus scorpius has not previously been found on the east coast of America. A young individual, catalogue-number 10374, collected at Eastport, Me., by the United States Fish Commission, may be compared with one a trifle larger, catalogue-number 22060, which 
was presented to the United States National Museum by Prof. Robert Collett. The agreement between these two in all essential particulars is very striking. We may safely record this species, then, at least as far south as Eastport. The true Cottus scorpius may be distinguished from the sub-species which follows by its narrower interorbital distance, and the lesser length of the dorsal spines, particularly the anterior ones.

\section{Table of Measurements.}

Species, Cottus scorpius Linn.

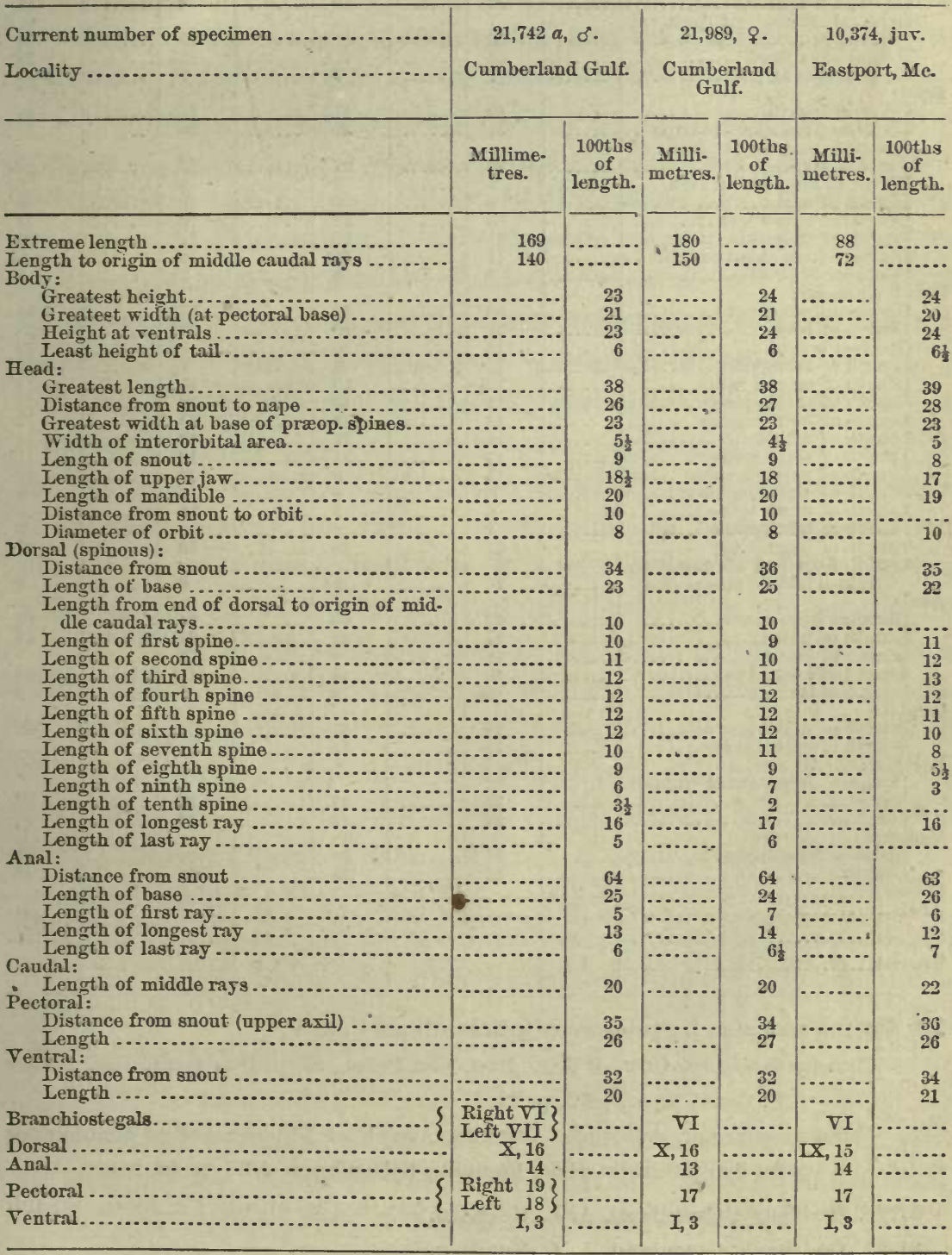


Table of Measurements-Continued.

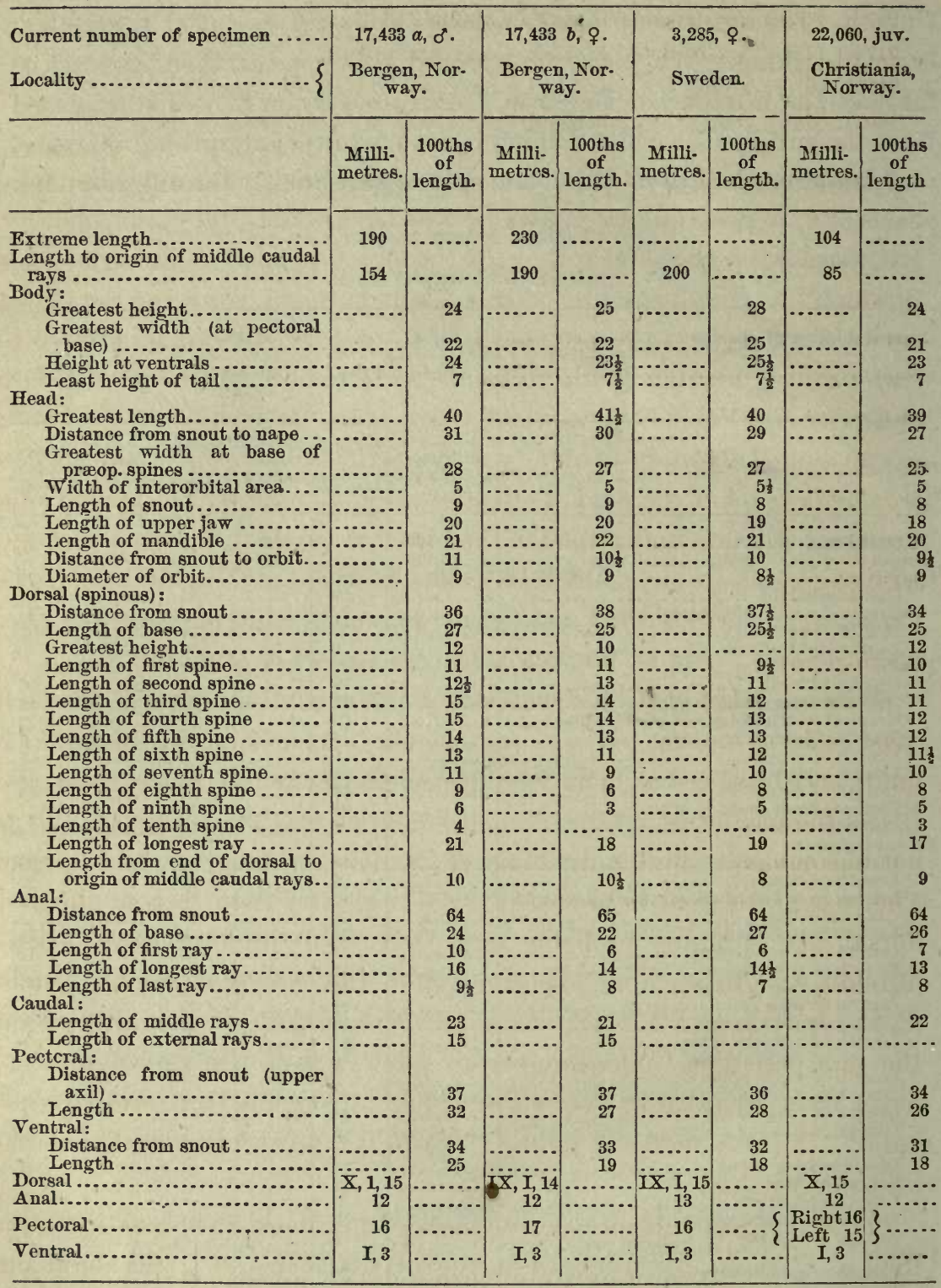

19. Cottus scorpius L., sub-species grönlandicus C. \& V.

Cottus grönlandicus CUv. \& VAL., Hist. Nat. Poiss., iv, p. 185: GrLl, Cat. Fishes E. Coast N. A., 1873, p. 22.

Cottus scorpius var. grönlandica LÜTKEN, Aftryk af Videnskabelige Meddelelser fra den naturhistoriske Forening Kjöbenhavn, 1876, p. 16.

21728. Godthaab, Greenland, A. L. Kumlien.

21729 Godthaab, Greenland, A. L. Kumlien. 
21730. Godthaab, Greenland, A. L. Kumlien.

21731. Godthaab, Greenland, A. L. Kumlien.

21740. (151.) đo. Niantilic Harbor, Cumberland Gulf, A. L. Kumlien.

21751. (67.) Young. Aretic Id., Cumberland Gulf, A. L. Kumlien.

16931. Many young. Cumberland Gulf, Lieut. W. A. Mintzer.

I have reached practically the same conclusion concerning the relations of C. scorpius and C.grönlandicus as Dr. Lütken, Malmgren, and Col. lett, since it is probable that they use the term "variety" in the same sense in which I use "sub-species." Dr. Lütken, however, supposes the Cottus variabilis of Ayres to be a synonym of $C$. scorpius sub-species grönlandicus; but it is identical with Cottus ceneus Mitchill. The Cottus Mitchilli of Cuvier and Valenciennes, which was a mere name based on the Cottus scorpius of Mitchill, is evidently a synonym of C. scorpius sub-species grönlandicus; but the name Cottus Mitchilli, as used by Dr. DeKay and Professor Gill and understood in the museum catalogues, was associated with the species which should be called $C$. aneus of Mitchill. DeKay's Cottus ceneus as described and figured is a compound of ceneus and octodecimspinosus. His C. Mitchilli is the true aneus of Mitchill.

C. ceneus Mitchill is the smallest of the marine sculpins of the east coast so far as known, and appears to be the least widely distributed. Its limits may be stated as Long Island on the south and Maine on the north. It has the narrowest interorbital space of our five known species. It is not uncommon to find individuals of $2 \frac{1}{2}$ inches in length full of spawn. The base of the anal is almost invariably shorter than that of the first dorsal. It is highly probable that DeKay's figure* of Cottus aeneus Mitchill was drawn from a specimen of Cottus octodecimspinosus Mitchill, the only known Eastern American sculpin with so long a spine on the præoperculum. The number of anal rays (13) in this figure has never been recorded in Cottus ceneus, but is common in C. octodecimspinosus. DeKay's figure of Cottus Mitchilli is a fair representation of the ceneus of Mitchill.

Cottus scorpius sub-species grönlandicus has about the same southern limit as $C$. oneus, but it ranges northward to Greenland. It is abundant at Wood's Holl, Massachusetts, in winter. The United States Fish Commission has found it common in summer at different points along the coast between Cape Cod and Halifax, Nova Scotia. At Salem and Gloucester it was caught from the wharves. The stomach of an adult of medium size, taken at Wood's Holl, Mass., by the United States Fish Commission, contained three crabs, Cancer irroratus. 
Cottus octodecimspinosus Mitchill is known from Halifax on the north to Beesley's Point, New Jersey, on the south, where it was collected by Prof. S. F. Baird in 1854. It is considered a shallow-water species; but the United States Fish Commission has a specimen from 68 fathoms in the Gulf of Maine, where the temperature was about $42^{\circ}$ Fahr. The greater portion of the examples were from 10 fathoms or less.

Add to these Cottus scorpioides of Fabricius, and it will complete the list of Eastern North American species of the genus Cottus so far as known.

As already intimated, Cottus scorpius sub-species grönlandicus is quite readily separated from the typical $C$. scorpius by its wider interorbital distance and its higher spinous dorsal, which differences are best exemplified in the specimens from Greenland, and appear, along with others, in the measurement tables.

Table of Measurements.

Species, Cottus scorpius sub-species grönlandicus.

\begin{tabular}{|c|c|c|c|c|}
\hline \multirow[t]{2}{*}{ 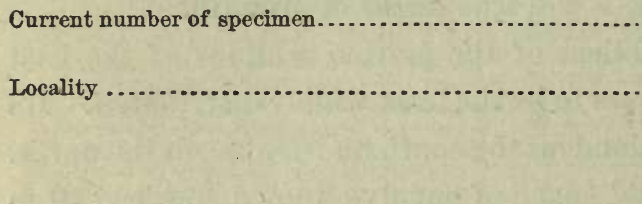 } & \multicolumn{2}{|c|}{21,731} & \multicolumn{2}{|c|}{21,730 . } \\
\hline & $\begin{array}{l}\text { Millime- } \\
\text { tres. }\end{array}$ & $\begin{array}{l}\text { 100ths of } \\
\text { length. }\end{array}$ & $\begin{array}{c}\text { Millime- } \\
\text { tres. }\end{array}$ & $\begin{array}{l}100 \text { ths of } \\
\text { length. }\end{array}$ \\
\hline Extreme length.... & & & 226 & \\
\hline $\begin{array}{l}\text { Length to origin of middle ca } \\
\text { Body: }\end{array}$ & 185 & & 186 & \\
\hline Greatest height............ & & 24 & & 23 \\
\hline t pectora & & 22 & & \\
\hline $\begin{array}{l}\text { Height at ventrals } . . . . . . \\
\text { Least height of tail } . . . . .\end{array}$ & & 24 & & 23 \\
\hline Length of caudal peduncle. & & $11^{5}$ & & 12 \\
\hline Head : & & & & \\
\hline $\begin{array}{l}\text { Greatest leng } \\
\text { Distance fron }\end{array}$ & & $\begin{array}{l}39 \\
28\end{array}$ & & 38 \\
\hline $\begin{array}{l}\text { Distance from snout to nape } \\
\text { Width of interorbital area.. }\end{array}$ & & $\begin{array}{c}28 \\
7 \frac{1}{8}\end{array}$ & & $\begin{array}{r}27 \\
6\end{array}$ \\
\hline Length of snont .......... & & $9^{\frac{1}{2}}$ & & $\begin{array}{l}6 \\
9\end{array}$ \\
\hline Len & & 19 & & 19 \\
\hline Len & & $20 \frac{1}{2}$ & & 20 \\
\hline $\begin{array}{l}\text { Dista } \\
\text { Diam }\end{array}$ & & 10 & $\ldots$ & 10 \\
\hline $\begin{array}{l}\text { Diameter of orbit ............ } \\
\text { Dorsal (spinous): }\end{array}$ & & & $\cdots$ & \\
\hline $\begin{array}{l}\text { Dorsal (spinous) : } \\
\text { Distance from snout ........ }\end{array}$ & & 35 & & \\
\hline Length of base ......... & & 27 & & 26 \\
\hline Len & & $16 \frac{1}{2}$ & $\ldots$ & \\
\hline h of second spine... & & $18^{\prime}$ & $\cdots$ & 16 \\
\hline 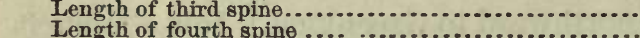 & & & & 16 \\
\hline 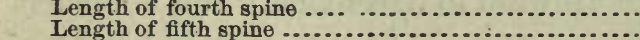 & & $\begin{array}{l}18 \\
19\end{array}$ & & 16 \\
\hline $\begin{array}{l}\text { Length of fifth spine ........ } \\
\text { Length of sixth spine...... }\end{array}$ & & $\begin{array}{l}19 \\
16 \frac{1}{2}\end{array}$ & $\cdots \ldots \ldots$ & 15 \\
\hline h spine................. & $\cdots$. & $14^{\frac{5}{2}}$ & & 13 \\
\hline h of eighth spine & & 11 & & 12 \\
\hline Length of ninth spin ${ }^{\prime} \ldots \ldots \ldots \ldots \ldots \ldots \ldots \ldots \ldots \ldots$ & .......... & 8 & ......... & $7 \frac{1}{2}$ \\
\hline 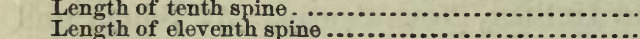 & & 5 & (n............ & $\begin{array}{l}5 \\
3\end{array}$ \\
\hline 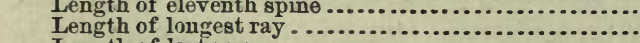 & & 17 & $\cdots$ & 19 \\
\hline 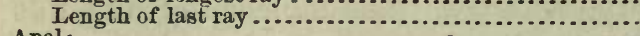 & & $6 \frac{1}{2}$ & $\cdots$ & 8 \\
\hline $\begin{array}{l}\text { Anal : } \\
\text { Distance from snout } \ldots \ldots \ldots \ldots \ldots \ldots \ldots . . . . . . .\end{array}$ & & & & \\
\hline 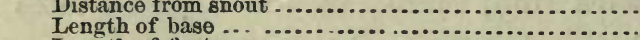 & & $\begin{array}{l}62 \\
25\end{array}$ & & $\begin{array}{l}62 \\
25\end{array}$ \\
\hline y & & 7 & $(\cdots \ldots . . .10$ & \\
\hline ray $\ldots \ldots \ldots \ldots \ldots \ldots \ldots \ldots \ldots \ldots \ldots \ldots \ldots$ & & 14 & & 15 \\
\hline Length of last ray & & & & \\
\hline
\end{tabular}


Table of Measurements-Continued.

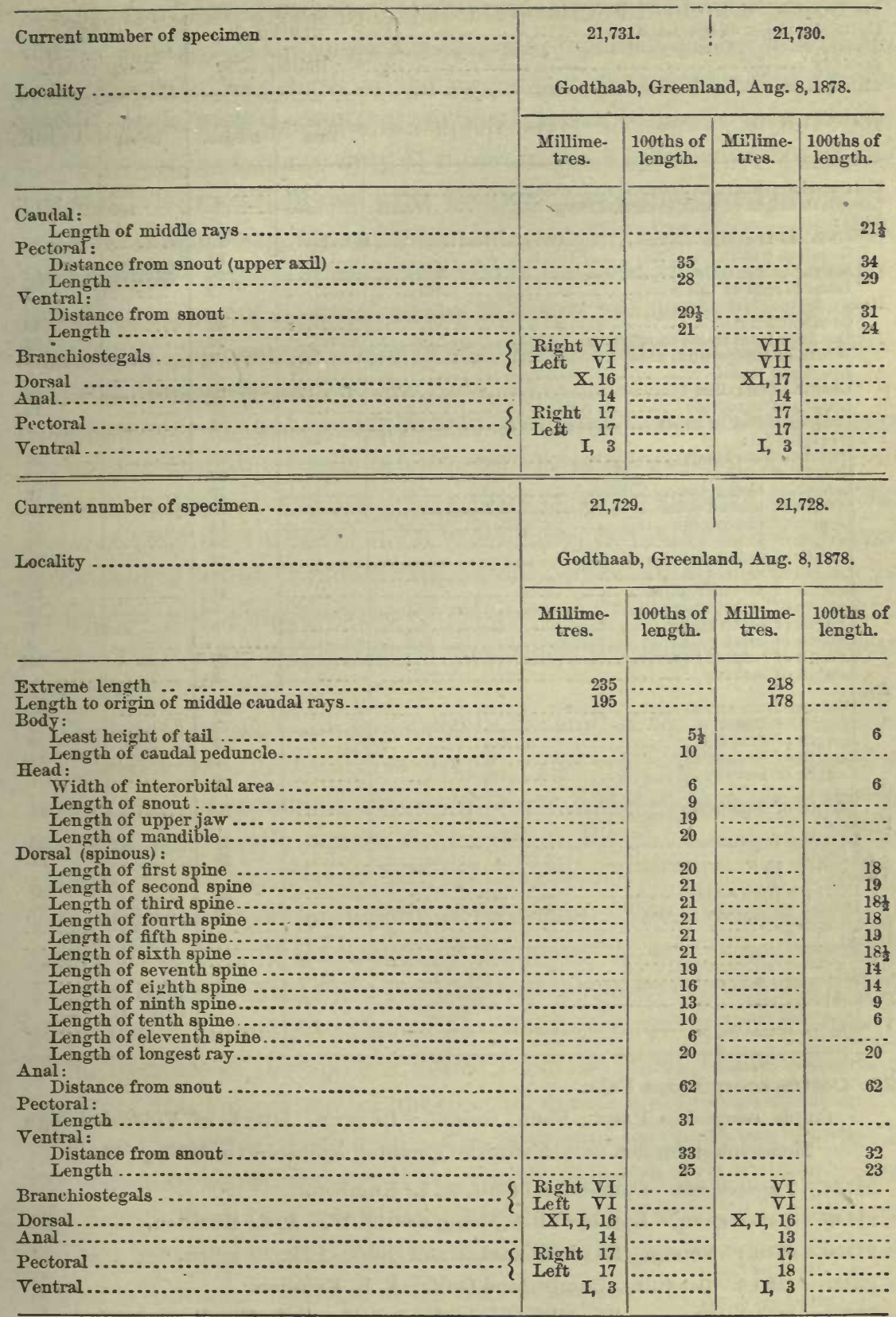

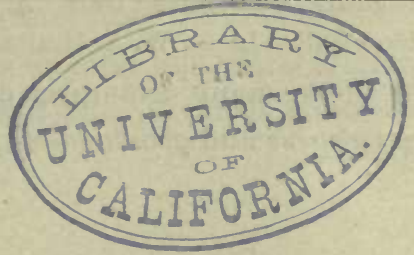


Table of. Measurements-Continued.

\begin{tabular}{|c|c|c|c|c|}
\hline \multirow[t]{2}{*}{$\begin{array}{l}\text { Current number of specimen } \ldots \ldots \ldots \ldots \ldots \ldots \ldots \ldots \ldots \ldots \ldots \\
\text { Locality } \ldots \ldots \ldots \ldots \ldots \ldots \ldots \ldots \ldots \ldots \ldots \ldots \ldots \ldots \ldots\end{array}$} & \multicolumn{2}{|c|}{$\begin{array}{l}21,025 a, \text { ㅇ. } \\
\text { Halifax, N.S. }\end{array}$} & \multicolumn{2}{|c|}{$\begin{array}{c}13,879 . \\
\text { Eastport, Me. }\end{array}$} \\
\hline & $\begin{array}{l}\text { Millime- } \\
\text { tres. }\end{array}$ & $\begin{array}{c}\text { 100ths of } \\
\text { length. }\end{array}$ & $\begin{array}{l}\text { Millime- } \\
\text { tres. }\end{array}$ & $\begin{array}{l}\text { 100ths of } \\
\text { length. }\end{array}$ \\
\hline $\begin{array}{l}\text { Extreme length ............ } \\
\text { Length to origin of mida }\end{array}$ & $\begin{array}{l}240 \\
108\end{array}$ & & 129 & \\
\hline $\begin{array}{l}\text { Length to origin of middle } \\
\text { Body: }\end{array}$ & 198 & & 106 & \\
\hline $\begin{array}{l}\text { Greatest height....... } \\
\text { Greatest width...... }\end{array}$ & & $\begin{array}{l}26 \\
24\end{array}$ & & 25 \\
\hline Height at ventrals.... & & $\begin{array}{l}24 \\
26\end{array}$ & & \\
\hline $\begin{array}{l}\text { Least height of tail... } \\
\text { Head: }\end{array}$ & & 7 & & 7 \\
\hline $\begin{array}{l}\text { Head } \\
\text { Distance from snout to }\end{array}$ & & 42 & & \\
\hline $\begin{array}{l}\text { Distance from } \\
\text { Width of inte }\end{array}$ & & 30 & & - 28 \\
\hline $\begin{array}{l}\text { Width of interorbits } \\
\text { Length of snout.... }\end{array}$ & & $\begin{array}{l}6 \frac{1}{2} \\
9\end{array}$ & $\cdots$ & $\begin{array}{l}6 \\
9\end{array}$ \\
\hline Length of ma & & 20 & (n) & $\begin{array}{r}9 \\
18\end{array}$ \\
\hline $\begin{array}{l}\text { Length of } n \\
\text { Long diame }\end{array}$ & $\cdots$ & 22 & a........... & 19 \\
\hline $\begin{array}{l}\text { Long diameter of orbit } \\
\text { Dorsal (spinous): }\end{array}$ & & & & $9 \frac{1}{2}$ \\
\hline ce from snout .. & & 38 & & \\
\hline & & 23 & & $\begin{array}{l}35 \\
25\end{array}$ \\
\hline Len & $\cdots$ & 12 & ... & 12 \\
\hline $\begin{array}{l}\text { Len } \\
\text { Len }\end{array}$ & & $13 \frac{1}{2}$ & $\cdots$ & 13 \\
\hline $\begin{array}{l}\text { Length of third spine } \\
\text { Length of fourth spine. }\end{array}$ & & $\begin{array}{l}14 \\
15\end{array}$ & $\cdots$ & $\begin{array}{l}14 \\
14\end{array}$ \\
\hline Length of fifth & & 14 & $\cdots \cdots$ & $\begin{array}{l}14 \\
14\end{array}$ \\
\hline Len & & $12 \frac{1}{2}$ & $\ldots .$. & 13 \\
\hline $\begin{array}{l}\text { Leng } \\
\text { Leng }\end{array}$ & & 11 & $\cdots$ & 12 \\
\hline $\begin{array}{l}\text { Length of eighth } \mathrm{s} \\
\text { Length of ninth sp }\end{array}$ & & $\begin{array}{l}8 \frac{1}{3} \\
6\end{array}$ & $\cdots \cdots$ & $\begin{array}{r}10 \\
7\end{array}$ \\
\hline Length of tenth spino.. & & 6 & & $\begin{array}{l}7 \\
5\end{array}$ \\
\hline Length of longest ray.. & ... & 18 & & $16 \frac{1}{2}$ \\
\hline $\begin{array}{l}\text { Length of last ray } . . . . . \\
\text { Anal: }\end{array}$ & (n......... & 8 & $\cdots$ & \\
\hline Anal: & & 64 & & \\
\hline Len & & 30 & (n........... & 25 \\
\hline Length of tirst ray........ & & $\stackrel{9}{147}$ & .... & 9 \\
\hline $\begin{array}{l}\text { Length of longest ray..... } \\
\text { Length of last ray ....... }\end{array}$ & & $\begin{array}{c}14 \frac{1}{2} \\
8\end{array}$ & - n....... & $12 \frac{1}{2}$ \\
\hline Caudal: & & & & \\
\hline Length of middle rays . & & $20 \frac{1}{2}$ & & 21 \\
\hline $\begin{array}{l}\text { Pectoral: } \\
\text { Distance from snout .... }\end{array}$ & & & & \\
\hline Length ...................... & (n....... & $\begin{array}{l}37 \\
28\end{array}$ & & $\begin{array}{l}36 \\
27\end{array}$ \\
\hline $\begin{array}{l}\text { Ventral: } \\
\text { Distance from snont }\end{array}$ & & & & \\
\hline $\begin{array}{l}\text { Distance from snont } \ldots . . \\
\text { Length } . . . . . .\end{array}$ & & $\begin{array}{l}32 \\
20\end{array}$ & $\cdots \cdot$ & 30 \\
\hline Branchiostegals........... & VI & $\begin{aligned} 20 \\
\ldots . . .2 .\end{aligned}$ & $\cdots \bar{Y}$ & \\
\hline Dorsal $\ldots \ldots \ldots \ldots \ldots \ldots \ldots \ldots \ldots \ldots \ldots \ldots$ & $\mathrm{IX}, 18$ & (n) & $\mathrm{X}, 17$ & …......... \\
\hline $\begin{array}{l}\text { Anal } \\
\text { Caudal }\end{array}$ & $\begin{array}{r}15 \\
+, 12,+\end{array}$ & & 14 & \\
\hline Pectoral .................... & 17 & & Right is & \\
\hline Ventral .................... & $\mathbf{I}, 3$ & & lLeft 1,3 & \\
\hline
\end{tabular}

\section{Cottus scorpioides Fabr.}

Cottus scorpioides FaBR., Faun. Grönld.: LÜTKEN, Aftryk af Videnskabelige Meddelelser fra den naturhistoriske Forening Kjöbenhavn, 1876, p. 12.

21744. 7 specimens. Cumberland Gulf, A. L. Kumlien.

21745. 4 specimens. Lat. $66^{\circ} 24^{\prime}$ N., long. $68^{\circ} 49^{\prime}$ W. A. L. Kumlien.

21750. (670.) Young. Head of Cumberland Gulf. A. L. Kumlien.

22327. (180.) † adult. Cumberland Gulf. A. L. Kumlien.

22330. (151.) Young. Niantilic, Cumberland Gulf. A. L. Kumlien.

22331. Young. Cumberland Gulf. Lieut. W. A. Mintzer.

Mr. Kumlien brought down many examples of a species of Cottus which closely resembles scorpius and grönlandicus, and yet agrees with 
neither of them. It is a species characterized by a very short head and short jaws, the head constituting only one-third of the total length without the caudal, and the upper jaw equalling less than one-seventh of the same leugth. The length of the upper jaw of $C$. grönlandicus equals slightly more than one-sixth of the total length without candal, and in C. scorpius it is contained only $5 \frac{1}{3}$ times in the length exclusive of the caudal. The species agrees with Fabricius's description and with Dr. Luitken's diagnosis of Cottus scorpioides. For the sake of comparison, I have prepared a table of measurements of the head and jaws of 9 additional specimens of $C$. grönlandicus to follow the measurements of $C$. scorpioides. The unit of length in the tables is the total length to the origin of the middle caudal rays.

Description.-The shape of the body resembles that of Cottus scorpius L., but the caudal peduncle is longer and more slender.

The greatest height of the body, which is at the ventrals, equals the distance from the tip of the snout to the nape, and is contained $4 \frac{1}{3}$ times in the length without caudal. The caudal peduncle is slender and long; its least height is less than the long diameter of the orbit, and its length to the origin of the middle caudal rays equals the length of the longest anal ray.

The length of the head, measured to the end of the opercular flap, is contained 3 times in the unit of length. The width of the head at the base of the præopercular spines equals the distance from the snout to the nape, and nearly equals the length of the anal base. The long diameter of the eye equals half the length of the upper jaw, and is very little less than the length of the snout. The distance between the eyes equals $\frac{1}{3}$ of the length of the mandible, and is contained 20 times in the unit of length. The length of the snout equals $\frac{1}{2}$ the length of the mandible, and is contained 14 times in the unit of length.

The distance of the spinous dorsal from the snout equals twice the length of the longest ray of the second dorsal and is nearly or quite equal to the length of the head. The first spine is contained 11 times, the second $9 \frac{1}{2}$ times, and the third, fourth, and fifth 9 times in the unit of length. From this point the spines diminish gradually in length to the last, which is $\frac{1}{3}$ as long as the first. The longest ray of the second dorsal is contained $6 \frac{1}{4}$ times in the unit of length.

The distance of the anal from the snout equals twice the length of the pectoral. The anus is directly under the origin of the second dorsal.

The length of the anal base is about equal to the distance from the 
snout to the nape. The first and last rays are usually equal in length, and equal the length of the snout. The longest anal ray equals in length the caudal peduncle.

The length of the middle caudal rays is contained from 5 to 6 times in the unit of length.

The distance of the pectoral from the snout is contained $3 \frac{1}{3}$ times, and its length $3 \frac{1}{3}$ to 4 times in the unit of length.

The distance of the ventral from the snout equals twice the length of the upper jaw. The length of the ventral in females is contained 5 times (in one nearly 6 times) in the unit of length; in males, about $4 \frac{1}{3}$ times.

Radial formula.-B. VI; D. IX-X, 15-16; A.11-13; P. 15-16; V. I, 3.

Dr. Liitken is of the opinion that "Cottus pachypus Guinther (from Port Leopold) is the genuine C. scorpioides," in which opinion I fully coincide after a comparison of Mr. Kumlien's specimens with Fabricius's description of $C$. scorpioides and the description of $C$. pacliypus.

Cottus scorpioides appears in Professor Gill's List of East Coast Fishes with a doubt as to its reference to the genus Cottus, to which geuus, however, it was properly referred by Fabricius.

Table of Measurements.

Species, Cottus scorpioides Fabr.

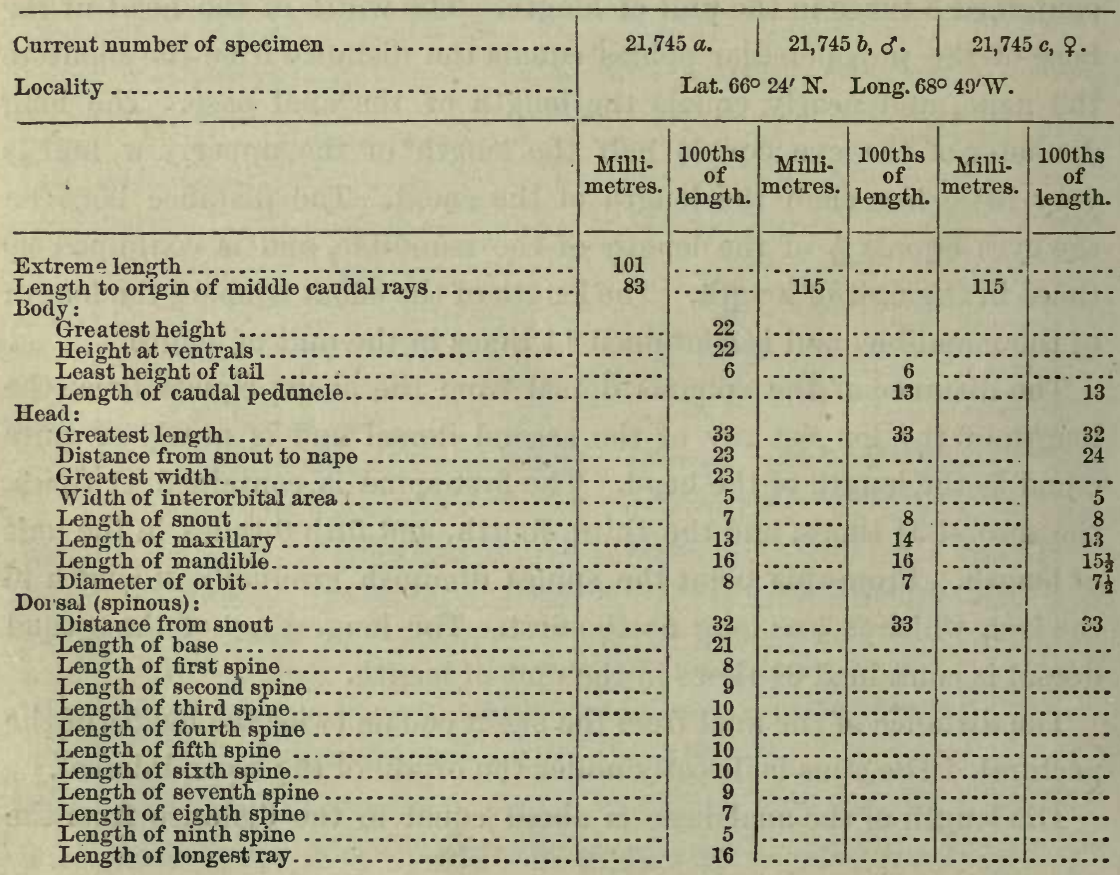


Table of Measurements-Continued.

Species, Cottus scorpioides Fabr.

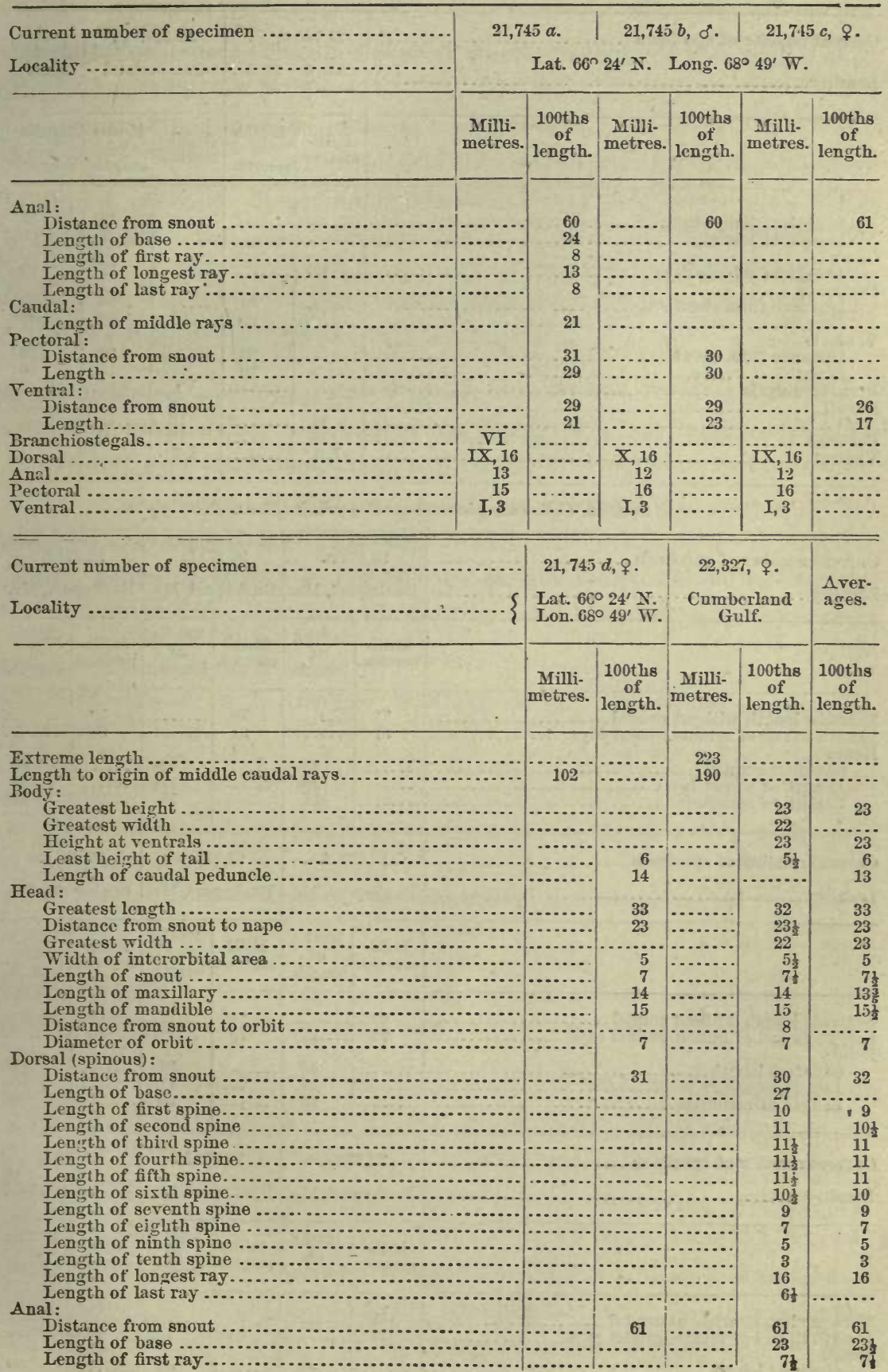




\section{Table of Measurements-C Continued.}

Species, Cottus scorpiodes Fabr.

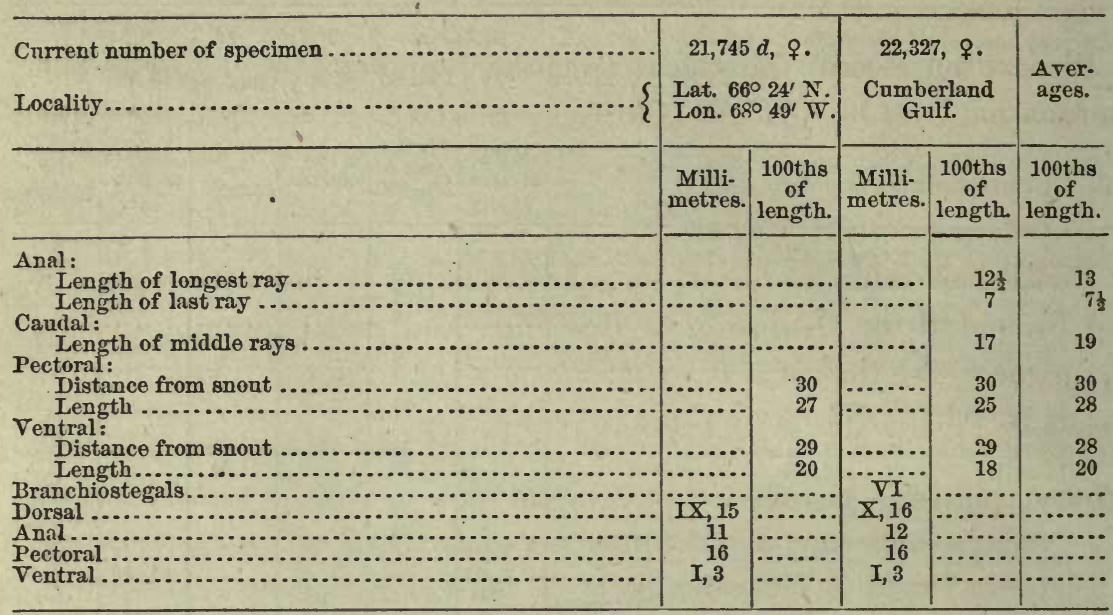

Species, Cottus scorpius sub-species grönlandicus.

\begin{tabular}{|c|c|c|c|c|c|c|}
\hline \multirow{3}{*}{ 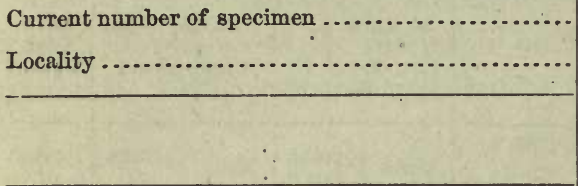 } & \multirow{2}{*}{\multicolumn{2}{|c|}{$\begin{array}{l}22,272 a \text {. } \\
\text { Bucksport, } \mathrm{Me} \text {. }\end{array}$}} & \multirow{2}{*}{\multicolumn{2}{|c|}{$\begin{array}{l}22,272 b \\
\text { Bucksport, Mo. }\end{array}$}} & \multirow{2}{*}{\multicolumn{2}{|c|}{$\begin{array}{l}22,272 c \text {. } \\
\text { Bucksport, } \mathrm{Me} \text {. }\end{array}$}} \\
\hline & & & & & & \\
\hline & $\begin{array}{l}\text { Milli- } \\
\text { metres. }\end{array}$ & $\begin{array}{l}\text { 100ths } \\
\text { of } \\
\text { length. }\end{array}$ & $\begin{array}{l}\text { Milli- } \\
\text { metres. }\end{array}$ & $\begin{array}{l}\text { iooths } \\
\text { of } \\
\text { length. }\end{array}$ & $\begin{array}{l}\text { Milli- } \\
\text { metres. }\end{array}$ & $\begin{array}{l}100 \text { ths } \\
\text { of } \\
\text { length. }\end{array}$ \\
\hline 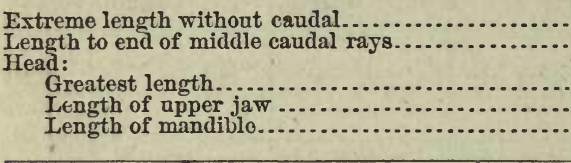 & \begin{tabular}{|c|}
71 \\
87 \\
$-\ldots \ldots$ \\
$\cdots \cdots$
\end{tabular} & $\begin{array}{l}40 \\
18 \\
21\end{array}$ & 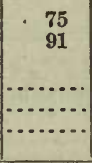 & $\begin{array}{l}39 \\
17 \frac{1}{2} \\
19\end{array}$ & $\begin{array}{r}72 \\
88 \\
\ldots \ldots \\
\ldots \ldots \\
\ldots \ldots\end{array}$ & $\begin{array}{l}\ldots \ldots \\
39 \\
18 \\
19 \frac{1}{2}\end{array}$ \\
\hline $\begin{array}{l}\text { Current number of specimen ....... } \\
\text { Locality ........................ }\end{array}$ & \multicolumn{2}{|c|}{$\begin{array}{l}22,272 d . \\
\text { cksport, } \mathrm{M} \theta\end{array}$} & \multicolumn{2}{|c|}{$\begin{array}{c}22,272 e . \\
\text { Bucksport, Me. }\end{array}$} & \multicolumn{2}{|c|}{$22,272 f$} \\
\hline - & $\begin{array}{l}\text { Milli- } \\
\text { metres. }\end{array}$ & $\begin{array}{l}\text { looths } \\
\text { of } \\
\text { length. }\end{array}$ & $\begin{array}{l}\text { Milli- } \\
\text { metres. }\end{array}$ & $\begin{array}{l}\text { 100ths } \\
\text { of } \\
\text { length. }\end{array}$ & $\begin{array}{l}\text { Milli- } \\
\text { metres. }\end{array}$ & $\begin{array}{l}\text { looths } \\
\text { of } \\
\text { length. }\end{array}$ \\
\hline 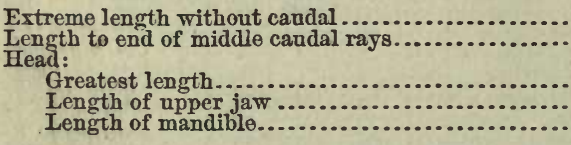 & 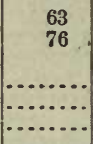 & $\begin{array}{c}\cdots \\
40 \\
17 \\
20\end{array}$ & \begin{tabular}{r|}
64 \\
79 \\
$\cdots \cdots$ \\
$\cdots \cdots$ \\
$\cdots \cdots$
\end{tabular} & $\begin{array}{r}\cdots \\
39 \\
17 \\
20\end{array}$ & $\begin{array}{l}66 \\
80\end{array}$ & $\begin{array}{l}39 \\
17 \\
19\end{array}$ \\
\hline Cnrrent namber of specimen ..................... & \multicolumn{2}{|c|}{$22,272 g$} & \multicolumn{2}{|c|}{$22,272 h$. } & \multicolumn{2}{|c|}{$22,272 i$} \\
\hline Locality .......... & \multicolumn{2}{|c|}{ Bucksport, Me. } & \multicolumn{2}{|c|}{ Bucksport, Me. } & \multicolumn{2}{|c|}{ Bucksport, Me. } \\
\hline - & $\begin{array}{c}\text { Milli- } \\
\text { metres. }\end{array}$ & $\begin{array}{l}\text { looths } \\
\text { of } \\
\text { length. }\end{array}$ & $\begin{array}{c}\text { Milli- } \\
\text { metres. }\end{array}$ & $\begin{array}{l}\text { 100ths } \\
\text { of } \\
\text { length. }\end{array}$ & $\begin{array}{l}\text { Milli- } \\
\text { metres. }\end{array}$ & $\begin{array}{l}\text { looths } \\
\text { of } \\
\text { length. }\end{array}$ \\
\hline 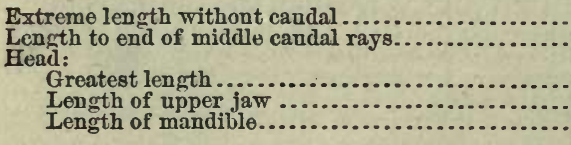 & $\begin{array}{l}58 \\
71\end{array}$ & $\begin{array}{c}40 \\
17 \\
19\end{array}$ & $\begin{array}{l}51 \\
63\end{array}$ & $\begin{array}{l}40 \\
18 \\
21\end{array}$ & $\begin{array}{l}57 \\
70\end{array}$ & $\begin{array}{c}39 \\
17 \frac{1}{2} \\
19\end{array}$ \\
\hline
\end{tabular}


21. Cottus quadricornis Linn.

Cottus quadricornis RicH., Last Arc. Voy., 1855, pp. 348-9 : GẗrrH., P. Z. S., 1877, p. 293.

Richardson records the species from the Coppermine River region and Coronation Gulf ( $68^{\circ} 30^{\prime}$ N., $110^{\circ}$ K. .).-Günther.

22. Cottus polaris Sabiue.

Cottus polaris Rich., Last Arc. Voy., 1855, p. 351.

Richardson refers to this species as occurring at North Georgia, lat. $75^{\circ} \mathrm{N}$., and at the Peninsula of Boothia. The radial formula appears to me more like that of a Centridermichthys than anything else, but the genus to which it properly belongs is uncertain.

23. Gymnacanthus pistilliger (Pall.) Gill, MS.

Cottus ventralis Cuv. \& VAL., Hist. Nat. Poiss., iv, p. 194: Colletr, Christiania Vid. Selsk. Forh. 1878, No. 14, (p. 15).

21732. (1373.) Godthaab, Disko Id., Greenland, A. L. Kumlien. D. XII, I, 16. A. 18. V. 3. Ventrals nearly reach vent.

21733. (1374.) Godthaah, A. L. Kumlien. D. XII, 15. A. 19. V. 3. Ventrals reach fifth ray of anal.

21734. Godthaab. A. L. Kumlien. D. XI, 16. A. 18. V. 3. Ventrals extend little more than half way to vent.

21735. Godthaab. A. L. Kumlien. D. XI, 17. A. 18. V.3. Ventrals reach third ray of anal.

21736. Godthaab. A. L. Kumlien. D. XII, 17. A. 19. V. 3. Ventrals nearly reach vent.

21737. Godthaab. A. L. Kumlien. D. XII, I, 15. A. 18. V. 3. Ventrals reach fourth ray of anal.

21741. (151.) Niantilic Harbor, Cumberland Gulf, A. L. Kumlien.

21743. (180.) Niantilic Harbor, A. L. Kumlien.

22332. Niantilic Harbor, Aug. 1876, Lieut. W. A. Mintzer.

17431. Christiania, Norway, M. G. Hetting, inspector of fisheries. D. XII, 14. A. 16. V. 3. Ventrals reach fourth ray of anal.

Dr. Liitken rejects the name Gymnocanthus, Swainson, because the genus was badly defined. There can be no difference of opinion as to the fact that the genus was poorly characterized; but there is an attempt at definition and a reference to a figure of the type-species, so that one need not hesitate as to what is intended. If we begin to reject names of genera because they are not accompanied by complete descriptions, we may find it difficult to draw the line between what we shall accept and what we shall reject. In retaining Swainson's name it may not 
be amiss to reproduce his description.* Concerning the specific name pistilliger, Dr. Luitken says: $\dagger$ "Influenced by Steindachner's notice (Wien. Sitzungsb. 1876) on C.pistilliger, Pallas, I have sought information concerning this species in the Berlin Museum; the type is only a bad half skin preserved in spirits; Prof. Peters has been so obliging as to send it to me for investigation, and I have thereby been able to convince myself that the 'pistils' which Pallas describes as soft threads with spongy heads are in reality only the half cruciform, spiny scales which distinguish a certain part of the side of the body in C. tricuspis. Since the name 'pistilliger' is thus founded on a misapprehension, its reputed priority (1811) cannot require that it be given the preference over the next in the series, and we should therefore fix upon the name Phobetor ventralis, Cur. \& Val." If we were to throw out all names which are beased upon a misapprehension it would involve us in a great deal of unnecessary confusion, and it would be difficult to decide how far the elimination should proceed. The fact that Dr. Luitken could recognize the peculiarity in which the specific name originated is a sort of apology for its adoption by Pallas.

\section{Icelus hamatus Kröyer.}

Ictlus hamatus GüNTH., P. Z. S., 1877, pp. 293, 476.

This species was collected in Discovery Bay, Franklin Pierce Bay, and at Cape Napoleon, in the month of August, by Captain Feilden, and in Franklin Pierce Bay, August 11, 1875, by Mr. C. Hart.

\section{Triglops pingelii Reinl.}

Triglops pingelii GÜNTH., P. Z. S., 1877, p. 476.

Taken in Franklin Pierce Bay, August 11, 1875, by Mr. C. Hart, naturalist on board H. M. S. "Discovery."

The United States Fish Commission has many specimens in its collections of 1877 and 1878.

*Nat. Hist. Fishes, Amphibians, \& Reptiles, II, London, 1839, pp. 181 \& 271.

p. 181. Gymrocantius. Nape of the head contraeted; eyes with bony orbits.

p. 271. GrminocaxtuUs Sw. Resembling in general aspect the last, (Cotus claviger, C. \& V.), but there are no upper orbits; spines of the head few and naked; ventral fins very long, and of 3 rays; dorsals distinct; the rays of the first naked on their terminal half (?); eaudal fin truncate.

$$
\text { G. ventralis, C. \& V. iv, pl. 79, fig. } 1 .
$$

† Aftryk af Videnskabelige Meddelelserfra den naturhistoriske Forening Kjöbenhavn, 1876, p. 10. 
Family, GASTEROSTEID无.

26. Gasterosteus insculptus Rich.

Gasterostens insculptus RicH., Last Arc. Voy., 1855, p. 356, pl. xxv.

The types were from Northumberland Sound, lat. $76^{\circ} 53^{\prime} \mathrm{N}$.

27. Gasterosteus pungitius Linn., sub-species brachypoda Bean.

In small streams on the sides of Oosooadlin Mountain, and in a little pond on the top, 1,500 feet above tide-level, Mr. Kumlien collected numerous examples of a many-spined stickleback, which resembles Gasterosteris pungitius Lini., in most particulars, but may be readily distinguished from it by its very short ventral spines. The tables of measurements and radial formulæ appended will show other differences, which are, however, not so important.

Description.-The greatest height of body is contained $5 \frac{3}{4}$ times in its length to origin of middle caudal rays (in gravid females, $4 \frac{1}{2}$ times); the greatest width, 10 times (in gravid females, 8 times). The height at ventrals is contained $5 \frac{3}{5}$ times in length of body (in gravid females, 5 times or slightly less). The least height of tail equals half the length of the first dorsal spine. The length of caudal peduncle is $\frac{1}{7}$ of length of body.

The length of head equals 4 times the length of upper jaw, and is from $\frac{1}{4}$ to $\frac{7}{25}$ of length of body. The greatest width of head nearly equals length of middle caudal rays. The distance between the eyes equals the length of snout, which equals the length of antecedent spine of soft dorsal. The length of the operculum equals the length of ventral spine, which is slightly less than a third of length of head. The length of mandible equals the long diameter of the orbit.

The distance of the spinous dorsal from the snout is from $\frac{1}{4}$ to $\frac{3}{10}$ of length of body, and is almost uniformly less than its length of base. The first and second spines of the dorsal are equal in length, and are about $\frac{2}{3}$ as long as the ventral spine. The last spine of the dorsal is slightly less than the first. The antecedent spine of the second dorsal is somewhat longer than the first of the spinous dorsal, and half as long as the first ray following it. The first ray of the soft dorsal is contained $8 \frac{1}{2}$ times in length of body, and is three times as long as the last ray.

The distance of the anal from the tip of snout equals $\frac{3}{5}$ of length of body; its length of base is twice the length of its first and longest ray, and slightly less than $\frac{1}{4}$ of length of body. The anal spine is half as long as the first anal ray (in young individuals, $\frac{2}{3}$ ).

The length of the middle caudal rays is contained $8 \frac{1}{2}$ times in length of body; the length of external rays, $7 \frac{1}{2}$ times.

The distance of the pectoral from the tip of snout is contained $3 \frac{1}{3}$ times Bull. Nat. Mus. No. $1 \tilde{5}-9$ 
in the total, and about equals twice its own length. When expanded, the pectoral extends usually to the 7th dorsal spine (6th to 8 th).

The distance of the ventral from the tip of snout slightly exceeds $\frac{7}{20}$ of length of body. The length of the ventral spine is always a little less than $\frac{1}{3}$ of the length of the head.

Radial formula.-D. IX-XI, I, 10-11; A. I, 9-11; C. +, 12, +; P.10; V. I, 1.

Color.-General color dull silvery, minutely punctulated with black; upper half of body with large irregular areas of black; chin, throat, and abdomen black in males, silvery in the females studied. Nilsson records a similar condition in G. pungitius.*

The relations of Gasterosteus pungitius var. brachypoda to the pungitius (=Pygosteus occidentalis (C. \& V.) Brevoort) of New England are showu in the table of comparative measurements which follows. I do not use the name Pygosteus occidentalis, for the reason that our many-spined stickleback bearing that name shows no characters by which it may be separated from the Gasterosteus pungitius of Linné as a species, and the genus Pygosteus has nothing to exclude it from Gasterosteus. The genus Pygosteus, although credited to Brevoort, was not defined by him; it appears in Gill's Cataloguet as a name only. The first to indicate characters by which it was thought the genus could be distinguished was Jordan; they are stated to be the following: "Dorsal spines 7 or more; sides mailed or not." $\ddagger$ So far as the squamation is concerned, the collections of the United States National Museum show all sorts of individual variation, and justify the ground taken by Günther in his arrangement of the varieties of $G$.aculeatus; certainly, the squamation is not even of specific importance. The number of dorsal spines in the specimens of G. pungitius studied ranges from 7 to 11 . In Gasterosteus inconstans, $\S$ Kirtland, the range is from 3 to 6 . I have seen a fresh-

*'"Variat abdomine nigro."-Prod. Ichth. Scand., 1832, p. 86.

tCatalogue of the Fishes of the Eastern Coast of North America from Greenland to Georgia, by Theodore Gill, Jan. 1861, p. 39.

$\ddagger$ Manual of the Vertebrates of the Northern United States, 1876, p. 248.

$\$$ Eucalia inconstans, Jordan, Manual of Vertebrates, 1876; Proc. Acad. Nat. Sci. Phila., 1877, p. 65. The generic characters ascribed to Eucalia are: (1) "Dorsal spines in a right line," which is also true in Gasterosteus aculeatus, L.; even in the many-spined stickleback, G. pungitius, I have frequently seen the last four or five spines in a right line, while the anterior ones preserved their zigzag arrangement; (2) "Ventral plates coalesced into a narrow plate on the median line between the ventral fins," just as in - G. aculeatus and G. pungitius; (3) "A distinct sub-quadrate post-pectoral plate," which is present in most sticklebacks; the "associated characters" indicated contain nothing generically distinctive. 
water stickleback from Maine,* which resembles G. pungitius in many respects, but has only 2 dorsal spines. The number of dorsal spines would seem, therefore, to be certainly of not more than specific value.

Gasterosteus nebulosus seems to me to be separated from G.pungitius by no constant character, but only by its habitat. Gasterosteus mainensis is identical with $G$.pungitius.

Apeltes (DeKay) Jordan is well separated from Gasterosteus by the structure of its pubic bones.

The United States National Museum has received from the Musée d'Histoire Naturelle, of Paris, one of the types of Gasterosteus blanchardi Sauvage, described from specimens sent from Boston, United States. This species is our common many-spined stickleback, G. pungitius, as will appear from the table of measurements, and the name must be regarded as a synonym of the latter. It is worthy of remark in passing that the shape of the post-pectoral plate in species of Gasterosteus, which has been employed as an important diagnostic character, is so variable, even on the two sides of the same fish, that it is not to be depended upon.

The sticklebacks of eastern North America, so far as obserred be me, may all be referred to the genera Apeltes and Gasterosteus.

The basis of the foregoing description of the stickleback collected by Mr. Kumlien is the table of measurements which follows. Only 8 examples were measured, but these show the extremes of variation in the numerous specimens secured. In none of the individuals does the length of the ventral spine exceed one-third of the length of the head.

Mr. Kumlien has sent me the following notes on the species: "The Gasterosteus was taken from a pond more than a thousand feet above the sea on the mountain side. Said ponds were not over 18 inches deep, and of course freeze solid in winter. In fact, there was but very little water at the time I procured the fish. It is impossible that they could have come up from below, as the pond empties by a series of perpendicular falls, some of them 30 feet or more. In my note-book I find that they were light greenish above, barred with dusky brown and black; beneath white, irregularly blotched with black. Caudal pinkish. Male (?) with a crimson spot at base of pectoral fin."

* Gasterosteus Atkinsii Bean, Proc. U. S. Nat. Mus. ii, p. - 
Table of Measurements.

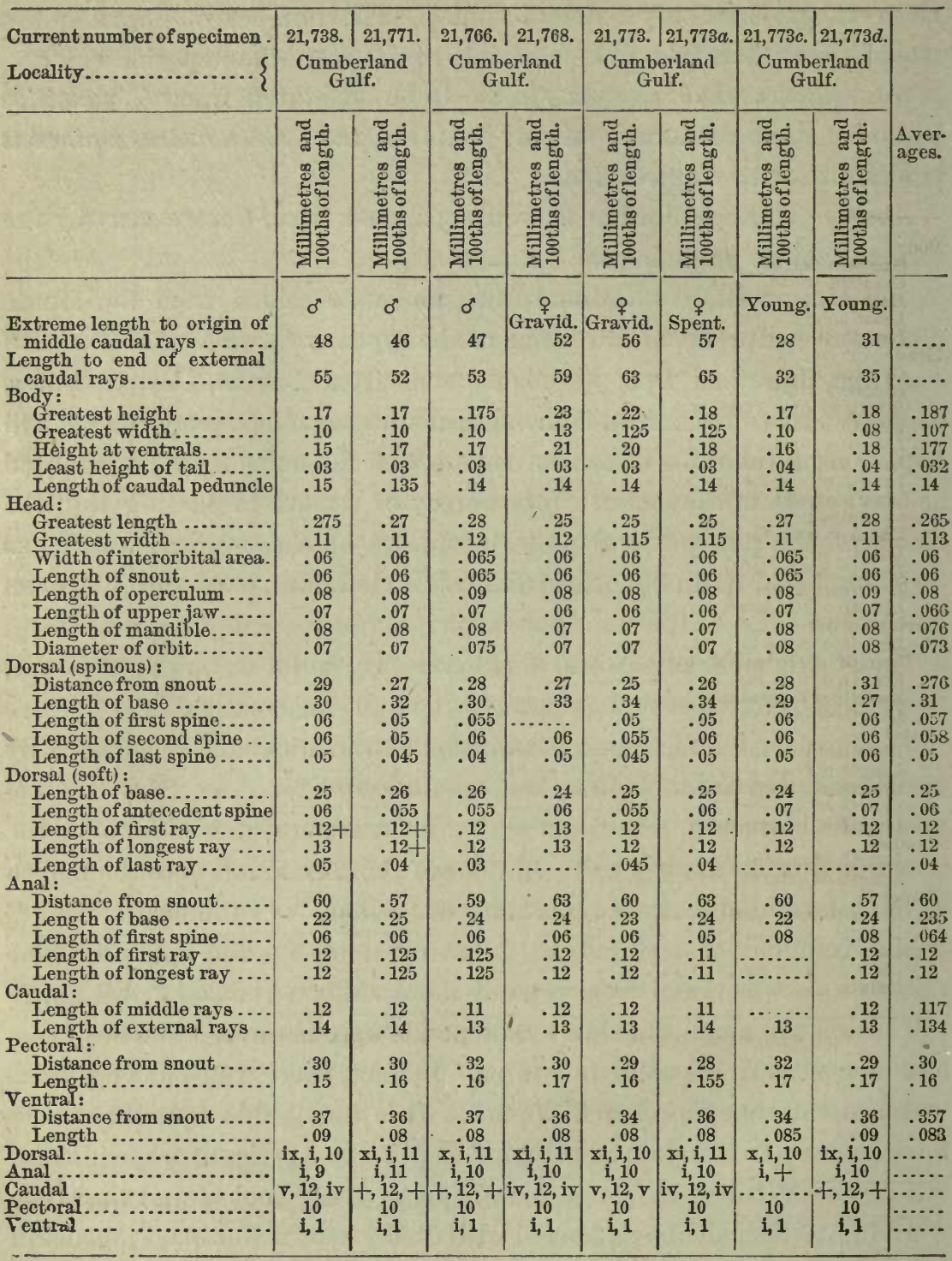


Table of Comparative Measurements.

Body:

Greatest height

Greatest widith

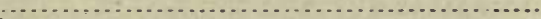

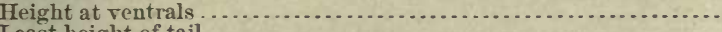

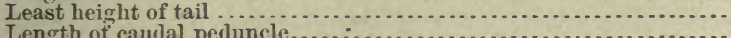

Head:

Greatest length

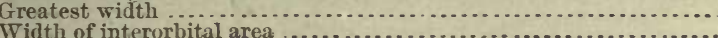

terorbital area

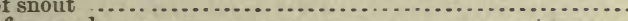

Length of operculum

Length of upper jaw.

Long diameter of eye

Dorsal (spinous):

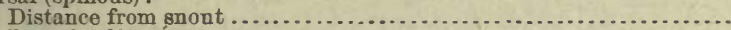

Length of base.

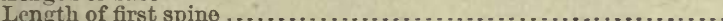

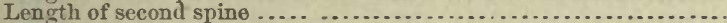

Length of last spine. .

Dorsal (soft) :

Length of base.

Lenoth of antecedent spino...

Length of first ray....

Length of longest ray

Anal :

Distance from snot.

Length of base.

Length of first spine.

Length of first ray.

Length of longest ray.-.

Caudal:

Length of middle rays

Lencth of external rass.

Pectoral:

Distance from snout

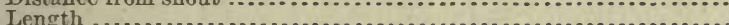

Ventral:

Distance from snout .......................................

Length

\begin{tabular}{|c|c|}
\hline $\begin{array}{l}\text { Gaster osteus } \\
\text { pungitiu }{ }^{*} \\
\text { Linn. (aver- } \\
\text { ages of } 7 \text { ex- } \\
\text { amples). }\end{array}$ & $\begin{array}{l}\text { G. pungitius } \\
\text { var. brachy- } \\
\text { poda Bean } \\
\text { (averages of } \\
\text { 8examples). }\end{array}$ \\
\hline $\begin{array}{l}\text { 1000ths of } \\
\text { length. }\end{array}$ & $\begin{array}{l}1000 \text { ths of } \\
\text { length. }\end{array}$ \\
\hline $\begin{array}{l}.170 \\
.100 \\
.170 \\
.036 \\
.150\end{array}$ & $\begin{array}{l}.187 \\
.107 \\
.177 \\
.032 \\
.140\end{array}$ \\
\hline $\begin{array}{l}.265 \\
.110 \\
.062 \\
.062 \\
.084 \\
.070 \\
.080 \\
.082\end{array}$ & $\begin{array}{l}.265 \\
.113 \\
.060 \\
.060 \\
.080 \\
.066 \\
.076 \\
.073\end{array}$ \\
\hline $\begin{array}{l}.286 \\
.276 \\
.066 \\
.066 \\
.050\end{array}$ & $\begin{array}{l}.276 \\
.310 \\
.057 \\
.058 \\
.050\end{array}$ \\
\hline $\begin{array}{l}.245 \\
.080 \\
.140 \\
.140 \\
. .\end{array}$ & $\begin{array}{l}.250 \\
.060 \\
.120 \\
.120 \\
.040\end{array}$ \\
\hline $\begin{array}{l}.570 \\
.220 \\
.086 \\
.130 \\
.130\end{array}$ & $\begin{array}{l}.600 \\
.235 \\
.064 \\
.120 \\
.120\end{array}$ \\
\hline $\begin{array}{l}.110 \\
.137\end{array}$ & $\begin{array}{l}.117 \\
.134\end{array}$ \\
\hline $\begin{array}{l}.300 \\
.160\end{array}$ & $\begin{array}{l}.300 \\
.160\end{array}$ \\
\hline $\begin{array}{l}.370 \\
.121\end{array}$ & $\begin{array}{r}.357 \\
.083\end{array}$ \\
\hline
\end{tabular}

* = Pygosteus occidentalis (C. \& V.) Brevoort, from which the averages were taken.

Table of Measurements.

Genus, Gasterosteus.

\begin{tabular}{|c|c|c|c|}
\hline Current number of specimen ................ & $\begin{array}{l}\text { Pungitius } \\
\text { L., 22,015 a. }\end{array}$ & $\begin{array}{l}\text { Pungitius } \\
\text { L., 22, } 015 \text { b. }\end{array}$ & $\begin{array}{l}\text { Blanchardi Sauvage } \\
\text { (type) (39) } 21,139 .\end{array}$ \\
\hline Locality.. & \multicolumn{2}{|c|}{$\begin{array}{l}\text { Christiania, Norway, R. Col- } \\
\text { lett. }\end{array}$} & Boston, U.S. \\
\hline & $\begin{array}{l}\text { Millimetres } \\
\text { and 100ths } \\
\text { of length. }\end{array}$ & $\begin{array}{l}\text { Millimetres } \\
\text { and 100ths } \\
\text { of length. }\end{array}$ & $\begin{array}{l}\text { Millimetres and 100ths } \\
\text { of length. }\end{array}$ \\
\hline $\begin{array}{l}\text { Extreme length to origin of middle caudal rays... } \\
\text { Length to end of external caudal rajs ............. }\end{array}$ & $\begin{array}{l}33 \\
38\end{array}$ & $\begin{array}{l}29 \\
34\end{array}$ & $\begin{array}{l}46 \\
52\end{array}$ \\
\hline $\begin{array}{l}\text { Gdy : } \\
\text { Greatest height ................ } \\
\text { Height at venth } \\
\text { Ieast height of tail................ } \\
\text { Length of candal peduncle.. }\end{array}$ & $\begin{array}{l}.18 \\
.10 \\
.18 \\
.04 \\
.13\end{array}$ & $\begin{array}{l}.18 \\
.10 \\
.18 \\
.04 \\
.13\end{array}$ & $\begin{array}{l}.16 \\
.09 \\
.16 \\
.04 \\
.135\end{array}$ \\
\hline
\end{tabular}


Table of Measurements-Continued.

- Genus, Gasterosteus.

\begin{tabular}{|c|c|c|c|}
\hline Current number of specimen................ & $\begin{array}{l}\text { Pungitius } \\
\text { L., } 22,015 \text { a. }\end{array}$ & $\begin{array}{l}\text { Pungitius } \\
\text { L., 22,015 b. }\end{array}$ & $\begin{array}{l}\text { Blanchardi Sauvage } \\
\text { (type) (39) } 21,139 .\end{array}$ \\
\hline \multirow[t]{2}{*}{ Locality ...................................... } & \multicolumn{2}{|c|}{$\begin{array}{l}\text { Christiania, Norway, R. Col- } \\
\text { lett. }\end{array}$} & \multirow{2}{*}{ 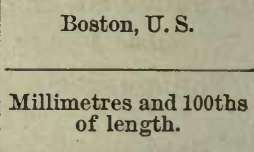 } \\
\hline & $\begin{array}{l}\text { Millimetres } \\
\text { and 100ths } \\
\text { of length. }\end{array}$ & $\begin{array}{l}\text { Millimetres } \\
\text { and 100ths } \\
\text { of length. }\end{array}$ & \\
\hline \multirow{2}{*}{\multicolumn{4}{|c|}{$\begin{array}{l}\text { Head : } \\
\text { Greatest length } \ldots \ldots \ldots \ldots \ldots \ldots \ldots \ldots \ldots \ldots \ldots \ldots \ldots \ldots\end{array}$}} \\
\hline & .28 & .30 & .28 \\
\hline Greatest width $\ldots \ldots \ldots \ldots \ldots \ldots \ldots \ldots \ldots$ & .12 & .13 & .12 \\
\hline 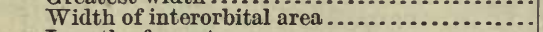 & .06 & .06 & .06 \\
\hline Length of snout...$\ldots \ldots \ldots \ldots \ldots \ldots$ & .06 & .06 & .06 \\
\hline Length of operculum......................... & .10 & .09 & .08 \\
\hline Length of maxillary................. & .07 & .07 & .07 \\
\hline Length of mandible $\ldots \ldots \ldots \ldots \ldots \ldots \ldots \ldots$ & .08 & .08 & .08 \\
\hline 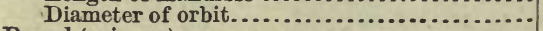 & .08 & .08 & .08 \\
\hline \multicolumn{4}{|l|}{$\begin{array}{l}\text { Dorsal (spinous) : } \\
\quad \text { Distance from snout }\end{array}$} \\
\hline Distance from snout.. & .29 & .30 & .27 \\
\hline Length of base ....... & .28 & .30 & .28 \\
\hline Length of first spine.. & .065 & .07 & .06 \\
\hline Length of second spine. & .07 & .07 & .065 \\
\hline Length of last spine.... & .055 & .055 & .055 \\
\hline \multicolumn{4}{|l|}{$\begin{array}{l}\text { Dorsal (soft) : } \\
\text { Length of base ........... }\end{array}$} \\
\hline Length of base ............ & .26 & .24 & .26 \\
\hline Length of antecedent spin & .08 & .08 & .07 \\
\hline Length of first ray ........ & .14 & .15 & .13 \\
\hline Length of last ray ......... & .04 & & .04 \\
\hline \multicolumn{4}{|l|}{$\begin{array}{l}\text { Anal: } \\
\text { Distance from snout.... }\end{array}$} \\
\hline Distance from snout... & .59 & .60 & .56 \\
\hline $\begin{array}{l}\text { Length of base } \\
\text { Length of first spine }\end{array}$ & .24 & .23 & .23 \\
\hline 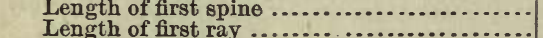 & .09 & .09 & .08 \\
\hline 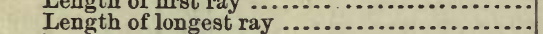 & .14 & $\begin{array}{l}.15 \\
.15\end{array}$ & .13 \\
\hline Length of last ray & .04 & & .045 \\
\hline \multicolumn{4}{|l|}{$\begin{array}{l}\text { Caudal: } \\
\text { Iength of middle rays.... }\end{array}$} \\
\hline Length of middle rays... & .13 & .13 & .12 \\
\hline \multicolumn{2}{|l|}{$\begin{array}{l}\text { Pectoral: } \\
\text { Distance from snout................ }\end{array}$} & & .14 \\
\hline $\begin{array}{l}\text { Pectoral: } \\
\text { Distance from snout.................... }\end{array}$ & .30 & .32 & .30 \\
\hline 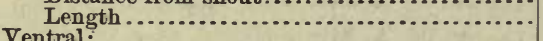 & .16 & .17 & .16 \\
\hline \multicolumn{4}{|l|}{$\begin{array}{l}\text { Ventral: } \\
\text { Distance from snout. }\end{array}$} \\
\hline 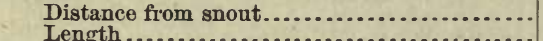 & .37 & .39 & .36 \\
\hline 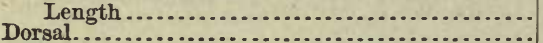 & $\nabla .13$ & .13 & .12 \\
\hline 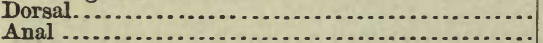 & $\mathrm{X}, \mathrm{I}, 12$ & IX, I, 10 & IX, I, 11 \\
\hline 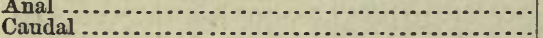 & IV 12,10 & $\begin{array}{r}\text { I, } 9 \\
+12+\end{array}$ & $\mathrm{V}, 12^{\mathrm{I}, 10}$ \\
\hline Pectoral ......................... & 9 & $T, 12,70$ & $v, 12,10$ \\
\hline Ventral ................................... & $\mathbf{I}, \mathbf{1}$ & $\mathrm{I}, \mathbf{1}$ & $\mathbf{I}, \mathbf{1}$ \\
\hline
\end{tabular}

Family, MICROSTOMIDA.

28. Mallotus villosus (Müll.) Cuv.

Mallotus villosus RICH., F. B. A., iii, 1836, p. 187.

Signalized from Bathurst's Inlet. Mr. Kumlien mentions "small herring-like fish that enter the sound in great numbers in early spring, but soon leave. They are called 'ice fish' by the whalers." I suppose they belong to the species named above.

Family, SALMONIDEA.

29. Salmo salar (Linn.) Günther.

Salmo salar KumLIEN, in lit.

Mr. Kumlien writes me that this salmon was obtained in quantities in the Cumberland waters, and that he recognized at least two species of 
Salmo, but could not secure specimens that were not split or otherwise mutilated.

Salvelinus Naresi occurs there, as will be seen in the present paper.

30. Salmo Hearnii Rich.

Salmo Hearnii RrcH., F. B. A., iii, 1836, p. 167.

The species was described from the Coppermine River, lat. $67042 \frac{1}{2}^{\prime} \mathrm{N}$.

31. Salvelinus alipes (Rich.) Gill \& Jordan.

Salmo alipes Rrch., F. B. A., iii, 1836, p. 169 : GÜNтh., P. Z. S., 1877, p. 476.

Boothia Felix (Rich.); Discovery Bay (Günth.).

32. Salvelinus nitidus (Rich.) Gill \& Jordan.

Salmo nitidus RrcH., F. B. A., iii, 1836, p. $1: 1$.

The species was described from Boothia.

33. Salvelinus Hoodii (Rich.) Gill \& Jordan.

Salmo Hoodii Rrch., F. B. A., iii, 1836, p. 173.

Richardson described it from Boothia Felix.

34. Salvelinus arcturus (Gïnth.) Gill \& Jordan.

Salmo arcturus GÜNTH. P. Z. S., 1877, p. 294, pl. xxxii.

Dr. Günther established the species upou specimens obtained in lat. $82^{\circ} 28^{\prime} \mathrm{N}$. and $82^{\circ} 34^{\prime} \mathrm{N}$.

35. Salvelinus Naresi (Günther) Bean.

Salmo Naresi Günther, Proc. Zoöl. Soc. Lond., iii, 1877, p. 476, pl. L.

22000 ९. Cumberland Gulf, Aug. 1876. Lieut. W. A. Mintzer.

22000 a. ․ . Cumberland Gulf, Aug. 1876. Lieut. W. A. Mintzer.

22000 b. §ै. Cumberland Gulf, Aug. 1876. Lieut. W. A. Mintzer.

Of this small charr, Lieutenant Mintzer secured the above-named specimens, and labellerl them "Salmon Trout." The larger of the two females contains well-developed ova, some of which are free in the cavity of the abdomen. The species agrees very closely with Dr. Giinther's description of S. Naresi. The description and table of measurements which follow will afford a means of estimating the correctness of an identification which records the species about 20 degrees south of the locality from which it was originally described.

Description.-The greatest height of the body is contained 5 times in the total length without caudal, and equals twice the length of the upper jaw. The height at the ventrals equals the distance from the tip of the snout to the nape. The least height of the caudal peduncle equals the length of the middle caudal rays.

The greatest length of the head is contained $4 \frac{1}{3}$ times in total length without caudal, and about equals twice the length of the base of the first 
dorsal fin. The greatest width of the head is a little less than half its length. The distance between the eyes equals their long diameter and half the length of the mandible. The length of the snout equals half the length of the middle caudal rays. The length of the operculum equals the distance between the eyes. The length of the upper jaw is contained from 10 to 11 times in total length without caudal, and the length of the mandible $7 \frac{3}{4}$ times. The distance from the snout to the orbit is $\frac{1}{4}$ or nearly $\frac{1}{4}$ of the distance from the same point to the base of the pectoral. The long diameter of the eye equals $\frac{1}{3}$ of the greatest height of the body. The teeth are arranged just as in the specimens examined and deseribed by Dr. Günther.

The distance of the first dorsal from the tip of the snout equals $\frac{3}{5}$ of the distance of the anal from the same point, and is contained $2 \frac{2}{9}$ times in total length without caudal. The length of the base of the first dorsal is contained $8 \frac{1}{2}$ to 9 times in total length without caudal, and of its longest ray, 7 times.

The adipose dorsal is placed at a distance from the tip of the snout, equal to $\frac{4}{5}$ of the total length, exclusive of the candal. Its height about equals the distance from the snout to the orbit.

The distance of the anal from the snout equals $\frac{3}{4}$ of the total length as before measured. The length of the anal base equals half the length of the head in the larger female, and ${ }_{10}^{1}$ of total length in the smaller. The longest ray of the anal equals twice the distance between the eyes, and the last ray equals half the length of the base of the first dorsal.

The length of the midle caudal rays is contained $2 \frac{1}{8}$ times in the length of the external rays and $12 \frac{1}{2}$ times in total length.

The distance from the tip of the snout to the base of the pectoral equals twice the greatest width of the head. The length of the pectoral equals the distance from the snout to the nape. The fin when extended falls short of the vertical through the origin of the first dorsal by about one-third of its own length.

The distance of the ventral from the tip of the snont equals 3 times the length of the pectoral. The length of the ventral equals $\frac{1}{8}$ of total length. The rentral terminates at a distance from the rent equal to the least height of the caudal peduncle.

Radial formula.-B. 10 ? to 11 ? ; D. 13 ; A. 11; P. 15 to 16 ; V. I, 9.

Cocca pylorica.-In the larger female, 28.

The coloration cannot be made out accurately. There are a few small spots on the side of the body, which now appear white. Parr marks are 
present in all the examples, and yet there is excellent reason for believing the largest specimen at least mature.

In the measurements the unit of comparison is the length to the origin of the middle caudal rays. The figure of S. Naresi is employed, and the agreement between that and the Cumberland Gulf specimens is striking.

Table of Measurements.

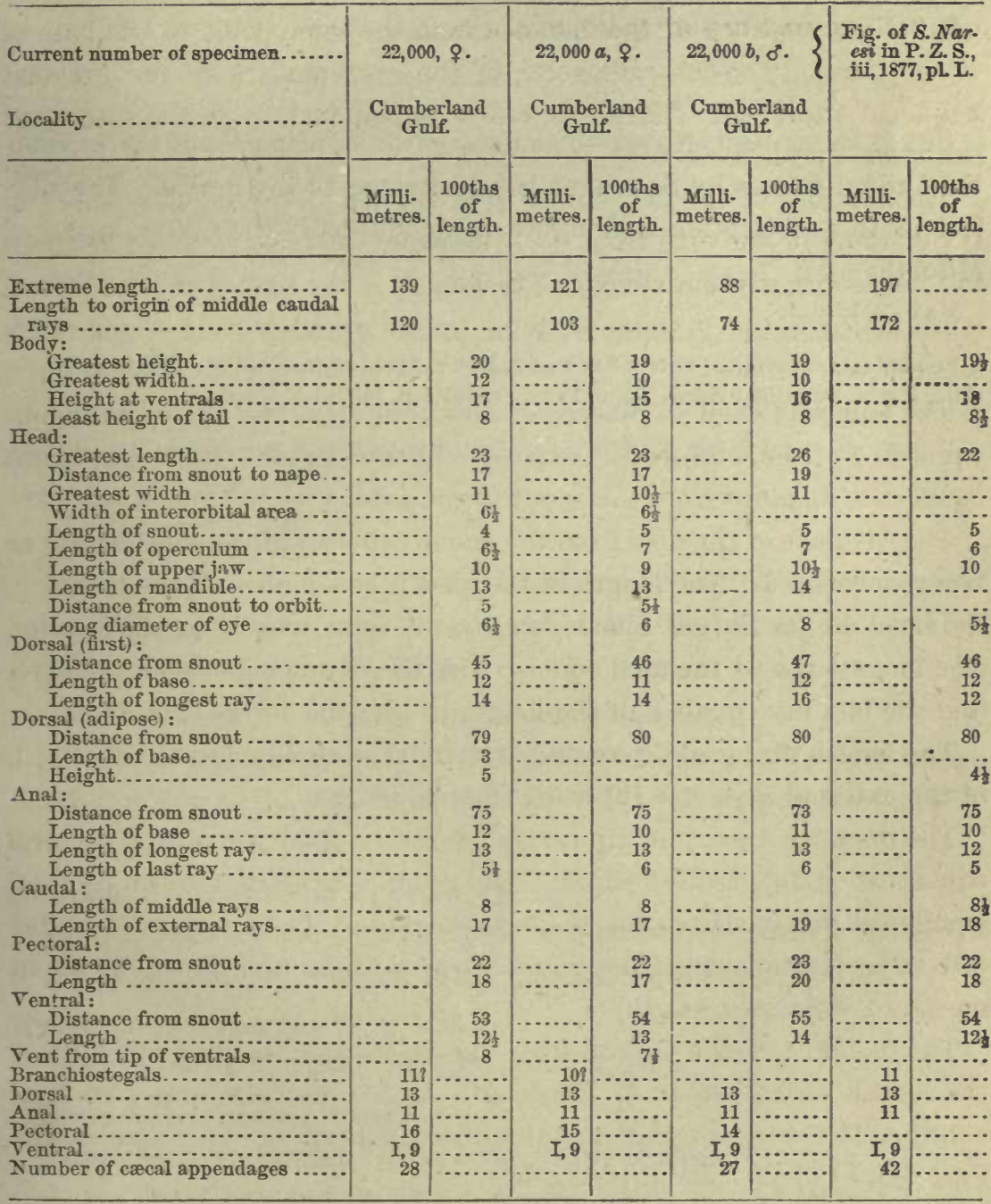

\section{Family, CLUPEID AE.}

36. Clupea harengus Linn.

Clupea harengus RICH., F. B. A., iii, 1836, p. 231.

Richardson mentions the occurrence of the herring at Bathurst's Inlet, $67 \circ \mathrm{N} ., 109^{\circ} \mathrm{W}$. 


\section{Family, SACCOPHARYNGIDAE.}

37. Saccopharynx flagellum Mitch.

Ophiognathus ampullaceus HARwOOD, Phil. Trans., 1827, p. 49, pl. 7 (fide Rich.). Saccopharynx ampullaceus RICH., F. B. A., iii, 1836, p. 271.

"The individual described by Dr. Harwood, measuring four feet and a half in length, was captured in the entrance of Davis Strait, by Captain Sawyer, of the ship Harmony."-RicH., l. $c$.

U. S. National Museum, April 3, 1879.

SUPPLEMENTARY NotE.-The description of a species of Cottus from the United States by Sauvage* has just come to my notice. The subject of the description and figure is undoubtedly the Cottus ceneus of Mitchill.

MaY 23, 1879.

* Cottus (Acanthocottus) anceps Sauvage, Nouv. Archiv. du Muséum d'Histoire Naturelle, Paris, Denxième Série, Tome Premier, 1878, p. 145, pl.i, fig. xiii. 


\section{CRUSTACEA.}

By S. I. SMITH.

The following crustaceans were all collected in the Gulf of Cumberland.

Crangon boreas J. C, Fabricius (Phipps).

A female (No. 145) $110^{\mathrm{mm}}$ in length, "Niantilic Island," September 24, 1877.

Hippolyte Grœnlandica Miers (J. C. Fabricius).

Two females : one (No. 1644) $100^{\mathrm{mm}}$ in length, from stomach of Cottus scorpius, September 6, 1878; the other (No. 207) $80^{\mathrm{mm}}$ long, from stomach of sculpin (No. 150), 1877.

Hippolyte Fabricii Kröyer.

A female (No. 537), 52 $2^{\mathrm{mm}}$ long, 7 fathoms, tide-hole, "Annanactook Island," June, 8, 1878; and a male (No. 862), $42^{\mathrm{mm}}$ in length, head of Cumberland Gulf, June 29, 1878.

Gammarus locusta J. C.Fabricius (= G. ornatus Milne-Edwards).

"Penny Harbor, latitude 660" (No. 225), October 4, 1877; "Arctic Island," low water (No. 65), September 13, 1877; "Annanactook Harbor" (No. 576), June 20, 1878.

Amathilla Sabini Bate and Westwood (Leach).

Head of Cumberland Gulf (No. 86); "Annanactook Harbor" (Nos. 584 and 593), 4 fathoms, June 19, 1878; (No. 585), Cumberland Gulf.

Hyperia medusarum Bate (O. F. Müller).

"Annanactook Harbor," No. 586, June 19, 1878.

\section{Caprella septentrionalis Kröyer.}

"Annanactook Harbor" (No. 583), "caught through crack in ice, 4 fathoms, on kelp," May 19, 1878; "Grave Island beach" (Nos. 626 and 627), June 27, 1878; (No. 420).

Lepas fascicularis Ellis and Solander.

Cumberland Gulf, at surface. 
Balanus balanoides Stimpson.

Large well-developed specimens, of the low, broad form. Arctic Island, September 13, 1877. This and the preceding were identified by Mr. E. B. Wilson.

There is also in the collestion a specimen of Hyas araneus Leach (No. 1420), from "Godthaah, Greonland, September 11, 1878." On its carapax were specimens of Balanus crenatus. 


\title{
ANNELIDES.
}

\author{
BY A. E. VERRILL.
}

\section{ANNELIDA.}

Harmothoe imbricata (L.) Malmgren.

Penny Harbor, Cumberland Gulf, low-water, October 4, 1877, lot 231\% Head of gulf, on gravel beach, May 28, and June 1, 1878, lots 642, 660, and 664 .

Nereis pelagica Linné.

के.

Penny Harbor, Cumberland Gulf, lat. 660, low-water, October 4 and 5,1877 , lots 221, 222, 237. Head of gulf, on gravel beach, May 28, 1878, lot 642 .

Phyllodoce Grönlandica Ersted (?).

A specimen in bad state of preservation. Cumberland Gulf.

Syllis, sp.

Penny Harbor, low-water, October 4, 1877. Head of Cumberland Gulf, gravel beach, low-water, May 28, 1878.

Cistenides granulata (Linné) Malmgren.

Cumberland Gulf, low-water.

Thelepus cincinnatus (Fabr.) Verrill.

Amphitrite cincinnata FABR., Fauna Grönl., p. 286, 1780.

Thelepus circinnatus MALMGReN, Nordiska Hafs-Annulater, in Öfversigt af

Kongl. Vet.-Akad. Forhandl. 1865, p. 387, pl. xxii, fig. 58 (specific name incorrectly spelled).

Lumara flava Strmpson, Invert. of Grand Manan, p. 30, 1853.

Cumberland Gulf. Common on the American coast south to Cape Cod, and in deeper water as far as Long Island Sound.

Malmgren and several other recent writers have erroneously written the name of this species "circinnatus." 
Spirorbis lucidus (Mont.) Mörch.

Very common in Cumberland Gulf, on ascidians, algæ, polyzoa, etc., low-water to 9 fathoms; Penny Harbor, October 4; Annanactook Harbor, May 20, 1878; head of the Gulf, May 28, 1878.

Spirorbis quadrangularis Stimpson.

Cumberland Gulf, low-water. One spccimen.

\section{GEPHYREA.}

Phascolosoma margaritaceum (Sars) Kor. \& Dan. (?).

Phascolosoma margaritaceum Koren and Danielssen, Fauna Litt. Norveg. iii, p. 135, pl. 15, figs. 43, 44, 1877 .

A large specimen, about 6 inches long, from the stomach of a Cottus, in Cumberland Sound, September 6, 1878 (lot 1685), probably belongs to this species.

Total length $150^{\mathrm{mm}}$; diameter of body, $18^{\mathrm{mm}}$; length of proboscis from anal opening to end, $112^{\mathrm{mm}}$. Body large, round, abruptly rounded posteriorly, with a slight mammilla at the tip; anteriorly it tapers gradually into the proboscis, which is long and becomes slender toward the enc. The surface appears nearly smooth to the eye, except that there are more or less irregular transverse wrinkles and slightly raised folds. Under a lens it is seen to be everywhere finely transversely wrinkled and striated, and in many parts reticulated with longitudinal wrinkles, while small, depressed, sucker-like organs are scattered over the surface of the body and base of the proboscis; at the posterior end of the body the longitudinal wrinkles become distinct grooves, converging to the tip, with rows of suckers between them, and the circular wrinkles, crossing the interspaces, are conspicuous. The proboscis is destitute of papillæ and hooks, and is smoother than the body, with faint indications of transverse lighter and darker bands of color. Tentacles numerous, slender. Internally the two dorsal retractors arise only a short distance behind the anal opening, their bases being wide apart toward the sides. The ventral retractors, arising near the middle of the body, are large and stout, with their thick bases close together, barely leaving space for the nervous cord to pass between them. Segmental organs large, thick, cylindrical, obtuse, dark brown, about $25^{\mathrm{mm}}$ long and $3^{\mathrm{mm}}$ in diameter; their openings somewhat in advance of the origin of the dorsal retractors and lower down on the sides. Intestine very long, forming a double coil of numerous turns, filling the posterior part of the body to the end. Generative organ voluminous, surrounding the intestine. A slender 
transverse muscle passes from the rectum to the opposite side of the body, and the rectum is attached to the adjacent wall by a large bundle of muscular fibers. Muscles of the body-wall form a continuous layer, without distinct fascicles.

\section{NEMERTINA.}

Amphiporus Stimpsoni Verrill.

Ommatoplea Stimpsoni GIRARD, in Stimpson, Invert. of Grand Manan, p. 28, fig. $18,1853$.

Gravel beach, low-water, Cumberland Gulf, June 1, 1878, lot 663. "Color, deep purplish brown above, lilac beneath." Also from reef in Penny Harbor, October 5, 1877, lot 222.

Amphiporus, sp.

Body thick, depressed, somewhat tapered to both ends, $25^{\mathrm{mm}}$ to $35^{\mathrm{mm}}$ long, as contracted in alcohol. Head with a small roundish cluster of minute ocelli on the pale antero-lateral margins. Neck with a slightly marked transverse groove, converging backward in form of a $\mathrm{V}$, on the dorsal surface. Color, in alcohol, dark bluish green; the under surface and margins of head yellowish white. In life, "bright pea-green."

Penny Harbor, Cumberland Gulf, lat. $66^{\circ}$, October 4, 1877, lot 225. Aretic Island, low-water, September 13, 1877, lot 66. 


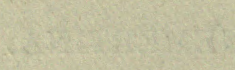

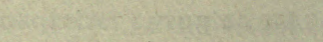

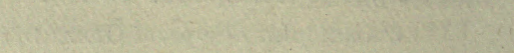




\section{MOLLUSKS.}

LIST OF SHELLS OBTAINED BY MR. LUDWIG KUMLIEN, NATURALIST TO THE HOWGATE EXPEDITION, 1877-78, AT POINTS IN CCMBERLAND SOUND, ARCTIC REGIONS, WEST FROM BAFFIN'S BAY.

BY W. H. DaLL.

The locality at which the schooner Florence, conveying the party, made her winter quarters, according to Mr. Kumlien's report, was not favorable for extensive collections in any department.

The prevalence of ice in the irregularities of the sound and other circumstances, especially the abrupt and rocky character of the shores, rendered it difficult to obtain specimens of invertebrates, which in point of fact were all collected at a few small areas of beach, some of which were a long distance from winter quarters.

Nevertheless, when the difficulties are considered, the results are very creditable to Mr. Kumlien's energy and perseverance, and are not without value for the study of geographical distribution.

The number of specimens is small; but twenty-four species are represented, some of which were also obtained by a party under Lieutenant Mintzer, U. S. N., who explored for minerals in nearly the same region a year or two previous to the visit of the Florence.

As was to be expected, none of the species are new : Modiolaria faba Fabr., which has almost been lost sight of by naturalists, and Glycimeris Kurriana Dkr., a species whose validity has been much questioned, were among the most interesting forms obtained.

The species are as follows (those with an asterisk are represented by only one or two specimens, and only Buccinum grönlandicum was at all numerous):

* Ommastrephes illecelrosa, Lesueur.

* Buccinum glaciale, Linné.

* Buccinum ciliatum, Fabr., var. Mölleri, Rve.

* Buccinum humphreysianum, Bennett (probably).

* Buccinum belcheri, Rve. 
Buccinum tenebrosum, Hancock, (typical).

Buccinum grönlandicum, Chemn.

* Trophon truncatus, Ström.

Margarita umbilicalis, Brod. \& Sby.

Margarita helicina, Fahr., vars.

Litorina grönlandica, Mörch.

Acmoea testudinalis, Linné.

Aeolidia papillosa, Linné.

* Dendronotus reynoldsii, Couthouy.

Mya truncata, Linné.

* Glycimeris Kurriana, Dkr. On mud fats.

Saxicava arctica, Linné.

* Astarte borealis, Gray; attached to kelp.

* Turtonia minuta, Fabr.; in nest of Modiolaria.

Modiolaria lavigata, Gray.

Modiolaria discors, Linné.

Modiolaria (Crenella) faba, Fabr.

Chiton (Tonicella) marmorea, Fabr.

i.hynchonella psittacea, Fischer; dead broken valves, apparently disyorged by some bird, were found on the hills at a considerable distance from the sea. They are evidently not fossil, and are probably to be found living in suitable places at low-water mark.

November 26, 1378. 


\section{MOLLUSCOIDS.}

BX A. E. Verrill.

\section{TUNICATA.}

\section{Ascidiopsis complanata Verrill.}

Ascidia complanata FABr., Fauna Grönlandica, p. 332, 1780.-VerriLl, Amer. Journ. Sci. i, p. 98, 1871, fig. 11.

Ascidia callosa Stimpsox, Invert. of Grand Manan, p. 19, 1853.

Ascidiopsis complanata Verrill, Amer. Journ. Sci. iii, p. 289, pl. viii, f. 8, 1872.

Some of the young specimens are translucent pale olive; others are older, with a dark olive-brown, thicker, and rougher test. It appears to be the most common species. It is broadly attached by one side, obliquely, and both tubes are on the upper side, near one end. They are both short and broad.

Lot No. 235, Penny Harbor, Cumberland Gulf, at low-water, October 4, 1877. No. 592, head of Cumberland Gulf, attached to roots of kelp, May 19, 1878. No. 595, Cumberland Gulf, May, 1878. No. 664, head of Cumberland Gulf, on gravel beach, June 1, 1878.

Halocynthia Verrill = Cynthia Sarigny (non Fabr., 1808).

The name Cynthia having been preoccupied, and no other tenable name having been given to the group, I propose to substitute Halocynthia for the typical section of Sarigny's genus, characterized by the square apertures, compound tentacular appendages of the mantle, and the development of two ovaries. The other subdivisions established by Savigny appear to be of generic value, in the modern sense.

Halocynthia rustica Verrill.

Ascidia rustica Linvé.-FAbricius, Fauna Grönlandica, p. 330, 1780, pars. Ascidia monoceros Möller, Kröyer's Naturhist. Tidssk., vol.iv, p. 95, 1842. Ascidia condylomata PACKArd, Mem. Boston Soc. Nat. Hist., i, p. 27\%, 1867. Cynthia monoceros Verrill, Amer. Journ. Sci., rol. i, p. 93, 1871.

Distinguished by the irregular, unequal warts and tubercles of the surface, the larger ones mostly situated above the middle, and by the more or less prominent subconical tubercle at the summit, between the bases of the tubes. This terminal tuberele is often surmounted by several hard chitinous points, and in the young a similar point often occurs 
on some of the other tubercles. The form of the body is more or less cylindrical, often two inches or more high and one in diameter, after preservation in alcohol. The tubes are terminal and divergent. Color, in life, reddish.

The very young specimens are low and nearly flat in contraction, and nearly smooth.

It is common on the Grand Banks, where it grows to a large size. It, lias not been found on the New England coast.

Lot No. 592, head of Cumberland Gulf, attached to roots of kelp, May 19,1878 . Both adult and young.

\section{Halocynthia echinata Verrill.}

Ascidia echinata LinNé.-FABricius, Fauna Grönlandica, p. 331.

Cynthia echinatu Strmp., Invert. of Grand Manan, p. 20, 1854.-Bixvey, in Gould, Invert. of Mass., p. 18, pl. xxiii, fig. 3260.-VERrLL, Amer. Journ. Sci. i, p. 96, 1871.

Lot No. 596, Cumberland Gulf, May 10, 1878.

Besides the two species of this genus brought home by the expedition, the following occur on the American coast north of Cape Cod: H. pyriformis (Rathke), Southern New England to Greenland; H. villosa (Fabr.), perhaps young of the preceding, Labrador to Greenland; H. tuberculum (Fabr. $)=$ Cynthia carnea (Ag.) Verrill = C.placenta Packard (young), Cape Cod to Greenland; H. pulchella Verrill (as Cynthia), Eastport, Me., to Grand Banks; H. partita (Stimp.), Massachusetts Bay to North Carolina.

\section{POLYZOA.}

Crisia eburnea (L.) Lamouroux.

Gulf of Cumberland. One specimen.

Diastopora patina (Lam.) Smitt.

Annanactook Harbor, on Laminaria, 7 fathoms, May 19; and on Halocynthia rustica, head of Cumberland Gulf, May 5, 1878.

Alcyonidium mytili Dalyell.

Gulf of Cumberland, on algæ. Godthaab, Greenland, on carapax of Hyas araneus.

Gemellaria loricata (Linné) Busk; Smitt.

Gemellaria dumosa Stimpsos, Invert. of Grand Manan.

Specimens three inches high, Penny Harbor, Cumberland Gulf, lowwater, October 4, 1877, lots 226 and 238, corered with fry of Crenella faba; same locality, May 28, 1878. 
Cellaria articuiata Smitt, ex Fabricius.

Sulicornaria borealis Busk.

Cellaria borealis Sмıтт, Öfversigt af Kongl. Vet.-Akad. Förh. 1867, p. 361, tab. $\mathrm{xx}$, fig. 17, 1867.

On Halocynthia rustica, attached to roots of Laminaria.

Head of Cumberland Gulf, May 19, 1878, lot 592. Some of the specimens are very young, with only a single clavate joint; others are mearly two iuches high, and beginning to branch.

Membranipora Sophiæe Busk.

With the last (lot 592). Also from Annanactook Harbor, May 19, 1878, on roots of Laminaria, 7 fathoms.

Escharina ansata (Johnst.) Gray.

Mollia vulgaris, forma ansata SмIтT, Översigt af Kongl. Vetenskaps-Akad. Förh. 1867, p. 14, tab. xxv, f. 78-83, 1867.

Several specimens occurred on the roots of Laminaria, 7 fathoms, Annanactook Harbor, May 19, 1878 (lot 597). Some agree with the var. ansata Smitt (Lepralia ansata Johnst.), but in most cases there are welldeveloped calcareous papillæ near the sides of the apertures as in the var. papillata.

I adopt the generic name Escharina given by Milne Edwards to a group, including the present species, in 1835 (in Lamarck, An. sans Vert., ed. 2, vol. ii, pp. 218, 230), and for which he cited as the type $E$. vulgaris (Moll.). Dr. Gray (List Brit. Animals in British Museum, p. $124,1848)$ also restricted the name to the same and closely allied species. Dr. Smitt, however, united this group with Hippothoa, which seems to be a sufficienty distinct genus.

The restricted genus Escharina, as I limit it, is characterized by the well-marked median sinus of the apertures of the zoæcia, together with the lateral avicularia, usually developed near one or both sides of the apertures. The mode of growth is usually Lepralia-like, but may also be Escharine. It is therefore equiralent, or nearly so, to the genus Schizoporella, recently proposed by Hincks for the same typical species.

The genus Escharoides, proposed by Edwards in the same work, has also been incorrectly used by some writers; for' although Gray restricted it, in 1848, to one of the original species, E. coccinea (Abildg.), thus making it equivalent, in part, to Discopora Smith, the last-named writer has applied it to a group, typified by E. rosacea, not included by Edwards. As the name should be restored, in accordance with Gray's limitation, I have proposed elsewhere the name Escharopsis, as a substitute for Escharoides of Smitt, including two Northern Atlantic specie:s 
$(E$. lobata $($ Lamx. $)=E$. Sarsii Smitt, and E. rosacea), both common in the Gulf of St. Lawrence. This genus, with an Escharine growth, has apertures much as in Escharina, except that the lateral avicularia are situated within their borders by the side of the sinus.

Discopora Lam., following Edwards, should be restricted to forms like D. Skenei, with median avicularia, the type of Lamarck being $D$. verrucosa, a species closely related to $D$. Skenei, but not the Cellepora verrucosa of Esper, a very different form, to which Gray erroneously restricted this generic name.

Celleporella hyalina 'L.) Gray.

Cellepora hyalina LiNNé.

Mollia hyalina Sмiтt, op. cit. p. 16, tab. xxv, f. 84, 85 .

Hippothoa hyalina SmrT, Florida Bryozoa.

Very common, Annanactook Harbor, 7 fathoms, on Laminaria, May 19, and 9 fathoms, May 20, 1878, lot 570. Penny Harbor, low-water, on Margarita helicina, October 4, 1877, lot 226. Gravel beach, head of Gulf of Cumberland, May 28, 1878, lot 642, and on Halocynthia rustica, lot วัт2, May 19. 


\title{
RADIATES.
}

\author{
BY A. E. VerRILL.
}

\section{ECHINODERMATA.}

Pentacta frondosa Jæger (Gunner, sp.).

Cucumaria frondosa Forbes, Brit. Starfishes, 1841.-DUBEN and Kores, 1844.

One large specimen, Godthaab, Greenland, August 11, 1878.

Strongylocentrotus Dröbachiensis A. Agassiz.

Penny Harbor, Gulf of Cumberland, reef at low-water, October, 4, 1877, lot 420 .

Leptasterias Grönlandica Verrill.

Asteracanthion Grönlandicus STEExst.-LÜTKEN, Oversigt over Grönlands Echinodermata, p. 29, 1857.

Head of Gulf of Cumberland, Niantilic Harbor, lot 144; low-water, September 25, 1877, lot 179; Arctic Island, lot 66; Penny Harbor, lat. $66^{\circ}$, at low-water, October 4, 1877, lot 224; also same locality, lot 290.

Leptasterias Mulleri Verrill, 1866.

Asteracanthion Mulleri SARs, Fauna Litt. Norreg., i, p. 56, f. 38, 39; Oversigt af Norges Echinodermer, p. 88.

Annanactook Harbor, 4 fathoms, May 19, 1878, lot 580.

Stephanasterias albula Verrill.

Asteracanthion albulus Strupsox, Invert. of Grand Manan, p. 14, fig. 5, 1853.

Asteracanthion problema STEENSTRUP.-LÜtKEx, op. cit. p. 30.

Common in Cumberland Gulf. Gravel beach at the head of the gulf, ete. The only lot with the date remaining is 649 , May 30,1878 . With lot 725 is the following note: "Dull.lilac abore, yellowish white beneath."

All the specimens are young, with the rays irregular in length and variable in number.

The genus Stephanasterias, proposed by me for this species several years ago, is characterized by a peculiar structure of the skeleton and spines as well as by its remarkable method of fission, so well elucidated by Dr. Liitken. When adult, there are usually six regular equal rays, such specimens becoming four or five inches in diameter. But in smaller specimeus, still undergoing self division, there are usually two to four 
longer rays, with three to five shorter reproduced rays on one side. The rays are rounded, and uniformly covered with small clustered spinules, arranged in divergent groups on each plate. The plates are regularly arranged, both transversely and longitudinally, and more closely united than in Asterias and Leptasterias. The plates of the rentral rows are directly united with the adambulacral, so as to leave no spaces between for the papulæ, which are, therefore, absent along the ventral surface next the adambulacral plates; on the dorsal surface they are usually arranged in pairs. The major pedicellarix are arranged along the edges of the ambulacral grooves, and a few usually occur in the adoral angles, between the bases of the rays.

\section{Ophioglypha nodosa Lyman.}

Ophiura nodosa LÜtKen, Addit. ad Hist. Ophiuridarum, p. 48, pl. ii, fig. 9, $a-b$, 1858.

Lot 249. Annanactook Harbor,' low-water, October 7, 1877. "Color crimson."

\section{HYDROIDA.}

Sertularia argentea Ellis and Sol.

Gravel beach, head of Cumberland Gulf, low-water, May 28, 1878.

Halecium tenellum Hincks.

Gravel beach, head of Cumberland Gulf, low-water, lot 642, May 28, 1878.

Obelia, sp.

With last. Also from Penny Harbor, low-water, October 4, 1877, attached to Acidiopsis complanata.

\section{ANTHOZOA.}

Urticina crassicorais Ehienberg, 1834.

Actinia crassicornis MÜLler, Prodromus, $17 \% 6$.

Tealia crassicornis Gosse, Ann. Nat. Hist.; Actinologia Brit., p. 209, pl. iv, fig. 1.

lihodactinia Davisii A(i.-Verril.L, Revision Polyps, in Mem. Boston Soc. Nat. Hist. vol. i, 1. 18, (author's copies, 1864).

Head of Cumberland Gulf, low-water, lot 667, on roots of Laminaria. Annanactook Harbor, May 19, 1878.

Bunodes spectabilis Verrill.

Actinia spectabilis Fabricrus, Fauna Grönlandica, p. 342, 1780.

Bunodes stella Verrill, Revision of Polyps Eastern Coast of U. S., in Mem. Joston Soc. Nat. Hist. i, p. 16, pl. i, figs. 1-8, 1864.

A more extensive acquaintance with this species, and a careful comparison with the description of Fabricius had, some time ago, caused me to unite my B. stella with the Greenlandic species (see Check-list of 
Maringe Invertebrata), although it had not been recorded from any locality between the Bay of Fundy and Greenland. The numerous specimens in this collection serve to confirm that conclusion.

Common at low-water in the Gulf of Cumberland (lots 179, 237, 664), Penny Harbor, October 4, lot 237. Gravel beach, head of gulf, June 1, 1878.

PORIFERA.

Two or three species of sponges, not yet determined, are in the collection. The most interesting, as well as most common one, forms elongated, erect, rather flaccid tubes, two or three inches high and .25 to .35 in diameter, open at top.

It occurred on the gravel beach, head of the gulf, attached to stones, June 13,1878 , lot 770 ; also in lot 643. 



\section{N S E C T S.}

DIURNAL LEPIDOPTERA.

BY W. H. EDWARDS.

Family, PAPILIONID Ė.

Sub-family, PAPILIONIN 瓜.

1. C. Hecla, Lefebrre.

Genus, Colias, Fabricius.

One female was taken at Quickstep Harbor, Gulf of Cumberland, latitude $66^{\circ}$. This species inhabits Southern Greenland and regions to the westward. It has been attributed to Iceland, but, as is now supposed, erroneously. It also inhabits Southern Lapland.

Mr. M'Lachlan, in his Report on the butterflies collected by the recent. British Arctic Expedition, states that $C$. Hecla was taken as far north as latitude $81^{\circ} 45^{\prime}$, at Hayes Sound; and he gives information obtained from Captain Feilden, R. N., attached to the Alert as naturalist, on the habits of Lepidoptera in these high latitudes. "During the short period when there is practically no night, butterflies are continuously on the wing, supposing the sun's surface not to be obscured by clouds or passing snow showers. That about one month in each year is the longest period in which it is possible for these insects to appear in the perfect state, and that about six weeks is the limit of time allowed to plantfeeding larvæ, during all the rest of the year the land being under snow and ice." Mr. M'Lachlan doubts if there is sufficient time in each year for the preparatory stages of the butterfly, - egg, larva, and chrysalis, and is lisposed to think that more than one year is necessary. In the northern United States, the larvæ of Colias frequently pass the winter when half-grown, or even younger, and I think it probable this is the habit of Hecla. From two to three weeks at the end of the short Arctic summer, and less time at the beginning in the following year, would seem to suffice for the whole round of transformations.

In Dr. Staudinger's Catalogue, Colias Boothii, Curtis, is put down as a synonym of Hecla; but, in the opinion of Mr. M'Lachlan, the two are distinct species. 
It is remarkable that the collection of butterflies made by the British Expedition, between latitude $78^{\circ}$ and $82^{\circ}$, well toward the Aretic Sea, should exhibit a greater number of species, namely, 5 , than is known in Șouthern Greenland, where we are told but 4 species, have hitherto been taken, and this northern series does not embrace the genus Chionobas, one or two species of which are found in Greenland. Besides C. Hecla and Argynnis Polaris, taken by Mr. Kumlien, were Argynnis Charidea, Iycona Aquilo, and, most surprising of all, Chrysophanus Phlocas, a species represented throughout the northern United States under a slightly different'form, Americana.

\section{f'amily, NYMPHALID $\not$.}

Sub-family, NrMPHaLina.

Genus, Argynnis, Fabricius.

\section{A. Freya, Thunberg.}

Two males were taken in Southwest Greenland. This species is distributed over the boreal regions of both continents; in America, from Greenland to Alaska; and it follows the Rocky Mountains as far to the south as Colorado. It is subject to very little variation.

\section{A. Polaris, Boisduval.}

One male was taken at Quickstep Harbor. This species is more restricted in distribution than Freya, and, so far as known, is limited to Northeast America, from Labrador to the Arctic Sea. It was taken by the British Expedition as far to the north as latitude $81^{\circ} 52^{\prime}$, and by the American Expedition (Polaris) at $81^{\circ} 50^{\prime}$. It varies much in color, and the example sent me by Mr. Kumlien is remarkably melanic on the upper surface, the hind wings especially showing scarcely any fulvous.

Sub-family, SATYRINe.

1. C. Semidea, Say.

Genus, Chionobas, Boisduval.

Oeno, Boisduval.

Two males were taken at Quickstep Harbor. One of these has the upper surface dark blackish-brown, and the discal belt on hind wings beneath distinctly outlined on both edges. The other is light or pale black-brown, and the belt is almost lost in the dense markings which cover the wing. But specimens from the White Mountains of New Hampshire show similar variation. This species inhabits Labrador, and the Rocky Mountains at very high altitudes as far south as Colo- 
rado and New Mexico. In the White Mountains it is abundant on the summit of Mount Washington; but in the territory between this region and Labrador it is unknown, as also between Mount Washington and the Rocky Mountains. How far to the northwest of the continent it flies is not known to me. It has not appeared in collections from Alaska, in which Freya was represented in considerable numbers. The peculiar distribution of this species, $C$. Semidea, by which it inhabits mountain summits thousands of miles apart and not the intervening country, and in the White Mountains of New Hampshire is thoroughly isolated and restricted to a very small area, is explained as in the case of plants similarly distributed and isolated (address of Prof. Asa Gray, Dubuque, 1872). The advance to the southwarl of the glacial ice pushed before it multitudes of plants and animals, forcing them along very distant lines of longitude in many cases; and when the receding of the ice took place, and a milder temperature began to prevail, some species which had obtained a foothold at the south remained there, finding a climate in which they could live, upon lofty mountains only, being. unable to exist in the lowlands. In the case of this butterfly, such a climate was found at or near the snow-line in the Rocky Mountains, and upon the summits of the White Mountains. 



\section{INSECTS.}

HYMENOPTERA, NOCTURNAL IEPIDOPTERA, DIPTERA, COLEOPTERA, NEUROPTERA, AND ARACHNIDA.

BY S. H. SCUDDER AND OTHERS.

The insects collected by Mr. Kumlien were very few in number, amounting to only sixteen species; and they appear to add little to our previous knowledge of the fauna. Nevertheless, as all lists from high northern localities possess a certain importance, the following is given. The Hymenoptera were determined by Mr. E. T. Cresson; the report on the Lepidoptera is by Mr. A. R. Grote; Mr. E. Burgess has named the Diptera, Dr. J. L. LeConte the Coleoptera, Dr. H. Hagen the Neuroptera, and Mr. J. H. Emerton the Arachnid.-SAMUEL H. SCUDDER.

The Diurnal Lepidoptera were placed in the hands of Mr. W. H.Edwards for examination, and appear on pp. 155-157.

\section{HYMENOPTERA.}

1. No. 944. Bombus lacustris Cress. One specimen; American Harbor, Gulf of Cumberland, July 6, 1878.

2. No. 1287. Bombus sp. near B. scutellaris Cress., and probably B. groenlandicus Smith. One specimen; Godhavn, Greenland, August 3, 1878.

3. No. 1431. Limneria sp. (not described). One specimen; Disko Fjord, Disko Island, Greenland, August 9, 1878.

\section{NOCTURNAL LEPIDOPTERA.}

4. Laria Rossii Curtis, Appendix to the Second Voyage of Sir J. Ross, lxi, Pl. A, fig. 10.

The specimens belonging to this species are (1) a dried larva, black, with yellowish brown hairs, and on each side a row of yellow tufts, aretiiform; (2) a slight cocoon formed of the larval hair like those of the genus Orgyia; (3) a single worn male specimen of the moth. The specimens were collected at Annanactook, Cumberland Island, the latter part 
of June. The cocoon has attached to it a fragment of a lichen and sereral coniferous needles, and was evidently formed on the ground; these objects are merely slightly attached and form no part of the structure itself. The cocoon, which is close in texture, yet very frail and light, contains the black and shining pupa, which is unusually thickly clothed with brownish hair.

Curtis says of this species: "It is a very abundant insect, especially in the caterpillar state, for about a hundred were collected on the 16th of June 1832, near Fury Beach." His description of the larva does not well accord with the present specimen. He says: "The caterpillar is large and hairy, and of a beautiful shining velvety black, the hairs being somewhat ochreous; there are two tufts of black hair on the back, followed by two of orange." His description of the pupa and web, as well as of the perfect insect, agrees with the specimens now received. He gives the food-plant of the larva as Saxifraga tricuspidata and $S$. oppositifolia.

I have recorded (Psyche, 1, 131) the occurrence of this species above the tree-line on Mount Washington, N. H. It is another instance of the distribution of our existing species of moths, through the ageney of the change in climate attending the Glacial Epoch.

5. No. 1431. Anarta melanopa (Thunb.).

A single specimen collected at Disko Fjord, Disko Island, August 9, 1878. This species has been taken above timber-line, 13,000 feet elevation, by Lieut. W. L. Carpenter, on Taos Peak, Rocky Mountains. It is found also in Labrador, and has been collected by Mr. George Dimmock near the summit of Mount Washington.

6. No. 1127.

A single specimen of a small dusky gray moth too much rubbed for positive identification and otherwise mutilated. The eyes are naked, the ocelli apparent. It was taken at Kikkerton Island, Gulf of Cumberland, July 25, 1878.

\section{DIPTERA.}

7. No. 1061. Culex sp. One specimen; American Harbor, Gulf of Cumberland, July 10, 1878.

8. Nos. 1061, 1127. Tipula arctica Curt. Two specimens; American Harbor, Gulf of Cumberland, July 10, 1878; and Kikkerton Island, Gulf of Cumberland, July 25, 1878.

9. No. 1431. Rhamphomyia sp., perhaps R. nigrita Zett. Two specimens; Disko Fjord, Disko Island, Greenland, August 9, 1878. 
10. A Tachinid of unrecognizable genus; two pupa cases and a fly which has escaped from one in confinement, with crumpled wings; found parasitic on the larva of Laria Rossii, Annanactook, Cumberland Sound.

11. No.12 3. Calliphora erythrocephala Meig. One specimen; Godthaab, Greenland.

12. No. 1098. Scatophaga apicalis Curt. (=? S. squalida Meig.). One specimen ; off' shore, Annerican Harbor, Cumberland Sound, July $13,1878$.

\section{COLEOPTERA.}

13. No. 1061. Amara hamatopus Dej. (Feronia); Stereocorus similis Kirby. One specimen; American Harbor, Cumberland Sound, July 10, 1878. The species is found generally throughout sub aretic America.

14. No. 1641. Agabus (Gaurodytes) tristis Aubé. Five specimens in poor preservation; Lake Caroline Mann, Cumberland Island, September 1, 1878. The species is abundant in Alaska and extends down to California in the Sierra region.

\section{NEUROPTERA.}

15. No. 1611. A Limnophilid, perhaps an Halesus. Several larval eases with dried larvæ in some of them; the cases are composed of minute scales of mica. Lake Caroline Manu, Cumberland Island, September 1, 1878.

\section{ARACHNIDA.}

16. No. 1061. Lycosa sp., probably $L$. gronla utica Thor. One tried specimen; American Harbor, Cumberlar d Sound, July 10, 1878.

Bull. Nat. Mus. No. $15-11$

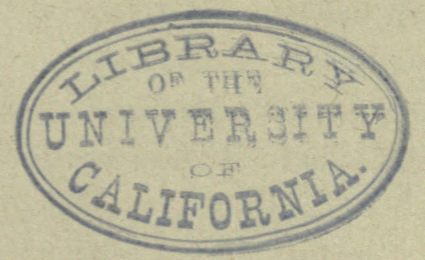





\section{PLANTS.}

LIST OF THE PLANTS COLLECTED AT POINTS IN CCMBERLAND SOUND BETWERN THE SIXTY-SIXTH AND SIXTY-SEVENTH PARALLELS OF NORTH LATITUDE AND QN THE SOCTH SHORES OF DISKO ISLAND, GREENLAND.

\section{BY Asa Gray.}

The Howgate Expedition arrired in Cumberland Sound about the middle of September, 1877; the ground was then covered with snow, but this melted on the southern slopes some days later, and exposed a few plants still in flower, Campanula rotundifolia, Lychnis apetala, Stellaria longipes, var. Edwardsii, \&c.

In the succeeding summer the Florence left her winter-harbor early iu July, and while there was yet considerable snow remaining in the valleys. At the time we left our winter-quarters there were but four or five plants in flower in the vicinity, such as Taraxacum Dens-leonis, Cochlearia officinalis, Saxifraga stellata, and Saxifraga rivularis, var. hyperborea.

Pyrola rotundifolia, var. pumila, showed buds on a southern slope by the last day of May, but the same plants were not in flower by July 7 . The season appeared to be unusually backward, frequent snow-storms prevailing till the latter days of June.

At America Harbor, on the east side, and nearly opposite Annanactook, the winter-harbor, plants were in much richer profusion and apparently more than a week earlier than at the former place.

As large a number of plants were collected here as our short stay would admit of. A few days were also spent at the Kikkerton Islands, and such of the islands as were accessible to us faithfully hunted over, but inany species were not yet in flower.

On the south shores of Disko Island, Greenland, we collected for a few days in August, and here the bulk of our plant-collection was made.

Many species were found here that we had collected in Cumberland, but they were strikingly more luxuriant and generally quite abundant. In the following list the species collected at points in Cumberland Sound will be indicated by the letter C; those from Disko Island, Greenland, by the letter G.-L. K. 
Thalictrum alpinum, L. G.

Ranunculus nivalis, L. C.

Ranunculus affinis, R. Br. C.

Ranunculus, not identified.

Papaver nudicaule, $\mathrm{L}$. $\quad \mathrm{C}$ and $\mathrm{G}$.

Arabis alpina, I\% G and $\mathrm{C}$.

Cochlearia officinalis, I. C.

Cochlearia arctica, Schl. G.

Draba stellata, Jacq. C.

Draba stellata, var. nivalis, Regl. C.

Draba crassifolia, Grah. G.

Draba hirta, L. C.

Silene acaulis, I. C and G.

Iychnis alpina, L. G.

Lychnis apetala, L. C.

Lychnis affinis, Wahl. $\mathrm{C}$ and $\mathrm{G}$.

Cerastium alpinum, L. $\mathrm{C}$ and $\mathrm{G}$.

Stcllaria longipes, Goldie.

Stellaria longipes, var. Edwardsii. $\mathrm{C}$ and $\mathrm{G}$.

Arenaria peploides, L. G.

Dryas octopetala, L.

Dryas octopetala, var. integrifolia, Ch. \& Sch. C and G.

Potentilla nivea, L. C.

Potentilla maculata, Pour. C.

Sibbaldia procumbens, L. G.

Alchemilla vulgaris, L. G.

Sauifraga rivularis, L. C.

Saxifraga rivularis, var. Iyperborea, Hook. C.

Saxifraga cermua, I. G.

Saxifraga stellaris, I. C.

Saxifraga nivalis, $\mathrm{L}$. $\mathrm{C}$ and $\mathrm{G}$.

Saxifraga ccespitosa, L. C and $G$.

Saxifraga tricuspidata, Retz. C and G.

Saxifraga oppositifolia, I. C.

Epilobium latifolium, L. C and G.

Archangelica officinalis, I. G.

Erigeron uniflorum, L. G.

Gnaphalium Norvegicum, Gunn. G.

Antennaria alpina, L. G and C. 
Arnica alpina, Murr. G.

Taraxacum Dens-leonis, Desf. G and U.

Taraxacum palustre, DC. C.

Campanula rotundifolia, L. $\mathrm{C}$ and $\mathrm{F}$.

Campanula unijlora, L. G.

Vaccinium uliginosum, L. C and G. (var.)

Arctostaphylos alpina, L. $\mathrm{C}$ and $\mathrm{G}$.

Cassiope hypnoides, Don. $\mathrm{C}$ and $\mathrm{G}$.

Cassiope tetragona, Don. C and G.

Bryanthus taxifolius, Gray. G.

Rhododendron Lapponicum, Wahl. $\mathbf{C}$ and $\mathbf{G}$.

Ledum palustre, L. $\quad \mathrm{C}$ and $\mathrm{G}$.

Loiseleuria procumbens, Desv. C asd (: .

Pyrola rotundifolia, $\mathrm{L}$.

Pyrola rotundifolia, var. pumila, Hoo $\dot{-} \cup$ and $G$.

Diapensia Lapponica, I. C and G.

Armeria vulgaris, L. $\mathrm{C}$ and $\mathbf{G}$.

Veronica alpina, L. G.

Euphrasia officinalis, L. G.

Bartsia alpina, L. G.

Pedicularis Langsdorffi, Fisch. G.

Pedicularis Langsdorffi, var. lanata.

Pedicularis hirsuta, L. C and G.

Pedicularis flammea, L. G.

Pedicularis Lapponica, L. G.

Mertensia maritima, Don. G.

Oxyria digyna, Campd. $\mathrm{C}$ and $\mathrm{G}$.

Polygonum viviparum, L. $\mathrm{C}$ and $\mathrm{G}$.

Empetrum nigrum, L. C.

Betula nana, L. C and G.

Salix herbacea, L. C and G.

Salix glauca, L. C.

Salix arcíica, R. Br.? C.

Habenaria albida, R. Br. G.

Habenaria hyperborea, R. Br. G. New to Greenland!

Tofieldia borealis, Wahl. $\mathrm{C}$ and $\mathrm{G}$.

Iuzula spadicea, DC. C.

Luzula spadicea, var. parviflora; Mey. G.

Luzula arcuata, Wahl. C. 
Luzula arcuata, var. hyperborea. C.

Eriophorum Scheuchzeri, Hoppe. $\quad$.

Eriophorum vaginatum, L. C.

Eriophorum polystachyum, L. $\quad$ U.

Carex lagopina, Wahl. G.

Carex rigida, Good. G.

Carex rariflora, Wahl. G.

Hierochloa alpina, L. $\mathrm{U}$.

Alopecurus alpinus, L. G.

Poa alpina, L. C and G.

Festuca ovina, L. C.

Festuca ovina, var. Ireviflora. $\mathrm{r}$.

Glyceria angustata, R. Br. G.

Woodsia hyperborea, R. Br. G.

Cystopteris fragilis, Bernh. Gे.

Aspidium Lonchitis, Sw. G.

Polypodium Dryopteris, L. G.

Equisetum arvense, L. $\mathbf{G}$ and $\mathbf{C .}$

Iycopodium Selago, L. G and $\mathbf{O}$. 


\section{LICHENS.}

LIST OF LICHENS COLLECTED IN THE VICINITY OF ANNANACTOOK HARBOR, CUMBERLAND SOLND, AT ABOUT LAT. $67^{\circ}$ N., LONG. $68^{\circ} 49^{\prime} \mathrm{W}$.

BY EdWARD TUCKERMAN.

Cetraria nivalis, (L.) Ach. G.

Cetraria cucullata, (Bell.) Ach. G.

Cetraria islandica, (L.) Ach. G.

Cetraria islandica, var. Delisce, Br. G.

Dactylina arctica, (Hook.) Nyl. G.

Alectoria ochroleuca.

Alectoria ochroleuca, var. cincinnata, Fr. G.

Alectoria ochroleuca, var. nigricans, Ach. G.

Alectoria jubata, (L.).

Alectoria jubata, var. chalybeiformis, Ach. G.

Theloschistes parictinus, (L.).

Theloschistes parietinus, var. pygmaus, Fr. D.

Parmelia saxatilis, (L.) Fr. G.

-Parmelia saxatilis, var. omphalodes, Fr. G.

Parmelia saxatilis, var. panniformis, Fr. G.

Parmelia physodes, (L.) Ach.

Parmelia physodes, var. encausta, Fr.

Parmelia physodes, var. alpicola, Nyl. G.

Parmelia stygia.

Parmelia stygia, var. lanata, (Mey.). G.

Parmelia conspersa, (Ehr.) Ach. G.

Parmelia centrifuga, (L.) Ach. G.

Umbilicaria vellea, (L.) Nyl. G.

Umbilicaria proboscidea, (L.) Stenh. G.

Umbilicaria proboscidea, var. arctica, Ach.

Umbilicaria anthracina, (Wahl.) Schœr. G.

Umbilicaria cylindrica, (L.) Delis. G.

Umbilicaria hyperborea, Hoffm. G.

Umbilicaria erosa, (Wel.) Hoffm. G. 
I'cligera canina, (L.) Hofrm. G.

Peltigera pulverulenta, (Tayl.) Nyl. G.

Pannaria hypnorum, (Hoffm.) Kœrb. G.

Placodium elegans, DC.

Placodium vitellinum, (Ehrh.) Hepp. G.

Lecanora rubina, (Vill.) Ach.

Lecanora rubina, var. opaca, $\Lambda$ ch.

Lecanora tartarea, (L.) Ach. G.

Lecanora oculata, (Dicks.) Ach.

Lecanora ventosa, (L.) Ach. G.

Stereocaulon tomentosum, Fr.

Stereocaulon tomentosum, var. alpinum, Lawr.

Stereocaulon paschale, (L.) Fr. G.

Stereocaulon demudatum, Flœrk. G.

Cladonia rangiferina, (L.) Hoff'm.

Cladonia rangiferina, var. alpestris, Sehœr.

Cladonia uncialis, (L.) Fr. G'.

Cladonia bellidiflora, Ach. (Schœr.). G.

Cladonia cornucopioides, (L.) Fr. G.

Cladonia cornucopioides, var. incrussatı, Anct. G.

Cladonia deformis, (L.) Hoffin. G.

Heterothecium pezizoidcum Ach. G.

Buellia papillata, (Sommerf.) Flot. G.

Sphorophorus fragilis, (L.) Pers. 


\section{ALG A.}

LIST OF ALGAE COLLECTED AT POINTS IN CUMBERLAND SOUND DURING THE AUTUIN OF 1877 .

\section{BY W. G. Farlow.}

Odonthalia dentata.

Rhodomela subfusca.

Rhodomela tenuissima.

Polysiphonia cretica.

Delesseria rostrata.

Delesseria alata.

Rhodophyllis reprerula.

Euthora cristata.

Phyllophora interrupta.

- Phyllophora membranifolia.

Ptilota plumosa, var. serrata.

Ceramium rubrum.

Callithamnion Pylaisai.

Callithamnion Rothii.

Chordaria flagelliformis.

Dictyosiphon foniculaceus.

Phlocospora tortilis.

Sphacelaria arctica.

Chatopteris plumosa.

Ectocarpus hiemalis.

Ectocarpus Farlowii.

Ectocarpus Landsburgii?

Ectocarpus firmus, vấr.

Monostoma —?

Cladophora arcta.

Ulothrix flacea.

Hamatococcus lacustris (Protococcus nivalis). 



\section{MINERALS.}

By F. M. ENDLICH.

The following is the catalogue of the minerals collected by Dr. Kumlien. Each one of the species is represented by a number of specimens Interesting, among them, is a collection of the supposed meteoric stones from Ovifak.

\section{Smithsonian}

number.

9580. Supposed METEoric stonts from Ovifak, Disko Island, Greenland.

9581. Granite, probably from a drift-bowlder, Greenland.

9582. Rose QUARTZ. A large number of specimens from Greenland.

583. ORTHOCLase, from Niantilic Gulf, Cumberland.

9584. Tourmaline, crystals with one end termination. Some of them are of considerable size. Color black. Niantilic Gulf.

9585. Muscovite, crystals and large plates. The latter contains some hematitic inclusions. Niantilic Gulf.

9586. Muscovite, crystals. Niantilic Gulf.

9587. ORтносlase, massive, yellow. Niantilic Gulf.

9588. Bıотіте, in small crystals. Niantilic Gulf.

9589. QUARTz, colorles's. Niantilic Gulf.

9590. Chalcedony, gray and blue. Disko Fjord.

9591. Argrllite, red, compact. Ovifak.

9592. Chalcopyrite, massive, in quartz. Cumberland Gulf.

9593. PyrRhotite, associated with some pyrite. Cumberland Gulf.

9594. Syокy QuARTz, massive. Cumberland Gulf.

9595. ChLokite, crystallized. Cumberland Gulf.

9596. Аратіте, crystalline. Cumberland Gulf.

9597. GARNET, variety, probably Spessartite, crystallized in clusters and single large crystals. Cumberland Gulf.

9598. Apophyllite. Small quantities associated with Chalcopyrite. Cumberland Gulf. 



\section{INDEX.}

Page.

Acidiopsis complanata

Acmæa testudinalis

Actinia crassicornis

spectabilis.................... 152

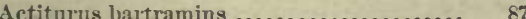

Egialitis hiaticula ......................

$$
\text { semipalmata }
$$

Egiothus holbülli

$$
\text { linaria. }
$$

Eolidia papillosa...................... 146

A gabus (Gaurodytes) tristis............. 161

A gingak .......................... 89

A glek ............................. 89

Agonidæ.......................... 116

A ják-kaljújak .......................... 38

Akagik ........................... 83

Akeiksek $.164,105$

Akparnak........................... 103

Alchemilla vulgaris .................... 164

Alcyonidium mytili ..................... 148

Alectoria jubata ..................... 167

jubata var, chaly beiformis....... $\quad 167$

ochroleuca ...................... 167

ochroleuca var. cincinnata....... 167

ochroleuca var. nigricans ........ 167

Alga

Alopecurus alpinus

Amara hæmatopus

Amarook

Amashuadly

Amathilla Sabini

Amgoouk or amusit

Ampelis garrulus .......................

Amphiporus

Amphiporus Stimpsoni....................

Amphitrite cincinnata...................

Anarak

Anas boschas

Ancoot......................28, 29, 30, 43, 44, 46

Ancoot angekok....................... 21, 27

Angekoks............................ 29

Annelida............................ 141

Annelids .............................. 141

Anser albifrons var. gambeli............. 88

hyperboreus.

Antennaria alpina.

(64.................

Anthoza

A patite .......................... 171

A peltes ............................ 131

A pophyllite.......................... 171

Arabis alpina ........................ 164

A rachnida .........................159, 161

Archangelica officinalis ................ 164

A retostaphylos alpina................. 165

Arenaria peploides.
Page.

Argynnis........

" Charidea..................... 156

Freja....................156, 157

Polaris. ............................ 156

Armeria rulgaris....................... 165

Arnica alpina ....................... 165

Ascidia callosa....................... 147

" complanata..................... 147

" condylomata .................. 147

" echinata....................... 148

“ monoceros ..................... 147

rustica....................... 147

Ascidiopsis complanata ................. 147

Aspidium Lonchitis...................... 160

Aspidophoroides monopterygius .......... 116

Astarte borealis........................ 146

Asteracanthion albulus ................. 151

Malleri ................. 151

problema ............... 151

Asterias............................. 152

Atánsa ............................ 20

Atluks .............................. 35, 39, 56

Aúkbinigan ......................... 27

Ankbinigan-machoni................... 27

Aurora borealis ........................ 31

A wingak............................. 53

Awouk............................. 63

Baird, Prof. S. F................... 120

Balanus balanoides...................... 140

crenatus ..................... 140

Bartsia alpina....................... 165

Bean, Tarleton H...................107, 113

Beluga catodon......................13, 24, 66

Betula nana .......................... 165

Biotite .............................. 171

Birds................................ 71

Blennius polaris...................... 115

Bombus lacustris...................... 159

scutellaris..................... 159

Borengadus polaris .................. 108

saida.....................107, 108

Bowhead Bird....................... 85

Brachyotus palustris.................. 81

Branta hutchinsii ..................... 88

Bryanthns taxifolius .................. 16.5

Buccinum belcheri ..................... $14 j$

ciliatum var. Mölleri ............ 145

glaciale................... 145

grönlandicum ................ 146

liumphreysianum.............. 145

tenebrosum ................. 146

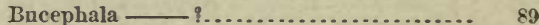

islandica.................... 89

Buellia papillata..................... 168 


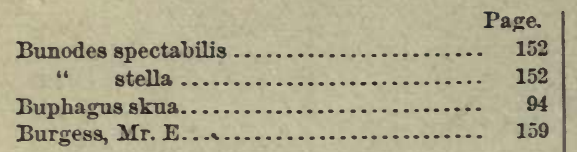

Cablunet

Calidris arenaria

Calliphora erythrocephala.

Callitbamnion Pylaisæi. Rothii.

Callocephalus vitulinus

Campanula rotundifolia uniflora .........

Canis familiaris var. borealis.............. 50

"occidentalis var. grisea-alba......... 52

Caprella.............................. 73

septentrionalis ................116, 139

Carex lagopina ........................ 166

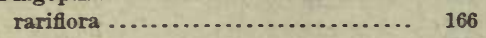

rigida........................... 166

Carpodacus purpureus .................. 75

Cassiope hypnoides ..................... 159 tetragona...................20,32, 165

Cellaria articulata...................... 149 borealis..................... 149

Cellepora hyalina ...................... 150

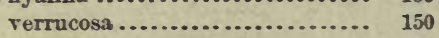

Centridermichthys .................... 127

Centroblennius nubilus ................ 115

Ceramium rubram .................... 169

Cerastium alpinum ................... 164

Cetacea ............................. 64

Cetraria cucullata..................... 167

islandica ..................... 167

islandica var. Delisæ............ 167

nivalis ....................... 167

Chatopteris plumosa.................... 169

Chalcedony.......................... 171

Chalcopyrite......................... 171

Chionobas........................... 156

Chionobas Semidea.................. 156, 157

Chiton (Tonicella) marmorea............. 146

Chlorite............................ 111

Chordaria flagelliformis ................. 169

Chrysomitris ......................... 76

Chrysomitris tristis ................... $\quad 76$

Chrysophanns Phalæas ................. 156

Cinclus .............................. 73

Cistenides granulata................... 141

Cistophora cristata....................13,47,64

Cladonia bellidiflora................... 168

cornncopioides................. 168

coruncopioides var. incrassata .... 168

deformis ....................... 168

rangiferina................... 168

rangiferina var.alpestris......... 168 uncialis....................... 168

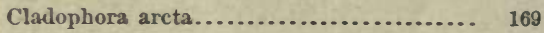

Clupea harengus ...................... 137

Clupeidæ............................ 137

Cochlearia .......................... 27

arctica..................... 164

officinalis ................91, 163, 164

Codlulik............................ 103
Page.

Codlunak ........................... 46

Colias ................................ 155

Colias Boothii ....................... 15j

. Hecla ............................155, 156

Collett, Prof........................... 109,

Colymbus arcticus ..................... 103

" septentrionalis.............. 103

torquatus................... 103

Corvus corax....................... 78

Cottidæ $\ldots \ldots \ldots \ldots \ldots \ldots \ldots \ldots \ldots \ldots \ldots . . . \ldots \ldots$

Cottns ............................... 138

Cottus aneus ....................... 119, 139

" crönlandicus..............60, 118, 119, 123

Mitchilli.................... 119

octodecimspinosus ..............119, $1: 0$

pachypus....................... 124

pistilliger..................... 128

polaris ....................... 127

quadricornis ..................... 127

" seorpioides ........10 $7,108,120,122,123,124$

“ scorpius ... $18,20,60,80,90,107,116,118,119,120$,

123

“ scorpius var. grōnlandicus.... 107, 118, 120

" variabilis .......................119, 127

Crangou boreas....................... 139

Crenella faba........................ 148

Cresson, Mr. E. T................... 159

Crisia eburnea......................... 148

Crustacea ...........................62, 139

Cucumaria frondosa................... 151

Cumberland Eskimo ..60, 61, 63, 64, 66, 83, 84, 85, 86, $89,93,94,95,98,99,101,103,104,105$

Cyamus ceti........................ 85

Cyclopteridæ ........................ 115

Cyclopterus lumpus...................10

" spinosus.................. 115

Cygnus _ $\quad$ ?........................ 88

Cymochorea leucorrhoa ................ 102

Cynthia........................... 147

carnea........................ 148

echinata.................... 148

monoceros................... 147

placenta....................... 148

Cystopteris fragilis................... 166

Dact $y$ lina arctina ..................... 161

Dall, W. H........................ 145

DeKay ............................ 119

Delesseria alata ...................... 160

rostrata................... 169

Delphinapterus leucas ................... $\quad 85$

Dendronotus reynoldsii.................. 146

Dr..Arøeca coronata .................... 74

Diapensia Lapponica.................... 165

Diastopora patina .................... 148

Dict yosiphon foniculacens .............. 169

Diptera ............................. 159

Discopora.......................... 149, 150

Skenei..................... 150

verrucosa.................... 150

Dinrnal Lepidoptera .................. 155

Draba crassifolia...................... 164

" hirta .......................... 164.

" stellata....................... 164 
Draba stellata var. nivalis.

Page.

Dryas octopetala... octopetala rar. integrifolia

Echinodermata .

Ectocarpus Farlowii

$$
\text { firmus, var. }
$$

hiemalis.

Landsburgii?

Edwards, W. H

Eeheemung

Emerton, J. H

Empetrum nigrum

Empidonax flaviventris.

Emukitilak.

Endlich, F. M.

Epilobium latifolium

Equisetum arvense..

160

164

Eriophorum polystachyum................. 166

Scheuchzeri.................. 166

vaginatum .................. 166

Escharina ............................149, 150

Escharina ansata......................... 149

. " lobata........................ 150

rosacea .........................149, 150

Sarsii.......................... 150

vulgaris ....................... 149

Escharoides ................................ 149

coccinea...................... 149

Eskimo cranium........................ $\quad 77$

Ethnology ............................. 13

Eucalia inconstans ...................... 130

Eumicrotremus spinosus ................. 115

Euphrasia officinalis ..................... 165

Euthora eristata......................... 169

Falco candicans .......................... 81

Farlow, W. G.......................... 169

Feilden, Captain, R. N .................. 155

Feneker, Governor Edgar ................. $\quad 70$

Festuca ovina........................... 166

ovina var. breviflora.............. 166

Fishes................................. 107

Fratereula aretica....................... 103

Fucus vesiculosus...................... 19, 26

Fulmarus glacialis ..................... 101

Gadidæ.................................. 108

Gadus fabricii........................... 108

". morrhna ..........................109, 110

" ogac.........................60, 107, 110

"

" ovak .......................... 110

" saida............................. 109

Gammari.............................. 57

Gammarus ............................... 73

locusta ....................... 139

ornatus ....................... 139

Garnet ............................ 171

Gasterosteidæ............................ 129

Gasterosteus aculeatus.................. 130

insculptus................. 129

mainensis .................... 131

nebulosus ................. 131
Gasterosteus pungitins.........107, 108, 129, 130, 131 “ subsp. brachypoda.. 129

Gemellaria dumosa....................... 148

loricata....................... 148

Gephyrea ........................... 142

Gill, Theodore.........................124, 130

Glyceria angustata...................... 166

Glycimeris Kurriana ....................145, 146

Gnaphalium Norvegicum................. 164

Goode, G. Brown........................ 113

Graculus carbo........................ 37

Granite ............................... 171

Gray, Asa .............................. 163

Grote, A. R . . . . . . . . . . . . . . . . . . . 159

Grus $-?$ (probably fraterculus) ........ 88

Gulo ............................. 53,71

Gunellus fasciatus..................... 115

Günther ................108, 110, 115, 116, 124, 130

Gymnacanthus pistilliger .................107, 127

Gymnelis viridis .......................107, 112

Gymnocanthus .........................127, 128

Habenaria albida...................... 165

". hyperborea .................. 165

Hæmatococeus lacustris (Protococens niva-

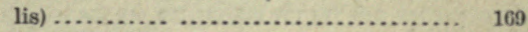

Hagen, Dr. H .......................... 159

Halecium tenellum ....................... 152

Halesus .............................. 161

Haliaëtus albicilla........................ 82

Halocynthia........................... 147

echinata ................... 148

partita ...................... 148

pulchella.................... 148

pyriformis ................. 148 rustica..............147, 148, 149, 150

tubereulum .................. 148

villosa...................... 148

Harelda glacialis ....................... 89

Harmothoe imbricata..................... 141

Hart, C........................... 128

Harwood, Dr .......................... 138

Heterothecitum pezizoideum.............. 168

Hierochloa alpina ...................... 166

Hippoglossus vulgaris..................... 108

Hippolyte Fabricii ...................... 139

Hippothoa hyalina .................... 150

Histrioniens torquatus ................... $ه 9$

Howgate, Captain ....................... 5

Hump-back of whalers ....................

Hyas araneus............................140, 148

Hydroida............................. 152

Hymenoptera ........................ 159

Hyperia medusarum.................... 139

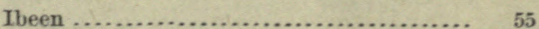

Ieelus hamatus....................... 128

Igahsook ............................. 101

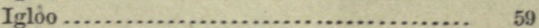

Insects ................................... 155, 159

Ishungak ............................. 94, 95

Ivik...................................... 63

Junco hyemalis .......................... 78 
Page.

Kadijuk

Kiaerrak.

Kaertooluk.

Kámik .... . . . . .

Karksauk

Kassigiak

Kernetook

Kiidmik

Killaugak

Killeluak.

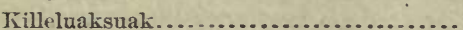

"Killer" of whalers

Kingalalik

Kingalik

Kioligak

Kiolik.

Kirksooeasu?

Kittiwake

Koodlukkaleak

Kopanauarsuk .........................

Kopernúak.........................

Kowolin.

Kuksuk ............................. 103

Kumlien, Mr ..5, 11, 47, 69, 107, 108, 109, 110, 112, 115,

$116,118,119,122,124,127,129,131,134,145,156,159,163$

Kung-núk-took.

Læmolipocila

Lærnodipodian crustaceans .................

Lagopus.

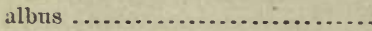

rupestris. ......................

Laminaria......................148, 149, 150, 152

Laria Rossii ..........................159, 161

Larus ............................... 13

argentatus..................... 97,99

franklini......................... 101

glaucus................24, 92, 95, 96, 97, 98

hutchinsii

98

leucopterus....................95, 97, 98

marinus ...............

Lecanora oculata...................... 168

rubina ....................... 168

rubina var. opaca .............. 168

tartarea..................... 168

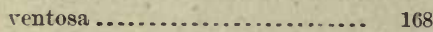

LeConte, D1. J. L..................... 159

Ledum palustre ..........................20,166

Lepas fascicularis .................... 139

Lepidoptera, Nocturnal ................. 159

Lepralia ansata ....................... $\quad 149$

Leptasterias.......................... 152

Grönlandica............... 151

Mulleri................... 151

Lepus glacialis ...................... 27, 53, 79

Lichens .......................... $\quad 167$

Limosa hudsonica.................... 87

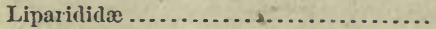

Liparis... ....................... 90

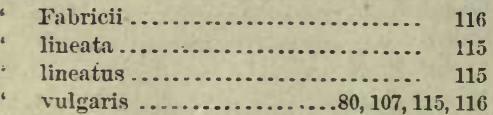

Page.

Litorina gröulandica .................. 146

Lobipes hyperboreus .................... 84,86

Loiseleuria procumbens................ 165

Lomvia arra ........................ 105

Loxia leucoptera ..................... $7:$

Lumara flara. ...................... 141

Lumpenus uubilns ................... 115

Lütken, Dr ............... 119, 124, 127, 128, 151

Luzula arcuata....................... 105 arcuata var. hyperborea ........... 166 spadicea....................... 165 spadicea var. parriflora............ 16.

Lycæna Aquilo...................... 156

Lychnis affinis ....................... 1C4

alpina ........................ 164

apetala ...................... 163,164

Lreodes ... . .................... $11:$ mucosus ..................107, 112, 11: paxillus ...................... $11 \mathrm{~s}$

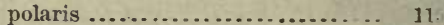

Lycodidæ ............................. 112

Lycopodium Selago .................... 166

Lycosa grœnlandica................... 161

Mácho ............................. 26

M'Lachlan, Mr ......................

Mallotus villnsus....................... 134

Mamma .......................... 33,34

Mammals ............................ 47

Margarita lelicina ...................146, 150 umbilicalis ................... 146

Megaptera longimana .................. 60

Membranipora Sophiæe ................ 149

Mergulus alle .......................103, 104

Mergus serrator...................... 94

Merlangus carbonarius................ 109

Mertensia maritina .................... 105

Microstomidx......................... 134

Mintzer, Lieut., C. S. X.................108, 145

Modiolaria (Crenella) faba...............145, 146

Mollia hyalina........................ 150

vulgaris ......................... 149

Molluscoids ........................... 147

Mollusks ............................ 73, 145

Monodon monoceros.................. 35, 67

Monostoma ......................... 164

Morrhua .......................... 104

Muktuk ............................. 20,65

Murænoides fasciatus ................. 115

Muscovite.......................... 171

Mustela erninea .......................

Mya truncata ..................... 146

Myodes torquatus................... 53

Naga ................................ 95

Xannok ............................ 48

Nannokes ............................ 49

Narksormutak ....................... $\quad$ i7

Narwhal of whalemen.................. 67

Nayardluk ........................ 99

Nayanarsuk......................... 99

Nemertina ........................ 343 
Page.

Yereis pelagica

141

Netsiavik

Netsick .

Yeuroptera.

55

Yowgah.

$.159,161$

Nowyalı.

Numenius borealis

Vyetea scandiaca.

Nymphalidre

Obelia .

Oceauites oceanica

Odonthalia dentata

Edemia

Ogjook

Okaitsok

Ukrodlook

Omiak

Ommastrephes illecebrosa

Ommatoplea Stimpsoni..

Oohndluk

Oojook

Oo-sook

Ophioglypha nodosa.

Ophiura nodesa.

Opigiuak

Opik

Opirksook

Orca gladiator

Orgyia

Orpingmatook

Orthoclase.

Ovifak

Oxyria digyna

Pirgouns fuetilus . $13,17,22,24,39,44,49,55,63,71$,

Pagophila eburnea

Pagophilus grenlandicus

33,61

Paijk

Pannaria hypnorum

Papaver nudicaule

Papilionidæ .

Parmelia centrifuga

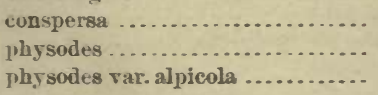

physodes var. alpicola

pliysodes var. encausta ...........

saxatilis

saxatilis var. ounphalodes

saxatilis var. pauniformis.

stygia .

styogia var, lanata

Pedicularis.

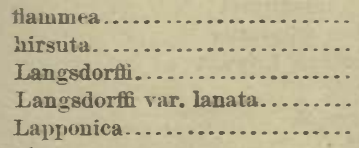

Peltigera canina

pulverulenta

Penuy, Cajptain

Pentacta frondosa
Pesholak.
Phalaropu

Page.

(14)

$13,24,32,4 l, 43,61$

Phloeospora tortilis..................... 16

Phobetor ventralis .................... 123

Phocena commnnis ................... 60

Phyllodoce Grõnlandiea ................ 141

Phyllophora interrupta................. 169

membranifolia .............. 169

Physalis antiquorum................... 640

Pickaninny pussy ....................... 55

Pingasnit ... ........................ 26

Pinicula enucleator...................... 75

Placodiunı elegans .................... 168

vitellinum ................... 168

Plants ............................... 168

Platessa glacialis..................... 108

l'latysounatichthys hippoglossoides........ 108

Plectrophanes lapponicus .............. 77 nivalis ...............76, 77,78

Pleuronectes Franklinii . . . . . . . . . . . . . . 108

glaber.................. 108

(Rhombus) glacialis......... 108

Pleuronectida $\ldots . . \ldots \ldots \ldots \ldots \ldots \ldots \ldots . .108$

Poa alpina . . . . . . . . . . . . . . . . . . 160

aretica ......................... 77,91

Pollachius carbonarius.................. 109

Polygonum viviparum .................. 165

Polypodium Dryopteris ................. . 166

Polrsiphonia aretica . ................... 169

Polysticta stelleri ..................... 89

Polyzoa ............................ 148

Porifera ............................ 153

Potentilla maculata ................... 164

nivea...................... 164

Protomedeia fasciata ................... $\quad 116$

Ptarmigans ........................... 72

Ptilota plumosa var. serrata............. 169

Puffinus kuhli....................... 102

" major ....................... 103

Pye ..............................

Pygosteus......................... 130

occidentalis ................ 130

Pyrola rotundifolia.................... 165

rotundifolia var. pumila...........163, 165

Pyrrhotite......................... 171

Pymhula ............................ 74

europea .................... 75

Quartz $\ldots \ldots \ldots \ldots \ldots \ldots \ldots \ldots \ldots \ldots \ldots \ldots, 171$

Fudiates .......................... 151

lae, Dr.......................... 108

Rangifer tarandus..................... 13,54

Rimuneulus affinis .................... 164

nivalis .................. 164

not identified................ 164

Razor-back....................... 66

Reeurvirostris americana............... 84

Reinhardtins hippoglossoides........... 108

Rhamphornyia....................... 161

nigrita................ 161

Rlfodactiuia Davisii.................. 152

Rhorledendron Lapponicum ............. 165 


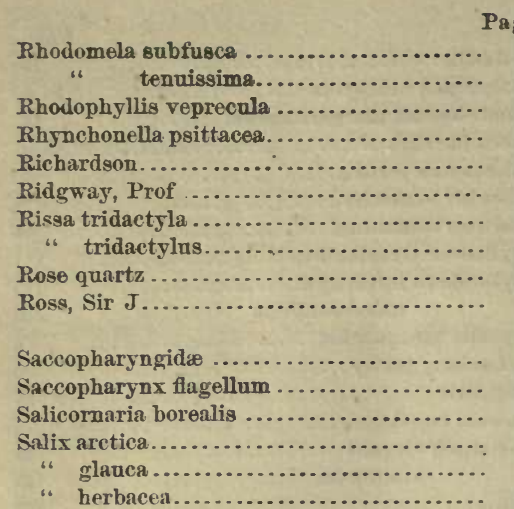

Salmo

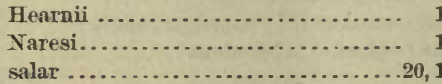

Salmonidm

Salvelinns alipes .......................

areturus

Hoodii

Naresi nitidus .

Sarbarsook

Satyrinæe

Saxicava arctice.

Saxicola wnanthe

Saxifraga cespitosa

$$
\text { nivalis }
$$

oppositifolia ...................

rivularis

rivalaris var. hyperborea $\ldots . .163,164$

stellaris...................... 16

stellata .................... 163

tricuspidata.

Scatophaga apicalis

Schischimani.

Schizoporella.

Scolocophagus ferruginens................

Scudder, S. H.

Sea-hen

Serbek

Sergvak

Sertularia argentea

Séseminé.

Shatgak

Sherman, Mr .

Sibbaldia procumbens

Sigereak

Silene acaulis

Siorakitsook

Sitta carolinensis

Siurus nævius

Smith, S. I

Smitt, Dr

Switz, Krärup

Smoky quartz

Somateria.

Somateria mollissima . . . . . . . . . . . . . . spectabilis

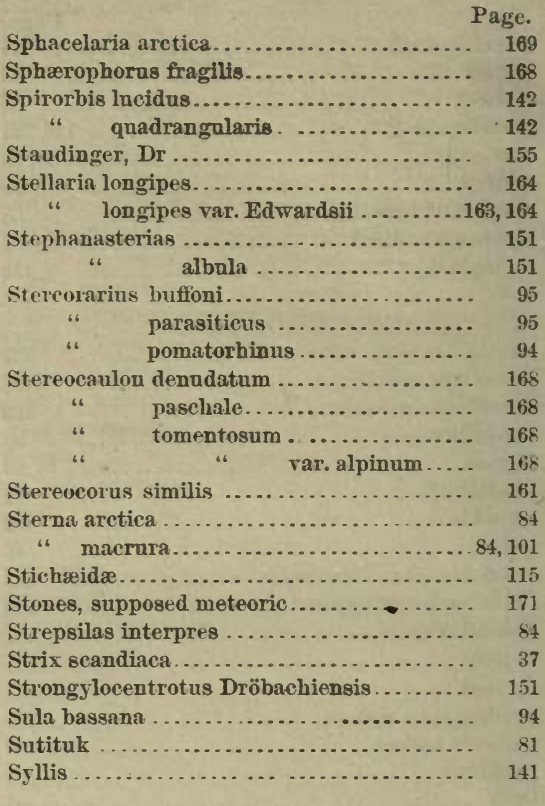

Tachycineta bicolor .................. 74

Taraxacum Dens-leonis .................163, 165 palustre...................163, 165

Tattarat ........................... 99

Tealia crassicornis ................... 152

Telligvak .......................... 84

Thalictrum alpinum .................... 164

Thelepus eincinnatus ................. 141

Theloschistes parietinus ................. 167

" var. pygmæus..... IH

Tigak ... ........................ 55,60

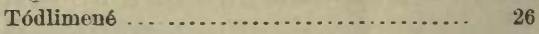

Tofieldia borealis...................... $\quad 165$

Toodlik ............................ 103

Tornæt............................ 29

Tornauiartook ..................... 89

Torngarsuk ........................ 29, 30

Totanus melanolencus................ 88

Tourmaline ........................ 171

Touyunaik ......................... 49

Trichechus rosmarus.................13, 47,63

Triglops pingelii ...................... 128

Tringa canutus ....................... 87

fuscicollis .................... 86 maritima ....................... 86 minutilla ...................... 86

subarquata .................... 87

Trophon truncatus..................... 146

Tuckerman, Edward ................... 167

Tadluak ............................ $\quad 78$

Tukagvajok .......................... 83

Tuktoo............................. 54

Tulluak ............................ 78

Tunak .............................. 3,14

Tunare ............................ 14 
Page. Page.

Tunnak

Tunnnk

Turdus aliciæ.

Turtonia minuta

Ulothrix flacea

Umbiliearia anthracina.

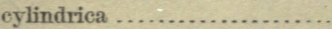

erosa .......................

hyperborea

proboscidea

proboscidea rar. aretica vellea

Uria carbo.

" grylle.
14 Uronectes Parryi

115

Ursus maritimus...................... $13,47,48$

Urticina crassicornis................... 152

Utamania torda ....................... 103

Vaccinium uliginosum ...........19, 73, 77, 80, 165

Veroniea alpina ........................... 165

Verrill, A. E.....................141, 147, 151

Vulpes lagopus ..................... 49, 77

Whale-bird ........................... 85

Xema sabinii......................... 101

Ziphidiontidæ $\ldots \ldots \ldots \ldots \ldots \ldots \ldots \ldots \ldots \ldots \ldots$ 1J5 






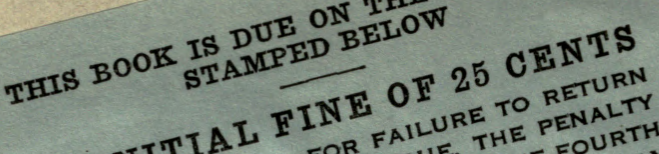

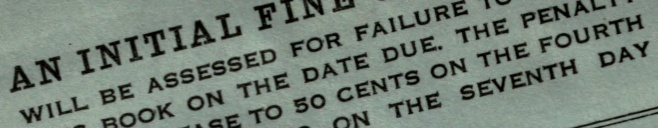
WILLS BOOK
THILL INCRESE TO $\$ 1.00$
WILL AND TO WILL AND
DAY OVRDUE.

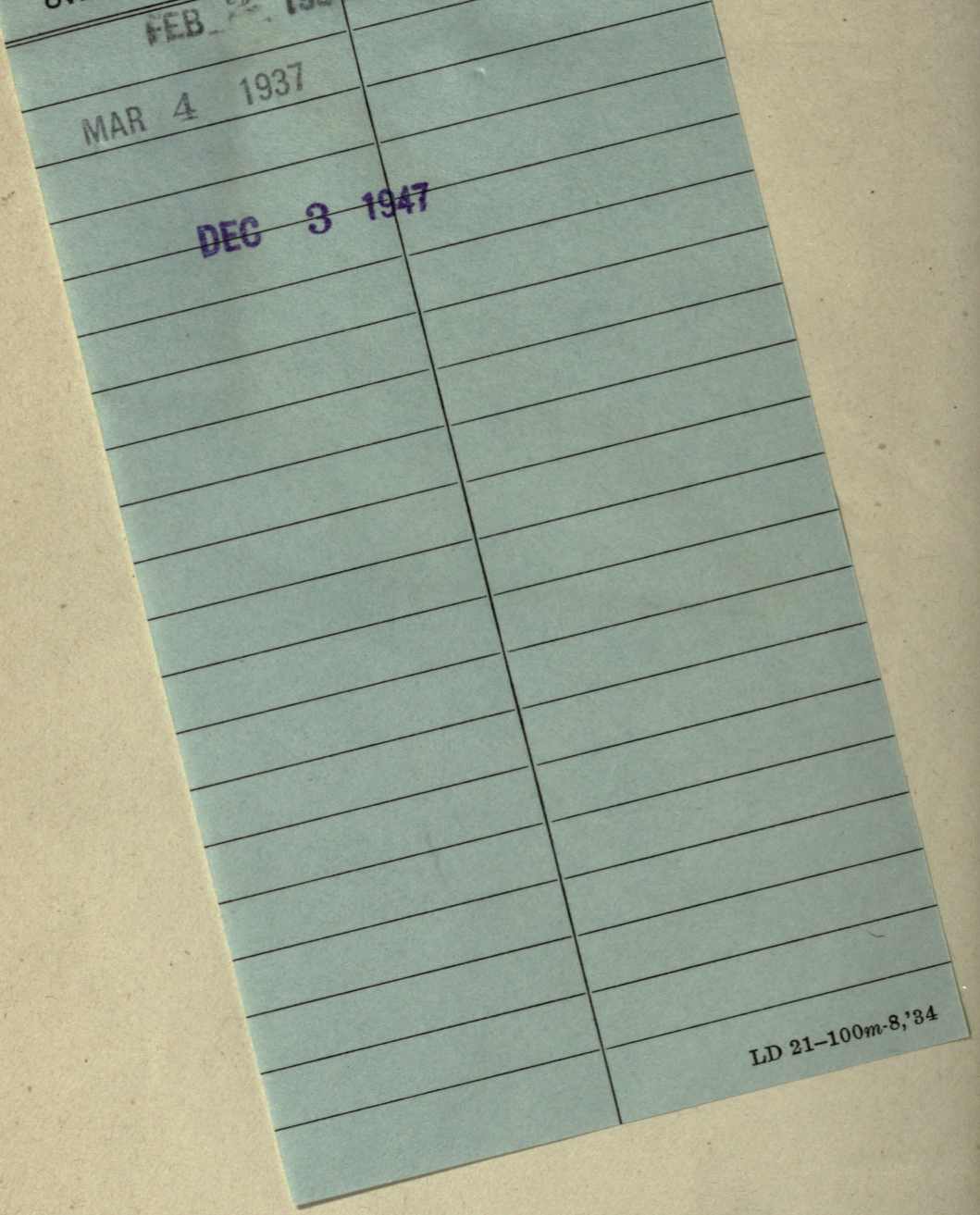




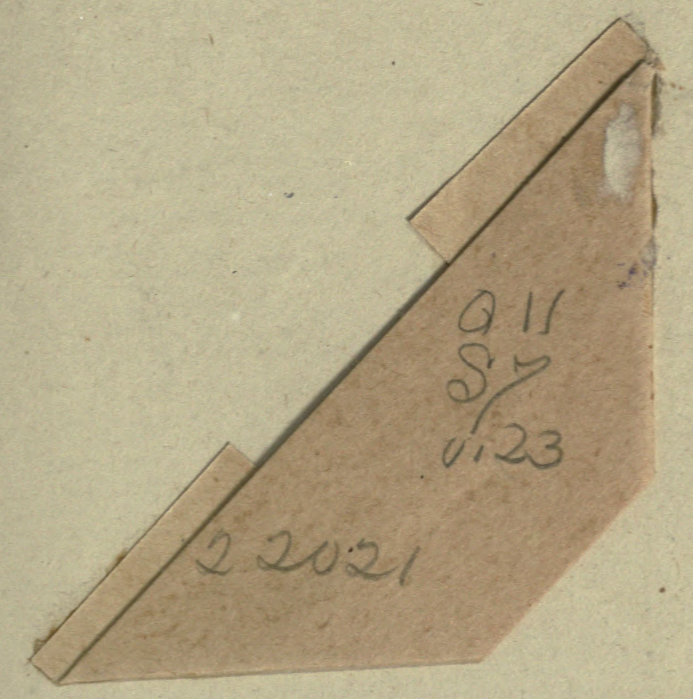

GENERAL LIBRARY - U.C. BERKELLY

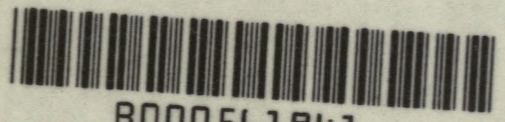
B000561941 


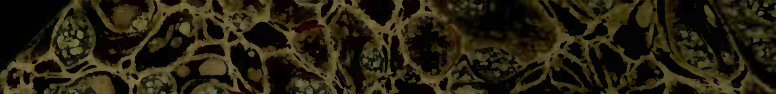

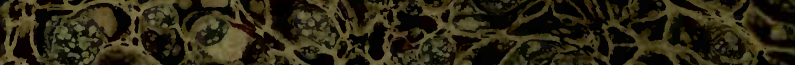

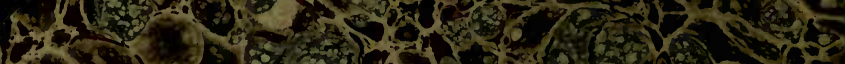

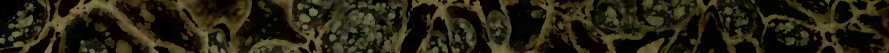

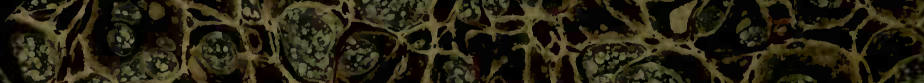

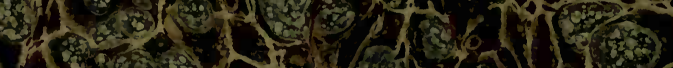

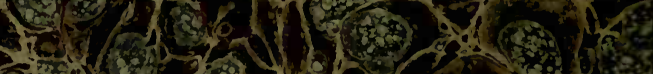

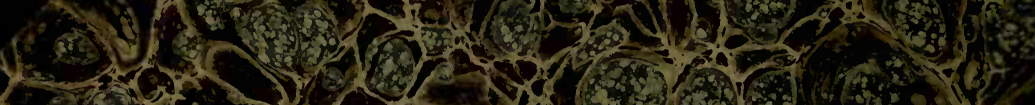

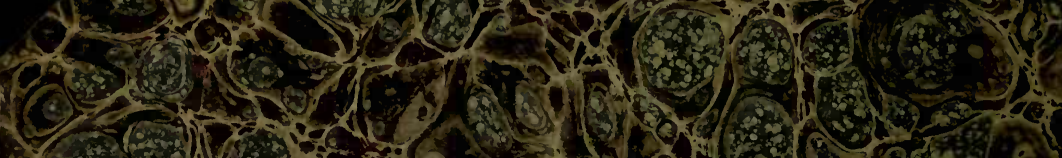

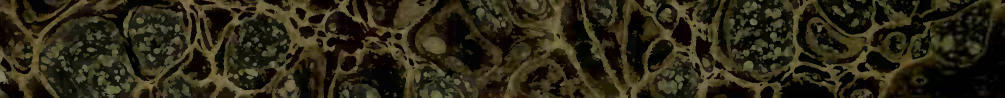

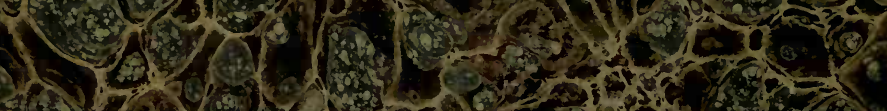

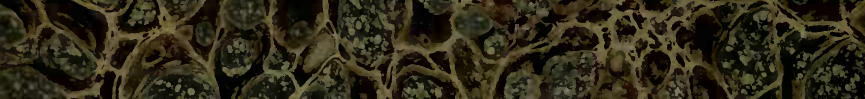

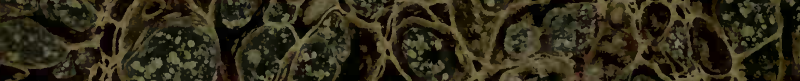
5. (2)

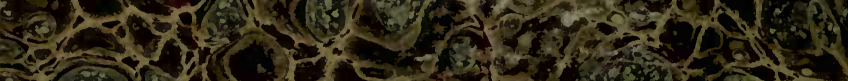

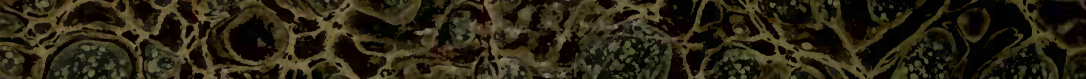

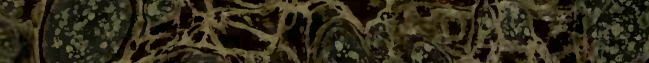
$3(6)$ (6)

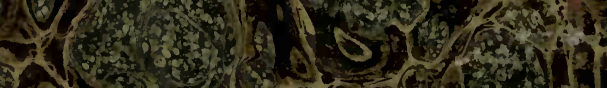

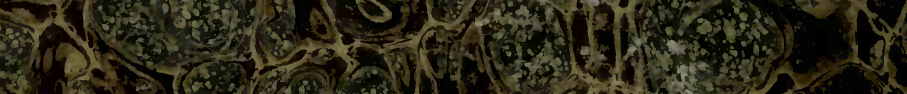

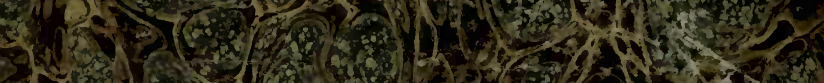

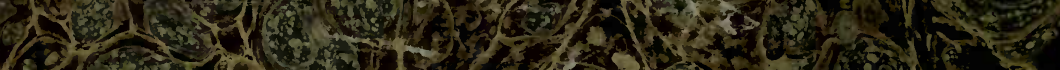
(9)

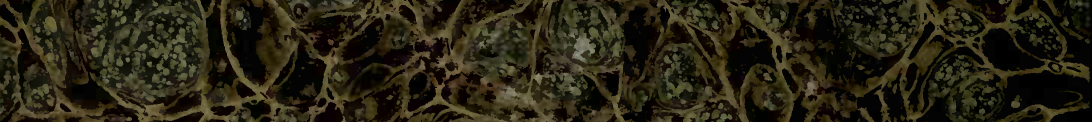

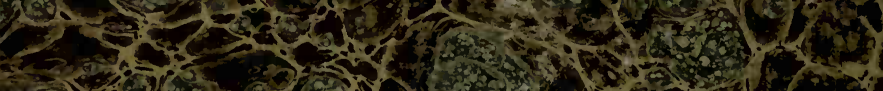

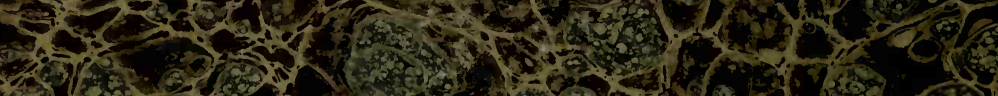

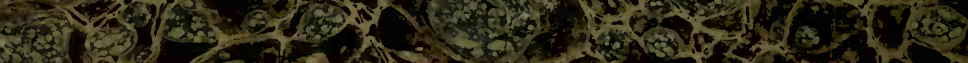

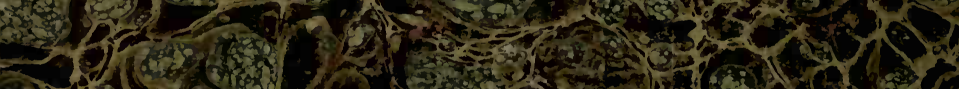

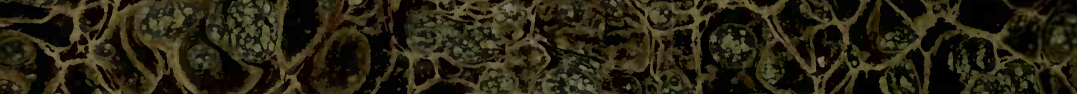

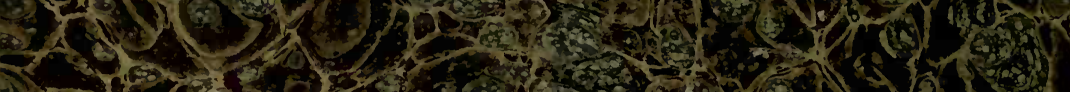

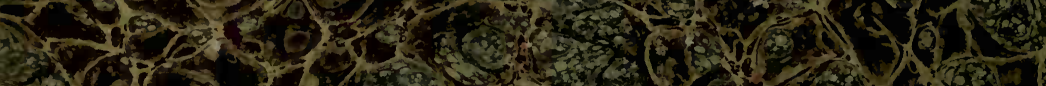

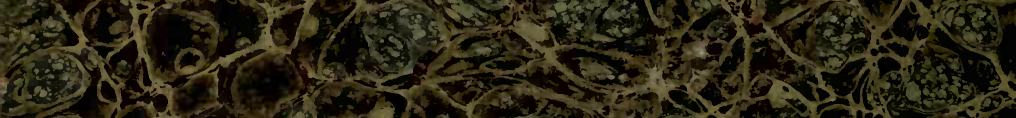

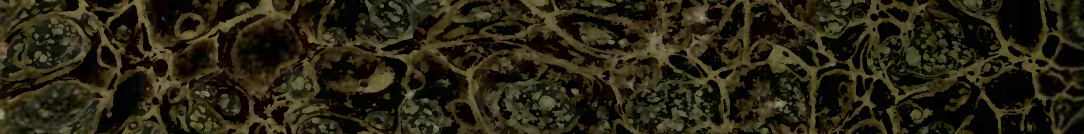

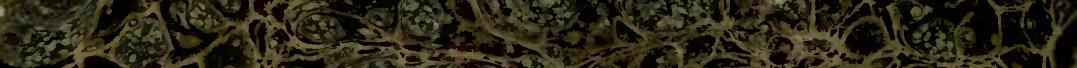

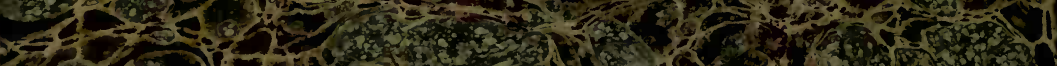

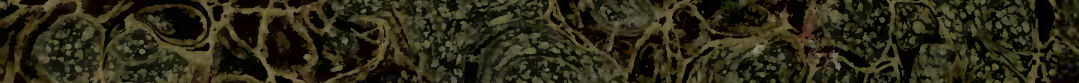

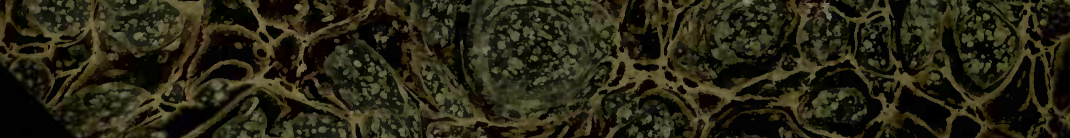

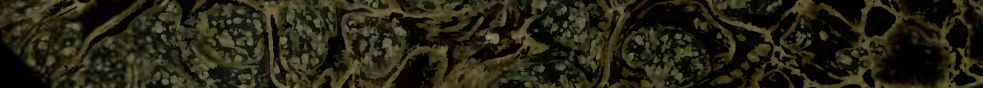
H.

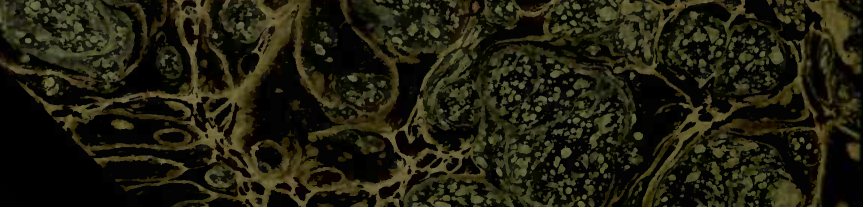

